\title{
Die Anerkennung von Diplomen in der Europäischen Gemeinschaft
}

Citation for published version (APA):

Schneider, H. E. G. S. (1995). Die Anerkennung von Diplomen in der Europäischen Gemeinschaft. [Doctoral Thesis, Maastricht University]. Rijksuniversiteit Limburg.

https://doi.org/10.26481/dis.19951026hs

Document status and date:

Published: 01/01/1995

DOI:

10.26481/dis.19951026hs

Document Version:

Publisher's PDF, also known as Version of record

\section{Please check the document version of this publication:}

- A submitted manuscript is the version of the article upon submission and before peer-review. There can be important differences between the submitted version and the official published version of record.

People interested in the research are advised to contact the author for the final version of the publication, or visit the DOI to the publisher's website.

- The final author version and the galley proof are versions of the publication after peer review.

- The final published version features the final layout of the paper including the volume, issue and page numbers.

Link to publication

\footnotetext{
General rights rights.

- You may freely distribute the URL identifying the publication in the public portal. please follow below link for the End User Agreement:

www.umlib.nl/taverne-license

Take down policy

If you believe that this document breaches copyright please contact us at:

repository@maastrichtuniversity.nl

providing details and we will investigate your claim.
}

Copyright and moral rights for the publications made accessible in the public portal are retained by the authors and/or other copyright owners and it is a condition of accessing publications that users recognise and abide by the legal requirements associated with these

- Users may download and print one copy of any publication from the public portal for the purpose of private study or research.

- You may not further distribute the material or use it for any profit-making activity or commercial gain

If the publication is distributed under the terms of Article $25 \mathrm{fa}$ of the Dutch Copyright Act, indicated by the "Taverne" license above, 
Die Anerkennung von Diplomen in der

Europäischen Gemeinschaft 
Ius Commune

Van dit proefschrift verschijnt een handelseditie in de Ius Commune Reeks onder ISBN 9062155014 


\section{Die Anerkennung von Diplomen in der Europäischen Gemeinschaft}

\section{PROEFSCHRIFT}

ter verkrijging van de graad van doctor aan de Rijksuniversiteit Limburg te Maastricht, op gezag van de Rector Magnificus, Prof. dr M.J. Cohen, volgens het besluit van het College van Dekanen, in het openbaar te verdedigen op

donderdag 26 oktober 1995 om 16.00 uur

door

Hildegard Erika Gertrud Sophie Schneider

geboren te Rottweil 
Promotores:

Prof. dr dr Albert Bleckmann (Westfälische Wilhelms-Universität, Münster i.W.)

Prof. dr Bruno De Witte

Beoordelingscommissie: Prof. dr René Barents (voorzitter)

Prof. dr Peter-Christian Müller-Graff (Ruprecht Karl Universität, Heidelberg)

Dr Peter Van den Bossche 
Ingeborg Schneider-Eble,

René, David und Sophia de Groot 


$$
\text { 1 }
$$

\section{Vorwort}

Die Problematik der Anerkennung von Diplomen innerhalb der Europäischen Gemeinschaft hat mich schon seit langem fasziniert. Da ich selbst mit einer ausländischen Qualifikation in einem anderen Mitgliedstaat tätig bin, fühlte ich mich mit dieser Thematik besonders verbunden. Der Richtlinie $89 / 48 / \mathrm{EWG}_{n}$ die auch auf juristische Berufe Anwendung findet, galt daher seit ihrer Verabschiedung durch den Rat mein besonderes Interesse. Mit einer Studie, in der die Umsetzungsmaßnahmen zu dieser Richtlinie in den einzelnen Mitgliedstaaten näher untersucht werden sollten, wollte ich einen Beitrag zu einer besseren Umsetzung und Anwendung dieser Anerkennungsrichtlinie leisten. Erst mittels einer rechtsvergleichenden Detailstudie kann man meiner Ansicht nach die Vorzüge und die Nachteile einzelner Umsetzungsmaßnahmen aufzeigen. Ein sollcher Vergleilch kann - so hoffe ich - dazu beitragen, verbesserte Umsetzungsmaßnahmen in Zukunft zu bewirken. Auch bezweckt die Studie, den einzelnen nationalen Behörden, die mit der Durchführung von Anerkennungsverfahren betraut sind, die Anwendung der Richtlinie sowie der einschlägigen Rechtsprechung des Europäischen Gerichtshofs zu erleichtern.

Der Abschluß einer längeren Studie gibt Anlaß, um verschỉedenen Personen zu danken. Dies ist eine besonders angenehme Aufgabe, die ich hiermit gerne erfülle. An erster Stelle gilt mein Dank Professor Dr Dr Albert Bleckmann (Westfallische Wilhelms-Universität) und Professor Dr Bruno De Witte (Rijksuniversiteit Limburg, Maastricht), die beide die Arbeit betreut haben. Sie waren zu jeder Zeit bereit, mich mit anregenden Diskussionen aufzumuntern und den Abschluß der Arbeit zu fördern. Professor Dr René Barents (Rijksuniversiteit Limburg, Maastricht/Europäischer Gerichtshof, Luxemburg), Professor Dr Peter-Christian Müller-Graff (Ruprecht Karl Universität, Heidelberg) und Dr Peter Van den Bossche ((Rijksuniversiteit Limburg, Maastricht) danke ich für die Bereitschaft, das Manuskript schnell und gründlich zu lesen und zu begutachten.

Eine Arbeit, die hauptsächlich eine Beurteilung der Umsetzungsmaßnahmen in den verschiedenen Mitgliedstaaten der Europäischen Gemeinschaft bezweckt, könnte nicht durchgeführt werden, wenn sich nicht verschiedene Personen bereit gefunden hãtten, mich ständig hinsichtlich der jüngsten Regelungen in den Mitgliedstaaten und auf Gemeinschaftsebene auf dem Laufenden zu halten. Mein besonderer Dank gilt dabei Jacqueline Minor von der Generaldirektion XV der Europäischen Kommission sowie 
Desirée Hoefnagel, zunächst niederländische Koordinatorin der Richtlinie 89/48/EWG, später Kommissionsbeamtin ebenfalls bei der Generaldirektion XV. Beide waren immer dazu bereit, meine Fragen schnell und gründlich zu beantworten. Im allgemeinen habe ich auch von den nationalen Koordinatoren nur Unterstützung erfahren. Ihnen allen gilt mein Dank.

Ein besonderes Dankwort gilt Wolfgang Kramer (Bonn). Auch er war immer dazu bereit, meine Wünsche nach Zusendung von Bundestags- und Bundesratsdrucksachen zu erfüllen. Daneben hat er sich auch noch der mühseligen Aufgabe unterzogen, das ganze Manuskript zu lesen und zu korrigieren. Um diesen Freundschaftsdienst war er mit Sicherheit nicht zu beneiden.

An der Rijksuniversiteit Limburg habe ich ebenfalls von vielen Personen Hilfe und Unterstützung erhalten. Viele Kollegen waren immer zu einem aufmunternden Wort oder zu einem anregenden Gespräch hinsichtlich der Problematik der Diplomanerkennung bereit. Einige Personen verdienen jedoch besondere Erwähnung. Angelique Bessems von der Universitätsbibliothek wurde nie müde, meine Wünsche nach CELEXNachforschungen zu befriedigen. Chantal Bartels hat als studentische Hilfskraft meine Literatursuche unterstützt. Auch Adriana Alvarez war während ihrer Tätigkeit in Luxemburg unermüdlich darin, mir die jüngsten Urteile einschließlich der deutschen Übersetzungen frisch von der Veröffentlichungsstelle des Europäischen Gerichtshofs zuzusenden. Jacqueline Schoonheim fand sich sehr kurzfristig bereit, die englische Zusammenfassung zu korrigieren. Dafür danke ich ihnen allen ganz herzlich. Ganz besonders muß ich mich auch bei Mireille Schiffelers und Petra Vranken vom Institut Metro bedanken, die das Manuskript druckreif gemacht haben. Ohne ihre Ruhe, Geduld und Genauigkeit wäre es mir vermutlich nicht gelungen, das Manuskript termingerecht beim Verlag einzureichen.

Zum Schluß möchte ich noch vier Personen danken, die alle in einer ganz besonderen, jeweils jedoch unterschiedlichen Weise, mit diesem Buch verbunden sind. An erster Stelle danke ich meiner Mutter, Ingeborg Schneider-Eble. Sie hat zusammen mit meinem leider bereits verstorbenen Vater meine verschiedenen Studien im In- und Ausland immer befürwortet und unterstützt. Damit hat sie einen Grundstein für diese rechtsvergleichende Arbeit gelegt. Auch hat sie niemals den geringsten Zweifel gezeigt, daß die einmal begonnene Forschung zu einem guten Ende kommen würde. René de Groot hat als Ehemann und Kollege weder Mühe noch Zeit gescheut, mich zu unterstützen. So manches Wochenende und manchen Urlaubstag mußte er opfern, um mir die Gelegenheit zu bieten, in Ruhe durcharbeiten zu können. Dafür kann ich ihm nicht genug danken. Auch unserem Sohn David gebürt ein besonderes Dankeswort. Er hat mit Geduld und beinahe ohne zu Murren den Abschluß "des Buches" erwartet. Nicht immer ist ihm dieses Warten leicht gefallen. Mit dem Gedanken an ein gemeinsames Fest war er jedoch immer zu trösten. Dieses Fest hat er daher auch ganz besonders verdient. Schließlich gilt mein Dank Sophia. Durch ihre Geburt hat sie zwar den Abschluß der Studie nicht unwesentlich verzögert. Die Freude, die diese kleine Persōnlichkeit in unser Leben gebracht hat, wiegt diesen Zeitverlust aber mehr als nur ein 
Vorwort

bißchen auf. Diesen vier Personen, die alle einen so wesentlichen Bestandteil meines Lebens bilden, möchte ich gemeinsam dieses Buch widmen, das ohne sie nie oder zumindest nicht in dieser Form entstanden wäre.

Hildegard Schneider

Maastricht, im August 1995 


\section{Inhaltsübersicht}

Vorwort $\ldots \ldots \ldots \ldots \ldots \ldots \ldots \ldots \ldots \ldots$ vii

Inhaltsverzeichnis $\ldots \ldots \ldots \ldots \ldots \ldots \ldots \ldots \ldots \ldots \ldots \ldots \ldots \ldots$

Abkürzungsverzeichnis $\ldots \ldots \ldots \ldots \ldots \ldots \ldots \ldots \ldots \ldots$ xxvii

Prolog .............................. 3

Teil I

Einleitung und Abgrenzung $\ldots \ldots \ldots \ldots \ldots \ldots \ldots$

Teil II

Die Freiheit des Personenverkehrs aufgrund des EG-Vertrages . . . . . . . . 27

Teil III

Die Freiheit des Personenverkehrs durch sektorielle Rechtsangleichung . . . . 99

Teil IV

Die Freiheit des Personenverkehrs durch allgemeine Regelungen zur gegenseitigen Anerkennung von Diplomen .................... 161

Teil V

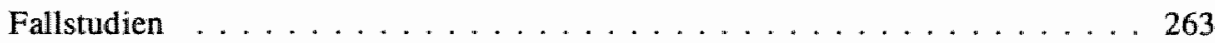

Fallstudie $\mathbb{I}$ : Die rechtsberatenden Berufe . . . . . . . . . . . 265

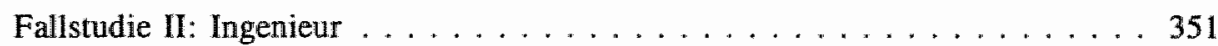

Fallstudie III: Lehrer . . . . . . . . . . . . . . . . . 365

Teil VI

Gesamtbeurteilung des horizontalen Ansatzes .............. . . 407 
Inhaltsubersiclat

Epilog . . . . . . . . . . . . . . . . . . 439

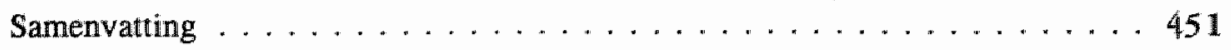

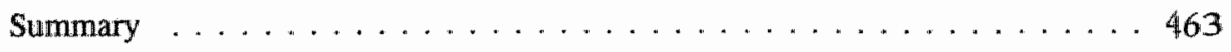

Literaturverzeichnis ................... 473

xii 


\section{Inhaltsverzeichnis}

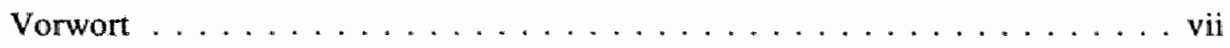

Inhaltsübersicht $\ldots \ldots \ldots \ldots \ldots \ldots \ldots \ldots \ldots \ldots$

Inhaltsverzeichnis $\ldots \ldots \ldots \ldots \ldots \ldots \ldots \ldots \ldots \ldots \ldots \ldots \ldots \ldots$

Abkürzungsverzeichnis $\ldots \ldots \ldots \ldots \ldots \ldots \ldots \ldots \ldots$ xxvii

Prolog .......................... 3

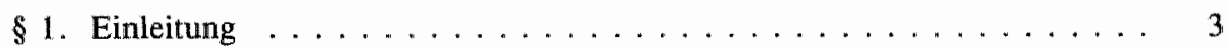

\$2. Der Binnenmarkt und die freien Berufe $\ldots \ldots \ldots \ldots$

§. Der Binnenmarkt und der öffentliche Dienst ............. 8

Einleitung und Abgrenzung $\ldots \ldots \ldots \ldots \ldots \ldots$

Teil I

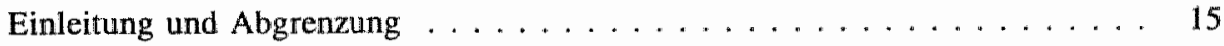

Teil II

Die Freiheit des Personenverkehrs aufgrund des EG-Vertrages . . . . . . . 27

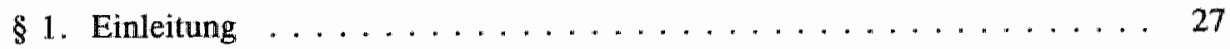

\$ 2. Inhalt und Abgrenzung der Begriffe "Gemeinsamer Markt" und "Binnen-

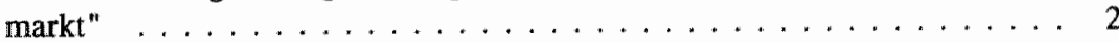


8. Die Grundfreiheiten $\ldots \ldots \ldots \ldots \ldots \ldots \ldots \ldots \ldots$

A. EInletTung . . . . . . . . . . . . . . . . . . . . .

B. DeR ANWENDUNGSBEREICH DER NIEDERLASSUNGSFREIHEIT . . . . . 3

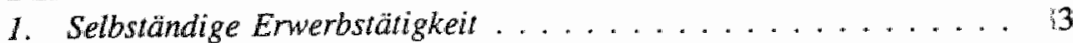

2. Freie Berufe ....................... 3

C. ABGRENZUNG DER NIEDERLASSUNGSFREIHEIT VON DEN ÜBRIGEN GRUNDFREIHEITEN $\ldots \ldots \ldots \ldots \ldots \ldots \ldots \ldots \ldots \ldots \ldots$ i. 5

1. Abgrenzung zwischen Niederlassungsfreiheit und der Arbeitnehmerfreizügigkeit ...................... 5

2. Abgrenzung zwischen der Niederlassungsfreiheit und der Dienstlei-

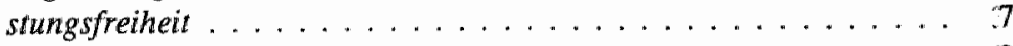

D. Die vertragliche AusgangSlage ... . . . . . . . . . . . . 9

1. Einleitung . . . . . . . . . . . . . . . . . . . . . 9

2. Der Gegenstand und der Umfang der Niederlassungsfreiheit . . . . 1

a. Gegenstand des Niederlassungsrecht ... . . . . . . . . 4

b. Umfang der Niederlassungsfreiheit ............

E. DIE RECHTSPRECHUNG ZU DEN GRUNDFREIHEITEN ........ 4

1. Die Rechtsprechung in den siebziger Jahren . . . . . . . . . . . . 46

a. Die Rechtssache Reyners . . . . . . . . . . . . . . . 46

b. Die Rechtssache van Binsbergen ............... 45

c. Die Rechtssache Thieffry . . . . . . . . . . . . . . 8

d. Die Rechtssache Patrick .................. . . 5

e. Der Fall Razanatsimba ... . . . . . . . . . . . . 51

f. Die Rechtssache van Wesemael ............... $\mathbb{\$}$

g. Die Rechtssache Knoors .................. . 5

h. Die Rechtssache Auer I ............................. . \&

2. Die Rechtsprechung in den achtziger Jahren . . . . . . . . 54
a. Die Rechtssache Brockmeulen ................. 54
b. Dile Rechtssache Webb ................. . . 54
c. Die Rechtssachen Auer $\mathbb{I}$ und Rienks ... . . . . . . . . . 56
d. Die Rechtssache Klopp . . . . . . . . . . . . . . . . . 56
e. Die Rechtssache Steinhauser . . . . . . . . . . . . . 57
f. Die Rechtssache Kommission gegen Frankreich . . . . . . . 57
g. Die Rechtssache Kommission gegen Deutschland . . . . . . . 58
h. Die Rechtssache Kommission gegen Belgien . . . . . . . . . 59

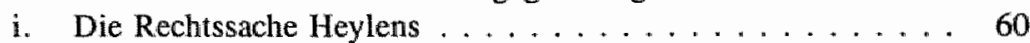
j. Die Rechtssache Gullung . . . . . . . . . . . . . 61
k. Die Rechtssache Van de Bijl . . . . . . . . . . . . . 62
3. Die Rechtsprechung in den neunziger Jahren . . . . . . . . . 64
a. Die Rechtssache Bouchoucha ... . . . . . . . . . . . . 64
b. Die "Fremdenführer" - Entscheidungen ... . . . . . . . 66
c. Die Rechtssache Vlassopoulou . . . . . . . . . . . . . 66
d. Die Rechtssache Manfred Säger gegen Dennemeyer . . . . . . 68 
e. Die Rechtssache Collective Antennevoorziening Gouda und die Rechtssache Kommission gegen die Niederlande . . . . . . . . .

f. Die Entscheidungen López Brea, Volker Steen und Batista Morais ... . . . . . . . . . . . . . . . . . 70

g. Die Rechtssache Newman . . . . . . . . . . . . . 71

h. Die Rechtssache Claus Ramrath . . . . . . . . . . . . . . 73

i. Die Rechtssache Kommission gegen Luxemburg . . . . . . . 74

j. Die Rechtssache Ferrer Laderer . . . . . . . . . . . . . 75

k. Die Rechtssache Dieter Kraus . . . . . . . . . . . . . . 75

1. Die Rechtssache Allué II ... . . . . . . . . . . . . . 80

m. Die Rechtssache Salomone Haim . . . . . . . . . . . . 80

n. Die Rechtssache Tawil-Albertini ... . . . . . . . . . 83

o. Die Rechtssache Scholz . . . . . . . . . . . . . . . . . . . 84

p. Die Rechtssache Kommission gegen Spanien . . . . . . . . . 85

q. Die Rechtssache Schindler .................. 86

F. BEDEUTUNG DIESER RECHTSPRECHUNG FÜR DIE ANERKENNUNG VON DIPLOMEN . . . . . . . . . . . . . . . . . . . . 87

\section{Teil III}

Die Freiheit des Personenverkehrs durch sektorielle Rechtsangleichung:

Der vertikale Ansatz . . . . . . . . . . . . . . . . . . . . . . . 99

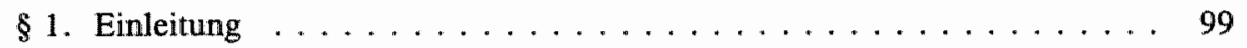

§ 2. Die Allgemeinen Programme und ihr Zeitplan .............. 101

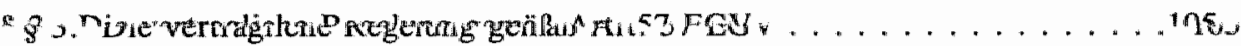

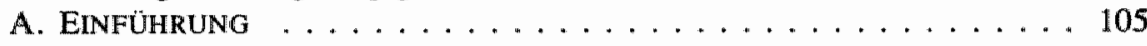

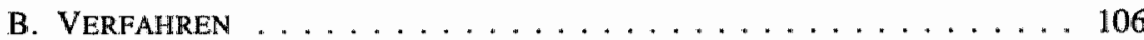

C. DIE Gegenseitige Anerkennung GemÄss ART. 57 ABS. 1 EGV . . 108

D. DIE KOORDINIERUNG GEMÄsS ART. 57 ABS. 2 EGV . . . . . . . . 111

8. 4. Der sektorielle Ansatz für die freien Berufe . . . . . . . . . . . 113

\$ 5. Die sektoriellen Richtlinien . . . . . . . . . . . . . . 118

A. DIE URSPRÜNGLICHEN ÄRZTERICHTLINIEN . . . . . . . . . . . 118

1. Entstehungsgeschichte der ursprünglichen Ärzterichtlinien ... . 118

2. Der Anwendungsbereich der ursprïnglichen Ärterichtlinien . . . 120

3. Die Systematik der Richtlinie 75/362/EWG . . . . . . . . . . 123

4. Der Inhalt der Richtlinie $75 / 362 / E W G \ldots \ldots 123$

a. Die Anerkennung richtlinienkonformer Diplome . . . . . . . 123

b. Drittstaatsdiplome . . . . . . . . . . . . . . . . . 124

c. DDR-Diplome . . . . . . . . . . . . . . . . 125

d. Die Anerkennung nicht richtlinienkonformer Diplome . . . . 126 
e. Facharztdiplome ..................... 126

f. Die Anerkennung richtlinienkonformer Facharztdiplome . . . . 127

g. DDR-Facharztdiplome . . . . . . . . . . . . . 127

h. Die Anerkennung nicht richtlinienkonformer Facharztdiplome 127

i. Sonstige Bestimmungen . . . . . . . . . . . . . . . 128

(1) Gemeinsame Bestimmungen betreffend das Niederlassungsrecht und den Dienstleistungsverkehr . . . . . . 128

(a) Das Recht zum Führen der Ausbildungsbezeichnung . . . 128

(b) Das Recht zum Führen der Berufsbezeichnung . . . . . . 128

(c) Das Recht auf Information über die Gesundheits- und Sozialvorschriften des Aufnahmestaats . . . . . . . . 129

(d) Sprachkenntnisse . . . . . . . . . . . . . . . . . . 129

(2) Besondere Bestimmungen betreffend das Niederlassungsrecht ..................... 131

(a) Zuverlässigkeitsnachweise ............... 131

(i) Zuverlässigkeitsnachweis bei erstmaliger Aufnahme der ärztlichen Tätigkeit ............... . . 131

(ii) Zuverlässigkeitsnachweis bei Verlegung der ärztlichen Berufsausübung von einem Mitgliedstaat in einen anderen ......................... . . 132

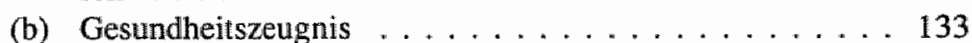

(c) Zulassungsverfahren ................... 133

(d) Eidesleistung . . . . . . . . . . . . . . . . 134

(e) Aufnahme in einen Berufsverband oder eine Berufskörperschaft . . . . . . . . . . . . . . . . . . 134

(f) Doppelniederlassung .................. 134

(3) Besondere Bestimmungen betreffend den Dienstleistungsverkehr ..................... 135

(a) Freistellung von der Mitgliedschaft bei einem Berufsverband des Aufnahmestaats . . . . . . . . . . . . 135

(b) Freistellung von der Kassenzulassung . . . . . . 136

(c) Anzeigepflicht . . . . . . . . . . . . . . 136

j. Die Vorbereitungszeit als Kassenarzt . . . . . . . . . . . 138

k. Schlußbestimmungen ................... . . . 138

B. DIE RIChTLINIE $93 / 16 /$ EWG . . . . . . . . . . . . . . . . 139

1. Die Systematik der Richtlinie $93 / 16 / E W G \ldots \ldots 139$

2. Synoptische Übersicht . . . . . . . . . . . . . . . . . . . 139

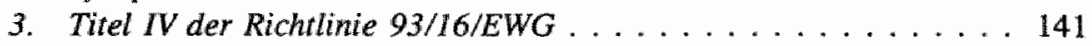

C. DIE ZAHNÄRZTERICHTLINIEN UND DIE TIERÄRZTERICHTLINIEN . . . . 142

D. DIE KRANKENSCHWESTER- Und HebammenRICHTLINIEN . . . . . . 144

E. DIE APOTHEKERRICHTLINIEN . . . . . . . . . . . . . . . 148

1. Entstehungsgeschichte der Apothekerrichtlinien . . . . . . . 148

2. Inhall der Apothekerrichtinien ................. 152

F. DIE ARCHITEKTENRICHTLINIE ... . . . . . . . . . . . 154

1. Inhalt der Architektenrichtlinie . . . . . . . . . . . 154 
2. Die Rechtsprechung zur Architektenrichtlinie ... . . . . . . 155

3. Die Umsetzung der Architektenrichtlinie . . . . . . . . . . . . 156

\section{Teil IV}

Die Freiheit des Personenverkehrs durch allgemeine Regelungen zur gegenseitigen Anerkennung von Diplomen: Der horizontale Ansatz . . . . . . . . . 161

1. Die Richtlinie 89/48/EWG über eñne allgemeine Regelung zur Anerkennung der Hochschuldiplome, die eine mindestens dreijährige Berufsausbildung abschlieben . . . . . . . . . . . . . . . . . . . . . . . 161

A. ENTSTEHUNGSGESCHICHTE DER RICHTLINIE 89/48/EWG . . . . . . 161

B. ANWENDUNGSBEREICH DER RICHTLINIE $89 / 48 /$ EWG $\ldots \ldots \ldots \ldots 164$

1. Persönlicher Anwendungsbereich .............. 164

2. Inhallicher Anwendungsbereich ............... 165

a. Vertragliche Ermächtigung ................ 165

b. Umfang des Anwendungsberichs .............. 166

c. Ausnahmen vom Anwendungsbereich ........... 167

(1) Problembereich: Krankenschwestern . . . . . . . . 167

(2) Problembereich: Rechtsanwälte . . . . . . . . . . 169

C. INHALT DER RICHTLINIE $89 / 48 /$ EWG . . . . . . . . . . . . . . . . . . 170

1. Der Begriff des Diploms im Sinne der Richtlinie 89/48/EWG . . 170

2. Das Endprodukt . . . . . . . . . . . . . . . . . . . . 172

3. Drittstaatsdiplome . . . . . . . . . . . . . . . 173

4. Parallele Ausbildungen ... . . . . . . . . . . . . . . . 175

5. Reglementierter Beruf und reglementierte berufliche Tätigkeit . . 177

a. Einleitung . . . . . . . . . . . . . . . . . . 177

b. Definition des reglementierten Berufes und der reglementierten beruflichen Tätigkeit ................. 178

(1) Reglementierung durch gesetzliches Tätigkeitsmonopol , 178

(a) Partielles und vollkommenes Tätigkeitsmonopol . . . . . 178

(b) Tätigkeitsmonopol für ein oder mehrere Berufsuntergruppen ......................... 181

(2) Reglementierung durch gesetzliches Titelmonopol . . . . 181

(a) Schutz der Berufsbezeichnung und Schutz des Ausbildungstitels . . . . . . . . . . . . . . . . . . . 182

(b) Titelmonopol durch strafrechtliche Sanktion . . . . . . 182

(3) Reglementierung durch das Sozialsystem . . . . . . . 183

(4) Reglementierung durch Berufsverbände . . . . . . . . 183

(5) Reglementierung durch die Laufbahnworschriften des öffentlichen Dienstes ................ 184

c. Konsequenzen der Reglementierung für die Umsetzung der

Richtlinie $89 / 48 /$ EWG . . . . . . . . . . . . . . . . 187

6. Gegenseitige Anerkennung gemäß Art. 3 der Richtlinie 89/48/EWG 188

7. Anpassungsinstrumente gemäß Art. 4 der Richtlinie 89/48/EWG . 193 
Inhalliswerzeichnis

a. Unterschiede in der Ausbildungsdauer ... . . . . . . . 193

b. Unterschiede in den Ausbildungsinhalten .......... 194

c. Beschrănkung der Wahlmöglichkeit . . . . . . . . . . . 194

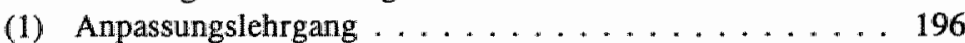

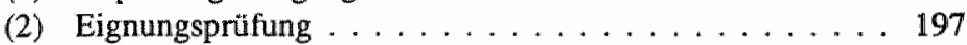

d. Kumulationswerbot . . . . . . . . . . . . . . . . . . . . 198

8. Anpassung gemäß Ant. 5 der Richtinie $89 / 48 / E W G$ für nicht vollqualifizierte Berufsangehörige . . . . . . . . . . . . 202

9. Verfahren vor der zuständigen Behörde . . . . . . . . . . 203

10. Fuhrung der Berufs- und Ausbildungsbezeichnung . . . . . . . 203

11. Nachweis van Zuverlässigkeit und Gesundheit . . . . . . . . . . 204

12. Koordinatoren und Koordinatorengruppe . . . . . . . . . . . 204

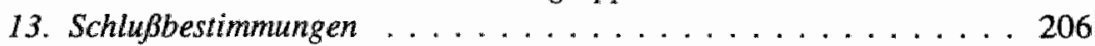

\$2. Die Umsetzung der Richtlinie $89 / 48 / \mathrm{EWG}$ über eine allgemeine Regelung zur Anerkennung der Hochschuldiplome, die eine mindestens dreijăhrige Be-

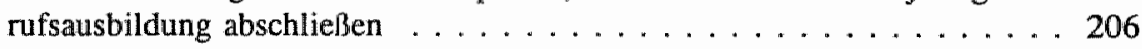

A. EinLEITUNG . . . . . . . . . . . . . . . . . . . . . . . 206

B. Die UMSETZUng duRCh SEKTORIELLE GESETZLiche REgelungeN . 210

1. Die Umsetzung der Richtlinie $89 / 48 / E W G$ in der Bundesrepubik Deutschland . . . . . . . . . . . . . . . . 210

2. Die Umsetzung der Richtlinie 89/48/EWG in Frankreich . . . . . 215

3. Die Umsetzung der Richtlinie 89/48/EWG in Griechenland . . . . 216

4. Die Umsetzung der Richtlinie 89/48/EWG in Luxemburg . . . . . 216

a. Die Umsetzungsregelungen .............. . 216

b. Beurteilung der Umsetzung hinsichtlich des allgemeinen Umset-

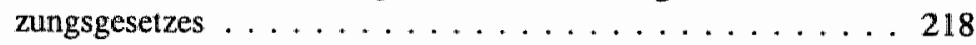

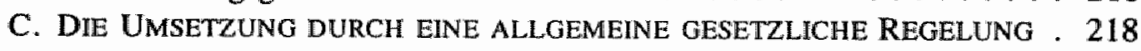

1. Die Umserzung der Richtlinie in Belgien . . . . . . . . . . . 219

2. Die Umsetzung der Richtlinie in Dänemark . . . . . . . . . . . 219

a. Die Umsetzangsregelung ... . . . . . . . . . . . 219

b. Durchführung von Anerkennungsverfahren ......... 221

c. Beurteilung der Umsetzung . . . . . . . . . . . . 222

3. Die Umsetzung der Richtlinie in Irland . . . . . . . . . 222

a. Die Umsetzungsregelung . . . . . . . . . . . . . 222

b. Beurteilung der Umsetzung . . . . . . . . . . . . 224

4. Die Umsetzung der Richtilinie in Italien . . . . . . . . . . . 224

a. Die Unsetzungsregelung . . . . . . . . . . . . . 224

b. Beurteilung der Umsetzung . . . . . . . . . . . . . 228

5. Die Umsetzung der Richtlinie in den Niederlanden . . . . . . . 229

a. Die Umsetzungsregelung . . . . . . . . . . . . . . . 229

b. Beurteilung der Umsetzung . . . . . . . . . . 230

6. Die Umsetzung der Richtlinie in Portugal . . . . . . . . . . . 230

a. Die Umsetzungsregelung ... . . . . . . . . . . . . 230

b. Beurteilung der Umsetzung . . . . . . . . . . 231

xviii 
Inhaltsverzeichnis

7. Die Umsetzung der Richtinie in Spanien ............ 232

a. Die Umsetzungsregelung ................ 232

b. Beurteilung der Umsetzung ............... 233

8. Die Unsetzung der Richtlinie in Vereinigten Königreich . . . . 233

a. Die Umsetzungsregelung . . . . . . . . . . . . . . 233

b. Durchführung von Anerkennungsverfahren ......... 235

c. Beurteillung der Umsetzung . . . . . . . . . . . 236

\$ 3. Die Richtlinie 92/51/EWG über eine zweite allgemeine Regelung zur Anerkennung beruflicher Befähigungsnachweise ................... 236

A. ENTSTEHUNGSGESCHICHTE DER RICHTLINIE $92 / 51 /$ EWG . . . . . . 236

B. ANWENDUNGSBEREICH DER RICHTLINIE $92 / 51 /$ EWG . . . . . . . 237

C. ABGRENZUNG DES ANWENDUNGSBEREICHS BEIDER ANERKENNUNGSRICHTLINIEN . . . . . . . . . . . . . . . . . . . 239

D. STRUKTUR DER RICHTLINIE 92/51/EWG . . . . . . . . . . 241

E. INHALT DER RICHTLINIE $92 / 51 /$ EWG . . . . . . . . . . . . . . 242

1. Der Begriff "Diplom" genäß der Richtlinie 92/5I/EWG . . . . . 242

a. Alternative 1: postsekundäre Ausbildung von 1 oder 2 Jahren 242

b. Alternative 2: Berufsausbildungen i.S. des Aahanges C . . . 244

c. Weitere Voraussetzungen . . . . . . . . . . . . . . 247

2. Drittstaatsdiplome . . . . . . . . . . . . . . . 248

3. Parallele und frühere Ausbildungsgänge . . . . . . . . . 248

4. Der Begriff "Prüfungszeugnis" gemäß der Richtinie 92/51/EWG . 250

5. Der Begriff "Befähigungsnachweis" gemäß der Richtlinie

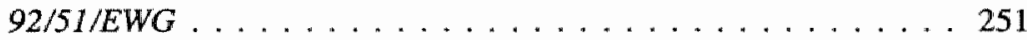

6. Der Begriff "reglementierte Ausbildung" gemäß der Richtlinie

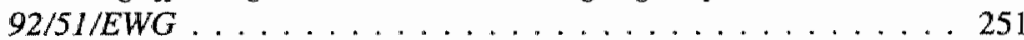

7. Anerkennungsregelung, wenn der Aufnahmestaat ein Diplom i.S. der Richtlinie 92/51/EWG oder der Richtlinie 89/48/EWG fordent . . 252

8. Anpassungsinstrumente gemäß Art. 4 der Richtlinie 92/51/EWG . 255

a. Unterschiede in der Ausbildungsdauer . . . . . . . . . . 255

b. Unterschiede in den Ausbildungsinhalten .......... 256

c. Die Einschränkungen der Wahlfreiheit . . . . . . . . . . . 257

d. Der Anpassungslehrgang . . . . . . . . . . . . . . . . 259

e. Die Eignungsprüfung . . . . . . . . . . . . . . . . . . . 260

9. Die Anerkennungsregelung, wenn der Aufnahmestaat ein Diplom fordert und der Antragsteller ein Prüfungszeugnis besitzt . . . . . 260

10. Anerkennungsregelung, wenn der Aufnahmestaat ein Prüfungszeugnis fordert . . . . . . . . . . . . . . . . . . . . 261

11. Die Sonderregelung für die Anerkennung sonstiger Qualifikationen 261

12. Die Schlußbestimmungen .................. 262 
Teill $\mathbf{V}$

Fallstudien

\section{Fallstudie I}

Die rechtsberatenden Berufe ...................... 265

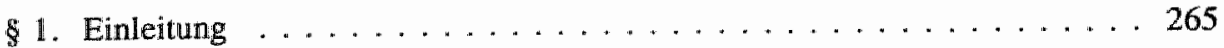

\$2. Die Ausnahmebestimmung des Art. 55 EGV . . . . . . . . . . . 266

83. Die Dienstleistungsrichtlinie $77 / 249 /$ EWG . . . . . . . . . . . . . 271

A. DER REgelungsbereich DER RICHTLINiE 77/249/EWG . . . . . . . . 271

B. DIE RECHTSPRECHUNG ZUR UMSETZUNG DER RICHTLINIE

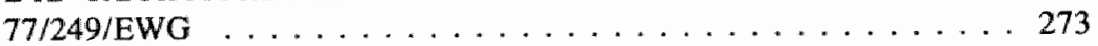

C. DAS VERHÄLTNIS ZWISCHEN DER RICHTLINIE 77/249/EWG UND DER

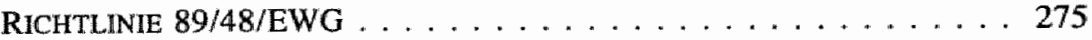

\$ 4. Der Entwurf der zukünftigen Niederlassungsrichtlinie . . . . . . . . . 276

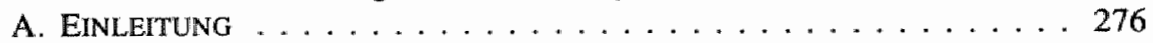

B. INHALT DES RICHTLINIENENTWURFS . . . . . . . . . . . . . 277

1. Allgemeine Übersicht ... . . . . . . . . . . . . . . 277

2. Erläuterungen zu den einzelnen Artikeln ... . . . . . . . 279

3. Kritik am Richtlinienentwurf . . . . . . . . . . . . . . 284

§. Reglementierung der rechtsberatenden Tătigkeit $\ldots \ldots \ldots \ldots \ldots$

§ 6. Der Begriff "rechtsberatender Beruf" im Sinne der Richtlinie 89/48/EWG 291

\$7. Die Umsetzung der Richtlinie $89 / 48 /$ EWG für die rechtsberatenden Beru-

fe . . . . . . . . . . . . . . . . . . . . . . . . . 292

A. DIE BUNDESREPUblik DEUTSCHLAND . . . . . . . . . . . . 293

1. Die rechtsberatenden Berufe in der Bundesrepublik Deutschland . 293

2. Der Rechtsanwait . . . . . . . . . . . . . . . . . . . . 295

a. Gesetz über die Eignungsprüfung für die Zulassung zur Rechtsanwaltschaft . . . . . . . . . . . . . . 295

b. Durchführung der Eignungsprüfung für Rechtsanwälte . . . . 304

3. Der Patentanwalt .................... . . 305

a. Gesetz über die Eignungsprüfung für die Zulassung zur Patent-

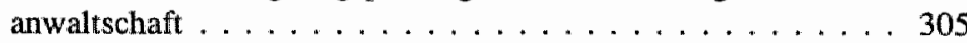

4. Wirtschaftsprüfer und vereidigter Buchprüfer . . . . . . . . . . . 309

a. Zweites Gesetz zur Ändenung der Wirtschaftsprüferordnung . 309

b. Prüfungsgebiete der Eignungsprüfung für Wirtschaftsprüfer . . 312

c. Prüfungsgebiete der Eignungsprüfung als vereidigter Buchprüfer . . . . . . . . . . . . . . . . . . 313 


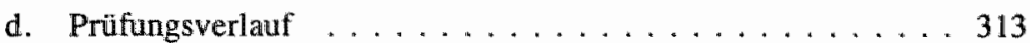

5. Steuerberater ... . . . . . . . . . . . . 315

a. Fünftes Gesetz zur Änderung des Steuerberatungsgesetzes . . . 315

6. Beurteilung der Umsetzung für die rechtsberatenden Berufe . . . 317

a. Beurteilung der Umsetzung für Rechtsanwälte . . . . . 317

b. Beurteilung der Umsetzung für die Patentanwälte, für Wirtschaftsprüfer und für die Steuerberater . . . . . . . . . . . . 319

B. DÄNEMARK . . . . . . . . . . . . . . . . 319

1. Einführung . . . . . . . . . . . . . . . . . . 319

2. Die rechtsberatenden Berufe in Dänemark . . . . . . . . 320

3. Beurteilung der Umsetzung für die rechtsberatenden Berufe . . . 322

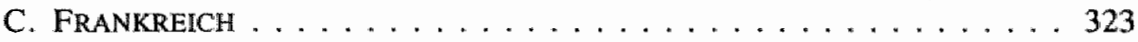

1. Einleitung . . . . . . . . . . . . . . . 323

2. Avocat . . . . . . . . . . . . . . . . . . . . 324

3. Beurteilung der Umsetzung für den Rechtsanwalt . . . . . . . . 325

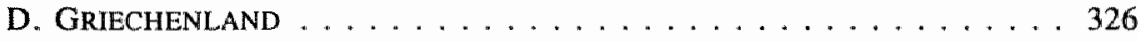

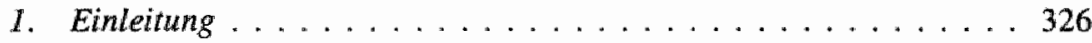

2. Beurteilung der Umsetzung für den Rechtsanwalt . . . . . . . . 328

E. IRLAND . . . . . . . . . . . . . . . . . . . . . . . . . . . . . . 329

1. Einführung . . . . . . . . . . . . . . . . . . . . 329

2. Die rechtsberatenden Berufe in Irland . . . . . . . . . 329

3. Solicitors . . . . . . . . . . . . . . . . . . . . . 329

4. Barristers . . . . . . . . . . . . . . . . . . . . 330

5. Beurteilung der Umsetzung für die rechtsberatenden Berufe . . . 331

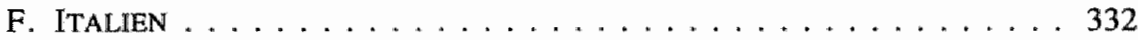

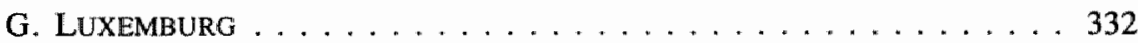

1. Einführung . . . . . . . . . . . . . . . . . 332

2. Beurteilung der Umsetzung für den Rechtsanwalt . . . . . . . . 333

H. NIEDERLANDE . . . . . . . . . . . . . . . . . . . . . . . . 334

1. Rechtsanwalt ................... 334

a. Einleitung . . . . . . . . . . . . . . . . 334

b. Inhalt der Regeling EG-verklaring . . . . . . . . . . 335

c. Inhalt des Reglements . . . . . . . . . . . . . 336

d. Beurteilung der Umsetzung für den Rechtsanwalt . . . . . 338

2. Patentanwalt . . . . . . . . . . . . . . . . . 340

a. Einleitung . . . . . . . . . . . . . . . . 340

b. Inhalt der Umsetzungsmaßnahme . . . . . . . . . 340

c. Beurteilung der Umsetzung für den Patentanwalt . . . . . . 341

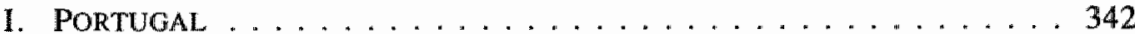

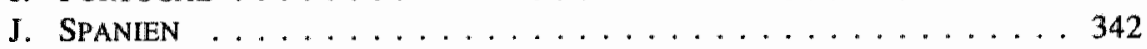

K. VEREINIGTES KÖNIGREICH $\ldots \ldots \ldots \ldots \ldots \ldots \ldots \ldots \ldots . \ldots . \ldots 343$

1. Einführung ..................... 343

2. Die rechtsberatenden Berufe im Vereinigten Königreich . . . . 344

a. Solicitor (England und Wales) . . . . . . . . . . . 344

b. Solicitor (Schottland) . . . . . . . . . . . . 347 
Inthalt:sverzeichnis

c. Solicitor (Nordirland) . . . . . . . . . . . . . . . 348

d. Barrister (England und Wales) . . . . . . . . . . . 349

3. Beurteilung der Umsetzung für die rechtsberatenden Berufe . . . 349

Fallstudie II

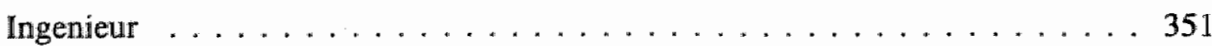

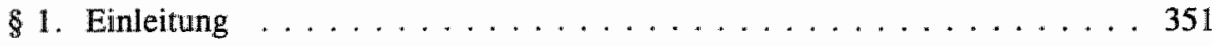

\$2. Eine sektorielle Richtlinie für Ingenieure . . . . . . . . . . . 354

\$3. Die Umsetzung der Richtlinie $89 / 48 /$ EWG für Ingenieure . . . . . . . 355

A. DIE BUNDESREPUBLIK DEUTSCHLAND . . . . . . . . . . . . 355

1. Die Reglementierung des Ingenieurberufes in der Bundesrepublik

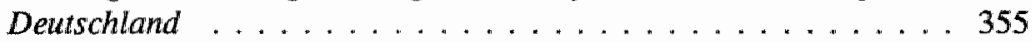

2. Umsetzungsmaßnahmen für Ingenieure in der Bundesrepublik Deutschland . . . . . . . . . . . . . . . . 356

3. Die Umsetzung durch Ländergesetzgebung . . . . . . . . . . . 357

a. Niedersachsen ..................... . . 357

b. Hamburg, Nordrhein-Westfalen, Rheinland-Pfalz . . . . . . 358

c. Baden-Württemberg, Hessen, Saarland, Sachsen-Anhalt, Schles-

wig-Holstein, Thüringen . . . . . . . . . . . . . 360

4. Beurteilung der Umsetzung für Ingenieure . . . . . . . . . . . . . 360

a. Beurteillung der Umsetzung für Ingenieure in Niedersachsen . 361

b. Beurteilung der Umsetzung für Ingenieure in Hamburg, Nord-

rhein-Westfalen und Rheinland-Pfalz ............ 362

c. Beurteilung der Umsetzung für Ingenieure in Baden-Württemberg, Hessen, Saarland, Sachsen-Anhalt, Schleswig-Holstein, Thüringen . . . . . . . . . . . . . . . . . . 362

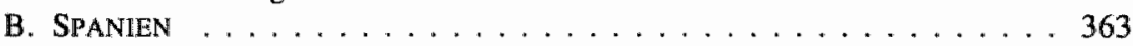

1. Die Umsetzungsregelung . . . . . . . . . . . . . . . . 363

2. Die Beurteilung der Umsetzung . . . . . . . . . . . . . . 363

C. ÖSTERREICH . . . . . . . . . . . . . . . . . . . . . . . 364

1. Die Umsetzungsregelung . . . . . . . . . . . . . . . . . 364

2. Beurteilung der Umsetzung . . . . . . . . . . . . . . . . . . 364

Fallstudie III

Lehrer ............................... 365

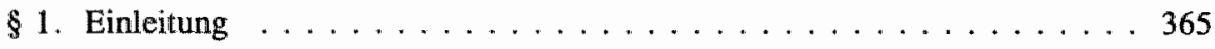

\$ 2. Konsequenzen des Art. 48 Abs. 4 EGV für den Lehrerberuf . . . . . . . 367

A. Einleitung . . . . . . . . . . . . . . . . . . . . 367

B. DiE SYSTEMATISCHE AKTION DER KOMMISSION .......... . 369

C. Reaktionen der MitgliedstaAten . . . . . . . . . . . 370 
1. Die Bundesrepublik Deutschland . . . . . . . . . . . . 370

2. Frankreich . . . . . . . . . . . . . . . 372

3. Italien . . . . . . . . . . . . . . . . . . . 373

4. Niederlande . . . . . . . . . . . . . . . . . . 373

5. Dänemark, Großbritannien und Irland . . . . . . . . . . 374

6. Spanien unä Portugal . . . . . . . . . . . . . . 374

D. VERGLEICH ZWISCHEN DER DEUTSCHEN UND DER NIEDERLÄNDISCHEN

REGELUNG . . . . . . . . . . . . . . . . . . . . . . 375

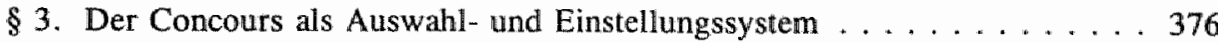

$\$ 4$. Die Umsetzung der Richtlinie 89/48/EWG für Lehrer $\ldots \ldots \ldots \ldots \ldots 378$

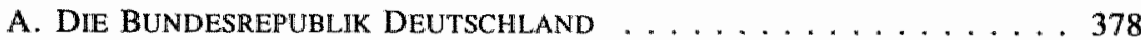

1. Die Reglementierung der Lehrerausbildung in der Bundesrepublik Deutschland . . . . . . . . . . . . . . . . . 378

2. Umsetzungsmaßnahmen für Lehrer in der Bundesrepublik Deutschland . . . . . . . . . . . . . . . . . . . . . . . . 379

3. Die Umsetzung in der Ländergesetzgebung . . . . . . . . . . 383

a. Hamburg . . . . . . . . . . . . . . . . . 383

b. Bayern . . . . . . . . . . . . . . . . . . 387

c. Hessen . . . . . . . . . . . . . . . . . . . . . 387

4. Beurteilung der Umsetzung für Lehrer . . . . . . . . . . . . 388

a. Beurteilung der Umsetzung für Lehrer in Hamburg . . . . . 388

b. Beurteilung der Umsetzung für Lehrer in Bayern . . . . . . 388

c. Beurteilung der Umsetzung für Lehrer in Hessen . . . . . . . 388

B. DÄNEMARK . . . . . . . . . . . . . . . . . . . . . . . 389

1. Die Reglementierung der Lehrerausbildung in Dänemark . . . . . 389

2. Umsetzungsmaßnahmen für Lehrer in Dänemark . . . . . . . . . 389

3. Beurteilung der Umsetzung . . . . . . . . . . . . . . . . . . 389

C. FRANKREICH . . . . . . . . . . . . . . . . . . . . . . . . . 390

1. Die Reglementienung der Lehrerausbildung in Frankreich . . . . 390

2. Hochschullehrer . . . . . . . . . . . . . . . . . . . 390

3. Beurteilung der Umsetzung . . . . . . . . . . . . . 391

D. IRLAND . . . . . . . . . . . . . . . . . . . . . . . . . . 392

1. Die Reglementierung der Lehrerausbildung in Irland . . . . . . . 392

2. Umsetzungsmaßnahmen für Lehrer in Irland . . . . . . . . . . 393

3. Beurteilung der Umsetzung . . . . . . . . . . . . . . . . . 393

E. LuXeMBurg . . . . . . . . . . . . . . . . . . . . . . . . . . . . 394

1. Die Reglementienung der Lehrerausbildung in Luxemburg . . . . 394

2. Umsetzungsmaßnahmen für Lehrer in Luxemburg . . . . . . . . . . 394

3. Die Umserzung für Lehrer des allgemeinen Sekundarschulbereichs 394

4. Loi du 13 août 1992 modifiant la loi modifiée du 10 juin 1980 portant planification des besoins en personnel enseignant de l'enseignement postprimaire . . . . . . . . . . . . . . . . . 395 
Inhallsverceichnis

5. Règlement grand-ducal du 26 novembre 1992 concernant le stage pédagogiqué des professeurs de l'enseignement secondaire . . . . . 395

6. Beurteilung der Umsetzung . . . . . . . . . . . . . . . . 396

7. Die Umsetzung für Lehrer des technisch-beruflichen Sekundarschulbereichs . . . . . . . . . . . . . . . . . . 397

F. NIEDERLANDE . . . . . . . . . . . . . . . . . . . . . . . 398

1. Die Reglementierung der Lehrerausbildung in den Niederlanden . 398

2. Umsetzungsmaßnahmen für Lehrer in den Niederlanden . . . . . 399

3. Beurteilung der Umsetzung . . . . . . . . . . . . . . . . . . . 400

G. VEREINIGTES KönIGREICH . . . . . . . . . . . . . . . . . . . 401

1. Die Reglementierung der Lehrerausbildung im Vereinigten Königreich . . . . . . . . . . . . . . . . . . . . . . . . 401

2. Umsetzungsmaßnahmen für Lehrer im Vereinigten Königreich . . . 401

a. England und Wales ... . . . . . . . . . . . . . . 402

b. Schottland ....................... 402

c. Nordirland ... . . . . . . . . . . . . . . . 403

3. Beurteilung der Umsetzang ................. 403

\section{Teil VI}

Gesamtbeurteilung des horizontalen Ansatzes . . . . . . . . . . . . . 407

$\$ 1$. Beurteilung der Umsetzung der Richtlinie $89 / 48 / E W G \ldots \ldots . \ldots . . . .407$

A. Formelle Kategorisierung . . . . . . . . . . . . . . . . . 407

1. Beurteilungsphase I: Anfang 1991 - Ende 1992 . . . . . . . . . 408

2. Beurteilungsphase II: Anfang 1993 bis Anfang 1995 . . . . . . . 409

B. Materielle Kategorisierung . . . . . . . . . . . . . . 411

C. VERGLEICH MIT DEM GENERELLEN UMSETZUNGSPROZENTSATZ DER MITGLIEDSTAATEN ... . . . . . . . . . . . . . . . . . 419

D. VERGLEICH MIT DER UMSETZUNGSÜBERSICHT DER KOMMISSION ZU DEN DIPLOMANERKENNUNGSRICHTLINIEN . . . . . . . . . . . 421

E. Gründe FÜr diE VERSPÄTETE UMSETZUNG . . . . . . . . . . . . . . 423

\$ 2. Die direkte Anwendung der Richtlinie 89/48/EWG . . . . . . . . . . 426

8. Vergleich zwischen dem horizontalen und dem vertikalen Anerkennungssystem . . . . . . . . . . . . . . . . . . . . . . . . . . . . . . . . . 429

A. EINFUHRUNG ... . . . . . . . . . . . . . . . . . . . . 429

B. Vor- UND NACHTELle DER BEIDEN ANERKENNUNGSSYSTEME . . . . . 430

C. SCHLUBFOLGERUNGEN FÜR EINE ZUKÜNFTIGE HARMONISIERUNGSPOLITIK . . . . . . . . . . . . . . . . . . . . . . . 434 
\& 1. Die Mitteilung der Kommission über die akademische und berufliche Anerkennung ......................... 439

\$2. Die Kompetenz der EG im Bereich der allgemeinen und beruflichen Bildung ... . . . . . . . . . . . . . . . . . . . . 443

A. Der ANWENDUNGSBEREICH des ART. 126 EGV . . . . . . . . . 443

B. Der ANWENDUngsbereICH des ART. 127 EGV . . . . . . . . . . 444

C. DAS VERHÄLTNIS DER ART, 126, 127 EGV ZU DEN BISHERIGEN KOM-

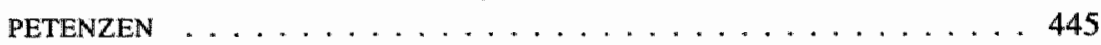

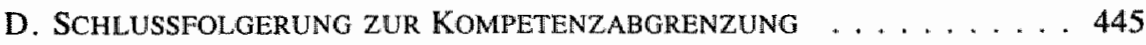

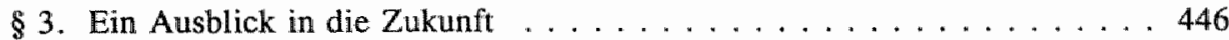

\section{Samenvatting,}

De erkenning van diploma's in de Europese Gemeenschap

Summary

The recognition of diplomas in the European Community . . . . . . . 463

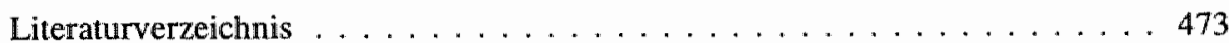




$$
\text { ( }
$$

\title{
Abkürzungsverzeichnis
}

\author{
a.a.O. \\ am angegebenen Ort \\ ABI. \\ Amtsblatt der Europaischen Gemeinschaften \\ Abs. \\ Absatz \\ AcP \\ AdvBl. \\ Archiv für civilistische Praxis \\ AJDA \\ Advocatenblad \\ AJCL \\ Annuaire Juridique de Droit Administratif \\ AJIL \\ AnwBl. \\ American Journal of Comparative Law \\ American Journal of International Law \\ Anwaltsblatt \\ AöR \\ Archiv des öffentlichen Rechts \\ Art. \\ Artikel \\ Aufl. \\ ausf. \\ AWD/RIW \\ Auflage \\ ausführlich \\ Außenwirtschaftsdienst / Recht der internationalen Wirt- \\ schaft \\ Bay VBI. \\ $\mathrm{BB}$ \\ Bd. \\ BGBI. \\ BGH \\ BNotO \\ BRAGO \\ BRAK-Mitt. \\ BRAO \\ BReg. \\ BR-Drucks. \\ BT-Drucks. \\ Bull. \\ BVerfG \\ BVerwG \\ bzw. \\ CCBE \\ $\mathrm{CDE}$ \\ Bayerische Verwaltungsblätter \\ Der Betriebs-Berater \\ Band \\ Bundesgesetzblatt \\ Bundesgerichtshof \\ Bundlesnotarordnung. \\ Bundlesrechtsanwaltsgebührenordnung \\ Mitteilungen der Bundesrechtsanwaltskammer \\ Bundesrechtsanwaltsordnung \\ Bundesregierung \\ Drucksache des Deutschen Bundesrates \\ Drucksache des Deutschen Bundestages \\ Bulletin der Kommission der Europäischen Gemeinschaften \\ Bundesverfassungsgericht \\ Bundesverwaltungsgericht \\ beziehungsweise \\ Conseil des Barreaux de la Communauté Europénne \\ Cahiers de droit européen
}




\begin{tabular}{|c|c|}
\hline CEDEFOP & Europäisches Zentrum für die Förderung der Berufsbildung \\
\hline CELEX & Communitatis Europeae Lex (= EG-Datenbank) \\
\hline CMLR & Common Market Law Reports \\
\hline CMLRev. & Common Market Law Review \\
\hline ColJTransL & Columbia Journal of Transnational Law \\
\hline $\mathrm{DB}$ & Der Betrieb \\
\hline d.h. & das heißt \\
\hline Dir.Sc.Int. & Diritto Scienzia Internationale \\
\hline Diss. & Dissertation \\
\hline DJT & Deutscher Juristentag \\
\hline DNotZ & Deutsche Notarzeitung \\
\hline Dok. & Dokument \\
\hline DöD & Der öffentliche Dienst \\
\hline DöV & Die öffentliche Verwaltung \\
\hline DRiG & Deutsches Richtergesetz \\
\hline DRiZ & Deutsche Richterzeitung \\
\hline DUZ & Deutsche Universitätszeitung \\
\hline DVBI. & Deutsches Verwaltungsblatt \\
\hline DVO & Durchführungsverordnung \\
\hline EA & Europa-Archiv \\
\hline ECU & European Currency Unit \\
\hline EEA & Einheitliche Europäische Akte \\
\hline EFTA & $\begin{array}{l}\text { Europäische Freihandelszone, Europaische Freihandels- } \\
\text { assoziation }\end{array}$ \\
\hline $\mathrm{EG}$ & Europäische Gemeinschaft(en) \\
\hline EGV & EG-Vertrag (nach dem 1. November 1993) \\
\hline EIPA & European Institut \\
\hline EJIL & European Journal of International Law \\
\hline ELR & European Law Review \\
\hline EP & Europäisches Parlament \\
\hline EU & Europäische Union \\
\hline EuGH & Gerichtshof der Europäischen Gemeinschaften \\
\hline EuGRZ & Europäische Grundrechtszeitschrift \\
\hline EuR & Europarecht \\
\hline EuZW & Europäische Zeitschrift für Wirtschaftsrecht \\
\hline EWG & Europäische Wirtschaftsgemeinschaft \\
\hline EWGV & $\begin{array}{l}\text { Vertrag zur Gründung der Europäischen Wirtschaftsgemein- } \\
\text { schaft (bis zum 1. November 1993) }\end{array}$ \\
\hline EWR & Europäischer Wirtschaftsraum \\
\hline f. & folgende Seite \\
\hline ff. & folgende Seiten \\
\hline FordhamInt.LJ & Fordham International Law Journal \\
\hline Foro It. & Foro Italiano \\
\hline FS & Festschrift \\
\hline GA & Generalanwalt \\
\hline
\end{tabular}


GATT

Gazz. Uff.

GB

GBI.

GBTE-Kommentar

GdP

GewArch

GG

$\mathrm{gg}$

GRUR Int.

GTE-Handbuch

GS

GYbIL

HarvILJ

Hrsg.

ICLQ

INF

Int.Bus.Law

Int. Lawyer

IPRax

JAG

JAO

$\mathrm{Jb}$.

$\mathrm{JbEI}$

JCP

JDI

Jg.

JO

JöR

JT

JTDE

Jur. Cl.

Jus

JWTL

$\mathrm{JZ}$

KMK
Allgemeines Zoll- und Handelsabkommen/General Agreement on Tariffs and Trade

Gazzetta Ufficiale

Gesamtbericht der Kommission

Gesetzblatt

v. d. Groeben-v. Boeckh--Thiesing-Ehlermann, Kommentar zum EWG-

Vertrag

Gazette du Palais

Gewerbearchiv

Grundgesetz für die Bundesrepublik Deutschland

gegebenenfalls

Gewerblicher Rechtsschutz und Urheberrecht, Auslandsund internationaler

Teil

Handbuch für Europaische Wirtschaft hsg. von Hans von der Groeben, Hans

von Boeckh, Jochen Thiesing und C.-D. Ehlermann, Loseblattsig. Baden-

Baden

Gedächnisschrift

German Yearbook of International Law

Harvard International Law Journal

Herausgeber

International and Comparative Law Quaterly

Die Information über Steuer und Wirtschaft

International Business Law

The International Lawyer

Praxis des Internationalen Privat- und Verfahrensrechts

Juristenausbildungsgesetz

Juristenausbildungsordnung

Jahrbuch

Jahrbuch der Europäischen Integration

Jurisclasseur périodique - La semaine juridique

Journal

Jahrgang

Journal Officiel

Jahrbuch des öffentlichen Rechts

Journal des Tribunaux

Journal des Tribunaux de droit européen

Juris-Classeur

Juristische Schulung

Journal of World Trade Law

Juristenzeitung

Kultusministerkonferenz 


KOM
KSE
LIEI
MDR
MittHV
MJ
MLR
m.w.N.
NewLJ
n.F.
NILR
NJB
NJW
NVwZ
NWVBl.
NZZ
OECD
PharmZ.
Prot.
RabelsZ
RBerG
RdA
Rev.franc.
adm.publ.
Rev.Marché
unique eur.
Rev. des Sc.
RGBl.
Riv.dir.eur.
RivDIPP
RdJB
Rdnr
RIW
RL
RMC
RM-Themis
Rs.
RTDE
RW
S.
SEPLIS
SEW
S.
RW

S.I.
Kommission

Kölner Schriften zum Europarecht

Legal Issues of European Integration

Monatsschrift für deutsches Recht

Mitteilungen des Hochschulverbands

Maastricht Journal of European and Comparative Law

Modern Law Review

mit weiteren Nachweisen

New Law Joumal

neue Fassung

Netherlands International Law Review

Nederlands Juristenblad

Neue Juristische Wochenschrift

Neue Zeitschrift für Verwaltungsrecht

Nordrhein-Westfällisches Verwaltungsblatt

Neue Zürcher Zeitung

Organisation für wirtschaftliche Zusammenarbeit und Entwicklung

Pharmazeutische Zeitung

Protokoll

Rabels Zeitschrift für ausländisches und internationales

Privatrecht

Rechtsberatergesetz

Recht der Arbeit

Revue française de Droit Administratif

Revue du Marché unique europénne

Revue des Sciences econoiques

Reichsgesetzblatt

Rivista di Diritto

Rivista di Diritto Internationale Privato et Processuale

Recht der Jugend und des Bildungswesens

Randnummer

Recht der Internationalen Wirtschaft

Richtlinie

Revue du Marché Commun

Rechtsgeleerd Magazijn Themis

Rechtssache

Revue trimestrielle du droit europeen

Rechtskundig Weekblad

Seite

Europäisches Sekretariat der Freien Berufe

Sociaal Economische Wetgeving

Statutory Instrument 
Slg.

Stb.

TBH

TBP

TexasILJ

UNESCO

VBIBW

Verfo

VGH

VO

Vorb.

VVDStl.

VwR

WEU

WIB

WissR

WR

WSA

WuV

WuW

WWU

YbEL

ZaöRV

ZAR

Z.B.

ZBR

ZfRV

ZGR

ZHR

Ziff.

ZPO

ZRP

ZVgl.R.Wiss
Sammlung der Rechtsprechung des EuGH

Staatsblad

Tijdschrift voor Bestuurswetenschappen en Publiekrecht

Tijdschrift voor Belgisch Handelsrecht

Texas International Law Journal

Organisation der Vereinten Nationen für Erziehung,

Wissenschaft und Kultur

Verwaltungsblätter für Baden-Württemberg

Verfahrensordnung

Verwaltungsgerichtshof

Verordnung

Vorbemerkung

Veröffentlichungen der Vereinigung deutscher Staatsrechts-

lehrer

Verwaltungsrecht

Westeuropäische Union

Die Woche im Bundestag

Wissenschaftsrecht, Wissenschaftsverwaltung, Wissenschaftsförderung, Zeitschrift für das Recht und die Verwaltung der wissenschaftlichen Hochschulen

Wirtschaft und Recht

Wirtschafts- und Sozialausschuß

Wirtschaft und Verwaltung

Wirtschaft und Wettbewerb

Wirtschafts- und Währungsunion

Yearbook of European Law

Zeitschrift für ausländisches und öffentliches Recht und Völkerrecht

Zeitschrift für Ausländerrecht

zum Beispiel

Zeitschrift für Beamtenrecht

Zeitschrift für Rechtsvergleichung, Internationales Privatrecht und Europarecht

Zeitschrift für Unternehmens- und Gesellschaftsrecht

Zeitschrift für das gesamte Handelsrecht und Wirtschaftsrecht

Ziffer

Zivilprozeßordnung

Zeitschrift für Rechtspolitik

Zeitschrift für vergleichende Rechtswissenschaften 
Prolog 


$$
\mid
$$

\section{Prolog}

\section{$\S 1$. Einleitung}

Der europäische Binnenmarkt warf seine Schatten voraus. In vielen Bereichen kündigten sich seit der Veröffentlichung des Weißbuchs der Kommission Veränderungen des rechtlichen Ordnungsrahmens an oder wurden zumindest gefordert'. Verschiedene Kräfte trieben die Diskussion voran. Zum Teil ging der Impuls unmittelbar von Bestrebungen der EG-Kommission zur Rechtsangleichung aus ${ }^{2}$, teilweise waren es nationale Interessen, die Veränderungen im bisherigen Ordnungsgefüge erstrebenswert erscheinen \ießen. Einen nicht unerheblichen Beitrag leistete die Rechtsprechung des Europäischen Gerichtshofs. Gerade in den letzten Jahren zeichnete sich der Gerichthof für einige einschneidende Entwicklungen hinsichtlich der Personenverkehrsfreiheit verantwortlich, nachdem er zuvor seit Mitte der siebziger Jahre vor allem der Warenverkehrsfreiheit zum Durchbruch werholfen hatte ${ }^{3}$. Die Haltung des Gerichtshofs zeigte sich in einer strengen Anwendung des Verbots diskriminierender Maßnahmen, unabhängig davon, ob diese direkt oder indirekt, offenkundig oder mehr versteckt aufgrund der Staatsangehörigkeit unterscheiden. Auch zeigte der EuGH gerade in jüngster Zeit eine stärkere Bereitschaft nichtdiskriminierende nationale Maßnahmen einem Proportionalitätstest zu unterwerfen, soweit diese als Beschränkungen geeignet sind, die Freiziigigkeit und den Dienstleistungsverkehr zu behindern.

Die zunehmende Durchsetzung der Freiheiten des Gemeinsamen Marktes, der Freizügigkeit, der Niederlassungs- und Dienstleistungsfreiheit, durchlöicherte die Schutzmauern, die von den nationalen Gesetzgebern und Berufsorganisationen um ihre Märkte,

1. Kommission der Europåüschen Gemeinschaften, Vollendung des Binnenmarktes, Weißbuch der Kommission an den Europäischen Rat vom 14. Juni 1985. Zur Entstehungsgeschichte Pelkmans/Bentler, Jahrbuch der Europaischen Integration 1985, 149 ff..

2. Im Laufe der sieben Jahre zwischen Veröffertilichung des WeiBbuchs und dem 1. Januar 1993 hat die Konmission 282 WeiBbuchworschläge yorgelegt. Hinzu kamen moch mehr als 30 weitere Vorschlage, deren Vorlage nachträglich noch als erforderlich angesehen wurde. Siehe dazu Trumpf 1992, 5. Siehe zuletzt dazu den Bericht der Kommission, Der Binnemmarkt in der Gemeinschaft - Bericht fur das Jahr 1993 - KOM (94) 55 endg. vom 14. März 1994.

3. Johnson/O'Keeffe, CMLRev. 1994, $1313 \mathrm{ff}$. 
ihre Ausbildungssysteme, ihre Berufs- und Standesordnungen gezogen wurden. Ein wachsender Wettbewerb zwischen inländischen und ausländischen Anbietern und Berufsgruppen ist zu konstatieren ${ }^{4}$. Konkurrenz beginnt sich zwischen den Ausbildungsbedingungen und den Berufs- und Standesordnungen des Inlands und denen des europäischen Auslands zu bilden. Die ungleichen Wettbewerbsbedingungen lassen den Ruf nach Anpassung und die Frage nach der Konkurrenzfähigkeit des inländischen Ordnungsrahmens laut werden ${ }^{5}$. Die Rechtsprechung des Europäischen Gerichtshofs trägt ein Übriges zur Diskussion bei ${ }^{b}$.

\section{§ 2. Der Binnenmarkt und die freien Berufe}

Eine Wandlung zeichnet sich vor allem bei den freien Berufen $a b^{7}$. Für diese gewinnen die Niederlassungs- und Dienstleistungsfreiheit in der EG zunehmend an Bedeutung ${ }^{8}$. Die deutsche Bundesregierung hat in ihrer Antwort auf eine Große Anfrage im Bundestag im April 1990 erklärt: "Die Entstehung des europäischen Binnenmarkts $\mathbb{1 9 9 2}$ vervollständigt die Betätigungsmöglichkeit der freien Berufe unter gleichberechtigten Bedingungen in allen Mitgliedstaaten. Etliche freie Berufe werden nicht mehr auf regionale oder lokale Tätigkeitsfelder beschränkt sein, sondern in größerem Maße grenzüberschreitend arbeiten können, als dies bisher der Fall war" 9 . Der Erweiterung des Tätigkeitsfeldes steht eine Intensivierung des Wettbewerbs im Inland gegenüber. "Tendenziell spricht einiges dafür, daß es vorzugsweise bei den Berufen zul einer Zunahme des Wenbewerbs in der Gemeinschaft kommen wird, die sehr eng mit der Wirtschaftstätigkeit verbunden sind, also etwa bei den Wirtschaftsprüfern, den Unternehmens- und Steuerberatern, den rechtsberatenden Freien Berufen sowie den Ingenieuren und Architekten. " ${ }^{10}$ In dem härteren Wettbewerb treffen auch inländisches und ausländischen Berufsrecht aufeinander". Besteht auf Gemeinschaftsebene zur Zeit keine Absicht zur

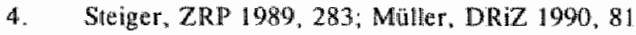

5. Hassemer/Kübler, 58. DJT, Tell E 73 f, Kühn, AnwBI. 4988,129 . Hauscllka AnwBI. 1988, 553; Zuck, NJW 1987, 3033; Zuck. E⿺GRZ 1987,585.

6. Dies gill vor allem für das Urteil in der Rechtssache Klopp, Unteil vom 12. Juli 1977, R5. 107/83, Sig. 1984, 297 \& sowie die Beanstandung der sogenamnten Gouvernantenklausel im Unteil vom 25 . Febnar 1988. Rs 427/85 - Kommission/Bundesrepublik Deutschland -, Slg. 1988, 1123. Die Entscheidungen Vlassopoulou, Urtail wom 7. Mai 1991, Rs-340/89 - Irène Vlassopoulou/Ministerium der Justiz, Bundes- und Europaangelegenheiten Baden-Württemberg, Slg. 19911-2357 und Kraus, Urteil vom 31. Măz 1993, Rs 19/92, Dieter Kraus/Land Baden-Würtemberg, Slg. 1993, 1-1663; NVwZ, 1993, 651 scheinen dagegen noch nicht auf den selben Widerhal bei den Berufsangehöngen zu stoßen.

7. Zum Wesen der freien Berufe siehe bereits Anraths 1930; Deneke 1956 und 1969; siehe auch SalhnertHerrmann/Rönnau/Trautwein, Teall I bis III; Wasilewski 1987; Insitut für Freie Berufe 1993.

8. Hack: Wasilewski in Erel/Hënemann, 7; Büschges, 121 .

9. Auskunft der Bundesregienung in: Lage der Freien Berufe im Zuge der Schaffung des europäischen Binnenmarktes, Antwort der Bundesregienung auf die Grobe Anfrage des Abgeord neten Doss u a. , Br. Drucks. 1146985 vom 26. April 1990, 18.

10. Bundesregierung, in: Luge der Freien Berufe, BT-Drucks, 11/6985, 23.

11. Kleine-Cosack, NJW 1988, 164, Rabe, NJW 1989, 1113, Schiefer, NJW 1987, 1978; Commichau, AnwBI. 1988. 314. 
Angleichung des Berufsrechts ${ }^{12}$, soll vielmehr ein Wettbewerb der Regelungssysteme gelten, so bedeutet dies jedoch, daß mit einer stärkeren Verwirklichung des Niederlassungsrechts für Freiberufler auch das Berufsrecht unter einen Anpassungs- und Veränderungsdruck zu stehen kommt.

Besonders bei den Juristen ist eine allgemeine Diskussionswelle bezüglich der Ausbildung ${ }^{13}$ sowie des Berufs- und Standesrechts zu konstatieren ${ }^{14}$. In der Bundesrepublik Deutschland haben die beiden Beschlüsse des Bundesverfassungsgerichts vom 14. Juli 1987 zum anwaltlichen Standesrecht die berufspolitische Diskussion eröfnet ${ }^{15}$. Inzwischen beruht diese Debatte zum Teil auch auf europäischen Triebfedern. Vor allem seit dem Urteil des EuGH vom 23. Februar 1988 zur Dienstleistungsfreiheit der Rechtsanwälte ${ }^{16}$ werden die unterschiedlichsten Auffassungen vertreten, welche Forderungen das Europäische Gemeinschaftsrecht an das nationale Berufsrecht stellt und wie sich der nationale Gesetzgeber auf die neuen Herausforderungen einstellen sollte $^{17}$. Auch die Richtlinie 89/48/EWG über die gegenseitige Anerkennung der Hochschuldiplome ${ }^{18}$, die auf juristische Berufe Anwendung findet, hat das Thre dazu bei-

12. Vgl. Kirschbaum, Diskussionsbeitrag in: Standort und Zukunft der Notare in Europa, MittBay Not 1990, Sonderheft, 29; Bundesregienung, im: Lage der Freien Berufe, BT-Drucks. 11/6985, 18.

13. Siehe dazu das ausfuhrliche Gutachten von Hassemer und Kübler zum 58. DJT 1990, Bd. I und die verschiedenen Bieiträge in Giehring/Haag/Hoffmam-Riem/Ott; aber auch die Beiträge von Bilda, Jus 1989, 681; Caesar, ZRP 1990, 346; Kötz ZRP 1980, 94; Großfeld, JZ 1986, 357; Basedow, NJW 1990, 959; Buchhol,, ZRP 1990, 254; Haas, BRAK-Mitt., 1989, 68; Hadding, NIW 1990, 1873; Hattenhaver, Jus 1989, 513; Koch, ZRP 1989, 281 ff; Koch, ZRP 1990, 41; Kroppil, Jus 1990, 75; Leo, Jus 1990, 242; Michaelis, Jus 1991, 798; Palm, JZ 1990, 609; Steiger, ZRP 1989, 283; Pieper, ZRP 1989, 201; Groffeld, NJW 1989, 875 ; Kotz, AnwBl. 1988, 320; Wassermann, NJW 1990, 1877 ;

14. Siehe dazu das Gutachten von Everling zum 58. DIT 1990, Bd.1 C 10; Van Camp 1989; Prütting 1990; Kübler 1982; Brüderle, ZGR 1990, $155 \mathrm{ff}$; Commichau, JZ 1988, 824 \#f; Deutscher Richter bund, DRiz 1992, $29 \mathrm{ff}$. Hahndorf in Dolzer/Hahndorf, $37 \mathrm{ff}$; Henning, DRiz 1992, 30; KespolhlWillemer, EuZW 1990, 88ff; Kewenig JZ 1990, 782 ff, : Rabe NJW 1989, 1113; Senninger. AnwBI. 1989, 298; Zuck, EuGRZ 1987, 585. In jüngster Zeit sprach sicl vor allem Alrens in deutlichen Worten für eine Deregulierung bei den rechtsberatenden Berufen aus, AnwB!. 1992, $247 \mathrm{ff}$. Altgemein zu den Standesordnungen der freien Berufe siehe Taupitz 1991.

15. BVerGE 76, 171 und BVerfGE 76, 176. Siehe dazu Schumann. AnwBI. 1990, 466 mit weiterem Nachweisen in Fußnote 9. Mit diesen beiden Entscheidungen wurde quasi das gesante anwalliche Standesrecht aufgehoben, da es über keine ausreichende gesetzliche Grundlage verfughte. Lediglich die Bestinmungen, die zur Weiterführung einer geord neten Rechtspflege unumgänglich nofwendig waren, blieben bestehen.

16. Urtell vom 23. Februar 1988, Rs 427/85 - Kommission/BR Deutschland -, Slg. 1988, 1123. Siehe dazu Blleckmann, JZ 1988, 509; Hausmann/Siegel in Prüting 1990, 105; Herbots "CDE 1988, 508; Korte, Migrantenrecht 1988, 272; Lonbay, ELR 1988, 347; Zuck, EuR 1988, 186

17. Bleckmann, JZ 1988, 509; Raczinski/Rogalla/Tomsche. AnwB1. 1989, 583; Stefener, AnwBI. 1988. 367: Weber, NVwZ 1990, 1ff; Winters, NJW 1988, 521; Zuck, EuGRZ 1987, 585; Zuck, EuR 1988 186; Zuck, BRAK.-Mitt. 1988, 278. Siehe allgemein auch Bakker in Jackson/Mc Goldnick, 325.

18. Richtlinie 89/48 des Rates vom 21. Dezember 1988 über eine allgeneine Regelung zur Anerkennung der Hochschuldiplome, die eine mindestens dreijăhrige Berufsausbildung abschliefen, ABI. $1989 \mathrm{Nr}$. L. 19 vom 24. Januar $1989,16$. 
getragen, die Gemüter zu erhitzen ${ }^{19}$. Die erwartete Richtlinie zur Niederlassung von Rechtsanwälten unter "home title", d.h. unter der Berufsbezeichnung des Herkunftslandes, wird den Umfang der Diskussion noch erweitern ${ }^{20}$.

Eine allgemeine, wirtschafts- und berufspolitische Debatte ergänzt jedoch diese europäischen Impulse ${ }^{2 t}$. Die Diskussion dreht sich vor allem um die Frage, ob die Markt-, Ausbildungs-, Berufs- und Standesordnungen der Vergangenheit heute noch zweckmäßig sind, ob sie den Bedürfnissen wachsender europäischer und internationaler Märkte noch genügen, ob sie nicht vielleicht eher die Berufsgruppen in ihrer Anpassungsfähigkeit behindern und zu Fehlentwicklungen geführt haben ${ }^{22}$. Deregullierung ist dabei häufig das Stichwort ${ }^{23}$.

Ausgelöst wurde diese Diskussion bei den Juristen durch den sprunghaften Anstieg der Zahl der Berufsangehörigen ${ }^{24}$. Besonders die Zunahme von Rechtsanwälten in Deutschlland auf mehr als 55.000 hat zur Auseinandersetzung mit der Frage geführt, ob die herkömmliche Ausbildung sowie das geltende Berufsrecht noch den gegenwärtigen Anfordlerungen gerecht wird ${ }^{25}$. Der ständig wachsende Zustrom auf die aus allen Nähten berstenden juristischen Fakultäten, die damit zusammenhängenden schlechten Studienbedingungen sowie die überlange Studiendauer haben die Debatte über Inhalt und Form des juristischen Studiums erneut aufflackern lassen ${ }^{26}$. Auch hier kann man zum

19. Wägenbaur, EuR 1987, 113; Commichau, IPRax 1989, 12; Everling, EuR 1989, 338; Everling, BRAK-Mitt. 1989, 166; Henninger. GewArch 1989, 259; Hüchting, BRAK-Mitt. 1989, 2; Tiemann, BRAK-Mitt. 1989, 3; Pertek, RMC 1990, 167; Laslett, LIEI 1990, 1; Barsade, The Intt. Lawyer 1994, 313 (318); Toumlin, NewLJ 1990, 1309; Baldi, RivDIPP 1991, 345; Beuve-Méry, RMC 1990, 293.

20. Kom (94) 572 endg., Vorschlag für eine Richtlinie des Europäischen Parlaments und des Rates zur Erleichterung der ständigen Ausübung des Rechtsanwaltsberufs in einem andleren Mitgliedstaat als dem, in dem die Qualifikation erworben wurde" Brüssel, den 21. Dezember 1994. Siehe dazu auch die Mitteilung in Agence Europe vom 28. Dezember 1994, 12. Hinsichthich der Entwicklung dieses Entwurts und dem ihm zugrunde liegenden CCBE Entwurfs sei auf Weil, Fordham Int. L. J. 1991-92, 699 sowie Barsade, The Int.Lawyer 1994, 313 (321) sowie Toumlin, Speech to the Foundation for European Studies am 24. Novernber 1993 verwiesen.

21. In der Bundesrepublik Deutschland bewirkten vor allem die Beschlüsse des Bundeswerfassungsgerichts vom 14. Juli 1987 zum anwaltichen Standesrecht eine breite berufspolitische Diskussion, BVerfGE 76, 171 und BVerGE 76, 176,; vgl. auch BVerfGE 77, 125

22. Basedow EuZW 1990, 73; Basedow, RabelsZ 1991, 410, Kühn, AnwB1. 1988, 129; Honmer, AnwBI. 1989 .651; Rabe, AnwB1. 1992, 146; Schmalz, BRAK-Mitt. 1989, 164. Siehe dazu auch den Beitrag won Van den Bergh in: Faure/Finsinger/Siegers/Van den Bergh, 21, der einen Teil der Berufs- und Standesregeln aus rechtsökonomischen Erwägungen ablehnt.

23. Deregulierungskomission, Erster Bericht 1990 sowie Abschlußbericht vom März 1991; Kay/Vickers, 228. Siehe auch Hassemer/Kübler, Gutachten zurn 58. DJT, E 108, die für eine Deregulierung der Juristenausbildung durch Regelungswerzicht pladieren sowie Ahrens, AnwBI. 1992, $247 \mathrm{ff}$.; Eidenmüller, MLR 1990, 604.

24. Everling, Gutachten zum 58. DJT, C 13 mit dem Hinweis auf die Prognose-Studie "Zur Zukunft der Anwaltschaft". AnwBl. Sonderheft Mürz 1987; Dellers, BRAK-Mitt. 1984, 113, der von einem Jahrzehme der Anwaltsschwemme spricht.

25. Strobel, AnwBI. 1988, 307; Everling, Gutachten gum 58. DJT, C 13

26. Hassemer/Kübler, Gutachten zum 58. DJT, E 38 weisen mit Nachdruck auf die unzumutbare Ausbildungssituation an deutschen juristischen Fakultäten hin. 
Teil wieder auf die europäischen Entwicklungen als Diskussionskatalysator verwei$\operatorname{sen}^{27}$. Denn unzweifelhaft ist die Studiensituation ebenso wie der Inhalt des juristischen Studiums von Einfluß auf die Wettbewerbsfähigkeit der deutschen Juristen mit ihren Kollegen aus den anderen Mitgliedstaaten ${ }^{28}$. Die Diskussion beschränkt sich natürlich nicht allein auf die Bundesrepublik Deutschland, auch in anderen Mitgliedstaaten, so etwa in Frankreich ${ }^{29}$, Großbritannien ${ }^{30}$ und Spanien ${ }^{31}$ haben die europäischen Entwicklungen zu einem Überdenken alter und häufig überholter Ausbildungssysteme sowie der Berufs- und Standesregeln geführt ${ }^{32}$. Das Ergebnis dieser in einigen Mitgliedstaaten vorgenommenen Umwälzungen der beruflichen Organisationsstruktur verdient in der Regel jedoch nicht das Prädikat "Deregulierung". Im Gegenteil, in Großbritannien und in Frankreich kann man weit eher eine Zunahme als eine Abnahme

27. So deutlich auch Behrens, der als Grund für die neuerliche Diskussion die Europäisierung der juristischen Berufe nennt, in Giehring/Haag/Hoffmann-Riem/Ott, 185 (1186). Siehe auch Basedow, NJW 1990, 959; Steiger, ZRP 1989, 283; Müllter, DRiZ 1990, 81; Staats, DRiZ 1990, 193. Willoweit, DUZ 1988, 17 spricht von einem Provinzialismus der deutschen Juristenausbildung; Willoweir/Großfeld, JZ 1990, 605. Siehe bereits Holch, NJW 1969, 1505.

28. Hassemer/Kübler, E73 beklagen bereits, daB Absolventen der deutschen Juristenausbildung nur schwer eine Beschäftigung bei den Institutionen der EG finden und verweisen dabei auf einen Vermerk der Kommission zur Einstellungspolitik vom 17. Januar 1989 (E 73. Fußnote 209); Kühn, AnwBl 1988, 129; Stobbe, NJW 1991, 2042.

29. Mit Gesetz Nr. 90.1259 vom 31. Dezember 1990 (JO vom 5. Januar 1991), das am 1. Januar 1992 in Kraft getreten ist, wurde der Beruf des Rechtsanwalts in Frankreich grundlegend geändert. Aufgrund der jüngsten Reformen wurde ein neuer Anwaltsberuf geschaffen. Seit dem 1. Januar 1992 besteht nur nach der avocat. Siehe dazu Bacrot/Fontbressin, Le nouvel Avocat; Sokol. The International Lawyer 1992, 1025 (1029); Sanglade in Tyrell/Yaqyb, 116. Mengel, AnwBl. 1993, 258. Zur Entwicklung Maier, AnwBI. 1989, 320: Henrichtreise 1992.

30. Anders als in Deutschland besteht in Großbritanuien eine wachsende Nachfrage nach Rechtsberatung. die von den praktizierenden Rechtsanwwillten nur mit Mühe bewältigt werden kann. Ebenso steigt die Anzahl won Gerichts- und Schiedswerfahren in London ständig. Auch in intemationalen Schiedsverfahren liegt London - zumindest zahlenmäBig - an der Spitze. Um dem großen Druck auf die Berufsgruppe entgegenzuwirken, aber auch um die Qualität der juristischen Dienstleistung zu verbessern, wurde durch den Lord Chancellor ein Reformprogramm im Januar 1989 vorgestellt: The Work and Organisation of the Legal Profession, Conveyancing by Authorised Practicioners und Contingency Fees. Vg1 dazu Spedding, 98: Triebel, AnwBI, 1989, 578 ff; : Abel, MLR 1989, 285; Bakker, AnwBI. 1993 245; Remmerz, Z.VgI.R.Wiss. 1994, 202; Smith, MLR 1989, 527. Dieses Reformprogramm hat jedoch nicht zu der wesentlichen Änderung der Berufsordnung geführt, die zunächst erwartet wurde. Allgemein zu den juristischen Berufen in Großbritannien, Tyrell/Yaqub, 300ff.; Wegerich 1992.

31. Martin Bernal, 115 weist auf Reformpläne für das juristische Studium in Spanien. Auf der 5. nationaIen Anwaltskonferenz in Palma de Majorca hatte auch die Berufsgnuppe für die Einfuhnung einer anwaltlichen Berufsausbildung plädiert, Borras, 9. Bisher muß̉ten jedoch Reformplâne, die eine berufliche Ausbildung nach dem Studienabschluß einführen wollten, aufgrund massiver Studentenproteste abgebrochen werden. Siehe zur Juristenausbildung in Spanien auch Dörig/Garcia-Castaner, AmwBI. 1990, 314 ff.; Calderón in Tyrell/Yaqub, 280

32. De Groot 1989, 14 plädiert für eine gnundsätzliche Umstrukturierung der Juristenausbildung in Europa Siehe dazu auch Neumayer, FS Zweigert, 505; Schmitthoff, JZ 1978, 498; Hondius, NJB 1991, 517 ; Steiger, ZRP 1989, 284; Flinterman, Publiek Domein 1988, 86; Jagtenberg, Ars Aequi 1989, 510. 
beruflicher Reglementierung konstatieren ${ }^{33}$. Stärkere Reglementienung bedeutet jedoch häufig eine Einbuße an Freizügigkeit innerhalb Europas. In den Niederlanden waren es vor allem die paramedizinischen Berufe und die Steuerberater, die eine gesetzliche Reglementierung ihres Berufstandes anstrebten. Mit diesem Wunsch stießien sie jedoch auf wenig Gegenliebe, da er in deutlichem Gegensatz zu der politisch erstrebten Deregulierung der Berufsreglementierung stand. Konflikte zwischen den Berufsgruppen und den einschlägigen Ministerien konnten daher nicht ausbleiben ${ }^{34}$.

\section{§ 3. Der Binnenmarkt und der öffentliche Dienst}

Es sind jedoch nicht nur die Juristen und auch nicht allein die freien Berufe, die von dieser Entwicklung unmittelbar betroffen sind. Auch der nationale öffentliche Dienst wird in zunehmendem Maße vom Konzept des Europäischen Binnenmarktes, von der Freizügigkeit der Arbeitnehmer, berührt. Dies bedeutet aber, daß das Beamtentum sich nicht mehr gänzlich diesem Wandel entziehen kann ${ }^{35}$. Wie bei den freien Berufen kann man auch für den öfentlichen Dienst eine zeitgleiche allgemeine politische Bewegung feststellen, die das traditionelle Beamtentum und seinen Tätigkeitsbereich generell zur Diskussion stellen möchte. Beide Strömungen haben jedoch zu einer Öffnung des bisher fast überall für Ausländer unzugänglichen Staatsdienstes geführt.

Maßgebend für diese Entwicklung waren wiederum Entscheidungen des EuGH ${ }^{36}$. In der Rechtsprechung des Europäische Gerichtshof sind die Bestimmungen über die Freizügigkeit stets weit ausgelegt gelegt worden. Der EuGH sieht die Gleichstellung der Arbeitnehmer aus den verschiedemen Mitgliedstaaten als einen zentralen Ansatz für die politische Fortentwicklung der Gemeinschaft ${ }^{37}$. So hat der Gerichtshof auch alle For-

33. Lonbay, ELR 1989, 363 nennt die Schaffung won zumindest drei neuen juristiscluen Berufe das Resultat einetr Debatte, die zur Verschmelzang der beiden Berufiszweige barrister und solicitor führen sollte. Auch die Kreation des "nouvel avocat" in Frankreich hat nicht zu einem weniger, sondern zu einem mehr an beruflicher Reglenentierung gefibhrt.

34. Schmeider 1994,88

35. Eschmann (1992); Becker, 2 mit Hinweisen auf die Diskussion anläflich des Deu tschen Beamtenbundes (Fulinote 11): Becker, Recht im Amt 1991, 178; Battis 1989; Dör. EuZW 1991, 565; Dubouis, rev framc. Droit adm. 1991, 903; Goehrlich/Brath. NVwZ 1989, 330; Groenedijk, NILR 1989, 107; Hochbaum, Der Staat 1990, 577; Jaeger, FS Delvaux, 139; Lenz, LIEI 1989, 75; Muller, Recht irm Ami 1990, 53; Riegel, ZTR 1991. 320; Riotte/ Fey, NWVBI. 1992, 7; Schäuble. 33; Stern, NWVBI. 1992, 7; Stiller, ZPPR 1991, 85; Thicle, DöD 1990, 229; Zjekow, DöD 1991, 11. Sehr krithisch hinsichtich dieser Entwickiung Lecheler, BayVBl. 1989, 417; Lecheler Die Verwallung 1989, 137; Lecheler 1990; Lecheler ZBR 1991.97; Loschelder, ZBR 1991, 102.

36. Urteile wom 17. Dezember 1980 und 26. Mai 192, Rs 149/79-Kommission/Belgien, SIg. 1980, 3881 und Slg. 1982, 1845; Urteil yom 3. Juni 1986, Rs 7/84 - Kommission/Frankreich, Slg. 1986, 1725 Urteil vom 3. Juni 1986, Rs 66/85 - Lawrie-Bium/Land Baden Würtembefg -, Slg. 1986.2121; Urteil vom 30. Mai 1989. Rs 33/1988 - Allúe und Coonan/Università degli studi di Venezia - , Slg. 1989, 1591; Urteil vom 27. November 1991, Rs C-4/91 - A. Bleis/Ministere de I'Education National, Sig.
1991, I-5627;

37. Wolker, GTE-Kommentar zum EWGV. Vorb. zu Art 48, Rdnr. $21 \mathrm{ff}$. 
men indirekter Diskriminierung untersagt ${ }^{38}$. Dagegen hat er die Ausnahme vom allgemeinen Recht auf Freizügigkeit für die Beschäftigung in der öffentlichen Verwaltung gemäß Art. 48 Abs. 4 EGV stets eng interpretiert ${ }^{39}$. Hierbei ist es ein feststehender Grundsatz in der Rechtsprechung des EuGH, daß Vertragsbegriffe wie der "Arbeitnehmer" ebenso wie "die Beschäftigung in der öffentlichen Verwaltung" als Germeinschaftsbegriffe angesehen werden und damit nach Gemeinschaftsrecht einheitlich auszullegen sind ${ }^{40}$. Als Konsequenz folgt hieraus, daß eine nicht unerhebliche Anzahl von Berufen, die häufig mit dem Beamtenstatus verknüpft sind, wie z.B. in Deutschland der Beruf des Lehrers an öffentlichen Schulen, von den europäischen Entwicklungen ebenso wie die freien Berufe berührt werden und hierauf reagieren mußten ${ }^{4 !}$.

Diese Rechtsprechung war von erheblichem Einfluß auf die Zulassungsregelungen zum öffentlichen Dienst in den Mitgliedstaaten ${ }^{42}$. Die Kommission hat diese Rechtsprechung zum Anlaß genommen, die Öffnung des öffentlichen Dienstes in den Mitgliedstaaten durchzusetzen ${ }^{43}$. Der öffentliche Dienst und die darin ausgeübten Berufe konn-

38. Urteil vom 12. Februar 1974, Rs 152/73 - Sotgit:/Deutsche Bundespost -, Slg. 1974, 153; Urteil vom 30. Mai 1989, Rs 33/88 - Allué und Coonan/Universitât Venedig - S1g. 1989, 1591; Unteil vom 8. Mai 1990, Rs C-175/88 - Biehl/Administration des contributions -. S/g. 1990 1 1779; In jüngster Zeit ist diese Rechtsprechung vor allem durch das Urteil vom 10. März 1993, Rs C-111/91. Kommissi on/Luxemburg, SIg. 1993, 1-817, Rdwr. 9 sowie das Urteil wom 23. Februar 1994, - I. Scholz/Opera Universitaria di Cagliari - Slg. 1994, 1-505, (521) Rdmr. 7 bestätigt worden. Siehe zur Frage der wersteckten Diskriminierung auch Wölker, im: GBTE-Kommentar zum EWGV, Art. 48, Rdnr 13 sowio Bleckmann. EuR 1987, 26 ff.

39. Zur Auslegung des Art. 48 Abs, 4 EWGV in der Literatur siehe bereits Wittkopp (1977) und Klinge (1980) sowie die ersten Kommentare zur Rechtsprechung des EuGH: Bleckmann. Administration publique 1981, 36; Druesne, RTDE 1981, 286; Wyat, ELR 1981, 454; Berchx, TBP 1982, 246; Karpenstein, in FS Constantinesco, 377. Bezuiglich der neueren Rechtsprechung sei verwiesen auf Curall, Rev. franc. d'adm, publ. 1988, 573; Goelurlich/Bräh. Dov 1987, 1038; Goehrlich/Bräth, NVwZ 1989, 330; Handoll ELR 1988, 223; Hochbaum/Eiselstein 1988; Hochbaum ZBR 1989, 33; Everling, DVBI. 1990, 226; Jaeger, Riv.dir.eur. 1990, 797; Everling in Baltis 1989, 23; Bartis, in Magiera 1990, 47; Hochbaum, Der Stat 1990, 577; Baclet-Hainque, AJDA 1990, 224. In jöngster Zeil sei auf die ausführliche Rechtsprechungsanalyse von Martin, CDE 1993, 555 sowie die beiden Monoggraphien aus 1992 von Eschmann und Becker verwiesen.

40. Urteil vom 17. Dezember 1980, Rs 149/79-Kommission/Belgien-(Zwischenurteil), Slg. 1980, 3881 (3901): Urteil vom 16. Juni 1987. Rs 225/85 - Kommission/Italien - Slg. 1987, 2625; Bleckmann, EuR 1987, 28 (45); Ewerling. DVBl. 1990, 225.

41. Nach einer Studie der Kommission aus dem Jahr 1988, Conditions of the Service of 'Teachers, 37, haben Lehrer in öfentlichen Schulen zumindest in sieben Mitgliedstaaten grundstatzlich Beamtenstatus. Niedobitek, 82; Handoll in De Witte, 1989, 31: Siehe dazu auch die Erörtenungem in der Fallstudie "Lehrer", Seite 365 .

42. Siehe dazu die verschiedenen Beiträge in Magiera/Stedentopf, Das Recht des öffentlichen Dienstes in den Mitgliedstaaten der Europäischen Gemeinschaft, sowie Verschueren, Migrantenrecht 1991, 10; Ziller 1988; Ziller 1993, 402 ff.; Ziller, Rev. franc. d"adm. publ. 1990, 467.

43. ABl. Nr. C 72 wom 18. März 1988 sowie der 11. Bericht der Kommission an das Europă ische Parlament, worin die Kommission wom Erfolg dieser Aktion Mitteilung macht, ABI. Nr. C 154 vom 6. Juni $1994,27 \mathrm{f}$. 
ten nicht mehr als terra reservata betrachtet werden. Deutschland ${ }^{44}$, Frankreich ${ }^{45}$ und Italien ${ }^{46}$ sahen sich gezwungen, einschneidende gesetzliche Änderungen ihres Beamtenrechts vorzunehmen. Spanien ${ }^{47}$ bereitete eine Gesetzesänderung vor. Dieser Gesetzesentwurf konnte schließlich im Dezember 1993 verabschiedet werden ${ }^{48}$ Nach dieser Neuregelung müssen die Angehörigen der anderen Mitgliedstaaten unter den selben Bedingungen wie Spanier in bestimmte Positionen im öffentlichen Dienst zugelassen werden ${ }^{49}$. Andere Mitgliedstaaten so etwa Luxemburg ${ }^{50}$, Griechenland ${ }^{51}$ und auch Belgien ${ }^{52}$ werden diesem Beispiel noch folgen müssen, wobei zumindest bei Griechenland und Belgien dies eine Verfassungsändenung erforderlich macht. In Dänemark ist 1990 durch eine Gesetzesänderung die Möglichkeit der Einstellung von Gemeinschaftsangehörigen unter beamten-ähnlichen Bedingungen geschaffen worden ${ }^{53}$. Auch in Großbritannien ist seit 1991 der Civil Service für Staatsangehörige der Mitgliedstaaten geöffnet. In Irland können Auswahlverfahren für den mittleren, gehobenen und höheren Dienst auf irische Staatsangehörige beschränkt werden ${ }^{54}$. Dies bedeutet jedoch keine gesetzliche Verpflichtung, so daß der irische Civil Service für Staatsange-

44. Mit dem Zehnten Gesetz zur Änderung dienstrechticher Vorschriften vom 20. Dezember 1993, BGBI. I, 2136 wurde nach einem schwierigen und stark umstrittenen Gesetzgebungswerfahren der affentliche Dienst im Beamtenverhältnis für Staatsangehörige der anderen Mitgliedstaaten geöffnet.

45. Duch Gesetz 91.715 vom 26. Juli 1991 wurde der Zugang zum französischen öffentlichen Dienst für Gemeinschaftsangehörige geöffnet. Gnundsätzlich bleibut zwar das Erfordernis der französischen Staatsangehörigkeit bestehen, hiervon kann jedoch gemäß Gemeralstatut 1983-86 Abschnitt I, Art. 5 bis bei solchen Stellen abgewichen werden, die weder unmittelbar noch mittelbar an der Ausübung hoheithcher Befugnisse des Staates teilhaben. Siehe dazu Ziller 1993, 405.

46. Decreto Legisłativo vam 3. Februar 1993, Nr. 93, Art. 37 sowie die Ausfuhrungsverordnung vom 7 . Februar 1994, Nr. 174 erlauben nun umter bestimmten Voraussetzung die Enennumg wom Gemeinschaftsangehörigen in den italienischen Staatsdienst.

47. Nach der bisherigem Regelung war für Staatsbeamte gemäll Art. 30 Abs. I Buchstabe a des Staats. beamtengesetzes die spanische Staatsangehörigkeit bei der Einstellung erforderlich. Siehe aber Proyecto de ley sobre el acceso a determinandos sectores de la function publica de los nationales de los demas estados miembros de la comumidad economia europea. Siehe aber das

48. Ley $\mathrm{Nr}$. 17/1993 vom 23. Dezember 1993, BOE Nr. 307 vom 24. Dezember 1993, 3472.

49. Art. 1 des Ley nr. 17/1993. Es handelt sich dabei vor allem um die Bereiche Wissensehaft und Forschung, Unterricht, Transport und das Gesundheitswesen.

50. Art. 2 des luxemburgischen Beamtenstatut bestimmt, dab nienand als Beamter eingestellt werden darf, der nicht die lluxemburgische Staatsangehörigkeit besitzt. Auch Angestellte des öffentlichen Diensts müssen gemäl3. Ant. 3 des Gesetzes von 1972 über das Dienstverhältnis die luxemburgische Staatsangehörigkeit besitzen.

51. Art. 4 Abs. 4 der griechischen Verfassung stellt die griechische Staatsangehörigkeit für den gesamter offentlichen Dienst fest

52. Art. 10 (früher Art. 6) der belgischen Verfassung bestimmt, daB worbehalulich gesetzlich vorgesehener Ausnahmen nur Belgier zivile und miltärische Ämter bekleiden können. Nach dem Bericht der Kommission wird jedoch in Belgien der Zugang zu Funktionen im Unterrichts- und Verkehrswesen fur Gemeinschaftsangehörige gebffnet. ABI. Nr. C vom 6. Jumi 1994, 27.

53. Änderung des $\$ 58$ disnisches Beamtengesetz vom 13. Juni 1990. Daneben bestimmt jedoch $\$ 27$ Abs. 1. der dainischen Verfassung, daß niemand zum Beamten emannt werden kann, der nicht die dänische Staatsangehörigkeit besitzt. Ob damit der Rechtsprechung genüge getan wird muß man jedoch bezwei-
feln. feln.

54. Civill Service Commissioners' Act 1956. 
hörige anderer Mitgliedstaaten grundsätzlich geöffnet ist ${ }^{55}$. In den Niederlanden wurde bereits anläßlich der Verfassungsänderung von 1982 die grundsätzliche Öffnung des öffentlichen Dienstes bewirkt ${ }^{56}$. Seit der Gesetzesänderung vom 20. April 1988 sind lediglich die Bereiche Justiz, Polizei, Diplomatischer Dienst und das Militär sowie einige bestimmte Vertrauenspositionen ${ }^{57}$ noch ausdrücklich niederländischen Staatsangehörigen vorbehalten ${ }^{58}$. Die niederländische Gesetzgebung kann dabei im Vergleich mit den anderen Mitgliedstaaten als sehr fortschrittlich bezeichnet werden. Die für Ausländer - einschließlich EG-Angehörige - ausgesch\|ossenen Berufe werden in einer Liste enumerativ aufgeführt. Auch in Portugal scheint man zu diesem System zu tendieren. Bisher wurde jedoch noch keine Liste erstellt ${ }^{59}$. Nach der heutigen Rechtslage sind zumindest die technischen Berufe im öffentlichen Dienst grundsätzlich für Ausländer geöffnet.

Diese Wandlung des öffentlichen Dienstes steht in engem Zusammenhang mit der Anerkennung der beruflichen Qualifikationen. Mit der grundsätzlichen Öffnung werden die Einstellungsbehörden in zunehmendem Maße mit Fragen nach der vergleichbaren Berufsbefähigung und der anrechenbaren Berufserfahrung konfrontiert ${ }^{60}$. Lehrer und Universitätsdozenten, Bibliothekare und Archivare, Kaminfeger, Vermessungsingenieure und Landschaftsgärtner, sie alle und noch viele anderen Berufe in der öffentlichen Verwaltung sind ebenso wie die reglementierten Berufe ${ }^{63}$ in der freien Wirtschaft von den allgemeinen Anerkennungsrichtlinien betroffen. Im Rahmen der verschiedenen Anerkennungssysteme sollte für alle diese Berufe der Binnenmarkt grundsätzlich offen stehen. In der täglichen Anwendungspraxis verursacht dieses Prinzip jedoch noch erhebliche Schwierigkeiten ${ }^{62}$. Einige der angesprochenen Probleme sollen in der folgenden Studie analysiert und - soweit möglich - gelöst werden.

55. Zu überprüfen wäre allerdings, in welchen Fällen von einer derartigen Eunschränkung auf irische Staallsangehörige Gebrauch gemacht wird.

56. Hiermit wurde eine Gesetzesänderung der vom 4. Juni 1858 datierenden Bestimmungen bezitglich Ausländeremennungen ermöglicht.

57. Z.B. das Amt des Bürgermeisters.

58. Siehe dazu dis Gesetz vom 20. Aprill 1988. Zur Beurteilung der niederländïschen Gesetzgebung aus rechtsvergleichender Sicht siehe Verschueren, Migrantenrecht 1991, 10 und Ziller, Rev. franc. A"adm. publ. 1990,467 .

59. Siehe dazu dem portugiesischen Länderbericht won de Sousa, in: Magiera/Siedentopf, 729

60. So stand etwa die anrechenbare Benfserfahrung gerade um Urteil vom 23. Februar 1994, - 1 Scholz/Opera Universitaria di Cagliari- "Sig. 1.994. I-50S ff. zur Diskussion.

61. Zum Begriff "reglementierter Beruf": Pertek 1994, 15.

62. Alleine im Jahr 1993 hat die Kommission vierzig Beschwerden hinsichtlich der Anwendung der Anerkenmungssysteme empfangen, ABI. Nr. C vom 6. Juni 1994, 28. 
Teil I

Einleitung und Abgrenzung 
Teil I

\section{Einleitung und Abgrenzung}

Die vorliegende Studie bezweckt nicht, auf alle im Prolog angeschnittenen Fragen eine Antwort zu geben. Dies würde den Rahmen einer Monographie sprengen. Vielmehr ist es das Ziel dieser Arbeit, einen Teilaspekt der beruflichen Mobilität in einem Binnenmarkt näher zu beleuchten. Bei diesem Teilaspekt handelt es sich um die Anerkennung der Diplome und Prüfungszeugnisse innerhalb der Mitgliedstaaten. Im Mittelpunkt steht daher die Richtlinie 89/48/EWG über eine allgemeine Regelung zur Anerkennung der Hochschuldiplome, die eine mindestens dreijährige Berufsbildung abschließen ${ }^{63}$. Sie verkörpert die "Europhorie", die nach Inkrafttreten der Einheitlichen Europâischen Akte allenthalben den europäischen Einigungsprozeß bestimmte. Leitmotiv dieser Richtlinie sollte das gegenseitige Vertrauen in die Qualität der Ausbildungen anderer Mitgliedstaaten sein. Die Umsetzung der Richtlinie 89/48/EWG in den Mitgliedstaaten und ihre Beurteilung formt das Zentralstück der Arbeit. Hierbei sollen die - oft kulturell bedingten - unterschiedlichen Methoden zur Sprache kommen.

Die Umsetzung der Richtlinie in den Mitgliedstaaten fand zum Teil in einer "prä-Maastricht", zum Teil in einer "post-Maastricht" Stimmung statt. Die teilweise erbittert geführte Diskussion um den Maastrichter-Vertrag ${ }^{64}$ hat - selbst wenn dieser in einigen Mitgliedstaaten mit überwälltigender Mehrheit ratifiziert worden ist ${ }^{65}$ - doch Narben hinterlassen. Statt dem rosigen Motto "Europa 1992" ist nun der Alltag wieder eingekehrt: Der Begriff "Subsidiarität" " bestimmt das gemeinschaftliche Handeln ${ }^{\text {(t). Wie }}$

63. Richtlinie 89/48/EWG vom 21. Dezember 1988, ABI. Nr. L 19 vom 24. Jamuar 1989, 46.

64. Vertrag über die Europäische Union vom 7. Februar 1992, ABI. Nr. C 224 vom 31. August 1992, 1 , in Kraft seit dem 1. Nowember 1993. Dazu Everling. CMLRev. 1992, 1053; Everling, DVBl. 1993, 936; Bleckmann, DVBI. 1992, 335; Sehr kritisch Curtin, CMLRev, 1993, 17;

65. Die Bundesrepublik Deutschlandi ist davon ein Beispiel.

66. Siehe dazu bereits Constantinesco, Integration 1990, 167; Constantinesco, EuZW $\| 991$, 561; Wimmer/Medener, Öster.JZ 1991, 586; Borchmann/Memminger, in: Die deutschen Länder, 17; Stewenig (1992); Heintzen, JZ 1991, 317 ; Hochbaum, DöV 1992, 285; Hummer, ZfRV 1992, 81; Konow;, DóV 1993. 405. Fußnote 2, der darin auf die unzähligen Berichte. Beschlüsse, Schlußfolgerungen und Mil teillungen verweist, die seit jüngster Zeit unter dem Stichwort "Subsidiaritht" die Aktenordner füllen. Kahl, AöR 1993, 414 ff,; Lambers, EuR 1993, 229; Pieper, DVBI. 1993, 705 ff.; Pieper 1994: Schima 1994 ; Siehe auch die kritischen Bemerkungen won Pescatore zum Subsidiaritätsprinzip in der 
Müller Graff zu Recht bemerkt, ist das Subsidiaritätsprinzip in der gemeinschaftspolitischen und rechtlichen Diskussion augenblicklich allgegenwärtig geworden ${ }^{67}$. Geprüft wird daher auch, inwieweit dieser Stimmungsumschwung Einfluß auf die Umsetzungsmethode und die Anwendung der Richtllinie hatte.

In der folgenden Studie wird in Teil Il ein Überblick über die Entwicklung des Gemeinschaftsrechts bezüglich der Niederlassungs- und Dienstleistungsfreiheit von Berufsangehörigen gegeben. Dabei wird die einschlägige Rechtsprechung zum Niederlassungsund zum Dienstleistungsrecht in chronologischer Folge erörtert. Bei dieser Analyse stehen vier Fragen bzw. Problembereiche im Mittelpunkt:

1. Enthält das Niederlassungsrecht neben einem Diskriminierungsverbot auch ein Beschränkungsverbot, d.h. verbietet Art. 52 EGV nücht nur offen und versteckt diskriminierende nationale Maßnahmen, sondern auch Beschränkungen, die unterschiedlos angewendet werden?

2. Die zweite Frage beschäftigt sich mit dem vom Gerichtshof entwickelten Verhältnismäßigkeitsprinzip ${ }^{68}$. Welche Beschränkungen sind aufgrund zwingender Allgemeininteressen gerechtfertigt? Wann können derartige nationale Maßnahmen als geeignet, erforderlich und verhältnismäßig angesehen werden, um einen Eingriff in die Freiheitsrechte zu rechtfertigen?

3. Der dritte Fragenkomplex betrifft die Stellung der Inländer. Der Gerichtshof hat in ständiger Rechtsprechung Sachverhalte, die keine gemeinschaftsrelevanten Berührungspunkte aufwiesen, streng abgewiesen ${ }^{69}$. Hieraus entwickelte sich eine unter dem Stichwort "umgekehrte Diskriminierung" häufig diskutierte und bisher nicht immer befriedigend gelöste Problematik ${ }^{70}$. Aber gerade im Rahmen der Niederlassungs-

66

NZZ vom 1S.16. September 1991, 13, worin er von einem Irweg der Unionspolitik spricht. Zum Verhältnis Binnenmarkt und Subsidiarită tsprinzip Müller-Graff, ZHR 1995, $34 \mathrm{ff}$.

67. Müller-Graff, ZHR 1995 34 (36), Siehe auch die verschiedenen Berichte in FIDE 1994; Ehlermann, Revue du Marehe Unique Eur. 1992, 215; Toth, CMLRev. 1992, 1079; Toth, ELR 1994, 268; Lenaents/Van Ypersele, CDE 1994, 3.

68. Dazu Usher, ELR 1975, 359ff; Schiller, RIW 1983, 928; Arnull, 70, ff.; Wyatt/Dashwood, 89f Schwarze 1988, Bd. II, 661 ff., $690 \mathrm{ff}$.

69. Stăndige Rechtsprechung seit dem Urteil vomn 28. März 1979, Rs 175/78 - Saunders - S1g. 1979, 1129. Ähnlich entschied der Gerichtshof awch im Unteil vom 27. Oktober 1982 - Rs 35 und 36/82 Morson und Jhanjan - Slg. 1982, 3723 sowie in der Entscheidung vom 28. Juni 1984, Rs 180/83 Moser/Land Baden-Württemberg -, Sig. 1984, 2539. In jüngter Zeit wurde in der Rechtssache Werner, Urtell wom 26. Januar 1993, Rs C-112/91 - Werner *, Slg. 1993, 1-429 emeut festgestellt daf die Vertragsbestimmungen nicht auf rein interne Sachwerhalte Anwendung finden. Siehe zu der Entscheidung Wernerjedoch die zu Recht kritischen Anmerkungen von Knobbe-Keuk, CMLRev. 1993 1230.

70. Bleckmann, RIW 1985, 917; Heintzen, EWS 1990, 82 ff; Prütting, JZ, 1989, 705 (711f.); Weis, NJW $1983,2721 \mathrm{f}$. Siehe allgemein zur Problematik der lnländerdiskriminierung Reitmaier 1984 und Schlachter 1984. Kritisch Jessurun d Oliviera 1990, 75; Wouters in Marias, EIPA 1994, 35; Gerade 
freiheit mußte der Gerichtshof dann eine differenzierte Haltung einnehmen, falls der Sachverhalt Inländer betraf, die selbst won ihren Freizigigkeitsrechten Gebrauch gemacht hatten und, die sich bei Rückkehr in den Ursprungsstaat zur Durchsetzung ihrer Rechte auf Gemeinschaftsnormen berufen haben ${ }^{71}$.

4. Das vierte Problemgebiet betrifft die Anerkennung von Drittstaatsdiplomen. Auch zu diesem Bereich mußte der Gerichtshof in jüngster Zeit wiederholt Stellung nehmen ${ }^{72}$.

Nach einer klassischen Analyse der Rechtsprechung des Gerichtshofs wird die Praxis des EuGH's in zwei Phasen eingeteilt ${ }^{73}$. Die erste Periode wird als sogenannte "foundation period" bezeichnet. In dieser Gründungsphase, die Weiler zwischen 1958 und Mitte der siebziger Jahre ansetzt, entwickelte der Gerichtshof seine grundlegenden Prinzipien. Nach Weiler fand in diesem Zeitabschnitt eine Konstitutionalisierung des Vertrages statt ${ }^{74}$. In der zweiten Phase, die in der Einteilung Weiler"s bis Mitte der achtziger Jahre andauerte, sah sich der Gerichtshof aufgrund der Entscheidungsunfähigkeit der anderen Gemeinschaftsorgane mehr und mehr in eine gesetzgeberische Rolle gedrängt. Dabei nutzte er diese durch eine extensive Auslegung der Freiheitsrechte dazu, die Kompetenzen der Gemeinschaft zu erweitern ${ }^{75}$. Die nunmehr zu erörternde Frage ist, ob die Rechtsprechung seit Mitte der achziger Jahre, d.h. nach dem Inkrafttreten der Einheitlichen Europäischen Akte, eine neue Entwicklungsphase eingeleitet hat. Diese Frage kann in der vorliegenden Studie nur beschränikt auf den freien Personenverkehr im Binnenmarkt erörtert werden. Festzustellen ist dabei, daß der Gerichtshof gerade in diesem Zeitraum dem Art. 5 EGV, d.h. der Gemeinschaftstreue der Mitgliedstaaten eine wachsende Bedeutung zugemessen hat ${ }^{76}$.

Aus der Gesamtanalyse der Rechtsprechung zum Niederlassungs- und Dienstleistungsrecht ergibt sich, daß vor allem in jüngster Zeit in einigen Entscheidlungen durchaus Ansätze zu finden sind, die auch für das Kapitel Niederlassungsrecht des EGV ein Beschränkungsverbot vertretbar erscheinen lassen. Dieses Beschränkungsverbot ist

70.

die Entscheidungen Werner, Urteil vom 26. Januar 1993, Rs C-112/91, Slg. 1993, 1-429 sowie Schumaker, Unteil vom 14. Februar 1995, Rs C-279/93 (noch nicht veröffentlicht, siehe aber EuZW 1995, 177) zeigen im Vergleich wie unbefriedigend dieser Lösungsansatz ist.

71. Urteil vom 7. Februar 1979, Rs 115/78 - J. Knoors/Staatssekretär für Wirtschaft -. Slg. 1979, 399 Urteil vom 6. Oktober 1981, Rs 246/80 - C. Broekmeulem/Huisarts Registratie Commissie -, Slg. 1981,2311

72. Urteil vom 9. Febnar 1994, Rs C-319/92 - Salomone Haim/Kassenzahnărztliche Vereinigung Nordrhein -, Slg, 1994, I-425; Urteil vom 9. Febraar 1994, Rs C-154/93 - Abdullah Tawil-Albertini/Ministere des Affaires sociales -, Slg. 1994, I-451.

73. Weiler, Yale Law lloumal 1991, 2403, ähndich auch bereits in einer friiheren Studie, Weiler, YbEL $1981,267$.

74. Weiler, Yale Law Journal 1991,2403 (2410 ff.).

75. Weiler, Yale Law Journal 1991, $2431 \mathrm{ff}$.

76. Zum Begriff der Gemeinschaftstreue bereits Bleckmann, DVBI. 1976, 483ff.; Bleckmann in Bieber/Ress, 161. Zur Entwicklung dieses: Rechtsbegriffs in der neueren Rechtsprechung siehe Temple Lang, CMLRew. 1990, 645; Due 1992. 
jedoch noch nicht in einer so umfassenden Weise ausgestaltet, daß eine der wichtigsten Zulassungsvoraussetzungen für reglementierte Berufe, nämlich der Nachweis der inländischen Examina, vollkommen bedeutungslos geworden ist. Für die Niederlassungsfreihell von freien Berufen bedeutet dies jedoch, daß die Anerkennung von Diplomen auf der Basis von Gemeinschaftsrichtlinien noch immer eine zentrale Frage ist ${ }^{7}$.

Der dritte Teil ist daher der Gemeinschaftspolitik hinsichtlich der Anerkennung von Diplomen gewidmet. Hierbei wurden von der Europäischen Gemeinschaft im Laufe der Jahre zwei unterschiedliche Strategien verfolgt. Die erste Strategie beruhte auf einem vertikalen Ansatz $z_{n}$ wobei jeweils gesonderte Richtlinien für die einzelnen Berufe beschlossen wurden ${ }^{78}$. Diese Form der sektoriellen Harmonisienung wird in der Untersuchung exemplarisch am Beispiel der Ärzterichtlinien dargestellt. Auf die weiteren sektoriellen Richtlinien wird nur insoweit eingegangen, als sich deutliche Unterschiede zur Konzeption der ursprünglichen Ärzterichtlinien aufzeigen lassen.

Die im Weißbuch der Kommission zum Binnenmarkt verkündete "neue Strategie" brachte einen Wandel in die bis dahin verfolgte Harmonisierungskonzeption ${ }^{79}$. Mit dieser "neuen Strategie" sollte die durch den EuGH im Rahmen der "Cassis de Dijon" Rechtsprechung ${ }^{80}$ für den freien Warenverkehr entwickelte Konzeption auf den Dienstleistungswerkehr und auf die freie Niederlassung übertragen werden ${ }^{81}$. Typisches Produkt dieses neuen Ansatzes ist die Richtlinie 89/48/EWG ${ }^{22}$. Mit dieser Richtlinie war die Gemeinschaft von ihrem bisherigen sektoriellen Harmonisierungskonzept abgewichen, um dagegen eine allgemeine Regelung zur Anerkennung von Hochschuldiplomen zu bewirken ${ }^{83}$. Die Richtlinie 89/48/EWG erhielt eine Ergänzung in Form der Richtlinie 92/51/EWG vom 18. Juni 1992 iber eine zweite allgemeine Regelung zur Anerkennung beruflicher Befähigungsnachweise ${ }^{84}$. Während die Richtlinie

77. Für die freien Berufe ist die Frage der Anerkennung won Diplomen etwa in eïnem vergleichbaren Maße von Bedeutung wie der Streit um die Sitztheorie für die Niederlassungsfreiheit won Gesellschaften.

78. Beuve-Mery in Philip 1989, 21.

79. Die "neue Strategie" bezüghich der Warenverkehrsfreiheit wurde won der Kommission bereits in ihrer Mitteilung den Rat und das Europäische Parlament vom 31. Januar 1985 mit dem Titel "Technische Harmonisienung und Normung: eine neue Konzeption", KOM (85) 19 endg. dargestellt. Siehe anch die Entschließung des Rates vom 7. Mail 1985 mit dem Titel "Neue Konzeption auf dem Gebiet der technischen Harmonisienung und Normung, AB!. 1985 Nr. C 136, 1. Dazu Lauwaars in Bieber/Dehoussel Pinder/Weiler (Hrsg.), 151 ff.

80. Urteil vom 20. Febmar 1979, Rs 120/78 - REWE-Zentral-AG/Bundesmonopolverwaltung für Branntwein -, Slg. 1979, $649 \mathrm{ff}$.

81. Dazu Schmitt von Sydow, in Bieber/Dehousse/Pinder/Weiler (Hrsg.), $79 \mathrm{ff}$; Bruha, Zä̈RV 1986, 1 (7f.o); Eyles, $23 \mathrm{ff}$." Schwartz, in FS von der Groeben, $362 \mathrm{ff}$.

82. Richtlinie 89/48/EWG vom 21. Dezember 1988, ABI. Nr. L 19 vom 24, Januar 1989, 16.

83. Boivin/Carnelutti, Rev. franc. adm. publ. 1988, 523; Pertek, RTDE 1989, 623; Joris/Veny, RW 1989 90, 521; Muller-Bermhardt, RdjB 1989, 130; Schneider, Ars Aequi 1989, 237; Beuve-Méry, RMC 1990, 293; Laslett, LIEI 1990, 1; Baldi, RivDIPP 1991, 345; Camellutti, Rev.du Marché Unique eur. 1991,23 .

84. Richulinie 92/51/EWG des Rates vom 18. Juni 1992 äber eine zweite allgemeine Regelung zur Anerkentung benuflicher Befahigungsnachueise in Ergänzung der Richtlinie 89/48/EWG, ABI. Nr. L 209 vom 24. Juli 1992, 25. 
linie 89/48/EWG sich an die Ausbildungsgruppe der Hochschul- und Fachhochschulabsolventen mit einer mindestens dreijährigen Ausbildung richtet, betrifft die zweite allgemeine Anerkennungsrichtlinie die Absolventen kürzerer Studiengänge, Fachschulund Sekundarschulabsolventen sowie Personen mit Berufserfahrung ${ }^{85}$. Die Regelungen beider Richtlinien werden in Teil IV erläutert.

Im vierten Teil wird auch die Umsetzung beider Richtlinien in den Mitgliedstaaten dargestellt und soweit möglich kritisch unter die Lupe genommen. Die Umsetzung der Richtlinie 89/48/EWG hat in den Mitgliedstaaten erhebliche Probleme verursacht. Diese beruhten teilweise auf dem Umfang des Regelungsbereichs, da die unterschiedlichsten Berufe von der Richtlinie erfaßt wurden. Andererseits bewirkte gerade diese Richtlinie, dali die nationalen Gesetzgeber und die verschiedenen Berufs- und Standesorganisationen ihre jeweiligen nationalen Berufsausbildungen kritisch unter die Lupe nahmen. Die damit ausgelösten Diskussionen verzögerten in nicht unerheblichem Maße die termingerechte Umsetzung der Richtlinie 89/48/EWG zum 4. Januar $1991^{86}$. Die Umsetzungsfrist für die Richtlinie 92/51/EWG lief am 18. Juni $1994 \mathrm{ab}$. Auch für diese Richtlinie gilt, daß der Umsetzungsprozeß sich sehr verzögert hat, wobei allerdings konstatiert werden kann, daß nicht dieselben Mitgliedstaaten sich einer Terminüberschreitung schuldig machten ${ }^{87}$.

Dieser Abschnitt bildet einen Schwerpunkt der Arbeit, da an Hand der unterschiedlichen Umsetzungsmaßnahmen gezeigt werden kann, wie Mitgliedstaaten europäische Gesetzgebung in das eigene Regelungssystem integrieren ${ }^{88}$. Hierbei zeigen sich die unterschiedlichsten Gestaltungsformen. Diese sind teilweise kulturell bedingt. Zum Teil beruht die unterschiedliche Vorgehensweise auch auf nationalen ökonomischen oder berufspolitischen Gründen. So kann die Liberalität einer bestimmten Umsetzungsmaßnahme ihre Ursache in einer pro-europäischen Grundhaltung haben, sie kann jedoch ebenso durch ökonomische Gründe verursacht sein, die eine Öffnung des nationalen Marktes für ausländische Berufsangehörige wünschenswert machen. Umgekehrt lassen sich wiederum einige restriktive Umsetzungsmaßnahmen u.a. mit den Einkommensverhältnissen der nationalen Berufsgruppe erklären. Die unterschiedlichen Umsetzungsstrategien werden besonders bei einigen, speziellen Berufsgruppen deutlich.

Der fünfte Teil der Arbeit ist darum drei unterschiedlichen Fallstudien gewidmet. Anhand dieser sollen die Probleme, die sich bei der Verwirklichung der Personenverkehrsfreiheit für die jeweiligen Berufsgruppen ergeben, stärker herausgearbeitet

85. Henninger, BB 1990, 73; Mohn, GewArch 1990, 203 zum Entwurf der Richtlinie 92/51/EWG.

86. Mit Ausnahrne von Irland hat kein Mitgliedstaat eine vollständig abgeschlossene Umsetzung bis zum gesetzten Termin vorlegen können. Nur wenige Mitgliedstaaten waren in der Lage die Frist zumindest in einem erträglichen Maß einzuhalten. Damit hat sich die von SEPLIIS geäußrte Kritik an der Kurze der gesetzten Umsetzungsfrist bewahrheitet, SEPLIS "Europe" wom 13/14. Februar 1989, 15. Siehe zur Umsetzung in den Mitgliedstaaten die Erörterungen Seite $206 \mathrm{ff}$..

87. So beweisen wor allem die Niederlande und Italien eine deutliche Verbessening im Hinblick auf das Umsetzungstempo.

88. Schwarz/Becker/Pollack, $71 \mathrm{ff}$. 
werdlen. Insbesondere wird auf die konkreten Konsequenzen der Umsetzung der Richtlinie 89/48/EWG für diese Berufe eingegangen. Die Wahl viel dabei auf die rechtsberatenden Berufe, die Ingenieure und die Lehrer. Diese Auswahl erfolgte, weil während des Umsetzungsprozeßes gerade diese drei Berufsgruppen Anlaß langwieriger Debatten waren. Auch sind, wie bereits im Prolog angesprochen, besonders die wirtschaftsbezogenen freien Berufe vom Binnenmarkt besonders betroffen.

Bei den rechtsberatenden Berufen wird zwischen den Rechtsanwälten, den Patentanwälten, den Wirtschaftsprüfern, den vereidigten Buchprüfern und den Steuerberatern sowie den Notaren unterschieden. Dabei stehen die Rechtsanwälte im Mittelpunkt der Erörterungen. Für die Rechtsanwälte bestand bisher eine Erleichterung der tatsächlichen Ausübung des freien Dienstleistungsverkehrs gemäß der Richtlinie $77 / 249 / \mathrm{EWG}^{89}$. Auf die anderen als "rechtsberatend" qualifizierten Berufe einschlieBlich der Notare fand diese Dienstleistungsrichtlinie keine Anwendung.

Die Notare nehmen bisher eine Sonderstellung ein ${ }^{90}$. Gemäß der Artikel 55 und 66 EGV finden auf "Tätigkeiten, die in einem Mitgliedstaat dauernd oder zeitweise mit der Ausübung öffentlicher Gewalt verbunden sind", die Vorschriften über die Niederlassungs- und Dienstleistungsfreiheit keine Anwendung. Einige Autoren sehen in dieser Ausnalhmebestimmung geradezu eine lex notariorum ${ }^{91}$. Die Frage ist, ob das Recht auf freie Niederlassung und freien Dienstleistungsverkehr für Notare aufgrund des Vorbehalts der öfentlichen Gewalt verwehrt ist oder, ob diese Beschränkung lediglich für einige Tätigkeitsbereiche gilt. Auch den Rechtsanwälten wurde das Niederlassungsrecht häufig mit unterschiedlicher Begründung verweigert ${ }^{92}$. So galt bis in die siebziger Jahre in Belgien, Frankreich, Luxemburg und den Niederlanden ein Staatsangehörig. keitsworbehalt für Rechtsanwälte ${ }^{93}$. Auch haben vor allem Luxemburg und die Bundesrepublik Deutschland eine Anwendung der Niederlassungsbestimmungen auf Rechtsanwälte unter Berufung auf Art. $55 \mathrm{EGV}$ bis zur Entscheidung in der Rechtssache Reyners kategorisch abgelehnt. Hiergegen hat der EuGH in der Sache Reyners festgestellt, daßi die staatlichen Belange genügend gewahrt seien, wenn die ausländischen Staatsangehörigen von denjenigen Tätigkeiten ferngehalten würden, die eine spezifische und unmittelbare Anteilnahme an der Ausüibung offentlicher Gewalt darstellen ${ }^{94}$. Wahrend des Umsetzungsprozesses der Richtlinie 89/48/EWG wurde der Fall der Notare erhitzt diskutiert. Einige Mitgliedstaaten haben aus dieser Diskussion die

89. Richulinie des Rates vom 22. März 1977 zur Erleichtenung der tatsächlichen Ausübung des freien Dienstleistungsverkehrs der Rechtsanwälte, ABI. L 78 vom 26. Mär 1977.

90. Siehe bereits Everling 1963, 115, der damals die Anwendung Marz 1977. unbestreitbar bezeichnete. Pithofer in dantals die Anwendung des Art. 55 EWGV auf Notare als

1. Siche

Not 1990, Sonderheft, 22. Witk 425 mit Hinweisen auf Fischer, DNotZ 1989, 477; Richter, Mit:BayHerzog, 2-608 $(55.06, \mathrm{c})$. Audinet 1959, 982: Lagu, Brangsch, AnwBl. 1962, 243; Lussan, Le Droit Européen 1958, 49.

93. Siehe dazu Mahieu/Baudrez, 21.

94. Urteil vom 21. Juni 1974, Rs 2/74 - Reyners/Belgien -, Slg. 1974, 631 (649). 
Konsequenz gezogen ${ }^{95}$, andere Mitgliedstaaten lehnen bis heute eine Einbeziehung cles Notars kategorisch ab. Zu dieser letzten Gruppe muß auch die Bundesrepublik Deutschland gerechnet werden ${ }^{\$ 6}$.

In diesem Teil wird neben den Umsetzungsmafinahmen und der Dienstleistungsrichtlinie für Rechtsanwälte auch der Richtlinienentwurf der Kommission zur Niederlassung von Rechtsanwälten unter "home title" besprochen ${ }^{97}$. Mit diesem Entwurf soll einem Rechtsanwalt der Berufszugang und die Berufsausübung in einem anderen Mitgliedstaat als dem, in dem er bereits die Berufszulassung erhalten hat in der Weise erleichtert werden, daß er seinen Beruf während einer zeitlich auf fünf Jahre begrenzten Periode unter der ursprünglichen Berufsbezeichnung ausüben darf. Dieser Vorschlag muß insoweit als eine Ergänzung des bisherigen Systems bezeichnet werden. Inwieweit dieser Entwurf die an ihn gestellten Erwartungen der Berufsangehörigen erfüllt, soll im Rahmen der Fallstudie erörtert werden.

Die zweite Fallstudie betrifft die Umsetzung für die Ingenieure. Auf den ersten Blick scheint der Beruf des Ingenieurs, schon immer sehr international orientiert, ein verhältnismäßig unproblematischer Umsetzungsfall zu sein. Dieser Eindruck täuscht jedoch ${ }^{98}$. Die weite Spannbreite derer, die sich Ingenieur nennen können, vom Elektroüber den Bau- bis zum Agraringenieur, die unterschiedlichen Ausbildungen und die vollkommen abweichenden Reglementierungen, haben bisher eine Spezialrichtlinie für Ingenieure zum Scheitern gebracht ${ }^{99}$. Die Probleme tauchten nun bei der Umsetzung der Richtlinie 89/48/EWG erneut wieder auf ${ }^{100}$. Zur Diskussion stand dabei vor allem die Frage der Reglementierung des Ingenieursberufes in einigen Mitgliedstaaten ${ }^{101}$

Die dritte Fallstudie ist der Umsetzung der Richtlinie 89/48/EWG hinsichtlich des Lehrerberufs gewidmet. Handelt es sich bei den Rechtsanwälten und Ingenieuren um zwei typische Vertreter der freien Berufe, so ist gerade das Lehramt an öffentlichen Schulen - insbesondere in der Bundesrepublik Deutschland - generell Teil des öffentli-

95. So haben z.B. Frankreich und die Nederlande die Richtlinie 89/48/EWG unter Beibehaltung des Staatsangehörigkeitsvorbehalt für die Notare umgesetzt

96. Bohrer, Mitt. des Bayerisehen Notarvereins, 16 (19).

97. Vorschlag für eine Richthinie des Europáischen Parlaments und des Rates zur Erleichtenung der ständigen Ausübung des Rechtsanwaltsbenfs in einem anderen Mitgliedstaat als dem, in dem die Qualifikation erworben wurde, KOM (94) $572 \mathrm{endg.}$

98. "Zuid" wantrouwt ingenieur uít "noord", Volkskrant vom 2. Mai 1994; Guerin, European Engineer 1990, 18/19. Orzack, Law and Human Behavior 1983, $251 \mathrm{ff}$.

99. Zu den unterschiedlichen Ausbildungen Comina 1983. Zur Problematik der Anerkennung von Ingenieuren in Europa siehe bereits de Crayencout, $\mathbb{R M C} 1969,299$; in jüngster Zeit vor allem Dankelman 1994. Pertek 1991; Hamelin in Philip 31 (37).

100. Pertek, EIPA 1990, 40 .

101. Dazu Pertek, Savoir 1992, 96ff. 
chen Dienstes ${ }^{102}$. Hieraus ergab sich lange Zeit ein problematisches Verhältnis zu Art. $48 \mathrm{Abs} .4 \mathrm{EGV}^{103}$. Grundsätzlich wird der Lehrerberuf nach heutigem Stand der Rechtsprechung keine derartige Ausübung hoheitlicher Tätigkeit darstellen, daß ein Mitgliedstaat sich in Übereinstimmung mit der Rechtsprechung des Gerichtshofes auf die Ausnahmebestimmung des Art.48 Abs, 4 EGV berufen könnte ${ }^{104}$. Jedoch ist die Emennung und der Status von Lehrem in den einzelnen Mitgliedstaaten sehr unterschiedlich geregelt. Hieraus ergeben sich die verschiedensten Probleme bezüglich der Umsetzung der Richtlinie 89/48/EWG.

Der letzte Teil ist einer generellen Beurteilung der Richtlinie 89/48/EWG über eine allgemeine Regelung zur Anerkennung der Hochschuldiplome und ihrer Umsetzung gewidmet. Desweiteren wird in einem Epilog der Versuch unternommen, zwei im Gemeinschaftsrecht getrennte Bereiche, nämlich die berufliche Anerkennung von Diplomen innerhalb der Gemeinschaft mit der Frage nach den Möglichkeiten und Grenzen einer europäischen Bildungspolitik zu verknüpfen. Für eine solche Politik müßte die klassische Einteilung und Abgrenzung Zwischen der akademischen und der beruflichen Anerkennung von Diplomen überwunden werden ${ }^{105}$. Anlaß für eine solche Diskussion sind einerseits die Richtlinien 89/48/EWG und 92/51/EWG, andererseits die verschiedenen Programme der Europäischen Gemeinschaft zur Förderung der Mobilität von Lernenden. So hat etwa das ERASMUS-Programm für Hochschulstudenten erheblich dazu beigetragen, die akademische Anerkennung der in einem anderen Mitgliedstaat erworbenen Studienresultate zu fördern ${ }^{106}$. Diese Entwicklung wird auch unter SOCRATES fortgesetzt ${ }^{107}$. Auch das vor dem Europäischen Gerichtshof geführte Verfahren von Dieter Kraus ${ }^{108}$ hat ein neues Licht auf das Verhältnis zwischen akademischer und beruflicher Diplomanerkennung sowie der Berufsausübung geworfen. Bei diesem Verfahren stand das Erfordernis einer behördlichen Gienehmigung

102. Eine Ausnahme besieht insoweit für die Lehrtätigkeit an Privatschulen. Da die Ausbildungsanfordentmgen an den Lehrkörper zwischen staatlichen und privaten Schulen in Deutschland gleich sind, ist eine Differenzienung wwischen den unterschiedlichen Schulträgern in Beziehung auf die Anerkennung won Diplomen nicht notwendig.

103. De Crayencour 1983,5 1 hielt eine A swendung der Freizügigkkeitsvorschriften für Lehrk rafte aufgrund von An. 48 Abs. 4 EWGV noch für ausgeschlossen.

104. Der Gerichtshof traf diese Entscheidung für Lehrer des Sekundarbereichs zwar mit sehr wenigen Worten der Begrundung, darum jedoch nicht weniger deutlich in der Rechtssache 4/91 - A. Bleis Urteil vom 27. September 1991, SIg. 1991, I-5627. Vor der Entscheidung Bleis wurde diese Auffassung bereits deutlich in der Literatur vertreten. Siehe dazu Handoll, in De Witte 1989, 31: Dörr. EuZW 1990, 565 (570); Lenz in Magiera 1990, 199, Battis in Magiera 1990, 47. In jüngster Zeit Wouters in Marias, EIPA 1994, 49. Dagegen aber vor allem Lecheler, Bay VBI, 1989, 417, Lecheler, 1991,102 .

105. Dazu Zilioli in De Witte 1989,51. Zur akademischen Anerkennung siehe Cox.

106. Antoine, RMC 1988, 554.

107. BeschluR 819/95 des Rates und des Europäischen Parlaments vom 14 . März 1995, AB1. Nr. L 87 vom 20. April 1995, 10

108. Urteil vom 23. Marz 1993, Rs C-19/92 - Dieter Kraus/Land Baden Württemberg -, SIg, 1993, 1-1663, NVwZ 1993, 661. Dazu Roth, CMLRew, 1993, 1251 
zur Führung eines ausländischen akademischen Grades zur Diskussion ${ }^{109}$. Hintergrund dieser Debatte bildet die Entwicklung zu einer Europäischen Union, in deren Kader die bildungspolitischen Kompetenzen der Gemeinschaft neu gefaßt sind ${ }^{110}$ und dementsprechend überdacht werden müssen "I. Im Rahmen dieser neuen Entwicklung. hat die Kommission durch eine Mitteillung an die Mitgliedstaaten die Diskussion hinsichtlich einer größeren Interaktion beider Anerkennungsbereiche eröffnet ${ }^{1 / 2}$. Die Kommission erhofft hierdurch die Schaffung eines offenen europäischen Raums für Berufe und Ausbildungsgänge zu bewirken.

109. Urteil vom 23. Mărz 1993, Rs C-19/92 - Dieter Kraus/Land Baden-Württemberg - Slg. 1993, I-1663.

110 . Siehe dazu die neu formulienten Art. 126 und $127 \mathrm{EGV}$.

111. Lenaerts, CMLRev. 1994, 7; Dohms, RdJB 1992, 451; Bergreen, RdJB 1992, 436; Dittmann/Fehrenbacher, RdJB 1992, 478

112. Mitteilung der Kommission über die akademische und professionelle Anerkennung von Hochschul- und Fachdiplomen vom 13. Dezember 1994, KOM (94) 596 endg. 
Die Freiheit des Personenverkehrs aufgrund des EG-Vertrages 


\section{Die Freiheit des Personenverkehrs aufgrund}

\section{des EG-Vertrages}

\section{$\S 1$. Einleitung}

Nach Art. 2 EWGV in seiner ursprünglichen Fassung war es Aufgabe der Gemeinschaft, "durch die Errichtung eines Gemeinsamen Marktes und die schrittweise Annäherung der Wirtschaftspolitik der Mitglliedstaaten ein harmonische Entwicklung des Wirtschaftslebens innerhalb der Gemeinschaft ... zu fördern". Auch in der Neufassung von Art. 2 EGV wurde die Zielsetzung nicht geändert. Dieses am Anfang des EG-Vertrages stehende Vertragsziel sowie die in Art. 3 EGV zur Verwirklichung dieses Zieles aufgeführten Tätigkeitsbereiche, zu denen die Beseitigung der Hindernisse für den freien Waren, Personen-, Dienstleistungs-und Kapitalverkehr zwischen den Mitgliedstaaten gehören, zeigen, daß es seit jeher im Bestreben der Vertragsgründer lag, einen homogenen wirtschaftlichen Raum zu schaffen, in dem Personen, Waren und Kapital sich ebenso ungehindert bewegen können, wie dies innerhalb nationaler Staatsgrenzen der Fall ist "13."

\section{§ 2. Inhalt und Abgrenzung der Begriffe "Gemeinsamer Markt" und "Binnenmarkt"}

Gemäßs dem ursprünglichen Vertragstext war in Art. 8 EWGV die stufenweise Verwirklichung des Gemeinsamen Marktes im Laufe einer Übergangszeit, die am 31. Dezember 1969 endete, geregelt. Dieser Vertragsartikel erhielt durch die Einheitliche Europäische Akte eine Ergänzung durch die Einfügung von Art. 8a EWGV ${ }^{114}$. Gemäß dieser nun als Art. 7a EGV nummerierten Bestimmung sollte die Gemeinschaft die erforderlichen Maßnahmen treffen ${ }_{w}$ um bis zum 31. Dezember 1992 den Binnenmarkt

113. Vgl. Predöhl/Jürgensen, Europäische Integration, in: Handwörterbuch dler Soziallwissenschaften, Bd. 3, 1961, 371, worin bereits won einem "Zusammenschluß mehrer Staatsräume zu einenn Wirtschaftsgebiet mit binnenmarktahnlichen Verhallnissen ${ }^{\text {ii }}$ gesprochen wird. Siehe auch das Urteil des EuGH vom 7. Juli 1976, Rs 118/75, - Watson - , Slg. 1976, 1185

114. In der theutigen Fassung Art. 7a EGV. 
schrittweise zu verwirklichen. Dieser Binnenmarkt umfaßt gemäß Art. 7a Abs. 2 EGV "einen Raum ohne Binnengrenzen, in dem der freie Verkehr von Waren. Personen, Dienstleistungen und Kapital gemäß den Bestimmungen dieses Vertrages gewährleistet sind". Auch in Art. 3 c) EGV ist der Binnemarkt durch "die Beseitigung der Hindernisse für den freien Waren-, Personen- , Dienstleistungs- und Kapitalverkehr zwischen den Mitgliedstaaten ${ }^{n}$ gekennzeichnet ${ }^{155}$.

Kritiker des Binnenmarktkonzeptes sahen hierin nur eine Wiederaufbereitung der ursprünglichen Zielvorstellung der Errichtung eines Gemeinsamen Marktes mit einer neuen Übergangszeit ohne Berücksichtigung der Rechtsprechung des Gerichtshofes " Diese Kritik war bei Inkrafttreten der EEA auch nicht ohne weiteres von der Hand zu weisen, hing sie doch in starkem Maße von der inhaltlichen Ausgestaltung der Binnenmarktkonzeption ab. Die Einfügung des heutigen Art. 7 a EGV sowie die Neuformulierung in Art. 3 c) EGV wirft dann auch die Frage auf, ob unter Binnenmarkt etwas wesentlich anderes gemeint sein soll als mit der Errichtung eines Gemeinsamen Marktes ${ }^{117}$.

In der Literatur wird teilweise die Auffassung vertreten, daß es sich um reine Synonyme handelt "18. Gestützt wird diese Ansicht auf die gemeinschaftliche Erklärung der Regierungsvertreter zu Art 8a EWGV in der Schlußakte zur EEA ${ }^{119}$. Gegen diese Ansicht sind jedoch Bedenken anzumelden. Für einen unterschiedlichen Inhalt spricht zunächst die reine Tatsache, daß dieser Begriff "Binnenmarkt" neu in den Vertragstext eingefügt worden ist, ohne die bereits gebräuchliche Terminologie zu ersetzen ${ }^{120}$. Die Verwendung beider Begriffe nebeneinander, läßt den Schluß zu, daß sich dahinter auch eine unterschiedliche inhalt liche Konzeption verbirgt. Diese Auffassung wird durch die Tatsache unterstützt, daß die unterschiedliche Terminologie in allen Vertragssprachen gewählt worden ist und sich nicht etwa zufällig in einen der Vertragstexte eingeschlichen hat ${ }^{121}$. Auch die bereits vor der EEA bestehende Rechtsprechung des EuGH, wonach

115. Zum Bimenmarkt als Rechtbegriff, Reich, EuZW 1991, 203. 116. So vor allem die deuthichen Befürchtungen won Pescatore, EuR 1986, 153 (157); Pescatore, CMLRew.
1986,11 .

117. Steindorff, ZHR 1986, 687 ff.; Krämer (1987); Hayder, RabelsZ 1989, 638 ff. Muller-Graff, EuR 1989. $122 \mathrm{f} \mathrm{m.w.N..}$

118. Beutler/Bieber/Pikorn/Streil, 47; Grabitz in Grabitz-Kommentar, Art. 8, adz, 3; anders noch Grabitz, Integration 1986, 95 (98 r), Bömer, DB 1989, 613,614: Langehe ime in: Grabitz, Kommentar, Art. 100 a, Rdz. 21; de Ruyt, 150 ff.

119. Langeheine in Grabitz, Kommentar. Art. $100 \mathrm{a}$, Rdz. 23.; Zur Bedeutung der von der Regienungskonferenz ingenommenen Erklänumgen vgl. Müller-Graff, EuR 1989, Fn. 114, Toth, CMLRew. 1986,
803, (812).

120. Müller-Graff 1989, 12; Bleckmann Europarecht, 8.

121. Die Situation, dall nur in einer Vertragssprache eine unterschiedliche Terminologie verwendet wird, ist in Art. 3 e EGKSV im Vergleich zu Art. 117 Abs. 1 EWGV gegeben, wo nur in der niederlãndischen Sprache ein Unterschied zwischen den beiden Verträgen hinsichtich des Begriffs "Angleichung" besteht. In der niederlandischen Fassung wird in Art. 3 e EGKSV der Begriff "egalisatie" verwendet,
wohingegen in Art. 117 Abs. 2 EWGV von "aanpassing." gesprochen wird. In den anderen Vertrags- 
der Begriff Gemeinsamer Markt "die Beseitigung aller Hemmnisse im innergemeinschaftlichen Handel mit dem Ziel der Verschmelzung der nationalen Märkte zu einem einheitlichen Markt, dessen Bedingungen denjenigen eines wirklichen Binnenmarktes möglichst nahekommen" 122 bedeutet, unterstützt den Standpunkt, daß es sich um zwei inhaltlich unterschiedliche Begriffe handelt ${ }^{123}$.

Die Frage stellt sich jedoch, inwieweit nach Umfang und Intensität beide Begriffe voneinander abweichen ${ }^{124}$. Nach der durch den EuGH gewählten Definition ist der Gemeinsame Markt als eine Vorstufe des Binnenmarktes anzusehen ${ }^{125}$. Der Binnenmarkt setzt einen Abbau aller innergemeinschaftlichen Handelshemmnisse voraus, so daß er auch als ein nationaler Markt auf Gemeinschaftsebene definiert werden kann. Diese Definition bezieht sich aber auf das interne Verhältnis, die Beziehung zu Drittstaaten bleibt hiervon unberührt. Danach verlangt der Binnenmarkt eine stärkere Integrationsintensität ${ }^{126}$. Diese Begriffswahl steht in einem gewissen Gegensatz zum Wortlaut des. Art. 7a EGV, der lediglich die vier Grundfreiheiten nennt. Mit der Orientierung des Binnenmarktes an der Verwirklichung der vier Grundfreiheiten wird zwar der bereits in Art. 3 a) - c) EWGV beschriebene Tätigkeitsbereich der Gemeinschaft aufgenommen, es scheint jedoch, als ob die Bereiche des Wettbewerbsrechts und des Steuerrechts trotz ihrer innergemeinschaftlichen Bedeutung außer Betracht bleiben. Die Ausschließung dieser beiden Bereiche würde jedoch im krassen Gegensatz zum der EEA zeitlich vorlaufenden Weißbuch der Kommission stehen, worin gerade die zur Errichtung eines Binnenmarktes notwendigen Maßnahmen auf dem Gebiet des Wettbewerbsund Steuerrechts ausführlich erörtert werden ${ }^{127}$. Auch enthält Art. 3 g) EGV eine deutliche Verbindung zwischen der Wettbewerbsfreiheit und Binnenmarkt ${ }^{128}$. Konsequenterweise setzt der Abbau von Handelshemmnissen ïm Binnenmarkt einen ungehinderten Wettbewerb voraus ${ }^{129}$.

121. $\rightarrow$

sprachen wird ein Begriff in beiden Artikeln verwendet. Siehe zur Verwendung unterschiedliche Begriffe in den verschiedenen Vertragssprachen die Analyse vom Lochner, ZSitatsw, Bd, 118, 1962. $35 \mathrm{tf}$.

122. Urteill vom 5. Mai 1982, Rs 15/81 - Gaston Schul - Slg. 1982, 1409 (1431). In der Rechtssache 26/76; Urteil vom 25. Oktober 1977, - Metro/Kommisssion -, SIg. 1977, 1875 (1905) stellt der Gerichtshof auf die Erreichung "binnenmarktahnlicher Verhälnisse" ab. Ahnlich auch in der $R$ 270/80, Urieil wom 9. Februar 1982 - Polydor/Harlequin - Slg. 1982, 329 (349).

123. Steindorff, ZFR 1986, 687 (689); Müller-Graff 1989, 11

124. Dazu Zacker, RIW 1989, 489.

125. Dauses, EuZW 1990, 8 (10); Schwarze/Becker/Pollak, $15 \mathrm{ff}$.

126. Ehlermann, CMLRev. 1987, 369f.

127. Kommission der Europäischen Gemeinschaften, Vollendung des Bimnenmarktes, Weißbuch der Kommission an den Europäischen Rat wom 14. Juni 1985, $\mathrm{Nr}$. 14 und $\mathrm{Nr}$. 19, $\mathrm{Nr}$. $157 \mathrm{ff}$.; siehe auch Teil 3 des Weißbuchs: Beseitigung der steverlichen Schranken.

128. Barents, CMLRev. 1993,85 (104). Siehe auch Art. 3 a und 102 a EGV, wonach die Gemeinschaft zur freien Markt- und Weltbewerbswirtschaft verpflichtet wird.

129. Sa bereits der Gerichtshof in seinem Urteil wom 13. Juli 1966, Rs 32/65 - Italien/Rat und Kommission, Slg. 389 (405). Siehe auch das Urteil vom 19. März 1991, Rs 202/88 - Erankreich/Kommission -, Slg. 1991, I-1223. Barents, CMLRev. 1993, 85 (104); Grabitz in: FS Steindorf, 1229 (1240) 


\section{§ 3. Die "Neue Strategie" der gegenseitigen Anerkennung von Normen}

Maßgeblich für das Verständnis des Binnenmarktkonzeptes ist das Weißbuch der Kommission "Vollendung des Binnenmarktes" von $1985^{130}$, das 300 Vorschläge für Harmonisierungmaßnahmen enthält. Dabei hat die Kommission ihre bisherige Harmonisierungskonzeption, die Detailregulierungen anstrebte, verlassen, und eine neue Phllosophie, beruhend auf dem Gedanken der funktionellen Gleichheit einzelstaatlicher Regelungen und der Propagierung des gegenseitigen Vertrauens, verkündet ${ }^{13 !}$. Steindorff sieht darin das Kennzeichen eines Binnnenmarktes. Dies bedeutet den Übergang vom Bestimmungsland-zum Herkunftslandprinzip im Waren-, Personen- und Dienstleistungsverkehrs ${ }^{132}$. Die Harmonisierung sollte auf die Gebiete beschränkt werden, die eine Öffnung der Märkte wegen zwingender Belange des Gemeinwohls bisher noch verhin derte. Dieser neue Harmonisierungsansatz wird auch mit dem Stichwort "Deregulierung" bezeichnet ${ }^{133}$ und liegt damit im allgemeinen politischen Trend ${ }^{134}$.

Seine Grundlage findet dieses Harmonisierungskonzept in der "Cassis de Dijon" Rechtsprechung des EuGH ${ }^{135}$. Dementsprechend wird nach einer Minimalharmonisierung ${ }^{136}$ der wesentlichsten Regelungen zum Herkunftslandprinzip übergegangen, wobei die unterschiedlichen Normen gegenseitig anerkannt werden ${ }^{137}$. Das bedeutet, daß eine Ware, die den Anforderungen des Herkunftsstaates genügt, ungehindert überall im Binnenmarkt Zugang finden muß, auch wenn die entsprechenden Regelungen des Empfangsstaates nicht erfüllt sind. In den Fällen, in denen eine Harmonisierung der Vorschriften und Normen nicht aus gesundheits-, sicherheits- oder industriepolitischen

130. Kommission der Europä ischen Gemeinschaften, Vollendung des Binnenmarktes, Weißbuch der Kommission an đen Europäischen Rat vom 14. Juni 1985

131. Kommission der Europäischen Gemeinschaften, Vollendung des Binnenmarktes, WeiBbuch der Kommission an den Europaischen Rat vom 14. Juni 1985, Nr. 61 ff, Dauses, EuZW 1990, 8.

132. Sleindorf, ZHR 1986, 687 (689);

133. Brulba, ZaokV 1986, 1. Trotz dieser Bezeichmung kommt man nicht umhin festzustellen, daf der Binnemmarkt ein nicht unerhebliches Maß an Regulierung ausgelöst hat. Eyles weist daher zu Recht darauf hin, daß der Begriff Deregulienung in diesem Zusanmenhang weriger quanitativ, d. h. um Sinne: des Abbaus der Normenflut, verstanden werden sollte, sondem vielmehr eine qualitative Komponente der Vermeidung einer Ubersteuenung des Wirtschaftssy stems und der Gesell schaft durch regulatorisches Recht beinhalte, Eyles, 26

134. Müller-Graff, Bimnemarktziel und Rechtsordnung: Binnenmarktrecht 1989, 34

135. Urteill vom 20. Februar 1979, Rs 120/78 - REWE-Zentral-AG/Bundesmonopolverwaltung für Bratumtwein -, Slg. 1979,649 ff. Siehe im einzelnen zur Rechisprechung des EuGH die Kommentienung zu. Art. 30 von Müller-Graff, GTE-Kommentar, Rdnr. 16 ff.; Marenco, CDE 1984, 291; White CMLRev. 1989; 243; Mortelmans, CMLRev. 1991, 115; Steiner, CMLRev. 1992, 749* Steindorf,
ZHR 1994, 149 (160).

136. Kritisch zur Minimalharmonisierung Taschner in GS Constantinesco, $775 \mathrm{f}$.

137. Kommission der Europäischen Gemeinschaften, Vollendung des Binnenmarktes, WeiBbuch der Kommission an den Europäischen Rat vom 14. Jumi 1985, Weilbuch, Nr. $77 \mathrm{ff}$, siehe auch Nr. 102 im Hinblick auf den freien Dienstleistungswerkehr finanzieller Produkte. Forwood/Clough, ELR 1986. 385 ff; Ewerling, Liber amicorum Pescatore 1987, 238. Zur neuen Hamonisienungskonzeption der Kommission siehe Sedemund in Schwarze 1987, 37; Gerritsen, RM-Themis 1989, 323. Zur Entwicklung dieses Harmonisienungskonzepts Schwartz in FS von der Groeben, 333. 
Gründen als wesentlich angesehen werden, muB die sofortige uneingeschränkte Anerkennung unterschiedlicher Qualitätsnormen die Regel sein ${ }^{138}$.

Diese neue Konzeption sollte auch für die Freizügigkeit der Arbeitnehmer und Selbständigen Früchte tragen. Nach Ansicht der Kommission sollten die Bürger der Gemeinschaft die Möglichkeit haben, ihren Beruf in anderen Mitgliedstaaten auszuüben, ohne zu Formalitäten verpflichtet zu sein, die sie letztlich von dieser Entscheidung abhalten könnten.

Für die Niederlassungsfreiheit der Selbständigen, so stellte die Kommission im Weißbuch fest, war bisher noch wenig erreicht worden ${ }^{139}$. Begründet wird dies mit den Schwierigkeiten, mit denen die Bemühungen zur Harmonisierung der beruflichen Qualifikationen behaftet sind. Diese Schwierigkeiten sollten durch ein allgemeines Amerkennungssystem überwunden werden. Kennzeichnend für dieses System sollte vor allem die von der Kommission propagierte Basisphilosophie sein, wonach die Anerkennung der Grade und Diplome ohne vorherige Harmonisierung stattfinden sollte. Dabei wurde von der Kommission der Grundsatz des gegenseitigen Vertrauens zwischen den Mitgliedstaaw ten sowie das Prïnzip der grundsätzlichen Vergleichbarkeit der Universitätsstudien und Ausbildungssysteme der Mitgliedstaaten als Kernelemente dieser Philosophie verankert.

Neu war dieser Ansatz keineswegs. Bereits 1974 hatte der Rat erklärt, daß die Richtlinien über die gegenseitige Anerkennung beruflicher Befähigungsnachweise und über die Koordinierung der Bedingungen für den Zugang zu einem Beruf so wenig wie möglich detaillierte Ausbildungserfordernisse vorschreiben sollen. Begrïndet wurde diese Leitlinie damit, daß trotz der Unterschiede, die hinsichtlich der Ausbildungsprogramme zwischen den Mitgliedistaaten bestehen, in der Praxis eine Vergleichbarkeit der Ausbildungsabschlüsse, die den Zugang zu gleïchartigen Tätigkeitsfeldern eröffnen, festgestellt werden kann ${ }^{140}$. Damals stieß diese Vorgehensweise jedoch auf Ablehnung bei der Kommission ${ }^{14 \|}$, die nicht ohne Grund eine Untergrabung ihrer Koordinierungsarbeiten befürchtete.

\section{\$ 4. Die Grundfreiheiten}

\section{A. EINLETTUNG}

Die Ausübung der freiberuflichen und gewerblichen Tätigkeit im europäischen Binnenmarkt wird wesentlich durch die vertraglichen Regelungen zum Niederlassungsrecht (Art. 52 bis $58 \mathrm{EGV}$ ) und zur Dienstleistungsfreiheit (Art. 59 bis $66 \mathrm{EGV}$ ) bestimmt.

138. Kommission der Europäischen Gemeinschaften, Vollendung des Binnenmarktes, WeiBbuch der Kommission an den Europäischen Rat vom 14. Juni 1985, Nr. 77.

139. Kommission der Europäischen Gemeinschaften, Vollendung des Bimmenmarktes, Weißbuch der Kom mission an den Europäischen Rat vom 14. Juni 1985, Nr. 91.

140. ABl. Nr. C 98 vom 20. August 1974 .

141. De Crayencour, 1983. 
In etwas geringerem Maße spielen auch die Bestimmungen zur Arbeitnehmerfreizügigkeit eine Rolle. Die ursprüngliche Einordnung dieser Vetragsvorschriften unter den Titel "Grundlagen der Gemeinschaft" zeigt die Bedeutung, die die Verfasser des Vertrages diesen Freiheiten zugemessen haben ${ }^{142}$. Die Freiheit des Personenverkehrs und die Dienstleistungsfreiheit wird häufig nicht unerheblich durch das nationale Berufsrecht beschränkt. Man kann von einer Kollision der nationalen Berufsreglementierung mit den durch Gemeinschaftsrecht garantierten Freiheiten sprechen ${ }^{143}$. Die hieraus resultierenden Beschränkungen lassen sich primär in zwei Kategorien unterteilen. Die eine Kategorie erfaßt alle Vorschriften, die die Niederlassung oder die Dienstleistungserbringung von EG-Ausländern von besonderen Voraussetzungen abhängig machen, die Inländer nicht zu erfüllen haben oder automatisch erfülen, so vor allem das Kriterium der Staatsangehörigkeit als Zulassungsvoraussetzung für einen bestimmten Beruf. Diese Regelungsgruppe kann als differenzierendes Niederlassungsrecht bezeichnet werden ${ }^{144}$. Zur zweiten Kategorie berufsrechtlicher Vorschriften gehören alle diejenigen nationalen Bestimmungen, die unterschiedlos auf In- und Ausländer Anwendung finden. Die zu dieser Kategorie gehörenden Regelungen lassen sich als nicht-differenzierendes Niederlassungsrecht zusammenfassen ${ }^{145}$. Neben diesen beiden Kategorien kann noch eine dritte Form der Berufsbeschränkung konstatiert werden. Es betrifft die sogenannte Inländerbeschränkung oder Inländerdiskriminierung. Es handelt sich dabei um eine Folgeerscheinung des Abbaus der Ausländerbeschränkungen im Binnenmarkt.

Im folgenden soll zunächst der Anwendungsbereich der Niederlassungsfreiheit für natürliche Personen dargestellt werden. Daran anschließend folgt eine Abgrenzung der Niederlassungsfreiheit von den übrigen auf Personen bezogenen Grundfreiheiten. Unter D wird die Frage erörtert, ob Art. 52 EGV sich in einem Abbau der diskriminierenden Vorschriften erschöpft oder, ob auch unterschiedlos auf Aus- und Inländer angewandte Berufsregeln in den Anwendungsbereich dieser Vorschrift fallen. Hierbei wird zunächst die vertragliche Ausgangslage und eine Übersicht des Literaturstands gegeben. Da die Interpretation des EG-Vertrages maßgeblich durch den EuGH bestimmt wird, ist zur Frage, ob die Art. 52 und 59 EGV ein Diskriminierungsverbot oder ein umfassendes Beschränkungsverbot beinhalten, die Rechtsprechung des Gerichtshofs von entscheidender Bedeutung. Unter E wird daher die Entwicklung der Rechtsprechung in drei Zeitabschnitten analysiert.

142. Ress/Ukrow, 13. Die Tatsache, daß der drite Teil des Vertrages nun mehr den Titel "Die Politiken der Gemeinschaft: trägt, hat an der Bedeutung der Grundfreiheiten nichts geändert.

143. Fischer 1993, 25.

144. So bereits Meyer-Marsilius . NWW 1960, 756. Siehe auch Herzog, 18, der diesen Begriff als terminolo gisch sauberer bezeichnet

145. Herzog, 21. 


\section{B. DER ANWENDUNGSBEREICH DER NIEDERLASSUNGSFREIHEIT}

\section{Selbständige Erwerbstätigkeit}

Die Art. 52 ff EGV gelten unstreitig für alle Gruppen der selbständigen Erwerbstätigkeit. Unter selbständiger Erwerbstätigkeit ist jede berufliche Tätigkeit zu verstehen, die unabhängig ausgeübt wird und dem Erwerb eines Einkommens dient ${ }^{146}$. Selbständig ist eine Tätigkeit dann, wenn sie auf eigene Rechnung und auf eigenes Risiko hin ausgeübt wird ${ }^{147}$. Ein Gewinnstreben im ökonomischen Sinn ist jedoch nicht das entscheidende Kriterium ${ }^{1+8}$ "Allein die Entgeltlichkeit der Leistung begründet die Anwendbarkeit des EG-Vertrages ${ }^{149}$. Nagy spricht in diesem Zusammenhang von einer "activité lucrative indépendent" 150 .

\section{Freie Berufe}

Die Niederlassungsfreiheit umfaßt nicht nur die gewerbliche Tätigkeit, sondern auch die sogenannten freien Berufe ${ }^{15 i}$. Innerhalb der europäischen Gemeinschaft unterscheiden nur wenige Mitgliedstaaten mit Legaldefinitionen zwischen Freiberuflern und gewerblich Tátigen. Lediglich in Deutschland, Frankreich, Griechenland und Italien wird diese Unterscheidung rechtlich gehandhabt. In Deutschland findet die besondere Stellung der freien Berufe ihren Niederschlag im Steuerrecht. Die zentralen Bestimmungen enthält das Einkommensteuergesetz in den $\S \S 15$ und $18^{152}$. Auch Österreich kennt eine derartige Unterscheidung im Steuerrecht ${ }^{153}$. Eine genaue Definition des Begriffs "Freier Beruf" kann man dieser Steuergesetzgebung jedoch nicht entnehmen. In allen anderen Mitgliedstaaten wird generell von Selbständigen gesprochen. In den Niederلanden ist der Begriff "Vrije beroepen" zwar geläufig, rechtliche Konsequenzen werden an diese Bezeichnung zur Abgrenzung von anderen Gewerbetreibenden nicht geknüpft. In Großbritannien wird für die Freiberufler im allgemeinen der Begriff "professionals" ver-

146. Vgl. Platz, 12; Kahlert, 11; Everling 1963, 15; Nagy, Wirtschafit und Recht 1969, 173, der von einer "activité lucrative independante" spricht.

147. Everling 1963, 16; Randelzhofer in Grabilz-Kommentar, Art. 52, Rdn 12; Kallier, 11; Platz, 12

148. Everling, BB 1958, 858.

149. Steindorf, NJW 1982,1902 (1905):

150. Nagy, Wirtschaft und Recht 1969,173

151. Everling 1963, 15; Platz, 12; Stadler, 6;

152. Gemal \&18 Abs. 1 Ziff. 1 des deutschen Einkommensteuergesetzes wird die freiberuftiche Tätigkeit wie folgt definiert: " Zur freiberu nichen Tätigkeit gehơren die selbstăndig ausgeübte wissenschafthiche, künstlerische, schriftstellerische, unterrichtende und erziehende "Tätigkeit, die selbstandige Berufstatigkeit der Äzte, Zahnärzte, Tierärzte, Rechtsamwältte, Notare, Patentanwälte, Vermessungsingenieure, Ingemieure, Architekten, Handelschemiker, Wirtschaftspriffer, Steuerberater, beratender Volks- und Betriebswirt, vereidigte Buchprüfer, (vereidigte Buchrevisoren), Steuerbevollmächtigte, Heilpraktiker, Dentisten, Krankengy mnasten, Journalisten, Bildberichterstatter, Dolmetscher, Obersetzer, Lotsen und ahnliche Berufe." Siehe zum Wesen der Freien Berufe bereits Anraths 1930. Zur Lage der Freien Berufe sielle Sahner/Herrmann/Rönnau/Tratuweitn, Teil I, II und III.

153. \$22 Abs. 1, Ziff. 1 des. Einkommenssteuergesetz von Österreich enthält eine ähnliche beuspielsweise Aufzählung. 
wendet. Auch mit dieser Qualifizierung sind jedoch keine rechtlichen, sondern höchstens soziale Konsequenzen verbunden. Trotz der Abwesenheit einer rechtlichen Abgrenzung zwischen Freiberuflichkeit und gewerbliche Berufsausübung bei der Mehrheit der Mitgliedstaaten, kennen alle Mitgliedstaaten gewisse gemeinsame Komponenten, die sie mit dem Begriff der Freiberuflichkeit verbinden. Hierzu gehören eine hohe Qualität der Ausbildung, persönliche Verantwortung, Unabhängigkeit in der Berufsausübung sowie Standespflichten. Gegenstand der Tätigkeit sind vornehmlich ideelle Leistungen. Des weiteren stehen freie Berufe häufig in einem besonderen, auf Dauer angelegten Vertrauensverhält tnis zum Klientel ${ }^{154}$.

Obwohl bei den freien Berufen die besondere Beziehung zum Beruf und zum Klientel besondlers betont wird ${ }^{155}$, und sie zumindest daher in einigen Mitgliedstaaten nicht als Gewerbe eingestuft werden ${ }^{156}$, kann die wirtschaftliche Seite dieser Berufsgruppe sicher nicht geleugnet werden. Auch Ärzte, Zahnärzre, Rechtsanwälte und Architekten erbringen ihre Leistungen nur gegen Bezahlung und bestreiten davon ihren Lebensunterhalt. Inwieweit die Unterscheidung zwischen Gewerbe und freiberuflicher Tätigkeit in der heutigen Zeit überhaupt noch zeitgemäß ist, kann an dieser Stelle jedoch dahingestellt bleiben.

Auch im Gemeinschaftsrecht gibt es keine Definition der freiberuflichen Tätigkeit, vielmehr geht der EG-Vertrag selbst von einer Einbeziehung der freien Berufe in die selbständige Erwerbstätigkeit aus. Art. 57 Abs. 3 EGV nennt ausdrücklich die ärztlichen, arztähnlichen und pharmazeutischen Berufe. Art. 60 EGV erwähnt bei den vom Vertrag geregelten Dienstleistungen neben den gewerblichen, kaufmännischen und handwerklichen auch die freiberuflichen Tätigkeiten.

Der EG-Vertrag bezieht sich - mit Ausnahme des Art. 57 Abs. 3 EGV - nicht auf Berufe, sondern auf Tätigkeiten. Der Vertrag berücksichtigt damit die Tatsache, daß in den einzelnen Mitgliedstaaten unterschiedliche Berufsbildbetrachtungen herrschen, die historisch bedingt sind ${ }^{157}$. So kann ein und die selbe Tätigkeit in verschiedenen Mitgliedstaaten eine unterschiedliche Berufsbezeichnung tragen, andererseits besteht auch die Môglichkeit, daß unter der gleichen Bezeichnung die Ausübung unterschiedlicher Tätigkeiten verstanden wird ${ }^{158}$. Die Vertragsstaaten haben es daher vermieden, den

154. Im Bericht der Bundesregierung über die Lage der Freien Benufe in Deutschland werden die folgenden zentralen Merkmale der freibenflichen Ttitigkeit genann: "Eigenverantwontung Dienste mit Gemeinwohlverpflichtumg und benufsethischer Bindung, persöhnlichs, vornehmlich kreative oder geistige Leistung. die regelmäßig auf besonders qualifizierter Ausbildung benhen und insbesondere in der Anwendung auf den individuellen Einzelfall bestehen." "Sithe dazu den Bericht der Bundesregierung 1991.8.

155. Chesne, 131: "les professsions libérales se caractérisent essentiellement par le rapport humain existant enitre professionel et client."

156. Ewerling 1963, 15; Stadler, 6;

157. Everling 1963, 110, Tomuschat ZaöRV 1967.53(70).

158. Randelehofer in Grabitz Kommentar, Art. 52 Rdn 17. 
Bestimmungen des Vertrages einen gemeinsamen Berufsbegriff zugrunde $z u$ legen ${ }^{15 \%}$. Das Gemeinschaftsrecht orientiert sich darum nicht an den durch die Mitgliedstaaten bestimmten Berufsbildern, sondern an der konkret ausgeübten Tätigkeit ${ }^{160}$. Die Tätigkeit kann in zwei Formen ausgeübt werden. Entweder begibt sich der Betreffende in den anderen Mitgliedstaat und läßt sich dort selbständig nieder, oder er errichtet dort eine Agentur, eine Zweigniederlassung oder eine Tochtergesellschaft über die er tätig wird. Die erste Form der Niederlassung besteht in der Neugründung beziehungsweise Übernahme eines beruflichen Mittelpunkts ${ }^{|6|}$. Die zweite Form der Niederlassung wird auch als établissement secondaire bezeichnet ${ }^{162}$.

\section{ABGRENZUNG DER NIEDERLASSUNGSFREIHEIT VON DEN ÜBRIGEN GRUNDFREIHEITEN}

\section{Abgrenzung zwischen Niederlassungsfreiheit und der Arbeitnehmerfreizügigkeit}

Während sich das Freizügigkeitsrecht aus den Artikeln 48 bis $5 \mathbb{1}$ EGV auf abhängige Beschäftigte bezieht, schützen die Bestimmungen im Niederlassungskapitel Gewerbetreibende, Freiberufler sowie Unternehmer, die eine selbständige Erwerbstätigkeit in einem anderen Mitgliedstaat aufnehmen und ausïben wollen. Für die Abgrenzung der Arbeitnehmerfreizügigkeit von der Niederlassungsfreilheit für Selbständige sind die Kriterien der Fremdbestimmtheit der Arbeit und das unternehmerische Risiko von Bedeutung ${ }^{163}$. Maßgebend für die selbständige Tätigkeit sind die Beteiligung an Gewinn und Verlust, die freie Bestimmung der Arbeitszeit und die Auswahl der Mitarbeiter ${ }^{164}$. Diese Unterscheidungskriterien erscheinen jedoch bei der derzeitigen Entwicklung einiger Freier Berufe nicht mehr so klar und deutlich zu sein, wie das vielleicht 1957 noch der Fall war. Gedacht werden muß z. B. an die zumindest in einigen Mitgliedstaa$\operatorname{ten}^{165}$ zu konstatierende zunehmende Expansion der Rechtsanwaltskanzleien zu GröBenordnungen vom mehr als 100 beschäftigter Rechtsanwälte ${ }^{166}$. Nur ein Bruchteil der in diesen Großkanzleien tätigen Anwälte sind Teilhaber der Kanzlei. Die Mehrheit ist im Angestelltenverhältnis beschäftigt. Auch bei den Wirtschaftsprüfern, Unternehmens- und Steuerberatern kann man eine ähnliche Entwicklung konstatieren. Diese Entwicklung steht in einem Spannungsverhälınis zu dem Grundgedanken, daß Angehörige der freien Berufe eine selbständige Erwerbstätigkeit ausüben. Die Frage, dlie in

159. Vgl. dazu die Schlußanträge von GA Mayras zu der Rs 2/74, Urteil vom 21 , Juni 1974 , Reyners/Belgien *. Sig. 1974,631 (666).

160. Stadler, 8.

161. Vignes, AFD1 1961, 675, nennt diese Form die "installation principale; zo denken ist etwa an die Grundung einer frejbenflichen Praxis.

162. Vignes, AFDI 1961, 675.

163. Hailbronner, Handkommentar, Art. 48 Rdn 2.

164. Urteil vom 14. Dezember 1989, Rs 3/87, - The Queen gegen Ministry of Agriculture (ex parte Agegate Ltd.) - Stg. 1989, 4459, (4493). Daxu Bleeker, SEW 1990, 954.

165. Dies gilt wor allem fur das Vereinigte Königreich und die Niederlande, aber auch in Belgien und Frankreich lassen sich ähnliche Entwickluingen feststellen.

166. So verfight etwa die britische Law Firm Clifford Chance über 230 Pantmer und über 900 Juristen im Angestelltenverhältmis (Stand 1992). 
diesem Zusammenhang gestellt werden muß, ist dann auch, welche Bestimmungen des EG-Vertrages auf - um beim Beispiel zu bleiben - einen Rechtsanwalt im Angestelltenwerhältnis Anwendung finden. Nicht immer werden die genannten Kriterien der Fremdbestimmtheit der Arbeit und des untemehmerischen Risikos eine deutliche Qualifizierung zulassen. Im allgemeinen wird man bei einem erfahrenen Anwalt kaum eine Fremdbestimmtheit der Arbeit feststellen können. Nur in geringem Maße kann von Weisungsbefugnis gesprochen werden. Etwas anderes gilt aber bezüglich des unternehmerischen Risikos. Angestellte Rechtsanwälte werden im allgemeinen nicht am Gewinn oder Verlust beteiligt.

Meines Erachtens mul zur Beantwortung der Frage auf den äußeren Zusammenhang abgestellt werden, in dem die Abgrenzungsproblematik steht. Handelt es sich um ein Problem der Zulassung zur Anwaltschaft in einem anderen Mitgliedstaat, d.h. um die Zulassung zu einer an sich selbständigen Tätigkeit, dann finden die Bestimmungen bezüglich der Niederlassungsfreiheit Anwendung. Betrifft es dagegen ein Problem im Innenverhältnis zwischen der Anwaltskanzlei und dem beschäftigten Rechtsanwalt - etwa ein Problem der Höhe des Gehaltes -, dann können in diesem Zusammenhang auf den selben Rechtsanwalt die Freizügigkeitsbestimmungen der Art. 48 ff. EGV Anwendung. finden. Diese Auffassung kann, zwar nur indirekt, durch die Rechtssache Vlassopoulou bellegt werden ${ }^{107}$. Irène Vlassopoulou war - laut dem im Sitzungsbericht niedergelegten Sachverhalt - seit Juli 1983 in einer deutschen Anwaltskanzlei in Mannheim tätig $^{168}$. Weder im Sitzungsbericht noch im Schlußantrag des Generalanwalts ${ }^{169}$ wird näher auf die Tatsache eingegangen, in welchem konkreten Beschäftigungsverhältnis Frau Vlassopoulou ihre Tätigkeit ausgeübt hat. Dabei war ein Angestelltenverhältnis ebenso denkbar wie die Berufsausübung als selbständiger Rechtsbeistand für griechisches Recht und Gemeinschaftsrecht. Der Gerichtshof scheint die Lösung dieser Frage jedoch für unbeachtlich gehalten zu haben, da im konkreten Fall die Zulassung zur Rechtsanwaltschaft und damit die Niederlassung als Rechtsanwältin im Streit stand. Dieser Streitpunkt konnte jedoch nach Ansicht des Gerichtshofs vollkommen losgelöst vom internen Arbeitsverhälimis als ein Problem der Niederlassungsfreiheit beurteilt werden. Eine ähnliche Haltung nahm der Gerichtshof in der Rechtssache Ramrath ein, wobei er es dem nationalen Gericht überließ, eine genaue Kategorisierung anhand des Tatbestandes worzunehmen 120

167. Urteil vom 7. Mai 1991. Rs C-340/89 - Irène Vlassopoulou gegen Ministerium für Justiz, Bundes- und Europaangelegenheiten Baden-Wurttemberg -, Slg. 1991, 1-2357 ff.

168. Urteil vom 7. Mai 1991, Rs C-340/89 - Irène Vlassopoulou gegen Ministerium für Justiz, Bundes- und Europaangelegenheiten Baden-Wiirttemberg -, Slg. 1991, 1-2357 (2358)

169. Unteil wom 7. Mai 1991, Rs C-340/89 - Irène Vlassopoullou gegen Ministerium für Justiz, Bundes- und Europaangelegenheiten Baden-Würtemberg -, Slg. 1991, 1-2357 (2365)

170. Urteil vom 20. Mai 1992 , Rs C-106/91 - Claus Ramrath gegen Ministre de la Justice -, Slg. 1992, I 


\section{Abgrenzung zwischen der Niederlassungsfreiheit and der Dienstleistungsfreiheit}

Die Bestimmungen über das Niederlassungsrecht gelten nur bei einer dauerhaften Tätigkeit in einem anderen Mitgliedstaat ${ }^{171}$. Handelt es sich dagegen lediglich um eine vorübergehende Berufsausübung in dem anderen Mitgliedstaat, so fallt diese unter das Kapitel Dienstleistungsverkehr (Art. $59-66^{\text {EGV) }}{ }^{172}$. Die Grenze zwischen den beiden Freiheiten läßt sich nicht immer genau ziehen, besonders dann nicht, wenn die Erbringung einer Dienstleistung mit einer zeitweiligen Tätigkeit in einem anderen Mitgliedstaat verbunden ist oder aber sich diese Tätigkeit ständig wiederholt. Everling nennt als Beispiel die Ausführung eines Baues, die lange Zeit in Anspruch nimmt und damit eine Quasiniederlassung erforderlich macht. Eine ähnliche Fallkonstellation ergibt sich, wenn mehrere kurzfristigen Einzelleistungen hintereinander erbracht werden müssen. Nach Everling wird man in diesen Fällen auf das Gesamtverhalten des Unternehmens - etwa auf die Einrichtung am Leistungsont, den Beitritt zu Verbänden des Aufenthaltstaats, die Aufrechterhaltung von Bindungen zum Heimatstaat und ähnlichen Kriterien abheben müssen ${ }^{173}$. Zur Abgrenzung wird häufig das Kriterium einer andauernden Integration in die Wirtschaft des Aufnahmestaates angeführt ${ }^{174}$. Als Zeichen für eine derartige Integration gilt das Vorhandensein einer ständigen Einrichtung. Goldman dahingegen nennt die Schaffung eines neuen Kundenkreises im Aufnahmestaat dank der dort ausgeübten Tätigkeit als Unterscheidungskriterium ${ }^{175}$. Der Kundenkreis als Unterscheidungsmerkmal scheint jedoch wenig überzeugend. Mit den Möglichkeiten der modernen Kommunikation kann ein Kundenkreis von jeder Stelle aufgebaut werden. Dies geschieht unabhängig davon, ob der Betreffende vorübergehend grenzüberschreitend und damit als Dienstleistungserbringer aktiv ist oder, ob eine dauerhafte wirtschaftliche Integration im Aufnahmestaat stattfindet. Auch kann ein Kundenkreis im Rahmen des passiven Dienstleistungsverkehrs aufgebaut werden

Die Notwendigkeit der Abgrenzung ergibt sich letztlich vor allem durch die Entwicklung der Rechtsprechung, die bisher die beiden Grundfreiheiten in einem unterschiedlichen Umfang zu gewähren scheint, obwohl - wie aufzuzeigen ist - in jüngster Zeit eine Veränderung der Rechtsprechung konstatiert werden kann ${ }^{176}$. Dabei hat der EuGH die Abgrenzungsfrage bisher noch nicht abschließend beantwortet ${ }^{17}$. Allerdings hat der Gerichtshof hinsichtlich Versicherungsunternehmen festgestellt, daß die Tätigkeit

171. Hailbronner, Handkommentar Art. 52 Rdn 4.

172. Troberg in GBTE, Erläuterungen zu den Arft. 52 und 59 EWGV; Randelzhofer, in: Grabitz, Enlduterumgen zu den Artt. 52 und $59 \mathrm{EWGV}$; Everling, Gutachten zum DJT, C $43 \mathrm{ff}$. Hailbronner, Handkommentar, Art. 52 Rdin 4

173. Evertling 1963,18

174. Wyat/Dashwood, 189 ; Jerrentrup, 56 spricht won der Absicht, sich langfristig in das Wirtschaftsleben des Aufnahmestalates zu integrieren.

175. Goldman/Lyon-Caen, Droit Commercial, 1983, 132/133.

176. Siehe dazu auch die Analy se der Rechtsprechung des EuGH von Marenco. Yb of European Law, 1991, $111 \mathrm{ff}$.

177. Hailbronner/Nachbaur, EuZW 1992, 105 (107); Randelshofer in Grabitz Kommentar, Art. 52, Rdne $8 \mathrm{f}$. 
eines Dienstleistungserbringers auch dann den Niederlassungsbestimmungen unterliegen kann, wenn keine wirkliche Zweigniederlassung oder Agentur im Sinne des Art. 52 EGV vorliegt, sondern lediglich eine ständige "Präsenz" unterhalten wird ${ }^{178}$. In Anbetracht der Definition des Art. 60 Abs. 1 EGV könne sich ein solches Versicherungsunternehmen nicht auf die Art. 59 und $60 \mathrm{EGV}$ berufen. In diesem Falle würden die Dienstleistungsbestimmungen von den Regeln zur Niederlassungsfreiheit verdrängt.

Die Kommission hat in ihren Bemerkungen vom 24. Juni 1994 in der Rechtssache C55/94 Gebhard gegen Anwaliskammer Mailand zur Interpretation der Dienstleistungsrichtlinie für Rechtsanwälte $77 / 249 /$ EWG $^{179}$ vorgeschlagen, die im freien Dienstleistungsverkehr ausgeübte Rechtsanwaltstätigkeit wie folgt zu definieren: Eine Tätigkeit, "die von einem Rechtsanwalt ausgeübt wird, dessen Tätigkeitsschwerpunkt sich in einem anderen Mitgliedstaat als dem des Empfängers der Dienstleistung befindet und das Hauptmerkmal dieser Dienstleistungen darin besteht, daß sie zeitweilig, gelegentlich und nicht auf Dauer erbracht werden." 180 Mit dieser Definition glaubt die Kommission bestimmte konkrete Probleme lösen zu können, die sich für Anwälte beil der Berufsausübung im Ausland ergeben. Es bleibt abzuwarten, ob der Gerichtshof diese Auslegung des Dienstleistungsbegriffs übernehmen wird. Meines Erachtens ist die Definition jedoch zu restriktiv. Dies gilt vor allem für die kumulative Begriffsbestimmung "zeitweilig, gelegentlich und nicht auf Dauer". Nach meiner Ansicht erscheint es ausreichend zu sein, wenn eines dieser Merkmale vorliegt. Auch eine regelmäßige, aber nicht auf Dauer angelegte Berufsausübung in einem anderen Mitgliedstaat erfüllt meines Erachtens die Voraussetzungen, um als Dienstleistung und nicht ais Niederlassung qualifiziert zu werden, falls zumindest keine dauerhafte Präsenz vorliegt.

Unabhängig von der Abgrenzung der beiden Freiheiten, ist zunehmend die Frage nach dem Sinn und Nutzen einer derartigen Unterscheidung zu stellen. Grundsätzlich sollen die Art. 52 und 59 EGV die Rechte der selbständig Erwerbstätigen innerhalb der Gemeinschaft gewährleisten. Als wesentliches Unterscheidungskriterium wird die Grenzüberschreitung gehandhabt. Dieses Kriterium verliert jedoch an deutlichen Konturen je stärker sich die Gemeinschaft zu einem wirtschaftlichen Binnenmarkt ohne Binnengrenzen entwickelt. Dies bedeutet zwar nicht die Aufgabe der staatlichen Jurisdiktion, die unterschiedliche rechtliche Einordnung erscheint vom ökonomischen Standpunkt willkürlich ${ }^{18: 1}$. Dies gilt um so mehr als gemäß Art. 66 EGV die Bestimmungen der Art 55 bis $58 \mathrm{EGV}$ auf die Dienstleistungsfreiheit Anwendung finden. Eine genaue Abgrenzung beider Freiheiten läßt sich daher nur solange rechtfertigen als beide in einem

178. Utteil vom 4. Dezember 1986, Rs 205/84 - Kommission/Deutschland -, Slg. 1986, 3755, Rdnr 21. Vgl. dazu Edwand, ELR 1987, 231; Hubner, IZ 1987, 330; Mortelmans, Ars Aequi 1987, 732; Schwintowski, NIW 1987, 521 (523 ff.); Steenbergen, CDE 1987, 542.

179. Richtlinie des Rates vom 23. März 1977. ABl. Nir. L 78 vom 26. März 1977, 17.

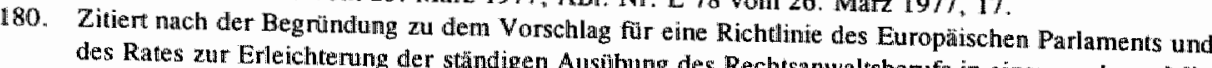
des Rates zur Erleichterung der ständigen Ausübung des Rechtsanwaltsberufs in einem anderen Mitgliedstagt als dem, in dem die Qualifikation erworben wurde, KOM (94) 572 endg., 2.

181. Wyatt/Dashwood, 182; Everling. BB 1958, 817 (819). 
unterschiedlichen Umfang ge-währt werden. Dies soll im folgenden anhand der vertraglichen Ausgangslage und der Rechtsprechung näher untersucht werden.

\section{Die vertragliche Ausgangslage}

\section{Einleitung}

Die durch den EG-Vertrag garantierten wirtschaftlichen Grundfreiheiten bilden zusammen mit den Wettbewerbsregeln, den Kern des Gemeinschaftlichen Marktes oder im Sinne von Art. 7a EGV den Binnenmarkt ${ }^{182}$. Dabei sind alle vier Freiheiten, der freie Warenverkehr ebenso wie die Freizügigkeitsbestimmungen, der Dienstleistungsverkehr sowie die Kapitalverkehrsfreiheit von ihrer Grundkonzeption von einem Diskriminierungsverbot ausgegangen. Wohlfahrt/Everling/Glaesner/Sprung nennen in ihrem ersten Kommentar zum EWG-Vertrag die Sondervorschriften, durch welche Ausländer bei der Aufnahme und Ausuibung ihrer Tätigkeit aلs Arbeitnehmer ${ }^{183}$ und ihrer selbständigen Erwerbstätigkeiten ${ }^{184}$ beschränkt werdlen. Die weitergehende Integration sollte auf der Basis von Harmonisierungsmaßnahmen erfolgen. Zum Erlaß dieser Harmonisierungsmaßnahmen für den Bereich der Niederlassungsfreiheit enthalten die Art. 54 Abs. 2, 56 Abs. 2 und 57 EGV, für die Dienstleistungsfreiheit die Art. 63 und 66 EGV die notwendige Befugnis.

Der EG-Vertrag sah für die Verwirklichung der Freizügigkeit der Selbständigen ein zweistufiges Verfahren vor. Auf der Grundlage Allgemeiner Programme sollte das eigentliche Gemeinschaftsrecht in der Form von Richtlinien gesetzt werden. Gemäß der Artt. 54 Abs.1 und 63 Abs.1 EGV stellte der Rat am 18. Dezember 1961 Allgemeine Programme zur Aufhebung der Beschränkungen der Niederlassungsfreiheit und des freien Dienstleistungsverkehrs auf ${ }^{185}$. Diese Programme bestimmten den Kreis der Begünstigten und die einzelnen Beschränkungen, die nach dem in diesen Programmen aufgestellten Zeitplan aufzuheben sind. Gleichzeitig wurde die jeweils parallele Prüfung angeordnet, inwieweit zur Durchführung der Liberalisierung der Freizügigkeit die gegenseitige Anerkennung der Diplome und sonstiger Befähigungsnachweise sowie weitere Koordinierung des Berufsrechts der Mitgliedstaaten gemäß der Artt. 57 und 66 EGV erforderlich seien. Die Rechtsnatur dieser Allgemeinen Programme war, da sie nicht in der Form eines der Rechtsakte des Art. 189 EGV ergangen waren, undeutlich ${ }^{185}$. Oppermann bezeichnet sie als eine sanktionslose Selbstbindung des Rates und

182. Behrens, EuR 1992, 145

183. Wohlfahr/Everling/Glaesner/Sprung, Kommentar zum EWGV, Vorb. vor Art. 48, Nr. 4.

184. WohlfahrtEverling/Glaesner/Sprung, Konmentar zum EWGV, Vorb. vor Art. 52. Nr. 4.

185. Abl. $1962,36 \mathrm{ff}$. und $32 \mathrm{ff}$.

186. Everling in: Das Europäische Gemeinschaftsrecht im Spannungsfeld von Politik und Wirtschaft, 105/107, bezeichnet ihre Rechtsnatur als ungeklä̆t. Im allgemeinen wird angenommen, das die Allgemeinenem. Programme keinen rechtsverbindlichen Charakter haben, vgl. Troberg in: GBTE Art 54 Rdnr. 3; Randelzhofer in Grabitz Kommentar wor Art. 52 Rdnr. 23; 
Die Freiheit des Personenwerkehrs aufgrund des $\mathbb{E}$ G-Vertrages

der Kommission zur fristgerechten Verwirklichung der Niederlassungs- und Dienstleistungsfreiheit ${ }^{187}$.

Nach Artt. 54 Abs. 2 und 63 Abs. 2 EGV sollten die Allgemeinen Programme als Vorstufe von Richtlinien dienen, mit deren Hilfe die in den Programmen umrissenen. Beschränkungen aufzuheben waren. Art. $54 \mathrm{EGV}$ ist in zeitlichen Zusammenhang mil Art. 52 EGV zu sehen. Danach waren bis zum Ende der Übergangszeit, d.h. dem 31. Dezember 1969, die Beschränkungen der freien Niederlassung aufzuheben. Diese Zielsetzung wurde jedoch nicht erreicht. Trotz des Eriasses von zahlreichen Richtlinien war die Liberalisierung bis zum Ende der Übergangszeit nicht auf allen Gebieten gleich weit fortgeschritten. Während die Niederlassungsfreiheit und die Dienstleistungsfreiheit im Handel, Handwerk und Industrie sowie in der Landwirtschaft weitgehend durchgesetzt war ${ }^{188}$, wurden die in den Allgemeinen Programmen angegebenen Zeitpläne vor allem für die Freiberuffer, die Banken und das Versicherungswesen in keiner Weise eingehallten. Bis zum Ende der Übergangsperiode wurden nur 6 Übergangsregelungen zur gegenseitigen Anerkennung der Diplome erlassen ${ }^{189}$.

Von der ursprünglichen Grundkonzeption des Diskriminierungsverbots hat der Gerichtshof sich zunächst im Hinblick auf die Warenverkehrsfreiheit gelöst und Art. $30 \mathrm{EGV}$ neben dem Diskriminierungsverbot auch einem Beschränkungsverbot unterworfen ${ }^{190}$. Gemäß Art. 30 EGV sind nicht nur diskriminierende Mal3nahmen, sondern auch nichtdiskriminierende bzw. unterschiedslos wirkende Beschränkungen verboten, soweit diese nicht aus zwingenden Erfordernissen u.a. dem Verbrauerschutz gerechtfertigt sind ${ }^{191}$. Damit war die ursprïngliche in EWG-Vetrag vorgegebene Paralllelität der Grundfreiheiten nicht mehr gegeben. Die Warenverkehrsfreiheit hatte sich gegenüber den anderen Freiheiten zu einem Verbot won diskriminierenden und nichtdiskriminierenden Maßnahmen weiterentwickelt.

Für die Anerkennung der Diplome ist jedoch nicht die Warenverkehrsfreiheit maßgebend, sondern im wesentlichen die Niederlassungsfreiheit, die Dienstleistungsfreiheit und in eingeschränkterer Form die Freizügigkeit der Arbeitnehmer. Für die Beantwortung der Frage, in welchem Umfang Mitgliedstaaten ihre eigenen Diplome als Voraussetzungen dieser Personenverkehrsfreiheiten verlangen können, ist es von entscheidender

187. Oppermann, 1991, 583; Siehe auch Randelzhofer im Grabiz, Kommentar, Vorb. vor Art. 52, Rdmr 23 .

188. Maestripier, RMC 1971, 48; Klinge 1990, 25 ff.. Vgl auch Richtlinie 64/427/EWG des Rates vom 7. Juli 1964 über die Einzelheiten der Übergangsmaßnahmen auf dem Gebiet der selbstandigen Tätigkeiten der be- und verarbeitenden Gewerbe der CIT-Hauptgnuppen $23-40$ (Industrie und Handwerk),
ABI. 1964, 1863 .

189. Richtlinie 64/222/EWG zum Groblhandel vom 25. Februar 1964, ABH. 1964, 857, Streil in Bie ber/Beutler/Pipkom/Streil, $298 \mathrm{f}$.

190. Urteil vom 11. Juli 1974, Rs 8/74 - Dassonville -, Slg. 1974, 837. Zur Dogmatik der Freiheitt des Warenverkehrs Dauses, RIW 1984, 197ff; Barents, CMLRev. 1991, 271 ff:

191. Urtelil vom 20. Februar 1979, Rs 120/78-Cassis de Dijon -, Slg. 1979, 649 (662); sielle auch Unteil vom 22. Juni 1982, Rs 220/81 - Robertson -. Slg. 1982, 2349 (2360). 
Bedeutung, festzustellen, welchen genauen Inhalt die auf Personen bezogenen Grundfreiheiten beim heutigen Stand der Rechtsprechung haben. Dabei wird in zunehmendem $\mathrm{Maße}$ in der Literatur diskutiert, ob der Gerichtshof die ursprüngliche Parallelität der Grundfreiheiten auf einem erweiterten Niveau mit einem umfassenden Beschränkungsverbot wieder errichtet hat ${ }^{192}$.

\section{Der Gegenstand und der Umfang der Niederlassungsfreiheit}

a. Gegenstand des Niederlassungsrecht

Der Begriff der Niederlassungsfreiheit ist im EGV - anders als in zahlreichen bilateralen Niederlassungsabkommen und Freundschafts-, Handels- und Schiffahrtsverträgen ${ }^{193}$ - nicht exakt umschrieben oder gar abschließend definiert ${ }^{194}$. Art. 52 Abs. 1 Satz 1 EGV spricht nur von einer schrittweisen Aufhebung der Beschränkungen der freien Niederlassung. Gemäß Art. 52 Abs. 2 EGV "umfaßt die Niederlassungsfreiheit die Aufnahme und Ausübung selbständiger Erwerbstätigkeiten" .... . "nach den Bestimmungen des Aufnahmelandes für seine eigenen Angehörigen". Dies bedeutet jedenfalls, daß3 natürliche und juristische Personen das Recht haben, sich in einem anderen Mitgliedstaat als ihrem Heimatstaat dauernd selbständig und zu den gleichen Bedingungen wie Inländer wirtschaftlich zu betätigen ${ }^{195}$. Gegenstand und Kern der Niederlassungsfreiheit ist damit die Inländergleichbehandlung ${ }^{196}$. Jede Form der Diskriminierung aufgrund der Staatsangehörigkeit ist damit untersagt. Persönlich Begünstigte des Niederlassungsrechts sind alle Staatsanghörigen der Mitgliedstaten, unabhängig von ihrem Wohnsitz. Dieser kann auch außerhalb der Gemeinschaft gelegen sein. Lediglich bei Ausübung hoheitlicher Gewalt können gemäß Art. 55 EGV die Angehörigen anderer Mitgliedstaiten von bestimmten konkreten Tätigkeiten ausgeschlossen sein.

Diese Bestimmung zielt nach ihrem Wortlaut auf eine Inländergleichbehandlung ab. Am Wort "umfassen" entzündet sich jedoch der Streit, ob die Niederlassungsfreiheit über das bloße Düskriminierungsverbot auch weitere Beschränkungen verbietet. Wie Müller-

192. So bereits Bleckmann, DVB! 1986, 69; nun vor allem Steindorf, EuR 1988, 19; Knobbe “Kewk. DB 1990, 2573; Behrens, EuR 1992, 145; Van Gerven/Wouters, 43; Wouters, MJ 1994 179

193. Nach Art. 10 des Europaischen Niederlassungsabkommen wom 13. Dezember 1955 (BGBI. 1959 II, 997) ist Ausländern jede Erwerbstätigkeit wie Inländern zu gestatten, sofern nicht nach Ansicht des Aufnahmestaates wichtige Gründe wirtschafthicher und sozialer An enigegenstehern. In Art. V Abs. $\mathbb{1}$ des Deutsch-französischen Niederlassungs- und Schiffahrtsvertrages vom 27. Oktober 1956 (BGB). $1957 \mathrm{~N}, 1661$ ) ist eine entsprechenda Regelung wie in Art. 10 des Europäischen Niederlassung sabkommen getroffen. Die Inlandergleichbehandlung gilt jedoch nicht für Tätigkeiten die Inländern vorbehalten oder einer Sonderregelung unterworfen sind. Eine ähnliche Regelung enthält auch Art. 9 des Deutsch-italierischen Freundschafis-, Handels- und Schiffahrtsventrages vom 21 . November 1957. Vgl. hierzu auch Randelzbofer, 1980, 29ff,; Hailbronner, Ausländerrecht, Rdnr. 345 ff..

194. Randelzhofer in Grabitz Kommentar, Art. 52 Rdnr. 2; Eyles, 39

195. Clausnitzer, EG-Handbuch. 183 (185).

196. Dies war und ist unumstritten. Siehe dazu Vignes, AFDI 1961, 668 (670); Crayencour (1981); Everling (1963); Dolzer (1986), 7; Fröhlich, 42; Herzog, 77; Jerrentrup, 7; Platz, 48; Reitmaier, 45; Schöne 84. 
Graff formuliert: "Umfassen läßı sich aber auch als Beinhalten ohne auszuschließen verstehen" 197

\section{b. Umfang der Niederlassungsfreiheit}

Die von der Niederlassungsfreiheit Begünstigten sollen unter den gleichen Voraussetzungen wie Inländer ihr Recht auf freie Niederlassung ausüben dürfen. Traditionsgemäß wurde das Niederlassungsrecht in internationalen Verträgen stets als Gebot zur Inländergleichbehandlung verstanden ${ }^{198}$, wobei diese Gleichbehandlung durch Sondervorschriften erheblich beschränkt wurde ${ }^{199}$. Es spricht einiges dafür, daß die Vertragsverfasser einen derartigen Inhalt des Niederlassungsrecht als selbstverständlich angenommen haben und kein allgemeines Beschränkungsverbot vor Augen hatten ${ }^{200}$. Auch die Kommentierungen zum Vertrag aus den Anfangsjahren lassen keinen anderen Schluß $z^{201}$. Danach bedeutet das Gebot der Inländergleichbehandlung bezüglich der Niederlassungsfreiheil lediglich eine Konkretisierung des al Igemeinen Diskriminierungswerbots des Art. 6 EGV, wobei Art. 52 EGV als lex specialis Vorrang vor dieser Bestimmung hat ${ }^{202}$.

Die Frage ist jedoch, ob sich das Gemeinschaftsrecht inzwischen von dieser inhaltlichen Bestimmung des Niederlassungsrechts entfernt hat. Problematisch ist nämlich, ob ein Migrant, der sich in einem anderen Mitgliedstaat niederläßt, den dort geltenden Vorschriften des Berufs- und Gewerberechts in vollem Umfang unterworfen ist. Diese Frage ist von besonderer Bedeutung im Rahmen der Diplomanerkennung und der Zulassung zum Beruf. Hierzu werden die unterschiedlichsten Auffassungen vertreten ${ }^{203}$. Strittig ist dabei, ob sich der Umfang der Niederlassungsfreiheit in einem weit auszule-

197. Muller-Graff, 1989, 24; Steindorff, EuR 1988, 21

198. Randelzhofer, 1980, 39; Dolzer, 1986,8.

199. Siehe dazu die Auflustung in Wohlfahr/Everling/Glaesner/Sprung, 1960, Vorb. vor Art. 52 Nr. 4; Grund sützlich ist in den Niederlassungsverträgen die Varpflichtung zur Inländergleichbehandlung unter den Vorbehalt des Aufenthaltsrechts gestellt worden. Siehe dazu Schütterle, Die Inländerbehandlungs$\mathrm{k}$ lausel in dem klassischen Handels- und Niederlassungsverträgen der Bundesrepublik Deutschland, 1970. Hailbronner, Auslä̀nderrecht, Rdnr. 366. Randelzhofer 1980, 39

200. Sehr überzeugend Evverling, FS für Hans vont der Groeben, 111.

201. Vgl. Wohlfahrt/Ewerling/Glaesner/Sprung, 1960, Vorb vor Art. $52 \mathrm{Nr}$. 3: "Der Vertrag beschränkt sich daher darmuf, als Ziel die Beseitigung der Ausländerdiskriminierungen, also der Bestimmungen die Auslander im Vergleich zu Inländern benachteiligen, aufzustellen..." ". Gaudet, SEW 1961, 52 (60); Bulletin der EWG 1961, Nr. 12, 10. Fröhlich, 42; Meyer-Marsilius, NJW 1960, 756 sprach berelts von eimem differenzierenden Niederlassungsrecht im Gegensatz zum nicht-differenzierenden Niderlassungsrecht, das gemälB den Ant. 54 und 57 EGV koordinient werden sollte.

202. Siehe hierzu bereits die Kommentierung in Wohlfahrt/Everling/Glaesner/Sprung, 1960, zu Art. $52 \mathrm{Nr}$ 2. Herzog, 20. Vgl. aber auch die Entscheidung des EuGH in der Rs 305/87, Unteil vom 30. Ma 1989, - Kommission gegen Griechenland -, Slg. 1989, $1461(1477)$;

203. Bleckmann, Wirtschaft und Verwaltung 1987, 1119; Bhumenwitz NJW 1989, 621; Gornig. NJW 1989; 1120; Friese, AnwBI. 1987, 3, Everling. Saarbricken 1989, 2 ff. 
genden Diskriminierungsverbot erschöpft ${ }^{204}$ oder, ob ein allgemeines Beschränkungsverbot angenommen werden kann ${ }^{205}$. Im letzten Fall wäre eine Beschränkung nur dann und nur soweit zulässig, als diese sich durch das Allgemeininteresse rechtfertigen ließe. Die Diskussion wird vor allem in der deutschen Literatur sehr erhitzt geführt. Dabei lassen sich im wesentlichen drei Strömungen unterscheiden, wobei noch Variablen zwischen diesen vertreten sind. Ein Teil der Literatur sieht in der Rechtsprechung zum Niederlassungsrecht lediglich ein Diskriminierungsverbot, wobei von einem sehr umfassenden Diskriminierungsbegriff ausgegangen wird, der auch das Verbot von versteckten Diskrimierungen umfassen soll ${ }^{206}$. Diese Aufassung wird von Everling sehr betont vertreten ${ }^{207}$. Ihm schließen sich vor allem Hailbronner ${ }^{208}$, Oppermann ${ }^{209}$, Troberg ${ }^{210}$ und Dolzer ${ }^{211}$ an. Dagegen meint Steindorff, in der Rechtsprechung des EuGH einen Übergang vom Aufnahmestaat- zum Herkunftsstaatprinzip konstatieren zu können ${ }^{212}$. Diese Ansicht wird insbesonders von Behrens ${ }^{213}$ geteilt. Eine dritte, vor allem von Bleckmann entwickelte Meinung, geht davon aus, daß die Grundfreiheiten des Gemeinsamen Markts als Grundrechte qualifiziert werden müssen und, daß̧ dies spätestens seit der Entscheidung Klopp ${ }^{214}$ - auch für die Niederlassungsfreiheit gel-

204. Art. 52 EGV als Diskriminienungsverbot sehen: Hailbronner, Handkonmentar, Art. 52 Rdnr. 14; ders. JuS 1991, 917 (919 f.); Randelzhofer in Grabilz, Kommentar zu Art. 52 Rdnr. 36; Troberg in GTE, Art. 52 Rdnrn. 17 f.; Everling, DB 1990, 1853 (1857); ders., EuR 1989, 338 (345); ders., 58. DJT, C 43 ff.; Oppermann, Rdnr. 1492; Nachbaur, EuZW 1991, 470; Dolzer in: Dolzer/Hahndorf, 8. Auch Rabe, AnwBl. 1987, 394 (396) und NJW 1987, 2185 (2188) sah Art. 52 noch ausschließlich als Diskriminierungsverbot, differenzierend dagegen Rabe, Bonn 1992; so auch Roth, RabelsZ 1990, $65(82)$.

205. Art. 52 EGV alls ein allgemeines Beschränkungsverbot sehen: Steindorf EuR 1988, 19; Belrrens, RabelsZ 1988, 498 (521 f.); Blumenwitz, NJW 1989, 621 (622); Knobbe-Keuk, DB 1990, 2573 (2576); Sack, JuS 1990. 352 (354 f.); Rees, EuZW 1990, 521.

206. Die Begriffswahl ist dabei nicht immer einheitlich. So wird stant von "versteckter" Diskriminienung auch won "indirekter", "mittelbarer", "werschleierter" und "vendeckter" Diskriminierung gesprochen. Fischer 1993, 65, Fn. 7 .

207. Everling 58. DJT, C 43 ff. Everling, Der Betrieb 1990, 1853 ff,; Everling, Saarbrucken 1990, 19 ff.; so auch Stadler, $63 \mathrm{ff}$; Troberg in GTE, Art. 52, Rdnr. 37/38;

208. Hailbronner, JuS 1991, 917 (919); ders. Handkommentar, Art. 52 Rdnr. 14.

209. Oppermann, Rdnr. 1492

210. Troberg in: GTE, Art. 52, Rdnr. 37f.; ders. GTE-Handbuch, Art. 52, 37f.

211. Dolzer in: Dolzer/Fandorf, 8

212. Steindorff, ZHR 1986, 687 ff.; Steindorff, EuR 1988, 19 ff.. Kritisch gegen diese Auffassung dagegen Troberg-GTE-Kommentar, Art. 52 Rdnir. 37/38.

213. Behrens, RabellsZ 1988, 498; Behrens, Jura 1989, 561 ; Behrens, EuR 1992, 145; Ähnlich auch Ehlers, NVwZ 1990, 810 (811); Gornig, NJW/ 1989, 1120; Raczinski/Rogalla/Tomsche, AnwBl. 1989. 583; Kewenig IZ 1990, 20 ; Sack, JuS 1990, 353; Knobbe-Keuk. Der Betrieb 1990, 2573 ff.; Knobbe-Keuk EuZW 1991, 649 (651); Scherer, WuV 1987, 159 (161); Suß, 61 ff.: Wagenbaur, EuZW 1991, 427 (429); Schöne, 140; Ress, EuZW 1990, 521; Ress/Urkrow, 18; Schnichels, 115.

214. Urteil vom 12. Juli 1984, Rs $107 / 83$ - Ordre des avocats au barreau de Paris gegen Onno Klopp -, Slg. 1984, 2971 ff. Siehe dazu die Urteillsanmerkungen von Borggreve, RTW/AWD 1984, 988; Gormiey, ELR 1984, 439; Mendelsohn, HarvardJIL 1985, 562; Watson, CMLRew. 1985, 743. 
te ${ }^{215}$. Bleckmann argumentiert dabei auch mit der nach seiner Auffassung bestehenden Parallelität der Grundfreiheiten ${ }^{216}$. In der ausländischen Literatur ist der Streit weniger vehement geführt. Zunehmend scheint sich jedoch die Auffassung durchzusetzen, daß auch die Niederlassungstreiheit bei nichtdiskriminierenden Maßnahmen einem Beschränkungswerbot unterliegt. Die nationalen Einschränkungen sind danach nur dann auf Gemeinschaftsangehörige anwendbar, wenn zwingende Allgemeininteressen dies rechtfertigen und die Maßnahme dem Verhältnismäßigkeitsgrundsatz entspricht ${ }^{217}$.

Für die Diplomanerkennung ist dieser Meinungsstreit von einschneidiender Bedeutung. Nationale Qualifikationsvoraussetzungen, die für den Berufszugang erforderlich sind, werden in der Literatur im allgemeinen als nichtdiskriminierende Regelungen, d.h. als Maßnahmen ohne Unterschied, eingestuft ${ }^{218}$. Falls Art. 52 EGV als reines Diskriminierungsverbot einzustufen ist, wäre die Anwendung aller nationaler Berufsregelungen auf eine im Ausland qualifizierte Person in vollem Umfang zulässig. Hält man dagegen auch auf Art. 52 EGV ein Beschränkungsverbot für anwendbar, so ließe sich das. Erfordernis einer nationalen Berufsqualifikation im Aufnahmestaat nur dann rechtfertigen, wenn diese Regelung durch ein zwingendes Allgemeininteresse gedeckt und verhältnismäßig ist. Zu einem anderen Ergebnis kann man nur dann kommen, wenn man das Erfordernis eimer nationalen Qualifikation als eine diskriminierende Maßnahme kennzeichnet ${ }^{219}$. In diesem Falle müßBten nach dem Grundsatz der Inländergleichbehandlung materiell gleichwertige Diplome auch als solche anerkannt werden.

\section{E. DIE RECHTSPRECHUNG ZU DEN GRUNDFREIHEITEN}

Die Weiterentwicklung der europäischen Gesetzgebung wäre ohne die Rechtsprechung des EuGH kaum denkbar. Der Gerichtshof hat Art. 52 EGV und auch Art. 59 EGV zu praktischer Bedeutung verholfen, indem er diese Normen für unmittelbar anwendbar erklärte $^{220}$. Nach den richtungsweisenden und grundlegenden Entscheidungen des Ge-

215. Bleckmann, GS Sasse II, 665 ff; Bleckmann, FS Carstens Bd 1, 43 (53 f.); Bleckmann, DVBI. 1986 69ff., Bleckmann, WiVerw $1987,119 \mathrm{ff}$, Bleckmann, Euk 1987, 18 (33): Bleckmann, JZ 1988, 509. Bleckman, Rdnr. $453 \mathrm{ff}, 1106 \mathrm{ff}, 1139 \mathrm{ff}$. In diese Richting argumentieren auch Blumenwitz, NJW 1989, 621; Gomig, NJW 1989, 1120; Friese 1989; Friese AnwB1. 1987, 3; Lichtenberg 1986, 146 f: Schöne, 105 ; Meier, NJW 1976, 1557 (1558); Schwarze EuGRZ 1986, 293 (296).

216. So bereits Bleckmann, DVB1 1986, $69 \mathrm{ff}$. . Siehe alher auch Behrens, EuR 1992, 145ff, der von einer Konvergenz der wirtschaftlichen Freiheiten spricht. 217. Barents/Brinklhorst, 282; Johnson/O'Keefe, CMLRev. 1994, 1313 (1314); Wouters in:" Gilliams/-
Nihoul/Wouters/Wytinck, TBH 1993, 497; Wouters in:Gilliams/Van Gerven/Wouters/Wytinck, TBH
1094,743 . 1994,743;

2.18. Fischer 1993, 73; Schöne, 92; Oppermann, Rdnr. 1524

219. Nachbaur, EuZW 1991, $470(471)$

220. Troberg, GTE zw Art. 52. 
richtshofes in den Rechtssachen Reyners ${ }^{221}$ und van Binsbergen ${ }^{222}$, sind die Artikel 52 und 59 EGV seit Ende der Übergangsperiode unmittelbar anwendbar ${ }^{223}$

$\mathrm{Zu}$ dem dargestellten Meinungsstreit in der Literatur ist die Rechtsprechung hinsichtlich der Dienstleistungstreiheit eindeutig: Nicht nur diskriminierende, sondern auch beschränkende Maßnahmen können im Widerspruch zur vertraglich gewährten Dienstleistungsfreiheit stehen, falls sie nicht durch ein Allgemeininteresse gerechtfertigt sind $^{224}$. Dies wird in der Literatur auch allgemein bestätigt ${ }^{225}$. Bezüglich der Niederlassungsfreiheit ist unzweifelhaft, daß nicht nur offene Diskriminierungen aufgrund der Staatsangehörigkeit verboten sind, "sondern auch alle versteckten Formen der Diskriminierung, die durch Anwendung anderer Unterscheidungsmerkmale tatsächlich zum gleichen Ergebnis führen" ${ }^{226}$. Eine ähnliche Formulierung findet sich bereits in Abschnitt III Buchstabe B des Allgemeinen Programms zur Aufhebung der Niederlassungsfreiheit ${ }^{227}$. Im folgenden soll die Entwicklung der Rechtsprechung zur Dienstleistungs- und zur Niederlassungsfreiheit in drei Zeitabschnitten dargestellt werden, um dadurch den heutigen Rechtszustand bestimmen sowie mögliche zukünftige Entwicklungen aufzeigen zu können.

221. Urteil vom 21. Juni 1974, Rs 2/74 - Reymers/Belgien -,Slg. 1974, 631; siehe dazu De Dorlodot, RMC 1974, 473; Louis, JT 1974, 549; Graziadei, Foro ital. 1974, IV 342; Bayless, Texass ILJ 1975, 419; Goose RIW/AWD 1975, 36: Nicolaysen EuR 1975, 135; Loussouarn RTDE 1975, 518, Manschot. AdvBl. 1975, 136: Bronkhorst SEW 1976, 330

222. Urteil vom 3. Dezember 1974 , Rs $33 / 74$ van Binsbergen/Bestuur van de Bedrijfsvereniging voor Metaalnijverheid, Slg. 1974, 1299; siehe dazu Manschot, AdvBI. 1975, 136; Bronkhorst Sew 1976. 330. Zur weiteren Entwicklung siehe auch Steindorff, Fordham Int. L.J. 1988, $347 \mathrm{ff}$

223. Rs 2/74 - Reymers/Belgien, Slg. 1974, 631, Leitsatz 2

224. Urteil vom 25. Juli 1991, Rs C-76/90 - Manfred Säger/Dennemeyer \& Co. Ltd -, Slg. 1991, I-4221 Siehe dazu Speyer, EuZW 1991, 588; Urteil vom 25. Juli 1991, Rs C-288/89-Stichting Collectieve Antennevoorziening Gouda u.a. gegen Commissariaat voor de Media -, Slg. 1991, I-4007. Siehe auch die erläuternde Mitteilung der Kommission über die Freiheit des grenzüberschreitenden Dienstleistung sverkehrs, AB. Nr. 334 1993, 3

225. Fischer 1993, 75: Speyer, EuZW 1991, 588; Everling, DB 11990, 1853 (1857); Roth in Dausesw Handbuch, E,I, Rdnr. 61 ff; Sedemund/Montag. NJW 1994, 630; Mülbert, ZHR 1995, 2 (28)

226. Ständige Rechtsprechung seit dem Urteil des EuGH vom 12. Februar 1974, Rs 152/73 - Sotgiu/Deutsche Bundespost - Slig. 1974153 (164) und dem Urteil vom 28. April 1977, Rs.71/76 - Thieffry “, Slg. 1977, 765 (777), Rdnr. 13/14; Siehe dazu auch die Urteile vom 5. Dezember 1989, Rs 3/88 - Kommission/talien ", Slg. 1989, 4035 (4059), Urteil vom 8. Mai 1990, Rs C-175/88 - Biehl -, Slg. 1990, 1779 (1793) und vom 10. März 1993, Rs C-111/91, - Kommission/Luxemburg -, Sig. 1993 "1-817. Rdnr. 9 sowie das Urteil vom 23. Febnuar 1994, Rs C-419/92 - I. Scholz/Opera Universitaria di Cagliari -. Sig. 1994 l-505 (521), Rdnr. 7

227. ABI. 1962, 36 (38) 


\section{Die Rechisprechung in den siebziger Jahren}

\section{a. Die Rechtssache Reyners}

In der Sache Reyners wurde ein Niederiänder, der in Belgien wohnte, studierte und alle erforderlichen belgischen Diplome erworben hatte, in Belgien nicht zur Rechtsanwaltschaft zugelassen, weil er die belgische Staatsangehörigkeit nicht besaß. Reyners erhob Klage beim Conseil d'Etat. Dieser legte dem Gerichtshof u.a. die Frage vor, ob Art. 52 EGV, auch ohne, daß die in den Artt. 54 Abs.2 und 57 Abs.1 EGV vorgesehenen Richtlinien ergangen sind, seit Ablauf der Übergangsperiode unmittelbar geltende Wirkung hat.

Diese Frage wurde von dem EuGH positiv dahingehend beantwortet, daß die unmittelbare Wirkung von Art. 52 EGV unabhängig davon ist, ob für bestimmte Bereiche die in den Artikeln 54 Abs.2 und 57 Abs. 1 EGV vorgesehenen Richtlinien ergangen sind. Nach Aussage des Gerichtshofes sollten die in Art. 54 EGV vorgesehenen Maßnahmen die Niederlassungsfreiheit zwar erleichtern, sie sollten jedoch nicht die Bedingung darstellen. Vielmehr sei - nach der Übergangszeit - der Grundsatz der Inländergleichbehandlung seinem Wesen nach geeignet, unmittelbar geltend gemacht zu werden. Seitdem ist der Einzelne berechtigt, sein grundsätzliches Recht auf Niederlassungsfreiheit im Falle von Beschränkungen vor den nationalen Gerichten unmittellbar geltend zu machen. Mit dieser Rechtsprechung wurden weitere Richtlinien zur Verwirklichung des Grundsatzes der Inländergleichbehandlung entbehrlich. Konsequenterweise zog die Kommission nach Erlaß des Urteils 11 Richtlinienvorschläge zum Abbau von Niederlassungsvoraussetzungen zurück ${ }^{228}$.

\section{b. Die Rechtssache van Binsbergen ${ }^{229}$}

Grundlegend für die weitere Entwicklung war bereits das erste Urteil des EuGH zur Dienstleistungsfreiheit. Seit dieser ersten Entscheidung in der Rechtssache van Binsbergen ging der Gerichtshof zu diesem Vertragskapitel über die bloße Inländergleichbehandlung hinaus. Der Fall betraf einen niederländischen Rechtsbeistand namens Kortman, der in den Niederlanden als Prozeßbevollmächtigter von van Binsbergen vor Gericht auftreten wollte, wobei bei dieser Instanz kein Anwaltszwang bestand. Kortman hatte im Laufe des Verfahrens seinen Wohnsitz nach Belgien verlegt. Daraufhin teilte ihm das Gericht mit, daß er nicht mehr befugt sei, als Rechtsbeistand in den Niederlanden aufzutreten, da nach der gesetzlichen Bestimmung nur in den Niederlanden ansässige Personen vor Gericht als Rechtsbeistand auftreten könnten. Der Centrale Raad van Beroep legte darauthin dem EuGH die folgenden Fragen vor:

228. 8. Gesamtbericht EG 1974, 81 $\mathrm{Nr}, 122 ;$ Stein/Hay/Waelbroek, 1976, $543 \mathrm{fr}$.

229. Utteil vom 3. Dezember 1974, Rs 33/74 - J.H.M. van Binsbergen gegen Bestuur van de Bedrijfsvereniging woor Metalnijwerheid -, Sig. 1974, 1299 ff. Siehe dazu auch Kok, SEW 1976, 251; Morse,
ELR 1975,67. 
1. Sind die Art. 59 und 60 EWGV unmittelbar anwendbar und begründen sie für den einzelnen Rechte, welche die nationallen Gerichte zu respektieren haben?

2. Welche Bedeutung haben, im Falle der Bejahung von Frage 1 , diese Artikel, insbesondere Art. 60 Abs. 3 EWGV?

Nachdem der Gerichtsh of die unmittelbare Anwendung der Art. 59 und 60 EGV grundsätzlich bejaht hatte, bezeichnete er, als zu beseitigende Beschränkungen nach diesen Artikeln alle Anforderungen, "die an den Leistenden namentlich aus Gründen der Staatsangehörigkeit oder wegen des Fehlens eines ständigen Aufenthalts in dem Staate in dem die Leistung erbracht wird, gestellt werden und nicht für im Staatsgebiet ansässige Personen gelten oder in anderer Weise geeignet sind, die Tätigkeiten des Leistenden zu unterbinden oder zu behindern." 230

Insbesondere der letzte Satzteil hat die weitere Entwicklung maßgebend bestimmt, da hier ein deutlicher Schritt über die Inländergleichbehandlung hinaus gesetzt ist. Diese Wortwahl war auch deshalb so bemerkenswert, weil sich der Gerichtshof nicht mit der Formulierung des Art. 60 Abs. 3 EGV auseinandersetzte. Allerdings hat der Gerichtshof eine Einschränkung vorgenommen, indem er hinzufügte: "In Anbetracht der Besonderheit der Dienstleistungen dürfen jedoch diejenigen an den Dienstleistungserbringer gestellten besonderen Anforderungen nicht als mit dem Vertrag unvereinbar angesehen werden, die sich aus der Anwendung durch das allgemeine Interesse gerechtfertigter Berufsregelungen - namentlich der Vorschriften über Organisation, Befähigung, Berufspflichten, Kontrolle, Verantwortung und Haftung - ergeben und die für alle im Gebiet des Staates, in dem die Leitstung erbracht wird, ansässigen Personen verbindlich sind." 231"

Mit dieser Betonung des "allgemeinen Interesses", wurde der Grundsatz aufgestellt, daß jede Regelung, die den freien Dienstleistungsverkehr in irgendeiner Weise behindert, nicht angewandt werden darf, wenn sie nicht durch das Allgemeininteresse gerechtfertigt ist. Diesen Grundsatz hat der EuGH in einer Reihe von Urteilen weiterentwickelt ${ }^{232}$ und schließlich im Urteil in der Rechtssache Webb zusammengefaß3t ${ }^{233}$. Ehe der Gerichtshof die Rechtsprechung zur Dienstleistungsfreiheit weiterentwickeln konnte, hatte

230. Urteil vom 3. Dezember 1974, Rs 33/74 - J.H.M. van Binsbergen gegen Bestuur van de Bedrijfivereniging voor Metaalnijverheid - , Slg. 1974, 1299, (1309) Rdinrn. 10/12.

231. Urtell vom 3. Dezember 1974 . Rs 33/74 - J.H.M. van Binsbergen gegen Bestuur wan de Bedriffsuerenigging voor Metaalnijverheid (Ersuchen um Vorabentscheidumg, vorgelegt vom Centrale Raad voor Beroep) -, Slg. 1974, 1299, (1309), Rdnat. 10/12.

232. Uneil vom 26. November 1975, Rs 39/75 * Robert Gerardus Coenen/Sociati-Economische Raad SIg. 19751547 ff: Urteil vom 18. Jamuar 1979 in den Rechtssachen 110/78 und 11/78 - Ministère public und Chambre Synicale des Agents artistiques et Impresarii de Belgique, ASBL/Willy van Wesemael und andere - ,Sig. 1979, 35 ff; Urteil vom 3. Februar 1982, Rs 62/81 und 63/81 - SecoSig.. 1982,223 ; Urteil vom 10 . Febnar 1982, Rs 76/81 - Transporoute - . \$lg. 1982, 417; Urtel vom 18. März 1980, Rs 52/79 - Debauve -, Slg. 1980, 833; Urteil vom 18. Mărz 1980, Rs 62/79 - Coditel - Slg. 1980, 881; Unteil vom 26. April 1988, Rs 352/85-Bond wan Adverteerders -, Slg. 1988, 2085.

233. Urteil vom 17. Dezember 1981, Rs 279/80 - Strafverfahren gegen Alfred John Webb -, S1g. 1981, $3305 \mathrm{ff}$. 
er zuvor in zweil Entscheidungen die Gelegenheit, den Imhalt des Diskriminierungsverbots im Niederlassungsrecht zu präzisieren.

\section{c. Die Rechtssache Thieffry ${ }^{234}$}

Trotz seiner epochemachenden Bedeutung für das Niederlassungsrecht ging der Gerichtshof in der Sache Reyners ausschließlich von einem Diskriminierungsverbot aus ${ }^{235}$. Dieses hat der Gerichtshof im Urteil Thieffry im Jahre 1977 unter Verweisung auf das Allgemeine Programm ${ }^{236}$ dahingehend präzisient und erweitert, daß3 nicht nur die offensichtlichen Diskriminierungen, sondern auch alle versteckten Diskriminierungen unzulässig sind ${ }^{237}$. Es handelte sich dabei um einen Belgier, der in Frankreich eine Eignungsprüfung für den Rechtsanwaltsberuf abgelegt und bestanden hatte, gleichwohl war ihm die Niederlassung als Anwalt in Frankreich verweigert worden. In dieser Sache beschäftigte sich der Gerichtshof auch eingehend mit der Frage nach dem Unterschied zwischen der akademischen Gleichwertigkeit von Diplomen und ihrer Wirkung im staatlichen Bereich. Diesem Lirteil lag der folgende, sehr spezielle Sachverhalt zugrunde:

Der belgische Rechtsanwalt Thieffry hatte seine Zulassung als avocat bei der Cour d'appel in Paris beantragt. Er ist Inhaber des vorgeschriebenen belgischen juristischen Diploms, dessen Gleichwertigkeit mit dem französischen Licenciat en droit von einer französischen Universität für akademische Zwecke anerkannt worden ist. Nachdem Thieffry die notwendige Praxiserfahrung in der Kanzlei eines bei der Cour d'appel zugelassenen französischen Rechtsanwaltes gewonnen hatte, erwarb er in Paris das Certificat d'aptitude à la profession d'avocat (CAPA), das französische Zeugnis über die Befähigung zum Rechtsanwalt. Daraufhin stellte er den Antrag bei der Cour d’appel, als Rechtsanwalt zugelassen zu werden. Diesen Antrag wies der Conseil de l'ordre mit der Begründung zurück, der Bewerber sei nicht Inhaber eines französischen Diploms zum Nachweis der Licence oder des docteur en droit. Der Cour d'appel legte dem EuGH die Frage vor, ob das Verlangen eines französischen Diploms eine gegen das Gemeinschaftsrecht verstoßende Beschränkung der Niederlassungsfreiheit darstellt, solange die in Art. 57 Abs. 1 und 2 EGV vorgesehenen Harmonisierungsrichtlinien noch fehlen.

234. Urteil wom 28. Aprill 1977, Rs 71/76 - Jean Thieffry/Conseil de l'Ordre des avoeats bei der Cour d"appel Paris - Sig. 1977, $765 \mathrm{ff}$.

235. Ebenso auch im Urteil vom 28. Juni 1977, Rs $11 / 77$ - Patrick -, Sig. 1977, 1199

236. Allgeneines Programm zur Aufhebung der Beschrånkungen der Niederlassumgsfreiheit vom 18 Dezember 1961, ABI 1962, 36.

237. Urteil vom 28. April 1977, Rs $71 / 76$ - Jean Thieffry/Conseil de l"Ordre des avocats bei der Cour d'appe Paris -, Slg. 1977, 765 (777) Rdnr. 13/14). Siehe dazu Wägenbaur EuGRZ 1977, 260; Dauwe, SEW 1978, 227; Dal, CDE 1978, 237; Crisham, CMLRev. 1978, 366. VgI. auch Unteil vom 28. November 1978, Rs 16/78 - Michel Choquet, Sig. 1978, 2293 ff. 
Die französische Regierung berief sich darauf, daß gemäß Art. 11 des französischen Gesetzes vom 31. Dezember 1971 bezüglich der Zulassung zum Rechtsanwalt, der Bewerber Inhaber der französischen licence oder des docteur en droil zu sein habe. Gemäß Art. 6 des französischen Dekrets vom 15. Februar 1921 begründe die Gleichwertigkeit einer von einer ausländischen Universität erteilten licence en droit keinen Anspruch auf das französische Diplom. Die von der Universität festgestellte Gleichheit gelte darum lediglich im Rahmen der akademischen Anerkennung zum Zwecke der Immatrikulation für das Weiterstudium zur Erlangung des docteur en droit. Die französische Regierung berief sich damit auf einen Unterschied zwischen der akademischen Anerkennung und derjenigen zur Ausübung des Berufes.

Thieffry dagegen trug vor, daß Art. 52 EGV eine Verpflichtung beinhalte, die über die bloße Inländerbehandlung hinausgehe. Das Verlangen nach einem nationalen Prüfungszeugnis, obwohl die Gleichwertigkeit beider Qualifikationen festgestellt sei, sei nicht erforderlich, um die Ziele der nationalen Gesetzgebung zu erreichen. Damit berief sich Thieffry bereits eindeutig auf den Verhältnismäßigkeitsgrundsatz, den er für verletzt ansah.

Der Gerichtshof folgte dieser Argumentation Thieffry's nicht, obwohl er in der Weigerung des französischen Conseil d'ordre, die Niederlassungsgenehmigung zu erteilen. unter den gegebenen Umständen als einen Verstoß gegen Art. 52 EGV sah. Der EuGH ging nicht auf die Frage ein, ob Art. 52 EGV über die bloße Inländerbehandlung hinausgehe, vielmehr begrüdete er seine Entscheidung damit, daß auch eine versteckte Diskriminierung im Rahmen der Niederlassungsfreiheit verboten sei ${ }^{238}$. Eine solche läge jedoch dann vor, wenn ein Unterschied zwischen der Wirkung der Gleichwertigkeit eines ausländischen Diploms nur für den akademischen und für den allgemein staatlichen Bereich gemacht wird. Dies gelte um so mehr, wenn der Migrant im Besitz eines Diploms des Niederlassungsstaates sei, das zur Niederlassung als Anwalt in diesem Staat vorgeschrieben sei und grundsätzlich zur Ausübung des Berufs berechtige. Unter Verweisung auf Art. 5 EGV stellt der Gerichtshof dabei fest, daß die tatsächliche Ausübung. der in Art. 52 EGV vorgesehenen Niederlassungsfreiheit nicht alleine mit der Begründung verhindert werden darf, daß die in Art. $57 \mathbb{E G V}$ vorgesehenen Richtlinien für einen bestimmten Beruf noch nicht erlassen sind ${ }^{239}$ "Die Begründung des Gerichtshofs überrascht insoweit, als er primär seine Argumentation auf die Tatsache abstellt, daß eine akademische Anerkennung der Gleichwertigkeit der Diplome vorliegt, wohingegen erst sekundär Erwähnung findet, daß Thieffry die zur Berufsausübung in Frankreich erforderliche Prüfung mit Erfolg abgelegt hat. Aus heutiger Sicht hătte es vielmehr auf der Hand gelegen, gerade diesen Punkt in den Mittelpunkt der Entscheidungsgründe zu stellen. Gerade weil der Gerichtshof zunächst festgestellt hat, daß die Berufsregelungen grundsätzlich im Allgemeininteresse gerechtfertigt sind, hätte er an diesem Punkt den

238. Urteil vom 28. April 1977, Rs 71/76 - Iean Thieffry/Conseül de I"Ordre des avocats bei der Cour: d'appel Paris -, Slg. 1977, 765 (777) Rdnr. 13/14.

239. Unteil vom 28. April 1977, Rs $71 / 76$ - Jean Thieffiry/Conseil de I"Ordre des avocats beí der Cour d'appel Paris -, Slg. 1977, 765 (777), Rdnr. 15/18. 
Verhältnismäßigkeitstest ansetzen können ${ }^{240}$. Zu einem solchen Schritt war der Gerichtshof 1977 jedoch offenkundig noch nicht bereit.

\section{d. Die Rechtssache Patrick}

Eine ähnliche Entscheidung traf der Gerichtshof am 28. Juni 1977 in der Sache Patrick $^{241}$. Bei Patrick handelte es sich um einen britischen Staatsangehörigen, der Inhaber eines im Vereinigten Königreich von der Architectural Association erteilten Architektendiploms war. Am 9. August 1973, d,h. noch vor der Entscheidung Reyners, beantragte Patrick in Frankreich die Genehmigung, dort den Architektenberuf ausüben zu dürfen. Interessanterweise war zu diesem Zeitpunkt in Frankreich aufgrund eines Gesetzes vom 31. Dezember 1940 zwar der Titel Architekt geschützt, die reine Berufsausübung hingegen für Franzosen nicht reglementiert ${ }^{242}$. So kongte, wer immer wollte bauen, solange er es vermied, sich Architekt zu nennen. Für ausländische Architekten bestimmte dagegen Art. 2 Abs. 2 des französischen Gesetzes vom 31. Dezember 1940: "Angehörige fremder Staaten erhalten die Genehmigung zur Ausübung des Architektenberufs in Frankreich unter den in den diplomatischen Abkommen festgelegten Voraussetzungen über die Gegenseitigkeit und bei Vorlage eines Befähigungsnachweises, der dem Diplom gleichwertig ist, das von französischen Architekten verlangt wird. Ausländer, die nicht unter vertragliche Abmachungen fallen, können die vorerwähnte $\mathrm{Ge}$ nehmigung ausnahmsweise erhalten " ${ }^{243}$. Obwohl zwischen Großbritannien und Frankreich kein derartiges Abkommen bestand, wurden die Diplome der Architectural Association durch Erlaß des französischen Ministers für kulturelle Angelegenheiten aus dem Jahre 1964 als grundsätzlich gleichwertig anerkannt. Dies hinderte den Minister jedoch nicht daran, Patricks Antrag mit Berufung auf den Ausnahmecharakter einer solchen Genehmigung abzulehnen. Diese Entscheidung war daraufhin Gegenstand einer Anfechtungsklage vor dem Tribunal administratif von Paris, das die Rechtssache beim EuGH vorlegte. Die Absurdität der im Streit stehenden Ablehnung wurde noch verstärkt durch die Tatsache, daß in Frankreich mit Gesetz vom 3. Januar 1977 - d.h. wiederum vor der Entscheidung des EuGH in der Sache Patrick - Architekten aus den Mitgliedstaaten beim Zugang zum Architektenberuf gemäß Art. 10 dieses Gesetzes inländischen Architekten gleichgestellt wurden. Die Entscheidung des Gerichtshofs war daher auch nicht sehr überraschend. Danach haben die Staatsangehörigen der Mitgliedstaaten gemäß Art.

240. GA Mayras in seimem SchußBantrag kommt wohil zu einem derartigen VerhältnismäBigkeitstest, obwollı! er zuvor festgestell hatte ${ }_{n}$ daf es sich um einen Fall einer versteckten Diskriminierung handelt, In der Zusammenfassung seiner Uberlegungen stellt er fest "..., daß das rein formate verlangen nach der von

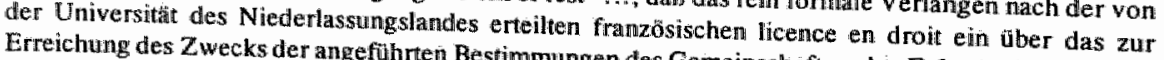
gehendes Hindernis fur die Zulahnen Bestimmungen des Gemeinschaftsrechts Erforderliche hinaus-

241. Unteil vom 28. Juni 1977, Rs. 11/77 - Richarchtsanwaltschaft darstelit." Slg. 1977, 795.

Slg. 1977, 1199 ff.. Siehe dazu Graziadei, Fough Patrick/Minister für kulturelle Angelegenheiten-. Dal, CDE 1978, 237. 242. Die Berufsausubungsregeln wurden erst mit Gesetz vom 3. Januar 1977 gramdlegend geändert. Süehe
dazu Wasilewski 1987.336 .

243. Die Ubersetzung des Gesetzestextes ist dem Tatbestand des Urteils entnommen, Syg. 1977, 1201 
52 EGV seit dem 1. Januar 1973 einen Anspruch auf Niederlassung unter den gleichen Voraussetzungen wie ein Inländer, auch ohne die Existenz einer Anerkennungsrichtlinie. Dieses Recht kann, soweit die gesetzlich vorgeschriebenen Voraussetzungen erfüllt sind, nicht von einer nur ausnahmsweise erteilten Genehmigung abhängig gemacht werden.

\section{e. Der Fall Razanatsimba ${ }^{244}$}

Die Entscheidung Razanatsimba betraf die Zulassung eines madagassischen Juristen als Rechtsanwalt in Frankreich. Razanatsimba hatte seine akademische juristische Ausbildung in Frankreich erhalten. Auch hatte er das französische Anwaltsexamen mit Erfolg abgelegt. Ihm wurde jedoch die Zulassung als Rechtsanwalt verweigert. In seinem Verfahren vor dem EuGH berief sich Razanatsimba auf Art. 62 des Vertrags von Lome vom 28. Februar $1975^{245}$ und die darin enthaltene Nondiskriminierungsbestimmung ${ }^{246}$. Nach seiner Auffassung mußte dieser Bestimmung entsprechend der Entscheidung Reyners ${ }^{247}$ ebenfalls direkte Wirkung zukommen. Der Gerichtshof lehnte jedoch sein Ersuchen mit der Begründung ab, daß der Vertrag von Lome keine Verpflichtung zur Gleichbehandlung mit EG-Angehörigen enthalte. Eine solche Verpflichtung könne allenfalls im Rahmen eines bilateralen Abkommes zwischen der Gemeinschaft und Drittstaaten entstehen, worin die Gegenseitigkeit der Anerkennungsverpflichtung ausdrücklich geregelt ist. Die Entscheidung zeigt deutlich, daß der Gerichtshof nicht bereit war, das Diskriminienngsverbot des EG-Vertrages auf internationale Vertragsbestimmungen zu übertragen, die eine derartige Verpflichtung nach ihrer ursprüng lichen Zielsetzung weder für die EG-Mitgliedstaaten noch für die AKP-Staaten beabsichtigte. Mit dem Hinweis auf die Reziprosität in bilateralen Verträgen ließ der Gerichtshof sehr wohl die Möglichkeit für die Zukunft offen, derartige Verträge mit Drittstaaten zu schließen ${ }^{248}$.

\section{f. Die Rechtssache van Wesemael}

Das Urteil van Wesemael ${ }^{249}$ verdient als wichtige Fortentwicklung der Rechtsprechung zu den Vertragsvorschriften über den freien Dienstleistungsverkehr besondere Beachtung. Die Entscheidung ist insoweit bemerkenswert, da sie zeitlich noch wor der Entscheidung in der Rechtssache $120 / 78$ - Cassis de Dijon - ergangen ist ${ }^{250}$. Die Sa-

244. Urteil vom 24. November 1977, Rs 65i77 - Jean Raxanartsimba *, Slg. 1977, 2229. Siehe dazu De Dorlodot, CDE 1978, $250 \mathrm{ff}$.: Smits, NJB 1978, 858.

245. ABI. Nr. L 25 vom 30. Januar 1976.1.

246. Laguette 1.987, 259

247. Uriell vom 21. Juni 1974, Rs 2/74 - Reyners/Belgien -.SIg. 1974, 631.

248. Ein derartiges bilaterales Abkommen kơnnte vor allem für US-amerikanische Anwälte von grofler Bedeutung sein. Siehe dazu Bharsade. The Int. Lawyer 1994, 313 (327)

249. Urteil vom 18. Januar 1979 in den Rechtssachen 110/78 und 11/78 - Ministère public und Chambre Synicale des Agents artistiques et Impresarii de Belgique, ASBL/Willy van Wesenael und andere Sig. 1979, 35 ff.. Siehe dazu die. Urteilsanmerkung won Streil, EuGRZ 1979, 617. fr..

250. Urteil vom 20. Februar 1979, Rs 120/78 - REWE-Zentral-AG/Bundesmonopolverwaltung fü Branntwein, Slg. 1979., $649 \mathrm{ff}$. 
che betraf ein belgisches Strafverfahren gegen französische Künstleragenturen, die belgischen Unterhaltungsetablissements Künstler vermittelt hatten, ohne über die nach belgischem Recht erforderliche Genehmigung zur Ausübung dieses Gewerbes zu verfügen. Der Gerichtshof kam in seiner Entscheidung zu dem Ergebnis, daß Art. 59 EGV es den Mitgliedstaaten mit unmittelbarer Wirkung für den Gemeinschaftsbürger verbietet, die Stellenvermittlung von Bühnenkünstlem Genehmigungserfordernissen zu unterwerfen, wenn der Künstleragent in seinem Herkunftsstaat ein vergleichbares Gienehmigungsverfahren durchlaufen hat und im übrigen dort einer angemessenen Beaufsichtigung unterstellt ist, die auch seine Tätigkeit in einem anderen Mitgliedstaat erfaßt.

\section{g. Die Rechtssache Knoors}

Die folgenden Entscheidungen betrafen nicht die Frage nach der Entwicklung eines Beschränkungsverbots. Im Mittelpunkt der Erörtungen stand vielmehr die Position der Inländer, die sich gegenüber ihrem Heimatstaat auf Gemeinschaftsrecht berufen. Dabei brachten die Urteile Knoors ${ }^{251}$ und Broekmeulen ${ }^{252}$ eine gewisse Erweiterung der Verpflichtung zur Inländergleichbehandlung im Falle von Rückwanderungen. Die Mitgliedstaaten wurden verpflichtet, auch bei eigenen Staatsangehörigen, die in anderen Mitgliedstaaten erworbenen, von ihnen als gleichwertig anerkannten Beschäftigungsnachweise zu berücksichtigen. Auch bei den Entscheidungen in den Fällen Auer I ${ }^{253}$ und Auer $I^{254}$ stand die Problematik der Inländergleichbehandlung zentral.

Der Niederländer Knoors hatte in Belgien ein Unternehmen für Zentralheizungs- und Gasinstallationen. Als er den Betrieb seines Vaters im niederländischen Heerlen übernehmen wollte, beantragte er Freistellung von den niederländischen Niederlassungsbestimmungen für Gewerbebetrüebe. Er berief sich dabei auf Art. 15 Abs. 1 Buchstabe $c$ de vestingswet Bedrijwen, wonach eine Befreiung für Begünstigte von EG-Richtlinien zu gewähren ist. Der Antrag wurde mit der Begründung zurückgewiesen, daß Knoors als niederländischer Staatsangehöriger in den Niederlanden nicht als Begünstigter im Sinne der Richtlinie angesehen werden könne. Im darauf folgenden Verfahren ging es um die Frage, ob auch Staatsangehörige des Aufnahmestaates als Begünstigte im Sinne des Art. 1 Abs. 1 der Richtlinie 64/427/EWG zu verstehen sind. Die niederländische Regierung vertrat dabei die Auffassung, daß der EG-Vertrag die Angehörigen des Aufnahmestaats nicht als die durch die Liberalisierungsmaßnahmen Begünstigte betrachte. Sie berief sich dabei auf den Wortlaut von Art. 52 EGV. Auch wies die niederländische Regierung auf die Gefahr der Umgehung nationaler Berufsvorschriften hin. Der Gerichtshof folgte diesem Vorbringen nicht: Zwar seien die Vertragsbestimmungen

251. Urteil vom 7. Februar 1979, Rs 115/78 - J. Knoors gegen Staatssekretär für Wirtschaft -, Slg. 1979, $399 \mathrm{ff}$. Morse, ELR 1979, 377.

252. Urteli vom 6. Oktober 1981, Rs 246/80 - C. Broekneulen/Huisarts Registratie Commissie - Slg. $1981,2311 \mathrm{ff}$. Dazu die Urteilsanmerkungen von Gormley, ELR 1982, 37, van Nuffel, SEW 1984, 539.

253. Urteil vom 7. Februar 1979, Rs 136/78 - Stratsache gegen Vincent Auer ", S1g. 1979, $437 \mathrm{ff.}$.

254. Unteil vom 22. September 1983, Rs 271/82 - Ministère public/Vincent Rodolphe Auer - Slg. 1983, $2727 \mathrm{ff}$. 
nicht auf rein interne Verhältnisse der Mitgliedstaaten anwendbar, doch könnten die eigenen Staatsangehörigen eines Mitgliedstaats nicht von der Anwendung des Gemeinschaftsrecht ausgeschlossen werden, wenn sie rechtmäßig im Hoheitsgebiet eines anderen Mitgliedstaats ansässig waren und dort eine nach dem Gemeinschaftsrecht anerkannte berufliche Qualifikation erworben haben. Sowohl das Allgemeine Programm zur Aufhebung der Beschränkungen des freien Dienstleistungsverkehrs als auch das Programm zur Aufhebung der Beschränkungen der Niederlassungsfreiheit bezeichnen als Begünstigte "die Staatsangehörigen der Mitgliedstaaten" ohne Unterscheidung nach Staatsangehörigkeit oder Aufenthaltsort. Hieraus zieht der EuGH die Schlußfolgerung, daß die Richtlinie 64/427/EWG auf einem weiten Begriff der durch ihre Bestimmungen "Begünstigten" beruht ${ }^{255}$. Hinsichtlich der Einwendung eines Mißbrauchs gemeinschaftsrechtlicher Regelungen zur Umgehung nationaler Berufsausbildungsvorschriften bestätigt der Gerichtshof grundsätzlich das berechtigte Interesse der Mitgliedstaaten, verneint die Möglichkeit eines derartigen Mißbrauchs jedoch ausdrücklich für den vorliegenden Fall, da durch die in der Richtlinie 64/427/EWG gegebenen Garantien ein solcher Umgehungstatbestand ausgeschlossen sei ${ }^{256}$.

\section{h. Die Rechtssache Auer I ${ }^{257}$}

Der Fall Auer betraf die Frage des Zeitpunkts des Diplomanerkennungsanspruchs nach der Tierarztrichtlinie 78/1026/EWG. Die Frist für die Durchführung der Richtlinie $78 / 1026$ war noch nicht abgelaufen. Daher konnte sich der Betroffene in einem Strafverfahren wegen unbefugter Berufsausübung nicht auf die Anerkennungsbestimmungen der Richtlinie berufen. Anders als in der späteren Entscheidung in der Rechtssache Vlassopoulou ${ }^{258}$ sah der Gerichtshof hier noch keinen Anlaß zu grundsätzlichen Ausführungen bezüglich Art. 52 EGV. Wie bereits für dlie Rechtssache Thieffry festgestellt, scheint die Zeit hierfür Ende der siebziger Jahre nach nicht reif gewesen.

255. Unteil wom 7. Februar 1979, Rs 115/78 - 1. Knocts/Staatssekretär für Wirtschaft - Sig. 1979, 399 (409), Rdnr, 17

256. Trotz dieser Feststelling scheint dieser Weg uber die leicluteren Niederlassangsbedingungen des Auslands, die strengeren Niederlassungsvorschriften zu umgehen, häufig genommen zu sein. Siehe dazu die Bemerkungen won de Wilde, SEW 1994, 775 (785) der dies als "route Knoors" bezeichnet. wobei er darauf hinweist, daf3 dieser "Niederlassungsschleichweg" seine Bedleutung in jüngster Zeit durch eine Modernisienung des niedierländischen Rechts verloren hat.

257. Urteil vom 7. Febnar 1979, Rs 136/78 - Strafsache gegen Vincent Auer -, S1g. 1979, 437 ff.

258. Umteil vom 7. Mai 1991, Rs C-340/89 - Irène Vlassopoulou/Ministerium für Justiz, Bundes- und Europenangelegenheiten Baden-Württemberg. Slg. 1-1991, $2357 \mathrm{ff..}$ 


\section{Die Rechtsprechung in den achtziger Jahren}

a. Die Rechtssache Broekmeulen ${ }^{259}$

Wie im Falle Knoors stellte sich auch in diesem Rechtsstreit die Frage, ob ein Niederländer sich in den Niederlanden auf Gemeinschaftsrecht berufen kann. Broekmeulen ist niederländischer Staatsangehöriger, dem die medizinische Fakultät der Katholischen Universität Löwen in Belgien das staatliche Diplom eines Doktors der Medizin, Chirurgie und Geburtshilfe irm Sinne des Art. 3 Buchstabe b der Richtlinie $75 / 362 / \mathrm{EWG}^{260}$ verliehen hatte. Inhaber dieses Diploms waren in Belgien berechtigt als selbständige praktische Ärzte tätig zu sein. Gemäß Art. 2 des Wet regelnde de uitoefening der geneeskunst (Gesetz über die Ausübung des Arztberufes) erhielt Broekmeulen die Genehmigung als Arzt in den Niederlanden tätig zu sein. Sein Antrag auf Einschreibung in das Register der anerkannten praktischen Ärzte wurde jedoch von der Huisarts registratie Commissie (Kommission für die Zulassung von praktischen Ärzten) mit der Begründung abgelehnt, daß er noch nicht die nach niederländischem Recht zur Eintragung erforderliche einjährige Ausbildung zum praktischen Arzt absolviert habe. Die Zulassungskommission war der Ansicht, daß das Anerkennungssystem der Richtlinie 75/362/EWG auf Broekmeulen wegen seiner niederländischen Staatsangehörigkeit keine Anwendung finden könne. Außerdem dürfe die Niederlassungsfreiheit für Ärzte nicht die Bemühungen der Mitgliedstaaten um die Einrichtung eines optimalen Gesundheitswesens beinträchtigen, deshalb sei eine analoge Anwendung von Art. 8 der Richtlinie 75/362/EWG gerechtfertigt. Gemäß Art. 8 kann ein Aufnahmestaat bei Fehlen bestimmter fachärztlicher Befähigungsnachweise Weiterausbildungsbedingungen auferlegen. Der Gerichtshof hat beide Argumente zurückgewiesen. Die mögliche Anwendung der Richtlinie auf einen Niederländer in den Niederlanden ergibt sich bereits aus dem Wortlaut des Art. 2 der Richtlinie 75/362/EWG, der keinerlei Einschränkungen bezüglich des Anwendungsbereichs enthält.

\section{b. Die Rechtssache Webb ${ }^{261}$}

In diesem Urteil beschäftigte sich der EuGH erstmals mit dem von der deutschen und dänischen Regierung geltend gemachten Einwand, Art. 60 Abs. 3 EGV begrenze die Dienstleistungsfreiheit auf die reine Inländergleichbehandlung. Dazu stellt er fest: "Art. 60 Abs. 3 soll es in erster Linie dem Leistungserbringer ermöglichen, seine Tätigkeit in dem Mitgliedstaat, in dem die Leistung erbracht wird, ohne Diskriminierung gegen-

259. Urteil wom 6. Oktober 1981, Rs 246/80 - C. Broekmeulen/Huisarts Registratie Commissie - Slg. 1981.2311 ff. Dazu die Urteilsanmerkungen von Gormley, ELR 1982, 37, van Nuffel, SEW 1984, 539.

260. Richtlinie 75/363/EWG des Rates für die gegenseitige Anerkennung der Diplome, Prafungszeugnisse und sonstigen Befähigungsnachweise des Arztes und für Maßnahmen zur Erleichtenung der tatsiachlichen Ausübung des Niederlassungsrechts und des freien Dienstleistungsverkehrs vom 16. Juni 1975. ABI. Nr. L 167 vom 30. Juni 1975.

261. Urteil vom 17. Dezember 1981, Rs 279/80 - Strafverfahren gegen Alfred John Webb * Sig. 19811, $3305 \mathrm{ff}$. Druesne, RTDE $1982,75$. 
über den Staatsangehörigen dieses Staates auszuüben. Er impliziert hingegen nicht, daß jede für die Staatsangehörigen dieses Staates geltende nationale Regelung, die normalerweise eine Dauertätigkeit von in diesem Staat ansässigen Unternehmen zum Gegenstand hat, in vollem Umfang auf zeitlich begrenzte Tätigkeiten angewandt werden könnte, die von in anderen Mitgliedstaaten ansässigen Unternehmen ausgeübt werden " ${ }^{262}$. Mit dieser Aussage folgte der Gerichtshof der Auffassung des Generalanwalts Sir Gordon Slynn in seinen Schlußanträgen ${ }^{263}$. Darin war dieser auf den Umfang des Beschränkungsbegriffes der Art. 59 ff. EGV näher eingegangen. Hierzu führte der Generalanwalt aus, daß "eine Prüfung der Artikel 59 bis 66 EG-Vertrag zeigt, daß die Diskriminierung aufgrund der Staatsangehörigkeit oder des Ortes der Niederlassung zwar, ....., einen schlüssigen Beweis für eine "Beschränkung" im Sinne des Art. 59 darstellt, jedoch kein wesentliches oder gar das ausschließliche Element einer solchen Beschränkung ist" ${ }^{264}$. Zur Begründung seiner Auffassung verwies Sir Gordon Slynn auf den Wortlaut von Art. 65 EGV und die Rechtssprechung des EuGH in den Rechtssachen van Binsbergen ${ }^{265}$ und Coenen ${ }^{266}$ sowie van Wesemael ${ }^{267}$.

Desweiteren stellte der Gerichtshof in Übereinstimmung mit der früheren Rechtsprechung erneut fest, daß der freie Dienstleistungsverkehr als fundamentaler Grundsatz des Vertrages nur durch Regelungen beschränkt werden dürfe, die durch das allgemeine Interesse gerechtfertigt sind und die für alle im Hoheitsgebiet des genannten Staates ansässigen Personen oder Unternehmen verbindlich sind. Eine solche Rechtfertigung wäre jedoch nur insoweit zulässig, als dem Allgemeininteresse nicht bereits durch die Rechtsworschriften Rechnung getragen ist, denen der Leistungserbringer in dem Staat unterliegt, in dem er ansässig ist. Seit dieser Entscheidung wurde zumindest von einem Teil der Literatur angenommen, daß der Beschränkungsbegriff im Rahmen der Dienst* leistungsfreiheit über das reine Diskriminierungsverbot hinausgeht und ein allgemeines Beschränkungsverbot enthält ${ }^{268}$. Andere Vertreter in der Literatur sehen diese Erweiterung erst mit der weiteren Rechtsprechung endgültig realisiert ${ }^{269}$.

262. Urteil vom 17. Dezember 1981, Rs 279/80 - Strafwerfahren gegen Alfred John Webb -, Slg. 1981 . 3305, Rdir. 16

263. Urteil wom 17. Dezember 1981, Rs 279/80 - Strafverfahren gegen Alfred John Webb -, Sig. 1981, $3328 \mathrm{ff}$.

264. Schlußanträge von Generalanwalt Sir Gordon Slynn in: Urteil vom 17. Dezember 1981, Rs 279/80 Strafverfahren gegen Alfred John Webb -, Sig. 1981, 3305 (3331).

265. Urteil vom 3. Dezember 1974, Rs 33/74 - J.H.M. van Binsbergen/Bestuur wan de Bedrijfsverenuging voor Metalnijwerheid -, Slg. 1974, $1299 \mathrm{ff}$.

266. Urteil vom 26. November 1975, Rs 39/75 - Robert Gerardus Coenen u -a./Sociaal-Economische Raad-. Slg. 1975, $1547 \mathrm{ff}$.

267. Urteil vom 18. Januar 1979 in den Rechtssachen 110/78 und 11/78-Ministère public und Chambre Synicale des Agents artistiques et Impresarii de Belgique, ASBL/Willy van Wesemael und andere Slg. $1979,35 \mathrm{ff}$.

268. Druesne 1986, 107; Bleckmann, Europarecht Rdnr. 1165

269. Hailbronner/Nachbaur, EuZW 1992, 105 zum Urteil vom 25. Juli 1991, Rs C-76/90 - Säger/Dennemeyer -, Slg. 1991, 1-4221. 
c. Die Rechtssachen Auer II ${ }^{270}$ und Rienks ${ }^{271}$

Beide Entscheidungen betrafen erneut die Anwendung der Tierarztrichtlinie 78/1026/EWG. Im Gegensatz zur Rechtslage in Auer I war nun jedoch der Umsetzungstermin für die Richtlinie verstrichen. In der Entscheidung Rienks stellte der Gerichtshof fest, daß die Aufnahme in eine berufsständige Kammer nicht mit der Begründung abgelehnt werden darf, daß der in einem anderen Mitgliedstaat erworbene Befähigungsnachweis für die Ausübung des Berufs nicht gültig ist , obwohl dieser nach den Richtlinien anzuerkennen ist. Der Fall Auer betrifft die Frage der zeitlichen Wirksamkeit einer Bescheinigung. Die Bescheinigung, worin Auer bestätigt wurde, daß er zur Ausübung des Tierarztberufs aufgrund einer Befähigung gemäß Art. 3 der Richtlinie 78/1026/EWG berechtigt ist, bewirkt keinen Rechtsanspruch ex nunc. Vielmehr kann sich ein Tierarzt auch dann auf eine derartige Bescheinigung berufen, wenn diese erst nach den Handlungen ausgestellt wurde, die zu einer strafrechtlichen Verfolgung des Betroffenen wegen unbefugter Berufsausübung geführt haben.

\section{d. Die Rechtssache Klopp}

Von besonderer Bedeutung für die weitere Entwicklung ist jedoch der vierte Beschluß des Gerichtshofs bezüglich eines Rechtsanwaltes. Es handelte sich um die Sache Klopp ${ }^{272}$. Diese Entscheidung wird von den Verfechtern eines umfassenden Beschränkungsverbots besonders hervorgehoben ${ }^{273}$. Der Fall betraf einen Düsseldorfer Rechtsanwalt, der bei der Rechtsanwaltskammer von Paris seine Zulassung als $\mathbb{R e c h t s a n w a l t ~}$ beantragt hatte. Es ging damil um die Frage der Zulässigkeit einer Doppelniederlassung. Klopp erfüllte unter dem Gesichtspunkt der erforderlichen Diplome und der persönlichen Eignung die Voraussetzungen für die Zulassung. Diese wurde ihm jedoch von der Pariser Anwaltskammer mit dem Hinweis verweigert, daß der Antragsteller nicht aus seiner Düsseldorfer Kanzlei ausscheide, vielmehr in Paris ein zweite Zulassung beantrage. Eine solche Doppelzulassung widerspräche aber der französischen Gesetzgebung und der Satzung der Anwaltskammer. Hiernach dürfe ein Rechtsanwalt nur eine einzige Kanzlei haben, und zwar im Bezirk des Tribunal de grande instance, bei dem er zugelassen ist.

Der Gerichtshof bestätigte in seiner Entscheidung zum Fall Klopp zunächst das Prinzip der Inländergleichbehandlung gemäß Art. 52 Abs. 2 EGV, wonach es in Ermanglung besonderer gemeinschaftsrechtlicher Vorschriften jedem Mitgliedstaat freisteht, die Ausübung des Rechtsanwaltsberufs für sein Hoheitsgebiet zu regeln. Er führte jedoch

270. Urteil wom 22. September 1983, Rs 271/82 - Ministère public/Vincent. Rodolphe Auer -, SIg. 1983, $2727 \mathrm{ff}$..

271. Urteil vom 15. Dezember 1983 - Strafverfahren gegen H.G. Rienks -, Slg. 1983, 4233.

272. Unteil vom 12. Juli 1984, Rs 107/83 - Ordre des avocats au barreau de ParisiOnno Klopp -, Sig. 1984, $2971 \mathrm{ff}$. Siehe dazu die Urteilsanmerkungen von Borggreve, RIW/AWD 1984, 988; Brunois, RTDE 1985, 65; Gormley, ELR 1984, 439; van der Wall, NJB 1985, 857; Watson CMLRev 1985, 743.

273. Dazu besonders Steindorff, ZHR 1986, 687; Steindorf, EuR 1988, 19; Knobbe-Keuk, DB 1990, 2573 mit weiteren Nachweisen. 
weiter aus, daß dieser Grundsatz nicht bedeutet, daß es einem Rechtsanwalt durch die Vorschriften eines Mitgliedstaats vorgeschrieben werden kann, im gesamten Gemeinschaftsgebiet nur eine Kanzlei zu unterhalten. Eine solche einschränkende Auslegung hätte nämlich zur Folge, daßß ein Rechtsanwalt, der sich einmal in einem bestimmten Mitgliedstaat niedergelassen hat, die Niederlassungsfreiheit nur noch in Anspruch nehmen könnte, wenn er seine bereits bestehende Niederlassung aufgeben würde ${ }^{274}$.

\section{e. Die Rechtssache Steinhauser}

In der Rechtssache Steinhauser ging es lediglich um eine Frage der Diskriminierung aufgrund der Staatsangehörigkeit ${ }^{275}$. Der deutsche Kunstmaler Steinhauser wohnte in Biarritz. Bei der dortigen Stadtverwaltung bewarb er sich um eine Hütte, die gemäß öffentlicher Ausschreibung für Verkaufsausstellungen von Kunstwerken verwendet werden sollten. Seine Bewerbung wurde mit dem Hinweis zurückgewiesen, daß er nicht im Besitz der erforderlichen französischen Staatsangehörigkeit sei. Der EuGH, dem die Sache won einem französischen Verwaltungsgericht vorgelegt worden war, sah in der Bedingung der französischen Staatsangehörigkeit einen eindeutigen Verstoß gegen Art. $52 \mathrm{EGV}$. Die darin vorgesehene Niederlassungsfreiheit beträfe nicht nur die Aufnahme einer selbständigen Erwerbstätigkeit, sondern auch deren Ausübung im weiten Sinn. Aufgrund der eindeutigen Vertragsverletzung wegen des Staatsangehörigkeitserfordernisses war es für den Gerichtshof in dieser Entscheidung nicht notwendig, auf den genauen Umfang des Beschränkungsbegriffs einzugehen ${ }^{276}$.

\section{f. Die Rechtssache Kommission gegen Frankreich}

In einem mit der Sache Klopp vergleichbaren Verfahren, diesesmal jedoch von der Kommission gegen Frankreich eingeleitet, stand die Niederlassungsfreiheit von Ärzten und Zahnärzten zur Diskussion ${ }^{277}$. Auch in diesem Fall stand die Frage der Doppelzulassung zentral. Nach französischem Recht konnte ein Arzt, der im Ausland zugelassen ist, nicht in Frankreich zur Ärzteschaft zugelassen werden ${ }^{278}$. Dementsprechend wurde von Ärzten, die in Frankreich tätig werden wollten, veriangt, zunächst ihre

274. Unteil von 12. Juli 1984, Rs 107/83- Ordre des avocats au barreau de Paris/Onno KHopp - Slg. 1984, 2971 Rdnr. 18.

275. Urteil wom 18. Juni 1985, Rs 197/84 - P. Steinhauser/Stadt Biarritz -, Slg. 1985, 1819 ff.

276. Dies gilt auch für andere gegen ein Staatsangehörigkeitserfordernis gerichtete Entscheidunget, so etwa in Urteil vom 15. Oktober 1986, Rs 168/85 - Kommission/Italien - Slg. 1986, 2945 tf; Urteil wom 12. November 1987 , Rs $198 / 86$ - Conradi - Slg. 1987, 469; Urteill vom 14. Januar 1988, Rs 63/86Kommission/talien -, Slg. 1988, 29 ff.: Urteil wom 15. März 1988, Rs 147/86 - Kommission/Griechenland -. Slg. 1988, $1637 \mathrm{ff}$; Urteil wom 14, Juli 1988, Rs. 38/87 - Kommission/Griecheniand Slg. 1988, 4415 ff.; Urteil wom 30. Mai 1989, Rs 305/87 - Kommission/Griechenland - Slg. 1989. 1461; Unteil vom 25. Juli 1991, Rs C-221/89. R gegen Secretary of State for Transport (ex parte Factortame) - Slg. $\$ 991,1-3905$

277. Urteil vom 30. April 1986, Rs 96/85-Kommission/Frankreich - Slg. 1986, 1475 ff. Siehe dazu wor allem Dubouis. Rew. de droit sanitaire et social 1986, 406 ;

278. Art. L 412 letzter Absatz des französischen Code de la sante publique in der durch Art. 10 des Geset zes Nr. 76-1288 wom 31. Dezember 1976 geänderten Fassung. 
Zulassung im Herkunftsstaat rückgängig zu machen. Eine entsprechende Regelung galt auch für Zahnärzte ${ }^{279}$. Dieses Verbot der Doppelzulassung hatte in die französische Gesetzgebung im Rahmen der Umsetzung der Ärzterichtlinie ${ }^{280}$ Eingang gefunden. Die Kommission sah darin einen VerstoB gegen Art. 52 und Art. 59 EGV. Auch beeinträchtige es die ordnungsgemäße Anwendung der Ärzte- und Zahnärzterichtlinie ${ }^{28 !}$ für die gegenseitige Anerkennung von Diplomen. Die französische Regierung versuchte, die Einschränkung damit zu rechtfertigen, daß ein Arzt oder ein Zahnarzt für den Patienten schnell erreichbar sein müsse. Nach ärztlichem Standesrecht seien Ärzte und Zahnärzte verpflichtet, die Kontinuität der ärztlichen Behandlung sicherzustellen. Diese Argumente wurden vom EuGH jedoch zurückgewiesen. Zunächst stellte der Gerichtshof fest, daß es französischen Ärzten von den Ärztekammern gestattet sei, in geringer Entfernung von der Hauptpraxis eine Zweitniederlassung zu eröffnen. Damit sah er die Diskriminierung der in Grenznähe niedergelassenen Ärzte als erwiesen, da diese keine Möglichkeit hatten, eine Zweitpraxis in Frankreich zu errichten. Für die Frage, ob es sich bei Art. 52 EGV ausschließlich um ein Diskriminierungsverbot handelt oder, ob dieser Artikel auch ein weitergehendes Beschränkungsverbot beinhaltet, ist der zweite vom Gerichtshof vorgebrachte Gesichtspunkt von größerer Bedeutung 282. Der Gerichtshof geht dabei auf die Frage der VerhältnismäBigkeit eines allgemeinen Verbotes ein, wobei er feststellt, "daß das Verbot, einen Arzt oder Zahnarzt, der weiterhin in einem anderen Mitgliedstaat zugelassen ist, in Frankreich zuzulassen, zu absolut und zu allgemein ist, als daß es durch die Notwendigkeit gerechtfertigt werden könnte, die Kontinuität der Krankenversorgung sicherzustellen oder in Frankreich das französische Standesrecht anzuwenden ${ }^{283 "}$. Mit dieser Feststellung kommt der Gerichtshof zur Entscheidung, daß Frankreich gegen seine Verpflichtungen aus den Art. 48, 52, 59 EGV verstoßen habe. Mehr als in der Entscheidung Klopp hat der Gerichtshof hier die französische Regelung einer Verhältnismäßigkeitsprüfung unterworfen und damit eigentlich bereits einen bedeutenden Schritt in Richtung eines allgemeinen Beschränkungsverbots gesetzt.

\section{g. Die Rechtssache Kommission gegen Deutschland}

In der Bundesrepublik unterliegen Versicherungsunternehmen, einschlie/3lich der in anderen Mitgliedstaaten niedergelassenen Unternehmen, dem Versicherungsaufsichtsgesetz $^{284}$. Nach $\$ 105$ Abs. 1 VAG bedürfen ausländische Versicherungsunternehmen, die im Inland durch Vertreter, Bevollmächtigte, Agenten oder andere Vermittler das Direktversicherungsgeschäft betreiben wollen, einer Erlaubnis. Außerdem haben

\footnotetext{
279. Ant L. 44 des Codle de la santé publique in der genannten Fassung.

280. Richthine 75/362/EWG des Rates vom 16. Juni 1975, ABL. L 167 vom 30. Juni 1975, 1.

281. Zahnärzterichulinie 78/686/EWG des Rates wom 25. Juli 1978, ABI. Nr. L 233 wom 24. August 1978 , 10.

282. Urteil vom 30. April 1986, Rs 96/85 - Kommission/Frankreich - Sig. 1986, 1475 (1486) Rdnr 13 und 14.

283. Urteil vom 30. April 1986, Rs 96/85 - Kommission/Frankreich - Slg. 1986, 1475 (1486) Rdmr 14.

284. VAG in der Fassung des Vierzehnten Änderungsgesetz vom 29. März 1983 zur Umsetzung der Richtlinie $78 / 473$ in innerstaatliches Recht (BGBI. I 1983, 377).
} 
diese Unternehmen gemäB \$106 Abs. 2 VAG eine Niederlassung zu errichten und dort alle die Niederlassung betreffenden Geschäftsunterlagen zur Verfügung zu halten. Desweiteren handelt gemäß $\$ 144$ a Abs. 1 VAG ordnungswidrig, wer in Deutschland einen Versicherungsvertrag abschließt oder den Abschluß vermittelt, ohne die zum Betrieb derartiger Versicherungsgeschäfte erforderliche Erlaubnis zu besitzen. Die Kommission beanstandete diese Bestimmungen, da sie nach ihrer Auffassung gegen die Art. 59 und 60 EGV sowie gegen die Richtlinie $78 / 473 / \mathrm{EWG}^{285}$ verstießen. Faktisch sei durch den Erlaubnisvorbehalt und das Niederlassungserfordernis die Dienstleistungsfreiheit auf dem Gebiet der Versicherungsvermittelung ausgeschlossen. In seinem Urteil Kommission/Deutschland ${ }^{286}$ stellte der Gerichtshof zunächst fest, daß "nicht nur die Beseitigung sämtlicher Diskriminierungen des Leistungserbringers aufgrund seiner Staatsangehörigkeit, sondern auch die Beseitigung aller Beschränkungen des freien Dienstleistungsverkehrs, die damit zusammenhängcn, daß der Leistungserbringer in einem anderen Mitgliedstaat als dem, in dem die Leistung erbracht wird, niedergelassen ist" gemäß Art. $59 \mathrm{EGV}$ notwendig sind ${ }^{287}$. Zur Verhältnismäßigkeit der Maßnahme bestimmte der EuGH dabei, daß die an den Leistungserbringer wegen der Besonderheit der betroffenen Dienstleistungen ${ }^{288}$ gestellten Anforderungen "sachlich geboten sein müssen, um die Einhaltung der Berufsregelungen und den Schutz der Interessen, den diese bezwecken, zu gewährleisten" ${ }^{289}$. Als weitere Voraussetzung fügte der Gerichtshof dabei hinzu, daß "das gleiche Ergebnis nicht durch weniger einschränkende Bestimmungen erzielt werden kann" 290 . Mit diesen Erwägungen erhielt der Proportionalitätstest seine inhallliche Konkretisierung.

\section{h. Die Rechtssache Kommission gegen Belgien ${ }^{291}$}

In diesem Verfahren hatte die Kommission Belgien vorgeworfen, gegen Art. 52 EGV zul verstoßen, indem bestimmte Leistungen der klinischen Biologie von der Erstattung durch die Sozialversicherungen ausgeschlossen wurden, falls diese in Laboratorien vorgenommen wurden, die von einer privatrechtlichen juristischen Person betrieben werden, deren Mitglieder, Gesellschafter und Geschäftsführer nicht alle zur Vornalhme von medizinischen Analysen befugte Personen sind. Die Kommission sah darin eine Verletzung des Gemeinschaftsrechts, da die belgische Regelung die Anbietung derartiger Dienstleistungen durch ausländische Laboratorien verhindere. Der Gerichthof hat diesen Vorwurf der Kommission deutlich zurückgewiesen und die belgische Regelung als mit Art. 52 EGV vereinbar angesehen: "Es ist zu bemerken, dab das belgische Recht Ärzte

285. Richtlinie 78/473/EWG des Rates zur Koordinierung der Rechts- und Verwaltungsworschriften auf dem Gebiet der Mitversicherung auf Gemeinschaftsebene, ABI. 1978 Nr. L $151,25$.

286. Urteill vom 4. Dexember 1986 in der Rs 205/84 - Kommission/Deutschland - Sig. 1986, 3755

287. Urteil vom 4. Dezember 1986 in der Rs 205/84 - Kommission/Deurschland -, Slg. 1986, $3755(3802)$

288. In diesem. Fill betraf es die Versicherungsdienstleishungen,

289. Unteil vom 4. Dezembef̂ 1986 in der Rs 205/84 - Kommission/Deutschland -, Slg. 1986, 3755, Rdnr 27.

290. Urteil wom 4. Dezember 1986 in der Rs 205/84 - Kommission/Deulschland *. Slg. 1986, 3755, Rdnr. 29.

291. Uneil vom 12. Februar 1987, Rs 221/85 - Kommission/Belgiten- "Slg. 1987, 719 
oder Apotheker, die Staatsangehörige anderer Mitgliedstaaten sind, nicht daran hindert, sich in Belgien niederzulassen oder dort ein Laboratorium für klinische Analysen zu betreiben, für die eine Erstattung durch die Sozialversicherung in Betracht kommt. Es handelt sich somit um Rechtsvorschriften, die unterschiedslos für die belgischen Staatsangehörigen und die Staatsangehörigen der anderen Mitgliedstaaten gelten und deren Imhalt und Ziele nicht die Annahme gestatten, daß sie zu diskriminierenden Zwecken erlassen worden sind oder derartige Wirkungen entfalten " ${ }^{292}$. Mit dieser Entscheidung scheint der Gerichtshof die von der Kommission vertretene Auffassung, zurückgewiesen zu haben, daß Art. 52 EGV nicht nur diskriminierende Maßnahmen, sondern auch unterschiedslos auf inländische und ausländische Staatsangehörige angewandte verbiete, sofern diese eine ungerechtfertigte Behinderung der letzteren bedeuten. Everling sieht in dieser Entscheidung deutlich eine Bestätigung dafür, dafl der Gerichtshof trotz der Entscheidungen Klopp ${ }^{293}$ und Kommission gegen Frankreich ${ }^{294}$ keine grundsätzliche Änderung im Sinne einer Erweiterung seiner bisherigen Rechtsprechung zum Niederlassungsrecht bezwecke ${ }^{205}$. Auch Arnull bezeichnet diese Entscheidung als eine Zurückweisung der von der Kommission vertretenen Auffassung, Art. 52 EGV als generelles Beschränkungsverbot aufzufassen ${ }^{29 \%}$.

\section{i. Die Rechtssache Heylens}

Die Rechtssache Heylens betraf keinen Fall der Niederlassungsfreiheit, sondern der Freizügigkeil gemäß Art. $48 \mathrm{EGV}^{297}$. Die vom Gerichtshofs in diesem Urteil getroffenen Feststellungen lassen sich aber ohne weiteres auf die Niederlassung von Selbständigen übertragen. Der Fall betraf die Anerkennung eines belgischen Fußballtrainerdiploms in Frankreich. In Frankreich ist der Zugang zum Beruf des Fußballtrainers durch eine Verordnung des französischen Staatssekretärs für Jugend und Sport vom 30. Juli 1965 reglementiert ${ }^{298}$. In Art. 6 dieser Verordnung ist die Anerkennung der Gleichwertigkeit eines ausländischen Diploms geregelt. Ein Antrag auf Anerkennung des belgischen Fußballtrainerdiploms als gleichwertig mit dem französischen Diplom eines Sporterziehers wurde vom Ministerium ohne Begründung abgelehnt. Desweiteren wurde Heylens jede Ausübung von entgeltlicher sportlicher Unterweisung in Frankreich untersagt. Gegen Heylens, der weiterhin als Trainer in Frankreich tätig war, wurde ein Strafverfahren eingeleitet, worin ihm die rechtswidrige Ausübung der Tätigkeit eines Fußballtrainers sowie das unbefugte Führen eines Titels zur Last gelegt wurde. Das Strafverfahren wurde bis zur Entscheidung des EuGH im Wege des Vorabentschei-

292. Urteill vom 12. Februar 1987, Rs 221/85 - Kommission/Belgien-, Slg. 1987, 719 (737)

293. Uneil vom 12. Juli 1984, Rs 107/83 - Ordre des avacats au barreau de Paris/Onno Klopp -, SIg. 1984, 2971.

294. Urteil vom 30. April 1986, Rs 9685 - Kommission/Frankreich -, Slg. 1986, 1475 ff. .

295. Everling, Gutachten 58. DJT, C 391 .

296. Armull, $76 \mathrm{f}$.

297. Urteil wom 15. Oktober 1987 Rs 222/86 - UNECTEF/Heylens -. Slg. 1987, 4097. Siehe dazu Dubouis, Rev. fr. de droit adm. 1988, 691; Timmermans, Ars Aequi 1989, 288. Wallace. ELR 1988 , 267.

298. JORF vom 26. Oktober 1965 
dungsverfahrens über folgende Frage ausgesetzt: "Stellt es in Ermanglung einer Richtlinie für den Beruf des Trainers einer Sportmannschaft eine Beschränkung der in den Artikeln 48 bis 51 EGV umschriebenen Freizügigkeit der Arbeitnehmer dar, wenn für die entgeltliche Ausübung der Tätigkeit als Trainer einer Sportmannschaft (Artikel 43 des Gesetzes vom 16. Juli 1984) der Besitz eines französischen oder eines ausländischen Diploms verlangt wird, das von einem Ausschuß durch eine nicht mit Gründen versehene Stellungsnahme, gegen die kein besonderer Rechtsbehelf gegeben ist, als gleichwertig anerkannt worden ist?"

Der Gerichtshof verwies zunächst auf seine Rechtsprechung bezüglich der Rechtssachen Patrick und Thieffry, in dem er erneut feststellte, daß das Fehlen einer Anerkennungsrichtlinie einen Mitgliedstaat nicht dazu berechtigt, Personen die Freizügigkeit zu verwehren, wenn aufgrund innerstaatlicher Rechtsvorschriften die Anerkennung ausländischer Diplome als gleichwertig möglich sei. Gemäß Art. 5 EGV obliege den Mitgliedstaaten, alle geeigneten Maßnahmen zu treffen, die Verpflichtungen aus dem Vertrag, d.h. auch die Gewährleistung der Freizügigkeit, zu erfüllen. Der Gerichtshof hat in diesem Urteil weiterhin erklärt, daß die Beurteilung der Gleichwertigkeit eines ausländischen Diploms ausschließlich danach erfolgen muß, "welches Maß an Kenntnissen und Fähigkeiten dieses Diplom unter Berücksichtigung von Art und Dauer des Studiums und der praktischen Ausbildung, deren Abschluß es bescheinigt, bei seinem Besitzer vermuten läßt" ${ }^{299}$. Die Kommission hat hieraus abgeleitet, daß die Mitgliedstaaten auch dann, wenn in ihrem nationalen Recht bisher für einen bestimmten Beruf ein Verfahren für die Anerkennung der von anderen Mitgliedstaaten ausgesteliten Befähligungsnachweise nicht vorgesehen ist, verpflichtet sind, die in einem anderen Mitgliedstaat erworbenen Qualifikationen zu berücksichtigen ${ }^{300}$. Desweiteren bezeichnete der Gerichtshof den Zugang zu einem Beruf als ein durch den EG-Vertrag garantiertes Grundrecht ${ }^{39 k}$. Hieraus wurde in der Literatur die Anerkennung des Gerichtshofs der vier Freiheiten als den Individuen garantierte subjektive Grundrechte abgeleitet ${ }^{302}$.

\section{j. Die Rechtssache Gullung}

Die Rechtssache Gullung ${ }^{303}$ betraf die Frage, ob sich ein in Deutschland niedergelassener Anwalt in Frankreich niederlassen durfte, ohne die in Frankreich geltenden Vorschriften $z u$ beachten, wonach der Rechtsanwaltsberuf die Zulassung zur Rechtsanwaltschaft voraussetzt. Dem Fall lag ein recht ungewöhnlicher Sachverhalt zugrunde: Gullung war ursprünglich in Frankreich als Notar niedergelassen. Er besaß sowohl die

299. Urteil vom 15, Oktober 1987, Rs 222/86 - UNECTEF/Heylens -, Slg. 1987, 4097 (4117), Rdnt. 13.

300. Siehe dazu das Varbringen der Kommission in dem späteren Verfahren Vlassopoulou, Urteil yom 7. Mai 1991, Rs C-340/89 - Irène Vlassopoulou/Ministerium für Justiz. Bundess-und Europaangelegenbeiten Baden-Württemberg -, Slg. 1991, 1-2357 (2363).

301. Urteil vom 15. Oktober 1987, Rs 222/86 - UNECTEF/Heylens -, Slg. 1987, 4098, Runr. 14

302. Coppel/O'Neill, CMLRev. 1992, 669 (689).

303. Urteil vom 19. Januar 1988, Rs 292/86 - Claude Gullung/Conseils de l'ondre des avocats du barreaw de Colmar et de Saveme - Slg. 1988, 111 ff. Siehe dazu Flecheux/Deniolle, La Sem.jur. 1988 II 20963; Korte. Migrantenrecht, 1988, 140; Lonbay, ELR 1988, 275; Brunois, RTDE 1988, 421 
französische als auch die deutsche Staatsangehörigkeit. Aufgrund eines Disziplinarverfahrens muBte er die Tätigkeit als Notar jedoch aufgeben. Er begab sich nach Deutschland, legte dort beide Staatsexamina ab ${ }^{304}$, und ließ sich nun in Deutschland als Anwalt nieder. Gleichzeitig eröffnete er ein Rechtsberaterbüro in Frankreich. Zuvor war ihm bereits die Niederlassung als Rechtsanwalt in Frankreich unter Hinweis auf seine Disziplinarstrafe verweigert worden. Die französische Anwaltskammer erließ darauthin einen Beschluß, wonach es allen dieser Rechtsanwaltskammer angehörenden Rechtsanwälten untersagt wurde, Gullung in der nach Gemeinschaftsrecht ${ }^{305}$ und gemäß der französischen Ausführungsmaßnahme ${ }^{306}$ vorgesehenen Weise Beistand zu leisten. Gegen diesen Beschluß hat Gullung Klage erhoben. Im Rahmen dieses Verfahrens wurden an den EuGH drei Fragen gestellt, wobei eine das Zulassungserfordernis betraf. Gullung hatte sich gerade gegen dieses Erfordernis der Zulassung zur Rechtsanwaltschaft widersetzt. Hierauf wiederholte der Gerichtshof seine bisherige Rechtsprechung, wonach die Mitgliedstaaten in Ermanglung gemeinschaftsrechtlicher Vorschriften gemäß Art. 52 EGV befugt seien, die Aufnahme und Ausübung eines Berufs an Voraussetzungen zu knüpfen, solange diese auch für die eigenen Angehörigen bestünden. Bezüglich der strittigen Vorschrift stellte der Gerichtshof fest, daßs sie unterschiedlos gelte.

Entscheidend für die Frage Diskriminierungsverbot oder auch Beschränkungsverbot, ist der darauf folgende Passus: "Durch dieses Erfordemis sollen nämlich die Zuverlässigkeit und die Beachtung der standesrechtlichen Grundsätze sowie die disziplinarische Kontrolle der Tätigkeit gewährleistet werden; es dient somit einem schutzwürdigen Zweck." Auch hier hat der Gerichtshof erneut neben der möglichen Diskriminierung auch das Vorliegen eines zwingenden. Allgemeininteresses (schutzwürdiger Zweck) sowie die Verhältnismäßigkeit der Bestimmung einer Kontrolle unterworfen.

\section{k. Die Rechtssache Van de Bijl ${ }^{307}$}

Der Rechtsstreit betraf wie bereits die Sache Knoors, die Stellung eines Inländers, der sich auf eine Übergangsrichtlinie berief. Van de Bijl ist Niederländer, der sich in den Niederlanden als selbständiger Maler niederlassen wollte. In den Niederlanden bedarf derjenige, der als selbständiger Maler tätig sein will, einer Genehmigung der Malerinnung. Eine Ausnahme von dieser Genehmigungspflicht gilt gemäß Art. 3 der Richtlionie 64/427/EWG ${ }^{308}$. Auf diese Ausnahme berief sich Van der Bijl unter Hinweis auf eine Bestätigung der zuständigen britischen Behörde, wonach er während eines Zeitraums

304. Diese Tatsache ist dem Sachbericht nicht zu entnehmen, muß jedoch unterstellt werden, da Gullung sich ansonsten nicht in Deutschland als Rechtsanwalt hätte niederlassen können.

305. Richtinie des Rates vorn 22. Mär 1977 zur Erleichterung der tatsachlichen Ausübung des freien Dienstleistungsverkehrs der Reclitsamwälte (77/249/EWG), ABI. Nr. L 78 vom 26. März 1977, 17.

306. Decret vom 22. März 1979 .

307. Urteil vom 27. September 1989, Rs 130/88 - Van die Bijll - Sig. 1989, 3039. Siehe dazu Van Nuffel. SEW 1992, 121

308. Richthinie des Rates voni 7. Juli 1964 äber die Einzelheiten der ÜbergangsmaBnahmen auf dem Gebiet der selbständigen Tätigkeit der be- und verarbeitenden Gewerbe der CITL-Hauptgruppen 23 bis 40 (Industrie und Handwerk). ABL. Nr. 117 wom 23. Juli 1964, 1863. 
von insgesamt vier Jahren und fünf Monaten als selbständiger Maler im Vereinigten Königreich tätig gewesen sei und zuvor eine den Berufsanforderungen entsprechende Fachausbildung erhalten habe. Gemäß Art. 4 Abs. 3 der Richtlinie 64/427/EWG erteilt das Aufnahmeland auf Antrag die Erlaubnis zur Ausübung der betreffenden Tătigkeit, wenn die gemäß Ant. 4 Abs. 2 der Richtlinie 64/427/EWG durch die zuständigen Stelle des Herkunftslandes nachgewiesene Tätigkeit mit den wesentlichen Punkten des vom Aufnahmeland mitgeteilten Berufsbild übereinstimmt und etwaige sonstige Vorschriften des Aufnahmelandes vorgesehen Bedingungen erfüllt sind. Der Freistellungsantrag wurde mit der Begründung abgelehnt, der Betroffene habe in dem von der britischen Behörde berücksichtigten Zeitraum eine unselbständige Tätigkeit in den Niederlanden ausgeübt. Auch handele es sich bei in der Bestätigung genannten Ausbildung um eine niederländische Ausbildung, die in den Niederlanden nicht als ausreichend anerkannt sei. Das vorlegende Gericht hat dem Gerichtshof vier Fragen hinsichtlich der Auslegung der Richtlinie 64/427/EWG gestellt. Die erste Frage betraf die Verpflichtung des Aufnahmestaates, die Bestätigung des Herkunftstaates anzuerkennen, selbst wenn diese Bestätigung nachweisbare Unrichtigkeiten oder Irrtümer enthält. Die zweite und dritte Frage bezogen sich auf den Begriff der "vorherigen Ausbildung". Die letzte Frage zielte auf die Auslegung des Begriffs "ununterbrochene Tätigkeit".

In der Entscheidung Knoors hatte der Gerichtshof bereits in einem orbiter dictum festgestellt, daß die Mitgliedstaaten durchaus ein berechtigtes Interesse haben können, zu verhindern, daß sich die eigenen Staatsangehörigen unter Mißbrauch der durch den Vertrag geschaffenen Erleichterungen der Anwendung ihrer nationalen Berufsausbildungsvorschriften zu entziehen versuchen ${ }^{309}$. Der vorliegende Sachverhalt in der Rechtssache Van der Bijl bot Anlaß\} genug, einen derartigen Mißbrauch der Gemeinschaftsregelungen anzunehmen. Unter diesem Gesichtspunkt sind die Entscheidungsgründe zu verstehen. Der Gerichtshof wollte sich deutlich nicht von einem Betrüger vor den Karren spannen lassen. So stellte der EuGH in Beantwortung auf die vierte Frage zunächst unter Hinweis auf Zweck und Aufbau der Richtlinie fest, daß es sich um eine tatsächliche Ausübung einer Tätigkeit in einem anderen Mitgliedstaat handeln muß, die allenfalls wegen (kurzer) Krankheit oder (üblicher) Urlaubszeiten unterbrochen sein darf ${ }^{310}$. Auch könne eine Ausbildung im Aufnahmeland nur dann anerkannt werden, wenn diese zuvor von dem Staat anerkannt worden ist, in dem die Ausbildung erfolgte. Nur dieser könne die Angemessenheit der Ausbildung für die fragliche Tätigkeit beurteilen ${ }^{311}$.

Neben diesen mehr textinterpretierenden Fragestellungen zielte die ersten Frage des vorlegenden Gerichts auf einen wesentlichen Punkt im Hinblick auf die Wirksamkeit der Richtlinie. Kann eine Mitgliedstaat die Bestätigung eines anderen Mitgliedstaats in

309. Urteil vom 7. Februar-1979. Rs 115/78 - J. Knoors/Statatssekretär für Wirtschaft -, Slg. 1979, 399, Rdnr. 25. Siehe zum Mißbrauchverbot bereits die Erwägungen in Urteil vom 3. Dexember 1974, Rs $33 / 74$ - van Binsbergen -, SIg. 1974, 1299.

310. Urteil vom 27. September 1989, Rs 130/88 - Van de Bijl -, Slg. 1989, 3039, Rdnr. 19.

311. Urteil vom 27. September 1989, Rs 130/88 - Van de Bijl ., Slg. 1989, 3039, Rdnr. 31/32. 
Zweifel ziehen? Grundsätzlich werneinte der Gerichtshof diese Möglichkeit. Das Aufnahmeland ist grundsätzlich an die Feststellungen gebunden, die in der vom Herkunftsstaat ausgestellten Bestätigung enthalten sind, da diese ansonsten ihre praktische Wirksamkeit verlieren würde. Im Falle won Zweifeln, steht es dem Aufnahmestaat frei, das Herkunftsland um zustätzliche Auskünfte zu ersuchen ${ }^{3 / 2}$. Von dieser grundsätzlichen Verpflichtung zur Anerkennung der vom Herkunftsland bestätigten Gegebenheiten, ist der Aufnahmestaat nur dann befreit, wenn feststeht, daß die Person in dem Zeitraum, der ihr als Berufstätigkeit im Herkunftsstaat bestätigt wird, tatsächlich im Aufnahmestaat tătig gewesen ist. Mit dieser Einschränkung wollte der Gerichtshof deutlich dem Mißbrauch gemeinschaftlicher Regelungen vorbeugen, ohne aber, so die deutlichen Worte in der Erwägung 22, die grundsätzliche Gebundenheit des Aufnahmestaates abschwächen zu wollen.

Die beidlen Entscheidungen "Gullung" und "Van der Bijl", die auf den ersten Blick einen restriktiveren Eindruck hinterlassen als einige zuvor ergangene Urteile, lassen sich vor allem durch das "betrügerische Element" erklären, das in beiden Fällen eine Rolle spielt. In beiden Entscheidungen wollte der Gerichtshof deutlich dem Mißbrauch von Gemeinschaftsnormen vorbeugen. Insoweit hat der Gerichtshof in diesen Fällen einen Proportionalitätstest eigener Art angewandt: In Fällen, bei denen die Freiheitsrechte Einzelner mit der Integrität der Anwendung europäischen Rechts kollidiert, entscheidet sich der Gerichtshof zugunsten der Integrität des Gemeinschaftsrechts und gegen dessen MiBbrauch.

\section{Die Rechtsprechung in den neunziger Jahren}

a. Die Rechtssache Bouchoucha ${ }^{313}$

Ähnlich wie der Fall Van der Bijl betraf auch die Rechtssache Bouchoucha die Behandlung eines Inländers. Bouchoucha ist französischer Staatsangehöriger mit einem französischen Diplom als Heilgymnast sowie einem britischen Diplom als Osterotherapeut. In Frankreich ist gemäß dem Code de la santé publique die Vornahme medizinischer Handlungen einzig und allein Ärzten gestattet. Bouchoucha geriet in Konflikt mit den französischen Autoritäten, die ihn beschuldigten, Heilbehandlungen vorgenommen zu haben, die Ärtten vorbehalten seien. Bouchoucha berief sich auf die Niederlassungstreitheit. Der Gerichtshof wurde angerufen um zu entscheiden, ob das britische Diplom, das in Großbritannien zur Vornahme der umstrittenen Behandlungsmethoden berechtigt, auch in Frankreich Berücksichtigung finden müsse. Der Gerichtshof verneinte diese Möglichkeit, solange keine gemeinschaftsrechtliche Regelung die Anerkennung des britischen Diploms bestimme ${ }^{314}$. Die Argumente, die eine restriktive Anwendung des Gemeinschaftsrechts in der Rechtssache Van der Bijl rechtfertigten, lassen sich jedoch

312. Urteil vom 27. September 1989, Rs 130/88 - Van de Bijl -. Slg. 1989, 3039 "Rdnr. 22-24.

313. Urteil vom 3. Oktober 1990, C-26/89 - Strafverfahren gegen M.G. Bouchoucha -, Slg. 1990, II-355I.

314. Unteil vom 3. Oktober 1990, C-26/89 - Strafwerfahren gegen M.G. Bouchoucha -, S1g. 1990, I-3551, Rolnr. 14/15. 
nicht ohne weiteres auf die Sachlage im Falle Bouchoucha übertragen. Der Erwerb eines britischen Diploms kann als solcher nicht als Mißbrauch des Gemeinschaftsrechts angesehen werden. Dies gilt um so mehr, als Bouchoucha französische Ärzte in den umstrittenen Behandlungsmethoden unterrichten durfte. Demnoch sah der Gerichtshof Anlaß, seine zum Mißbrauch des Geneinschaftsrechts bereits gemachten Bemerkungen weiter auszuführen, daß nämlich "ein Mitgliedstaat ein berechtigtes Interesse daran haben kann, zu verhindern, daß sich einige seiner Staatsangelörigen unter Mißbrauch der durch den Vertrag geschaffenen Erleichterungen der Anwendung ihrer nationalen Berufsausbildungsvorschriften entziehen... Dies wäre insbesondere dann der Fall, wenn ein Staatsangehöriger eines Mitgliedsstaats unter Vorlage eines Diploms, das er in einem anderen Mitgliedstaat erworben hat und desssen Bedeutung und Wert gemeinschaftsrechtlich nicht anerkannt sind, seinen Herkunftsmitgliedstaat dazu verpflichten könnte, ihm die Ausübung der Tätigkeiten, auf die sich dieses Diplom bezieht, in seinem Hoheitsgebiet zu erlauben, sofern der Zugang zu diesen Tätigkeiten dort den Inhabern einer höheren Qualifikation vorbehalten ist, die die gegenseitige Anerkennung auf Gemeinschaftsebene genießt, und dieser Vorbehalt nicht als willkürlich erscheint" 315 . Die Entscheidung läßt sich im Vergleich zu dem nur einige Monate später ergangenen Urteil in der Rechtssache Vlassopoulou ${ }^{316}$ nur insoweit erklären, daß Bouchoucha auch nach britischer Rechtslage nicht als Arzt qualifiziert war ${ }^{3 ! 7}$. In seinem Fall handelte es sich vielmehr um einen Beruf, der in Frankreich nicht existiert und der reglementierte Tätigkeitsbereich einem anderen Beruf, nämlich Ärzten, ausschließlich vorbehalten ist ${ }^{318}$. Gemäß dieser Sachlage wären die französischen Autoritäten zur Anerkennung der beruflichen Qualifikation Bouchoucha's auch nach den Prinzipien der Richtlinie 89/48/EWG nicht verpflichtet ${ }^{319}$. Der Tenor des Urteils stellt daher ausdrücklich auf eine "arztähnliche Tätigkeit wie etwa die Osteopathie" ab, die in dem betreffenden Mitgliedstaat "den Inhabern eines Diploms eines Doktors der Medizin" vorbehalten ist. Auch Generalanwalt Van Gerven verweist in seinem Schlußantrag in der Rechtssache Kraus ${ }^{320}$ darauf hin, daß dieser Bereich besonders sensibel ist ${ }^{321}$. Die Entscheidung Bouchoucha muß daher alls Sonderfall gewertet werden.

315. Urteil vom 3. Oktober 1990, C-26/89 - Strafverfahren gegen M, G. Bouchoucha "SIg. 1990, Im3551, Rdns. $14: 15$

316. Unteil vom 7. Mai 1991, Rs C-340/89 - Irène Vlassopoulou/Ministerium für Justiz, Bundes- und Europaangelegenheiten Badenw Württemberg, Slg. 1-1991, $2357 \mathrm{ff}$.

317. In diesem Falle hätte sein Diplom nach Gemeinschaftsrecht aufgrund der Ärzterichtınie anterkannt werden müssen.

318. Vergleiche hierzu auch die Ausfïhrungen won GA Van Gerven in seimen Schlufanträgen in der Rs C19/92 - Dieter Kraus/Land Baden-Würtemberg -, Slg. 1993, I-1663 ff., Rdnr. 16, wobei er urvter Hinweis auf Art. 57 Abs. $3 \mathrm{EGV}$ auf die besondere Sensibilitatt dieser Regelungsmaterie hinweist.

319. Im Gegensatz zur Sachlage in der Rechtssache Vlassopoulou, wo die Anerkennung einer griechischen Anwallsqualifikation in Deutschland als Rechtsanwalt zur Diskussion stand. Siehe dazu die Ausfiulyrung Seite 66 .

320. Urteil vom 23. März 1993, Rs C-19/92 - Dieter Kraus/Land Baden-Württemberg, Slg. 1993, I-1663.

321. Siehe aucl die Sonderregelung in Art, 57 Abs. 3 EGV. 


\section{b. Die "Fremdenfuhrer" - Entscheidungen}

In den "Fremdenführer"-Entscheidungen ${ }^{322}$ hat der Gerichtshof seine bisherige Rechtsprechung zur Dienstleistungsfreiheit insoweit zusammengefaßt, indem er feststellte: "Die Anforderungen können daher nur dann als vereinbar mit den Artikeln 59 und 60 EG-Vertrag angesehen werden, wenn nachgewiesen ist, daß im Hinblick auf die betreffende Tätigkeit zwingende Gründe des Allgemeininteresses bestehen, die Beschränkungen des freien Dienstleistungsverkehrs rechtfertigen, daß das Algemeininteresse nicht bereits durch die Vorschriften des Staates, in dem der Leitsungserbringer niedergelassen ist, gewahrt ist und daß das gleiche Ergebnis nicht durch weniger einschneidende Regelungen erreicht werden kann ${ }^{323 " . ~ I m ~ U n t e r s c h i e d ~} \mathrm{zu}$ den Urteilen Webb ${ }^{324}$ und Kommission gegen Deutschland ${ }^{325}$ begründete der Gerichtshof seine Entscheidungen nicht mehr damit, daß er den zeitlichen Charakter einer Dienstleistung unterstrich.

\section{c. Die Rechtssache Vlassopoulou ${ }^{326}$}

Irène Vlassopoulou wurde 1982 als Rechtsanwältin Athen zugelassen. Seit Juli 1983 arbeitete sie unter Verantwortung und Aufsicht eines deutschen Rechtsanwaltes in Mannheim. Als griechische Staatsangehörige muß sie insoweit als Arbeitnehmer i.S. des Art. 48 EGV qualifiziert werden. Im November 1984 wurde ihr die Erlaubnis zur Besorgung fremder Rechtsgeschäfte gemäß dem Rechtsberatergesetz für das griechische Recht und das Gemeinschaftsrecht erteilt. Am 13. Mai 1988 beantragte Frau Vlassopoulou die Zulassung zur Rechtsanwaltschaft und als Rechtsanwältin beim Amtsgericht Mannheim sowie bei den Landgerichten Mannheim und Heidelberg. Nachdem ihr Antrag abgelehnt worden war, legte sie Beschwerde beim Bundesgerichtshof ein, der dem EuGH die Frage nach Verletzung der Niederlassungsfreiheit nach Art. 52 EGV vorlegte.

In seinen Schlußanträgen ging Generalanwalt Van Gerven ausführlich auf die bisherige Rechtsprechung des Gerichtshofs zum Niederlassungsrecht ein ${ }^{327}$. In seiner Analyse

322. Urteile vom 26. Februar 1991 in den Rechtssachen C-154/89- Kommission/Frankreich -, 51g. 1991. I-659; C-180/89- Kommission/Itallien - Slg. 1991, 1-709 und C-198/89 - Kommission/Griechenland-, Slg. 1991, 1-727. Siehe dazu die Urteilsanmerkung von Fierstra, SEW 1992, $821 \mathrm{ff}$.

323. Urteile wont 26. Februar 1991, Rs C-154/89- Kommission/Frankreich - Slg. 1991, I-659 Rdnr. 15 Rs 180/89-Kommission/Italien - Slg. 1991, 1-709 Rdnr. 18: Rs 198/89-Kommission/Griechenland-, Slg. $19911-727$ Rdnr. 19.

324. Uneil vom 17. Dezember 1981, Rs 279/80 - Strafverfiaren gegen Alfred John Webb ", Slg. 1981, $3305 \mathrm{ff}$.

325. Urteill vom 4. Dezember 1986 in der Rs 205/84 - Kommission/Deutschland -, Slg. 1986, 3755, Rdnr. 26.

326. Urtel vom 7. Mai 1991, Rs C-340/89 - Irène Vlassopoulou/Ministerium für Justiz, Bundes- und Europaangelegenheiten Baden-Wirttemberg -, Sig 1-1991, 2357 ff. Dazu Nachbaur, EuZW 1991, 470; Strein CMLRev. 1992, 625.

327. Urteil vom 7. Mai 1991, Rs C-340/89 - Irène Vlassopoulou/Ministerium für Justiz, Bundes* und Europaangelegenheiten Baden-Würtemberg -, Slg. 1-1991, 2357 (2365 ff). Dazu Van den Bossche in Alvarez, 67 
des Urteils Klopp sieht der Generalanwalt eine Bestätigung, daß auch ohne Unterschied geltende Vorschriften doch gegen Art. 52 EGV verstoßen können, "wenn dieses Vorschrift grenzüberschreitende Niederlassungen von Angehörigen anderer Mitgliedstaaten in einer Weise erschwert, daß die tatsächliche Ausübung der ihnen durch den Vertrag verbürgten Niederlassungsfreiheit verhindert, ohne daß dies durch objektive Grinde gerechtfertigt werden könnnte ${ }^{328}$. Aus dem Urteil des Gerichtshofs in den verbundenen Rechtssachen Wolf und Dorchain ${ }^{329}$ leitet Generalanwalt Van Gerven ab, "daß der Gerichtshof in Art. 52 EGV nicht nur ein Verbot der Diskriminierung aus Gründen der Staatsangehörigkeit sieht, sondern daß diese Bestimmung auch einer nationalen Regelung entgegensteht, die es Gemeinschaftsbürgern ohne objektive Rechtfertigung erschwert, jede Art von Erwerbstätigkeit außerhalb ihres eigenen Mitgliedstaates auszuüben." ${ }^{330}$ Bezüglich der Pflicht zur Berücksichtigung bereits erworbener Qualifikationen stellte er dabei fest, daß es den Mitgliedstaaten verboten sei, Gemeinschaftsbürgern die Ausübung ihres Berufs im gesamten Gebiet der Gemeinschaft unnötig zu erschweren, insbesondere dann, wenn sie sich in mehr als einem Mitgliedstaat niederlassen wollen. In diesem Zusammenhang sieht Generalanwalt Van Gerwen auch die Parallellen zur Rechtsprechung hinsichtlich des Waren- und Dienstleistungsverkehrs, wobei er dabei einräumt, daß die Rechtsprechung zum freien Warenverkehr und zum Dienstleistungsverkehr bedeutend weiter geht als die Rechtsprechung zur Niederlassungsfeiheit ${ }^{331}$. Der Gerichtshof hat in seiner Entscheidung diesen Teil der Erwägungen des Generalanwalts aufgegriffen und festgestellt: "..daß nationale Qualifikationsworaussetzungen, selbst wenn sie ohne Diskriminierung aufgrund der Staatsangehörigkeit angewandt werden, sich dahin auswirken können, daß sie Staatsangehörige der anderen Mitgliedstaaten in der Ausübung des ihnen durch Art. 52 EGV gewährleisteten Niederlassungsrechts beeinträchtigen. Dies kann der Fall sein, wenn die fraglichen nationalen Vorschriften, die von dem Betroffenen in einem anderen Mitgliedstaat bereits erworbenen Kenntnisse und Fähigkeiten unberücksichtigt lassen" ${ }^{332}$. Dabei unterstrich der Gerichtshof, daß die Mitgliedstaaten aus Art. 5 EGV der Verpflichtung unterliegen, alle Maßnahmen zu unterlassen, welche die Verwirklichung der Ziele des Vertrages gefährden können. Hieraus hat der Gerichtshof die Konsequenz gezogen, daß ein Mitgliedstaat, bei dem die Zulassung zu einem Beruf durch das Erfordernis eines Diploms oder einer beruflichen Qualifikation reglementiert ist, verpflichtet ist, die in einem anderen

328. Urteill vom 7. Mai 1991, Rs C-340/89 - Irène Vlassopoulow/Ministerium für Justiz, Bundes- und Europaangelegenheiten Baden-Wïrtemberg *, SIg. 1-1991, 2357 (2369).

329. Urteil vom 7. Juli 1988 in den werbundenew Rechtssachen 154/87 und 155/87 - Wolf und Dorchain-, SIg. $1988,3897 \mathrm{ff}$.. Siehe auch das gleichlaurende Urteil vom selben Tag in der Rechtssache 143/87Sranton -, Slg. 1988, $3877 \mathrm{ff}$.

330. GA Van Gerwen in seinen SchluBantragen zu dem Urteil vom 7. Mai 1991. Rs C-340/89 - Irène Vlassopoulou/Ministerium für Justiz, Bundes- und Europaangelegenheiten Baden-Württemberg -, Silg. I-1991, $2357(2370)$.

331. Unteil vom 7. Mai 1991 , Rs C-340/89 - Irèn Vlassopoulou/Ministerium für Justiz., Bundes- und Europaangelegenheiten Baden-Würtemberg -. Slg. 1-1991, 2357 (2372).

332. Urteil vom 7. Mai 1991, Rs C-340/89 - Irène Vlassopoulou/Ministerium für Juswiz, Bundes- und Europaangelegenheiten Baden-Winrtemberg -, Sig. 1-1991, 2357 Rdnr. 15. Sielwe dazu Gosgeries, JT 1991, 389: Lonbay, ELR 1991, 389; Nachbaur, EuZW 1991, 470; Stein, CMLRev. 1992, 625; Fierstra, SEW 1992, 640 . 
Mitgliedstaat erworbenen und durch Diplome bescheinigten Fachkenntnisse im Zulassungsverfahren mit zu berücksichtigen ${ }^{333}$. Dazu heißt es im Leitsatz des Urteils: "Art. 52 EWGV ist dahingehend auszulegen, daß die Behörden eines Mitgliedstaats, bei denen ein Gemeinschaftsangehöriger die Zulassung zum Anwaltsberuf beantragt, der bereits in seinem Herkunftsland als Rechtsanwalt zugelassen und im erstgenannten Mitgliedstaat als Rechtsbeistand tấtig íst, prüfen müssen, inwieweit die Kenntnisse und Fähigkeiten, die durch das von dem Betroffenen in seinem Herkunftsland erworbene Diplom bescheinigt werden, den nach dem Recht des Aufnahmestaats vorgeschriebenen Kenntnissen und Fähigkeiten entsprechen; entsprechen diese Diplome einander nur teilweise, so können die betreffenden nationalen Behörden von dem Antragsteller den Nachweis verlangen, daß er die fehlenden Kenntnisse und Fähigkeiten erworben hat."

\section{d. Die Rechtssache Manfred Säger gegen Dennemeyer}

Die Rechtsprechung Webb sowie die Fremdenführer-Entscheidungen wurden in der Rechtssache Säger gegen Dennemeyer ${ }^{334}$ erneut bestätigt. Dieser Fall betraf die Dienstleistungserbringung auf dem Gebiet der Patentüberwachung. Hierin hat der Gerichtshof unter Verwendung einer Formulierung aus dem Urteil in der Rechtssache Webb ${ }^{335}$ darauf hingewiesen, daß "der freie Dienstleistungsverkehr als fundamentaler Grundsatz des Vertrages nur durch Regelungen beschränkt werden [darf], die durch zwingende Gründe des Allgemeininteresses gerechtfertigt sind und die für alle im Hoheitsgebiet des Bestimmungsstaats tätigen Personen und Unternehmen gelten, und zwar nur insoweit, als dem Allgemeininteresse nicht bereits durch die Rechtsvorschriften Rechnung getragen ist, denen der Leistungserbringer in dem Staat unterliegt, in dem er ansässig ist. Diese Anforderungen müssen insbesondere sachlich geboten sein, um die Einhaltung der Berufsregelungen und den Schutz der Empfänger von Dienstleistungen zu gewährleisten und dürfen nicht über das hinausgehen, was zum Erreichen dieser Ziele erforderlich ist ${ }^{10336}$.

An die Zulässigkeit einer Beschränkung des freien Dienstleistungsverkehrs werden somit im wesentlichen zwei Voraussetzungen geknüpft. Zum einen müssen "zwingende Gründe des Allgemeininteresses" vorliegen, zum anderen mub die Beschränkung für alle

333. Armulliacobs in: Schermers 1993, 272 (278).

334. Urteil vom 25. Juli 1991, Rs C-76/90 - Manfred Säger/Dennemeyer \& Co. Lot -, Slg. 1991, 1-4221 Siehe dazu Speyer, EuZW 1991, 588, der besonders darauf hinweist. daß in Abwandlung zu der bereits in def Entscheidung Wesemael gewahlten Formulienng, hier festgestellt wird, dan "Art. 59 auch die Aufhebung aller Beschrainkungen - selbst wenn sie unterschiedlos für einheimische Dienstleistende sowje für Dienstleistende anderer Mitgliedstaaten gelten - vertangt, wetwn sie geeignet sind, die Tattigkeït des Dienstleisters, der in einem anderen Mitgliedstaat ansässig ist und dor rechtmäBig ährliche Dienstleistungen erbringt, zu unterbimclen oder zu behindern. "

335. Urteil vonu 17. Dezember 1981, Rs 279/80 - Strafverfahren gegen Alfred John Webb - Sig. 1981,
$3305 \mathrm{ff}$.

336. Urteil wom 25. Juli 1991, Rs. C-76/90 - Manfred Säger/Dennemeyer \& CO. Ltd. - SIg. 1991, I-4221.
Rdnr. 15. 
Teilnehmer am Wirtschaftsleben in gleicher Weise gelten. Desweiteren muls die Beschränkung sachlich geboten, geeignet und verhaltnismäßig sein.

e. Die Rechtssache Collective Antennevoorziening Gouda ${ }^{337}$ und die Rechtssache Kommission gegen die Niederlande ${ }^{338}$

Beide Entscheidungen, die am selben Tag wie das Urteil Säger/Dennemeyer ausgesprochen wurden, betrafen Fragen des niederländischen Medienrechts. In der Rechtssache Gouda hatte der niederländische Raad van State dem Gerichtshof drei Fragen bezüglich der Auslegung von Art. $59 \mathrm{EGV}$ vorgelegt. Zunächst stellte der Gerichtshof unter Hinweis auf seine Entscheidung in der Rechtssache $352 / 85^{339}$ erneut fest, daß diskriminierende Einschränkungen des Dienstleistungsverkehrs mit dem Gemeinschaftsrecht nur dann vereinbar sind, wenn sie ausdrücklich unter Art. 56 EVG fallen. Nichtdiskriminierende Behinderungen fallen ebenfalls unter Art. 59 EGV, "sofern die Anwendung der innerstaatlichen Rechtsworschriften auf ausländische Erbringer von Dienstleistungen nicht durch zwingende Gründe des Allgemeininteresses gerechtfertigt ist..." ${ }^{340}$. Interessant ist diese Entscheidung an dieser Stelle vor allem wegen der inhaltlichen Ausführungen des Gerichtshofs zu der Frage, welche Gründe als "'zwingende Gründe des Allgemeiminteresses ${ }^{\text {" }}$ angeführt werden können und unter welchen Bedingungen derartige Beschränkungen als gerechtfertigt anzusehen sind. Unter Verweisung auf seine frühere Rechtsprechung nennt der EuGH die folgenden Gründe ${ }^{341}$ : Bestimmte Berufsregeln ${ }^{342}$, Schutz des geistigen Eigentums ${ }^{343}$, Schutz der Arbeitnehmer ${ }^{344}$, Schutz der Verbraucher ${ }^{345}$, die Erhaltung des nationalen historischen und künstlerischen Erbes ${ }^{346}$, die Aufwertung der archäologischen, historischen und künstlerischen Reichtümer und die bestmögliche Verbreitung von Kenntnissen über das künst-

337. Urteil vom 25. Juli 1991, Rs C.288/89 - Stichting Collectiewe Antennewoorziening Gouda u a./Commisariaat voor de Media - Sig. 1991, 1-4007.

338. Urteil vom 25. Juli 1991, Rs C-353/89-Kommission/Königreich der Niederlande. Slg. 1991, 1-4069. Siehe zu beiden Entscheidungen Feenstra, CMLRev, 1993, 424

339. Urteil wom 26. April 1988. Rs 352/85 - Bond wan Adventeerders -, Slg. 1988, 2085, Rdnrn. 32/33.

340. Urteill vom 25. Juli 1991, Rs C-288/89- Stichung Collectieve Antennevoorziening Gouda a. a /Commisariat voor de Media -, Slg. 1991, \$ 4007, Rdnt. 13.

341. Utteil vom 25. Juli 1991, Rs C-288/89 - Stichting Collectieve Anternevoorziening Gouda u.a./Commisariaat voor de Media -, Slg. 1991, 1-4007, Rdnr. I 4 \%.

342. Unteil vom 18. Jamuar 1979 in den Rechtssachen 110/78 and 11/78- Ministere public und Chambre Synicale des Agents artistiques et Impresarii de Belgique, ASBL/Willy van Wesemael und andere Sig. 1979, 35. Rdnr. 28.

343. Urteil wom 18. Marz 1980, Rs 62/79 - Coditel -, Slg. 1980, 881

344. Ureil yom 17. Dezember 1981, Rs 179/80 - Webb-, Sig. 1981, 3305, Rdnr. 19; urteil vom 3 . Fiebruar 1982, verbundene Rs 62/81 und 63/81-Seco -, Slg. 1982, 223, rdnr 14: Urteil vom 27, Mărz 1990, Rs C-113/89 - Rush Portugesa -, Slg. 1990, 1- 1417, Rdnr. 18.

3.45. Urteile vom 4, Dezember 1986, Rs 220/83-Kommission/Frankreich, S\|g. 1986, 3663, Rdnr. 20; Rt 252/83 - Kommission/Dänemark -, S\#g. 1986, 3713, Rdnr. 20; Rs 205/84 - Kommission/DeutschlandSlg. 1986, 3755, Rdnr. 30; Rs 206/84 - Kommission/Irland -, Slg. 3817, Rdnr. 20; Unteile vom 26. Februar 1991, C-180/89 - Kommission/Italien - Slg. 1991, 1-709, Rdnr. 20 und C-198/89- Kommission/Griechenland -, Slg. 1991, 1-727, Rdar. 21.

346. Urteil vom 26. Februar 1991, C-180/89 - Kommission/laliem -, Slg. 1991, 1-709, Rdar. 20. 
Dike Freitheit des Personenwerkehrs aufgrund des EG-Vertrages

lerische Erbe des Landes ${ }^{347}$. Im Hinblick auf die vorgelegte Frage antwortete der Gerichtshof, dals auch eine nationale Kulturpolitik zur Erhaltung einer pluralistischen Meinungsfreiheit grundsătzlich einen zwingenden Grund des Allgemeininteresses darstellen könne ${ }^{348}$. Im konkreten Fall vermeinte er jedoch die Notwendigkeit der kon kreten Regelung, um den angestrebten Zweck zu erreichen.

In der zweiten Rechtssache beanstandete die Kommission das niederländische Mediawet. In dieser Entscheidung wiederholte der Gerichtshof wörtlich seine in der Rechtssache Gouda gemachten Ausfuhrungen ${ }^{349}$. Hinsichtlich der Proportionalität des Eingriffs durch die nationale Regelung überprüfte der EuGH in den darauf folgenden Erwägungen die Geeignetheit und Erforderlichkeit der Maßnahme sowie die Notwendigkeit eines schrittweisen Übergangs vom alten zum neuen Rundfunksystem. Erneut verneinte der Gerichtshof die Proportionalität des Eingriffs, da dieser über das von ihm verfolgte Ziel des Schutzes der Meinungsfreiheit hinausgehe.

\section{f. Die Entscheidungen López Brea ${ }^{350}$, Volker Steen ${ }^{35 t}$ und Batista Morais ${ }^{352}$}

Die Rechtssache López Brea ${ }^{353}$ betraf die spanische Regelung hinsichtlich eines spanischen Grundstücksmaklers, der in keiner Weise von seinem Freizïgigkeitsrecht Gebrauch gemacht hatte. Der Portugiese Batista Morais ${ }^{354}$ berief sich als Besitzer einer Fahrschule in Lissabon auf Gemeinschaftsrecht, da er sich durch eine portugiesische Regelung, die die Ausübung des Berufs geographisch einschränkte, in der Berufsausübung beschränkt sah. Volker Steen ${ }^{355}$, ein deutscher Staatsangehöriger, berief sich in einem Ernennungsverfahren bei der Deutschen Bundespost auf die Art. $7^{366}$ und $48 \mathrm{EWGV}$, da er die beamtenrechtichen Bestimmungen als diskriminierend ansah. Auch Steen hatte zu keinem Zeitpunkt in einem anderen Mitgliedstaat als der Bundesrepublik Deutschland gearbeitet. Die drei Eratscheidungen betrafen somit jeweils einen Sachverhalt, den der Gerichtshof als rein interne Angelegenheit einstufte. Die Bestim-

347. Unteile vom 26. Februar 1991, C-154/89 - Kommission/Frankreich -, Slg. 1991, I-659, Rdint. 17; C198/89 - Kommission/Griechenland - Sig. 1991, 1-727, Rdnr. 21

348. Urteill vom 25. Jull 1991, Rs C-288/89 - Stichting Collectieve Antennevoorziening Gouda u a / CommiSariant voor de Medig - Sig. 1991, I-4007, Rdnr. 23.

349. Urteil vom 25.Juli 1991, Rs C-353/89-Kommission/Königreich der Niederlande, Slg. 1991, I-4069.

350. Unteil vom 28. Januar 1992, verbundene Rs C-330/90 und C-311/90-Ministerio Fiscal/ López Brea und Hidalgo Palacios -, Slg, 1992, $1-323$.

351. Urteil yom 28. Januar 1992, Rs 332/90-Volker Steen -, Sig. 1992, I-341

352. Urteil vom 19. Marz 1992, Rs C-60/91 - Batista Morais -. Slg. 1992, 1-2085.

353. Urteill vom 28. Januar 1992, verbundene Rs C-330/90 -, Sig. 1992, I-2085. und Hidalgo Palacios $\ldots$ Slg. 1992, 1-323.

354. Urteil vom 19. März 1992, Rs C-60/91 - Batista Morais -, Slg. 1992, 1-2085.

355. Urteil vom 28. Januar 1992, R's 332/90 - Volker Steen -, Slg. 1992, J-341.
356. Nun mehr Art.6 EGV. 
mungen des Gemeinschaftsrecht konnten deshalb keine Anwendung finden ${ }^{357}$. Die Haltung des Gerichtshof's bei "rein internen Sachverhalten" ist eindeutig und sehr restriktiv. Eine Anwendung des Gemeinschaftsrechts wird in diesen Fallen kategorisch verneint. Diese Rechtsprechung ist von der Grundstruktur der Gemeinschaftskompetenzen zwar erklärlich, sie ist jedoch in zunehmenden Maße problematisch, wie sich gerade im Vergleich zwischen den Entscheidungen López. Brea und Newman zeigt ${ }^{358}$. Inhaltlich nahezu identische Fälle werden unterschiedlich beurteilt, nur weil im einen Fall, nämlich bei der Rechtssache Newman auch ein Migrant betroffen war.

\section{g. Die Rechtssache Newman}

In der Rechtssache Newman u.a. ${ }^{359}$ handelte es sich um ein Ersuchen um Vorabentscheidung über die Auslegung der Art. 52 und 57 EGV sowie der Richtlinie $67 / 43 /$ EWG $^{360}$. Die Entscheidung in dieser Sache hat der bereits in Heylens ${ }^{361}$ und Vlassopoulou ${ }^{362}$ entwickelten Rechtsprechung noch eine weitere Dimension gegeben. Die dem Gerichtshof vorgelegten Fragen stellten sich im Rahmen eines Strafverfahrens, das der Colegio oficial de agentes de la propriedad inmobiliaria ${ }^{363}$ gegen die Aguirre Newman SA, vertreten durch deren beauftragte Verwaltungsratsmitglieder S. Aguirre und S.K. Newman, wegen unbefugter Ausübung des Immobilienmaklerberufs eingeleitet hat. Newman hatte in Spanien ohne die nach spanischem Recht erforderliche dreijährige Berufsausbildung mit staatlichem Abschluß seinen Beruf als Immobilienmakler mit britischer Qualifikation ausgeübt. Es ging dabei u.a. um die Frage, ob die gemeinschaftsrechtlichen Regelungen über die Niederlassungsfreiheit beim gegenwärtigen Stand der Durchführung des Art. 57 Abs. 1 EGV eine strafrechtliche Verurteilung gestatten, wenn der Betreffende im Besitz eines Befähigungsnachweises ist, der seinem Herkunftsland rechtmäßig ausgestellt ist, dieser Befähigungsnachweis im Aufnahmestaat jedoch nicht anerkannt ist. Desweiteren wollte das vorlegende Gericht darüber aufgeklärt

357. Ständige Rechisprechung seit dem Unteil vom 28. Marz 1979. Rs 175/78- Saunders -, Slg. 1979 1129. Ahnlich entschied der Gerichtshof auch im Urteil vom 27. Oktober 1982 - Rs 35 tnd $36 / 82$ Morson und Jhanjan * Slg. 1982, 3723 sowie in der Entscheidung vom 28. Juni 1984, Rs 180/83. Moser/Land Baden-Württermberg, Slg. 1984, 2539. In jüngster Zeit wurde in der Rechtssache Werner, Unteil wom 26. Januar 1993, Rs C-112/91 - Werner ". Slg. 1993, 1429 emeut festgestellt, dal die Vertragsbestimmungen nicht auf rein interne Sachverhalte Anwendung finden.

358. Ähnlich anch der Vergleich zwischen der Rechtssache Wermer, Urteil vom 26, Januar 1993, Rs C $112 / 91$ - Werner -. Sig. 1993, I-429 und der Rechtssache C-279/93 - Schumaker - Urteil vom 14 Februar 1995 (noch nicho weröffentlicht). Kritisch dazu Knobbe-Keuk, EuZW 1995, 167

359. Urteil vom 7. Mai 1992, Rs, C 104/91 - Colegio Oficial de Agentes de la Propriedad Inmobiliaria Ministerio fiscal gegen J.L. Aguirre Borrell, S.K. Newman, S. Aguirte Gil de Biedma, M.I. Cepeda Ruiz, P. Aguirre Gil de Biedma -, Slg. 1992, I-3003. Stehe dazu Boutard Labarde, JDI 1993, 425.

360. Richtlinie 67/43/EWG des Rates vom 12. Januar 1967 uber die Verwirklichung der Niederlassungsfreiheit und des freien Dienstleiswngsverkelars für selbständige Thitigkeiten auf dem Gebiet 1 . der "Immobliengeschäfte (auler 6401)" (Gnuppe aus 640 ISIC), 2. einger "sonstiger Dienste fur das Geschäftsleben ${ }^{\text {th }}$ (Gruppe 839 ISIC), ABI. $1967 \mathrm{Nr} .10,140$.

361. Urteil wom 15. Oktober 1987. Rs 222/86-UNECTEF/Heylens -, SIg. 1987, 4097

362. Urtell worn 7. Mai 1991, Rs C-340/89 - Irène Vlassopoulou/Ministerium für Justiz, Bumdes- und Europarangelegenheitem. Baden-Württemberg - Stg. 1-1991, 2357

363. Uhersettzung: Kammer der Immoblienmakler 
werden, ob mangels gemeinschaftlicher Anerkennungsregelung gemäß Art. 57 Abs. 1 EGV, ein Mitgliedstaat befugt ist, weiterhin von den Betroffenen wor der Zulassung zum Beruf des Immobilienmaklers die Ablegung einer Prüfung zu verlangen. Auf diese letzte Frage ging der Gerichtshof zunächst ein. Dabei wiederholte er unter Verweisung auf die Entscheidungen Heylens ${ }^{364}$ und Vlassopoulou ${ }^{365}$, die grundsätzliche Feststellung, daß ein Mitgliedstaat, solange keine Harmonisierung der Zugangs voraussetzungen zu einem Beruf vorliegt, berechtigt ist, die Vorlage eines Diploms zu verlangen, in dem die notwendigen Kenntnisse und Fähigkeiten bescheinigt werden. Hierbei bestätigte der Gerichtshof aber auch die in der Entscheidung Vlassopoulou aufgestellte Verpflichtung an den Mitgliedstaat, das Diplom des Herkunftslandes und die darin bescheinigten Kenntnisse mit den nach nationalem Recht vorgeschriebenen Kenntnissen und Fähigkeiten zu vergleichen ${ }^{366}$. Als Ergänzung zu den bisherigen Entscheidungen müssen jedoch die weiteren Passagen des Urteils gewertet werden. Der Gerichtshof stellt darin genaue Maßstäbe an die Qualität des Prüfungsverfahrens auf, in dessen Rahmen der Diplomvergleich vorgenommen werden soll. Zunächst muß dieses Prüfungsverfahren den Behörden des Aufnahmestaates ermöglichen, objektiv festzustellen, ob ein auslãndisches Diplom seinem Inhaber gleiche oder zumindest gleichwertige Kenntnisse und Fähigkeiten wie das innerstaatliche Diplom bescheinigt ${ }^{367}$. Führt diese vergleichende Prüfung zu der Feststellung, daß die bescheinigten und die nach nationalem Recht verlangten Kenntnisse einander entsprechen, so muß die Anerkennung ausgesprochen werden ${ }^{368}$. Letztlich unterstreicht der Gerichtshof sehr deutlich, daß die Prüfung im Rahmen eines ordnungsgemäßen Verfahrens vorgenommen werden muß, "das mit den Erfordernissen des Gemeinschaftsrechts in bezug auf den effektiven Schutz der den Gemeinschaftsangehörigen vom Vertrag verliehenen Grundrechte in Einklang steht ${ }^{369}$." Jede Entscheidung muß daher mit Gründen versehen sein und gerichtlich überprüft werden können.

364. Urteil wom 15. Oktober 1987, Rs 222/86 - UNECTEF/Heylens *, SHg. 1987. 4097, Rdmr. 10.

365. Unteil wom 7. Mai 1991, Rs C-340/89-Irène Vlassopoulon/Ministerium für Justiz, Bundes- und Europaangelegenheiten Baden-Wintemberg -, Slg. 1-1991, 2357, Rdnr. 9.

366. Urteil vom 7. Mai 1991, Rs C-340/89 - Irene Vlassopoulou/Ministerium für Justiz, Bundes- und Europaangelagenlaeiten Baden.Wüntemberg “ Slg. 1-1991, 2357, Rdnr. 16; Urteil vom 7. Mai 1992, Rs C 104/91 - Colegio Oficial de Agentes de la Propriedad Immobiliaria, Ministerio fiscal/J. L. Aguirre Borrell, S.K. Newman, S. Aguirre Gil de Biedma. M.J. Cepeda Ruiz, P. Aguirre Gil de Biedma Sig. 1992, 1-3003, Rdni. 11 .

367. Urteil vom 7. Mai 1992, Rs C 104/91 - Colegio Oficial de Agentes de lla Propriedad Inmobiliaria, Ministerio fiscallJ.L. Aguirre Borrell, S.K. Newman, S. Aguirre Gil de Biedma, M.J. Cepeda Ruix, P. Aguirre Gil de Biedma -, Romr. 12

368. Urteil vom 7. Mail 1992, Rs C 104/91 - Colegio Oficial de Agentes de la Propriedad Inmobiliaria, Ministerio fiscal/J.L. Aguirre Bormell, S.K. Newman, S. Aguirre Gil de Biedma., M.J. Cepeda Ruiz, P. Aguirre Gil de Biedma -, Rdnr. 14.

369. Urteil vom 7. Mai 1992, Rs C $104 / 91$ - Colegio Oficial de Agentes de la Propriedad Inmobiliaria, Ministerio Fiscal/J.L. Aguirre Borrell, S.K. Newman, S. Aguirte Gil de Biedma, M.J. Cepeda Ruiz, P. Aguirre Gil de Biedna -, Rdnr. 15 


\section{h. Die Rechtssache Claus Ramrath ${ }^{370}$}

Die vom luxemburgischen Conseil d'État vorgelegte Rechtssache betraf Fragen bezüglich der freien Ausübung des Wirtschaftsprüferberufs. Diese Fragen stellten sich in einem Rechtsstreit zwischen Claus Ramrath und dem luxemburgischen Justizminister. Ramrath war im September 1988 die Zulassung als Wirtschaftsprufer in Luxemburg. entzogen worden, nachdem er dem Institut des réviseur Anfang 1988 mitgeteilt hatte, daß er nunmehr als Angestellter eines in Deutschland niedergelassenen Unternehmens tätig ist. Begründet wurde der Entzug der Zulassung damit, daß Ramrath keine gemäß Art. 3 Abs. 1 Buchstabe $c$ des Wirtschaftsprüfergesetzes ${ }^{37 !}$ notwendige berufliche Niederlassung in Luxemburg habe. Ferner fehle ihm aufgrund seines Angestelltenverhältnisses bei dem deutschen Unternehmen Treuarbeit AG, die nach Art. 6 Wirtschaftsprüfergesetzes notwendige berufliche Unabhängigkeit. Für die ordnungsgemäße Überwachung des Berufs sei jedoch die dauerhafte Anwesenheit eines Wirtschaftsprüfers in dem Staat, in dem die Prüfungen vorgenommen werden, notwendig. Ramrath legte gegen den Entzug der Zulassung Klage ein. Ramrath machte in dem Verfahren vor dem Conseil "d État geltend, daß ihm die Zulassung aus diskriminierenden Gründen entzogen worden sei, da es nach der luxemburgischen Rechtslage zulässig und mit der beruflichen Unabhängigkeit vereinbar sei, als Wirtschaftsprüfer bei einer in Luxemburg zugelassenen juristischen Person angestellt zu sein, wohingegen ein Angestelltenverhältnis bei einer juristischen Person in einem anderen Mitgliedstaat nicht geduldet werde; selbst dann nicht, wenn das Recht dieses Mitgliedstaates für angestellte Wirtschaftsprüfer gleichartige Erfordernisse beziiglich der Unabhängigkeit vorsehe.

Das vorlegende Gericht hat an den EuGH drei Fragen gestellt. Die erste Frage bezog sich auf die Problematik der doppelten Niederlassung. Auf diese Frage antwortete der Gerichtshof unter Hinweis auf seine Rechtsprechung in den Rechtssachen Klopp ${ }^{372}$, Stanton ${ }^{373}$ und Wolf und Dorchain ${ }^{374}$ klar und eindeutig, daß es einem Mitgliedstaat verwehrt ist, von einer Person, die einen Beruf ausübt, zu verlangen, daß sie im Gebiet der Gemeinschaft nur eine Niederlassung hat ${ }^{375}$. Die zweite und dritte Frage zielten darauf, ob es gegen die Freizügigkeitsbestimmungen des EG-Vertrages verstoße, wenn ein Mitgliedstaat die Ausübung des Wirtschaftsprüferberufs von Bedingungen wie dem Erfordernis ständiger beruflicher Einrichtungen, der tatsächlichen Anwesenheit im Mitgliedstaat und der Überwachung der Einhaltung won Standesregeln abhängig mache, obwohl die betreffende Person bereits in einem anderen Mitgliedstaat zur Ausübung dieses Berufs zugelassen sei.

370. Uneil vom 20. Mai 1992, Rs C-106/91 - Claus Ramrath/Ministre de la Justice -, Stg. 1992, 1-3351. Siehe dazu die Urteilsanmerkung von Wouters, TBH 1993, 344.

371. Gesetz vom 28. Juni 1984 zur Regelung des Berufs des Wirtschaftsprüfers, Mémorial 1984, 1346.

372. Urteil vom 12. Julli 1984 Rs 107/83 - Klopp - Slg. 1984, 2971 Rdnr. 19.

373. Urteil vom 7. Juli 1988, Rs 143/87 - Stanton -, Slg. 1988, 3877, Rdnur. 11.

374. Unteil vom 7. Juli 1988, verbundene Rs $154 / 87$ und 155/87 Wolf und Dorchain, Stg. 1988, 3897 , Rdnr. 11.

375. Urteil vom 20. Mai 1992, Rs C-106/91 - Claus Ramrath/Ministre de la Justice, Slg. 1992, I-3351 (3382) Ranr. 20/21. 
Zunächst stellte der Gerichtshof bei der Beantwortung dieser beiclen Fragen fest, daß die im luxemburgischen Wirtschaftsprüfergesetz niedergelegten Voraussetzungen, an der Gesamtheit der Freizügigkeitsworschriften des EG-Vertrages zu mesisen sind ${ }^{376}$. Die tatsăchliche Feststellung, ob der Wirtschaftsprüfer, der in einem anderen Mitgliedstaat Unternehmensprüfungen vornehmen möchte, rechtlich als Angestellter, als selbständig Erwerbstätiger oder als Dienstleistender einzustufen ist, obliege aber dem nationalen Gericht. Nach dieser Feststellung und dem grundsätzlichen Hinweis, daß der freie Dienstleistungsverkehr im Sinne des Art. 59 EGV das Gebot der Beseitigung sämtlicher Diskriminierungen des Leistungserbringers umfaßt, kommt der Gerichtshof zu den Erwägungen, ob Beschränkungen der Freizügigkeit aufgrund des Allgemeininteresses gerechtfertigt sind ${ }^{377}$. Bezugnehmend auf seine Rechtsprechung zu Fremdenführern in der Rechtssache C-180/89, Kommission/Italien ${ }^{378}$ stellt der EuGH fest, daß die Freizügigkeit als tragender Grundsatz des Vertrages nur durch Regelungen beschränkt werden darf, die durch das Allgemeininteresse gerechtfertigt sind und die für alle Personen und Unternehmen gelten, die diese Tätigkeiten im Hoheitsgebiet des fraglichen Mitgliedstaates ausüben. Diese Beschränkungen sind auch nur insoweit zulässig, als dem Allgemeininteresse nicht bereits durch Rechtsvorschriften Rechnung getragen ist, denen der Gemeinschaftsbürger in dem Mitgliedstaat unterliegt, in dem er ansässig ist ${ }^{379}$.

\section{i. Die Rechtssache Kommission gegen Luxemburg ${ }^{380}$}

Beinahe zeitgleich mit der Entscheidung Ramrath ${ }^{381}$ erging ein Urteil gegen Luxemburg, worin ebenfalls die Frage der Doppelniederlassung zur Debatte stand. Der Rechtsstreit betraf die luxemburgischen Regelungen bezüglich der Ausübung des Arzt-, Zahnarzt- und Tierarztberufs ${ }^{392}$. Die Kommission rügte die Tatsache, dalß gemäß Art. 16 dieses Gesetzes Ärzte und Zahnärzte nur eine einzige Praxis haben dürfen. Für Tierärzte enthält Art. 29 des Gesetzes eine vergleichbare Einschränkung. Unter Berufung auf seine ständige Rechtsprechung ${ }^{383}$ erklärte der EuGH erneut, daß das Niederlas-

376. Urteil wom 20. Mai 1992, Rs C-10691 - Claus Ramrath/Ministre de la Justice, Slg. 1992, 1-3351 (3383) Rdnr. 24.

377. Unteil vom 20. Mai 1992, Rs C-106/91 - Claus Ranrath/Ministre de la Justice, Slg. 1992, 1-3351 (3384) Rdnrn. $27-29$.

378. Urteil vom 26. Februar 1991, Rs C-180/89 - Kommission/ltalien, Slg. 1991, 1-709, Rdnr. 17.

379. Urteil vom 20. Mai 1992. Rs C-106/91 - Claus Ramrath/Ministre de la Justice, Slg. 1992, 1-3351 (3384) Rdinr. 29

380. Urteil vom 16. Juni 1992, Rs C-351/90 Kommission/Grofherzogtum Luxemburg, SIg. 1992, 1-3945.

381. Urteil vom 20. Mai 1992, Rs C-106/91-Claus Ramrath/Ministre de la Justice, Slg. 1992, I-3351.

382. Gesetz vom 29. April 1983 uber die Ausübung des Arzt-, des Zahnarzt- und des Tierarztberufs (Mémorial A - Nr. 31 vom 10. Mai 1983, 746.

383. Urteill vom 12. Juli 1984, Rs 107/83 - Klopp -, Slg. 1984, Rdnr. 19; Urteille vom 7. Juli 1988, Rs 143/87 - Stanton -, Slg. 1988, 3877, Rdnr. IIt und verbundene Rs 154/87 und 155/87 - Wolf und Dorchain -, Slg. 1988, 3897, Rdnr. 11; Urteil vom 20. Mai 1992, Rs C-106/91 - Ramnrath -, Slg. 1992, I-3351, Rdnr. 20. 
sungsrecht auch die Möglichkeit umfasse, im Gebiet der Gemeinschaft mehr als eine Stätte für die Ausübung einer Tätigkeit einzurichten und beizubehalten ${ }^{384}$ "

\section{j. Die Rechtssache Ferrer Laderer ${ }^{385}$}

Wie die Entscheidungen López Brea ${ }^{386}$ and Newman ${ }^{387}$ betraf der Rechtsstreit erneut die Zulassung zum Beruf des Immobilienmaklers. In Spanien ist dieser Beruf durch königliches Dekret reglementiert ${ }^{38}$, mit der Folge, daß, wenn Handlungen, die diesem Beruf vorbehalten sind, ohne die entsprechende Qualifikation vorgenommen werden, eine strafbare Amtsanmaßung vorliegt. Im Gegensatz zur Newman ist Frau Ferrer Laderer jedoch keine Gemeinschaftsangehörige, sondern besitzt die schweizerische Staatsbürgerschaft. Hieraus ergibt sich, daß die Vertragsvorschriften über die Freizügigkeit nicht einschlägig sind. Die Tatsache, daß sie mit einem spanischen Staatsangehörigen verheiratet ist, ändert daran nichts. Als Ehefrau eines Spaniers konnte sich Frau Ferrer Laderer ebenfalls nicht auf die Vertragsbestimmungen berufen, da es sich dadurch wie im Falle Lópes Brea um eine rein interne Situation handelt. Wäre Frau Ferrer Laderer z. B. mit einem italienischen Staatsangehörigen verheiratet, der von seinem Freizigigkeitsrecht Gebrauch gemacht hat, wäre die Situation zu ihren Gunsten anders zu beurteilen.

\section{k. Die Rechtssache Dieter Kraus ${ }^{389}$}

Bei dem vom Verwaltungsgericht Stuttgart vorgelegten Rechtsstreit ging es um die Frage der Vereinbarkeit einer nationalen Regelung mit dem Gemeinschaftsrecht, wonach zum Führen eines in einem anderen Mitgliedstaal erworbenen akademischen Grades eine vorherige staatliche Genehmigung erforderlich ist. Dieter Kraus hatte an der Universität Edinburgh den akademischen Grad eines "Master of Laws (LL.M.) erworben. Er begehrte diesen "LL.M." ohne vorherige Genehmigung in Baden-Württemberg führen zu dürfen. In Baden-Württemberg ist das Reichsgesetz uber die Führung akademischer Grade vom 7. Juni 1939 (AkadGFG) ${ }^{300}$ noch immer geltendes Recht. Nach diesem Gesetz ist zur Führung eines ausländischen akademischen Grades eine Genehmigung erforderlich. Verstöße gegen diese Genehmigungspflicht werden mit Freiheits-oder mit

384. Urteil vom 16. Juni 1992, Rs C-35L/90 Kommission/Großherzogtum Luxemburg, Slg. 1992, 1-3945, Rdnr. 11 .

385. Urteil wom 25. Juni 1992, Rs C-147/91 - Strafverfahren gegen Michẻle Ferrer Laderer, Slg. 1992, 1

386. Urteil vom 28. Januar 1992, verbundene Rs C-330/90 und C-31 1/90 - Ministerio Fiscal gegen López Brea und Hidalgo Palacios -, Slg. 1992, I-323.

387. Urteil vom 7. Mai 1992, Rs C 104/91 - Colegio Oficial de Agentes de la Propriedad Inmobiliaria, Ministerio fiscal gegen I.L. Aguirre Borrell, S.K. Newman, S. Aguirre Gil de Biedma, M.J. Cepeda Ruiz, P. Aguirre Gil de Biedma -, Sig. 1992, 1-3003.

388. Decret Nr. 3248/69 vom 4. Dezember 1969.

389. Unteil vom 23. Mărz 1993, Rs C-19/92 - Dieter Kraus gegen Land Baden-Würtemberg, Sig. 1993, I-1663. Siehe auch die Urteilsveroffentlichung in NVwZ 1993, 661 sowie die Urteilsbesprechungen von Wouters in: Gilliams/Van Gerven/Wouters/Wytink, Tijdschrift voor Belgisch Handetsrecht 1994. 743 (774), Huglo, RTDE 1993, 658.

390. RGB1. $19391,985$. 
Geldstrafe geahndet. Die Genehmigungspflicht gilt grundsätzlich sowohl für Inländer wie für Ausländer. Ausländer sind von dem Genehmigungserfordernis lediglich dann befreit, wenn sie sich in der Bundesrepublik in amtlichen Auftrag oder vorübergehend - für einen Zeitraum von nicht mehr als drei Monaten - und nicht zu Erwerbszwecken aufhalten. Vor seinem Magisterstudium in Edinburgh hatte Dieter Kraus das erste juristische Staatsexamen mit Erfolg abgelegt. Nach seiner Rückkehr aus Schottland arbeitete er eine kurze Zeit als wissenschaftlicher Angestellter an der Universität Tübingen. In dieser Periode hatte er dem Ministerium für Wissenschaft und Kunst BadenWürttemberg eine Kopie seiner Graduierungsurkunde übersandt und um eine Bestätigung gebeten, daß der Führung dieses Grades in der Bundesrepublik nach dieser Anzeige nichts mehr entgegensteht. Demgegenüber bestand das Ministerium auf einem förmlichen Genehmigungsverfahren. Dies führte zum Rechtsstreit vor dem Verwaltungsgericht Stuttgart, das dem EuGH folgende Frage zur Vorabentscheidung vorgelegt hat:

"VerstöBt es gegen Artikel 48 EGV oder alle sonstige Vorschriften des Gemeinschaftsrechts, anhand deren die Streitfrage beantwortet werden kann, wenn ein Mitgliedstaat der Europäischen Gemeinschaft seinen Staatsangehörigen das Führen eines aufgrund eines Postgraduiertenstudiums erworbenen akademischen Grades in Orginalform, den sie in einem anderen Mitgliedstaat erworben haben und der nicht den Zugang zu einem Beruf eröffnet, sondern für dessen Ausübung günstig ist, in seinem Hoheitsgebiet erst nach Einholung einer staatlichen Genehmigung erlaubt und das Führen des akademischen Grades ohne diese Genehmigung mit Strafe bedroht ist?"

Von der Einzelfallgenehmigung waren in Baden-Württemberg im Zeitpunkt dieser Vorlagefrage lediglich französische und niederländische akademische Grade befreit, inzwischen ist durch Verordnung eine weitere allgemeine Genehmigung für anwendbar erklärt worden, mit der das Führen zahlreicher in einer ausführlichen Anlage aufgenommener ausländischer akademischer Grade zugelassen ist ${ }^{391}$. Auch andere Bundesländer haben in dieser Periode diesbezügliche Änderungen vorgenommen ${ }^{392}$. So hat das Land Nordrhein-Westfalen durch Gesetz vom 6. Dezember 1991 das Führen von akademischen Graden der staatlichen oder staatlich anerkannten Hochschulen der Mitgliedstaaten der Europäischen Gemeinschaft einschließlich der Europäischen Hochschulen in Florenz und Brügge und der päpstlichen Hochschulen in Rom für zustimmungsfrei erklärt ( $\$ 141$ Abs. 1 des Gesetzes über die wissenschaftlichen Hochschulen des Landes Nordrhein-Westfalen) ${ }^{393}$. Gemäß dieser Bestimmung muß der Grad grundsätzlich in der Form geführt werden, die dem Wortlaut der Verleihungsurkunde entspricht. Der Berechtigte darf dem Grad eine Übersetzung zufügen, soweit dies aus sprachlichen

391. Allgemeine Genehmigung zur Führung von Hochschulgraden, Amtsblatt Wissenschaft und Kunst Baden-Württemberg vom 19. Juni 1992.

392. Sithe etwa für Rheinland-Pfalz das Rundschreiben des Ministeriums für Wissenschaft und Weiterbildung yom 14. Mai 1992, ABl. Rheinland-Pfalz 1992, 365 -390; sowie die Berichtigung dieses Rundschreibens vom 28 . September 1993, 489.

393. Fünftes Gesetz zur Änderung des Gesetzes über die wissenschaftichen Hochschulen des Landes Nordrhein-Westialen vom 6. Dezember 1991, GNBINW 1991, 518. 
Gründen erforderlich ist. Ferner ist er berechtigt, die im Herkunftsstaat übliche Abkürzung zu verwenden und durch einen Zusatz auf den Herkunftsstaat oder die verleihende Hochschule hinzuweisen. Begründet wurde diese Gesetzesänderung mit dem allgemeinen Hinweis auf die Richtlinie $89 / 48 / \mathrm{EWG}$ und der Tatsache, daß nach dieser Regelung eine allgemeine Berechtigung zur Führung der zugehörigen Berufs- und Ausbildungsbezeichnungen, dem sogenannten effectus civilis besteht. Es bestehe daher kein Grund, bei den (Hochschul-)Graden, obwohl sie nicht Gegenstand der Richtlinie 89/48/EWG seien, engherziger zu sein. Diese Grade bedürften keines stärkeren Schutzes als die materielle Qualifikation, die sie ausdrücken ${ }^{394}$. Allerdings - so die weitere Begründung - werde die Führung in der entsprechenden deutschen Form nicht vorgesehen, weil sie der Entwicklung eines europäischen Bildungsbewußtseins entgegenwir$\mathrm{ke}^{395}$. Inzwischen haben etwa die Hälfte der Bundesländer eine allgemeine Genehmigung eingeführt. Dabei handelten sie auf der Grundlage eines entsprechenden Beschlusses der Kultusministerkonferenz (KMK) ${ }^{396}$. Dieser BeschluB der Kultusministerkonferenz war vermutlich auch die zumindest mittelbare Ursache des Rechtsstreits in der Sache Kraus. Ebenso wie die allgemeine Genehmigungsregelung von Baden-Württemberg enthält auch der KMK-Beschluß keinen Hinweis auf die an britischen Universitäten erworbenen LL.M. Titel. Beim KMK-Beschluß beruhte dieses Unterlassen vermutlich auf einem Versehen, jedenfalls nicht auf einer bewußten Ausschließung der britischen Titel.

Die Rechtssache Kraus ist kein klassischer Fall der Niederlassungsfreiheit. Es geht vielmehr um einen Inländer, der einen im Ausland erworbenen akademischen Grad im Iniand verwenden möchte. Der Gerichtshof sah sich deshalb genötigt, zunächst die gemeinschaftsrechtliche Relevanz bei vorliegendem Sachverhalt darzustellen ${ }^{397}$. In diesem Zusammenhang stellte der Gerichtshof fest, daß ein akademischer Grad, obwohl er normalerweise keine Zugangsworaussetzung für einen unselbständigen oder selbständigen ausgeibten Beruf ist, für den Inhaber dennoch einen Vorteil für den Zugang zu einem solchen Beruf oder für das berufliche Fortkommen bedeutet. Die Niederlassung als Selbständiger werde durch die Möglichkeit, im Ausland erworbene akademische Grade vorzuweisen, erheblich erleichtert ${ }^{398}$.

394. So die amthiche Begründung zu dem Gesetzesentwurf zur Änderung des Gesetzes über die wissenschaft lichen Hochschulen des Landes Nordrhein-Westfalen, Drucksache 11/1880 vom 10. Juni 1991, 7.

395. Zum Verhältnis zwischen akademischer und berufsbezogener Anerkennung siehe die Enörterumgen im Epilog.

396. Allgemeine Genehmigung zur Führung von Hochschuigraden aus Mitgliedstaaten der Europåischen Gemeinschaft, Österreich und der Schweiz, der Papstichen Hochschulen in Rom sowie der Hochschulen in Florenz und Brügge, KMK-Beschluf vom 9. November 1990, Sammlung der Beschlússe der KMK Nr. 1976.

397. Die Anwendung des Gêmeinschaftsrechts bejahte der Gerichtshof unter Hinweis auf seine Rechuspre chung, vgl, dazu die Uirteile vom 7. Februar 1979, Rs 115/78 - Knoors ., Slg. 1979, 399. Rdnr. 24, und 3. Oktober 1990, C-61/89 - Bouchoucha -. Slg. 1990, 1-3551, Rdnir. 13

398. Urteil wom 23. März 1993. Rs C-19/92 - Dieter Kraus/Land Baden-Würtemberg, Slg, 1993, 1- 1663 Rdnr 18 and 22. Dazu Huglo, RTDE 1993, 655 (657). 
Entscheidend fur die untersuchte Fragestellung, ob Art. 52 EGV neben einem Diskriminierungsverbot auch ein Beschränkungsverbot enthält, sind jedoch die folgenden Ausführungen des Gerichtshofs:

"Daher stehen die Artikel 48 und 52 jeder nationalen Regelung über die Voraussetzungen für die Führung eines in einem anderen Mitgliedstaat erworbenen ergänzenden akademischen Grades entgegen, die zwar ohne Diskriminierung aus Gründen der Staatsangehörigkeit anwendbar ist, die aber geeignet ist, die Ausübung der durch den EGVertrag garantierten grundlegenden Freiheiten durch die Gemeinschaftsangehörigen einschließlich der Staatsangehörigen des Mitgliedstaats, der die Regelung erlassen hat, zu behindern oder weniger attraktiv zu machen ${ }^{399}$."

Diese Passage, die als solche schon sehr bemerkenswert ist, da der EuGH deutlich auch nicht diskriminierende Regelungen als mit Art. 48 und 52 EGV unvereinbar erklärt, soweit sie eine Behinderung für die Verwirklichung der Grundfreiheiten darstellen, wird durch einen weiteren Satz ergänzt, der die Parallele mit der Rechtsprechung zum Dienstleistungswerkehr endgültig vollzieht ${ }^{400}$ :

"Anders verhielte es sich nur, wenn milt einer solchen Regelung ein berechtigter Zweck verfolgt würde, der mit dem EG-Vertrag vereinbar und aus zwingenden Gründen des Allgemeininteresses gerechtfertigt wäre." Dabei verweist der Gerichtshof auf seine Erörterungen in der Rechtssache Thieffry ${ }^{401}$. Dieser Hinweis ist nicht sehr überzeugend, da keine der beiden zitierten Stellen "zwingende Gründe des Allgemeininteresses" als einzigen Rechtfertigungsgrund für eine Beschränkung der Niederlassungsfreiheit nennen. Die Formulierung ist vielmehr beinahe wörtlich den Entscheidungen zurn Dienstleistungswerkehr in den Rechtssachen Webb ${ }^{402}$ und Manfred Säger gegen Dennemeyer ${ }^{403}$ entnommen ${ }^{404}$. Die Übereinstimmung mit diesen beiden Entscheidungen wird noch verdeutlicht durch die Tatsache, daß die mit dem Allgemeininteresse begründete Beschränkung geeignet und erforderlich sein muß, den mit ihr verfolgten Zweck zu erreichen ${ }^{405}$. Dabei stellte der Gerichtshof allerdings fest, dal das Gemeinschaftsrecht es den Mitgliedstaaten grundsätzlich zum Schutz der Öffentlichkeit vor irreführender Verwendung akademischer Titel gestattet, die Voraussetzungen für die

399. Urteil vom 23. Marz 1993, Rs C-19/92 - Dieter Kraus/Land Baden-Württemberg, Slg. 1993, I-1663 Ranr. 32 .

400. Johnson/O'Keefe, CMLRev. 1994, 1313 (1333)

401. Urteil vom 28. April 1977, Rs 71/76 - Thieffry -. Slg 1977, 765, Rdinr. 12 und 15

402. Urteil vom 17. Dezember 1981, Rs 279/80 - Strafverfahren gegen Alfred John Webb -, Slg. 1981, $3305 \mathrm{ff}$.

403. Urteil vom 25. Juli 1991, Rs C-76/90 - Manfred Säger/Demnemeyer \& Co. Lid -, Slg. 1991, I-4221.

404. Siehe dazu die Erönerungen Seite 54 und 68.

405. Urteil vom 23. März 1993 "Rs C-19/92 - Dieter Kraus/Land Baden-Württemberg, SIg. 1993, 1-1663 Rdnr. 32. Vergleiche dazu auch die Fornulierung in den Fremdenführer-Entscheidungen, Unteile wom 26. Februar 1991 in den $\mathbb{R s}$ C-154/89 - Kommission/Frankreich - C-180/89 - Kommission/Italien -. und C-198/89 - Kommission/Griechenland, Slig. 1991, 1-727; ähnlich auch das Urteil vom 20. Mai 1992, Rs C-106/91 - Ramrath -Slg. 1992, I-3351, Rdnr. 29. 
Verwendung in nicht diskriminierender Weise und unter Beachtung der VerhältnismäBigkeit festzulegen. Obwohl der Gerichtshof in seinen weiteren Erörterungen in der Rechtssache Kraus den Maßstabe für die Proportionalität der Regelung des Landes Baden-Württemberg in einer wesentlich schwächeren Weise anlegt als dies in den genannten Entscheidungen zur Dienstleistungsfreiheit der Fall ist ${ }^{406}$ "so muB dennoch festgestellt werden, daß mit der Entscheidung Kraus die nach Bleckmann's Auffassung bestehenden Parallelität der Grundfreiheiten ${ }^{407}$, ihren Niederschlag in der Wortwahl des Gerichtshofs gefunden hat.

Die Sache Kraus hatte jedoch auf nationaler Ebene noch ein Nachspiel. Am 26. August 1993 erging das Urteil des Verwaltungsgerichts Stuttgart ${ }^{408}$. Hierin wurde die Klage von Dieter Kraus abgewiesen. Begründet wurde die Abweisung der Klage unter anderem damit, daß $\S 2$ AkadGFG dem Gebot der Verhältnismäßigkeit entspricht, "da die Genehmigungspflicht ein angemessenes Mittel darstellt, um das Ziel des Gesetzes, nämlich eine Kontrolle des Titel-Wesens, zu erreichen." Eine weitere Begründung für die Erfüllung des Verhältnismäßigkeitsgebots gibt das Gericht nicht. Das Verwaltungsgericht geht dabei nicht auf die Frage ein, ob die Kontrolle des Titel-Wesens ein solch berechtigter Zweck darstellt, der sich durch zwingende Gründe des Allgemeininteresses gerechtfertigt ist. Auch unterwirft das Verwaltungsgericht die Regelung nicht einer strengen Verhältnismäßigkeitsprüfung. Dabei hätte eine solche Prüfung vor der Hand gelegen. Nach der derzeitigen Rechtslage wird die Führung zahlreicher akademischer Grade in Baden-Württemberg automatisch anerkannt ${ }^{409}$. Hierunter auch z.B. der LL.M-Titel der irischen Universitäten oder der Grad "Master of Jurisprudence" der britischen Universitäten. Eine allgemeine Genehmigung gilt auch für die französischen und niederländischen akademischen Grade einschließlich der juristischen Titel. Meines Erachtens hätte darum die Notwendigkeit und Verhältnismäßigkeit einer Inividualentscheidung für den LL.M-Grad der Universität von Edinburgh besonders begründet werden müssen. Wie Generalanwalt Van Gerven im Anschluß auf das Vorbringen der Kommission ausführt, wäre die Öffentlichkeit bereits durch das strafrechtliche Verbot der Führung falscher Titell in ausreichendem Maße geschützt. Würde ein weitgehenderer Schutz als erforderlich erachtet, "so könnte vorgeschrieben werden, daß neben der Bezeichnung der Name und gegebenenfalls auch der Ort der verleihenden Lehranstalt aufgeführt werden ${ }^{410}$ " Nach meiner Ansicht hätte die baden-württembergische Regelung daher am Kriterium der Notwendigkeit scheitern müssen. Gewißl wäre es durchaus wünschenswert gewesen, daß der EuGH selbst eine deutlichere Position hinsichtlich der Notwendigkeit der Maßnahme eingenommen hätte.

406. Der Gerichtshof prüt nur äuferst marginal die Notwendigkeil der Regelung.

407. So bereits Bleckmann, DVBI 1986, $69 \mathrm{ff}$.

408. AZ: 8 K 3897/89 siehe daxu auch VBIBW 3/1994, 116 mit der Urteilsanmerkung von Mecking

409. Allgemeine Genehmigang zur Führung won Hochschulgraden, Amtsblatt Wissenschiaft und Kunst Baden-Würtemberg vom 19. Juni 1992. GA Van Gerwen hat in seinem SchluBantrag in der Rechtssache Kraus ausdrüklich auf diese neue Regellung hingewiesen.

410. Schlưlanträge des GA Van Gerwen, Urteil vorn 23. Mär 1993, Rs C-19/92 - Dieter Kraus/Land Baden-Württemberg, Rdnr. 13. 
Kraus hat gegen die Entscheidung des Verwaltungsgerichts Berufung eingelegt. Die Entscheidung des Verwaltungsgerichthofs Mannheim in dieser Angelegenheit muß abgewartet werden.

\section{Die Rechtssache Allué II}

Die Rechtssache Allué II betraf erneut das italienische Dekret $\mathrm{Nr} .382$ wom 11 . Juli 1980, wonach gemäß A.rt. 28 Fremdsprachenlektoren an itallienische Universitäten nur mit Zeitverträgen eingestellt werden ${ }^{411}$. Bereits 1989 hatte der EuGH in seiner Entscheidung Allué I bezüglich dieses Dekrets bestimmt, daß auch verschleierte Formen der Diskriminierung gegen Art. 48 Abs. 2 EGV verstoßen ${ }^{412}$. In Allué II wählte der Gerichtshof dagegen eine andere Formulierung. Auf das Vorbringen der itallienischen Regierung antwortet der EuGH: "..., daß die Bestimmungen des EWGV es den Mitgliedstaaten nicht verbieten, unterschiedslos geltende Maßnahmen zur Sicherung der ordnungsgemäßen Verwaltung ihrer Universitäten zu erlassen, die insbesondere die Staatsangehörigen der anderen Mitgliedstaaten treffen könnnen. Bei derartigen Maßnahmen ist jedoch der Grundsatz der Verhältnismäßigkeit zu wahren, das heißt, sie müssen zur Erreichung des angestrebten Zwecks geeignet, und notwendig sein. " 413 Mit dieser Wortwahl hat der Gerichtshof auch bezüglich Art. 48 Abs. 2 EGV einen erneuten Schritt in die Richtung auf ein Beschränkungsverbot gemacht und damit die Entscheidung Kraus bestätigt. Der Hinweis des Gerichtshofs, daß von der italienischen Regelung hauptsächlich Ausländer betroffen seïn können, ändert an dieser Feststellung nichts, da sich der Gerichtshof nicht auf die Position eines Falles der versteckten Diskriminierung zurückzog, sondern bewußt von einer unterschiedslos geltenden Regelung ausging, die dern Verhältnismäßigkeitsgrundsatz unterliegt ${ }^{* 14}$.

\section{m. Die Rechtssache Salomone Haim ${ }^{415}$}

Die Rechtssache Haim ist von besonderer Bedeutung für die Anerkennungsproblematik bei Drittstaatsdiplomen. Die Entscheidung ist jedoch ebenfalls von Interesse für die Beantwortung der Frage, ob auch bei Vorliegen einer Anerkennungsrichtlinie die Rechtsprechung des Europäischen Gerichtshofs zu Art. 52 EVG im Falle einer Regelungslücke Anwendung findet.

Haim ist italienischer Staatsangehöriger, der 1946 das Studium der Zahnmedizin in Istanbul abgeschlossen hatte und dort bis 1980 als niedergelassener Zahnarzt praktizier-

411. Unteil vom 2. August 1993, verbundene Rs C-259, 331 und 332/91-Allue, Coonan u. A. - Slg. 1993 , [-4309; ]Z 1994, 94 mit einer Anmerkung won Steindorff.

412. Urteil vom 30. Mai 1989, Rs 33/88 - Allué u.a. gegen Universita degli studi di Venezia -, Slg. 1989. 1591. So auch im Unteil vom 15. Januar 1986, Rs 41/84 - Pinna -, Slg. 1986, 1

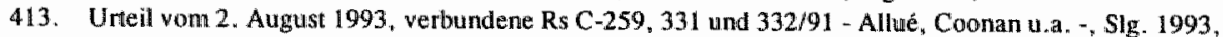
I-4309 Rdnr. 15.

414. So auch Steindorf, JZ $1994,95(96)$.

415. Urteil vom 9. Februar 1994, Rs C-319/92 - Salomone Haim/Kassenzahnärztliche Vereinigung Nordtrhein -, Sig. 1994, I-425. 
te. 1980 verlegte er seinen Wohnsitz nach Belgien, wo sein türkisches Diplom 1982 nach Ablegung einer Prüfung als dem belgischen Diplom gleichwertig anerkannt wurde. Danach arbeitete Haim acht Jahre lang als Zahnarzt mit Kassenzulassung in Belgien. Im September 1981 hatte die zuständige Behörde in Deurschland Haim die Approbation als Zahnarzt gemäß $\$ 13$ des Gesetzes über die Ausübung der Zahnheilkunde erteilt. Danach arbeitete er für eine gewisse Zeit als Assistent in der Praxis seines Sohnes, der selbst als Kassenzahnarzt niedergelassen ist. Haim beantragte im Juli 1988 bei der Kassenzahnärztlichen Vereinigung Nordrhein die Aufnahme in das Zahnarztregister. Voraussetzung für eine Eintragung ist gemäß $\S 3$ Abs. 2 Buchstabe b der Zulassungsverordnung für Kassenzahnärzte (Zahnärzte-ZV) neben der Approbation die Ableistung einer mindestens zweijährigen Vorbereitungszeit. Die KVN lehnte den Antrag Haim's mit der Begründung $\mathrm{ab}$, daß er diese Voraussetzung nicht erfülle und sich auch nicht auf die Ausnahmeregelung des $\$ 3$ Abs. 4 Zahnärzte-ZV berufen könne. Diese Bestimmung läßt eine Ausnahme im Hinblick auf den verpflichtenten Vorbereitungsdienst für Zahnärzte zu, "die in einem anderen Mitgliedstaat der Europäischen Gemeinschaften ein nach den gemeinschaftsrechtlichen Vorschriften anerkanntes Diplom erworben haben und zur Berufsausübung zugelassen sind. Widerspruch, Klage und Berufung Haim's blieben erfolglos. Das Bundessozialgericht hat im Revisionsverfahren dem Europäischen Gerichtshof die Auslegung von Art. 20 der Richtlinie $78 / 686 / \mathrm{EWG}^{416}$ und von Art. $52 \mathrm{EGV}$ betreffende Vorabentscheidungsfragen vorgelegt.

Die ersten beiden Fragen betreffen die Interpretation des Art. 20 der Richtlinie 78/686/EWG. Art. 20 der Richtlinie 78/686/EWG bezieht sich auf den besonderen Fall der Zulassung zum Kassenzahnarzt. Danach dürfen Mitgliedstaaten, die von ihren eigenen Staatsangehörigen für die Zulassung zum Kassenzahnarzt die Ableistung einer Vorbereitungszeit verlangen, diese für eine Übergangsperiode von acht Jahren nach Bekanntgabe der Richtlinie auch von Staatsangehörigen der anderen Mitgliedstaaten verlangen, wobei die Dauer einer solchen Vorbereitungszeit sechs Monate nicht überschreiten darf. Seit dem 30. Juni 1986, die ein nach Gemeinschaftsrecht anerkanntes Diplom in einem anderen Mitgliedstaat erworben haben, von der Ableistung der Vorbereitungs zeit in Deutschland gemäß $\$ 3$ Abs. 4 und 5 Zahnärzte-ZV befreit. Die erste Frage des vorlegenden Gerichts zielt darauf, ob das gemäß Art. 20 der Richtlinie 78/686/EWG bestehende Verbot, nach dem 30 . Juni 1986 von Gemeinschaftsangehörigen einen Vorbereitungsdienst zu verlangen, auch dann gilt, wenn der Betreffende nicht im Besitz eines gemäß Art. 3 der Richtlinie 78/686/EWG anzuerkennenden Befähigungsnachweis ist. Die zweite Frage betrifft die Problematik der Drittstaatsdiplome, nämlich, ob die Befreiung von der Vorbereitungszeit dann gilt, wenn das Drittstaatsdiplom von einem anderen Mitgliedstaat als einem in Art. 3 der Richtlinie genannten Diplom gleichwertig anerkannt worden ist.

Beide Fragen bezüglich Art. 20 der Richtlinie 78/686/EWG hat der Gerichtshof für Haim negativ beantwortet. Bezüglich der ersten Frage stellte der EuGH fest, daß Art.

416. Richtininie 78/686/EWG des Rates vom 25. Juli 1978 für die gegenseitige Anerkennung der Diplome, Prüfungszeugnisse und sonstige Befähigungsnachweise des Zahnarztes, ABI. Nr. L. 233, 1. 
20 der Richt]inie 78/686/EWG es einem Mitgliedstaat nicht verbietet, auch nach Ablauf der achtjăhrigen Frist eine Vorbereitungszeit für die Zulassung als Kassenzahnarzt zu verlangen, wenn der Betreffende keinen in Art. 3 der Richtlinie genannten Befähigungsnachweis besitzt. Bei der Beantwortung der zweiten Frage werwies der Gerichtshof auf Art. 1 Abs. 4 der Richtlinie 78/687/EWG, wonach die Mitgliedstaten durch die Anerkennungs- und Koordinierungsrichtlinie in keiner Weise gehindert sind, Inhabern von Drittstaatsdiplomen die Aufnahme und Ausübung der Zahnarzttätigkeit in ihrem Gebiet nach ihren innerstaatlichen Vorschriften zu gestatten. Aus dieser Bestimmung zog der Gerichtshof unter Hinweis auf sein Urteil vom selben Tag in der Rs C-154/93 ${ }^{417}$ die Schlußfolgerung, daß die Anerkennung eines Drittstaatsdiploms durch einen Mitgliedstaat die anderen Mitgliedstaaten auch dann nicht bindet, wenn dieser Befähigungsnachweis in einem oder mehreren Mitgliedstaaten als gleichwertig anerkannt worden ist $^{488}$.

Die dritte durch das vorlegende Gericht hilfsweise gestellte Frage betraf die Auslegung von Art. 52 EGV und zwar dahingehend, ob ein Mitgliedstaat gemäß dieser Bestimmung befugt ist, einem Staatsangehörigen eines anderen Mitgliedstaates die Zulassung als Kassenzahnarzt mit der Begründung der fehlenden Vorbereitungszeit zu verweigern, ohne zu prüfen, ob diese Voraussetzung in Anbetracht der erworbenen Berufserfahrung als ganz oder teilweise erfüllt anzusehen ist. Bei der Beantwortung dieser Frage verwies der Gerichtshof auf seine Entscheidung in der Rechtssache Vlassopoulou ${ }^{419}$, worin er festgestellt hat, daß nationale Qualifikationsworaussetzungen auch bei nichtdiskriminierender Anwendung eine Beinträchtigung des in Art. 52 EGV gewährleisteten Niederlassungsrechts bewirken können ${ }^{420}$. Gemäß dem in der Entscheidung Vlassopoulou entwickelten Grundsatz forderte der Gerichtshof auch in der Rechtssache Haim, daß die zuständigen nationalen Stellen bei der Prüfung, ob die nach nationalem Recht bestehende Verpflichtung zur Ableistung eines Vorbereitungszeit erfüllt ist, die Berufserfahrung des Betreffenden einschließlich der als Zahnarzt mit Kassenzulassung in einem anderen Mitgliedstaat erworbenen Berufserfahrung zu berücksichtigen ${ }^{421}$. Mit dieser Feststellung forderte der EuGH eine durch die zuständigen Stellen vorzunehmende Vergleichsprüfung. Bei einer solchen Prüfung werden die in der Rechtssache Newman entwickelten Verfahrensgrundsätze berücksichtigt werden müssen. Undeutlich ist allerdings, ob der Gerichtshof lediglich die in einem anderen Mitgliedstaat erworbene Berufserfahrung in dieses Vergleichsverfahren einbeziehen will oder, ob die Berufserfahrung in ihrer Gesamtheit einschließlich der in einem Drittstaat erworbenen Erfahrung Berücksichtigung finden muß.

417. Urteil rom 9. Februar 1994, Rs C-154/93 - Tawil-Albertini -, Slg. 1994, I-451 (463), Rdnr. 13

418. Urteil vom 9. Februar 1994, Rs C-31.9/92 - Salomone Haim/Kassenzahnärztliche Vereinigung Nondrhein, Slg. 1994, 1-425, Rdnr. 21.

419. Urteil vom 7. Mai 1991, Rs C 340/89 - Vlassopoulou -, Slg. 1991, 1-2357.

420. Urteil vom 7. Mai 1991, Rs C 340/89 - Vlassopoulou -, Slg. 1991, 1-2357, Rdnr. 15.

421. Urteil vom 9. Februar 1994, Rs C-319/92 - Salomone Haim/Kassenzahnarztliche Vereinigung Nondrhein, SIg. 1994, 1-425, Rdnr 28/29. Dazu, Huglo, RTDE 1994, 465 (471). 


\section{n. Die Rechtssache Tawil-Albertini ${ }^{422}$}

Abdullah Tawil-Albertini, ein französischer Staatsangehöriger, erwarb 1968 in Beirut das Diplom eines Doktors der Zahnchirurgie. Dieses Diplom warde nocl vor Inkrafttreten der Richtlinie 78/686/EWG in Belgien als gleichwertig mit dem in Belgien gesetzlich vorgeschriebenen Diplom anerkannt. AuBerdem haben auch die britischen und irischen Behörden die Gleichwertigkeit des Diploms anerkannt. Unter Berufung auf diese Anerkennungen durch drei Mitgliedstaaten beantragte Tawil-Albertini die Zulassung zum Zahnarztberuf in Frankreich. Diese Genehmigung wurde ihm am 2. Mai 1986 vom Ministerium für soziale Anglegenheiten verweigert. Gegen diese Entscheidung hat der Betroffene erfolglos $\mathbb{K}$ lage erhoben. Das Berufungsgericht hat das Verfahren ausgesetzt und dem EuGH eine Frage bezüglich der Auslegung von Art. 7 der Richtlinie 78/686/EWG gestellt. Art. 7 der Richtlinie 78/686/EWG betrifft die Anerkennung von Diplomen auf der Basis von wohl erworbenen Rechten. Es geht dabei um die Anerkensung von Diplomen, die in einem Mitgliedstaat erworben sind vor Beginn der Anwendung der Richtlinie 78/687/EWG, d.h. vor Koordinierung der Mindestanforderungen. Art. 7 verpflichtet die Mitgliedstaaten zur Anerkennung dieser "Altdiplome" soweit der Diplominhaber über eine Bescheinigung verfügt, daß er in den letzten fünf Jahren mindestens drei Jahre die betreffende Tätigkeit ununterbrochen tatsächlich und rechtmäßig ausgeuibt hat. Die Frage des vorlegenden Gerichtes zielte darauf, ob Drittstaatsdiplome, die in einem der Mitgliedstaaten anerkannt sind ebenfalls in den Anwendungsbereich des Art. 7 der Richtlinie 78/686/EWG fallen.

Der Gerichtshof hat diese Frage äußerst bündig beantwortet. In seiner Rechtserwägung Rdnr. 14 stellt er lapidar fest: "Art. 7 betrifft nur die von den Mitgliedstaaten ausgestellten Diplome". Zuvor hatte der EuGH wie bereits in der Sache Haim darauf hingewiesen, daß das automatische Anerkennungssystem der Richtlinie 78/686/EWG darauf beruht, daß mit der Richtlinie 78/687/EWG gleichzeitig die Mindestanforderumgen festgestellt wurden, denen die Zahnarztausbildung in den einzelnen Mitgliedstaaten genügen muß ${ }^{423}$. Gerade diese Koordinierung der Ausbildungsworaussetzungen fehlt jedoch im Verhältnis zu Drittstaaten grundsätzlich. Sie kann lediglich durch den Abschluß von Abkommen zwischen dem jeweiligen Mitgliedstaat und Drittstaaten bewirkt werden. Hieraus ergibt sich auch die Konsequenz des Art. 1 Abs. 4 der Richtlinie 78/687/EWG, wonach jeder Mitgliedstaat selbst die Anerkennung von Drittstaatsdiplomen gestatten, aber auch verweigern kann. Die Frage des vorlegenden Gerichts hat der EuGH dahingehend beantwortet, daß nach Art. 7 der Richtlinie 78/686/EWG die Mitgliedstaaten nicht verpflichtet sind, Drittstaatsdiplome anzuerkennen.

Mit dieser Entscheidung hat der Gerichtshof die Ansicht zur Interpretation won Art. 1 Abs. 4 der Richtlinie 78/686/EWG der Kommission, die bereits in einer Antwort auf

422. Uneil vom 9. Februar 1994, Rs C-154/93 - Abdullah Tawil-Albertini/Ministere des Affaires sociales. Sig. 1994, I-4511.

423. Urtell wom 9. Februar 1994, Rs C-154/93 - Abdullah Tawil-Albertini/Ministre des Affaires sociales Slg. $1994,1-451$ (463) Rdnr. 11. 
eine schriftliche Anfrage eines Abgeordneten des Europäischen Parlaments niedergelegt worden ist, bestätigt: "Die automatische Anerkennung beruht nämlich auf Verfahren, die das gegenseitige Vertrauen đer Mitgliedstaaten gewährleisten...". "Aus Art. 1 Abs. 4 geht hervor, daß die Mitgliedstaaten nicht bereit waren - und noch immer nicht bereit sind -, einer in einem Drittland erworbenen Ausbildung dasselbe Vertrauen entgegenzubringen, da der Mitgliedstaat, der diese Ausbildung anerkennt, diese nicht in der gleichen Weise wie die in seinem Gebiet absolvierte Ausbildung überwachen kann $^{424 " . ~ D a ~ d a s ~ w o r l e g e n d e ~ G e r i c h t ~ k e i n e ~ F r a g e ~ h i n s i c h t l i c h ~ d e r ~ B e r u ̈ c k s i c h t i g u n g ~}$ der Berufserfahrung des Betroffenen gestellt hat, sah der Gerichtshof anscheinend keine Notwendigkeit, diesen Punkt im vorliegenden Verfahren zu erörtern.

\section{o. Die Rechtssache Scholz ${ }^{425}$}

Die Rechtssache Scholz betrifft keine Frage der Niederlassungsfreiheit, sondern die Werknehmerfreizügigkeit. Die Entscheidung ist jedoch für die Berücksichtigung der früheren Berufstätigkeil in einem anderen Mitgliedstaat von großer Bedeutung. Da gerade diese Frage sowohl bei der Anwendung der Vlassopoulou-Rechtsprechung als auch bei der Durchführung der Richtlinie 89/48/EWG eine zentrale Rolle spielt, ist die Besprechung dieser Entscheidung an dieser Stelle gerechtfertigt. Der Rechtsstreit betraf die Anstellung einer Kantinenbediensteten an der Universität Cagliari. Im Anstellungsverfahren wurde an Bewerber Pluspunkte vergeben, soweit sie früher in der öffentlichen Verwaltung beschäftigt waren. Eine der nicht erfolgreichen Bewerberinnen war Ingetraud Scholz, eine gebürtige Deutsche, die durch Eheschließung die italienische Staatsangehörigkeit erworben hatte. Frau Scholz war von 1965 bis 1972 bei der deutschen Postbehörde als Postbedienstete beschäftigt. Sie verlangte, daß diese Berufserfahrung bei ihrer Bewerbung mit zu berücksichtigen sei. Dagegen vertrat der Auswahlausschuß die Ansicht, daß lediglich eine in der öfentlichen Verwaltung Italiens erworbene Berufserfahrung Berücksichtigung finden müsse. Aufgrund dieser Einstufung wurde die Einstellung von Ingetraud Scholz als Kantinenbedienstete verhindert. Gegen diese Entscheidung hat sie Klage beim zuständigen Verwaltungsgericht erhoben. Dieses hat dem Gerichtshof folgende Frage zur Vorabentscheidung vorgelegt:

"Sind die Art. 7 und 48 EWG-Vertrag sowie Art. 1 und 3 der Verordnung Nr. 1612/68 dahingehend auszulegen, daß sie es verbieten, daß bei einem offentlichen Auswahlverfahren zur Besetzung von Stellen, die nicht zu denjenigen gehören, für die der Vorbehalt des Art. 48 Abs. 4 EWG-Vertrag gilt, der Berufstätigkeit in einer öffentlichen Verwaltung eines anderen Mitgliedstaats jede Bedeutung abgesprochen wird, wenn die Berufstätigkeit in einer Verwaltung des Staates, in dem das Auswahlverfahren ausgeschrieben wird, als brauchbarer Befähigungsnachweis für die endgültige Einstufung in dem Auswahlverfahren berïcksichtigt wird?"

424. Antwort anfif die schriftliche Anfrage Nr. 257/93, ABI. Nr. C 297, 26. Siehe auch die Antwort auf die Anfrage Nr. 690/93, ABI. Nr. C 292, 39.

425. Urteil von 23. Februar 1994. Rs C $419 / 92$ - Ingetraud Scholz/Opera Universitaria di Cagliari and Cinzia Porcedda -. Slg. 1994, 1-505. 
Der Gerïchtshof hat diese Frage bestätigend beantwortet, nämlich dahingehend, daß Art. $48 \mathrm{EGV}$ es tatsächlich den Mitgliedstaaten verbietet, bei der Berücksichtigung der früheren Berufstätigkeit einen Unterschied zu machen, ob diese Tätigkeit im öffenthichen Dienst dieses Mitgliedstaats oder in dem eines anderen Mitgliedstaats ausgeübt worden ist. Der Gerichtshof qualifizierte diese unterschiedliche Behandlung bei der Einstufung als eine nicht gerechtfertigte mittelbare Diskriminierung ${ }^{426}$.

\section{p. Die Rechtssache Kommission gegen Spanien ${ }^{427}$}

Wie bereits die früheren Entscheidungen des EuGH gegen Griechenland, Frankreich und Italien ${ }^{428}$ geht es auch in dieser Rechtssache um Vorschriften zur Tätigkeit von Fremdenführern. Es handelt sich dabei um eine spanische Verordnung aus dem Jahr $1964^{429}$. Nach den Bestimmungen dieser Verordnung durfte der Beruf des Fremdenführers in Spanien nur von den Personen ausgeübt werden, die beim zuständigen Ministerium eine Prüfung abgelegt hatten. Zu dieser Prüfung werden nach Art. 13 Buchstabe a der Verordnung nur Personen mit spanischer Staatsangehörigkeit zugelassen. Unberechtigte Berufsausübung wurde gemäß Art. 7 der Verordnung mit Sanktionen belegt. Ausländische Touristengruppen konnten zwar von einen Reisebegleiter aus dem eigenen Land betreut werden, sie waren aber verpflichtet, wiederum aufgrund Art. 13 a der Verordnung sich durch einen spanischen Fremdenführer-Dolmetscher begleiten zu lassen. Die Kommission beanstandete zunächst, daß das Erfordernis der spanischen Staatsangehörigkeit, um zur Fremdenführerprüfung zugelassen zu werden, mit den Art. 48, 52 und 59 EGV nicht vereinbar ist. Diese Rüge hat der Gerichtshof als evidente Vertragsverletzung bestätigt ${ }^{430}$. die zweite Beanstandung der Kommission betraf die Tatsache, daß Spanien bezüglich Gemeinschaftsbürgern, die in einem anderen Mitgliedstaat das Diplom des Fremdenführers erworben haben, kein Anerkennungsverfahren für diese Qualifikationen anbiete. Die spanische Regierung berief sich hinsichtlich dieser Rüge einerseits auf die zur Durchführung der Richtlinie $75 / 368 /$ EWG $^{431}$ erlassenen Maßnahmen sowie auf die Umsetzung der Richtlinie $89 / 48 / \mathrm{EWG}^{432}$ in Spanien. Auch

426. Unteil vom 23. Februar 1994, Rs C-419/92 - Ingetraud Scholz/Opera Universitaria di Cagliari und Cinzia Porcedda -, Slg. 1994, I-505 (521), Rdnr. 11. Siehe dazu Johnson/O'Keefe, CMLRev. 1994, $1313(1332)$

427. Urteil vom 22. März 1994, Rs C-375/92 - Kommission/Spanien -. Slg. 1994, I-923. Dazu Huglo, RTDE $1994,465(470)$

428. Urteile vom 26. Februar 1991 in den Rechtssiachen C-154/891 - Kommission/Frankreich -n Slg. 1991, I-659, C-180/89 - Kommission/Italien -, Slg. 1991, I-709 und C-198/89 - Kommission/Griechenland-" Slg. 1991, 1-727. Siehe dazu Seite 60.

429. BOE vom 26. Februar 1964.

430. Urteil vom 22. März, 1994, Rs C-375/92 - Kommission/Spanien - Slg. 1994, I-923 (940), Rdnnn 9/10.

431. Richtlinie 75/368/EWG des Rates wom 16. Juni 1975 uber Malsnahmen zur Erleichterung der tatsächlichen Ausubung der Niederlassungsfreiheit und des freien Dienstleistungsverkehts für einige Tätigkeiten (aus ISIC-Hẳuptgruppe 01 bis ISIC-Hauptgruppe 85), insbesondere Übergangsma 3 nathmen für diese Tätigkeiten, ABI. Nr. L 167, 22.

432. Richtinie 89/48/EWG des Rates vom 21. Dezember 1988 ubber eine allgemeine Regelung zur Anerken nung der Hochschuldiplome, die eine mindestens dreijăhrige Berufsausbildung abschließen, A.E. 1989 Nr. L 19 wom 24. Januar 1989,16 
hinsichtlich dieser zweiten Beanstandung bestätügte der Gerichtshof die Verletzung der Art. 48,52 und $59 \mathrm{EGV}$. Hinsichtlich der vorgebrachten Einwendungen Spaniens stellte der Gerichtshof fest, daß der Beruf des Fremdenführers übereinstimmend mit Art. 2 Abs. 5 der Richtlinie $75 / 368 / \mathrm{EWG}$ in der spanischen Umsetzungsregelung ausgenommen war ${ }^{433}$. Die spanische Umsetzung der Richtlinie 89/48/EWG betrefie zwar auch den Beruf des Técnico de Empresas y Actividades Turistica (Fachmann für Unternehmen und Tătigkeiten im Fremdenverkehrsbereich) ${ }^{434}$, dieser Beruf sei jedoch nicht identisch mit demjenigen des Fremdenführers ${ }^{435}$. Als dritten Punkt beanstandete die Kommission unter Berufung auf die Fremdenführenurteile ${ }^{436}$, daß das Erfordernis einer Gewerbeerlaubnis, deren Erteilung die Absolvierung einer mit einer Prüfung abgeschlossenen Berufsausbildung voraussetze, mit Art. 59 EGV nicht vereinbar sei. Zu diesem Punkt bestätigte der Gerichtshof seine bisherige Rechtsprechung, wobei er eine Formulierung wählte, die beinahe wörtlich mit der im Urteil Kommission gegen Griechenland ${ }^{437}$ übereinstimmt ${ }^{438}$. Danach verstöß die spanische Regelung grundsä́tzlich gegen Art. $59 \mathrm{EGV}$, soweit die Dienstleistungen darin bestehen, die betreffenden Touristen an anderen Orten zu führen als in Museen oder an Geschichtsdenkmälern, die nur mit einem spezialisierten berufsmäßigen Fremdenführer besichtigt werden können. Als letzten Punkt beanstandete die Kommission die Tatsache, daß Spanien auch nach wiederholter Aufforderung der Kommission nicht die Rechtsvorschriften übermittelt habe, die die Communidades Autönomas auf dem Gebiet der umstrittenen Verordnung von 1964 erlassen haben. Der Gerichtshof bestätigte die Auffassung der Kommission, die hierin einen Verstoß Spaniens gegen Art. 5 EGV sah.

\section{q. Die Rechtssache Schindier ${ }^{439}$}

Die Rechtssache Schindler betraf die Beurteilung nationaler Vorschriften, die die Durchführung bestimmter Lotterien im Gebiet eines Mitgliedstaats verbieten. Der Rechtsstreit betraf die Beschlagnahme von Werbematerial für die Süddeutsche Klassenlotterie aufgrund britischer Rechtsvorschriften. Diese enthieiten ein allgemeines Verbot von Lotterieveranstaltungen. Von diesem Verbot waren lediglich örtliche Lotterien ausgenommen soweit ihr Gewinn gemeimü̈tzigen Zwecken zufloß. Nationale Lotterien waren ver-

433. Siche Art. 2 Buchstabe tes Königlichen Dekrets Nr. 439 vom 30 . April 1992, BOE $\mathbb{N r}$. 11 vom 8. Mai 1992.

434. Könghliches Dekret Nr. 76.7 vom 26. Juni 1992, BOE $\mathrm{Nr}$. 170 vam 16. Juli 1992 iWm Dekret Nr. 1665 von 25. Oktober 1991, BOE $\mathrm{Nr} .80$ vom 22. November 1991.

435. Urteil vom 22. März 1994, Rs C-375/92 - Konmission/Spanien -r Slg. 1994, I-923 (942), Rdnr. $16 / 17$.

436. Urtelle wom 26. Februar 1991 in den Rechtssachen C-154/89 - Kormission/Frankre 1-659; C-180/89 - Kommission/Italien -, S1g. 1991, 1-709 und C-198/89 - Kormmission/Griechenland-. Sig. $1991,1-727$.

437. Urteil vom 26. Februar 1991Rs C-198/89- Kommission/Griechentand-, S1g. 1991, 1-727, Rdnr. 2.

438. Urteil vom 22. Mârz 1994, Rs C-375/92 - Kommission/Spanien -, SIg. 1994, I-923 (943) Rdnr.21.

439. Urteil vorn 24. Marz 1994, Rs 275/92 - Her Majesty's Customs and Exercise/G. und J. Schindler, Slg. 1994, I-1039. EuZZW 1994, 311 mit einer Anmerkwng von Stein; Gormley, ELR 1994, 644" Sedemund/Montag. NJW 1995, 1126 (1128), 
boten, ebenso der Verkauf von Losen für ausländische Lotterien und deren Vermarktung ${ }^{400}$. Nachdem der Gerichtshof zunächst die Anwendung der Vorschriften des Warenverkehrs, der Freizïgigkeit und des Kapitalverkehrs auf den vorliegenden Rechtsstreit verneint hatte ${ }^{44 !}$, mußte er sich mit der Frage auseinandersetzen, ob die britische Regelung eine Beschränkung des Dienstleistungsverkehrs darstellt. Unter Verweisung auf seine Rechtsprechung in der Sache Säger ${ }^{442}$ stellte der Gerichtshof erneut und unmißverständlich fest, daß nationale Rechtsvorschriften selbst bei unterschiedsloser Geltung unter Art. 59 EGV fallen, wenn sie geeignet sind, die Tătigkeit des Dienstleistenden, der in einem anderen Mitgliedstaat ansässig ist und dort rechtmäßig ähnliche Dienstleistungen erbringt, zu behindern ${ }^{443}$. Nach dieser Festsstellung mußte der Gerichtshof die Frage beantworten, ob die strittigen Rechtsvorschriften im Hinblick auf zwingende Gründe des Allgemeininteresses gerechtfertigt und verhåltnismäßig waren. Alle intervenierenden Regierungen hatten Rechtfertigungsgründe wie Verbraucherschutz, Verbrechensbekämpfung, Schutz der öffentlichen Sittlichkeit, Begrenzung der Nachfrage von Glückspielen angeführt, die einschränkende nationale Maßnahmen rechtfertigen. Dagegen vertrat die Kommission die Auffassung, daß ein Lotterieverbot wie im britischen Recht, selbst wenn es auf zwingenden Gründen des Allgemeininteresses beruhe, nicht mit Art. 59 EGV vereinbar sei, da die Ziele, die es verfolge, mit weniger einschneidenden Mitteln erreicht werden könnten. Der Gerichtshof war damit deutlich gerufen, nicht nur zu den Rechtfertigungsgründen als solchen Stellung zu nehmen, sondern vor allem die Verhältnismäßigkeit der einschränkenden Maßnahme zu überprüfen. Unter Berufung auf die besondere Natur der Lotterien stellte der Gerïchtshof fest, daß Gründe der Sozialpolitik und der Betrugsbekämpfung, auch ein nationales Einfuhrverbot von Werbematerial für ausländische Lotterien rechtfertigen können. Ein solches Einfuhrverbot sei nämlich für den Schutz erforderlich, den der Mitgliedstaat in seinem Gebiet sicherstellen will ${ }^{444}$. Bedauerlicherweise ging der Gerichtshof an dieser Stelle nicht deutlicher auf das Vorbringen der Kommission ein, die weniger einschneidende Maßnahmen als ein totales Einfuhrverbot, für ebenso geeignet ansah, die gerechtfertigten Ziele zu erreichen.

\section{F. Bedeutung dieser ReChtsprechung für die ANERKENNUNG VON DiPLOMEN}

Bei der Analyse der Rechtsprechung standen vier Problembereiche im Mittelpunkt: Zunächst wurde die Entwicklung der Rechtsprechung in drei Zeitabschnitten hinsichtlich der Frage untersucht, ob Art. 52 EGV nicht nur offen und versteckt diskriminierende

440. Mit Gesetz vom 21. Oktober 1993 hat sich dieser Rechtszustand in Großbritannien gmunsätzlich geảndert (National Lottery etc. Act 1993).

441. Urteil vom 24. März 1994, Rs 275/92 - Her Majesty"s Customs and Exercise/G. und J. Schindler, Slg. 1994. I-1039, Rdnr. 30.

442. Unteil vom 25. Juli 1991, Rs C-76/90 - Säger/Dennemeyer -, Slg. 1991, 1-4221, Rdnr, 12.

443. Urteill vom 24. Márz 1994, Rs 275/92 - Her Majesty"s Customs and ExerciselG. und J. Schindler, SIg. 1994, I-1039, Rdnr. 43.

444. Urteil vom 24. März 1994, Rs 275/92 - Her Majesty's Customs and Exercise/G. und J. Schindler, Slg. 1994, 1-1039, Rdinr. 62. 
nationale Maßnahmen verbietel, sondern auch Beschränkungen, die unterschiedslos angewendet werden?

Bis zu den Entscheidungen Vlassopoulou, Newman, Ramrath und Kraus, d.h. bis zu Beginn der neunziger Jahre, war die Mehrheit in der Literatur ${ }^{445}$ zu Recht davon ausgegangen, daß der Gerichtshof grundsätzlich die Niederlassungsfreiheit als ein zwar sehr umfassendes Diskriminierungsverbot interpretiert ${ }^{446}$, obwohl die ersten Ansätze zu einem darüber hinausreichenden Beschränkungsverbot vor allem bei der Entscheidung gegen Frankreich ${ }^{44}$ sowie im Urteil Heylens ${ }^{448}$ für die Freizügigkeit von Arbeitnehmern bereits $1986 \mathrm{zu}$ konstatieren sind. Diese Entscheidungen waren jedoch in ihrer Aussage noch nïcht deutlich und konstant genug. Es schien vielmehr so, als ob der Gerichtshof den zuvor gemachten Schritt woran mit der Entscheidung in der Rechtssache gegen Belgien wieder zurücknehmen wollte ${ }^{49}$. Die Urteile Vlassopulou, Newman, Ramrath und Kraus dagegen haben eine Entwicklung eingeleitet, die weit über die Ansätze der achtziger Jahre hinausgeht, und die in ihrer Folge auch eine deutliche Kontinuität angibt. Den letzten Schritt zu einem Verbot unterschiedlos angewendeter Beschränkungen - soweit sie nicht durch zwingende Allgemeininteressen gegefertigt werden können - hat der Gerichtshof in der Entscheidung Kraus ${ }^{450}$ gesetzt. Dieses Urteil ist im März 1993 ergangen, d.h. zwei Monate nach der in Art. 7a EGV gebotenen Vollendung des Binnenmarkts. Dieser zeitliche Zusammenhang ist meines Erachtens nicht rein zufällig. Wie bereits das Ende der Übergangsperiode 1970 in der Rechtsprechung Anlaß zu grundllegenden Entscheidungen bezüglich der Personenverkehrsfreiheit geboten hat, scheinen nunmehr die Freizügigkeitsrechte im Lichte der Binnenmarktkonzeption interpretiert zu werden, d.h. in zunehmendem Maße wird das Herkunftsstaatsprinzip zum entscheidenden Faktor. Diese Entwicklung hat sich zeitlich mit Beginn der neunziger Jahre herauskristallisiert, wobei alle drei Formen der Personenverkehrsfreiheiten, d.h. die Niederlassungsfreiheit, die Freizügigkeit für Arbeitnehmer und die Dienstleistungsfreiheit, diese Entwicklung parallel vollzogen haben. In der Rechtssache Ramrath überließ es der Gerichtshof dem nationalen Gericht die Abgrenzung zu treffen, ohne dabei selbst unterschiedliche Konsequenzen für den jeweiligen Freizügigkeitsbereich zu ziehen. Damit hat der Gerichtshof konkludent die Parallelität der Personenverkehrsfreiheiten unterstelti ${ }^{451}$.

445. Everling 58. DJT, C 43 ff. Everling, DB 1990, 1853 ff.; Everling, Saarbrücken 1990, 19 ff.; Hailbronner, JuS 1991, 917 (919): Hailbronner, Handkommentar, Art. 22 Rdnr. 14: Oppermann, Rdnr. 1492; Stadler, 63 ff.; Hailbronner/Nachbaur 1992, 29 ff; Roth in Dauses-Handbuch des EG-Wirtschaftsrechts, E,I, Rdnr. 61 ff; Troberg in: GTE-Konmentar, Art. 52, Rdnr. 37f.; Troberg, GTEHandbuch, Art. 52, 37f.

446. Everling, Saarbrücken 1989; Everling DB 1990, 225 ff. mit weiteren Nachweisen

447. Urteil vom 30. April 1986. Rs 96/85 - Kommission/Frankreich -, Slg. 1986, 1475 ff.

448. Urteil wom 15. Oktober 1987 Rs 222/86 - UNECTEF/Heylens -, Slg. 1987, 4097.

449. Urteil vom 12. Februar 1987, Rs 221/85 - Kommission/Belgien-, Slg. 1987, 719.

450. Urteil vom 23. März 1993, Rs C-19/92 - Dieter Kraus/Land Baden-Württemberg -, Slg. 1993, I-1663.

451. Urteil vom 20. Mai 1992, Rs C-106/91 - Claus Ramrath/Ministre de la Justice -, Sig. 1992, I-3351. 
Mit der Entscheidung Vlassopoulou scheint mir der erste wesentliche Schritt in Richtung eines Beschränkungsverbots gesetzt zu sein, obwohl der Gerichtshof nicht in vollem Umfang den Ausführungen des Generalanwalts Van Gerven gefolgt ist. Interessanterweise ist dieser entscheidende Schritt noch vor der Entscheidung Dennemeyer für den Dienstleistungsverkehr gemacht worden ${ }^{452}$. Nach der bisherigen Rechtsprechumg in Vlassopoulou, Newman und Kraus bezieht sich dieses Beschränkungsverbot jedoch ausschließlich auf die Aufnahme der Tätigkeit und nicht auf deren Ausübung, es sei denn, es handelt sich um eine Frage der Doppelniederlassung. Insoweit sind die Parallelen zum Waren und Dienstleistungsverkehr nicht weit zu suchen. Auch beim Warenverkehr bezieht sich das Beschränkungsverbot bisher ausschließlich auf Waren, die grenzüberschreitend vom Herkunftsland in den Aufnahmestaat importiert werden. Nur in diesem Zusammenhang gilt die Rechtsprechung zu Art. 30 EGV. Würde der Produzent dagegen versuchen, eine Produktionsstätte im Aufnahmestaat zu errichten, so wäre eine Beibehaltung der Produktionsmethoden nur insoweil garantiert, als sie mit den nationalen Bestimmungen des Aufnahmestaates übereinstimmen. Wäre dies nicht der Fall, so müßte der Produzent eine Umstellung derselben vornehmen. Das Gemeinschaftsrecht böte ihm keinen Schutz und keine Garantie zur Beibehaltung.

Überträgt man nun diesen Gedankengang unter Berücksichtigung der oben dargestellten Rechtsprechung auf die Niederlassungsfreiheit von Selbständigen, so kann man feststellen, daß die Unterschiede gar nicht so groß sind wie häufig dargestellt. Betrifft die streitige nationale Regelung den Zugang zum Beruf, d.h. das grenzüberschreitende Element liegt in dem Übergang von einer nationalen Berufsgruppe zu der eines anderen Mitgliedstaates, dann mu. $\beta$ diese nationale Bestimmung einer Prüfung aufgrund des Verhältnismäßigkeitsprinzips unterworfen werden. Handelt es sich dagegen bei der nationalen Bestimmung um eine Berufsausübungsregel, so muß die Person, die sich niedergelassen und sich damit in das wirtschaftliche Leben des Aufnahmestaates integriert hat, sich diese Regel entgegenhalten lassen, solange dies in einer nicht diskriminierenden Weise geschieht. Für diesen Fall gilt das Aufnahmestaats- und nicht das Herkunftstandprinzip. Von diesem Grundsatz ist der Gerichtshof allerdings in der Sache Alluẻ II in gewisser Hinsicht bezüglich Art. 48 EGV abgewichen ${ }^{453}$. Die streitige italienische Regelung betraf die Dauer des Vertragsverhältnisses von Fremdsprachenlektoren. Man könnte diese Regelung als eine Berufsausübungsbestimmung qualifizieren, obwohl sie auch bei der Entscheidung des Migranten zur Aufnahme der Tätigkeit von entscheidender Bedeutung ist. Der Zugang zum Beruf wird durch die gesetzlich festgelegte Dauer des Arbeitsverhältnisses mitbestimmt. Auch hatte die Regelung versteckt diskriminierende Merkmale. Unter dieser Gesamtbetrachtung läßt sich auch die Entscheidung Allué II in der vorgenommenen Weise klassifizieren und muß daher nicht als eine Ausnahme qualifiziert werden.

452. Urteil vom 25. Jull 1991, Rs C-76\%90- Manfred Sager/Dennemeyer \& Co. Lad -, S\$g. 1991 . $1-4221$.

453. Urteil vom 2. August 1993, verbundene Rs C-259, 331 und 332/91 - Allué, Coonan u.a. "Rür. 1819. 


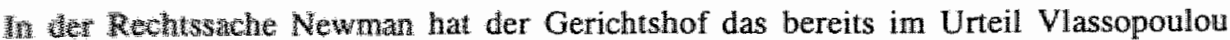

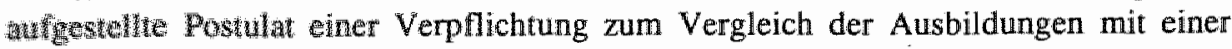

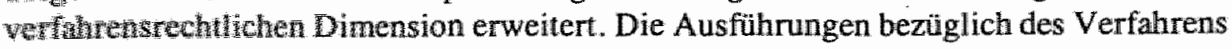
2ed cken Vergetehsprutung mit dem lapidaren Hinweis auf die unterschiedlichen Regelungs-

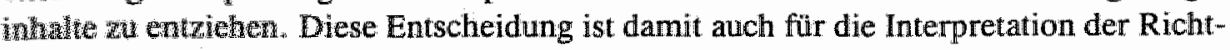
Ime 35/48/EWG und der darin festgelegten Verfahrensvorschriften von Bedeu-

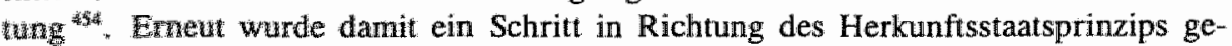
㪍ache Deduthangsnachweises sowie die Zulassung zum Beruf zu erfolgen hat. Dabei muß die getwotene Entscheidung und die gegebene Begründung einer gerichtlichen Überprüfung standhalten kơmen. Die Forderung nach einer begründeten Entscheidung sowie nach Gewä:mang einer gerichtlichen Überprüfung dieser Entscheidung ist für die Interpretathon der Richtlinie 89/48/EWG von großer Bedeutung. Gemäß Art. 8 Abs. 2 der Hochschulrchthie sind die Mitgliedstaaten ebenfalls verpflichtet, ihre Entscheidung mit Grinden zu versehen und einen gerichtlichen Rechtsbehelf gegen die Entscheidung selbst oder gegen ihre Unterlassung zu gewähren ${ }^{455}$. Durch die Entscheidung Newman wird an diese formale Verpflichtung eine inhaltliche Dimension geknüpft, die die zuständigen Behörden bei ihren Entscheidungen nicht unberüicksichtigt lassen können. Vielmehr müssen auch die nationalen Gerichte bei der Überprüfung der Anerkennungsentscheidungen den vom EuGH gesetzten Maßstab zugrundelegen.

Die mit der Entscheidung Kraus gezogene Parallele zwischen dem Umfang der Dienstleistungsfreiheit einerseits und der Freizügigkeit sowie der Niederlassungsfreiheit andererseits wird in Zukunft auch bei Anerkennungsentscheidungen eine Rolle spielen. Mitgliedstaaten werden, wenn keine schwerwiegenden Allgemeininteressen betroffen sind, die Anerkennung eines Diploms nicht grundsätzlich weigern können, selbst wenn ein solches nicht in vollem Umfang in den Regelungsbereich der allgemeinen Anerkennungsrichtlinien fällt. Aber auch bei Diplomen, die von der in der Richtlinie gegebenen Definition etfaßt sind, wird die Anerkennung unter Berücksichtigung dieser Rechtsprechung zu erfolgen haben. Dieser Schluß läßt sich zumindest aus der Entscheidung Haim ziehen, worn der Gerichtshof die Verpflichtung zur Berüicksichtigung von gewonnener Berufserfahrung auch bei Vorliegen und Anwendbarkeit einer Anerkennungsrichtlinie grundsätzlich gemäß Art. $52 \mathrm{EGV}$ bestätigte ${ }^{4.56}$. Konsequenzen können sich dabei vor allem für die Zulässigkeit der Forderung nach Kompensation bei zeitlich oder inhaltlich abweichenden Ausbildungen ergeben ${ }^{457}$.

454. Siehe dazu die Ausführungen Seitte 203 .

455. Siehe dazu die Erörtenungen Seite 203.

456. Urteil vom 91. Februar 1994, Rs C-319/92 - Salomone Haim/Kassenzahnärztliche Vereinigung Nordrhein -, Sig, 1-425. Insoweit kann der Ansicht von Sedemund/Montag, NJW 1994, 630, wonach die ausländischen Anwälte seit der Unsetzung der Richtlinie 89/48/EWG in einer schlechteren Lage sich befinden sollen, nicht gefolgt werden. Auch nach der Umsetzung der Richtlinie 89/48/EWG in das nationale Recht sind die Behörden grundsätzlich zu einer Prüfung der Gleichwertigkeit der Diplome bzw. sonstigen Kenntnisse verpflichtet.

457. Siehe dazu die Erörtenngen zu Ant. 4 der Richtlinie $89 / 48 /$ EWG auf Seite 193 . 
Die Rechtssache Scholz ${ }^{458}$ hat zwar keinen direkten Beitrag zur Entscheidung bezïg\ich der Zulässigkeit von nichtdiskriminierenden Beschränkungen geliefert, da der Gerichtshof die Nichtberücksichtigung der in einem anderen Mitgliedstaat erworbenen Berufserfahrung als eine mittelbare Form der Diskriminierung eingestuft hat, dennoch ist das Urteil in diesem Zusammenhang von großer Bedeutung für die Anwendung der in Vlassopoulou und Newman entwickelte Grundsătze auf die Arbeitnehmer im öffentlichen Dienst.

Läßt sich somit die erste Frage zusammenfassend dahingehend beantworten, daß der Gerichtshof nunmehr die Grundfreiheiten des Personenverkehrs als allgemeines Beschränkungsverbot interpretiert, so muß diese Beurteilung jedoch mit einer gewissen Einschränkung versehen werden. Grundsätzlich kann man erwarten, daß der Gerichtshof aus der Entwicklung seiner Rechtsprechung zur Warenverkehrsfreiheit Lehren gezogen hat ${ }^{459}$. Die im Urteil Keck ${ }^{460}$ explizit gewordene Relativierung der DassonvilleFormel wird vermutlich auch für die Personenverkehrsfreiheiten Früchte abwerfen ${ }^{46}$. Dies bedeutet, daß damit innerstaatliche Regelungen, die nur einen äußerst entfernten Bezug zum innergemeinschaftlichen Personenverkehr haben - diesen jedoch nicht ein deutig behindern -, nicht unter das Beschränkungsverbot fallen werden ${ }^{462}$. Damit bleibt für die Mitgliedstaaten die Möglichkeit, historisch gewachsene und kulturell begründete Beruffs- und Standesregeln zu erhalten, soweit diese nicht die Niederlassungsfreiheit und den Dienstleistungsverkehr behindern oder gar gefährden.

Die zweite untersuchte Frage betraf das vom Gerichtshof entwickelte Verhältnismäßigkeitsprimzip ${ }^{463}$. Bereits in seiner ersten Entscheidung zur Dienstleistungsfreiheit hat der Gerichtshof eine grundsätzliche Einschränkung der Freiheit im Falle allgemeiner Interessen zugelassen: "In Anbetracht der Besonderheit der Dienstleistungen dürfen jedoch diejenigen an den Dienstleistungserbringer gestellten besonderen Anforderungen nicht als mit dem Vertrag unvereinbar angesehen werden, die sich aus der Anwendung durch das allgemeine Interesse gerechtfertigter Berufsregelungen - namentlich der Vorschriften über Organisation, Befähigung, Berufspflichten, Kontrolle, Verantwortung und Haftung - ergeben und die für alle im Gebiet des Staates, in dem die Leistung erbracht wird, ansässigen Personen verbindlich sind" 464. Im Anschluß an die Ent-

458. Urteil vom 23. Februar 1994, Rs C-419/92 - Ingetraud Scholz/Opera Universitaria di Cagliari und Cinzia Porcedda. Sig. 1994, -505

459. Steiner, CMLRey. 1992,749. Zur Neuorientierung des Europäischen Gerichtshofs siehe auch Joliet, JTDE 1994, 145

460. Urteil vom 24. Nowember 1993. Rs C-267/91 und C-268/91 - Keck und Mithouard -. Sig, 1993. I.

461. Dubach, DVBI. 1995, 595 (603).

462. Alnnlich auch Wouters in Wouters/Schneider, $101(117 / 118)$.

463. Dazu Usher, ELR 1975, 359ff; Schiller, RIW 1983, 928; Arnull., 70, ff.; Wyatt/Dashwood, 89f Schwarze 1988, Bd. II, 661 ff. Mattera, Rev. Marché unique eur. 1991, 191; de Burca, YbEL 1993. 105.

464. Urteil vom 3. Dezember 1974, Rs 33/74 - J.H.M. van Binsbergen/Bestuur van de Bedrijfswereniging voor Metaalnijverheid -, Slg. 1974, 1299. 
scheidung van Binsbergen hat der Gerichtshof diesen Grundsatz weiterentwickelt ${ }^{465}$. Welche Beschränkungen sind nun aufgrund zwingender Allgemeininteressen gerechtfertigt? Wann können derartige nationale Maßnahmen als geeignet, erforderlich und verhältnismäßig angesehen werden, um einen Eingriff in die Freiheitsrechte zu rechtfertigen?

In der Entscheidung Stichting Collectieve Antennevoorziening Gouda u.a. gegen Commisariaat voor de Media ${ }^{466}$, ein Urteil, das nur zwei Monate nach der Entscheidung Vlassopoulou und zeitgleich mit der Entscheidung Dennemeyer verkündet wurde, gab der Gerichtshof hinsichtlich der Dienstleistungsfreiheit unter Verweisung auf seine bisherige Rechtsprechung eine Übersicht der Bereiche, die als zwingende Allgemeininteressen angenommen werden können. Nach dieser Auflistung gilt dies für bestimmte

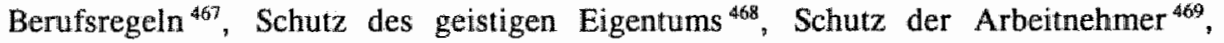
Schutz der Verbraucher ${ }^{470}$, die Erhaltung des nationalen historischen und künstlerischen Erbes ${ }^{471}$, die Aufwertung der archäologischen, historischen und künstlerischen Reichtümer und die bestmögliche Verbreitung von Kenntnissen über das künstlerische Erbe des Landes ${ }^{472}$. In der Entscheidung Goudla antwortete der Gerichtshof auf die vorgelegte Frage, daß auch eine nationale Kulturpolitik zur Erhaltung einer pluralistischen Meinungsfreiheit grundsätzlich einen zwingenden Grund des Allgemeininteresses darstellen könne ${ }^{473}$. In der Sache Schindler akzeptierte der Gerichtshof schließlich Gründe der Sozialpolitik und der Betrugsbekämpfung als derartige zwingende Allgemeininteressen ${ }^{474}$. Alle diese Entscheidungen betreffen die Dienstleistungsfreiheit, können jedoch grundsätzlich auf die Niederlassungsfreiheit übertragen werden.

46.5. Zu Art. 48 EGV stehe in diesem Zusammenhang das Urteil wom 2. August 1993, verbundene Rs C259/91 und C-331/91. Allue und Coonan u.a. - JZ2 1994, 94 mit einer Anmerkung von Steindorff sowie das Urteil wom 20. Oktober 1993, Rs C-72/92 - Spotti/Bayern - (noch nicht veroffentlicht).

466. Unteil wom 25. Juli 1991, Rs C-288/89. Stichting Collectieve Antennevoorziening Gouda u.a./ Com musariat woor de Media -, Slg. 1991, [-4007, Rdnr.14.

467. Urteil vom 18 . Jamuar 1979 in den Rechtssachen $110 / 78$ und $11 / 78$ - Ministère public und Chambre Synicale des Agents artistiques et Impresarii de Belgique, ASBL/Willy wan Wesemael und andlere - . Slg. 1979, 35, Rdnr, 28

468. Urteil vom 18. Matz 1980, Rs 62/79-Coditel - Slig. 1980, 881

469. Urteil vom 17. Dezember 1981, Rs 179/80 - Webb -, Slg. 1981, 3305, Rdur, 19; Urteil vam 3. Februar 1982, verbundene Rs 62/8॥ und 63/81-Seco - Sig. 1982, 223, Rdnr 14; Urteil wom 27 März 1990, Rs C-113/89-Rush Portugesa -, Slg. 1990, 1-1417, Rdar. 18.

470. Urteile vom 4. Dezember 1986, Rs 220/83 - Konmission/Frankreich, Slg. 1986, 3663, Rdnr. 20; Rs 252/83 - Kommission/Dänemark -, Slg. 1986, 3713, Rdnr. 20; Rs 205/84 - Kommission/ Dentschland -. Slg. 1986, 3755, Rdnr. 30; Rs 206/84 - Kommuission/Irland -, Slg. 3817, Rdnr. 20; Urteile vom 26. Februar 1991, C-180/89 - Kommission/Lalien - Slg. 1991, I-709, Rdnt. 20 und C-198/89-Kommission/Griechenland -, Slg. 1991, I-727, Rdnr. 21.

471. Urteil vom 26. Febnar 1991, C-180/89 - Kommission/Italien ", Slg. 19911, I-709, Rdnr. 20.

472. Urteile vom 26. Februar 1991, C-154/89 - Kommission/Frankreich \%, Sig. 1991, 1-659, Rdinr. 17; C. 198/89 - Kommission/Griechenland -, Slg, 1991, 1-727, Rdnr. 211.

473. Unteil vom 25. Juli 1991 , Rs C-288/89 - Stichting Collectieve Antennevoorziening Gouda u.a. $/$ Commisariaat voor de Media -, Slg. 1991, 1-4007, Rdnr. 23.

474. Urteil wom 24. März 1994, Rs 275/92 - Her Majesty's Customs and Exercise/G. wnd I. Schindler, Slg. 1994, 1-1039. 
In der Rechtssache Kraus ${ }^{475}$ wurde diese Liste durch das schutzwürdige Interesse an einer kontrollierten Titelführung zur Vorbeugung von Betrug ergänzt ${ }^{476}$. Zuvor hatte der Gerichthof bereits in der Rechtssache Kommission gegen Frankreich ${ }^{\text {on }}$ die Schutzwürdigkeit der Kontinuität der Krankenversorgung anerkannt, ohne dabei jedoch diese als zwingendes Allgemeininteresse zu bezeichnen. Dagegen sind weder wirtschaftliche Ziele noch Erwägungen administrativer Art, beispielsweise die Arbeitserleichterung für die Behörden des Aufnahmelandes, als Rechtfertigungsgründe zulässig ${ }^{478}$.

Bei Betrachtung dieser Auflistung könmen in Fragen der Anerkennung von Diplomen in Zukunft die folgenden Allgemeininteressen von Bedeutung sein:

Eindeutig gilt dies für die kontrollierte Titelführung. In der Rechtssache Kraus wurde dieses Allgemeininteresse an einer kontrollierten Titelführung lediglich für die akademische Titelführung anerkannt. Dieses läßt sich jedoch ohne weiteres auf die Berufstitelführung übertragen, zumal der Verbraucherschutz in diesem Falle größer ist als bei rein akademischer Titelführung. Neben dem Verbraucherschutz, dem Schutz bestimmter Berufsregeln könnte auch der Schutz nationaler kulturpolitischer Interessen für die Anerkennung von Diplomen von Bedeutung werden. Dagegen lassen sich administrative Schwierigkeiten bei der Beurteilung der unterschiedlichen Quallifikationen sowie der entsprechenden Berufserfahrung nicht zur Rechtfertigung anführen.

Auch bei Vorliegen eines Allgemeininteresses muß die Maßnahme als solche jedoch verhältnismäßig sein ${ }^{479}$. Der Gerichtshof batte in verschiedenen Entscheidungen die Gelegenheit darauf hinzuweisen, daß eine nationale Maßnahme selbst bei Vorliegen eines zwingenden Allgemeininteresses nur dann die Proportionalitätsprüfung erfolgreich besteht, wenn die Regelung geeignet, erforderlich und verhältnismäßig ist, das gegebene Allgemeininteresse zu schützen ${ }^{480}$. In der Rechtssache Kraus hat der Gerichtshof meines Erachtens diese zwingenden Voraussetzungen nicht genügend unterstrichen. Gerade die Frage nach der Erforderlichkeit und der Verhältnismäßigkeit des nationalen Genehmigungsverfahrens hätte eine kritischere Prüfung durchaus gerechtfertigt ${ }^{4811}$. Dies hatte zur Folge, daß auch das nationale Verwaltungsgericht den Proportionalitätstest nur unzulänglich durchgeführt hat. Dagegen hat der Gerichtshof in der Rechtssache Allué II die italienische Regelung einer strengen Proportionalitätsprüfung unterworfen. Dabei hat der Gerichtshof festgestellt, daf̧ eine etwaige Kündigung überzähliger I.ektoren im Falle ungenügender finanzieller Mittel für die Freizügigkeit der Arbeitnehmer weniger

475. Urteil vom 23. März 1993, Rs C-19/92 - Dieter Kraus/Land Baden-Würtemberg, Slg. 1993, 11663

476. Hierzu bereits das Urteil vom 27. September 1989. Rs. 130/88 - Van de Bujl -, Slg. 1989, 3039

477. Urteil vom 30. Aprill 1986, Rs 96/85-Kommissiom/Frankreich *, Sig. 1986, 1475 ff. .

478. Sedemund/Montag. NJW 1994, 625 (631) mit weiteren Hinweisen auf die Rechtsprechumg.

479. Zum VerhälmismäBigkeitspininzip in diesem Sinne de BurcA, YbEL 1993, 105 (126 ff.). Siehe auch Vam Gerven in $\mathbb{F S}$ Schoordijk, $75 \mathrm{ff}$; Van Gerven. RM Thems, 1995, 233.

480. Unteall vom 2. August 1993, verbundene $\mathbb{R s}$ C-259, 331 und 332/91-Allué Coonan u. *a. "SIg. 1993, I 4309 Rdnr. $18 / 19$.

481. Huglo, RTDE 1993, 655 (658). 
beschrämkend sei als eine grundsätzliche Begrenzung der Vertragsdauer auf ein Jahr ${ }^{482}$.

Der dritte untersuchte Fragenkomplex betrifft die Stellung der Inländer. Der Gerichtshof hat in ständiger Rechtsprechung Sachverhalte, die keine gemeinschaftsrelevanten Berührungspunkte aufwiesen, streng abgewiesen ${ }^{483}$. Hieraus entwickelte sich eine unter dem Stichwort "umgekehrte Diskriminierung" häufig diskutierte und bisher nicht befriedigend gelöste Problematik ${ }^{48}$. Gerade die vergleichbaren Sachverhalte in den Rechtssachen Lópes Brea, Ferrer Laderer und Newman zeigen besonders deutlich wie unbefriedigend dieser Lösungsansatz ist. In den ersten beiden Entscheidungen lehnte der Gerichtshof die Anwendung des Gemeinschaftsrechts ab, da es sich nach Ansicht des Gerichtshofs um rein interne Angelegenheiten handelte. Dagegen kamen in der Rechtssache Newman auch die spanischen Beteiligten in den Genuß der Entscheidung, weil das gemeinschaftsrechtlich relevante Element in der Tatsache zu sehen war, daß ein britischer Staatsangehöriger betroffen war. Auch die Entscheidung in der Rechtsache Werner kann in dieser Hinsicht nicht überzeugen ${ }^{485}$. Hätte Herr Werner behauptet, in seinem Privathaus gelegentlich Patienten zu empfangen und zu behandeln, so hätte einer Anwendung des Gemeinschaftsrechts nichts im Wege gestanden. Dann hätte er sich nämlich jedenfalls auf die Bestimmungen der Dienstleistungsfreiheit gemäß der Art. 59 EGV ff. berufen kônnen ${ }^{486}$.

Im Rahmen der Niederlassungsfreiheit mußte der Gerichtshof dann eine differenzierte Haltung einnehmen, wenn der Sachverhait Inländer betraf, die selbst von ihren Freizügigkeitsrechten Gebrauch gemacht hatten und, die sich bei Rückkehr in den Ursprungs-

482. Urteil vom 2. August 1993, verbundene Rs C-259, 331 und 332/91 - Allué, Coonan u.a. -, S1g. 1993, II $\sim 309$ Ranr. $18 / 19$.

483. Suăndige Rechtsprechung seit dem Urteil vom 28. März 1979, Rs 175/78 - Saunders *, Slg. 1979, 1129. Ahnlich entschied der Gerichtshof auch im Uirteil vom 27 . Oktober $1982-$ R5 35 und $36 / 82$. Morson und Jhanjan -, Sig. 1982, 3723 sowie in der Entscheidung wom 28. Juni 1984, Rs $180 / 83$. Moser/Land Baden-Wurttemberg. SHg. 1984, 2539. In jüngster Zeit wurde in der Rechussache Werner, Urteil vom 26. Januar 1993, Rs C-112/91. Werner \%. Slg. 1993, I-429 erneut festgestellt, da月 die Vertragsbestimmungen micht auf rein interne Sachverhalte Anwendung finden. Siche zu der Entscheidung Werner jedoch die zu Recht kritischen Anmerkungen von Knobbe-Keuk, CMLRev, 1993, 1230.

484. Bleckmann, RIW 1985, 917; Heintzen, EWS 1990, 82 ff; Prütting, JZ 1989, 705 (711f.); Weis, NJW 1983, $2721 \mathrm{f}$.. Siehe allgemein zur Problematik der Inländendiskrimimierung Reitmaier 1984 und Schlachter 1984. Gerade die Entscheidungen Werner, Urteil vom 26. Jamuar 1993, Rs C-112/91, Slg. 1993, I-429 sowie Schumaker, Urteil wom 14. Februar 1995, Rs C-279/93 (noch nicht veröffentlicht, siehe aber EuZW 1995, 177) zeigem im Vergleich wie unbefriedigend dieser Lösungsansatz ist.

485. Entscheidung Werner, Urteil vom 26. Januar 1993, Rs C-112/91, Sig. 1993, 1-429.

486. Zur Amwendung von Art. 59 EGV in der Rechtssache Werner sind die Ausführungen von GA Darmon in seinen Schlußanträgen wesentlich überzeugender. Der Gerichtshof hätte zumindest den Versuch untemehmen können, auf diesem Weg eine befriedigendere Lösung zu finden. Huglo, RTDE 1993, $655(663)$ 
staat zur Durchsetzung ihrer Rechte auf Gemeinschaftsnormen berufen haben ${ }^{487}$. Der Gerichtshof hat sich grundsätzlich dafür entschieden, daß sich ein Angehöriger eines Mitgliedstaats in diesem auf die in einem anderen Mitgliedstaat erworbenen beruflichen Qualifkationen berufen kann, um in seinem eigenen Mitgliedstaat einen reglementierten Beruf auszuüben ${ }^{488}$. Dennoch scheint der Gerichtshof die Befürchtung zu hegen, ein solches Vorgehen könnte zu einem Mißbrauch von Gemeinschaftsrecht führen. Wie die Rechtssachen Gullung und Van der Bijl zeigen, sind derartige Befürchtungen auch nicht prinzipiell von der Hand zu weisen. Dennoch erscheint mir die Grundhaltung des Gerichtshofs kritisierbar. Die zunehmende und erleichterte Migration wird auch die Fälle der Rückmigranten steigen lassen. Es ist nach meiner Meinung mit dem Binnenmarktkonzept nicht vereinbar, diese Gruppe einer grundsätzlichen Prüfung hinsichtlich des Mißbrauchs von Gemeinschaftsrecht zu unterwerfen. Wann müßte man gerade im Falle der Anerkennung von Diplomen von einem "Mißbrauch" sprechen? Läge ein Mißbrauch bereits dann vor, wenn ein Migrant bewußt seine Ausbildung zu einem reglementierten Beruf in einem anderen Mitgliedstaat absolviert, weil diese kürzer oder leichter ist, um anschließend im Rahmen der generellen Anerkennungssysteme in seinem Herkunftsstaat die Anerkennung seiner Berufsqualifikation zu bewirken? Meiner Ansicht nach muß diese Frage verneint werden. Hier geht es nicht um einen Mißbrauch des Gemeinschaftsrecht, sondern um einen im Binnenmarkt akzeptierten Wettbewerb der Ausbildungssysteme. Es ist dabei allerdings nicht auszuschließen, daß dieser Wettbewerb einen "Deleware-effekt" bei den verschiedenen Ausbildungssystemen verursachen wird. Dies wurde jedoch von den Mitgliedstaaten mit dem Grundsatz der gegenseitigen Anerkennung billigend in Kauf genommen.

Das vierte untersuchte Problemgebiet betraf die Anerkennung von Drittstaatsdiplomen. Der Gerichtshof hatte hierzu in jüngster Zeit in zwei Entscheidungen Stellung zu neh: men ${ }^{489}$. In beiden Entscheidungen hat der Gerichtshof sich grundsätzlich gegen eine automatische Anerkennung von Drittstaatsdiplomen auf der Basis der sektoriellen Richtlinien ausgesprochen. Eine andere Entscheidung müllte hinsichtlich der generellen Anerkennungsrichtlinien 89/48/EWG und 92/51/EWG erfolgen, da beide Spezialbestimmungen hinsichtlich der Anerkennung von Drittstaatsdiplomen enthalten. Interessant war jedoch in der Entscheidung Haim ${ }^{490}$ die Verweisung auf die vom Gerichtshof in der Sache Vlassopoulou entwickelten Grundsâtze. Danach mußte auch im Falle eines Dritt-

487. Urteill wom 7. Febnar 1979, Rs 115/78 - J. Knoors/Staatsseknetär für Wirtschaft -, Slg. 1979, 399. Urteil wom 6 . Oktober 1981 , Rs $246 / 80$ - C. Broekmeulen gegen Huisarts Reguistratie Commissie * Sig. 1981, 2311; Urteil vom 3. Oktober 1990, C-26/89-Strafverfahren gegen M.G. Bouchoucha * Slg. 1990, 1-3551: Uneil vom 23. Marz 1993, Rs C-19/92 - Dieter Kraus gegen Land Baden Würitemberg, Sig. $1993,1-1663$.

488. Urteil vom 7. Februar 1979, Rs 115/78-1. Knoors/Staatssekretär für Wirtschaft -, S1g. 1979, 399. Rdnr. 24/25.

489. Unteil vom 9. Februar 1994, Rs C-319/92 - Salomone Haüm/Kassenzahnäratiche Vereinigung Nordmein *, Slg. 1994, I-425; Urteil vom 9. Februar 1994, Rs C-154/93 - Abdullah Tawil-Albertini/Ministere des Affaires sociales -, Sig. 1994, I-451.

490. Urteil vom 9. Februar 1994, Rs C-319/92 - Salomone Haim/Kassenzahnärtliche Vereinigung Nordrhein, Slg. I-425. 
staatsdiploms die erworbene Berufserfahrung gemäß Art. 52 EGV Berücksichtigung finden. Diese Entscheidung ist aus zwei Gründen besonders bemerkenswert: Zum einen macht sie deutlich, daß nach der Auffassung des Gerichtshofs die in den Rechtssachen Vlassopoulou, Newman und Kraus entwickelten Grundsätze auch dann Anwendung finden, wenn der Regelungsbereich bereits von einer Richtlinie abgedeckt ist. Dies ist vor allem im Falle von Regelungslücken in den Anerkennungssystemen von grundlegender Bedeutung. Die Anwendung der in den genannten Entscheidung niedergelegten Grundsätze ist damit auch nach dem Inkrafttreten der Anerkennungsrichtlinien perpetuiert. Zum zweiten ist der Gerichtshof nicht eindeutig im Hinblick auf die Frage, ob die von ihm geforderte Vergleichsprüfung sich lediglich auf die in einem anderen Mitgliedstaat erworbene Berufserfahrung beziehen muß oder, ob die Berufserfahrung in ihrer Gesamtheit einschließlich der Erfahrung in einem Drittstaat der Vergleichsprüfung unterliegt. Die zweite Lösung scheint meines Erachtens dem Ziel und Zweck einer Vergleichsprüfung mehr zu entsprechen. Allerdings muß dabei eingeräumt werden, daß ein derartiger Vergleich die nationalen Behörden bereits für den Bereich der Mitgliedstaaten vor beinahe unlösbare Probleme stellen kann. Im Falle der Einbeziehung von "Drittstaatserfahrung" potenzieren sich diese verwaltungstechnischen Probleme noch erheblich, abhängig davon wie bekannt und vergleichbar das Berufssystem in einem Drittstaat ist. 
Teil III

Die Freiheit des Personenverkehrs durch sektorielle Rechtsangleichung: Der vertikale Ansatz 


\section{Die Freiheit des Personenverkehrs durch sektorielle}

\section{Rechtsangleichung: Der vertikale Ansatz}

\section{\$1. Einleitung}

Zwischen 1975 und 1985 wurden für mehrere Berufe Richtlinien erlassen, die eine automatische Anerkennung der Diplome aus einem anderen Mitgliedstaat zur Folge haben. Davon wurde für sechs Berufe, die dem Gesundheitssektor zugerechnet werden können, auch eine Koordinierung der Ausbildung durch Richtlinien vorgenommen. Die Mitgliedstaaten wurden verpflichtet, in ihren Ausbildungen einen gewissen Mindeststandard zu garantieren. Es handelt sich dabei um Richtlinien für Ärzte ${ }^{49 !}$, Krankenschwestern bzw. - pfleger ${ }^{492}$, Zahnärzte ${ }^{493}$, Tierärzte ${ }^{494}$, Hebammen ${ }^{495}$ und Apotheker ${ }^{496}$. Ohne eine Angleichung der Ausbildung erfolgt die Anerkennung der

491. Richtlinie 75/362/EWG vom 16. Juni 1975 (Anerkennung), Richthinie 75/363/EWG vom 16. Juni 1975 (Koordinierung), ABI. Nr. L 167 vom 30. Juni 1975, It und 14. Dazu Anrys, JT 19975, 453; Berscheid/Kirschbaum 33 ff.; Rochard 86 ff,; de Rosa in Tizzano 1985, 277 ff.; Rosam Abbing, 77 ff.; Rowe, CDE 1976, 736; Séché, CDE 1976, 32; Soubey rol, RTDE 1976, 601; de Vries, Tijdschrift vor Gezondheidsrecht 1977, 27; Wägenbaur, CDE 1976, 707; Wägenbaur, RMC 1977, 311.

492. Richtlinie 77/452/EWG vom 27. Juni 1977 (Anerkennung), Richtlinie 77/453/EWG vom 27. Juni 1977 (Koordinierung). ABI. Nr. L. 176 vom 15. Juli 1977, I und 8. Dazu Loy, Jura Europae, Niederlassungsrecht III, $00.50-47$.

493. Richtlinie 78/686/EWG wom 25. Juli 1978 (Anerkennung). Richulinie 78/687/EWG vam 25. Juli 1978 (Koordinierung), ABI. Nr. L 233 vom 24. August 1978, 1 und 10. Dazu Notte; Pertek, Savoir 1990, 677; Pertek, J.Cl. Europe, Fasc. 740.

494. Richtlinie 78/1026/EWG vom 18. Dezember 1978 (Anerkennung), Richtlinie 78/1027/EWG vom 18. Dezember 1978 (Koordinierang), ABI. Nr. L 362 vom 23. Dezember 1978, 1 und 7. Dazu Wägenbaur, RTDE 1979, 653.

495. Richtlinie 80/154/EWG vom 21. Jaruar 1980 (Anerkennung), Richtlinie 80/155/EWG vom 21. Januar 1980 (Koordinierung), ABI. Nr. L. 33 vom 11. Februar 1980, 1 und 8. Dazu Loy in Jura Europae. Niederlassungsrecht III, 00:50 - 53; Orzack/Calogero in Lopata 1990, 43.

496. Richtlinie 85/432/EWG vom 16. September 1985 (Koordinierung). Richtlinie 85/433/EWG vom 16. September 1985 (Anerkennung). ABI. Nr. L 253 vorn 24. September 1985, 34 und 37. Dazu Ahlgrimm. PharmZ 1993,1865; Beuve-Méry, L'evolution pharmaceutique 1987, 12; Kraus, $81 \mathrm{ff}$; Ress/Ukrow, 27 ff. 
Architektendiplome ${ }^{497}$. Für Rechtsanwälte wurde 1977 eine Richtlinie ausschließlich zur Erleichterung der tatsächlichen Ausübung des freien Dienstleistungsverkehrs erlas$\operatorname{sen}{ }^{498}$. Eine tatsächliche allgemeine Anerkennung der juristischen Diplome wurde mit dieser Richtlinie nicht angestrebt.

Für bestimmte Berufe im handwerklichen und kaufmännischen Bereich wurde durch Richtlinien ein besonderes Verfahren zur Anerkennung der beruflichen Qualifikationen eingefuhrt ${ }^{499}$. Diese Richtlinie werden im allgemeinen mit dem Begriff "Übergangsmaßnahmen" bezeichnet. Für Verkehrsunternehmer wurden in dem genannten Zeitraum Richtlinien erlassen, die den Zugang zum Beruf ${ }^{500}$ sowie die Anerkennung der Diplome bei grenzüberschreitendem Verkehr ${ }^{50 \text { ॥ }}$ regeln. Für Unternehmer im Bereich des Binnenschiffsgüterverkehrs wurde 1987 eine Richtlinie erlassen, die den Zugang zum Beruf und die Anerkennung der einschlägigen Diplome zu erleichtem bezweckt ${ }^{502}$. Im November 1994 wurden schließlich noch die Mindestanforderungen für die Aus-

497. Richtlinie 85/384/EWG vom 10. Juni 1985 (Anerkennung), ABI. Nr. L 223 vom 21. August 1985, 15. Dazu Loy, Jura Europae, Niederlassungsrecht III. 00.50 - 55 .

498. Richtlinie 77/249/EWG vom 22. März 1977. ABI. Nr. L. 78 won 26. Mär 1977, 17. Siehe dazx: Annecchino un Tizzano 1985, 301 (305 ff.); Brangsch, NJW 1981, 1177; Boie, NJW 1977, 1567; de: Brauw, CDE 1978, 33; Bronkhorst, ELR 1977, 224; Brwois, RTDE 1977, 397; Carbone, RivDirEur 1978, 493; Dubois, EG 1977, 8; Girolami, Temi Romana 1980, 757; Giuffrida, Temi Romana, 1982. 546; Kranz, RIW 1978; Laguette, 241 ff, : Mauro/Weil, AnwB1. 1981, 128; Neri, 467; Panebianco, Dir. Sc. Int. 1981, 765; Pettiti, RMC 1977, 239; Schneider, L. 1979, 31 ff; Spedding, 185 ff; Van Camp 32 ff; Watters, ELR 1978, 265; Wilson, Harv. Int. L.J. 1978, 379.

499. Richtlinien 64/222/EWG. 64/223/EWG, 64/224 vom 25. Februar 1964, ABI. Nr. 56 vom 4. April 1964, $857 \mathrm{ff}$. (Großhandell und Vernittungstäthgeit in Handel, Industrie und Handwerk Richtlinien 64/427/EWG, 64/428/EWG, 64/429/ vom 7. Juli 1964, AB1. Nr. 17 wom 23. Juli 1964. 1863. ff. (Industrie und Handwerk);

Richtinien68/364/EWG, 68/365/EWG, 68/366/EWG,68/367/EWG,68/368/EWG, 68/369/EWG vom 15. Oktober 1968. ABI. Nr, 260 vom 22. Oktober 1968,6 ff. (Einzellhandel); (Persom liche Dienste): (Nahrungsmittel und Genubmittelgewerbe, Getrankeherstellung) (Filmwerleih)

Richtlinien 70/522/EWG, 70/523/EWG vom 30. November 1970, ABH. Nr. L 267 vom 10. Dezember $1970,14 \mathrm{ff}$. (Kohlengrobluandel);

Richtimien 75/368/EWG, 75/369/EWG wom 16. Juni 1975, ABI. Nr. L 167 vom 30. Juni 1975 (Verschiedene Tartigkeiten); (Reisegewerbe):

Richulinie 77/92/EWG vom 13. Dezember 1976, AB1. Nr. L 26 von 31. Januar 1977 (Versicherungsagenten und -makler);

Richtlinie 82/470/EWG vom 29. Juni 1982, ABI. Nr. L. 213 vom 21. Juli 1982 (Hilfsgewerbetreibende des Verkehrsp:

Richtline 82/489/EWG vom 19. Jull 1982, AB1. Nr. L 218 vom 27. Juli 1982 (Friseure)

500. Richtinaie 74/561/EWG vom 12. November 1974, ABI. L 308 vom 19. November 1974 (Zugang zum Beruf des Guterkraftunternehmers);

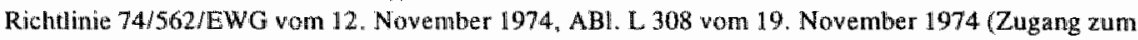
Benuf des Personenkraftuntemehmers).

501. Richtlinie 77/796/EWG vom 12. Dezember 1977. ABI. Nr. L 334 vom 24. Dezernber 1977 über die gegenseitige Anerkennung der Diplome, Prüfungszeugnisse und sonstige Befähigungsnachweise für die Beförderung von Gütern und die Befordenung von Personem im Straßenverkehr und uber Mamahmen zur Förderung der tatsächlichen Inanspnochnahme der Niederlassungsfreiheit der betreffenden Verkehrsunternehmer.

502. Richtlinie 87/540/EWG vom 9. Nowember 1987, ABl. Nr. L 322 vom 12. November 1987. 
bildung von Seeleuten in einer Richtlinie festgelegt ${ }^{503}$. Die von dieser Richtlinie erfaßten Berufe fallen zwar prinzipiell unter das Anerkenmungssystem der Richtlinien $89 / 48 / \mathrm{EWG}^{504}$ und $92 / 51 / \mathrm{EWG}^{\text {s0s }}$; da diese Richtlinien jedoch kein gemeinschaftliches Minimumniveau vorschreiben, sollten derartige Mindestanforderungen unter dem Gesichtpunkt der Sicherheit des Seeverkehrs durch die Richtlinie 94/58/EG des Rates garantiert werden. Hierbei wird auf international geregelte Ausbildungsnormen verwiesen. Bezüglich der Anerkennung der Befähigungsnachweise verweist Art. 9 der Richtlinie 94/58/EG des Rates ausdrücklich auf die entsprechenden Bestimmungen der Richtlinien 89/48/EWG und 92/51/EWG.

Betrachtet man dieses Ergebnis nur als solches, so könnte man mit der Bilanz gar nicht so unzufrieden sein ${ }^{506}$. Schaut man dagegen auf die zeitliche Planung, die diesen Richtlinien zugrunde lag, so kann man besser verstehen, daß Kommissionsbeamte beim Gedanken an eine Wiederaufnahme des sektoriellen Ansatzes ein Schaudern erfaßt ${ }^{507}$. Das Bild vom gebrannten Kind, welches das Feuer fürchtet, tritt einem vor Augen. Wir müssen also Erfolg oder Mißerfolg des sektoriellen Weges anhand der historischen Entwicklung messen. Maßgebend dafür sind die in den Allgemeinen Programmen aufgestellten Zeitvorgaben.

\section{§ 2. Die Allgemeinen Programme und ihr Zeitplan}

In Art. 54 Abs. 1 i.V. mit Art. 63 EWGV wurde der Rat verpflichtet, vor dem Ende der ersten Stufe Allgemeine Programme zur Verwirklichung der Niedlerlassungs- und Dienstleistungsfreiheit aufzustellen. Die erste Stufe endete am 31. Dezember 1961. Termingerecht wurde am 18. Dezember 1961 das Allgemeine Programm zur Aufhebung der Beschränkungen der Niederlassungsfreiheit sowie gleichzeitig das Allgemeine Programm zur Verwirklichung der Dienstleistungsfreiheit beschlossen 508 . In den Allgemeinen Programmen wird in Abschnitt I der Kreis der Begünstigten bestimmt ${ }^{50 \%}$. Abschnitt Il betrifft die Aufhebung der Behinderungen, die für Staatsangehörige aus anderen Mitgliedstaaten bei Einreise, Ausreise und beim Aufenthalt gelten. Abschnitt

503. Richtinie 94/58/EG des Rates vom 22. November 1994 uber die Mindestanforderungen für die Ausbildung won Seeleuten, ABl. Nr. L 319 wom 12. Dezember 1994, 28.

504. AB1. Nr. L. 19 vom 4. Januar 1989,16

505. ABI. Nr. L. 209 vom 24. Jwli 1992, 25.

506. Zilioli in De Witte 1989, 53; Beuve-Méry in Philip 1989, 21.

507. Scherer, WiVerw 1987, 159 (174). Einige Benafsgnappen, so die Rechtsanwălte, Wirtschaftsprifer und Ingenieure, hoffen allerdings, die Kommission doch noch von der Notwendigkeit einer sektoriellen Richtlinie für den jeweiligen Beruf überzeugen zu können. Bei den Rechtsanwälten scheinen diese Hoffnungen vom Erfolg gekrömt zu werden. Der Beratende Ausschulf der zwölf nationalen Anwaltschaften (CCBE) hat Ende Oktober 1992 eine Richtinie zur Verwirklichung der Niedlerlassungsf reilheit für Rechtsanwälte angenommen, deren teilhweise Ubemahme dunch die Komnnission in Form eines eturopäischen Richtlinienentwurf nun vorliegt. Siehe dazu Seite 276. Auch die FE ANI verkörpert ähnliche Bestrebungen für die Ingenieure. Fur die Wirtschaftsprifer vgl. die Hinweise bei Hillman, Die Wirtschaftsprifung: 1986,386 (388)

508. AB1, 1962, 32 and 36 .

509. Maas, $1965,27 \mathrm{ff}$. 
Der verrikalle Antatz

III und IV enthalten einen Maßnahmenkatalog zur Aufhebung der genannten Beschrânkungen sowie einen Zeitplan. Dazu gehört gemäß Abschnitt III B. auch die Aufhebung der Voraussetzung, von denen die Aufnahme oder Ausübung einer selbständigen Tätigkeit auf Grund einer Rechts- oder Verwaltungsvorschrift oder auf Grund von Verwaltungspraktiken abhängt, soweüt diese Voraussetzungen zwar unabhängig von der Staatsangehörigkeit gelten, jedoch ausschließlich oder vorwiegend Ausländer bei der Aufnahme oder Ausübung dieser Tätigkeit behindern. In einem gesonderten Abschnitt V wird die gegenseitige Anerkennung von Diplomen sowie die Koordinierung der Ausübungsvorschriften erwähnt. Dabei wird ausdrücklich festgestellt, daß für die einzelnen selbständigen Tätigkeiten die Erforderlichkeit derartiger Anerkennungs- und Koordinierungsregelungen geprüft werden soll. Gemäß Abschnitt V Satz 2 können bis zur gegenseitigen Anerkennung der Diplome oder bis zur Koordinierung Übergangsregelungen angewandt werden ${ }^{510}$. Dem Text der Allgemeinen Programme sind außerdem Anlagen beigefügt, aus denen sich ergibt, innerhalb welchen Zeitraums die Niederlassungsfreiheit für welche Berufsgruppe verwirklicht sein soll.

Dieser Zeitplan ist im allgemeinen weit überschritten worden. In einer ersten Zwischenbilanz hatte Oppermann bere its 1964 festgestellt, daß es den Gemeinschaftsorganen bisher kaum gelungen war, die erforderlichen Richtlinien nach den Fristen der Allgemeinen Programme zu verabschieden ${ }^{511}$. Als Hauptgrund nannte er die große Zahl berufsrechtlicher Fragen, die sich bei der Ausarbeitung der Richtlinien stellten. 1964 waren vor allem bezüglich der freien Berufe noch keine Richtlinien erlassen worden, wobei allerdings mit Ausnahme der Presseberufe zu diesem Zeitpunkt auch keine tatsächliche Fristüberschreitung festgestellt werden konnte ${ }^{512}$. Die Richtlinien für die freien Berufe mußten gemäß der Anlagen II bis IV in den Jahren 1964 bis 1969 ergehen. Eine Fristüberschreitung konnte allerdings bereits zu diesem Zeitpunkt vorhergesagt werden, da auch die Ausarbeitung der Richtlinienentwürfe mehr Zeit beanspruchte als zunächst geplant.

Diese Schwierigkeiten traten sicher nicht vollkommen unvorhergesehen auf. Bei der Abfassung der Allgemeinen Programme scheint man sich ihrer sehr wohl bewußt gewe$\operatorname{sen} z u$ sein $^{513}$. Diese Auffassung wird durch die in Abschnitt $\mathrm{V}$ genannte Möglichkeit bestätigt, bis zur endgültigen Ausarbeitung der Koordinierungsrichtlinien Übergangsregelungen zu erlassen. Durch diese Übergangsregelungen sollte die Aufnahme und Ausübung selbständiger Tätigkeiten einstweilen erleichtert werden. Seit den sechziger Jahren hat die Gemeinschaft für zahlreiche Berufssparten, insbesondere im Bereich von Handel, Handwerk, Industrie und Landwirtschaft, derartige Richtlinien geschaffen, nach denen die berufliche Qualifikation allein aufgrund einer entsprechenden Berufserfahrung

510. Wägenbuatur, Nuove Tendenze, 210.

511. Oppermann, BB 1964, 563 . 512. Für die Presseberufe hätte eine Liberalisierung gemäß Anlage 1 Gruppe 839 bis Ende 1963 erfolgen
sollen.

513. Storm/Flooghout, RM Themis 1980,432 (473). 
Teill III

nachgewiesen werden kann ${ }^{514}$. Als Vorbild kann Art. 2 der Richtlinie 82/489/EWG angeführt werden ${ }^{515}$. Dieser bestimmt die Anerkennung im Falle, daß der Berufsangehörige den Friseurberuf sechs Jahre ununterbrochen als Betriebsleiter oder als Selbständiger ausgeübt hat. Die Anerkennung muß ebenfalls ausgesprochen werden, falls eine dreijăhrige Berufsausbildung durch ein staatliches Zeugnis nachgewisen wird. Ist diese Bedingung erfüllt, genügt desweiteren eine dreijährige Berufsausübung als Selbständiger oder Betriebsleiter. Eine dreijährige Berufsausübung als Selbständiger oder Betriebsleiter ist auch dann ausreichend, wenn der Betroffene daneben eine mindestens fünfjährige Tätigkeit als Arbeitnehmer nachweisen kann. Ähnliche Regelungen finden sich auch in den übrigen "Übergangsmaßnahmen". Ziel dieser Anerkennungsbestimmung war jedenfalls keine Koordinierung der nationalen Ausbildungsbestimmungen. Dies wurde für die Richtlinie 82/489/EWG auch ausdrücklich vom EuGH in seinem Urteil wom 16. Februar 1995 in der Rechtssache Aubertin bestätigt ${ }^{516}$.

Obwohl in diesen Richtlinien ausdrücklich vorgesehen war, daß sie lediglich bis zur Koordinierung der nationalen Ausbildungs- und Ausübungsvorschriften wirksam bleiben sollten, wurden sie nie ersetzt und gelten noch immer. Es gilt das Adagium "c'est. le provisoire qui dure ${ }^{\text {517 }}$. Bei einigen dieser Richtlinien wird unter Anerkennung dieser Tatsache der Begriff "Übergangsmaßnahme" nicht mehr verwendet ${ }^{5 / 8}$. Spätestens seit Verabschiedung der zweiten allgemeinen Anerkennungsrichtlinie 92/51/EWG muf zumindest von einem vorläufigen "Ewigkeitswert" dieser Richtlinien ausgegangen werden, da dort ihre fortdauernde Gültigkeit ausdrücklich unterstellt wird ${ }^{s / 9}$. Inzwischen wird in der Kommisssion jedoch erwogen diese Übergangsregelungen durch ein drittes allgemeines Anerkennungssystem zu ersetzen, wobei auch eine grundlegende, den Entwicklungen angepaßte Reform des ursprünglichen Systems geplant ist. Die dahingehenden Überlegungen haben jedoch bisher ledig einen Konzeptcharakter. Geplant wird vor allem eine Konsolidierung der Übergangsrichtlinien. Dabei wird in Erwägung gezogen, eine neue Nomenklatur zu verwenden. Nach dem bisherigen System wird auf die CITI-Nomenklatur verwiesen. Diese ist jedoch veraltet. Desweitern sollen rechtlich überholte Richtlinien aufgehoben werden. Dies gilt insbesondere für Bestimmungen, womit Beschränkungen bezüg]lich der Staatsangehörigkeit aufgehoben werden. Da die Art. 48. 52 und $59 \mathrm{EGV}$ seit Ablauf der Übergangsfrist unmittelbar anwendbar sind, sind diese Richtlininien obsolet geworden.

514. So z.B. Richtlinie 64/222/EWG; Richtlinie 64/427/EWG; Richtlinile 68/364/EWG; Richtlinie 68/368/EWG; sitehe dazu die Auflistung bei Klinge 1990, $25 \mathrm{f}$.

515. Richtlinie 82/489/EWG wom 19. Juli 1982, ABI. Nr. L 218 vom 27. Julli 1982 uber Mafnahmen zur Erteichterung der tatsächlichen Ausubung des Niederlassungsrechts und des Rechts auf freien Dienstleishungsverkehr für Friseure.

516. Urteil vom 16. Februar 1995, verbundene Rs C-29/94, C-30/94, C-31/94, C-32/94, C-33/94, C-34/94 und C-35/94 - Aubertin u.t. -, Rdnr. 12 (noch nicht veröffentlicht).

517. Storm/Hooghoudt, RM Thiemis 1980, 432 (473); "Troberg, GTE-Handbuch, Art. 57 Rdnr. 34 spricht von einem Provisorium auf Dauer.

518. So zB. bei der Richtlinie 82/489/EWG worn 19. Jull 1982, AB1. N. L 218 vom 27. Juli 1.982 zur Erleichterung der Ausübung des Friseurberufs.

519. Ant 2 der Richtlunie 92/51/EWG. Siehe dazu Seite 238. 
Weitere Reformbestrebungen betreffen die systematische Angleichung einiger Bestimmungen. Dieses Verfahren wird als Kodifikation bezeichnet, innerhalb derer ein konsolidierter Text für den Nachweis der persönlichen Zuverlässigkeit und der finanziellen Leistungsfähigkeit sowie der Berufshaftpflichtversicherung zu erstellt werden soll. Auch soll eine Konsolidierung der in den verschiedenen Übergangsrichtlinien unterschiedlich geforderten Berufserfahrung vorgenommen werden. Nach dem bisherigen System gibt es zehn verschiedene Kategorien, die auf zwei Kategorien reduziert werden sollen. Grundsätzlich ist beabsichtigt, diese "dritte allgemeine Regelung" in die bestehenden allgemeinen Anerkennungssysteme zu integrieren. Trotz dieser Reformbestrebungen kann man nicht leugnen, daß gerade aufgrund der Übergangsrichtlinien die Allgemeinen Programme in den Bereichen Handel, Handwerk, Industrie und Landwirtschaft weitgehend innerhalb der vorgegebenen Zeitpläne verwirklicht werden konnten ${ }^{520}$.

Dies ist dagegen für die freien Berufe nicht gelungen. Der Grund hierfür liegt darin, daß man zunächst die unterschiedlichen Vorschriften in den Mitgliedstaaten bezüglich der Berufsausbildung, der Berufszulassung und der Berufsausübung vereinheitlichen wollte, bevor die Diplome anerkannt werden konnten. Hier stellt sich natürlich die Frage, warum man nicht auch für die freien Berufe zunächst $z u$ Übergangsrichtlinien gegriffen hat, bevor man den mühsamen Weg der Koordinierung einschlug. Die Antwort lautet: Dieser Weg stand in den 60er Jahren für die Mehrheit dieser Berufe noch nicht offen. Verschiedene Gründe können hierfür angeführt werden. Zunächst war der Zugang zu den meisten freien Berufen in den Mitgliedstaaten Ausländern verwehtt ${ }^{52 !}$. Es mußten deshalb jedenfalls Richtlinien ergehen, die eine Authebung des Staatsangehörigkeitserfordernisses bewirkten. Für die ärztlichen, arztähnlichen und pharmazeutischen Berufe setzte Art. 57 Abs. 3 EWGV auch die Koordinierung der Ausübungsbedingungen voraus. Gerade die Berufe des Gesundheitssektors deckten aber den größten Bereich der klassischen freien Berufe ab. Für den Beruf des Rechtsanwalts vertraten zumindest die Bundesrepublik Deutschland und Luxemburg die Auffassung, daß dieser unter Art. 55 EWGV falle und als solcher gänzlich von der Niederlassungsfreiheit ausgenommen sei ${ }^{522}$. Letztlich dürfte die Tatsache, daß freie Berufe sich durch ein hohes Ausbildungsniveau auszeichnen, ein nicht unwesentliches Zögern verursacht haben, diese hochwertige Ausbildung durch Berufserfahrung kompensieren zu lassen.

520. Clausnitzer in Lenz, EG-Handbuch, 194.

521. Dies galt z.B. in fünt def sechs ursprünglichen Mitgliedstaaten für den Beruf des Rechtsanwalts. Auch die klassischen freien Benufe im Gesundheitsbereich, enwa Ärzte, Tierärte und Apotheker, standen unter einem Staatsangehörigkeitsworbehalt.

522. Der Standpunkt der Bundesrepublik ubermisht vor allem deshalb, weil diese im Gegensatz zu den damals funf anderen Mitgliedstaaten kein Statsangehörigkeitserfordernis für die Ausübung des Rechtsanwaltsberufes kannte. Begrïndet wurde die Anwendung des Art. 55 EWGV mit der Umschreibung des Rechtsanwaltes in der Bundesrechtsanwaltsordnung als "unabhängiges Organ der Rechtspflege". Siehe dazu Arendt, Barreau et médecins, 38 (55). 


\section{§ 3. Die vertragliche Regelung gemäß Art. 57 EGV}

\section{A. EINFÜHRUNG}

Art. 57 EGV sollte gemäß der ursprünglichen Zielsetzung die Schwierigkeiten mildern, die sich aus den für Inländer und Ausländer übereinstimmend geltenden Rechtsvorschriften der Mitgliedstaaten für die Niederlassung der Angehörigen anderer Mitgliedstaaten ergeben ${ }^{523}$. Der Wechsel aus einem beruflichen System in das eines anderen Mitgliedstaats sollte erleichtert werden. Gemäß Art. 66 EGV sollte unter entsprechender Anwendung von Art. 57 EGV auch eine Koordinierung der Rechts- und Verwaltungsvorschriften zur Erleichterung der Erbringung von Dienstleistungen vorgenommen werden. Für die Freizügigkeit von Arbeitnehmern dagegen enthalten die Art. $48 \mathrm{ff}$. EGV keine entsprechende Bestimmung. Diese Regelungslücke hat zumindest zu Beginn der Koordinierungsarbeiten einige nicht unerhebliche Schwierigkeiten verursacht ${ }^{524}$ " Die ersten Koordinierungs- und Anerkennungsrichtlinien für Ärzte ${ }^{52.5}$, Krankenschwestern bzw. -pfleger ${ }^{526}$, Zahnärzte ${ }^{527}$ und Tierärzte ${ }^{528}$ wurden daher nicht nur auf die Art. 49, 57, 66 EGV gestützt, sondern erwähnen ebenfalls Art. 235 EGV als Rechtsbasis ${ }^{529}$. Erst ab 1980 bei den Richtllinien für Hebammen ${ }^{530}$, Apotheker ${ }^{531}$ und Architekten ${ }^{532}$ wurde eine Verweisung nach Art. 235 EGV für nicht mehr erforderlich angesehen.

Art. 57 EGV enthält drei Abschnitte. Art. 57 Abs 1 EGV gibt die Möglichkeit zum Erlaß von Anerkennungsrichtlinien, dagegen bietet Art. 57 Abs. 2 EGV die notwendige Rechtsgrundlage zur Koordinierung der Bestimmungen der Mitgliedstaaten, die die Aufnahme und Ausübung beruflicher Tätigkeiten regeln. Letztlich bestimmt der dritte Abschnitt, daß die schrittweise Aufhebung der Beschränkungen für die ärztlichen, arztähnlichen und pharmazeutischen Berufe, gerade die Koordinierung der Bedingungen für dỉe Ausübung dieser Berufe in den Mitgliedstaaten, voraussetzt. Mit dieser Regelung

523. Wohlfahrt/Everling/Glaesner/Sprung, Kommentar zu Art. 57.

524. Wăgenbaur. CDE 1976, 707 (7094.)

525. Richtlinie 75/362/EWG vom 16. Juni 1975 (Anerkennung), Richtlinie 75/363/EWG vom 16. Juni 1975 (Kootdinienung), ABI. Nir. L 167 vom 30. Juni 1975, I und 14

526. Richtlinie 77/452/EWG vom 27. Juni 1977 (Anerkennung), Richtlinie 77/453/EWG wom 27. Juni 1977 (Koordinierung), ABI. Nr. L 176 vom 15. Juli 1977, 1 und 8.

527. Richtinie 78/686/EWG vom 25. Juli 1978 (Anerkennung), Richtinie 78/687/EWG wom 25. Juli 1978 (Koordinierungh. ABL. Nr. L. 233 vom 24. August 1978, 1 und 10.

528. Richtinie 78/1026/EWG vom 18. Dezember 1978 (Anerkenmung), Richthinie 78/1027/EWG vom 18. Dezember 1978 (Koordinienug), ABI. Nr. L 362 vom 23. Dezember 1978, 1 und 7 .

529. Einige Delegationen salhen in der Erweiterung der Anerkennung auf Arbeitnehmer eine Vertragsergänzung. So Troberg in GTE-Handbuch, Art. 57, Fulrote 11.

530. Richtlinie 80/154/EWG wom 21. Januar 1980 (Anerkennung), Richtinie 80/155/EWG vom 2L. Januar 1980 (Koordinierung), ABL. Nr. L. 33 vom 11 . Februar 1980,1 und 8.

531. Richtlinie 85/432/EWG vom 16. September 1985 (Koordinierung), Richtinie 85/433/EWG wom 16 . September 1985 (Anerkemnung), ABI. Nr. L 253 wom 24. September 1985, 34 und 37.

532. Richtlinie 85/384//EWG vom 10. Juni 1985 (Anerkennung) ABI. Nr. L 223 vom 21. August 1985, 15. 
wollte man ursprünglich gewährleisten, daß die Ausübung von Heilberufen in den verschiedenen Mitgliedstaaten vergleichbar strengen Ausbildungsbedingungen und Standesregeln unterliegt. Im Gegenschluß3 konnte aus dieser Bestimmung gefolgert werden, daß bei den übrigen Berufen die Koordinierung der Berufsregelungsvorschriften nicht notwendige Voraussetzung für den Abbau der Beschränkungen ist ${ }^{533}$.

\section{B. VERFAHREN}

Art. 57 EGV wurde im Laufe der Zeit mehrmals geändert. Die Änderungen betrafen im wesentlichen Verfahrensfragen. Gemäß der bis 1987 geltenden Fassung ${ }^{534}$ gall das Prinzip der Einstimmigkeit für die Sachgebiete, die zumindest in einem Mitgliedstaat durch Gesetz geregelt waren sowie für das Bankwesen und die medizinischen Berufe. Faktisch bedeutete dies, daß bei nahezu allen Koordinierungsvorhaben bis 1987 das Erfordernis der Einstimmigkeit die Regel war, da zumindest die erste allgemeine Bedingung fast immer erfüllt war ${ }^{535}$. Mit Inkrafttreten der Einheitlichen Europäischen Akte wurde das Zusammenarbeitsverfahren für die Beschlußfassung in Art. 57 Abs. 2 Satz 3 EGV eingefügt. Einstimmigkeit blieb immer noch dann erforderlich, wenn die Duchführung der Koordinierungsrichtlinie in mindestens einem Mitgliedstaat eine Änderung bestehender gesetzlicher Grundsätze der Berufsordnung hinsichtlich der Ausbildung und der Bedingungen für den Zugang natürlicher Personen zum Beruf umfaßt. Nach Troberg ist diese Änderung auf Drängen der deutschen Delegation in die Einheitliche Europäische Akte eingebracht worden, um hierdurch den Bestand des deutschen Handwerksrechts, insbesonders der Meisterprüfung zu garantieren ${ }^{536}$. Durch den Unionsvertrag wurde die Abstimmungsmodalität in den Art. 57 Abs. 1 und 2 EGV erneut geăndert. Nunmehr gilt nicht mehr das Verfahren der Zusammenarbeit, sondern das Mitentscheidungsverfahren gemäß Art. 189b EGV für die allgemeinen Abstimmungen. Das Erfordernis der Einstimmigkeit bei Änderung der gesetzlichen Grundsätze der Berufsordnungen gemäß Art. 57 Abs. 2 Satz 2 EGV blieb bestehen.

Der dritte Absatz von Art. 57 EGV hat keine Veränderung erfahren. Dies ist insoweit bemerkenswert, da die zeitliche Reihenfolge, die Art. 57 Abs. 3 EGV für die medizinischen und arztähnlichen Berufe zwischen einer vorherigen Koordinierung und der nachfolgenden Aufhebung von Beschränkungen herstellte, nach heute allgemeiner Auffassung gegenstandslos ist ${ }^{537}$. Begründet wird diese Ansicht in der Literatur allerdings unterschiedlich. Troberg verweist in erster Linie auf das Ende der Übergangszeit, womit das Verbot der Niederlassungsbeschränkungen direkt anwendbar geworden ist,

533. Wohlfahr/Everling/Glaesner/Sprung, Kommentar zu Art. 57, Rdnr. 6.

534. Art. 57 EGV wurde durch Art. 6 Abs. 6 und 7, sowie durch Art. 16 Abs. 2 der Einheitlichen Europäischen Akte geăndert. Diese Änderangen traten am 1. Jatli 1987 in Kraft.

535. Troberg in GTE-Handbuch, Aut. 57, Rdnr. 10.

536. Troberg in GTE-Handbuch, Art. 57 Rdnr. 11, sieht das Einstimmigkeitserfordernis jedoch nur für die Fälle gegeben, welche ordnungspolitisch relevante, an die "'Grundlagen des Gewerberechts reichende Umstellungen" betreffen. Daher schließt er eine etwaige Anwendung dieser Abstimmungsregelung kategorisch auf Übergangsmaßnahmen aus.

537. Troberg in GTE-Handbuch, Art. 57 Rdnr. 7; Hailbronner, Handkonmentar, Art. 57, Rdnr. 14. 
wohingegen Hailbronner den zwischenzeitlichen Erlaß der entsprechenden Koordinierungsrichtlinien als Erklärung anführt ${ }^{538}$. Die letztgenannte Auffassung kann zur Begründung nicht vollständig überzeugen. Zwar stimmt es grundsätzlich, daß die wichtigsten medizinischen und arztähnlichen Berufe in den Anwendungsbereich einer Koordinierungsrichtlinie fallen. Dies gilt jedenfalls für die Ärzte, Zahnärzte und Tierärzte einschließlich der Spezialisten ${ }^{539}$. Auch für andere Berufe des Gesundheitswesens wie etwa Hebammen, Krankenschwestern und -pfleger, die unter Umständen als arztähnliche Berufe qualifiziert werden können ${ }^{540}$, sowie für die Apotheker ist durch Koordinierungsrichtlinien ein europäisches Mindestniveau geschaffen. Andere paramedizinischen und arztähnlichen Berufe sind jedoch nicht koordiniert worden. Dies soll auch in Zukunft nicht geschehen. Vielmehr ist gerade für diese Berufe bewußt eine Anerkennung gemäß der beiden allgemeinen Anerkennungsrichtlinien 89/48/EWG und 92/51/EWG geschaffen worden, die keine Koordinierung voraussetzt ${ }^{541}$. Würde man nun die Bedeutung von Art. 57 Abs. 3 EGV auch heute noch davon abhängen lassen, ob bereits die entsprechenden Koordinierungsrichtlinien ergangen sind, so wäre nun mehr die Zulässigkeit der Anwendung der beiden allgemeinen Anerkennungsrichtlinien auf diese Berufsgruppe davon abhängig, ob die genannten paramedizinischen Berufe als "arztähnliche Berufe" i. S. des Art. 57 Abs. 3 EGV einzustufen sind oder nicht. Im Falle der Verneinung könnte eine Anerkennung gemäß den Richtlinien 89/48/EWG und 92/51/EWG erfolgen. Anderenfalls müßten zunächst doch noch die notwendigen Koordinierungsmaßnahmen gemäß Art. 57 Abs. 2 EGV vorgenommen werden. Dieses Ergebnis wäre jedoch nicht praktikabel. Auch erscheint - gerade nach der Analyse der Rechtsprechung zum Niederlassungsrecht - wonach eine zunehmende Tendenz dahingehend konstatiert werden konnte, daß nicht nur Art. $59 \mathrm{EGV}$, sondern auch Art. $52 \mathrm{EGV}$ ein allgemeines Beschränkungsverbot enthält, eine vertraglich gebotene Pflicht zur Koordinierung bestimmter Berufe als Voraussetzung für die Anerkennung der Berufsqualifikationen nicht mehr vertretbar. In Art. 30 EWRA, der im wesentlichen inhaltlich mit Art. $57 \mathrm{EGV}$ übereinstimmt, wurde diese Sonderregelung für die Heilberufe auch nicht mehr aufgenommen. Begründet wurde dieser Unterschied mit der bestehenden Rechtspraxis in der $\mathrm{EG}^{\text {542 }}$. Zwar ist diese Argumentation für die Interpretation von Art. 57 EGV rechtlich nicht bindend, sie kann jedoch als Indikation für den Meinungsstand bei den Mitgliedstaaten und der Kommission gewertet werden.

538. Diese Begründung wird von Troberg in GTE-Handbuch nur sekundär in Art. 57, Fulinote 8 erwälhnt

539. Siehe dazu die Ausführungen Seite 118 und Seite $142 \mathrm{ff}$.

540. Van Gerven in Smit/Herzog yerweist in seinem Kommentar zu Art. 57 unter 57.10 ausdricklich auf die in den Mitgliedstaaten unterschiedlich vertretenen Auffassung hinsichtlich des Begriffs "arztähnlich". Danach lassen sich z.B. Krankenschwestern nach der französischen, miederländischen und italienischen Auffassung ưnter den Begriff arztähnich subsumieren, wohingegen diese Qualifikation nach deutscher Verkehrsauffassung nur Berufsangehörigen mit einer selbständigen Heil befugnis zustcht

541. So nehmen die gesund heitstechnischen Berufe einen besonderen Platz in der Richtinie 92/51/EWG ein Siehe dazu die Ausführungen Seite 235.

542. Norberg U.a., EEA Law, 422. 


\section{Die gegemsertige Anerkennung gemÄss ART. 57 ABS. 1 EGV}

Art. 57 Abs. I EGV dient als Rechtsgrundlage für den Erlaß von Richtlinien für die gegenseitige Anerkennung von Diplomen, Prüfungszeugnissen und sonstigen Befăhigungsnachweisen. Der Wortlaut der Bestimmung macht keinen Unterschied zwischen den sogenannten akademischen Diplomen und den berufsbezogenen Ausbildungsnachweisen, obwohl die Ziellsetzung der Regelung eine Erleichterung der Aufnahme und Ausübung selbstândiger Tätigkeit bezweckt. Aufgrund dieser engen Verknüpfung zwischen der Aufnahme und Ausübung einer Berufstätigkeit und der Anerkennung eines Diploms wurde in der Literatur die Ansicht vertreten, daß Art. 57 Abs. 1 EGV sich ausschließlich auf die sogenannte "professionelle" Anerkennung bezieht, während die "akademische" Anerkennung vom Ermächtigungsbereich der Bestimmung ausdrücklich ausgeschlossen sei ${ }^{543}$. Der Unterschied zwischen beiden Anerkennungssystemen soll darin bestehen, daß die "professionelle" Anerkennung sich auf eine formelle Qualifikation bezieht, wohingegen die akademische Anerkennung lediglich die Integration von im Ausland erworbenen Studienresultaten in das Erziehungssystem eines anderen Mitgliedstats bexweckt ${ }^{544}$. Als Beispiele für akademische Anerkennung wird vor allem auf bilaterale Verträge sowie multilaterale Verträge im Rahmen des Europarates $^{545}$ oder der Unesco ${ }^{546}$ verwiesen. Diese prinzipielle Unterscheidung überzeugt jedoch nicht. In vielen Fällen ist ein rein akademisches Diplom zu gleicher Zeit auch die Zugangsqualifikation zu einem Beruf. Dies hängt im wesentlichen von der Reglementierung des Berufs ab. Es gibt Berufe - vor allem im öffentlichen Dienst -, deren Reglementierung ausschließlich darin besteht, eine bestimmte Schul-oder postsekundäre Ausbildung ohne eine weitere berufsbezogene Qualifizierung oder ein Berufsexamen zu verlangen. In einem solchen Fall ist das akademische Diplom, z.B. das Abitur, gleichzeitig auch das Diplom, das den Zugang zum Beruf reglementiert. Damit kann ein derartiges akademisches Diplom in den Anwendungsbereich von Art. 57 Abs. 1 EGV fallen. Sowohl in der Richtlinie 89/48/EWG als auch in der Richtlinie $92 / 51 /$ EWG ist der Anwendungsbereich der Richtlinien eindeutig auf derartige akademische Diplome

543. Lenaerts, CMLRev, 1994, 5 (16)

544. Teichler (1990) hat in seiner Studie über "recognition" den Begriff" Anerkennung wie folgt definient: Die prinzipielle Bereitschaft, das im Ausland erbrachte Studim im eigenen Land als gleichwertig zu akzeptieren bzw, anzuenkennen, 12 und 54.

545. Europäische Konvention über die Gleichwertigkeit der Reifezeugnisse (European Convention on the Equivalence of Diplornas leading to Admission to Uniwersities) vom 11. Dezember 1953, 218 U. N.T.S 125; Europaisches Übereinkommen uber die Gleichwertigkeit der Studienzeiten an den Universităten (European Convention on the Equivalence of Periods of University Study) vom 15. Dezember 1956, 278 U.N.T.S 73; Europäisches Übereinkommen über die akademische Anerkennung von akademischen Graden und Hochschulzengnissen (European Convention on Academic Recognition of University Qualifications) vom 14. Dezember 1959, 444 U.N.T.S 195. Dazu Cox, 15 ff.

546. Übereinkommen über die Anerkennumg won Universithitsstudien, Hochschulzeugnissen und akademischen Graden in den arabischen und europäischen Mittelmeerstaaten wom 17 . Dezember 1976; Ubereinkommen über die Anerkennung von Studien, Diplomen und Graden im Hochschulbereich in den Staaten der europäischen Region vom 21. Dezember 1979; Siehe dazu das deutsche Ratifükationsgesetz vom 2. September 1994, BGBI. II Nr. 42 vom 16. Septenber 1994, 2321. 
Teil m

erweitert, die die Aufnahme eines reglementierten Berufs bestimmen bzw. die Reglementierung des Berufs darstellen ${ }^{547}$.

In seiner Entscheidung in der Rechtssache Kraus hat der EuGH ebenfallls die Anerkennung eines akademischen Titels unter den Anwendungsbereich der Art. 48 und 52 EGV gezogen ${ }^{548}$. Der Titel "LL.M" berechtigt als solcher in keiner Weise zur Aufnahme und Ausübung reglementierter juristischer Tätigkeit. Dennoch hat der Gerichtshof die Anwendung der Art. 48 und 52 EGV bejaht. In diesem Zusammenhang stellte der Gerichtshof fest, daß ein akademischer Grad, obwohl er normalerweise keine Zugangsvoraussetzung für einen unselbständigen oder selbständigen ausgeübten Beruf ist, für den Inhaber dennoch einen Vorteil für den Zugang zu einem solchen Beruf oder für das berufliche Fortkommen bedeutet ${ }^{549}$. Die Niederlassung als Selbständiger werde durch die Möglichkeit, im Ausland erworbene akademische Grade vorzuweisen, erheblich erleichtert ${ }^{55 /}$. Desweiteren hat der Gerichtshof in der Entscheidung festgestellt, daß noch keine Harmonisierungsmaßnahmen in diesem Bereich ergangen sind ${ }^{551}$. Zwar fehlt ein ausdrücklicher Hinweis auf Art. 57 Abs. 1 EGV, da diese Entscheidungsgründe jedoch in direktem Zusammenhang mit den Richtlinien 89/48/EWG und 92/51/EWG genannt werden ${ }^{552}$, können die Feststellungen nur so ausgelegt werden, daß der Gerichtshof eine Anwendung von Art. 57 EGV im Bereich der akademischen Titelführung nicht grundsätzlich verneint, vielmehr als adäquate Ermäclatigungsgrundlage ansieht.

Diese Interpretation ist von besonderer Bedeutung im Hinblick auf die Tatsache, da/3 die Entscheidung Kraus in einem Zeitpunkt erging, als der geänderte Vertragstext einschließlich der neu gefaßten Art. 126 und 127 EGV bekannt war. Zwar war das Inkrafttreten des Maastrichtervertrags in diesem Augenblick noch nicht mit letzter Sicherheit garantiert, der Gerichtshof hätte jedoch, falls er dies gewollt hätte, die Gelegenheit benützen können, eine erste Abgrenzung zwischen den Bereichen vorzunehmen ${ }^{553}$. Eine solche Abgrenzung wurde statt dessen - nach meiner Ansicht bewußt - unterlassen,

547. Silehe dazu die Erörterungen auf den Seiten 186 und 211 .

548. Umeil wom 23. März 1993, Rs C-19/92 - Dieter Kraus/Land Baden-Wurttemberg - Slg. 1993, 1663. Rdnr. $16 \mathrm{ff}$.

549. Urteil vom 23. Mărz 1993, Rs C-19/92 "Dieter Kraus/Land Baden-Würtemberg “, Sig. 1993, 1663. Rdnr, 20.

550. Urteil vom 23. März 1993, Rs C-19/92 - Dieter Kraus/Land Baden-Württemberg “, Slyg. 1993, 1663, Rdinr. 22.

551. Urteil vom 23. März 1993, Rs C-19/92 - Dieter Kraus/Land Baden-Württemberg -, Slig.. 1993, 1663. Rinr. 24 und 27.

552. Urteil vom 23. Mhrz 1993, Rs C-19/92 - Dieter Kraus/Land Baden-Württemberg - Slg. 1993, 1663, Rdmr. 25 und 26. Bei beiden Richtinien ist jedoch Art. 57 Abs. 1 EGV die wesentliche Rechisgrundla$g e^{2}$

553. In seinem ERASMUS-Urteil vom 30. Mai 1989, Rs 242/87 - Kommission/Rat - hat der Gerichtshof

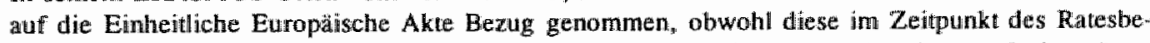
schlusses noch nicht in Kraft getreten war, Slg. 1989, 1425 ff. Ranr, 36. Allerdings muß eingeräum werden, daß im Unterschied zur Entscheidung Kraus das ERASMUS-Unteil zu einem Zeitpunkt erging, als die EEA bereits in Kraft getreten war. Pertek, RTDE 1991, 132; Gillams, RW 1989-90, 494. 
obwohll Generalanwall Van Gerven durch seine Analyse zu Art. 128 EWGV in Verbindung mit Art. 7 EWGV (in der ursprünglichen Vertragsfassung) den Gerichtshof ausdrücklich $\mathrm{zu}$ einer derartigen Abgrenzung zumindest hinsichtlich Art. $128 \mathrm{EWGV}$ eingeladen hat ${ }^{\$ 54}$

In der ERASMUS-Entscheidung hatte der Gerichtshof zur Abgrenzung zwischen Art. 57 und 128 EWGV bemerkt, daß das ERASMUS-Programm unter seinem Aktionspunkt 3 zwar die Mobilität durch die akademische Anerkennung von Diplomen und Studienperioden fördern möchte, die angestrebten Maßnahmen jedoch nur vorbereitend und stimulierend seien. Mit Bezug auf den worbereitenden Charakter des Aktionsprogrammes entschied sich der Gerichtshof gegen die ausschließliche Anwendbarkeit von Art. 57 EWGV ${ }^{55}$. Aus dieser Argumentation kann jedoch abgeleitet werden, daß, falls keine worbereitenden und rein stimulierenden Maßnahmen zur Debatte stehen, der Gerichtshof Art. 57 EWGV Vorrang gegenüber Art. $128 \mathrm{EWGV}$ in seiner ursprünglichen Fassung eingeräumt hätte. Der Gerichthof hat dabei nicht darauf hingewiesen, daß es sich um eine akademische Anerkennung handelt, die bereits ipse jure außerhalb des Anwendungsbereichs von Art. 57 EWGV stünde. Eine solche Stellungsnahme hätte man jedoch erwarten müssen, falls der Gerichtshof eine Regelung bezüglich akademischer Anerkennung nicht durch Art. 57 EWGV gedeckt sah. Der Wortlaut von Art. 57 EGV ist zu diesem Punkt durch den Unions-Vertrag nicht geändert. Auch enthält Art. B des EU. Vertrags die ausdrückliche Garantie, daß der gemeinschaftliche Besitzstand voll gewahrt wird. Diese Garantie des acquis communautaire ist auf die Interpretation des Gerichtshofs bezüglich Art. $57 \mathrm{EGV}$ anwendbar, so daß meines Erachtens auch nach heutiger Rechtslage Art. 57 EGV als Rechtsgrundlage für Richtlinien dienen könnte, die eine Regelung der akademischen Anerkennung von Diplomen beabsichtigen ${ }^{556}$.

Inhaltlich müßte eine derartige Regelung lediglich garantieren, daß durch die Anerkennung ein Vorteil hinsichtlich des beruflichen Fortkommens des Diplominhabers bewirkt werden soll. Diese Schlußfolgerung läß 3 sich auch mit der Argumentation des Gerichtshofs bezüglich der Anwendung der Richtlinien 89/48/EWG und 92/51/EWG in der Rechtssache Kraus belegen ${ }^{55}$. Der Gerichtshof hat die Anwendung dieser Richtlinien nicht mit dem Argument abgelehnt, daß sie in keinem Fall auf akademische Anerkennungen Anwendungen finden, vielmehr entschied sich der Gerichtshof gegen die Anwendbarkeit der Richtlinie 89/48/EWG ausschließlich aus dem Grund, daß diese Richtlinie lediglich den Bereich einer mindestens dreijährigen Hochschulausbildung erfasse, wohingegen der umstrittene akademische Grad am Ende nur eines Studienjahrs erwor-

554. Urteil vom 23, März 1993, Rs C-19/92 - Dieter Kraus/Land Baden-Württemberg. Slg. 1993, 1663, SchluBanträge des GA Van Gerven, Rdnr. 22 ff. unter Hinweis auf die Rechtsprechung des Gerichtshofs in den Rechtssachen 293/183 - Gravter - Urteil wom 13. Februar 1985, Slg. 1985, 593 und 24/86 . Kommission/Rat (ERASMUS) ., Urteil rom 30. Mai 1989, Slg. 1989, 1425.

555. Urteil vom 30. Mai 1989, Rs 242/87 - Kommission/Rat -, Slg. 1989, 1425 ff. Rdnr. 14 und 20.

556. Zur Abgrenzung zwischen Art. 57 EGV und Art. 126 und 127 EGV siehe die Erörterungen im Epilog.

557. Urteil vom 23. Mare 1993, Rs C-19/92 - Dieter Kraus/Land Baden-Württemberg -, Slg. 1993, 1663, Ranr. 25 und 26 . 
ben sei ${ }^{558}$. Diese Argumentation überzeugt zwar nicht vollkommen, da der LL.M. Grad erst nach AbschluB eines juristischen Grundstudiums erworben werden kann ${ }^{559}$, die rechtswissenschaftlichen Studien dauern jedoch in allen Mitgliedstaaten mindestens drei Jahre ${ }^{560}$. Zusammengerechnet bedeutet dies jedoch immer eine universitäre Ausbildung von mindestens drei Jahren. Für die Frage der Anwendung von Art. $57 \mathrm{Abs}$. 1 EGV auf den Bereich der akademischen Anerkennung ist diese Argumentation jedoch ohne Bedeutung. Die Anwendung der Richtlinie 92/51/EWG, die auch Anerkennungsregelungen von einjährigen Ausbildungen beinhaltet, wurde nämlich lediglich mit dem Hinweis auf die noch nicht abgelaufene Umsetzungsfrist verworfen ${ }^{561}$. Nach Ablauf der Umsetzungsfrist scheint der Gerichtshof einer Anwendung der Richtlinie 92/51/EWG auch auf Fälle akademischer Anerkennung nicht prinzipiell ablehnend gegenüber zu stehen.

\section{DiE KoORdinierung GEMÄSS ART. 57 ABs. 2 EGV}

Art. 57 Abs, 2 EGV gibt die Ermächtigung zum Erlaß von Richtlinien zur Koordinierung der Rechts- und Verwaltungsvorschriften der Mitgliedstaaten über die Aufnahme und Ausübung selbständiger Tätigkeiten. Neben dem Begriff "Koordinierung" werden im EG-Vertrag noch ähnliche vergleichbare Begriffe benützt: Angleichung, Annäherung, Anpassung, Abstimmung, Harmonisierung, Rechtsangleichung und Vereinheitlichung. Vor allem in den Anfangsjahren der Gemeinschaft hat diese unterschiedliche Begriffswahl zur Diskussion in der Literatur Anlaß gegeben, ob hinter den verschiedenen Begriffen auch ein unterschiedlicher Intensitätsgrad des Integrationsvorgangs zu suchen ist $^{562}$.

So vertrat vor allem Monaco die Auffassung, daß die Verfasser des Vertrages bewußt zwischen dem Gebrauch der einzelnen verwendeten Formulierungen unterschieden haben, um dadurch eine Intensitätsabstufung $\mathrm{zu}$ bewirken ${ }^{563}$. Dagegen verneinte ein anderer Teil der Literatur einen prinzipiellen Unterschied zwischen den Begriffen ${ }^{564}$. Die Kommission hatte bereits in ihrem 4. Gesambericht die Begriffe Angleichung, Harmonisierung und Koordinierung synonym verwendet. Lochner zeigt in seiner

558. Urteil vom 23. März 1993, Rs C-19/92 - Dieter Kraus/Land Baden-Wiirtemberg -, Slg. 1993, 1663 , Runr. 25.

559. Im Urteil wom 23. März 1993, Rs C-19/92 - Dieter Kraus/Land Baden-Württemberg -, Sig. 1993, 1663. Rdnr. 18 und 19 erkennt der Gerichsshof selbst, daß der umstrittene Grad eine zusătzliche Qualifikation darstellt.

560. Lonbay in De Witte/Forder. 75 (78). Siehe auch die durch die Kommission veröffentlichen Lănderberichte "Legall Education and Training in tomorrow"s Europe".

561. Urteil yom 23. März 1993, Rs C-19/92 - Dieter Kraus/Land Baden-Württemberg -, Sig. 1993, 1663 Rdnr. 26.

562. Herzog, $47 \mathrm{ff}$

563. Monaco, Rev. Int. de droit comparé 1960,61 (64). Ihm folgend auch Everling in Wohlfarth/Everling/Glaesner/Sprung, Kommentar zu Art. 57 Abs. 2 EWGV.

564. Siehe vor allem die ausfïhrliche Analyse von Lochner, ZStaatsw. Bd. 118, 1962, 35 ff., aber auch Everling 1963. 63, der im Gegensatz zu seiner 1960 im Kommentar noch vertretenen Auffassung nun einrumt "dak die Begriffe sich nur schwer von einander abgrenzen lassen. 
Analyse der unterschiedlichen Sprachfassungen des Vertrages, daß eine andere Auffassung auch kaum vertretbar ist, da bereits die verschiedenen sprachlichen Abfassungen des damaligen EWG-Vertrages nicht konsequent die unterschiedlichen Begriffe verwenden ${ }^{565}$. Daher ist seit Beginn der sechziger Jahre die absolut herrschende Auffassung, dafl die Begriffe Koordinierung, Rechtsangleichung und Harmonisierung nicht woneinander abgrenzbar sind ${ }^{\text {stos }}$.

Ziel der Koordinierung ist die Anpassung der Rechts- und Verwaltungsvorschriften der Mitgliedstaaten über die Aufnahme und Ausübung selbständiger Tätigkeit. Zu diesen Regelungen müssen die nationalen Zulassungsvoraussetzungen ebenso wie das Berufsordnungsrecht gerechnet werden. Die Formulierung ist bezüglich der kontinentalen Rechtssysteme verhältnismäBig eindeutig, da das Berufsrecht in der Regel durch formelles Gesetz, Verordnungen oder Ministerialerlasse geregelt ist, die alle unter die Begriffsbestinmung "Rechts- und Verwaltungsvorschriften" subsumiert werden können. Weniger eindeutig erscheint mir die Wortwahl bezüglich des Berufsrechts im Vereinigten Königreich und Irland. Die Zulassungsvoraussetzungen und das Berufsordnungsrecht einer wesentlichen Gruppe der reglementierten Berufe ist in beiden Mitgliedstaaten durch die chartered bodies autonom geregelt. Die chartered bodies müssen als privatrechtliche Organisation klassifiziert werden, obwohl sie häufig durch eine royal charter besonders beliehen sind und hieraus auch ihre Regelungsbefugnis ableiten ${ }^{567}$. Es dürfte sehr schwierig sein , die Berufsregelungen der chartered bodies als Rechts- und Verwaltungsworschriften der Mitgliedstaaten zu qualifizieren, so dal eine Koordinierung dieser Berufsgruppen bereits an diesem Element scheitern könnte.

Inhaltlich ist das Koordinierungskonzept der Kommission nicht nur auf das grenzüberschreitende Element im Rahmen der Niederlassungs- und Dienstleistungsfreiheit gerichtet. Vielmehr haben die gemäß Art. 57 Abs. 2 EGV ergangenen Koordinierungsvorschriften auch Bezug auf rein innerstaatlich ausgeübte Berufsausubungs- und -zulassungsregelungen. Die Kommission that es daher auch grundsătzlich abgelehnt, ein koordiniertes Recht lediglich für die grenzüberschreitende Tätigkeit (Unternehmen mit einer vocation européenne) zu schaffen ${ }^{568}$.

In der ursprünglichen Konzeption wollte die Kommission auf der Basis von Art. 57 Abs. 2 EGV allerdings eine andere Form von "Europäischen Berufen" schaffen, wobei angestrebtes Ziel eine im wesentlichen Unifizierung der jeweiligen Ausbildungs- und Zulassungsvoraussetzungen war. Die Tatsache, daf man bereits Mitte der siebziger Jahre von diesem ursprünglichen Konzept abgewichen ist, beruhte nicht auf dem Zweifel der grundsätzlichen Rechtmäßigkeit einer derartigen Harmonisierungskonzeption im Rahmen von Art. 57 Abs. 2 EGV, sondern auf der politischen Beschlußunfähigkeit im

565. Lochner, ZStatsw. Bd. 118, 1962, 39

566. Troberg in GTE-Handbuch, Art. 57 Rdar. 27; Hailbronner, Handkommentar, Art. 57 Rdnr. 6.

567. Siehe zu den chartered bodies much die Erörterungen in Zusammenhang mit dem allgemeinen. Anerkennungssystem gemä.乃 der Richtlinie 89/48/EWG auf Seite 183 .

568. Troberg in GTE-Handbuch Art. 57 Rdnr. 28 
Teil III

Rat. Die im folgenden noch darzustellenden Koordinierungsrichtlinien haben jedenfalls keine Unifizierung der Berufsausbildungen bewirkt, allenfalls garantieren sie eine Gleichwertigkeit der Ausbildungen. Auf Basis dieser Gleichwertigkeit erfolgt gemäß dem sektoriellen System die Anerkennung.

\section{§ 4. Der sektorielle Ansatz für die freien Berufe}

Die sektoriellen Richtlinienentwürfe für die Anerkennung der Diplome beruhten auf Art. 57 Abs. 1 EWGV. Sie wurden in der Regel ergänzt durch zwei weitere Entwürfe. Erstens einen Richtlinienentwurf gemäß Art. 57 Abs. 2 EWGV zur Koordinierung der Rechts- und Verwaltungsvorschriften der Mitgliedstaaten über die Aufnahme und Ausübung der jeweiligen selbständigen Tätigkeit; und zweitens einen Richtlinienentwurf zur Auflhebung der diskriminierenden Beschränkungen gemäß Art. 54 Abs. 2 EWGV ${ }^{569}$.

Diese Vorgehensweise beruhte auf der damals herrschenden Grundphilosophie, daß eine Anerkennung der Diplome, Prüfungszeugnisse und sonstiger Befähigungsnachweise für die Mitgliedstaaten und die einzelnen Berufsangehörigen nur dann akzeptabel ist, wenn zuvor eine weitgehende Koordinierung der Ausbildungsgänge stattgefunden hat. Dementsprechend legte die Kommission zu Beginn der Arbeiten großen Wert auf die Koordinierung der Berufsausbildung ${ }^{570}$. Der sektorielle Harmonisierungsansatz wurde aber auch von dem Gedanken beseelt, eine europäische Identität der einzelnen Berufe zu schaffen. Soweit sektorielle Richtlinien verabschiedet werden konnten, ist diese Zielsetzung weitgehend gelungen, da die Vertreter der nationalen Berufsorganisationen in den Verbindungsausschüssen regelmäßig Kontakt miteinander pflegen und sich dadurch ein europaweites Informationsnetz bilden konnte ${ }^{57 !}$.

Seit 1967 hat die Kommission dem Rat verschiedene Richtlinienentwürfe bezüglich der Niederlassungsfreiheit und der gegenseitigen Anerkennung von Diplomen unterbreitet $^{572}$. Dabei handelte es sich im Bereich der freiberuflichen Tätigkeit zunåchst vor allem um medizinische ${ }^{573}$ und pharmazeutische Berufe ${ }^{574}$. Neben diesen Berufen auf dem Gebiet des Gesundheitswesens gab es auch Entwürfe für Architekten ${ }^{575}$ und Ingenieure ${ }^{576}$. Interessanterweise sah der ursprüngliche Entwurf für Ingenieure keine gegenseitige Anerkennung der Diplome vor, sondern sollte als Übergangsmaßnahme lediglich eine Erleichterung der Niederlassung bewirken ${ }^{577}$. Die Ausbildung für Ingenieure war in den Mitgliedstaaten zwar sehr unterschiedlich geregelt, kein Mit-

569. Wägenbaur, Nuove Tendenze, 211

570. De Crayencour, RMC 1970, 447; de Crayencour 1981, 14

571. Minor in Pertek EIPA 1992, 3

572. Glorieu*, Barreau et médicins face au droit d'établissement 1968, 117, ff; Lando, CMLRev. 1971. 343; Mortelmans, SEW 1974, 613 (619)

573. ABI. Nr. C 54 vom 28. April 1969, 8. De Crayencour, RMC 1969, 167.

574. De Crayencour; RMC 1969, 167

575. Siehe dazu de Crayencour, RMC $1968,570-577$.

576. De Cravencour, RMC 1969, 299.

577. ABI. Nr. C 99 vom 30. Juli 1969, 1. 
gliedstaat verlangte jedoch die Staatsangehörigkeit als Voraussetzung zur Berufsausübung, so daß diese Abweichung vom Grundschema möglich erschien.

Alle diese Entwürfe beruhten auf Vorarbeiten der Dienststellen der Kommission. Diese bemühte sich dabei um eine enge Zusammenarbeit mit den Mitgliedstaaten ${ }^{578}$. Dieses Bemühen um Zusammenarbeit hatte sowohl formelle wie auch sachliche Gründe. Frankreich hatte 1965 - im Rahmen seiner "Politik des leeren Stuhls" - eine Konsultationsverpflichtung der Kommission gegenüber den Mitgliedstaaten gefordert ${ }^{579}$. Dies führte zu einer nach dieser politischen Krise verabschiedeten Erklärung über die Zusammenarbeit zwischen Rat und Kommission vom 29. Januar 1966, in der es heißt: "Es ist wünschenswert, daß die Kommission, bevor sie einen Vorschlag von besonderer Bedeutung annimmt, in geeigneter Weise über die Ständigen Vertreter mit den Regierungen der Mitgliedstaaten Fühlung nimmt" ${ }^{580}$. Eine Zusammenarbeit ist aber gerade bei derartigen Richtlinien, die eine Harmonisierung oder Koordinierung der Berufszugangs- und -ausübungsregelungen bewirken wollen, auch aus sachlichen Gründen geboten, da die Kommission, um eine solche Harmonisierung vornehmen zu können, die Rechtslage in allen Mitgliedstaaten kennen muß. Deshalb haben die Dienststellen der Kommission mit den jeweiligen Berufsorganisationen in den Mitgliedstaaten und dem Verbindungsausschuß, der aus Vertretern dieser Berufsorganisationen auf europäischer Ebene besteht, noch vor Verabschiedung der Entwürfe einen regen Gedankenaustausch geführt ${ }^{581}$.

Trotz dieser gemeinsamen Vorarbeiten blieb der Erfolg vor allem für die akademischen freien Berufe aus. Einige der Entwürfe blieben bereits im Vorverfahren stecken. Andere Entwürfe, und zwar die bezüglich der Ärzte, Apotheker und Architekten, erreichten das Ratsniveau, doch ebenfalls ohne sichtbaren Erfolg. Im November 1971 - beinahe zehn Jahre nach Verabschiedung der Allgemeinen Programme - fand die erste Sitzung der Bildungs- bzw. Erziehungsminister statt. Damit trat eine Veränderung ein. Wesentlich war ein Wandel der Zielvorstellung.

Die sechziger Jahre waren geprägt won der Idee, ein Höchstmaß an Koordinierung der Berufsworschriften zu verwirklichen. Maximalkoordinierung war das gesetzte Ziel. Diese Zielvorstellung beruhte auf dem Grundgedanken, daß eine gegenseitige Anerkennung der Diplome deren Gleichwertigkeit ihrem Wesen nach voraussetzt ${ }^{582}$. Obwohl man bei Beginn der Arbeiten dawon ausging, daß bei den europäischen Ländern die Gleichwertigkeit im großen und ganzen unterstellt werden kann, hatte man doch die Hoffnung - vielleicht sollte besser won Illusion gesprochen werden -, mit der Koordinierung "Europäische Berufe" zu schaffen. Dieser Koordinierungsansatz hatte genaue

578. Im Rahmen đieser Zusammenarbeit wird den Ständigen Vertretern bereits der erste Vorentwurf für eine Richthinie ubermittelt.

579. Harbrecht, 86/87" Kraus, 41.

580. EG-Bull. 3/1966, 8.

581. Siehe zum Verfahren de Craityencour 1981, 59.

582. Everling, 1963,60 . 
quanitiative Regelungen zum Ziel, wobei die Studienzeiträume mit einem genau bestimmten Fächerkatalog gefüllt werden sollten ${ }^{583}$. Wie Troberg zu Recht bemerkt, bedeutete diese Methode im Extremfall eine Harmonisierung der gesamten Bildungspolitik ${ }^{584}$

Es war nicht nur die Kornmission, die diese Maximalkoordinierung anstrebte, auch das Europäische Parlament war von der Definition eines Berufes auf europäischer Ebene beseelt ${ }^{585}$. Selbst die Berufsverbände standen der Maximalkoordinierung nicht feindlich gegenüber. Im Gegenteil, sie schlugen in die selbe Kerbe, in dem sie ihr starkes Interesse an einer Koordinierung der Standespflichten auf europäischer Ebene zum Ausdruck brachten ${ }^{585}$.

Es drängt sich die Frage auf, warum - trotz dieser gemeinsamen Begeisterung für die Schaffung eines europäischen Berufes - der Erfolg bei den freien Berufen so lange ausblieb und das gesamte Vorhaben letztlich zu einem "Katzenjammer" bei allen Betroffenen geführt hat. War der Anspruch, die Zielsetzung zu hoch? Waren die eingesetzten Mittel zu gering?

Unzweifelhaft war der Regelungsaufwand und die Verwaltungstätigkeit der Kommission bei der vertikalen Vorgehensweise sehr groß und die von de Crayencour genannte Zahl hiermit beschäftigter Kommissionsbeamter nicht ausreichend ${ }^{\$ 87}$. Grundsätzlich muß aber festgestellt werden, daß die uneingeschränkte Euphorie bezüglich der Schaffung "Europäischer Berufe" nur von kurzer Dauer war. Allzu bald zeigte sich, daß diese Vorgehensweise äußerst zeitraubend und schwierig werden würde. Es mehrten sich auch innerhalb der Kommission die warnenden Stimmen. Die unterschiedliche historische Entwicklung, die einige Berufe durchlaufen hatten, ließ die Koordinierung der Berufsausbildungen stocken. Es zeigte sich nämlich, daß die Berufsbilder trotz terminologischer Entsprechung der Berufsbezeichnung erheblich voneinander abwichen. Außjerdem wiesen die Ausbildungsgänge, die den Zugang zu den beruflichen Tätigkeiten eröffneten, nach Struktur, Inhalt und Dauer häufig große Unterschiede auf. Dies galt vielleicht weniger für die klassischen medizinischen Berufe, obwohl auch hier die Unterschiede nicht zu unterschätzen waren, als für einen technischen Beruf wie den Ingenieur. Für diesen Beruf konnte schon auf nationalem Niveau kaum ein einheitliches Berufsbild festgestelit werden, im internationalen Rahmen potenzierte sich diese Vielfalt.

583. Troberg in GTE-Handbuch, Art. 57, Rdnr. 37

584. Troberg in GTE-Handbuch, Art. 57, Rdnr. 37.

585. Siehe dazu die Stellungsnahme des Europalischen Partaments zu den ursprünglichen Richtlinienentwä rfen für Architekten: "Die Rechtsvorschriften müssen möglichst weitgeherud, aber progressiv koordinien werden; diase Koordinierung setat eine bestimmte Definition des Berufs auf europăischer Ebene voraus". ABI. Nr. C 72 vom 19 . Juli $1968,5$.

586. De Crayencour, 1981, 68, Roth, EuR 1986, 340 (346)

587. De Crayencour nennt die "Tatsache, dal die Kommission über zu wenig Bedienstete furr die Durchfübrung der Aufgabe verfugte, als eine wesentliche Ursache fur die Verzögenung, 1981, 14. 
Die erste Sitzung der Erziehungsminister im November $1971 \mathrm{kam}$ letztlich nur noch als Katalysator hinzu, um den bereits eingeleiteten Wandel in Worte zu fassen. Die Erziehungsminister forderten die Kommission auf, die Möglichkeit einer "allgemeinen gegenseitigen Anerkennung der Diplome"' zu prüfen ${ }^{588}$. Hinter dieser Auffassung stand die Hoffnung, daß sich für die gegenseitige Anerkennung der Diplome eine einfachere Methode finden ließie, wenn man von einer Übereinstimmung des kulturellen Niveaus der Mitgliedstaaten ausginge. De Crayencour übte an diesem neuen Ansatz unverhohlene Kritik, indem er zwar den Pragmatismus und den europäischen Geist dieser Idee lobte, sie aber als wirklichkeitsfern bezeichnete ${ }^{589}$. Ob dieser neue Ansatz bei den Erziehungsministern tatsächlich bis in das tiefste Inneren vom europäischen Geist durchdrungen war, mag bezweifelt werden. Weit wahrscheinlicher ist, daß gerade die Erziehungsminister eine zunehmende materielle Einmischung der Gemeinschaft im Bildungsbereich befürchteten. Trotz der Kritik durch de Crayencour setzte sich der neue Ansatz jedoch durch. Auch innerhalb der Kommission drängte man auf eine Wandlung der Konzeption ${ }^{50}$, wobei der Beitritt Großbritanniens, Dänemarks und Irlands 1973 sicher diesen Sinneswandel mitbeeinflußte. Mit nunmehr neun Mitgliedstaaten und damit neun unterschiedlichen Bildungssystemen - darunter so abweichende wie das britische und irische - konnten die Hoffnungen auf einen zügigen Abschluls von Koordinierungsrichtlinien mit quanitativen Detailregelungen endgültig begraben werden. Die neuen Mitgliedstaaten plädierten daher für eine qualitative Betrachtungsweise. Ziel der Koordinierung sollte nicht ein minutiös koordinierter Ausbildungsweg sein, vielmehr sollte die Vergleichbarkeit des "Endproduktes" der unterschiedlichen Ausbildungen angestrebt werden. Diese neue Betrachtungsweise gewann an Zustimmung. In einer Entschließung des Rates der Erziehungsminister vom Juni 1974 wurde der ursprüngliche Koordinierungsansatz dann eigentlich zu Grabe getragen ${ }^{591}$. Der Rat hat darin die folgende Leitlinie formuliert:

"Da man trotz der Unterschiede, die hinsichtlich der Ausbildungsprogramme zwischen den Mitgliedstaaten bestehen, in der Praxis eine Vergleichbarheit der Ausbildungsabschlüsse, die den Zugang zu gleichartigen Tätigkeitsfeldern eröffnen, in groben Umrissen feststellt, sollten die Richtlinien über die gegenseitige Anerkennung der beruflichen Befähigungsnachweise und über die Koordinierung der Bedingungen für den Zugang zu einem Beruf so wenig möglich detaillierte Ausbildungserfordernisse vorschreiben. "

Mit diesem neuen Ansatz konnte bei den sektoriellen Richtlinien der Durchbruch gelingen. Hintereinander wurden für die folgenden Berufsgruppen die Richtlinien verabschiedet:

588. De Crayencour 1981, 73

589. De Crayencour, 1981, 73.

590. Vogelaar, CMLRev. 1975, 211 (222): "Hamnonization had been forced onto the defensive"

591. Entschliebung des Rates vom 6. Juni 1974, ABI. Nr. C 98 vom 20. August 1974, I. 
1975 für die Ärte,

1977 für die Krankenschwestern und -pfleger,

1978 für die Zahnärzte und die Tierärzte,

1980 für die Hebammen und letztlich

1985 für die Apotheker und Architekten.

Verzichtet wurde nunmehr auf genaue Vorschriften hinsichtlich der Vorlesungsstunden und Studieninhalte. Lediglich die Gesamtausbildungsdauer für die einzelnen Berufe sowie die Mindestdauer bei fachspezifischer Weiterbildung wird bestimmt ${ }^{592}$. Wie bereits die Zeitabstånde zwischen den einzelnen Richtllinien vermuten lassen, wurde es aber auch nach diesem ersten Durchbruch nicht einfacher, selbst eine derartige Koordinierung der Ausbildungen zu erreichen. Bei der Apothekerrichtlinie hat es immerhin 18 Jahre gedauert bis man sich im Rat einigen konnte. Dabei wurde eine wirklich freie Niederlassung für Apotheker auch mit diesen Richtlinien nicht erreicht ${ }^{593}$. Die Architektenrichtlinie zeigt am deutlichsten, daß die Kompromißbereitschaft an enge Grenzen gestoßen war. Der Rat hat lediglich eine Anerkennungsrichtlinie verabschiedet. Eine allgemeine Koordinierung unterblieb. Allerdings müssen die gegenseitig anzuerkennenden Diplome aufgrund eines Studiengangs erworben werden, für den bestimmte Mindestregeln festgelegt sind ${ }^{594}$. Die Methode, die bei den medizinischen Berufen noch zu Resultaten geführt hatte, versagte im weiteren. Diese Tatsache kann auf unterschiedlichen Ursachen beruhen. Unzweifelhaft war die Regelung der medizinischen Berufe einfacher zu verwirklichen als die Koordinierung der technischen Berufe, da in allen Mitgliedstaaten für die Berufsausübung der Heiberufe eine im großen und ganzen vergleichbare Hochschulausbildung gefordert wird ${ }^{595}$. Bei den Architekten war es gerade die kurze Ausbildung an den deutschen Fachhochschulen, die den Widerstand der anderen Mitgliedstaaten für so lange Zeit aufrecht hielt ${ }^{596}$. Der Beitritt weiterer Mitgliedstaaten hat sicher nicht zur Vereinfachung des Problems beigetragen. Letztlich muß festgestellt werden ${ }_{n}$ daß spätestens seit Mitte der siebziger Jahre, die Notwendigkeit einer neuen Strategie von allen Betroffenen eingesehen worden ist, mit den Beschliussen des Europäischen Rates von Fontainebleau 1984, dem Weißbuch der Kommission 1985 und schlieflich der Richtlinie 89/48/EWG hat diese neve Strategie Gestalt bekommen.

592. So muß z.B. gemä\$ Art. 1 Abs. 2 der Richtinie 75/363/EWG die ärztiche Gesamtausbildung mindesters 6 Jahre oder 5900 Stunden theoretischen und prakcischen Unterricht an einer Universität umfassen.

593. So kennt das Apothekenrecht der meisten Mitgliedstaaten ein an geographischen oder wirtschaftlichen Kriterien orientientes Konzessionssystem. Siehe dazu Ress/Ukrow, 177, die in ihrer rechtsvergleichenden Studie zu der Feststellung kormen, daß nur in Großbritannien und Deutschland sich eine Liberalisienung der Apothekenniederlassung durchgesetzt hat.

594. Wãgenbaur, EuR 1987, 113 (116). Schneider, AA. 1989, 368 (371).

595. So Oppermann bereits 1964, BB 1964, 563 (567)! Diese Argumentation gilt allerdings nicht für die Ausbildurgen der Krankenschwestem und der Hebammen. Für beide Berufe können starke Abweichungen hinsichtlich der Ausbildungsregelungen konstatiert werden.

596. Eine sektorielle Regelung für Ingenieure scheiterte an der deutschen Fachhochschulausbildung, die als Bestandteil eines automatischen Anerkennungssystems wor allem won Italien als unakzeptabel angesehen wurde. 


\section{§. Die sektoriellen Richtlinien}

\section{A. DIE URSPRÜNGLICHEN ÄRZTERICHTLINIEN}

\section{Entstehungsgeschichte der ursprïnglichen Ärzterichtlinien}

Im März 1969 hatte die Kommission dem Rat drei Richtlinien-Vorschläge zur Herstellung der Freizügigkeit der Ärzte unterbreitet ${ }^{597}$. Hierbei handelte es sich an erster Stelle um eine Richtlinie zur Verwirklichung der Niederlassungsfreiheit und des freien Dienstleistungswerkehrs. Nicht erwähnt war die Tätigkeit des Arztes im Angestelltenverhältnis. Nach diesem Entwurf sollten die eindeutig diskriminierenden Beschränkungen bezüglich der Niederlassung und des Dienstlleistungsverkehrs aufgehoben werden. Art. 3 des Entwurfes verweist dabei ausdrücklich auf das Staatsangehörigkeitserfordernis, das noch in Deutschland ${ }^{598}$. Frankreich ${ }^{599}$, Italien ${ }^{600}$ und Luxemburg ${ }^{601}$ galt. Der zweite Richtlinienentwurf betraf die Anerkennung der Diplome, Prüfungszeugnisse und sonstige Befähigungsnachweise, wohingegen nach dem dritten Entwurf dic Koordinerung der Rechrs- und Verwaltungsvorschriften über die Aufnahme und Ausübung der ärztlichen Tätigkeit vorgenommen werden sollte. Zu diesen Richtlinienentwürfen gaben der Wissenschafts- und Sozialausschuß ${ }^{602}$ und das Europäische Parlament ${ }^{603}$ ihre Stellungsnahmen ab. In beiden Stellungsnahmen wurde die Erweiterung der Richtlinienbestimmungen auf die Tätigkeit des Arztes im Angestelltenverhältnis empfohlen. Begründet wurde diese Erweiterung mit dem Argument, daß der Beruf des Arztes sich nicht in angestellte und selbständig niedergelassene Ärzte aufteilen lasse. Vielmehr wäre es gebräuchlich, im Verlauf einer beruflichen Laufbahn abwechselnd in der einen oder der anderen Form tätig zu sein. Es gäbe selbst Ärzte die beide Tätigkeitsformen gleichzeitig ausübten. Diese Argumentation überzeugte auch die Kommission. Sie erweiterte daraufhin die Entwürfe dementsprechend.

Die Erweiterung der Richtlinienbestimmungen auf die angestellten Ärzte erleichterte jedoch in keiner Weise die Beschlußfassung im Rat, da die Stellung der Ärzte in öffentlichen Krankenhäusern sehr umstritten war ${ }^{604}$. Vor allem Frankreich und Italien, wo Ärzte in öffentlichen Krankenhäusern einen öffentlichrechtlichen Status ${ }^{605}$ haben, ver-

597. ABl, Nr. C 54 vom 28. April 1969,8. Zur weiteren Entwicklung siehe aucin Wägenbaur, RTDE 1973, $426 \mathrm{ff}$

598. \$ 3 Abs. 1 der Bundesärzteordnung in der Fassung wom 2. Oktober 1961, BGBil. I, 1857.

599. Code de la Santé Publique, 4. Buch, Titel I, Art. L. 356

600. Testo unico delle leggi sanitarie, art, 99 bis 103 und Decreto legislativo del Capo provvisorio dello Stato, Nr. 233 vom 13. September 1946, Gaz. Uff, wom 23. Oktober 1946.

601. Gesetz wom 5. August 1939 nnd Gesetz vom 10. Jull 1901, Art. 1: Mémorial, 1153

602. Stellungnahme vom 29. Januar 1970. ABI. Nr. C 36 vom 28. März 1970, 17.

603. Stellungnahme vom 6. Juli 1970, ABI. Nr. C 101 vom 4. August 1970, 13 .

604. Wägenbaur, CDE 1976,707 (709f.).

605. In Frankreich spricht man won "agents publics" "in Italien von "pubblici impiegati", wobei die ganze Kontroverse bezuglich Akt 48 Abs. 4 EGV auf der Zuständigkeit des Verwaltungsrichters für beide beruhte. Siehe dazu Maestripieri, 1971, 26; Webert, $70 \mathrm{ff}$ 
traten die Auffassung, daß die Einstellung von ausländischen Ärzten an öffentlichen Krankenhäusern gemäß Art. 48 Abs. 4 EWGV ausgeschlossen sei, da diese Tätigkeit zumindest auf ihrem Hoheitsgebiet als eine Beschäftigung in der öffentlichen Verwaltung qualifiziert werden müsse ${ }^{606}$. Die Arbeit im Rat begann im Juni 1970 und erst nach 5 Jahren mit schwierigen Unterhandlungen wurden die Richtlinien - reduziert auf zwei ${ }^{607}$ - verabschiedet. Die Urteile zu Art. 52 und Art. 59 EWGV in den Rechtssachen Reyners und van Binsbergen ${ }^{699}$, die im Laufe des Jahres 1974 ergangen Waren, erübrigten nämlich nach Ansicht der Kommission den Erlaß einer Richtlinie zur Verwirklichung der Niederlassungs freibeit und des freien Dienstleistungsverkehrs. Diese Auffassung wurde vom Rat auch geteilt.

Die Zeit zwischen 1970 und 1975 war - wie bereits festgestellt - durch ein zähes Feilschen im Rat bestimmt ${ }^{610}$. Nicht nur über die Frage der Stellung der Ärzte in öffentlichen Krankenhäusern, auch über die Inhallte der zu koordinerenden Ausbildungen insbesonders der Facharztausbildungen, konnte keine Einigung erzielt werden. Die Erweiterung der Gemeinschaft um drei neue Mitgliedstaaten mit einer teilweise sehr unterschiedlichen Regelungsstruktur führte zu neuen Schwierigkeiten ${ }^{611}$. Vor allem die britische Delegation vertrat die Auffassung, daß der beschrittene quantitative Ansatz mit Vorschriften über Mindestausbildungen unbefriedigend sei, es müßten vielmehr auch qualitative Erwägungen eine Rolle spielen ${ }^{612}$. Sie schlug die Einsetzung eines beratenden Ausschusses vor ${ }^{613}$.

Ralf Dahrendorf beschloß deshalb als verantwortlicher Kommissar, ein Hearing für eimen Beruf in der Gemeinschaft zu veranstalten. Die Wahl fiel auf den Beruf des Arztes, weil hier die Diskussionen im Rat hinsichtlich der Richtlinienentwürfe verhältnismäßig weit fortgeschritten waren. Teilweise beruhte die Entscheidung für die Ärzte auch auf der Überlegung, daß es sich um einen Beruf handelt, bei dem die Probleme der Begriffsbestimmung weniger zahlreich erschienen als in anderen Fällen ${ }^{614}$. Dieses Hearing fand Ende Oktober 1973 in Bruissel statt. Eingeladen waren alle nationalen Berufsverbände der Ärzte, Vertreter der Hochschul rektorenkonferenzen, der Lehrkörper

606. Wägenbaur, CDE 1976,707 (710); de Crayencour, 1981,96: Rochard, 80ff.

607. Siehe dazu Seite $120 \mathrm{ff}$

608. Urteil wom 21. Juni 1974, Rs 2/74 - Reyners * Sig. 1974, 661

609. Urteill vom 3. Dezember 1974, Rs, 33/74 - van Binsbergen -, Slg. 1974, 1299

610. Siehe dazu den sehr pessimistischen Artikel von de Crayencour, RMC 1973, 258 im Gegensatz zu seiner wesentlich positiveren Stellungsnahme in RMC $1970,447$.

611. De Crayencour 1981, 77; Mortellmans SEW 1974, 613 (621).

612. Entwhrf einer Entschließßung des Rates betreffend Leitlinien fïr die gegenseitige Anerkennung der Diplome, Prüfungszeugnisse und sonstige Befahigungsnachweise gema Art. 57 EWGW, KOM (74) 254 endg. Anlage III, Vermerk der Delegation des Vereinigten Königreichs. Siehe dauz auch de Crayencour, 1981,77.

613. Die britische Hallung war nicht unverständlich in Anbetracht des nationalen Ausbildungssystems. Die im allgemeunen wesentlich kürzeren Ausbitdungen irm Vereinigten Königreich finden ihre Rechtfertigung in der Intensität der Unterrichtsgestaltung.

614. Hearing über die gegenseitige Anerkennung der beruflichen Befhhigungsnachweise im Ralmem der Niederlassungsfreiheit für Ärzte, KOM (74) 254 endg.. Anhang 2, 3. 
der medizinischen Fakultăten, der Medizinstudentenvereinigungen, der Krankenhausund Krankenkassenorganisationen sowie der Verbraucherorganisationen. Die Ergebnisse dieses Hearings - getragen von einer so großen Basis innerhalb der Berufsgruppe ermöglichte schließlich den Durchbruch ${ }^{615}$, wobei man sich grundsätzlich auf die qualitative Vorgehensweise einigte.

Entscheidenden Anteil am Erfolg kommt dabei auch der Rechtsprechung des Europäischen Gerichtshofs aus dieser Periode $\mathrm{zu}^{616}$. Eine Reihe politisch schwer lösbarer Probleme wurde durch diese Rechtsprechung beseitigt, so daß sich der Druck auf den Rat zur Verabschiedung gemeinschaftlicher Regelungen auf diesem Sektor erheblich verstärkte.

\section{Der Anwendungsbereich der ursprünglichen Arzterichtlinien}

Die ursprünglichen Ärzterichtlinien ${ }^{617}$, die am 16. Juni 1975 vom Rat beschlossen wurden, sind die ersten sektoriellen Richtlinien, die eine Anerkennung der Diplome für eine Berufsgruppe innerhalb der Gemeinschaft gewährleisten ${ }^{618}$. Sie sind auf die Art. $49,57,66$ und 235 EWGV gestützt und betreffen damit sowohl die Niederlassungsfreiheit, den freien Dienstleistungsverkehr als auch die Freizügigkeit für die angestellten Ärte. Gemäß Art. 1 der Richtlinie 75/362/EWG gilt sie für die Tätigkeit als Arzt. Etwaige Tätigkeiten, die über das rein ärztliche Berufsfeld hinausgehen, so etwa die Krankenhausleitung, sind nicht vom Regelungsbereich der Richtlinien umfaßt.

Die Richtlinien wurden ergänzt durch einen Beschluß des Rates zur Einsetzung eines Beratenden Ausschusses für die ärztliche Ausbildung ${ }^{619}$, einen Beschluß zur Ein-

615. Hearing über die gegenseitige Anerkennung der beruflichen Befähigungsmachweise in Rahmen der Niedertassungsfreiheit für Arzte "KOM (74) 254 endg. Anhang 2.

616. Urtell wom 21. Juni 1974, Rs 2/74 - Reyners * Slg. 1974, 661; Urteil vom 3. Dezember 1974, Rs. $33 / 74$ - wan Binsbergen -, Slg. 1974, 1299, Unteil wom 12. Februar 1974, Rs 152/73 - Sotgiu/Deutsche Bundespost - Slg. 1974, 153.

617. Richtlinie 75/362/EWG vom 16. Juni 1975, AB1. Nr. L 167 vom 30. Juni 1975, 1, geändert durch Beitritswertrag vom 19. November 1979, ABI. 1979 $\mathrm{Nr}$ L 291 vom 19. November 1979, 9, RL 82/76/EWG vom 26. Jamuar 1982, ABI. Nr. L 43 vom 15. Februar 1982, 21. Beitriltsvertrag vom 12. Jani 1985. ABl. Nr. L 302 vom 15. November 1985, 158; RL 89/594/EWG vom 30. Oktober 1989. ABI. Nr. 341 vom 23. November 1989, 19 (Anerkennug).

Richtlinie 75/363/EWG vom 16. Juni 1975, ABl. Nr. L 167 wom 30. Juni 1975, 14 , geăndert durch RL 82/76/EWG vom 26. Januar 1982, ABI. Nr. L 43 vom 15. Februar 1982, 21, und RL 89/594/EWG wom 30. Oktober 1989, ABI. Nr. L 341 wom 23. November 1989,19 (Koordinerung).

618. Siehe dazu Anrys, JT 1975, Nr. 4920, 453; Wagenbaur, CDE 1976, 707; Rowe ${ }_{\text {w }}$ CDE 1976, 736; Kaschmia, La Rev. du pract. 1977, Nr. 38; Wägenbaur, RMC 1977, 311 ff.; Guigue, Rec. Dalloz 1978, 163; Soubeyrol, RTDE 1976, $601 \mathrm{ff}$; de Vries, Tijdschrift voor gezondheidsrecht 1977, $27 \mathrm{ff}$. Zur Umsetzung der Ärzterichtlinien siehe Bösche, NJW 1978, 575; Forlatï 1983, 1299; Hurwitz 1990 bespricht dagegen in seiner Studie "The Free Circulation of Physicians within the European Community" die empirischen Konsequenzen der Richtlinien auf die Mobilitäl von Ärzten inmerhalb der Gemeinschaft. Siehe auch Webert, 1982; Karle/Kennedy, Eur. Joumal of education 1989, 399 ff.; Pentek, J. CI Europe, Fasc. 740.

619. ABI. Nr. L 167 vom 30. Juni 1975, 17. 
setzung eines Ausschusses hoher Beamter für das offentliche Gesundheitswesen ${ }^{620}$, einer Empfehlung betreffend die Staatsangehörigen des Großherzogtums Luxemburg, die Inlhaber eines in einem Drittland ausgestellten Diploms sind ${ }^{621}$, und einer Empfehlung zur klinischen Ausbildung des Arztes ${ }^{622}$. Desweiteren gab der Rat bei Annahme der Texte eine Erklärung zu den Art. 12 und 22 der Richtlinie 75/362 (Anerkennungsrichtlinie) und zur Stellung der Krankenhausärzte $a b^{623}$

Der Richtlinientext wurde seit seiner Verabschiedung 1975 mehrmals geändert. Diese Änderungen beruhten teilweise auf dem Beitritt Griechenlands ${ }^{624}$. Spaniens und Portugals ${ }^{625}$, der jeweils eine textuelle Ergänzung hinsichtlich der Diplome dieser Mitgliedstaaten erforderlich machte. Sie wurden jedoch auch inhaltlich ergänzt ${ }^{626}$. Eine weitere wichtige Änderung bewirkte die Richtlinie 86/457/EWG vom 15. September 1986 über eine spezifische Ausbildung in der Allgemeinmedizin ${ }^{627}$. Danach darf ein praktischer Arzt ab dem I. Januar 1995 innerhalb des Kassenwesens nur noch mit einer entsprechenden Zusatzausbildung tätig werden.

Im Interesse der Rechtssicherheit und Klarheit erschien es der Kommission letztlich notwendig, alle Änderungen der Richtlinien 75/362/EWG und 75/363/EWG sowie den Inhalt der Richtlinie 86/457/EWG in einer Gesamtkodifikation zusammenzufassen. Desweiteren wurde diese Zusammenfassung zum Anlaß genommen, um bestimmte technische Änderungen und Erleichterungen hinsichtlich der Anwendung der Richtlinien durchzuführen. Die Kadifizierung wurde als Richtlinie 93/16/EWG zur Erleichterung der Freizügigkeit für Ärzte und zur gegenseitigen Anerkennung ihrer Diplome, Prüfungszeugnisse und sonstige Befähigungsnachweise an 5. April 1993 vom Rat verabschiedet ${ }^{628}$.

620. ABI. Nr. L, 167 vom 30. Juni 1975. 19.

621. ABI. Nr. L 167 wom 30. Jumi 1975, 20.

622. AB1. Nr. L 167 vom 30. Juni 1975, 21.

623. ABI. Nr. C 146 vom 1. Juli 1975, 1 .

624. ABI. Nr. L 291 vom 19. November $1979,90$.

625. ABI. Nr. L 302 vom 15. Nowember 1985,158

626. Die inhaltiche Ergänzung erfolgte durch đie Richtlinie 81/1057/EWG vom 14. Dezember 1981, ABI Nr. L 385 vom 31. Dezember 1981,25 , die Richtinie $82 / 76 / \mathrm{EWG}$ vom 26. Januar 1982 , ABI. $\mathrm{Nr}$ L 43 vom 15. Februar 1982,21 sowie durch Kapitel 1 der Richtlinie 89/594/EWG vom 30. Oktober 1989 ABI. Nr. L 341 vom 23. November 1989, 19. Eine enneute Anpassung des Richtlinientextes erfolgte durch das Abkommen vom 2. Mai 1992 über den Europäischen Wirtschaftsraum.

627. ABI. Nr. L 267 vom 19. September 1986, 26.

628. ABI. Nr. L 165 vom 7. Juli 1993, 1 . 
Die ursprünglichen Richtlinien sind weitgehend in den Mitgliedstaaten umgesetzt ${ }^{629}$. In Deutschland mußte die $86 / 457 /$ EWG durch die Bundesländer umgesetzt werden ${ }^{630}$. In Österreich bedurfte es zur selbständigen Ausübung des ärztlichen Berufs als praktischer Arzt oder als Facharzt nach der bisherigen Rechtslage ( $\$ 3$ Abs. 1, 2 und 5 Ärztegesetz) sowie für die Eintragung in die Ärzteliste der österreichischen Staatsangehörigkeit ${ }^{631}$. Es bestand insoweit Handlungsbedarf. Auch mußten einige Bereiche der praktischen Ausbildung entsprechend der Richtlinien geändert werden. Ab 1995 gillt auch in Österreïch die Voraussetzung einer mindestens zweijährigen Weiterbildung zum Arzt für Allgemeinmedizin, um im Rahmen des Sozialverischerungssystems ärztllich tätig zu sein.

629. Belgien: Ar. royal vom 21. Juni 1978, Moniteur Belge vom 1. Julli 1978; Armin. vom 22. Oktober 1976, Moniteur Belge wom 23. November 1976; Gesetz vom 4. April 1980; Mon. Belge 21. Mai 1980; Ar. min. vom 20. Juli 1983, Moniteur Beige vom 6. August 1986, 10038; Ar. min. vom 20. Juli 1986, Moniteur Belge vom 6. August 1986, 10041; Ar. min vom 26. September 1986, Moniteur BeIge vom 31. Oktober 1986, 14925/14926.

Deutschland" Gesetz vom 16. Juli 1977, BGBI. I vom 20. August 1977; Verord. vam 20. Juli 1977. BGBI I vom 26. Juli 1977; Neufassung der Bundesärzteordnung vom 16. April 1987, BGBI. I vom 24. April 1987, 1218; Gesetz von 23. Mär 1992, BGBI. I wom 7. April 1992, 719; Gesetz vom 27. April 1993. BGBd. I vom 30. April 1993, 512; Berichtigung vom 23. August 1993, BGBI. I von 4. September 1993,1529

Dänemark: Lov $\mathrm{Nr}^{2}, 275$ vom 26. Mai 1976

Frankreich: Loi Nr. 16-1288 vom 31. Dezember 1976, JO vom 1. Januar 1977; Ar. min vom 16. Oktober 1977, JO vom 20. Oktober 1977, 13111;

Griechenland: decr. pres. vom 27. März 1986, fek Nr. 31 vom 27. März 1986.

Irland: SI Nr. 288 vom 8. Dezmber 1976.

Italien: Legge Nr. 217 wom 22. Mai 1978. Gaz. uff. Nr. 146 vom 29. Mai 1978

Luxemburg: Loi vom 2. August 1977, Mem. Nr. 49 vom 11. August 1977, Loi vom 29. Aprill 1983, Mem. Nr. 31 wom 10. Mail 1983.

Niederlande: Min verond. Staatscourant vom 12. März 1984. Besluiten 1976 und 1978; Gesetz, Sthl. wom 2. April 1984. Siehe aber auch Wet op de beroepen in de individuele gezondheidszorg vom 11 November 1993, Stbl. 1993, 655; dazu Schneider 1994, 87.

Portugal: Decr. lei Nr. $326 / 87$ von 1. September 1987 sowie Decr. leil Nr. 73790 vom 6 . Màrz 1990 und Decr. lei Nr. $210 / 91$ vom 12. Juni 1991; Decr. lei $35 / 92$ vom 14. März 1992 " Decr. leï Nr. 114 wom 4. Juni 1992; Decr. lei 128/92 wotth 4. Juli 1992.

Spanien: Real decr. Nr, 3303/1978, BOE vom 29. Dezember 1978 und Real decr. 1691/1989, BOE vom 15. Januar 1990 ; Real decr. $1275 / 1992$ vom 23. Oktober 1992, BOE Nr. 283 vom 25. November 1992 ; Real decr. 853/1993 vom 4. Juni 1993.

Ver. Köngreich: Reg med. qualif. order 1977; SI 1981 vom 18. März 1981; SI Nr. 432 von 1981; SI Nr. 1642 van 1986. Zur Unsetzung bis 1982 siehe Webert.

630. Baden-Württemberg: Gesetz vom 5. April 1990, GBI. 1990, 123; Bayern: Gesetz wom 22. Dezember 1989, GVBI. 1989, 708; Bremen: Gesetz vom 19. Dezember 1989, GVBI. 1989, 434; Hamburg: Gesetz vom 5. Marz 1991, GVB1. 1991, 70; Hessen, Gesetz vom 25. Mai 1990, GVB1. 1990, 1.77; Niedersachsen: Gesetz vom 21. März 1990, GVB1. 1990, 81; Nordrhein-Westfalen: Gesetz vom 12. Dezember 1989, GVBI. 1989, 678; Rheinland-Pfalz: Gesetz vom 28, Dezember 1989, GVBע. 1989, 261: Schleswig-Holstein: Gesetz wom 11. März 1990, GVB1. $1990,132$.

63. Z. Zurn medizinischen Versorgungssystem in Österreich siehe Anmann'Arnold. 


\section{Die Systematik der Richtlinie $75 / 362 / E W G$}

Die Richtlinie 75/362/EWG ist in acht Kapitel untergliedert. Kapitel I bezeichnet den allgemeinen Anwendungsbereich der Richtlinie. Kapitel II bestimmt die Anerkenmung der Diplome, Prüfungszeugnisse und sonstige Befähigungsnachweise des Arztes, soweit sie in Übereinstimmung mit der Koordinerungsrichtlinie 75/363/EWG und damit richtlinienkonform sind. Kapitel III ist den fachärztlichen Diplomen gewidmet, die allen Mitgliedstaaten gemeinsam sind, während Kapitel IV sich auf die Anerkennung der fachärztlichen Diplome bezieht, die lediglich in zwei oder mehreren Mitgliedstaaten ausgestellt werden. Kapitel $\mathrm{V}$ betrifft die erworbenen Rechte und damit die Anerkennung nicht richtlinienkonformer Diplome. In Kapitel VI wird die Führung der Ausbildungsbezeichnung geregelt. Kapitel VII betrifft die Maßnahmen zur Erleichterung der tatsächlichen Ausübung des Niederlassungsrechts ind des Rechts auf freien Dienstleistungsverkehr. Hierbei wird unterschieden zwischen Bestimmungen, die lediglich auf eine der beiden Freiheiten Anwendung finden, und solchen, die für beide gemeinsam gelten. Kapitel VIII enthält einige Schlußbestimmungen, u.a. eine Regelung bezüglich der Vorbereitungszeit für die Zulassung zum Kassenarzt ${ }^{632}$ sowie einen Spezialartikel (Art. 24) für angestellte Ärzte.

\section{Der Inhalt der Richtlinie 75/362/EWG}

\section{a. Die Anerkennung richtlinienkonformer Diplome}

Kernstück der Regelung sind Art. 2 und 3 der Anerkennungsrichtlinie, in denen die gegenseitige Anerkennung der Diplome bestimmt ist, die den Anforderungen des Art. I der Koordinierungsrichtlinie entsprechen. Die Anerkennung erfolgt quasi automatisch, da die Diplome im Aufnahmestaat lediglich einer formalen Prüfung unterworfen werden dürfen. Nicht geprüft werden darf dagegen der Inhalt der ärztlichen Ausbildung im Herkunftsstaat. Diese Anerkennung erfolgt auf der Grundlage von bestimmten Mindestausbildungsbedingungen, die in der Koordinierungsrichtlinie für die Mitgliedstaaten verbindlich festgelegt sind (z.B. Mindestausbildungszeit von 6 Jahren oder 5500 Unterrichtsstunden). Nur im Falle erheblicher Zweifel an der Echtheit des Diploms kann der Aufnahmestaat vom Herkunftstaat eine Bestätigung verlangen. Bezweifelt ein Mitgliedstaat die Qualität einer Ausbildung und ihre Übereinstimmung mit den Mindestanforderungen der Richtlinien, so ist er nicht befugt, hierüber ein Urteil zu fällen. Vielmehr muß er diese Frage der Kommission zur Prüfung unterbreiten ${ }^{633}$.

Art. 2 der Richtlinie 75/362/EWG setzt für die Anerkennung voraus, daß der Antragsteller über ein in Art. 3 der Richtlinie 75/362/EWG genanntes Diplom verfügt. Art.

632. Diese Bestimmung betrifft den' besonderen Fall der Zulassung zum Kassenarzt in der Bundesrepublik Deutschiand.

633. Siehe dazu die Erklärung des Rates zu Art. 22 bei der Annahme der Texte uber die Niederlassungsfreiheit und den freien Dienstleistungsverkehr für Ärzte in der Gemeinschaft, AB1. Nr. C 146 wom I. Juli 1975. 1. 
3 wurde im Laufe der Zeit mehrmals geändert und ergänzt. Inzwischen wurde diese Bestimmung durch die neue Richtlinie 89/594/EWG in der Form erweitert, daß die Anerkennung auch für die Diplome eines anderen Mitgliedstaates gilt, die nicht ausdrücklich in der Richtlinie aufgeführt sind. Maßgebend ist vielmehr eine Bescheinigung des betroffenen Mitgliedstaates, daß dieses Diplom den Erfordernissen der Richtlinie 75/363/EWG (Koordinierungsrichtlinie) entspricht und er dieses Diplom seinen anderen in Art. 3 genannten Diplomen gleichstellt (Art. 9 Abs. 3 der Anerkennungsrichtlinie). Mit dieser Ergänzung sollte eine flexiblere Reaktion auf neue und alte Diplome ermöglicht werden, solange diese den Mindestkriterien der Koordinierungsrichtlinie entsprechen.

Die Approbation als Arzt ist für eine Anerkennung nicht erforderlich. Entscheidend ist nur, daß der Antragsteller im Besitz aller geforderten Diplome des Herkunftstaates ist. Umgekehrt ist der Nachweis der Approbation auch nicht ausreichend, um eine Anerkennung in einem anderen Mitgliedstaat zu bewirken, da diese in manchen Fällen auch aufgrund von Drittstaatsdiplomen erfolgen kann. Drittstaatsdiplome sind jedoch nicht von den Regelungen der gegenseitigen Anerkennung gemäß der Richtlinie 75/362/EWG erCaßt 6.34

Der Begriff Herkunftsstaat ist nicht immer ganz glücklich, da die Anerkennung auch zugunsten der eigenen Staatsangehörigen wirkt, die ihre Ausbildung in einem anderen Mitgliedstaat erworben haben und ihren Beruf im Heimatstaat ausüben wollen. Der Europäüsche Gerichtshof hat in der Rechtssache Broekmeulen deutlich festgestellt, daß die Richtlinien auch für die eigenen Staatsangehörigen gelten, die das Diplom in einem anderen Mitgliedstaat erworben haben ${ }^{635}$. An sie dürfen auch keine zusätzlichen Ausbildungserfordernisse gestellt werden. Im Falle Broekmeulen ging es um einen Niederländer, der in Belgien das belgische Arztdiplom erworben hatte. Die Niederlande kannten zu diesem Zeitpunkt die zusätzliche Ausbildung zum "huisarts". Die Huisarts Registratie Commissie verlangten diese Zusatzausbildung auch von Broekmeulen bei seiner Rückkehr in die Niederlande und verweigerten daher die Eintragung Broekmeulens in das Register der anerkannten praktischen Ärzte. Von einem Belgier hätten die niederländischen Behôrden dagegen eine derartige Zusatzausbildung nicht verlangt.

\section{b. Drittstaatsdiplome}

Die Anerkennung wirkt nur zugunsten der Angehörigen der Mitgliedstaaten und nur im Bezug auf die in der Gemeinschaft erworbenen Diplome. Bisher werden die Mitgliedstaaten lediglich durch eine Empfehlung aufgefordert, Drittstaatsdiplome anzuerkennen. Diese betrifft den Sonderfall Luxemburgs, weil dort wegen Fehlens einer Universität eine vollständige ärztliche Ausbildung nicht möglich ist. Luxemburger sind daher ge-

634. Siehe dazu Seite $80 \mathrm{ff}$. sowie die Erörterungen auf Seite 429.

635. Urteil vom 6. Oktober 1981, Rs 246/80 - C. Broekmeulen/Huisarts Registratie Commissie - S1g. 1981, 2311. Dazu Seite 54. 
zwungen, ihre Ausbildung außerhalb des Großherzogtums abzuschließen ${ }^{636}$. Eine ähnliche Empfehlung erging auch bei Abschluß des Abkommens zum Europäischen Wirtschaftsraum. In diesem Falle betrifft die Erklärung die Staatsangehörigen von Island, die in der Regel aufgrund der besonderen Ausbildungssituation in Island ihre universitäre Ausbildung und Fachspezialisierung im Ausland erhalten ${ }^{637}$.

In der Kommission wird jedoch allgemein eine Erweiterung der Anerkennung auf Drittstaatsdiplome im Bereich der sektoriellen Richtlinien erwogen. Hiermit soll eine Regelungsübereinstimmung mit den beiden Richtlinien des allgemeinen Anerkennungssystems hergestellt werden. Bisher haben die Mitgliedstaaten jedoch zögernd hinsichtlich einer derartigen Erweiterung reagiert, da mit Drittstaaten keine Koordinierung der Ausbilldungssysteme vorgenommen ist und das sektorielle Anerkennungssystem auch über keine Kompensationsinstrumente im Vergleich zum allgemeinen Anerkennungssystem verfügt. Wie oben dargestellt ${ }^{638}$, hat der Gerichishof in jüngster Zeit zweimal zur Frage der Anerkennung von Drittstaatsdiplomen Stellung nehmen müssen ${ }^{639}$. In beiden Fällen hat der EuGH eine automatische Anerkennung won Drittstaatsdiplomen bei sektoriellen Richtlinien abgelehnt. Allerdings hat der Gerichtshof in der Rechtssache Haim in Anschluß an seine Rechtsprechung "Vlassopoulou" die Verpflichtung gemäß3 Art. 52 EGV zur Überprüfung und Berücksichtigung der einschlägigen Berufserfahrung bestätigt.

\section{c. DDR-Diplome}

Von der Regelung bezüglich Drittstaatsdiplome gab es auch in der ursprünglichen Fassung der Ärzterichtlinien eine Ausnahme. Diese betraf die DDR-Diplome. Die Bundesrepublik Deutschland hatte während der Verhandlungen der sektoriellen Richtlinien auf eine Spezialbestimmung für DDR-Diplome bestanden. Für DDR-Diplome bestimmte die ursprüngliche Fassung der Richtlinie die Vorlage einer zusätzlichen Bescheinigung der Behörden der Bundesrepublik, worin die Gleichwertigkeit dieses Diploms mit dem in der Bundesrepublik ausgestellten bestätigt wird (Art. 3 Buchstabe a) Ziffer 3 der Anerkennungsrichtlinie ${ }^{(4 / C)}$. Inzwischen hat die Kommission in ihrem Maßnahmepaket für die Zeit nach dem Beitritt eine völlige Gleichstellung der DDRDiplome mit denen der Bundesrepublik vorgestellt, da die DDR-Diplome als richtlinienkonform angesehen werden können ${ }^{64 !}$.

636. Emptehlung 75/366/EWG vom 16. Juni 1975, ABl. L. 167 vom 30. Jumi 1975, 20.

637. Gemeinsame Erklänung betreffend Staatsamgehörige der Republik Island, die Inhaber eines im einem Drittland erteilten Diploms als Facharzt., Fachzahnarzt, Tierarzt, Apotheker, praktischer Arzt oder Architekt sind.

638. Siehe Seite 80 ff..

639. Urteil vom 9. Februar 1994, Rs C-319/92 * Salomone Haim/Kassenzahnärztliche Vereiniguag Nordrhein -, Slg. $1994,1-425$ sowiedas Urteil vom selben Tag in der Rs C-154/93 - Tawil-Albertini ", Slg. 1994, $1-451$.

640. In der ursprünglichen Fassung der Richtinie 75/362/EWG thandelte es sich um Art. 3 Buchstabe a) Ziffer 2.

6541. ABI. L Nr. 266 vom 28. September 1990, $₫ 2$ 


\section{d. Die Anerkennung nicht richtlinienkonformer Diplome}

Handelt es sich um ein Diplom, das vor Inkrafttreten der Ärzterichtlinien ausgestellt ist; so gilt Art. 9 Abs. 1 der Anerkennungsrichtlinie. Dieser Artikel wurde im Hinblick auf die erworbenen Rechte durch die Richtlinie 81/1057/EWG erweitert ${ }^{642}$. Mit dieser Ergänzung sollte eine Regelungslücke bezüglich der Diplome geschlossen werden, die den Mindestanforderungen an die Ausbildung entsprechend der Koordinierungsrichtlinie nicht genügen, soweit diese Ausbildung nach dem Beginn der Anwendung der Richtlinien abgeschlossen, aber vor dem Beginn ihrer Anwendung aufgenommen wurde. Zusätzlich zum Diplom muß der Antragsteller durch eine Bescheinigung nachweisen, daß er während der letzten fünf Jahre mindestens drei Jahre ununterbrochen, tatsächlich und rechtmäßig als Arzt tätig war. Undeutlich nach dem Wortlaut der Bestimmung ist, ob won dieser Regelung auch die Tätigkeit in einem anderen Mitgliedstaat erfaßt wird, der nicht das in Frage gestellte Diplom ausgestellt hat. Dies ist jedoch erforderlich, da ansonsten die Freizügigkeit des Betroffenen unverhältnismäßig beschränkt wäre. Allerdings ist dabei davon vorauszusetzen, daß die Tätigkeitsbescheinigung von dem Mitgliedstaat ausgestellt wird, in dem die Tätigkeit tatsächlich und rechtmäßig stattfand ${ }^{643}$.

\section{e. Facharztdiplome}

Die Richtlinie unterscheidet zwischen Facharztdiplomen, die in allen Mitgliedstaaten bekannt sind - auf sie finden die Art. 4 und 5 der Anerkennungsrichtlinie Anwendung und Facharztdiplomen, die lediglich in zwei oder mehreren Mitgliedstaaten ausgestellt werden. In diesem Fall gelten die Art. 6 und 7 sowie Art. 5 der Anerkennungsrichtlinie. Bei den in allen Mitgliedstaaten bekannten ärztlichen Fachrichtungen handelt es sich inzwischen nach mehrmaligen Anpassungen um vierzehn Facharztgebiete ${ }^{4}$. Diese werden in allen Mitgliedstaaten gegenseitig anerkannt. Bei den in Art. 7 Abs. 2 der Anerkennungsrichtlinie aufgeführten Fachrichtungen, die nur in zwei oder mehreren Mitgliedstaaten als Facharztgebiete bekannt sind, gelten die Anerkennungsregeln nur zwischen den Mitgliedstaaten, die ebenfalls in Art. 7 Abs. 2 der Anerkennungsrichtlinie für das entsprechende Fachgebiet genannt sind.

642. Richtlinie 81/1057/EWG vom 14. Dezember 1981, ABI. L 385 vom 31. Dezember 1981, 25.

643. Berscheid/Kirschbaum, 39.

644. Anásthesiologie, Chirurgie, Neurochinurgie, Frauenheilkunde und Geburtshilfe, Innere Medizin., Augenheilkunde, Hals-, Nasen-, Ohrenheilkunde, Kinderheilkunde. Lungen- und Bronchialheilkunde, Urologie, Orthopädie, Pathologie ${ }_{n}$ Neurologie und Psychiatrie. Die letzten drei genarnten Fachrichtun gen wurden erst durch die Richtlinie 89/594/EWG in den Katalog der allen Mitgliedstaaten gemeinsamen Fachrichtungen aufgenommen. 


\section{f. Die Anerkennung richtlinienkonformer Facharztdiplome}

Auch im Falle der Facharztdiplome muß zwischen richtlinienkonformen Diplomen und nicht richtlinienkonformen Diplomen unterschieden werden. Hinsichtich der allen Mitgliedstaaten gemeinsamen Facharztgebiete bestimmt Art. 4 der Anerkennungsrichtlinie, daß die in Art. 5 der Anerkennungsrichtlinie aufgelisteten Diplome automatisch anerkannt werden, soweit die ihnen zugrunde gelegte Ausbildung den Art. 2, 3, 4 und 8 der Koordinierungsrichtlinie entsprechen. Eine vergleichbare Regelung findet sich auch in Art. 6 der Anerkennungsrichtlinie für die Facharztdiplome, die nur in einigen Mitgliedstaaten als eigenständige Fachrichtung bekannt sind. Hierbei wird auf die Art. 2, 3, 5 und 8 der Koordinierungsrichtlinie und die darin geforderten Mindestausbildungsbedingungen verwiesen.

Entsprechend der Regelung für das ärztliche Grunddiplom muß ein Mitgliedstaat auch die fachärztlichen Befähigungsnachweise anerkennen, die den in den Art. 5 und 7 der Anerkennungsrichtlinie aufgeführten Bezeichnung nicht entsprechen, sofern eine Bescheinigung des Mitgliedstaates vorliegt, die die Übereinstimmung mit den Anforderungen der Koordinierungsrichtlinie und die Gleichstellung mit den aufgeführten Facharztdiplomen bestätigt (Art. 9 Abs. 3 der Anerkennungsrichtlinie).

\section{g. DDR-Facharztdiplome}

Im Gegensatz zu der Bestimmung in Art. 3 Buchstabe a) Ziffer 3 der Anerkennungsrichtlinie enthält Art. 5 keine entsprechende Regelung für die DDR-Facharztdiplome. Auch im Maßnahmenpaket der Kommission aus Anlaß3 der deutschen Einheit findet sich keine besondere Regelung dieser Materie. Die DDR-Facharztdiplome werden daher, falls sie ihre Richtlinienkonformität durch die deutschen Behörden bestätigt wird, gemäß Art. 9 Abs. 3 der Anerkennungsrichtlinie anerkannt werden müssen.

\section{h. Die Anerkennung nicht richtlinienkonformer Facharztdiplome}

Falls ein Facharztdiplom vor Beginn der Anwendung der Koordinienungsrichtlinie ausgestellt ist, bestimmt Art. 9 Abs. 2 der Anerkennungsrichtlinie die Anerkennung, auch wenn die Mindestanforderungen nicht erfüllt sind. In diesem Falle kann der Aufnahmestaat die Vorlage einer Bescheinigung verlangen, woraus hervorgeht, daß die betreffende fachärztliche Tätigkeit tatsächlich und rechtmäßig während eines Zeitraums ausgeiibt worden ist, der der verdoppelten Differenz zwischen der fachärztlichen Weiterausbildung im Herkunftsstal und der in der Koordinierungsrichtlinie genannten Mindestdauer der Fachausbildung entspricht. Dies bedeutet z.B. bei einer Differenz zwischen der tatsächlichen Facharztausbildung und der in der Koordinienungsrichtlinie festgelegten Mindestausbildung von zwei Jahren, daß der Aufnahmestaat vom Migranten den Nachweis einer vierjährigen fachärztlichen Berufserfahrung verlangen kann. Eine Ausnahme von dieser Regel gilt dann, wenn auch im Aufnahmestaat die vor Inkrafttreten der Richtlinie verlangte Facharatausbildung kürzer war als in den Art. 4 und 5 
Der vertikale Ansact

der Richtlinie 75/363/EWG vorgesehen ist. In diesem Fall wird die Differenz nach den Facharztausbildungen im Herkunfts- und im Aufnahmestaat berechnet.

\section{i. Sonstige Bestimmungen}

Der Richtlinientext macht einen Unterschied zwischen Bestimmungen, die gemeinsam das Niederlassungsrecht und den Dienstleistungsverkehr berühren, solchen Maßnahmen, die nur das Niederlassungsrecht betreffen sowie Bestimmungen, die nur bei grenzüberschreitender Dienstleistung gelten. Unerwähnt ist dabei die ärztliche Tätigkeit im Angestelltenverhä]tnis. Aufgrund der sachlichen Vergleichbarkeit bei der Niederlassung als selbständiger Arzt und der Aufnahme der ärztlichen Tärigkeit im Angestelltenverhältnis, muß davon ausgegangen werden, daß die Richtlinienbestimmungen, die die Niederlassung betreffen, auch Anwendung auf die ärztliche Tätigkeit im Angestelltenverhältnis finden.

(1) Gemeinsame Bestimmungen betreffend das Niederlassungsrecht und den Dienstleistungsverkehr

Die Richtlinie macht einen deutlichen Unterschied zwischen der Führung der Ausbildungsbezeichmung und der Führung der Berufsbezeichnung. Vom systematischen Standpunkt aus ist die Regelung der Ausbildungsbezeichnung in Art. 10 der Anerkennungsrichtlinie, während das Führen der Berufsbezeichnung in Art. 18 der Richtlinie zu finden ist, nicht sehr glücklich, da beide Bestimmungen doch in einem sehr engen Zusammenhang gesehen werden müssen.

(a) Das Recht zum Führen der Ausbildungsbezeichnung

Gemäß Art. 10 Abs. 1 der Anerkennungsrichtlinie sind die Ärzte und Fachärzte, deren Diplom aufgrund der Richtlinie anerkannt werden muB, dazu berechtigt, die in ihrem Heimat- oder Herkunftsstaat gültige rechtmäßige Ausbildungsbezeichnung und gegebenenfalls die betreffende Abkürzung im Aufnahmestaat zu führen. Der Aufnahmestaat muß keine Übersetzung der Ausbildungsbezeichung zugestehen. Vielmehr kann er vorschreiben, daß neben der Ausbildungsbezeichnung auch Name und Ort der Lehranstalt oder des Prüfungsausschusses genannt wird. Bei Verwechslungsgefahr mit einer Ausbildungsbezeichnung des Ausbildungsstaats, die eine zusätzliche Ausbildung voraussetzt, kann dieser gemäß Art. 10 Abs. 2 der Anerkennungsrichtlinie eine bestimmte Form worschreiben. Zweck der Regelung ist eine gewisse Warnfunktion gegenüber den potentiellen Patienten.

(b) Das Recht zum Führen der Berufsbezeichnung

Falls in einem Aufnahmestaat Vorschriften bezüglich der Berufsbezeichnung bei Ausübung der ärztlichen und fachärztlichen Tätigkeit bestehen, so bestimmt Art. 18 der Anerkennungsrichtlinie, daß die Personen, die die Anerkennungsvoraussetzungen der 
Art. 2, 4, 6 und 9 der Richtlinie erfüllen, zur Fuihrung der Berufsbezeichnung und gegebenenfalls der Facharztbezeichnung des Aufnahmestaats berechtigt sind.

(c) Das Recht auf Information über die Gesundheits- und Sozialvorschriften des Aufnahmestaats.

Gemäß Art. 20 Abs. 1 der Anerkennungsrichtlinie sind die Mitgliedstaaten dazu verpflichtet, den Begünstigten die Möglichkeit zur Information über die Gesundheits- und Sozlialvorschriften sowie gegebenenfalls über die Standesregeln des Aufnahmestaats zu bieten. In der Regelung wird die Einrichtung von entsprechenden Informationsstellen angeregt. Die Mitgliedstaaten haben diese Anregung auch aufgegriffen und solche Informationsstellen eingerichtet ${ }^{\$ 45}$

\section{(d) Sprachkenntnisse}

Sehr versteckt findet man in Art. 20 Abs. 3 der Anerkennungsrichtlinie auch noch einen Passus hinsichtlich der Sprachkenntnisse. Diese Regelung ist offensichtlich ein Kompromiß, der erst nach jahrelanger Diskussion zustande kam ${ }^{646}$. Laut De Crayencour waren die zuständigen Stellen der Kommission zunächst bemüht, eine Bestimmung bezüglich einer Anpassungszeit in den Richtlinientext aufzunehmen ${ }^{64 "}$. Auch der Ständige Ausschuß der Ärzte, das Europäische Parlament ${ }^{648}$ und der Wirtschafts- und Sozialausschun ${ }^{649}$ befürworteten eine Anpassungszeit. In dieser Periode sollte dem Zuwanderer unter Anleitung eines nationalen Berufsangehörigen die Gelegenheit gegeben werden, sich mit den Rechts- und Standesvorschriften sowie mit der Sprache des Aufnahmestaats näher vertraut zu machen ${ }^{650}$. Gleichzeitig sollte dem Aufnahmestaat aber untersagt werden, eine entsprechende Sprachprüfung abzunehmen. Dieser Gedanke stieß jedoch auf die Kritik des Juristischen Dienstes der Kommission, der in einer Ampassungszeit eine vertragswidrige Diskrimimierung sah ${ }^{65 .}$. Diese Argumentation sowie der Gedanke, daß eine Anpassungszeit den freien Dienstleistungsverkehr erheblich erschweren, wenn nicht gar vereiteln würde, haben dazu geführt, daß die Idee einer Anpassungszeit verworfen wurde. Statt dessen einigte man sich nach weiteren Diskussionen auf die in Art. 20 Abs. 3 der Anerkennungsrichtlinie verfaßte Kompromibformel.

645. Siehe dazu die in Berscheid/Kirschbaum im Anhang enthaltene Liste, $143 \mathrm{ff}$.

646. Siche dazu de Crayencour, 1981, 87; Berscheid/Kirschbaum. 27; Rochard, $112 \mathrm{ff}$.

647. De Crayencour, RMC 1969, 167 (173).

648. Siehe die Stellungmahme des Europässchen Parlaments in Doc. $80 / 70,44$

649. Siehe die Stellungnahme des Wïtschafts-und SozialausschuB, ABI. Nr. C 36 vom 28. Marz 1970, 17

650. De Cralyencour, 1981, 87. Der Gedarke einer Anpassungszeit war auch durch den Wirtschafts-und Sozlalausschuf bezüglich der Niederiasstung von Apothekern propagiert worden. Siehe dazu die Stellungnahme des Wintschafts- und Sozialauschusses zu dem ersten Richtlinienvorschlag der Kommission bezüglich der Anerkennung von Apothekerdiplomen, ABI. N. C 36 vom 28, März 1970, $12 \mathrm{f}$.

651. De Crayencour, 1981, 88, der im Hinblick auf die Argumentation des Juristischen Dienstes auf das. Allgemeine Programm für die Durchfühnung des. Niederlassungsrechuts verweist, whonach unter den Bestimmungen einschränkender Art ausdrucklich "ein Aufenthalt oder eine worherige Probezeit im Gastland" erwahnt wird. Siehe dazu das Allgemeine Programm, "Titel III, A, Buchstabed. 
Danach tragen die Mitgliedstaaten dafür Sorge, daß die Begünstigten gegebenenfalls in ihrem Interesse und im Interesse ihrer Patienten die Sprachkenntnisse erwerben, die sie für die Ausübung ihrer Berufstätigkeit im Aufnahmeland benötigen. Undeutlich ist nach dieser Formulierung, ob "das Sorge tragen der Mitgliedstaaten" auch in Form einer Sprachprüfung geschehen kann. Nach Auffassung der Kommission ist es den Mitgliedstaaten untersagt, derartige Prüfungen abzuhalten ${ }^{652}$. De Crayencour verweist auf eine Diskussion zwischen der Kommission und dem Vereinigten Königreich über eine entsprechende Prüfung. Danach hat sich das Vereinigte Königreich bereit erklärt, auf dije umstrittene Sprachprüfung zu verzichten ${ }^{653}$.

Für Ärzte im Angestelltenverhältnis wird vertreten, daß Art. 3 der Verordnung $1612 / 688^{654}$ gilt. Gemäß dieser Bestimmung können im Anbetracht der Besonderheit der zu vergebenden Stelle die erforderlichen Sprachkenntnisse verlangt werden ${ }^{65 s}$. Hieraus ließe sich eine entsprechende Anwendung für die selbständige ärztliche Tätigkeit argumentieren $^{656}$. Dagegen halten Séchét ${ }^{657}$ und Rowe ${ }^{658}$ die diesbezügliche Anwendung der Verordnung $1612 / 68$ auf die Ärzte im Angestelltenverhältnis für ungerechtfertigt. Nach den Regeln "lex posterior derogat legi priori" und "lex specialis derogat legi generali" müßßten auch für die angestellten Ärzte die Bestimmungen der Anerkennungsrichtlinie, d.h. in diesem Falle Art. 20 Abs. 3 gleichermaßen gelten ${ }^{659}$. Grundsätzlich ist diese Auffassung vorzuziehen, da sie eine ansonsten unverständliche unterschiedlliche Behandlung von selbständigen und angestellten Ärzten verhindert. Dies gilt um so mehr, da bei einem angestellten Arzt die Sprachikenntnisse auch im Einstellungsverfahren geprüft werden können, so daß die ansonsten geforderte ethische Eigenverantwortlichkeit des Arztes einer gewissen Überprüfung unterliegt. Es erscheint nämlich äußerst unwahrscheinlich, daß ein Arzt, bei dem bereits im Rahmen seines Einstellungsverfahrens ein deutlicher Mangel an Sprachkenntnissen festgestellt wird, überhaupt angestellt wird. Allerdings - und hier läßt sich ein gewisser Widerspruch nicht leugnen - steht diese Auffassung in einem Spannungsverhältnis zu Art. 24 der Anerkennungsrichtlinie, der gerade für die angestellten Ärzte auf die Verordnung $1612 / 68$ verweist ${ }^{600}$.

652. Berscheid/Kirschbaum, 27

653. De Crayencour, $1981,88$.

654. Verordnung (EWG) Nr. 1612/68 des Rates vom 15. Oktober 1968 über die Freizügigkeit der Arbeitnehmer innerhalb der Gemeinschaft, ABI. Nr. L 257 vom 19. Oktober 1968, 2

655. Berscheid/Kirschbaum, 55

656. Rochard, 117 .

657. Seche, CDE 1976, $32(40)$

658. Rowe, CDE 1976, 736 (746ff.)

659. Wagenbaur, CDE 1976, 707 (722); Rochard, 11.7

660. Die allgenteinen Anerkennungsrichtlinien 89/48/EWG und 92/5//EWG enthalten keinen Hinweis auf die Verordnung 1612/68. Eine besondere Sprachpnüung wird daher von der Kommission generell als unzulässig abgelehnt. Allendings werden die Eignungsprufungen in der Sprache dles Aufnahmestaates durchgeführ. Einige Mitliedstaten haben das Bestehen der Eignungsprüfung von den gezeigten sprachlichen Leistungen abhängig gemacht. 
(2) Besondere Bestimmungen betreffend das Niederlassungsrecht

(a) Zuverlässigkeitsnachweise

Hinsichtlich der freien Niederlassung kennt die Anerkennungsrichtlinie Bestimmungen über die Anerkennung von Zuverlässigkeitsnachweisen. Hierbei unterscheidet die Richtlinie zwischen der erstmaligen Aufnalhme der ärztlichen Tätigkeit (Art. 11) und der Verlegung der Berufsausübung von einem Mitgliedstaat in einen anderen Mitgliedstaat (Art. 12).

(i) Zuverlässigkeitsnachweis bei erstmaliger Aufnahme der ärztlichen Tätigkeit

Nach Art. 11 Abs. 1 der Anerkennungsrichtlinie kann ein Aufnahmestaat, der selbst für die erstmalige Aufnahme der ärztlichen Tätigkeit einen Zuverlässigkeitsnachweis von den eigenen Staatsangehörigen verlangt, gemäß Art $1 \downarrow$ Abs. 1 der Anerkennungsrichtlinie die Vorlage eines derartigen Zuverlässigkeitsnachweises auch vom Migranten verlangen. In diesem Fall muß der Aufnahmestaat eine von der zuständigen Behörde des Heimat- oder Herkunftsstaats ausgestellte Bescheinigung als ausreichenden Beweis anerkennen. Falls im betreffenden Herkunftsstaat für die Aufnahme der ärztlichen Tätigkeit kein Zuverlässigkeitsnachweis verlangt wird, kann der Aufnahmestaat gemäß Art. 11 Abs. 2 der Anerkennungsrichtlinie einen Strafregisterauszug oder, wenn dieser nicht beigebracht werden kann, einen gleichwertigen Nachweis verlangen ${ }^{661}$. An dieser Regelung wurde verschiedentlich Kritik geübt ${ }^{662}$. Zurecht wurde auf die Unterschiedlichkeit zwischen der "persönlichen Zuverlässigkeit" und der Tatsache des "Vorbestraftseins" hingewiesen. Auch bestehen zwischen den Mitgliedstaaten gravierende Unterschiede bezüglich der Strafbarheit von Handlungen und den hieraus gezogenen beruflichen Konsequenzen, so daß sich Problemfälle ergeben können.

Eine eigenartige Bestimmung enthält Art. 11 Abs. 3 der Anerkennungsrichtlinie. Danach kann der Aufnahmestaat, der von schwerwiegenden und genau bestimmten Tatbeständen Kenntnis erhält, die sich außerhalb des. Hoheitsgebiets des Aufnahmestaats und vor der Niederlassung ereignet haben, den Heimat- oder Herkunftsstaat davon unterrichten. Der Aufnahmestaat hat in diesem Fall kein eigenes Ermittlungsrecht. Vielmehr muB er es den Behörden des Herkunftsstaats überlassen, die Richtigkeit der Angaben zu überprüfen und gegebenenfalls Konsequenzen im Hinblick auf die auszustellende Bescheinigung zu ziehen. Diese Bestimmung war im ersten Richtlinienentwurf von 1969 nicht enthalten ${ }^{663}$. Laut de Crayencour hat dieser Passus auf Drängen der deutschen Delegation Eingang in den Richtlinientext gefunden ${ }^{664}$. Unklar ist, ob der Aufnahmestaat unabhängig von der Entscheidung des Herkunftsstaats seine eigenen Folgerungen aus

661. Ein Strafregisterauszug ist z.B. in Grobbritannien unbekannt.

662. Anrys, JT 1975, 453 (458); Wägenbaur, CDE 1976. 707 (715); Rowe, CDE 1976, 736 (744); Rochard, 92.

663. ABI. Nr. C 54 vom 28. April 1969,8

664. De Crayencour, 1981, 86. 
dem Ergebnis der Ermittlungen ziehen darf. Liest man jedoch Art. 11 Abs. 1 und Abs. 3 der Anerkennungsrichtlinie im Zusammenhang, so muß man daraus den Schluß ziehen, daß der Aufnahmestaat an die Entscheidung des Heimat- oder Herkunftsstaats in vollem Umfang gebunden ist. Zieht der Herkunftstaat aus dem Ergebnis der Ermittlungen keine berufsrechtlichen Konsequenzen, so kann der Aufnahmestaat gezwungen sein, die betreffende Person zur ärztlichen Tätigkeit zu zulassen, obwohl in einem vergleichbaren Fall bezüglich eines eigenen Staatsangehörigen eine Ablehnung erfolgen würde ${ }^{665}$.

(ii) Zuverlässigkeitsnachweis bei Verlegung der ärztlichen Berufsausübung von einem Mitgliedstaat in einen anderen

Art. 12 der Anerkennungsrichtlinie betrifft nicht den Fall der allgemeinen Ehrbarkeitsnachweise, sondern konkrete Verstöße bei Ausübung der ärztllichen Tätigkeit. Gemäß Art. 12 Abs. 1 ist der Herkunftsstaat verpflichtet, dem Aufnahmestaat, der selbst über entsprechende Rechts- und Verwaltungsworschriften verfügt, die erforderlichen Auskünfte über Disziplinarmaßnahmen wegen schwerwiegenden standeswidrigen Verhaltens oder über die strafrechtliche Verurteilung, welche die Ausübung des Berufs im Heimatoder Herkunftsstaat betreffen, zu übermitteln. Art. 12 Abs. 2 der Anerkennungsrichtlinie entspricht wörtlich Art. 11 Abs. 3, bezieht sich somit auf den Fall, daß der Aufnahmestaat Kenntnis von schwerwiegenden Verstössen des Zuwanderers erlangt und diesbezüglich die überprüfung durch den Heimat- oder Herkunftsstaat ersucht ${ }^{666}$. Grundsätzlich sorgen die Mitgliedstaaten dabei für die Vertraulichkeit der übermittelten Angaben (Art. 11 Abs. 3 und Art. 12. Abs. 3 der Anerkennungsrichtlinie).

Zu Art. 12 der Anerkennungsrichtlinie hat der Rat bei der Annahme des Textes eine ausdrückliche Erklärung abgelegt ${ }^{667}$. Darin heißt es: "Der Rat stellt fest, daß sich die Mitgliedstaaten im Hinblick auf die Anwendung des Art. 12 verpflichten, den Grundsatz. zu beachten, daß der Aufnahmestaat mit Ausnahme derjenigen Fälle, die sich auf in seinem eigenen Hoheitsgebiet vollzogenen Handlungen beziehen, den Rechtsvorteil des Niederlassungsrechts nur dann aussetzen oder verweigern kann, wenn in den vom Heimatoder Herkunftsstaat übernittelten Auskünften Sanktionen genannt sind, durch welche dem Betreffenden das Recht auf Ausübung seiner Tätigkeit in seinem Heimats- oder Herkunftsstaat vorübergehend oder endgültig abgesprochen wird."

665. Wie de Crayencour zu Recht bemerkt, dürften diese Fülle jedoch sehr selten sein, da die berufsrechtlichen Regelungen in den Mitgliedstaaten zwar unterschiedlich sind, schwerwiegende Vergehen gegen den beruflichen Ethos jedoch im allgemeinen überall geahndet werden. Siehe dazu de Crayencour. 1981,86

666. Siehe oben Seite 131

667. AB1. Nr. C 146 vom 1. Juli $1975,1$. 


\section{(b) Gesundheitszeugnis}

Ein Aufnahmestaat, der von seinen eigenen Staatsangehörigen für die Aufnahme oder die Ausübung der ärztlichen Tätigkeit ein Gesundheitszeugnis über den körperlichen und geistigen Gesundheitszustand verlangt, kann die Vorlage eines solchen Zeugnisses auch vom Zuwanderer fordern. In diesem Fall muß der Aufnahmestaat gemäß Art. 13 die entsprechende Bescheinigung des Heimat- oder Herkunftsstaat anerkennen. Wenn dieser ein derartiges Zeugnis nicht verlangt ${ }^{668}$, so erkennt der Aufnahmestaat eine von der zuständigen Behörde des Heimat- oder Herkunftsstaat ausgestellte Bescheinigung an.

Rochard verweist bezüglich dieser Bestimmung auf den Streit in der Literatur. Einige Autoren vertraten die Auffassung, daß die Vorlage eines Gesundheitszeugnisses auch im Falle der ärztlichen Dienstleistung erforderlich sein solle ${ }^{669}$. Zurecht vertritt Rochard dagegen die Ansicht, daß eine solche Erweiterung den Dienstleistungsverkehr in einer unproportionalen Weise beschränken würde ${ }^{670}$. Dies gilt um so mehr, als es einem Aufnahmestaat freisteht - falls ein Arzt tatsächlich nicht über den erforderlichen körperlichen oder geistigen Gesundheitszustand verfügt, um die ärztliche Tätigkeit auszuüben - ihm auch nur die vorübergehende Tätigkeit zu verweigern. Denn jede Dienstleistung unterliegt den innerstaatlichen Vorschriften des Mitgliedstaats, in dem sie erbracht wird ${ }^{671}$.

\section{(c) Zulassungsverfahren}

Das Zulassungsverfahren muß gemäß Art. 15 Abs. 1 der Anerkennungsrichtlinie innerhalb kürzester Frist, spätestens aber drei Monate nach Einreichung der vollständigen Unterlagen abgeschlossen werden. Diese Frist kann im Falle eines Verfahrens gemäß Art. 11 Abs. 3 oder Art. 12 Abs. 2 der Anerkennungsrichtlinie ausgesetzt werden. In diesem Fall muß der konsultierte Mitgliedstaat seine Antwort binnen drei Monaten erteilen, andernfalls setzt der Aufnahmestaat das Zulassungsverfahren nach Ablauf der Frist fort ( Art. 15 Abs. 2). Welche Konsequenz der Aufnahmestaat bei Schweigen des Heimat- oder Herkunftsstaat zu ziehen hat, ist dem Richtlinientext nicht deutlich zu entnehmen. Entweder er erteilt dem Antragsteller ungeachtet etwaiger Zuverlässigkeitsbedenken die Berufszulassung, oder aber er setzt das Verfahren unter Verstoß der Fristenbestimmung des Art. 15 Abs. 2 der Anerkennungsrichtlinie so lange aus, bis der säumige Mitgliedstaat auf wiederholte Nachfrage geantwortet hat. Beidle Lösungen sind nicht sehr befriedigend. Wie Anrys zu Recht bemerkt, hat diese Bestimmung zur Folge, daß die Untätigkeit eines Mitgliedstaats die rechtmäßige Anwendung der Richtlinie in einem anderen Mitgliedstaat verhindern kann ${ }^{6 / 2}$.

668. Dies betrifft Großbritannien, Irland, Italien und Luxemburg.

669. Rochard, 98; siehe dazu auch Wägenbaur, CDE 1976, 707 (718)

670. Rochard, 99; siehe dazu auch Anrys, JT 1975, 453 (458)

671. Rochard, 99.

672. Anrys, IT 1975, 453 (459); Rochard, 97 
Undeutlich ist auch die Regelung etwaiger Rechtsmittel. Zwar wird die Einlegung eines Rechtsmittels im Anschluß an das Zulassungsverfahren in Art. 15 Abs. 1 der Anerkennungsrichtlinie erwähnt, Mitgliedstaaten werden durch diese Regelung jedoch nicht verpflichtet, einen gerichtlichen Rechtsbehelf nach innerstaatlichem Recht einzurichten ${ }^{673}$. In der Regel dürfte zwar in den meisten Mitgliedstaaten ein Rechtsbehelf bestehen, von dem der Betreffende, wenn keine Entscheidung ergangen ist, nach Ablauf der Frist Gebrauch machen kann, dies ist jedoch nicht zwingend ${ }^{674}$.

\section{(d) Eidesleistung}

Art. 15 a regelt schlielßlich den Fall, daß im Aufnahmestaat für die Aufnahme oder die Ausübung der ärztlichen Tätigkeit eine Eidesleistung oder eine feierliche Erklärung verlangt wird ${ }^{675}$. Können die Angehörigen eines anderen Mitgliedstaats diese Formel nicht benutzen oder ist sie ihnen nicht zumutbar, so muß der Aufnahmestaat eine geeignete gleichwertige Formel zur Verfügung stellen.

(e) Aufnahme in einen Berufsverband oder eine Berufskörperschaft

Grundsätzlich ist in allen Mitgliedstaaten die Zulassung zur Berufsausübung an die Mitgliedschaft bei dem entsprechende Berufsverband bzw. Berufskörperschaft gekoppelt. Die Anerkennungsrichtlinie enthält keine eigenständige Bestimmung bezüglich der Aufnahme in einen Berufsverband oder eine Berufskörperschaft des Aufnahmestaats. Vielmehr enthält der erste Erwägungsgrund der Anerkennungsrichtlinie einen deutlichen Hinweis auf den Grundsatz der Inländergleichbehandlung. Danach ist seit Ablauf der Übergangszeit jede Diskriminierung aufgrund der Staatsangehörigkeit untersagt. Dieser Grundsatz gilt auch für die Eintragung oder Mitgliedschaft bei Berufswerbänden oder Berufskörperschaften. Die Mitgliedstaaten waren somit nach Ablauf der Übergangszeit verpflichtet, etwaige Staatsangehörigkeitsbedingungen bei Aufnahme in eine Berufskörperschaft entsprechend anzupassen ${ }^{676}$.

\section{(f) Doppelniederlassung}

Problematisch war für längere Zeit die Frage der Doppelniederlassung. Nach dem Recht einiger Mitgliedstaaten war eine Doppelniederlassung verboten ${ }^{677}$. In diesen Mitgliedstaaten war die Mitgliedschaft bei der entsprechenden Berufskörperschaft nur möglich, wenn der Zuwanderer zuvor aus dem Berufsverband seines Herkunftsstaats ausgetreten war. Frankreich verlangte z.B. eine entsprechende Bescheinigung über den Austritt aus

673. Hier ist ein deuticher Untersehied zu der Verfahrensbestimmung des Art. 8 Abs. 2 der Richtlinie 89/48/EWG festzustellen.

674. Siehe dazu auch Wägenbaur, RMC 1977, 311(313).

675. Es kann sich dabei um einen spezifischen Berufseid handeln. Gedacht werden kann jedoch auch im Falle eines Krankenhausarztes an einen Eid bei Aufnahme in das Beamtenverhältnis.

676. Siehe dazu auch die Antwort der Kommission auf eine schriftliche Anfrage in ABI. Nr. C 242 vom 22. Oktober 1975, 27.

677. Belgien, Detuschland, Frankreich und Luxemburg. 
dem Berufsverband des Herkunftsstaats ${ }^{678}$. Seit den Entscheidungen des EuGH in den Rechtssachen Klopp ${ }^{679}$ und Kommission gegen Frankreich ${ }^{680}$ ist die Frage der Doppelniederlassung grundsätzlich geklärt ${ }^{681}$. Im Verfahren gegen Frankreich stand gerade die Doppelniederlassung von Ärzten und Zahnärzten im Streit. Dabei hat der Gerichtshof in deutlichen Worten festgestellt, "daß das Verbot, einen Arzt oder Zahnarzt, der weiterhin in einem anderen Mitgliedstaat zugelassen ist, in Frankreich zuzullassen, zu absolut und zu allgemein ist, als daß es durch die Notwendigkeit gerechtfertigt werden könnte, die Kontinuität der Krankenversorgung sicherzustellen oder in Frankreich das französische Standesrecht anzuwenden ${ }^{682 "}$. Trotz dieser eindeutigen Worte mußte der Gerichtshof 1992 in einem Verfahren gegen Luxemburg erneut zur Frage der Doppelniederlassung von Ärzten, Zahnärzten und Tierärzten Stellung nehmen ${ }^{663}$. Es überrascht nicht, daß der Gerichtshof in seinem Urteil gegen Luxemburg seine ständige Rechtsprechung bestätigte.

(3) Besondere Bestimmungen betreffend den Dienstleistungsverkehr

Die Anerkennungsrichtlinie kennt zwei besondere Regelungen für den Dienstleistungsverkehr ${ }^{684}$. Diese enthalten gewisse Freistellungen von der Mitgliedschaft bei einem Berufsverband (Art. 16 Abs. 1) und der Kassenzulassung (Art. 17) im Staat der Dienstleistung. Auch ist ein Anzeigeverfahren (Art. 16 Abs. 2) geregelt.

(a) Freistellung von der Mitgliedschaft bei einem Berufsverband des Aufnahmestaats

Im Falle einer grenzüberschreitenden Dienstleistung ist der Arzt von einer Mitgliedschaft bei einem Berufsverband oder einer Berufskörperschaft im Staat der Dienstleistung befreit. Der dienstleistende Arzt unterliegt jedoch den beruflichen und administrativen Disziplinarmaßnahmen des Aufnahmestaats (Art. 15 Abs. 1 Satz 2). Damit besteht für den Arzt, der eine grenzüberschreitende Dienstleistung erbringt, eine doppelte Disziplinaraufsicht, nämlich seitens des Herkunftsstaats wie seitens des Aufnahmestaats.

678. Art. $\mathbb{L} 412$ letzter Absatz des französischen Code de la santé publique in der durch Art. 10 des Ge. setzes Nr. 76-1288 vom 31. Dezember 1976 geănderten Fassung sowie Art. 1/Nr. 6 des Dekrets 77 456 vom 28. April 1977, JORF vom 30. April 1977, 2508,

679. Urteil wom 12. Juli 1984, Rs $107 / 83$ - Ordre des avocats au barreau de Paris/Onno Klopp - SIg. 1984, 2971. Siehe dazu Borgreve, RIW 1984, 988; Bnunois, RTDE 1985, 65; Gormley, ELR 1984, 439", Mendelsohn, Harv. Int. L. J. 1985, 562; Watson, CMLRev, 1985, 743.

680. Urteil vom 30. April 1986, Rs 96/85 - Kommission/Frankreich -, SIg. 1986, 1475

681. Siebe zu beiden Entscheidungen die Ertauterungen Seite $56 \mathrm{f}$..

682. Unteil wom 30. April 1986, Rs $96 / 85$ - Kommission/Frankreich -, Slg. 1986, 1475, Rdnr. 14 .

683. Urteil wom 16. Juni 1992, Rs C 351/90 - Kommission/Luxemburg -, Slg. 1992. 1-3945. In selben Zeitraum erging auch die Entscheidung in der Rs C 106/91 - Ramrath - , Slg. 1992, I-3351 $20 \mathrm{rr}$ Doppelniederlassung von Wirtschaftsprufern. Dazu Seite $73 \mathrm{f}$..

684. An diesen Sonderregelungen wurde won Rowe Kritik geübt, CDE 1976, 736 (744). 
Mitgliedstaaten ist es dabei zugestanden, eine vorübergehende automatisch eintretende Eintragung oder eine Pro-forma-Mitgliedschaft bei einem Berufsverband, einer Berufskörperschaft odler einem Register vorzusehen, um die in ihrem Gebiet geltenden Disziplinarvorschriften anwenden zu können. Voraussetzung ist dabei allerdings, daß durch dieses Erfordernis die Dienstleistung in keiner Weise verzögert oder erschwert wird. Auch dürfen dem Leistungserbringer durch diese Maßnahme keine zusätzlichen Kosten entstehen ${ }^{6.5}$.

\section{(b) Freistellung von der Kassenzulassung}

Im Falle einer grenzüberschreitenden Dienstleistung in einem Aufnahmestaat, der zur Abrechnung für Tätigkeiten zugunsten von Patienten, die sozialversichert sind, vom. Arzt die Mitgliedschaft bei einer Körperschaft des öffentlichen Rechts verlangt ${ }^{60 \%}$, hat dieser Mitgliedstaat den Dienstleistungserbringer von diesem Erfordernis zu befreien (Art. 16 Satz 1). Der Mitgliedstaat ist dabei allerdings berechtigt, vom betroffenen Arzt vor oder in dringenden Fällen so rasch wie möglich nach Erbringung der Dienstleistung, eine Unterrichtung der betreffenden Körperschaft zu verlangen (Art. 16 Satz 2).

\section{(c) Anzeigepflicht}

Gemäß Art. 16 Abs. 2 der Anerkennungsrichtlinie kann der Aufnahmestaat verlangen, daß der Dienstleistungserbringer von seiner Tätigkeit den zuständigen Behörden des Aufnahmestaats Meldung macht, falls ein vorübergehender Aufenthalt im Aufnahmestaat erforderlich ist. In dringenden Fällen kann die Anzeige auch unverzüglich nach Erbringung der Dienstleistung erfolgen. Diese Bestimmung ist nicht besonders glücklich formuliert, da sie verschiedene Fragen aufwirft. Es ist dabei weder deutlich, wann von einem vorübergehenden Aufenthalt im Aufnahmestaat gesprochen werden muß, noch besteht Klarheit über die Definition eines "dringenden Falles". Besonders unbefriedigend erscheint diese Anzeigeverpflichtung in Grenzgebieten. Muß bereits von einem vorübergehenden Aufenthalt gesprochen werden, wenn ein Arzt einen Hausbesuch bei einem Patienten in direkter Grenznähe ausführt, d.h. bei einem Verbleib von etwa einer Viertelstunde? Oder beginnt der vorübergehende Aufenthalt und damit die Anzeigepflich: erst bei einem eim- oder mehrtägigem Aufenthalt, etwa in den Fällen; in denen ein Spezialist zur Ausführung einer schwierigen Operation in den Aufnahmestaat gerufen wird?

Liegt ein Fall der Anzeigepflicht vor, dann kann der Aufnahmestaat jedenfalls gemäB Art. 16 Abs. 3 vom betreffenden Arzt mehrere Dokumente verlangen. Diese Dokumente müssen die rechtmäßige Ausübung des Berufs im Niederlassungsstaat und den Besitz der nach der Richtlinie erforderlichen Diplome bestätigen. Dabei dürfen diese Dokumente laut Art. 16 Abs. 4 bei ihrer Vorlage nicht älter als zwölf Monate sein. Gerade die

685. Dieser Unterabsatz wurde durch die Richtinie 82/76/EWG hinzugefügt.

686. Dies gilt z.B. in der Bundesrepublik, wo die Zulassung als Kassenarzt verlangt wird. Eine ahnliche Situation besteht auch in Großbritannien im Hinblick auf die Mitgliedschaft im National Health Service. 
Tetil III

Kombination beider Vorschriften zeigt die Absurdität für den in Grenznähe tätigen Arzt. MußB dieser Arzt nun bei Hausbesuchen, die ihn über die Grenze führen, grundsätzlich neben seiner Arzttasche eine Dokumentenmappe bei sich führen, wobei deren Inhalt alle zwölf Monate erneuert werden muß? Muß dieser Arzt jeden einzelnen Besuch an die zuständige Behörde melden? In diesem Falle würden die Spezialbestimmungen für dèn Dienstleistungsverkehr im Vergleich zu den Niederlassungsbestimmungen keine Erleichterung des Verfahrens bedeuten, sondern müßten als schwerwiegende Behinderung qualifiziert werden. Dies würde jedoch der Grundintention der Richtlinie widersprechen, die den Dienstlleistungsverkehr einem gegenüber der Niederlassung vereinfachten Verfahrenssystem unterwerfen wollte ${ }^{687}$. Auch könnte bel einer derartigen Interpretation ein VerstoB gegen Art. $62 \mathrm{EGV}$ vorliegen, zumindest dann, wenn aufgrund bilateraler Verträge bezüglich grenzüberschreitenden Tätigkeiten bisher ein liberaleres System angewendet wurde ${ }^{688}$.

Die deutsche Umsetzung dieser Vorschrift unterstreicht die Zweideutigkeit der Bestimmung. $\$ 10$ a des Gesetzes zur Änderung der Bundesärzteordnung ${ }^{689}$ regelt die Erbringung von Dienstleistungen. Bei dieser Bestimmung ist das Erfordernis des vorübergehenden Aufenthalts ersetzt durch eine allgemeine Verweisung auf Art. 60 EWGV. Nach $\S 10$ a Abs. 2 des Gesetzes zur Änderung der Bundesärzteordnung unterliegt der Dienstleistungserbringer, der vorübergehend den ärztlichen Beruf in Deutschland ausübt, somit der Anzeigeverpflichtung. Dieser Austausch der Begriffe "vorübergehender Aufenthalt" gegenüber "vorübergehende Ausübung des ärztlichen Berufs" erscheint mir bedenklich, da man meiner Ansicht nach bei einem Hausbesuch von ungefähr fünfzehn Minuten kaum von einem vorübergehenden Aufenthalt sprechen kann, jedoch sehr wohl von einer vorübergehenden Ausübung des Berufs. Die beiden Begriffe sind somit nicht ohne weiteres austauschbar. Die Voraussetzung des "vorübergehenden Aufenthalts" scheint auch sehr bewußt in den Richtlinientext aufgenommen Zu sein, da der Richtlinientext ansonsten, d.h. Art. 16 Abs. 2, 1. Halbsatz der Anerkennungsrichtlinie, auch ohne diese Zufügung bereits den vom deutschen Gesetzgeber angenommenen Sinn, nämlich "vorübergehende Ausübung des Berufs" gehabı hätte. Der Zusatz "vorübergehender Aufenthalt" muß somit als Einschränkung der allgemeinen Befugnis der Mitgliedstaaten, eine Anzeige im Falle einer Dienstleistung zu verlangen, aufgefaßt werden ${ }^{690}$. Auch andere sprachlichen Fassungen der

687. Siehe dazu den 11. Erwägungsgrund der Richtlinie 75/362/EWG

688. In der amtlichen Begründung zum Umsetzungsgesetz in der Bundesrepublik wurde kurz auf diese Problematik hingewiesen ohne jedoch eine Losung anzutragen. Vielmehr wird darin festigestellit, dah die Klärung der Frage irn einzelnen noch nicht abgeschlossen ist, siehe dazu BT-Drucksache 7/5314 vom 4 Juni $1976,10$.

689. Durch das Gesetz zur Ändenung der Bundesärzteordnung vom 16. August 1977 wurden dïe Richtlinien 75/362/EWG und 75/363/EWG in das deutsche Recht umgesetzt, BGBI. 11977 vom 20. August 1977. 1581 .

690. Eine andere Ansicht scheinen Kirschbaum/Berscheid zu wertreten, da sie davon ausgehen, daß der Mitgliedstaat, "in den sich der dienstleistungserbringende Arzt voribergehend begibt" "eine Anzeigeverpflichtung worschreben darf, siehe Kirschbaum/Berscheid, 59. Auch Hackl zieht meiner Ansicht 
Richtlinie 75/363/EWG bestätigen diese Auffassung, da auch in diesen Texten eine ausdrückliche Einschränkung zu finden ist ${ }^{691}$.

\section{j. Die Vorbereitungszeit als Kassenarzt}

Die in Deutschland erforderliche Vorbereitungszeit für die Zulassung als Kassenarzt war in den Verhandlungen lange Zeit umstritten, da sie von anderen Delegationen als Erschwerung der Freizügigkeit angesehen wurde ${ }^{692}$. Die schließlich gefundene Kompromißlösung bestand darin, daß diese Vorbereitungszeit von den Angehörigen der anderen Mitgliedstaaten nach Ablauf einer Übergangszeit nicht mehr verlangt werden darf (Art. 21). Die Dauer der Vorbereitungszeit durfte jedoch sechs Monate nicht überschreiten. Die Übergangsfrist war fünf Jahre nach Bekanntgabe der Richtlinie d.h. 1980, abgelaufen. Seither ist es unzulässig, von Angehörigen der anderen Mitgliedstaaten eine entsprechende Vorbereitungszeit zu verlangen ${ }^{693}$. Diese Bestimmung eröffnet allerdings die Möglichkeit zur Inländerdiskriminierung und wurde daher auch stark kritisiert.

\section{k. Schlußbestimmungen}

Neben den üblichen Regelungen hinsichtlich der Umsetzung (Art. 25) und der Anwendung der Richtlinie (Art. 23, 26) enthält das Schlußkapitel auch eine Regelung in Art. 22 der Anerkenmungsrichtlinie, falls der Aufnahmestaat begründete Zweifel an der Qualität der Ausbilldungen hegt. Zu dieser Bestimmung hat der Rat bei der Verabschiedung der Richtlinien ebenfalls eine Erklärung abgegeben ${ }^{694}$. Hierin heißt es: "Hat ein Mitgliedstaat ernste Zweifel daran, daß die von einer Behörde eines anderen Mitgliedsstaats ausgestellten Diplome, Prüfungszeugnisse oder sonstige Befähigungsnachweise, die bei ihm zur Anerkennung eingereicht werden, auf einer Ausbildung beruhen, die den durch die Richtlinie 75/362/EWG festgelegten Mindestbedingungen entspricht, so muß er diese Frage selbstverständlich der Kommission unterbreiten. Diese prüft die Frage binnen möglichst kurzer Frist und bestätigt gegebenenfalls den betreffenden Mitgliedstaaten, daß die Ausbildungsbedingungen eingehalten worden sind. " Mit dieser Erklärung sollte verhindert werden, daß Art. 22 benützt wird, um bei allgemeiner Kritik an der Ausbildung in einem Mitgliedstaat dessen Diplomangehörige

690. $\rightarrow$

nach etwas voreilig den SchluB, daß das dentsche Berufsrecht den Vorgaben des Art. 16 und 17 der Anerkernungsrichtinie fur Ärte entspricht, siehe Hackl, 204.

691. In der englischen Fassung lautet Art. 16 Abs. 2: "The host Member State may require the person concerned to make a prior declaration to the competent authorities conceming the provision of his services where they involve a temporary stay in itts territory." Die niederlandische Fassung: "De ontvangende stat kan voorschrijven dat de begunstigde van tevoren aan de bevoegde instanties verklaart dat hij deze diensten verricht ${ }_{n}$ ingeval dit een tijdlijk verblijf op zijn grondgebied meebrengt."

692. Wägenbaur, RMC 1977, 311 (318).

693. Zu dieser Problematik Webert, 76, mit einer sehr deutlichen Kritik an der deutschen Regelung, zumal eine entsprechende Anpassung nicht termingerecht erfolgte.

694. ABI. Nr. C 146 vom 1. Juli 1975, 1 . 
grundsätzlich abzulehnen. Art. 22 kann zur Verifikation der Qualităt der Ausbildung in einem Individualfall herangezogen werden.

\section{B. Die RichtLinte 93/16/EWG}

\section{Die Systematik der Richtlinie 93/16/EWG}

Die Kodifikationsrichtlinie $93 / 16 /$ EWG vereinigt in sich den wesentlichen Inhalt der Richtlinien 75/362/EWG, 75/363/EWG, 881/1057/EWG, 82/76/EWG sowie 86/457/EWG und 89/594/EWG. Die Zusammenfassung der genannten Richtlinien in einen einzigen Text bestimmt auch die Systematik der Richtlinie. Die Richtlinie 93/16/EWG ist in fünf Titel unterteilt. Titel I bestimmt den Anwendungsbereich der Richtlinie, Titel II enthält die Anerkennungsbestimmungen, d.h. dieser Teil ist im wesentlichen identisch mit der Richtlinie 75/362/EWG. Titel III regelt die Koordinierung der Rechts- und Verwaltungsvorschriften betreffend der ärztlichen Tätigkeit und betrifft damit den Regelungsbereich der Richtlinie 75/363/EWG. Die Bestimmungen bezüglich einer spezifische Ausbildung in der Allgemeinmedizin, die bisher in der Richtlinie 86/457/EWG niedergelegt waren, sind nun in Titel IV der Richtlinie 93/16/EWG zu finden. Titel V enthält schließlich allgemeine Schlußbestimmungen.

\section{Synoptische Übersicht}

Die Richtlinie 93/16/EWG enthält in einer Beilage eine synoptische Übersicht. Anhand dieser soll im folgenden die neue Rechtslage dargestellt werden:

\section{Konkordanztabelle}

\begin{tabular}{|c|c|c|c|c|c|c|}
\hline 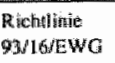 & $\begin{array}{l}\text { Richulinic } \\
75 / 362 / \text { EWHO }\end{array}$ & $\begin{array}{l}\text { Rieanclinie } \\
751363 / \text { EWO }\end{array}$ & $\begin{array}{l}\text { Richntinic } \\
\text { 86.457/EWO }\end{array}$ & $\begin{array}{l}\text { Richstinie } \\
\text { 81/105\%/INWG }\end{array}$ & $\begin{array}{l}\text { Riclutlinie } \\
\text { 89/594/EWG }\end{array}$ & $\begin{array}{l}\text { R ichatlinis } \\
\text { R2 } 776 \text { GWG }\end{array}$ \\
\hline Arrilkèl 1 & $\begin{array}{l}\text { Artiket I und } \\
24\end{array}$ & & & & & \\
\hline Artiked 2 & Artikel 2 & & & & & \\
\hline Artinkel 3 & Artikel 3 & & & & & \\
\hline Arrikel 4 & Arifkel 4 & & & & & \\
\hline Arrikel S & Artikel 5 & & & & & \\
\hline Arrikel 6 & Artikel 6 & & & & & \\
\hline Arrikel 7 & Artikel T & & & & & \\
\hline Arrtiket 8 & Artikel s & & & & & \\
\hline $\begin{array}{l}\text { Ariakel 9: } \\
\text { Abs. } 1\end{array}$ & Arcikel 9, Abs.1 & & & Artikel I & & \\
\hline $\begin{array}{l}\text { Arritikel } 9 \\
\text { Anter } 2\end{array}$ & Artikel 9. Albs 2 & & & Artikell i & & \\
\hline
\end{tabular}




\begin{tabular}{|c|c|c|c|c|c|c|}
\hline $\begin{array}{l}\text { Rictadinie } \\
\text { 9M/16/EWG }\end{array}$ & $\begin{array}{l}\text { Riterhlinie } \\
\text { 75r362UEWG }\end{array}$ & $\begin{array}{l}\text { Dethel inie } \\
75 / 363 \text { :FWG }\end{array}$ & $\begin{array}{l}\text { Richelinie } \\
86 / 457 \text { J EWG }\end{array}$ & $\begin{array}{l}\text { Richulinie } \\
\text { 81/1057/EWG }\end{array}$ & $\begin{array}{l}\text { Richthinie } \\
\text { 89/594EWG }\end{array}$ & $\begin{array}{l}\text { Richtintie } \\
82 / 76 \text { EWG }\end{array}$ \\
\hline $\begin{array}{l}\text { Artikel } 9 . \\
\text { Alsw } 3\end{array}$ & $\begin{array}{l}\text { Autikel } 9 \text { bis, Alos. } \\
1\end{array}$ & & & & & \\
\hline $\begin{array}{l}\text { Arriket } 9 n \\
\text { Absi.4 }\end{array}$ & $\begin{array}{l}\text { Afriknei } 9 \text { bis, Abss. } \\
2\end{array}$ & & & & & \\
\hline $\begin{array}{l}\text { Artikel 9. } \\
\text { Albs:5 }\end{array}$ & Antikel 9. Abs. 3 & & & & & \\
\hline $\begin{array}{l}\text { Arrikel 9. } \\
\text { Abs.6. }\end{array}$ & & & & & Antikel 9 , Abs 1 & \\
\hline Artikel 9. & & & & & Artikel 9, Abs.2 & \\
\hline Arrikel 10 & Artikel 10 & & & & & \\
\hline Arrikel II & Artikel 11 & & & & & \\
\hline Aotikel 12 & Arikles 12 & & & & & \\
\hline Antiket 13 & Artikal 13 & & & & & \\
\hline Artikel is & Arikel 14 & & & & & \\
\hline Anikel is & Artikikel 1.5 & & & & & \\
\hline Arrikel 16 & Arrikel 15 bis & & & & & \\
\hline Artikel 17 & Artikel 16 & & & & & \\
\hline Artituel 18 & Artikel 17 & & & & & \\
\hline Arrikel 19 & Arrikel 18 & & & & & \\
\hline Arujol 20 & Artikkel 20 & & & & & \\
\hline Artiket 21 & Artikell 21 & & & & & \\
\hline Arlikell 22 & Artikel 22 & & & & & \\
\hline Artikel 23 & & Artikell & & & & \\
\hline Arithell 34 & & Arikel 2 & & & & \\
\hline $\begin{array}{l}\text { Artikel } 25 \\
\text { Abris } 1\end{array}$ & & Araiket 3, Abs.1 & & & & \\
\hline $\begin{array}{l}\text { Artikel } 25, \\
\text { Abs: } 2\end{array}$ & & Arrikel 3, Abs.2 & & & & \\
\hline 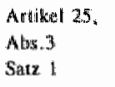 & & $\begin{array}{l}\text { Mrtikel 3, Abs } 3 \\
\text { Satz } 1\end{array}$ & & & & \\
\hline $\begin{array}{l}\text { Artikel } 25 \\
\text { Abs } 3 \\
\text { Sarz } 2\end{array}$ & & & & & & Artikes is \\
\hline Arrikel 26 & & Artikel 4 & & & & \\
\hline Artikel 27 & & Anlikel 5 & & & & \\
\hline Artikell 28 & & Artikel 7 & & & & \\
\hline Artiket 29 & & Artikiel & & & & \\
\hline Artikel 30 & & & Arrikel il & & & \\
\hline Artikel 31 & & & $\begin{array}{l}\text { Arliked 2, Abss. I, } \\
2 \text { und } 3\end{array}$ & & & \\
\hline
\end{tabular}




\begin{tabular}{|c|c|c|c|c|c|c|}
\hline $\begin{array}{l}\text { Richtlinie } \\
\text { 9316/EWG }\end{array}$ & $\begin{array}{l}\text { Richllinie } \\
75 / 3622 \text { EWG }\end{array}$ & $\begin{array}{l}\text { Riciulinie } \\
75 / 363 / \text { EWG }\end{array}$ & $\begin{array}{l}\text { Rochthinie } \\
86 / 457 / E \text { E }\end{array}$ & $\begin{array}{l}\text { Richthinie } \\
\text { 811057EWG }\end{array}$ & $\begin{array}{l}\text { Richntinie } \\
89 / 5 \% 4 / 6 W G\end{array}$ & $\begin{array}{l}\text { Richtinive } \\
\text { Ran6rEWG }\end{array}$ \\
\hline Arrikel 32 & & & Arrikel 3 & & & \\
\hline Antikel 33 & & & Arrikel 4 & & & \\
\hline Artikel 34 & & & Aurt ikell 5 & & & \\
\hline Arcikel 35 & & & Artikel 6 & & & \\
\hline Artikel 36 & & & Arrikel 7 & & & \\
\hline Autikel 37 & & & Aroikel 8 & & & \\
\hline Artiket $3 \%$ & & & Artikel 9 & & & \\
\hline Artikel 39 & & & Mrikel 10 & & & \\
\hline Arliket 40 & & & Mrtikel If & & & \\
\hline Arrikel 4II & & & Artikel 12, Abs.2 & & & \\
\hline Antilicel 42 & Artikel 23 & & Artike! 2, Alss 4 & & & \\
\hline Arrikel 43 & Antikel 26 & Artikel 10 & & & & \\
\hline \multicolumn{7}{|l|}{ Artikel } \\
\hline Arrikel 45 & Artikel 27 & & & & & \\
\hline Anlage I & Anlage & & & & & \\
\hline Anlinge il & & & & & Anlage & \\
\hline
\end{tabular}

Aus der tabellarischen Übersicht wird deutlich, daß die Bestimmungen der ursprüng. lichen Arztrichtlinie 75/362 nahezu parallel mit den Artikeln 1 bis 22 der Richtlinie 93/16/EWG verlaufen. Die Bestimmungen der Richtlinie 75/363/EWG sind in den Art. 23 bis 29 der Richnlinie 93/16/EWG aufgenommen, diejenigen der Richtlinie 86/457/EWG in den Art. 30 bis 42 der Richtlinie 93/16/EWG.

\section{Titel IV der Richlinie $93 / 16 / E W G$}

Die zuletzt genannten Artikel 30 ff. der Richtlinie 93/16/EWG hinsichtlich der Ausbildung zum Allgemeinmediziner haben seit dem 1. Jarnuar 1995 eine besondere Bedeutung erhalten. Ab diesem Zeitpunkt gestatten die Mitgliedstaaten gemäß3 Art. 36 Abs. 1 der Richtlinie 93/16/EWG die Niederlassung als praktischer Arzt mit Kassenzulassung nur noch mit einer entsprechenden Ausbildung. Ausgenommen von dieser Verpflichtung sind lediglich die Ärzte, die sich auf wohlerworbene Rechte berufen können. Die inhaltliche Ausgestaltung dieser wohlerworbenen Rechte kann jeder Mitgliedstaat selbst bestimmen. Ein Arzt, der sich vor dem 1. Januar 1995 in einem anderen Mitgliedstaat niedergelassen hat, erhält auf Antrag eine Bescheinigung ausgestellt, die ihn zur Kassenniederlassung als praktischer Arzt berechtigt, ohne eine entsprechende Ausbildung genossen zu haben. Diese Regelung gillt auch gegenüber Ärzten, die, nachdem sie in ihrem Herkunftsstaat die ärztliche Qualifikation erworben haben, sich in einem anderen Mitgliedstaat als praktischer Arzt niedergelassen haben und nun zurück in ihrem Herkunftsstaat eine Niederlassung als praktischer Arzt mit Kassenzulassung anstreben, ohne die entsprechende Ausbildung im Herkunftsstaat durchlaufen zu haben. Derartige Pro- 
blemfälle haben sich vor allem im Verhälnis zwischen den Niederlanden und Großbritannien ergeben. Ein in den Niederlanden ausgebildeter Arzt konnte sich bis zum 1. Januar 1995 in Großbritannien als general practioner (GP) niederlassen, ohne die in den Niederlanden vorgeschriebene "huisartsopleiding" absolviert zu haben. Ist dieser Niederländer im Besitz einer durch die zuständigen Behörden von Großbritannien ausgestellten Bescheinigung, nach der er am 31. Dezember 1994 im Vereinigten Königreich als GP niedergelassen war, so müssen die zuständigen Instanzen in den Niederlanden seinen Antrag auf Zulaasung zum "huisarts" positiv bescheiden. Eine Weigerung oder die Zulassung unter der Bedingung einer Prüfung oder Zusatzausbildung liefe den Art. 36 und 37 der Richtlinie 93/16/EWG zuwider.

\section{DIE ZAHNÄRZTERICHTLINIEN UND DIE TIERÄRZTERICHTLINIEN}

Die Zahnärzterichtlinien ${ }^{695}$ sind insbesondere auf Art. 49, 57, 66 und 235 EWGV gestützt. Ihre Systematik entspricht weitgehend den ursprünglichen Ärzterichtlinien. Es gibt dabei allerdings eine Besonderheit für Italien und Spanien. Zum Zeitpunkt der Verabschiedung der Richtlinien gab es in Italien den Beruf des Zahnarztes noch nicht als solchen ${ }^{696}$. Die Zahnheilkunde wurde in Italien nur durch Arzte gepflegt. Der italienischen Regierung wurde durch die zahnärztlichen Richtlinien die Auflage gemacht, innerhalb von sechs Jahren den Zahnarztberuf einzuführen ${ }^{697}$. Eine vergleichbare Regelung mußte beim Beitritt Spaniens eingefügt werden, da auch in Spanien zum Zeitpunkt des Beitritts die Zahnheilkunde nur durch Ärzte ausgeübt wurde. Spanien erhielt eine Übergangsregelung von vier Jahren ${ }^{698}$. Inzwischen sind die Richtlinien in allen ursprünglichen Mitgliedstaaten weitgehend umgesetzt ${ }^{699}$. In Österreich ist es ebenfalls

695. Richtlinie 78/686/EWG vom 25. Juli 1978, ABI. Nr. L. 233 vom 24. August 1978, l; geändert durch Beitrittswertrag wom 19. Nowember 1979, ABI. Nr. L291 vom 19. November 1979, 9; Beitrittsvertrag vom 12. Juni 1985, ABI. Nr. L 302 vom 15. November 1985, 9; RL 89/594/EWG wom 30. Oktober $1989 \mathrm{ABl}$. Nr. 341 wom 23. November 1989, 19 (Anerkennung).

Richtlinie 78/687/EWG vom 25. Juli 1978, AB1. Nr. L 233 vom 24. August 1978, 10 (Koordinienung). Dizu Morse, ELR 1978, $494 \mathrm{ff}$; de Vries, Tijdschrift woor gezondheidsrecht 1983, $109 \mathrm{ff}$. sowie ausphinrlich Siil 1988.

696. Orzack, Soc. Sci. \&edicine 1981,807 ff:- Allgemein zur Zahnarztausbildung in den Mitgliedstaaten siehe Notte 1979.

697. Diese Frist hief für Italien am 28. Juli 1984 ab. Siehe dazu Orzack, Soc. Sci \& Med. 1981, 807 (814) Die Kommission kritisierte jedoch die Anwendung der Richtlinie: Rs C-40/93.

698. Diese Frist lief für Spanien am 31. Dezember 1990 ab.

699. Belgien: Ar. royal vom 8. Juni 1983, Moniteur Belge wom 1. Jull 1983, 8672; Ar.min. vom 20. Juli 1983, Monituer Belge vom, 6. August 1983, 1046; Ar. nin. von 26. September 1986, Moniteur Bielge vom 31. Oktober 1986, 14928.

Deutschland: Zahnürztegesetz vom 25. Februar 1983, BGB1. I vom 1. Marrz 1983, 187; Verordnurng BGB1. I vom 20. Dezember 1983; Neufassung des Gesetzes vom 16. April 1987, BGB1. I vom 24. April 1987, 1225; Gesetz vom 23. März 1992, BGBl. I vom 7. April 1992, 719; Gesetz vom 27. April 1993, BGBl. I vom 30. April 1993, 512; Berichtigung vom 23. August 1993, BGBI. I vom 4. September 1993, 1529.

Dänemark: Lov vom 25 . Januar 1980 .

Frankreich: Loi, JO vom 24, Dezember 1980; Ar. min, JO vom 21. Februar 1981. 
erforderlich, eine den Kriterien der Richtlinie 78/686/EWG entsprechende Ausbildung sowie auch eine eigene Berufsgruppe zu schaffen. Wie bereits im Falle Italiens und Spanies bestand der Zahnarztberuf in Österreich nicht als eigenständiger Beruf. Aus diesem Grund muß in Österreich ein eigenes Zahnärztegesetz, ein gesondertes Zahnarztstudium sowie eine sellbständige Berufskammerstruktur für Zahnärzte noch geschaffen werden. Wegen des beträchtlichen Umfangs der erforderlichen Maßnahmen wurde mit Österreich im Rahmen der EWR-Verhandlungen eine sechsjährige Übergangsfrist bis zum 1. Januar 1999 vereinbart ${ }^{700}$.

Auch die Tierärzterichtlinien ${ }^{701}$ sind auf die Art. 49 57, 66 und 235 EWGV gestützt. Bei den Verhandlungen zu den Tierärzterichtlinien konnte ebenso wie bei der Verabschiedung der Regelung für die Zahnärzte von den Arbeiten an den Ärzterichtlinien profitiert werden. Auch diese Richtlinien folgen in ihrer Systematik weitgehend den Ärzterichtlinien. Schwierigkeiten bereitete allerdings die Einbeziehung amtlicher Tätigkeiten, die von freiberuflichen Tierärzten in nicht unerheblichem Umfang ausgeübt werden (z.B. Schlachttier- und Fleischuntersuchungen). Die Mitgliedstaaten vertraten während der Verhandlungen die Ansicht, daß3 diese Tätigkeiten die Ausnahmetatbestände der Ausübung öffentlicher Gewalt (Art. 55 EWGV) oder der Beschäftigung in der öffentlichen Verwaltung (Art. 48 Abs. 4 EWGV) erfüllen könnten. Im Interesse der Liberalisierung des Tierarztberufes haben sich die Mitgliedstaaten in einer Ratserklärung zu den Richtlinien verpflichtet, EG-Angehörige auch bezüglich dieser Tätigkeiten wie

699. $\rightarrow$

Griechenland: decr. pres. Nr. 98/86, Fek Nr. 35 vom 31. März 1986, 479

Irland: SI Nr. 30 aus 1980.

Italien: Legge Nr, 409 vom 24. Juli 1985, Gaz.uff. Nr. 69 vom 13. August 1985.

Luxemburg: Loi vom 29. April 1983, Mem. Nr. 31 vor 10. Mai 1983, sowie Mem vom 28.

Oktober 1983.

Niederlande: Min verord., Staatscourant vom 12. Marz 1984.

Portugal. Decr.lei Nr. $327 / 87$ vom 27. August 1987 sowie Decr. lei Nr. $33 / 92$ vom 5. März 1992. Spanien: Ley 10/86 vom 17. März 1986, BOE Nr. 68 vom 20. März 1986; Real decr. Nr. 970/1986, BOE vom 11. April 1986 und Real decr. 1418/1990 vom 26. Oktober 1990, BOE yom 20. November 1990; Real decr. 675/1992 vom 19. Juni 1992, BOE Nr. 178 vom 25. Juli 1992.

Ver.Königreich: SI 1980 vom 21. Mai 1980.

Siehe aber die Kritik der Kommission an der spanischen, deutschen und italienischen Umsetzung in ihrem achten Jahresbericht an das Europäische Parlament, ABI. Nr. C 338 vom 31 . Dexember 1991 , 28 sowje das Verfahren der Kommission gegen Luxemburg. Rs. C-351/90, das zu einer Venurteilung von Luxemburg am 16 . Juni 1992 geführt hat, Slg. 1992, I-3945. Auch in ihrem elften Jahresbericht an das Europäische Parlament wiederholte die Kommission ibre Kritik an der spanischen, deutschen und italienischen Umsetzung und Anwendung der Zahnarztrichtlinien, ABI. Nr. C 154 vom 6. Juni 1994. 30.

700. Österreichische Erläuterungen zum Abkommen über den Europäischen Wirtschaftsraum, Band 3, 1155

701. Richtlinie 78/1026/EWG vom 18. Dezernber 1978, ABI. Nr. L 362 vom 23. Dezember 1978, 1 geändert durch Beitrittswertrag wom 19. November 1979, ABI. Nr. L 291 vom 19. November 1989 9; Beitrittsvertrag yom 12. Juni 1985 ABI. Nr. L 302 vom 15. November 1985, 9, RL. 89/594/EWG vom 30. Oktober 1989, ABI. Nr. L 341 vom 23. November 1989, 19 (Anerkennung).

Richtlinie 78/1027/EWG vom 18. Dezember 1978, ABl. 1978 Nr. L 362 wom 23. Dezember 1978. 7 geändert durch RL 89/594/EWG vom 30. Oktober 1989. ABI. Nr. L 341 vom 23. November 1989, 19 (Koordinerung). Dazu Morse, ELR 1979, 111 ff; Wägenbaur, RTDE 1979, 653 ff.. 
ihre eigenen Staatsangehörigen zu behandeln ${ }^{702}$. Die Mitgliedstaaten können jedloch die Zulassung zu diesen Tätigkeiten von einem Fachgespräch abhängig machen, in dem der Tierarzt nachzuweisen hat, daß er mit den einschlägigen Rechtsvorschriften des Aufnahmestaates vertraut ist ${ }^{703}$. Auch diese Richtlinien sind weitgehend in den Mitgliedstaaten umgesetzt ${ }^{704}$.

\section{DIE KRANKENSCHWESTER- UND HEBAMMENRICHTLINIEN}

Die Richtlinien für Krankenschwestern und Krankenpfleger ${ }^{705}$ sind ebenfalls auf Art. 49, 57, 66 und 235 EWGV gestützt. Ihre Systematik entspricht weitgehend den ursprünglichen Ärzterichtlinien. Die Koordinierungsrichtlinie 77/453/EWG enthält eïnen Anhang, in dem die wesentlichen Inhalte eines Ausbildungsprogramms für Krankenschwestern und Krankenpfleger, die für die allgemeine Pflege verantwortlich sind, festgelegt sind ${ }^{706}$. Danach muß die Ausbildung in einen theoretischen und technischen Unterricht und eine klinisch-praktische Ausbildung unterteilt sein. Im Gegensatz zu den Ärzterichtlinien enthalten die Krankenschwesterrichtlinien keine Bestimmungen bezüglich spezialisierter Fachausbildungen. Die Richtlinien betreffen ausschließlich die Krankenschwesterausbildungen, die für die allgemeine Pflege qualifizieren. Sonderausbildungen sind durch den Regelungsbereich der Richtlinien nicht gedeckt. Diese Tatsache hat zu beachtlichen Problemen bei der Anerkennung von Spezialkrankenschwestern geführt, so z.B. bei Krankenschwestern, die eine Sonderausbildung für den Bereich der Psychiatrie, der Kinder- und Säuglingspflege oder als Gemeindeschwester

702. ABI. Nr. C 308 vom 23. Dezember 1978 ,

703. Eine derartige Prüfung wird $z . B$. in Frankreich verlangt.

704. Belgien: Ar. royal vonn 23. Juni 1981, Moniteur Belge yom 11. August 1981, 9966.

Deutschland: Tierärztegesetz, BGBl. I vom 27. Februar 1980; Tieraizteordnung vom 20. November 1981, BGBI. I vom 26. Nowember 1981, 1193; Gesetz vom 23. Marz 1992, BGBI. I vom 7. April 1992. 719; Gessetz vom 27. April 1993, BGBI. I wom 30. April 1993, 512; Berichtigung vom 23. August 1993, BGBI. I nom 4. September 1993, 1529 .

Dänemark: Bekendtgoerelse Nr. 312 und Nr. 313 vom 25. März 1980

Frankreich: Loi 82-899, JO vom 21. Oktober 1982, 3179; Ar. min, JO vom 14. November 1982; Decr. Nr. 83 306 vom 17. Juni 1983.

Griechenland: decr. pres. Nr. 506/84, fek von 14. November 1984.

Irland: SI $\mathrm{Nr}$. 391 of 1980.

Italien: Legge Nr. 750 vom 8. November 1984, Gaz.uff. Nr. 310 vorn 10. November 1984.

Luxemburg: Loi vom 29. April 1983, Mem. Nr. 31 vom 10. Mai 1983, 1214 sowie Mem vom 28. Oktober 1983.

Niederlande: Wet op uitoefening van diergeneeskunst, staatscourant vom 5. Mảrz 1984: Kon. Besluit vom 13. Februar 1984.

Portugal: Decr.lei Nr, $399 / 89$ vom 11. November 1989.

Spanien: Real decr. Nr. 331/1989, BOE Nr. 81 vom 5. April 1989; Real decr. Nr. 335/1992 vom 3 . April 1992, BOE Nr. 102 wom 28. April 1992.

Ver.König reich: SI Nr. 1951 von 1980 und SI Nr. 205 von 1981.

705. Richtlinie 77/452/EWG vom 27. Juni 1977 (Anerkennung), Richtlinie 77/453/EWG vom 27. Juni 1977 (Koordinienung), ABI. Nr. L 176 von 15. Juli 1977, 1 und 8. Dazu Quinn. 168 ff.; Morse. ELR $1977,363$.

706. Zur Krankenschwesterausbbildung in den Mitgliedstaaten siehe die einzelnen Beiträge in Quninn 1980. 
Teill III

erhalten haben. Die Reglementierung und Ausbildung derartiger Spezialisierungen ist in den Mitgliedstaaten in keiner Weise als einheitlich zu bezeichnen. In einigen Mitgliedstaaten werden Spezialisierungen in der Form eines Aufbaustudiums bewirkt, andere Mitgliedstaaten kennen spezialisierte Fachausbildungen, wobei diese Ausbildungen nicht gleichzeitig zur allgemeinen Krankenpflege im Sinne der sektoriellen Anerkennungsrichtlinien qualifizieren. Diese Tatsache verursacht ein kompliziertes und häufig unbefriedigendes Konkurrenzverhältnis zu den beiden Richtlinien $89 / 48 / \mathrm{EWG}$ und 92/51/EWG des allgemeinen Anerkennungssystems ${ }^{707}$.

Auch die Anerkennung des allgemeinen Krankenpflegepersonals nach dem System der sektoriellen Richtlinien kann nicht in jeder Hinsicht als befriedigend bezeichnet werden.. So ergeben sich vor allem dann Probleme, wenn im Aufnahmestaat mehrere parallele Qualifikationen bestehen, die jedoch eine unterschiedliche Einstufung bewirken. Diese Sachlage ist zumindest bisher z.B. in den Niederlanden gegeben. Kommt der Antragsteller aus einem Mitgliedstaat, der nur eine generelle Qualifikation im. Sinne der Richtlinie kennt, entstehen bei der Einstufung der betreffenden Personen im Aufnahmestaat häufig Probleme.

Die Umsetzung der Krankenschwesterrichtlinien ist in allen Mitgliedstaaten erfolgt ${ }^{70 \%}$. Im Falle von Belgien, Deutschland und Spanien wurde diese Umsetzung jedoch erst mit erheblichen Verzögerungen bewirkt. Die Ausbildungen in den drei neuen Mitgliedstaaten entsprechen dem in der Richtlinie 77/453/EWG niedergelegten Mindeststandard. Das österreichische Krankenpflegegesetz mußte allerdings insofern angepaßt werden, daß Diplome in der allgemeinen Krankenpflege, die in den Ländern des EWR erworben wurden, ohne weitere Nostrifizierung zur Berufsausübung in Österreich berechtigen.

707. Siehe zu diesem Konkurrenzverhälmis die Ausführungen Seite 166

708. Belgien: Ar. royall vom 8. Juni 1983, Moniteur Belge vom 1. Juli 1983, 8672; Ar.min. vom 20. Juli 1983, Monitewr Belge vom 6. August 1983, 1046; At. min. vom 26. September 1986, Moniteur Belge vom 31 . Oktober $1986,14928$.

Deutschland: Krankenpflegegesetz vom 4. Juni 1985, BGBl. I wom 22. Oktober 1985, 1973; Gesetz vom 23. März 1992, BGBL. I vom 7. April 1992, 719; Gesetz vom 27. April 1993, BGB1. I vom 30. April 1993, 512; Berichtigung wom 23. August 1993, BGBI. I won 4. September 1993, 1529.

Dänemark: Lov Nr, 670 vom 13. Dezember 1978 .

Frankreich: Loi, JO vom 13. Juli 1980; Ar. min, JO vam 27. Juli 1980; Ar, min., JO vom 6. Marz 1981; Circul. $\mathrm{Nr}$. 4 vom 4. August 1980.

Griechenland: decr. pres. Nr. 40 vom 29 , Januar 1986.

Irland: SII Nr. 237 vom 22 . Julli 1980.

Italien: Legge $\mathrm{Nr}$. 905 wom 18. Dezember 1980, Gaz.uff. $\mathrm{Nr}$. II vom 2. Jamuar 1981 .

Luxemburg: Loi vom 18. November 1967, Mem. Nr. 78 vom 2. Juni 1967, 1214 sowie Mem $\mathrm{Nr}$. 29 vom 2. Juni 1977 .

Niederlande: Min werond. Besluit vom 22. Juni 1977.

Portugal: Decr.lei Nr. 332/87 vom 1. Oktober 1987 sowie Decr. lei Nr. 21/92 vom 8 . Februar 1992. Spanien: Real decr. Nr. 305/1990, BOE Nr. 57 wom 7. März 1990 und Real decr. $1275 / 1993$ vom 23. Oktober 1992, BOE Nr. 283 vom 25. November 1992.

Ver. Königreich: SI Nr. 1604 vom 6. Dezember 1.979. 
Die Hebammen ${ }^{709}$ wurden am 21 . Januar 1980 vom Rat verabschiedet. Sie sind auf Art. 49, 57 und 66 gestützt. Damit waren die Hebammenrichtlinien die ersten sektoriellen Richtlinien, die nicht mehr ergänzend auf Art. 235 EWGV gestützt sind. Die Systematik der Hebammenrichtlinien entspricht weitgehend der der ursprünglichen Ärzterichtlinien. In Art. 1 der Anerkennungsrichtlinie sind die von der Richtllinie betroffenen Berufe unter der jeweiligen Berufsbezeichnung der Mitgliedstaaten aufgelistet. Diese Liste muß in Zusammenhang mit Art. 4 der Koordinierungsrichtlinie gelesen werden, worin der Tätigkeits- und Aufgabenbereich von Hebammen genauer bestimmt ist. Gemäß der Richtllinien kann die Hebammenausbilldung in den Mitgliedstaaten auf verschiedene Weise organisiert werden. Gemäß Art. 1 Abs. 2 der Koordinierungsrichtlinie muß die Ausbildung entweder eine spezielle Ausbildung als Hebamme auf Vollzeitbasis sein, die theoretische und praktische Studien von mindestens drei Jahren umfafit. In diesem Falle wird der Schulabschluß nach den ersten zehn Jahren allgemeiner Schulausbildung vorausgesetzt. Nach der zweiten Alternative muß eine mindestens 18 Monate dauernde Spezialausbildung zur Hebamme auf Vollzeitbasis verlangt werden, wobei der Zugang zu dieser Hebammenausbildung von der Befähigung zur Krankenschwester im Sinne der Krankenschwesterrichtlinie 77/452/EWG abhängig gemacht werden muß. Beide Systeme gelten im Prinzip als gleichwertig nebeneinander ${ }^{700}$. Gemäß Art. 2 der Anerkennungsrichtlinie sind an die automatische Anerkennung jedoch noch weitere Bedingungen geknüpft.

709. Richtlinie 80/154/EWG von 21. Januar 1980 (Anerkennung), Richtlinie 80/I55/EWG vom 21. Januar 1980 (Koordinitenung), ABl. Nr. L 33 vom 11. Februar 1980, 1 und 8. Dazu Bent, Joumal of Adwanced Nursing 1982, 384 - 386; Orzack/Calogero in Lopata 1990, 43 ( 58 ff.).

710. Wahrend den Verthandlungen wurde vor allem von Grofbritannien und Irland die Notwendigkeit einer Krankenschwesterausbildung unterstrichen, wohingegen Frankreich und Dänemark eine derartige Vorausbildung für nicht erforderlich ansahen, Orzack/Calogero in Lopata 1990, 43 (62). 
Die Richtlinien sind in den Mitgliedstaaten umgesetzt ${ }^{71}$. Obwohl davon ausgegangen werden kann, daß die Richtlinien grundsätzlich ordnungsgemäß in das nationale Systern implementiert sind, können bei der praktischen Anwendung des Anerkennungssystems erhebliche Schwierigkeiten entstehen. Eine besondere Problemlage besteht im Verhältnis zwischen Belgien und den Niederlanden. In den Niederlanden durchlaufen Hebammen eine besonderen dreijährige Spezialausbildung. Diese Ausbildung wird allgemein als schwer und sehr anspruchswoll angesehen. Der Zugang zu dieser Ausbildung ist besonders regllementiert. Hauptgrund für diese schwierige und anspruchsvolle Ausbildung ist die besondere Rolle, die Hebammen in den Niederlanden in der Geburtshilfe erfüllen. In den Niederlanden wird ein GroBteil der Geburten als Hausgeburten oder polyklinisch durchgeführt. In beiden Fällen werden diese Geburten, solange keine Komplikationslage gegeben ist, ausschließlich unter der Aufsicht und Kontrolle einer Hebamme durchgeführt. Ein Arzt ist bei einer solchen Normalgeburt in der Regel nicht anwesend. Auch die Betreuung der Schwangeren vor der Geburt sowie die Pflege und Überwachung des Zustands der Wöchnerin und des Neugeborenen ist zum überwiegenden Teil Aufgabe der Hebamme. Nur eine verhältnismäßig geringe Zahl der Normalgeburten sowie Komplikationsfälle werden unter der Leitung eines Arztes durchgeführt. Mit diesem Geburtensystem sind die Niederlande in Europa weitgehend einmalig. In den meisten anderen Mitgliedstaaten ist die Krankenhausgeburt unter ärztlicher Leitung der Normalfall, die Hausgeburt die absolute Ausnahme. Dies gilt auch für Belgien. In Belgien werden die Mehrzahl der Geburten in Krankenhäusern durchgeführt. Belgien hat bei der Ausbildung von Hebammen die zweite Alternative gewählt, d.h. in Belgien besteht die Hebammenausbildung aus einem Aufbaustudium nach einer abgeschlossenen Ausbildung zur allgemeinen Krankenpflege ${ }^{7 ! 2}$ "Dieses System ist für das belgische Geburtensystem auch adäquat, da es sich in der Regel um Krankenhausge-

711. Belgien: Ar. royal vom 8. Juni 1983, Moniteur Belge vom 1. Juli 1983, 8672; Armin. wom 20. Juli 1983. Moniteur Belge vom 6. August 1983, 10049; Ar, min. vom 26. Septernber 1986. Moniteur Belge vom 31. Oktober 1986, 14929.

Deutschland: Hebammengesetz von 4. Juni 1985, BGBI. I vom II. Juni 1985, 902; Änderungsverordnungen vom 22. Mai 1986 und vom 18. November 1986, BGB1. 1986, 833 und 1732; Geserz vom 23. März 1992, BGBI. I vom 7. April 1992, 719; Gesetz vom 27. April 1993, BGBI. I vom 30. April 1993, 512; Berichtigung vom 23. August 1993, BGBI. II vom 4. September 1993, 1529.

Dänemark: Nr. 727 vom 22. Dezember 1982.

Frankreich: Loi 84-391, JO vom 26. Mai 1984.

Griechenland: decr. pres. Nr. $97 / 86$, fek nr. 35 vom 31. Marz 1986, 475.

Irland: SI Nr. 20 von 1983.

Italien: Legge Nr. 29 vom 13. Juni 1985, Gaz.uff. Nr. 146 vom 22. Juni 1985.

Luxemburg: Regl. vom 22. Augusit 1985, Mem. Nr. 55 vom 7. September 1985.

Niederlande: Min verord., Staatscourant vom 12. März 1984.

Portugal: Decr. lei Nr. 333/87 vom 1. Oktober 1987 sowie Decr. lei Nr. $15 / 92$ vom 4. Februar 1992. 713.

Spanien: Real Decr. Nr. 1017/1991, BOE Nr. 155 vom 29. Juni 1991" Decr. vom 23. Oktober 1992, BOE $\mathbb{N r}$. 283 vom 25 . November 1992; Real Decr. Nr. 279/94 vom 18. Februar 1994, BOE Nr. 72 vom 25. März 1994.

Ver. Königreich: SI Nr. 921 vom 1. Juli 1983.

712. Eine ähnliche Regelung besteht in Großbritannien. Dazu Orzack, Higher Education 1980, 307 (308); Orzack/Calogero in Lopata $1990,43(48 \mathrm{f})$. 
burten unter der Leitung eines Arztes handelt, so daß eine gute Integration der Hebamme in das Krankenhaussystem nur wünschenswert sein kann ${ }^{713}$.

Die Problemlage entsteht, wenn die beiden Systeme vermischt werden. Da die $\mathrm{Zu}$ lassung zur Hebammenausbildung in den Niederlanden stark limitiert und reglementiert ist, tendieren niederländische Krankenschwestern dazu, nach Belgien auszuweichen. Ihr niederländisches Krankenschwesterdiplom muß auf der Basis der Richthinie 77/452/EWG in Belgien anerkannt werden. Sie erfüllen daher die Voraussetzung zur Zulassung zur belgischen Hebammenausbildung. Nach AbschluB dieser Zusatzausbildung erhalten sie das belgische Hebammendiplom, das entsprechend der Art. 2 und 3 der Richtlinie 80/154/EWG wiederum in den Niederlanden anerkannt werden muß. Man kann diese Handlungsweise nicht grundsätzlich als Mißbrauch des Gemeinschaftsrechts bezeichnen. Es ist meines Erachtens jedoch verständlich " daß die zuständigen Behörden und die Berufsvertretung in den Niederlanden nicht sehr glücklich über diese Entwicklung sind. Die niederländische Krankenschwesterausbildung in Kombination mit der belgischen Hebammenausbildung kann nicht als gleichwertig mit der niederländischen Hebammenausbildung angesehen werden. Diese Tatsache ist im Verhälnnis zu den Niederlanden problematischer als im Verhältnis zu anderen Mitgliedstaaten angesichts der oben dargestellten besonderen Rolle der Hebamme im Geburtshilfesystem. Rechtlich läßt sich dieses Problem nur auf Gemeinschaftsebene lösen ${ }^{714}$. In der Praxis scheint die Anerkennung der belgischen Hebammendiplome mit der Verpllichtung zu einem Praktikum unter der Aufsicht von einer in den Niederlanden qualifizierten Hebamme verknüpft zu werden. Diese Praxüs widerspricht jedoch eindeutig der gemeinschaftsrechtlichen Verpflichtung zur automatischen Anerkennung.

\section{E. DIE APOTHEKERRICHTLINIEN}

\section{Enrstehungsgeschichte der Apothekerrichtinien}

Die "Richtlinie zur Koordinierung der Rechts- und Verwaltungsvorschriften über bestimmte pharmazeutische Tätigkeiten" 715 , sowie die "Richtlinie über die gegenseitige Anerkennung von Diplomen, Prüfungszeugnissen und sonstigen Befähigungsnachweisen des Apothekers und über Maßnahmen zur Erleichterung der tatsächlichen Ausübung des Niederlassungsrechts für bestimmte pharmazeutische Tätigkeiten" 716 wurden vom Rat am 16. September 1985 erlassen. Der Erlaß beider Richtlinien war das

713. In Zukunft soll die Hebammenausbildung auch in Belgien als Sonderausbildung geregelt werden.

714. Falls die belgische Hebammenausbildung geändert wird, kann sich die Problemlage vermutlich entschustrfen.

715. Richtlinie 85/432/EWG vom 16. September 1985. ABI. $1985 \mathrm{Nr}$. L 253 vom 24. September 1985,34 (Koordinerung).

716. Richtlinie 85/433/EWG vom 16. September 1985, ABL. 1985 Nr. L 253 vom 24. September 1985, 37 geăndert durch RL 85/584/EWG vom 20. Dezember 1985, ABI. Nr. L 372 vom 31. Dezember 1985 42. (Anerkennung). 
Ergebnis eines langiährigen und mühsamen Entscheidungsprozesses ${ }^{717}$. Insoweit ist auch die Entstehungsgeschichte dieser Richtlinien von Interesse.

Bereits im März 1969 hatte die Kommission, zusammen mit den ersten Entwürfen für Arrzte, verschiedene Richtlinienvorschläge zur Verwirklichung der Niederlassungsfreiheit auf pharmazeutischem Gebiet vorgelegt ${ }^{718}$. Insgesamt handelte es sich um nicht weniger als sieben Richtlinien. Die Spannbreite des geplanten Regelungsbereichs erstreckte sich vom Abbau nationaler Beschränkungen im Bereich der Arzneimittelherstellung ${ }^{719}$ und des Großhandels mit Arzneimitteln ${ }^{720}$ uber die Koordinierung der Vorschriften für die selbständigen Tätigkeiten der Arzneimittelherstellung ${ }^{72 !}$, des GroBhandels $^{722}$ und des Kleinvertriebs von Arzneimitteln ${ }^{723}$ bis hin zur Anerkennung von Diplomen und Prüfungszeugnissen ${ }^{724}$ und der Koordinierung der Ausbildungsworschriften der Apotheker ${ }^{725}$. Keiner dieser Vorschläge stieß auf grundsätzliche Kritik beim Wirtschafts- und Sozialausschuß ${ }^{726}$ oder beim Europäischen Parlament ${ }^{727}$, wobei das Europäische Parlament jedoch einige Änderungsvorschläge unterbreitete. Diese betrafen jedoch nicht die Anerkennung der Diplome oder die Koordinierung der Ausbildungsvorschriften. Vom Wirtschafts- und Sozialausschuß wurden hinsichtlich dieser beiden Entwürfe einige redaktionelle Anmerkungen gemacht. Desweiteren schllug der Wirtschafts- und Sozialausschu/3 bezüglich der Anerkennungsrichtlinie vor, daß ein Apotheker sich im Rahmen einer sechsmonatigen Anpassungszeit an die Situation in einem anderen Mitgliedstaat vertraut machen solle.

Der Entwurf der Kommission bezüglich der Koordinierung der Ausbildung für Apotheker war bemerkenswert, da die Kommission im ersten Erwägungsgnund ausdrücklich betonte, daß kein einheitliches Ausbildungsprogramm angestrebt sei. Vielmehr sollte lediglich ein für die Anerkennung erforderliches Mindestprogramm festgelegt werden. $\mathrm{Zu}$ diesem Mindestprogramm zählte eine mindestens fünf Jahre umfassende Hochschulausbildung und ein Praktikum von mindestens sechsmonatiger Dauer. Damit wurde als Mindestausbildung für Apotheker ein elfsemestriges Studienprogramm vorgeschlagen. Dieser Richtlinienvorschlag hätte zumindest in der Bundesrepublik Deutschland eine erhebliche Änderung der bestehenden Ausbildungsordnung bewirkt,

717. Siehe dazu ausfihrlich Kraus, 81 ff. sowie Orzack 1977, 95 (114); Ahlgrimm, Pharm.Z. 1981, 459, Ahlgrimn, Pharm.Z. 1983, 1865; Gornig, Deutsche Apotheker-Zeitung $1989,1252 \mathrm{f}$.

718. ABH. Nr. C 54 wom 28. April 1969, 32-52.

719. ABI. Ni. C 54 vom 28. April 1969, $32-34$

720. ABI. Nr. C 54 vom 28. April $1969,38-41$.

721. ABI. Nr. C $\$ 4$ vom 28. April $1969,35-38$.

722. ABI. Nr. C 54 vom 28. April 1969, $41-44$.

723. ABl, Nr. C 54 wom 28. April 1969, $44-48$.

724. ABI. Nr. C 54 vom 28. April 1969, 48 - 49.

725. ABl. Nr. C 54 vom 28. April 1969, $50-51$.

726. ABl. Nr. C 36 vom 28. März 1970, 1.

727. ABl. Nr. C 143 vom 3. Dezember $1970,19$. 
da zu diesem Zeitpunkt das Pharmaziestudium in sieben Semestern absolviert werden konnte $^{28}$.

Trotz der geringen Kritik war keiner der Entwürfe vom Erfolg gekrönt. Aus unterschiedluchen Gründen wurden sie zwischen 1974 und 1976 von der Kommission zurückgezogen. Die Richtlinienvorschläge bezüglich der Anerkennung der Diplome und der Koordinierung der Ausbildung von Apotheker ereilte dieses Schicksal am 8. Dezember 1976. Grund für diesen Rückzieher war die zwischenzeitliche Verabschiedung der Ärzterichtlinien ${ }^{729}$. Die Kommission war nunmehr entschlossen, die Struktur der Apothekerrichtlinien diesen beiden Erfolgsmodellen anzupassen.

Zwischen der Veröffentlichung der sieben Richtlinienvorschläge und ihres Verschwindens von der Bildfläche hatte die Kommission noch zwei weitere Richtlinienvorschläge veröffentlicht ${ }^{730}$. Diese Richtlinienvorschläge betrafen zum einen die Koordinierung der Rechts- und Verwaltungsvorschriften für die selbständige Tätigkeiten des Kleinvertriebs von Arzneimitteln, zum anderen eine Richtlinie zur Verwirklichung der Niederlassungsfreiheit und des freien Dienstleistungsverkehrs für die selbständige Tätigkeiten des Kleinvertriebs von Arzneimitteln. Mit diesen Richtlinienvorschlägen wurde ein sehr heikles Thema in die Diskussion eingeführt, nämlich die Möglichkeit einer geographischen Beschränkung von Apotheken.

Problematisch war dieses Thema insoweit, als gerade die Frage der Beschränkung der Gründungsfreiheit neuer Apotheken Anlaß für ein Verfahren vor dem Bundeswerfassungsgericht war ${ }^{731}$. In seiner Entscheidung vom 11. Juni $1958^{732}$ hatte das Bundesverfassungsgericht die Eingriffsmöglichkeit des Gesetzgebers in das durch das Grundgesetz in Art. $12 \mathrm{GG}$ garantierte Grundrecht der Berufsfreiheit anhand einer als "Drei-Stufen-Theorie" berühmt gewordenen Abwägungsformel dargestellt ${ }^{733}$. Das Bundesverfassungsgericht unterscheidet dabei zwischen einer ersten Stufe, die reine Berufsausübungsregeln betriff, einer zweiten Stufe, in der die Aufnahme der Berufstätigkeit von bestimmten subjektiven Faktoren abhängig ist, und schließlich einer dritten Eingriffsstufe. Diese bezieht sich auf Regelungen, die die Berufsaufnahme und damit die Berufswahl von der Erfüllung objektiver Bedingungen abhängig macht, auf die der Berufsangehörige selbst keinen Einfluß hat. Da es sich dabei um den auch schwerwiegendsten Eingriff in die Berufsfreiheit handelt, hält das Bundeswerfassungsgericht

72:. Auch die Bundes-Apothekerordinung und die Approbationsordnung für Apotheker aus dem Jahre 1971 schrieb eine Mindeststudiendatuer von sieben Hochschulsemestern wor. Diese Ausbildung wurde durch ein einjăhriges Praktikum ergănzt, BGBI. 1, 1377.

729. Siehe oben Seite 119 ff.

730. Diese Veröffentlichurg erfolgte allerdings nicht im Amtsblatt, sondern lediglich in einem Kommissionsdokument KOM (72) 1375 endg. vom 17. November 1972.

731. Gemälf dem bayerisehen Gesetz vom 16. Juni 1952 über das Apothekenwesen, GVBl 1952,181 konnte die Erlanbnis zur Neugründung einer Apotheke von ihrer Notwendigkeit im Hinblick auf Zahl und Dichte der Bevölkerung abhängig gemacht werden.

732. BVerfGE 7, 377ff.

733. Kraus, 137. 
derartige Regelungen nur dann für verfassungskonform, wenn auf diese Weise nachweisbare und höchstwahrscheinlich schwere Gefahren für ein überragend wichtiges Gemeinschaftsgut abgewehrt würden ${ }^{734}$.

Im Hinblick auf die Beschränkung der Neugründung won Apotheken vertrat das Bundesverfassungsgericht die Ansicht, daß diese nicht durch eine gesundheitpolitische Notwendigkeit gerechtfertigt sei mit der Konsequenz, daß der entsprechende Erlaubnisvorbehalt mit Bedürfnisprüfung des bayerischen Apothekergesetzes wegen Verstoßes gegen Art. $12 \mathrm{GG}$ für verfassungswidrig erklärt wurde. In der deutschen Literatur fand das "Apothekerurteil" grundsätzlich Zustimmung ${ }^{735}$. Bachof bezeichnete es selbst als "Wegweiser für die ganze künftige Auslegung der Berufsfreiheit und darüber hinaus für die Grundrechtsinterpretation überhaupt" ${ }^{736}$. Diese Voraussage hat sich auch bewahrheitet. Die "Drei-Stufen-Theorie" hat auch über die Jahrzehnte hin ihre Gültigkeit in der deutschen Verfassungsrechtsprechung behalten.

Vor diesem Hintergrund muß man die beiden Richtlinienvorschläge aus dem Jahre 1972 sehen. Eine Konfrontation mit der deutschen Delegation war unvermeidlich, da eine derartige geographische Beschränkung der Niederlassungsfreiheit auf verfassungsrechtliche Bedenken in der Bundesrepublik stieß. Im selben Zeitpunkt stand jedoch auch der Beitritt Dänemarks, Irlands und Großbritanniens unmittelbar bevor. Von diesen drei neuen Mitgliedstaaten kennen zwei - Großbritannien und Irland - eine unbeschränkte Gründungsfreitheit von Apotheken. Angesichts dieser Situation war es daher nicht verwunderlich, daß auch diesen beiden Richtlinienvorschlägen kein Erfolg beschieden war. Sie wurden, nachdem auch der Wirtschafts- und Sozialausschuß ${ }^{737}$ und besonders das Europäische Parlament ${ }^{738}$ kritisch dazu Stellung genommen hatten, von der Kommission daher bereits im Juli 1974 zurückgezogen. Zwei Jahre später ereilte die Richtlinienentwürfe bezüglich der Anerkennung der Diplome und der Koordinierung der Apothekerausbildung dasselbe Schicksal.

Es dauerte mehrere Jahre bis die Kommission zwei neue Richtlinienvorschläge am 28. Januar 1981 veröffentlichte. Dabei handelte es sich um einen Entwurf für eine Richtlinie zur Koordinierung der Rechts- und Verwaltungsvorschriften über bestimmte pharmazeutische Tätigkeiten ${ }^{739}$, sowie um einen zweiten Richtlinienentwurf für die gegenseitige Anerkennung der Diplome, Prüfungszeugnisse und sonstige Befähigungsnachweise des Apothekers und für Maßnahmen zur Erleichterung der tatsächlichen Ausübung des Niederlassungsrechts für bestimmte pharmazeutische Tätigkeiten ${ }^{740}$. Inhaltlich unter-

734. BVerfGE 7, $377(405-408)$.

735. Von Ameln, 12; Bachof, JZ 1958, 468; Kraemer, DVB1 1958, 850.

736. Bachof, JZ 1958, 468.

737. ABI. Nr. C 8 vom 31. Januar 1974,8 .

738. Entschlieforng mit der Stellungsnahme des EP wom 13. Juni 1974, ABI. Nr. C 76 von 3. Juli 1974, 48.

739. ABI. Nr. C 35 vom 18. Februar 1981, 3

740. ABI. Nr. C 35 vom 18. Februar 1981, 6. 
schieden sich beide Richtlinienvorschläge von ithren Vorgängern aus den Jahren 1969 und 1972. Die Kommission hat deutlich aus der Vergangenheit ihre Lehren gezogen und enthielt sich daher einer Regelung auf den sensiblen Bereichen der geographischen Beschrănkung, der Eigentumsverhältnisse an Apotheken und des Abgabemonopols ${ }^{741}$. Sie überließ diesen Regelungsbereich statt dessen den Mitgliedstaaten. Daher ist es auch nach derzeitiger Rechtslage möglich, daß einige Mitgliedstaaten, die geographische Verteilung von Apotheken reglementieren, um eine ordnungsgemäße Versorgung der Bevölkerung mit Arzneimitteln zu gewährleisten. Auch kann unter diesem Gesichtspunkt die Zahl der neu zu errichtenden Apotheken in einigen Mitgliedstaaten begrenzt werden, solange diese Beschränkungen nach objektiven und nicht diskriminierenden Kriterien erfolgen. Nach der heutigen Rechtslage gelten derartige Niederlassungsbeschränkungen in der Mehrheit der Mitgliedstaaten. Lediglich Deutschland, Großbritannien und Irland sehen won einer derartigen Reglementierung $a b^{742}$.

\section{Inhalt der Apothekerrichtinien}

Die "Richtlinie zur Koordinierung der Rechts- und Verwaltungsvorschriften über bestimmte pharmazeutische Tätigkeiten" ${ }^{743}$, sowie die "Richtlinie über die gegenseitige Anerkennung von Diplomen, Prüfungszelugnissen und sonstigen Befähigungsnachweisen des Apothekers und über Maßnahmen zur Erleichterung der tatsächlichen Ausübung des Niederlassungsrechts für bestimmte pharmazeutische Tätigkeiten " 744 beschränken sich daher ausschließlich auf die Koordinierung der Ausbildung und der Anerkennung der Diplome. Im Gegensatz zu den anderen sektoriel beide Richtlinien lediglich auf Art. 49 EWGV und Art. 57 EWGV gestützt. Art. 52 EWGV findet keine Erwähnung, da die tatsächliche freie Niederlassung durch die beiden Richtlinien nicht in vollem Umfang gewährt wird. Ebenfalls unerwähnt ist Art. 66 EWGV. Ein freier Dienstleistungsverkehr von pharmazeutischen Vertretern, der gleichzeitig einen freien Warenverkehr aller pharmazeutischen Produkte bedeutet hätte, war mit den Apothekerrichtlinien ebenfalls nicht bezweckt.

Inhaltlich erstrebt die Richtlinie 85/432/EWG eine Koordinierung der beruflichen Eignung. Gemäß Art. 2 der Richtlinie muß die Pharmazieausbildung in den Mitgliedstaaten den hierin genannten Mindesterfordernissen entsprechen. Der Inhaber eines derartigen Diploms muß zu den in Art. 1 Abs. 2 genannten Tätigkeiten grundsätzlich zugelassen werden, wobei in einigen Mitgliedstaaten eine ergänzende Berufserfahrung verlangt wird. Dazu heißt es in der 6. Erwägung zu der Anerkennungsrichtlinie 85/433/EWG, daß eine in einem anderen Mitgliedstaat erworbene angemessene prak-

741. KOM (81) 4 endg. vom 28. Januar 1981, 3 .

742. Siehe dazu die ausführliche Studie von Ress/Ukrow.

743. Richtlinie 85/432/EWG vom 16. September 1985, ABI. 1985 Nr. L 253 vom 24. September 1985, 34, (Koordine rung).

744. Richtlinie 85/433/EWG vom 16. September 1985, ABI. $1985 \mathrm{Nr}$. L 253 vom 24. September 1985, 37. geändert durch RL 85/584/EWG wom 20. Dezember 1985, ABI. Nr. L 372 vom 31 . Dezember 1985, 42. (Anerkennung). 
tische Erfahrung von gleicher Dauer als ausreichende Bedingung anzusehen ist. Bei den in Art. 1 Abs. 2 der Koordinierungsrichtlinie handelt es sich um die folgenden Tâtigkeitsbereiche:

- die Herstellung der Darreichungsform;

- die Herstellung und Prüfung von Arzneimitteln;

- die Arzneimittelüberprüfung in einem Laboratorium;

- die Lagerung, Qualitätserhaltung und Abgabe von Arzneimitteln auf der Großhandelsstufe;

- die Herstellung, Prüfung und Abgabe von Arzneimitteln in der Öffentlichkeit zugänglichen Apotheken;

- die Herstellung, Prüfung und Abgabe von Arzneimitteln in Krankenhausapotheken; - die Information und Beratung über Arzneimittel.

Angesichts der in den meisten Mitgliedstaaten bestehenden geographischen Beschränkungen bei neu zu eröffnenden Apotheken mußte vor allem "die Herstellung, Prüfung und Abgabe von Arzneimitteln in der Öffentlichkeit zugänglichen Apotheken" einem weitgehenden Vorbehalt unterstellt werden. Gemäß Art. 1 Abs. 3 der Koordinierungsrichtlinie können die Mitgliedstaaten, die zum Zeitpunkt des Erlasses der Richtlinie ein Auswahlsystem kennen, wonach die Gründung neuer Apotheken im Rahmen eines einzelstaatlichen Systems geographischer Aufteilung beschlossen wird, dieses Auswahlverfahren beibehalten und auf die Staatsangehörigen der anderen Mitgliedstaaten anwenden. Interessant bei dieser Regelung ist die Begrenzung der Ausnahmebestimmung auf bestehende Systeme. Deutschland und Großbritannien wäre es nach dieser Bestimmung verwehrt, nachträglich noch ein vergleichbares System einzuführen... Bei den newen Mitgliedstaaten gilt dagegen die Situation im Zeitpunkt des Beitritts. Für Österreich bedeutet dies die Zulässigkeit des bisher gehandhabten Auswahlverfahrens.

Die Mitgliedstaaten haben die beiden Richtlinien inzwischen größtenteils umgesetzt ${ }^{745}$. Allerdings mußten von der Kommission Verfahren gegen Belgien ${ }^{746}$,

745. Belgien: Ar. royal wom 9. November 1992, Monteur Belge vom 11. Dezember 1992, 26842; A royal vom 9. November 1992, Moniteur Belge vom 11. Dezember 1992, 26843.

Deutschland: Gesetz zur Umsetzung der Apothekerrichtlinie vom 23. Iwii 1988, BGBI. I 1988, 1077 Drittes Gesetz zur Änderung der Bundlesapothekenordnung vom 19. Jurni 1989, BGBI. I 1989, 1106 A pprobationsord nung für A potheker vom 19. Juli 1989, BGBi. I vom 28. Juli 1989, 1489; Gesetz vom 23. März 1992, BGBl. I wom 7. April 1992, 719; Gesetz vom 27. April 1993, BGB1. I vom 30. April 1993, 512, Berichtigung vom 23. August 1993, BGBI. I vom 4. September 1993, 1529.

Dänemark: Bekendtgoerelse Nr. 318 vom 20 . Juni 1988 sowie Nr. 720 vom 1. Dezember 1988 Frankreich: Loi 87-588 und 87-583, JORF vom 31. Juli 1987; Ar. Mini, JORF wom 5. Dezember 1987; Décr. 90-421 vom 16. Mai 1990, JORF vom 22. Mai 1990, 9119.

Griechenland: Décr. min. Nr. A4/5226 vom 6. November 1987, Nr. A4/3894 vom 10. Nowember 1988 sowie vom 24 . Februar 1993 .

Irland: SI Nr. 239 von 1987

Italien: deer. wom 31. Oktober 1988, Gaz.uff. Nr. 109 wom 12. Mai 1989; Decr. leg. Nr. 258, Gaz. uff. $\mathrm{Nr}, 191$ wom 16 . August $1991,9$. 
Italien ${ }^{747}$ und Luxemburg ${ }^{748}$ eingeleitet werden ${ }^{749}$. Belgien und Luxemburg wurden entsprechend vom EuGH verurteilt ${ }^{750}$. Das Verfahren gegen Italien führte dagegen zu keiner Verurteilung ${ }^{751}$.

Für Österreich gilt, daß die in den Richtlinien vorgeschriebene Dauer des Pharmaziestudiums sowie das einjährige Berufspraktikum der österreichischen Ausbildung entspricht. Insoweit war eine Anpassung nicht erforderlich. Jedoch mußte in Österreich ein selbständiges staatliches Apothekerdiplom eingeführt werden, das zur Berufsausübung sowohl als selbständiger wie auch als angestellter Apotheker berechtigt.

\section{F. DIE ARCHITERTENRICHTLINIE}

\section{Inhalt der Architektenrichtinie}

Im Gegensatz zu den Richtlinien der medizinischen Berufe ist die Anerkennung der Architekten-Diplome nicht mit einer Koordinierung der Ausbildungen verknüpft. Vielmehr macht die Architektenrichtlinie ${ }^{352}$ die Anerkennumg vom Vorliegen bestimmter Ausbildungskriterien quantitativer und qualitativer Art abhängig, ohne daß die Mitgliedstaaten zu einer entsprechenden Ausgestaltung ihrer Ausbildungen verpflichtet werden. Die Mindestdauer der Architektenausbildung war Gegenstand schwieriger Verhandlungen ${ }^{753}$. Der schließlich gefundene Kompromiß sieht grundsätzlich eine Studiendauer von vier Jahren vor (Art. 4 Abs. 1 Buchstabe a)). Langjähriger Zankapfel

745. $\rightarrow$

Luxernburg: Loi vom 31. Juli 1991, Mem. Nr. 60 vom 29. August 1991, 1137

Niederlande: Min. Besluit, Staatscourant $\mathrm{Nr}$. 70 vom 22. April 1988.

Portugal: Decr.lei $\mathrm{Nr}$. 31/88 vom 3. Februar 1988 sowie Decr. lei Nr. 212/79 vom 12. Juli 1979 und Decr. lei $\mathrm{Nr}$. $76 / 93$ vom 31. Dezember 1993 und Decreto lei $\mathrm{Nr}$. 111/94 vom 28. April 1994. Spanien: Real decr. Nr. 1667/1989 vom 22. Dezember 1989. BOE Nr. 4 vom 4. Januar 1990; Real decr. Nr. 1595/1992 vom 23. Dezemaber 1992. BOE Nr. 34 vom 9. Februar 1993.

Ver. Königreich: The Parmaceutical qualifications (EEC Recognition) regulations 1987, SI Nr. 457 von 1987 sowie The pharmaceutical qualification order 1987, SI Nr. 2202 won 1987.

746. $\mathrm{C}-167190$

747. C- $152 / 90$

748. C- $168 / 90$

749. Siehe dazu den achten Jahresbericht der Kommission an das Europäische Parlament, ABI. Nr. C 338 vom 31. Dezenaber 1991, 27.

750. Unteile vom 16. Mai 1991, Rs C-167/90 - Kommission/Belgien -, Slg. 1991, I-2535; Rs C-168/90 Kommission/Luxemburg. Slg. 1991, I-2539. Siehe dazu Ress/Ukrow, 45 Fn. 1 und 119 Fn. 1

751. Im elften Jahresbericht der Kommission an das Europäische Parlament stellte diese jedoch erneut fest. daß Italien die Richtlinie nicht vollständig umgesetzt hat. Auch die belgische Umsetzung wies Mängel in Bezug auf das Ausbildungsprogramm auf. Hinsichtlich der deutschen Unasetzung kritisierte die Kommission das Verbot der Doppelniederlassung, ABI. Nr. C 154 vom 6. Juni 1994, 30.

752. Richtinie 85/384/EWG vom 10. Juni 1985, ABI. 1985 Nr. L 223 worn 21. August 1985, 15, geändert durch RL 85/614/EWG vom 20. Dezember 1985, ABI. Nr. L 376 vom 31. Dezember 1985, 1; RL 86/17/EWG vom 27. Januar 1986, ABI. Nr. 27 vom 1. Februar 1986, 71 (Anerkennung).

753. De Crayencour, 1981, 115; Orzack, Higher Education 1980, 307 (314); Orzack, Law and Human Behavior 1983, 251-263. 
waren die deutschen Fachhochschulen. Als Kompromiß wurde schließlich eine Unterscheidung zwischen den Fachhochschulausbildungen mit vierjähriger und denen mit dreijähriger Ausbildung getroffen. Im Falle der letzteren reicht eine dreijährige Ausbilldung aus, sofern der Bewerber grundsätzlich zusätzlich eine vierjährige Berufserfahrung in der Bundesrepublik nachweist ${ }^{754}$. Dabei ist vorgesehen, diese Regelung zu einem späteren Zeitpunkt im Lichte der gewonnenen Erfahrungen zu überprüfen.

Fachhochschulen mit einer vierjährigen Ausbildung werden dagegen ohne Zusatzerfordernis anerkannt. Diese Problematik war bereits Gegenstand von zwei Verfahren vor dem EuGH ${ }^{755}$.

Die Richtlinie betrifft sowohl selbståndige wie angestellte Architekten. Erfaßt sind dabei alle Tätigkeiten auf dem Gebiet der Architektur, cie üblicherweise unter der Berufsbezeichnung "Architekt" ausgeführt werden. Diese Formulierung wurde gewählt, da in einigen Mitgliedstaaten diese Tätigkeiten sowohl von Architekten als von anderen Berufsangehörigen ausgeübt werden, z.B. von Ingenieuren. Innen- und Landschaftsarchitekten sowie Städteplaner fallen nicht unter die Architektenrichtlinie, sondern unter die Hochschuldiplomrichtlinie 89/48/EWG.

Die Architektenrichtlinie unterscheidet zwischen älteren und neueren Diplomen.

Die älteren Diplome sind in Art. 11 aufgelistet, während die Anerkennung der neueren Diplome sich nach Art. 2 und 3 bestimmt. Hierzu wird regelmäßig eine Liste der Kommission veröffentlicht. Grundsätzlich gilt dabei die Regel, daß falls der Aufnahmestaat zusätzlich zu seinem nationalen Diplom ein berufliches Praktikum verlangt, dieser Nachweis auch von einem ausländischen Diplominhaber verlangt werden kann.

\section{Die Rechtsprechung zur Architektenrichtlinie}

Der belgische Hof van Cassatie hat im Rahmen eines Vorabentscheidungsersuchens den EuGH mit der Frage konfrontiert, ob ein vierjähriges Architekturstudium an einer deutschen Fachhochschule, das zwei obligatorische Praxissemester einschließt, die Voraussetzungen gemäß Art. 4 Abs. 1 Buchstabe a) der Richtlinie 85/384/EWG erfüllt ${ }^{756}$. In der Rechtssache Egle ging es damit um die Frage, ob im Falle eines einjährigen Praktikums während einer insgesamt vierjährigen Fachhochschulausbildung tatsächlich von einer vierjährigen Ausbildung i.S. des Art. 4 Abs. 1 Buchstabe a) der Richtlinie 85/384/EWG gesprochen werden kann oder, ob von dem Kandidaten zusätzlich der Nachweis einer vierjährigen Berufserfahrung verlangt werden kann. Der Gerichtshof stellte dabei fest, daß der Unterricht im Bereich der Architektur gemäß Art.

754. Art. 4 Abs. 1 Unterabs. 2 der Richtlinie 85/384/EWG

755. Urteill vom 21. Januar 1992 , Rs C $310 / 90$ - Nationale Raad van de Orde van Archítecten/Ulrich EgleSIg. 1992, 1-177 ff. und Urteil wom 8. April 1992, Rs C-166/91 - Gerhard Bauer/Conseil national de I"ordre des architectes - SIg. 1992, 1-2797 ff.

756. Unteil vom 21. Januar 1992, Rs C 310/90-Nationale Raad van de Orde van Architecten/Uluich Egle*, Sig. 1992, I-177 ff 
3 der Richtlinie 85/384/EWG die theoretischen und praktischen Aspekte der Ausbildung in ausgewogener Form berüicksichtigen muß. Daraus folge, daß der Begriff des Studiums auf den praktischen Unterricht angewendet werden kann, an dem die Studenten teilnehmen müssen, wenn sie das Architektendiplom erhalten wollen ${ }^{757}$. Hieraus zog der Gerichtshof den Schluß, daß eine Ausbildung, die vier Jahre dauert und die von der Fachhochschule organisierte und begleitete Praxissemester umfaßt, als vierjähriges Studium auf Vollzeitbasis anzusehen ist. Eine vergleichbare Entscheidung traf der Gerichtshof auch in der Rechtssache Bauer ${ }^{758}$. Dagegen verneinte der Gerichtshof in der Rechtssache Dreessen die Gleichstellung eines von der Abteilung "Allgemeiner Hochbau" von der Staatlichen Ingenieurschule für Bauwesen in Aachen 1966 ausgestellten Diploms mit einem der in Art. 11 der Richtlinïe aufgelisteten älteren Diplomen $^{75 \%}$.

\section{Die Umsetzung der Archirektenrichtimie}

Die Architektenrichtlinie war für die Niederlassungsfreiheit bis August 1987 in das nationale Recht umzusetzen. Für die Dienstleistungsfreiheit bestand eine ein Jahr länger dauernde Frist. Allgemein kann man eine erhebliche Fristüberschreitung konstatieren. Einige Mitgliedstaaten haben erst 1992 die Richtlinie umgesetzt, bei einigen steht die Umsetzung auch bis zum heutigen Tag noch aus ${ }^{760}$. Dies betrifft vor allem auch die deutschen Bundesländer, die nach interner Gesetzgebungskompetenz für die Umsetzung der Richtlinie die Verantwortung haben. Auch Griechenland scheint trotz einer Verurteilung durch den Gerichtshof wegen mangelnder Umsetzung im Jahr 1991 bisher

757. Urteil vom 21. Januar 1992, Rs C 310/90 - Natiomale Raad van de Orde van Architecten/UIrich Egle*, Slg. 1992, 177. $\mathrm{Nr}, 9$

758. Urteil vom 8. April 1992, Rs C-166/91 - Gerhard Bauer/Conseil national de l'ordre des architectes Sig. 1992, 2797.

759. Urteil wom 9. August 1994, Rs C-447/93 - N. Dreessen/Nationale Ratad wan de Orde van Architecten-, SIIg: 1994, $1-4087$

760. Belgien: Ar. royal wom 4. Juli 1989. Moniteur Belge vom 13. September 1989, 8672; Ar. roy. vom 12. September 1990, Moniteur Belge vom 19. Oktober 1990, 20020; Decr. wlaams. gemeenschap. vom 12. Juni 1991. Moniteur Belge vom 4, Juli 1991, 14907.

Dentschland: Umseczungsmabnahmen in Hessen: Erlab vom 10. Januar 1989; Nordmein-Westfalen: Gesetz vom 10. Januar 1989 und Bayern: Gesetz wom 4. Juni 1989 sowie Gesetz vom 10. August 1990, GVBI. 1990, 278; Hamburg: Gesetz vom 21. Januar 1991. GVBI. 1991, 12; Berlin: Gesetz vom 19. Juli 1994, GVBI. 1994, 253; Sachsen: Säichsisches Architektengesetz vom 19. April 1994, GVB:. 1994, 765.

Dämemark: Bekendtgoerelse $\mathrm{Nr} .478$ rom 2 . Juli 1987 .

Frankreich: Decr. 91-1218 vom 29. November 1991, JO wom 5. Dezember 1991; Ar. min., JO vom 11. Februar 1992; Ar. min., Jo vom 11. Februar 1992.

Irland: SI Nr. 15 von 1989.

Italien: Decr. leg. Nr. 129 vom 27. Januar 1992, Gaz. uff. Nr. 41 vom 19. Februar 1992.

Luxemburg: Loi vom 18. Dezember 1988, Mem. Nr. 72 vom 28. Dezember 1988.

Niederlande: Kon. Besluit, Siats blad 1987, 347; Min. besch., Staatscona rant 1988, 190.

Portugal: Decr.lei Nr. 14/90 vom 8. Januar 1990.

Spanien: Real decr. Nr. $1081 / 1989$ wom 28. August 1989; BOE Nr. 214 wom 7. September 1989.

Ver. Konigreich: SI Nr. 1824 wom 21. Oktober 1987. 
keine Umsetzungsmaßnahme erlassen zu haben ${ }^{761}$. Inhaltliche Kritik hatte die Kommission vor allem hinsichtlich der spanischen Umsetzung ${ }^{762}$.

Für Innen-, Garten- und Landschaftsarchitekten gilt die Architektenrichtlinie - wie bereits festgestellt - nicht. Auf diese Berufe findet vielmehr grundsätzlich die allgemeine Anerkennungsrichtlinie 89/48/EWG Anwendung. Nach dem Inkrafttreten der Richtlinie 89/48/EWG hat diese Tatsache zu einigen Problemen geführt. Einige Mitgliedstaaten hatten bis zur Verabschiedung der Richtlinie 89/48/EWG auch auf die speziellen Architektenberufe einschließlich der Städteplaner die Umsetzungsregelungen der Ara chitektenrichtlinie oder vergleichbare nationale Regelungen angewandt ${ }^{763}$. Die Umsetzung der Richtlinie 89/48/EWG bedeutete, daß sich in diesen Mitgliedstaaten die Frage ergab, $o b$ das bisherige Anerkennungssystem nach den Grundsätzen der Architektenrichtlinie für Innen-, Garten- und Landschaftsarchitekten noch Anwendung finden sollte oder, ob die Diplome dieser Berufsgruppen nunmehr nach dem allgemeinen System und den entsprechenden Umsetzungsregelungen anerkannt werden muBten. Eine Anerkennung nach der Richtlinie 89/48/EWG bedeutete jedoch in einigen Fällen eine erhebliche Erschwerung des Anerkennungsprozesses. Dies galt vor allem in den Fällen, in denen der Beruf des Antragstellers im Herkunftsstaat nicht reglementiert ist ${ }^{764}$. Nach dem System der Richtlinie 89/48/EWG kann in einem solchen Fall der Aufnahmestaat den Nachweis einer zweijährigen Berufserfahrung verlangen, wohingegen die Architektenrichtlinie eine derartige Regelung nicht kennt.

Nach meiner Meinung muß in den Mitgliedstaaten, in denen bisher die Diplome der Innen-, Garten- und Landschaftsarchitekten nach dem nationalen System als gleichwertig anerkannt wurden, diese Anerkennungspraxis beibehalten werden. Es wäre widersinnig, wenn die Richtlinie $89 / 48 /$ EWG, die grundsätzlich eine Erleichterung des Personenverkehrs bezweckt, Anlaß und Rechtfertigung einer erheblichen Erschwernis sein könnte. Eine derartige Anwendung der Richtlinie könnte selbst eine Vertragsverletzang bewirken. Im Falle einer Konkurrenz der Regelungen sollte der "gemeinschaftsfreundlicheren" Regelung Vorrang gewährt werden.

761. Siehe auch das Urteil vom 7. November 1991 , Rs 309/90 - Kommission/Griechenland -, SHg. 1991. I-5311.

762. Elfter Jahresbericht der Kommission an das Europäische Parlament, AB1. Nr. C 154 wom 6. Juni 1994 30.

763. So konmten z.B. in den Niederlanden gemäß dem Wet op de achitectentitel ausländische Diplome von Innenarchitekten als gleichwertig anerkannt werden. Die Diplominhaber durften sich wach einer ministeriellen Anerkennung in das niederländische Architektenregister eintragen.

764. So ist z.B. der Benuf Innenarchitekt in Belgien nicht reglementient. Zur Definition eines reglementierten Berufs siehe Pertek, YbEL 1992, 293. Nach seiner Auffassung ist ein Beraf im Sinne der Richtlinie 89/48/EWG reglementiert, wenn der Beruf in der Regel unter einer bestimmten Berufsbezeichmung ausgeübt wird, die bestimmten Diplominhabern gesetzlich worbehalten ist. Dabei wird dieses Berufsmonopol durch straftechtliche Sanktionen geschützt. Siehe dazu die Erörtemungen Seite 177 ff. 
Die Freiheit des Personenverkehrs durch allgemeine Regelungen zur gegenseitigen Anerkennung von Diplomen: Der horizontale Ansatz 


\section{Die Freiheit des Personenverkehrs durch allgemeine}

\section{Regelungen zur gegenseitigen Anerkennung von}

\section{Diplomen: Der horizontale Ansatz}

\section{\$ 1. Die Richtlinie $89 / 48 /$ EWG über eine allgemeine Regelung zur Anerkennung der Hochschuldiplome, die eine mindestens drei- jährige Berufsausbildung abschließen}

\section{A. ENTSTEHUNGSGESCHICHTE DER RICHTLINIE 89/48/EWG}

Spätestens seit Anfang der achtziger Jahre wurde zunehmend deutlich, daß dic Aussichten, für jeden Beruf zwei gesonderte Richtinien bezüglich Anerkennung des Diploms und Koordinierung der Ausbildung zu verabschieden, immer geringer wurden ${ }^{765}$. Diese Aussicht verringerte sich weiterhin, weil die bereits vollzogene und die noch ausstehenden Erweiterungen der Gemeinschaft, die Unterschiedlichkeit der Rechts- und Interessenlage in den Mitgliedstaaten noch erheblich vergrößerte.

Die langwierigen Verhandlungen um die Architektenrichtlinie und die Apothekerrichtlinien bewirkten letztlich, daß der Glaube an eine vollständige sektorielle Harmonisierung endgültig erschüttert worden ist. Fehlte bereits bei der Architektenrichtlinie aufgrund der unterschiedlichen Ausbildungsgänge und Berufsbilder die Bereitschaft zur Koordinierung der Ausbildungen, so war vollkommen deutlich, daß für die noch zu harmonisierenden Berufe eine Übereinstimmung nie erzielt werden würde ${ }^{765}$. Es mußte daher ein anderer Weg gefunden werden.

765. Wägenbaur, EuR 1987, 13 (177). Schneider, Ars Aequi 1989, 368\%

766. Unter diesen Berufen befanden sich schlieBlich so schwierige Fälie wie der Beruf des Rechtsanwalts und des. Ingenieurs, die beide bereits auf eine langjälnrige Verhandlungsgeschichte zuriuckblicken konnten. Auch war zu diesem Zeitpunkt noch nicht deutlich, ob bei den Apothekern und den Architektern uberhaupt eine Einigung erzielt werden konnte. 
Auf seiner Tagung in Fontainebleau im Juni 1984, d.h. noch ein Jahr vor Verabschiedung der Architekten- und der Apothekerrichtlinien, erklärte der Europäische Rat, die Schaffung eines allgemeinen Systems für die Gleichwertigkeit der Hochschuldiplome sei unerläßlich ${ }^{767}$. Gleichzeitig setzte er einen Ad-hoc-AusschuB für das Europa der Bürger ein, der die entsprechenden Maßnahmen vorbereiten sollte. Dieser Ausschuß wurde nach seinem Vorsitzenden kurz Adonnino-Ausschuß genannt. Die Kommission; müde gestritten in langjährigen Verhandlungen, begrüßte diesen Vorschlag des Europäischen Ratesi und erklärte, "selbst zu der Überzeugung gelangt zu sein, daß ein globales und flexibleres Konzept gefunden werden muß, um einen wirklichen Durchbruch auf dem Gebiet des Rechts der freien Niederlassung zu erzielen ${ }^{768 . "}$ Dabei empfahl die Kommission eine Anerkennung der Diplome ohne vorherige Harmonisierung der Ausbildungswege. Die Anerkennung sollte mit einer Ausgleichsregelung hinsichtlich der jeweiligen Berufserfahrung werbunden werden ${ }^{769}$. Diese Konstruktion hatte sich bereits bei richt-akademischen Berufen bewährt ${ }^{770}$.

Mit dieser neuen Strategie kamen der Europäische Rat und die Kommission eigentlich auf einen Beschluß des Rates aus 1974 zurück ${ }^{71}$. Damals hatte der Rat bereits folgende Leitlinie postuliert: "Da man trotz der Unterschiede, die hinsichtlich der Ausbildungsprogramme zwischen den Mitgliedstaaten bestehen, in der Praxis eine Vergleichbarkeit der Ausbildungsabschlüsse, die den Zugang zu gleichartigen Tätigkeitsfeldern eröffnen, in groben Umrissen feststellt, sollten die Richtlinien über die gegenseitige Anerkennung der beruflichen Befähigungsnachweise und über die Koordinerung der Bedingungen für den Zugang zu einem Beruf so wenig wie möglich detaillierte Ausbildungserfordernisse vorschreiben." Roth nennt diese Entschließung nicht zu Unrecht einen Vorläufer der im Weißbuch von 1985 verkündeten meuen Strategie ${ }^{72}$. Zum damaligen Zeitpunkt hielt die Kommission den Gedanken "der allgemeinen gegenseitigen Anerkennung" won Diplomen noch für illusorisch ${ }^{773}$ !

Der Adonnino-Ausschuß, an dessen Arbeit auch die Kommission teilnahm, legte dem Europäiischen Rat in Brüssel im März 1985 seinen ersten Bericht vor, worin der Gedanke einer allgemeinen Regelung zur Anerkennung der Diplome und sonstigen Prüfungszeugnisse ohne vorherige Harmonisierung entwickelt wurde ${ }^{774}$. Die Regelung sollte auf dem Grundsatz des gegenseitigen Vertrauens und der Vergleichbarheit des

767. Beilage 7/85 BullEG, 5

768. KOM (84) endg. Europa der Bürger - Durchführung der SchluBfolgenungen dles Europäischen Rates von Fontainebleau.

769. Siehe dazu auch KOM (85) 355 endg. Vorschag für eine Richtlinie des Rates über eine allgemeine Regelung zur Anerkennung der Hochschuldiplome, 2.

770. Siehe Richtlinie des Rates vom 19. Juli 1982 aber Maßnahmen zur Erbichterung der tatsächlichen Ausübung des Niederlassungsrechts und des Rechts auf freien Dienstleistungswerkehr für Friseure ABI. Nr. L. 218 vom 27. Juli 1982,

771. Entschließ3ung des Rates vom 6. Juni 1974, ABI. 1974 Nr. C 98 wom 20. August 1974, 1.

772. Rath. EuR 1986, 340 (346).

773. Siehe dazu die Kritik von de Crayencour 1981, 72 ff. insbesondere 77

774. Beilage 7/85 BullEG, $9 \mathrm{ff}$. 
Teil IV

Ausbildungsniveaus beruhen. Nur im Falle von erheblichen strukturellen Unterschieden zwischen den Ausbildungsgängen sollte ein Ausgleich in Form von Berufserfahrung vorgesehen werden. Im Weißbuch der Kommission an den Europäischen Rat vom Juni 1985 findet sich ein entsprechender Hinweis auf den Bericht des Adonnino-Ausschußes, wobei die Kommission ihren Willen bekundet, dem Rat noch im Laufe des Jahres einen Richtlinienentwurf über ein allgemeines Anerkennungssystem vorzulegen ${ }^{7 / s}$. Dieses Anerkennungssystem sollte auf den folgenden Grundsätzen beruhen ${ }^{776}$ :

- Gegenseitiges Vertrauen zwischen den Mitgliedstaaten;

- Vergleïchbarkeit der Universitätsstudien;

- Gegenseitige Anerkennung der von einem Mitgliedstaat ausgestellten Diplome, ohne vorherige Harmonisierung der Ausbildungsbedingungen;

- Ausgleich der Unterschiede in der Ausbildung durch Berufserfahrung;

- Ausdehnung des Anerkennungssystems auf Arbeitnehmer.

Bereits im Juli 1985, d.h. einen Monat später, erfüllte die Kommission ihr Versprechen und unterbreitete dern Rat ihren Vorschlag über eine allgemeine Regelung zur Anerkennung der Hochschuldiplome ${ }^{m}$. Hierin erläuterte die Kommission den neuen Harmonisierungsansatz. Ziel der horizontalen Vorgehensweise sei es, ohne Vorbedingung, d.h. ohne Koordinierung der Ausbildungsgänge, rasch dem individuellen und unmittelbaren Bedarf derjenigen zu entsprechen, die als Hochschulabsolventen eine berufliche Tätigkeit in einem anderen Land ausüben wollen. Als Kompensationsinstrumente sah der Richtlinienentwurf den Nachweis der Berufserfahrung oder einen Anpassungslehrgang vor. Zu diesem Vorschlag haben das Europäische Parlament ${ }^{778}$ und der Wirtschafts- und Sozialausschuß ${ }^{779}$ ihre Stellungsnahmen abgegeben. Im Mai 1986 legte die Kommission einen geänderten Vorschlag vor, wobei sie unter anderem auch diesen Stellungsnahmen Rechnung trug 780 .

Eine Änderung betraf den Titel der Richtlinie. Die vorgeschlagene Richtlinie sollte die Anerkennung der Hochschuldiplome ausschließlich zum Zweck des Zugangs zu einer beruflichen Tätigkeit regeln. Die akademische Anerkennung sollte ausdrücklich nicht von ihr erfaßt werden. Verschiedentlich war Kritik an dem ersten Entwurf dahingehend geäußert worden, daß diese Zielsetzung nicht klar ersichtlich sei ${ }^{781}$. Die Kommission änderte daher den Titel sowie den vierten Erwägungsgrund und die Art. 1 und 12 entsprechend. Andere Änderungen betrafen die Definitionen des Hochschuldiplomes und des Anpassungslehrganges.

775. Weilbuch der Kommission, Vollerudung des Binnenmarkts, Juni 1985, Nr. 92/93.

776. Weilbuch der Kommission, Vollendung des Binnenmarkts, Juni 1985, Nr. 93. Stehe dazu auch Roth, EuR 1986, 340 (344), Wägenbaur, EuR 1987, 113 (117).

777. KOM (85) endg. vorm 22. Juli 1985.

778. Entschliefung vom 14. November 1985 , ABI. Nr. C 345 yom 31. Dezember 1985, 76

779. Stellungnahme vom 29. Januar 1986, ABI. Nr. C 75 vom 3. April 1986, 5.

780. KOM (86) 257 endg., 1.; siehe dazu auch Wägenbaur CMLRew. 1986, 91.

781. So z.B. der Andenungsworschlag des Europäischen Parlaments, ABH. Nr. C 345 vom 31 . Dezember 1985, 76; siehe auch die Kritik des Bundesrates in: BR-Drucksache: 404/85 (BeschluB), 3. 
Trotz dieser Änderungen konnte jedoch keine Einigung erzielt werden. Besonders die Frage, ob die Richtlinie auf die rechtsberatenden Berufe und die Lehrer Anwendung finden sollte, wurde teilweise erhitzt diskutiert ${ }^{792}$. Auch die Frage, ob die deutschen Fachhochschulen unter das System der Richtlinie fallen, gehörte zu den Streitpunkten $^{783}$. Letztlich konnte ein Kompromiß dadurch erzielt werden, daß neben dem Anpassungslehrgang auch eine Eignungsprüfung als Anpassungsinstrument in den Richtlinentext aufgenommen wurde. Damit wurde vor allem den deutschen Bedenken Rechnung getragen, daß durch die Zulassung von ausländischen Juristen "erhebliche Gefahren für die Rechtspflege" entstehen könnten ${ }^{784}$. Andererseits konnte die deutsche Delegation bewirken, daß - entgegen den ursprünglichen Entwürfen - der Abschluß der gesamten Sekundarschule nicht mehr zur Bedingung gemacht und damit eine Öffnung für die Fachhochschulen geboten wurde. Im Juni 1992 konnte schließlich im Rat der gemeinsane Standpunkt festgelegt werden. Die Richtlinie 89/48/EWG wurde am 21. Dezmber 1988 im Rat verabschiedet ${ }^{785}$. Gemäß Art. 12 Abs. 1 der Richtlinie 89/48/EWG waren die Mitgliedstaaten bis zum 4. Januar 1991 zu ihrer Umsetzung verpflichtet.

\section{B. ANWENDUNGSBEREICH DER RICHTLINIE 89/48/EWG}

\section{Persönlicher Anwendungsbereich}

Zum Zeitpunkt der Umsetzungsverpflichtung galt die Richtlinie $89 / 48 / \mathbb{E} W G$ für die Staatsangehörigen der damals zwölf Mitgliedstaaten. Seit dem 1. Januar 1994 ist die Richtlinie gemäß Art. $30^{786}$ und Annex VII ${ }^{787}$ des Abkommens über den Europäischen Wirtschaftsraum (EWR) auch für die EFTA-Staaten verbindlich geworden, die

782. Für die Berufsgruppe der Anwdilte sieh die Tagungsberichte der Universitäi Lyon III zu einer diese Thematik betreffenden Konferenz am 22./23. November 1985. Vergleiche zu der Problenatik auch die Stellung nahme des Bundesrates zum ersten Richtlinienentwurf in BR-Drucksachen 404/85 vom 29. November 1985, 4, worin mit Vehemenz vertreten wird, daf weder die juristischen Berufe noch das Lehramt von der Richtinie erfaßt werden solle. Diese Auffassung wurde auch noch wom Rechtsausschulh in seiner Empfehing an den Bundesrat in BR-Drucksache 546/1/87 vom 25. Jannar 1988 geăufert. Sie fand jedoch keinen Widerhall mehr in Beschlub des Bundesrates zu einer konsolidierten Fassung des Richtinienentwurfs, BR-Drucksache 546/87 vom 5. Februar 1988, 2.

783. Art. I a) der Richtlinienentwürfe unterstellte bei dem Diplominhaber den Abschluß der gesamten Sekundarschule. Dies bedeutete, daB Diplominhaber mit der deutschen Fachhochschul reife nicht in den GenuB der Anerkennung kommen komiten.

784. BR-Drucksache $404 / 85$ vom 29. November 1985,4

785. Richtlinte des Rates wom 21. Dezember 1988 über eine allgemeine Regelung zur Anerkennung der Hochschuldiplome, die ene mindestens drejährige Berufsausbildung abschließen, ABI. Nr. L. 19 won 24. Januar 1989,16

786. Art 30 EWRV lautet: "Um Arbeitnehmem und selbständig Erwerbstätigen die Aufnahme und Ausubung von Erwerbstätigkeiten zu erleichtern, treffen die Vertragsparteie ndie erforderlichen MaßBnahmen mach Anhang VII zur gegenseitigen Anerkennung von Diplomen. Prufungszeugnissen und sonstigen Befahigungsmachweisen sowie zur Koordinienung der Rechts- und Vetwaltungsworschriften der Vertragsparteien über die Aufnahme und Ausübung von Erwerbstätigkeiten durch Arbeimehmer und selbständig Erwerbstätige."

787. In Anhang VII ist die Richtlinie $89 / 48 / \mathrm{EWG}$ unter $\mathrm{A} \mathrm{Nr}$ \ aufgeführt. 
das EWR-Abkommen ratifiziert haben. Dies sind Norwegen und Island sowie Österreich, Finnland und Schweden. Der Beitritt Österreichs, Finnlands und Schwedens zur Europäischen Union am 1. Januar 1995 hat für den Anwendungsbereich der Richtlinie keine Erweiterung bewirkt, da diese Staaten bereits mit dem Inkrafttreten des EWRAbkommens an die Richtlinie 89/48/EWG in vollem Umfang gebunden waren. Zum heutigen Zeitpunkt können sich daher neben den Angehörigen der fünfzehn EU-Mitglitedstaaten auch die Staatsangehörigen von Island und Norwegen auf die Richtlinie berufen.

Die schweizerische Bevölkerung hat die Ratifizierung des EWR-Abkommens in einer Volksabstimmung abgelehnt. Bezüglich Liechtenstein gilt das EWR-Abkommen bisher ebenfalls noch nicht. Liechtenstein hat nach dem negativen Ergebnis der Volksabstimmung in der Schweiz beschlossen, die Ratifizierung des EWR-Vertrages bis zur Lösung der Problematik um die Liechtenstein-schweizerischen Zollunion aufzuschieben, obwohl in Liechtenstein die Bevölkerung grundsätzlich einen Zutritt zum EWR bejaht hat. Dies bedeutet, daß zur Zeit weder Schweizer noch Liechtensteiner in den Genuß des Anerkennungssystems kommen.

\section{Inhaltlicher Anwendungsbereich}

\section{a. Vertragliche Ermächtigung}

Die Richtlinie stützt sich auf die Ermächtigung in den Art. 49, 57 Abs.1, 66 EWGV zur Herstellung der Freizügigkeit, des Niederlassungsrechts und des freien Dienstleistungsverkehrs. Sie soll dazu beitragen, für den Bereich der reglementierten Berufe, die ein mindestens dreijähriges Hochschulstudlum voraussetzen, die Freizïgigkeit zu verwirklichen. Bisher stand dem entgegen, daß in den einzelnen Mitgliedstaaten nach deren nationalen Rechts- und Verwaltungsworschriften unterschiedliche Diplome für den Zugang oder die Ausübung eines Berufes gefordert wurden ${ }^{788}$.

Die Richtlinie ist insbesondere gestützt auf Art. 57 Abs. 1 EGV, der den Rat zum Erlaß von Richtlinien für die gegenseitige Anerkennung von Diplomen ermächtigt. Es handelt sich damit nicht um eine Richtlinie gemäß Art. 57 Abs. 2 EGV zur Koordinierung der Rechts- und Verwaltungsvorschriften der Mitgliedstaaten über die Aufnahme und Ausübung selbständiger Tätigkeit. Der Bundesrat hat in seinem Beschluß vom 5. Februar 1988 noch eine Ergänzung des Richtlinienentwurfes um Art. 57 Abs. 2 EGV mit der Begründung vorgeschlagen, der Richtlinienentwurf enthalte in Teilbereichen wesentliche Elemente einer Koordinierung der Rechts- und Verwaltungsvorschriften der Mitgliedstaaten über die Aufnahme und Ausübung selbständiger Tätigkeiten ${ }^{789}$. Diese Auffassung konnte sich augenscheinlich nicht durchsetzen. Eine derartige Ergänzung hätte auch die Verabschiedung der Richtlinie endgültig gefährden können, da gemäß Art. 57

788. So die deutsche amtliche Begründung in: BT-Drucksache 11/6154.

789. BR-Drucksache $546 / 87$ vom 5 . Februar 1988, 1 . 
Abs. 2 Satz 2 EWGV in diesem Fall für den Ratsbeschluß Einstimmigkeit erforderlich gewesen wäre.

Von der Richtlinie 89/48/EWG unberührt bleiben daher die Ausbildungsbedingungen und berufsrechtlichen Regelungen. Diese bleiben in der Kompetenz der Mitgliedstaaten. In den Erwägungsgründen der Richtlinie wird - zur Beruhigung der verschiedenen Standesorganisationen - ausdrücklich darauf hingewiesen, daß eine Änderung der die Berufsausübung und die Berufsethik betreffenden Bestimmungen nicht angestrebt wird ${ }^{790}$. Auch regelt die Richtlinie 89/48/EWG nur den Berufszugang nach Erwerb der Berufsbefähigung gemäß den jeweiligen nationalen Vorschriften in einem Mitgliedstaat und ermöglicht nicht etwa einen Zugang zu Ausbildungsabschnitten in einem anderen Mitgliedstaat. Anders ausgedrückt, die Richtlinie bezweckt die berufliche Anerkennung zur Ausübung einer beruflichen Tätigkeit und nicht die akademische Anerkennung zur Fortsetzung einer Ausbildung.

Gemäß Art. 2 Abs.1 der Richtlinie 89/48/EWG gilt diese Richtlinie für alle Angehörigen eines Mitgliedstaates, die als Selbständige oder in einem Beschäftigtenverhältnis eimen reglementierten Beruf in einem anderen Mitgliedstaat ausüben wollen. Diese ausdrückliche Erweiterung des Anwendungsbereiches auf abhängig Beschäftigte ist deswegen erforderlich, weil Art. 57 EWGV nur für das Niederlassungs- und Dienstlleistungsrecht gillt und die Vorschriften über die Freizügigkeit der Arbeitnehmer keine entsprechende Bestimmung enthalten ${ }^{791}$. Diese Erweiterung entspricht der Praxis bei früheren sektoriellen Richtlinien. Sie bewirkte eine heftige Diskussion um die Anwendung der Richtlinie auf die durch Laufbahnvorschriften des öffentlichen Dienstes reglementierten Berufe. Die Anwendung der Richtlinie auf den Beruf der Lehrer war damit ermöglicht ${ }^{792}$.

b. Umfang des Anwendungsberichs

Die in Art. 2 Abs. 2 der Richtlinie 89/48/EWG vorgenommene Abgrenzung ist eine rein negative. Die Richtlinie nennt keine Berufe, die in den Anwendungsbereich fallen. Insoweit ist der Regelungsumfang der Richtlinie 89/48/EWG unbestimmt und allgemein, da keine Liste beigefügt ist, in der die einschlägigen Berufe enumerativ aufgezählt sind. Vielmehr sind durch die gewählten Definitionen in Art. 1 eine Vielzahl verschiedener Berufe von ihr betroffen. Eine genaue Feststellung des Regelungsbereiches kann für alle Mitgliedstaaten wohl erst nach einigen Jahren erfolgen ${ }^{793}$. Diese Vorgehensweise er-

790. Siehe den 10. Erwägungsgrund der Richtinie 89/48/EWG. Dieser Erwägungsgrund wurde im Laufe des Verfahrens mehrmals geändent. Siehe KOM (86) 257 endg., 2.

791. Muller-Bernhardt, RdJB 1989, 130 (133); Wàgenbaur "EüR 1987, 113 (115).

792. Berscheid/Kirschbaum, 118.

793. Auch ein Vertreter der Kommission konnte in einer Befragung durch das Select Committee on the European Communities des House of Lords bezüglich des Richtlinienentwurfs keine genaue Antwort auf die Frage geben, wieviele Berufe nun tatsächlich von der Richtlinie betroffen sind: M. Petite: "We can only have an approximate idea of the number of professions concerned. The reason why is that 
Teil IV

leichtert die Anwendung der Richtlinie auch bei geänderten Ausbildungsvoraussetzungen in den einzelnen Mitgliedstaaten über Jahre; sie erschwert jedoch deutlich die Anwendung der Richtlinie in den Mitgliedstaaten und die Kontrollmöglichkeit bezüglich der Umsetzung. Es läßt sich nämlich - ohne dabei grundsätzlich von einer Böswilligkeit der Mitgliedstaaten auszugehen - nur schwer beurteilen, ob die Richtlinie tatsächlich vollständig umgesetzt ist ${ }^{794}$.

\section{c. Ausnahmen vom Anwendungsbereich}

Die Richtlinie gilt gemäß3 Art. 2 Abs. 2 der Hochschuldiplomrichtlinie nicht für die Berufe, die bereits durch eine sektorielle Richtlinie abgedeckt sind. Bei den sektoriellen Richtlinien betrifft dies in erster Linie die Ärzte, Tierärzte, Zahnärzte, Apotheker, Architekten ${ }^{795}$ sowie die Fachärzte für Allgemeinmedizin, da bei diesen Berufen das Kriterium einer mindestens dreijährigen Hochschulausbildung ansonsten erfüllt ist. Auch Krankenschwestern und Hebanmen, soweit ihre Ausbildungen dieses Kriterium erfüllen, können von dieser Ausnahmebestimmung erfalßt sein. Diplome für diese Berufe werden ausschließlich gemäß den sektoriellen Regelungen beurteilt.

Dieser Grundsatz wird in einigen Mitgliedstaaten insoweit durchbrochen, als es dort medizinische und paramedizinische Berufe gibt, die zwar sehr eng verwandt sind mit den durch die sektoriellen Richtlinien geregelten Berufen, jedoch nicht vom Regelungsgehalt dieser Richtlinien erfaßt werden. Diese Diskrepanz hat bei der Umsetzung und Anwendung der allgemeinen Anerkennungsrichtlinie zu erheblichen Problemen vor allem für Krankenschwestern mit einer Spezialausbildung geführt.

\section{(1) Problembereich: Krankenschwestern}

Die Richtlinien 77/452/EWG und 77/453/EWG ${ }^{796}$ betreffen Krankenschwestern und Krankenpfleger, die für die allgemeine Pflege verantwortlich und dementsprechend ausgebildet sind. Diese Richtlinien kennen, anders als die Ärzte- und Zahnärzterichtlinien keine Regelungen für Spezialisten. Dabei gibt es jedoch in einigen Mitgliedstaaten selbständig reglementierte Berufe oder berufliche Tätigkeiten für spezialiell ausgebildete

793. $\rightarrow$

bastically the directive does not directly address the professions but it addresses the professional activities. This is a significant difference because an activity can be covered in the Member States by either similar professions or by overlapping professions.. Select Committee of the House of Lordls $1986,14(\mathrm{Q} 42)$.

794. Diese Kritik wurde bereits von Wägenbaur im Hinblick auf den Richtlinienentwurf geäiuert, EuR $1987,113(120)$

795. Zur Umsetzungsproblematik hinsichtlich Innen-, Garten- und Landsehaftsarchitekten siehe die Ausfiihrungen Seite 157 .

796. Richtinien des Rates wom 27. Juni 1977, ABl. Nr L 176 wourn 15. Julli 1977, 1 und 8. 
Krankenschwestern ${ }^{797}$. Diese Krankenschwestern konnten bisher keine Anerkennung. ihrer Spezialqualifikation auf der Grundlage der sektoriellen Richtlinie bewirken. Mit der Verabschiedung des allgemeinen Anerkennungssystems kônnen diese Ausbildungen jedoch teilweise gemäß den Bestimmungen der Richtlinie 89/48/EWG anerkannt werden. Dabei ergaben sich bei verschiedenen Fallkonstellationen unterschiedliche Probleme.

VerhältnismäBig unproblematisch erwies sich der Fall, wenn eine Krankenschwester, die in Irland eine Spezialausbildung für Psychiatrie genossen hat, in Großbritannien eine vergleichbare Tätigkeit ausüben möchte. Da auf diesen spezialïsierten Krankenschwesternberuf die sektorielle Richtlinie keine Anwendung findet, gilt das allgemeine Anerkenjungssystem gemäß der Richtlinie $89 / 48 / \mathrm{EWG}$, falls die Voraussetzungen dieser Richtlinie ansonsten erfüllt sind. Problematischer ist der Fall wenn die irische Psychiatriekrankenschwester in Frankreich tätig werden möchte. Dort wird dieser Tătigkeitsbereich von Krankenschwestern ausgeübt, die allgemein nach der sektoriellen Rïchtlinie ausgebildet sind. In diesem Falle müBte überprüft werden, ob die irische Krankenschwester neben ihrer Spezialausbildung auch die allgemeine Qualifikation $\mathbb{A}_{\text {..S. }}$. der sektoriellen Richtlinie besitzt. Ist dies der Fall, erfolgt die Anerkennung automatisch nach der sektoriellen Richtlinie. Ihre Zusatzausbildung müßte dann als besondere Erfahrung bewertet werden. Liegt keine allgemeine Qualifikation vor, ist zu überprüfen, ob eine Anerkennung ihrer Ausbildung und beruflichen Erfahrung nach den durch die Rechtsprechung in den Rechtssachen Heylens ${ }^{798}$, Vlassopouloul ${ }^{799}$ und Newman ${ }^{B 00}$ entwickelten Grundsätzen erfolgen muß. Diese Problematik trat besonders im Verhältnis zwischen Belgien und Frankreich auf. Wenn eine belgische Gemeindekrankenschwester ohne allgemeine Schwesternqualifikation gemäß der sektoriellen Richtlinie in Frankreich als Krankenschwester arbeiten möchte, müßte die Anerkennung gemäß den durch die Rechtsprechung entwickelten Prinzipien erfolgen. Im umgekehrten Fall, d.h. wenn eine französische Krankenschwester, die gemäß dem sektoriellen System qualifiziert ist, in Belgien eine Tätigkeit als spezialisierte Krankenschwester, z.B. Kinderkrankenschwester, aufnehmen möchte, dann müßte die Anerkennung nach dem System der Richtlinie 89/48/EWG erfolgen, weil in Belgien Kinderkrankenschwester ein selbstăndig reglementierter Beruf ist.

797. So kenat z. B. Belgien eine Sonderausbidlung für die Geneindeschwester. In Großbritannien und Irland gibt es besonders ausgebildete Krankenschwestern auf dem Gebiet der Psychiatrie. In den Niederlanden, Belgien und Irland genießen Kinderkrankenschwestern eine Spezialausbildung.

798. Unteil wom 15. Oktober 1987, Rs 222/86 - UNECTEF/Heylens -, Slg. 1987, 4097. Siehe dazu Du bouis, Rew. fr. de droit adm. 1988,691

799. Urteil vonn 7. Mai 1991, Rs C-340/89 - Irène Vlassopoulou/Ministerium für Justiz, Bundes- und Europarngelegenheiten Baden-Württemberg - S1g. 1-1991. $2357 \mathrm{ff}$.

800. Urteil wom 7. Mai 1992, Rs C 104/91 - Colegio Oficial de Agentes de la Propriedad Inmobiliaria, Ministerio fiscal/J.L. Aguirre Borrell, S.K. Newman, S. Aguirre Gil de Biedma, M.J. Cepeda Ruiz, P. Agturre Gil de Biedma -, S\g. 1992, 1-3003. 


\section{(2) Problembereich: Rechtsanwälte}

Problematisch ist auch der Fall für Rechtsanwällte. Hier besteht ein gewisses Konkurrenzverhältnis zwischen der Dienstleistungsrichtlinie für Rechtsanwälte ${ }^{\text {and }}$ und der Hochschuldiplomrichtlinie. Zweifelhaft ist, ob die Richtlinie 77/249/EWG als sektorielle Richtlinie im Sinne des Art. 2 Abs. 2 der Richtlinie 89/48/EWG eingestuft werden muß, womit der Anwendungsbereich der Hochschuldiplomrichtlinie auf die Niederlassungsfreiheit für Rechtsanwälte beschränkt würde ${ }^{802}$.

Hierbei sind mehrere Fallgruppen zu unterscheiden: Einerseits die Dienstleistung unter der Berufsbezeichnung des Herkunftsstaates, d.h. die Berufsausübung unter "home title" $\mathrm{e}^{\prime \prime}$ andererseilts die grenzüberschreitende anwaltliche Tätigkeit unter Verwendung der Berufsbezeichnung des Aufnahmestaates. Dritte Möglichkeit ist die als "établissement sauvage" bezeichnete Niederlassung unter "home title", die in einigen Mitgliedstaaten aufgrund der dortigen Rechtslage zwar möglich aber nicht sehr erwünscht ist ${ }^{803}$ "Im ersten Fall gilt ausschließlich die Richtlinie 77/249/EWG. Der zweite Fall wird grundsätzlich durch das Anerkennungssystem der Richtlinie 89/48/EWG erfaßt. Der Betroffene muß seine Anerkennung gemäß diesem System bewirken. Hat er die Anerkennung seiner beruflichen Qualifikation unter Umständen nach Ablegung einer Prüfung erreicht, dann kann der Migrant unter der Berufsbezeichnung des Aufnahmestaates tätig sein. Meines Erachtens ist dabei seine Freizügigkeit nicht ausschließlich auf die Niederlassung im Aufnahmestaat beschränkt. Gedacht werden kann auch an eine Doppelniederlassung, wobei der Migrant nun in beiden Staten zur Führung des jeweiligen Berufstitels berechtigt ist, oder selbst an eine grenzüberschreitende Tätigkeit. In diesem Fall hat der Betroffene die Wahl die Berufsbezeichnung des Herkunftstaates oder die des Aufnahmestaates zu führen. Der dritte Fall ist bisher weder durch die Dienstleistungsrichtlinie noch durch die Hochschuldiplomrichtlinie abgedeckt. Nach bisheriger Rechtslage ist es eine Frage der nationalen Rechtsordnung, ob eine derartige Niederlassung unter "home

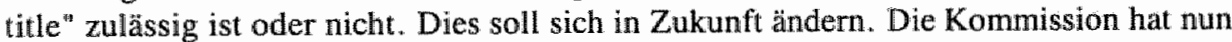
nach Vorarbeiten durch den CCBE einen entsprechenden Richtlinienentwurf vorgelegt, der die beiden bestehenden Richtlinien ergänzen soll, so dal3 in Zukunft auch die dritte Variante von einem europäischen Regelungssystem erfaßt wird ${ }^{304}$.

801. Richtlinie 77/249/EWG des Rates vom 22. März 1977 zur Erleichtenung der tatsächlichen Ausitbung des freien Dienstleistungsverkehrs der Rechtsanwälte, ABU. Nr. L. 58 vom 26. Marz 1977.

802. Siehe zur Dienstle istungsrichthinie 77/249/EWG die Erơrterungen Seite 270 .

803. Vor allem Brüssel und Paris haben sich zu Zentren der "établissement sauvage" herausgebildet. Die framzösische Reaktion war eine Ändenung der gesetzlichen Berufsorganisation durch Schaffung eine: neuen Anwaltsberufes, der die bisher bestehenden Benfe "avocat" und "conseil juridique "vereinte. Siehe dazu die Erläuterungen von Bacroude Fontebressin 1992. Diese Maßnahme bewirkte eine Einschränkung der Niederlassung unter "home title". Siehe dazu unten Seite 412

Agence Europe vom 28. Dezember 1994, 12. KOM (94) 572. 


\section{INHALT DER RICHTLINIE 89/48/EWG}

\section{Der Begriff des Diploms im Sinne der Richtinie 89/48/EWG}

Die Anwendung der Richtlinie 89/48/EWG setzt ein Diplom i.S. des Art 1 Buchstabe a) voraus. Unter "Diplomen" versteht die Richtlinie "alle Diplome, Prüfungszeugnisse oder sonstige Prüfungsnachweise". . Diese müssen "in einem Mitgliedstaat von einer nach seinen Rechts- und Verwaltungsworschriften bestimmten zuständigen Stelle ausgestellt werden. Aus ihnen muß hervorgehen, daß der Diplominhaber ein mindestens dreijähriges Studium oder ein dieser Dauer entsprechendes Teilzeitstudium an einer Unniversität oder einer Hochschule oder einer anderen Ausbildungseinrichtung mit gleichwertigem Niveau absolviert und gegebenenfalls die uber das Studium hinaus erforderliche berufliche Ausbildung abgeschlossen hat." Der Richtlinientext - zumal in seinen verschiedenen sprachlichen Fassungen - gibt keine genauen Kriterien für die Beantwortung der Frage, was unter einer Ausbildungseinrichtung mit gleichwertigem Niveau wie eine Hochschule zu verstehen ist. In der französischen Fassung des Richtlinientextes findet sich der Begriff des "enseignement supérieur", in der englischen Version wird von "higher education", in der niederländischen von "hoger onderwijs" gesprochen. Diese Begriffswahl hat zu einer Fülle von Abgrenzungsproblemen geführt, weil die Richtlinie selbst keine Definition bietet ${ }^{805}$. Grundsätzlich wird man von der Rechtslage in den Mitgliedstaaten ausgehen müssen. Unter das Kriterium Ausbildungseinrichtungen mit gleichwertigem Niveau wie die Universitäten und Hochschulen fallen jedenfalls in Deutschland gemäß dem Hochschulrahmengesetz auch die Fachhochschulen ${ }^{\text {. }}$ Dieses Ergebnis wurde besonders von der Bundesrepublik Deutschland im Hinblick auf die Ingenieursausbildung an den Fachhochschulen angestrebt, da hiermit eine Aufwertung dieser Ausbildungsform erhofft wird ${ }^{807}$. Für Großbritannien gehören neben den Universitäten auch die Polytechnics in den Anwendungsbereich der Richtlinie. Nach Verabschiedung der Richtlinie wurde in Großbritannien eine Umbenennung der Polytechnics vorgenommen. Diese nennen sich inzwischen zum überwiegenden Teil ebenfalls Universität, so daß etwaige Zweifel bezüglich der Anwendung hierdurch gänzlich beseitigt wurden. Die Niederlande zăhlen die Universitäten und die HBO-Einrichtungen zu den Anstalten des "hoger onderwijs" 808.

805. Winkel, Der freie Beruf 8, 1991, 22.

806. Gernäl \& 1 des HRG sind Hochschulen in Sinne des Hochschulrahmengesetzes die Universitäten, die Pälagogischen Hochschulen, die Kunsthochschulen, die Fachhochschulen und die sonstigen Einrichtungen des Bildungswesens, die mach Landesrecht staatliche Hochschulen sind.

807. Gerade die Stellung der deutschen Fachhochschulen war bei den Verhandlungen zur Architektenrichtlinie sehr umstritten. Dort wutde schließlich ein Kampromiß erzielt, durch den die FachhochschuIdiplome mit einer vierjährigen Ausbildungsdlauer ohne Zusatzerfordemis anerkannt werden. Beträgt dagegen die Ausbildungszeit weniger als vier, mindestens aber drei Jahre, wird zusätzlich der Nachweis einer viejjăhrigen Berufserfahrung verlangt, der von der zustämdigen Architektenkammer in der Bundesrepublik bescheinigk sein muß (Art. 4 Abs. 1 Unterabs. 2 der Architekten-Richtlinie). Der Streit unn die Stellung der Fachhochschulen bewirkte das Scheitern der sektoriellen Richtlinie für Ingenieure.

808. Art. 1. 1.b Wet op het hoger onderwijs en wetenschappelijk onderzoek (W.H.W) vom 8. Oktober 1992, Sib. 593. 
Die Einbeziehung der deutschen Fachhochschulen in das Anerkennungssystem war Angesichts des Kommissionsentwurfes nicht selbstverständlich. Der Entwurf bezog sich deutlich auf Hochschuldiplome unter Ausschluß der Fachhochschuldiplome. Dazu hieß es in Art. 1 Buchstabe a) des Kommissionsentwurfs, daß im Sinne der Richtlinie als Hochschuldiplom jedes Diplom gilt...., das "von einer Universituät oder einer als gleich. wertig anerkannten anderen Hochschuleinrichtung nach einem mindestens dreijährigen Studiengang ausgestellt wird, der in der Regel nur Inhabern eines Zeugnisses zugänglich ist, mit dem der erfolgreïche Abschluß der gesamten Sekundarschule bescheinigt wird" ${ }^{1 "}$. Besonders der Hinweis auf den Abschluß der "gesamten Sekundarschule" hätte eine Einbeziehung der Fachhochschuldiplome verhindert, da eine derartige Bedingung einen Sekundarschulnachweis des Typs Abitur, baccalauréat oder maturità unterstellt. Die Fachhochschulreife bedeutet aber ein Jahr weniger als das Abitur. Der Kommissionsvorschlag ist nicht überraschend, da er in einem Zeitpunkt vorgelegt wurde, in dem die zähen Verhandlungen bezüglich der Architektenrichtlinie noch in vollem Gang waren. Gerade bei der Architektenrichtlinie waren die Fachhochschuldiplome für Architekten langjähriger Streitpunkt. Die Kommission befürchtete daher nicht von ungefähr, daß eine ähnliche Diskussion beziiglich der Ingenieurdiplome, die von der allgemeinen Anerkennungsrichtlinie erfaßt werden sollten, sich wiederholen könnte. Der Streit bei den Architekten hatte nur mit der grundsätzlichen Einigung auf eine vierjährige Ausbildung beigelegt werden können, wobei für Fachhochschuldiplome mit einer dreijährigen Ausbildung eine Sonderregelung getroffen wurde ${ }^{90 \%}$ "Diese Lösung konnte aber bei der allgemeinen Hochschulrichtlinie nicht gewählt werden, da damit ein Großteil der Ausbildungen an Universitäten im Vereinigten Königreich und in Irland außerhalb des Anwendungsbereichs der Richtlinie gestellt worden wären. Auch der Wirtschafts- und Sozialausschuß und das Europäische Parlament haben in ihren Stellungnahmen keine prinzipielle Kritik an dieser Bedingung geäußert ${ }^{810}$. Der geănderte Kommissionsvorschlag von 1986 enthielt noch die entsprechende Bedingung, so daß davon ausgegangen werden muß, daß die Streichung des Passus erst zu einem verhältnismäßig späten Zeitpunkt im Rat vorgenommen worden ist. Ob dieser Wandel auf den inzwischen gemachten Erfahrungen mit der Architektenrichtlinie beruht oder im Rahmen des Tauzieliens um andere umstrittene Bereiche zustande gekommen ist, kann nicht hundertprozentig nachvollzogen werden.

Die als "Diplome" in Art. 1 Buchstabe a) der Richtlinie 89/48/EWG definierten Hochschulabschlüsse der Mitgliedstaaten umfassen auch Staatsprïfungen, die einen mindestens dreijährigen Studiengang voraussetzen, wie z.B. das juristische Staatsexamen oder die Lehramtsprüfungen in der Bundesrepublik Deutschland. Diese Feststellung ist nicht so selbstverständlich, wie sie zunächst erscheint. Der Bundesrat erhob gegen den ersten Entwurf der Richtlinie gerade zu diesem Punkt entscheidende Kritik ${ }^{811}$. Nach der damalls vertretenen Auffassung des Bundesrates sollte die Richtlinie in den Fällen, in

809. Siehe dazu Seite 147.

810. Der WSA schlug dies bezüglich lediglich eine Ergänzung vor:...Abschluß der gesamten von: einem Mitgliedstaat anerkannten Sekundarschule bescheinigt wird."

811. BR-Drucksache 404,85 vom 29 . Nowember $1985,3$. 
denen der Aufnahmestaat den Zugang zu einer beruflichen Tätigkeit oder deren Ausübung von einer Staatsprüfung abhängig macht , keine Anwendung finden. Diese Ansicht konnte sich jedoch - zumall sie zumindest für den Bereich der Bundesrepublik Deutschland die Herausnahme aller Lehrer und aller rechtsberatenden Berufe aus dem Geltungsbereich der Richtlinie bedeutet hätte - nicht durchsetzen. Der Bundesrat hat daher 1988 diese Forderung auch nicht aufrecht gehalten ${ }^{812}$. Ob zwischen diesem Nachgeben bezüglich der Staatsprüfungen und dem Streichen des umstrittenen Sekundarschulabschlusses in der Definition des Diploms gemäß Art. 1 Buchstabe a) der Richtlinie 89/48/EWG ein direkter Zusammenhang besteht, kann nicht nachgewiesen werden, auszuschließen ist er jedoch nicht. Im Gegenteil, es spricht einiges dafür, daß die Bundesrepublik als Preis für die Einbeziehung der Fachhochschuldiplome in das Anerkennungssystem, dieses Ergebnis akzeptiert hat ${ }^{813}$.

\section{Das Endprodukt}

Aus dem Diplom muß desweiteren hervorgehen, "daß der Zeugnisinhaber über die beruflichen Voraussetzungen verfügt, die für den Zugang zu einem reglementierten Beruf oder dessen Ausübung in diesem Mitgliedstaat erforderlich sind, wenn die durch das Diplom, Prüfungszeugnis oder einen sonstigen Befähigungsnachweis bescheinigte Ausbildung uberwiegend in der Gemeinschaft erworben wurde" (Art. 1 Buchstabe a) zweiter Gedankenstrich). Ist in einem Mitgliedstaat der Zugang zum Beruf zusätzlich von einer an die Prüfung anschließenden einführenden Tätigkeit unter Anleitung einer Person, die den vollen Berufsstatus hat, abhängig, ist erst mit dem Zeugnis über den Abschluß dieser einführenden Tätigkeit "die über das Studium hinaus erforderliche Ausbildung" abgeschlossen. Man spricht in diesem Zusammenhang von dem sogenannten "Endprodukt" 8:14. Ein typisches Beispiel für ein "Endprodukt" ist der Beruf des Rechtsanwalts. In nahezu allen Mitgliedstaaten bedarf der Rechtsanwalt zur Zulassung nicht nur den Nachweis seiner akademischen Qualifikation, sondern auch eine Bescheinigung der praktischen Ausbildung ${ }^{815}$. Diese praktische Berufsausbildung kann unterschiedlich ausgestaltet sein. So wird in einigen Mitgliedstaaten die berufliche Ausbildung ausschließlich von der jeweiligen Berufsorganisation durchgeführt und examiniert. In anderen Mitgliedstaaten gibt es eine durch staatliche Behörden vorgeschriebene und geprüfte Praxisausbildung. Auch die Referendarzeit mit der absch\|ießenden Zweiten Staatsprüfung, muß als eine solche Ausbilldung angesehen werden. Der Inhaber eines Universitätsdiploms, ohne die anschließende für die Ausübung eines bestimmten Berufes geforderte Praxisausbildung, fällt daher nicht unter den Anwendungsbereich der Richtlinie, da er nicht als Endprodukt qualifiziert werden kann.

812. Siehe dazu Bergreen, Schulverwaltung 1988, 299 (304).

813. In diesem Zusammenhang war die Einfügung der Eignungsprütung als Anpassungsinstrument sicher von grober Bedeutung.

814. Dieser Begriff unterliegt wegen det Versachlichung einer Person allerdings der Kritik und wird inzwischen im amtlichen Jargon durch den Ausdruck "qualifizierter Berufsangehöriger" ersetzt. Wegen der Kürze und Prägnanz soll der Begriff "Endprodukt" im folgenden weiterverwendet wenden.

815. Eine Ausnahme gilt lediglich fitr Spanien. 
Weiteres Kriterium für die Qualifikation zum "Endprodukt" ist, daf die Gesamtausbildung "überwiegend" in der Gemeinschaft stattgefunden hat. Die Anforderung "überwiegend" hat bei der Umsetzung der Richtlinie zu unterschiedlichen Interpretationen geführt. Einige Mitgliedstaaten sahen nur dann das Kriterium "überwiegend" in der Gemeinschaft genossene Ausbildung erfüllt, wenn die Ausbildung zumindest zu zwei Drittel in der Gemeinschaft stattgefunden hat. Diese Interpretation ist $m$. E. jedoch zu restriktiv. Eine überwiegend in der Gemeinschaft genossene Ausbildung liegt auch dann vor, wenn diese zu mehr als fünfzig Prozent in der Gemeinschaft absolviert worden ist. Ansonsten müssen die Anerkennungskriterien für Drittstaatsdiplome gelten.

\section{Drittstaatsdiplome}

Als ergänzende Malnahme zur Richtlinie 89/48/EWG hat der Rat eine Empfehlung erlassen, derzufolge die Regierungen der Mitgliedstaaten auch solchen Personen den Zugang zu geregelten Berufen und ihre Ausübung ermöglichen sollen, die ihr Diplom, Prüfungszeugnis oder sonstige Befähigungsnachweise in einem Drittstaat erhalten haben und deren fachliche Voraussetzungen ähnlich sind wie die der Inhaber der Diplome eines Mitgliedstaats ${ }^{816}$.

Mit dieser Empfehlung wird zunächst kein einklagbares subjektives Recht auf Anerkennung von Diplomen aus Drittstaaten eröffnet, es wird jedoch der indirekte Anwendungsbereich der Richtlinie 89/48/EWG erheblich erweitert. Im Falle, daß die betroffene Person Inhaber eines Diploms aus einem Drittstaat ist, das durch einen anderen Mitgliedstaat anerkannt ist, muß sie eine mindestens dreijährige Berufserfahrung nachweisen, die ebenfalls von dem Mitgliedstaat bescheinigt wird, der das Diplom, das Prüfungszeugnis oder den Befähigungsnachweis des Drittlandes anerkannt hat. Dies bedeutet jedoch, daß auch Drittstaatsdiplome, soweit die nötige Berufserfahrung nachgewiesen werden kann, unter den Anwendungsbereich der Richtlinie fallen. Mit dieser Bestimmung weicht die Richtlinie 89/48/EWG von den sektoriellen Richtlinien ab, die keine Anerkennung von Drittstaatsdiplomen kennen.

Diese Bestimmung ist nicht nur für EG-Angehörige von Bedeutung, sondern auch Z.B. für den Drittstaat-Ehegatten eines Migranten. Zwar bestimmt Art. 2 der Richtlinie 89/48/EWG lediglich, daß die Richtlinie für alle Angehörigen der Mitgliedstaaten gilt. Beachtlich sind hierbei jedoch auch die grundsälzlichen Regeln bezüglich der Familienangehörigen von migrierenden Arbeitnehmern, die in der Verordnung (EWG) Nr. $1612 / 68$ des Rates niedergelegt sind ${ }^{817}$. Gemäß Art. 11 der Verordnung (EWG) Nr. 1612/68 hat der Ehegatte eines Migranten das Recht, im gesamten Hoheitsgebiet des Aufnahmestaates irgendeine Tätigkeit im Lohn- oder Gehaltsverhältnis auszuüben. Gemäß der Rechtsprechung des EuGH in der Rechtssache Gül muß Art. 11 der Verordnung (EWG) Nr. 1612/68 dahingehend ausgelegt werden, daß der Ehegatte eines Ge-

816. ABI. Nr. L 19 vom 24. Januar 1989,24

817. Verordnung (EWG) Nr. 1612/68 des Rates vom 15. Oktober 1968, ABI. Nr. L 257 vom 19. Oktober 1968. 
meinschaftsangehörigen, der in einem Mitgliedstaat als Arbeitnehmer oder Selbständiger tätig ist, selbst wenn er Angehöriger eines Drittstaates ist, Anspruch auf Inländergleichbehandlung hat ${ }^{818}$. Im Falle Gül handelte es sich um einen türkischen Staatsangehörigen, dessen britische Ehegattin als Friseuse in der Bundesrepublik Deutschland tätig war. Er selbst war im Besitz eines Arztdiploms der Unversität Istanbul. Aufgrund dessen hatte er in der Bundesrepublik eine befristete Zulassung erhalten, die auch mehrfach verlängert worden war. Sein Antrag auf unbefristete Zulassung wurde jedoch mit đer Begründung zurückgewiesen, daß gemäß $\$ 10 \mathrm{Ab} .3$ der Bundesärzteordnung lediglich mit Deutschen verheiratete ausländische Ärzte zugelassen würden. Diese Bestimmung gälte aber nicht für die ausländischen Ehegatten von EG-Angehörigen. Der EuGH betonte in seiner Entscheidung. daß Art. 11 der Verordnung 1612/68 das Recht des Ehegatten - unabhängig von seiner Staatsangehörigkeit - auf Tätigkeiten im Arbeitnehmerverhältnis begründe. Für diesen Ehegatten müssen dieselben Regeln hinsichtlich des Zugangs zum Beruf wie hinsichtlich der Berufsausübung gelten wie für Inländer.

Überträgt man nun diese Rechtsprechung auf die Richtlinie 89/48/EWG, so muß Art. 2 der Richtlinie 89/48/EWG in der Form gelesen werden, daß die Richtlinie nicht allein für die Angehörigen der Mitgliedstaaten gilt, sondern auch für einen eventuell mit migrierenden Ehepartner. Dies erweitert jedoch den Anwendungsbereich der Anerkennung von Drittstaatsdiplomen nicht unerheblich. Voraussetzung ist allerdings, daß das Drittstaatsdiplom bereits in einem Mitgliedstaat anerkannt worden ist und der Drittstaatsangehörige eine dreijährige Berufserfahrung in diesem Mitgliedstaat nachweisen kann.

Unverständlicherweise finden sich keine vergleichbaren Bestimmungen in der Richtlinie 73/148/EWG im Falle der Niederlassungs- und Dienstleistungsfreilheit. Die Richtlinie 73/148/EWG enthält zwar ebenso wie die Verordnung 1612/68/EWG das grundsätzliche Recht des Drittstaats-Ehepartners eines Migranten in einen anderen Mitgliedstaat einzureisen und sich darin aufzuhalten (Art. 1 Abs. 1 d) der Richtlinie 73/148). Dieses Recht wird jedoch in der Richtlinie nicht ergänzt durch eine mit Art. 11 der Verordnung 1612/68/EWG vergleichbaren Bestimmung. Hieraus könnte konkludiert werden, daß der Ehepartner eines migrierenden Arbeitnehmers das Recht hat eine Tätigkeit im Lohndienst oder als Selbständiger aufzunehmen, während dieses Recht dem Ehepartner eines migrierenden Selbständigen verweigert werden könnte.

Gedacht werden muß also an die folgende Fallkonstellation: Ein Spanier ist mit einer Argentinierin werheiratet. Diese verfügt über ein argentinisches Ingenieursdiplom, das in Spanien anerkannt wird ${ }^{819}$. Nachdem das Ehepaar fünf Jahre in Madrid tätig gewesen ist, beschließen sie gemeinsam ein Ingenieurbüro in Mailand zu eröffnen. In einem

818. Urteil vom 7. Mai 1986, Rs 131/85 - Emür Gül/Regierungspräsident Düsseldorf -, Slg. 1986, 1573.

819. Die engen Beziehungen Spaniens zu den Staaten Sudamerikas haben zur Folge, dal auf Grund bilateraler Abkommen eine derartige Anerkennung nicht unwahrscheinlich ist. Siehe dazu auch das Urteil dies EuGH rom 7. Juli 1992, Rs C-369/90 - Micheletti -, SIg. 1992 1-4239; dazu de Groot in Coen/Hol scheidt/Pieper, Fs Bleckmann, 87. 
sollchen Fall sind die italienischen Autoritäten gemäß der Richtlinie 89/48/EWG nicht nur verpflichtet, das Diplom des Spaniers anzuerkennen ${ }^{820}$, sondern auch das des argentinischen Ehepartners.

\section{Parallele Ausbildungen}

Gemäß Art. 1 Buchstabe a) letzter Absatz werden einem Diplom im obigen Sinne die Ausbildungsnachweise gleichgestellt, die von einer zuständigen Behörde in einem Mitgliedstaat als gleichwertig anerkannt sind und in bezug auf den Zugang oder die Ausübung eines reglementierten Berufs die gleichen Rechte verleihen. Mit dieser Regelung sollten die vor allem in Großbritannien und Irland gebräuchlichen parallelen Ausbildungswege in das Anerkennungssystem einbezogen werden. Nach der ursprünglichen Zielsetzung sollte dieser Bestimmung auch nur auf diese Fälle beschränkt Anwendung finden ${ }^{821}$. Im Gegensatz zu Drittstaatsdiplomen müssen die parallelen Ausbildungen, um in das Anerkennungssystem der Richtlinie zu fallen, innerhalb der europäischen Gemeinschaft erfolgt sein. Eine alternative Ausbildung in einem Drittstaat, selbst wenn diese im Heimatstaat als gleichwertig anerkannt worden ist, kommt nicht in den Genuß3 der Anerkennung gemäß dem System der Richtlinie.

Während der Umsetzungsperiode stellte sich jedoch die Frage, ob dieser Absatz nicht auch auf frühere Ausbildungsgänge angewandt werden könnte, die nicht den $\mathbb{K}$ riterien der Richtlinie 89/48/EWG entsprachen, die aber im Laufe der Zeit durch Ausbildungsgänge ersetzt worden sind, die nun durchaus die Voraussetzungen der Richtlinie 89/48/EWG erfüllen.

Gedacht werden muß etwa an die Grundschullehrerausbildung in Frankreich, die nicht das Kriterium einer dreijährigen Hochschulausbildung erfüllte. Es handelte sich dabei um eine sogenannte Bac +2 Ausbildung, d.h. baccalaureat mit anschließender zweijähriger Ausbildung. Derartige Ausbildungen wurden inzwischen auf drei Jahre verlängert, wobei die Inhaber der früheren Ausbildungsdiplome nach innerstaatlichen Anerkennungsregeln den Absolventen der verlängerten Ausbildung gleichgestellt wurden.

Die Frage, die bei der Umsetzung der Hochschulrichtlinie gestellt wurde, war daher, ob diese innerstaatlich als gleichwertig anerkannten "Altdiplominhaber" auch in den Genuß der Hochschulrichtlinie kommen könnten. Dazu lassen sich unterschiedliche Meinungen vertreten. Einerseits kann man sich auf den klaren Wortlaut der Richtlinie bezüglich der Ausbildungslänge berufen. Danach wäre eine Anerkennung eines solchen "Altdiploms" nicht möglich, da es nicht die in Art.1 Buchstabe a) zweiter Gedanken"

820. In diesem Fall könnte eine Anerkennugg des spanischen Diploms auch unter Anwendung des Kulturabkommens zwischen Spanien und Italien won 1957 erfolgen, das Hochschulabschußiqualifikationen umfafs. Danach kơnnen die Licenciados und Doctores spanischer Universitaten die entsprechenden italienischen Qualifikationen erhalten, wenn sie eine oder zwei Prüfungen bestanden und die Abschlluharbeit verteidigt haben (Ministerialeriah vom 29. Mai 1964).

821. Sielhe dazu auch die entsprechende nicht veröffentlichte Ratserklärung. 
strich Richtlinie 89/48/EWG geforderte Voraussetzung eines dreijährigen Studiums erfüllt. Andererseits bietet der Wortlaut des letzten Absatzes von Art.1 Buchstabe a) der Richtlinie 89/48/EWG anscheinend die Möglichkeit, gerade diese Fälle früherer Ausbildungsgänge für die Betroffenen in befriedigender Weise zu lösen. Voraussetzung ist dabei lediglich, daß die Gleichwertigkeit der alten mit der neuen Ausbildung bezilglich des Zugangs und der Ausübung des betreffenden Berufes von der zuständigen Behörde des Herkunftsstaates deutlich bescheinigt wird.

Gegen diese Interpretation spricht lediglich die Entstehungsgeschichte der Richtlinie 89/48/EWG, wonach diese Vorschrift angeblich nur den Fall paralleler Ausbildungsgänge zu regeln beabsichtigte ${ }^{822}$. Wortlaut und Motive stehen sich somit in einem scheinbaren Widerspruch gegenüber. Die Entstehungsgeschichte, die Gedanken und Motive des Gesetzgebers, sind im europäischen Recht nur sehr bedingt Teil der Gesetzesinterpretation ${ }^{823}$. Dies gilt bereits für die Verträge, deren travaux préparatoire lange Zeit nicht veröffentlicht waren. Der Gerichtshof hat bei Interpretationsfragen sich auch nie ausdrücklich durch die historische Interpretation leiten lassen ${ }^{824}$. Vielmehr berief er sich hauptsächlich auf eine funktionale, dynamisch-teleologische Interpretation mit unter selbst gegen den ausdrücklichen Wortlaut einer Vertragsbestimmung ${ }^{825}$. Pechstein weist in einer Analyse zur Bedeutung von Protokollerklärungen darauf hin. daß ihre Berücksichtigungsfähigkeit um so größer ist, je größer die - bekanntgewordenern - politischen Probleme bei der Verabschiedung des zugrundeliegenden Rechtsakts waren $^{826}$. Ob es sich bei der Regelung der parallelen Ausbildungen und ihrem Verhältnis zu "Altdiplomen" um ein solches politisches Problem handelt, ist jedoch unbekannt. Die Mehrdeutigkeit der Bestimmung spricht dagegen. Wahrscheinlicher ist, daß die "Altdiplome" bei den Unterhandlungen nicht zur Sprache gekommen sind, so daß dazu lediglich eine Lücke besteht, nicht jedoch eine bewußte Ausgrenzung.

Durch Verabschiedung der Richtlinie 92/51/EWG hat sich die angesprochene Problematik für die "Altdiplome" in Bezug auf die Richtlinie 89/48/EWG entschärft, da darin eine gewisse Durchlåssigkeit zwischen verschiedenen Ausbildungsniveaus vorgesehen ist $^{827}$.

822. Dies isit dem Hinweis auf die nicht veröfentlichte Protokollerklärung des Rates zu entnehmen

823. Zwar stellt der Gerichtshof wereinzelt auch auf die Vorgeschichte einer Maßrahme ab, diese Falle grehören jedoch zu den Ausnahmen. Siehe etwa das. Unteil vom 5.Juni 1973, Rs 81/72 - Kommission/Rat -, Slg. 1973, $575(583 \mathrm{f})$

824. Siehe zu den Auslegungsmethoden des Gerichtshofs gnindsätzlich. Bredimas; Hoffmann-Becking, Normautbau und Methode (1973); Bleckmann, NJW 1982, 1177.

825. Siehe dazu bereits Ophüls, in: FG für Muller-Armack, 279; Bernhardt, Zur Auslegung des Europäischen Gemeinschaftsrechts, 17; Bleckmann, EuR 1979, 239; Bleckmann NJW 1982, 1777; Bleckmann, Europarecht, $125 \mathrm{ff}_{, \text {; }}$; Zuleeg EuR 1969, 97.

826. Pechstein. EuR 1990, 249 (252).

827. Siehe dazu die Erörtenungen Seite 248 . 


\section{Reghementierter Beruf und reglementierte berufliche Tätigkeit}

\section{a. Einleitung}

Für den Umfang des Anwendungsbereiches der Richtlinie ist der Begriff des reglementierten Berufes von entscheidender Bedeutung. Voraussetzung für die Anwendung der Richtlinie 89/48/EWG ist, daß der Beruf im Aufnahmestaat reglementiert ist. Ohne Reglementierung in einem bestimmten Tätigkeitsbereich bedarf ein Beruf grundsätzlich keiner Anerkennung, da sein Ausübung ohne berufsregelnde Einschränkung erfolgen kann. Eine Liberalisierung erübrigt sich, da die Freiziigigkeit innerhalb der Gemeinschaft ohne dies gewährleistet ist. Gedacht werden muß z. B. an den Beruf des Unternehmensberaters oder Management Consultant. In keinem der Mitgliedstaaten ist diese berufliche Tätigkeit bisher durch Berufsgesetz reguliert. Weder der Tätigkeitsbereich noch der Titel genießen einen berufsrechtlichen Schutz ${ }^{828}$. Damit steht für diese Berufsgruppe der Binnenmarkt offen. Die Berufsausübung in Form der Dienstleistung oder der Niederlassung in einem anderen Mitgliedstaat bedarf keiner Anerkennung beruflicher Qualifikationen im Aufnahmestaat.

Problematisch sind dagegen besonders die Fälle, bei denen zwei verschieden reglementierte Berufe einen vergleichbaren Tätigkeitsbereich in zwei Mitgliedstaaten abdecken. Ebenso problematisch ist, wenn ein reglementierter Beruf in einem Mitgliedstaat in einem anderen Mitgliedstaat lediglich Teil eines reglementierten Berufs ist.

Was aber ist unter einem reglementierten Beruf zu verstehen? Trotz seiner zentralen Bedeutung für den Anwendungsbereich der Richtlinie 89/48/EWG, bereitete die Beantwortung dieser Frage bei cler Umsetzung der Richtlinie häufig Schwierigkeiten. Nicht für alle Fâlle ließ sich eine eindeutige und befriedigende Entscheidung treffen ${ }^{829}$. Dabei manifestierten sich die unterschiedlichen Traditionen in den einzelnen Mitgliedstaaten sehr deutlich ${ }^{830}$. Das Prinzip der reglementierten beruflichen Tätigkeit ist stark durch die französische und deutsche Rechtstradition geprägt. Für Deutschland gilt eine intensive Reglementierung für die freien Berufe ebenso wie für das Gewerbe und das Handwerk. In Frankreich ist es vor allem der medizinisch und paramedizinische Bereich der stark reglementiert ist. Auch Belgien, Österreich und die Mittelmeerländer können zumindest im Bereich der freien Berufe als stark reglementiert eingestuft werden. Anderen Mitgliedstaaten ist die gesamte Konzeption des reglementierten Berufes dagegen eigentlich wesensfremd. Besonders in Dänemark, und dies gilt wohl für ganz Skandinavien, scheinen nur sehr wenige Berufe im Sinne der Richtlinie reglementiert

828. Institut für Freie Berufe. 273.

829. So stellte sich die Frage insbesondere bei den Ingenieuren in Dänemark., Frankreich und den Niederlanden. Diese drei Mitgliedstaaten" vertreten die Ansicht, daß es sich um einen unreglementierten Beruf hawdelt, und verneinten deshalb eine Umsetzungswerpflichnng. Siehe dazu die Ausfuhrungen auf Seite 351 ff..

830. Im 7. Erwägungsgrumd wird in diesem Zusammenhang von unterschiedlichen soziologischen Verhältnissen in den Mitgliedstaaten gesprochen. 
zu sein ${ }^{831}$. Aber auch in Großbritannien und Irland gibt es zwar eine Form der Reglementierung durch die chartered bodies, diese Reglementierung entspricht jedoch nur ansatzweise den berufsrechtlichen Regelungen wie sie vor allem in Deutschland und Frankreich bekannt sind. Die Niederlande sind heute dem Mittelfeld zu zuordnen. Berufliche Reglementierungen sind nicht unbekannt und auch micht selten, werden jedoch im Rahmen der allgemeinen. Deregulierung der letzten Jahre eher abgebaut als verstärkst ${ }^{832}$. Die Widersprüchlichkeit dieser politischen Tendenz mit der Richtlinienkonzeption führte bei der Umisetzung zu einigen Reibungspunkten ${ }^{833}$.

\section{b. Definition des reglementierten Berufes und der reglementierten beruflichen Tätigkeit}

Art. 1 Buchstabe c) und d) der Richtlinie 89/48/EWG definiert den reglementierten Beruf als " die reglementierte berufliche Tätigkeit oder die reglementierten Tätigkeiten

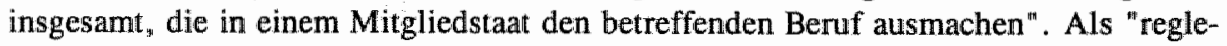
mentierte berufliche Tätigkeit" bezeichnet die Richtlinie "eine berufliche Tätigkeit, deren Aufnahme oder Ausübung in einem Mitgliedstaat direkt oder indirekt durch Rechtsund Verwaltungsvorschriften an den Besitz eines Diploms gebunden ist".

Art und Umfang solcher Reglementierung varilieren teilweise erheblich zwischen den Mitgliedstaaten ${ }^{834}$. Hierbei müssen verschiedene Fallgruppen unterschieden werden:

(1) Reglementierung durch gesetzliches Tätigkeitsmonopol

(a) Partielles und vollkommenes Tätigkeitsmonopol

Als strengste Form der Reglementierung einer beruflichen Tätigkeit gilt, wenn die Aufnahme oder Ausübung der beruflichen Tätigkeit an den Besitz eines bestimmten Diploms gebunden ist ${ }^{83.5}$. Bei dieser Reglementierung ist bereits der Tätigkeitsbereich geschützt: ${ }^{836}$. Eine unbefugte Ausübung der Tätigkeit kann sanktioniert werden ${ }^{837}$. Als ein deutliches Vorbild für ein Tätigkeitsmonopol kann der Beruf des Rechtsanwaltes bezeichnet werden. An diesem Beispiel lassen sich auch die verschiedenen Formen eines

831. Im Rahmen des EWR-Vertrages stellte sich diese Problematik emeut, da auch die EFTA-Länder sich in stark und schwach reglementierte Staaten einordnen Iassen. Bei den drei neuen EG.Mitgliedstaaten kann vor allem Osterreich als stark reglementiert bezeichnet werden, wohingegen Schweden ein schwach reglementierter Stat ist. Finmland nimmt eine Mittelposition ein.

832. De Wilde, SEW 1994, 775 behauptet, daf die Reglementienung der gewerblichen Berufe in den Niederlanden neben Deutschland und Belgien am regelungsintensivsten gewesen ist... Diese stark regulierten Niederlassungsvoraussetzangen sollen jedoch in Zukunft abgebaut werden.

833. Unstritten ist $x$.B., ob der Ingenieursberuf in den Niederlanden als reglementiert betrachtet werden muR. Siehe dazu die Ausfuhrungen Seite 352

834. Müllet-Bernhardt, RdJB 1989, 130 (132).

835. Bei einer derartigen beruflichen Reglementienung spricht man won einem Tätigkeitsmonopol.

836. Pertek, YbEL 1992, 293; Pertek 1994, 68 If..

837. Siehe 2.B. Art. 436 Abs. I des niederländischen Wetboek van Strafrecht: "Hij die, niet toegelaten tout de uitoefenig wan een beroep waartoe de wet toelating vordert, buiten noodzaak dat beroep cuitoefent, wordt gestraft met geldboete van de tweede categorie." 
Tätigkeitsmonopols illustrieren. In allen Mitgliedstaaten gibt es eine Reglementierung für bestimmte anwaltliche Tätigkeiten ${ }^{838}$. So kennen alle Mitgliedstaaten den Anwaltszwang bei bestimmten Gerichten ${ }^{839}$. Dieser Anwaltszwang bezieht sich grundsätzlich auf đie im nationalen Rechtssystem niedergelassenen Anwälte. Die Berufsausübung vor Gericht ist bei einem Tätigkeitsmonopol der niedergelassenen Rechtsanwälte für Personen, die nicht im jeweils nationalen Rechtssytem als Rechtsanwalt zugelassen sind, ausgeschlossen, d.h. ausländische Rechtsanwälte werden durch diese Reglementierung von der forensischen Tätigkeit ausgeschlossen. Damit besteht in allen Mitgliedstaaten ein partielles Tätigkeitsmonopol bezüglich der forensischen Tätigkeit der Rechtsanwälte. Die Bezeichnung "partielles Tätigkeitsmonopol" ergibt sich daraus, daß die anwaltliche Tätigkeit sich nicht auf die Vertretung vor Gericht beschränkt, sondern andere außergerichtliche Komponenten, insbesonders eine rechtsberatende umfaßt ${ }^{840}$.

Diese Unterscheidung zwischen forensischem und rechtsberatendem Tätigkeitsbereich eines Rechtsanwalts gill zumindest für die kontinentalen Rechtssyteme. Die berufsrechtliche Situation in Großbritannien und Irland ist wesentlich komplizierter. In England und Wales kann man von einem Tätigkeitsmonopol der Barrister für die höheren Gerichte, d.h. High Court, Court of Appeal und House of Lords ausgehen. Dagegen gehört die rechtiche Beratung, die Vorbereitung won Klagen sowie die Vertretung bei niederen Instanzen in den beruflichen Tätigkeitsbereich des Solicitors. Dennoch wird man nicht von einem rechtlichen Beratungsmonopol der Solicitors sprechen können, da die Rechtsberatung auch durch andere Berufe oder nicht qualifizierte Laien (Legal Consultant) ausgeübt werden kann, ohne gegen eine berufsrechtliche Regelung zu verstoßen.

In der Bundesrepublik Deutschland ist dagegen das anwaltliche Tätigkeitsmonopol über den Anwaltszwang bei Gericht ${ }^{84 \|}$ hinaus auf die rechtsberatende Tätigkeit erweitert, die nur von Anwälten oder von als Rechtsbeistände zugelassenen Personen ausgeübt

838. Gollsmith, Barreau et médecins face au droit d"établissement, 70 (75)

839. Siehe z.B. für Belgien: Art. 440 Ger. Wet, für Dänemark: Art. 131 Low (Administration of Justice Acl), wobei allerdings gemä Art. 259 (Administration of Justice Act) grundsätzlich jederman selbst bei Gericht als Kläger und Beklagter auftreten kann; für Deutschland: 78 Abs. 1 ZPO: "Vor den Landgerichten und wor allen Gerichten des höheren Rechtszuges mủssen Parteien sich durch einen bei dem Prozeffgericht zugelassenen Rechtsanwalt als Bewollmächtigten vertreten lassen. "Bezuglich der anwaltichen Vertretung im Strafprozell siehe \$138 StPO; für Griechenland: Art. 94 Abs. 1 ZPO (gr); für Italien: Art.82 und 83 ZPO (it) und Art. 125 StPO (it); fur die Niedterland: Art. 133 ZPO. Art.

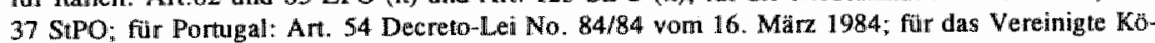
nigreich: Halsbury, Laws of England (4th ed., wol. 3 (1), 308-323.; Sollicitors Act 1974, section 22. Siehe bezüglich der Reglementienung der juristischen Berufe die ausfübrliche Studien von Cambell; Lonbay (1991); Tyrrell/Yaqub sōwie Martin Bernal (1990).

840. Brïderle, ZGR 1990,155 (161) bezeichnet die Rechtsberatung als ein eigenständiges Leistungsangebot.

841. \$78 Abs. I ZPO bestimmt, daß Parteien sich vor den Landgerichten und wor allen Gerichten des höheren Rechtszuges durch einem beim Prozebgericht zugelassenen Rechtsanwalt als Bevollmächtigten vertireten lassen müssen. 
werden darf ${ }^{842}$. Dieses Tätigkeitsmonopol der Anwälte müssen diese lediglich mit Notaren sowie Steuerberatern, Patentanwälten und Wirtschaftsprüfern auf ihrem jeweiligen Fachgebiet sowie Wissenschaftlern teilen. In diesem Fall besteht ein naheza "vollkommenes Tätigkeitsmonopol" \$43. Bis zur Neufassung der Bundesrechtsanwaltsordnung $1989^{844}$ war es für einen ausländischen Juristen aus einem Mitgliedstaat der Europäischen Gemeinschaften, verboten, sich innerhalb der Bundesrepublik auch unter "home títle" niederzulassen und zum eigenen Rechtssystem rechtsberatend tätig zu: $\operatorname{sein}^{8+5}$, falls er keine Zulassung als Rechtsbeistand bewirkt hatte ${ }^{846}$. Dieses Verbot bezog sich auch auf die Rechtsberatung über das Recht der Europäischen Gemeinschaften. Eine Zuwiderhandlung konnte gemäß $\$ 8$ Abs. 2 RBerG als Ordnungswidrigkeit mit einer Geldbuße von bis zu zehntausend Deutsche Mark geahndet werden. GemäB der $\$ \$ 206,207$ BRAO ist es nun Anwälten aus den Mitgliedstaaten der EG, der WTO und im Falle verbürgter Gegenseitigkeit auch aus anderen Staaten gestattet, sich in der Bundesrepublik niederzulassen, wenn sie in die zuständige Rechtsanwaltskammer aufgenommen sind. Ihre Rechtsbesorgungsbefugnis ist jedoch auf ausländisches und internationales Recht, vor allem auf das Recht des Herkunftstaates beschränkt. Auch müssen sie die ausländische Berufsbezeichnung unter Angabe des Herkunftstaates führen. Damit blieb das Tätigkeitsmonopol der deutschen Rechtsanwälte zum deutschen Recht bis zur Umsetzung der Richtlinie 89/48/EWG erhalten. Eine ähnliche Situation besteht in Portugal, wo die rechtsberatende Tätigkeit mit wenigen Ausnahmen den advogados vorbehalten ist ${ }^{847}$. In Frankreich hat man durch das Zusammenfügen von zweil ursprünglich getrennten Berufen, dem "avocat" und dem "conseiller juridique", erst in jüngster Zeit ein Tätigkeitsmonopol geschaffen ${ }^{848}$. Diese Entwicklung wurde unter dem Vorwand

842. \$1 Abs. 1 Rechtsberatergesetz (RBerG): "Die Besorgung fremder Rechtsangelegenheiten, einschließlich der Rechtsberatung und der Einziehung fremder oder zu Einziehungszwecken abgetretener Forderungen, darf geschäfitsmäbig - ohne Unterschied zwischen haupt- und nebenberuflicher oder entgeltllcher wnd unentgeltlicher Tătigkeit - nur von Personen betrieben werden, denen dazu von der zuständïgen Behörde die Erlaubnis erteitt ist." Dieser Erraubnüsvorbehalt bezieht sich naturlich nicht auf Rechtsanwälte und Notare. Ausnahmen bestehen für Steuenberater, Patentanwälte und Wintschaftsprüfer auf ihrem jeweiligen Fachgebiet sowie die gutachterliche Tätigkeit von Wissenschaftlern.

Briderle, ZGR 1990, 155 (161) plädiert auch für die Beibehaltung der prinzipiellen Bindung der Rechtsberatung an den Anwaltsstatus oine allerdings hierfür deutliche Argumente anzufulhren.

843. Bain/Fndróo/Simpson, Semaine juridique 1988 I Doctrine, 3324, wobei diese ihre Bedenken daruber äußsern, daß die Tatigkeitsmonopole der Anwaltschaft eher zunehmen als abgebaut werden.

844. Gesetz zur Anderung des Berufsrechts der Rechtsanwälte und der Patentanwälte vom 13. Dezember 1989, BGB1. 1, 2135, womit ein zwolfter Teil (\$8 206 und 207) in die Bundesrechtsamwaltsordnung eingefingt wurde. Vgl. dazu Clausnitzer, ZRP 1989, 85 und BRAK-Mitt. 1989, 59; Everling, BRAKMitt, 1989, 166; Vetter, BRAK-Mitt. 1990, 2; Zuck, NJW 1990, 1026.

845. \$ 8 Abs. 1 RBerG: "Ordnungswidrig handelt, wer 1. fremde Rechtsangelegenheiten geschäftsmä/Big besorgt, ohne die nach diesem Artikel erforderliche Erlaubnis zu besitzen."

846. Siehe $\$ 1$ Abs. 2 Ziffer 6, wonach die Rechtsberatungserlaubnis erteilt wird: "Rechtskundigen in einem ausländischen Recht für dlie Rechtsbesorgung auf dem Gebiet dieses Rechts und des Rechts der Europäischen Gemeinschaften."

847. Art. 53 Abs. I i. V. mit Art. 54 Abs. I Decreto-Lei Nr.84/84 vom 16. März 1984.

848. Seit dem 1. Januar 1992 wird die Ausübung der rechtsberatenden Tätigkeit durch den neu geschaffenen "avocat" monopolisiert. Dieser besitzt auch das Vertretungsmonopol beim Tribunal de Grande Instance. Der avoué d"appel dagegen verfügt über ein Vertretungsmonopol beim Cour d'Appel. 
des besseren Schutzes der Rechtsuchenden eingeleitet. Tatsächlich dient diese Gesetzgebung hauptsächlich der Abwehr unliebsamer Konkurrenz ${ }^{849}$.

\section{(b) Tätigkeitsmonopol für ein oder mehrere Berufsuntergruppen}

Es hängt dabei von der Berufsorganisation des Mitgliedstaates $a b$, ob dieses anwaltliche Monopol von einer oder mehreren Berufsuntergruppen ausgeübt wird. Gedacht werden $m u B z . B$. an die beiden anwaltlichen Berufe in Italien: avvocato und procuratore oder in Spanien: Abogado und Procurator ${ }^{850}$. In Frankreich kann man auch nach der Berufsreform von 1990 noch zwischen dem avocat und dem avoué unterscheiden. Der avoué ist ausschließlich beim Cour d'Appel zugelassen und hat insoweit ein eigenes reglementiertes Tätigkeitsmonopol. Auch in Deutschland kann man hinsichtlich der am BGH zugelassenen Anwälten von einer gewissen Berufsuntergruppe mit einem eigenen Tätigkeitsmonopol sprechen.

In den Niederlanden unterscheidet man sprachlich wie in Spanien und Italien zwischen dem Advocaat und Procureur. Im Gegensatz zu Italien und Spanien bedarf es für die Niederlassung in der einen oder anderen Berufsform jedoch nicht einer besonderen Qualifikation. Vielmehr sind in der Praxis die meisten Anwälte auch als Prokureur niedergelassen. Diese Unterscheidung kann daher nicht als eine Berufsuntergruppe mit einem eigenen reglementierten Tätigkeitsmonopol bezeichnet werden. Auch die Cassationsanwälte erfüllen in den Niederlanden im Gegensatz zu den deutschen Revisionsanwälten meines Erachtens nicht das Kriterium einer selbständig reglementierten Berufsuntergruppe. Zwar sind in den Niederlanden lediglich die in Den Haag niedergelassenen Anwälte zu Cassationsverfahren beim Hoge Raad zugelassen. Diese örtliche Beschränkung kann jedoch nicht als die Formulierung einer Berufsuntergruppe qualifiziert werden, da es jedem Rechtsanwalt grundsätzlich freisteht, sich in Den Haag niederzulassen. Er bedarf dazu keiner besonderen Qualifikation.

\section{(2) Reglementierung durch gesetzliches Titelmonopol}

In Art. 1 Buchstabe d) erster Gedankenstrich und die Präambel der Richtlinie wird der Begriff der reglementierten beruflichen Tätigkeit noch näher erläutert und über das reine Tä̆tigkeitsmonopol hinaus erweitert. Danach wird eine berufliche Tătigkeit, deren Aufnahme frei ist, auch von der Definition erfaßt, wenn diese Tätigkeit in Verbindung mit einem Titel ausgeübt wird, der alleine denjenigen vorbehalten ist, die bestimmte Qualifikationsvoraussetzungen erfüllen ${ }^{851}$. Es besteht in diesen Fällen kein Tätigkeitsmonopol, jedoch haben die Titelinhaber ein Titelmonopol ${ }^{852}$.

849. Vor allem die großen amerikanischën Kanzleien, die sich in Paris gefestigt haben, sind seit llangem ein Dorn im Auge der französischen Advokatur.

850. Lonbay 1991, Report Spain.

851. 7. Erwägungsgrund der Richtinie $89 / 48 / \mathrm{EWG}$

852. Berscheid/Kirschbaum, 122. 
Beim Titelmonopol muß zwischen einer Berechtigung zur Führung der Berufsbezeichnung und einer Berechtigung zur Führung des Ausbildungstitels unterschieden werden. In einigen Mitgliedstaaten sind beide Bereiche - akademische und professionelle Titelführung - eng miteinander verknüpft, in anderen Mitgliedstaten bedeutet dagegen die Reglementierung in einem Bereich nicht zwingend eine Reglementierung im anderen. Unterschiedlich sind in verschiedenen Mitgliedstaaten die Titelführungsbestimmungen für den Beruf des Ingenieurs ${ }^{853}$.

(b) Titelmonopol durch strafrechtliche Sanktion

Eng mit der Frage nach einem Titelmonopol verknüpft, ist die strafrechtliche Sanktion bei unbefugter Titelanmaßung. In den meisten Mitgliedstaaten bestehen strafrechtliche Bestimmungen, die einen Mißbrauch von Berufsbezeichnungen, Titeln und akademischen Graden ahnden. Die Ausgestaltung dieser strafrechtlichen Regeln ist jedoch unterschiedlich:

In der Bundesrepublik Deutschland bestimmt $\$ 132$ a StGB:

"Wer unbefugt

1. inländische und ausländische Amts- und Dienstbezeichnungen, akademische Grade, Titel odler öffentliche Würden führt,

2. die Berufsbezeichnung Arzt, Zahmarzt, Tierarzt, Apotheker, Rechtsanwalt, Patentanwalt, Wirtschaftsprüfer, vereidigter Buchprüfer, Steuerberater und Steuerbevollmächtigter führt,....

3. $\ldots$.

4. ...

wird mit einer Freiheitsstrafe bis zu einem Jahr oder mit einer Geldstrafe bestraft."

Ähnliche allgemeine Regelungen findet man in Art. 259 des französischen Code penal, Art. 498 des italienischen Codice penale sowie in Art. 321 des spanischen Codigo penal. Dabei ist das Strafmaß allerdings sehr unterschiedlich. In Italien besteht die Strafe neben einer Geldstrafe in der Veröffentlichung dles Urteils! Wesentlich eingeschränkter sind die entsprechenden strafrechtlichen Bestimmungen in Belgien und in den Niederlanden. In Art. 227 ter des belgischen Strafwetboek steht ein Verbot, den Titel "advocaat" anzunehmen ohne bei der Anwaltskammer eingeschrieben zu sein. Ähnlich bestimmt Art. 435 Abs. 3 des niederländischen Wetboek van Strafrecht, daß derjenige, der unbefugt den Titel "advocaat" oder "procureur" führt mit einer Geldbuße bestraft wird. Desweiteren werden noch einige andere im Wet op het wetenschappelijk onder- 
wijs (Gesetz für den wissenschaftilichen Unterricht) und im Wet op het hoger onderwijs (Gesetz für den höheren Unterricht) genannte Ausbildungstitel strafrechtlich geschützt.

Im Hinblick auf die Freizügigkeit wird ein mit strafrechtlichen Mitteln sanktionierter Titelschutz dann problematisch, wenn das unbefugte Führen von ausländischen Titel unter Strafe gestellt wird. Dies kann am Beispiel "advocaat" in den niederländischen und belgischen Strafrechtsbestimmungen verdeutlicht werden. Beide Bestimmungen beinhalten eine Verbotsregel. Nach Art. 227 ter des belgischen Strafwetboek ist es verboten in der Öffentlichkeit den Titel "advocaat" zu führen ohne "op het tableau van de Orde" eingeschrieben zu sein. Gilt diese Bestimmung auch für den niederländischen "advocaat" ? Schließlich sind die berufsbezeichnenden Begriffe identisch. Macht sich ein niederländischer "advocaat" in Belgien strafbar, wenn er seinen nationalen Berufstitel in der Öffentlichkeit verwendet? Kann er als Rechtfertigung anführen, daß3 er in den Niederlanden "op het tableau van de Orde" eingeschrieben steht? Ein vergleichbares Dilemma besteht zwischen Deutschland und Österreich. Das Beispiel zeigt die Problematik der Regelungen im internationalen Verband. Ziel und Zweck der strafrechtlichen Regelungen war, den Verbraucher vor unqualifizierten Personen zu schützen, die den Schein einer Berufszugehörigkeit erweckten. Der Schutz vor qualifizierten ausländischen Berufsangehörigen, die nach ihrem nationalen System zur identischen Titelführung berechtigt sind, war sicher niemals mit den strafrechtlichen Bestimmungen bezweckt. Sie stammen vielmehr noch deutlich aus einer Zeit, in der die Berechtigung zur Berufsausübung an der territorialen Grenze des nationalen Rechtssystems endete. Bei einer zunehmenden grenzüberschreitenden Berufstätigkeit sind diese Bestimmungen nicht mehr adăquat ${ }^{854}$.

(3) Reglementierung durch das Sozialsystem

Eine Reglementierung ist auch dann zu bejahen, wenn die Vergütung der Tätigkeit oder die Erstattung durch das einzelstaatliche System der sozialen Sicherheit an den Besitz eines Diploms gebunden ist. Diese Form der Reglementierung betrifft Berufe im Gesundheitswesen. Gedacht werden muß an den Psychologen oder Psychotherapeuten, der nur dann eine Abrechnung seines Honorars über die Krankenkassen vornehmen darf, wenn seine Berufsausbildung anerkannt ist.

(4) Reglementierung durch Berufsverbände

Falls in einem Mitgliedstaat die Reglementierung der beruflichen Tätigkeit von Verbänden oder Organisationen ausgeübt wird, deren Ziel die Wahrung des Standesniveaus ist, und diese Ausübung der Berufsregelung durch den Mitgliedstaat anerkannt wird,

854. Allerdings behauptet Michel Gout, Leiter der französischen Delegation des CCBE, während einer Unterfragung durch das Select Committee an European Communities of the House of Lords, dafl das Bedü rfnis nach tatsảchlicher und persönlicher Rechtsberatung im Ausland, das in den achtziger Jahren noch sehr grob war, nun aufgrumd zunehmender Technologisienung wieder nachgelassen hat, House of Lords 1995,61 
dann ist eine derartig reglementierte berufliche Tätigkeit einer staatlich geregelten gleichzustellen. Im Anhang zur Richtlinie findet sich ein Verzeichnis der Berufsverbände oder -organisationen, die diese Bedingungen des Art. 1 Buchstabe d) Absatz 2 der Richtlinie 89/48/EWG erfüllen. Diese Regelung wurde in die Richtlinie wegen der besonderen Berufsorganisation Großbritanniens und Irlands aufgenommen. In beiden Mitgliedstaaten wird ein wesentlicher Teil der Regelungsgewalt bezüglich der Beruffausbildung und der Standesregeln durch die Mitglieder des jeweiligen Berufsverbandes ausgeủbt, den sogenannten chartered bodies ${ }^{855}$. Diese Berufsverbände und -organisationen können sich darum nicht der Anwendung der Richtlinie und ihres Regelungsgehalts entziehen, in dem sie sich auf ihre private Natur berufen ${ }^{856}$.

\section{(5) Reglementierung durch die Laufbahnvorschriften des öffentlichen Dienstes}

In einigen Mitgliedstaaten, so vor allem in Deutschland und Frankreich, gibt es eine Reihe von Berufen, die nur dann reglementiert sind, wenn sie im öfentlichen Dienst ausgeübt werden ${ }^{857}$. Diese Reglementierung kann als eine Sonderform eines Tätigkeitsmonopols bezeichnet werden. Die rechtliche Gestaltung dieser Reglementierung ist sehr unterschiedlich. Auch weicht - selbst bei begrifflicher Übereinstimmung - die inhaltliche Ausgestaltung dessen, was in den einzelnen Mitgliedstaaten unter dem Begriff öffentlicher Dienst bzw. öffentliche Verwaltung verstanden wird, sehr voneinander $a b$. Ein Vergleich ist daher nur sehr schwer möglich ${ }^{858}$. In Deutschland findet die Reglementierung durch Laufbahnvorschriften statt.

Umstritten ist, ob die Richtlinie überhaupt auf derartige Berufe Anwendung findet: Zunächst muß dabei konstatiert werden, daß der Richtlinientext keine genaue Lösung zu diesem Problem bietet, da anders als im Falle der Reglementierung durch die britischen und irischen Berufsorganisationen, der beruflichen Reglementierung im öfentlichen Dienst kein spezieller Passus gewidmet ist. Befürworter einer Anwendung der Richtlinie 89/48/EWG berufen sich einerseits auf die Definitionen des reglementierten Berufes und der reglementierten beruflichen Tätigkeit gemäß Art. 1 Buchstabe c) und d) der Richtlinie 89/48/EWG, die auf die reglementierten Berufe und reglementierte berufliche Tätigkeiten im öffentlichen Dienst ebenso Anwendung finden können wie außerhalb in Privatsektor. Auch wird Art. 3 der Richtlinie 89/48/EWG zur Unterstützung dieses Arguments herangezogen. Danach kann einem Angehörigen eines Mitgliedstats der Zugang zu dem entsprechenden Beruf oder dessen Ausübung "unter denselben Voraussetzungen wie bei Inländern" nicht wegen mangelnder Qualifikation verweigert werden, wenn er bestimmte in Art. 3 Buchstabe a) und b) angegebene Voraussetzungen.

855. Siehe dazu die Auflistung in Annex C II in: The single market, Europe open for proffessions, UKK implementation, 2. Auflage 1991, 25.

856. Präambel der Richulinie 89/48/EWG.

857. Dies gilt z.B. in Deutschland für den Benf des Archivars, des Bïbliothekars und des Museumkonservators.

858. Siethe dazu die durch das Bundesministerium des Innern angeregte Studie der Hochschule für Verwaltungswissenschaften in Speyer: Magiera/Siedentopf, Das Recht des offentlichen Dienstes in dem Mitgliedstaaten der Europäischen Gemeinschaft, 1994; ahnlich die Studie von Ziller 1993. 
erfullt. Wichtig ist an dieser Stelle die Formulierung "unter denselben Voraussetzungen wie bei Inländern". Hieraus wird abgeleitet, daß darunter auch der Zugang zum öffentlichen Dienst unter denselben Voraussetzungen wie bei Inländem zu verstehen ist.

Gegner einer Anwendung berufen sich dagegen ausdrücklich auf den drittletzten Erwägungsgrund der Richtlinie 89/48/EWG, wonach die allgemeine Regelung zur Anerkennung der Hochschuldiplome in keiner Weise die Anwendung von Art. 48 Abs. 4 EWGV und Art. 55 EWGV präjudiziert ${ }^{859}$. Dieser Saz schließt eine Anwendung jedoch nicht aus. Er verweist vielmehr als orbiter dictum auf die Tatsache, daß die Anerkennung von Diplomen unabhängig davon beurteilt werden muB, ob eine Tätigkeit gemäß der Rechtsprechung des. Europäischen Gerichtshofes als eine "Beschäftigung in der öffentlichen Verwaltung" im Sinne des Art. 48 Abs. 4 EGV oder als ein "Ausübung öffentlicher Gewalt" gemäß Art. 55 EGV qualifiziert werden kann.

Die Problematik läßt sich am einfachsten mit der Unterstellung einer Doppelstaatsangehörigkeit illustrieren ${ }^{860}$. Hat ein Doppelstaatler das Diplom eines Staates, er möchte jedoch Zugang zum entsprechenden Beruf des anderen Staates - wobei dieser Beruf nach der bisherigen Rechtsprechung des EuGH und nach Ansicht der Kommission unter den Ausnahmetatbestand von Art. 48 Abs. 4 EGV zu subsumieren ist, z.B. der Beruf des Richters $^{861}$ - so ist der Aufnahmestaat gemäß der Richtlinie 89/48/EWG dennoch verpflichtet, die Frage der Anerkennung des Diploms zu entscheiden. Diese Entscheidung mußB unabhängig von den weiteren Zugangsworaussetzungen, etwa der Staatsangehörigkeit, gefallt werden. Tatsächlich erscheint der Fall eines Richtes mit ausländischer Berufsbefähigung reichlich konstruiert, dies gilt jedoch nicht für einige andere Berufe, die nach Auffassung zumindest einiger Mitgliedstaaten noch unter einen der beiden Ausnahmetatbestände fallen, z.B. der Notar und der Handelskapitän.

Dies gilt umsomehr, wenn bestimmte Tätigkeiten und Berufe, die nach nationalem Recht im öffentlichen Dienst ausgeübt werden, ohne daß sie nach der Rechtsprechung des EuGH unter den Ausnahmetatbestand des Art. 48 Abs. 4 EGV zu subsumieren sind. Die Entwicklung bezüglich des Lehrerberufs rechtfertigt diese Auffassung. Bereits nach der Entscheidung Lawrie Blum ${ }^{862}$ mehrten sich die Stimmen, die die Lehrtätigkeit an offentlichen Schulen und damit den Beruf des Lehrers insgesamt außerhalb des Anwen-

859. Feuerich, NJW 1991, 1144 (1145): Vor allem Lecheler vertritt diese Auffassung in verschiedenen Verôfenthichungen, so in Battis 1989, 127; Lechler, BayVB1. 1989, 417.

860. Diese Fălle sind seit der Anpassung der Statsangehörigkeitsgesetzgebung in den meisten europâtischen Stalaten an das Prinzip der Gleichberechtigung von Mann und Firau auch nicht mehr selten. Siehe tlazu de Groot 1989, 312, der feststellt, daß dadurch dem Prinzip der Gleichberechitigung bei dem Erwerb inre sanguinis Vorrang vor dem Wunsch gegeben wurde, möglichst eïner Doppelstatichkeil worzubeugen.

861. Der Beruff des Richters fallt unzweifellhaft unter die Ausnahmebestimmung des A.t. 48 Abs. 4 EGV. Siehe dazu die systematische Aktion der Kommission zur Liberalisierung des ôffentichen Dienstes, ABI. Nr. C 72 vom 18. Mär 1988, worin die Kommission die Rechtspflege ausdrücklich dem Anwendungsbereich von Art. 48 Abs. 4 EGV anrechnete. Siehe dazu Seite 369 ff.

862. Unteil vom 3. Juli 1986, Rs 66/85 - Lawrie Blum/Land Baden-Wüttemberg, Sig. 1986, 2121. 
dungsbereiches von Art. 48 Abs. 4 EGV gestellt sehen wollten ${ }^{86}$. Auch die systematische Aktion der Kommission zielte auf eine Öffnung des Unterrichtswesens an staatlichen Bildungseinrichtungen für Lehrer aus anderen Mitgliedstaaten. Die Entscheidung A. Bleis ${ }^{864}$ hat die Gesamtentwicklung letztlich nur bestätigt und in gewissem Sinne abgeschlossen ${ }^{\text {8*s. }}$. Der Fall des Lehrers zeigt damit deutlich, daß grundsätzlich reglementierte Berufe und reglementierte berufliche Tätigkeiten im öffentlichen Dienst in den Anwendungsbereich der Richtlinie 89/48/EWG fallen. Die Mitgliedstaaten haben dementsprechend UmsetzungsmaßBnahmen bezüglich des Lehrerberufs vorgenommen bzw. eingelleitet ${ }^{\$ 66}$.

Als weiteres Argument gegen die Anwendung der Richtlinie 89/48/EWG auf die Tätigkeit im öffentlichen Dienst wird angeführt, daß diese im öffentlichen Dienst kein klar umschriebenes Berufsbild betrifft. Vielmehr wäre ein Beamter im Laufe seiner Karriere im öffentlichen Dienst mit der Wahmehmung unterschiedlicher Tätigkeitsbereiche betraut. Ein äquivalentes Berufisbild bestünde nicht. Damit könne die Anerkennung einer Befähigung zu einem entsprechenden Beruf überhaupt nicht stattfinden. Mit dieser Argumentation wird eine andere Form der beruflichen Tätigkeit im öffentlichen Dienst angesprochen als etwa beim Beruf des Lehrers. Wie bereits die Richtlinie 89/48/EWG in den Definitionen in Art. 1 Buchstabe c) und d), muß auch bezüglich der Tätigkeit im öffentlichen Dienst zwischen einem "reglementierten Beruf" und einer "reglementierten beruflichen Tätigkeit" unterschieden werden.

Bei dem Beruf des Lehrers handelt es sich um einen reglementierten Beruf mit einem bestimmten Berufsbild. Zwar sind die Voraussetzungen in den einzelnen Mitgliedstaten hinsichtlich des Zugangs und der Ausübung dieses Berufes nicht identisch, es gibt jedoch ein äquivalentes Berufsbild. Dies gilt auch für den Archivar und den Bibliothekar soweit diese Berufe im öffentlichen Dienst reglementiert sind ${ }^{867}$. Eine Anwendung der Richtlinie 89/48/EWG muß für diese "reglementierten Berufe im öffentlichen Dienst" grundsătzlich bejaht werden.

Schwieriger sind die Fălle zu beurteilen, in denen in einem Mitgliedstaat die Tätigkeit im öffentlichen Dienst nicht von einem bestimmten, sondern lediglich von "einem" erfolgreichen Hochschulstudüum abhängig gemacht wird, ohne eine genauere Qualifikation, welches Hochschulstudium verlangt wird. Handelt es sich damit um eine reglementierte berufliche Tätigkeit? Muß die Richtlinie 89/48/EWG auch auf diese Fälle angewandt werden? Meines Erachtens sind beide Fragen zu bejahen. Auch die allgemeine Anforderung in der Form "abgeschlossenes Hochschulstudium" muß als eine Reglementierung im Sinne von Art. 1 Buchstabe d) der Richtlinie 89/48/EWG geweriet

863. Wolker in GTE-Handbuch, Kommentar zu Ant. 48.

864. Unteil vom 27. November 1991, Rs C 4 - A. Bleis/Ministère de l'Education National -, S $\mathbf{g} .1991$, I5627 .

865. Siche dazu die Fallstudie "Lehrer" Seite 368

866. Siehe dazu die Fallstudie: Lehrer, Seite 378.

867. So z.B. un der Bundesrepublik Deutschland und in den Niederlanden. 
werden, da hier die Aufnahme einer beruflichen Tätigkeit an den Besitz eines Diploms gebunden ist. Der Nachweis eines abgeschlossenen Hochschulstudiums, soweit es sich um eine Mindeststudienzeit von drei Jahren handelt, erfüllt die Definition eines Diploms im Sinne von Art. 1 Buchstabe a) der Richtlinie 89/48/EWG. Die Richtlinie spricht nicht von einem bestimmten Diplom. Auch enthält die Richtlinie keine Ausnahmebestimmungen, nach denen die Anwendung auf diese Fälle auszuschließen wäre. Bestätigt wird diese Auffassung durch die am 18. Juni 1992 erlassene zweite allgemeine Regelung zur Anerkennung beruflicher Befähigungsnachweise ${ }^{868}$. Art. 9 der Richtlinie 92/51/EWG regelt den Fall, daß in einem Mitgliedstaat der Zugang zu einem Beruf nur vom Besitz eines Nachweises über eine allgemeine Schulbildung abhängig gemacht wird. Dabei unterstellt Art. 9 der Richtlinie 92/51/EWG eindeutig, daß das allgemeine Erfordernis einer abgeschlossenen Schulbildung eine Reglementierung im Sinne dieser Richtlinie darstellt. Beide Fälle sind miteinander vergleichbar. Wenn bei der Verpflichtung zum Nachweis einer allgemeinen Schulbildung von einer Reglementierung gesprochen werden muß, so gilt dies entsprechend für den Nachweis eines Hochschulstudiums.

Die Frage der beruflichen Reglementierung im öffentlichen Dienst kann nicht unabhängig von der Rekrutierung des öffentlichen Dienstes beurteilt werden. In diesem Zusammenhang hat sich der Concours, wie er in einigen Mitgliedstaaten veranstaltet wird ${ }^{869}$, während des Umsetzungsverfahrens als äußerst problematisch erwiesen. Umstritten ist, ob es sich dabei ausschließlich um ein Einstellungsverfahren handelt oder, ob der Concours auch Ausbildungselemente enthält ${ }^{870}$.

\section{c. Konsequenzen der Reglementierung für die Umsetzung der Richtlinie 89/48/EWG}

Die gesetzgeberische Entscheidung für eine bestimmte berufliche Tätigkeit ein absolutes, ein partielles Tätigkeitsmonopol oder lediglich ein Titelmonopol zu errichten, hat weitreichende Konsequenzen für die Freizügigkeit zwischen den Mitgliedstaaten und damit für die Umsetzung der Rïchtlinie 89/48/EWG. Bei einem absoluten Tätigkeitsmonopol ist eine Gesamtumsetzung bezüglich dem Zugang und der Ausübung des Berufes erforderlich. Besteht ein partielles Tätigkeitsmonopol, so ist nur der Teil der Berufsausübung i.S. der Richtlinie reglementiert und bedarf der Umsetzung. In den Niederlanden besteht z.B. lediglich ein Tätigkeitsmonopol der Rechtsanwälte für bestimmte forensische Aktivitäten ${ }^{871}$, eine Reglementierung der rechtsberatenden Tätigkeit ist dagegen.

868. Richtlinie 92/51/EWG wom 18. Juni 1992 über eine zweite allgemeine Regelung zur Anerkennung beruflicher Befähigungsnachweise in Ergänzung zur Richtlinie 89/48/EWG, ABI. Nr. L 209 wom 24. Juli $1992,25$.

869. In Frankreich, Luxemburg. Italien, Portugal und Spanien wird der Concours zur Rekrutierung der Beschäftigten in der öffentlichen Verwaltung veransialtet.

870. Siehe dazu die Erörterungen für die Lehrer Seite $376 \mathrm{ff}$.

871. In den Niederlandem unterscheidet man zwischen adwocaten und procureurs. Beide Titel sind gemäl Art. 9a und 69a Advocatenwet geschützt. Es handelt sich dabei jedoch nicht um zwei unterschiedliche Berufe wie etwa die Unterteilung in barrister und solicitor nach englischem Recht. Vielmehr kann eine 
volllkommen unbekannt. Somit besteht im Hinblick auf das Tätigkeitsmonopol ein Umsetzangsbedarf nur für die forensische Aktivitäten eines Anwalts. Der Rechtsanwaltsberuf in den Niederlanden verfügt aber nicht allein über ein partielles Tätigkeits-, sondern anch über ein Titelmonopol ${ }^{872}$. Bei der Umsetzung bedeutet dies, daß dem Tätigkeitsmonopol und dem Titelmonopol Rechnung getragen werden muß. Hat ein Mitgliedstaat einen bestimmten Beruf lediglich bei Ausübung im öfentlichen Dienst reglementiert, so besteht ein Umsetzungsbedarf auch lediglich für diesen Bereich.

Reine Titelmonopole sind von der Regelungsintensität schwächer einzustufen als Tätugkeitsmonopole. Die schwächere Reglementierung wird im allgemeinen national damit begründet, daß der Schutz der Allgemeinheit für einen bestimmten Beruf eine weitergehende Reglementierung nicht erforderlich macht, während andere Berufe insbesondere die des Gesundheitssektors wegen der betroffenen Schutzgüter eine einschneidendere gesetzliche Reglementierung hinnehmen müssen ${ }^{873}$. Bei der Umsetzung der Richtlinie sollte dieser Unterschied gemäß dem Grundsatz der Verhältnismäßigkeit berücksichtigt werden. Der Europäische Gerichtshof hat das Verhältnismäßigkeitsprinzip verschiedentlitch in seiner Rechtsprechung betont ${ }^{874}$. Es wäre daher unbillig, wenn ein Mitgliedstaat bei einer reinen Tïrelreglementierung, die durch die Richtlinie gegebene Möglichkeit der Anpassungsinstrumente, in vollem Umfang einsetzen würde.

\section{Gegenseitige Anerkennung gemäß Art. 3 der Richtlinie $89 / 48 / E W G$}

Die Richtlinie geht davon aus, daß die Hochschulabschlüsse in den Mitgliedstaaten der Europäischen Gemeinschaft sowie die von ihnen anerkannten Drittstaatsdiplome grundsätzlich gleichwertig sind. In dieser Prämisse der Gleichwertigkeit manifestiert sich die bereits im Weißbuch der Kommission niedergelegte Forderung nach dem gegenseitigen Vertrauen in die Qualität der in einem anderen Mitgliedstaat absolvierten Ausbildung ${ }^{875}$. Zentral steht daher in Art. 3 der Richtlinie $89 / 48 /$ EWG die gegen seitige Anerkennung von Diplomen. Es ist deshalb einern Mitgliedstaat verwehrt, einem

871. $\rightarrow$

Person die Funktionen advocat und procureur kombinieren. In der Praxis ist dies auch die Regel. Im Falle der forensischen Tatigkeit geht es um die Funktion als "procureurs". Diese haben bei Prozessen vor den Arrondissmentsrechtbanken wnd bei den Gerechtshoven ein Monopol fur bestimmte Prozefhandlungen; Art. 133, 290, 295429 d Wetboek van Burgerlijke Rechtswordering.

872. In den Niederlanden ist das unbefugte Führen des Anwaltstitets ausdrücklich in Strafgesetzbuch verboten: Art. 435 Abs. 3 Wetboek van Strafrech: "Met geldboete van de tweede categorei wordt bestaft:... hij die zonder daartoe gerechtigt te zijn de titel van advocaat of van procureur... woert ${ }^{*}$ sowie die Titelschutzbestimmungen in Art. 9a und 69a Adwocatenwet. Siehe für Deutschland \& 17 Abs. 1 Bundesrechtsanwaltsordnung (BRAO). "Mit đem Erlöschen, der Rücknahme oder dem Widernuf der Zulassung zur Rechtsanwaltschaft erlischt die Befugnis, die Berufsbezeichnung "Rechtsanwalt" zu fuibren. Die Bezeichnumg darf auch nicht mit einem Zusatz, der auf die frühere Berechigung hinweust, geführt werden."

873. Siehe dazu den Bericht der Bundesregierung "Zur Lage der Freien Berufe", BT-Dinucks. 11/6985 vom 26. April $1990,18$.

874. de Burca, YbEL 1993, 105; Craig/de Burca, 340-349

875. Vgl. Weißbuch, Vollendung des Binnenmarkts Juni 1985, Nr. 93 
Angehörigen eines Mitgliedstaates den Zugang zu oder die Ausübung eines reglementierten Berufes wegen mangelnder Qualifikation zu verweigern, wenn der Betroffene das Diplom besitzt, das in einem anderen Mitgliedstaat zur Ausübung dieses Berufes berechtigt.

Dies gilt gemäß Art. 3 Buchstabe b) der Richtlinie 89/48/EWG auch dann, wenn der in Frage stehende Beruf im Herkunftsland nicht reglementiert ist, der Betroffene aber über einen Ausbildungsnachweis verfügt, aus dem hervorgeht, "daß der Inhaber ein mindestens dreijähriges Studium oder ein dieser Dauer entsprechendes Teilstudium an einer Universität oder einer Hochschule oder einer anderen Ausbildungseinrichtung mit gleichwertigem Niveau in einem anderen Mitgliedstaat absolviert hat." Dieser Ausbildungsnachweis muß von einer nach den Rechtsvorschriften des Mitgliedstaates bestimmten Stelle ausgestellt sein. Ferner muß der Betroffene diesen Beruf vollzeitlich zwei Jahre llang in den vorhergehenden zehn Jahren in einem Mitgliedstaat ausgeübt haben ${ }^{876}$. Nachteil dieser Bestimmung ist, daß Staaten, die wegen ihrer geringen Reglementierung beruflicher Zugangs- und Ausübungsvoraussetzungen im Vergleich zu anderen Mitgliedstaaten liberal und offen waren, nun aufgrund von Art. 3 Buchstabe b) der Richtlinie 89/48/EWG für ihre eigenen Staatsangehörigen eine schlechtere Ausgangsposition geschaffen haben. Dies hat bereits zur Konsequenz, daß Berufsangehörige nicht reglementierter Berufe ihre Herkunftsstaaten zur Reglementierung drängen, um damit in den vollen Genuß einer direkten Anerkennung gemäß Art. 3 Buchstabe a der Richtlinie 89/48/EWG zu kommen. Diese Entwicklung ist, da sie eigentlich unter dem Vorzeichen einer Deregulierung vorgenommen wird, wollkommen widersinnig.

Bei der Umsetzung und Anwendung der Richtlinie 89/48/EWG haben sich die Worte "Zugang zu diesem Beruf" als problematisch erwiesen. Die Bestimmung setzt voraus, $\mathrm{da} ß$ in den Mitgliedstaaten weitgehend äquivalente Berufsbilder bestehen. Dies ist nicht immer der Fall. Häufig kann ein Endprodukt für mehrere Berufe qualifiziert sein. Typisches Beispiel eines mehrfachen Endprodukts ist der deutsche Einheitsjurist, der gleichzeitig als Endprodukt für den Beruf des Anwalts, des Richters, des Staatsanwalts, des Juristen im öffentlichen Dienst fungieren kann. Bei der Umsetzung mußte dieser Mehrfach-Qualifikation Rechnung getragen werden. Schwierig sind auch die Fälle zu entscheiden, in denen einem einzigen Beruf in einem Mitgliedstaat zwei Berufe in einem anderen Mitgliedstaat gegenüber stehen. Diese Problematik ergibt sich bei den juristischen Berufen in erster Linie im Verhältnis der kontinentaleuropäischen Anwälte zu den englischen und irischen barristers und solicitors. Aber auch innerhalb der kontinentalleuropäischen Mitgliedstaaten gibt es häufig mehrere juristische Berufe in einem Mitgliedstaat ${ }^{87}$. Diese Verschiedenheit der beruflichen Systeme und der damit verbundenen Berufsbilder kann dazu führen, daß die gemäß Art. 3 der Richtlinie 89/48/EWG zu

876. Der WSA hatte in seiner Stellungnahme um Streichung won Art. 3 Buchstabe b) ersucht. Diesetn Ersuchen ist die Kommission jedoch nicht nachgekommen.

877. Gedacht werden muß etwa an die spanischem "Procuradores de los Tribunales de España" im Vergleich zu den spanischen "Abogados". Auch Italien kennt den Beruf des "Avvocato" neben dem des "Procuratore" 
fallende Entscheidung, ob ein Fall der Zulassung zum entsprechenden Beruf in einem anderen Mitgliedstaat worliegt, sehr schwierig ist.

Die Problematik beschränkt sich in keiner Weise auf die juristischen Berufe. Auch bei anderen Berufen, etwa bei den Lehrern und bei den Ingenieuren tauchen ähnliche Schwierigkeiten auf. So war es in Deutschland nicht unumstritten, ob der in nur einem Fach ausgebildete Lehrer im Vergleich zu seinem in zwei Fächern ausgebildeten deutschen Kollegen, als Angehöriger eines anderen Berufs zu qualifizieren ist oder, ob es sich um ein Defizit in der Ausbildung handelt, das den Anpassungsbestimumungen unterliegt ${ }^{878}$. Die deutsche Umsetzungsregelungen - soweit sie bisher vorliegen ${ }^{879}$ gehen glücklicherweise von der zweiten Alternative aus ${ }^{880}$ "Ähnliche Probleme ergeben sich dann, wenn die Ausbildung zum Lehrer sich auf bestimmte Unterrichtsund Altersstufen bezieht, diese Stufen im Herkunft- und im Aufnahmestaat sich aber nicht entsprechen ${ }^{881}$. Problematisch erwiesen sich bei der Umsetzung auch einige Berufe, die nur im angelsächsischen Bereich vorkommen, auf dem europäischen Kontinent jedoch unbekannt sind. Dies galt z.B. für den "Chartered Surveyor". Unter dieser Berufsbezeichnung werden unterschiedliche Berufstätigkeiten ausgeübt, die nach kontinentaleuropäischem Verständnis zu unterschiedlichen Berufen gehören; so etwa zum Beruf des Immobilienmaklers und des Vermessungsingenieurs.

Bei den Ingenieuren sehen einige Mitgliedstaaten z. B. den Agraringenieur als Ingenieur an, andere hingegen nicht. Bedeutet dies, daß Agraringenieure die Freizügigkeit nur innerhalb der Mitgliedstaaten genießen können, die ebenfalls den Beruf "Agraringenieur" kennen? Die Frage ist nicht eindeutig zu beantworten. Zunächst hängt sie davon $a b$; ob der entsprechende Beruf im Aufnahmestaat überhaupt reglementiert ist. Falls dies nicht der Fall ist, kann dem Betreffenden die Berufsausübung nicht verweigert werden, es sei denn, die fragliche berufliche Tätigkeit unterläge dem Tätigkeitsmonopol eines anderen Berufes ${ }^{822}$. Gibt es dagegen einen reglementierten Beruf, der allerdings nicht unter der Berufsbezeichnung "Agraringenieur" ausgeübt wird, dann stellt sich die Frage der Anwendung von Art. 3 der Richtlinie 89/48/EWG. Art. 3 Buchstabe a) spricht von "Zugang zu diesem Beruf" und nicht von "Zugang zu dieser beruflichen Tätigkeit". Hieraus könnte abgeleitet werden, daß bei abweichender Berufsbezeichnung auch verschiedene Berufe vorliegen, die eine Ablehnung der Anwendung von Art. 3

878. Der Meimungsstreit erinnert ein wenig an die deutsche zivilrechtliche Diskussion bezüglich "Manget" oder "aliud".

879. Sielte dazu die Fallsiudie "Lehrer" Seite 379 f..

880. Allerdings sind in einigen Bundesländern, die bisher noch keine Umsetzungsnegelung erlassen haben, Anträge auf Anerkennung berejts wegen des fehlenden zweiten Faches abgewiesen wonden.

881. Diese Problematik besteht in der Bundesrepublik beneits im Hinblick auf die unterschiedlichen Lelirerausbildungen der einzelnen Bundesländer; słe potenziert sich bei unterschìedlichen Lehrerausbildungen in zwölf Mitgliedistaaten.

882. Vgl. dazu etwa das ânztliche Monopol bezüglich der Heilbetätigung in Frankreich, das im Fall Bouchoucha zur Diskussion stand. Siehe dazu Urteil wom 3. Oktober 1990, Rs C-26/89 - Strafverfahren gegen Bouchoucha -, Slg. 1990, 1-3551. 
rechtfertigen könnte, da nicht auf die konkrete berufliche Tätigkeit abgestellt werden müßte.

Für eine derartige Interpretation spricht die Tatsache, daß der endgültige Richtlinientext in diesem Punkt von dem ursprünglichen Entwurf der Kommission abweicht. Im ursprünglichen Kornmissionsentwurf stand deutlich unter Art. 3 Buchstabe a) " ... Zugang zu dieser Tätigkeit..." . Das Europäische Parlament hat in seinem Änderungsvorschlag zu Art. 3 Buchstabe a) lediglich die Worte "Hochschuldiplom" durch "berufliche Qualifikation" ersetzt. Die von der Kommission vorgeschlagenen Worte "Zugang zu dieser Tătigkeit" wurden dagegen vom Parlament nicht beanstandet. Auch der Wirtschafts- und Sozialausschuß hatte in seiner Stellungnahme keine Kritik zu diesem Punkt. Der Austausch der Wort "Tätigkeit" durch "Beruf" fand daher während der Ratsverhandlungen statt. Diese Änderung muß als ausgesprochen unglücklich bezeichnet werden, da sie die Tür zu einer restriktiven Auslegung von Art. 3 und damit der ganzen Richtlinie geöffnet hat.

Eine derartige restriktive Interpretation erscheint mir jedoch weder unter Berücksichtigung der Gesamtkonzeption der Richtlinie 89/48/EWG noch angesichts der Rechtsprechung des Europäischen Gerichtshofs haltbar. In Art. 1 c) der Richtlinie 89/48/EWG wird bei der Definition des reglementierten Berufes der Zusammenhang zu der reglementierten beruflichen Tätigkeit deutlich angegeben. Die Richtlinie bezweckt eine Gesamtregelung für alle reglementierten Berufe und beruflichen Tätigkeiten auf dem in Art. 1 Buchstabe a) angegebenen Ausbildungsniveau. Dieser Zweck wäre jedoch gefährdet, könnten Mitgliedstaaten durch restriktive Interpretation des Art. 3 die Anwendung der Richtlinie für eine Teil der Berufe grundsätzlich verneinen. Der Gerichtshof hat in seinen Entscheidungen zu Art. 48 Abs. 4 EGV ${ }^{883}$ aber auch in den Fällen Heylens ${ }^{834}$ und Vlassopoulou ${ }^{885}$ die funktionelle Sicht auf einen bestimmten Beruf und die damit verbundene berufliche Tătigkeit betont. Könnten Mitgliedstaaten die Anwendung von Art. 3 der Richtlinie 89/48/EWG einzig und allein von einem nationalen Berufsbilld abhängig machen, so wäre damit der Diskriminierung Tür und Tor geöffnet. Unterschiedliche Berufsbilder und Berufsbezeichnungen in den Mitgliedstaaten sind in vielen Bereichen nicht die Ausnahme sondern die Regel. Gerade bei den rechtsberatenden Berufen würde man zu keiner oder nur sehr beschränkten Anwendung der Richtlinie kommen, wenn man auf eine Identität des Berufes und der Berufsbezeichnung abstellen würde.

Diese Interpretation hat aber für die Umsetzung der Richtlinie weitreichende Folgen. Es bedeutet, daß nicht nur die reine nationale Berufsbezeichnung und das national formulierte Berufsbild entscheidend sind, sondern die konkret ausgeübte berufliche Tätigkeit. Für die Umsetzung der Richtlinie bezüglich des Anwaltsberufes bedeutet dies,

883. Siehe die auf Seite 368 aufgelistete Rechtsprechung.

884. Urteil vom 15. Oktober 1987, Rs 222/86 - UNECTEF/Heylens -, Slg. 1987, 4097.

885. Urteil vom 7. Mai 1991, Rs C-340/89 - Irene Vlassopoulow/Ministerium der Justiz, Bundes- und Europaangeleggenheiten Baden-Württemberg. Slg. 1991, 1-2357. 
daß nicht mur die in der Rechtsanwaltdienstleistungsrichtlinie genannten "Anwaltsberufe im engeren Sinn" entsprechend umgesetzt werden müssen, sondern auch alle anderen "Anwaltsberufe im weiten Sinn", wie sie in einigen Mitgliedstaaten bekannt sind Dies bedeutet z.B. für die Law Societies im Vereinigten Königreich, daß sïe in Erwägung nehmen müssen, ob ein niederländischer oder französischer Notar als Solicitor gemäß Art. 3 der Richtlinie 89/48/EWG zugelassen werden muß, da die berufliche Tätigkeit des kontinentaleuropäischen-römischen Notars in Großbritannien durch den Solicitor ausgeübt wird ${ }^{837}$.

Wo die Grenze zwischen den einzelnen Berufen gezogen werden kann, wird sich wohl erst durch die Rechtsprechung bestimmen lassen. Selbst bei einer Verneinung der Anwendung von Art. 3 der Richtlinie 89/48/EWG wegen Verschiedenheit der Berufe ist die zuständige Behörde verpflichtet, die vom EuGH in der Rechtssache Vlassopoulou ${ }^{888}$ aufgestellten Grundsätze zu berücksichtigen. Gedacht werden muß an folgenden Fall: Ein Übersetzer beantragt in einem anderen Mitgliedstaat die Anerkennung als Sprachlehrer. Zunächst wird die zuständige Behörde prüfen müssen, ob die Ausbildung zum Übersetzer im Herkunftsstaat mit der Ausbildung zum Sprachlehrer übereinstimmt oder nicht. In Falle der Bejahung würde es sich um ein "Mehrfachendprodukt" handeln, vergleichbar dem deutschen Assessor nach abgeschlossener zweiten juristischen Staatsprüfung. Dies hätte zur Konsequenz, daß eine grundsätzliche Anerkennung gemäß Art. 3 Buchstabe a) oder Buchstabe b) erfolgen müßte. Die Entscheidung zwischen beiden Möglichkeiten wäre abhängig davon, ob der Beruf im Herkunftsstaat reglementiert ist oder nicht. Handelt es sich dagegen um zwei vollkommen unterschiedliche Ausbildungen mit dementsprechend abweichendem Berufsbild, so könnte der Aufnahmestaat die Anwendung der Richtlinie 89/48/EWG unter Berufung auf die in Art. 3 enthaltene Bedingung "Zugang zu diesem Beruf" verneinen. Mit dieser Entscheidung wäre der Fall jedoch nicht abgeschlossen. Die zuständige Behörde müßte nun überprüfen, ob Teilbereiche der Sprachausbildung insoweit übereinstimmen, daß sie als "in einem anderen Mitgliedstaat erworbenen Kenntnisse und Fähigkeiten" mit zu berücksichtigen sind $^{8 * 9}$. Man kann nicht leugnen, daß in der Regel die zuständigen Behörden bei einer solchen Einzelfallentscheidung überfordert sein werden ${ }^{190 !}$

Das Europäische Parlament hat bei seinem Änderungsvorschlag an Art. 3 der Richtlinie 89/48/EWG einen zweiten Abschnitt zugefügt. Hierin hieß es: "Beim Zugang zu oder

886. Dies bedeutet, dall u.U. der italienische Procuratore ebenfalls zum Rechtsamwaltsberuf in Deutschland zugellassen werden muB und nicht nur der in der Dienstleistungsrichtinie genannte Avvocato. Entscheidend ist dabei die Definition der beruftichen Tätigkeit, die durch die nationalle, in diesem Falle italienische, gesetaliche Regelung bestimmt wiril.

887. Die Law Society hat bereits im Falle einer französischen Notaranwärterin die Anwendung der Richtlinie bejaht und sie zur Eignungsprüfung für solicitors zugelassen.

888. Urteil vom 7. Mai 1991, Rs C-340/89 - Irene Vlassopoulou/Ministerum der Justiz, Bundes- und Europaangelegenheiten Baden-Württemberg, Slg. 1991, 1-2357.

889. Urteil vom 7. Mai 1991, Rs C-340/89 - Irene Vlassopoulou/Ministerum der Justiz, Bundes- und Europaangelegenheiten Baden-Württemberg, Slg. 1991, I-2357.

890. Hailbronner, JuS 1991, 917 (920). 
der Ausübung einer beruflichen Tätigkeit hat der in Absatz 1 genannte Angehörige eines anderen Mitgliedstaates alle im Aufnahmestaat geltenden beruflichen Vorschriften zu beachten, und er unterliegt den Rechtsverfahren zur Umsetzung dieser Vorschriften." Dieser Vorschlag hat keinen Eingang in den endgültigen Richtlinientext gefunden. Undeutlich ist, ob der im ersten Absatz des Art. 3 vorkommende Ausdruck "unter denselben Voraussetzungen wie bei Inländern" einen vergleichbaren Inhalt decken soll. Der Wirtschafts- und Sozialausschuß ging in seiner Stellungnahme davon aus, indem er erklärtte, der Ausschuß interpretiere den Ausdruck "unter denselben Voraussetzungen wie Inländer" dahingehend, "daß der Angehörige eines Mitgliedstaates nach Absatz 1 beim Zugang zu einer beruflichen Tätigkeit sämtliche im Aufnahmestaat für die Ausübung des Berufs geltenden Regeln zu beachten hat. Die in dem betreffenden Staat geltenden gesetzlichen Bestimmungen finden auf ihn Anwendung, und er wird Angehöriger des betreffenden Beruffstandes mit allen damit verbundenen Rechten und Pflichten." Ob diese Interpretation korrekt ist, läßt sich aus der deutschsprachigen Fassung der Bestimmung nur schwer entnehmen. Der französische und englische Text der Richtlinie unterstützt jedoch die Auslegung des Wirtschafts- und Sozialausschusses.

\section{Anpassungsinstrumente gemäß Art. 4 der Richtlinie 89/48/EWG}

Art. 3 der Richtlinie 89/48/EWG hindert den Aufnahmestaat nicht daran, im. Falle von unterschiedlicher Dauer oder unterschiedlichen Inhalts der Ausbildung, an den Antragsteller zusätzliche Anforderungen zu stellen, um seine sachgerechte Anpassung an das neue berufliche Umfeld zu gewährleisten. Zu diesem Zweck regelt Art. 4 der Richtlinie 89/48/EWG verschiedene Formen von Anpassungsinstrumenten. Dieses System der Kompensation verwässert bis zu einem gewissen Grad das Prinzip der globalen Anerkennung; es war jedoch wegen des komplexen Anwendungsbereichs der Richtlinie wohl unvermeidlich ${ }^{891}$ "Die Anpassungsinstrumente können in zwei Gruppen unterschieden werden. Zum einen geht es um die Kompensation einer unterschiedlichen Ausbildurygsdauer. Bei der zweiten Gruppe handelt es sich um die Kompensation im Falle von unterschiedlichen Ausbildungsinhalten.

a. Unterschiede in der Ausbildungsdauer

GemäB Art. 4 Abs. 1 Buchstabe a) der Richtlinie 89/48/EWG kann die Kompensation unterschiedlicher Ausbildungsdauer durch den Nachweis von Berufserfahrung erbracht werden. Unter Berufserfahrung wird gemäß Art. 1 Buchstabe e) der Richtlinie 89/48/EWG die tatsächliche und rechtmäßige Ausübung des betreffenden Berufs in einem Mitgliedstaat verstanden. In einem Fall von kürzerer Ausbildung darf die Dauer der verllangten Berufserfahrung das Doppelte der fehlenden Ausbildungszeit nicht uber-

891. Die Komplexität wird besonders dadurch dewnich, daß Z B. aus der Sicht des britischen Ausbildungs systems unter den Anwendungsbereich der Richtinie ca. 80 Bierufe fallen, wgl. dazu die Auflistung in: The Single Market, Europe open for Professions, 2. Auflage 1991, 20 ff. Aber auch in anderen Mitgliedstaten hamdelt es sich um jeweils 30 bis 40 versehiedene teglementiente Berufe, so etwa in den Niederlanden, in Portugal und in Spanien. 
schreiten, wenn sich diese auf ein Studium oder auf ein unter der Aufsicht eines Ausbilders absolviertes und mit einer Prüfung abgeschlossenes Berufspraktikum bezieht (Art. 4 Abs. 1 Buchstabe a) 1. Alternative). Zu denken ist hierbei an die unterschiedliche Studiendauer in den Mitgliedstaaten. Von dem Inhaber z.B. eines Bachelor of Arts. Diploms, erlangt nach einem dreijährigen Studium in Großbritannien, könnte der Nachweis einer zweijăhrigen Berufserfahrung verlangt werden, weil das vergleichbare Studium in Deutschland acht Semester dauert. Dies gilt auch, wenn die Berufspraktika z.B. die Referendarzeit oder eine mit ihr vergleichbare berufliche Ausbildungsperiode, die mit einer Prüfung abgeschlossen wird, von unterschiedlicher Dauer waren. In beiden Fällen gilt, daß die fehlende Ausbildungszeit durch das Doppelte an Berufserfahrung kompensiert werden kann...

Bezieht sich die fehlende Ausbildungszeit auf eine mit Unterstützung eines qualifizierten Berufsangehörigen erworbene Berufspraxis, so darf die geforderte Kompensation die fehlende Ausbildungsperiode nicht überschreiten (Art. 4 Abs. 1 Buchstabe a) 2. Alternative). Dies bedleutet, daß abhängig davon, ob die Praxisausbildung ein mit einer Prüfung abgeschlossenes Berufspraktikum darstellt oder die Praxiserfahrung mit Unterstützung eines qualifizierten Berufsangehörigen erworben wird, die mögliche Kompensationsperiode unterschiedlich lang sein kanm. Dies dürfte häufïg eine Frage der Qualifikation sein.

\section{b. Unterschiede in den Ausbildungsinhalten}

Wenn sich die bisherige Ausbildung des Antragstellers wesentlich von der des Aufnahmestaates unterscheidlet und damit nicht von seinem Diplom abgedeckt wird, kann der Aufnahmestaat als Kompensation einen Anpassungslehrgang oder eine Eignungsprüfung verlangen (Art. 4 Abs, 1 Buchstabe b) 1. Alternative der Richtlinie 89/48/EWG). Dies gilt auch dann, wenn die reglementierte berufliche Tätigkeit im Aufnahmestaat umfassender ist als im Herkunftsstaat des Antragstellers und diesem Unterschied im Tätigkeitsumfang Rechnung getragen wird durch eine besondere Ausbildung deren Fächerkatalog nicht durch das Diplom des Antragstellers gedeckt wird (Art. 4 Abs. 1 Buchstabe b) 2 . Alternative der Richtlinie 89/48/EWG).

Falls der Antragsteller einen Beruf ausübt, der in seinem Herkunftstaat nicht reglementiert ist und er die Voraussetzungen des Art. 3 Buchstabe b) erfillt, fällt auch er in den Anwendungsbereich des Art. 4 Buchstabe b), wenn die von ihm bisher ausgeübte berufliche Tătigkeit nicht alle Bereiche umfaßt, die im Aufnahmestaat zu der reglementierten beruflichen Tätigkeit gerechnet werden (Art. 4 Abs. 1 Buchstabe b) 3. Alternative der Richtlinie 89/48/EWG).

\section{c. Beschränkung der Wahlmöglichkeit}

Der Aufnahmestaat, der von dieser Möglichkeit der Kompensation Gebrauch macht, muß dem Antragsteller gemäß Art. 4 Buchstabe b) Unterabs. 2 der Richtlinie 89/48/EWG die Wahl zwischen dem Anpassungslehrgang und der Eignungsprüfung 
lassen. Von diesem Grundsatz läßt die Richtlinie dann eine Ausnahme zu, wenn es sich um einen Beruf handelt, dessen Ausübung eine genaue Kenntnis des nationalen Rechts erfordert und die Beratung und/oder der Beistand in Fragen des innerstaatlichen Rechts ein wesentlicher und ständiger Bestandteil der beruftichen Tätigkeit ist. In diesem Falle wird die Wahl dem Aufnahmestaat überlassen ${ }^{892}$. Die Definition des rechtsberatenden Berufs, der eine Beschränkung der Wahlmöglichkeit zuläßt, hat Anlaß zur Diskussion gegeben. Zwei Voraussetzungen müssen mindestens erfüllt sein, um einen Beruf als einen "rechtsberatenden" im Sinne der Richtlinie zu qualifizieren. Die Ausübung des Berufs macht die genaue Kenntnis des nationalen Rechts erforderlich, und es muß sich um eine beratende oder Beistand verleihende Tätigkeit handeln. Diese Definition enthält eine sicherlich unbeabsichtigte Lücke. Die rechtsprechende Tätigkeit wird von ihr nicht erfaßt. Wie oben festgestellt, findet die Richtlinie auch Anwendung auf die Berufe, die unter den Ausnahmetatbestand des Art. 48 Abs. 4 EGV zu subsumieren sind ${ }^{893}$. Bei wörtlicher Anwendung des Art. 4 Buclistabe b) Unterabs. 2 Satz 2 der Richtlinie 89/48/EWG wäre es den Mitgliedstaaten gestattet, die Wahl des Antragstellers hinsichtlich der Anpassungsinstrumente beim Zugang zur Rechtsanwaltschaft zu beschränken, während eine derartige Einschränkung im Falle eines Richters nicht möglich wäre. Dieses Ergebnis erscheint widersinnig, jedoch handelt es sich auch um ein bisther nur theoretisches Beispiel ${ }^{894}$.

Weder die Eignungsprüfung als Anpassungsinstrument noch dieser Ausnahmetatbestand für die rechtsberatenden Berufe waren im Entwurf der Kommission vorgesehen. Erst die nach Veröffentlichung des Entwurfs einsetzende Diskussion im Rat sowie auch unter den juristischen Berufsständen hat zu einer Änderung des ursprünglichen Richtlinientextes geführt, wobei die Bundesrepublik mit ihrer Haltung gegen die Anerkennung juristischer Studien ihr Schärflein zu dieser Passage beigetragen hat ${ }^{895}$. Betroffen davon sind im wesentlichen die Berufe des Rechtsanwalts, Patentanwalts, Steuer-

892. Alle Mitgliedstaaten haben für die juristischen Benufe die Eignungsprufung als Anpassungsinstrument gewahlt. Ursprünglich hatte Dänemark den Anpassungslehrgang erwogem. Unter EinfluB der Umsetzungsentwürfe der anderen Mitgliedstaten hat Dänemark dieses. Vorhaben jedoch fallen lassen und sich ebenfalls für die Eignungsprüfung entschieden

893. Siehe Selte 367

894. Die Nuederlande haben allerdings zunăchst einen Antrag gemäß Art. 10 der Richtlinie 89/48/EWG gestellt, um die Wahlmöglichkeit auch für Richter zu beschränken. Dieser Antrag wurde jedoch wieder zurückgezogen, nachdem die Kommission die Beschränkung der Wahlmöglichkeiten gemäß Art. 4 Buchstabe b) Unterabs. 2 Satz 2 der Richtlinie 89/48/EWG für die rechtsprechenden Berufe grund sătzlich bejaht hat.

895. Siehe dazu den ausführlichen Beschluil des Bundesrates, worn bereits Vorschläge hinsichtlich der inhaltlichen Ausgestaltung der Eignungsprüfung für Rechtsanwälte unterbreitet werden, BR-Dnucksache $546 / 87$ vom 5. Februar $1988,3$. 
beraters ${ }^{8 \%}$ und Wirtschaftsprüfers. Der unter den Mitgliedstaaten umstrittene Beruf Notar wird jedenfalls von der Definition erfaßt ${ }^{397}$.

Möchte der Aufnalimestaat die Wahlmöglichkeit des Antragstellers auch für andere Berufe beschräriken, muß er den Entwurf einer dementsprechenden Vorschrift an die: Kommission unter Beifügung von Gründen übermitteln (Art. 10 der Richtlinie 89/48/EWG). Die Kommission wird die anderen Mitgliedstaaten von diesem Vorhaben unverzilglich unterrichten. Der Mitgliedstaat darf die Einschränkung der Wahlmöglichkeit nur dann erlassen, wenn sich die Kommission innerhalb einer Frist von drei Monaten nicht dagegen ausgesprochen hat (Art. $10 \mathrm{der}$ Richtlinie 89/48/EWG) ${ }^{898}$.

\section{(1) Anpassungslehrgang}

Nach der Definition in Art. 1 Buchstabe f) der Richtlinie 89/48/EWG muß der Anpassungslehrgang im Aufnahmestaat unter der Verantwortung eines qualifizierten Berufsangehörigen erfolgen. Der Wirtschafts- und Sozialausschuß plädierte in seiner Stellungnahme zu Art. 4 auf eine Erweiterung dahingehend, daß der Anpassungslehrgang im Aufnahmeland oder anderswo unter Aufsicht eines im Aufnahmeland ausgebildeten Berufsangehörigen absolviert werden kann. Diese Erweiterung wurde jedoch nicht in den endgültigen Richtlinientext übernommen. Die Dauer des Anpassungslehrganges darf drei Jahre nicht überschreiten. Der Lehrgang ist Gegenstand einer Bewertung, wobet die Einzelheiten des Anpassungslehrgangs und seine Bewertung durch den Aufnahmestaat zu erfolgen hat. Der Anpassungslehrgang kann gegebenenfalls durch eine Zusatzausbildung ergänzt werden. In welcher Formen die Bewertung eines Anpassungslehrgangs durchgeführt werden darf, ist sehr umstritten. Grundsätzlich hat sich der Rat in einer Erklärung dagegen ausgesprochen, da/3 die Bewertung die Form einer Prüfung annimmt. Würde ein Kandidat nach einem dreijährigen Anpassungslehrgang mit einer Abschlußprüfung konfrontiert, dann wäre der Unterschied zur Eignungsprüfung vollkommen verwischt. Der Betroffene müßte nach der Anpassung doch noch seine Eignung unter Beweis stellen. Wie die Bewertung des Anpassungslehrgangs inhaltlich gestaltet werden kann, wenn keine Prüfung vorgenommen werden darf, ist nicht deutlich. Un-

896. Latut der amtlichen Begründung des Gesetzesentwurfes zur Anderung des Steuerberatergesetzes, BTDrucksac he 11/7665 vom 10. August 1990,9, gibt es in keinem Mitgliedstaat einen mit dem deutschen Steuerberater vergleichbaren reglementienten Beruf. Die Beschränkung der Wahlmöglichkeit für den Steuerbetater wird in dem Regienngsentwurf damit begrindet, dab die Steuerberatung ein Bestandkeil der Rechtspifege sei, so daß eine Eignungsprüfung verlangt werden körne, vgl. dazu auch BT-Drucksache 11/8343 vom 29. Oktober 1990, 14. Siehe dazu unten Seite 315.

897. Das Notariat ist mit Sicherheit eine reglementierte Benufsform. Inwieweit Notare sich auf die Ausnailhmeregel des An. 55 EGV benfen können, wind auf Seite 266 erörtert.

898. Bisher wurden bei der Kommission nur sehr wenige Ancräge gemäß Art. 10 der Richtlinie 89/48/EWG gestellt. Die meisten Anträge wurden zunächst durch die Niederlande vorgelegt. Es handelt sich dabei um die folgenden Berufe: Richter in den werschiedenen Instanzen, verschiedene maritime Berufe u.a.

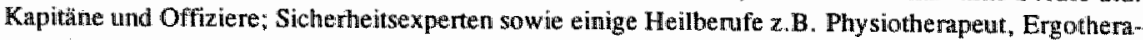
pewt, Logopäde und Diètist, Staatscourant 36 vom 21. Februar 1994, 3. Die Niederlande haben diesen Antrag jedoch 20 einem spätteren Zeitpunkt wieder zurückgezogen. 
deutlich ist auch, wie ein erfolgreicher Kandidat die Bewertung seiner Anpassung im Rahmen einer Bewerbung benützen kann.

\section{(2) Eignungsprüfung}

Gemäß Art. $1 \mathrm{~g}$ ) der Richtlinie 89/48/EWG dürfen mit der Eignungsprïfung ausschließlich die beruflichen Kenntnisse des Antragstellers überprüft werden, die zur Ausübung des betreffenden Berufes im Aufnahmestaat erforderlich sind. Die Eignungsprüfung darf damit nicht zu einer Wiederholungsprüfung bereits im Herkunftsstaat erworbener akademischer Kenntnisse ausarten. Dieser Grundsatz ergibt sich bereits aus der Rechtsprechung des Gerichtshofes in den Rechtssachen Heylens, Vlassopoulou und Newmann. Es wäre daher unzulässig, wie Everling zu Recht feststellt, die Eignungsprüfung nach Art einer zweiten Staatsprüfung auszugestalten ${ }^{899}$. Die Gefahr ist natürlich groß, daß Eignungsprüfungen zu einer meist etwas verschlankten nationalen Prüfung werden. Diese Gefahr ist besonders dann gegeben, wenn die für die Organisation der Eignungsprüfung zuständige Behörde mit der Behörde identisch ist, die für die nationalen Prüfungen verantwortlich ist. Für die Prüfer ist bereits aus psychologischen Gründen eine klare Unterscheidung zwischen Eignungsprüfung und nationaler Berufszulassungsprüfung nur sehr schwer aufrechtzuerhalten. Trotzdem haben die meisten Mitgliedstaaten als für die Eignungsprüfung zuständige Behörde gerade die entsprechenden nationalen Prüfungsinstanzen angewiesen.

Die Eignungsprüfung ist - wie bereits festgestellt - erst in einem sehr spăten Stadium der Verhandlungen in den Richillinientext eingefügt worden. Diese Erweiterung war mit Sicherheit nicht im Sinne der Kommission, da der Prüfungsgedanke eigentllich im Gegensatz zu der Grundphilosophie der Richtlinie steht, nach der das gegenseitige Vertrauen in die Qualität der Ausbildung bestimmend sein soll ${ }^{900}$.

Mit der Möglichkeit einer tatsächlichen Prüfung sollten vor allem die Bedenken zersteut werden, die gegen die Anwendung der Richtlinie auf die rechtsberatenden Berufe vorgebracht waren. Die Mitgliedstaaten sollten die Gelegenheit erhalten, die Kenntnisse des nationalen Rechts - soweit sie für die Ausübung des Berufes erforderlich sind - beim Antragsteller zu überprüfen, da aufgrund der abweichenden Rechtssysteme nicht so selbstverständlich wie bei anderen Berufen davon ausgegangen werden kann, daß ein qualifizierter Berufsangehöriger eines Mitgliedstaates auch in einem anderen Mitgliedstaat seinen Beruf erfolgreich ausüben kann ${ }^{901}$.

899. Everling, 58. DJT, Bd. 1, C 49, Everling, EuR 1989, 338 (348), siehe dazu auch Lang, BRAK-Mitt. 1990,13 .

900. Select Committe of the House of Lords, Antwort M. Petite, 18 (Q 60) "der zu diesem Zeitpunkt noch die Möglichkeit eines Examens verneint.

901. Die Begründetheit dieser Bedenken wurde auch, von dem Vertreter der Kommission eingeräumt, Select Committee of the House of Lords, Antwort M. Petite, 18 (Q 61). 


\section{d. Kumulationsverbot}

Der Aufnahmestaat darf die Anpassungsinstrumente des Art. 4 Abs. 1 Buchstabe a) und Buchstabe b) nicht kumulativ anwenden, d.h. von dem Antragsteller kann entweder zur Kompensation einer unterschiedlichen Ausbildungsdauer der Nachweis über eine entsprechende Berufserfahrung verlangt werden oder, er kann im Falle wesentlicher Un terschiede der Ausbildungsinhalte vor die Wahl zwischen einem Anpassungslehrgang und der Ablegung einer Eignungsprüfung gestellt werden (Art. 4 Abs. 2 der Richtlinie 89/48/EWG). Dieses Kumulationswerbot bezüglich der Anpassungsinstrumente kann in. bestimmten Fällen sehr problematisch sein.

Gedacht werden muB z.B. an den Fall des spanischen Rechtsanwalts (Abogado). Ein spanischer Jurist kann sich mit Abschluß seines Universitätsstudiums sofort als Rechtsanwalt niederlassen ${ }^{902}$. Die spanische Juristenausbildung kennt bisher ${ }^{903}$ keine spezielle an die akademische anschließende Berufsausbildung etwa in der Form der deutschen Referendarzeit oder der in anderen Mitgliedstaaten üblichen Trainingsperiode unter Aufsicht eines qualifizierten Berufsangehörigen. Mit Erlangung seines Universitätsdiploms ist der spanische Jurist damit als Endprodukt im Sinne der Richtlinie zu qualifizieren. Dieses Endprodukt verfügt jedoch, anders als seine Kollegen aus den anderen Mitgliedstaaten, über keine Berufserfahrung. Wird von ihm nun eine Eignungsprüfung zum Nachweis seiner Kenntnis hinsichtlich des Rechtssystems des Aufnahmestates verlangt, so muß diese Eïgnungsprüfung gemäß Art. 1 Buchstabe g) dem Umstand Rechnung tragen, daß der Antragsteller in seinem Herkunftsstaat über eine berufliche Qualifikation verfügt.

Für diesen besonderen Fall erscheint das Kumulationsverbot gemäß Art. 4 Abs. 2 der Richtlinie 89/48/EWG zu einem befremdenden Ergebnis zu führen, da der Aufnahmestaat vor die Alternative gestellt wird, entweder die fehlende berufsbezogene Ausbildung. zu negieren und lediglich im Rahmen einer Eignungsprüfung die zur Berufsausübung wesentlichen Kenntnisse des Antragstellers bezüglich des internen Rechts zu prüfen damit den spanischen Antragsteller gleich zu behandeln wie Antragsteller aus anderen Mitgliedstaaten, die sehr wohl über eine Praxisausbildung verfügen - oder aber für spanische Juristen ohne Berufserfahrung eine Sonderregelung einzuführen; wobei die Wahl u.U. auf die Forderung nach Absolvierung eines Anpassungslehrganges fallen könnte. Dies würde jedoch voraussetzen, daß die Mitgliedstaaten ihre Wahl zwischen Anpassungslehrgang und Eignungsprüfung nicht generell treffen müssen, sondern sie von der Vorausbillung des Antragstellers abhängig machen können ${ }^{904}$. Daraus ergibt sich die Frage, ob die Mitgliedstaaten unterschiedliche Anforderungen stellen dürfen oder vielleicht sogar müssen, je nachdem wo und welche Fächer ein Antragsteller studiert hat. Bedeutet dies, daß die zuständligen Behörden gezwungen sind, inhaltliche Ver-

902. Lonbay 1991, Report Spain.

903. Die Einführung einer beruflichen Trainingsperiode wurde in Spanien zwar des häufigeren diskutier:" der Gedamke fand bisher jedoch werig Gefallten bei den Berufsangehörigen und den Studenten.

904. Siehe dazu auch Goffin, JT 1992, 489 (493). 
gleichsprüfungen zwischen den einzelnen Ausbildungssystemen und den hierin vermittelten Kenntnissen vorzunehmen?

Betrachtet man diese Frage im Lichte der Rechtsprechung des Gerichtshofs, insbesondere in der Sache Heylens ${ }^{905}$ und im Rahmen der Entscheidungen Vlassopoulou ${ }^{906}$ und Newman ${ }^{907}$, so erscheint es nicht abwegig, die Frage zumindest in gewissen Grenzen positiv zu beantworten. SchlieBlich hat der Gerichtshof die Pflicht der Mitgliedstaaten postuliert, die in einem anderen Mitgliedstaat erworbenen Diplome, Prüfungszeugnisse und sonstigen Beschäftigungsnachweise, die der Betroffene erworben hat, um den entsprechenden Beruf in einem anderen Mitgliedstaat auszuüben, "in der Weise zu berücksichtigen, daß er die durch diese Diplome bescheinigten Fachkenntnisse mit den auch nationalem Recht vorgeschriebenen Kenntnissen und Fähigkeiten vergleicht ${ }^{908}$ " Der EuGH konkretisierte diese Pflicht und das gebotene Verfahren noch wie folgt:

"Führt diese vergleichende Prüfung zu der Feststellung, daß die durch das ausländische Diplom bescheinigten Kenntnisse und Fähigkeiten den nach den nationalen Rechtsvorschriften verlangten entsprechen, so hat der Mitgliedstaat anzuerkennen, daß dieses Diplom die in diesen Vorschriften aufgestellten Voraussetzungen erfüllt. Ergibt der Vergleich hingegen, daß diese Kenntnisse und Fähigkeiten einander nur teilweise entsprechen, so kann der Aufnahmemitgliedstaat von dem Betroffenen den Nachweis, daß er die fehlenden Kenntnisse und Fähigkeiten erworben hat, verlangen.... Ist im Aufnahmemitgliedstaat die Absolvierung eines beruflichen Vorbereitungsdienstes oder eines Berufspraktikums vorgeschrieben, so haben die nationalen Behörden zu beurteilen, ob eine im Herkunfts- oder im Aufnahmemitgliedstaat erworbene Berufserfahrung als diesem Erfordernis teils oder entsprechend angesehen werden kann ${ }^{909}$."

Bei der Anwendung der Richtlinie 89/48/EWG und ihrer Interpretation ist diese Rechtsprechung zu berücksichtigen. Dies ergibt sich einerseits aus der allgemeinen Bindungs-

905. Urteil vom 15. Oktoluer 1987, Rs 222/87 UNECTEF/Heylens - ., Slg. 1987, 4097.

906. Untell vom 7. Mai 1991, Rs C-340/89 - Irene Vlassopoulou/Ministerium der Justiz, Bundes und Europaangelegenheiten Baden-Wüttemberg, SIg. 1991, 1-2357.

907. Unteil vom 7. Mai 1992, Rs C 104/91-Colegio Oficial de Agentes de la Propriedad Inmobiliaria Ministerio fiscal/J.L. Aguirre Borrell, S.K. Newman, S. Aguirre Gil de Biedma, M.J. Cepeda Ruiz, P. Aguirre Gil de Biedma -, Slg. 1992, L-3003.

908. Urteil vom 7. Mai 1991, Rs C-340/89 - Irene Vlassopoulou/Ministerium der Justiz, Bundes- und Europarangelegenheiten Baden-Wurttemberg. SIg. 1991, 1-2357.

909. Unteil wom 7. Mai 1991. Rs C-340/89 - Irene Vlassopoulou/Ministerium der Justiz, Bundes- tind Europaangelegenheiten Baden-Württemberg, Slg. 1991, I-2357. 
wirkung von Vorabentscheidungen gemäß Art. $177 \mathrm{EGV}^{910}$, andererseits aber auch aus dem in Art. 5 EGV eingebetteten Grundsatz der Gemeinschaftstreue ${ }^{\text {gi! }}$.

Auch die Präambel der Richtinie 89/48/EWG geht davon aus, daß jeder Aufnahmestaat, in dem ein Beruf reglementiert ist, die in einem anderen Mitgliedstaat erworbenen Qualfikationen zu berücksichtigen und zu beurteilen hat, ob sie den von ihm geforderten entsprechen. Daraus folgt, daß jeder Antrag individuell beurteilt werden muß. Bei dieser Beurteilung muß die konkrete Ausbildung des Antragstellers im Herkunftstaat mit der geforderten im Aufnahmestaat verglichen werden. Dabei müssen etwaige individuelle Besonderheiten in die Beurteilung mit einfließen.

Dies kann jedoch bedeuten, daß je nach Sachlage Antragsteller aus den verschiedenen Mitgliedstaaten unterschiedlich zu behandeln sind. Hailbronner wendet gegen eine konkrete Vergleichsprüfung beziìglich der Unterschiede der betroffenen nationalen Rechtsordnungen ein, daß eine solche die zuständigen Behörden der Mitgliedstaaten überfordern würde ${ }^{912}$. An anderer Stelle führt er, konkret auf den Fall Vlassopoulou Bezug nehmend aus, daß eine vorgeschaltete Prüfung, ob die Eignungsprüfung nicht auch entfallen könnte, wenn die im Heimatstaat erworbenen Kenntnisse und Fähigkeiten der mit der Zweiten juristischen Staatsprüfung erworbenen Befähigung zum Richteramt in der Bundesrepublik entsprechen, nicht im Einklang mit der Richtlinie 89/48/EWG vorgesehen sei. Hailbronner verweist dabeli auf den Wortlaut des Art. 4 Abs. 1 b) Satz 3 der Richtlinie 89/48/EWG , wonach dem Aufnahmestaat für die juristischen Berufe die Wahl zwischen Eignungsprüfung und Anpassungslehrgang überlassen wird ${ }^{913}$

Diese Auffassung kann nicht geteilt werden. Ausgangspunkt der Richtlinie 89/48/EWG ist der in Art. 3 niedergelegte Grundsatz der gegenseitigen Anerkennung von Diplomen. Hierzu bilden die Anpassungsinstrumente des Art. 4 die Ausnahme und sind dementsprechend lediglich restriktiv anzuwenden. Zwar gibt Art. 4 Abs. 1 Buchstabe b) Satz 3 der Richtlinie 89/48/EWG den Mitgliedstaten das Wahlrecht zwischen den beiden Anpassungsinstrumenten in Bezug auf die rechtsberatenden Berufe. Die Anwendung von Art. 4 Abs. 1 Buchstabe b) Satz 3 setzt jedoch grundsätzlich voraus, dal die Bedingungen von Art. 4 Abs. 1 Buchstabe b) Satz 1 der Richtlinie 89/48/EWG erfüllt sind. Dies gilt für die rechtsberatenden Berufe ebenso wie für alle anderen Berufe.

910. Siehe dazu die deutlichen Worte des EuGH in seinem Urteil vom 16. Januar 1974, Rs 166173 Rheinmühlen/Einfulur- und Vorratsstelle Getreide, Sig. 1974, 33 (38): "Art. 177 ist von entscheidender Bedeutung dafür, dafl das vom Vertrag geschaffene Recht wirklich gemeinsames Recht bleibt; es soll gewalhrleisten, daf dieses Recht in den Mitgliedstaaten immer dieselbe Wirkung hat. Allnulich in der Rs 107/76, Urteil von 24. Mai 1977 - Hoffmann La Roche/Centrafarm -, Slg. 1977, 957 (972), Datuses, JZ 1979; 125, Everling, Das Vorabentscheidungsverfahren 1986, 66; Pescatore, Bay VerwB1. 1987, 33 (43).

911. Vgl dazu Blecknann, RTW 1981, 653; Avenarius, NVwZ 1988, 385 (387),

912. Hailbronner, JuS 1991, 917 (920), so ebenfalls Nachbaur, EuZW 1991, 470 (472).

913. Hailbronner, JuS 1991, $917(918)$. 
Zwar wird bei den rechtsberatenden Berufen in der Regel Alternative 1 des Art. 4 Abs. 1 Buchstabe b) der Richtlinie 89/48/EWG, d.h. wesentlich unterschiedliche Ausbildungsinhalte erfüllt sein, dies ist jedoch nicht immer zwingend gegeben ${ }^{914}$. Gedacht werden kann etwa an die geringen Unterschiede zwischen dem Rechtssystem von England und Wales mit dem irischen ${ }^{915}$. Große Übereinstimmung besonders im Zivilrecht kann man ebenfalls für Frankreich und Belgien feststellen ${ }^{916}$. Auch in der Präambel wird diese Tatsache kurz gestreift: "Vor allem die Unterschiede zwischen den Rechtssystemen der Mitgliedstaaten, selbst wenn sie von Mitgliedstaat zu Mitgliedstaat von unterschiedlicher Bedeutung sind, rechtfertigen Sonderregelungen, weil die durch Diplom, Prüfungszeugnisse oder sonstige Befähigungsnachweise bescheinigte Ausbildung auf einem Rechtsgebiet des Herkunftslandes im allgemeinen nicht die juristische Kenntnisse abdeckt, die im Aufnahmeland auf dem entsprechenden Rechtsgebiet verlangt werden". Zwar liegt die Betonung auf der Unterschiedlichkeit der Rechtssysteme, gerade aber der Hinweis darauf, daß die Unterschiede zwischen den Rechtssystemen graduell verschieden sind und, daß lediglich im allgemeinen die juristischen Kenntnisse nicht übereinstimmen, rechtfertigt die Annahme, daß die zuständigen Behörden jeden Fall unter Berücksichtigung aller Umstände zu beurteilen haben. Bei dieser Beurteilung müssen auch Vorkenntnisse auf Grund der Verwandtschaft der Rechtssysteme oder auf Grund eines Auslandsstudiums berücksichtigt werden ${ }^{917}$.

Auch Art. 8 der Richtlinie 89/48/EWG, der die Regelung des Verwaltungsverfahrens beinhaltet, unterstützt diese Auffassung. Gemäß Art. 8 Abs. 2 muß nämlich die Entscheidung der zuständigen Behörde des Aufnahmestaates mit Gründen versehen sein. Von diesem Begründungserfordemis sind auch die rechtsberatenden Berufe nicht ausgenommen. Wäre dem Antragsteller, der im Besitz der erforderlichen Diplome ist, lediglich die grundsätzliche gesetzgeberische Entscheidung des Mitgliedstaates zwischen Eignungsprüfung und Anpassungslehrgang mitzuteilen, so wäre eine Begründungspflicht

914. Generalanwalt Van Gerven hat bereits in seinem Schlufiantrag in der Sache Vlassopoulou deutliche Zweifel an der von der Bundesrepublik Deutschand vorgetragenen Ansicht , geäulBert, mach der die Quallifikationen und beruflichen Erfahrungen eines Rechtsanwaltes vollkommen irrelewant seien, wewn er sich in einem anderen Mitgliedstat miederlassen will. Van Gerven hall diese Auffassung schon weigen der historischen Verwandtschaft zwischen mehreren nationalen Rechts systemen in den Mitgliedstaten für nicht vertretbar, siehe SchluBanträge C-340/90, Rdnr. 13 .

915. Daher unterstellt Irland bei Antragstellern aus England und Wales auf Grund der Verwandischaft der Rechtssysteme mehr vorhandene Kenntnis des irischen Rechts als bei Antragstellern aus Schottland. Im algemeinen werden daher englische solicitors/barristers in Irland und irische solicitors/barristers in England und Wales automatisch anerkannt.

916. Der belgische Code civil ist grundsatzlich identisch mit dem französischen Code Napoleon, obwolit beide Gesetze sich auf Grund von Gesetzesändenungen seit dem vorigen Jahrhundert in manchen Punkten unterschiedlich entwickelt haben. Die Niederlande hatten bis zum 31. Dezember 1991 ebenfalls ein bürgerliches Gesetzbuch das weitgehend eine Ubersetzung des Code Napoleon's war. Mit der Eunfühnung des Neuen Binggerlichen Gesetzbuches am 1. Januat 1992 haben sie sich jedoch teilweise won diesem französischen Erbe getrennt. Dieses neue Gesetz zeigt eine gewisse Verwand tschaft mit

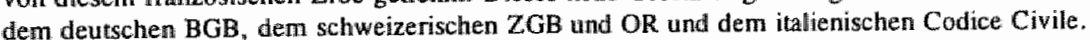

917. Vergleiche dazu auch die Ausführurgen von GA Van Gerven in seinen SchluBantragen zu der Rechts sache Vlassopoulou, C-390/90, Rdnr. 15. Danach müssen die nationalen Behörden eine solche Untersuchung auf Grund ihrer Verpflichtung aus Art. 5 EGV durchfuhren. 
ubberflüssig, weil gegen diese gesetzgeberische Entscheidung der Antragsteller doch keine Rechtsmittel geltend machen könnte.

\section{Anpassung gemäß Art. 5 der Richtlinie 89/48/EWG für nicht vollqualifizierte Beruffs- angehörige}

Gemäß Art. 5 der Richtlinie 89/48/EWG steht es jedem Mitgliedstaat frei, dem Antragsteller zur Verbesserung seiner Anpassung an das berufliche Umfeld zu gestatten, den ilim fehlenden Teil der praktischen Ausbildung mit der Unterstïtzung eines qualifizierten Berufsangehörigen im Aufnahmestaat zu absolvieren. Da Art. 5 der Richtlinie 89/48/EWG jedoch lediglich eine "kann" - Vorschrift enthält, bleibt es den Mitgliedstaaten überlassen, ob sie dieses Angebot machen möchten. Jedenfalls kann ein Antragsteller keinen Rechtsanspruch hierauf stützen. Die Unverbindlichkeit dieser Regelung ist bedauerlich, da gerade die Absolvierung der praktischen Ausbildung eine ideale Gelegenheit zur Appassung in einem anderen Mitgliedstaat böte. Es überrascht jedoch nicht, daß die Regelung in dieser Form ergangen ist. Eine weitergehende Verpflichtung der Mitgliedstaaten hätte die bereits bestehenden Schwierigkeiten bei der Abgrenzung zwischen der akademischen und der professionellen Anerkennung noch vergrößert.

Obwohl Art. 5 der Richtlinie 89/48/EWG nur eine für die Mitgliedstaaten unverbindliche Norm enthält, war die Regelung dennoch Anlaß eines Klageverfahrens in GroBbritannien wor dem Master of the Rolls ${ }^{918}$. Es handelte sich dabei um einen deutschen Antragsteller mit lediglich einem juristischen Staatsexamen, der die Anerkennung als Solicitor bewirken wollte. Die Law Society hatte diesen Antrag mit der Begründung abgewiesen, der Antragsteller verfüge nicht über die notwendigen berufsqualifizierenden Voraussetzungen, nämllich den erfolgreichen Abschluß des zweiten Staatsexamens. Gegen diese Entscheidung legte der Antragsteller Berufung beim Master of the Rolls mit der Begründung ein, eine Anerkennungsverpflichtung bestehe aufgrund von Art. 5 der Richtlinie 89/48/EWG. Der Master of the Rolls sah dagegen keine Verpflichtung zur Anerkennung auf der Basis von Art. 5 und lehnte daher den Antrag ab. Diese Entscheidung ist absolut korrekt. Man mag bedauern, daß der Richtlinientext in diesem Punkt für die Mitgliedstaaten nicht verbindlicher formuliert ist, da damit eine sicher sehr gute Anpassung an das berufliche Umfeld gewährleistet wäre. Beim derzeitigen Stand des Gemeinschaftsrechts kann jedoch keine Verpflichtung der Mitgliedstaaten zur Aufnahme von Migranten in das berufliche Ausbildungssystem angenommen werden.

Ein ähnlicher Fall spielte auch in den Niederlanden. Ein belgischer Studienabsolvent beantragte die Zulassung zur Rechtsanwaltsausbildung aufgrund der Richtlinie 89/48/EWG. Er begründete seinen Antrag mit der Tatsache, daß er als Studienabsolvent bereits als Endprodukt zu qualifizieren sei; nur hilfsweise berief er sich auf Art. 5 der Richtlinie 89/48/EWG. Auch dieser Antrag wurde abgelehnt. Der Fall zeigt jedoch

918. Der Master of the Rolls fungiert als gerichtliche Instanz gemäB Regulation 13 (4) der European Communities (Recognition of Professional Qualifications) Regulation 1991 für die Entscheidungen der Law Society in Ancrkennungswerfahren. 
deutlich die schwierige Abgrenzung zwischen einem akademischen und einem professionellen Endprodukt ${ }^{919}$.

\section{Verfahren vor der zuständigen Behörde}

Gemäß Art. 12 Satz 1 der Richtlinie 89/48/EWG waren die Mitgliedstaaten verpflichtet, die Richtlinie bis zum 4. Januar 1991 umzusetzen. In der selben Frist mußten sie gemäß Art. 9 Abs. 1 der Richtlinie 89/48/EWG die zuständigen Behörden bezeichnen, die ermächtigt werden, die Anträge entgegenzunehmen und die in der Richtlinie genannten Entscheidungen zu treffen. Das Verfahren über einen Antrag auf Ausübung eines reglementierten Berufs muß von der zustăndigen Behörde spätestens vier Monate nach Vorlage der vollständigen Unterlagen abgeschlossen werden (Art. 8 Abs. 2 der Richtlinie 89/48/EWG). Der Aufnahmestaat erkennt dabei die dem Antrag beigefügten und von den zuständigen Behörden ausgestellten Bescheinigungen an. Gegen die getroffene Entscheidung oder gegen deren Unterlassung steht dem Antragsteller ein gerichtlicher Rechtsbehelf zur Verfügung, dessen Ausgestaltung sich nach den Regeln des Aufnahmestaates richtet. Art. 9 Abs. 3 der Richtlinie 89/48/EWG verpflichtet die Mitgliedstaaten zum Aufbau eines Informationssystems, das die erforderlichen Auskünfte über die Anerkennung von Diplomen zur Verfügung gestellt werden.

\section{Fuhrung der Berufs- und Ausbildungsbezeichnung}

Wird ein Antrag gemäß Art. 3 der Richtlinie 89/48/EWG positiv beschieden oder erfüllt der Betroffene mit Erfolg eine der Bedingungen des Art. 4 der Richtlinie 89/48/EWG, so hat er gemäß Art. 7 Abs. 1 der Richtlinie 89/48/EWG das Recht, die entsprechende Berufsbezeichnung des Aufnahmestaates zu führen. Daneben besitzt er gemäß Art. 7 Abs. 2 der Richtlinie 89/48/EWG die Befugnis, um die Ausbildungsbezeichnung in der Sprache des Herkunftstaates zu benützen. Der Aufnahmestaat kann in einem solchen Fall verlangen, daf dieser Ausbildungsbezeichnung Name und Ort der Lehranstalt oder des Prüfungsausschusses zugefügt werden.

Wird ein Beruf durch einen Berufsverband oder eine Organisation im Sinne des Art. 1 Buchstabe d) der Richtlinie 89/48/EWG reglementiert, so ist der Betroffene nur dann zur Führung der entsprechenden Berufsbezeichnung berechtigt, wenn er seine Mitgliedschaft bei diesem Verband oder Organisation nachweisen kann (Art. 7 Abs. 3 der Richtlinie 89/48/EWG). Diese wiederum sind bei der Entscheidung über die Aufnahme zum Mitglied und den damit verbundenen Qualifikationsanforderungen an die in den Art. 3 und 4 der Richtlinie 89/48/EWG niedergelegten Bedingungen gebunden. Zusätzliche Ausbildungsanforderungen sind damit ausgeschlossen.

919. Siehe auch die Erörterungen auf Seite 221 hỉnsichtlich der dănischen Umsetzung, worin diese Problematik teillweise durch den Gesetzgeber gelöst worden ist. 


\section{Nachweis von Zuverlässigkeit und Gesundheit}

Gemäß Art. 6 der Richtlinie 89/48/EWG muß der Aufnahmestaat, falls er für den Zugang zu einem reglementierten Beruf einen Zuverlässigkeitsnachwelis oder ein Gesundheitsattest fordert, die von der zuständigen Behörde des Herkunftsstaates ausgestellte Bescheinigung, daß den Anforderungen Genüge getan wird, als ausreichend akzeptieren. Hierbei kann gefordert werden, daß die Bescheinigung nicht älter als drei. Monate ist.

\section{Koordinatoren und Koordinatorengruppe}

Wegen der Zahl der von der Richtlinie betroffenen Berufe und der damit verbundenen Komplexität der Umsetzungsmaterie, wurden die Mitgliedstaaten gemäß Art. 9 Abs. 2 der Richtlinie 89/48/EWG verpflichtet, einen Richtlinienkoordinator zu ermennen. Seine Funktion sollte darin bestehen, die einheitliche Anwendung der Richtlinie in einem Mitgliedstaat zu fördern. Auch sollte er die Tätigkeit der verschiedenen zuständigen Behörden koordinieren. Gleichzeitig wurde bei der Kommission eine Koordinierungsgruppe eingerichtet, um den Informationsaustausch zwischen den Mitgliedstaaten und die Umsetzung der Richtlinie zu erleichtern. Diese Maßnahme zur Erleichterung einer Richtlinienumsetzung war bisher beispiellos, wurde jedoch allgemein von den Mitgliedstaaten als âßußerst positiv empfunden ${ }^{920}$. Die Einrichtung einer Koordinatorengruppe wird aufgrund der gemachten Erfahrungen inzwischen auch für die Umsetzung anderer Richtlinien erwogen. Dennoch hatte mit Ausnahme von Irland kein Mitgliedstaat die Richtlinie vollständig bis zum 4 . Januar 1991 umgesetzt ${ }^{\text {921 }}$. Diese Verspätung kann jedoch nicht der Koordinatorengruppe als solche angerechnet werden, da ihre Funktion hauptsächlich im Informationsaustausch zu sehen ist. Die Effizienz einer derartigen Einrichtung hängt jedoch nicht unwesentlich davon $a b$, über welche innerstaatlichen Mittel und Rechte ein Koordinator verfügt, um auf nationalem Niveau den in der Gruppendiskussion erreichten Meinungsstand auch tatsächlich umzusetzen. Zu diesem Punkt: lassen sich starke Diskrepanzen zwischen den einzelnen Mitgliedstaaten feststellen.

Die Rolle des nationalen Koordinators wurde von den Mitgliedstaaten unterschiedlich ausgefüllt. So waren in den einzelnen Mitgliedstaaten verschiedene Ministerien federführend mit der Koordination betraut. Die Mehrzahl der Länder ernannten alls Koordinator einen Beamten im Bereich des Erziehungs- und Bildungsministeriums. Dies galt für die Niederlande, Portugal, Luxemburg und Irland. Auch die neuen Mitgliedstaaten Schweden und Finnland haben das Erziehungsministerium mit der Koordination der Richtlinie 89/48/EWG beauftragt. Diese Wahl beruhte auf dem deutlich erziehungspolitischen Gehalt der Richtlinie. Einige andere Mitgliedstaaten dagegen sahen die Richtlinie vor allem als Teil des Binnemarktprojekts. Diese Mitgliedstaaten delegierten

920. Hoefnagel in Pertek EIPA 1992 , 63. So auch Harkin, der erste irische Koordinator, während einer Tagung im ELPA 1993.

921. Statutory Instrument S.I. No. 1 of 1991, Regulation entitled European Communities (General System of the Recognition of Higher Education Diplomas) Regulations, 1991, 
die Koordination der Richtlinie zum Wirtschaftsministerium. Dies gilt für Deutschland, Dänemark, Großbritannien ${ }^{922}$ sowie für Österreich. In Spanien übernahm das staatliche Sekretariat der Universitäten die Koordination. In Italien wurde das Ministerium mit der Koordination der Richtlinie beauftragt, das allgemein zur Koordination der Gemeinschaftsangelegenheiten befugt ist. In Deutschland wurde neben dem Koordinator auf Bundesebene noch ein weiterer Koordinator auf Länderniveau bestimmt. Auch in Belgien gibt es neben einem nationalen Koordinator noch Koordinatoren bei den beiden Gemeinschaften. Damit hielten diese beiden Mitgliedstaaten mit ihrer federalen Struktur Rechnung.

Die unterschiedliche Ausgestaltung hinsichtlich der Provenienz des Koordinators hatte bei der Umsetzung auch inhaltliche Konsequenzen. Zunächst war es eine der Aufgaben des Koordinators die Art und Weise der Umsetzung zu bestimmen. Hierzu war eine Katalogisierung der von der Richtlinie 89/48/EWG betroffenen Berufe notwendig. Nach dieser Auflistung der reglementierten Berufe mußte der Koordinator entscheiden, ob er die Umsetzung im Wege einer allgemeinen gesetzlichen Regelung durchführen wollte und gesetzlich konnte, oder, ob eine sektorielle Einzelumsetzung pro Beruf der gebotene Weg war.

Diese Grundsatzentscheidung haben die einzelnen Koordinatoren unterschiedlich getroffen. In den Niederlanden, Dänemark, Großbritannien und Irland wurde durch die jeweiligen nationalen Koordinatoren zugunsten einer allgemeinen gesetzlichen Regelung entschieden. Dagegen trafen der deutsche, der luxemburgische und der französische Koordinator ihre Wahl zugunsten einer sektoriellen Umsetzung. Mit dieser Wahl änderte sich teillweise der Aufgabenbereich dieser Koordinatoren. Für die Koordinatoren, die sich für eine generelle Umsetzung entschieden hatten, stand nun mehr der Entwurf dieser allgemeinen gesetzlichen Regelung im Mittelpunkt ihrer Koordinatorentätigkeit. Sie mußten unter Berücksichtigung der Interessen anderer Ministerien, Behörden und Berufsgruppen einen nationalen Gesetzesentwurf vorlegen und durch den GesetzgebungsprozeB schleußen. Sie waren damit an der inhaltlichen Ausgestaltung der Umsetzungsmaßnahme unmittelbar beteiligt. Diese Aufgabe war oft nicht einfach, da sie mit ihrem Gesetzesworhaben die direkten Interessen und Kompetenzen anderer Behörden tangierten. Konflikte zwischen dem Koordinator und den anderen betroffenen Instarizen waren dabei beinahe unvermeidlich ${ }^{523}$.

Hatten sich die Koordinatoren dagegen für eine sektorielle Umsetzung entschieden, dann bestand ihre Aufgabe tatsächlich mehr in der Koordinierung des Umsetzungsprozeßes mit den jeweills zuständigen Behörden. Die Rolle des Koordinators ist in diesem Fall weniger eine inhaltlich gestaltende als eine den Umsetzungsprozeß bewachende

922. Ministry of Trade and Industry.

923. Désirée Hoefnagel, die erste niederländ ische Koordinatorin der Richtlinie 89/48/EWG, beschreibc sehr deutlich die Probleme, mit denen sie in der ersten Umsetzungsphase konfrontient war, in Pertek (Hrsg.) $1992,63(66 \mathrm{f}$.) 
Funktion. In diesem Fall hängt es sehr von den Rechten und der Autorität des nationalen Koordinators $a b$, ob er dieser Kontrollfunktion adäquat gerecht werden kann.

Nicht unbedeutend für eine zügige Umsetzung ist dabei auch die Tatsache, in wie weit der nationalle Koordinator bereits im Vorfeld beim Zustandekommen der Richtlinie unmittelbar beteiligt war. Auch in diesem Punkt lassen sich deutliche Unterschiede zwischen den Mitgliedstaten anweisen. Einige Koordinatoren haben an der Unterhandlung der Richtlinie maßgeblich teilgenommen, andere Koordinatoren wurden mit der Richtlinie erst nach ihrer Verabschiedung im Rat zum ersten Mal konfrontiert.

\section{Schlußbestimmungen}

Die Art. 11, 12 und 13 der Richtlinie 89/48/EWG enthalten die üblichen Bestimmungen bezüglich der Umsetzung. Danach mußte die Richtlinie gemäß Art. 12 innerhalb von zwei Jahren nach Bekanntmachung, d.h. am 4. Januar 1991 von den Mitgliedstaaten umgesetzt und die entsprechenden Regelungen an die Kommission mitgeteilt sein. Desweitern verpflichtet Art. 11 die Mitgliedstaaten zu einer Berichterstattung alle zwei Jahre, worin der Kommission die Anwendung der Richtlinie einschließlich der Problemfälle mitgeteilt wird. Dieser Bericht mußß eine statistische Übersicht enthalten. Gemäß Art. 13 ist die Kommission wiederum verpflichtet, dem Rat und dem Europäischen Parlament spätestens fünf Jahre nach Ablauf des Umsetzungstermins über die Anwendung der Richtlinie zu berichten und gegebenenfalls Verbesserungsvorschläge zu unterbreiten. Dieser Bericht muß daher bis zum 4. Januar 1996 vorgelegt werden.

\section{§ 2. Die Umsetzung der Richtlinie 89/48/EWG iber eine allgemeine Regelung zur Anerkennung der Hochschuldiplome, die eine min- destens dreijährige Berufsausbildung abschließen}

\section{A. EINLEITUNG}

Die Unsetzung der Richtlinie 89/48/EWG erfolgte in den Mitgliedstaaten auf unterschiedliche Art und Weise. Einige Mitgliedstaaten wählten den Weg eines allgemeinen Umsetzungsgesetzes, das für alle reglementierten Berufe gilt. Andere Mitgliedstaaten entschieden sich für den sektoriellen. Weg, d.h. die Umsetzung erfolgte durch Spezialgesetzgebung für jede Berufsgruppe. Die berufsspezifische Umsetzung hat den Vorteil der Deutlichkeit für die einzelnen Berufsgruppen, sie bewirkt jedoch zugleich, daß die Gesamtumsetzung der Richtlinie auf sich warten läßt. Auch läßt sich kaum feststellen, ob eine sektorielle Umsetzung auch tatsächlich umfassend vorgenommen worden ist. Dagegen weckt die Umsetzung durch ein allgemeines Gesetz den Schein der Vollkommenheit. Dieser Schein trügt jedoch häufig insoweit, als die notwendigen Ausführungsmaßnahmen durch Verordnungen auf sich warten lassen. 
Die Umsetzang sollte bis zum 4. Januar 1991 abgeschlossen sein ${ }^{924}$. Dieser Termin. ist in von den meisten Mitgliedstaaten weit überschritten worden. Mit Ausnahme von Irland hatte kein Mitgliedstaat die Richtlinie vollständig bis zum 4. Januar 1991 umgesetzt $^{925}$. Das Vereinigte Kömigreich folgte an zweiter Stelle mit einer generellen gesetzlichen Umsetzung, die am 17. April 1991 in Kraft trat ${ }^{926}$. Die dänische Regelung, ebenfalls eine generelle gesetzliche Regelung, trat am 11. Mai 1991 in Kraft ${ }^{927}$. Italien veröffentlichte termingerecht zwar einige Kriterien hinsichtlich der Anerkennung von Diplomen ${ }^{928}$, diese können jedoch nicht als eine vollständige Umsetzung bezeichnet werden. Inzwischen hat Italien ein allgemeines Gesetz erlassen, es fehlen teillweise jedoch noch die notwendigen Ausführungsmaßnahmen ${ }^{929}$. Portugal ${ }^{930}$ und Spamien ${ }^{931}$ setzten die Richtlinie ebenfalls durch ein allgemeines Gesetz um, wobei auch für diese Mitgliedstaaten die notwendigen Ausführungsmaßnahmen über einen erheblichen Zeitraum noch größtenteils fehlten. Erst in den Jahren 1993 und 1994 haben Portugal und Spanien diese Umsetzungslücken zum Teil geschlossen. Von einer vollständigen Umsetzung kann jedoch bisher noch nicht gesprochen werden.

Die Bundesrepublik Deutschland wählte nicht den Weg der Umsetzung mittels einer allgemeinen gesetzlichen Regelung, sondern setzte die Richtlinie durch verschiedene, auf die jeweilige Berufsgruppe bezogene Gesetze um. Für einige dieser Berufe erfolgte die Umsetzung fristgemäß ${ }^{932}$, bei anderen dagegen ließ die Umsetzung auf sich warten. Die Verzögerung war zum Teil wohl dadurch bedingt, daß auf Länderebene eine $\mathrm{im}$ wesentlichen übereinstimmende gesetzliche Lösung gesucht und gefunden werden mußte. Dieser Umsetzungsprozeß hat vor allem bei den neuen Bundesländern zu erheblichen Verzögerungen geführt. Selbst vier Jahre nach Inkrafttreten der Richtlinie 89/48/EWG ist der Umsetzungsprozeß noch nïcht in allen Bundesländern vollständig abgeschlossen, wobei auch einige der alten Bundesländer sich der Säumigkeit schuldig

924. Art. 12 Abs.1 der Richtlinie 89/48/EWG.

925. Statutory Instrumert S.I No.1 of 1991. Regulations entitled European Communities (General Systery for Recognition of Higher Education Diplomas) Regulations, 1991

926. Statutory Instruments 1991 No. 824. Professional Qualifications, The European Communities (Recogrition of Professional Qualifications) Regulations 1991

927. Act concerning access to pursue certain professions in Denmark for nationals of the European Communities and the Nordic countries, Nr. 291 wom 8. Mai 1991.

928. Gesetz vom 29. Dezember 1990, n. 428, "Disposizioni per l"adempimento di obblighu derivati dall" appartenenza dell"Italia alle Communită earope (legge communitaria per il 1990)", Art. 8, Gazzetta Ufficialle, n. 10 vom 12. Januar 1991.

29. Daza Seite 224 .

930. Decreto-Lei 289/91 vom 10. August 1991, Diario da Republica nr. 183 vom 10. August 1991

931. Real Decreto $1665 / 1991$ de 25 de actobre, por el que es regula el sistema general de renoncimiento de los titalos de Enseñanza Superior de los Estados membros de la Communidad Econónica Europea que exigen una formación minima de tres años de duración, BOE Nr. 280 vom 22 . November 1991. 37916.

932. Die gesetzliche Umsetzung für die rechtsberatenden Benfe, d.h. Rechtsanwalt, Patentanwalt, Steuerberater und Wirtschaftspunfer erfolgte fristgemäß zum 1. Januar 1991 . Diese Berufe fallen unter den gesetzgeberischen Regelungsbereich des Bundes. Die ergakinenden Verordnungen folgtten teil weise mit wenn auch geringer Verspätung. Dagegen erfolgten die Unsetzungsmaßnahmen für Ingenieure und Lehreư in einigen Bundesländern mit ertheblicheir Verspătung. 
gemacht haben. Der Weg der sektoriellen Umsetzung wurde auch von Frankreich ${ }^{\text {ss }}$ und Luxemburg ${ }^{934}$ mit der Konsequenz beschritten, daß die Umsetzung der Richtlinie nicht termingerecht abgeschlossen wurde. Inzwischen sind in Frankreich und Luxemburg - soweit ersichtlich - sämtliche notwendigen Ausführungsmaßnahmen ergangen. Luxemburg hat dabei quasi zum Abschluß der sektoriellen Umsetzung diese durch ein allgemeines Umsetzungsgesetz ergänzt ${ }^{935}$.

Die Niederlande, Belgien und Griechenland waren lange Zeit die absoluten Schlußlichter Im UmsetzungsprozeB. Gegen sie wurden von der Kommission auch Verfahren gemäß Art. 169 EGV eingeleitet. Obwohl in den Niederlanden ein Entwurf zu einem allgemeinen Umsetzungsgesetz bereits frühzeitig als Ministerialentwurf vorlag, erfolgte der Abschluß des notwendigen Gesetzesverfahrens erst zu Beginn des Jahres 1994. Inzwischen gibt es in den Niederlanden jedoch ein allgemeines Umsetzungsgesetz ${ }^{936}$. Dieses gilt grundsätzlich für alle von der Richtlinie betroffenen Berufe. Eine Ausnahme wurde lediglich für die Patentanwälte ${ }^{937}$ und für die Wirtschaftsprüfer gemacht, für die jeweils eine spezielle sektorielle Regelung getroffen worden ist ${ }^{938}$. Für die Lehrer gibt es eine ministerielle Vorschrift vom 9. Februar 1992, die bis zum Inkrafttreten des allgemeinen Umsetzungsgesetzes direkt angewandt wurde ${ }^{939}$. Mit Inkrafttreten des Allgemeinen Gesetzes gilt diese Regelung als Ausführungsmaßnahme. Auch haben die Niederlande schließlich die für die Rechtsanwälte zuständige Behörde angewiesen ${ }^{940}$. Dieser Beschluß wurde durch weitere Ausführungsmaßnahmen für Rechtsanwälte ergänzt $^{\text {94! }}$.

933. Dazu Seite 215.

934. Diese sektoriellen Umsetzungen bezogen sich auf Benfe des Gesundheitsbereichs, Lehrer und rechtsbereatende Berufe. Für die Rechtsanwälte erfolgte die Umsetzung durch Gesetz wom 10. August 1991, Amtsblatt des Großherzogtums Luxemburg. Recueil de legisation wom 27. August 1991 "A * No 58" 1119.

935. Loi du 13 août 1992 portant a) transposition de la directive du Conseil (89/48/CEE) relative à un système général de reconnaisance des diplômes $d$ "enseignement supérieur qui sanctionnent des formations professionelles d une durée minimale des trois ans; b) créations d'un serwice de corordination pour la reconnaisance de diplổmes à des füns professionnelles, Mémorial Nr. 67 vom 11. September 1992.

936. Wer van 15 december 1993 , houdende regelen betreffende een algemeen stellsel von erkenning van in de Lid-Staten van de Europese Gemeenschappen behaalde hoger-onderwijsdiploma's waarmee beroepsopleidingen van ten minste drie jaren worden afgesloten (Algememe wet erkenning EG-hogeronderwijsdiploma's), Dieses Gesetz trat am 19. Januar 1994 in Kraft. Staatsblad 1994, 29.

937. Octrooigemachtigden

938. Patentanwalte: Besluit vom 8. Juli 1991 tot wijziging van het Octrooigemachtigden-reglement (Stb. 1968, 595), Staatsblad 1991, 409; Wirtschaftsprüffer: Gesetz vom 6. August 1994, Stb. 1994, 465.

939. Ministerie van Onderwijs en Wetenschappen: Regeling onderwijsbevoegdheid EGi-onderdanen vom 9 Febnar 1992.

940. Besluit wom 15. Juni 1994, Stb 1994, 457. Angewiesene Behörde ist der "Algemene Raad van de Nederlandse orde van advocaten".

941. Regeling EG-verklaring advocaten vom 31. Oktober 1994/Nr. 464984/94/6, Staatscourant vom 8. November 1994 sowie die Verordening op de proeve van bekwaamheid vom 25 . November 1994 und das dazu festgestellte Reglement vom 7. Dezember 1994. 
Auch in Belgien wurde ein Entwurf zu einem generellen Umsetzungsgesetz vorbereitet, der jedoch auf Grund der Regierungskrise im Herbst 1991 und den dadurch notwendig gewordenen Neuwahlen vom belgischen Parlament nicht verabschiedet worden ist. Aufgrund der verfassungsrechtlichen Veränderungen in Belgien erschien zunächst die Verabschiedung eines allgemeinen Umsetzungsgesetzes unwahrscheinlich. Die verteilte Gesetzgebungsbefugnis zwischen den einzelnen Gebietsteilen läßt für eïnige Berufe mur noch eine sektorielle Lösung $\mathrm{zu}^{942}$. Die ersten sektoriellen Umsetzungsmaßnahmen sind auch getroffen worden ${ }^{943}$. Im März 1993 wurde erneut ein allgemeiner Entwurf zur Verabschiedung beim belgischen Parlament eingereicht ${ }^{944}$, worin durch königlichen Beschluß die notwendige Regelungsbefugnis an die Regierung übertragen werden soll. Diesem Entwurf war ein glücklicheres Schicksal beschieden als seinem Vorgänger. Er wurde schließlich im April 1994 verabschiedet ${ }^{945}$. Inzwischen wurde auch für den Beruf des Vermessungsingenieurs eine Regelung getroffen ${ }^{\text {\$46 }}$. De Gerichtshof hat Bellgien aufgrund der fehlenden Umsetzungsmaßnahmen am 13. Juli 1995 verurteilt ${ }^{\text {9A7 }}$

Griechenland hat sich grundsätzlich für die sektorielle Umsetzungsmethode entschieden. Die griechischen Umsetzungsmaßnahmen ließen jedoch sehr lange auf sich warten. Inzwischen liegen jedoch die ersten sektoriellen Regelungen vor ${ }^{948}$. Dennoch wurde im Juli 1993 ein Verfahren gemäß Art. 169 EGV von der Kommission gegen Griechenland eingeleitet. Dies hat auch zul einer Verurteilung Griechenlands wegen unzureichender Umsetzung der Richtlinie $89 / 48 /$ EWG geführt $^{949}$. In der Entscheidung wurde einerseits das Fehlen von Umsetzungsmaßnahmen bezüglich von der Richtlinie betroffenen Berufe andererseits die Tatsache gerügt, daß Griechenland bisher nicht die zuständigen Behörden i. S. des Art. 9 der Richtlinie 89/48/EWG angewiesen hat, die auf nationaler Ebene mit der Ausführung der Anerkennungsentscheidungen betraut werden sollen.

942. Dies gilt vor alliem für den Lehrerberuf.

943. Umsetzungsmalinahmen für Lehrer:

Ausführungsmaßnahmen der flämischen, Gemeinschaft: Decret vom 12. Juni 1991, Moniteur Belge vom 4. Juli 1991 sowie der Ausführungsbeschlui bezughlich der Anpassungsinstrumente vom 30. September 1992, Moniteur Belge wom 22. Oktober 1992.

AusführungsmalBahahmen der wallonischen Gemeinschaft: Décret vom 27. März 1991, Moniteur Belge vom 25. Mai 1991; Décret vom 26. Jun 1992, Moniteur Belge vom 10. September 1992.

Diese Maßnahmen können jedoch nicht als vollstïndig angesehen werden.

944. Ontwerp wan wet tot uitwoering van de in toepassing van thet verdrag van de Europese Econonische Gemeenschap uitgevaardigde verordeningen, richtlijnen en beschikkingen inzake diploma's, getuig schriften en andere titels vereist voor het uitoefenen van een beroep of een beroepsactiviteit vom 29. Marz 1991, (695-1 (1992-1993)).

945. Loi de délegation générale vom 29. April 1994, Moniteur Belge vom 29. Juli 1994.

946. AR protégeant le titre professionel et l'exercice de la profession vom 18. Januar 1995, Moniteur BeIge vom 7. Mảrz 1.995.

947. Urteil vom 13. Juli 1995, Rs C-216/94 (noch nicht veröffentlicht).

948. So sind inzwischen Umsetzungsregelungen für die Anerkennung der Rechtsanwälte und für paramedizinische Berufe veroffentlicht worden. Ministerieller Beschluh A4/4112/92 vom 31. Juli 1992 "JO Nr 502 vom 5. August 1992 für die paramediziniscliken Berufe und das präsidentielle Decret $\mathrm{Nr} .52 / 93$ vom 28. Januar 1993, JO Nr. 20 vom 18. Februar 1993 für die Rechtsanwälte.

949. Urteil vom 23. März 1995, Rs C-365/93 - Kommission/Griechenland - (noch nicht veröffenticht) 
Im Gegensatz zu einigen der alten Mitgliedstaaten erwiesen sich die drei neuen Mitgliedstaaten Finnland ${ }^{950}$, Österreich ${ }^{951}$ und Schweden ${ }^{952}$ erheblich umsetzungsfreudiger. Thre Umsetzungsgesetzgebung erfolgte weitgehend termingerecht noch vor Inkrafttreten des Abkommens zum Europäischen Wirtschaftsraum am $\mathbb{1}$. Januar 1994. Auch die anderen EWR-Staaten, Norwegen ${ }^{953}$ und Island ${ }^{954}$ haben sich an ihre Umsetzungspflicht gehalten.

\section{B. DIE UMSETZUNG DURCH SEKTORIELLE GESETZLICHE REGELUNGEN}

Die sektorielle Umsetzungsmethode wurde von der Bundesrepublik Deutschland, von Frankreich, Luxemburg und Griechenland gewählt. Luxemburg hat neben den sektoriellen Regelungen auch noch ein allgemeines Umsetzungsgesetz verabschiedet, so daß von einer Mischung der beiden Umsetzungsmethoden gesprochen werden kann, wobei jedoch im Falle von Luxemburg der Schwerpunkt auf der sektoriellen Umsetzung liegt. Auch im Falle Belgiens und der Niederlande kann man von einer Mischform sprechen. Grundsätzlich haben sich diese beiden Staaten jedoch für eine Umsetzung durch ein allgemeines Gesetz ausgesprochen.

Bei den neuen Mitgliedstaaten haben sich Österreich und Schweden für die sektorielle Umsetzungsmethode entschieden. Auch Norwegen führt die Umsetzung durch sektorielle gesetzliche Anpassungen aus.

\section{Die Umsetzung der Richtlinie 89/48/EWG in der Bundesrepubik Deutschland}

Die Bundesrepublik Deutschland setzte die Richtlinie durch verschiedene sektorielle Gesetze um, d.h. die Umsetzung erfolgte für jeden reglementierten Beruf durch ein gesondertes Gesetzgebungsverfahren. Mit dieser berufsbezogenen Umsetzung hatte die Bundesrepublik einen anderen Weg als z.B. Dänemark, Irland oder Großbritannien

950. Allgemeines Umsetzungsgesetz: Lag nr. 1597 vom 30. Dezember 1992; Ausführungsregelung: Assetus, Nr. 1622 aus 1993 sowie ein weiteres Unsetzungsgesetz: Laki vom 28. Juni 1994.

951. Umsetzung bezïglich gesundheits-technischer Bernfe: Allgemeines Gesetz vom 31. Juli 1992, das am 1. September 1992 in Kraft getreten ist. Psyiotherapeut: Psychotherapiegesetz vom 7 . Juni 1990 ; Psychologe: Psychologengesetz vom 7. June 1990" Rechtsanwälte: EWR-Rechtsanwaltsgesetz; Wirtschaftsprif fer und Steuerberater: Änderung vom 4. Dezember 1992 des Wirtschafts- und Steuerberatergesetzes won 1955; Ingenieure: Ziviltechnikergesetz 1993 \$ 32, 7f, vom 4 März 1994; Beamte: EWRDienstrechtsanpassungsgesetz vorn 20. Mai 1994; Förster: Änderung wom 30. Dezember 1993 des Förstergesetzes von 1975.

952. Rechtsanwailte: Gesetz/Lag vom 17. Dezember 1992, SFS 1992:1511; Paramedizinische Berufe: Gesetz/Lag SFS 1992: 1562; Verondnung/Förordning 1993:1662; Physotherapeuten: Gesetz/Lag 1993:1652; Hochschulenverondinung/Högskoleförordening 1993:100; Wirtschaftspnüfer: Förordenüng SFS 1992:1222; Kirchliche Berufe: Lag 1993:793; Förordening 1992:997 sowie Ausfühnungsma: nahmen SKFS 1991:15; SKFS 1992: 12; SKFS 1993:7.

953. Norwegen führte verschiedlene einzelne Anpassungen hinsichtlich paramedizinischer Berufe aus. Auch anderte es die Zulassung zum Beruf des Rechtsanwalts.

954. Lög nr. 83/1993 (Act on Recognition of Education and Certificates, 18 May 1993); Reglugerd nr. 244 (Regulation for the Medical Professions falling under Directive 89/48/EEC, 25 March 1994). 
gewählt, wo die Richtlinie durch ein allgemein für alle Berufe geltendes Gesetz umgesetzt worden war. Die berufsspezifische Umsetzung hat den Vorteil der Deutlichkeit für die einzelnen Berufsgruppen, sie bewirkte jedoch zugleich, daß die Gesamtumsetzung der Richtlinie auf sich warten ließ und auch bei weiten nicht vollständig bis zum gesetzten Termin abgeschlossen war ${ }^{955}$. Für die Bundesrepublik Deutschland lag eine sektorielle Umsetzung jedoch wegen der föderalen Struktur und der damit verbundenen zwischen Bund und Ländern verteilten Gesetzgebungskompetenz vor der Hand, da die Umsetzung für einige Berufe durch Bundesgesetzgebung, für andere jedoch durch Landesgesetzgebung zu erfolgen hatte ${ }^{956}$.

Nachteil einer sektoriellen Umsetzung ist die Undeutlichkeit und Unsicherheit, ob tatsächlich alle von der Richtlinie erfaßten reglementierten Berufe, auch tatsächlich bei den Umsetzungsverfahren berücksichtigt und davon erfaßt sind. Dies gilt umsomehr in einem föderalen System mit einer verteilten Gesetzgebungskompetenz. Auch hat die Bundesrepublik keine offizielle Liste veröffentlicht, die eine einfache Überprüfung ermöglichen könnte. Eine an die EG-Kommission gerichtete inoffizielle Liste ${ }^{957}$ ist weder deutlich noch in allen Punkten korrekt, zumal einige hierauf erwähnten Berufe in der Bundesrepublik nicht von der Richtlinie 89/48/EWG erfaßt werden, sondern zu dem Regelungsbereich der zweiten Anerkennungsrichtlinie zu rechnen sind ${ }^{95 \$}$.

Auch hat die Bundesrepublik deutlich reglementierte Berufe, die jedoch nach ihrer Auffassung die Ausnahmetatbestände des Art. 55 EGV $^{959}$ oder des Art. 48 Abs. 4 EGV ${ }^{960}$ erfüllen, automatisch von der Umsetzung ausgeschlossen, obwohl die Bedingung der Staatsangehörigkeit unabhängig von der Frage des erforderlichen Diploms beurteilt werden kann. Es fehlt bisher auch eine Umsetzung der maritimen Berufe, so z.B. des Kapitäns der Handelsmarine, obwohl auch hier sich die Frage stellt, inwieweit bei diesem Beruf Art. 55 EGV zur Anwendung kommt.

Im Zuständigkeitsbereich des Bundes stand die Umsetzung für die rechtsberatenden Berufe im Vordergrund, während etwa die Lehrer, Ingenieure Innenarchitekten, Garten- und Landschaftsarchitekten sowie die Städteplaner unter die Landesgesetzgebung fielen. Diese Kompetenzverteilung wird durch das Grundgesetz bestimmt. Nach Art. 30 GG ist die Ausübung der staatlichen Befugnisse und đie Erfüllung der staatlichen Aufgaben Sache der Länder, soweit das Grundgesetz keine andere Regelung trifft oder zuläBt. Nach Art. 70 Abs. 1 GG haben die Länder das Recht der Geseizgebung, soweit das Grundgesetz nicht dem Bund Gesetzgebungsbefugnisse verleiht. Hiernach gehört das Recht der Gesetzgebung hinsichtlich der genannten Berufe in die alleinige Zuständigkeit

955. Der UmsetzungsprozeB hat sich vor allem auf Länderebene erheblich verzögert. Auch vier Jahre nacth dem gesetzten Datum kann noch nicht von einer vollständigen Umsetzung gesprochen werden.

9156. Winkel, Der freie Beruf 8, 1991, 22

957. Mitteilung der Regierung der Bundesrepublik Dentschland an die Kommission der Europäischen Gemeinscliaften vom 7. Juli 1989 .

958. Z.B. der Optiker, Sprachheälpädagoge und der Radiologe.

959. So z.B. den Notar.

960. Z.B. Richter, Staatsanwalt und Rechtspfleger 
Der horizontale Ansatz

der Länder ${ }^{\text {} * i . ~ A u c h ~ d i e ~ B e s t i m m u n g ~ d e r ~ Z u g a n g s v o r a u s s e t z u n g e n ~ f u ̈ r ~ d e n ~ B e r u f ~ d e s ~}$ Lehrers betrifft die Länderhoheit. Die Umsetzung auf Bundesebene für die rechtsberatenden Berufe erfolgte termingerecht. Die Koordinierung der Umsetzung auf Länderebene verursachte dagegen Verzögenungen.

Die Bundesländer haben sich bei der Anpassung der Landesgesetze zum Schutz der Berufsbezeichnung "Ingenieur" weitgehend auf einen Musterentwurf geeinigt. Lediglich Niedersachsen hat einen eigenen Weg beschritten. Wichtig war dabei das Einvernehmen der Länder, auf eine Eignungsprüfung oder einen Anpassungslehrgang zu verzichten. Trotz dieser grundsätzlichen Übereinstimmung hat der Umsetzungsproze $\beta$ in den einzelnen Bundesländem sich über eine erhebliche Zeitspanne gestreckt ${ }^{962}$.

Bei denjenigen Architektenberufen, die nicht unter die Architektenrichtlinie fallen ${ }^{963}$, bestand ebenfalls ein Umsetzungsbedarf, der eine Anpassung der Landesarchitektengesetze erforderlich machte. Hier sollten die Bundesländer vergleichbar wie im Falle der Ingenieure verfahren. Da die meisten Bundesländer noch mit der Umsetzung der Architektentichtlinie im Verzug waren ${ }^{964}$, gestaltete sich die Umsetzung für die von der Richtlinie 89/48/EWG erfaßten Architektenberufe als sehr schwierig. Mit Ausnahme von Baden-Württemberg ${ }^{965}$, Bayern ${ }^{966}{ }^{\text {, Berlin }}{ }^{967}$, Hessen ${ }^{968}$, Niedersachsen $^{969}$, Nordrhein-Westfalen ${ }^{970}$, Rheinland-Pfalz ${ }^{971}$ und Sachsen ${ }^{972}$ hat bisher

961. Siehe daza die Entscheidung des Bundesverfassungsgerichts vom 25. Jumi 1969, womit das Bundesgesetz zum Schutze der Benfsbezeichnung "Ingenieur" vom 7. Julli 1965 in der Fassung vom 19. Juni 1969 für nichtig erklärt worden ist. In der Entscheidung heißt es: "Der Schutz der Benufsbezeichnung "Ingenieur" muß, soweit er notwendig ist, keineswegs durch Bundesgesetz erfolgen. Eine einheitliche Regelung durch inhaltlich übereinstimmende Ländergesetze ist durchaus denkbar und praktikabel." BVerfGE 26, 246, (257).

962. Siehe im eimzelnen dazu die Fallstudie: Ingenieure.

963. Z.B. Garten- und Landschaftsarchitekten, Innenarchitekten.

964. Soweit Unsetzungsmaßnahmen inzwischen vorliegen, sind diese mehrheirlich erst nach 1991 erlassen. worden

965. Gesetz zur Änderung des Architektengesetzes vom 20. Juni 1994, Gesetzblatt. BW Nr. 14 vom 14. Juli 1994.

966. Gesetz zur Änderung des Bayerischen Architektengesetzes, wom 10. August 1990, Bayerisches Gesetz: und Verondnungsblatt $\mathrm{Nr} .15 / 1990$ sowie die Bekanntmachung der Neufassung des Bayerischen Architek tengesetzes vom 31. August 1994, GVB Nr. 23.

967. Berliner Architekten- und Bawkammergesetz (ABKG) vom 19. Juli 1994, GVB Nr, 40 vomi 29. Juli 1994.

968. Hessisches Architektengesetz i.d. Fassung vom 4. Oktober 1977 zulletzt geändert durch Gesetz vom 25. Septeriber 1991, GVBI. I, 301.

969. Neufassung des Niedersächsischen Architektengesetzes vom 17. Juli 1990, GVB Nr. 30 vom 27. Juli 1990.

970. Gesetz über den Schutz der Berufsbezeichnungen "Archütekt", "Archtitektin", "Stadtplaner" und Stadtplanerin" sowie über die Architektenkammer, über den Schutz der Berufsbezeic hrung "Beratendier Ingenieur" und "Beratende Ingenieurin" sowie äber die Ingenieurkammmer-Bau-Baukammemgesetz ((BawKaG NW) - vom 15. Dezember 1992, Gesetz- und Verordnungsblatt für das Land NondrheinWestfallen vom 30, Dezember 1992,534 ff. Diese Umsetzung gilt auch für Innen- und Landschaftsarchitekten. 
kein Bundesland entsprechende Schritte unternommen. Damit ist der Umsetzungsprozeß in den Bundesländern für diese Berufsgruppe bisher nur zur Hälfte abgeschlossen. Die bayerische Umsetzung ist insoweit bedenklich, als sie lediglich nach der Architektenrichtlinie verweist, dabei auch die von der Richtlinie 89/48/EWG erfaßten Architektenberufe, so etwa den Innenarchitekt, entsprechend regelt.

Bei den Lehrerberufen hat die Richtlinie 89/48/EWG zunächst im nationalen Bereich einen politischen Anstoß gegeben, um die Anerkennung der teilweise recht unterschiedlichen Lehramtsausbildungen zwischen den Bundesländern zu verbessern ${ }^{973}$, da bisher ein freier Personenverkehr zwischen den einzelnen Bundesländern für Lehrer quasi unmöglich war. Auf der Grundlage dieser Regelung vereinbarten die Länder einen Musterentwurf zur Umsetzung der Hochschuldiplom-Richtlinie ${ }^{974}$, worin die Grundsätze für das Antragsverfahren sowie für die Gestaltung des Anpassungslehrgangs und der Eignungsprüfung niedergelegt sind.

Auf Bundesebene wiederum war eine Anpassung des Beamtenrechtsrahmengesetzes erforderlich, wodurch auch Staatsangehörigen aus anderen Mitgliedstaaten der Zugang zu den Ämtern des öffentllichen Dienstes und zum Berufsbeamtentum ermöglicht werden sollte. Verschiedene Berufe sind in der Bundesrepublik lediglich dann reglementiert, wenn sie im öffentlichen Dienst ausgeübt werden. Es handelt sich dabei um eine Reglementierung, die im deutschen Laufbahnrecht festgelegt ist. Trotzdem war diese Änderung des Beamtenrechtsrahmengesetzes nur teilweise durch die Richtlinie 89/48/EWG inspiriert, nämlich insoweit die Laufbahnvorschriften angepaßt werden mußten, zum wesentlichen Teil war dieses Gesetzesvorhaben jedoch eine Reaktion auf das Drängen der EG-Kommission ${ }^{975}$, die Zugangsbestimmungen zum öffentlichen Dienst an die Rechtsprechung des EuGH anzupassen ${ }^{976}$. Der erste Änderungsentwurf scheirerte im Vorverfahren am Bundesrat. 1992 wurde ein neuer Entwurf eines 10. Gesetzes zur Änderung dienstrechtlicher Vorschriften in das Gesetzgebungsverfahren eingebracht ${ }^{97 \%}$. Sein Schicksal war lange Zeit ungewiß, da hierzu im InnenausschuB des Bundestages im April 1993 eine Sachverständigenanhörung stattfand, so daß mit der endgültigen Verabschiedung erst zu einem wesentlich späteren Zeitpunkt gerechnet

971. $\rightarrow$

971. Landesgesetz zur Anderung des. A rchitektengesetzes Rheinland-Pfalz wom 30. März 1993, Gesetz-und Verordnungsblatt Rheinland-Pfalz wom 13. April 1993, 160ff..

972. Sächsisches Architektengesetz vom 19. April 1994, GVBl. Ni. 23 vom 6. Mai 1994, 1, 765.

973. Beschluli der KMK wom 5. Oktober 1990: Gegenseitige Anerkennung won Lehramtsprufungen und Lehramtsbefăhigungen. KMK Erg. Lieferung 68, Mai 1991, Sammlung Luchterhamd, Personal im Schulwesen (Lelurer), 715.

974. Richtlinie des Rates der Europäischen Gemeinschaften vom 21. Dezember 1988 über eine allgemeine Regelung zur Anerkennung der Hochschuldiplome, die eine mindestens dreijăhrige Benufsausbildung abschließen - Umsetzung in innerstaatliches Recht für die Berufe des Lehrers, Beschalub der KMK vom 14. September 1990, KMK Erg. Liefenung 69, September 1991, Sammlung Luchterhand, Personal im Schulwesen (Lehrer), 718.

975. Siehe dazu die systematische Aktion der Kommission zur Liberalisierung des öffentlichen Dienstes, AB1. Nir. C 72 vom 18. März 1988, 2.

976. Dazu Seite $370 \mathrm{ff}$.

977. Gesetzesentwurf der Bundesregierung, BR-Drucksache 555/92 vom 14. August 1992. 
werden mußte. Gegen diese Erwartungen konnte das Gesetzgebungsverfahren doch noch innerhalb des Jahres 1993 abgeschlossen werden. Mit dem Zehnten Gesetz zur Änderung dienstrechtlicher Vorschriften vom 20. Dezember 1993 wurde schließlich nach einem schwierigen und stark umstrittenen Gesetzgebungsverfahren der öffentliche Dienst im Beamtenverhältnis für Staatsangehörige der anderen Mitgliedstaaten geöffnet ${ }^{978}$. Diese Öffnung des öffentlichen Dienstes auf Bundesebene wurde bisher von neun Bundesländern in ihrem Bereich ergänzt ${ }^{979}$.

Durch die langwierige Gesetzesanpassung auf Bundesebene verzögerte sich für einige Berufe die Umsetzung nicht unerheblich ${ }^{989}$. Auch sahen sich einige Bundesländer nicht in der Lage, ohne beamtenrechtliche Grundlage auf Bundesebene eine Umsetzung für die Lehrer vorzunehmen ${ }^{981}$. Bei einigen Bundesländern beruhte die Verzögerung angeblich zusätzlich auf einem Regierungswechsel bzw. -umbildung ${ }^{982}$. Bei den neuen Bundesländern muBten für verschiedene Bereiche, erst die erforderlichen landesspezifischen Rechtsgrundlagen geschaffen werden. Dies gilt z.B. für die Ingenieure und Lehrer durch die Notwendigkeit einer Verabschiedung der Ingenieursgesetze und der entsprechenden Gesetze für Schul- und Lehrerbildungsangelegenheiten durch die Länderparlamente. Diesen Gesetzesorganen war der Vorrang einer gemeinschaftsrechtlichen Umsetzungsverpflichtung nicht in aller hinsicht deutlich. Inzwischen wurde die Richtlinie in zwölf der sechzehn Bundesländer für den Lehrerberuf im wesentlichen umgesetzt " dabei fehlen in einigen Bundesländern noch die notwendigen Ausführungsbestimmungen ${ }^{983}$. Bei den vier säumigen Bundesländern handelt es sich um Baden-Württemberg, Brandenburg, Mecklenburg-Vorpommern und Sachsen-Anhalt.

Paramedizinische Berufe, die in mehreren Mitgliedstaaten unter den Anwendungsbereich der Richtlinie fallen, sind in Deutschland davon nicht erfaßt, weil die betroffenen Ausbildungen nicht an Ausbildungseinrichtungen mit gleichwertigem Niveau wie Univer-

978. BGBI. I. 2136.

979. Bayern: GVB Nr. 18/1994 1, 613; Bremen: Gesetz zur Änderung dienstrechticher Vorschriften wom 1. März 1994, GVB Nr. 12 vom 16. Marz 1994; Hamburg: Drittes Gesetz zur Änderung dienstrechtlicher Vorschriften: Hessen: Sechstes Gesetz zur Andenung dienstrechtlicher Vorschriften vam 21. Dezember 1994, GVB, Teil I vam 28. Dezember 1994; Nordrhein-Westfahlen: Siebtes Gesetz zur Anderung dienstrechthicher Vorschriften; $R$ heinland-Pfalz, Art. 27 a des Landesbeamtengesetzes; Zwe ites Gesetz zur Ändenung dienstrechticher Vorschriften vom 21. Dezember 1993: Saarland: Gesetz zur Anderung dienstrechticher Vorschriften; Sachsen: Bekanntmachung der Neufassung des Beamtengesetzes voni 16. Juni 1994, GVB Nr. 39/1994 vom 14. Juni 1994; Thüringen: Beamtengesetz vom 10. Juni 1994, GVB Nr. 20 vom 17. Jurii 1994, Teill 1, 593

980. So etwa fur den Archivar, den Bobliothekar und den Museumskonservator, Berufe die lediglich reglementiert sind, wenn sie im offentlichen Dienst ausgeäbt werden.

981. In einzelnen Landern, ż., B. in Niedersachsen, wurden zum Teil bereits eingeleitete Umsetzungsworha ben der Kultusministerien zurückgestellt, da von Seiten der jeweiligen Staatzkanzleien bzw. Innenministerien geltend gemacht wurda, dal die Umsetzung der Hochschulrichtlinie erst nach einer Ändenung des Beamtenrechtsratumengesetzes und den entsprechenden Ändenungen der Landesbeamtengesetze erfolgen könne.

982. Dieser Grund wurde zumindest zumichst in Baden-Württemberg genannt. Eine Umsetzungsverzögenung von über vier Jahtren läßst sich jedoch mit Sicherheit nicht durch Neuwahlen rechtfertigen!

983. Siehe dazu die Erörtenungen in der Fallsudie: Lehrer, Seite $379 \mathrm{ff}$. 
sitäten bzw. Hochschulen stattfinden oder aber der Ausbildungszeitraum nichi die geforderten drei Jahre dauert. Diese Berufe werden nun zum gröften Teil durch Anhang C der zweiten allgemeinen Richtlinie 92/51/EWG in den Genuß des Durchstiegs kommen ${ }^{984}$. Eine Ausnahme hiervon bildet der Diplompsychologe. Dieser fällt nach der deutschen Reglementierung in den Bereich des ersten allgemeinen Systems. Als klinischer Psychologe kann er im Staatsdienst angestellt sein, als Freiberufler findet eine Form der Reglementierung durch die Zulassung zur Abrechnung über die Krankenkassen statt. Da die Krankenkassen unter die staatliche Aufsicht des Bundeswirtschaftsministerium fallen, wurde die Umsetzung durch das Ministerium in Form von Richtlimien an die Krankenkassen vorgenommen ${ }^{925}$.

\section{Die Umsetzung der Richtlinie 89/48/EWG in Frankreich}

Wie die Bundesrepublik hat auch Frankreich den sektoriellen Umsetzungsweg gewählt. Eine verfassungsrechthiche Notwendigkeit bestand hierfür nicht, doch entspricht die sektorielle Gesetzgebung mehr der französischen Rechtstradition. Im Gegensatz zur Bundesrepublik nahmen gerade die paramedizinischen Berufe einen Schwerpunkt bei den erforderlichen Umsetzungsmaßnahmen ein. Für elf paramedizinische Berufe ergingen teils identische, teils nahezu wörtlich übereinstimmende Umsetzungsregeln ${ }^{986}$. Ein weiterer Schwerpunkt der französischen Umsetzung betraf die von Frankreich als "rechtsberatend" eingestuften Berufe ${ }^{987}$. Es handelt sich dabei um neun Berufe, für die Umsetzungsmaßnahmen getroffen sind ${ }^{988}$. Neben diesen beiden Hauptblöcken, den rechtsberatenden und paramedizinischen Berufen, betrafen weitere Umsetzungen den

984. Siehe dazu Seite $252 \mathrm{ff}$.

985. Ob diese Maßnahme als ausreichende Unsetzung gewertet werden kann muß die Praxis weisen.

986. Es thandelt sich um die folgenden Benfe: Optiecien-lunetier, Pédicure-podologue, Reéducation psychomotrice. Trournisseurs de chaussures orthopediques et de fourniures de gros appareillage de prothèse et d"orthèse, "Technicien dans un laboratoire de biologie médicale, Electrotadiologie médicale, Orthoptistè, Masseur-kinésithérapeute, Orthophoniste, Audioprothésiste

987. Ob diese Einstufung in allen Fällen berechtigt ist, kann bestritten werden.

988. Für den Avocals au Conseil d'Eutat et à la Cour de Cassation durch Décret no $91-1125$ vom 28. Oktober 1991, JO vom 30. Oktaber 1991 und durch Arrëté vom 22. November 1991, JO vom 14. Dezember 1991

Für den Avocat durch Loi No 90-1259 wom 31. Dezember 1990. JO vorn 5. Januar 1991 und Décret no 91-1197 yom 27. Nowember 1991, JO 28. November 1991.

Für den Administrateur er mandatair judiciair a la liquidation des entreprises Loi No $90-1259$ vom 31. Dezember 1990, JO vom 5 . Jamuar 1991 und durch Décret No $91 \% 1030$ vom 8. Oktober 1991. JO vom 9. Okttober 1991 .

Für den A voué durch Décret No 90-1210 vom 21. Dezember 1990, JO vom 31 Dezember 1990 worin de Zugangsbedingungen für bestimmte öffentliche Ämter festgelegt wurden. Das entsprechende Décret No 90-1210 vom 21. Dezember 1990 gilt auch für den Commissaires-priseur, für den Huissier de Justice, für den Greffier de Tribunaux de Commerce und für den Notair. Für diese Berufe gilt auch der arrêté vom 31. Dezember 1990, Jo yom 9. Januar 1991, für den Agent en brevet durch Décret No 92-360 vom 1. April 1992, J0 vom 3. April 1992. Siehe dazu Pertek J.CI. Europe, Fasc. 731. 
Sozialarbeiter (Assistant de service social) ${ }^{989}$ und die Lehrer ${ }^{990}$. Die Umsetzung hinsichtlich der Lehrer ist wegen des Concours sehr umstritten ${ }^{991}$. Auch fehlten lange Zeit die für die Beschäftigung im öffentlichen Dienst notwendigen Durchführungsbestimmungen zum Staatsangehörigkeitsvorbehalt, obwohl die korrespondierende gesetzliche Regelung bereits am 26. Juli 1991 ergangen ist ${ }^{922}$. Inzwischen sind jedoch verschiedene Ausführungsmaßnahmen hierzu erlassen ${ }^{993}$. Ingenieure, die in Deutschland unter den Anwendungsbereich der Richtlinie fallen, sind in Frankreich nicht reglementiert ${ }^{924}$. Eine Umsetzung der Richtlinie für die Ingenieure war daher nicht erforderlich.

\section{Die Umsetzung der Richtlinie 89/48/EWG in Griechenland}

Die Umsetzung in Griechenland hat bisher nur das Anfangsstadium erreicht. Es liegt eine präsidentielle Verordnung für Rechtsanwälte ${ }^{9 s 5}$ sowie eine Verordnung hinsichtlich der Anerkennung von Berufen des Gesundheitswesens ${ }^{996}$ vor.

\section{Die Umsetzung der Richtlinie 89/48/EWG in Luxemburg}

\section{a. Die Umsetzungsregelungen}

Grundsätzlich wurde in Luxemburg die sektorielle Umsetzungsmethode für die einzelnen Berufsgruppen gewählt. Dazu wurden für einige Berufe Umsetzungsmaßnahmen verabschiedet. So liegen bisher schulstufenbezogene Spezialregelungen für Lehrer ${ }^{997}$

989. Umsetzung erfolgte durch Loi No 91.73 vom 18. Januar 1991, JO wom 20. Janwar 1991, décret No 91-795 vom 16. August 1991, JO vom 22. Augusi 1991 und arrêtés vom 21. Oktober 1991, Jo vom 6. Dezember 1991.

990. Arrêtés vom 2. Januar 1991. JO vom 8. Januar 1991.

991. Siehe dazu Seite 376

992. Loi sur l'ouverture de la fonction publique vom 26. Juli 1991.

993. Für die Beschäftigung im offentlichen Dienst: Décret nr. 94-741 vom 30. August 1994, Jo vom 1. Septemer 1994. Décret nr. 94-743 vom 30. August 1994, JO vom 1. September 1994.

Für die Beschäftigung an Krankenhäusern: Décret nr. 93-101 vom 19. Januar 1993, JO vom 28. Januar 1993 und Décret nr. 93-659 vom 25. Mărz 1993, JO vom 26. März. 1993. Décret nr. 94-616 vom 21. Juli 1994, JO vom 23. Juli 1994.

Für die Beschäftigung üm Unterrichtswesen: Décret nr. 92-1246 wom 30. Nowember 1992, JO vom 2. Dezember 1992. Décret nr. 93-6) vom 13. Januar 1993, JO vom 19. Januar 1993. Décret nr. 94-163 vom 16. Februar 1994, JO vom 25. Februar 1994

994. Pertek, Savoir 1992, 96 (108); Siehe dazu die Ausführungen Seite $351 \mathrm{f}$.

995. Décret présidentiel no. 52 vom 15. Februar 1993, Jo vom 18. Februar 1993.

996. Décret no 4112 vorn 31. Juli 1992, JO vorm 5. August 1992 (Der Titel in französicher Übersetzung lautet: "Reconnaissance dles titres professionnels pour l'exercice de professions de santé et de prvoyance conformement à la directive 89/48/CEE du Conseil des Communautes Européennes").

997. Primärschulbereich-Instituteur: Loi du 18 avril 1992; Règlement grand-ducal du 22 juin 1992 concernant les modlalités de l'épreưve d"aptitude et du stage d'adaptation préwus pour les candidats déterneurs d'un diplônes êtranger d'instituteur pour être admis à la fonction d'instizuteur. 
sowie Umsetzungsmaßnahmen für den Rechtsanwalt ${ }^{998}$, verschiedene Berufe des Gesundheitswesens ${ }^{999}$ und für den Wirtschaftsprüfer ${ }^{1000}$ vor. Diese Umsetzungsmaßnahmen wurden jedoch durch ein allgemeines Umsetzungsgesetz noch ergänzt ${ }^{1001}$. Mit diesem Gesetz wurden einige allgemeinen Regelungen zur Umsetzung der Richtlinie 89/48/EWG erlassen. Art. 2 des Gesetzes vom 13. August 1992 enthält die Ermächtigung, wonach die weiteren Ausführungsmaßnahmen für die einzelnen Berufe jeweils durch ein Règlement grand-ducal erfolgen sollen. In diesen Großherzoglichen Verordnungen sollen auch die zuständigen Behördlen angewiesen werden. Rein tatsächlich waren einige der Ausführungsmaßnahmen durch ein Règlement grand-ducal bereits vor der Verabschiedung der gesetzlichen Regelung erlassen. In dem Gesetz vom 13. August 1992 wurde des weiteren in Art. 3 bestimmt, daß eine motivierte Entscheidung über einen Anerkennungsantrag innerhalb von drei Monaten zu nehmen ist. Mit dieser Fristsetzung wurde die Bearbeitungszeit für die Behörden im Vergleich zur Richtlinie um einen Monat verkürzt. Da eine solche Verkürzung nur im Sinne des Antragstellers sein kann, ist eine derartige Bestimmung mit Sicherheit nicht zu beanstanden. Sie entspricht auch dem ansonsten in Luxemburg geltenden Verwaltungsrecht. Art. 3 Satz 4 des allgemeinen Gesetzes regelt die gerichtliche Überprüfung der ergangenen Entscheidung durch den Conseil d'Etat, Comité du Contentieux. Es handelt sich dabei um die einzige tatsächliche und rechtliche Instanz. Hiermit wird die Verpflichtung aus Art. 8 Abs. 2 Satz 2 der Richtlinie 89/48/EWG erfüllt. Ferner weist. Art. 4 des all gemeinen Gesetzes den nationalen Koordinator beim Unterrichtsministerium an. Damit wurde die Verpflichtung aus Art. 9 Abs. 2 der Richtlinie 89/48/EWG noch gesetzlich nachträglich legitimiert, da der Koordinator bereits nach Verabschiedung der Richtlinie 89/48/EWG, d.h. bereits seit Anfang 1989 seine Tätigkeit aufgenommen hatte.

997.

Sekundarbereich: Loi du 13 aoot 1992 modifiant la loi modifiée chu 10 juin 1980 portant planification des besoins en personnel enseignant de l"enseignement postprimaire. Règlement grand-ducal du 26 novembre 1992 concernant le stage pêdagogicue des professeurs de l'enseignement secondaire. Règle ment grand-ducal du 26 janvier 1993 déterminant les conditions d'admissions au concours de recrutement, la formation scientifique et pédagogique et les conditions de nomination des différentes fonctions enseignantes de l"enseignement secondaire technique.

998. Loi du 10 aocht 1991 sur la profession d'awocalt, Amusblatt des Großherzogtums Luxemburg A - No 58 vom 27. August 1991, 1110.

999. Die Umsetzung erfolgte durch Règlement grand-ducal du 3 octobre 1991 relatif a la reconnaissance des diphômes obtenus dans un pays membre des Communautés Europé́énnes dans certain professions de antá für die folgenden Berufe: assistant d'hygiènie sociale, assistant social, masseur-kinésitherrapeute, laborantin, orthophoniste, infirmier hospitalier gradué.

1000. Rẻglement grand-ducal du 29 janvier 1993 déterminant les conditions de qualification professionelle des réviseur d"entreprises.

1001. Loi du 13 août 1992 pontant a) transposition de la directiwe du Conseil (89/48/CEE) relative à un système générall de reconna isance des dịplômes d"enseignement supérieur qui sanctionnent des formations professionelles d'une duree minimale des trois ans; b) crétations d un service de coordination pour la reconnaisance de diplómes à des fins professionnelles, Mémorial Nr. 67 wom 11. September 1992. 
Das allgemeine Umsetzungsgesetz vom 13. August 1992 muß als eine Auffangmalinahme gewertet werden, weil die wesentlichen inhaltlichen Umsetzungsregeln in den Ausführungsmaßßnahmen für die einzelnen Berufe $z u$ finden sind. Positiv muß die Verkürzung der Bearbeitungsfrist beurteilt werden. Nach Verabschiedung des Gesetzes hätte jedoch eine Anpassung der Ausführungsmaßnahmen erfolgen sollen, weil nicht alle Bestimmungen in den Ausführungsverordnungen mit den allgemeinen gesetzlichen Regelungen übereinstimmen, so daß Widersprüche unvermeidlich sind.

\section{DiE UMSETZung DURCH EINE ALLGEMEINE GESETZLICHE REGELUNG}

Die Umsetzung durch eine allgemeine gesetzliche Regelung wurde von Belgien ${ }^{1002}$ " Dänemark ${ }^{1003}$, Irland ${ }^{1004}$, Italien ${ }^{1005}$, Portugal ${ }^{1006}$, Spanien ${ }^{1007}$, den Niederllanden $^{1008}$ und dem Vereinigten Königreich ${ }^{1009}$ gewählt. Im Falle der Niederlande handelt es sich tatsächlich um eine Mischung beider Umsetzungsmethoden, weil für einige Berufe sektorielle Maßnahmen erlassen wurden. Auch enthält das allgemeine Gesetz spezifische Regelungen für die einzelnen Berufe. Auch für Belgien ist eine Mischung beider Umsetzungsmethoden zu erwarten. Von den neuen Mitgliedstaaten hat lediglich Finnland ${ }^{\text {t010 }}$ die Umsetzung durch eine allgemeine gesetzliche Regelung bewirkt. Von den Staaten des Europäischen Wirtschaftsraums hat Island ein allgemeines Umsetzungsgesetz verabschiedet ${ }^{1011}$.

1002. Belgien ist datbei ein Sonderfall. Die allgemeine gesetzliche Regelung enthält lediglich eine Delegationsbefugnis, so daß die weiteren Maßnahmen durch ministerielle Verordnung genommen werden können.

1003. Act concerning access to pursue certain professions in Denmark for nationals of the European Commu. mities and the Nordic countries, Nr. 291 vom 8. Mai 1991.

1004. Statutory Instrument S.I. No.1 af 1991, Regulations entitled European Communities (General Systemi for Recognition of Higher Education Diplomas) Regulations, 1991

1005. Decreto Legislativo vom 27. Januar 1992, Nr. 115, Atuazione della directiva n 89/48/CEE relativa ad un sistema generale die riconoscimento dei diplomi di instruzione superiore che samzionano formazioni professionali di una durata minima di tre anni, Gazzetta Ufficiale vom 18. Jamuar 1992, $\mathrm{Nr} .40$.

1006. Decreto Lei no. 289/91 vom 10. August 1991, Diario da Republica nr. 183 vom 10. August 1991.

1007. Real Decreto $1665 / 1991$ de 25 de octobre. por el que es regula el sistema getneral de renoncimiento de los tíulos de Enseñanza Superior de los Estados membros de la Communidad Económica Europea que exigen una formación minima de tres años de duración, BOE núm. 280 wom 22 . November 1991 " 37916.

1008. Algemene Wet erkenning EG-hoger-anderwijsdiploma's, Stb. Nr. 29/1994.

1009. Statutory Instrument 1991 No. 824 Professional Qualifications, The European Communities (Recognition of Professional Qualifications) Regulations 1991.

1010. Allgemeines Umsetzungsgesetz: Lag Nr. 1597 rom 30. Dezember 1992

1011. Lóg nr. 83/1993 (Act on Recognition of Education and Certificates) wom 18. Mai 1993; Reglugend nur. 244 (Regulation for the Medical Professions falling under Directive 89/48/EEC) vom 25. Marrz 1994 


\section{Die Umsetzung der Richtlinie in Belgien}

Bisher liegt ein Delegationsgesetz vor, wodurch der Regierung die allgemeine Befugnis erteilt wird, weitere Ausführungsmaßnahmen $\mathrm{zu}$ erlassen ${ }^{1012}$. Diese fehlen jedoch weitgehend. Bisher liegen auf nationalem Niveau lediglich die Ausführungsmaßnahmen für den Vermessungsingenieur ${ }^{1013}$ und den Wirtschaftsprüfer vor, wobei in Belgien bei diesem Beruf zwischen Reviseur d'Entreprises ${ }^{1014}$ und Expert Comptable ${ }^{1015}$ unterschieden wird. Aufgrund der föderalen Gliederung. Belgiens, sind für die Umsetzung hinsichtlich einiger Berufe nicht die nationalen Autoritäten, sonderen die einzelnen Gemeinschaften verantwortlich. Dies gilt besonders für die Lehrberufe. Demeatsprechend haben auch die flämische und die wallonische Gemeinschaft bestimmte Ausführungsverordnungen für diese Berufsgruppe erlassen ${ }^{1016}$. Diese Umsetzungsmaßnahmen sind jedoch nicht vollständig. Die Re:htsanwälte sollten auf nationalem Niveau umgesetzt werden. Diese Regelungen sind jedoch bisher nicht ergangen. Obwohl Belgien sich ursprünglich für ein allgemeines Umsetzungsgesetz entschieden hatte, kann die Form der Umsetzung weitgehend als sektoriell bezeichnet werden. Die zunehmende Föderalisierung Belgiens läßt vermutlich keine andere Form mehr zu.

\section{Die Umsetzung der Richtlinie in Dänemark}

\section{a. Die Umsetzungsregelung}

Die dänische Umsetzung erfolgte durch eine generelle gesetzliche Regelung (Umsetzungsgesetz) ${ }^{1017}$, die durch eine ministerielle Verordnung (Verordnung) vom selben Tag ergänzt wird ${ }^{1018}$. Federführend und verantwortlich für die Umsetzung ist die dänische "Commerce and Companies Agency" (CCA) (Wirtschaftsministerium) (Art.

1012. Loi de délegation générale vom 29. April 1994, Moniteur Belge vom 29. Juli 1994.

1013. AR protégeant le titre professionel et l'exercice de la profession vom 18. Januar 1995, Moniteur Belge yom 7. Mairz 1995

1014. Die Ausfühnungsnaßnahmen für den Reviseur d'Entreprises sind nicht unmittelbar aufgrund der Richtinie 89/48/EWG ergangen. Siehe jedoch den Arrêté vom 13. Oktober 1987 und den Arrêté vom 14. Februar 1987.

1015. Der Expert Comptable verfügt über eine eingeschränkte Prüfungsbefungnis Die Umsetzung erfolgte durch Arreté vom 20. April 1990, worin die Bestimmungen hinsichtlich der Ampassungsstage und der Eignungsprüfung niedergelegt sind.

1016. Ausfuhnungsmaßnahmen der flämischen Gemeinschaft: Dëcret vom 12. Juni 1991, Moniteur Belge vom 4. Jali 1991 sowie der Ausfuhrungsbeschluß vom 30. September 1992, Moniteur vom 22. Oktober 1992.

Ausfühnungsmaßnahmen der wallonischen Gemeinschaft: Decret vom 27. Marz 1991, Moniteur Belge wom 25. Mai 1991; Décret vom 26. Juni 1992, Moniteur Belge vom 10. September 1992.

1017. Act concerning access to pursue certain professions in Denmark for nationals of the European Communities and the Nordic countries, Nr. 291 vom 8 . Mai 1991

1018. Executive Order on access to pursue certain professions in Denmark for nationals of the European Communties with higher-education diplomas awarded of at least three years" duration Nr. $_{2} 292$ vom 8 . Mai 1991. Gemäß Art. 6 der Verordnung tratt diese am 11. Mai 1991 in Kraft. 
4 Abs. 1 und 5 Abs. 1 des Umsetzungsgesetzes). Die CCA tritt auch als Richtlinienkoordinator im Sinne des Art. 9 Abs. 2 der Richtlinie 89/48/EWG auf (Art. 2 Abs. 1 der Verordnung). Die CCA bestimmt die zuständige Behörde für den jeweiligen reglementierten Beruf, der in den Anwendungsbereich der Richtlinie fällt (Art. 4 Abs. 2 des Umsetzungsgesetzes). In einer Anlage zu der Umsetzungsmaßnahme werden die in Dänemark reglementierten Berufe sowie die von der $\mathrm{CCA}$ angewiesenen zustândigen Behörden aufgelistet (Art. 2 Abs. 2 der Verordnung). Es handelt sich dabeil um 18 reglementierte Berufe ${ }^{1019}$.

In Art. 1 Abs. 1 des Umsetzangsgesetzes ist die grundsätzliche Anwendung der Umsetzungsmaßnahme auf reglementierte Berufe im Sinne der Richtlinie 89/48/EWG aus den Mitgliedstaaten der Gemeinschaft geregelt. Diese Bestimmung wird durch Art. 1 der Verordnung ergänzt, worin hinsichtlich der inhaltlichen Voraussetzungen auf die Art. 1 Buchstabe a und 3 der Richtlinie 89/48/EWG verwiesen wird.

Art. 1 Abs. 2 des Umsetzungsgesetzes erweitert den Anwendungsbereich entsprechend auf die reglementierten Berufe, deren Anerkennung bereits in Abkommen der nordischen Staaten niedergelegt ist. Dementsprechend regelt Art. 2 Abs. 1 des Umsetzungsgesetzes, daß sowohl Angehörige eines Mitgliedstaates der Europäischen Gemeinschaften, die die Bedingungen der Richtlinie 89/48/EWG erfüllen, als auch Staatsangehörige der nordischen Staaten gemäß den Voraussetzungen der genannten Abkommen, befugt sind ${ }_{\text {in }}$ Dänemark sich beruflich niederzulassen oder ein Arbeitsverhältnis einzugehen.

Art. 3 des Umsetzungsgesetzes gibt der zuständigen Behörde die Befugnis im Einzelfall zu entscheiden, ob die entsprechenden Voraussetungen für die Ausübung eines bestimmten Berufes erfüllt sind. Hierbei wird jeder Fall individuell beurteilt. Die zuständige Behörde wird den Antragsteller über ihre Entscheidung informieren (Art. 3 Abs. 1 der Verordnung). Dabei ist sie gemäß Art. 3 Abs. 2 der Verordnung befugt, gegebenenfalls die Berufsiausübung von der Erfüllung bestimmter Bedingungen im Sinne der Kompensationsinstrumente des Art. 4 der Richtlinie 89/48/EWG abhängig zu machen.

Interessanter Weise regelt Art. 4 der Verordnung auch die Befugnis der zuständigen Behörde eine Entscheidung zu treffen, falls ein Antragsteller unter Anleitung eines qualifizierten Berufsangehörigen den aus einer Berufspraxis bestehenden Teil der Berufsausbildung ableisten möchte, den er im Herkunftsstaat bisher nicht abgeleistet hat. Es handelt sich also um den Fall, daß ein Antragsteller nicht als Endprodukt qualifiziert werden kann und damit eigentlich keinen Rechtsanspruch auf Anerkennung gemäß der Richtline 89/48/EWG geltend machen kann. Diese Umsetzungsbestimmung ist sehr löblich, weil Dänemark damit den Anwendungsbereich der Richtline entsprechend Art. 5 der Richtlinie $89 / 48 /$ EWG erweitert hat. Hierzu bestand keine gemeinschaftsrechtliche

1019. Für den rechtsberatenden Bereich im engeren Sinn werden der Rechtsanwalt und der "Rechtsanwaltsanwärter" (sollicitors clerk) genannt. Für beide Berufe ist das Justizministerium als zuständige Behörde angewiesen worden. 
Verpflichtung. Die Regelung erscheint jedoch besonders vernünftig, weil gerade die Ablegung des praktischen Berufsausübungsteils eine intensive Anpassung an das berufliche Umfeld des Aufnahmestaates garantiert.

Gemäß3 Art. 5 Abs. 2 des Umsetzungsgesetzes bestimmt die CCA, ob und in wellcher Höhe Gebühren für die Bearbeitung des Antrags auf Anerkennung anfallen. Diese Bestimmung wurde in Art. 5 Abs. 2 der Verordnung näher ausgefüllt. Danach beträgt die Gebühr für eine Antragsbearbeitung DKK 500.-. Falls diese Gebühr nicht termingerecht bezahlt wird, kann der Antrag abgewiesen werden. Gemäß Art. 6 des Umsetzungsgesetzes können für den Fall, daß von dem Antragsteller ein Anpassungslehrgang oder die Ablegung einer Eignungsprüfung verlangt wird , die hierdurch entstehenden Kosten in Rechnung gebracht werden. Die Höhe des Betrages wird durch die für die Ausführung der Kompensationsmaßnahme zuständige Behörde bestimmt.

Gemäß Art. 7 des Umsetzungsgesetzes ist sowohl die CCA als auch die angewiesene Behörde befugt, vom Antragsteller alle für die Entscheidung notwendigen Unterlagen zu verlangen. Art. 8 des Umsetzungsgesetzes bestimmt den Tag des Inkrafttretens. Laut Art. 9 des Umsetzungsgesetzes findet die Anerkennung hinsichtlich der Gemeinschaftsangehörigen (vgl. Art. 1 Abs. 1 des Umsetzungsgesetzes) keine Anwendung auf das Gebiet der Faroe Inseln und Grönland. Der Anwendungsbereich kann jedoch durch königlichen Beschluß erweitert werden.

\section{b. Durchführung von Anerkennungsverfahren}

Nach dem ersten Erfahrungsbericht gemäß Art. 11 der Richtlinie 89/48/EWG wurden in Dänemark für alle reglementierten Berufe etwa 30 Anerkennungsverfahren eingeleitet. Hierbei handelte es sich hauptsächlich um Physiotherapeuten, Übersetzer und Lehrer. In etwa der Hälfte der Fälle wurde eine direkte Anerkennung und Zulassung zur Ausübung des Berufes im Sinne des Art. 3 der Richtlinie 89/48/EWG ausgesprochen. Bei den Übersetzern mußte geprïft werden, ob die Voraussetzungen des Art. 3 Buchstabe b erfüllt waren, weil dieser Beruf in den Herkunftsstaaten nicht reglementiert ist. Interessanterweise wurden auch deutsche Heilgymnasten als zur Ausübung der Physiotherapie zugelassen, obwohl die in Deutschland ausgebildeten Heilgymnasten nicht in den Anwendungsbereich der Richtlinie 89/48/EWG fallen, weil ihr Prüfungszeugnis nicht als Diplom im Sinne des Art. 1 Buchstabe a der Richtlinie 89/48/EWG qualifiziert werden kann ${ }^{1020}$.

1020. Nach der Neufassung des Masseur- und Phy siotherapiegesetzes vom 26. Mai 1994, BGB1. I vom 31. Maï 1994, 1084 fallen die deutschen Physiotherapeuten jedoch unter die in der Anlage C der Richdinie 92/51/EWG aufgelisteten Benfe. Siehe auch die Änderung dieser Anlage durch die Richtlinie 94/38/EG vom 26. Juli 1994, ABI. Nr. L 217 vom 23. August 1994, 8. 


\section{c. Beurteilung der Umsetzung}

Die dänische Umsetzungsregelung muß insgesamt sehr positiv beurteilt werden. Die Regelungen sind sehr deutlich und zugänglich für die Migranten. Die Zugänglichkeit der Umsetzungsregelung zeigt sich bereits an der Tatsache, daß alle Anerkennungsanträge an eine Adresse gerichtet werden müssen (Art. 5 der Verordnung). Gemeinschaftsangehörigen wird damit nicht - wie in einigen anderen Mitgliedstaaten - zugemutet die verwaltungsrechtliche Zuständigkeit der entsprechenden Behörden näher zu erforschen. Auch garantiert die gewählte Methode der Einzelfallentscheidung eine optimale Anwendung der Richtlinie. Allerdings muß eingeräumt werden, daß die geringe Zahl der Anerkennungsanträ̀ge eine derartige Regelung zuläßt, während eine vergleichbare Lösung andere Mitgliedstaaten vor erhebliche verwaltungstechnische Probleme stellen würde. Die freiwillige Umsetzung von Art. 5 der Richtlinie 89/48/EWG, die nur in setr wenigen Umsetzungsregelungen $\mathrm{zu}$ finden ist, muß3 ebenfalls positiv hervorgehoben werden, da sie meines Erachtens eine optimale Integration des Migranten in das neue berufliche Umfeld garantiert.

\section{Die Umsetzung der Richtlinie in Irland}

\section{a. Die Umsetzungsregelung}

Irland hatte die Ehre, als erster Mitgliedstaat durch ein allgemeines Gesetz rechtzeitig eine nahezu vollständige Umsetzung vorzulegen. Die irische Umsetzung erfolgte durch eine generelle gesetzliche Regelung (S.I. No.1/1991) ${ }^{102 \|}$, die durch einige weitere ausführende Maßnahmen ergänzt wird ${ }^{1022}$. Federführend verantwortlich für die Umsetzung ist das irische Erziehungsministerium. Bezeichnend für die Umsetzungsmafsnahme ist, daß sie sehr wortgetreu die Bestimmungen der Richtlinie übernimmt. Die Regelung enthält irischer Gesetzgebungstechnik entsprechend zunächst eine Auftistung von Definitionen und Begriffsumschreibungen, die im allgemeinen wörtlich mit denen der Richtlinie 89/48/EWG übereinstimmen.

Kernbestimmung des Umsetzungsgesetzes ist Section 4. Diese entspricht im wesentlichen Art. 3 der Richtlinie 89/48/EWG. Gemäß Section 5 kann die zuständige Behörde im Falle unterschiedlicher Ausbildungsdauer (Section 5 Buchstabe a) oder unterschiedlicher Ausbildungsinhalte (Section 5 Buchstabe b) das Kompensationsinstrumentarium des Art. 4 der Richtlinie 89/48/EWG entsprechend einsetzen. Auch hier entspricht der Wortlaut der Umsetzungsmaßnahme weitgehend dem der Richtlinie. Im Falle, daß die Ausbillung des Antragstellers von kürzerer Dauer ist als die entsprechende irische Berufsausbildung, so kann der Antragsteller die Differenz durch Berufserfahrung kom-

1021. Statutory Instrument S.I. No.1 of 1991, Regulations entitled European Communities (General System for Recognition of Highter Education Diplomas) Reguiations, 1991.

1022. Statutory Instruments S.I. No 177 of 1991, Superior Court Rules (No. 2) of 1991; Statutory Instrument S.I. No. 84 of 1991. The Solicitors Acts 1954 and 1960 (European Community Lawyers) (Feesi), Regulations, 1991; Stanutory Instrument S.I. No. 85 of 1991. 
Teil rV

pensieren. In der Zweiten Anlage wird die Weise der Kompensation bei unterschiedlicher Ausbilldungsdauer näher erläutert.

Hinsichtlich der Berufe, die in der Dritten Anlage aufgelistet sind, hat sich der irische Gesetzgeber für die Eignungsprüfung als Kompensationsinstrument entschieden. Die Liste betrifft Berufe, deren Ausübung nach Auffassung der irischen Regierung eine genaue Kenntnis des nationalen Rechts erfordert (Art. 4 Abs. 1. Buchstabe b). Es handelt sich dabei um die folgenden Berufe und Berufsverbände:

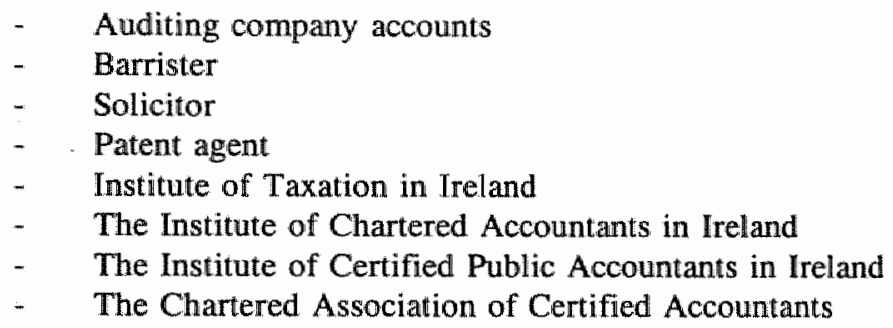

Die zuständige Behörde ist gemäß Section 6 S.I. No. 1/1991 befugt, Inhalt und Form der Eignungsprüfung zu bestimmen, wobei sie die Tatsache, daß der Antragsteller bereits über eine vollständige Berufsausbildung verfügt, mit zu berücksichtigen hat. Dabei wird jeder Fall individuell beurteilt. Eine entsprechende Regelung für den Anpassungslehrgang enthält Section 7 S.I. No. 1/1991. Gemäß dieser Bestimmung ist die zuständige Behörde für die Dauer, den Inhalt und die Bewertung des Anpassungslehrganges. Des weiteren regelt diese Behörde den beruflichen Status des Antragstellers während des Anpassungslehrganges.

Section 8 enthält in $\S 1$ die Bestimmung, daß die von der zuständigen Behörde der Mitgliedstaaten ausgestellten Bescheinigungen anerkannt werden. Diese Regelung entspricht in ihrem Wortlaut weitgehend Art. 8 Abs. 1 der Richtlinie 89/48/EWG. Section $8 \& 2$ bezieht sich auf den Nachweis der Ehrenhaftigkeit sowie auf die Bescheinigung, $\mathrm{daB}$ der Antragsteller nicht in Konkurs geraten ist oder sich schwerwiegend standeswidriges Verhalten zu schulden hat kommen lassen. Die Umsetzungbestimmung häit sich dabei an den Wortlaut des Art. 6 der Richtlinie 89/48/EWG.

Gemäß Section 9 kann der Antragsteller, der die Zulassungsvoraussetzungen erfültt, nach Wahl die irischen Berufsbezeichnungen oder die des Herkunftstaates führen. Diese Bestimmung entspricht Art. 7 Abs. 1 und Abs. 2 der Richtlinie 89/48/EWG. Der zweite Absatz von Section 9 regelt den in Irland für die im zweiten Teil der Ersten Anlage aufgelisteten Berufe, die durch Berufswerbände reglementiert werden. Diese Regelung wird durch Art. 7 Abs. 3 der Richtlinie 89/48/EWG gedeckt.

Section 10 entspricht Art. 8 Abs. 2 Satz 1 der Richtlinie 89/48/EWG. Section 11 regelt den gerichtlichen Rechtsbehelf gegen eine Entscheidung oder das Unterlassen einer Entscheidung der zuständigen Behörde. Das Gerichtsverfahren wird beim High Court 
durchgefürt. Hierzu ist noch eine Spezialbestimmung ergangen: Superior Court Rules (No. 2) of 1991 , Statutory Instruments S.I. No. 177 of 1991.

Klage gegen eine Entscheidung muß innerhalb 42 Tage nach Zugang eingereicht werden. Im Falle des Unterlassens einer Entscheidung muß die Klage innerhalb 42 Tage nach Ablauf der vier Monate Frist erhoben werden. Mit dieser Regelung ist auch Art. 8 Abs. 2 Satz 2 der Richtlinie 89/48/EWG ordnungsgemäß umgesetzt. Gemäß Section 12 \& 1 ernennt der Erziehungsminister einen Koordinator für die Umsetzung und Einheitskontrolle hinsichtlich der Richtlinie 89/48/EWG.

\section{b. Beurteilung der Umsetzung}

Die allgemeine gesetzliche Regelung (S.I. No. 1/1991) entspricht in ihrem Wortlaut weitgehend der Richtlinie 89/48/EWG. Soweit erforderlich haben die einzelnen Berufsorganisationen Ausführungsbestimmungen erlassen. Dies gilt besonders für die rechtsberatenden Berufe und die Lehrer 1023 , ansonsten wird jeder Einzelfall anhand des allgemeinen Gesetzes von der zuständigen Behörde beurteilt. Nach dem Erfahrungsbericht des irischen Koordinators sind während der ersten Periode bis 1992 keine wesentlichen Schwierigkeiten bei der Anwendung der Umsetzungsmaßnahme aufgetreten. Sehr häufig wurden direkte Anerkennungen ausgesprochen. Es handelte sich allerdings in der Mehrzahl der Fälle um Antragsteller aus Großbritannien.

\section{Die Umsetzung der Richtlinie in Italien}

\section{a. Die Umsetzungsregelung}

Italien hat in einem Gesetz vom 29. Dezember 1990, d.h. rechtzeitig vor dem durch Art. 12 der Richtlinie 89/48/EWG gesetzten Termin, einen ersten Ansatz zur Umsetzung unternommen ${ }^{1024}$. Mehr als einen ersten Versuch zur Umsetzung stellt diese Veröffentlichung jedoch nicht dar, weil darin lediglich die allgemeine Verpflichtung Italiens bekundet wird, die Richtlinie 89/48/EWG anzuwenden. Diese Verpflichtung ergibt sich jedoch bereits aus dem Gemeinschaftsrecht selbst. Das Gesetz vom Dezember 1990 mit dem bezeichnenden Namen "legge comunitaria per il 1990" kann als eime Art Säuberungsaktion angesehen werden, wobei der Versuch unternommen wird, alle noch ausstehenden Umsetzungsverpflichtungen in einem Gesetz zu bündeln, um damit zumindest den Anschein einer nationalen Umsetzung zu erwecken. Die Richtlinie 89/48/EWG befindet sich damit auch in guter Gesellschaft mit noch anderen ausstehenden Umset-

1023. Siehe dazu die Fallstudien für die rechtsberatenden Berufe Seite 329 und für die Lehrer Seite 392

1024. Legge vom 29. Dezember 1990, Nr. 428 Disposizioni per l'ademimento di oblighi derivanti dall 'apparterenza dell"Italia alle Comumità europee (legge comunitaria per il 1990), Gazzetta Ufficiale wom 12 Jamuar 1991, Art. 8 
zungsmaßnahmen ${ }^{1025}$. Warum eine derartige Gesetzgebungsaktion unternommen wird, ist undeutlich, da sie in keiner Weise eine konkrete und detaillierte Unsetzung hinsichtlich der Richtlinie 89/48/EWG ersetzt. Art. 8 Buchstabe f) des legge comunitaria bestimmt dann auch, daß die genauen Ausführungsbestimmungen noch durch die zuständigen Behörden zu erlassen sind. Man kann sich des Eindrucks nicht erwehren, daß die ganze Säuberungsaktion nur im Hinblick auf eventuelle Vertragsverletzungsverfahren der Kommission durchgeführt wird. Italien will in Brüssel zumindest seinen guten Willen zeigen ${ }^{1026}$. Die neue Umsetzungstechnik hat jedenfalls dazu geführt, daß Italien in der Umsetzungsstatistik nun einen der ersten. Ränge einnimmt ${ }^{1027}$.

Inzwischen ist eine weitere allgemeine Umsetzungsmaßnahme ergangen und zwar in Form des Decreto Legislativo vom 27. Januar $1992{ }^{1028}$ "Auch hierbei handelt es sich wiedenum nur um eine Teilumsetzung, weil die notwendigen Ausführungsmaßnahmen in diesem Gesetz nicht enthalten sind. Anhang A des Decreto Legislativo nennt eine Reihe von reglementierten Berufen und die für diese Berufe zuständigen Behörden. Ob diese Liste der reglementierten Berufe als vollständig angesehen werden kann ${ }_{\text {ist dem }}$ Text nicht deutlich zu entnehmen. Dagegen spricht Art. 11 des Decreto Legisaltivo, worin in Ergänzung zu Anhang noch weitere zuständigen Behörden angewiesen werden. Gemäß Art. 11 Buchstabe a) i.V.m. Anhang A werden zwölf Berufe dem Zuständigkeitsbereich des Justizministeriums zugewiesen ${ }^{1029}$. $\mathrm{Ob}$ die Zuständigkeit des Justizministeriums mit der Intention getroffen ist, diese Berufe als rechtsberatend i.S. von Art. 4 Buchstabe b) Unterabs. 2 der Richtlinie 89/48/EWG einzustufen, kann daraus nicht abgeleitet werden. Eine solche Einstufung wäre zumindest bei einigen der Berufe auch äußerst zweifelhaft, so etwa beim Biologo, Chimico, Agronomo e forestale, Geologo, Ingegnere, Psicologe, Consulente di lavoro. Die Behauptung, daß diese Berufe nur mit genauen Kenntnissen des nationalen Rechts ausgeübt werden könnten, wobei ein Schwerpunkt der Berufsausübung bei der Rechtsberatung liegt, würde wohl weder bei der Kommission noch vor dem Gerichtshof Erfolg haben. Anders liegt der Fall beim Attuario, Awvocato, Procuratore und mit gewissen Einschränkungen beim Commercialista und beim Agente di cambio. Vier weitere Berufe sind den Zuständigkeitsbereichen anderer Ministerien zugeteill. Dabei handelt es sich um den Consulente proprietà

1025. So geht z.B. in Art. 9 des legge comunitaria per il 1990, um die Einschreibung von Gemeinschaftsangehörigen in die Journalistenreguster, einem doch schon recht alten Streipunkt im Hinblick auf die Diskriminienng aufgrund der Stastsangehörigkeit. Im Anhang A des legge comumitaria werdery $\mathrm{u}$.a. auch die Architektenurichtinien sowie die Anpassungsrichtinie 82/76/EWG bezigglich der Ärztericht linie genannt.

1026. Italien hat diese neue Unsetzungstechnik mit dem Fabri-Geserz aus den Jahr 1987 und wor allem mi dem La Pergola-Gesetz aus dem Jahr 1989 eingefüht. Siehe dazu Capelli, 9. Zur Situation bis 1985 La Pergola-Del Duca, A.LL 1985, 598.

1027. Siehe dazu die Ausfihrungen Seite $417 \mathrm{f}$.

1028. Decreto Legisłativo vom 27. Januar 1992, Nr. 115, Attuaxione della directiva n 89/48/CEE relativa ad un sistema generale die riconoscimento det diploum di instmizione superiore che sanzionano formazioni professionall di una durata minima di tre anni, Gaxzetta Ufficiale wom 18. Januar 1992, Nr. 40.

1029. Es handelt sich dabei um folgende Benufe: Attuario, Avvocato, Procuratore, Commercialista, Biologo, Chimico, Agronomo e forestale, Geologo. Ingegnere, Agente di cambio, Psicologe, Consulente di lavoro. 
industriale, dem Tecnico sanitario di radiologia medica, verschiedene Lehrerberufe und dem Esperto in materia di pianificazione territoriale. Bei dem Consulente proprietå industriale könnte es sich um einen Beruf handeln, für den Italien eine Beschränkung der Wahlmöglichkeit gemäB Art. 4 Buchstabe b) Unterabs. 2 der Richtlinie 89/48/EWG in Anspruch nimmt.

Vergleicht man den Aufbau des Decreto Legisativo mit anderen allgemeinen Umsetzungsgesetzen, so muß er als ungewöhnlich bezeichnet werden. Die anderen Mitgliedstaaten, die eine Umsetzung durch ein allgemeines Gesetz vorgenommen haben, haber. sich hinsichtlich des Aufbaus und der Systematik der Umsetzungsgesetze hauptsächlich vom Richtlinientext leiten lassen ${ }^{1030}$. Dies kann für die italienische Umsetzung nür in gewïssem Umfang bestätigt werden.

Art. 1 des Decreto Legislativo enthält in Abs. 1 die Anerkennungsbestimmung, wenn der Beruf im Herkunftstaat reglementiert ist. Die Anerkennung für den Fall, daß der Beruf im Herkunftstaat nicht reglementiert ist, findet sich dagegen in Art. 3 des Decreto Legislativo. Art. 1 Abs. 3 des Decreto Legislativo enthält die Diplomdefinition. Dagegen betrifft Art. 1 Abs. 4 des Decreto Legislativo die Anerkennung von Drittstaatsdiplomen. Dabei weicht die gewählte Definition des Dritstaatsdiploms vom Richtlinientext ab. Gemäß Art. 1 Buchstabe a) Unterabs. 2 der Richtlinie 89/48/EWG handelt es sich um ein innerhalb der Gemeinschaft erworbenes Diplom, wenn die bescheinigte Ausbildung überwiegend in der Gemeinschaft erworben wurde. Im Umkehrschluß bedeutet dies, daß ein Drittlanddiplom eine überwiegend außerhalb der Gemeinschaft erfolgte Ausbildung unterstellt. Eine überwiegend in der Gemeinschaft erworbene Ausbildung ist bereits dann gegeben, wenn mehr als $50 \%$ der Ausbildung in der Gemeinschaft stattgefunden hat. Dagegen definiert Art. 1 Abs. 4 des Decreto Legislativo ein Drittlanddiplom bereits hinsichtlich einer Ausbildung, die über ein Drittel in einem Drittstaat stattgefunden hat ${ }^{103 !}$. Diese Definition läuft meiner Ansicht nach der Richtlinie zuwider, weil sie den Kreis der Drittlanddiplome erweitert, so daß diese Diplome unter die zusätzliche Bedingung des Nachweises einer dreijährigen Berufserfahrung im anerkennenden Mitgliedstaat fallen ${ }^{1032}$.

Art. 5 des Decreto Legislativo enthält eine Beschreibung der Form und Dauer der Ausbildung, die bei einem Diplom i. S. dieser Ausführungsverordnung unterstellt wird. Dabei wird in Abs. 2 eine Regelung im Falle einer unterschiedlichen Ausbildungsdauer getroffen. Diese Bestimmung entspricht weitgehend Art. 4 Abs 1 a) der Richtlinie 89/48/EWG. Allerdings findet sich erst in Art. 6 Abs. 4 des Decreto Legislativo ein Hinweis darauf, daß die Anpassungsinstrumente hinsichtlich der Dauer (Art. 5 des Decreto Legislativo) und hinsichtlich des unterschiedlichen Inhalts der Ausbildung (Art. 6 des Decreto Legislativo) nicht gleichzeitig vorn Aufnahmestaat verlangt werden dürfen (Art. 4 Abs. 2 der Richtlinie 89/48/EWG). Art. 6 des Decreto Legislativo enthält die

1030. Vgl. dazu die Umsetzungsgesetze von Dânemark, Großbritannien und Irland.

1031. "per una durata superiore a un terzo"

1032. Siehe dazu Seite 173. 
Regelung der Anpassungsinstrumente im Falle substantieller Unterschiede im Rahmen der Ausbildung. Hierbei wird gemäß Art. 6 Abs. 1 des Decreto Legislativo die Wahl grundsätzlich dem Kandidaten überlassen. Eine Ausnahme von der Wahlfreiheit findet sich in Art. 6 Abs. 2 für die Berufe procuratore legale, avvacato, commercialista et consulente per la proprieta industriale. Für diese Berufe wird die Eignungsprüfung als Anpassungsinstrument bestimmt. Eine Erweiterung dieser Liste kann jedoch gemäß Art. 6 Abs. 3 durch den Ministerrat auf Vorschlag des Mimisters für Gemeinschaftsangelegenheiten und mit Zustimmung des entsprechenden Fachministers vorgenommen werden. Dies setzt jedoch die Einhaltung des durch die Richtlinie 89/48/EWG in Art. 10 vorgegebenen Verfahrens voraus. Art. 7 des Decreto Legislativo enthält die Definition des Anpassungslehrganges, wobei diese Definition weitgehend mit der des Art. 1 f) der Richtlinie 89/48/EWG übereinstimmt. Dies gilt ebenso für die in Art. 8 des Decreto Legislativo getroffene Wortwahl hinsichtlich der Definition der Eignungsprüfung. Gemäl Art. 9 des Decreto Legislativo wird an die einschlägigen Fachminister die genauere Ausgestaltung und Anwendung der Anpassungsinstrumente durch Verordnung überwiesen, wobei diese Verordnungsgebung in Abstimmung mit dem Minister für Gemeinschaftsangelegenheiten und dem Bildungsminister zu erfolgen hat. Weiterhin ist selbst eine Konsultation des Staatsrates geboten.

Art. 10 des Decreto Legislativo enthält das Verfahren hinsichtlich der vorzulegenden Dokumente. Bemerkenswert ist dabei das Verlangen nach einer Übersetzung aller Dokumente auf italienisch, die durch die diplomatischen und konsularischen Behörden auf ihre Korrektheit im Hinblick auf das Orginal zu überprüfen sind. Diese Überprüfung kann allerdings auch durch einen traduttore ufficiale (beeidigten Übersetzer) vorgenommen werden. Zumindest die Vorlageverpflichtung bei einem Konsulat oder einer Botschaft scheint weit überzogen. Abhängig davon, wellche Voraussetzungen von einem traduttore ufficiale verlangt werden, erscheint diese Bestimmung zumindest an der Grenze der Zulässigkeit. Art. 11 des Decreto Legisativo bezieht sich auf die zuständigen Behörden und bestimmt die einzelnen Ministerien je nach Zuständigkeitsbereich. Art. 12 des Decreto Legislativo bestimmt den Verfahrensverlauf, wobei interessanterweise gemălB Art. 12 Abs. 3 eine Frist von 30 Tagen bestimmt wird, innerhalb der das zuständige Ministerium den Antrag auf seine Vollständigkeit zu überprüfen und gegebenenfalls den Kandidaten auf die fehlenden Stücke hinzuweisen hat.. Eine entsprechende Verfahrensbestimmung findet sich nicht in der Richtlinie 89/48/EWG. Da dadurch jedoch nur die italienischen Behörden zur zügigen Abwicklung des Anerkennungsverfahrens angehalten werden, kann eine solche Regelung nicht beanstandet werden. Der weitere Verlauf des Verfahrens ist jedoch äußerst kompliziert, weil gemäß Art. 12 Abs. 4 des Decreto Legislativo dazu verschiedene Behörden zusammenarbeiten müssen, so daß kaum mit einem im Sinne der Richtlinie 89/48/EWG rechtzeitigen Abschluß des Verfahrens innerhalb von 4 Monaten gerechnet werden kann. Gemäß Art. 13 des Decreto Legislativo bewirkt die Anerkennung das Recht den entsprechenden Beruf auszuüben, vorbehaltlich der Bedingungen, die auch an italienische Bürger gestellt werden. Art. 13 Abs. 2 bis 4 des Decreto Legislativo enthält Verweisungen auf Art. 48 , 55 und 66 EWGV. Art. 14 enthält die Berechtigung zur Führung des in Italien gebräuchlichen Berufstitels sowie des im Heimatstaat erworbenen akademischen Grades. 
Art. 15 betrifft die Ausführung der Anpassungsinstrumente. Mangels entsprechender Ausführungsmaßnahmen wird die Verantwortung hierfür den entsprechenden Minüsterien ubertragen. Art. 16 bezieht sich auf die weiteren Voraussetzungen wie Nachweis der Ehrenhaftigkeit und Gesundheit.

\section{b. Beurteilung der Umsetzung}

Die Umsetzung ist noch in keiner Weise abgeschlossen, weil bisher keine weiteren Ausfihrungsverordnungen ergangen sind, so daß die praktische Anwendung der Richtlinie vor allem im Hinblick auf die Ausgestaltung eines möglichen Anpassungslehrganges oder einer Eignungsprüfung nicht beurteilt werden kann. Es kann jedoch bereits num festgestellt werden, daß das Anerkennungsverfahren zu kompliziert ist, um einen zügigen Verlauf zu garantieren. Nach dem ersten Erfahrungsbericht gemäß Art. 11 waren nur sehr wenige Anerkennungsverfahren endgültig abgeschlossen. In jüngster Zeit haben die zuständigen Behörde allerdings verschiedene Anerkennungsverfahren auf der Grundlage des Decreto legislativo durchgeführt, ohne daß die entsprechenden Durchführungsmaßnahmen bisher ergangen sind. Die jeweiligen Anträge wurden als Einzelfall entschieden und veröffentlicht. Ob hieraus abgeleitet werden kann, daß die italienischen Behörden, abweichend von der urspruinglichen Intention des Gesetzgebers, ohne weitere Ausführungsverordnungen die Anerkennungsverfahren durchführen möchten, kann nicht mit Sicherheit festgestellt werden ${ }^{1033}$. Jedenfalls müßten für die Berufe, für die eine Eignungsprüfung verbindlich worgeschrieben werden soll, noch konkrete Ausfuihrungsbestimmungen erlassen werden. Ansonsten kann nicht von einer abgeschlossenen Umsetzung gesprochen werden.

Inhaltlich lassen sich noch die folgenden Kritikpunkte anführen:

Die grundsätzliche Verwendung des Begriffs "titoli" an Stelle des in der Richtlinie selbst benützten Terminus "diplomi" entspricht zwar dem herkömmlichen italienischen Sprachgebrauch, ist jedoch in diesem Zusammenhang sehr verwirrend, weil der Begriff "Titel" in der Richtlinie auch im Sinne der Führung eines Berufstitels vorkommt. Besser wäre es sicher gewesen, die in der Richtlinie verwendete Terminologie auch im Rahmen der Umsetzungsgesetzgebung zu verwenden. Von inhaltlich einschneidender Bedeutung ist jedoch die im Decreto legisativo gegebene Definition eines Drittstaatsdiploms, weil diese nicht derjenigen der Richtlinie entspricht. Folglich wird der Anwendungsbereich der Richtlinic in einer restriktiven Weise eingeschränkt. Ebenso zweifellhaft ist auch die Zulässigkeit einer Beurteilung des Anpassungslehrganges in der Form, daß im Falle einer negativen Beurteilung eine Wiederholungsmöglichkeit geboten wird (Art. 7 Abs. 4 Decreto legisativo). Dies könnte zur Konsequenz haben, dali ein Kandidat sich länger als die durch die Richtlinie als maximal vorgegebenen drei Jahre anpassen muß. Dagegen erscheint die Regelung, nach der die Eignungsprüfung erst nach einer Frist von sechs Monaten wiederholt werden darf (Art. 8 Abs. 3 Decreto legislativo), gerechtfer-

1033. Es könnte auch sein, daß die Behörden Schadensersatzverfahren fürchten, falls sie nicht innerhalb einer angemessener Frist entscheiden. 
tigt zu sein. Dies gilt um so mehr als keine Einschränkung der Anzahl der Wiederholungsmöglichkeiten geregelt wird.

Nicht geregelt ist im Decreto legislativo die Möglichkeit einer gerichtlichen Überprüfung der Anerkennungsentscheidung. Hierin könnte ein Verstoß gegen Art. 8 Abs. 2 Satz 2 der Richtlinie 89/48/EWG bestehen, es sei denn, das allgemeine itallienische Verwaltungsprozeßrecht garantiert einen derartigen gerichtlichen Rechtsbehelf gegen Entscheidungen der Verwaltung. Aus Gründen der Deutlichkeit wäre in diesem Falle deshalb ein entsprechender Hinweis auf den gebotenen Rechtsgang angezeigt gewesen.

\section{Die Umsetzung der Richtlinie in den Niederlanden}

\section{a. Die Umsetzungsregelung}

In den Niederlanden wurde bereits am 12. März 1992 an die "Tweede Kamer der Staten-Generaal" ein Gesetzesentwurf zur allgemeinen Umsetzung der Richtlinie 89/48/EWG ${ }^{1034}$ angeboten. Der Abschluß des Verfahrens zog sich jedoch sehr lange hinaus. Erst im Dezember 1993 wurde der Gesetzesentwurf schließlich vom Parlament verabschiedet. Als Algemene Wet erkenning EG-hoger-onderwijsdiploma's trat dieses Gesetz an 19. Januar 1994 in Kraft ${ }^{1035}$. Neben der generellen Umsetzung wurden bisher in den Niederlanden drei sektorieile Maßnahmen verabschiedet, von denen eine die Anerkennung von Lehrern regelt ${ }^{1036}$, die anderen beiden die Anerkennungsbestimmungen von Patentanwälten und von Wirtschaftsprüfern beinhalten ${ }^{1037}$.

Das allgemeine Umsetzungsgesetz ist in drei Kapitel unterteilt. Kapitel I enthält Legaldefinitionen sowie Bestimmungen hinsichtlich der Reichweite des Gesetzes. Das zweite Kapitel regelt die Anerkennung und das Anerkennungsverfahren. Das letzte Kapitel betrifft konkrete Gesetzesänderungen hinsichtlich verschiedener Gesetze, die von der Richtlinie betroffen sind. Gerade diese konkreten Gesetzesänderungen im Rahmen eines allgemeinen Umsetzungsgesetzes sind typisch für die niederländische Umsetzung. In keinem der anderen allgemeinen Umsetzungsgesetze findet sich ein vergleichbarer Katalog. Auch inhaltlich überrascht Kapitel III insoweit als Gesetzesändenung in Bereichen vorgenommen werden, die in den meisten anderen Mitgliedstaaten als außerhalb des Anwendungsbereichs der Richtlinie 89/48/EWG gesehen werden ${ }^{1038}$. Gemäß Art. 13 des Allgemeinen Umsetzungsgesetzes wird das Wet op het Notarisambt (Notariatsgesetz) geändert. Mittels Art. 14 des Allgemeinen Umsetzungsgesetzes wird ein neuer

1034. Regelen betreffende een algemeen stelsel vam erkenning van in de Lid-Staten van de Europese Gemeenschappen behaaldie hoger-onderwijsdiploma's waamee beroepsopleidingen van ten minste drie jaren worden afgesloten (Algemeen wet erkemning EG-hoger-onderwijsdiploma's).

1035. Stb 1994, 29 und 30.

1036. Siehe dazu die Erläutenungen in der Fallstudie "Lehrer" Seite 398.

1037. Siehe dazu die Fallstudie "rechtsberatende Berufe" Seite 334.

1038. Dies gilt z. B. für das Notariat und für verschiedene Tätigkeiten in der Justiz. 
Artikel in das Wet op de rechterlijke organisatie (Gerichtsverfassungsgesetz) eingefügt. Entsprechende Änderungen werden gemäß den Art. 16, 17, 19 und 26 des Umsetzungsgesetz für weitere Berufe im Bereich der Justiz vorgenommen ${ }^{1039}$. Mit diesen Umsetzungsmaßriahmen haben die Niederlande eine sehr umfassende Umsetzung auch fir Berufe vorgenommen, die grundsätzlich noch einem Staatsangehörigkeitsvorbehalt unterliegen. Neben diesen unterschiedlichen Berufen auf dem Gebiet der Justiz, des Grundbuchwesens und des Notariats sind es wor allem die Rechtsanwälte, die maritimen Berufe einschließlich der Lotsen, die Garten- und Landschaftsarchitekten, die Städteplaner, unterschiedliche Lehrtätigkeiten sowie paramedizönische Berufe, die mittels konkreter Gesetzesänderungen im dritten Kapitel wom Anerkennungsmechanismus erfaßt werden.

\section{b. Beurteilung der Umsetzung}

Die allgemeine niederländische Umsetzungsregelung kann insgesamt positiv beurteilt werden. Bedauerlich ist jedenfalls, daß sie aufgrund der erheblichen Verspätung keine Vorbildfunktion erfüllen konnte. Besonders bemerkenswert und positiv hervorzuheben ist, daß die Umsetzungsregelung sehr umfassend ist, d.h. auch Berufe, die in anderen Mitgliedstaaten bewußt außerhalb des Anwendungsbereichs der Richtlinie gestellt wurden, so z.B. der Notar oder der Richter, werden von der Umsetzungsregelung erfaßt. Eine abschließende Beurteilung kann jedloch nur anhand der einzelnen Ausführungsmaßnahmen vorgenommen werden ${ }^{1040}$. Nach dem ersten Erfahrungsbericht der niederländischen Koordinatorin wurden die Verfahren vor der Verabschiedung des allgemeinen Anerkennungsgesetzes aufgrund übergangsrechtlicher Regelungen entschieden. Es handelte sich dabei vor allem um Anerkennungswerfahren hinsichtlich Lehrer ${ }^{1041}$ und hinsichtlich paramedizinischer Berufe. Insgesamt betraf es 56 Anerkennungsverfahren.

\section{Die Uwsetzung der Richtlinie in Portugal}

\section{a. Die Umsetzungsregelung}

Die Umsetzung in Portugal erfolgte durch Decreto-Lei no. 289/91 vom 10. August $1991^{1042}$. In einem Anhang zu diesem allgemeine Gesetz werden die in Portugal reglementierten Berufe aufgelistet sowie die zuständigen Behörden angewiesen. In Art. 16 des Decreto-Lei werden für jeden einzelnen der reglementierten Berufe die Verabschiedung von Ausführungsmaßnahmen angekündigt. Bisher fehlt es jedoch zum größten

1039. Beroepswet, Pachtwet, Wet op de Raad van State, Kadasterwet.

1040. Siehe dazu die Fallstudien für die rechtsberatenden Berufe Seite 334 und für die Lehrer Seite 398.

1041. Siehe dazu die Fallstudie "Lehrer" Seite 399

1042. Diario da Republica Nr. 183 vont 10. August 1991. 
Teil an der konkreten Ausführung dieser Bestimmung ${ }^{1043}$. Die Durchführung von Anerkennungsverfahren könnte durch die zuständigen Behörden aufgrund des DecretoLei für jeden Einzelfall erfolgen, zumal in Art.. 14 des Decreto-Lei diesen Behörden ein sehr weitreichender Entscheidungsspielraum eingeräumt wird. Tatsãchlich haben die portugiesischen Autoritäten bisher eine Anwendung der Richtlinie 89/48/EWG unter Berwfung auf die fehlenden Ausführungsmaßnahmen weitgehend verweigert.

Inhaltlich entsprechen die im Decreto-Lei no. 289/91 gewählten Definitionen weitgehend der Richtlinie. Art. 7 Abs. 3 b) des Decreto-Lei muß jedoch als Ausnahme besonders hervorgehoben werden. Gemäß dieser Bestimmung muß ein Anpassungslehrgang nicht weniger als drei Jahre dauern. Diese Formulierung steht im absoluten Widerspruch zu der in Art. 4 Abs. 1 b) der Richtlinie 89/48/EWG gegebenen Definition, wonach der Anpassungslehrgang höchstens eime Periode von drei Jahren umfassen darf. Vermutlich handelt es sich bei der portugiesischen Regelung um ein sprachliches Versehen und nicht um ein bewußtes inhaltliches Abweichen vom Richtlinientext, denmoch sollte ein solcher Fehler zur Vermeidung von Mißverständnissen und Fehlentscheidungen so schnell möglich durch eine Anpassung der Formulierung im Gesetzestext behoben werden.

\section{b. Beurteillung der Umsetzung}

Mit Ausnahme der genannten Textstelle, die sicherlich einer Korrektur bedarf, läßt sich eine inhaltliche Beurteilung der portugiesischen Umsetzung nur sehr schwer vornehmen, weill bisher kaum weitere Ausführungsmaßnahmen verabschiedet worden sind. Auch liegt bisher kein Umsetzungsbericht gemäß Art. 11 der Richtlinie vor. Insoweit kommt die Umsetzung durch ein allgemeines Gesetz ohne konkrete Ausgestaltung einer Nichtumsetzung sehr nahe. Unverständlich ist, warum die portugiesischen Instanzen, die als zuständige Behörden im Sinne von Art. 9 Abs. 1 der Richtlinie 89/48/EWG angewiesen worden sind, nicht aufgrund des Decreto-Lei und den für das einzelne Anerkennungsverfahren eingereichten Unterlagen, die einzelnen Anerkennungsanträge entscheiden. Dies wäre meines Erachtens grundsätzlich möglich, weil das allgemeine Gesetz alle zur Entscheidung wesentlichen Bestimmungen der Richtlinie in die nationale Rechtsordnung umgesetzt hat.

1043. Lediglich für die Wirtschaftsprüfer und die Rechtsanwälte sind inzwischen Ausfühnungsgesetze erlassen worden. Wirtschaftsprufer: Decreto-lei nr. 422-A/93. Diario da Republica Nr. 303 vom 30. Dezember 1993. Rechtsanwalte: Decreto-lei nr. 33/94 vom 6. September 1994, Diario da Republica Nr. 206 vom 6. September 1994. Auch wurde am 8. Januar 1991 eine Regelung für ausländische Assistenten für Frendsprachenunterricht und Landeskunde (Erlaß Nr. 8/91) verabschiedet. 


\section{Die Umsetzung der Richtlinie in Spanien}

\section{a. Die Umsetzungsregelung}

Die allgemeine spanische Umsetzung wurde mit dem Königlichen Beschluß $\mathrm{Nr}$. $1665 / 1991$ vom 25. Oktober 1991 verwirklicht ${ }^{1044}$. Danach sollten gemäß der letzten Bestimmung Ausführungsmaßnahmen für jeden einzelnen reglementierten Beruf erlassen werden ${ }^{1045}$. Eine genaue Auflistung der in Spanien im Sinne der Richtlinie 89/48/EWG reglementierten Berufe findet sich in einer Anlage. Die angekündigten Ausfuhrungsbestimmungen fehlen jedoch wie in Portugal noch zum größten Teil ${ }^{1046}$. Verabschiedet wurden lediglich die Ausführungsmaßnahmen für acht technische Berufe ${ }^{1047}$ sowie für die durch die Rechtsprechung bereits so berühmnt gewordenen Immobilienmakler ${ }^{1048}$. Dagegen ist eine Regelung für die Zulassung zum öffentlichen Dienst Ende 1993 in Kraft getreten ${ }^{1049}$. Dieses Gesetz betrifft nicht direkt die Umsetzung der Richtlinie 89/48/EWG, sondern die Abschaffung des Staatsangehörigkeitserfordernis für die Beschäftigung in der spanischen Verwaltung. Diese Regelung ist jedoch für die Zulassung von auslăndischen Lehrern von großer Bedeutung.

Gemäß Art. 5 a wurden vier im Anhang II genannte Berufe als rechtsberatend eingestuft. Für diese Berufe soll die Eignungsprüfung als Kompensationsinstrument verpflichtet sein. Es handelt sich dabei um den Abogado, den Procurador, den Auditor de Cuentas und den Graduado Social. Diese Einordnung ist bei den ersten drei der genannten Berufe nicht überraschend, da es sich um Rechtsanwălte und Wirtschaftsprüfer handelt, ungewöhnlich dagegen erscheint auf den ersten Blick die Einordnung des "Graduado Social" als rechtsberatend. Bei dem Graduado Social handelt es sich jedoch um einen Spezialistén des Arbeits- und Sozialrechts, der sein Klientel auch in den entsprechenden Gerichtsverfahren vertritt, so daß die vorgenommene Qualifizierung gerechtfertigt erscheint. Obwohl die Eignungsprïfung als Kompensationsinstrument für diese Berufe vorgesehen ist, fehlen auch hier die notwendigen Ausführungsmal3nahmen.

1044. Real Decreto $1665 / 1991$ de 25 de octabre, por el que es regula el sistema general de renoncimiento de los tifulos de Ensenanza Superior de los Estados membros de la Communidad Económica Europea que exigen una formación minima de tres años de duración, BOE núm. 280 vom 22. November 1991. 37916

1045. Siehe dazu den Hinweis unter " Disposiciones finales".

1046. Für die juristischen Berufe "abogado" und "procurador" hat das Justizministerium einen Entwurf vorbereitet, worin eine Eignungsprufung als. Kompensationsinstrument vorgesehen ist. Dieser Verondnungsentwurf ist jedoch bisher nicht in Kraft getreten.

1047. Verordnung vom 12. April 1993, BOE Nr. 94 vom 20. April 1993.

1048. Verondnung wom 4. März 1993, BOE Nr. 66 vom 18. Mărz 1993.

1049. Gesetz 17/93 vom 23. Dezember 1993. 


\section{b. Beurteilung der Umsetzung}

Die Tatsache, daß bisher kaum Ausführungsmaßnahmen erlassen sind, erschwert eine abschließende Beurteilung der spanischen Umsetzung sehr erheblich, weil anders als im Falle von Dänemark, Großbritannien und Irland nicht vorgesehen ist, die Anerkennungswerfahren auf der Basis einer Einzelfallentscheidung zu treffen. Vielmehr werden die sektoriellen Ausführungsverordnungen für die Durchführung der Anerkennungsverfahren als zwingend notwendig erachtet. Damit ist aber die Umsetzung trotz der Veröffentlichung einer allgemeinen Regelung für einen erheblichen Bereich in einer Weise unvollständig, die an eine Nichtumsetzung grenzt. Wie bereits für Portugal festgestellt, sollten die zuständigen Behörden dazu übergehen, die Entscheidungen auf der Basis des allgemeinen Umsetzungsgesetzes zu treffen. Nach dem Erfahrungsbericht des spanischen Koordinators wurden in der ersten Periode bis 1992 tatsächlich 201 Anerkennungen direkt ausgesprochen, während in 33 Fällen Kompensationen in Form einer Eignungsprüfung oder eines Anpassungslehrgangs werlangt wurden. Die in dem Erfahrungsbericht worgelegten Zahlen beziehen sich jedoch nicht nur auf Berufe i.S. der Richtlinie 89/48/EWG, sondern es werden auch Berufe genannt, die von einer sektoriellen Richtlinie erfaßt sind. In diesen Fällen mußte eine automatische Anerkennung bereits aufgrund dieser $\mathbb{R}$ ichtlinien vorgenommen werden.

\section{Die Umsetzung der Richtinie im Vereinügten Königreich}

\section{a. Die Umsetzungsregelung}

Die britische Umsetzung erfolgte durch eine generelle gesetzliche Regelung (No. 824) ${ }^{1050}$. Federführend verantwortlich für die Umsetzung ist das Department of Trade and Industry (DTI). Bezeichnend für die Umsetzungsmaßnahme ist die sehr wortgetreue Übermahme der Bestimmungen der Richtlinie. Die Regelung enthält britischer Gesetzgebungstechnik entsprechend zunächst eine Auflistung von Definitionen und Begriffsumschreibungen, die im allgemeinen wörtlich mit denen der Richtlinie 89/48/EWG übereinstimmen.

Kernbestimmung des Umsetzungsgesetzes ist die Regelung 5 (Right to practice in the United Kingdom). Diese entspricht im wesentlichen Art. 3 der Richtlinie 89/48/EWG. Gemäß der Regelung 6 kann die zuständige Behörde im Falle unterschiedlicher Ausbildungsdauer ( $6 \$ 1$ Buchstabe a) oder unterschiedlicher Ausbildungsinhaite ( 6 \& Buchstabe b) das Kompensationsinstrumentarium des Art. 4 der Richtlinie 89/48/EWG entsprechend einsetzen. Auch hier entspricht der Wortlaut der Umsetzungsmaßnahme weitgehend dem der Richtlinie. Ist die Ausbildung des Antragstellers von kurzerer Dauer als die entsprechende britische Berufsausbillung, so kann der Antragsteller die

1050. Statutory Instrument 1991 No. 824 Professional Qualifications "The European Communities (Recognition of Professional Qualifications) Regulations 1991, das mit Ausnahme der Bestimmungen 11 und 12 arm 17. April 1991 in Kraft trat. 
Differenz durch Berufserfahrung kompensieren. In der Zweiten Anlage wird die Weise der Kompensation bei unterschiedlicher Ausbildungsdauer näher erläutert.

Hinsichtlich der Berufe, die in der Dritten Anlage aufgelistet sind, hat sich der Gesetzgeber für die Eignungsprufung als Kompensationsinstrument entschieden $(6 \& 2)$. Es handell sich dabei um Berufe, deren Ausübung eine genaue Kenntnis des nationalen Rechts erfordert ( Art. 4 Abs. 1 Buchstabe b der Richtlinie 89/48/EWG):

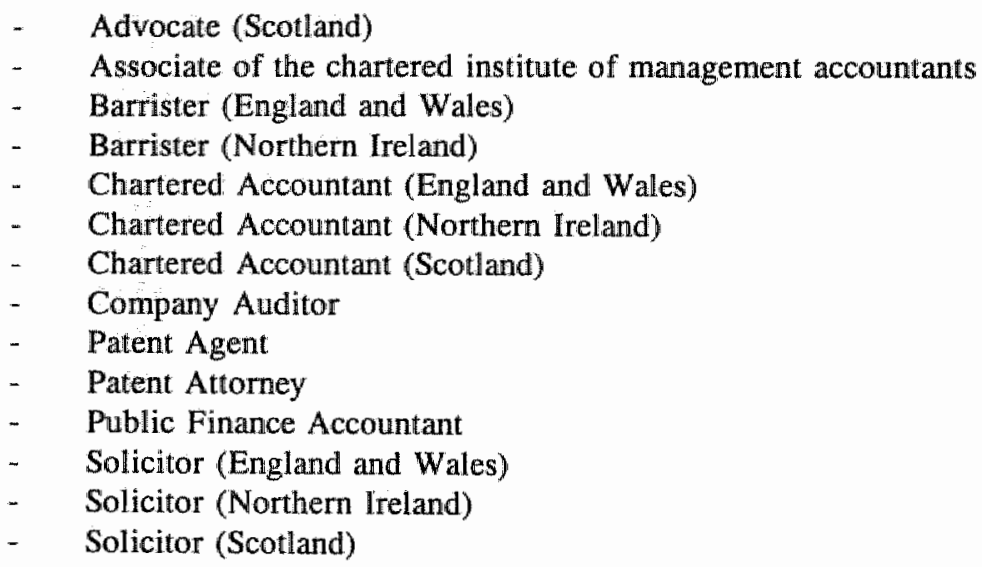

Die zuständige Behörde ist gemäß Regelung $7 \$ 2$ befugt Inhalt und Form der Eignungsprüfung zu bestimmen. Dabei ist die Tatsache, daß der Antragsteller bereits über eine vollständlige Berufsausbildung verfügt, zu berücksichtigen $(7 \S 1)$. Geprüft werden soll lediglich, inwieweit die beruflichen Kenntnisse den Antragsteller zur Ausübung des entsprechenden Benufes im Vereinigten Kömigreich reichen. Dabei wird jeder Fall individuell beurteilt. Der Status des Antragstellers während der Vorbereitung auf die Eignungsprüfung wird ebenfalls durch die zuständige Behörde bestimmt.

Eine entsprechende Regelung für den Anpassungslehrgang entluält Regelung 8. Gemäls dieser Bestimmung ist die zuständige Behörde für die Dauer, den Inhalt und die Bewertung des Anpassungslehrganges verantwortlich. Des weiteren regelt diese Behörde den beruflichen Status des Antragstellers während des Anpassungslehrganges ( $8 \S 4$ ).

Regelung 9 enthält in $\$ 1$ die Bestimmung, daß die von der zuständigen Behörde der Mitgliedstaaten ausgestellten Bescheinigungen anerkannt werden. Diese Regelung entspricht in ihrem Wortlaut weitgehend Art. 8 Abs. 1 der Richtlinie 89/48/EWG. Regelung $9 \$ 2$ bezieht sich auf den Nachweis der Ehrenhaftigkeit sowie auf die Bescheinigung, daß der Antragsteller nicht in Konkurs geraten ist oder sich schwerwiegend standeswidriges Verhalten zu schulden hat kommen lassen. Die Umsetzungbestimmung hält sich dabei an den Wortlaut des Art. 6 der Richtlinie 89/48/EWG. 
Gemäl Regelung $10 \& 1$ kann der Antragsteller, der die Zulassungsvoraussetzungen erfullt nach Wahl die britischen Berufsbezeichnungen ( $10 \& 1$ Buchstabe a) oder die des Herkunftstaates führen ( $10 \$ 1$ Buchstabe b). Im Falle, daß die letztgenannte Variante gewählt wird, kann die zuständige Behörde vorschreiben, daß neben dieser Bezeichnung Name und Ort der Lehranstalt aufgeführt werden. Diese Bestimmung entspricht Art. 7 Abs. 1 und Abs. 2 der Richtlinie 89/48/EWG. Der dritte Absatz von Regelung 10 regelt die Frage der Titelführung für die im zweiten Teil der Ersten Anlage aufgelisteten Berufe, die durch Berufsverbände reglementiert werden, die durch einen königlichen Beschluß (Royal Charter) errichtet sind. Die Führung des entsprechenden Titels ist in diesen Fällen nur bei Mitgliedschaft im Berufswerband gestattet. Diese Regelung wird durch Art. 7 Abs. 3 der Richtlinie 89/48/EWG gedeckt. Regellung 11 enthält Sonderbestimmungen für Wirtschaftsprüfer, Regelung 12 beinhaltet entsprechende Sonderbestimmungen für Wirtschaftsprüfer in Nordirland.

Regelung $13 \& 1$ entspricht Art. 8 Abs. 2 Satz 1 der Richtlinie 89/48/EWG. \& 4 der Bestimmung regelt den gerichtlichen Rechtsbehelf gegen eine Entscheidung. Das Unterlassen einer Entscheidung der zuständigen Behörde wird gemäß Regelung $13 \& 3$ als abweisender Bescheid angesehen, der am letzten Tag während der vier Monate Frist ergangen ist. Das Gerichtsverfahren wird bei den Gerichten durchgefüht, die in der Vierten Anlage aufgelistet sind. Generell handelt es sich dabei um Verfahren vor einem County Court beziehungsweise vor einem Sheriff Court im Falle einer Klage in Schottland. Für einige der rechtsberatenden Berufe gilt ein abweichendes Verfahren ${ }^{\text {tos! }}$. Die Klage gegen eine Entscheidung muß innerhalb von drei Monaten nach Zugang der Entscheidung eingereicht werden. Im Falle des Unterlassens einer Entscheidung muB die Klage innerhalb von drei Monaten nach Ablauf der vier Monate Frist erhoben werden. Mit dieser Regellung ist Art. 8 Abs. 2 Satz 2 der Richtlinie 89/48/EWG ordnungsgemäß umgesetzt.

\section{b. Durchführung von Anerkennungsverfahren}

Die Durchführung von Anerkennungsverfahren wird in Großbritannien zum größten Teil den Berufsorganisationen (Chartered bodies) als zuständigen Behörden überlassen. Diese haben auf unterschiedliche Art und Weise auf die Richtlinie reagiert, abhängig davon, ob mit einer größeren Zahl an Anträgen gerechnet wurde. Hinsichtlich der Berufe, die in der Dritten Anlage aufgelistet sind, für die der Gesetzgeber sich für die Eignungsprüfung entschieden hat, haben die Berufsorganisationen genauere Ausführungsbestimmungen ausgearbeitet. Aus dem ersten Erfahrungsbericht des britischen Koordinators geht hervor, daß in der ersten Periode bis 19922.711 Anerkennungsverfahren eingeleitet worden sind. 2050 Anerkennungen wurden dabei direkt ausgesprochen, während sich 115 Kandidaten einer Eignungsprüfung unterziehen mußten. In 43 Fällen wurde ein Anpassungslehrgang durchgeführt. Trotz der hohen Zahl wurde nur in fünf Fällen 
Berufung gegen die Entscheidung eingelegt. Keines dieser Berufungsverfahren führte jedoch zu einer gerichtlichen Überprüfung der Entscheidung.

\section{c. Beurteilung der Umsetzung}

Die allgemeine gesetzliche Regelung (No. 824) entspricht in ihrem Wortlaut weitgehend der Richtlinie 89/48/EWG. Soweit erforderlich haben die einzelnen Berufsorganisationen Ausführungsbestimmungen erlassen. Dies gilt besonders für die rechtsberatenden Berufe und die Lehrer ${ }^{1052}$, ansonsten wird jeder Einzelfall anhand des allgemeinen Gesetzes von der zuständigen Behörde beurteilt. Die hohe Zahl der bisher im Vereinigten Königreich durchgeführten Anerkennungsverfahren, zeigt deutlich, daß das System funktioniert. Dabei erhielt die absolute Mehrheit eine sofortige Anerkennung ohne Anwendung von Kompensationsinstrumenten ${ }^{1053}$.

\section{\$ 3. Die Richtlinie $92 / 51 /$ EWG über eine zweite allgemeine Regelung zur Anerkennung beruflicher Befähigungsnachweise}

\section{A. ENTSTEHUNGSGESCHICHTE DER RICHTLINIE 92/51/EWG}

Das Europäische Parlament hatte bereits bei der ersten Lesung des Vorschlags der Kommission für die spätere Richtlinie 89/48/EWG die Auffassung vertreten, daß mit dem Richtlinienentwurf nur ein Teil der Anerkenmungsprobleme hinsichtlich der Diplome gelöst würden. Dementsprechend hatte das Europäische Parlament die Kommission aufgefordert, die notwendigen Maßnahmen zu treffen, um "die Anerkennung der Gesamtheit der beruflichen Befähigungsnachweise zugunsten der Bürger der Gemeinschaft, die keinen Zugang zu einer Hochschulausbildung hatten", sicherzustellen ${ }^{1054}$. Auch der Wirtschafts- und Sozialausschuß bezeichnete in seiner Stellungnahme den Kommissionsvorschlag als einen ersten Schritt, dem ein "analoges Vorgehen in anderen Fällen folgen sollte" 1055 .

Noch vor der Annahme der Richtlinie 89/48/EWG teilte die Kommission dem Rat mit, sie beabsichtige, die Grundsătze der allgemeinen Regelung zur Anerkennung der Hochschuldiplome auf alle Diplome auszudehnen, die für die Ausübung reglementierter Berufe in den Mitgliedstaaten verlangt werden ${ }^{1056}$. Sie bestätigte diese Absicht auch in ihrem dem Europäischen Parlament vorgelegten Arbeitsprogramm für $1989^{1057}$.

1052. Sielte dazu die Fallstudien für die rechtsberatenden Benfe Seite 343 und für die Lehrer Seite 400.

1053. Im Ja/rr $₫ 991$ wurden bei 1665 Anträgen die automatische Anerkennung in 1189 der Fälle ausgespro chen. Allerdings betraf dies zurn überwiegenden Teil die Anerkennung von irischen Berufsangehörigen und Lehrern.

1054. Entschließung des EP, ABI. Nr. C 345 vom 31. Dezember 1985, 81 .

1055. Stellungnathme des WSA, Dok. WSA 90/86 vom 19. Januar 1986, 6.

1056. Bericht über den Stand der Arbeiten gemäß Art. 8b EWGV vom 17. November 1988, KOM (88) 650 endg., 15

1057. DOK. (SEK) I endg., 27. 
Im Sommer 1989 hatte die Kommission schließlich den ursprünglichen Vorschlag für eine ergänzende Richtlinie vorgelegt ${ }^{1058}$, in der vor allem eine Regelung für kürzere Hochschulausbildungen vorgeschlagen wurde. Hierauf gaben das Europäische Parlament ${ }^{1059}$ und der Wirtschafts- und Sozialausschuß ${ }^{1060}$ ihre Stellungnahmen $a b$. Das Europäische Parlament vertrat dabei u. a. die Auffassung., daß eine Erweiterung der Anerkennungskonzeption bezüglich der paramedizinischen Berufe erfolgen müsse ${ }^{106 !}$. Mit diesem Änderungsvorschlag wies das Europäische Parlament auf ein Problemgebiet hin, das die weitere Diskussion um die Richtlinie maßgebend bestimmen sollte.

Die Kommission legte daraufhin einen geänderten Vorschlag vor ${ }^{1062}$ " Nach dem ursprünglichen Zeitplan sollte die Richtlinie bereits im Juli 1991 in Kraft treten ${ }^{1063}$. Diese Planung konnte jedoch in keiner Weise eingehalten werden. Erst im Juni 1992 ließ sich die gewünschte Einigung im Rat erzielen, wobei den Mitgliedstaaten eine zweijährige Frist für die Umsetzung eingeräumt wurde.

\section{B. ANWENDUNGSBEREICH DER RICHTLINIE 92/51/EWG}

Die Richtlinie 92/51/EWG, die am 18. Juni 1992 vom Rat verabschiedet worden ist ${ }^{\text {1064 }}$, bedeutet eine Ergänzung und eine Ausweitung des Konzeptes, das der Richtlinie $89 / 48 /$ EWG zugrundeliegt ${ }^{1065}$. Durch sie soll ein geschlossenes System entstehen, das allen Gemeinschaftsangehörigen das Recht gibt, die in einem anderen Mitgliedstaat erworbenen Berufsqualifikationen in einem Aufnahmestaat anerkennen zu lassen, falls ein der Qualifikation entsprechender Beruf oder eine berufliche Tätigkeit dort reglementiert ist. Die von Lonbay ausgesprochene Hoffnung, die Kommission möge dieses komplizierte Vorhaben aufgrund der Vlassopoulou-Entscheidung als überflüssig fallen lassen, wurden somit nicht erfiillt ${ }^{1066}$.

Die Richtlinie 92/51/EWG ist ebenso wie die allgemeine Hochschuldiplom-Richtlinie auf die Artikel 49,57 Abs. 1 und 66 EWGV gestützt, wobei wie bei der ersten allge-

1058. KOM (89) 372 endg. - Syn 209 vom 8. August $1989 ;$ AB!. Nr. C 263 vom l6. Oktober 1989, 1.

1059. ABI. Nr. C 149 vom 18. Juni 1990, 149

1060. AB1. Nr. C 75 wom 26. März 1990, 11 .

1061. ABI. Nr. C 149 vom 18. Juni 1990, 146, 2. Änderungsworschlag.

1062. Geänderter Vorschag: A.BI. Ni. C 217 vom 1. September 1990, 4.

1063. Im geänderten Vorschlag war dieser Termin urn ein Jahr verschoben.

1064. Richtinie 92/51/EWG des Rates vom 18. Iuni 1992 über eine zweite allgemeine Regelung zur Anerkenurung beruflicher Befähigungsnachweise in Ergänzung zur Richtlinie 89/48/EWG, ABU, Nr L 209 vom 24. Juli 1992, 25 .

1065. Vorschliag für eine Richtlinie des Rates über eine zweite allgemeine Regelung zur Anerkennung beruflicher Befahigungsnachweise in Ergänzung zur Richtlinie 89/48/EWG, KOM (89) endg. - SYN 209,1 .

1066. Lonbay spricht in diesem Zusammenthang won "the diabolically complex and completely unnecessary proposed second gemeral system" ,ELR 1991, 507 (516). Siehe auch die kritischen Bemerkungen von Henninger, BB 1990, 73 (76), der für den Fortbestand des dualen Ausbildungssystems in Deutschland fürchtet. 
meinen Regelung keine Sonderbestimmungen für den Dienstleistungsverkehr aufgenommen sind. Von der Richtlinie 92/51/EWG erfaßt sind vor allem Ausbildungsgänge im postsekundären Bereich von weniger als drei Jahren sowie Ausbildungen, die an einer Sekundarschule abgeschlossen wurden und gegebenenfalls durch eine Berufsausbildung oder durch Berufspraxis ergänzt werden ${ }^{1067}$.

Die Richtlinie 92/51/EWG soll, wie ihr Name auch suggeriert, eine Ergänzung der allgemeinen Hochschulrichtlinie 89/48/EWG darstellen. Sie ist daher nur im Zusammenhang mit dieser zu lesen und zu verstehen ${ }^{1068}$. Wie die erste Richtlinie gilt auch die ergânzende allgemeine Regelung nicht für reglementierte Berufe, für die bereits aufgrund besteherder Einzelrichtlinien eine Regelung zur Anerkennung der beruflichen Befähigungsnachweise getroffen ist ${ }^{106 \%}$.

Dies gilt namentlich für Einzelrichtlinien, mit der die gegenseitige Anerkennung von Ausbildungsgängen eingefuhrt wird, die vor Eintritt in das Erwerbsleben abgeschlossen werden ${ }^{1070}$. Ebenfalls vom Anwendungsbereich der Richtlinie 92/51/EWG ausgeschlossen werden die reglementierten Berufe und Tätigkeiten, die Gegenstand einer Einzelrichtlinie sind, die hauptsächlich auf die Anerkennung von technischen Fähigkeiten abzielt, die auf einer in einem Mitgliedstaat erworbenen Berufserfahrung beruht ${ }^{1071}$. Gedacht werden muß hierbei an die häufig als "Übergangsrichtlinien" bezeichneten Regelungen, die insbesondere handwerkliche und kaufmännische Tätigkeiten betreffen ${ }^{1072}$. Es handelt sich dabei um Richtlinien, von denen einige vor mehr als 25 Jahren erlassen wurden ${ }^{1073}$ "Die Bezeichnung "Übergangsrichtlinien" beruht darauf, daß ursprünglich vorgesehen war, diese Regelungen durch ausführliche Anerkennungsrichtlinien zu ersetzen ${ }^{1074}$. Da diese Richtlinien im Laufe der Jahre ihre Funktionsfähigkeit unter Beweis gestellt haben, bestand kein Wunsch, ihren Regelungsbereich in das System der Richtlinie 92/51/EWG aufzunehmen ${ }^{1075}$.

Problematisch war jedoch, daß einige dieser Übergangsrichtlinien ausschließlich für selbständige Tätigkeiten galten. Um nun zu verhindern, daß bei Ausübung der selben Tätigkeit im Arbeitnehmerverhältnis dlie ergänzende Richtlinie 92/51/EWG zur Anwendung kåme, wodurch die Ausübung der gleichen Tätigkeit, je nachdem, ob sie in abhängiger Beschäftigung oder selbständig ausgeübt wird, verschiedenen rechtlichen

1067. Siehe 9. Erwägungsgrund der Richtlinie 92/51/EWG

1068. Siehe 5. Erwägungsgnund der Richtlinie 95/51/EWG

1069. Siehe den 6. Erwägungsgrund und Art. 2 Abs, 2 der Richtlinie 92/51/EWG und Art.2 Abs. 2 der Richtlinie 89/48/EWG.

1070. Süehe dazu den 6. Erwägungsgrund der Richtlinie 92/51/EwG und Art. 2 zweiter Absatz der Richulinie 92/51/EWG.

1071. Siehe den 7. Erwägungsgrund der Richtlinie 92/51/EWG und Art. 2 Abs. 2 der Richlinie 92/51/EWG

1072. Dazu Klinge 1990, 26; Klinge, GewA 19883,296 ; Klinge, WiVerw $1987 / 3,137 \mathrm{ff}$; Clansnitzer, EGHandbuch, $211 \mathrm{ff}$.

1073. Siehe die in Anhang A der Richtlinie 92/51/EWG aufgelisteten Richtlinien.

1074. Jeder, 6; Klinge 1990, 26; Clausnitzer, EG-Handbuch, 211

1075. Auch erwies sich eine Koordinierung im Bereich der handwerklichen Berufstätigkeit als sehr schwierig. 
Anerkennungsregelungen unterliegen würde, wurde beschlossen, den Anwendungsbereich der Übergangsrichtlinien auch auf abhängig Beschäftigte zu erweitern ${ }^{1076}$.

Diese Erweiterung wurde in einer gesetzgebungstechnisch ungewöhnlichen Form durchgeführt, die sich nicht durch besondere Deutlichkeit auszeichnet. In Art. 2 Abs. 3 der Richtlinie 92/51/EWG heißt es nämlich, daß die in Anhang B aufgeführten Richtlinien auch für die Ausübung der in diesen Richtlinien genannten Tätigkeiten in abhängiger Beschäftigung gelten. Die Erweiterung wurde somit nicht durch eine Ergänzung in den entsprechenden Richtlinien oder durch eine Spezialrichtlinie bewirkt, sondern durch eine Verweisung auf einen Anhang im dritten Absatz eines Artikels einer Richtlinie, die nicht in einem direkten Zusammenhang mit den zu ändernden Richtlinien steht! Im ursprünglichen Entwurf der Richtlinie hatte die Kommission zumindest noch einen eigenen Artikel für diese Ergänzung reserviert ${ }^{107}$. $\mathrm{Zu}$ bezweifeln ist, ob ein sollches Änderungsverfahren für die Behörden der Mitgliedstaaten nachvollziehbar ist.

In der Kommission wird allerdings erwogen alle Übergangsrichtlinien zu konsolidieren. Dieses Projekt wurde unter der Bezeichnung "dritte allgemeine Richtlinie" von der Kommission initiiert ${ }^{1078}$. Im Zuge einer solchen Konsolidierung müßte auch die Regelung in Art. 2 Abs. 3 der Richtlinie 92/51/EWG in den konsolidierten Richtlinientext aufgenommen werden.

\section{ABGRENZUNG DES ANWENDUNGSBEREICHS BEmER ANERKENNUNGSRICHTLINIEN}

Für die Abgrenzung der Anwendungsbereiche beider Anerkennungsrichtlinien ist die Unterscheidung von Ausbildungsniveaus entscheidend. Die ergänzende Regelung umfaßßt die beiden Berufsausbildungsniveaus, die von der Richtlinie 89/48/EWG nicht erfaßt sind. Nimmt man beide Richtlinien zusammen, so handelt es sich damit um die folgenden drei Ausbildungsniveaus:

- Das erste Niveau bezieht sich auf die Sekundarschulausbildung.

- Das zweite Niveau betrifft die kurzen Studiengänge und alle in einem Anhang C aufgeführten Studiengänge.

- Beim dritten Niveau handelt es sich um Studienabschlüsse nach einem Studium von mindestens drei Jahren ${ }^{1079}$.

Da die Richtlinie 92/51/EWG zwei Ausbildungsniveaus und die Richtlinie 89/48/EWG ein drittes Ausbildungsniveau erfaßt, soll im Rahmen der Richtlinie 92/51/EWG nun neben einer innerhalb des jeweiligen Ausbildungsniveaus vorgesehenen Anerkennung auch die Anerkennung zwischen diesen Stufen in einem gewissen Maße ermöglicht

1076. Siehe den 7. Erwägungsgnund der Richtlinie 92/51/EWG und Art.2 dritter Absatz der Richtlinie 92/51/EWG unter Verweisung auf die in Anhang B aufgeführten Richtinien.

1077. Art. 16 des Richtlinienentwurfes, ABI. Nr. C 263 vom 16. Oktober 1989, 1

1078. Siehe dhazu SEPLIS, Juli 1995, 7.

1079. KOM (89) 372 endg. - SYN 209, 5. 
werden ${ }^{160}$. Dabei ist ein Durchstieg vom untersten zum höchsten Niveau jedoch ausgerchlosser.

Diese Durchlässigkeit zwischen den einzelnen Ausbillungsniveaus hat zu einer äuBerst komplexen Gesamtregelung geführt. Wurde bereits hinsichtlich der Richtlinie 89/48/EWG der Umfang und die Komplexität der Regelung beklagt ${ }^{1081}$, so wird diese nun um ein Vielfaches von der neuen ergänzenden Richtlinie übertroffen. Auch ist đie Richtinie 92/51/EWG ein Klassisches Beispiel eines europäischen Giesetzgebungsvorganges: Ein zwar komplizierter, aber durchaus noch verständlicher Kommissionsentwurf kann sich bis zur Entscheidung im Rat zu einem textlichen Monstrum verwandeln ${ }^{1082}$. Besonders auffallend ist der Unterschied zwischen Art. 1 des Kommissionsentwurfes und der endigültigen Fassung des Art. 1 der Richtlinie 92/51/EWG. Allerdings muß zugegeben werden, daß die Neufassung der Definition zu einer erheblichen Erweiterung des Anwendungsbereiches der Richtlinie geführt hat, die inhaltlich sehr zu begrïBen ist. Alle textlichen Unklarheiten sind jedoch nicht durch die Vergrößerung des Anwendungsbereichs bedingt. Die Undeutlichkeit wird noch verstärkt durch die Tatsache, daß die unterschiedlichen sprachlichen Fassungen der Richtlinie 92/51/EWG an einigen nicht unerheblichen Punkten voneinander abweichen ${ }^{1083}$.

Die Mitgliedstaaten waren gemäß Art. 17 Abs. 1 der Richtlinie 92/51/EWG verpflichtet, diese bis zum 18. Juni 1994 umzusetzen. Diese Umsetzung war und ist nicht einfach. Zwar konnte man bei der Umsetzung dieser Richtlinie grundsätzlich von den im Laufe der letzten drei Jahre bezüglich der Hochschulrichtlinie gewonnenen Erfahrungen profitieren ${ }^{1084}$, jedoch ergaben sich nicht unerhebliche Schwierigkeiten, um überhaupt nur den Regelungsbereich d.h. die von der Richtlinie erfaßten reglementierten Berufe festzustellen. Hierbeil manifestierte sich ein noch wesentlich größeres Informationsdlefizit, als dies bereits bei der Umsetzung der Richtlinie 89/48/EWG der Fall war.

Es muß berïcksichtigt werden, daß anders als in den klassischen Freien Berufen, die bereits traditionsgemäl\} einen internationallen Austausch sowohl auf akademischem wie beruflichem Niveau kannten und damit auch weit eher bereit waren, das vielbe-

1080. Berscheid/Kirschbaum, 136, die eine erste kurze Erlfuterung zum Richtlinienentwarf geben. Siehe auch Lebibrock, EuZW 1992, 465

1081. Winkel, Der freie Beruf 8, 1991, 22

1082. Lonbay, ELR 1991, 507 (516).

1083. An dieser Stelle möchte ich ebenfalls auf Ant 1 a) zweiter Gedankenstrich, Unterabs. i) der Richtlinie 92/51/EWG verweisen, wo es in der deutschen Fassung heilbt ".... - wobei eine Voraussetzung für die Zuilassung zu einem solchen Ausbildungsgang in der Regel der Abschluß der für die Aufnalhme eines Hochschulstudtums erforderlichen Sekundarausbildung ist - .."', wohingegen der englische Text ant dieser Stelle von ". . the suicessful completion of the secondary course required to abtain entry to university or higher education..." spricht. Auch die riederländische und französische Fassung verwenden die Begriffe "universitair of hoger anderwijs" bzw. I"enseignement universitaire ou supérieur.

1084. Diese Hoffnung sprach auch der WSA in seiner Stellungnahme aus , ABI. Nr. C 75 vom 26. Mairz $1990,11 \mathrm{Nr}, 1.8$. 
schworene gegenseitige Vertrauen in die Ausbildungssysteme der anderen Mitgliedstaaten aufzubringen, ein solcher Austausch bei den von der ergänzenden Richtlinie erfaßten Berufen im allgemeinen unbekannt ist.

Desweiteren entstehen nicht unerhebliche Probleme, wenn die Diplome des Herkunftstaates und die reglementierte Tätigkeit des Aufnahmestaates unterschiedlichen Ausbildungsniveaus zugerechnet werden müssen. In der Richtlinie sind verschiedene Varianten geregelt, falls die von einem Zuwanderer absolvierte Ausbildung nicht dem im Aufnahmestaat geforderten Niveau entspricht. Bei der praktischen Anwendung der Richtlinie sind Streitfälle sicher unvermeid $\|$ ich, so daß mit verschiedenen Verfahren vor dem EuGH gerechnet werden muß.

\section{STRUKTUR DER RICHTLINIE 92/51/EWG}

Die Richtlinie 92/51/EWG ist in elf Kapitel unterteilt. Desweiteren verfügt die Richtlinie über vier mit $A, B, C, D$ bezeichnete Anhänge.

Kapitel I enthält in Art. 1 die Definitionen und entspricht dabei in seinem Aufbau im wesentlichen der Hochschuldiplom-Richtlinie. Teilweise entspricht auch der Wortlaut der einzelnen Bestimmungen dem der Richtlinie 89/48/EWG. Dies gilt namentlich für die Definitionen der Begriffe Aufnahmestaat, reglementierter Beruf und Berufserfahrung. Einige der Definitionen haben zwar teilweise den selben Wortlaut, sind jedoch mit Ergänzungen versehen. Dies gilt für die Definitionen der Begriffe reglementierte berufliche Tätigkeit, Anpassungsliehrgang und Eignungsprüfung. Diese Ergänzungen sind geprägt durch die Erfahrungen bei der Umsetzung der Richtlinie 89/48/EWG. Abweichende Definitionen oder Neuschöpfungen enthalten die Begriffe Diplom, Prüfungszeugnis, Befähigungsnachweis und reglementierte Ausbildung. Vor allem der Begriff "Diplom" im Sinne der ergänzenden Regelung ist vom Begriff "Diplom" der Richtlinie 89/48/EWG zu unterscheiden.

Kapitel II bestimmt in Art. 2 den Anwendungsbereich der Richtlinie. Art. 2 erster Absatz ist gleichlautend mit Art. 2 der Richtlinie 89/48/EWG. Die Absätze 2 und 3 verweisen auf die bereits genannten Übergangsrichtlinien ${ }^{1085}$.

Mill Kapitel III beginnen die materiellen Anerkennungsregelungen. Dabei enthalten die Art. 3 und 4 die Anerkennungsregeln, die gelten, wenn der Aufnahmestaat ein Diplom im Sinne der Richtlinie 92/51/EWG oder der Richtlinie 89/48/EWG verlangt. Es handelt sich damit um eine Anerkennung zwischen Ausbildungsniveau 2 und 3. Kapitel IV regelt die Anerkennung zwischen Ausbildungsniveau 1 und 2. Kapitel $\mathrm{V}$ bestimmt die Fälle, wenn der Aufnahmestaat lediglich ein Prüfungszeugnis fordert. Kapitel VI wiederum enthält Sonderregelungen für die Anerkennung sonstiger Qualifikationen. 
Kapitel VII entspricht den Art, 6,7 und 8 der Richtlinie 89/48/EWG. Die Kapitel VIII, IX, X, und XI regeln Verfahrensfragen bezüglich der Koordinierung, der Wahl zwischen Anpassungslehrgang und Eignungsprüfung, der Änderung der Anhänge $C$ und D sowie bezüglich der Umsetzung. Auch in diesen Kapiteln finden sich weitgehend übereinstimmende Formulierungen wie in den entsprechenden Artikeln der Hochschulrichtlinie.

\section{E. INHALT DER RICHTLINIE 92/51/EWG}

Vergleicht man die Richtlinie 92/51/EWG mit der Richtlinie 89/48/EWG so fällt als erster gravierender Unterschied die Definition des Begriffes "Diplom" auf. Gemäß Art. 1 der Richtlinie 89/48/EWG gelten als Diplome alle Diplome, Prüfungszeugnisse und sonstige Beschäftigungsnachweise, mit denen ein Studium von mehr als drei Jahren bescheinigt wird. Die Begriffe Diplome, Prïfungszeugnisse und Beschäftigungsnachweise werden demnach in dieser Richtlinie als Synonyme verwendet. Dies gilt nicht für die Richtlinie 92/51/EWG. Hier werden in Art. 1 Buchstabe a) der Begriff "Diplom", in Art. 1 Buchstabe b) der Begriff "Prüfungszeugnis" und in Art. 1 Buchstabe c) schließlich der Begriff "Befähigungsnachweis" jeweils als eigenständige Begriffe mit unterschiedlicher Bedeutung definiert. Als allgemeiner Terminus wird dagegen die Bezeichnung "Ausbildungsnachweis" verwendet. Die unterschiedliche Begriffswerwendung ist bedingt durch die verschiedenen Ausbildungsniveaus, denen in der Richtlinie Rechnung getragen wird. Dementsprechend kommt in den Kapiteln III bis VI der Richtlinie 92/51/EWG, die die verschiedenen Anerkennungsregelungen enthalten, die unterschiedliche Begriffsverwendung erneut deutlich zum Tragen. Danach bezieht sich der Begriff "Diplom" i.S. von Art. 1 Buchstabe a) der Richtlinie 92/51/EWG auf die mittlere Ausbildungsstufe, der Begriff "Prüfungszeugnis" auf die unterste Stufe.

\section{Der Begriff "Diplom" gemäß der Richtlinie 92/51/EWG}

Gemäß Art. 1 Buchstabe a) der Richtlinie 92/51/EWG gilt als Diplom jeder Ausbildungsnachweis, aus dem hervorgeht, daß der Diplominhaber entweder - als erste Alternative - einen postsekundären Ausbilldungsgang von mindestens einem Jahr beziehungsweise eine Teilzeitausbildung von entsprechender Dauer absolviert hat oder aber - als zweite Alternative - einen der in Anhang $\mathrm{C}$ aufgeführten Ausbildungsgänge mit Erfolg abgeschlossen hat.

a. Alternative 1: postsekundäre Ausbildung von 1 oder 2 Jahren

Neben dem Studium von ein oder zwei Jahren wird als weitere Voraussetzung bei Alternative 1 geforderte, daf für die Zulassung zu einer solchen postsekundären Ausbi]dung in der Regel der Abschluß der für die Aufnahme eines Hochschulstudiums erforderlichen Sekundarausbildung ist. An diesem Punkt ist die deutsche Fassung der Richt- 
linie äußerst unglücklich. Wie bereits an anderer Stelle ausgeführt ${ }^{1086}$, weicht der deutsche Text von der englischen, französischen und niederländischen Fassung ab.

Unter dem Abschluß der für die Aufnahme eines Hochschulstudiums erforderlichen Sekundarausbildung versteht man im allgemeinen einen Ausbildungsnachweis des Typs "Abitur", "baccalaureat", "maturita". Mit der Formulierung in der deutschen Fassung der Richtlinie können Zweifel entstehen, ob die Fachhochschulreife unter diese Definition zu subsumieren ist. Die deutsche Fachhochschulreife ist nämlich gerade keine Qualifikation, die einen unmittelbaren Hochschulzugang ermöglicht. Sie ist kein Abitur. Würde man die Analyse der Richtlinie 92/51/EWG allein auf den deutschen Text stützen, so könnte man zu dem Schluß kommen, daß die Fachhochschulreife nicht ausreichend ist, um unter die genannte Definition zu fallen. Der englische, französische und niederländische Text, worin von Zugang zu "university or higher education", "universitair of hoger onderwijs" und. "l'enseignement universitaire ou supérieur" gesprochen wird, rechtfertigt jedoch das gegenteilige Ergebnis, das auch durch den Sinn und Zweck der Bestimmung bestätigt wird. Es wäre wohl widersinnig, die Fachhochschulreife zwar für ein Diplom des dritten Ausbildungsniveaus als ausreichend anzusehen, dies jedoch für Diplome des zweiten Niveaus zu verneinen. Der Begriff "Hochschulstudium" muß daher einschließlich des Fachhochschulstudiums - im Sinne des englischen "higher education" - verstanden werden. Dieses Ergebnis ist z.Z. allerdings von mehr theoretischer Natur, da es meines Wissens weder Fachhochschulausbildungen noch Hochschulstudien in Deutschland für reglementierte Berufe gibt, die weniger als drei Jahre dauern ${ }^{1087}$. Diese Studiengänge werden aber von der Richtlinie 89/48/EWG erfaßt. Die kurzen Studiengänge sind dagegen in Belgien, Frankreich, Griechenland und Großbritannien ${ }^{108 *}$ sehr geläufig. Würde in Deutschland in der Zukunft ein solch kurzer Studiengang an einer Fachhochschule oder an einer Universität eingeführt, dann müßte dieser unter die Definition des Art. 1 Buchstabe a) zweiter Gedankenstrich Ziffer i) gerechnet werden.

Die Forderung nach einer abgeschlossenen Sekundarausbildung, die den Zugang zur Hochschule gewährt, läßt jedoch noch andere Fragen aufkommen. In einigen Mitgliedstaaten kennt man neben dem traditionellen Sekundarabschluß durch Erlangung der

1086. Siehe Seite 240

1087. Als Ausnahme von diesem Grundsatz könnte ein zweijähriger wirtschaftswissenschaftlicher Studiengang an der Universitä: Augsburg, der als Versuch eingerichtet worden ist, bezeichnet werden. Da dieses Studium jedoch nïcht zu einem reglementierten Beruf fuhr, ist es fur diese Thematik nur vom einer beschränkten Relevanz.

1088. In Grolbbritannien könnte sich deren Bedeutung noch verstärken, falls die von der Regierung aus Ersparnisgründen geplante Verkürzung der Universitütsstudien auf mehrheitlich zwei Jalire tatsächlich durchgeführt wird. Selbst klassische Ausbilldungen. wie die juristische wirden damit in den Anwendungsbereich der Richtlinie 92/51/EWG fallem. Bisher gibt es nur ein zwe ijähriges juristisches Studium an der Uniwersită Buckingham. 
allgemeinen Hochschulreife auch noch andere Formen des Hochschulzuganges ${ }^{1089}$. Bei einer rein wörtlichen Interpretation des Richtlinientextes könnten Kandidaten, die über einen solchen Seiteneinstieg zum Diplominhaber geworden sind, mit Schwierigkeiten konfrontiert werden. Hierbei stellt sich die Frage, ob das Kriterium "Hochschulzugang" individucll erfüllt sein muß oder lediglich allgemein den Ausbildungsbedingungen des postsekundären Studiums zugrunde gelegt wird. Für die zweite Alternative sprechen die Worte "...in der Regel ...". Diese Worte unterstellen, daß grundsătzlich die von der Richtlinie erfaßten postsekundären Ausbildungen eine Sekundarausbildung, die zur Hochschulreife führt, voraussetzen, daß von dieser Bedingung jedoch auch abgewichen werden kann. Dies bedeutet für den individuellen Fall, daß - falls in einem Mitgliedstaat ein Seiteneinstieg als gleichwertig mit der Erlangung der Hochschulreife anerkannt wird - dieser Fall auch die von der Richtllinie gestellten Voraussetzungen erfüllt.

\section{b. Alternative 2: Berufsausbildungen i.S des Anhanges $\mathrm{C}$}

Gemäß Art. 1 Buchstabe a) zweiter Gedankenstrich Ziffer ii) gilt auch als Diplom, wenn der Nachweis erbracht wird, einen in Anhang $C$ aufgeführter Ausbildungsgang mit Erfolg absolviert zu haben. Diese Variante ist erst durch den geänderten Vorschlag der Kommission in das System der Richtlinie aufgenommen worden. Die Erweiterung erfolgte vor allem wegen der insbesonders in Deutschland und Luxemburg bestehenden Berufsausbildungen im Bereich der paramedizinischen Berufe sowie der medizinischtechnischen Handwerksberufe, die nach dem ersten Entwurf der Richtlinie auf dem untersten Niveau des Prüfungszeugnisses verblieben wären, obwohl diese Einstufung aufgrund der Qualifikation der Berufe nicht gerechtfertigt gewesen wäre ${ }^{1090}$. Andere Mitgliedstaaten wie die Niederlande, Dänemark und Großbritannien hatten ähnliche Probleme ${ }^{1091}$. Es ging dabei auch nicht um eine reine Prestigefrage. Für die Freizügigkeit eines Migranten innerhalb der Gemeinschaft ist es vielmehr von entscheidender Bedeutung, auf welchem Niveau seine Ausbildung eingestuft wird. Besitzt er ein Hochschuldiplom oder ein Diplom i.S. der Richtlinie 92/51/EWG, so ist seine Freizügigkeit, abgesehen von den möglichen Anpassungsmechanismen, weitgehend uneingeschränkt. Besitzt er dagegen ein Prüfungszeugnis, dann sind inm die Mitgliedstaaten, die eine Hochschulausbildung voraussetzen, verschlossen.

1089. So gibt es 2.B. in den Niederlanden das sogenannte colloquium doctum, eine individuelle Prüfung der verschiedenen Fakult țten, die es Kandidaten ohne Hochschulreife emöglicht durch einen Seiteneinstieg den Zugang zu einer bestimmten Fakultät zu erlangen.

1090. Der Bundesrat hatte in seinen Stellungnahmen zu den Richtliniementwürfen die Bemachteiligung der deutschen paramedizinischen Berufe stark hervorgehoben, falls diese nicht entweder in Einze Urichtlinien geregelt oder als gleichwertig mit der Hochschulausbildung unterhalb von drei Jahren in den anderen Mitgliedstaaten angesehen würden. Siehe dazu BR-Drucksache $484 / 89$ wom 10. November 1989, und vom 16. Februar 1990, 4. Die zweite Alternative hat schlieBlich Eingang in den Richtlinientext gefunden. Berscheid/Kirschbaum, 135.

1091. Bei diesen Mitgliedstaaten waren weniger die paramedizinischen als die Seeschiffahrtsbenfe und vechnischen Berufe betroffen. 
Der Streit um Aufnahme dieser Berufe in die Definition des zweiten Ausbildungsniveaus hat die Verabschiedung der Richtlinie nicht unwesentlich verzögert. An dieser Stelle zeigten sich erneut kulturelle Ausbildungsunterschiede zwischen den Mitgliedstaaten, die sich nicht oder nur sehr schwierig in eine allgemein geltende Definition pressen lassen. Der urspüngliche Kommissionsentwurf hatte sich bei der Definition des Diploms wesentlich vom romanischen Bildungssystem bestimmen lassen. Die darauf gerichtete Kritik führte zu dem Versuch, für alle qualifizierten Berufsabschlüsse der Mitgliedstaaten eine allgemeine Definition zu finden. Dieser Versuch scheiterte. Einigung konnte schließlich nur über die Zufügung eines Anhang $C$ erzielt werden. Damit war die Diskussion selbstverständlich nicht abgeschlossen, da nun das Tauziehen um die Aufnahme in den illusteren Kreis begann.

Bei den betroffenen Ausbildungsgängen handelt es sich nicht um Hochschulstudien. Sie setzen häufig auch keine Hochschulreife voraus. Das Ausbildungsniveau ist jedoch nach Ansicht einiger Mitgliedstaaten dem der kurzen Studiengänge vergleichbar ${ }^{10 \% 2}$. In Anhang $\mathrm{C}$ werden neben den paramedizinischen Berufen und den medizinisch-technischen Handwerksberufen auch Berufe der Seeschifffahrt, einige technische Berufe sowie besondere Bildungs- und Ausbildungsgänge im Vereinigten Königreich genannt.

Bei den paramedizinischen Berufen wird gemäß Anhang C Nr. 1 eine Gesamtausbildung von mindestens dreizehn Jahren unterstellt, wovon eine mindestens dreijährige Fachausbildung sein mußß. Bezüglich dieser fachlichen Ausbildung werden drei Varianten vorgestellt. Minimal muß eine zweijährige Ausbildung an einer Fachschule nachgewiesen werden, die durch eine einjährige Berufspraxis oder ein einjähriges Praktikum ergänzt wird. Es gibt jedoch auch die Variante einer zweieinhalbjährigen Ausbildung an einer Fachschule mit sechsmonatigem Praktikum und letztlich eine dreijährige Ausbildung an einer Fachschule mit anschließenden Spezialkursen. Mit dieser Regelung ist gelungen alle die qualifizierten Berufe, die keine Reifeprüfung i.S. eines baccalauréat, Abiturs oder maturità voraussetzen, aber eine Gesamtausbildung von 13 Jahren haben, als Diplom einzustufen. Nicht dagegen erfaßt sind die Berufe, die eine Gesamtausbildung von $121 / 2$ Jahren oder weniger haben, wie etwa in Deutschland der medizinisch-technische Assistent oder der Diätassistent ${ }^{1093}$.

Entsprechende Regelungen wie bei den paramedizinischen Berufen finden sich auch für die anderen in Anhang $\mathrm{C}$ aufgenommenen Berufszweige. Dabei variiert die erforderliche Ausbildungsdauer ${ }^{1094}$. Im allgemeinen wird aber neben einer acht- bis neunjährigen Pflichtschulzeit eine mehrjährige Berufsausbildung gefordert ${ }^{10 \% 5}$.

1092. Berscheid/Kirschbaum, 135.

1093. Leibrock, EuZW 1992465 (467).

1094. Als eine der längsten Ausbildungen wird der niederländische Gerichtsvollzieher (gerechtsdeurwaarder) genannt. Bei diesem Beruf beläuft sich die Gesamtausbildung auf 19 Jahre.

1095. Siehe zu den unterschiedlichen Ausbildungssystemen die Veröffentlichung von EURYDICE und CEDEFOP: Strukturen der allgemeinen und beruflichen Bildung in den Mitgliedstaaten der Europäischen Gemeinschaft, Brüssel 1991. 
Der Streit um Anhang $C$ ist mit der Verabschiedung der Richtlinie in keiner Weise beendet. Gemäß Art. 15 Abs. 1 der Richtlinie 92/51/EWG können die Verzeichnisse der Ausbildungsgänge in den Anhängen $C$ und $D$ von jedem betroffenen Mitgliedstiat auf begriundeten Antrag bei der Kommission geändert werden. Die Kommission prüft den betreffenden Ausbildungsgang, wobei sie Vergleiche mit den in anderen Mitgliedstaaten gestellten Ausbildungsanforderungen zieht. Wesentliches Kriterium bei der Entscheidung sollte gemäß Art. 15 Abs. 2 der Richtlinie 92/51/EWG sein, ob der Diplominhaber über einen vergleichbar hohen beruflichen Ausbildungsstand verfügt wie ein Absolvent eines postsekundären Ausbildungsgangs gemäß Art. 1 Buchstabe a) Unterabs. 1 zweiter Gedankenstrich Ziffer i) der Richtlinie 92/51/EWG. Entscheidend ist dabei auch đas $\mathrm{Maß}$ an Verantwortung und Selbständigkeit bei der Berufsausübung. Mit berücksichtigt sollte dabei werden, ob in einem Mitgliedstaat für den gleïchen Beruf ein Diplom i.S. der Richtlinie 89/48/EWG verlangt wird. Die durch die Richtlinie 92/51/EWG garantierte Durchlässigkeit zwischen den Ausbildungsstufen macht eine kritische Überprüfung einer Ausbildung vor Aufnahme in den Anhang $C$ besonders erforderlich. Die Kommission wird bei der Entscheidung von einem Ausschuß unterstützl, der unter Vorsitz der Kommission aus Vertretern der Mitgliedstaaten zusammengesetzt ist:

Gemäß Art. 15 Abs. 4 der Richtlinie 92/51/EWG gibt der Ausschuß eine Stellungnahme zus einem von der Kommission vorgestellten Entwurf ab. Diese Stellungnahme wird mit Mehrheit abgegeben, wobei die Stimmen entsprechend Art. 148 Abs. 2 EGV gewogen werden. Die Kommission nimmt an dieser Abstimmung nicht teil, sie erläßt jedoch die unmittelbar geltende Maßnahme. Weicht die Entscheidung der Kommission von der Stellungnahme ab, so muß ihre Durchführung um zwei Monate aufgeschoben werden. Innerhalb dieses Zeitraums kann der Rat mit qualifizierter Mehrheit einen anderslautenden BeschluB fassen. Gemäß Art. 15 Abs. 7 der Richtlinie 92/51/EWG teilt die Kommission dem betreffenden Mitgliedstaat den Entschluß mit und veröffentlicht gegebenenfalls das geänderte Verzeichnis im Amtsblatt.

Der Streit um Aufnahme in Anhang $C$ konzentrierte sich zunächst darauf, daß Ausbildungen, die quasi das Boot gerade verpaßt haben - so etwa die deutschen medizinischtechnischen Assistenten mit ihrer 12 1/2jăhriger Ausbildung - durch Erweiterung des Anwendungsbereiches doch noch in den Genuß dieser Bestimmung geraten zu lassen. Ob die Kommission und der Ausschuß dabei die Qualität der betroffenen Ausbildungen nach den in Art. 15 Abs. 2 der Richtlinie 92/51/EWG genannten Kriterien beurteilen können, darf sehr bezweifelt werden. Quantitative Kriterien lassen sich - wie die Erfahrungen bei den sektoriellen Richtlinien beweisen - viel einfacher aufstellen und überprüfen als qualitative. Eine andere Möglichkeit ist, die nationale Ausbildung entsprechend zu verlängern ${ }^{1096}$. Die Aufnahme eines Berufes in den Anhang $C$ ist nämlich auch nachträglich möglich, wenn die Ausbildung so geändert wird, daß sie die

1096. Diese Erfahnung hat im sektoriellen Bereich bereits die deutsche pharnazeutische Ausbildung. Auch die Ausbildung zum Physiotherapeuten wurde durch Gesetz vom 26. Mai 1994 entsprechend angepaBt, BGBI. I vom 31. Mai 1994, 1084. 
für die Aufnahme erforderlichen Kriterien erfüllt. Seit Verabschiedung der Richtlinie wurde Anhang $\mathrm{C}$ bereits einmal ergänzt ${ }^{1097}$.

Unklar ist, ob dieses Verfahren gemäß Art. 15 der Richtlinie 92/51/EWG auch von einem. Mitgliedstaat eingeleitet werden kann, der Bedenken gegen einen bestimmten Ausbildungsgang mit dem Ziel erhebt, die Vermeldung dieser Ausbildung in Anhang $C$ durch die Kommission und den Ausschuß entsprechend der in Art. 15 genannten Kriterien überprüfen zu lassen. Der Wortlaut von Art. 15 Abs. 1 der Richtlinie 92/51/EWG steht dieser Möglichkeit nicht entgegen. Gemäß dieser Bestimmung kann "jeder betroffene Mitgliedstaat" den Antrag auf Revision bei der Kommission einreichen. In der Regel dürfte dies einen Mitgliedstaat betreffen, der eine nationale Ausbildung durch Aufnahme in Anhang $\mathrm{C}$ einem weiterreichenden Freizügigkeitsregime unterstellen möchte. Der umgekehrte Fall ist jedoch ebenfalls denkbar. Ein Mitgliedstaat wird von Diplominhabern überschwemmt, wobei die Qualität der Ausbildung ernsthafte Zweifel hervorruft. Grundsätzlich müßte dieser Mitgliedstaat die in Anhang $\mathrm{C}$ aufgeführte Ausbildung gemäß den in Art. 3 und 4 der Richtlinie 92/51/EWG genannten Prinzipien anerkennen. Dabei stehen lediglich die Anpassungsinstrumente gemäß Art. 4 der Richtlinie 92/51/EWG zur Verfügung. Diese Situation wäre äußerst unbefriedigend, wenn kein Korrektiv i.S. von Art. 15 der Richtlinie 92/51/EWG möglich wäre. Der Mitgliedstaat kann daher ebenfalls als "betroffen" i.S. von Art. 15 Abs. 1 der Richtlinie 92/51/EWG bezeichnet werden. Allerdings muß eine einmal von der Kommission nach der Stellungnahme des Ausschusses über eine bestimmte Ausbildung getroffene Entscheidung für alle Mitgliedstaaten bindend sein. Ansonsten könnte sich ein solches Verfahren bezüglich einer Berufsausbildung mehrmals wiederholen. In einem solchen Falle müßte die Kommission einen solchen Wiederholungsantrag als offensichtlich unbegründet direkt zurückweisen können.

\section{c. Weitere Voraussetzungen}

Die Ausbildungsnachweise müssen von einer in einem Mitgliedstaat dafür zuständigen Stelle ausgestellt sein und es muß aus ihnen hervorgehen, daß der Diplominhaber über die beruflichen Qualifikationen verfügt, die für den Zugang zu einem reglementierten Beruf oder dessen Ausübung erforderlich sind. Diese beiden letztgenannten Voraussetzungen entsprechen nahezu wöttlich Art. 1 Buchstabe a) erster und dritter Gedankenstrich der Richtlinie 89/48/EWG. Vorausgesetzt wird somit wie beil der Richtlinie 89/48/EWG ein sogenanntes Endprodukt.

1097. Richtinie 94/38/EG der Kommission vom 26. Juli 1994, ABL. Nr. L 217 wom 23. August 1994, womit Anderungen der Anhänge $C$ und $D$ vorgenommen wurden. Diese Anderungen betrafen vor allem einige deutsche paramedizinische Benfe, die neu in Anhang $C$ aufgeligtet werden, z.B. der Physiotherapeut sowie der Diätassisten, sowie die Berufe Kaufmännischer Assistent und Technischer Assistent, die Eingang in Anhang D gefundien haben. Dagegen hat Italien einige Berufe von der Liste des Anhangs C streichen lassen, da die Ausbildung zu diesen Berufen inzwischen die Kriterien der Richtinie 89/48/EWG erfüllen. 
Der horizontale Ansatz

\section{Dritrstaatsdiplome}

Grundsätzlich muß die Ausbildung überwiegend in der Gemeinschaft stattgefunden haben. In Erweiterung zu diesem Grundsatz kann die Ausbildung auch an Ausbildungseinrichtungen außerhalb der Gemeinschaft stattgefunden haben, wenn die Ausbildung gemåß den Rechts-und Verwaltungsvorschriften eines Mitgliedstaates vermittelt worden ist. Dies gilt im wesentlichen für Ausbildungen in den französischen und niederländischen überseeischen Gebieten.

Handelt es sich dagegen um Dritstatsatiplome, dann wird von dem Inhaber der Nachweis einer dreijährigen Berufserfahrung verlangt, die von dern Mitgliedstaat bescheinigt wird, der den Ausbildungsnachweis eines Drittstaates anerkannt hat. Diese Regelung entspricht der allgemeinen Hochschulrichtlinie. Dagegen weicht diese Bestimmung von den sektoriellen Richtlinien ab, die keine Anerkennung von Drittstaatsdiplomen kennen. Bezïglich der Drittsstaatsdiplome besteht somit eine merkwürdige Divergenz zwischen den allgemeinen Anerkennungsrichtlinien und den sektoriellen Richtlinien. Die unterschiedliche Behandlung fallt vor allem deshalb auf, weil verwandte Berufsgruppen betroffen sind. Wenig einleuchtend erscheint, warum das Drittstaatsdiplom eines Krankengymnasten anerkennungsfähig ist, wohingegen das Drittstaatsdiplom einer Hebamme nicht unter diesen Genuß fallen soll. Eime entsprechende Anpassung der sektoriellen Richtlinien sollte deshalb möglichst rasch vorgenommen werden.

\section{Parallele und frïhere Ausbilaiungsgänge}

Gemäß Art. 1 Buchstabe a) letzter Absatz werden einem Diplom im obigen Sinne die Ausbildungsnachweise gleichgestellt, die von einer zuständigen Behörde in einem Mitgliedstaat als gleichwertig anerkannt sind und in Bezug auf den Zugang oder die Ausübung eines reglementierten Berufs die gleichen Rechte verleihen. Die Formulierung dieses Absatzes entspricht weitgehend der des Absatzes 1 a) letzter Absatz der Richtlinie 89/48/EWG. Wie bereits zur Hochschulrichtlinie ausgeführt ${ }^{1098}$, sollten mit dieser kryptischen Formulierung einige Spezialfälle paralleler Ausbildungsgänge, die im Vereinigten Königreich neben dem Hauptausbildungsgang angeboten werden, in den Anwendungsbereich der Richtlinie 89/48/EWG einbezogen werden. Damit sollte diesem Abschnitt nach der urspünglichen Zielvorstellung nur ein sehr beschränktes Anwendungsfeld eingeräumt werden. Die Diskussion um die sogenannten Altstudiengänge hat jedoch die Regelung in einem total neuen Licht erscheinen lassen und den möglichen Anwendungsbereich um ein erhebliches Maß erweitert. Diese Neuorientierung wurde nicht von allen Mitgliedstaaten als wünschenswert angesehen. Auch fehlte es bei der extensiven Interpretation dieses Absatzes an einer deutlichen Grenzziehung. Die Richtlinie 92/51/EWG trägt jedoch zu einer gewissen Entschärfung der Problematik bei.

1098. Siehe dazu die Erörterungen auf Seite 165 bezüglich der entsprechenden Bestimmung der Richtlinie 89/48/EWG. 
Durch die in der Richtlinie 92/51/EWG gewährte Durchlässigkeit zwischen dem dem zweiten und dem dritten Ausbildungsniveau wird zumindest nach Inkraftreten der ergänzenden Richtlinie am 18. Juni 1994 eine Anerkennung gemäß dem Kapitel III dieser Richtlinie vorgenommen werden müssen, soweit die betroffenen "Altdiplome" die Voraussetzungen des zweiten Niveaus erfüllen ${ }^{1059}$. Das bedeutet für die französischen Diplominhaber mit einem sogenannten Bac +2 Diplom die Anerkennung in einem Aufnahmestaat, der ein Diplom i.S. der Richtlinie 89/48/EWG verlangt, gemäß den in Art. 3 der Richtlinie 92/51/EWG genannten Bedingungen.

Es erscheint jedoch vertretbar, daß diese Kandidaten sich in der Übergangsperiode bis zur Umsetzung der Richtlinie 92/51/EWG auf den Art. 1 Buchstabe a) letzter Absatz der Richtlinie 89/48/EWG berufen, um eine Anerkennung zu einem früheren Zeitpunkt $z u$ bewirken. Um ein gutes Funktionieren beider Richtlinien zu garantieren und widersprüchliche Ergebnisse zu vermeiden, wäre es daher den Mitgliedstaaten geraten, bereits vor der tatsächlichen Umsetzung der Richtlinie 92/51/EWG diese Spezialfälle entsprechend zu entscheiden.

Problematisch sind jedoch die früheren Ausbildungen, die nicht das zweite Niveau erffullen und damit auch nicht gemäß dem Kapitel 3 der Richtlinie 92/51/EWG mit einer Durchlässigkeit zum dritten Niveau rechnen können. Gedacht werden muB an Berufe, für deren Ausübung in der Vergangenheit keine akademische oder dazu gleichwertige Ausbildung der zweiten oder dritten Stufe verlangt war, die jedoch inzwischen aufgrund gesellschaftspolitischer Entwicklungen auf der höchsten Stufe reglementiert sind. Dies gilt z.B. in Deutschland für den Beruf des Steuerberaters ${ }^{1100}$. Problematisch sind ebenfalls in der Bundesrepublik die Ausbildungsgänge, die in der früheren DDR auf einem nicht akademischen Niveau angeboten worden sind, während eine zumindest dem Namen nach vergleichbare Ausbildung in der Bundesrepublik auf dem zweiten oder dritten Ausbildungsniveau stattgefunden hat ${ }^{1101}$. In beiden Fällen wurde innerstaatlich aus rechtspolitischen Erwägungen eine Gleichstellung gewährt. Die Frage ist jedoch, ob eine derartige, politisch gebotene, innerstaatliche Gleichstellung die Voraussetzungen erfüllt, die in Art.1 Buchstabe a) letzter Absatz der Richtlinie 89/48/EWG verlangt werden.

Hierbei sind die folgenden Erwägungen zu berücksichtigen:

Würde man für die angesprochenen Fälle, wo es um eine Durchlässïgkeit vom ersten zum dritten Ausbilldungsniveau geht, bis zur Umsetzung der Richtlinie 92/51/EWG eine Anerkennung gemäß Art.1 Buchstabe a) letzter Absatz der Richtlinie 89/48/EWG gewährleisten, so würde man ein äußerst widersprüchliches Ergebnis in Kauf nehmen, weil nach der Umsetzung der Richtlinie 92/51/EWG ein Rechtsanspruch auf eine der-

1099. Siehe dazu die Ausfuhrungen Seite $175 \mathrm{f}$.

1100. Bis 1975 war der Benf des Steuerberaters in der Bundesrepublik Deutschland nur unwollkommen regllementiert.

1101. Z.B. Kanrute die DDR eine Ausbildung zum "Ingenieur" an einer Fachschule, die in keiner Weise mit einer technischen Hochschule oder einer Fachhochschule verglichen werden kann. 
artige Anerkennung nicht mehr bestünde. Die Richtlinie 92/51/EWG kennt nämlich lediglich eine Durchlässigkeit zwischen dem zweiten und dem dritten Niveau. Eine Durchlässigkeit von der ersten nach der dritten Ausbildungsstufe ist dabei bewußt nicht vorgesehen ${ }^{1102}$. Nach Verstreichen des Umsetzungstermins am 18. Juni 1994 muß aber meines Erachtens der Richtlinie 92/51/EWG sowohl nach dem Prinzip des lex posterior aber auch als lex specialis in diesem Punkt Vorrang gegenüber der allgemeinen Hochschulrichtlinie eingeräumt werden. Dies gilt um so mehr, als die Anwendung von Art. 1 Buchstabe a) letzter Abschnitt der Richtlinie 89/48/EWG auf die "Altdiplome" aufgrund der Entstehungsgeschichte - wie an anderer Stelle bereits ausgeführt ${ }^{1103}$. nicht unumstritten ist.

\section{Der Begriff "Prüfungszeugnis" gemäß der Richtlinie 92/51/EWG}

Gemäß Art. 1 Buchstabe b) zweiter Gedankenstrich der Richtlinie 92/51/EWG gilt als Prüfungszeugnis jeder Ausbildungsnachweis, aus dem hervorgeht, daß der Zeugnisinhaber nach Abschlluß einer Sekundarschulausbildung eine Ausbildung entweder an eïner speziellen Ausbildungseinrichtung oder in einem Unternehmen oder im Wechsel zwischen beiden abgeschlossen hat. Es darf sich dabei nicht um eine Ausbildung i.S. von Art. 1 Buchstabe a) der Richtlinie 92/51/EWG handeln, da man ansonsten von einem. "Diplom" sprechen müßte.

Merkwürdig mutet die Verwendung des Begriffes "Sekundarschulausbildung" an, im Vergleich zu dem in Art 1 a) zweiter Gedankenstrich der Richtlinie 92/51/EWG verwendleten Begriff "Sekundarausbildung". Die unterschiedliche Begriffswahl läßt auch unterschiedliche Inhalte vermuten. Im ersten Entwurf der Richtlinie hieß es an dieser Stelle "daß der Zeugnisinhaber eine Sekundarschulausbildung an einer allgemein- oder berufsbildenden Einrichtung abgeschlossen hat." Die Zusätze "allgemein- und berufsbildend" wurden in der endgültigen Fassung der Richtlinie weggelassen. Ohne diese näheren Bestimmungen muß davon ausgegangen werden, daß unter der Sekundarschulausbildung jede schulische Ausbildung zu verstehen ist, die durch einen am Ende der Pflichtschulzeit oder danach ausgestellten Ausbildungsnachweis bescheinigt wird.

GemäB Art. 1 Buchstabe b) dritter Gedankenstrich der Richtlinie 92/51/EWG wird ebenfalls als "Prüfungszeugnis" ein Ausbildungsnachweis qualifiziert, aus dem hervorgeht, daß der Zeugnisinhaber eine technische oder berufliche Sekundarschulausbildung durchlaufen und daran anschließend eine berufliche Ausbildung an einer Ausbildungseinrichtung oder in einem Unternehmen abgeschlossen hat. Warum diese Alternative in den Richtlinientext Eingang gefunden hat, ist nicht deutlich, weil sie bereits von der Regelung gemåß dem zweiten Gedankenstrich erfaßt scheint; dies gilt zumindest

1102. Dies ergibt sich bereits aus den Erläuterungen der Kommission zu dem ersten Entwurf der Richtlinie 92/51/EWG, siehe dazu KOM (89) 372 endg. - SYN 209, 7, wo die verschiedenen Formen der Anerkennung zwischen den einzelnen Ausbildungsn weaus erklărt werden Leibrock, EuZW 1992,465 (467).

1103. Siehe oben Seite 175. 
dann, wenn eine weite Interpretation des Begriffes Sekundarschulausbildung zugrunde gelegt wird.

Bei beiden Alternativen muß aus dem Ausbildungsnachweis hervorgehen, daß der Zeugnisinhaber über die beruflichen Qualifikationen verfügt, die für den Zugang zu einem reglementierten Beruf oder dessen Ausübung in diesem Mitgliedstaat erforderlich sind. Auch bei dem Prüfungszeugnis muß damit der Nachweis erbracht werden, daß es sich bei dem Zeugnisinhaber um ein Endprodukt handelt. Für die übrigen Voraussetzungen werden die selben Formulierungen wie in Art. 1 Buchstabe a) der Richtlinie 92/51/EWG verwendet. Dabei bezieht sich der letzte Abschnitt des Art. 1 Buchstabe b) der Richtlinie 92/51/EWG auf "Drittstaatsprüfungszeugnisse" sowie Parallelausbildungen.

\section{Der Begriff "Befähigungsnachweis" gemäß der Richtlinie 92/51/EWG}

Die Definition des Begriffes "Befähigungsnachweis" gemäß Art. 1 Buchstabe c) erster Gedankenstrich der Richtlinie 92/51/EWG wird an erster Stelle in einer negativen Weise vorgenommen. Dabei wird festgestellt, daß ein Befähigungsnachweis jeder Nachweis ist, der eine Ausbildung abschließt und nicht Teil eines Diploms i.S. der Richtlinie 89/48/EWG bzw. eines Diploms oder Prüfungszeugnisses i.S. der ergänzenden Regelung ist. Mit dieser Definition soll wohl ein Restbereich möglicher Ausbildungsgänge abgedeckt werden. Es erscheint jedoch äußerst problematisch, einen klaren Trennungsstrich zwischen einem Prüfungszeugnis einerseits und einem Befähigungsnachweis andererseits zu ziehen. Im allgemeinen wird man davon ausgehen können, daß die Ausbildungsgänge, für die ein Befähigungsnachweis ausgestellt wird, weder sehr lang noch sehr intensiv sein können.

Diese Auffassung wird durch die gemäß Art. 1 Buchstabe c) zweiter Gedankenstrich gebotene Alternative bestätigt. Nach dieser Bestimmung sind die Nachweise, die im Anschluß an eine Beurteilung der persönlichen Eigenschaften, Kenntnisse und Fähigkeiten des Antragstellers von einer zuständigen Stelle ausgestellt und Voraussetzungen für die Ausübung eines Berufes sind, ebenfalls als Befähigungsnachweis zu qualifizieren, ohne daß der Nachweis einer vorherigen Ausbildung erforderlich ist ${ }^{1104}$. Interessanterweise enthält Art. 1 Buchstabe c) keinen Hinweis auf Befähigungsnachweise, die in Drittstaaten erworben wurden.

\section{Der Begriff "reglementierte Ausbildung" gemäß der Richtlinie 92/51/EWG}

Der Begriff "reglementierte Ausbildung" gemäß Art. 1 Buchstabe g) der Richtlinie 92/51/EWG ist eine Neuschöpfung dieser Richtlinie. In der Richtlinie 89/48/EWG kommt dieser Begriff nicht vor. Auch im ursprünglichen Entwurf der Richtlinie war er noch nicht enthalten ${ }^{1105}$. Die in Art. 1 Buchstabe g) gegebene Definition zeichnet

1104. Gedacht werden muB z.B. in den Niederlanden an das sogenannte "middenstandsdiploma"

1105. KOM (89) 372 endg. - SYN 209. 
sich dabei nicht durch besondere Deutlichkeit aus. Gemäß Art. 1 Buchstabe g) der Richtlinie 92/51/EWG hat man unter einer reglementierten Ausbildung jede Ausbildung zu verstehen, die speziell auf die Ausübung eines bestimmten Berufs ausgerichtet ist und die aus einem "gegebenfalls durch eine Berufsausbildung, ein Berufspraktikum oder eine Berufspraxis ergänzten Ausbildungsgang besteht". Die Formulierung kann nur als eine KompromiBlösung verstanden werden. Mit dieser Regelung sollten wohl einerseits die besonders strukturierten Bildungs- und Ausbildungsgänge im Vereinigten Königreich erfaßt werden $" 1166$, andererseits sollten auch die an Berufsschulen und Berufsbildungszentren angebotenen Ausbildungsgänge abgedeckt werden.

\section{Anerkennungsregelung, wenn der Aufnahmestaat ein Diplom i.S. der Richtlinie 92/5I/EWG oder der Richtlinie 89/48/EWG fordert}

Art. 3 der Richtlinie 92/51/EWG regelt die Fälle der Anerkennung innerhalb des Ausbildungsniveaus 2 und zwischen den Ausbildungsniveaus 2 und 3. Die Durchlässigkeit zwischen den Ausbildungsniveaus 2 und 3 stieß in der Entwurfsphase auf den Einwand einer unerwünschten Nivellienung der Anerkennungsniveaus ${ }^{1107}$. Diese Auffassung konnte sich nicht durchsetzen. Allerdings bestimmt Art. 3 letzter Absatz der Richtlinie 92/51/EWG eine Ausnahme von dem Durchlässigkeitsprinzip. Danach muß der Aufnahmestaat die Anerkennung gemäß Art. 3 der Richtlinie 92/51/EWG dann nicht durchführen, wenn in diesem Staat der Zugang zu einem reglementierten Beruf oder dessen Ausübung vom Besitz eines Diploms i.S. der Richtlinie 89/48/EWG abhängig gemacht wird, das unter anderem den erfolgreichen Abschluß eines postsekundären Ausbildungsgangs von mehr als vier Jahren voraussetzt.

Grundsätzlich kann aber gemäß Art. 3 der Richtinie 92/51/EWG der Aufnahmestaat einem Antragsteller, der im Besitz eines Diploms ist " ${ }^{10 \%}$, nicht den Zugang oder die Ausübung eines reglementierten Berufes wegen mangelnder Qualifikation verweigern. wenn dieses Diplom Zugangs- oder Ausübungsvoraussetzung für den entsprechenden Beruf im Herkunftsstaat ist (Art. 3 Buchstabe a) der Richtlinie 92/51/EWG). In Art. 3 Buchstabe a) der Richtlinie 92/51/EWG zeigt sich die Durchlässigkeit des Systems sehr deutlich, wobei die folgenden Fallkonstellationen denkbar sind:

Der Aufnahmestaat fordert ein Diplom i.S. der Richtlinie 89/48/EWG unterhalb der Vier-Jahresgrenze, der Antragsteller besitzt ein Diplom i.S. der Richtlinie 92/51/EWG oder der Aufnahmestaat verlangt ein Diplom i.S der Richtlinie 92/51/EWG, der Antragsteller verfugt über ein Diplom i.S. der Richtlinie $89 / 48 /$ EWG oder i.S. der Richtlinie $92 / 51 / \mathrm{EWG}$.

1106. Siehe dazu Anhang D der Richthinie 92/51/EWG mit dem Hinweis auf im Vereinigten Königreich reglementierten Ausbildungsgänge.

1107. Siehe den Beschlub des. Bundesrates zum Richtlinienentwurf, BR-Drucksache 484/89 vom 16. Februar $1990,3$.

1108. Diplom im Sinne der Richtlinie 89/48/EWG oder der Richtlinie 92/51/EWG. 
Eine Anerkenmung kann ebenfalls nicht wegen mangelnder Qualifikation verweigert werden, wenn der Antragsteller diesen Beruf zwei Jahre lang vollzeitig in den vergangenen zehn Jahren in einem anderen Mitgliedstaat ausgeübt hat, der diesen Beruf nicht reglementiert hat. Voraussetzung ist dann jedoch, daß der Antragsteller über entsprechende Ausbildungsnachweise verfügt (Art. 3 Buchstabe b) der Richtlinie 92/51/EWG).

Grundsätzlich stimmen insoweit Art. 3 der Richtlinie 89/48/EWG und Art. 3 der Richtlinie 92/51/EWG überein. Es sind jedoch einige Abweichungen zu konstatieren. Diese beruhen teilweise auf Erfahrungen mit der Richtlinie 89/48/EWG. Eine derartige Anpassung gegenüber der ersten allgemeinen Regelung findet sich z.B. in Art. 3 Buchstabe b) bezüglich der Teilzeitbeschäftigung. Gemäß Art. 3 Buchstabe b) der Richtlinie 89/48/EWG muß der Antragsteller den Beruf vollzeitllich zwei Jahre lang ausgeübt haben. Unterschiedlich dazu regelt Art. 3 Buchstabe b) der Richtlinie 92/51/EWG neben der zweijährigen vollzeitlichen Beschäftigung eine dieser Zeit entsprechende Dauer bei teilzeitlicher Beschäftigung. Bei der Richtlinie 89/48/EWG war diese Problematik übersehen worden, obwohl eine Korrektur bezüglich der Studiendauer gemäß Art. 1 Buchstabe a) zweiter Gedankenstrich der Richtlinie 89/48/EWG vorgenommen worden ist ${ }^{1109}$.

Der Versuch Art. 3 Buchstabe b) ebenso wie Art. 3 Buchstabe a) der Richtlinie 92/51/EWG in mögliche Fallkonstellationen einzuteilen, erweist sich als schwieriger. Die Einteilung läßt Regelungslücken offenbar werden.

Art. 3 Buchstabe b) zweiter Gedankenstrich enthält zunächst eine nähere Bestimmung der vom Antragsteller geforderten Ausbildungsnachweise. Befremdend ist dabei, daB in Art. 3 Buchstabe b) zweiter Gedankenstrich lediglich die Definition des "Diploms" i. S. des Art. 1 Buchstabe a) zweiter Gedankenstrich, Ziffer i) der Richtlinie 92/51/EWG wiederholt wird ohne Hinweis auf die gemäß Ziffer ii) in Anhang $C$ aufgeführten Ausbildungsgänge. Eine Lösung zu diesem Problem bietet auch nicht Art. 3 Buchstabe b) dritter Gedankenstrich. Hierin findet sich lediglich als mögliche Alternative ein Hinweis auf die reglementierten Ausbildungen i.S. von Anhang D.

Art. 3 Buchstabe b) regelt offensichtlich die folgende Alternativen:

Der Aufnahmestaat verlangt ein Diplom i. S. der Richtlinie 89/48/EWG oder i.S. der Ruchtlinie 92/51/EWG, der Antragsteller hat einen Beruf, der im Herkunftsland nicht reglementiert ist, zwei Jahre lang ausgeübt und er erbringt gemäß Art. 3 Buchstabe b) zweiter Gedankenstrich den Nachweis eines Diploms der Kategorie "Bac +2 " oder einer reglementierten Ausbildung i.S. von Anhang D der Richtlinie 92/51/EWG.

1109. Im ersten Entwurf zur Richtlinie 89/48/EWG ist in Art. 1 lediglich von einem dreijährigen Studiengang die Rede. Siehe KOM (85) 355 endg., 5. Eine Anpassung dieser Bestimmung bezüglich Teilzeitstudien erfolgte erst nach Kritik durch das Europäische Parlament. 
Der horizontale Ansalz

Auf den ersten Blick erscheinen jedoch zwei weitere, denkbare Möglichkeiten nichi geregelt:

Fall 1: Der Antragsteller hat einen der in Anhang C aufgeführten Ausbildungsgänge absolviert sowie den Beruf zwei Jahre lang in einem Mitgliedstaat ausgeübt, der den entsprechenden Beruf nicht reglementiert hat. Nun möchte der Antragsteller den Beruff im Aufnahmestaat ausüben, der ein Diplom i.S. der Richtlinie 92/51/EWG verlangt.

Fall 2: Der Antragsteller verfügt über ein Diplom i.S. der Richtlinie 89/48/EWG und hat einen nicht reglementierten Beruf zwei Jahre lang ausgeübt. Auch er möchte den entsprechenden Beruf in einem Aufnahmestaat ausüben, der ein Diplom i.S. der Richtlinie $92 / 51$ /EWG verlangt.

Undeutlich ist, ob die Lösung zu Fall 1 in Art. 3 Buchstabe b) Unterabsatz 2 der Richtlinie 92/51/EWG gesucht werden kann. Dort heißt es, daß die zweijährige Berufserfahrung nicht werlangt werden kann, wenn die Ausbildungsnachweise des Antragstellers den Abschluß einer reglementierten Ausbildung bestätigen. Fraglich ist, ob die in Anhang $C$ aufgelisteten besonders strukturierten Ausbildungsgänge als reglementierte Ausbildung i.S. des Art. 1 Buchstabe g) der Richtlinie 92/51/EWG zu verstehen sind. Für diese Lösung spricht, daß ansonsten die Erweiterung der Diplomdefinition um die in Anhang $C$ aufgenommenen Ausbildungen keinen deutlichen Niederschlag im Anerkennungssystem der Richtlinie 92/51/EWG gefunden hätte. Die Durchlässigkeit zwischen dem zweiten und dem dritten Ausbilldungsniveau auch für diese Berufe zu verwirklichen, war jedenfalls das erklärte Ziel bei Abänderung des Richtlinienentwurfes. Verwunderlich ist dann allerdings, daß ein spezieller Hinweis auf Anhang $\mathrm{C}$ unterlassen worden ist.

Zur Lösung des Problems trägt bis zu einem gewissen Grad ein Blick in die anderen sprachlichen Fassungen der Richtlinie bei. Die englische Fassung spricht hinsichtlich der in Anhang $\mathrm{C}$ aufgeführten Ausbildungsgängen von "education and training courses", in Art. 1 Buchstabe g) wird die reglementierte Ausbildung mit "regulated education and training" bezeichnet. Dieser Begriff wird auch in Art. 3 Buchstabe b) Unterabsatz 2 verwendet.

Eine befriedigende Lösung zu Fall 2 kann nur im Umkehrschluß gewonnen werden. Wenn bereits der Nachweis eines Diploms is. von Art. 1 Buchstabe a) zweiter Gedankenstrich Ziffer i) der Richtlinie 92/51/EWG als ausreichend gemäß Art. 3 Buchstabe b) zweiter Gedankenstrich anerkannt werden muß, so gilt dies natürlich erst recht für ein Diplom der dritten Ausbildungsstufe. Warum ein solcher Passus ausdrücklich in Art. 3 Buchstabe a) im Falle einer Reglementierung im Herkunftsstaat aufgenommen worden ist, während eine entsprechende Regel in Art. 3 Buchstabe b) fehlt, ist nicht deutlich. 


\section{Anpassungsinstrumente gemäß Art. 4 der Richtlinie 92/5I/EWG}

Art. 3 der Richtlinie 92/51/EWG hindert den Aufnahmestaat nicht daran "im Falle von unterschiedlicher Dauer oder unterschiedlichem Inhalt der Ausbildung, an den Arttragsteller zusätzliche Anforderungen zu stellen, um seine sachgerechte Anpassung an das neue berufliche Umfeld zu gewährleisten. Zu diesem Zweck regelt Art. 4 der Richtlinie 92/51/EWG verschiedene Formen von Anpassungsinstrumenten. Insoweit entspricht Art. 4 der Richtlinie 92/51/EWG dem ebenfalls in Art. 4 geregelten Anpassungsinstrumentarium der Hochschuldiplom-Richtlinie.

Die Anpassungsinstrumente können in zwei Gruppen unterschieden werden. Zum einen geht es um die Kompensation einer unterschiedlichen Ausbildungsdauer. Bei der zweiten Gruppe handelt es sich um die Kompensation im Falle von unterschiedlichen Ausbildungsinhalten. Auch diese Unterscheidung entspricht Art. 4 der ersten allgemeinen Regelung.

a. Unterschiede in der Ausbildungsdauer

Gemäß Art. 4 Abs. 1 Buchstabe a) der Richtlinie 92/51/EWG kann die Kompensation unterschiedlicher Ausbildungsdauer durch den Nachweis von Berufserfahrung erbracht werden. Unter Berufserfahrung wird gemäß Art. 1 Buchstabe h) der Richtlinie 92/51/EWG die tatsächliche und rechtmäßige Ausübung des betreffenden Bierufs in einem Mitgliedstaat verstanden. Diese Definition entspricht wörtlich Art. 1 Buchstabe e) der Richtlinie 89/48/EWG.

Im Falle, daß der Antragsteller gemäß Art. 3 Abs.1 Buchstabe a) oder b) der Richtlinie 92/51/EWG eine kürzere Ausbildungsdauer nachweist, darf die Dauer der verlangten Berufserfahrung das Doppelte der fehlenden Ausbildungszeit nicht überschreiten, wenn sich diese auf einen postsekundären Ausbildungsgang oder auf ein unter der Aufsicht eines Ausbilders absolviertes und mit einer Prüfung abgeschlossenes Berufspraktikum bezieht ( Art. 4 Abs. I Buchstabe a) erster Gedankenstrich). Handelt es sich dagegen um eine mit Unterstützung eines qualifizzierten Berufsangehörigen erworbene Berufspraxis, so darf die verlangte Berufserfahrung die fehlende Ausbildungszeit nicht überschreiten (Art. 4 Abs. 1 Buchstabe a) zweiter Gedankenstrich). Wie bereits hinsichtlich der gleichlautenden Bestimmung in Art. 4 Abs. 1 Buchstabe a) der Richtlinie 89/48/EWG bemerkt, dürfte es häufig nicht einfach sein, den Unterschied zwischen einem unter Aufsicht absolvierten Berufspraktikum und einer mit Unterstützung eines qualifizierten Berufsangehörigen erworbenen Berufspraxis festzustellen ${ }^{1110}$. Für die vom zweiten System erfaßten Berufe gilt dies in noch stärkerem Maße, da gerade bei den in Anhang $\mathrm{C}$ aufgelisteten Berufsausbildungen die praktische Ausbildung einen wesentlichen Teil der Gesamtausbildung betrifft. Entscheidendes Kriterium bleibt das Prüfungselement am Ende des Berufspraktikums, während die mit Unterstützung eines Berufsangehörigen

1110. Sühe oben Seite 193 
erworbene Berufspraxis ein erhebliches $M a B$ an Eigenverantwortlichkeit und Selbständigkeit unterstellt. In keinem Fall darf die Dauer der verlangten Berufserfahrung vier Jahre überschreiten.

Keine Berufserfahrung darf dagegen verlangt werden, wenn der Antragsteller über ein Diplom i.S. der ersten allgemeinen Regelung verfügt, d.h. des dritten Ausbildungsniveaus, und seinen Beruf in einem Aufnahmestaat ausüben möchte, der eine Ausbildung i.S. đer Anhänge $C$ und $D$ reglementiert hat. Diese Regelung betrifft z. $B$, einen niederländischen Physiotherapeuten, der sich in Deutschland als Krankengymnast niederlassen will. Da es sich dabei um einen Fall des Durchstiegs won Ausbildungsniveau 3 nach Ausbildungsniveau 2 handelt, d.h. von einer höheren nach einer niederen Ausbildungsstufe, braucht kein Nachweis über eine entsprechende Berufserfahrung erbracht werden. Eine andere Lösung wäre für den Migranten auch kaum akzeptabel. Dies gill umsomehr, weil gerade die in Anhang $\mathrm{C}$ aufgelisteten Ausbildungen häufig länger sind als die postsekundären Hochschulausbildungen i.S. der Richtlinie 89/48/EWG. Würde hier der Kompensationsmechanismus eingesetzt, so würde dies zu einer ungewünschten Abwertung der Diplome der höchsten Stufe führen.

Als Sonderfall können in diesem Zusammenhang die Diplome i.S. der Richtlinie 89/48/EWG bezeichnet werden, die den erfolgreichen Abschluß eines postsekundären Ausbildungsgangs von mehr als vier Jahren voraussetzen. Für sie gilt - wie bereits oben ausgeführt ${ }^{\text {III }}$ - Art. 3 Abs. 1 der Richtlinie 92/51/EWG nicht. Mitgliedstaaten sind daher nicht verpflichtet, eine Durchlässigkeit auf dieser Ebene zu gewähren. Ëne Kompensation der unterschiedlichen Ausbildungsdauer mit Berufserfahrung ist zumindest im Rahmen dieser Richtlinie nicht möglich ${ }^{112}$. Mitgliedstaaten bleiben jedoch verpflichtet, auch in diesen Fällen die vom EuGH in den Urteilen Heylens und Vlassopoulou aufgestellten Grundsâtze zu beachten. Dies bedeutet im konkreten Fall eine Berücksichtigung der Ausbildungsnachweise gemäß Art. 52 EWGV, ohne daß eine Anerkennungspflicht gemäß der Richtlinie 92/51/EWG besteht. Grundsätzlich steht es Mitgliedstaaten selbstverstăndlich frei, ein liberaleres System für diese Fälle zu garantieren. Eine derartige Liberalität ist jedoch in Anbetracht der Erfahrungen, die während der Verhandlungen zu der Architektenrichtlinie gewonnen werden konnten, nicht sehr wahrscheinlich ${ }^{11 / 3}$

\section{b. Unterschiede in den Ausbildungsinhalten}

Wenn sich die bisherige Ausbildung des Antragstellers auf theoretische oder praktische Fachgebiete erstreckt, die sich wesentlich von der des Aufnahmestaates unterscheiden und damit nicht won seinem Diplom "114 abgedeckt sind, kann der Aufnahmestaat als Kompensation einen Anpassungslehrgang oder eine Eignungsprüfung verlangen (Art.

1111. Suehe oben Seite 352

1112. Leibrock, EuZW 1992, 465 (466).

11ll3. Siehe oben Seite 154.

1114. Der Begriff "Diplom" umfaßBt an dieser Stelle die Definitionen beider Richtlimien. 
4 Abs. 1 Buchstabe b) erster Gedankenstrich der Richtlinie 92/51/EWG). Dies gilt auch dann, wenn die reglementierte berufliche Tätigkeit im Aufnahmestaat umfassender ist als im Herkunftstaat des Antragstellers und diesem Unterschied im Tätigkeitsumfang Rechnung getragen wird durch eine besondere Ausbildung, deren Fächerkatalog nicht durch das Diplom des Antragstellers gedeckt wird (Art. 4 Abs. 1 Buchstabe b) zweiter Gedankenstrich der Richtlinie 92/51/EWG).

Beide Alternativen entsprechen nahezu wörtlich Art. 4 Abs. 1 Buchstabe b) der Richtlinie 89/48/EWG. Im Unterschied dazu wird nicht der allgemeine Begriff "Fâcher" verwendet, sondern ist nun die Rede von "theoretischen und/oder praktischen Fachgebieten". Diese Wortwahl bedeutet eine Verdeutlichung gegenüber dem ersten System und beendigt auch die Diskussion über die inhaltliche Ausgestaltung der Eignungsprüfung und des Anpassungslehrganges. Beide können sich damit sowohl auf theoretische als auf praktische Fachgebiete beziehen.

Falls der Antragsteller einen Beruf ausübt, der in seinem Herkunftstaat nicht reglementiert ist, und er die Voraussetzungen des Art. 3 Buchstabe b) erfüllt, fällt auch er in den Anwendungsbereich des Art. 4 Buchstabe b), wenn die von ilhm bisher ausgeübte berufliche Tätigkeit nicht alle Bereiche umfaßt, die im Aufnahmestaat zu der reglementierten beruflichen Tätigkeit gerechnet werden (Art. 4 Abs. 1 Buchstabe b) dritter Gedankenstrich der Richtlinie 92/51/EWG).

Der Aufnahmestaat, der von dieser Möglichkeit der Kompensation Gebrauch macht, muß dem Antragsteller die Wahl zwischen dem Anpassungslehrgang und der Eignungsprüfung lassen. Möchte ein Mitgliedstaat die Wahlmöglichkeit des Antragstellers beschränken muß er die Kommission von diesem Vorhaben gemäß Art. 14 der Richtlinie 92/51/EWG unverzüglich unterrichten. Das für diesen Fall vorgegebene Verfahren entspricht Art. 10 der Richtlinie $89 / 48 /$ EWG.

\section{c. Die Einschränkungen đer Wahlfreiheit}

Vom Prinzip der Wahlfreiheit läßt die Richtlinie dann gemäß Art. 4 Abs. 1 Buchstabe b) Unterabsatz 3, erster Gedankenstrich eine Ausnahme zu, wenn es sich um einen Beruf handelt, dessen Ausübung eine genaue Kenntnis des nationalen Rechts erfordert und die Beratung und/oder der Beistand in Fragen des innerstaatlichen Rechts ein wesentlicher und ständiger Bestandteil der beruflichen Tätigkeit ist. In diesem Falle wird die Wahl dem Aufnahmestaat überlassen ${ }^{1115}$. Diese Ausnahme für die rechtsberatenden Berufe entspricht wörtlich der Bestimmung des ersten Systems.

Die Aufnahme juristischer Berufe in das zweite allgemeine Anerkennungssystem stieß: in der Entwurfsphase auf grundsätzliche Kritik. Dabei wurde von deutscher Seite die

115. Der Anwendungsbereich dieser Bestimmung dürfte beschränkı sein, da die klassischen rechtsberatenden Berufe nach der Hochschuldiplomrichtlinie anerkannt werden. Der in Anlang $C$ unter 4 aufgefuhrte niederländische "gerechtsdeurwaarder" könnte jedoch von dieser Einschränkung betroffen sein. 
Ansicht vertreten, die Hochschuldiplomrichtlinie trage dem Bedürfnis nach Gewährleistung der Freizugigkeit für diese Berufskategorie bereits hinreichend Rechnung. Ein darüber hinausgehendes Bedürfnis, eine gemeinschaftsrechtliche Anerkennungsregelung auch für juristische Berufe zu erlassen, die nicht eine allgemeine Hochschulausbildung von mindestens drei Jahren verlangen, bestehe nicht ${ }^{1116}$. Diese Auffassung konnte sich jedoch nicht durchsetzen. Das läßt sich gerade durch die Aufnahme einer derartigen Ausnahmebestimmung für die rechtsberatenden Berufe belegen. So handelt es sich z.B. beim Beruf des Gerichtswollziehers um einen rechtsberatenden Beruf im Sinne des zweiten allgemeinen Systems ${ }^{117}$. Dabei mul jedoch konstatient werden, daß bei einem Gerichtsvollzieher zwar die "genaue Kenntnis des nationalen Rechts" als für die Ausübung des Berufs erforderlich angesehen werden muB, zweifelhafter erscheint, ob die zweite Bedingung, nämlich "die Beratung und/oder der Beistand in Fragen des innerstaatlichen Rechts", tatsächlich ein wesentlicher und ståndiger Bestandteil der beruflichen Tätigkeit ist.

Hinter dieser Kritik stand die Befürchtung, neben der Durchlässigkeit zwischen den Ausbildungsniveaus auch den Zugang zu den traditionellen juristischen Berufen für Berufe des mittleren Ausbildungsniveaus garantieren zu müssen. Diese Befürchtung ist jedoch weitgehend unbegründet. Bei der Anerkennung gemäß Art. 3 der Richtlinie 92/51/EWG gilt grundsätzlich, daß der Antragsteller ein Diplom oder entsprechende Ausbildungsnachweise besitzt, die in einem anderen Mitgliedstaat erforderlich sind, um Zugang zu eben diesem Beruf im Hoheitsgebiet dieses Staates zu erhalten oder ihn dort auszuüben. Dies bedeutet aber, daß das Recht auf Ausübung des Rechtsanwaltsberufs in einem Aufnahmestaat nur von Personen beansprucht werden kann, die in ihrem Herkunftsstaat berechtigt sind, diesen Beruf unter einer entsprechenden Berufsbezeichnung auszü̈ben. Diese Feststellung darf allerdings nicht in der Weise verstanden werden, daß der Kandidatenkreis auf tatsächlich niedergelassene Rechtsanwälte beschränkt ist. Berechtigt ist vielmehr jedes Endprodukt, das im Herkunftsstaat die Zulassung zu dem entsprechenden Beruf erhalten könnte ${ }^{118}$. Da in Großbritannien keine gesetzliche Mindeststudienzeit für das juristische Studium besteht, kann der Durchstieg zwischen beiden Systemen für den Beruf des Rechtsanwaltes nicht vollkommen ausgeschlossen werden. Es handelt sich dabei jedoch um einen Ausnahmefall ${ }^{119}$.

Die Wahlfreiheit gilt auch nicht, wenn im Aufnahmestaat ein Diplom i.S. der Richtlinie 89/48/EWG aufgrund eines Ausbildungsganges von mehr als drei Jahren verlangt wird, der Antragsteller dagegen lediglich ïber eine Diplom der zweiten Ausbildungsstufe verfügt (Art. 4 Abs. 1 Buchstabe b) Unterabs. 3, zweiter Gedankenstrich). Diese Be-

1116. So der Bundesrat in seinem BeschluB zum Richtlinienentwurf vom 16. Februar 1990. BR-Drucksache $484 / 89,3$

1117. Der niederlândische "gerechtsdeurwaarder" wird ausdrücklich in Anhang $C$ unter 4 genannt.

1118. In Deutschland bedeutet dies alle Persomen, die das Zweite juristische Staatsexamen erfolgreich abgeschlossen thaben, u.a. Assessoren, Rechtsanwälte, Staatsanwälte, Richter und Notare.

1119. So keunt die University of Buckingham, die einzige Privatuniversität in England, ein abgeschlossenes juristisches Studium nach zwei Jahren. 
stimmung bewirkt eine starke Relativierung des propagierten Durchlässigkeitsprinzips, da die Mindeststudienzeit der kontinentaleuropäischen Mitgliedstaaten - mit Ausnahme won der Studienzeit an deutschen Fachhochschulen - in der Regel vier Jahre beträgt und damit eine Beschränkung der Wahlfreiheit ermöglicht.

\section{d. Der Anpassungslehrgang}

Gemäß Art. 1 Buchstabe i) der Richtlinie 92/51/EWG muß der Anpassungslehrgang unter der Verantwortung eines qualifizierten Berufsangehörigen erfolgen. Die Dauer des Anpassungslehrganges darf gemäß Art. 4 Abs. 1 Buchstabe b) der Richtlinie 92/51/EWG drei Jahre nicht überschreiten. Der Lehrgang ist Gegenstand einer Bewertung, wobei die Einzelheiten des Anpassungslehrgangs und seine Bewertung durch den Aufnahmestaat zu erfolgen hat. Der Anpassungslehrgang kann gegebenfalls durch eine Zusatzausbildung ergänzt werden. Insoweit entsprechen sich die Definitionen beider Richtlinien.

Art. 1 Buchstabe i) Abs. 2 der Richtlinie 92/51/EWG betrifft die Rechtstellung des Lehrgangteilnehmers. Darin werden die zuständigen Behörden der Mitgliedstaaten angewiesen die Rechtstellung der Lehrgangsteilnehmer, insbesondere hinsichtlich des Aufenthaltsrechts sowie der Pflichten, Rechte und Sozialleistungen, der Entschädigungen und Entgelte in Übereinstimmung mit dem geltenden Gemeinschaftsrecht festzulegen. Diese Bestimmung ist wesentlich ausführlicher und detaillierter als in der ersten allgemeinen Regelung. Sie weist mit ihrer Formulierung deutlich auf Problempunkte bei der Umsetzung und Anwendung der Richtlinie 89/48/EWG. Die Auflistung der Regelungsmaterie, obwohl sicher nicht enumerativ zu verstehen ${ }^{1220}$, bewirkt eine konkrete Umsetzungsverpflichtung für die Mitgliedstaaten auch bezüglich dieser "Nebenbereiche" der Anerkennungsproblematik.

Verwunderlich ist, daß diese Verpflichtung ausdrücklich an die zuständigen Behörden der Mitgliedstaaten, d.h. an die Exekutive gerichtet ist, und nicht an die Mitgliedstaaten allgemein und damit an die nationalen Gesetzgeber ${ }^{121}$. Es stellt sich daher die Frage, ob die Umsetzung dieser Verpflichtung ausschließlich durch die zuständigen Behörden vorgenommen werden darf. Dies ist meiner Ansicht nach nicht der Fall. Garantiert werden muß eine gemeinschaftskonforme d.h. jedenfalls nicht diskriminierende Regelung der Rechtstellung des Lehrgangsteilnehmers. Auch muß die Regelung so formuliert sein, daß sie die freie Wahl des Kandidaten zwischen Anpassungslehrgang und Eignungsprüfung nicht beeinträchtigt. Tatsächlich erscheint mir im Hinblick auf die Rechtssicherheit und Überprüfbarheit der Entscheidung eine allgemeine Regelung im Rahmen der Umsetzungsgesetzgebung zurnindest in den kontinentaleuropäischen Mitgliedstaaten wünschenswerter als eine ad hoc Entscheidung der zuständigen Behörde bei jedem Lehrgangsteilnehmer.

1120. Dies wird durch die Verwendung des Wortes "insbesondere" bestätigt.

1121. Siehe zu dieser Problematik: Bleckmann, ZGR 1992, 364 (374). 
Die zuständige Behörde sollte sich auf die Abwicklung des einzelnen Verfahrens konzentrieren, ohne dabei selbst in die Rolle des Gesetzgebers zu schlüpfen. Die Pflichten der zuständigen Behörde sollten sïch daher darauf beschränken, dem Antragsteller neben der Zustellung des mit Gründen versehenen Bescheids über seinen Anerkennungsantrag auch Mitteilung über seine zukünftige Rechtsstellung als Lehrgangsteilnehmer bzw. als Prüfling zu machen.

Etwas anderes mag in Großbritannien und Irland gelten, da die große Autonomie der chartered bodies sich nicht nur auf die Anerkennungsregelung für einen bestimmten Beruf erstreckt, sondem auch die Rechtsstellung der einzelnen Berufsangehörigen und damit auch die Rechtsstellung eines Lehrgangteilnehmers betrifft. In diesem Falle mag eine allgemeine Regelung durch die chartered bodies angemessen sein.

\section{e. Die Eignungsprüfung}

Gemå3 Art. 1 j) der Richtlinie 92/51/EWG darf mit der Eignungsprüfung ausschließlich die beruflichen Kenntnisse des Antragstellers überprüft werden, die zur Ausübung des betreffenden Berufes im Aufnahmestaat erforderlich sind. Die Eignungsprüfung darf damit nicht zu einet Wiederholungsprüung bereits im Herkunftsstaat erworbener akademischer Kenntnisse ausarten. Die Bestimmung entspricht wörtlich Art. 1 g) der Richtlinie $89 / 48 / \mathrm{EWG}$.

\section{Die Anerkennungsregelung, wenn der Aufnahmestaat ein Diplom fordert und der Antragsteller ein Prüfungszeugnis besitzt}

Befremdend ist zunächst die Überschrift zu diesem Kapitel. Hier steht wörtlich: "Anerkennungsregellung, wenn der Aufnahmestaat ein Diplom fordert und der aus einem anderen Mitgliedstaat stammende Antragsteller ein Prüfungszeugnis oder einen entsprechenden Ausbildungsnachweis besitzt." Dieser Satz ist insoweit bemerkenswert als er bei dem Antragsteller unterstellt, daß dieser aus einem anderen Mitgliedstaat stammt. Diese Bedingung findet sich jedoch nicht in Art. 2 Abs. 1 der Richtlinie 92/51/EWG. Hier heißt es deutlich "alle Angehörigen eines Mitgliedstaates" ohne die Bedingung, daßB der Antragsteller aus einem anderen Mitgliedstaat als dem Aufnahmestaat zu stammen hat. Dies gilt auch für die Richtlinie 89/48/EWG. Der Anwendungsbereich dieser Richtlinie bezieht sich ausdrücklich sowohl auf Migranten wie auf die eigenen Staatsangehörigen, die Inhaber eines ausländischen Diploms sind. Mit dieser Regelung sollte der Rechtsprechung des Gerichtshofes bezüg】ich Rückwanderen Rechnung getragen werden ${ }^{1122}$. Um so befremdender ist diese Überschrift, zumal sie keine Widerspiegelung im Regelungstext findet.

1122. Urteil vom 7. Februar 1979, Rs 115/78 - Knoors -, Slg. 1979, 399; Unteil vom 7. Februar 1979, Rs 1981,2311 . 
Beil der Umsetzung der Richtlinie 92/51/EWG sollte daher davon ausgegangen werden, daß es sich bei dieser Einschränkung des Anwendungsbereiches auf "Antragsteller aus anderen Mitgliedstaaten" um ein redaktionelles Versehen handelt. Weder die Rechtsprechung des Gerichtshofes noch Art. 2 der Richtlinie 92/51/EWG lassen einen anderen Schluß zu, als daß der gesamte Regelungsbereich der Richtlinie auch auf Rückwanderer anwendbar ist.

Kapitel IV regelt in Art. 5 der Richtlinie 92/51/EWG den Durchstieg vom untersten zum mittleren Ausbildungsniveau. Im Aufbau entspricht Art. $5 \mathrm{im}$ wesentlichen dem Anerkennungssystem gemäß Art. 3 der Richtlinie 92/51/EWG.

\section{Anerkennungsregelung, wenn der Aufnahmestaat ein Prüfungszeugnis fordert}

Wenn in einem Mitgliedstaat zum Zugang oder zur Ausübung eines reglementierten Berufes ein Prüfungszeugnis verlangt wird, so kann gemäß Art. 6 a) der Richtlinie 92/51/EWG die Anerkennung nicht verweigert werden, wenn der Antragsteller über ein Diplom oder ein Prüfungszeugnis verfügt, das in einem anderen Mitgliedstaat Zugang zu diesem Beruf gewährt. Der Diplombegriff bezieht sich hierbei auf die Definitionen beider allgemeinen Richtlinien.

\section{Die Sonderregelung für die Anerkennung sonstiger Qualifikationen}

Wird der Zugang in einem Mitgliedstaat von einem Befähigungsnachweis abhängig gemacht, so kann gemäß Art. 8 a) der Richtlinie 92/51/EWG die Ausübung dieses Berufes nicht verweigert werden, wenn der Antragsteller den entsprechenden Befähigungsnachweis, der in einem anderen Mitgliedstaat zur Berufszulassung oder -ausübung erforderlich ist, besitzt oder gemäß Buchstabe b) der Bestimmung, die in einem anderen Mitgliedstaat erworbenen Qualifikationen nachweist. Bemerkenswert ist dabei, daß bei den Befähigungsnachweisen und bei den Qualifikationen vorausgesetzt wird, daß diese in einem Mitgliedstaat erworben wurden. "Drittstaatsqualifikationen" stehen außerhalb des Anerkennungssystems.

Weitere Voraussetzung des Anerkennung gemäß Art. 8 der Richtlinie 92/51/EWG ist, daß in besonderen Bereichen eine Gleichwertigkeit garantiert sein muß. Namentlich genannt werden die Bereiche Gesundheit, Sicherheit, Umweltschutz und Verbraucherschutz. Diese Liste ist jedoch nicht als abschließend anzusehen. Felllt der erforderliche Befähigungsnachweis oder kann der Antragsteller die entsprechenden Qualifikationen nicht nachweisen, so gelten die Rechts- und Verwaltungsworschriften des Aufnahmestaats.

Wird in einem Mitgliedstaat der Berufszugang won einem bestimmten Schulabschluß abhängig gemacht, so darf einem Migranten gemäß Art. 9 der Richtlinie 92/51/EWG die Berufsaufnahme nicht verweigert werden, wenn er eine entsprechende Qualifikation besitzt. Dieser Artikel ist besonders interessant im Hinblick auf die Frage der akademischen Anerkennung von Diplomen. Die Reglementierung des Berufs besteht in diesem 
Falle ausschließlich in Form einer schulischen Qualifikation. Anerkannt wird ein wergleichbarer Schulabschluß, z. B. das Abitur, die Mittlere Reife oder ein Grundschullabschluß. Bei diesen Befähigungsnachweisen handelt es sich aber grundsätzlich um rein akademische Diplome ${ }^{1123}$.

\section{Die Schlußbestimmungen}

Die weiteren Kapitel entsprechen weitgehend denen der Richtlinie 89/48/EWG. Gemäß Art. 17 der Richtlinie 92/51/EWG waren die Mitgliedstaaten verpflichtet, die Richtlinie bis zum 18. Juni 1994 umzusetzen. Die überwiegende Mehrheit der Mitgliedstaaten waren nicht in der Lage diesen Termin einzuhalten. Lediglich Italien ${ }^{1124}$, Luxemburg ${ }^{1125}$, Finnland ${ }^{1126}$ und die Niederlande ${ }^{1127}$ haben eine fristgerechte Umsetzung mit der Verabschiedung eines allgemeinen Umsetzungsgesetzes vorgelegt. Dänemark folgte mit der Veröffentlichung eines allgemeinen Umsetzungsgesetzes im Januar $1995^{1128}$. Frankreich ${ }^{1129}$ und Deutschland ${ }^{1130}$ haben sektorielle Teilumsetzungsmaßnahmen erlassen. Eine vollständige Umsetzung liegt bei diesen beiden Mitgliedstaaten noch nicht vor.

1123. Siehe daxu die Eronterungen auf Seite 425.

1124. Decreto legislativo vom 2. Mai 1994, Mr. 319, Gaz. Uff. Nr. 123 vom 28. Mai 1994.

1125. Règlement vom 2. Juni 1994, Mémorial A Nr. 49 vom 17. Juni 1994.

1126. Gesetz/Laki vom 28. Jumi 1994 sowie Verordnung/Asetus vom 28 . Juni 1994

1127. Gesetz vom 29. Juni 1994, Stbl. 640, 1994 und Beschluß vom 29. Juni 1994, Stbl. 641.

1128. Gesetz Nr。 52 wom 19. Januar 1995.

1129. Die französischen Unisetzungsmafnahmen beziehen sich hauptsächlich auf paramedizinische Berufe.

1130. Diätassistent: Gesetz vom 8. Mărz 1994, BGBI. I 1994, 446; Physiotherapeut: Gesetz vom 26. Mai 1994, BGBI. I 1994, 1084; Handwerker: Gesetz zur Änderung der Handwerksordnung vom 20. Dezember 1993, BGBL. I 1993,2256 
Teil V

Fallstudien 
Teil V

Fallstudie I

\section{Die rechtsberatenden Berufe}

\section{\$1. Einleitung}

Vor mehr als 125 Jahren erschien ein Buch mit dem Titel "Freie Advocatur" von Rudolf Gneist ${ }^{1131}$. Darin forderte Gneist den freien Zugang zur Advokatur vor allem aus Gründen des sprunghaft gestiegenen Bedarfs. "Nur für die Amtsanschauung erscheint der Anwalt zunächst als Gehilfe des Richters zur Ermittlung der prozessualen Wahrheit. Viel allgemeiner ist das Bedürfnis des Beistandes, Prozesse zu verhüten, um das Publikum vor Schaden, die Rechtswerhältnisse vor Verwirrung und Verdunklung zu bewahren". Er sprach sich für eine Öffnung des Notariats für Anwälte aus und nahm prinzipiell Stellung gegen berufsrechtliche Verbote und Beschränkungen. "Wenn wir fortfahren, gegen die Natur des Menschen und der geistigen Arbeit das Lebenselement des geistigen Wetteifers aus dem Juristentum zu exstirpieren, wird es dahin kommen, daß wir mit der solidesten Vorbildung, dem bestgeordneten Kursus, dem größten Fleiß unsere Juristen durch ihre Mittelmäßigkeit sprichwörtlich machen."

Trotz dieser weisen und in vielen Punkten noch sehr aktuellen Worte vor mehr als Inundert Jahren ist die Geschichte der rechtsberatenden Berufe in diesem Jahrhundert weit mehr durch berufsrechtliche Beschränkungen als durch eine Liberalität der Zulassung geprägt ${ }^{1132}$. Diese Grundhaltung bestimmte auch die ersten zwanzig Jahre innerhalb der Europäischen Gemeinschaften. Bis heute stößt die zunehmende Liberalisierung des grenzüberschreitenden Rechtsberatungswerkehrs auf Widerstand. Zunächst stand die Anwendung des Art. 55 EGV auf den Beruf des Rechtsanwalts im Mittelpunkt der Diskussion. Es folgten Auseinandersetzungen über den Umfang der Dienstleistungsfreiheit. Nachdem diese beiden Punkte im wesentlichen durch die Rechtsprechung des Gerichtshofes gelöst werden konnten, steht nun die Niederlassungsfreiheit für Rechtsanwälte zur Debatte. Eine Lösung dieser Problematik bietet die Richtlinie 89/48/EWG, da mit der Anerkennung die Niederlassung unter Verwendung der Berufsbezeichnung des Aufnahmestaates gewährt werden muß. Diese Lösung wird jedoch den Bedürfnissen

1131. Rudolf Gneist, Freie Advokatur. Die erste Fonderung aller Justizreform zu PreußBen, Bertin $\mathbb{1 8 6 7 .}$

1132. Dies galt in besonderem Maße für die Bundesrepublik Deutschland. kritisch dazu Friese 1989; Firiese, AnwB1. 1987, 3. Ansätze zur Veränderung sind erst in jüngster Zeit zu konstatieren. 
des internationalen Rechtswerkehrs nur bedingt gerecht. Wesentlich adäquater für viele international operierenden Rechtsanwälte ist eine Niederlassung unter "home title", die die Möglichkeit eröffnet, rechtsberatend zum eigenen Rechtssystem tätig zu sein, ohne eine vollkommene Integration in den Berufsstand des Aufnahmestaates anzustreben, die nur durch Ablegung einer Eignungsprüfung bewirkt werden könnte ${ }^{1133}$. Es überrascht daher nicht vollkommen, daß der Rat der Anwaltschaft der Europäischen Gemeinschaft (CCBE) ${ }^{1134}$ gerade nun nach fünfzehnjähriger Debatte und mehreren vergeblichen Versuchen einen Vorschlag für eine Richtlinie zur Regelung des Niederlassungsrechts der Rechtsanwälte angenommen hat ${ }^{1135}$. Der CCBE hatte dabei die nicht unbegründete Hoffnung, daß diese von den Berufsvertretern in der Gemeinschaft beschlossene Richtlinie sich zu einem von der Kommission vorgelegten Richtlinienentwurf entwickeln wird, der in Zukunft als sektorielle Richtlinie für Rechtsanwälte die Niederlassung unter "home title" sowie eine vereinfachte Diplomanerkennung bestimmen soll. Zwar hat die Kommission sich grundsätzlich dahingehend geäußert, keinerlei Ambitionen zu haben, der sektoriellen, d.h. vertikalen Harmonisierungskonzeption neues Leben einzublasen, eine mögliche Niederlassungsrichtlinie für Rechtsanwälte wurde jedoch immer als Ausnahme yon dieser Regel bezeichnet, unter der Voraussetzung, daß im CCBE eine Einigung erzielt werden konnte. Nachdem diese Voraussetzung erfüllt wurde, konnte nun die Kommission auf dieser Basis einen Entwurf erarbeiten ${ }^{1136}$. In welchem Verhältnis die drei für Rechtsanwälte dann geltenden Rïchtlinien, d.h. die Dienstleistungsrichtlinie 77/249/EWG, die Hochschuldiplomrichtlinie 89/48/EWG und die zukünftige Niederlassungsrichtlinie, zueinander stehen werden, wird in Zukunft noch auszuloten sein. Prinzipiell kann jedoch von einem Nebeneinander der drei Systeme ausgegangen werden ${ }^{1137}$.

\section{§ 2. Die Ausnahmebestimmung des Art. 55 EGV}

Gemäß Art. 55 EGV findet auf Tätigkeiten, die in einem Mitgliedstaat dauernd oder zeitweise mit der Ausübung offentlicher Gewalt verbunden sind, das Niederlassungsrecht in dem betreffenden Mitgliedstaat keine Anwendung, d.h. der Mitgliedstaat ist befugt, die betreffende Tätigkeit einem Staatsangehörigkeitsvorbehalt $z u$ unterwerfen.

1133. Nach der heutigen Rechtslage ist die Rechtsberatung in Frankreich, Griechenland, Italien, Luxemburg, Österreich, Portugal und Spanien für dlie einheimischen Rechtsanwälte reserviert. Eime Ausnahmeregelung gilt in diesen Staten lediglich für dienstleistende Rechtsanwälte.

1134. Siehe zur Rolle des CCBE: Goebel, Fondham Int. Law Journal 1991-1992, 556 (601-606).

1135. Die Annahme des Vorschlags erfolgte am 23. Oktober 1992 in Lissabon wobei die nach der Salzung erforderliche Mehtheit von zehn der zwölf nationalemen Delegationen; sich für diesen Entwurf aussprachen. Nur Spanien und Luxemburg stimmten gegen diesen Entwurf, so daß vom "Wunder von Lissabon" $^{\text {t }}$ die Rede war. Siehe dazu Weil, BRAK-Mitt. 1993, 2. Zur Vorgeschichte dieses CCBE-Entwarfs. siehe Weil, Fordham Int. Law Journal 1991-1992, 699 (703 ff.). Zum früheren Entwurf aus dem Jahr 1982 (Achener-Entwurf), siehe Goebel, Tulane Law Review 1989,443, (499-503): Spedding, 156-168.

1136. Agence Europe vom 28. Dezember 1994, 12. KOM (94)572 endg.. Dazu die ausführliche Studie des House of Lords, Select Committe of the European Communities, The Right of Establishment for
Lawyers, 1995 .

1137. Zum Verhăltnis Dieristleistungsrichtlinie und Hochschulrichtlinie siehe die Erörtenungen Seite 420 
In den Anfangsjahren waren alle Mitgliedstaaten mit Ausnahme der Niederlande 1438 der Ansicht; daß der Beruf des Rechtsanwalts auf Grund von Art. 55 EGV außerhallb des Anwendungsbereichs der Freizügigkeitsrechte fiel ${ }^{1439}$. Diese Ansicht wurde am stairksten und längsten von Luxemburg und der Bundesrepublik Deutschland vertreten ${ }^{1140}$. Schaus - der Vertreter Luxemburgs bei den Vertragsunterhandlungen - vertrat die Auffassung, ein Beruf müsse gänzlich außerhalb des Anwendungsbereichs des EWG-Vertrages stehen, falls bestimmte Tätigkeiten in Ausübung öffentlicher Gewalt ausgeübt würden. Dies müsse jedoch bei Rechtsanwälten bejaht werden ${ }^{1141}$. Aus deutscher Sicht wurde zur Rechtfertigung der Anwendung von Art. 55 EGV darauf verwiesen, daß in einigen Bundesländern ebenso wie in Frankreich ${ }^{1142}$ Anwälte zu Hilfsrichtern ernannt werden könnten ${ }^{143}$. Der Rechtsanwalt als "Organ der Rechtspflege" falle eindeutig unter die Voraussetzungen von Art. 55 EGV ${ }^{1144}$. Generalanwalt Mayras stellte in seinen Schlußanträgen in der Rechtssache Reyners fest, daß die Frage nach der Niederlassungsfreiheit der Rechtsanwälte seit dem Inkrafttreten des Vetrages so lebhafte Kontroversen und so heftige Meinungsverschiedenheiten zwischen den einzelnen Rechtsarnwaltskammern und Regierungen ausgelöst hat, "daßß die Tätigkeit der Gemeinschaftsorgane lahmgelegt war und bis zur Stunde keine positive Maßnahme ergriffen werden konnte, um die Tätigkeiten des Rechtsanwalts auf Gemeinschaftsebene zu liberalisieren ${ }^{1145}$ " Er nannte es daher auch einen Glücksfall, daß dem Gerichtshof die Gelegenheit geboten wurde, dieses Problem zu lösen. Auch in der Literatur wurde über diese Frage eine heftige Diskussion geführt ${ }^{146}$. Mit dem Urteil in der Rechts-

1138. Van der Felz, Adv. Bl. 1966, 197; Stevens R.W. 1969, 1922; Dabei bestand aber auch in den Niederlanden ein Staatsangehörigkeitsworbehalt für die Zulassung zur Anwaltschaft.

1139. Van der Felz (1965), 142; Stevens, R.W. 1969, 1922; Dieser Überblick beruhte auf einer Umfrage der Kommission, Van Camp, 105 , FuBnote 29.

1140. Desmet, R.W. 1967-1968, 723; Arendt. Barreau et medecins (1968), 52 ff.. In der Rechtssache Reyners vertraten vor allem Luxemburg und die nationale Rechtsanwaliskammer von Belgien die Ansicht, dal der Anwaltsberuf' als Gamzes sich den Vertragsworschriften entziehe. Dagegen war die devitsche Regienung der Auffassung, die enge Verbindung zwischen dem Beruf des Reclatsanwalts und der Aufnahme der öffentlichen Gewalt werbiete eine Liberalisierung für weite Teibereiche des Berufs; Urtell vom 21 . Jumi 1994, Rs 2/74 - Reyners/Belgischer Staat -, Slg. 1974, 631 (653), Rdnr. 35 ff.

1141. Schaus, J.T. 1962, 73 .

1142. Art. 30 loi du 22 ventôse an XII, 13. Mârz 1804.

1143. Arnold, Anwbl. 1959, 28 unter Hinweis auf \& 10 Abs. 2 GVG; Ehrling in Groeben/Boeckh-Kommentar (1958). Art. 55 Rdinr. 1 .

1144. \$1 BRAO

1445. Schlußanträge des Generalanwalts Mayras, Urteil vom 21. Iuni 1974, Rs 2/74 - Reyners/Belgischer Statat - SHg. 1974, $631(658)$.

1146. Siehe dazu Ehrling in: Groeben/Boeckh-Kommentar (1958), Art. S5 Rdnr. 1; Arnold, AñwB. 1959 27: Audinet, JDI 1959, 982; Brangsch, AmwB1, 1962, 234; Lussan 1958, 49; wan der Felz, Adw.B1. 1966, $197 \mathrm{ff}$; Maestripierieri, (1972), $158 \mathrm{ff}$ : Terré, JDI 1967, $265 \mathrm{ff}$; Laguette, RTDE 1966, 242 1966, $197 \mathrm{fr}$, Maestripiencour, RMC 1970, $163 \mathrm{ff}$; de Dorlodot, RMC 1975, $477 \mathrm{ff}$; de Brauw, R. W. 1973-1974, 1810 ; Schaus ${ }_{\|} \mathrm{JT} 1962,73$; de Crayencour, Barreau et méclecins (1968), 34; Lequlercq, Barreau et médecins; 77 ff. Möhring, NJW 1965, 1633; Hollch, NFW 1969, 1505 sowie dlie sethr ausfithrliche historische und rechtsvergleichende Analyse von Tomuschat, ZaöRV 1967, 53. 
sache Reyners 1974 hat dieser Streit für Rechtsanwälte schließlich ein Ende gefunden ${ }^{147}$. Der Gerichtshof stellte unmißverständlich fest: "Die in Artikel 55 Absatz 1 des EWG-Vertrages vorgesehene Ausnahme vom Grundsatz der Niederlassungsfreiheit ist auf diejenigen in Artikel 52 bezeichneten Tätigkeiten zu beschränken, düe für sich genommen eine unmittelbare und spezifische Teilnahme an der Ausübung öfentlicher Gewalt mit einschließ3en; hierzu sind im Rahmen eines freien Berufes wie dem des Rechtsanwaltes nicht Tätigkeiten wie die Rechtsberatung und der Rechtsbeistand zu rechnen, desgleichen nicht die Vetretung und die Verteidigung des Auftraggebers vor Gericht, selbst wenn das Gesetz die Wahrnehmung dieser Aufgaben durch den Rechtsanwalt zwingend oder ausschließlich worschreibt."

Für andere rechtsberatende Berufe, so etwa vor allem für den Notar ${ }^{1148}$, aber wie es schien selbst für den Wirtschafts- bzw. Versicherungsprüfer ${ }^{1449}$, war und ist die Auseinandersetzung noch bei weitem nicht abgeschlossen. In der jüngsten Zeit hatte der Gerichtshof jedoch mehrfach die Gelegenheit seine in der Rechtssache Reyners begonnene Interpretation des Art. 55 EGV weiter zu entwickeln ${ }^{4150}$. In der Rechtssache C-306/89, - Kommission gegen Griechenland -, hat der Gerichtshof mit Urteil vom 10. Dezember 1991 entschieden, daß der Fall eines Kraftfahrzeugsachverständigen nicht unter die Ausnahmebestimmung des Art. 55 EGV fällt. Der Gerichtshof hat in diesem Verfahren, wie bereits auch in der Rechtssache Reyners darauf abgestellt, daß die Gutachten des Sachverständigen ebenso wie die Wahrnehmung der typischen Aufgaben des Rechtsanwalts die Gerichte nicht bindet, sondern die "richterliche Beurteilung und die freie Ausübung der Rechtsprechungsbefugnis unberührt lassen" 1151. In der Rechtssache 147/86 - ebenfalls ein Verfahren Kommission gegen Griechenland - hat der Gerichtshof festgestellt, daß den durch Art. 55 EGV anerkannten Ausnahmen vom Grundsatz der Niederlassungsfreiheit Grenzen gesetzt sind, wodurch verhindert werden soll, daß der EG-Vertrag durch einseitige Maßnahmen der Mitgliedstaaten "seiner

1147. Urtell vom 21. Juni 1974, Rs 2/74-Reyners/Belgischer Stat -, Slg. 1974, 631. Goebel, Fordham Int. L.J. $1991-92,588$ weist auf die uberraschende Ähnlichkeit zwischen diesem Unteil und einer nahezu zeitgleich ergangenen Entscheidung des U.S. Supreme Court (413 U.S. 717 (1973)) hirn. Dazu auch Spedding. $211 \mathrm{ff}$.. Die Entschedung des Supreme Courts kömte u.U. den EuGH beeimflußt haben.

1148. Everling 1963, 115 bezeichnete die Anwendung des Art. 55 EWGW auf Notare als unbestreitbar. Die von Everling im Gutachten zum 58. DJT, C 18 gewählte Formulienung ist dagegen vorsichtiger: "Unter den anderen rechtsberatenden Berufen dürtten die Notare ausgeschlossen sein, da sie offenttiche Urkundsbeamtem sind." ; siehe dlazu auch Fischer, DNotZ 1989, 467 (471 f.)

1149. Siehe dazu das Urteill wom 13. Juli 1993, in der Rs C-42/92 *Adrianus Thijssen/Controledienst woor verzekeringen . SIg. 1-4047, wobej es um die Frage ging, ob das Gemeinschaftsrecht es erlaubt, dafl der Zugang zur Ausübung der Tătigkeit eines zugelassenen Versicherungsprüfers belgischen Staatsangehörigen vorbehalten wird.

1150. Unteil vom 15. Marz 1988, Rs 147/86 Kommission/Griechenland, Slg. 1988, 1637; Urtell vom 110 Dezember 1991, Rs C-306/89, - Kommission/Griechenland - Slg. 1991, 1-5863. Urteil vom 13. Juli 1993, Rs C $-42 / 92$ - Adrianus Thijssen/Controledienst voor verzekeringen - , Slg. 1993, 1-4047.

1151. Siehe dazu das Urteil vom 10. Dezember 1991, Rs C-306/89, - Kommission/Griechemland -, Slg. 1991, I-5863 Rdnr. 7 und das Unteil vom 21. Juni 1974, Rs 2/74 - Reyners/Belgischer Staat - , Slg1974, 631, Rdnt. 52/53. 
praktischen Wirksamkeit in diesem Bereich beraubt wird" ${ }^{\text {1152 }}$. Dabei betonte der Gerichtshof den Ausnahmecharakter des Art. 55 EGV. Seine Tragweite müsse sich daher auf das beschränken, was zur Wahrung der Interessen, die diese Vorschrift den Mitgliedstaaten zu schützen erlaubt, unbedingt erforderlich ist ${ }^{1153}$. Generalanwalt Lenz hat in seinen Schlußanträgen in der Rechtssache Thijssen festgestellt, daß Belgien für die Regelung hinsichtlich des zugelassenen Wirtschaftsprüfers diesen Nachweis der zwingenden Erforderlichkeit nicht erbracht hätte. Dies bedeutet aber, daß das Verlangen der Staatsangehörigkeit unter Berufung auf Art. $55 \mathrm{EGV}$ für Wirtschaftsprüfer dem Verhältnismäß3igkeitsgrundsatz widerspricht ${ }^{1154}$. Der Gerichtshof ist dem Generalanwalt in dieser Sache gefolgt ${ }^{1555}$. Ob aus dieser Rechtsprechung bereits Schlulusse für den Notar gezogen werden können, muß noch abgewartet werden.

Die Antwort dürfte wesentlich von der Organisation des Notariats in den einzelnen Mitgliedstaaten abhängen ${ }^{1156}$. Dabei war das französische Notariatsgesetz von 1803 für die rechtliche Ausgestaltung in vielen Mitgliedstaaten von grundlegender Bedeutung ${ }^{157}$. Dies gilt für einen Teil des deutschen Notariats aber insbesondere für Belgien, Italien, Luxemburg, die Niederlande ${ }^{1158}$, Spanien und Österreich. In Deutschland gibt es neben dem freiberuflichen Notariat auch das Anwaltsnotariat und das Beamtennotariat. Dagegen kennen Großbritannien ${ }^{1159}$, Irland, Dänemark und Portugal kein freiberufliches Notariat. In Großbritannien und Irland werden die Aufgaben des Notars im wesentlichen durch die Solicitors wahrgenommen, während es in Dänemark und Portugal Beamtennotare gibt. Auch werden in Dänemark die notariellen Funktionen teilweise durch Richter wahrgenommen. Es kann angenommen werden, daß insoweit die portugisieschen und dänischen Notare unter die Ausnahmeregelung des Art. 48 Abs. 4 EGV fallen, zumal ihr Aufgabenbereich sehr begrenzt ist. In Großbritannien und Irland werden die "notariellen" Funktionen des Solicitors nicht ausdrücklich unter den Ausnahmetatbestand des Art. 55 EGV subsumiert ${ }^{1160}$.

1152. Urteil vom 15. März 1988, Rs 147/86 - Kommission/Griechenland, Slg. 1988, 1637, Rdnr. 8.

1153. Urtell vom 15. März 1988, Rs 147/86 - Kommission/Griechenland, S4g. 1988, 1637, Rdnr. 7.

1154. Schludantuage des Generalanwalt Lenz vom 24. Marz 1993 in der Rs C-42/92 - Adrianus Thijssen/Controledienst voor verzekeringen - Slig. 1993, 1-4047.

1155. Urteil vom 13. Juli 1993, Rs C-42/92 - Adrianus Thijsen/Controledienst voor verzekeringen - , Slg 1993. 1-4047. Dazu Wouters, Tijdschrift voor rechtspersonen en vennootschap 1993, 466 ff?

1156. Siehe dazu die Beiträge in den Mitteilungen des Bayerischen Notarvereins, Sonderheft 1990, Standort und Zukunft der Notare in Europa. Bisher betrachten die Mehrheit der Mitgliedstaaten das Amt des Notars mit der Ausübung offenticher Gewalt im Sinne des Art. 55 EGV verbunder, daza die Landerinformationen in Jura Europae, Niederlassungsrecht.

11 157. Institut für Freie Berufe (Hrsg), 207 ff. Zum französischen Notariat siehe von Randenborgh 1990.

1158. In den Niederlanden wird zur Zeit eine Neufassung des Notargesezes (Wet op het Motarisambt aus dem Jahr 1842) erwogen (Gesetzentwurf 23 706), siehe dazu die Spezialnummer des NJB vom 19. Mai 1995.

1159. Eine Ausnahme gilt für den Bereich der London Notaries. Diese können jedoch nichll als Notare im kantinenualrechulichen Sinne werstanden werden. Es handelt sich vielmehr um Spezialisten in internatio nalen Rechtsfragen.

1160. Siehe aber die Ausnahmeregelung in Art. 1 Abs. 2 der Richtinie 77/249/EWG sowie im Entwurf zur zuküftigen Niederlassungsrichtlinie die Bestimmung in Art. 2 Abs. 2. 
Die Aufgabenbereiche für Notare sind aber auch in den noch verbleibenden Mitgliedstaaten durchaus unterschiedlich reglementiert ${ }^{1161}$. Von den einzelnen Aufgaben wird es in Zukunft abhängen, ob der Beruf - soweit er freiberuflich ausgeubt wird - unter den Ausnahmetatbestand des Art. 55 EGV fällt ${ }^{1162}$. Hierbei erscheint es mir wesentlich, ob die notarielle Tätigkeit hauptsächlich auf die individuelle Vertragsgestaltung gerichtet ist, oder ob die öffentliche Beglaubigung im Mittelpunkt der Berufsausübung steht. Es erscheint mir vertretbar, daß die individuelle Vetragsgestaltung und Rechtsberatung, etwa im Falle von Erbverträgen und Testamenten sowie Verträgen zur Vermögensverteilung, ein Tätigkeitsbereich ist, der nicht als Ausübung der öfentlichen Gewalt im Sinne des Art. 55 EGV zu qualifizieren ist. Dies ergibt sich bereits daraus, daß in zunehmendem Maße andere Berufe und auch Institutionen, soz. B. Rechtsanwälte, Steuerund Vermögensberater sowie Banken, in diesen Bereich der notariellen Tätigkeit drängen. Teilweise wird für diesen Bereich argumentiert, die Sonderstellung des Notars rechtfertige sich durch die Tatsache, daß der Notar bei der Rechtsberatung der Parteien eine neutrale Stellung einnehmen müsse: Dieses Argument erscheint mir nïcht genügend schlagkräftig zu sein, um diesen Bereich der notariellen Tätigkeit einem Staatsangehörigkeitsvorbehalt zu unterwerfen. Einerseits kann man auch von einem Rechtsanwalt oder einem anderen rechtsberatenden Berufsangehörigen, der zwei Parteien zu einem Rechtsproblem berät, ohne daß es sich um ein anhängiges Streitverfahren handelt, erwarten, daß ein die Interessen beider Parteien berücksichtigender Rat gegeben wird, so daß die Rolle des Notars keine besondere ist. Andererseits kann eine derartige neutrale Position auch von einem ausländischen Berufsangehörigen erwartet werden. Dies ist eine Frage der Standesregelln und weniger eine Frage der Staatsangehörigkeit. Hinsichtlich der notariellen Beurkundung liegt die Rechtslage dann anders, wenn diese einen besonders öffentlichrechtlichen Charakter hat. Der Notar übt diese Funktion als Träger eines öfentlichen Amtes aus, wobei seine Tätigkeit einer strengen staatlichen Kontrolle unterliegt. Für diesen Tätigkeitsbereich erscheint mir zur Zeit die Anwendung des Art. 55 EGV noch gerechtfertigt. Dach dieses Gebiet unterliegt einem Wandel. In zunehmendem Maße wird die gegenseitige Anerkennung von ausländischen Urkunden und Beglaubigungen internationalisiert. Die Anwendung von Art. $55 \mathrm{EGV}$ auf diesen Tätigkeitsbereich der Notare erscheint mir dann ihre Berechtigung zu verlieren, sobald die Beglaubigungen und Urkunden auslänđischer Notare im nationalen Rechtsverkehr die selbe Bedeutung und Gültigkeit haben wie die der inländischen Kollegen. Von diesem Moment an ist meines Erachtens die Anwendung von Art. 55 EGV nur noch ein Argument, um ungeliebte Konkurrenz vom einheimischen Markt fernzuhalten. Dieser Wandel dürfte sich in der nächsten Zukunft mehr und mehr vollziehen, da die steigende Entwicklung des internationalen Dienstleistungsverkehrs nicht vor diesem Gebiet haltmachen wird. Die zunehmende Internationalisierung der anderen rechtsberatenden Berufe und die damit verbundene grenzüberschreitende Dienstleistungserbringung sind hierfür bereits beispielhaft. 


\section{§ 3. Die Dienstleistungsrichtlinie 77/249/EWG}

\section{A. Der Regelungsbereich DeR RichtLinie 77/249/EWG}

Der ursprüngliche Vorschlag für eine Richtlinie für Rechtsanwälte stammte vom $\mathbb{1 6}$. April 1969. Dieser hatte jedoch aufgrund der deutschen und luxemburgischen Haltung zu Art. 55 EWGV im Rat nicht verabschiedet werden können ${ }^{1163}$. Die Urteile in den Rechtssachen Reyners und van Binsbergen brachten in diese Situation eine Veränderung, so daß die Kommission in der Lage war einen veränderten Vorschlag vorzulegen, der über den Anwendungsbereich des ursprünglichen Entwurfs selbst hinausging ${ }^{1164}$. Dieser führte letztlich zur Verabschiedung der Richtlinie 77/249/EWG über die Dienstleistungen von Rechtsanwälten ${ }^{1165}$. Diese Richtlinie ist auf die Ant. 57 und 66 EWGV gestützt. Offensichtlich sah man noch keine Notwendigkeit, eine Rechtsgrundlage hinsichtlich der im abhängïgen Beschäftigungsverhältnis stehenden Rechtsanwälte anzugeben. Im vierten Erwägungsgrund der Richtlinie wird ausdrücklich auf die Tatsache hingewiesen, daß diese sich lediglich auf den Dienstieistungsverkehr bezieht, während die Vorschriften über die Anerkennung der Diplome noch nicht erlassen sind. Dieser Erwägungsgrund steht in einem gewissen Spannungsverhältmis zur Wahl der Rechtsgrundlage, die gerade in ihrem Abs. 1 die Anerkennung der Diplome bezweckt. Auch wird mit der Richtlinie keine Koordinierung der Ausbildung im Sinne des Art. 57 Abs. 2 EGV angestrebt. Konsequenz dieser Regellungsentscheidung ist, daß der Begünstigte bei der Ausübung seiner Dienstleistungsfreiheit verpflichtet ist, die Berufsbezeichnung des Herkunftstaates, d.h. des Staates in dem der Rechtsanwalt niedergelassen ist, zu führen.

Gemäß Art. 1 der Richtlinie 77/249/EWG gilt diese Richtlinie im Rahmen der durch sie gesetzten Grenzen ausschließlich für die in Form der Dienstleistung ausgeübten Tätigkeiten der Rechtsanwälte. Dabei werden die Mitgliedstaaten in Art. 1 Satz 2 der Richtlinie 77/249/EWG ausdrücklich dazu ermächtigt, die Abfassung förmlicher Urkunden, mit denen das Recht auf Verwaltung des Vermögens verstorbener Personen verliehen oder mit denen ein Recht an Grundstücken geschaffen oder übertragen wird, bestimmten Gruppen von Rechtsanwälten vorzubehalten. Zur Bestimmung der Begünstigten enthält Art. 1 Abs. 2 die Liste der Berufsbezeichnungen in den einzelnen Mitgliedstaaten. Aufgrund der mittlerweile in Belgien und Italien eingetretenen Veränderungen müßte diese Liste eigentlich angepaßt werden. So sollte für Belgien auch die Bezeichnung "Rechtsanwalt", für Italien der Beruf des "Procuratore legale" in den Richtlinientext Eingang finden. Art. 2 der Richtlinie 77/249/EWG enthălt die Anerkennungs-

1163. De Crayencour 1981,99.

1164. Geänderter Vorschlag der Kommission vonn 25. Juli 1975; siehe dazu Winkel "NIW 1976, 415.

1165. Richtinie 77/249/EWG des Rates zur Erteichterung der tatsächlichen Ausübung des freien Dienstleistamgswerkehrs der Rechtsanwälte., ABl. Nr. L 78 vom 23. Marz 1977, 17. Siehe dazu Boie, NJW 1977. 1567; Bronkhourst, ELR 1977, 224; Brunois, RTDE 1977, 397; De Brauw, CDE 1978, 33; Dubois, EG 1977, 8; Laguette 1987, 241 -248; Kranz, RIW 1978, 160; Pettiti, RMC 1977, 239; Walters, ELR 1978, 265; Wilson Harw. ILJ 1978, 379 . 
bestimmung, Art. 3 die Regelung über die zu führende Berufsbezeichnung. Wie bereüts im vierten Erwägungsgrund angegeben wird der Begünstigte werpflichtet, die im Herkunftsstaat gültige Berufsbezeichnung zu führen, wobei er zusätzlich die Berufsorganisation, deren Zuständigkeit er unterliegt oder das Gericht, bei dem er zugelassen ist, anzugeben hat.

Art. 4 und 5 der Richtlinie 77/249/EWG betreffen die inhaltliche Ausgestaltung der Dienstleistungserbringung. Gemäß Art. 4 Abs. 1 wird die rechtsanwaltliche Tätigkeit vor Gericht oder vor Behörden gemäß der Bedingungen des Aufnahmestaates ausgeübt, wobei allerdings das Erfordernis des. Wohnsitzes sowie die Zugehörigkeit zu der innerstaatlichen Berufsorganisation ausgeschlossen sind ${ }^{1166}$. Der dienstleistende Rechtsanwalt muß sich dabei gemäß Art. 4 Abs. 2 an die Standesregeln des Aufnahme- und des Herkunftstaates halten. In diesem Falle spricht man von einer doppelten Deontologie $^{1167}$. Diese doppelte Deontologie ist in einigen Fällen nicht unproblematisch. Goffin ${ }^{168}$ nennt dazu als Beispiel die Verpflichtung des englischen solicitors um Kontakt mit Zeugen aufzunehmen, während nach belgischem Recht eine derartige Kontaktaufnahme mit möglichen zukünftigen Zeugen für den Anwalt ausdrüicklich verboten ist. Die Problematik ist nicht einfach zu. lösen. MuB sich der englische solicitor in Belgien an die Regel des Kontaktverbots halten? Darf der belgische Rechtsanwalt in GroBbritannien Kontakt mit Zeugen aufnehmen? Ist er dazu u.U. im Rahmen einer ordnungsgemäßen Prozeßführung sogar verpflichtet? ${ }^{1169}$ Hinsichtlich anderer nicht mit der Rechtspflege verbundenen Tätigkeiten bleibt der Rechtsanwalt gemäß Art. 4 Abs. 4 den im Herkunftsland geltenden Bedingungen und Standesregeln unterworfen. Grundsätzlich ist er jedoch angehalten, gewisse berufsrechtliche Regelungen des Aufnahmestaats einzuhalten. Die Formulierung in Abs. 4 ist in dieser Hinsicht nicht eindeutig. Es heißt darin wörtlich "Diese Regeln sind nur anwendbar, wenn sie von einem Rechtsanwalt beachtet werden können...". Daraus kann abgeleitet werden, daß diese Regeln nur dann eingehalten werden müssen, wenn dies nicht zu einer ungerechtfertigten Behinderung des Dienstleitungsverkehrs führt ${ }^{170}$. Art. 4 Abs. 3 ist den Sonderverhältnissen in GroBbritannien und Irland gewidmet. Dabeï gelten für den dienstleistenden Rechtsanwalt grundsảtzlich die Standesregeln für solicitors, es sei denn, die gesamten Tätigkeiten sind barristers oder advocates vorbehalten.

Art. 5 der Richtlinie 77/249/EWG betrifft die Dienstleistung im Rahmen der Rechtspflege. Es war vor allem diese Bestimmung, die bei der Umsetzung Anlaß zur Diskussion gab. Nach diesem Artikel können die Mitgliedstaaten im Falle der Vertretung und Verteidigung von Mandanten im Bereich der Rechtspflege es dem dienstleistenden Rechtsanwalt auferlegen, daß sie entsprechend der örtlichen Gepflogenheit beim Präsidenten des Gerichts und dem Vorsitzenden der Amwaltskammer eingeführt sind. Dabei

1166. Dazu Brangsch, NJW 1981, 1179; Leleux CDE 1976, 685

1167. De Brauw, CDE 1978, 42.

1168. Goffin, JT 1983,606

1169. Nach Van Camp, 40, mïssen in diesen Zweifelsfällen die Regeln des Aufnahmestaates Vorrang haben.

1170. Vam Camp, 51; Storm/Hooghoudt, RM Themis 1980, 478 . 
können sie verpflichtet werden, mit einem beim angerufenen Gericht zugelassenen Rechtsanwalt bzw. avoué oder procuratore einvernehmlich zu handeln. Aus dem Begriff "Einvernehmen" in der deutschen Umsetzung die beanstandete "Gouvernantenklausel", die eine derartige Zusammenarbeit mit einem örtlichen Anwalt auch in den Fällen vorschrieb, in welchen nach deutschem Prozeßrecht kein Anwaltszwang bestand. Gemäß Art. 7 Abs. 1 der Aufnahmestaat vom Dienstleistungserbringer einen Nachweis seiner Eigenschaft als Rechtsanwalt verlangen. Im Falle der Verletzung der Standesregeln entscheiden die zuständigen Behörden des Aufnahmestaates gemäß Art. 7 Abs. 2 über die rechtlichen Folgen dieses Verhaltens.

Art. 6 bezieht sich auf die Rolle eines Syndikus. In verschiedenen Mitgliedstaaten sind die durch einen Arbeitsvertrag an ein staatliches oder privates Unternehmen verbundenen Rechtsanwälte von der Vertretung und Verteidigung dieses Unternehmens im Bereich der Rechtspflege ausgeschlossen. Einige Mitgliedstaaten verbieten selbst die Tätigkeit als Rechtsanwalt in einem Unternehmen gänzlich, da die Selbständigkeit des Berufes in diesen Fällen nicht garantiert sei. Art. 6 gestattet diesen Mitgliedstaaten die Anwendung einer Sonderregelung auf ausländische Rechtsanwälten, die im Dienstverband zu einem Unternehmen. Die Regelung kann als Kompromiß zwischen den beiden Systemen angesehen werden. Danach können diese Rechtsanwälte im Bereich der Rechtspflege von der Vertretung und Verteidigung ihres Unternehmens ausgeschllossen werden.

Art. 8 enthält schließlich die üblichen Umsetzungsverpflichtungen. Nach Abs. 1 muBten die Mitgliedstaaten innerhalb von zwei Jahren die erforderlichen Maßnahmen ergreifen und sie nach Abs. 2 der Bestimmung an die Kommission mitteilen.

\section{B. DIE RECHTSPRECHUNG ZUR UMSETZUNG DER RICHTLINIE 77/249/EWG}

Die Umsetzung der Richtlinie 77/249/EWG, zu der die Mitgliedstaaten gemäß Art. 8 Abs. 1 binnen zwei Jahre verpflichtet waren, erwies sich zunächst als nicht unproblematisch. Die meisten Mitgliedstaaten überschritten die gesetzte Frist, bei zumindest zwei Umsetzungsregelungen mußten erhebliche inhaltliche Mängel gerügt werden.

Die ursprüngliche Umsetzung der Richtlinie in der Bundesrepublik durch Gesetz vom 16. August $1980^{1171}$ hat nicht nur in der Literatur Anlaß zur Diskussion gegeben ${ }^{1772}$, sondern letzlich wegen der sogenannten "Gouvernantenklausel ${ }^{1173 " ~ i n ~} 84$ des Durchführungsgesetzes ein Vertragsverletzungsverfahren gegen die Bundesrepublik Deutschland ausgelöst, das mit der Verurteilung in nicht weniger als sechs Punikten

1171. BGBI. I rom 22. August 1980, 1453.

1172. Brangsch, NJW 1981, 1177; Schulz, Anw.B1. 1981, 41.

1173. So der treffende Ausdruck won Rabe, NJW 1987, 2187. 
am 25. Februar 1988 endete $^{1174}$. Das deutsche Umsetzungsgesetz enthielt einige âußerst zweifelhafte Bestimmungen: So bestimmte $\$ 4$ Abs. 1, daß Handlungen die nicht im Einvernehmen mit einem deutschen Rechtsanwalt vorgenommen wurden, ohne juristische Folgen sind. Im Verfahren gegen Deutschland hat die Kommission im wesentlichen die folgenden Punkte gerügt: Sie beanstandete zunächst die Verpflichtung, im Einvernehmen mit einem deutschen Anwalt zu handeln, wenn prozeßrechtlich kein Anwaltszwang bestand. Des weiteren hielt die Kommission die Regeln hinsichtlich des Beweises eines bestehenden Einvernehmens mit einem deutschen Rechtsanwalt für zu extensiv. Auch durfte der Dienstleistungserbringer nur bei Gericht auftreten, falls er tatsächlich in Begleitung eines deutschen Anwalts erschien. Diese Regelung galt awch für Gefängnisbesuche. Des weiteren stand die territoriale Exklusivität, die dem dienstverrichtenden Rechtsanwalt bei zivillechtlichen Streitverfahren vor dem Landgericht; Oberlandesgericht und Bundesgerichtshof eine nur sehr beschränkte Rolle einräumte, unter der Kritik. Der Europäische Gerichtshof ist der Kommission in allen wesentlichen Punkten gefolgt.

Auch die französische Umsetzung der Richtlinie 77/249/EWG blieb nicht unbeanstandet ${ }^{175}$ "Gerügt wurde dabei auch die Tatsache, daß französische Staatsangehörige, die in einem anderen Mitgliedstaat niedergelassen sind, von der Dienstleistung in Frankreich ausgeschlossen waren. Ansonsten entsprach die Kritik in etwa derjenigen an der deutschen Umsetzung. Es wurde vor allem beanstandet, daß die Einvernehmensbestimmungen im Sinne des Art. 5 der Richtlinie auf Fälle Anwendung finden sollte, bei denen kein Anwaltszwang bestand. Die Umsetzungen der anderen Mitgliedstaaten blieben mit der Ausnahme von Spanien dagegen anscheinend ungerügt ${ }^{176}$. Nicht unbedenklich ist dabei die Regelung in Art. 5 der britischen Umsetzungsgesetzes, wonach eine einvernehmliche Zusammenarbeit mit einem örtlichen Rechtsanwalt micht nur für die Rechtspflege, sondern für alle Fälle der Zusammenarbeit mit Behörden angeordnet wird ${ }^{1177}$. Spanien hat eine diesbezügliche Änderung seiner ursprünglichen Umsetzungsregelung ${ }^{1178}$ im September 1988 vorgenommen ${ }^{179}$.

1174. Urteil wom 25. Februar 1988 Rs $427 / 85$ - Kommission/BR Deutschland -, Slg. 1988, 1123. Siehe dazu dive Urteilsanmerkung von Bleckmann, JZ 1988, 506 (511), der aus dem Urteil auch entsprechende Schlüsse für die Niederlassungsfreiheit von Rechtsanwalten zieht. Siehe auch Lonbay, ELR 1989, 347; Eidenmüller, MLR 1990, 604; Pease, Int. Lawyer 1988, 543.

1175. Urteil rom 9. August 1991 - Rs 294/89 - Kommission/Frankreich ", Slg. 1991, 3591. Dacu die Urteilsanmerkung von Schweitzer/Fixon, IZ 1991, 252-255.

1176. Belgien: Gesetz vom 2. Dezember 1982, Moniteur belge wom 8. Januar 1983; Dänemark: Gesetz vom 14. März 1979; Irland: S.I. vom 28. Februar 1970; Italien: Legge nr. 31 wom 9. Februar 1982, Gaz. uff. Nr. 42 vom 12. Febnar 1982; Luxemburg: Memorial wom 14. Mai 1980; Niederlande: Wet vom 15. Oktober 1980, Staatsbl. Nr. 558 vom 30. Oktober 1980; Portugal: Decreto-lei Nr. 119/86 vom 28. Mai 1986, diario vom 28. Mai 1986. In Frankreich war die Richtlinie ursprünglich durch Decret (J.O. vom 23. Mäz 1979) umgesetzt. Im Rahmen der Reformen wurden auch die vom Gerichtshof beanstandeten Regelungen neugefalist.

1177. Service of Lawyers Order 1978. Dazu Brangsch, NJW 1981, 1180

1178. Real decreto vom 21. Märe 1986, Nr. 607/86, BOE vom 1. April 1986, Nr. 78, 991

11.79. Änderung des Art. 6 des Real decreto $607 / 86$ vom 21. März 1986 durch das Real decreto vom 16 September 1988, Nr. 1062/1988, BOE Nr. 227, 1917. Dazu Friese. AnwBl. 1990, 87/88. 
Die Bundesrepublik hat inzwischen aus dem Urteil die Konsequenzen gezogen und ein neues Gesetz verabschiedet ${ }^{1180}$. Wichtigste Folge dieser Gesetzesänderung ist, dail die Beschränkung der Vertretungsbefugnis, die sich aus dem Erfordernis der Zulassung bei einem bestimmten Gericht ergeben, für Anwälte aus anderen Mitgliedstaaten mit Ausnahme der Vertretung beim BGH keine Anwendung findet. Allerdings darf der dienstleistende Rechtsanwalt seinen Mandanten nicht in Berufungssachen vor den Zivilsenaten der Oberlandesgerichte vertreten, falls er bereits in erster Instanz Bewollmächtigter war. Diese Regelung gilt auch für deutsche Rechtsanwällte. Dagegen bedarf der dienstleistende Anwalt bei Gerichten, vor denen kein Anwaltszwang besteht, keines Einvernehmens mehr mit einem inländischen Anwalt. Ansonsten genügt es, wenn das Einvernehmen bei der ersten Handlung gegenüber dem Gericht schriftlich nachgewiesen wird. Für die Einvernehmenstätigkeit erhält der deutsche Rechtsanwalt dementsprechend lediglich eine Gebühr ( $\$ 24$ a BRAGO).

\section{DAS VERHÄLTNIS ZWISCHEN DER RICHTLINIE 77/249/EWG UND DER RICHTLINIE $89 / 48 / E W G$}

Gemäß Art. Art. 2 Abs. 2 der Richtlinie 89/48/EWG gilt diese nicht für Berufe, die bereits Gegenstand einer sektoriellen Richtlinie sind, mit der in den Mitgliedstaaten eine gegenseitige Anerkennung der Diplome eingeführt wird. Wie bereits ausgeführt, wird im viertten Erwägungsgrund der Richtlinie 77/249/EWG ausdrücklich darauf hingewie-

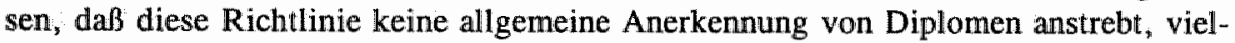
mehr lediglich eine Erleichterung des Dienstleistungsverkehrs für Rechtsanwälte anstrebt; soweit diese bei der Dienstleistungserbringung ihren "home title" verwenden. Die Verwendung von Art. 57 EGV als Ermächtigunsgrundlage bezieht sich somit ausschließlich auf die Berechtigung zur Führung des ausländischen Titels bei der Dienstleistungserbringung. Nur unter diesem Teilaspekt der grenzuiberschreitenden Berufsausübung kann die Richtlinie 77/249/EWG als Einzelrichtlinie i.S des Art. 2 Abs. 2 der Richtlinie $89 / 48 / \mathrm{EWG}$ qualifiziert werden. Grundsätzlich muß daher für die anwaltliche Dienstleistung unter "home title" die ausschließliche Anwendung der Richtlinie 77/249/EWG bejaht werden ${ }^{1181}$. Will somit ein Rechtsanwalt im Dienstleistungsverkehr unter der Berufsbezeichnung des Herkunftstaates tätig werden, so wird diese Berufsausübung durch die jeweiligen Umsetzungsgesetze zur Richtlinie 77/249/EWG bestimmt. Beabsichtigt ein Rechtsanwalt dagegen die Niederlassung in einem anderen Mitgliedstaat unter der Berufsbezeichnung des Aufnahmestaates, so wird er sich dem Anerkennungs- und Anpassungssystem der Hochschuldiplomrichtlinie unterwerfen müssen ${ }^{1182}$. Insoweit ist die Konkurrenz zwischen beiden Richtlinien deutlich. Die

1180. Erstes Gesetz vom 14. Mărz 1990 zur Änderung des Gesetzes zur Durchfühnung der Richtlinie des Rates der Europäischen Gemeinschaften vom 22. März 1977, BGB1. 1, 479.

1181. Berscheid/Kinschbaum, 118 .

1182. Zum Verhältnis zwischen Dienstleistungsfreiheit und Z we itniederlassung in einem anderen Mitglliedstaat ist das beim EuGH anhangige Verfahren C-55/94 Gebhard/Anwaltskammer Mailand von Bedeutung. In dieser Rechissache steht die Frage zentral, ob das gemäB italienischem Reche bestehende Verbot ainer Kanzleieröfnung für die im Awsland niedergelassene Rechusanwälte, die in Italien Dienstleistun- 
Lage wird dann problematisch, wenn ein Kandidat erfolgreich eine Anerkennung gemäB der Richtlinie 89/48/EWG bewirkt hat, er sich danach jedoch gegen eine Niederlassung im Aufnahmestaat entscheidet, vielmehr zukünftig im Rahmen der Dienstleistung sich der Berufsbezeichnung des Aufnahmestaates bedienen will. Für diesen Fall bietet Art. 2 Abs. 2 der Richtlinie 89/48/EWG keine befriedigende Lösung. Meines Erachtens muB hier der Hochschuldiplomrichtlinie und ihrem System Vorrang eingeräumt werden, da dieses System hinsichtlich der Integrationsintensivität weitreichender ist, und der Kandidat bewiesen hat, daß seine Kenntnisse des nationalen Rechts des Aufnahmestaates eine derartige Titelführung rechtfertigen. Die Warnfunktion gegenüber dem Verbraucher, die durch die Verpflichtung zur Führung des "home title" gemäß Art. 3 der Richtlinie 77/249/EWG erfüllt werden soll, verlyert damit ihre Rechtfertigung. Keine Lösung bieten beide Richtlimien für den Rechtsanwalt, der sich unter "home title" in einem Mitgliedstaat niederlassen will. Seine Möglichkeiten werden bisher ausschließlich durch die nationale Gesetzgebung des Aufnahmestaates bestimmt. An diese Situation sollte die durch den CCBE 1992 ausgearbeitete Richtlinie Veränderung bringen ${ }^{1183}$. Dieser CCBE-Vorschllag ist von der Kommission aufgegriffen worden.

\section{§ 4. Der Entwurf der zukünftigen Niederlassungsrichtlinie}

\section{A. EINLEITUNG}

Unter der Federfürung des Kommissars Vanni d'Archirafi hat die Kommission im Dezember 1994 - d.h. genau fünf Jahre nach Annahme der Richtlinie 89/48/EWG beschlossen, dem Rat und dem Europäischen Parlament einen Richtlinienvorschlag zu Erleichterung der Niederlassung von Rechtanwälten, die ihre Tätigkeit außerhalb ihres Herkunftslandes unter ihrem ursprünglichen Titel ausüben wollen, zu unterbreiten ${ }^{1184}$. Die Rechtsgrundlagen dieses Richtlinienvorschlags sind insbesondere die Art. 57 Abs. 1 EGV hinsichtlich der gegenseitigen Anerkennung der Befähigung zur Berufsausübung, Art. 57 Abs. 2 EGV erster und dritter Satz hinsichtlich der Bestimmungen

1182. $\rightarrow$

gen erbringen, gegen die Richtlinie 77/249/EWG verstöBt. Generalanwalt Léger stellte in seinen SchluBanträgen wom 20. Juni 1995 fest, daß die Eröffnung einer Kanzlei für einen dienstleistenden Rechtsanwalt unter Umständen eine. Notwendigkeit ist; ein generelles staatliches Verbot zur Eröffnung: einer Kanzlei im Aufnahmestaat könne daher gegen Art. 59 EGV verstossen, Rdnr. 85. Der Fall: beweist erneut die Fragwürdigkeit der Unterscheidung zwischen Niederlassung and Dienstleistung. siehe dazu Wyatt/Dashwood, 278; Kapteyn/VerLoren van Themaat; 429

183. CCBE Draft Directive on the Right of Establishment for Lawyers, angenommen vom CCBE am 23. Oktober 1992. Zur Vorgeschichte siehe auch Toulmin in House of Lords 1995, 71; Weil, Fordham Int. Law Journal 1991-1992, $699(703 \mathrm{ff}$.).

1184. KOM (94) 572 endg. Inzwischen fallt der Richtlinienentwurf in den Zuständigkeitsbere ich des ebenfalls italienischen Kommissars Monti. Zun Richtinienentwarf siehe die ausfuhrliche Studie des House of Lords, Select Committe on the European Communities, July 1995. 
über die gemeinsame Berufsausübung ${ }^{1185}$ und Art. 49 EGV hinsichtlich der in einem abhängigen Beschäftigungsverhältnis stehenden Rechtsanwälte. Die Berücksichtigung der im Aufnahmestaat erworbenen Berufserfahrung gründet sich auf Art. $52 \mathrm{EGV}$ im Sinne der Auslegung in der Rechtssache Vlassopoulou ${ }^{1186}$. Nach den Ausführungen der Kommission bedarf keine der in dem Richtlinienentwurf vorgesehenen Bestimmungen in einem Mitgliedstaat eine Änderung gesetzlicher Grundsätze der Berufsordnung hinsichtlich der Ausbildung und der Bedingungen für den Zugang natürlicher Personen zum Beruf im Sinne des Art. 57 Abs. 2 Satz 2 EGV. Nur Griechenland und Italien, denen bisher die gemeinsame Berufsausübung unbekannt ist, müssen die Regelungen über die gemeinsame Berufsausübung im Richtlinienvorschlag zu einer Änderung der nationalen Berufsordnungen führen. Eine Entwicklung zur Erlaubnis gemeinsamer Berufsausübung sei jedoch in beiden Staaten zu erwarten ${ }^{1187}$.

\section{B. INHALT DES RICHTLINIENENTWURFS}

\section{Allgemeine Übersicht}

Ziel dieses Richtlinienentwurfs ist die Schaffung einer Übergangszeit von fünf Jahren, während der ein Anwalt im Aufnahmestaat unter der Titelführung des Herkunftslandes tätig sein kann. Während dieser Zeit ist der Migrant berechtigt, Rechtsberatung zum Recht des Herkunfts- und des Aufnahmelandes sowie zum Gemeinschafts- und internationalen Recht zu erteilen. Spätestens nach Ablauf der fünfjährigen Frist muß der Anwalt sich obligatorisch in den Berufsstand des Aufnahmestaates eingliedern.

Diese Eingliederung kann gemäß Art. 10 des Richtlinienvorschlags auf drei Weisen geschehen, abhängig von der Integrationsintensität des Migranten in dac Rechtssystem des Aufnahmestaats:

1. Der Anwalt, der mindestens drei Jahre lang im Recht des Aufnahmestaates, einschließlich des Gemeinschaftsrechts "effektiv und ständig" tätig war, erwirbt er die Befugnis zur Titelführung des Aufnahmestaates automatisch, d.h. eine Eignungsprüfung oder ein Anpassungslehrgang, wie dies nach dem Anerkennungssystem der Richtlinie 89/48/EWG als Kompensation verlangt werden kann, ist in diesem Fall nicht erforderlich.

1.185. Die Frage der gemeinsamen Berufsausübungen betriff verschiedene Regelungen im Richthinienentwurf bezüglich " Zweigniederlassungen" sowie bezïglich Kanzleien, die aus Anwälten des Aufnahme- und des Herkunftstaates zusammengesetzt sind und, die ihre Aktivitäten in unterschiedlichen Rechtsformen (z B. als BGB-Gesellschaft, partnership, société civile professionelle usw.) ausüben möchten.

1186. Urteil vom 7. Mai 1991, Rs C-340/89 - Irène Vlassopoulou/Ministerium für Justiz, Bundes- und Europaangelegenheiten Baden-Württemberg. Slg. 1-1991, 2357.

1187. KOM (94) $572 / 2,7$. In der endgültigen Fassung des Richtlinienentwurfs ist eine Sottderregelung fú Italien und Griechenland in Art. 15 nicht methr enthalten, obwohl hierauf in den Erläuterangen moch Bezug genommen wird. KOM (94) 572 endg., 13. 
2. Wenn die mindestens drejjährige "effektive und ständige" Tätigkeit des Anwalts sich nicht auf das Recht des Aufnahmestaats einschließlich des. Gemeinschaftsrechts erstreckt, kann eine Eignungsprüfung gemäß Art. 4 der Richtlinie 89/48/EWG verlangt werden Diese Eignungsprüfung darf sich jedoch lediglich auf das Prozeßrecht und das Standesrecht des Aufnahmestaates beziehen.

3. Falls der Migrant diese Voraussetzungen nicht erfüllt, d.h. weniger als drei Jahre im Aufnahmestaat tätíg war oder keine ständige und effektive Berufsausübung im Aufnahmestaat nachweisen kann, kann er jederzeit die Eingliederung in der Berufsstand des Aufnahmestaates über das herkömmliche System der Richtlinie 89/48/EWG bewirken.

Mit der vorgeschriebenen Vollintegration nach einer Übergangszeit von fünf Jahren und einer automatischen Berechtigung zur Führung des Berufstitels des Aufnahmestaates unter den gemäß Art. 10 Abs. 1 des Richtlinienentwurfs genannten Bedingungen weicht der Kommissionsvorschlag deutlich vom ursprünglichen Vorschlag des CCBE $a b$. Der Entwurf des CCBE sah lediglich zwei Variationen vor: Einerseits die Niederlassung unter Beibehaltung des Herkunftstitels und andererseits die fakultative Vollintegration in die Anwaltschaft des Aufnahmestaates nach dem Anerkennungssystem der Hochschuldiplomrichtlinie; d.h. in der Regel nach erfolgreicher Eignungsprüfung. Im April 1993 wurden die Mitgliedstaaten durch die Kommission hinsichtlich eines Vorentwurfs konsultiert, der sich im wesentlichen auf die CCBE-Vorlage stützte. Mit Ausnahme von Luxemburg haben alle Mitgliedstaaten zunächst diese Intitiative grundsätzlich befürwortet ${ }^{1188}$. Dies gilt auch für die drei neuen Mitgliedstaaten, die sich 1993 noch als Mitglieder des EWR generell positiv zu den von der Kommission vorgegebenen Leitlinien äußerten. Lediglich Österreich brachte einige Bedenken hinsichtlich der Tatsache vor, dals die Rechtsanwälte, die unter "home titel" praktizieren, doch berechtigt sein sollen, hinsichtlich des Rechts des Aufnahmestaates rechtsberatend tätig zu sein.

Von dem im CCBE erreichten Konsens distanzierten sich jedoch Anfang 1994 einige Delegationen ${ }^{189}$. Die französische und die spanischen Rechtsanwälte verlangten nunmehr die obligatorische Integration ohne Zusatzprüfung in die Anwaltschaft des Aufnahmestaates nach einer befristeten Berufsausübung unter der ursprünglichen Berufsbezeichnung "190. Andere Mitgliedstaaten widersetzen sich gegen die Verpflichtung zur Vollintegration. Auch wollen sie nicht auf die Möglichkeit einer Eignungsprüfung gänzlich verzichten ${ }^{1191}$.

1188. Die Vertneter Luxemburg "s im CCBE hatten sich bereits gegen diesen Vorschlag ausgesprochen; Siehe dazu Howse of Lords 1995, 38 ff "Gegen den CCBE-Entwurf hatte sich auch die spanische Delegation ausgesprochen. Die Gründe der spanischen Delegation waren jedoch andere als die der luxemburgischen. Spanien wollte eine Vollintegration der ausländischen Rechtsanwälte nach drei Jahrem, während dive Vertreter Luxemburg's eine Niederlassung unter "home title" nicht durch Art. 52 EGV gedeckt sahen.

1189. Reichert, SEPLIS-Lettre, Januar 1995, $1 / 2$.

1190. KOM (94) 572,2

1191. In diese Richtung tendieren vor allem Großbritarnien und Deutschland. 
Der nun vorgelegte Kommissionsentwurf versucht einen Mittelweg zwischen diesen Positionen einzuschlagen. Ob dieser Standpunkt vom Erfolg gekrönt sein wird, mußB die Zukunft noch weisen. Der Richtlinienentwurf wird im Wege des Mitentscheidungswerfahrens gemäß Art. $189 \mathrm{~b}$ EGV beraten werden. Nach der ursprünglichen Planung war eine Stellungsnahme des Europäischen Parlaments für April 1995, der gemeinsame Standpunkt des Rates für Juni 1995, die Billigung des Parlaments im November 1995 vorgesehen ${ }^{1192}$. Von diesem Zeitschema mußte bereits abgewichen werden. Nunmehr ist die Stellungnahme des Europäischen Parlaments für Juni 1995 terminiert. Mit der Annahme des Richtlinienentwurfs kann daher frühestens Mitte 1996 gerechnet werden.

An dem Entwurf wurde bereits heftige Kritik geäußert ${ }^{1193}$. In einem Beschluß vom 21. Juni 1995 erklärte der Rechtsausschuß des Deutschen Bundestages, daß für eine Niederlassungsrichtlinie für Rechisanwälte kein Bedarf bestündle ${ }^{1194}$. Joachim Gres, CDU-Bundestagsabgeordneter und Mitglied des Rechtsausschusses des Deutschen Bundestages hat in einem Zeitungsartikel eine Verwässerung des Rechtsanwaltstitels sowie Gefahren für den Verbraucherschutz beschworen "1195. Dieser Kritik kann zumindest in der von Gres und dem Rechtsausschuß geäußerten Form nicht gefolgt werden. Andererseits enthält der Richtlinienentwurf erhebliche Mängel, die sehr wohl einer kritischen Revision unterworfen werden sollten ${ }^{1196}$. Im folgenden sollen daher die Regelungen im einzelnen besprochen werden.

\section{Erläuterungen zu den einzelnen Artikeln}

Art. 1 des Richtlinienentwurfs enthält den Anwendungsbereich der Richtlinie sowie einen Definitionskatalog. Danach ist die Richtlinie auf die ständige Ausübung des Rechtsanwaltsberufs gerichtet, wobei sowohl selbständige als auch abhängig beschäftigte Rechtsanwälte in den Anwendungsbereich der Richtlinie fallen sollen. Hinsichtlich der Dienstleistungserbringung regelt Art. 1 Abs. 4 des Richtlinienentwurfs ausdrücklich, daß dieser keine Anwendung auf die Dienstleistungen findet, die unter die Richtlinie 77/249/EWG fallen. Hinsichtlich der Berufsausübung im abhängigen Beschäftigungsverhältnis regelt Art. 1 Abs. 3 i.V. mit Art. 8 des Richtlinienentwurfs, daß ein im Aufnahmestaat unter seiner ursprünglichen Berufsbezeichnung eingetragener Rechtsanwalt als abhängig Beschäftigter eines anderen Rechtsanwalts, einer Anwaltswereinigung oder -sozietăt oder eines öffentlichen oder privaten Unternehmens tätig sein kann, wenn der Aufnahmestaat dies für die einheimischen Rechtsanwälte gestattet, d.h. die Zulässigkeit einer Tätigkeit im Beschäftigungsverhältnis bestimmt sich nach dem Rechts-

1192. Reichert, SEPLJS-Lettre, Januar 1995, 2.

1193. Der RechtssauschuB des Bundestenges sprach sich bereits im Sommer 1994 für die Beibehaltung der derzeitigen Rechtslage und gegen den CCBE-Kompromiß aus. Siehe auch die Empfehlungen des Select Committee on the European Community des House of Lordls, The Right of Establishment for Lawyers vom 11. Juli 1995, 19. Im Gegensatz zum Rechtsausschuß des Deutschen Bundestages bejahte das. Select Committe grundsätzlich die Notwendigkeit einer Niederlassungsrichtlinie für Rechtsanwilte, 17.

1194. WiB wom 28. Juni 1995, 3 .

1195. Gres, Die Welt vom 24. April 1995.

1196. Financial Times, August. 101995,8 . 
system des Aufnahmestaats. Auch Art. 11 des Richtlinienentwurfs geht von dieser Prämisse aus. Soweit eine gemeinsame Berufsausübung im Aufnahmestaat gestattet ist, muß3 eine derarige Berufsausübung unter den in Art. 11 genannten Modalitäten auch den unter ihrer ursprünglichen Berufsbezeichnung tätigen Rechtsanwälten gestattet werden.

Gemäß Art. 1 Abs. 2 Buchstabe a) ist unter dem Begriff "Rechtsanwalt" jede Person zu verstehen, die Angehörige eine Mitgliedstaats ist und ihre Berufstätigkeit unter einer der aufgelisteten Bezeichnungen auszuüben berechtigt ist. Bei der Liste der Berufsbezeichnungen wird auf die in der Richtlinie 77/249/EWG genannten Berufsbezeichnungen Bezug genommen, wobei einige inzwischen eingetretenen Anderungen hinsichtlich Belgien, Italien und Luxemburg Berücksichtigung gefunden haben "197. Mit dieser Auflistung weicht der Richtlinienentwurf von der Richtlinie 89/48/EWG ab. GemäB dem allgemeinen System ist es entscheidend, ob die betreffende Person im Besitz der akademischen und beruflichen Qualifikation ist, die zum Zugang zu einem reglementierten Beruf berechtigt. Die Berechtigung zur Berufstitelführung ist nach dem allgemeinen Anerkennungssystem nicht das entscheidende Kriterium, obwohl beide Kriterien häufig erfullt sein werden. Als Beispiel kann der deutsche Assessor genannt werden. Dieser erfüllt grundsätzlich die Voraussetzungen der Richtlinie 89/48/EWG; er ist jedoch ohne eine Zulassung zur Anwaltschaft nicht berechtigt, den Titel Rechtsanwalt zu führen und fällt damit weder in den Anwendungsbereich der Richtlinie 77/249/EWG noch unter Art. 1 Abs. 2 Buchstabe a) des Richtlinienentwurfs. Konsequenterweise muß eine Person gemäß Art. 3 Abs. 1 des Richtlinienentwurfs, die beabsichtigt, sich im Ausland als Rechtsanwalt niederzulassen, zunächst eine Zulassung im Inland bewirken. Diese Lösung kann in einigen Fällen sehr gekünstelt wirken. Begründet wird dieses Erfordernis damit, daß đie zuständige Behörde des Aufnahmestaats sich vergewissern kann, ob die im Herkunftsstaat geltenden Berufs- und Standesregeln eingehalten werden ${ }^{1158}$ "

Art. 1 Abs. 2 Buchstabe b) und c) enthalten die Definitionen der Begriffe "Herkunftsstaat" und "Aufnahmestaat". Beim Herkunftsstaat handelt es sich um den Staat, in dem der Betroffene seine Anwaltsqualifikation erworben hat. Der Richtlinienentwurf nimmt dabei keinen Bezug auf die Staatsangehörigkeit. Herkunftsstaat in diesem Sinne muß daher nicht der Mitgliedstaat sein, dessen Staatsangehörigkeit der Rechtsanwalt besitzt. Auch kann es sich beim Aufnahmestaat um den eigenen Mitgliedstaat handeln. Wesentlich ist lediglich, daß der Betroffene in diesem Staat den Beruf des Rechtsanwalts nach den Bestimmungen der zukünftigen Richtlinie ausüben möchte. Mit diesen Definitionen wird die Rechtsprechung des Europäischen Gerichtshofs in den Entscheidungen Knoors und Broekmeulen berulicksichtigt ${ }^{1199}$. Unter dem Begriff "ursprüngliche Berufsbezeichnung" im Sinne des Art. 1 Abs. 2 Buchstabe d) des Richtlinienentwurfs ist die Berufsbezeichnung des Mitgliedstaats zu verstehen, in dem der Rechtsanwalt vor Ausübung der Anwaltståtigkeit im Aufnahmestaat das Recht erworben hat, diese Bezeich- 
nung zu führen. Dies dürfte in der Regel der Herkunftsstaat sein. Aus der Formulierung könnte man jedoch schließen, daß auch andere Fälle von dieser Definition abgedeckt werden sollen.

Schließlich enthält Art. 1 Abs. 2 Buchstabe e) noch die Definition von "Gruppe". Nach dieser Regelung fällt unter diese Definition jeder nach dem Recht eines Mitgliedstaats errichtete Zusammenschlu/3 mit oder ohne Rechtspersönlichkeit, in dem Rechtsanwälte ihre Berufstảtigkeit gemeinsam und unter einem gemeinsamen Namen ausüben. In den Erläuterungen zum Richtlinienentwurf heißt es hierzu, daß in einer Mehrheit der Mitgliedstaaten der Rechtsanwaltsberuf in Form einer Gruppe ausgeübt werden kann und die Anwaltssozietät sich in diesen Mitgliedstaaten vor allem für Rechtsanwälte mit dem Arbeitsschwerpunkt im Bereich des Wirtschaftsrechts zunehmend entwickelt ${ }^{1200}$. Hingewiesen wird jedoch auf die Tatsache, daß in Griechenland und Italien eine gemeinsame Berufsausübung nach bisheriger Rechtslage verboten ist, wobei beide Mitgliedstaaten in Zukunft die Zulassung won Anwaltssozietäten anstreben. Obwohl daher die Mitgliedstaaten mehrheitlich Zusammenschlüsse zwischen Rechtsanwälten zulassen, ist die rechtlliche Ausgestaltung sehr unterschiedlich. Einige Mitgliedstaaten gestatten eine Anwaltssozietät nur in der Form einer Personengesellschaft, andere dagegen erlauben auch die Errichtung einer Kapitalgesellschaft, wobei allerdings eine Anpassung an die besonderen Merkmale der Anwaltstätigkeit vorgenommen werden muß.

Zu diesem Punkt bestimmt Art. 11 Abs. 1 des Richtlinienentwurfs, daß Rechtsanwälte, die Mitglied ein und derselben Gruppe im Herkunftsstaat sind, ihre berufliche Tätigkeit im Rahmen einer Zweigstelle oder Agentur ihrer Gruppe in Aufnahmestaat ausüben können. Lediglich dann, wenn die im Herkunftsstaat geitenden Bestimmungen mit den Regelungen des Aufnahmestaats unvereinbar sind, gelten grundsätzlich die grundlegenden Regelungen des Aufnahmestaates, soweit ihre Beachtung im allgemeinen Interesse zum Schutz der Mandanten und Dritter gerechtfertigt sind. Mit dieser Formulierung wird deutlich die "Cassis de Dijon" Rechtsprechung als Anwendungsmaßstab herangezogen. In den Erläuterungen wird darauf hingewiesen, daß der Kommissionsentwurf sich ausdrücklich auf die Gründung von Agenturen und Zweigniederlassungen unter Ausklammerung von Tochtergesellschaften beschränkt. Begründet wird diese Beschränkung damit, daß bei der Gründung einer neuen Gesellschaft in einem anderen Mitgliedstaat in der Form einer Tochtergesellschaft es "normal" ist, "daß die Gesellschafter in vollem Umfang die innerstaatlichen Rechtsvorschriften des Aufnahmestaats beachten müssen." 1201 Nicht eingegangen wird dabei auf die Frage, ob diese "Normalität" mit Art. 52 EGV übereinstimmt. Zur Unterstützung dieser Argumentation wird noch worgetragen, daß die Gründung von Tochtergesellschaften im Vergleich zur Gründung von Agenturen und Zweigniederlassungen im Rechtsanwaltsberuf nur eine untergeordnete Rolle zu spielen scheint.

1200. Erlaututerungen zu Art. $11, \mathrm{KOM}$ (94) 572 endg., 12.

1201. Erläuterungen zu Art. 11, KOM (94) 572 endg.. 12. 
Gemäß Art. 11 Abs. 2 muß jeder Mitgliedstaat zwei oder mehreren Rechtsanwältem derselben Gruppe oder aus demselben Herkunftsstaat die Möglichkeit zumindest einer gemeinsamen Form der Berufsausübung gewähren. Falls ein Aufnahmestaat mehrere Rechtsformen auf nationaler Ebene bietet, so müssen diese auch für migrierende Rechtsanwälte offenstehen. Die genauen Modalitäten dieser gemeinsamen Berufsausübung richten sich nach den Bestimmungen des Aufnahmestaats. Diese Regelung wird in Art. 11 Abs. 3 des Richtlinienentwurfs noch ergänzt. Dieser Absatz bezweckt die Errichtung multinationaler Anwaltskanzleien. In den Erläuterungen hierzu heißt es, daß derartige multinationale Kanzleien nicht nur den Interessen der betroffenen Rechtsanwälte, sondern auch denen der Mandanten dienen, weil sie eine optimale Nutzung der Komplementarität der angebotenen Dienste sichern. ${ }^{1202}$ Auch bei den multinationalen Kanzleien richten sich die Modalitäten der gemeinsamen Berufsausübung nach den Bestimmungen des Aufnahmestaates. Gemäß Art. $\mathbb{1}$ Abs. 4 des Richtlinienentwurfs betrifft den Rechtsanwalt, der in seinem Herkunftsstaat Mitglied einer Gruppe ist. In diesem Falle hat er den Aufnahmestaat hiervon in Kenntnis zu setzen und alle zweckdienlichen Auskünfte über die Gruppe zu erteilen. Gemäß Art. 12 haben die im Aufnahmestaai unter ihrer ursprünglichen Berufsbezeichnung tätigen Rechtsanwälte das Recht, die Gruppe anzugeben, der sie im Herkunftsstaat angehören. Dabei kann der Aufnahmestaat verlangen, daß die Rechtsform im Herkunftsstaat sowie die Namen der im Aufnahmestaat tätigen Mitglieder genannt werden.

Abweichend von dieser Regel kann ein Aufnahmestaat, der selbst Sozietäten mit Angehörigen andere Berufe oder die Kontrolle einer Gruppe durch standesfremde Personen für die Ausübung des Rechtsanwaltsberufes untersagt, einem Rechtsanwalt gemäß Art 11 Abs. 5 des Richtlinienentwurfs die Betätigung als Mitglied einer Gruppe verwehren. Diese Ausnahmeregelung gilt aber ausschließlich in den Fällen, in denen die Entscheidungsbefugnis in der betroffenen Gruppe mehrheitlich von Personen ausgeübt wird, die nicht die Qualifikation eines Rechtsanwalts haben. Mit dieser Regelung soll ein Kompromiß zwischen zwei Extremen geschlossen werden. Einerseits gibt es Mitgliedstaaten, die zur Garantie der beruflichen Unabhängigkeit von Rechtsanwälten lediglïch Individualniederlassungen oder reine Anwaltssozietäten gestatten ${ }^{1203}$. Andere Mitgliedstaaten erlauben die mehrfầcherige Sozietät oder die Einbringung branchenfremden Kapitals bei der Anwaltssozietät in Form einer Kapitalgesellschaft. Aufnahmestaaten, in denen Beschränkungen in dieser Hinsicht gelten, können dies aufgrund Art. 11 Abs. 5 einem Rechtsanwalt jedoch nur dann entgegenhalten, wenn die Entscheidungsbefugnis in der betreffenden Gruppe mehrheitlich bei Nicht-Rechtsanwälten liegt. Der betroffene Rechtsanwalt kann sich aber individuell auf die Richtlinie berufen. Nur sein Recht gemäß Art. 12 des Richtlinienentwurfs zur Führung der Gruppenbezeichnung wird. bescluränkt.

1202. Erläuterungen zu Art. 11, KOM (94), 572 endg., 13.

1203. Italien und Griechenland erlauben bisher nur die individuelle Berufsausübgung. 
Gemäß Art. 2 des Richtlinienentwurfs hat jeder Rechtsanwalt das Recht auf vorübergehende Berufsausübung unter der ursprünglichen Berufsbezeichnung des Herkunftsstaats. Mit dieser zeitlichen Begrenzung weicht der durch die Kommission vorgelegte Richtlinienentwurf erheblich vom ursprünglichen CCBE-Entwurf ab. Nach dem CCBEEntwurf sollte die Berufsausübung unter "home titlle" zeitlich vollkommen unbeschränkt ermöglicht werden. Gemäß der nun im Richtlinienentwurf vorgelegten Bestimmung ist dieses Recht auf 5 Jahre beschränkt. In diesem Zeitraum hat der betroffene Rechtsanwalt die Befugnis die gleichen beruflichen Tätigkeiten auszuüben wie die unter der Berufsbezeichnung des Aufnahmestaats niedergelassenen Rechtsanwälte. Ausdrücklich genannt wird die Rechtsberatung im Recht des Herkunftsstaats, im Gemeinschaftsrecht, im internationalen Recht und im Recht des Aufnahmestaats. Von diesem Prinzip enthalten die Absätze 2 und 3 gewisse Ausnahmen. Absatz 2 bezieht sich auf die Errichtung von Testamenten und Grundstücksakten. Soweit diese Befugnis nicht Notaren, sondern einer bestimmten Gruppe von Rechtsanwälten vorbehalten ist, können die unter der ursprünglichen Berufsbezeichnung praktizierenden Rechtsanwälte von diesem Tätigkeitsbereich ausgeschllossen werden ${ }^{\lfloor 204}$. Mit dieser Regelung wurde der Besonderheit des Berufs des Solicitors in Großbritanmien und Irland Rechnung getragen. In beiden Mitgliedstaaten sind die Solicitors zur Erstellung von förmlichen Urkunden befugt. Die Kommission hält diese Ausnahmeregelung für gerechtfertigt, da sich die Richtlinie auf die typischen Berufstätigkeiten des Rechtsanwalts, d.h. Rechtsberatung und Rechtsbeistand, konzentriert ${ }^{1205}$. Art. 5 Abs. 3 des Richtlinienentwurfs betrifft den forensischen Tätigkeitsbereich. Ähnlich wie in der Richtlinie 77/249/EWG kann der Aufnahmestaat im Falle des Anwaltszwangs dem unter "home title" praktizierenden Rechtsanwalt die Bedingung auferlegen, diese Tätigkeit im Einvernehmen mit einem beim angerufenen Gericht zugelassenen Rechtsanwalt, oder im Falle von Frankreich und Italien mit einem bei điesem Gericht tätigen "avoué" oder "procuratore" auszuüben. Einzige Bedingung fïr die Ausübung dieses Rechts ist die Eintragung gemäß Art. 3 des Richtlinienentwurfs bei der zuständigen Behörde des Aufnahmestaats. Nach Auffasung der Kommission muß dabei der Begriff des "einvernehmlichen Handelns" entsprechend der einschlägigen Rechtsprechung des EuGH ausgelegt werden ${ }^{120 \%}$. Dies bedeutet jedenfalls, daß ein Mitgliedstaat ein derartiges Einvernehmen nur für die Fälle vorschreiben kann, bei denen wor dem betreffenden Gericht ein Rechtsbeistand gesetzlich vorgeschrieben ist ${ }^{1207}$.

Gemäß Art. 4 des Richtlinienentwurfs muß der unter "home title" praktizierende Rechtsanwalt die Berufsbezeichnung in der Amtsprache des Herkunftsstaats führen. Bei Verwechslungsgefahr mit der Berufsbezeichnung des Aufnahmestaats, kann die Angabe des Herkunftsstaats verlangt werden. Eine derartige Verwechslungsgefahr ist etwa im Verhältnis zwischen Deutschland und Österreich sowie zwischen Belgien und den Nieder-

1204. Vergleiche dazn die Regelung in Art. 1 Abs. 2 der Richtlinie 77/249/EWG

1205. Erläuterungen zu Art. 5 KOM (94) $572 \mathrm{endg} ., 8$

1206. Urteil wom 25. Februar 1988, Rs 427/85 - Kommission/Deutschland -, Sig. 1988, 1123; Urteil vom 10. Juli 1991, Rs C-294/89, - Kommission/Frankreich *, Silg. 1991, 3591.

1207. Erläutenungen zu Art. 5, KOM (94), 572 endg.. 8 
landen und Belgien und Frankreich denkbar. Im Verhältnis zwischen Großbritannien und Irland wird sich die Problematik kaum ergeben, da beide Staaten von einer automatischen Anerkennung gemäß Art. 3 der Richtlinie 89/48/EWG zumindest hinsichtlich England und Wales ausgehen. Des weiteren kann der Aufnahmestaat gemåß Art. 4 Abs. 2 des Richtlinienentwurfs die Nennung der Berufsorganisation oder des Zulassungs: gerichts verlangen. Da es sich in allen Fällen um eine Doppelzulassung handelt unterliegt der betroffene Rechtsanwalt auch gemäß Art. 6 des Richtlinienentwurfs sowohl den Berufs- und Standesrechten des Herkunftsstaats wie denen des Aufnahmestaats hinsichtlich aller dort ausgeübten Tätigkeiten. Dabei kann der Aufnahmestaat für die auf seinem Gebiet ausgeübten Berufstätigkeiten den Abschluß einer Berufshaftpflichtversicherung oder den. Beitritt zu einer Berufsgarantiekasse verlangen, soweit nicht bereits eine gleichwertige Garantie nach den Regeln des Herkunftstaats nachgewiesen wird. Im Falle einer Verletzung der Berufs- und Standesregeln des Aufnahmestaats gilt das Disziplinarverfahren dieses Mitgliedstaats gemäß Art. 7 des Richtlinienentwurfs. Art. 9 des Richtlinienentwurfs regelt die Begründungspflicht sowie die Gewährung von Rechtsmitteln im Falle einer Verweigerung oder Rücknahme einer Eintragung sowie bei Entscheidungen zur Verhängung von Disziplinarstrafen. Die Formulierung dieser Bestimmung entspricht weitgehend den entsprechenden Regelungen in den Richtlinien 89/48/EWG und 92/51/EWG.

Spätestens nach Beendigung der fünfjährigen Frist im Sinne des Art. 2 des Richtlinienentwurfs muß der betreffende Rechtsanwalt sich voll in das Rechtssystem des Aufnahmestaats integriert haben, d.h. die Tätigkeit unter "home title" wird grundsätzlich auf fünf Jahre beschränkt. Die vollständige Eingliederung erfolgt nach den in Art. 10 des Richtlinienentwurfs genannten Verfahren. Wie bereits dargestellt, unterscheidet Art. 10 des Richtlinienentwurfs zwischen drei Formen der Integration in das Rechtssystem des Aufnahmestaats. Kann der betreffende Rechtsanwalt den Nachweis einer mindestens dreijährigen effektiven und ständigen Tätigkeit im Recht des Aufnahmestaats einschließlich des Gemeinschaftsrechts erbringen, so muß seine Eingliederung automatisch, d.h. ohne eine etwaige Eignungsprüfung im Sinne des Art. 4 Abs. 1 Buchtabe b) der Richtlinie $89 / 48 / \mathrm{EWG}$ erfolgen. Handelt es sich lediglich um eine dreijährige effektive Tätigkeit im Aufnahmestaat ohne Nachweis, daß diese Tätigkeit sich auf das Recht des Aufnahmestaats bezogen hat, so kann von dem betreffenden Rechtsanwalt lediglich eine Eignungsprüfung verlangt werden, die sich auf das Standes- und Prozeßrecht des Aufnahmestaats bezieht. Letztlich kann der im Sinne des Art. 2 des Richtlinienentwurfs vorübergehend tătige Rechtsanwalt gemäß Art. 10 Abs. 3 des Richtlinienentwurfs innerhalb der fünfjährigen Frist jederzeit die Anerkennung seines Diploms gemäß der Richtlinie 89/48/EWG beantragen, um damit die Vollintegration zu bewirken. Die weiteren Bestimmungen enthalten im wesentlichen die üblichen Schlußbestimmungen.

\section{Kritik am Richtlinienentwurf}

Das Regelungssystem des Richtlinienentwurfs weist erhebliche Mängel auf. Zunächst ist es vollkommen unersichtlich, warum eine Beschränkung der Tätigkeit unter ursprünglicher Berufsbezeichnung im Sinne des Art. 2 des Richtlinienentwurfs auf fünf 
Jahre erfolgen soll ${ }^{1208}$. Welche Maßnahmen sind gegen einen Rechtsanwalt zu ergreifen, der nach Ablauf dieser Frist eine Vollintegration in den Berufsstand des Aufnahmestaats gemäß dem System des Art. 10 des Richtlinienentwurfs verweigert oder die Eignungsprüfung nicht besteht? Kann diesem Rechtsanwalt die Berufsbefähigung im Aufnahmestaat entzogen werden? Beginnt die Frist erneut zu laufen, falls dieser Anwalt sich vorübergehend in seinen Herkunftsstaat zurückzieht, um sich danach im Aufnahmestaat wieder niederzulassen? Könnte einem solchen Rechtsanwalt die erneute Einschreibung im Aufnahmestaat verweigert werden? Welches Allgemeininteresse kann eine derartige Frist bzw. die Verweigerung der Neuzulassung rechtfertigen? Der Fragenkatalog zu diesem Punkt ließe sich ohne Schwierigkeiten noch erheblich erweitern. Keine dieser Fragen läßt sich meines Erachtens befriedigend und mit Art. 52 EGV übereinstimmend beantworten.

Es ist jedoch nicht nur die Fünfjahresfrist, die unverständlich und nach meiner Meinung vertragswidrig ist, auch die unterschiedlichen Verfahren gemäß Art. 10 des Richtlinienentwurfs lassen erhebliche Zweifel an ihrer Zulässigkeit und Praktikabilität entstehen. Nach dem ersten Verfahren erfolgt die Vollintegration nach drei Jahren ohne Eignungsprüfung, wenn der betreffende Nachweis einer effektiven und ständigen Tätigkeit im Recht des Aufnahmestaats einschließlich des Gemeinschaftsrechts erbringt. Dabei ist gemäß Art. 10 Abs. 1 Unterabs. 2 Satz 3 unter "effektiver und ständiger Tätigkeit" die tatsächliche Ausübung des Berufs ohne längere Unterbrechung zu verstehen. Diese Definition steht in merkwürdigem Kontrast zur Rechtsprechung des Gerichtshofs hinsichtlich Doppelniederlassung, worin er ausdrücklich das Kriterium einer ständigen Anwesenheit als Voraussetzung der Niederlassung abgelehnt hat ${ }^{1209}$. Die Kommission verweist in ihren Erläuterungen ${ }^{1210}$ auf das Urteil des Gerichtshofs in der Rechtssache Van de Bijl ${ }^{12 n}$. Dieser Hinweis ist nicht sehr überzeugend, weil es sich gerade in der Rechtssache "Van de Bijl" um einen Fall des Mißbrauchs gemeinschaftsrechtlicher Regelungen handelte. Bei Rechtsanwälten, die nach dem System der vorliegenden Richtlinie in zwei Mitgliedstaaten niedergelassen sein müssen (Art. 3 des Richtlinienentwurfs), kann von einem derartigen Mißbrauch des Gemeinschaftsrechts nicht gesprochen werden, wenn sie bei ihrer Berufsausübung in beiden Mitgliedstaaten tätig sind. In diesem Falle steht jedoch das Verlangen nach einer ständigen Anwesenheit im Widerspruch zu dem nach Art. 52 EGV garantierten Recht auf Doppelniederlassung.

Des weiteren muß der Rechtsanwalt den zuständigen Stellen des Aufnahmestaats alle zweckdienlichen Informationen und Dokumente insbesondere über die Zahl und die Art der von ihm bearbeiteten Rechtssachen vorlegen. Zunächst erscheint bereits zweifelhaft,

1208. Diese Regelung wurde auch von allen Personen, die durch das House of Lords Select Committee zum Richtlinienentwurf unterfragt worden waren, auf das Schärfste kritisiert, House of Lords 1995, 10. Toumlin nannte dabei zwei Gründe: 1. Es besteht kein objektiver Rechtfertigungsgrund für diese Regelung, 2. die Bestimmung ist unverhaltnismäßig, House of Lords 1995, 69.

1209. Urteil vom 12. Juli 1984, Rs 107/83 - Klopp -, Slg. 1984, 2971

1210. Erläutenungen 21 Art $10, \mathrm{KOM}(94), 572$ endg., 11.

1211. Urteil vom 27. September 1989, Rs $130 / 88$ - van de Bjjl - Slg. 1989, 3039. Siehe dazu die Erläuterungen auf Seite 62 . 
ob eine derartige Verpflichtung zur Informationsbeschaffung mit dem in den Mitgliedstaaten allgemein anerkannten Vertrauensprinzip zwischen Mandanten und Rechtsanwallt vereinbar ist. $Z$ war heißt es in Art. 10 Abs. 5 des Richtlinienentwurfs, daß die mit der Prüfung des Antrags befaßten Vertreter đer zuständigen Behörde die Vertraulichkeit der erlangten Information garantieren, eine derartige Garantie kann jedoch die Standespflicht des Rechtsianwalts zur Geheimhaltung nicht entkräftigen. Abgesehen hiervon bleibt undeutlich, welche Kriterien genau erfüllt sein müssen, um von einer "effektiven Tätigkeit im Recht des Aufnahmestaats" sprechen zu können. Da der Betroffene hierzu den Nachweis erbringen muß, ist damit zu rechnen, daß die Mitgliedstaaten bei der Umsetzung dieser Regelung eine restriktive Haltung einnehmen werden. Im Falle eines Prozesses dürfte es für den betroffenen Rechtsanwalt schneller und einfacher sein, eine Anerkennung gemäß Art. 10 Abs, 2 des Richtlinienentwurfs za bewirken, d.h. im Rahmen einer Eignungsprüfung zum Standes- und ProzeBrecht des Aufnahmestaats. Mit dieser Schlußfolgerung kann bereits heute festgestellt werden, daß die automatische Integration im Sinne des Art. 10 Abs. 1 des Richtlinienentwurfs eine Worthülse ohne effiziente Anwendung wird.

Art. 10 Abs. 1 des Richtlinienentwurfs läßt auch hinsichtlich der Position des Gemeinschaftsrechts einige Fragen offen. Die effektive und ständige Tätigkeit muß sich gemäß Art. 10 Abs. 1 Satz 1 des Richtlinienentwurfs auf das Recht des Aufnahmestaats einschließlich des Gemeinschaftsrechts beziehen. Dagegen spricht Art. 10 Abs. 1 Unterabs. 2 lediglich über den Nachweis der ständigen und effektiven Tätigkeit im Recht des Aufnahmestaats. Das Gemeinschaftsrecht wird an dieser Stelle nicht mehr erwähnt. Es muß unterstellt werden, daß es sich hierbei lediglich um ein Redaktionsversehen handelt, obwohl dieses bezeichnend ist für die vermutliche Interpretation dieser Bestimmung im Falle einer Umsetzung in den Mitgliedstaaten. Aus der Sicht des Aufnahmestaats kann diese Regelung äußerst unbefriedigend sein. Weist ein Rechtsanwalt z.B. eine ständige und effektive Tätigkeit von drei Jahren nach, in denen er ausschließlich zum europäischen Kartellrecht rechtsberatend tătig gewesen ist, so erfüllt er meines Erachtens die Voraussetzungen des Art. 10 Abs. 1 Satz 1 des Richtlinienentwurfs und muß daher ohne Ablegung einer Eignungsprüfung die Befugnis erhalten, seinen Beruf unter der Berufsbezeichnung des Aufnahmestaats auszuüben. Die von einigen Mitgliedstaaten geäußerten Zweifel an einer derartigen Regellung erscheinen mir aus Gründen des Mandantenschutzes nicht vollkommen abwegig. Dennoch kann angenommen werden, daß ein solcher Rechtsanwalt sich wohl kaum plötzlich nach der Vollintegration im Bereich des Straf-, Zivil- oder Verwaltungsrecht des Aufnahmestaats betätigen wird. Das Beispiel zeigt jedoch überdeutlich, daß für einen solchen Spezialisten im Kartellrecht die Vollintegration nicht besonders interessant ist. Eine dauerhafte Niederlassung unter Verwendung der Berufsbezeichnung des Herkunftsstaats würde seinen Interessen voll genügen.

Auch an dem Integrationswerfahren gemäß Art. 10 Abs. 2 des Richtlinienentwurfs kann Kritik geäußert werden. Kann ein Rechtsanwalt eine dreijährige effektive und ständige Tätigkeit im Aufnahmestaat nachweisen, so soll für ihn eine auf das Standes- und Prozeßrecht verkürzte Eignungsprüfung anwendbar sein. In diesem Falle erscheint das 
Erfordernis einer effektiven und ständigen Tätigkeit im Aufnahmestaat noch weniger gerechtfertigt als in der ersten Alternative. Ist bei Abs. 1 dieses Erfordernis noch in direktem Zusammenhang mit der Kenntnis des Rechts des Aufnahmestaats zu sehen, so fehlt dieser Zusammenhang im Falle einer Integration gemäß Abs. 2 vollständig, da der Rechtsamwalt in der Regel im Recht seines Herkunftsstaats oder dem Internationalen Recht Rechtsberatung erteilt haben wird. Aus Sicht des Aufnahmestaats erscheint es dagegen nicht gerechtfertigt, grundsätzlich die Eignungsprüfung lediglich auf das Prozeß3- und Standesrecht zu beschränken. Gemäß Art, 4 der Richtlinie 89/48/EWG muß sich die Eignungsprüfung auf Rechtsgebiete beziehen, die für die Berufsausübung notwendig sind, und deren Kenntnis bei dem Antragsteller nicht aufgrund seiner Vorausbildung oder Berufserfahrung unterstellt werden können. Bei einem Rechtsanwalt, der drei oder mehr Jahre im Aufnahmestaat hinsichtlich des Rechts des Herkunftsstaat rechtsberatend tätig war, kann eine Kenntnis des materiellen Rechts des Aufnahmestaats nicht unbedingt als selbstverständlich unterstelt werden. Es ist dagegen zu erwarten, daß der Rechtsanwalt sich mit dem Standesrecht und unter Umständen auch mit dem Prozeßrecht des Aufnahmestaats vertraut gemacht hat. Die gemäß Art. 10 Abs. 2 des Richtlinienentwurfs gerade auf diese Rechtsgebiete beschränkte Eignungsprüfung geht daher meines Erachtens vollständig am eigentlichen Bedürfnis vorbei. Die Regelung läßt sich nur soweit erklären, als die Kommission eine gewisse Garantie der Vollintegration gewähren möchte. Der Fall des migrierenden Rechtsanwalts mit ständiger und effektiver Berufsausübung im Aufnahmestaat, der nach Ablauf der Fünfjahresfrist die Eignungsprüfung nicht besteht, soll lediglich eine theoretische Möglichkeit sein ohne praktische Bedeutung sein. Ob mit dieser Regelung der Mandantenschutz voll gewährleistet wird, kann zumindest bezweifelt werden. An dieser Stelle zeigt sich erneut, daß eine Regelung, nach der der Rechtsanwalt auf Dauer unter seinem ursprünglichen Berufstitel rechtsberatend tätig sein könnte, einer derartigen Scheinintegration vorzuziehen wäre.

Auch der dritte Absatz von Art. 10 des Richtlinienentwurfs muß kritisiert werden. Hierbei ist vor allem die gewählte Formulierung sehr miBverständlich. Nach dem Wortlaut dieser Regelung kann der Rechtsanwalt während des in Art. 2 genannten Zeitraums von fünf Jahren jederzeit die Anerkennung seines Diploms nach der Richtlinie 89/48/EWG beantragen. Diese Formulierung wirft zumindest die Frage auf, welche Konsequenz mit dem Ablauf dieser Frist verknüpft werden soll. Meiner Ansicht nach ist eine zeitliche Begrenzung dieses Rechtsanspruchs vollkommen unmöglich, da dieser in deutlichem Widerspruch zur Richtlinie 89/48/EWG steht. In ihren Erläuterungen zu Art. 10 Abs. 3 des Richtlinienentwurfs führt die Kommission dementsprechend auch aus, daß Absatz 3 als eine Erinnerung an die in der Richtlinie 89/48/EWG grundsätzlich gewährte Anerkennungsmöglichkeit aufzufassen ist ${ }^{1212}$. Damit muB Art. 10 Abs. 3 des Richtlinienentwurfs als überflüssig gestrichen werden. In der heutigen Form sind bei der Umsetzung lediglich Mißverständnisse zu erwarten. Mitgliedstaaten könnten hierin eine Aufforderung zur restriktiven Anwendung des allgemeinen Anerkennungssystems sehen. Eine solche Auslegung kann jedoch nicht beabsichtigt sein.

1212. Erläuterungen zu Art. 10, KOM (94), 572 endg. 11. Siehe aber die Kritik des CCBE in House of Lords 1995, Minutes of Evidence, 3 
Fallstudie 1: Die rechtsberatenden Berufe

Unter Berücksichtigung der verschiedenen Kritikpunkte halte ich eine gründliche Revision des worgelegten Richtlinienentwurfs für unbedingt erforderlich. Der französische Standpunkt, der seinen Niederschlag in Art. 2 des Richtlinienentwurfs gefunden hat, und eine Vollintegration nach Frist von fünf Jahren zwingend vorschreibt, wird nach meiver Ansicht weder den Interessen der Mehrheit der migrierenden Rechtsanwälte gerecht, noch ist er praktisch durchführbar ${ }^{1213}$. Eine strenge und konsequente Anwendung der Fristenregelung liefe meines Erachtens auch Art. 52 EGV zuwider. Die vorgeschlagenen Integrationsverfahren in Art. 10 des Richtlinienentwurfs soliten ebenfalls überdacht werden. Dabei ist zu berücksichtigen, daß eine erleichterte und im Einzelfall selbst automatische Anerkennung bereits nach dem System der Richtlinie 89/48/EWG unter Berücksichtigung der in den Entscheidungen Vlassopoulou ${ }^{1214}$ und Newman ${ }^{12 ! 5}$ entwickelten Interpretation des Art. 52 EGV möglich sein muß.

\section{\$ 5. Reglementierung der rechtsberatenden Tätigkeit}

Die Feststellung der Reglementienung des Berufes und der beruflichen Tätigkeit ist bei der Umsetzung und Anwendung des allgemeinen Anerkennungssystems gemäß der Richtlinie 89/48/EWG ein Schlüsselbegriff. Vielfach drehte sich die Diskussion um die Frage des Umfangs der Reglementierung. Auch für die Bedeutung des vorgellegten Richtlinienentwurfs wird diese Frage entscheidend sein. Grundsätzlich muß bei dieser Diskussion zwischen der Reglementierung der Zulassung zum Rechtsanwalt unter der Berufsbezeichnung des Aufnahmestaates - einschließlich der damit verbundenen Berufsausübung vor Gericht - und der allgemeinen Rechtsberatung unterschieden werden. In einigen Mitgliedstaaten, so etwa in Frankreich, stand zunächst nur die Zulassung zur forensischen Tätigkeit als Rechtsanwalt zur Debatte, weil bis 1971 die Rechtsberatung unreglementiert war. Zwischen 1971 und 1990 war die Niederlassung als Conseil juridique für ausländische Rechtsanwälte eine Möglichkeit, die die Rechtsberatung unter "home title" bot ${ }^{1216}$. Erst mit der jüngsten Reform der Anwaltschaft, ergibt sich die Problematik des Anwaltsmonopols für die Rechtsberatung in vollem Umfang auch in Frankreich ${ }^{1217}$. Eine ähnliche restriktive Entwicklung kann auch für Luxemburg konstatiert werden 1218 .

In anderen Mitgliedstaaten, so vor allem in der Bundesrepublik Deutschland; bestand ein weitgehendes Rechtsanwaltsmonopol für den gesamten Bereich einschließlich der Rechtsberatung. Daher war nicht nur die Zulassung zur Anwaltschaft, sondern auch die

1213. Ahnlich auch die Schluffolgenungen des Select Committees des House of Lords 1995, 17.

1214. Urteil vom 7. Mai 1991, Rs C-340/89 - Iréne Vlassopoulou/Ministerium für Justiz, Bundes- und Europatangelegenheiten Baden-Würtemberg, Sig. 1-1991, 2357.

1215. Unteill vom 7. Mai 1992, Rs C-104/91 - Colegio Oficial de Agentes de la Propriedad Immobiliaria, Ministerio fiscall..L Aguirre Borrel, S.K. Newman u.a. -, Slg. 1992, I-3003.

1216. Zum Conseil juridique siehe Goebel, Tulane Law Review 1989, 443 (464-469)

1217. Siehe dazu Sokøl, The International Lawyer 1992, 1025; Raoult, The Fnench System in: Daly/Goebel; Goebel, Fondham Int. Law Journal 1991-1992, 556 (563).

1218. Loi du 10 aoüt 1991 sur la profession d'awocat, Memorial 1991, A-No.58, 1110. 
Rechtsberatung insgesamt - einschließlich der Beratung zum Recht des Heimatstaates - für Rechtsanwälte aus den anderen Mitgliedstaten problematisch.

Das Rechtsberatungswesen auch für ausländische Rechtsanwälte wurde in Deutschland bis zur Reform von $1989^{1219}$ wesentlich durch das im Dritten Reich am 13. Dezember 1935 erlassene "Gesetz zur Verhütung von Mißbräuchen auf dem Gebiet der Rechtsberatung" 1220 bestimmt. Damit wurde ein allgemeines Verbot der geschäftsmäßigen Rechtsberatung eingefïhrt. Wer vom Verbot des Art. 1 und Art. 2 RBerG ausgenommen sein wollte, bedurfte für seine Beratungstätigkeit einer besonderen Zulassung. Von dem Verbot ausgenommen waren lediglich einige enumerativ aufgezählte Berufsgruppen. Zu den erlaubnisfreien Rechtsberatern zählten die Rechtsanwälte, Notare, Patentanwälte, Steuerberater und Wirtschaftsprüfer. Von diesen Berufen hatte wiederum nur der Rechtsanwalt eine volle Rechtsberatungsbefugnis inne, während den sonstigen erlaubnisfreien Berufen nur eine Teilbefugnis zustand. Begründet wurde diese Gesetzgebung mit der Notwendigkeit, sachkundige Rechtsberatung sowie die wirtschaftliche Unabhängigkeit der Rechtsberater zu gewährleisten. ${ }^{122 !}$. Tatsächlich hatte die Neuordnung der Rechtsberatung im Jahre 1935 wohl eher einen anderen Grund. Durch die Zulassungsverpflichtung im Rechtsberatungsgesetz war es möglich, die bereits 1933 entlassenen jüdischen Beamten und Richter, ebenso wie die von der Anwaltsliste gestrichemen jüdischen Anwälte, auch von der sonstigen Rechtsberatung auszuschlieBen ${ }^{1222}$. Das Rechtsberatungsgesetz wurde zwar nach dem Zusammenbruch des nationalsozialistischen Systems in einigen Punkten geändert ${ }^{1223}$, im wesentlich ist es jedoch bis heute Inkraft ${ }^{1224}$.

Vor diesem Hintergrund muß man die Frage der Niederlassung von ausländischen Rechtsanwälten auch unter "home title" sehen. Die Zulassungsbestimmungen zum Rechtsanwaltsberuf finden sich in $\$ \$ 4$ bis 17 BRAO. Maßgebend war dabei bis zur Umsetzung der Richtlinie $89 / 48 / \mathrm{EWG}^{1225}$ ausschließlich die Befähigung zum Richteramt ${ }^{1226}$. Eine Niederlassung unter "home title" war bis 1989 nicht vorgesehen. Bis 1989 bedurfte es daher für die Rechtsberatung auch für ausländische Rechtsanwălte, die im Recht des Herkunftstaats beratend tätig sein wollten, einer ausdrückïichen Erlaubnis gemäß Art. 1 RBerG. Gemäß 1 Abs. 1 Nr. 6 RBerG kann diese Genehmigung

1219. Durch Gesetz zur Åndenung des Berufsrechts der Rechtsanwälte vom 13. Dezember 1989 wurde ein Zwölfter Teil ( $\$$. 206 und 207) in die Bundesrechtsanwaltsordnung (BRAO) eingefügt. Dazu Junius, The German System, in: Daly/Goebel.

1220. RGBI I, 1478. Am selben Tag wie das RBeratG wurde auch eine Ändenung der Rechtsanwaltsordinung erlassen, RGBI. I, 1470. Siehe dazu von Schweinitz, 38

1221. Amtiche Begründung zum RBeratG, RStBl. 1935, 1526 (1528)

1222. Von Schweimitz, 53 mit genauen Zahlenangaben in FuBnote 34.

1223. So wurde 1958 die Gesetzesüberschrift wereinflacht.

1224. Zum Rechtsberatergesetz siehe Alltemhoff/Busch u.a..

1225. Gesetz zur Unsetzung der Richtline des Rates vom 21. Dezember 1988 íber eine allgemeine. Regelung zur Anerkennung der Hochschuldiplome, die eine mindestens drejjăhrige Benfsausbildung abschließen, für die Benfe des Rechtsanwalts und des Patentanwalts vom 6. Juli 1990, BCBI. I 1990, 1349. Dazu die Erörterungen auf Seite 295.

1226. \$4 BRAO a.F. in Verbindung mit $\$ 5$ DRiG. 
Rechtskundigen in einem ausländischen Recht für die Rechtsbesorgung auf dem Gebiet dieses Rechts und des Rechts der Europäischen Gemeinschaften erteilt werden. Voraussetzung für die Erlaubniserteilung ist gemäß $\$ 1 \mathrm{Abs} .2 \mathrm{RBerG}$, daß der Antragsteller die für den Beruf erforderliche Zulässigkeit, persönliche Eignung sowie genügend Sachkunde besitzt. Des weiteren darf das Bedürfnis nicht bereits durch eine hinreichende Zahl won Rechtsberatern gedeckt sein ${ }^{1227}$. Auch die Erteilung der Erlaubnis bedeutete nicht zwangsläufig eine Berufsausübung unter "home title"', weil gemäß Art. 1 Abs. 1 Satz 3 RBerG, die Rechtsberatung nur unter der der Erlaubnis entsprechenden Berufsbezeichnung ausgeübt werden darf. Dieser Regelungsmechanismus hat sicher dazu beigetragen, daß sich in Deutschland bisher kaum ausländische Rechtsanwälte niedergelassen haben ${ }^{1228}$.

Die Situation für ausländische Rechtsanwälte, die rechtsberatend in der Bundesrepublik Deutschland tătig sein wollen, hat sich durch die Reformen der Bundesrechtsanwaltsordnung won $1989^{1229}$ und $1994^{1230}$ erheblich verbessert. Gemäß § 206 Abs. 1 BRAO kann nun ein Staatsangehöriger eines Mitgliedstaates der EU oder des EWR, der seine berufliche Tätigkeit unter einer in $\$ 1$ der Dienstleistungsrichtlinie genannten Berufsbezeichnung ausübt, sich unter dieser Berufsbezeichnung zur Rechtsbesorgung auf dem Gebiet des ausländischen und internationalen Rechts in Deutschland niederlassen, wenn er auf Antrag in die für den Ort seiner Niederlassung zuständigen Rechtsanwaltskammer aufgenommen ist. Diese Gesetzesänderung, die eine Öffnung des bisher für europäische Anwälte beinahe vollkommen verschlossenen Territoriums bewirkt hat, erklärt vielleicht die unerwartet niedere Zahl der Anträge auf Anerkennung der Diplome gemäß der Richtlinie 89/48/EWG ${ }^{1231}$. Mit der jüngsten Reform von 1994 wurde dieser Prozeß noch weiter fortgesetzt. Nun gilt auch für die Parteistaaten der Welthandelsorganisation eine entsprechende Regelung gemäß dem neu eingefügten $\$ 206$ Abs. 2 BRAO. Dieser ist am 1. Januar 1995 in Kraft getreten. Für Rechtsanwälte aus weiteren Staaten, die nicht der Welthandelsorganisation angehören, gilt gemäß $\S 206 \mathrm{Abs} .3$ BRAO das Reziprozitătsprinzip, d.h. das Bundesjustizministerium bestimmt durch Rechtsverordnung die Staaten für die die Gegenseitigkeit verbürgt ist. Über den Antrag auf Aufnahme in die Rechtsanwaltskammer entscheidlet gemäß $\$ 207$ Abs. 1 die Landesjustizverwaltung. Der ausländische Rechtsanwalt ist dabei verpflichtet, jährllich eine Bescheinigung hinsichtlich seiner Berufszugehörigkeit im Herkunftsstaat vorzulegen.

1227. Diese Bedurfnisklausel wurde bereits 1955 in einem Urteil des Bundesverwaltungsgerichts als mit Art. 12 Abs. 1 GG nicht vereinbar erklär, BVerwGE 2, 85

1228. Im Gegensatz zu Brilssel, Paris, London, die als Tummelplatz großer ausländischer Kanzleien bezeich net werden können, gibt es in Deutschland kein wirkliches Zentrum für die internationale Rechtsberatung. Selbst am Börsenplatz Frankfurt steckt eine entsprechende Entwicklung noch in den KinderschuWen. Zur Situation in den einzelnen Mitgliedstaaten: Adamson, 11; Tyrell/Yaqub, $69 \mathrm{ff}$; ; etwas veraltet Cambell 1982; Katz 1986

1229. Zwölther Teil ( $\$ 206$ und 207) eingefuhrt durch Gesetz vom 13 . Dezember 1989, BGBI. 1, 2135. \& 206 Abs. 1 wurde erneut durch Art. 35 EWR-Ausfuhrungsgesetz vom 27. April 1993, BGB1 1, 512 ergänzt.

1230. Durch Gesetz vom 30. August 1994, BGBl. I, 1438 wurde ein neuer $\$ 206$ Abs. 2 eingefügt.

1231. Seit 1991 wurden lediglich etwa 50 Verfahren durchgeführt. 
Vergleicht man die deutsche mit der französischen Entwicklung, so stehen diese sich diametral gegenuiber. Frankreich hat aus einem weitgehend offenen Rechtsberatungsraum durch Neureglementierung des Rechtsanwaltsberufs eine nahezu geschlossenes System entwickelt, während Deutschland den entgegengesetzten Weg eingeschlagen hat. Begründen läßt sich diese unterschiedliche Entwicklung wohl nur mit der Haltung der Ständevertretungen in den beiden Mitgliedstaaten hinsichtlich einer Öffnung des Marktes. In Frankreich haben die beruflichen Ständeorganisationen eine zunehmend ablehnende Position gegen die ausländischen Großkanzleien eingenommen ${ }^{1232}$, während die Bundesrechtsanwaltskammer ebenso wie der Deutsche Anwaltverein ${ }^{1233}$ die Möglichkeit einer grenzüberschreitenden Berufstätigkeit auch für deutsche Rechtsanwälte begrüBen und in diesem Zusammenhang die Öfnung des deutschen Markts befürworten. Damit hat sich die Position der deutschen Berufsvertretungen mehr der Haltung der englischen Law Society angenähert, die in einer liberalen Anerkennungspolitik eine Garantie dafür sieht, London als Zentrum für den internationalen Rechtsverkehr weiter auszubauen ${ }^{1234}$. Die Umsetzungsmaßnahmen zur Richtlinie 89/48/EWG widerspiegeln teilweise diese Tendenz, teilweise - und dies gilt besonders für die Bundesrepublik - hat die Haltung der Berufsvertretungen allerdings noch keinen deutlichen Niederschlag in der einschlägigen Umsetzungsgesetzgebung gefunden ${ }^{1235}$.

\section{§ 6. Der Begriff "rechtsberatender Beruf" im Sinne der Richtlinie 89/48/EWG}

GemäB Art. 4 Abs. 1 Buchstabe b) der Richtlinie 89/48/EWG können Mitgliedstaaten bei Berufen, deren Ausübung die genaue Kenntnis des nationalen Rechts erfordert und bei denen die Beratung und/oder der Beistand in Fragen des innerstaatlichen Rechts ein wesentlicher und ständiger Bestandteil der beruflichen Tätigkeit ist, die Wahlmöglichkeit des Antragstellers zwischen einer Eignungsprüfung und einem Anpassungslehrgang einschränken ${ }^{1236}$. Bei anderen Berufen müssen die Mitgliedstaaten, falls sie die Wahlmöglichkeit beschrănken möchten, das Verfahren gemäß Art. 10 der Richtlinie 89/48/EWG einhalten. Diese Regelung hat zumindest in den Niederlanden zu einigen Problemen geführt. Die Niederlande haben in ilhrem Allgemeinen Umsetzungsgesetz. $^{1237}$ Ausführungsmaßnahmen für verschiedene juristische Berufe erlassen, die nicht unter die genaue Definition des Art. 4 Abs. 1 Buchstabe b) zu subsumieren waren. Dies gilt z.B. für den Beruf des Richters und des Staatsanwalts. In beiden Fällen kann man nicht von einer "rechtsberatenden" Tätigkeit sprechen. Das Unterrichtsministerium wollte daher für diese Berufe eine Ausnahmeregelung gemäß Art. 10 der Richtlinie

1232. Es handelt sich dabei wor allem um amerkanische und britjsche Wirtschaftskanzleten. Kritisch zur Rechtsentwicklung in Framkreich, Goebel, Fordham Int. Law Joumal 1991-1992, 556 (618 ff.).

1233. Der Deutsche Anwaltwerein bietet selbst einen Lehrgang zur Vorbereitung auf die Eignungsprufung an.

1234. Toulmin, House of Lords $1995,70 \ldots$ "it has substantially enriched the life of legal London..."

1235. Allerdings bestätigt die hohe Erfolgsquote bei den Eignungsprüfungen diese Tendenz.

1236. Siehe dazu die Erôrterungen auf Seite 194.

1237. De Algemene wet erkenning EG-hoger-onderwijsdiploma's, Stb. 1994, 29. 
89/48/EWG bewirken ${ }^{1238}$. Die Kommission hat jedoch die direkte Anwendung des Art. 4 Abs. 1 b) auf die genannten juristischen Berufe bestätigt, obwohl diese nicht genau unter die Definition der Bestimmung zu subsumieren sind ${ }^{1239}$. Eine Ausnahmegenehmigung gemäß Art. 10 der Richtlinie war somit nicht erforderlich. Das Beispiel zeigt, daß bei der Verabschiedung der Richtlinie 89/48/EWG ihre Anwendung auf Berufe der Justiz nicht direkt erwogen worden ist, obwohl diese unter die generelle Definition eines reglementierten Berufes im Sinne der Richtlinie fallen. Ansonsten hätte man beil der Abfassung des Richtlinientextes eine allgemeinere Formulierung - z.B. juristische Berufe, die eine genaue Kenntnis des nationalen Rechts voraussetzen - gewählt.

Einige Mitgliedstaaten haben allerdings den Begriff "rechtsberatend" bei der Umsetzung sehr weit ausgedehnt. Pertek kritisiert nicht zu Unrecht die französische Umsetzungsmaßnahme, in der der Beruf "commissaire-priseur" 1240 als rechtsberatend im Sinne der Richtlinie 89/48/EWG eingestuft wurde, mit der Konsequenz, daß von Angehörigen dieses Berufes aus anderen Mitgliedstaaten eine Eignungsprüfung zum französüschen Recht verlangt wird ${ }^{1241}$. Bei einer derartig weiten Interpretation des Begriffs "rechtsberatend" besteht die Befürchtung, daß eine Eignungsprüfung zur Abschreckung unlliebsamer Konkurrenz eingeseizt wird. Einer derartigen Interpretation und Umsetzung muB daher mit Vorsicht begegnet werden.

\section{$\S 7$. Die Umsetzung der Richtlinie 89/48/EWG für die rechtsberaten- den Berufe}

Alle Mitgliedstaaten haben bestimmte Berufe als "rechtsberatend" im Sinne der Richtlinie 89/48/EWG qualifiziert. In der Mehrzahl der Fälle handelt es sich um die Berufe Rechtsanwalt, Wirtschaftsprüfer und Patentanwalt. In einigen Mitgliedstaaten erhielten auch andere Berufe diese Qualifikation ${ }^{1242}$. Die Mitgliedstaaten haben für diese Berufe im allgemeinen eine Eignungsprüfung vorgesehen ${ }^{1243}$. Die Umsetzung ist nicht in allen Mitgliedstaaten vollkommen abgeschlossen ${ }^{1244}$. So fehlen in Italien, Portugal und Spanien noch die inhalthichen Regelungen zur Eignungsprüfung. Auch die dänische Situation zu diesem Punkt ist nicht wollkommen deutlich. Negativ hervorgehoben werden riuß jedoch Belgien, daß noch keine einzige Ausführungsmaßnahme für Rechtsanwälte

1238. Entsprechende Anträge - jedoch mit anderer Begründung - wurden auch für verschiedene paramedizinische und maritime Berufe gestellt.

1239. Die Kommission hielt die Einschränkung der Wahlmöglichkeit bei diesen Berufen für angemessem.

1240. Auktionator

1241. Pertek, YbEL, 1992, 320.

1242. Dies gillt vor allem fur Frankreich und die Niedertande.

1243. Nur in Dänemark ist die Rechtslage hinsichtlich Rechtsanwälte nicht deutlich.

1244. Zur Umsetrung hinsichtlich Rechtsanwälte siehe Wackie Eysten, AdvBl. 1993, 662; Arends, AdvBl 1994. 282; Adamson, $46 \mathrm{ff}$ 
erlassen hat ${ }^{1245}$. Allerdings können sich ausländische Rechtsanwälte seit 1984 auf einer sogenannten B-Liste bei den Brüsseler Gerichten einschreiben, so daß sie als Teilhaber und Angestellte bei einer belgischen Anwaltskanzlei tätig sein können ${ }^{1246}$. Durch diese Regelung wird u.U. das Bedürfnis nach einer Anerkennung gemäß dem System der Richtlinie 89/48/EWG beschränkt ${ }^{1247}$. Die Verzögerung der Umsetzung in Belgien für den Beruf des Rechtsanwalts läßt sich kaum erklären, da es sich hierbei um einen Beruf handelt der auf nationalem Niveau umzusetzen ist, so daß die verfassungsrechtlichen Schwierigkeiten, die bei anderen Berufen den Umsetzungsprozef verzögert haben, in diesem Falle kaum eine Rolle spielen dürften.

Die neuen Mitgliedstaaten haben dagegen alle Umsetzungsmaßnahmen verabschiedet. Im Falle von Österreich handelt es sich dabei um eine Regelung, die weitgehend der deutschen Ausführungsregelung entspricht ${ }^{1248}$. In Schweden wurde die Dienstleistungsrichtlinie und die Richtlinie 89/48/EWG ebenfalls mit einem Gesetz umgesetzt ${ }^{1249}$. Die Verpflichtung zur Ablegung einer Eignungsprüfung für juristische Berufe wurde in Finnland im Rahmen der Ausführungsverordnung niedergelegt ${ }^{1250}$. Norwegen hat die Umsetzung der Dienstleistungsrichtlinie und der Richtlinie 89/48/EWG für Rechtsanwälte mit Königlichem Dekret vom 10. Dezember 1993 vorgenommen ${ }^{1251}$. Dieses Dekret enthält auch eine Regelung bezüglich der anwaltlichen Tätigkeit unter "home title".

\section{A. Die BundesRepublik Deutschland}

\section{Die rechtsberatenden Berufe in der Bundesrepublik Deutschland}

Die Bundesrepublik qualifizierte als rechtsberatende Berufe im Sinne der Richtlinie 89/48/EWG den Rechtsanwalt, den Patentanwalt, den Wirtschaftsprüfer und den Steuerberater. Für Notare, Richter und Staatsanwälte wurde eine Ulmsetzung unter Berufung auf Art. 55 und Art. 48 Abs $_{n} 4$ EGV nicht erwogen.

1245. Durch Urteil wom 13. Juli 1995 wude Belgien daher wegen der Nichtumsetzung der Richtlinie 89/48/EWG verurteilt (noch nicht veröffentlicht). Siehe aber Nr. 21/95 der Wochenübersicht des Europäischen Gerichtshofs

1246. Règlement d'Ordre Intéreur de l'Ordre des Avocats du Barreau de Bruxelles, arts. 69-79. Siehe dazu Van Camp 83; De Savornin Lohman/Cath, AdvBI. 1984. 321; Goebel, Fordham Int. L.J. 1991-92. 556 (561). Zur belgischen Situation allgemein Mathieu/Baudrez.

1247. Auch werden in Belgien anscheinend automatische Anerkennumgen ausgesprochen.

1248. EWR-Rechtsanwaltsgesetz 1992, BGBI. (Österreich) vom 14. Januar 1993, 481. Mit diesem Gesetz wurde die Dienstleistungsrichtlinie und die Hochschulrichillinie für Rechtsanwälte umgesetzt. Die Eignungsprifung wird dabei in \$8 Abs. 1 zwingend vorgeschrieben. Auch wurde das Eifforderis der österreichischen Staatsangehörigkeit für die Angehörigen des Europäischen Wirtschaftsraums anfgehoben (Artikel II des Gesetzes).

1249. Lag om ändering i rättegangsbalken wom 17. Dezember 1992, SFS 1992:1511.

1250. Umsetzungsgesetz: Laki vom 28. Juni 1994; sowie $\$ 5$ der Ausführungsverordnung: Aselus vorn 28. Juri 1994.

251. Regulation concerning the right of foreign lawyers to provide legal aid in Norway and concerning foreign qualifications as a basis for a licence to practice law in Norway. 
Die Bundesrepublik. Deutschland hat mit Gesetz vom 6. Juli 1990 die Richtlinie für die reglementierten Berufe des Rechtsanwalts und des Patentanwalts ${ }^{1252}$, mit Gesetz wom 20. Juli 1990 für die Wirtschaftsprüfer ${ }^{1253}$ ungesetzt. Beide Gesetze traten am 1. Ja nuar 1991 und damit rechtzeitig vor dem durch Art. 12 der Richtlinie 89/48/EWG gesetzten Termin in Kraft. Auch für den Beruf des Steuerberaters wurde eine vergleich bare Umsetzungsregelung durch eine Änderung des Steuerberatergesetzes vom 13. Dezember 1990 vorgenommen ${ }^{1254}$.

Für alle als rechtsberatend qualifizierten Berufe wurde die Eignungsprüfung als Anpassungsinstrument gemäß Art. 4 Buchstabe b) der Richtlinie $89 / 48 /$ EWG gewählt. In der amtlichen Begründung für diese Wahl im Falle der Rechts- und Patentanwälte heiBt es, daß diese Berufe durch die Rechtsberatung und den Beistand in Fragen des innerstaatlichen deutschen Rechts geprägt sind. Deshalb sei bei ihnen eine genaue Kenntnis des innerstaatlichen Rechts vorauszusetzen, uber die die Diplominhaber aus anderen Mitgliedstaaten in der Regel nicht verfügten. Auch sei die deutsche Rechtsordnung mit keiner anderen europäischen Rechtsordnung so nahe werwandt, daß für die Zwecke der Rechtsberatung die Kenntnis jenes anderen Rechtssystems ausreichen könnte. Das rechtsuchende Publikum vertraue darauf, daß die als Rechtsanwalt oder Patentanwalt in der Bundesrepublik tätigen Personen in einer gründlichen Ausbildung die Kenntnisse insbesondere des deutschen Rechts - erworben haben, die für eine ordnungsgemäße Beratung und Vertretung erforderlich sind. Da mit seiner Zulassung zur Rechtsanwaltschaft oder Patentanwaltschaft der ausländische Diplominhaber voll in den Beruf integriert würde, d.h. auch den inländischen Titel führen dürfe, sei daher mil diesem Vertrauen des Klientels Rechnung zu tragen gewesen und daher der Berufszugang von dem Bestehen einer Eignungsprüfung anhängig zu machen. Ein Anpassungsiehrgang könnte nicht die selbe Garantie bieten, da dieser lediglich Gegenstand einer Bewertung ${ }^{125 s}$ sei; die jedoch keinesfalls in Form einer schriftlichen oder mündlichen Prïfung erfolgen dürfe ${ }^{1256}$. Eine Eignungsprüfung diene auch den Interessen des Antragstellers, weil es ihm überlassen bleibe, wo und auf welche Weise er sich in das deutsche Recht einarbeite. Hierdurch könne die Anpassungszeit sich auch für ihn erheblich verkürzen ${ }^{1257}$. Falls er nämlich bereits über die erforderlichen Rechtskenntnisse verfüge, bedürfe er keines zeitraubenden Anpassungslehrgangs. Nicht zuletzt mindere der Zwang, zunächst eine Eignungsprüfung zu bestehen, das Risiko für den Zuwanderer,

1252. Gesetz zur Urnsetzung der Richtlinie des Rates vom 21 . Dezember 1988 uber eine aligemeine Regelung zur Anerkennung der Hochschuldiplome, die eine mindestens dreijährige Beruf sausbilldung abschlie Ben, für die Berufe des Rechtsanwalts und des Patenanwalts vom 6. Juli 1990, BGBI. I vom 14. Juli 1990, 1349. Dazu Weil, BRAK-Mitt. 1991, 15 ff." Lang, BRAK-Mitt. 1990, 13 ff,.

1253. Zweites Gesetz zur Anderung der Wirtschaftspruferordnung vom 20. Juli 1990, BGBI. I vom 27. Juli $1990,1462$.

1254. Fünftes Gesetz zur Änderung des Steuerberatergesetzes vom 13. Dezember 1990, BGB1. I vom 19. Dezember 1990,2756 .

1255. Art. 1 lit. f der Richtinie 89/48/EWG.

1256. Anutliche Begründung, BT-Dr 11/6154, so bereits die nicht veróffentlichte Protokollerklärung Nr.11 zur Richtlinie 89/48/EWG.

1257. So auch der 9. Enwägungsgrund in der Präambel der Richtlinie 89/48/EWG. 
Fehler bei der Rechtsberatung zu begehen und dafür in Regreß genommen zu werden ${ }^{12 s:}$

In Art. 1 des "Gesetzes zur Umsetzung der Richtlinie des Rates vom 21. Dezember 1988 über die allgemeine Regelung zur Anerkennung der Hochschuldiplome, die eine mindestens dreijährige Berufsausbildung abschließen, für die Berufe des Rechtsanwalts und des Patentanwalts" vom 6. Juli 1990 erfolgte die Umsetzung der Richtlinie für den Beruf des Rechtsanwalts und in Art. 2 für den Beruf des Patentanwalts durch das "Gesetz über die Eignungsprüfung für die Zulassung zur Patentanwaltschaft". Art. 3 und 4 des Gesetzes sind den notwendigen Änderungen der Bundesrechtsanwaltsordnung beziehungsweise der Patentanwaltsordnung gewidmet. Art. 5 des Gesetzes enthält die zu diesem Zeitpunkt noch notwendige Berlinklausel. Art. 6 des Gesetzes regelt das Inkrafttreten. Das Gesetz für die Eignungsprüfung für die Zulassung zur Rechtsanwaltschaft erhielt eine inhaltliche Ergänzung mit der Verordnung über die Eignungsprüfung für die Zulassung zur Rechtsanwaltschaft vom 18. Dezember $1990^{1259}$.

Durch das Gesetz zur Änderung der Wirtschaftsprüferordnung vom 20. Juli 1990 wurde in die Wirtschaftsprüferordnung ein neuer Achter Teil eingefügt, worin in den $\$ \$ 131$ $\mathrm{g}$ ff die Eignungsprüfung für Wirtschaftsprüfer oder vereidigte Buchprüfer geregelt ist.

\section{Der Rechtsanwalt}

a. Gesetz über die Eignungsprüfung für die Zulassung zur Rechtsanwaltschaft

\$1 Abs. 1 des Eignungsprüfungsgesetzes enthält die gesetzgeberische Entscheidung für die Eignungsprüfung als Zulassungsvoraussetzung zur Rechtsanwaltschaft. $\S 1$ Abs. 2 verweist auf die Diplomdefinition des Artikels 1 Buchstabe a) der Richtlinie 89/48/EWG. Ausdrücklich hervorgehoben wird, daß auch ein Diplom, das auf Grund einer Ausbildung ausgestellt wurde, die nicht überwiegend in der Europäischen Gemeinschaft stattgefunden hat, zur Ablegung der Eignungsprüfung berechtigt, wenn der Inhaber den entsprechenden Beruf tatsä̈chlich und rechtmäßig mindestens drei Jahre ausgeuibt hat und dies von dem Mitgliedstaat bescheinigt wird, der das Diplom ausgestellt oder anerkannt hat. Ob mit dieser Formulierung die Richtlinie hinsichtlich der Drittstaatdiplome ganz korrekt umgesetzt ist, mag zweifelhaft erscheinen, weil in $\S 1$ Abs. 2 des Eignungsprüfungsgesetzes von einer Ausbildung gesprochen wird, die nicht ubberwiegend in der Europäische Gemeinschaft stattgefunden hat. Dagegen spricht Artikel 1 Buchstabe a) der Richtlinie 89/48/EWG von einem Diplom, das in einem Drittland erworben und durch einen Mitgliedstaat anerkannt wurde. Die Umsetzung zeigt einen graduellen Unterschied, der bei der Entscheidung, ob ein Kandidat zur Prüfung zugelassen wird entscheidlend sein kann. Hat z.B. ein Brite seine Juristenausbildung. einschließlich der Solicitorausbildung in Hongkong oder Kanada genossen und wurde

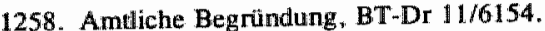

1259. Verondmung für die Zulassung zur Rechtsanwaltschaft, BGB1. 1990, Teil 1, 2881. Diese Verordnung erging mit Zustimmung des Bundesrates gemäB Ant. 80 Abs. 2 GG. 
diese Ausbildung in Großbritannien anerkannt, so müßte diese Person - vorausgesetzt, sie verfügt über die notwendige dreijährige Berufserfahrung - nach dem. Wortlaut der Richtlinie 89/48/EWG zur Eignungsprüfung zugelassen werden. Dieses Ergebnis ergibt sich nicht zwingend aus \$1 Abs. 2 Satz 2 des Eignungsprüfungsgesetzes, weil eine Ausbildung, die nicht überwiegend in der Europäische Gemeinschaft stattgefunden hat, nicht per se mit einer Ausbildung gleichgesetzt zu werden braucht, die überhaupt nicht im Gemeinschaftsgebiet absolviert worden ist. Eine gemeinschaftskonforme Auslegung müfte jedoch dazu führen, daß ein entsprechender Bewerber dennoch zur Eignungsprüfung zugelassen werden müßte. Die Formulierung in $\$ 3 \mathrm{Abs} .2 \mathrm{Nr} .3$ der Verordnung über die Eignungsprüfung für die Zulassung zur Rechtsanwaltschaft vom 18. Dezember $1990^{126 \%}$ scheint diese Interpretation zu bestätigen, da hierin vom Antragsteller als Voraussetzung für die Zulassung zur Eignungsprüfung u.a. entweder der Nachweis verlangt wird, daß er mehr als die Hälfte der Mindestausbildungszeit in Mitgliedstaaten abgeleistet hat ${ }^{1261}$ oder, daß er eine Bescheinigung über eine mindestens dreijährige Berufsausübung in einem Mitgliedstaat erbringt. Mit diesem Wortlaut scheint die Zielsetzung der Richtlinie 89/48/EWG hinsichtlich der Drittlanddiplome hinreichend erfüllt zu sein. Es wäre jedoch besser gewesen auch im Umsetzungsgesetz eine unmißverständliche Formulierung zu wählen.

Gemäß $\$ 2$ des Eignungsprüfungsgesetzes ist die Eignungsprüfung eine ausschließ》ich die beruflichen Kenntnisse des Antragstellers betreffende staatliche Prüfung, mit der seine Fähigkeit, den Beruf des Rechtsanwalts in der Bundesrepublik Deutschland auszuben, beurteilt werden soll. Mit dieser Formulierung, wird dem in Artikel 1 Buchstabe g) definierten Zweck der Eignungsprüfung Rechnung getragen. Bei der Prüfungsform muß dabei berücksichtigt werden, daß der Antragsteller in einem Mitgliedstaat bereits über eine berufliche Qualifikation verfügt, die ihn zur Ausübung eines Anwaltsberufes berechtigt. Die dem deutschen Rechtsanwaltsberuf entsprechenden Berufe der anderen Mitgiriedstaaten sind in einer Anlage zum Eignungsprüungsgesetz aufgelistet. Danach gelten als Rechtsanwaltsberufe:

in Belgien: Avocat/Advocaat, in Dänemark: Advokat, in Frankreich: Avocat, in Griechenland: Dikigoros, in Irland: Barrister, Solicitor, in Italien: Avvocato, in Luxemburg: Avocat-avoué, in den Niederlanden: Advocaat,

1260. Verordmung für die Zulassung zur Rechtsanwaltschaft, BGBI. 1990, Teil I, 2881. Diese Verordnung. erging mit Zustimmung des Bundesrates gemalB Art. 80 Abs. 2 GG.

1261. In der amtlichen Begründung des Justizministeriums für den Bundesrat heiBt es zu diesem Punkt, daß3 eine Ausbildung als "nicht überwiegend in der Gemeinschaft erworben" gilt, wenn nicht mehr als die Halfte der Mindestausbildungszeit in einem oder in mehreren Mitgliedstaten absolvient wurde, siehe BR-D nucksache $712 / 90$ wom 16 . Oktober $1990,12$. 


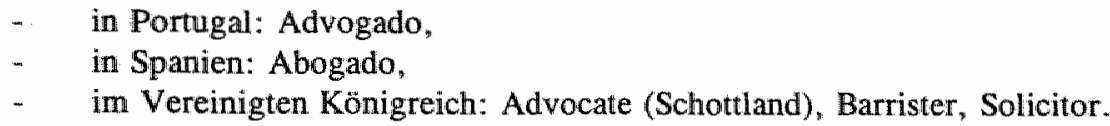

Diese Liste entspricht der Dienstleistungsrichtlinie für Rechtsanwälte 77/249/EWG. Eine derartige Auflistung ist nicht unproblematisch, weil es mehr juristische Berufe gibt, die ein Diplom voraussetzen, das die Befähigung zur Niederlassung als Rechtsanwalt gewährt ${ }^{1262}$. Gerade bei einer Umsetzung der Richtlinie in Deutschland, wo bisher in der juristischen Ausbildung am Einheitsjuristen festgehalten wird ${ }^{1263}$, ist es verwunderlich, daß dieser Tatsache nicht Rechnung getragen worden ist ${ }^{1264}$.

Prüfungsamt für die Eignungsprüfung ist das für die Zweite juristische Staatsprüfung zuständige Prüfungsamt ( $\$ 3$ Abs. 1 des Eignungsprüfungsgesetzes) ${ }^{1265}$. Mehrere Bundesländer können durch Vereinbarung ein gemeinsames Prüfungsamt bestimmen $^{1266 .}$. Auch kann gemäß $\S 3$ Abs. 2 des Eignungsprüfungsgesetzes vereinbart werden, daß die Zuständigkeit eines Prüfungsamts sich auf die Eignungsprüfung von Antragstellem aus einzelnen Mitgliedstaaten beschränkt. Die Prüfung wird von einer Kommission von mindestens drei Prüfern abgenommen ( 8 Abs. 3 des Eignungsprïfungsgesetzes). In der Verordnung über die Eignungsprüfung für die Zulassung zur Rechtsanwaltschaft vom 18 . Dezember $1990^{1267}$ wird diese Regelung noch näher bestimmt. Gemäß $\S 2$ der Verordnung sind der Präsident des für die Zweite juristische Staatsprüfung zuständigen Prüfungsamts, seine Vertreter und die hauptamtlichen Prüfer sowie die zu Prüfern berufenen Rechtsanwälte als Prüfer in dem Verfahren einzusetzen. Über die Zulassung zur Prüfung entscheidet das Prüfungsamt. Die Zulassung wird gemäß \& 4 Abs. 2 des Eignungsprüfungsgesetzes versagt, wenn der Antragsteller die gesetzlichen Voraussetzungen nicht erfüllt oder die geforderten Unterlagen oder Erklärungen nicht abgibt. Dem Antrag sind gemäß $\S 3$ Abs. 3 der Verordnung ein handgeschriebener Lebenslauf, die erforderlichen Diplome, der Nachweis, daf der Antragsteller mehr als die Hälfte der Mindestausbildung in Mitgliedstaaten abgeleistet hat oder über eine mindestens dreijährige Berufsausübung in einem Mitgliedstaat verfügt, der Nachweis der Staatsangehörigkeit eines Mitgliedstaates, die Angabe der Wahlfächer sowie die Bestimmung des Faches für die zweite Aufsichtsarbeit, eine Versicherung, dal der Antragsteller die Zulassung zur Eignungsprüfung bei keinem anderen Prüfungsamt gestellt hat sowie eine Erklärung, ob und bei welchen Prüfungsämtern ein Ver-

1262. Sie dazu die Erörterungen auf Seite 270

1263. Miiller, DRiZ 1990, 8 Iff

1264. Im Vergleich dagegen ist die Umsetzung der Law Society für England und Wales wesentlich korrekter: obwohl auch dort Mängel im Hinblick auf die Vollständigkeit der Liste festgestellt werden können. Siehe dazu Seite 333

1265. Dies bedeutet, daB alle Justizministerien der Lăndier als zuständige Behönde gemå 1 Art. 9 Abs. 1 der Richtlinie $89 / 48 /$ EWG angewiesen wurden.

1266. Die Länder Hessen, Nord thein-Westfalen und Rheinland-Pfalz haben sich im Rahmen einer Verwal tungswereinbarung auf die Zuständigkeit des Justizprüfungsamtes des Landes Nordrhein-Westfalen in Düsseldorf zur Abnahme der Eignungsprüfungen geeinigt.

1267. BGBH. 1990, Teil 1, 2881. 
fahren erfolglos versucht worden war, beizufügen. Die erforderlichen Diplome und Befähigungsnachweise sind im Orginal mit einer beglaubigten Übersetzung vorzulegen. Dabei fallen unter den Begriff des Dïploms nicht nur die Nachweise über den erfolgreichen Abschluß eines mindestens dreijährigen Hochschulabschluß, sondern auch sonstige Zeugnisse, die im Herkunftsstaat für die Zulassung zur Anwaltschaft erforderlich sind. Hierzu gerechnet werden muß etwa die Bescheinigung über eine "mit Unterstützung eines qualifizierten Berufsangehörigen erworbene Berufspraxis" (Art. 4 Abs. 1 Buchstabe a) zweiter Anstrich der Richtlinie 89/48/EWG) ${ }^{1268}$.

Aus der Formulierung des $\& 3$ Abs. 2 der Verordnung, wonach der Antrag und die beizufügenden Unterlagen, soweit sie vom Antragsteller stammen, in der deutschen Sprache einzureichen sind, läßt sich ableiten, daß der Antrag schriftlich zu erfolgen hat ${ }^{1269}$. Das Erfordernis der dentschen Sprache nicht nur hinsichtlich der Prüfungsleistungen ( $\$ 6$ Abs. 1 Satz 2 des Eignungsprüfungsgesetzes), sondern für das gesamte Verfahren, wird damit begründet, daß es sich um ein Verwaltungsverfahren im Sinne der Verwaltungsverfahrensgesetze handelt. Verwiesen wird auf $\& 2 \mathrm{Abs}$. $3 \mathrm{Nr} .2$ der Länderverwaltungsverfahrensgesetze in Verbindung mit $\$ 23$ Abs. 1 des Verwaltungsverfahrensgesetzes ${ }^{1270}$. Grundsätzlich ist es sicher korrekt, anzunehmen, daß es sich bei der Abwicklung des Eignungsprüfungsverfahrens um ein Verwaltungsverfahren handelt. Es fragt sich jedoch, ob der Hinweis auf die entsprechenden Bestimmungen des Verwaltungswerfahrensgesetz ausreichend ist, die Sprachregelung auch nach gemeinschaftsrechtlichen Maßstäben zu rechtfertigen. Besser wäre gewesen, eine inhalt]iche Begründung für die Notwendigkeit der deutschen Sprachkenntnisse zu geben.

Nach der Zulassung zur Eignungsprüfung kann der Antragsteller nur aus wichtigem Grund von der Prïfung zurücktreten. Liegt kein wichtiger Grund vor, so gilt die Prüfung als nicht bestanden ( $\$ 4$ Satz 2 der Verordnung). Die Zuständigkeit innerhalb des Prüfungsamtes für die Entscheidung, ob ein wichtiger Grund vorliegt, regelt sich nach $\$ 1$ der Verordnung in Verbindung mit dem Landesrecht ${ }^{1271}$. Wann ein wichtiger Grund gegeben ist, wird in der Verordnung nicht ausgefuhrt. Ebensowenig ist ersichtlich, warum eine solche Regelung überhaupt in die Verordnung aufgenommen worden ist. Zwar entspricht diese Regelung bei einem Rücktritt von einer Prüfung dem nach deutschem Prüfungsrecht üblichen ${ }^{1272}$, doch ist fraglich, ob diese Bestimmung mit dem Sinn und Zweck der Richtlinie übereinstimmt. Schließlich soll die Eignungsprüfung keine Staatsprüfung im Sinne des Zweiten juristischen Staatsexamens darstellen, wo ein unentschuldigter Rücktritt geahndet werden kann. Es soll vielmehr einem Berufsangehörigen aus einem anderen Mitgliedstaat die Gelegenheit geboten werden, um die für die

1268. Sielne die amtliche Begründung zur Verordnung, BR-Drucksache $712 / 90,12$.

1269. So die amtliche Begrindung zur Verordnung, BR-Drucksache 712/90, 11 ; Vgl. dazu auch Feuerich, NJW 1991, $1144(1149)$

1270. Amtliche Elegründung zur Verordnung, BR-Drucksache $712 / 90,13 \mathrm{f}$

1271. Arntliche Begrioindung zti 4 der Verordnung, BR-Dr $712 / 90,14$

1.272. So die amtliche Begründung zu $\$ 4$ der Verordnung, BR-Drucksache 712/90, 14: vgl. dazul auch Feuerich, NJW 1991, 1144 (1149). 
Berufsausübung zwingend notwendigen Kenntnisse des deutschen Rechts nachzuweisen. Laßt sich eine solche Regelung wegen der hohen Anzahl der Examenskandidaten ${ }^{1273}$ für die Staatsprüfungen rechtfertigen, so erscheint sie im Falle der Eignungsprüfung unproportional. Jedenfalls scheint eine Notwendigkeit für diese Rücktrittsklausel zum Schutz der Prüfungsämter vor unzähligen, nicht ernsthaften Anträgen nicht gegeben.

\$ 5 des Eignungsprüfungsgesetzes bestimmt die Prüfungsfächer. Danach sind Prüfungsfächer das Pflichtfach Zivilrecht, zwei Wahlfächer und das Recht über das berufliche Verhalten der Rechtsanwälte. Der Antragsteller bestimmt je ein Wahlfach aus zwei Wahlfachgruppen. Die Wahlfachgruppe 1 besteht aus dem Öffentlichen Recht und dem Strafrecht; für die Wahlfachgruppe 2 werden die durch das Pflichtfach nicht abgedeckten Bereiche des Zivilrechts, das Handelsrecht, das Arbeitsrecht, das Öffentliche Recht und das Strafrecht genannt. Dem Antragsteller ist es dabei versagt, zweimal dasselbe Wahlfach in beiden Wahlfachgruppen zu wählen. \$ 6 der Verordmung erläutert den genauen Inhalt des Fächerkataloges.

Die Eignungsprüfung im Pflichtfach Zivilrecht erstreckt sich auf den Allgemeinen Teil des Bürgerlichen Gesetzbuchs, das Schuldrecht und das Sachenrecht "einschlieflich besonderer Ausprägungen außerhalb des Bürgerlichen Gesetzbuchs". Zu den "besonderen Ausprägungen außerhalb des Bürgerlichen Gesetzbuchs" ist etwa das Gesetz zur Regelung des Rechts der Allgemeinen Geschäftsbedingungen zu zählen ${ }^{1274}$. Auch das Verfahrensrecht unter Einschluß der Grundzüge des Gerichtsverfassungs-, Zwangsvollstreckungs- und Insolvenzrechts gehören zum Prüfungsstoff. Gemäß der amtlichen $\mathrm{Be}-$ gründung ist der Zuschnitt der Wahlfächer so gewählt, daß sie nach Umfang und Schwierigkeitsgrad vergleichbar sind ${ }^{1275}$.

Das Wahlfach Öffentliches Recht umfaßt nach \&6 Abs. 2 Nr. 1 der Verordnung die Grundrechte, das allgemeine Verwaltungsrecht und Verwaltungsverfahrensrecht. Aus dem Bereich des besonderen Verwaltungsrechts wurden das Recht der öffentlichen Sicherheit und Ordnung sowie Grundzüge des Baurechts ausgewählt. Prüfungsstoff ist ferner das. Verwaltungsprozeßrecht einschließlich der Grundlagen im Gerichtsverfassungsrecht. Nicht zum Wahlfach Öffentliches Recht gehören das Völkerrecht und das Europarecht, weil bei diesen Gebieten davon ausgegangen wird, daß sie durch die Ausbildung in jedem Mitgliedstaat abgedeckt sind ${ }^{1276}$. Solange weder das Völkerrecht noch das Europarecht in den Pflichtfachkatalog der deutschen juristischen Ausbildung aufgenommen sind, können sich jedenfalls deutsche Bewerber in anderen Mit-

1273. Dies gilt zumal für die Referendare, die im Zeitpunkt der Staatsprüfung besoldete Beamte sind:

1274. Amtliche Begründung zu $\$ 6$ der Verordnung, BR-Dr. 712/90, 15.

1275. Amtliche Begrindung zu 8 der Venordnung, BR-Dr. 712/90, 17.

1276. Amtliche Begnündung zu 6 der Verordnung, BR-Dr. $712 / 90,16$; siehe dazu kritisch Everling, BRAK-Miti 1989, 166 (171). 
gliedstaaten nicht auf eine vergleichbare Argumentation berufen ${ }^{127}$ ! Insoweit ist die amtliche Begründung zum Gesetzesentwurf, wonach das Recht der Europäischen Gemeinschaften und das Völkerrecht als durch die Ausbildung in jedem Mitgliedstaat abgedeckt anzusehen ist ${ }^{1278}$, für die Bundesrepublik Deutschland nur sehr eingeschränkt zutreffend.

Gemäß 8 Abs. 2 Nr. 2 der Verordnung umfaßt der Prüfungsstoff für das Wahlfach Strafrecht die allgemeinen Lehren des Strafrechts, den Besonderen Teil des Strafgesetzbuches und das Strafprozeßrecht einschließlich der Grundlagen des Gerichtsverfassungsrecht. Das Nebenstrafrecht gehört damit trotz seiner großen Bedeutung in der Praxis nicht zum Prüfungsstoff. Dies entspricht jedoch der Regel der juristischen Staatsprüfungen ${ }^{1279}$.

Im Wahlfach Zivilrecht werden die Grundzüge des Familien- und Erbrechts einschließlich des dazugehörenden Verfahrensrechts geprüft ( $\$ 6 \mathrm{Abs}$. $2 \mathrm{Nr}$. 3 der Verordnung). Dieser gerade für die anwaltliche Praxis sehr wichtige Bereich wird von dem Pflichtfach Zivilrecht nicht abgedeckt.

Beim Wahl fach Handelsrecht werden in $\S 6$ Abs. $2 \mathrm{Nr} .4$ der Verordnung die Grundzüge des Handels- und Gesellschaftsrechts sowie des Wertpapierrechts ohne das Wechselund Scheckrecht als Prüfungsgebiete aufgeführt. Die Ausklammerung des Wechsel- und Scheckrechts wird damit begründet; daß diese Gebiete bereits durch internationale Übereinkommen harmonisiert sind, so daß die Kenntnis davon beim Antragsteller unterstellt wird ${ }^{1280}$. Warum diese Begründung nicht auch zumindest teilweise für das Gesellschaftsrecht gelten kann, das ebenfalls in weiten Bereichen auf Harmonisierungsrichtlinien der Europäische Gemeinschaft beruht, wird nicht ausgeführt.

Das Wahlfach Arbeitsrecht schließlich umfaßt die Grundzüge des Individualarbeitsrechts und des kollektiven Arbeitsrechts sowie das dazugehörende Prozeßrecht ( $\$ 6$ Abs. 2 Nr. 5 der Verordnung).

Vergleicht man nun diesen Katalog der Wahlfachgebiete und der in der Verordnung aufgelisteten Prüfungsfächer in seiner Gesamtheit mit dem in den meisten Bundesländern von den Kandidaten der juristischen Staatsprüfung verlangten Prüfungsstoff, so handelt es sich zwar um ein abgeschlanktes Verfahren, jedoch sind wenige den Prüfungsstoff betreffende Lücken festzustellen ${ }^{1281}$

1277. Vgl. dazu \& 5 a Abs. 2 DRiGi, wonach Gegenstand des rechtswissenschaftichen Studiums vor allem die Kernfächer Bürgerliches Recht, Strafrecht, Öffentliches Recht und Verfahrensrecht eiruschlieBlich der rechtswissenschaftichen Methode mit ihren philosophischen, geschichtichen und gesell schaftichen. Grundlagen sind. Allerdings hat inzwischen Baden-Württemberg das Fach "Europarecht" gamäB \& JAO zum Prlichtfach erthoben.

1278. Amtliche Begrimdung zum Gesetzesentwurf, BT-Dr. 11/6154, 13.

1279. Aratliche Begründung zu $\$ 6$ der Verordnung, BR-Dr. 712/90, 17 .

1280. Amthiche Begründung, BR-DR 712/90.

1281. Siehe dazu die Ausbildungs- und Prüfungsordnungen der einzelnen Bundesländer» \$ DRiG. 
Der gravierende Unterschied liegt darin, daß dem Antragsteller zur Eignungsprüfung eine Wahlmöglichkeit geboten wird: Aus den genannten fünf Wahlfächern zwei zu wahlen, dabeï jedenfalls entweder das Öffentliche Recht oder das Strafrecht. Der Kandidat für die juristische Staatsprüfung hingegen wird mit dem gesamten Prüfungsstoff konfrontiert wird. Auf diese Wahlmöglichkeit wird auch entsprechend hingewiesen, um die Liberalität der Regelung zu unterstreichen. Es ist aber gerade die Wahlmöglichkeit, die Zweifel an der Korrektheit der Umsetzung aufkommen läßt.

Nach Art. 1 Buchstabe g) der Richtlinie 89/48/EWG dürfen die Prüfungsfächer nur die Sachgebiete umfassen, die auf Grund eines Vergleichs zwischen der in der Bundesrepublik verlangten und der bisherigen Ausbildung des Antragstellers, won seinem Diplom nicht gedeckt sind. Hierbei dürfen in die Liste nur die Sachgebiete aufgenommen werden, ohne deren Beherrschung es nicht möglich ist, den Beruf des Rechtsanwalts in Deutschland auszuüben ${ }^{1282}$. In der amtlichen Begründung wird die Wahl der Eignungsprüfung an Stelle des Anpassungslehrganges mit der Tatsache gerechtfertigt, die deutsche Rechtsordnung sei mit keiner anderen Rechtsordnung so nahe verwandt, daß die Kenntnis jener anderen genügen könnte, um in Deutschland rechtsberatend als Anwalt tätig zu sein ${ }^{1283}$. Der in den Wahlfächern aufgeführte Prüfungsstoff soll nun gerade die Sachgebiete umfassen, ohne deren Beherrschung die Berufsausübung unmöglich sein soll. Wie vereinbart sich nun diese Behauptung mit der gebotenen Wahl. Angenommen ein Antragsteller wählt die Wahlfachgruppen Nr. 2 (Strafrecht) und Nr. 3 (Spezialbereiche des Zivilrechts), dann scheinen die angeblich unumgänglichen Kenntnisse des Öffentlichen Rechts, des Handels- und Arbeitsrecht nicht mehr erforderlich oder zumindest nicht mehr prüfungserheblich zu sein.

Gemäß \& 6 Abs. 1 des Eignungsprüfungsgesetzes besteht die Prüfung aus einem schriftlichen und einem mündlichen Teil. Beide Prüfungsabschnitte sind auf deutsch abzulegen. Die schriftliche Prüfung umfaßt zwei Aufsichtsarbeiten. Eine der Aufsichtsarbeiten bezieht sich auf das Pflichtfach, die andere auf das von dem Antragsteller zu bestimmende Wahlfach ( $\$ 6$ Abs. 2 des Eignungsprüfungsgesetzes). Die Aufsichtsarbeiten haben nach $\$ 7$ Abs. 1 der Verordnung Aufgaben aus der beruflichen Praxis eines Rechtsanwalts zum Gegenstand. Die Bearbeitungszeit für eine Aufsichtsarbeit beträgt fünf Stunden. Der Antragsteller wird zur mündlichen Prüfung nur zugelassen, wenn mindestens eine Aufsichtsarbeit den Anforderungen genugt; andernfalls gilt die Prüfung als nicht bestanden.

1282. Protokollerklărung $\mathrm{N}_{\mathrm{r}}$ 15; amtliche Begründung zum Gesetzesentwurf, BT-Dr. 11/6154, 13; Ewerling, BRAK-Mitt 1989, 166 (171)

1283. Dagegen hat Frau Vlassopoulou in ihrem Verfahren gerade die Verwandtschaft zwischen dem griecliischen und dem deutschen Recht unterstrichen. Durch den Beitritt Österreichs muß diese Ansicht erneut relativiert werden. Siehe auch die die Unterschiedlichkeit der Rechissysteme stark relativierende Auffassung von GA Van Gerven in seinen Schlußanträgen zum Ureil vom 7, Mai 1991, Rs C-340/89 Auffassung von GA Van Gerven in für Justiz. Bundes- und Europaangelegenheiten Baden-Württemberg -, Slg. I-2357, (2365), Rdnr 13; Dazu Van den Bossche in Alvarez, 67 (71). 
Gemáß $\$ 5$ der Verordnung erläßt das Prüfungsamt dem Antragsteller auf Antrag bestimmte schriftliche Prüfungsleistungen, wenn er durch ein Prüfungszeugnis nachweist, daß er in seiner bisherigen Ausbildung in einem Pflichtfach oder einem Wahlfach die für die Ausübung des Rechtsanwaltsberufs in der Bundesrepublik Deutschland erforder lichen materiellrechtlichen und verfahrensrechtlichen Kenntnisse im deutschen Recht erworben hat. Diese Bestimmung ist, obwohl sie einen liberalen Eindruck erweckt, als äußerst rigide zu bezeichnen. In welchen Fällen kann ein Antragsteller durch Prüfurigszeugnisse materiellrechtliche und verfahrensrechtliche Kenntnisse im deutschen Recht nachweisen? Die Möglichkeiten sind sehr beschränkt:

Der Antragsteller könnte die Erste juristische Staatsprüfung bestanden haben ${ }^{1284}$. In diesem Fall muß jedoch die Frage gestellt werden, ob ein Eignungsprüfungsverfahren überhaupt noch erforderlich oder - besser gesagt - zulässïg ist. Würde man dieses auf die mündliche Prüfung beschränken, so dürfte eigentlich nur das deutsche Berufs- und Standesrecht für Rechtsanwälte geprüft werden, da die erforderlïchen materiellrechtlichen und verfahrensrechtlichen Kenntnisse unterstellt werden könnten. Dieses Ergebnis mutet jedoch sehr bizarr an, da die Kenntnisse des anwaltlichen Standesrechts weder im Ersten noch im Zweiten juristischen Staatsexamen zum Prüfungsstoff gehören. Undeutlich ist, ob ein an einer deutschen Universität erworbener Ausbildungsnachweis einschließlich eines abgeschlossenen Magisterdiploms oder eine Promotion über ein Thema hinsichtlich des deutschen Rechts ${ }^{1285}$ als Prüfungszeugnis im Sinne des $\$ 5$ der Verordnung gewertet würde.

Gemäß $\S 6$ Abs. 4 des Eigmungsprüfungsgesetzes besteht die mündliche Prüfung aus einem Kurzwortrag und einem Prüfungsgespräch. Während der mündlichen Prüfung werden die Kenntnisse des Antragstellers im Recht für das berufliche Verhalten der Rechtsanwallte, im zweiten Wahlfach und - falls eine Aufsichtsarbeit den Anforderungen nicht genügt - zusätzlich im diesbezüglichen Fach geprüft. Das Berufs- und Standesrecht der Rechtsanwälte als Prüfungsgebiet - so mützlich die Kenntnis hierin für die berufliche Praxis auch sein mag - überrascht insoweit, als dieses Gebiet nicht zum Prüfungsstoff der Staatsexamina gehört. Anscheinend kann sich ein deutscher Jurist als Rechtsanwalt unbelastet von jeglicher Kenntnis im Berufs- und Standesrecht niederlassen, wohingegegen der ausländische Rechtsanwalt den Nachweis seines Wissens erst noch zu erbringen hat.

Die Gegenstände des Kurzvortrages und des Prüfungsgespräches sind gemäß $\S 7 \mathrm{Abs}$. 2 der Verordnung der beruflichen Praxis eines Rechtsanwaltes zu entnehmen. Die Vorbereitungszeit für einen Kurzvortrag beträgt zwei Stunden, seine Dauer etwa fünfzehn Minuten. Gemäß der amtlichen Begründung ist der Kurzvortrag in freier Rede zu

1284. Gerade diese Sachlage war bei Durchfürung des ersten Eignungsprufungsverfahrens wor dem Justizprufungsamt in Stutgart gegeben. (Telephonische Information aus dem Justizprifungsamt in Stuttgart).

1285. Siehre dazu den Fall Vlassopoulou, Unteil vom 7. Mai 1991, Rs C-340/89 - Irène Vlassopoulou/Ministerium für Justiz, Bundes- und Europaangelegenheiten Baden-Württemberg, S1g. 1-2357 (2360). 
halten. Mit dem Kurzvortrag soll danach der Antragsteller zeigen, daß er in der Lage ist, einen Sachverhalt und die rechtlichen Überlegungen zu seiner Lösung auf dem maßgeblichen Prüfungsgebiet frei und verständlich darzustellen und einen praktisch brauchbaren Vorschlag zu unterbreiten. Dem Antragsteller wird zugestanden, während seines freien Vortrags in deutscher Sprache einen Stichwortzettel als Gedankenstütze zu verwenden, soweit nicht Texte abgelesen werden ${ }^{1286}$. Die Dauer des Prüfungsgespräches ist für jeden Prüfungsteilnehmer auf etwa fünfundvierzig Minuten festgelegt. Aus der Formulierung dieser Bestimmung läßt sich ableiten, daß gegebenenfalls mehrere Prüfungsteilnehmer $\mathrm{zu}$ einer mündlichen Prüfung zusammengefügt werden und die Dauer der Prüfung sich nach der Anzahl der Teilnehmer verlängert. Dies entspricht der üblichen Praxis bei den mündlichen Staatsprüfungen. In der amtlichen Begründung heißt es zu diesem Punkt, daß die Antragsteller möglichst in gleichem Maße zu Wort kommen sollen, wobei eine genaue zeitliche Gleichheit nicht erforderlich ist und auch kaum einzuhalten wäre. Im Hinblick auf die Wahlfächer werden aber bei mehreren Prüfungsteilnehmern Teile des Prüfungsgesprächs nur einzelne Teilnehmer betreffen. Lediglich das Recht für das berufliche Verhalten der Rechtsanwälte ist immer Prüfungsgegenstand für alle Prüfungsteilnehmer ${ }^{1287}$.

Die Prüfungskommission entscheidet nach $\S 7$ des Eignungsprüfungsgesetzes auf Grund des Gesamteindrucks der in der schriftlichen und mündlichen Prüfung erbrachten Leistungen mit Stimmenmehrheit, ob der Antragsteller über die erforderlichen Kenntnisse verfügt. Gemäß $\S 11$ der Verordnung berät die Prüfungskommission im Anschluß an die Prüfung. Die Entscheidung ist dem Antragsteller nach Abschluß der Beratung bekanntzugeben. Das Prüfungsamt erteilt hierüber eine schriftliche Bestätigung. Das Ergebnis der Prüfung wird nicht in einer Note festgelegt, sondern besteht in der Feststellung, daß der Antragsteller die für die Ausübung des Berufs eines Rechtsanwalts in der Bundesrepublik Deutschland hat ${ }^{1288}$.

Erscheint der Antragsteller ohne ausreichende Entschuldigung nicht zur Anfertigung einer Aufsichtsarbeit, zu der er geladen ist, oder gibt er eine Arbeit nicht oder nicht fristgerecht $a b$, ist die Prüfungsleistung als mißlungen zu bewerten ( $\$ 9$ Abs. 1 der Verordnung). Bei Nichterscheinen zum Termin der mündlichen Prüfung oder, wenn der Kandidat die Prüfung nicht bis zum Ende wahrnimmt, gilt die Prüfung gemäß \& 9 Abs. 2 der Verordnung als nicht bestanden. Im Falle eines Täuschungsversuches während der schriftlichen oder der mündlichen Prüfung wird die Arbeit als mißlungen bewertet beziehungsweise muß die mündliche Prüfung wiederholt werden. In schweren Fällen wird die gesamte Prüfung für nicht bestanden erklärt. Entscheidungsbefugt ist für diese Fälle ebenfalls das Prüfungsamt ( $\$ 10$ der Verordnung).

Gemäß $\S \&$ des Eignungsprüfungsgesetzes kann die Prüfung wiederholt werden. $\$ 12$ Abs. 1 der Verordnung beschränkt die Zahl der Wiederholungsmöglichkeiten allerdings

1286. Amtliche Begründung, BR-Dr 712/90, BT-Dr 11/6154.

1287. Amtliche Begründung, BR-Dr 712/90.

1288. Feuerich, NJW 1991, 1144 (1150). 
auf zwei. Diese Beschrãnkung wird in der amtlichen Begründung damit erklärt, daß nach drei gescheiterten Versuchen die Wahrscheinlichkeit, daß ein weiterer Versuch erfolgreich sein würde, so gering sei, daß diese Belastung dem Prüfungsamt nicht zugemutet werden könne ${ }^{1289}$. Die Prüfungskommission kann dabei gemäß $\$ 12 \mathrm{Abs}$. 2 der Verordnung bestimmen, daß der Wiederholungsversuch nicht vor Ablauf einer bestimmten Frist unternommen werden darf. Damit soll einer aussichtslosen neuen Prüfung unmittelbar nach der gescheiterten vorgebeugt werden. Die Frist darf jedoch nicht mehr als ein Jahr betragen.

Nach $\$ 13$ der Verordnung gelten für die Auswahl der Aufsichtsarbeiten und des Kurzvortrags, die Bestimmung von Zeit und Ort der Prüfung, die Verwendung von Kennziffern, die Zulassung von Hilfsmitteln, die Höchstzahl der Teilnehmer einer mündlichen Prüfung, die Prïfungsaufsicht und ihre Befugnisse, die Gewährung von Prüfungserleichterungen für Behinderte, die Geltendmachung und der Nachweis eines Rücktrittsund Entschuldigungsgrundes, die Geltendmachung und die Folgen von Beeinträchtigungen des Prüfungsverfahrens, die Niederschriften über das Prüfungsverfahren und die Einsicht in die Prüfungsakten, die Vorschriften für die zweite juristische Staatsprüfung des Landes entsprechend, in dem das Prüfungsamt oder ein gemeinsames Prüfungsamt eingerichtet ist.

\section{b. Durchführung der Eignungsprüfung für Rechtsanwälte}

Die Eignungsprüfung wurde im ersten Jahr ihres Bestehens nur in wenigen Fällen durchgeführt ${ }^{1200}$. Das erste Verfahren fand vor dern Justizprüfungsamt des Landes Baden-Württemberg in Stuttgart statt, zwei. weitere Eignungsprüfungen wurden vom bayerischen Justizprüfungsamt organisiert. Hiervon endeten zwei Prüfungsverfahren mit der Zulassung zum Rechtsanwalt in der Bundesrepublik. Ein Kandidat hat die Prüfung nicht bestanden. In Nordrhein-Westfalen wurde ebenfalls ein Verfahren mit Erfolg abgeschlossen. Die geringe Zahl der Anmeldungen zur Eignungsprüfung bestätigte in keiner Weise die Erwartungen, die mit einem Ansturm auf die Eignungsprüfung rechneten. Inzwischen wurden etwa 50 Verfahren durchgeführt. Die Mehrzahl davon konnten erfolgreich abgeschlossen werdlen. Dieses Ergebnis zeigt, daß bei der Anwendung des Anerkennungsmechanismus mehr Milde waltet, als die Regelungen vermuten lassen.

1289. Amtliche Begründung, BR-Dr 712/90

1290. Insgesamt wurden im ersten Jahr nach der Unusetzung acht Verfahren durchgefühn, wovon fünf positiv mit einer Anerkennung abgeschlossen werden konnten. Seither hat sich die Anzahl auf etwa 50 erlyöht, von denen die überwiegende Mehrheit positiv entschieden wurden. 


\section{Der Patentanwalt}

a. Gesetz über die Eignungsprüfung für die Zulassung zur Patentanwaltschaft

$\$ 1$ und $\$ 2$ des Eignungsprüfungsgesetzes für Patentanwälte sind in ihrem Wortlaut identisch mit den entsprechenden Paragraphen im Gesetz über die Eignungsprüfung für dìe Zullassung zur Rechtsanwaltschaft. $\$ 1$ Abs. 1 des Eignungsprüfungsgesetzes für Patentanwälte enthält die grundsätzliche gesetzgeberische Entscheidung für die Eignungsprüfung. In der amtlichen Begründung wird auf die Ausfuhrungen hünsichtlich der Eignungsprïfung für Rechtsanwälte verwiesen ${ }^{1291}$. Zur Eignungsprïfung sind die Angehörigen der Mitgliedstaaten zuzulassen, die die Voraussetzungen für den Zugang zu einem "reglementierten" Anwaltsberuf für den gewerblichen Rechtsschutz erfülen. Von den Berufen, die sich in den anderen Mitgliedstaaten mit der Beratung und Vertretung auf dem Gebiet des gewerblichen Rechtsschutzes befassen, setzen die in der Anlage zu $\$ 1$ des Gesetzes aufgeführten Berufe ein Diplom im Sinne der Richtlinie voraus. Es handelt sich dabei gemäß der Anlage um die folgenden Berufe:

- in Frankreich: Conseil en brevets d'invention

- in Italien: Consulente in Proprietă Industriale oder Consulente in Brevetti

- in Luxemburg: Conseil en Propriêté Industrielle

- in den Niederlanden: Octrooigemachtigde

- in Portugal: Consultore em Propriedade Industrial

- $\quad$ in Spanien: Agente de la Propriedad Industrial

Fälschlicherweise heißt es in der amtlichen Begründung, daß es in Belgien keinen reglementierten Beruf für die Beratung und Vertretung auf dem Giebiet des gewerblichen Rechtsschutzes gibt. Dieser Fehler wurde durch Artikel 3 der Dritten Verordnung zur Änderung der Ausbildungs- und Prüfungsordnung vom 14. Dezember 1990 berichtigt ${ }^{122}$. Mit dieser Änderung der Anlage zu \$ 1 des Gesetzes über die Zulassung zur Patentanwaltschaft wird der folgende Zusatz eingefügt:

\section{- in Belgien: Mandataire Agréé/Erkend Gemachtigde}

In Irland wird die entsprechende Beratung und Vertretung durch den "Registered Patent Agent" und dem "Registered Trade Mark Agent" durchgeführt. Im Vereinigten Königreich besteht seit dem Inkrafttreten des Copyright, Designs und Patents Act 1988 keine berufliche Reglementierung mehr, vorher war die Zulassung als Chartered Patent Agent notwendig. Fälschlicherweise heißt es in der amtlichen Begründung, daß der Zugang zu den genannten Berufen in Irland und in Großbritannien keinen Hochschulabschluß voraussetze und damit die Richtlinie auf sie aus diesem Grund keine Anwendung fände. Diese Information ist jedoch hinsichtlich des irischen Registered Patent Agent nicht vollkommen korrekt. Zwar wird gemäß Art. 7 der Registers of Patent Agents and 
Clerks Rules, $1966^{1293}$ ein Universitätsdiplom nicht ausdrücklich verlangt, es heiBt darin jedoch unter b) daß der Antragsteller "has a knowledge of engeneering and either chemistry or physics of the standard of the first university examination in those subjects. " Irland selbst geht eindeutig von einer Reglementierung des Patent Agent im Sinne der Richtlinie 89/48/EWG aus, da dieser Beruf ausdrücklich im irischen Umsetzungsgesetz erwähnt wird ${ }^{1294}$. Auch in Großbritannien geht die nationale Umsetzungsregelung davon aus, daß der Patent Agent die Voraussetzungen der Richtlinie 89/48/EWG erfülllt ${ }^{1295}$. Eine entsprechende Korrektur der deutschen Umsetzung ist daher erforderlich. Das Beispiel zeigt jedoch, wie schwierig es für die Behörden in den Mitgliedstaaten ist, die genaue Reglementierung bestimmter Berufe in anderen Mitgliedstaaten festzustellen und die eigene Umsetzung darauf einzurichten.

Damit gibt es ausschließlich in Dänemark und in Griechenland keinen reglementierten Beruf für die Beratung und Vertretung auf dem Gebiet des gewerblichen Rechtsschutzes. Der für Marken und Patente zuständige Berufstand in Dänemark heißt Patentagenters. Dieser Beruf ist jedoch weder hinsichtlich des Titels noch hinsichtlich der Berufsausübung geschützt, auch gibt es keinerlei rechtlich bestimmten Ausbildungsvoraussetzun$\operatorname{gen}^{12 \%}$.

GemäB $\$ 3$ des Gesetzes über die Zulassung zur Patentanwaltschaft wird die Eignungsprüfung vor der für die Patentanwaltschaft zuständigen Kommission beim Patentamt abgelegt ${ }^{1297}$. Nach $\& 4$ Abs. 1 des Gesetzes über die Zulassung zur Patentanwaltschaft entscheidet der Präsident des Patentamtes über die Zulassung zur Eignungsprüfung. Liegen clie Voraussetzungen des Artikel 1 der Richtlinie 89/48/EWG vor, besteht grundsätzlich ein Rechtsanspruch auf Zulassung. Der Antragsteller muß jedoch die notwendigen Ërklärungen abgeben und die Unterlagen vorlegen, aus denen hervorgeht, $\mathrm{da} ß$ er diese Voraussetzungen erfüllt. Gemäß $\S 44$ Abs. 2 der geänderten Ausbildungsund Prüfungsordnung für Patentanwälte ${ }^{1298}$ sind dem Antrag ein eigenhändig geschriebener Lebenslauf, die erforderlichen Diplome, der Nachweis, daß der Antragsteller mehr als die Hälfte der Mindestausbildung in Mitgliedstaaten abgeleistet hat oder über eine mindestens dreijährige Berufsausübung in einem Mitgliedstaat verfügt, der Nachweis der Staatsangehörigkeit eines Mitgliedstaates, die Angabe des Wahlfaches und des Fachs für die zweite Aufsichtsarbeit sowie eine Erklärung darüber, ob silch der Antragsteller erfolglos einer Eugnungsprüfung unterzogen hat, beizufügen. Gemäß $\$ 44$ Abs. 3 der Ausbildungs- und Prüfungsordnung sind der Antrag sowie die beigefügten Unterlagen soweit diese vom Antragsteller stammen, in deutscher Sprache einzureichen. Die sonstigen Unterlagen sind mit einer beglaubigten Übersetzung vorzulegen.

1293. Statutory Instuments, S.I No 139 of 1966.

1294. Statutory Instrument S.I. No 1 of 1991, Frist Schedule, Part I, 19.

1295. Siehe dazu die Ausführungen wul Seite 334

1296. Wassilewski (1987), 307

1297. Das Deutsche Patentamı wurde als zuständige Behörde gemäB Art. 9 Abs. 1 der Richtinie 89/48/EWG angewiesen.

1298. Dritte Verordnung zur Ändenung der Ausbildungs- und Prufungsordnung gemäß \& 12 der Patentanwaltsverordnung yom 14, Dezember 1990, BGBI. I 1990, 2824. 
In \$ 5 des Eignungsprüfungsgesetzes für Patentanwälte werden die Prüfungsfächer für die Eignungsprüfung bestimmt. Laut der amtlichen Begründung beschränkt sich der Prüfungsstoff auf eine Auswahl an Rechtsgebieten, die einerseits durch die Ausbildung des Bewerbers im Ausland nicht abgedeckt, andererseits für die Ausübung des Patentanwaltsberufes von entscheidender Bedeutung sind. Auf Rechtsgebiete, die bereits harmonisiert sind oder in den Mitgliedstaaten kaum Unterschiede aufweisen, wird dagegen verzichtet. Gegenstand der Eignungsprüfung kann zudem nur sein, was auch in der Patentanwaltsprüfung geprüft wird ${ }^{1299}$. Gemäß $\$ 5$ Abs. 1 des Eignungsprüfungsgesetzes für Patentamwälte erstreckt sich die Eignungsprüfung auf zwei Pflichtfächer, ein Fach nach Wahl des Antragstellers und das Recht für das berufliche Verhalten von Patentanwälten. Pflichtfächer sind gemäß Abs. 2 zum einen das Verfahren zur Erlangung, Aufrechterhaltung, Verteidigung und Anfechtung eines Patents oder eines Warenzeichens vor den nach deutschem Recht zuständigen Behörden und Gerichten sowie das Gebrauchsmusterrecht einschließlich des entsprechenden Verfahrensrechts $(\$$ 5 Abs. $2 \mathrm{Nr}$. 1 des Eignungsprüfungsgesetzes für Patentanwälte); zum anderen gehören zum Prüfungsstoff des zweiten Pflichtfachs - wegen ihrer besonderen Prägung im nationalen Recht - das Bürgerliche Recht, Handelsrecht und Zivilprozeßrecht, soweit diese Rechtsgebiete für die Tätigkeit des Patentanwalts von Bedeutung sind $(\$ 5 \mathrm{Abs}$. 2 Nr. 2 des Eignungsprüfungsgesetzes für Patentanwälte) ${ }^{1300}$. Wahlfächer sind das Wettbewerbsrecht einschließlich des Kartellrechts und das Recht der Arbeitnehmererfindungen. Gemäß $\$ 6$ Abs. 1 des Eigmungsprüfungsgesetzes für Patentanwälte besteht die Prüfung aus einem schriftlichen und einem mündlichen Teil. Sie wird in deutscher Sprache abgelegt. Die schriftliche Prüfung umfaßt zwei Aufsichtsarbeiten. Eine Aufsichtsarbeit hat das erste Pflichtfach gemäß $\S 5$ Abs. 2 Nr. 1 des Eignungsprüfungsgesetzes für Patentanwälte, die andere hat nach Wahl des Antragstellers das zweite Pflichtfach - Bürgerliches Recht, Handelsrecht und Zivilprozeßrecht - oder das Wahlfach zum Gegenstand.

86 Abs. 3 des Eignungsprüfungsgesetzes für Patentanwälte schließt Antragsteller, deren beide Aufsichtsarbeiten den Anforderungen nicht genügen, von der mündlichen Prüfung aus. Absatz 4 regelt den mündlichen Teil der Prüfung. Neben dem Berufs- und Standesrecht für Patentanwälte wird das durch die schriftliche Prüfung nicht abgedeckte Prüfungsfach geprüft. Ist die Aufsichtsarbeit in einem Fach mißlungen, so erhält der Antragsteller in der mündlichen Prüfung Gelegenheit, auch in diesem Fach hinreichende Kenntnisse nachzuweisen. Laut $\$ 44$ e der Ausbildungs- und Prüfungsordinung haben die Aufsichtsarbeiten die Lösung von Aufgaben aus der beruflichen Praxis eines Patentanwalts zum Gegenstand. Die mündliche Prüfung setzt sich aus einem in freier Rede zu haltenden Vortrag und einem auf Praxisfälle gerichteten Prüfungsgespräch zusammen.

Die Prüfungskommission entscheidet auf Grund des Gesamteindrucks der in der schriftlichen und mündlichen Prüfung erbrachten Leistungen mit Stimmenmehrheit, ob der Antragsteller die für den Beruf des Patentanwalts in der Bundesrepublik Deutschland

1299. BT-Drucksache 11/6154,21.

1300. Amtliche Begründung in BT-Drucksache 11/6154, 21. 
erforderlichen Kenntnisse aufweist. Gemäß $\$ 44 \mathrm{~g}$ der Ausbildungs- und Prüfungsordnung darf der Antragsteller, falls er die Eignungsprüfung nicht bestanden hat, sie zweimal wiederholen. Der Prüfungsausschuß bestimmt den frühest möglichen Zeitpunkt für eine Wiederholung der Eignungsprüfung, dabei darf die durch den Prüfungsausschuß gesetzte Frist nicht mehr als ein Jahr betragen.

Im Gegensatz zur Eignungsprüfung für Rechtsanwälte wird bei der Eignungsprüfung für Patentanwälte eine Prüfungsgebühr erhoben. Gemäß \& 9 des Eignungsprüfungsgesetzes für Patentanwälte hat der Antragsteller, der zur Eignungsprüfung zugelassen wird, an den Prásidenten des Patentamts eine Prüfungsgebühr in Höhe von 500 Deutsche Mark zu entrichten. Begründet wird diese Gebührenregelung damit, daß auch von Bewerbern, die zur Patentanwaltsprïfung zugelassen sind, eine entsprechende Prüfungsgebühr erhoben wird. Es solle damit der mit der Zahlung einer Entschädigung an die Mitglieder der Prüfungskommission verbundene Aufwand abgegolten werden ${ }^{1301}$. Warum diese Begründung nicht auch bei der Eignungsprüfung für Rechtsanwälte gilt, wird nicht erlăutert. Der Unterschied \äßt sich nur damit erklären, daß bei der Zweiten juristischen Staatsprüfung im Gegensatz zu den Patentanwaltsprüfungen keine Gebühren erhoben werden, da die geprüften Assessorkandidaten im Zeitpunkt der Prüfung noch als Referendare im Beamtenverhältnis stehen und daher eine Prüfungsgebühr unzulässig wäre. Es gibt insoweit keinen Prăzedenzfall für die Juristen, und eine Prüfungsgebühr nur von den Kandidaten der Eignungsprüfung zu verlangen hätte wohll als unzulässige Diskriminierung eingestuft werden müssen.

Art. 4 des Gesetzes zur Umsetzung der Richtlinie 89/48/EWG für die Berufe des Rechtsanwalts und des Patentanwalts enthält Änderungen der Patentanwaltsordnung. Diese werden wegen des Zugangs zur Patentanwaltschaft von Bewerbern, die die Eignungsprüfung bestanden haben, notwendig. Dementsprechend wird $\$ 5$ Abs. 1 der PatAnwO durch einen Zusatz ergänzt, wonach zur Patentanwaltschaft nicht nur zugelassen werden kann, wer die Befähigung zum Patentanwalt erworben hat, sondern auch, wer die Eignungsprüfung bestanden hat. Gemäß des neugefaßten \& $11 \mathrm{Abs}$. 1 der PatAnwO ist auch der erfolgreiche Absolvent der Eigmungsprüfung berechtigt, den Titel "Patentassessor" zu führen. Die in $\$ 13$ Abs. 3 Satz 2 PatAnwO verlangte mindestens halbjăhrige Tätigkeit bei einem Patentanwalt zur Einführung in die freiberufliche Praxis, wird von demjenigen, der seine berufliche Qualifikation für die Bundesrepublik Deutschland durch die Eignungsprüfung erworben hat, nicht verlangt ( $\$ 13$ Abs. 4 PatAnwO). Eine andere Regelung verstieße gegen Art. 4 Abs. 2 der Richtlinie 89/48/EWG. Diese untersagt, vom Antragsteller gleichzeitig den Nachweis von Berufserfahrung und das Bestehen einer Eignungsprüfung zu verlangen.

Ferner werden die bisher in $\$ 87$ Abs. 2 Satz 1 PatAnwO enthaltenen Worte "der Deutscher im Sinne des $\$ 116$ Abs. 1 des Grundgesetzes ist" gestrichen. Diese Änderung des $\$ 87$ Abs. 2 Satz 1 PatAnwo ermöglicht es, Patentanwälte, die mit einer

1301. Amtliche Begrindung in BT-Drucksache 11/6154, 22. 
fremden Staatsanghörigkeit aus anderen Mitgliedstaaten der Europäischen Gemeinschaft zuwandern, zu ehrenamtlichen Richtern für die Gerichte in Patentanwaltsachen zu berufen. Letztlich wird durch die Änderung des $\$ 184 \mathrm{Abs}$. 1 Satz 1 der PatAnwO für die Verwaltungsakte, die zur Durchführung der Eignungsprüfungsverfahren ergehen, die Zuständigkeit der Gerichte in Patentanwaltsachen begründet ${ }^{1302}$. Diese Regelung entspricht der bestehenden gerichtlichen Zuständigkeit bei der Anfechtung von Verwaltungsakten in Patentanwaltssachen. Mit dieser Bestimmung erfüllt die Umsetzung \& 8 der Richtlinie 89/48/EWG.

\section{Wirtschaftsprüfer und vereidigter Buchprïfer}

\section{a. Zweites Gesetz zur Änderung der Wirtschaftsprüferordnung}

Die Umsetzung erfolgte durch Einfügung eines neuen achten Teils in die Wirtschaftsprüferordnung (WPO), worin die Eignungsprüfung für den Wirtschaftsprüfer oder vereidigten Buchprüfer geregelt wird ${ }^{1303}$. Beide Berufe sind in der Bundesrepublik Deutschland reglementiert, wobei der Zugang zu diesen Berufen abhängig von Diplomen im Sinne des Art. 1 Buchstabe a der Richtlinie 89/48/EWG ist. Wirtschaftsprüfer haben gemäß $\$ 2$ Abs. 1 WPO die berufliche Aufgabe, die Jahresabschlüsse wirtschaftlicher Unternehmen durchzuführen, während nach $\$ 129$ Abs. 1 Satz 4 WPO die vereidigten Buchpräfer insbesondere für die Jahresabschlußprüfung mittelgroßer Gesellschaften mit beschränkter Haftung zuständig sind. In der amtlichen Begründung zu dem Gesetzesentwurf wird die Wahl der Eignungsprüfung als Kompensationsinstrument damit begründet, daß für die Ausübung beider Berufe in erheblichem Maße Kenntrisse des nationallen deutschen Rechts erforderlich seien, über die ein Migrant nicht oder jedenfalls nicht in dem erforderlichen Maße verfügt ${ }^{1304}$.

In dem achten Teil regelt $\S 131 \mathrm{~g}$ WPO die Zulassung zur Eignungsprüfung als Wirtschaftsprüfer, \$131 i WPO diejenige als vereidigter Buchprüfer. Gemäß $\$ 131 \mathrm{~g}$ Abs. 1 WPO kann ein Staatsangeböriger eines Mitgliedstaats, der in einem anderen Mitgliedstaat als der Bundesrepublik ein Diplom erlangt hat, das ihn zur Pflichtprüfung von Jahresabschüssen und anderen Rechnungsunterlagen im Sinne des Art. 1 Abs. 1 der Achten Gesellschaftsrecht-Richtlinie ${ }^{1305}$ in diesem Mitgliedstaat berechtigt, als Wirts-

1302. Dies sind die Oberlandesgerichte und der Senat für Patentanwaltsachen beim Bundesgerichtshof.

1303. Zweites Gesesetz zur Ändenung der Wirtschaftsprufferordnung vom 20. Julli 1990, BCBI. If wom 27 Juli $1990,1462(1463)$

1304. Amtliche Begründung zu dem Entwarf eines Zweiten Gesetzes zur Änderung der Wirtschaftspriferordnum BR-Drucksache $10 / 90$ wom 5. Januar $1990,13 \mathrm{ff}$.

1305. Achte Riclatlinie des Rates wom 10. April 1984 auf Grund von Art. 54 Abs. 3 Buchstabe g EWGV uber die Zulassung der mit der Pflichtpräfung der mit der Rechunungslegung beauftragten Personen. (84/253/EWG), ABl. 1984 Nr. L 126, 20. Diese Richtlinie hätte bis zum 1. Jamuar 1990 umgesetzt $(84 / 253 / \mathrm{EWG})$, ABI. $1984 \mathrm{Nr} . \mathrm{L} 126,20$. Dicse sein müssen. Dieser Verpflichtung sind noch nicht alle Mitgliedstaten nachgekommen. So feht es büsher an der Umsetzung durch Dänemark, Irland, Italien und die Niederlande. Deufstand, den vereidigten Buchprüfer, geschaffen. 
chaftsprüfer bestellt werden, wenn er eine Eignungsprüfung als Wirtschaftsprüfer abgelegt hat. Das Umsetzungsgesetz enthält keine Auflistung der Berufe, die dem Wirtschaftsprifer und dem vereidigten Buchprüfer in anderen Mitgliedstaaten entsprechen. In der amtlichen Begrundung zu dem Gesetzesentwurf wird der Verzicht auf eine derartige Auflistung damit begrïndet, daß der Beruf des gesetzlichen AbschluBprüfers gegenwärtig auf Grund der Achten Gesellschaftsrecht-Richtlinie in verschiedenen Mitgliedstaaten neu gestaltet wird ${ }^{1306}$. Damit stellt sich aber die Frage nach dem von der Unsetzung erfaßten Personenkreis.

Die Achte Gesellschaftsrecht-Richtlinie regelt die Qualifikation der Personen, die in den Mitgliedstaaten zur Pflichtprüfung von Jahresabschlüssen und Rechnungsunterlagen von Gesellschaften und Konzernen befugt sind. Wegen der historisch bedingten Unterschiedlichkeit der Ausbildungssysteme und der in den Mitgliedstaaten geforderten Qualifikation für Abschlußprüfer, konnte im Rahmen der Achten Gesellschaftsrecht-Richtlinie keine volle Rechtsangleichung der Berufsausbildung, sondern lediglich die Garantie einer Mindestqualifikation erreicht werden ${ }^{1307}$. Die Achte Gesellschaftsrecht-Richtlinie betriff - wie in den Erwägungsgründen ausdrücklich festgestellt wird - nicht die Nederlassungsfreiheit und den Dienstleistungsverkehr von Abschlußprüfern ${ }^{130 \%}$. Dementsprechend dirfen laut Art. 11 der Achten Gesellschaftsrecht-Richtlinie Personen, die thre Befahigung ganz oder teilweise in einem anderen Staat erworben haben, nur dant zugelassen werden , wenn sie den Nachweis der Rechtskenntnisse erbracht haben, die 3 meweiligen Mitghiedstaat für die Pflichtprüfung von Jahresabschlüssen verlangt werten. In Art. 1 der Achten Gesellschafts-Richtlinie werden aber die berufstypischen Aufgaben definiert. Auf den zu diesen Aufgaben in den Mitgliedstaaten zugelassenen Personenkrews wird in $\$ 131 \mathrm{~g}$ Abs. 1 WPO Bezug genommen. Dabei kann es sich um Personen wandeln, deren Aufgabenfeld im Herkunftsstaat nicht alle beruflichen Tätigkeiten whtaht, die won Wirtschaftsprüfer oder vom vereidigten Buchprüfer wahrgenommen werden:

In $\$ 131 \mathrm{~g} \mathrm{Abs.} 2$ WPO wird auf die Diplomdefinition des Art. 1 Buchstabe a) der Richtlinie 89/48/EWG verwiesen. Ein Diplom auf Grund einer Ausbildung, die nicht ubberwiegend in den Europäischen Gemeinschaften stattgefundlen hat, berechtigt zur Ablegung der Eignungsprüfung, wenn der Inhaber tatsächlich und rechtmäß3ig mindestens drei Jahre Berufserfahrung als gesetzlicher Abschlußprüfer hat und dies von dem Mitgliedstaat bestätigt wird, der das Diplom ausgestellt oder anerkannt hat $(\$ 131 \mathrm{~g}$

1306. Amtliche Begründung zum Entwurf eines Zweiten Gesetzes zur Ändenung der Wirtschaftsprüferordviung, BR-Drucksache $10 / 90$ vom 5. Januar 1990,10 .

1307. Nach Art. 6 der Achten Gesellschaftsirecht-Richtlinie mu B das Examen als gesetzlicher AbschluBprüfer - neben Prufungsgebieten, die nicht das Recht zum Gegenstand haben - mindestens die folgenden Sachgebiete umfassen: Vorschriften über die: Aufstellung des Jahresabschlusses und des konsolidierten Abschlusses sowie Bewertung und Erfolgswermittlung. Rechtsvorschriften und Standesregeln bezüglich der Abnahme des Abschlusses und, zumindest soweit die Rechnungspnüung dawon berührt wird, das Gesellschaftsrecht, Konkursrecht, Steuerrecht, das Bürgerliche Recht und Handelsrecht sowie das Arbeits- vind Sozialversichenungsrecht.

1308. 11. Erwầgung. 
Abs. 2 Satz 2 WPO). Gemäß Abs. 3 der Bestimmung entscheidet uber die Zulassung zur Eignungsprüfung die für die Wirtschaft zuständige oberste Landesbehörde ${ }^{130 \%}$. Der Bewerber hat seinen Antrag auf Zulassung an die oberste Landesbehörde zu richten, in deren Bereich der Bewerber seine berufliche Niederlassung begründen möchte ${ }^{1310}$. Falls dies noch nicht feststeht, kann der Bewerber den Antrag an eine oberste Landesbehörde seiner Wahl richten. Mehrere Bundesländer können die Zuständigkeit auch insoweit durch Vereinbarung verteilen, daß Bewerber aus einzelnen Herkunftsländern jeweils an eine bestimmte oberste Landesbehörde verwiesen werden ${ }^{131 !}$. Für das Prüfungsverfahren wird eine Gebühr in Höhe von 500,- DM erhoben. Die Gebührenregelung entspricht der Bestimmung für Patentanwälte

Gemäß $\$ 1$ Abs. 2 der Prüfungsordnung für die Eignungsprüfung als Wirtschaftsprüfer oder als vereidigter Buchprüfer vom 13. März $1991^{1312}$ sind dem Antrag ein Lebenslauf mit genauen Angaben über den beruflichen Werdegang und ein Staatsangehörigkeitsnachweis beizufügen. Daneben ist eine Bescheinigung der zuständigen Behörde des Herkunftsstaates erforderlich, aus der hervorgeht, daß der Bewerber über die notwendigen beruflichen Qualifikationen verfügt, die ihn zur unmittelbaren Zulassung zur Pflichtprüfung von Jahresabschlüssen und anderer Rechnungsunterlagen berechtigen ${ }^{1313}$. Falls der Bewerber in Besitz eines Drittstaatdiplomes ist, muß er eine Bescheinigung des Mitgliedstaates vorlegen, der das Diplom anerkannt hat, worin bestätigt wird, daß er über eine mindestens dreijährige Berufserfahrung als gesetzlicher Abschlußprüfer verfügt. Daneben muß der Antragsteller eine Erklärung hinsichtlich des gewünschten Wahlfachs der mủndlichen Prüfung abgeben. Der Bewerber muß des weiteren erklären, ob und bei welcher Stelle er bereits früher einen Antrag auf Zulassung zur Prüfung eingereicht hat.

Gemäß $\$ 1$ Abs. 3 der Prüfungsordnung sind der Antrag und die beigefügten Unterlagen, soweit sie vom Bewerber stammen, in deutscher Sprache einzureichen; sonstige Unterllagen sind mit einer beglaubigten Übersetzung vorzulegen. Befremdlich ist, daß laut dieser Bestimmang die beglaubigte Übersetzung lediglich durch einen in der Bundesrepublik Deutschland ermächtigten Übersetzer erstellt werden darf. Diese Regelung

1309. Dies ist in der Regel das Wirtschaftsministerium des jeweiligen Bundeslandes.

1310. GiemäB is Wirtschaftsprufferordnung sind auch bei Bewerbern mit deutschen Diptonen für die Bestellung als Wirtschaftsprüfer oder vereidigter Buchprifer die obersten Landesbehlö rden zustïndig, in dem der Bewerber seine berufliche Niederlassung begründen oder seine benfliche Taltigkeit aufnehmen will. Bei den obersten Landesbehörden handelt es sich um die Wïtschaftsministerien der Lander.

1311. Für den Bereich der Läfnder Bremen, Hamburg, Niedersachsen, Mecklenburg-Vorpommern und Schleswig-Holstein haben diese Länder die Zuständigkeit für die Zulassung zur Eignungsprifung auf das Land Hamburg übertrage. Für den Bereich der Länder Hessen, Rheinland-Pfallz, Saarland und Thüringen besteht ein gemeinsamer PrüfungsausschuB bei der bbersten Landesbehörde des Landes Hesisen.

1312. Prüfungsordnung für die Eignungsprüfung als Wirtschaftsprüfer oder als vereidigter Buchprufer nach dem Achten Teil der Wirtschaftsprüferordnung vom 8. März 1991, BGBI. I vom 20, März 1991, 675.

1313. Vgl, dazu Art. 1 Abs. I der Richtinie des Rates vom 10. April 1984 (84/253/EWG), AB1. Nr. L 126. 20. 
weicht won der entsprechenden Bestimmung in der Verordnung über die Eignungsprüfung für die Zulassung zur Rechtsanwaltschaft $a b$. Dort wird nämlich lediglich eine beglaubigte Übersetzung verlangt ohne jede weitere Qualifikation (\$3 Abs. 3 der Verordnung für die Zulassung zur Rechtsanwaltschaft). Die amtliche Begründung zu der Prüfungsordnung gibt bedlauerlicherweise keine Aufschluß darüber, warum in diesem Punkt von der Regelung für Rechtsanwälte und Patentanwälte abgewichen wird.

Gemäß $\$ 131$ h Abs. 1 WPO legen die zugelassenen Bewerber die Eignungsprüfung vor einem Prüfungsausschuß ab, der bei der obersten Landesbehörde eingerichtet wird. Der Prüfungsauschuß setzt sich aus einem Vertreter der obersten Landesbehörde, einem Vertreter der Finanzverwaltung und zwei Wirtschaftsprüfern zusammen ( $\$ 2$ Abs. 2 der Prüfungsordnung). Den Vorsitz führt der Vertreter der obersten Landesbehörde. Die Prüfung bestelıt aus einem schriftlichen und aus einem mündlichen Teil. Die schriftliche Prüfung besteht aus zwei Aufsichtsarbeiten. Für jede Aufsichtsarbeit stehen dem Bewerber vier bis sechs Stunden zur Verfügung. Körperbehinderte Kandidaten können eine Fristverlängerung von einer Stunde bewilligt bekommen. Die Prüfung wird in deutscher Sprache abgelegt. Sie bezieht sich auf die Rechtskenntnisse des Bewerbers. Die volksund betriebswirtschaftlichen Ausbildungsteile werden als bekannt unterstellt und dementsprechend anerkannt.

Weist ein Bewerber durch ein Prüfungszeugnis nach, daß er in seiner bisherigen Ausbildung die für die Ausübung des Berufes in der Bundesrepublik erforderlichen Kenntnisse in einem Prüfungsgebiet bereits erworben hat, so wird ihm gemäß $\$ 7$ der Prüfungsordnung auf Antrag die Prüfungsleistung durch die oberste Landesbehörde erlassen. Diese Regelung entspricht weitgehend $\$ 5$ der Verordnung über die Eignungsprüfung für Rechtsanwälte. Unterschiedlich ist allerdings, daß bei der Eignungsprüfung für Rechtsanwälte ledliglich schriftliche Prüfungsleistungen erlassen werden, während diese Beschränkung in $\$ 7$ der Prüfungsordnung nicht besteht.

\section{b. Prüfungsgebiete der Ë̈gnungsprüfung für Wirtschaftsprüfer}

Die Prüfungsgebiete der Eignungsprüfung für Wirtschaftsprüfer sind in $\$ 131 \mathrm{~h} \mathrm{Abs.}$ 3 WPO genannt. Laut der amtlichen Begründung zur Prüfungsordnung konzentriert sich die Eignungsprüfung auf Prüfungsgebiete, die für die praktische Berufsarbeit von besonderer Bedeutung sind ${ }^{1314}$. In $\$ 4$ Prüfungsordnung werden sie im einzelnen aufgeführt. Danach handelt es sich bei der schriftlichen Prüfung um je eine Aufgabe aus dem Gebiet des Wirtschaftsrechts ${ }^{1315}$ und des Steuerrechts ${ }^{1316}$. Als Prüfungsgebiete der mündlichen Prüfung werden in $\& 4$ Abs. 2 Prüfungsordung das wirtschaftliche Prüfungs-

1314. Amtliche Begritudung zur Prüfungsondnung für die Eignungsprüfung als Wirtschaftsprüfer oder als vereidigter Buchprüfer, BR-Dnucksache 24/91 vom 17. Januar 1991, 15.

1315. Hierzu gerecllmet werden die Grundzäge des Bürgerlichen Rechts und des Handellsrechts sowie das Recht der Kapitalgesellschaften und der Unternehmensverbindungen.

1316. Gepriff werden die Abgabenordnung mit Nebengesetzen, die Finanzgerichtsordnung, Einkommen-und Korperschaftssteuer, Bewernungsgesetz und Grundzüge des AuBensteuerrechts. 
wesen ${ }^{1317}$, das Berufsrecht der Wirtschaftsprüfer und ein vom Bewerber zu bestimmendes Wahlfach aufgelistet. Das Wahlfach kann sich auf besondere Teile des Stewerrechts ${ }^{1318}$, auf das Insolvenzrecht, das Arbeits- und Sozialversicherungsrecht oder auf Besonderheiten beziehen, die sich bei der Prüfung von Genossenschaften, Kreditinstituten und Versicherungsunternehmen ergeben. Hinsichtlich der zuletzt genannten Besonderheiten bei der Prüfung von Kreditinstituten und Versicherungsunternehmen sowie für das wirtschaftliche Prüfungswesen und hinsichtlich des Rechts der Kapitalgesellschaften wird darauf hingewiesen, daß diese Gebiete nur insoweit Prüfungsgegenstand sind, als sie nicht durch europäische Richtlinen angeglichen sind oder das Recht der Bundesrepublik Deutschland, auf Grund von in den Richtlinien eingeräumten Wahlmöglichkeiten, spezielle Regelungen enthält ( $\$ 4$ Abs. 3 der Prüfungsordnung).

\section{c. Prüfungsgebiete der Eignungsprüfung als vereidigter Buchprüfer}

Die Eignungsprüfung zum vereidigten Buchprüfer ist im wesentlichen identisch geregelt. Auch hier wird für den schriftlichen Teil gemäß $\$ 5$ Abs. 1 der Prüfungsordnung je eine Aufgabe aus dem Wirtschaftsrecht und dem Steuerrecht ausgegeben. In der mündlichen Prüfung werden Fragen zum wirtschaftlichen Prüfungswesen, zum Berufsrecht der vereidigten Buchprüfer sowie zum Wahlfach gestel"tt, soweit diese Fächer mit der praktischen Berufsarbeit eines vereidigten Buchprüfers zusammenhängen. Als Wahlfächer werden ebenfalls besondere Teile des Steuerrechts ${ }^{1319}$, des Insolvenzrechts und des Arbeits- und Sozialversicherungsrechts genannt. Der größte Unterschied zur Eignungsprüfung der Wirtschaftsprüfer besteht darin, daß der gesellschaftsrechtliche Prüfungsteil sich auf das Recht der Gesellschaft mit beschränkter Haftung (GmbH) bezieht, während der Wirtschaftsprüfer seine Kenntnisse hinsichtlich der Kapitalgesellschaften und Unternehmensverbindungen nachweisen muß. Dies gilt sowohl für die Kenntnisse des Gesellschaftsrechts als auch des wirtschaftlichen Prüfungswesens.

\section{d. Prüfungsverlauf}

Der Prüfungsverlauf entspricht weitgehend der Eïgnungsprüfung für die Zulassung zur Rechtsanwaltschaft. Zunächst wird die schriftliche Prüfüng abgenommen. Jede Auf sichtsarbeit ist von zwei Mitgliedern des Prüfungsausschusses selbständig daraufhin zu bewerten, ob sie den Anforderungen genügt. Falls eine der schriftlichen Arbeiten den Anforderungen nicht genügt, ist das betroffene Prüfungsgebiet Gegenstand der mündlichen Prüfung. Der Bewerber ist aber von der mündlichen Prüfung ausgeschllossen, wenn beide Aufsichtsarbeiten als nicht genügend bewertet worden sind.

1317. Hieru werden die rechtlichen Vorschriften ther Rechnungslegung sowie die Pflichtprüfung des Jahresabschlusses und des Lageberichts won Kapicalgesell schaftem einschlielich des Konzernabschlusses genannt.

1318. Vermōgenssteuer, Erbschaftssteuer, Gewerbesteuer und Gundsteuer.

1319. Vermögensteuer, Erbschaftssteuer, Gewerbestever, Grundsteuer. 
In der mündlichen Prüfung werden aus den in $\$ 4$ Abs. 2 (Wirtschaftsprüfer) und $\$ 5$ Abs. 2 (vereidigte Buchprüfer) genannten Prüfungsgebieten Fragen gestellt, soweit diese mit der praktischen Berufsarbeit eines Wirtschaftsprüfers oder eines vereidigten Buchpruffers zusammenhängen ( $\$ 9$ Abs. 3 der Prüfungsordnung). Die Dauer der Prüfung soll laut 89 Abs. 4 der Prüfungsordnung für den einzelnen Bewerber eine Stunde nicht überschreiten. Aus der Formulierung dieser Bestimmung kann abgeleitet werden, daf ein Zusammenlegen mehrerer Kandidaten auf einen mündlichen Prüfungstermin für möglitch erachtet wird. In diesem Falle würde sich die Prüfungszeil entsprechend der Teilnehmerzahl jeweils um eine Stunde werlăngern, so daß etwa bei fünf Bewerbern eine mindestens fünfstündige mündliche Prüfung abgenommen würde. Die Dauer könnte sich jedoch noch verlängern, falls ein oder mehrere Kandidaten in einem schriftlichen Teil versagt haben. Für die Prüfung des betroffenen Faches kann nämlich eine weitere halbe Stunde einberaumt werden ( $\$ 9$ Abs. 4 Satz 2 der Prüfungsordnung). Die mündliche Prüfung ist nicht öffentlich. Anderen bereits zur Eignungsprüfung zugelassenen Berwerbern, kann gestattet werden, einmal bei einer mündlichen Prüfung zuzuhören ( $\$ 9 \mathrm{Abs}$. 5 und 6 der Prüfungsordnung). Diese Regelung entspricht $\$ 1.4$ Abs. 3 und 4 der Prüfungsordnung für Wirtschaftsprüfer.

Gemäß $\$ 10$ der Prüfungsordnung entscheidet der Prüfungsausschuß im Anschluß an die mündliche Prüfung auf Grund des Gesamteindrucks der in der schriftlichen und in der mündlichen Prüfung erbrachten Leistungen. Die Entscheidung wird mit Stimmenmehrheit getroffen. Der Bewerber kann während der Prüfung zurücktreten. Als Rücktritt gilt gemäß \& 11 Abs. 1 der Prüfungsordnung das Fernbleiben eines Kandidaten ohne triftigen Grund bei einem Prüfungsteil. In diesem Falle muß die gesamte Prüfung wiederholt werden. Eine Wiederholung der Eignungsprüfung ist nur zweimal zulässig ( $\$ 12 \mathrm{Abs}$. 1 der Prüfungsordnung). Abweichend von den Bestimmungen für Rechtsanwälte $(\$ 12$ der Verordnung) und Patentanwälte ( $\$ 44 \mathrm{~g}$ Ausbildungs- und Prüfungsverordnung) kann durch den Prüfungsausschuf kein frühest möglicher Wiederholungstermin bestimmt werden. Vielmehr ist gemäß $\$ 12$ Abs. 2 der Prüfungsordnung für đie Wiederholung der Prüfung eine neue Zulassung erforderlich. Diese Regelung entspricht \& 21 der Prüfungsordnung für Wirtschaftsprüfer. Auch die Vorschrift hinsichtlich der Ahndung eines Täuschungsversuches ( $\$ 13$ Prüfungsordnung) ist eine Kopie der entsprechenden Bestimmung in der Prüfungsordnung für Wirtschaftsprüfer (\$23).

Die Umsetzung der Richtlinie 89/48/EWG für Wirtschaftsprüfer wurde in der Bundesrepublik Deutschland zugleich zum Anlaß genommen, andere die Niederlassungsfreiheit behindernden Bestimmungen für deutsche und ausländische Berufsangehörige entsprechend anzupassen. Dies führte zur zusätzlichen Änderung einiger Bestimmungen der Wirtschaftsprüferordnung.

Die Änderungen von 3 WPO betreffen die Möglichkeit der Niederlassung im Ausland unter Beibehaltung der Niederlassung in der Bundesrepublik. Nach bisher geltendem Recht durfte gemäß \& 3 Abs. 2 Satz 2 WPO nur eine Zweigniederlassung errichtet werden, unabhängig davon, ob diese im Inland oder in einem anderen Staat gelegen war. Durch eine Ergänzung von $\$ 3$ Abs. 2 Satz 2 WPO wird nun erreicht, daß diese 
Begrenzung der Zahl der Zweigniederlassungen nicht für Zweigniederiassungen in anderen Staaten gill. Interessanterweise ist die Formulierung so gewählt, daß diese Erweiterung der Niederlassungsfreiheit nicht auf Zweigniederlassungen in anderen Mitgliedstaaten der Europäischen Gemeinschaften beschränkt ist, sondern für alle Zweigniederlassungen in anderen Staaten gilt. Zugleich wird mit dieser Regellung der Fall erfaßt, daß ein ausländischer Berufsangehöriger unter Beibehaltung der Niederlassung in einem anderen Staat sich zum Wirtschaftsprüfer oder vereidigtem Buchprüfer in der Bundesrepublik bestellen läßt. In Ergänzung zu dieser Bestimmung war auch eine Änderung der Wohnsitzwerpflichtung notwendig. Gemäß $\$ 16$ Abs. 2 Nr. 2 WPO darf nunmehr die Bestellung zum Wirtschaftsprüfer nicht versagt werden, wenn der Berufsangehörige seinen Wohnsitz in einem anderen Mitgliedstaat hat.

Gemäß einer Ergänzung in $\$ 18$ Abs. 2 Satz 3 WPO wird neben der Führung der deutschen Berufsbezeichnung auch die in anderen Staaten zu Recht geführte Berufsbezeichnung für die Tätigkeit des gesetzlichen Abschlußprüfers zugestanden. Mit dieser Bestimmung wird Art. 7 Abs. 2 der Richtlinie 89/48/EWG Rechnung getragen. Letztlich ermöglicht eine Änderung von Art. 76 Abs. 1 Satz 1 WPO, die das Erfordernis der đeutschen Staatsangehörigkeit entfallen ließ, daß auch Angehörige anderer Mitgliedstaaten zu ehrenamtlichen Richtern für die Gerichte in Wirtschaftsprüfersachen berufen werden können. Diese Änderung entspricht der des $\$ 87$ Abs. 2 Satz 1 PatAnwO.

\section{Stenerberater}

a. Fiinfites Gesetz zur Änderung des Steuerberatungsgesetzes

In der Bundesrepublik Deutschland ist der Steuerberater ein reglementierter Beruf im Sinne der Richtlinie 89/48/EWG. Die Umsetzung erfolgte durch gesetzliche Änderung des Steuerberatungsgesetzes vom 13. Dezember $1990^{1320}$. Für den Beruf des Steuerberaters wurde eine systematisch vergleichbare Umsetzungsregelung wie für den Wirtschaftsprüfer gewählt. Gemäß der amtlichen Begründung zum Gesetzesentwurf: zur Anderung des Steuerberatergesetzes besteht in keinem anderen Mitgliedstaat ein mit dem deutschen Steuerberater vergleichbarer freier Beruf ${ }^{1321}$. Diese Auskunft ist zumindest in Bezug auf Frankreich nicht ganz korrekt, da dort zumindest die Berufsbezeichnung "Conseil Fiscal" gesetzlich geschützt ist und das Führen des Titels von bestimmten fachlichen und persönlichen Qualifikationsmerkmalen abhängig gemacht wird ${ }^{1322}$. In anderen Mitgliedstaaten wird die Steverberatung won den Wirtschaftsprüfern wahrgenommen ${ }^{1323}$. Mit der Begründung, daß es in den anderen Mitgliedstaaten keinen dem

1320. Fünftes Gesetz zur Ändenung des Steuerberatungsgesetzes wom 13. Dezember 1990, BGBI. I vom 19 Dezember $1990,2756$.

1321. Amtliche Begrïndung zum Entwurf eines Fünften Gesetzes zur Änderung des Steverberatergesetzes BT-Drucksache 11/7665, 9; siehe aber auch BT-Drucksache 11/8343.

1322. Wasulewski 1987, 293 mit Hirweis auf das Gesetz vom 31 . Dezember 1971 und das decret vom 13. Juli 1972.

1323. Belgien, Dänemark, Luxemburg. 
deutschen Steuerberater vergleichbaren Berufsstand gibt, wird auch die Eignungsprüfung als notwendiges Kompensationsinstrument gerechtfertigt, ohne allerdings im Gesetzesentwurf näher darauf einzugehen, warum die Wahl zwischen Eignungsprüfung und Anpassungslehrgang in diesem Falle dem Mitgliedstaat überlassen sein sollte. Die Entscheidung für die Eignungsprüfung als einziges Kompensationsmittel läßt sich aber wohl wie bei den anderen rechtsberatenden Berufen mit den zur Berufsausübung erforderlichen Kenntnissen deutschen Rechts rechtfertigen.

Durch die Gesetzesänderung wurden in $\S 36$ Steuerberatungsgesetz die Absätze 3 und 4 eingefügt. Danach ist ein Bewerber, der in Besitz eines Diploms ist, das ihn in einem anderen Mitgliedstaat zur selbständigen Hilfe in Steuersachen berechtigt, zur Eignungsprüfung zuzulassen. Verwiesen wird dabei auf die Diplomdefinition des Art. 1 Buchstabe a der Richtlinie 89/48/EWG. Falls der Bewerber aus einem Mitgliedstaat kommt, der den Beruf des Steuerberaters nicht reglementiert, so muß er ein mindestens dreijähriges Studium, das auf die Ausübung dieses Berufs vorbereitet, und eine zweijähige vollzeitige Berufstätigkeit nachweisen, um zur Eignungsprüfung zugelassen werden. In der amtlichen Begründung wird die Eignungsprüfung als Steuerberaterprüfung bezeichnet, für die jedoch bestimmte Erleichterungen gelten ${ }^{1324}$. Eine derartig verkürzte Form der Steuerberaterprüfung war bisher nur für Wirtschaftsprüfer und vereidigte Buchprüfer in \$ 13 der Durchführungsverordnung zum Steuerberatergesetz (DVStB) vorgesehen. Mit der erfolgreich abgelegten Eignungsprüfung erwirbt der Kandidat die selben Rechte wie durch die bestandene Steuerberaterprüfung.

Gemäß $\$ 37$ a Abs. 2 Steuerberatungsgesetz gliedert sich die allgemeine Steuerberaterprüfung in einen schriftlichen Teil aus drei Aufsichtsarbeiten und eine mündliche Prüfung. Sie ist vor einem Prüfungsausschuß abzulegen, der bei der für die Finanzverwaltung zuständigen obersten Landesbehörde zal bilden ist ${ }^{1325}$. Gemäß $\& 37$ a Abs. 3 Steverberatungsgesetz bezieht sich die Prüfung auf verschiedene Prüfungsgebiete. Dazu gehören Steuerliches Verfahrensrecht, Ertragssteuer, Besitzsteuer, Verbraucherund Verkehrsteuer, Betriebswirtschaft und Rechnungswesen, Volkswirtschaft, aber auch Grundzüge des Bürgerlichen Rechts und des Wirtschaftsrechts sowie das Berufsrecht.

Die Eignungsprüfung soll sich nun gemäß $\$ 37$ b Abs. 2 Steuerberatungsgesetz auf die zur Berufsausübung notwendigen Rechtskenntnisse auf den oben genannten Gebieten beziehen, d h. die volks- und betriebwirtschaftlichen Ausbildungsteile werden anerkannt. Die Eignungsprifung gliedert sich in einen schriftlichen Teil aus zwei Aufsichtsarbeiten und eine mündliche Prüfung. Die örtliche Zuständigkeit für die Prüfung richtet sich nach dem Ort, an dem der Bewerber im Zeitpunkt der Antragstellung hauptberuflich tätig ist. Befindet sich der Ort der hauptberuflichen Tätigkeit oder der stattdessen maßBgebliche Wohnsitz nicht in Deutschland, so richtet sich die Zuständigkeit nach der

1324. Bundestatsdrucksache $324 / 90$ vom 11 . Mai $1990,17$.

1325. Darnit wurden die für die Finanzverwaltung zuständigen obersten Landesbehörden, d.h. die Finanzministerien der Länder als zuständige Behörde gemäß Art. 9 Abs. 1 der Richtlinie 89/48/EWG angew jesern. 
Herkunft des Antragstellers. Die Bundesländer haben insoweit eine in $\$ 37$ c Abs. 2 Steuerberatungsgesetz niedergelegte Verteilung nach Herkunftsland vorgenommen. Danach ist für Bewerber aus Italien der Prüfungsausschuß in Bayern, für Bewerber aus Griechenland das Land Baden-Württemberg, für Bewerber aus Spanien und Portugal das Land Hessen zuständig. Briten und Iren werden von einem Prüfungsausschuß in Niedersachsen examiniert. Bewerber aus Belgien und den Niederlanden legen die Prüfung vor dem Prüfungsausschuß des Landes Nordrhein-Westfalen ab. Rheinland-Pfalz behandelt die Bewerbungen aus Frankreich, das Saarland die luxemburgischen Anträge. Schließlich ist für Kandidaten aus Dänemark der Prüfungsausschuß im Land Schleswig-Holstein zuständig.

Der Antrag muß auf einem bundeseinheitlichen Vordruck gestellt werden. Er und die beigefügten Unterlagen sind, soweit sie vom Antragsteller stammen, in deutscher Sprache einzureichen.

\section{Beurteilung der Umsetzung für die rechtsberatenden Berufe}

a. Beurteilung der Umsetzung für Rechtsanwälte

Die Bundesrepublik Deutschland hatte bei der Umsetzung der Richtlinie 89/48/EWG hinsichtlich dem Rechtsanwalt eine Vorreiterposition eingenommen. Schon sehr frühzeitig veröffentlichte sie ihren Entwurf ${ }^{1326}$. Dies ist auch nicht weiter verwunderlich, weil der Bundesrat bei seinem Beharren auf der Eignungsprüfung für die rechtsberatenden Berufe quasi einen Entwurf der Eignungsprüfung ausgearbeitet hatte ${ }^{1327}$. Der Einfluß dieser Vorarbeiten auf die spätere Umsetzungsgesetzgebung ist deutlich zu spüren. Die Vorreiterposition der Bundesrepublik hat dazu geführt, daß die Umsetzungsmaßnahme auch Vorbildcharakter erhielt. Dies ist sehr bedauerlich, da die konkrete Ausgestaltung der Eignungsprüfung in der Durchführungsverordnung an die Grenzen der Richtlinienkonformität stößt, wenn sie diese selbst nicht überschreitet. Kritik an der deutschen Gesetzgebung bedeutet damit auch Kritik an den meisten anderen bisher veröffentlïchten Ausführungsmaßnahmen. Einige Mitgliedstaaten haben ihre Ausführungen selbst noch mit erschwerenden Ergänzungen versehen.

Bedenklich ist zunächst die Länge der Prüfung. Die schriftliche Prüfung bezieht sich auf zwei Aufsichtsarbeiten mit einer Bearbeitungszeit von je fünf Stunden. Die mündliche Prüfung setzt sich aus einem Kurzvortrag von etwa 15 Minuten und einem anschließenden Prüfungsgespräch von etwa einer Dreiviertelstunde zusammen. Für die Vorbereitung des Kurzvortrages werden zwei Stunden gewährt. Als Gesamtprüfungszeit einschließlich der Vorbereitungszeit für den Kurzvortrag erwarten den Kandidaten somit nicht weniger als 13 Stunden. Diese Prüfungszeit verlängert sich im allgemeinen daw durch, daß entsprechend der Tradition bei den mündlichen Prüfungen der beiden Staatsexamina, mehrere Kandidaten in einem Prüfungstermin gemeinsam geprüft werden 
Fallstudie I: Die rechtsberatenden Benufe

kỏnnen. Eine mündliche Prüfung, die sich insgesamt über vier Stunden erstreckt ist darrit nicht auszuschließen ${ }^{1328}$ !

Der Aufbau und die Gestaltung der Eignungsprïfung lassen somit weitaus eher auf ein nur um geringe Teile gemindertes $Z$ weites Staatsexamen schließen als auf eine Eignungsprüfung. Im Sinne der Richtlinie 89/48/EWG hätte man viel umfassender der Tatsache Rechnung tragen müssen, daß es sich bei den Bewerbern um bereits qualifizierte Berufsangehörige handelt. Von einem gegenseitigen Vertrauen in die Qualität der Ausbildung anderer Mitgliedstaaten ist wenig zu spüren. Die weitgehende Übereinstimmung zwischen Staatsexamen und Eignungsprüfung in beinahe allen Punkten mit Ausnahme der gebotenen Wahlmöglichkeit ${ }^{1329}$ zwischen einzelnen Fächern ist so offensichtlich, daß bereits hierin ein Verstoß gegen die Umsetzungsverpflichtung der Richtlinie 89/48/EWG gesehen werden kann. Des weiteren trägt die Umsetzung der Rechtsprechung des EuGH in den Rechtssachen Heylens ${ }^{1330}$ "Vlassopoulou ${ }^{1331}$ und Newman ${ }^{1332}$ wenig Rechnung ${ }^{1333}$. Zwar wird in $\$ 5$ der Verordnung eine Freistellung von Prüfungsteilen grundsätzlich ermöglicht, die Formulierung der Bestimmung ist jedoch so gewăhlt, daß eine tatsächliche Überprïfung des Einzelfalls - es sei denn, der Kandidat kann seine Kenntnisse durch Prüfungszeugnisse beweisen - nicht gewährleistet ist.

Problematisch ist auch die Tatsache, daß hinsichtlich der vergleichbaren Berufe in den anderen Mitgliedstaaten auf die Dienstleistungsrichtlinie 77/249/EWG und auf die darin aufgeführten Anwaltsberufe verwiesen wird. Das deutsche Vorbild wurde von anderen Mitgliedstaaten in diesem Punkt kopiert ${ }^{1334}$. Dies ändert jedoch nichts daran, daß hiermit eine unzulässige Einschränkung des Anwendungsbereiches der Richtlinie 89/48/EWG getroffen worden ist. Ironischerweise werden vor allem die deutschen Einheitsjuristen, die nicht als Rechtsanwälte in Deutschland niedergelassen sind, unter einer solchen Einschränkung zu leiden haben, wenn sie selbst in einem anderen Mitgliedstaat mit einer vergleichbaren Regelung konfrontiert werden.

Die deutsche Umsetzung ist jedloch noch aus anderen Gründen fragwürdig. Diese stehen aber nicht in direktem Zusammenhang mit der Freizügigkeit innerhalb der Europäischen Gemeinschaft. Der Umfang des geforderten Prüfungsstoffes und die Art der Prüfung erscheinen vielmehr auch im krassen Gegensatz mit der in Deutschland selbst im Rahmen der Reform der deutschen juristischen Ausbildung geführten Diskussion zu ste-

1328. Allein die unerwartet geringe Zahl der Kand idaten werhindert eine solche Marathonprüfung bisher, Sehr kritisch zur Länge der Eignungspriffung Lang. BRAK-Mitt. 1990, $13 \mathrm{ff}$

1329. Zur Fragwürdigkeüt der Wahlmöglichkeút sei auf die Erörterungen Seite 291 verwiesen.

1330. Urteil vom 15. Oktober 1987 Rs 222/86 - UNECTEF/Heylens -, Slg. 1987, 4097.

1331. Urtejl vom 7. Mai 1991, Rs C-340/89 - Irène Vlassopoulou/Ministerium für Justiz, Bundes- und Europaangelegenheiten Baden-Würtremberg, Slg. $\mathbb{1 - 2 3 5 7}$

1332. Urteil vom 7. Mai 1992, Rs 104/91 - Collegio Oficial de Agentes de la Propiedad Inmobilaria, Ministerio fiscal/I.L Aguirre Borrell, S. K. Newman u. a. - Slg. 1992, J-3003.

1333. Siehe dazu die Austührngen Seite $270 \mathrm{ff}$.

1334. So $z$, Ban Luxemburg und Griechenland. 
hen ${ }^{1335}$. In dieser Debatte wird gerade der Umfang des Prüfungsstoffes für die Länge des Studiums und die schlechten Ergebnisse bei den Staatsprüfungem verantwortlich gemacht ${ }^{1336}$. Erhebliche Zweifel werden geäußert, ob eine derartige Prüfungsform den heutigen Berufsanforderungen überhaupt noch gerecht wird ${ }^{1337}$. Gerade die Veränderlichkeit der Gesetzgebung, teilweise verursacht durch europäische oder internationale Harmonisierung, jedoch mindestens ebenso notwendig durch immer raschere Veränderungen in den verschiedensten technischen Bereichen sowie im sozialen und wirtschaftlichen Gefüge der heutigen Gesellschaft, führt dazu, daß der Jurist immer seltener auf die im Studium erworbenen Kenntnisse vertrauen darf. Immer häufiger gilt der Satz vom Strich des Gesetzgebers, der ganze Bibliotheken zu Makulatur verwandelt ${ }^{1338 .}$ Vom Juristen wird daher zu Recht eine rasche Ampassungsfähigkeit an die sich verändernde Gesetzgebung erwartet.

b. Beurteilung der Umsetzung für die Patentanwälte, für Wirtschaftsprüfer und für die Steuerberater

Auch bei diesen Umsetzungsmaßnahmen ist grundsätzlich zu beanstanden, daß die Umsetzung durch eine äußerst schematische Anwendung der Eignungsprüfung geprägt ist, wobei die inhaltliche Ausgestaltung im wesentlichen durch die bereits bekannten nationalen Berufsprüfungen bestimmt wird. Dabei wird einer der Grundgedanken der Richtlinie 89/48/EWG, nämlich die Beurteilung des Einzelfalles, kaum berücksichtigt. Schematisch wird unterstellt, daß die Bewerber nicht über die für die Berufsausübung notwendigen Kenntnisse des deutschen Rechts verfügen. Der Einsatz der Eignungsprüfung als Kompensationsinstrument wird dadurch zur Regel und bildet nicht - wie von der Richtlinie 89/48/EWG unterstellt - die Ausnahme.

\section{B. DÄNEMARK}

\section{Einführung}

Dänemark hat im Vergleich zu anderen Mitgliedstaaten sehr frühzeitig die Umsetzung der Richtlinie durch Erlaß eines allgemeinen Umsetzungsgesetzes und der zugehörigen Verordnung vorgenommen ${ }^{1339}$. Grundsätzlich wird die dänische Umsetzung dabei bestimmt durch die pragmatische Fall zu Fall Methode. Jede Entscheidung wird individuell getroffen. Ursprünglich tendierte Dänemark als einziger Mitgliedstaat zum Anpassungslehrgang als geeignetes Anpassungsinstrument im Sinne des Art. 4 Abs. 1

1335. Siehe aben Seite $2 \mathrm{ff}$.

1336. GroBfeld, JZ 1986, 357.

1337. So hat z.B. die 62. Konferenz der Justizminister und -senatoren am 4. bis 6. Juli 1991 mit großer Mehrheit gefordert, daß u.a. die Ausbildungsdauer reduziert werden muB, wobei der Prüfungsstoff erbeblich beschränkt werden soll. Siehe dazu auch den Gesetzesentwurf des. Bundesrates vom 30. Apríl 1992 "BT-Drucksache 12/2507. Auch die Freischug" Regellung wurde zur Verkürzung der Ausbilldungsdauer eingefuhrt.

1338. J. von Kirchmann, Über die Wertlosigkeit der Jurisprudenz als Wissenschaft, 1848

1339. Siehe dazu die Ausfithnungen auf Seite 220. 
Buchstabe b) der Richtlinie 89/48/EWG für die rechtsberatenden Berufe. Unter dem Eindruck der Umsetzungsgesetzgebung in den anderen Mitgliedstaaten entschied sich Dänemark jedoch ebenfalls für die Eignungsprüfung. Bisher hat das Justizministerium als zuständige Behörde jedoch noch keine Regelung für eine Eignungsprüfung veröffentlicht, obwohl entsprechende Anträge auf Zulassung zur Anwaltschaft bereits gestellt worden sind. Damit liegt ein Versto $\beta$ gegen das Umsetzungsgebot vor, da von einer abgeschlossenen Umsetzung erst dann gesprochen werden kann, wenn auch alle notwendigen Ausführungsbestimmungen ergangen sind. Falls die Anträge nicht innerhalb der in Art. 8 Abs. 2 der Richtlinie 89/48/EWG gestellten Frist von vier Monaten beschieden werden, steht den Betroffenen der Rechtsweg offen. Dabei wird auch entschieden werden müssen, ob die Richtlinie 89/48/EWG direkt anwendbar ist ${ }^{1340}$.

\section{Die rechtsberatenden Berufe in Dänemark}

In der dänischen Liste, die der Umsetzungsgesetzgebung als Anhang beigefügt ist, werden zwei eindeutig juristische Berufe erwähnt: Der Anwalt (Advokat) und der Stagiaire (advokatfuldgmagtig). Für beide Berufe wurde das Justizministerium als zuständige Behörde angewiesen. Nach Auffassung des dänischen Justizministerüums handelt es sich bei beiden Berufen um reglementierte Berufe im Sinne der Richtlinie 89/48/EWG. Hinsichtlich der Reglementierung wird auf die retsplejeloven (Administration of Justice Act) verwiesen ${ }^{134 !}$. Problematisch ist, ob der advokatfuldmægtig als Endprodukt qualifiziert werden kann. Nach der Definition des Art. 1 Buchstabe a) der Richtlinie 89/48/EWG setzt ein Diplom im Sinne der Richtlinie voraus, daß der Diplominhaber ein mindestens dreijähriges Studium absolviert und gegebenenfalls die über das Studium hinaus erforderliche berufliche Ausbildung abgeschlossen hat. Die dänische Auffassung unterstellt zwei getrennte Berufe, die weitgehend unabhängig voneinander ausgeübt werden. Diese Trennung der Berufe zwischen advokatfuldmagtig und advokat ist zunächst nicht einleuchtend. Vielmehr scheint es sich bei dem advokatfuldmagtig eindeutig um eine Vorstufe zum advokat zu handeln. Der "Beruf" advokatfuldmægtig ist zunächst auf die dreijährige Ausbildung zum advokat beschränkt und scheint daher nicht auf unbestimmte Zeit ausgeübt zu werden. Damit ähnelt der advokatfuldmagtig weit mehr dem deutschen Rechtsreferendar oder dem niederländischen Advocaatstagiair als etwa dem italienischen procuratore. Bei dem letzten handelt es sich zwar in gewisser Weise auch um eine Vorstufe zum avvocati, jedoch wird der Beruf des procuratore bis zum Zeitpunkt đes Übergangs zum avvocati unabhängig ausgeübt. Es gibt selbst eine eigene Liste der procuratori. Diese unabhängige Berufsausübung kann bei dem advokatfuldmagtig gerade nicht angenommen werden. Vielmehr erhält der advokatfuldmægtig erst nach dreijährigem Praktikum ein Zertifikat des Justizministeriums, das ihn zur

1340. Siehe Seire 424

1341. The consolidated Administration of Justice Act, Volume 1, Chapter 6, as published by the Order of the Ministry of Justice No 748 of 1. Dezember 1989, as amended by Act No 403 of 13. Jumi 1990 . Für die Zulassung zum Advokat ist gemäB Art. 119 (2), Unterabs. 1 - 4 und Art. 121 des Administratïon of Justice Act ein juristisches Diplom sowie eine dreijăhrige praktische Ausbildung erforderlich. die in der Regel als advokatfuldmegtig abgeleistet wird. 
Ausübung des Anwaltsberufes berechtigt. Unter diesen Gesichtpunkten müßte dem advokatfuldmagtig die Qualität eines Endproduktes abgesprochen werden.

Andererseits kann einem qualifizierten Anwalt in Dänemark die selbständige Berufsausübung etwa im Falle des Konkurses verboten werden. In einer solchen Situation besteht für diesen Anwalt die Möglichkeit bei einem anderen selbständig niedergelassenen Anwalt als advocatfuldmægtig im Lohndienstverhältnis tätig zu sein. Aus dieser Perspektive läßt sich die Auffassung des dänischen Justizministeriums, von zwei selbständigen Berufen auszugehen, vertreten, da in diesem Falle der advocatfulmægtig weit eher mit einem niederländischen $K$ andidaatnotaris verglichen werden kann. In dieser Berufsgruppe vereinigen sich ebenfalls beide Elemente, das Ausbildungselement und die nicht selbständige Tätigkeit.

Mit dieser Beurteilung stellt sich jedoch ein schwieriges Problem. Wellcher Staat ist berechtigt zu beurteilen, ob der advokatfuldmægtig ein Endprodukt im Sinne der Richtlinie ist oder nicht? Obliegt diese Beurteilung Dänemark oder dem jeweiligen Aufnahmestaat? Hierbei müssen nach der oben vorgenommenen Berufsanalyse zwei Fallgruppen unterschieden werden: Zum einen der Fall des advocatfulmægtig, der sich noch in der Ausbildung befindet und in seinem bisherigen beruflichen Werdegang noch zu keinem Zeitpunkt als advocat zugelassen war, zum anderen der Berufsangehörige, der nach abgeschlossener Ausbildung aus den verschiedensten Gründen der beruflichen Stellung als advocatfulmægtig den Vorzug vor einer selbständigen Niederlassung als advocat gegeben hat. Im letzten Fall erscheint die Endproduktproblematik geklärt zu sein. Ein derartiger Kandidat muß meines Erachtens zu einem Anerkennungsverfahren zugelassen werden. Eine Ausnahme besteht dann, wenn die Gründe, die eine selbständige Niederlassung in Dänemark verhindern, einen Ausschluß aus berufsrechtlichen Erwägungen rechtfertigen ${ }^{1342}$.

Der Fall des adwocatfulmagit in der Ausbildung ist schwieriger zu entscheiden. Grundsätzlich erkennt der Aufnahmestaat gemäß Art. 8 Abs. 1 der Richtlinie 89/48/EWG als Nachweis dafür, daß die in den Art. 3 und 4 genannten Voraussetzungen erfüllt sind, die von den zuständigen Behörden der Mitgliedstaaten ausgestellten Bescheinigungen an. Bedeutet dies nun, daß der Aufnahmestaat keinen Einfluß darauf hat, ob eine Ausbildung als Endprodukt qualifiziert werden kann oder nicht? Eine einfache Lösung zu diesem Problem gibt es nicht. Die Antwort muß meines Erachtens jedoch in Art. 3 Buchstabe a) i.V. mit Art. 5 der Richtlinie 89/48/EWG gesucht werden. Gemäß Art. 3 Buchstabe a) kann der Zugang zu einem reglementierten Beruf im Aufnahmestat grundsätzlich nicht verweigert werden, wenn der Antragsteller das Diplom besitzt, das in einem anderen Mitgliedstat erforderlich ist, um Zugang zu diesem Beruf zu erhalten. Angenommen der advokatfuldmægtig möchte nach Deutschland. Die Zulassung zur

1342 Einen ähnlichen Fall hat auch die englische Law Soctety in diesem Sinne entschieden. Es handelte sich dabei allerdings nicht um einen advocatfulmegtig, sondern um einen französischen Notariatskandidaten, der nach abgeschlossener Notarausbilidung in Frankreich die Zulassung als Solicitor in England amstrebte. 
Rechtsanwaltschaft kann ihm gemäß Art. 3 verweigert werden, weil er noch nicht das zur Zulassung in Dänemark erfoderliche Anwaltszertifikat besitzt. MuB er dann als Rechtsreferendar angenommen werden? Auch diese Frage kann verneint werden. Art: 5 der Richtlinie 89/48/EWG ist lediglich als "Kann-Vorschift" formuliert. Eine Verpflichtung der Mitgliedstaaten, die Möglichkeit zur Ableistung des praktischen Teils der Berufsausbildung im Aufnahmestaat zu eröffenen, kann hieraus nicht abgeleitet werden. Wie ist jedoch der umgekehrte Fall zu beurteilen? Der Rechtsreferendar begibt sich nach Dänemark und verlangt die Zulassung als advokatfuldmægtig. Dieser Fall ist in der dänischen Umsetzung ausdrüicklich vorgesehen. Gemäß Art. 4 der Verordnung kann die zuständige Behörde eine positive Entscheidung treffen, falls ein Antragsteller unter Anleitung eines qualifizierten Berufsangehörigen den aus einer Berufspraxis bestehenden Teil der Berufsausbildung ableisten möchte, den er im Herkunftsstaat bisher nicht abgeleistet hat. $\mathrm{Ob}$ der Rechtsreferendar einen Anspruch auf Zulassung gemäß Art. 3 der Richtlinie 89/48/EWG geltend machen könnte, ist dagegen zweifelhaft, da er wiederum von seinem Herkunftsstaat nicht als Endprodukt qualifiziert werden würde.

\section{Beurteilung der Umsetzung für die rechtsberatenden Berufe}

Eine endgültige Beurteilung der Umsetzung hïnsichtlich der rechtsberatenden Berufe in Dänemark kann noch nicht vorgenommen werden, weil die Umsetzung bis zur Bekanntgabe und Organisation der Eignungsprüfungen oder der Anpassungslehrgänge noch nicht abgeschlossen ist. Bis dahin liegt ein Verstoß Dänemarks gegen die Umsetzungsverpflichtung vor. Undeutlich ist auch, ob Dänemark andere Berufe als nur die beiden genannten als rechtsberatende Berufe qualifizieren möchte. Dadurch würde eine Einschränkung der Wahlfreiheit im Hinblick auf die Anpassungsinstrumente vorgenommen. Hinsichtlich der rechtsberatenden Berufe muß allerdings festgestellt werden, daß die dänische Reglementierung der anwaltlichen Tätigkeit und des anwaltlichen Monopols als eine verhältnismäßig schwache Reglementierung eingestuft werden $k a n n$, so daß in der praktischen Ausübung des Berufes ausländische Anwälte nur mit geringen Schwierigkeiten rechnen müssen ${ }^{1343}$. Auch hat Dänemark zusammen mit der britischen und der niederländischen Regierung sich im Falle Klopp deutlich hinter den Düssseldorfer Anwalt gestelltt hat ${ }^{1344}$. In Dänemark war es vor Umsetzung der Richtlinie $89 / 48 / E W G$ bereits möglich, sich als Rechtsanwalt unter "home title" niederzulassen ${ }^{1345}$. Da die dänische Haltung hinsichtlich der Anerkennung von der Fall zu Fall Methode geprägt ist, kann man damit rechnen, daß einige Anerkennungen ohne Eignungsprüfung ausgesprochen werden. Dies wird sicher dann der Fall sein, wenn ausländische Anwälte bereits länger in Dänemark tätig sünd.

Bisher hat man in der praktischen Anwendung der Richtlinie den Kandidaten die Möglichkeit eröffnet, bis zum Abschluß des. Verfahrens und der endgültigen Verabschiedung

1343. Lonbay 1991

1344. Urteil vom 12. Juni 1984, Rs $107 / 83$ - Ordre des avocats au barreau de Paris/Onno Klopp -, Slg. 1984,2971 (2979).

1345. Johanson in Dolzer/Hahndorf/Johanson u.a.., 17 
einer Kompensationsregelung, die rechtsberatende "Tätigkeit als advocatfuldmgtig auszuszuszuüben. Dies setzt jedoch eine eindeutige Zusammenarbeit mit einem niedergelassenen dänischen Anwalt voraus. Eine selbständige Niederlassung ist insoweit bisher ausgeschlossen. Man muß3 jedoch davon ausgehen, daß ein derartig als advocatfuldmgtig tätiger Kandidat nicht mehr zusätzlich einer Eignungsprüfung unterworfen werden darf. Vielmehr muß eine derartige Berufsausübung als eine Form der Anpassung i.S. eines Ampassungslehrganges gewertet werden, so daß Dänemark zumindest für eine Übergangszeit als Anpassungsinstrument für die rechtsberatenden Berufe den Anpassungslehrgang in gewissem Sinne eingeführt hat. Dies entspricht wiederum dem ursprïnglichen dänischen Umsetzungsvorhaben.

\section{FRANKREICH}

\section{Einleitung}

Frankreich qualifizierte als rechtsberatende Berufe im Sinne der Richtlinie 89/48/EWG den Avocats au Conseil d'Etat et à la Cour de Cassation, den Avocat, den Avoué, den Administrateur et mandatair judiciair à la liquidation des entreprises, den Commissairespriseur, den Huissier de Justice, den Greffier de Tribunaux de Commerce, den Agent en brevet und den Notair. Für diese Berufe wurden auch Umsetzungsmaßnahmen vorgenommen ${ }^{1346}$. Grundsätzlich entschied sich auch Frankreich für die Eignungsprüfung.

Da die Umsetzung der Richtlinie 89/48/EWG nahezu zeitgleich mit der Umgestaltung des Rechtsanwaltsberufs in Frankreich erfolgte, muß die Umsetzung für die rechtsberatenden Berufe auch in diesem Gesamtzusammenhang beurteilt werden. Durch das Gesetz No 90-1259 vom 31. Dezember $1990^{1347}$ wurde das ursprüngliche Gesetz No 71-1130 vom 31. Dezember 1971 in sehr einschneidender Weise geändert. Es wurde

1346. Für den Avocats au Conseil d'Etat at a la Cour de Cassation durch Décret no 91-1125 vom 28. Oktober 1991, Jo vom 30. Oktober 1991 und durch Arrêté vom 22. November 1991, JO vom 14 Dezember 1991 .

Für den Avocat durch Loi No 90-1259 worn 31. Dezember 1990 , JO vom 5.1.1991, Décrett mo 91-1197 vom 27. November 1991, JO 28. November 1991 und Arrêté vom 7. Januar 1993, JO vom 29. Januar 1993

Für den Administrateur et mandatair judiciair à la liquidation des entreprises (gerichulich bestellter Sequester) Loi No $90-1259$ vom 31. Dezember 1990, JO vom 5. Januar 1991 und durch Décret No 91-1030 vom 8. Oktober 1991 Jo vom 9. Oktober 1991,

Für den Awoué durch Décret No 90-1210 vom 21. Dezember 1990, J0 vom 31. Dezember 1990 worin die Zugang sbedingungen für bestimmte öfentliche Ämter festgelegt wurden. Das entsprechende Décret: No $90-1210$ vom 21. Dezember 1990 gilt auch tür den Commissaines-prisenr, firr den Huissieur de Justice (Gerichtsvollzieher), für den Greffier de Tribunaux de Commerce 9Urkundsbeamter beim Handelsregister) und fur den Notair (Notar); für diese Benfe gilt auch der arrette vom 31 . Dezember 1990. JO vom 9. Januar 1991 ,

Für den Agent en brevet (Patentanwalt) durch Decret No 92-360 vom 1. April 4992, JO vom 3. April 1992.

1347. JO vom 5 . Januar 1991. 
damit ein neuer Anwaltsberuf geschaffen, der die alten Rechtsanwälte (avocats und avoués) und die Conseils juridiques ${ }^{1348}$ unter einer Berufsbezeichnung vereinigt ${ }^{1349}$. Diese Änderung trat am 1. Januar 1992 in Kraft.

\section{Avocat}

Bereits 1985 hatte die Rechtsanwaltskammer von Paris eine Regelung eingeführt, die die Zulassung ausländischer Rechtsanwälte als französische avocats gewährleistete. Nach dieser Regelung war es für ausländische Rechtsanwälte mit einer achtjährigen Berufserfahrung möglich eine Zulassungsprüfung abzulegen.

Die Umsetzung der Richtlinie 89/48/EWG für den avocat wird bestimmt durch das Gesetz No 90-1259 vorn 31. Dezember $1990^{1350}$, dem Décret no 91-1197 vom 27. November $1991^{1351}$, sowie dem arrêté vom 7. Januar $1993^{1332}$, worin die inhaltlichen Modalitäten der Eignungsprüfung für Rechtsanwälte festgelegt wurden. Verantwortlich für den Erlaß der Ausführungsmaßnahme ist das Justizministerium, das die Ausgestaltung der Eignungsprüfung nach Beratung mit dem Conseil national de barreaux vornehmen sollte. Dieser Conseil national de barreaux ist als zuständige Behörde für die Durchführung der Anerkennungsverfahren sowie die Organisation der Eignungsprüfungen angewiesen worden.

Der Antragsteller muß gemäß Art. 69 des décret die Eignungsprüfung vor der selben Prüfungskommission ablegen, die auch für die Berufsprüfung ${ }^{1353}$ für französische Anwälte (C.A.P.A.) verantwortlich ist. Der Fächerkatalog der Eignungsprüfung ist ebenfalls dem Zulassungsexamen für französische Rechtsanwälte entnommen. Dieser besteht insgesamt aus sieben Fächern:

- Zivilrecht

- Strafrecht

- Verwaltungsrecht

- Handelsrecht

- Sozial recht

- Europarecht

- Standesrecht

1348. Der Conseil juridique war bis 1971 überhaupt nicht reglementiert. Nach 1971 gab es den juristischen Beruf des Consell juridique, dieser stand jedoch auch für ausländische Juristen offen. Erst durch die Verschmelzung mit dem Beruf des Rechtsanwalts wird anch die Rechtsberatung in Frank reich reglementiert und monopolisiert. Siehe dazu Goebel, Fordham Int. L.J. 1991-92, 556 (563).

1349. Siehe dazu Benabent, JCP 1991, I, 3490.

1350. JO vom 5. Januar 1991; Einschiägig für die Umsetzung der Richtlinie ist dabei Art. 11.

1351. 10 28. November 1991. In Art. 99 des Décrets ist die Zulassung zur Anwaltschaft tuir Diplominhaber im Sinne der Richtlinie $89 / 48 /$ EWG geregelt sowie die grundsätzliche Entscheidung für die Eignungsprifung als Konpensationsinstrument getroffen.

1352. Jo vom 29. Januar 1993

1353. Certificat d'aptitude à la profession d'avocat. 
Die Fächer der Eignungsprüfung werden danach bestimmt, welche Rechtsgebiete in der Ausbildung des Kandidaten fehlen. Dabei darf die Prüfung sich maximal auf vier Fächer beziehen. Falls die Ausbildungen im wesentlichen übereinstimmen, wird der Antragsteller von der Prüfung freigestellt. Ansonsten bestimmt sich die Anzahl der Fächer individuell nach der Ausbildung des Betroffenen. Grundsätzlich wird die Eignungsprüung mündlich abgenommen. Hat die Prüfungskommission eine Prüfung in vier Fächern bestimmt, so wird die Eignungsprüfung schriftlich abgenommen. Bemerkenswert ist, dals eine Prüfung im Europarecht, falls der Kandidat in seiner Ausbildung keine Kenntnisse in diesem Rechtsgebiet erworben hat, obligatorisch sein kann.

\section{Beurteilung der Umsetzung für den Rechtsanwalt}

Insgesamt muß die französische Umsetzung positiv beurteilt werden. Der Inhalt und der Umfang der Eignungsprüfung richtet sich individuell nach der Ausbildung und Erfahrung des Kandidaten. Damit entspricht die Organisiation der Prüfung den in der Richtlinie 89/48/EWG niedergelegten Prinzipien. Positiv bewertet werden muß ebenfalls, daß die Eignungsprüfung lediglich mündlich abgenommen wird. Vergleicht man diese Regelung mit den entsprechenden Bestimmungen in Deutschland, Luxemburg, den Niederlanden und Großbritannien, die teilweise sehr umfangreiche schriftliche Prüfungen in mehreren Fächer vorschreiben, so ist die Liberalitäl der französischen Umsetzungsmaßnahme zu unterstreichen.

Trotz dieser grundsätzlich positiven Beurteilung, muß jedoch bemerkt werden, daß die Neuordnung der französischen Berufsordnung sich auf die Niederlassungsfreiheit insgesamt sehr negativ ausgewirkt hat. Frankreich hat dadurch eine dem Strom der Zeit entgegengesetzte Entwicklung eingeleitet. Ob darin bereits ein Verstoß gegen Art. 52 EGV in Verbindung mit Art. $5 \mathrm{EGV}$ zu sehen ist, mag man bezweifeln. Es wäre jedoch interessant, dies in einem Testfall $z u$ untersuchen ${ }^{1354}$. Die französische Haltung hinsichtlich dem Niederlassungsentwurf, die eine Vollintegration nach einer Fünfjahres frist verlangt, ist meines Erachtens auch nur in diesem Zusammenhang zu verstehen ${ }^{135 s}$. In diesem Sinne kann die Gesamtregelung der französischen Berufsordnung nicht als gemeinschaftsfreundlich bezeichnet werden.

1354. Geprüft werden mühte dabei auch, ob die Neuregelung gegen Art. 52 EGV in Verbindung mit Art $53 \mathrm{EGV}$ verstöbt. Siehe dazu die Ausführungen Seite 412.

1355. Süehe dazu Seite $376 \mathrm{ff}$. 
Follstudie 1: Die rechtsberatenden Berufe

\section{GRIECHENLAND}

\section{Einleitung}

In Griechenland wurde für die Umsetzung der Richtlinie 89/48/EWG die sektorielle Methode gewählt. Dies gilt auch für den Beruf des Rechtsanwalts. Die Umsetzung erfolgte durch ein décret presidentiel vom 28. Januar $1993^{1356}$. Das décret folgt in seinem Aufbau weitgehend der Richtlinie 89/48/EWG, wobei in Art. 2 des décrets ein Definitionskatalog aufgestellt ist. Die hierin gegebenen Definitionen stimmen zum Teil wörtlich mit den Definitionen aus Art. 1 der Richtlinie 89/48/EWG überein. Problematisch ist dabei allerdings, daß sowohl in Art 2 als auch in Art. 3 des décrets auf die Berufsbezeichnung Rechtsanwalt werwiesen wird, wie sie in dem décret presidentiel $\mathbf{n}$. 258/1987 verwendet wird. Dabei handelt es sich jedoch um die Umsetzungsmaßnahme hinsichtlich der Dienstleistungsrichtlinie für Rechtsanwälte. Mit diesem Hinweis wird der Anwendungsbereich der Richtlinie $89 / 48 / \mathrm{EWG}$ in unzulässiger Weise beschränkt, da nicht jeder, der die Kriterien eines Endprodukts für den Beruf des Rechtsanwalts im Herkunftsstaat erfïllt, tatsächlich auch im Zeitpunkt der Antragstellung auf Anerkennung als Rechtsanwalt niedergelassen sein muß. Eine ähnliche Problematik ergab sich auch bei den Umsetzungsmaßnahmen für Rechtsanwälte in anderen Mitgliedstaa$\operatorname{ten}^{1357}$.

Problematisch ist auch Art. 4 des décrets, worin unter Hinweis auf Art. 3 der Richtlinie 89/48/EWG die Zulassung zur Berufsausübung in Griechenland geregelt ist. Hierin scheint unterstellt zu werden, daß jeder Antragsteller an einer Eignungsprüfung teilnehmen muß. Diese automatische Unterstellung, daß bei allen Kandidaten eine Eignungsprüfung erforderlich ist, widerspricht der Zielsetzung der Richtlinie 89/48/EWG. Danach sollte die Anerkennung gemäß Art. 3 der Richtlinie der Normalfall darstellen, die Kompensationsinstrumente des Art. 4 der Richtlinie dagegen lediglich die Ausnahme. Etwas anderes gilt auch nicht für die rechtsberatenden Berufe. Die Richtlinie 89/48/EWG gewăhrt in Art. 4 Abs. 1 Buchstabe b) Satz 3 den Mitgliedstaaten für die rechtsberatenden Berufe eine Einschränkung der Wahlmöglichkeit. Die Anwendung von Art. 4 Abs. 1 Buchstabe b) Satz 3 setzt jedoch grundsätzlich voraus, daß die Bedingungen von Art. 4 Abs. 1 Buchstabe b) Satz 1 der Richtlinie 89/48/EWG erfült sind. Dies gilt für die rechtsberatenden Berufe ebenso wie für alle anderen Berufe. Irène Vlassopoulou hat gerade unter Berufung auf die Verwandtschaft zwischen dem griechischen und dem deutschen Rechtssystem ihre Anerkennung in Deutschlland argumentiert ${ }^{1358}$. Ein umgekehrter Fall wäre somit ebenso denkbar.

1356. Decret presidentiel Nr. $52 / 93$ vom 28 . Jaruar 1993, JO Nr. 20 vom 28 . Februar 1993.

1357. So z.B. im Falle der Bundesrepublik.

1358. Urteil vom 7. Mai 1991, Rs C-340/89 - Irène Vlassopoulou/Ministerum für Justiz, Bundes- und Europangelegenheiten Baden-Württemberg - Slg. [-1991, 2357. 


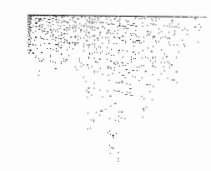

Art. 6 des décrets beinhaltet eine korrekte Umsetzung von Art. 7 der Richtlinie 89/48/EWG. Art. 7 des décrets bestimmit die Zusammenstellung der Prüfungskommission. Es handelt sich dabei um eine besondere Einrichtung, die speziell mit der Abnahme der Eignungsprüfung betraut wird. In Art. 7 Abs. 2 des décrets wird bestimmt, daß die Eignungsprüfung zweimal jährlich abgehalten werden soll, wobei ein Termin im März und ein Termin im September vorgesehen ist. Zu beanstanden ist dabei lediglich, daß das genaue Datum der Eignungsprüfung lediglich 15 Tage vorher an die Anwaltskammern mitgeteilt wird. Diese Terminbestimmung erscheint etwas kurzfristig.

Art. 8 betrifft die Antragstellung. Danach muß der Antrag bis zum Ende des Monats Februar bzw. August vor dem Eignungsprüfungstermin gestellt werden. Diese Fristsetzung erscheint grundsätzlich gerechtfertigt. Die Regelung erweckt den Eindruck, daß ein Antragsteller an der folgenden Eignungsprüfung teilnehmen kann. Wann dem Kandidaten diese Entscheidung mitgeteilt wird und, ob er hiergegen eine gerichtliche Überprüfung bewirken kann, ist in dem décret nicht geregelt. Undeutlich ist auch, zumindest in der französischen Übersetzung, welche Dokumente der Kandidat vorzulegen hat. Jedenfalls muß der Kandidat einen Staatsangehörigkeitsnachweis erbringen (Art. 8 a). Undeutlich sind jedoch die Unterschiede zwischen Art. 8 b) "copie du titre d'étude ou un certificat correspondant" und c) "certificat d'êtude". Der Hinweis in Art. $8 \mathrm{~d}$ ) auf ein certificat gemäß art. 6 des dëcrets soll sich vermutlich nicht auf Art. 6 sondern auf Art. 5 des dècrets beziehen! Bedenklich ist wiederum Art. 8 e), worin eine Bestätigung der beruflichen Ehrenhaftigkeit des Antragstellers durch die Anwaltskammer des Herkunftsstaates veriangt wird. Hiermit wird wiederum unterstellt, daß der Antragsteller als Rechtsanwalt im Herkunftsstaat niedergelassen ist. Art. 8 Abs. 2 des décrets betrifft die Drittstaatsdiplome. In der Umsetzungsregelung wurde jedoch eine Umkehrung der beweisrechtlichen Regelung im Vergleich zur Richtlinie 89/48/EWG getroffen, die nicht sehr zufriedenstellend erscheint. Nach Art. 8 Abs. 2 muß nun jeder, der keine dreijährige Berufserfahrung nachweisen kann, den Nachweis erbringen, daß er den größeren Teil seines Studiums innerhalb der Europäischen Gemeinschaft absolviert hat. Die umgekehrte Lösung entsprechend Art. 1 a) der Richtlïnie 89/48/EWG wäre mit Sicherheit befriedigender gewesen.

Art. 9 des dếcrets enthält die inhaltliche Gestaltung der Eignungsprüfung. Die Eignungsprüfung ist grundsätzlich schriftlich und mündlich. Prüfungssprache ist griechisch. Prüfungsstoff im schriftlichen Verfahren sind jedenfalls die Fächer Ziwilrecht und Zivilprozeßrecht, sowie nach Wahl des Kandidaten Verfassungs- und Verwaltungsrecht oder Handelsrecht. Die mündliche Prüfung bezieht sich jedenfalls auf das Fach, welches nicht für die schriftliche Prüfung gewählt worden ist. Des weiteren wird der Kandidat mündlich über die anwaltlichen Standesregeln, sowie nach Wahl des Kandidaten im Strafund StrafprozeBrecht oder im Arbeitsrecht geprüft.

Bedenklich an dieser Regelung ist zunächst die Tatsache, dal3 keinerlei Freistellungsmöglichkeiten gegeben sind, falls ein Kandidat bereits über die notwendigen Kenntnisse verfügt. Auch die Wahlmöglichkeit zwischen zwei Fächern in der mündlichen Prüfung ist nicht unproblematisch, da damit die von der Richtlinie 89/48/EWG unterstellte 
Fallstudie I: Die rechtsberatenden Benfe

Notwendigkeit der Kenntnis für die Ausübung des Berufes zumindest fragwürdig erscheint. Nicht unproblematisch ist auch die Tatsache, daß gemäß Art. 9 . Abs. 2 Satz 2 nur im Falle, daß der Kandidat in der schriftlichen und in der mündlichen Prüfung einen Notendurchschnitt von sechs auf zehn erzielt, die sprachlichen Kenntnisse nicht als Ablehnungsgrund herangezogen werden dürfen. Diese Formulierung unterstellt, daß in anderen Fällen eine Ablehnung mit mangelnden Sprachkenntnissen begründet werden kann. Positiv kann festgestellt werden, daß keine Beschränkung der Wiederholungsmöglichkeiten geregelt ist. Auch die Bestimmung in Art. 10 des décrets hinsichtlich der Ernennungsmöglichkeiten am Cour d'appel und am Cour de Cassation muß sehr positiv bewertet werden.

Undeutlich dagegen ist die Bestimmung in Art. 11 des décrets. Danach wird ein erfolgreícher Kandidat zum griechischen Rechtsanwalt ernannt und dem griechischen Anwaltsgesetz unterstellt wird. Welche genauen inhaltlichen Konsequenzen hieraus folgen, ist nicht bekannt. Es müßte überpruft werden, ob in Griechenland noch ïmmer ein Staatsangehörigkeitsvorbehallt für Rechtsanwälte gilt. Dieser wäre zwar gemeinschaftswidrig, könnte jedoch bei einigen Verfahren zu unnötigen Komplikationen führen!

\section{Beurteilung der Umsetzung für den Rechtsanwalt}

Wie bereits für die Bundesrepublik Deutschland erörtert, ist die Unterstellung in Art. 2 Abs. 1 und Art. 3 des décrets, daß der Kandidat in einem anderen Mitgliedstaat als Rechtsanwalt niedergelassen sein muß, sehr problematisch. Hiermit wird das in der Richtlinie 89/48/EWG vorausgesetzte "Endprodukt" fälschlich mit einem niedergelassenen Rechtsanwalt gleichgesetzt. Sehr bedenklich ist die Tatsache, daß die Eignungsprüfung für jedes Anerkennungsverfahren unterstellt wird ohne, daß die Möglichkeit der Freistellung von der ganzen oder einem Teil der Prüfung geregelt ist. Das décret enthält auch keine Verfahrensbestimmungen im Sinne des Art. 8 der Richtlinie 89/48/EWG hinsichtlich der Entscheidungsfrist sowie hinsichtlich einer gerichtlichen Überprüfung der Entscheidung. Hierin kötnnte ein Verstoß gegen die Verfahrensvorschriften der Richtlinie zu sehen sein, es sei denn, es bestehen allgemeine verwaltungsrechtliche Vorschriften, die eine Entscheidungsfrist gewährleisten und eine gerichtliche Überprüfung der Entscheidung ermőglichen. Die Wahlmöglichkeit hinsichtlich der Fächer in der mündlichen Prüfung ist nicht unbedenklich. Die Wahlmöglichkeit in der schriftlichen Prüfung wird durch die Tatsache gerechtfertigt, daß das nicht gewählte Fach jedenfalls Prüfungsstoff der mündlichen Prüfung ist. Die Möglichkeit aufgrund mangelnder Sprachkenntnisse abgewiesen zu werden, ist auf grund der gewählten Formulierung nicht unproblematisch, obwohl anerkannt werden muß, daß eine anwaltliche Tätigkeit ohne die Beherrschung der Landessprache kaum vorstellbar ist. Die Regelung in Art. 8 Abs. 2 des décrets hinsichtlich Drittstaatsdiplome erscheint nicht sehr praktikabel. 


\section{E. IRLAND}

\section{Einführung}

Die Situation in Irland entspricht der Großbritanniens weitgehend. Auch hier wird ein wesentlicher Teil der Regelungsgewalt hinsichtlich der Berufsausbildung und der Standesregeln durch die Mitglieder des jeweiligen Berufsverbandes ausgeübt, den sogenannten chartered bodies ${ }^{1359}$.

\section{Die rechtsberatenden Berufe in Irland}

Im allgemeinen Umsetzungsgesetz (S.I. No 1 of 1991) werden in Schedule 3 die Berufe genannt, die nach Ansicht Irlands nationale Rechtskenntnisse unterstellen. Die Formulierung von Schedule 3 ist etwas mißverständlich, da teilweise die Berufe, teilweise die Berufsorganisationen genannt werden. Neben den klassischen juristischen Berufen Solicitor und Barrister betrifft die Bestimmung verschiedene Formen des Accountant ${ }^{1360}$, den Auditor of company accounts, den Patent Agent und den Tax Consultant. Für alle diese Berufe wurde die Eignungsprüfung alls Anpassungsinstrument gewählt ( 5 S.I.), wobei die jeweils gemäß Schedule 1 angewiesenen Berufsorganisationen für die konkrete Ausgestaltung der Eignungsprüfung verantwortlich sind.

\section{Solicitors}

Zuständige Behörde ist die "Incorporated. Law Society of Ireland". Diese erließ in Ergänzung zu den Solicitors Acts 1954 und 1960 eine spezielle Umsetzungsverordnung, die unter dem Titel "Qualified Lawyers (European Community) Regulations 1991 am 25. März 1991 in Kraft getreten ist ${ }^{1361}$. Der Antragsteller muß den Antrag an die Law Society richten, wobei gemäß Section 3 der Regulation 1991 die folgenden Dokumente beizufügen sind: Akademische und berufliche Ausbildungsnachweise (a qualified Lawyer), ein durch Berufsorganisation oder Heimatgericht ausgestellter Nachweis der Ehrenhaftigkeit, Bescheinigungen darüber, daß der Antragsteller nicht in Konkurs geraten, kein Standesverfahren gegen ihn anhängig oder die Berufsausübung untersagt ist, noch wegen einer Straftat verurteilt ist.

Die Law Society wird daraufhin innerhalb von vier Monaten entscheiden, ob der Antragsteller sich - und gegebenenfalls in welchen Fächern - einer Eignungsprüfung unterziehen muß. Dies wird von Fall zu Fall entschieden. Die Eignungsprüfung setzt sich aus einem schriftlichen und einem mündlichen Teil zusammen. Die mündliche Prüfung

1359. Siehe dazu die Auflistumg in Schedule 1, wobei ein Unterschied gemacht wird zwischen Berufsorganisation, bei denen die Berufsausübung auf gesetzlichen Bestimmungen beruht (Part 1) und anderen Berufsorganisationen, die durch den Stat anerkannt sind, jedoch selbst den Benuf und die Berufsausubung autonom regein (Part 2).

1360. Certified accountant, Certified public accountant, chartered accountant

1361. Statutory Instrument S.1. No. 85 of 1991 
bezieht sich auf die anwaltlichen Standesregeln. Während der schriftlichen Prüfung werden die folgenden Fächer geprüft (section 4 \& 1 Regulation 1991):

a) Verfassungsrecht und nach Wahl des Kandidaten entweder Strafrecht oder Gesellschaftsrecht

b) Law of Contract and Law of Tort

c) Land Law and Conveyancing;

d) Probate and Taxation

e) Solicitors' Accounts

GemäB Section 4 \& Regulation 1991 sind Solicitors aus Nordirland und England und Wales grundsätzlich von der Eignungsprüfung befreit. Diese Bestimmung entspricht der für irische Solicitors in England und Wales geltenden Bestimmung. Für andere Kandidaten gilt die Befreiung von der Eignungsprifung nur in Ausnahmefällen (Section $4 \$$ 3 Regulation 1991).

Für die Bearbeitung des Antrages, die Organisation der Eigmungsprüfung sowie letztlich für die Zulassung zur Roll of Solicitors werden von der Law Society gesondert Gebühren erhoben, deren Höhe von Zeit zu Zeit bestimmt wird (Section 5 Regulation 1991). Die gesamten Gebühren sind gesondert geregelt und zwar in dem Statutory Instrument S.I. No. 84 of 1991. Danach beträgt die Gebühr für die Antragsbearbeitung IR $f$ 100.00. Die Organisation der Eignungsprüfung wird ein Kostenfaktor von IR $£ 800.00$ veranschlagt. Dieser Betrag soll unter den einzelnen Kandidaten anteilmäßig verteilt werden. Für die Einschreibung auf die Roll of Solicitors ist nochmals IR $£ 100.00 \mathrm{zu}$ entrichten.

\section{Barristers}

Das Council of the Honorable Society of King's Inn wurde als zuständige Behörde bestimmt. Dieses erließ mit Wirkung vom 4. Januar 1991 eine Regelung hinsichtlich der Anerkennung von Juristen aus den anderen Mitgliedstaaten der Gemeinschaft. (Rule 19 (A) Qualified Lawyers from other EC Member States). Der Antragsteller ( im Text wird der Begriff "Migrant" verwendet) muß dern Antrag die folgenden Dokumente beifügen: Original oder beglaubigte Kopien der akademischen und beruflichen Ausbildungsnachweise, ein durch Berufsorganisation oder Heimatgericht ausgestellter Nachweis der Ehrenhaftigkeit, Bescheinigungen darüber, daß der Antragsteller nicht in Konkurs geraten, kein Standesverfahren gegen ihn anhängig oder die Berufsausübung untersagt ist. Des weiteren soll der Antragsteller die Unterlagen beifügen, die Anlaß geben könnten, ihn von der Eignungsprüfung ganz oder teilweise zu befreien. Auch muB der Antragsteller die vorgeschriebene Bearbeitungsgebühr für den Antrag entrichtet haben.

Der Antrag wird innerhalb von vier Monaten bearbeitet. Dem Antragsteller wird mitgeteilt, ob er direkt zur Society zugelassen wird, sich einer Eignungsprüfung unter- 
ziehen muß oder sein Antrag gänzlich abgelehnt wird. Die Entscheidung wird je nach Sachlage entschieden.

Die Eignungsprüfung setzt sich aus einem schriftlichen und einem mündlichen Teil zusammen, wobei die schriftliche Prüfung sich auf die folgenden Gebiete bezieht:

A) A Paper on irish Legal System and Irish Constitutional Law

B) A Paper on the law of torts and contract and at the election of the Migrant either the law of property (including equity and trusts) or criminal law

C) A Paper on evidence and practice and procedure (in relation to the practice and procedures of the Circuit and District Courts either criminal or civil practice and procedure at the option of the Migrant).

The oral assessment shall evaluate the Migrant's preparation and oral presentation of a case and his knowledge of the Rules of ethics and Code of Conduct for Barristers

Der schriftliche Teil der Eignungsprüfung wird zweimal jährlich organisiert. Der Kandidat wird nur dann zur mündlichen Prüfung zugelassen, wenn er mit Erfolg die schriftlichen Teile abgelegt hat. Der Antragsteller ist verpflichtet, sich allen Prüfungsabschnitten bei einem Prüfungstermin zu unterziehen. Der Prüfungsantritt muß innerhalb von zwei Jahren nach Zulassung zur Eignungsprüfung erfolgen.

Ungewöhnlich ist letztlich noch Rule 19 (A) (g):

Grundsätzlich ist danach der Migrant verpflichtet "to keep not less than two terms Commons", d.h. für eine gewisse Periode an den von der Society veranstalteten offiziellen Dinners teilzunehmen. Von dieser Regel kann der Kandidat jedoch befreit werden.

Der Kandidat ist ferner verpflichtet, die für die Eignungsprüfung erhobene Gebühr zu entrichten. Kenntnisse der gälischen Sprache werden nicht verlangt.

\section{Beurteilung der Umsetzung für die rechtsberatenden Berufe}

Die Umsetzungsmaßnahme der Incorporated Law Society of Ireland entspricht weitgehend der Regelung der Law Society von England und Wales ${ }^{1362}$. Die Fächerwahl für die Eignungsprüfung ist sehr umfangreich, ob hierin eine unzulässige Diskriminierung zu sehen ist, hängt jedoch wesentlich davon $a b$, wie die Eignungsprüfung inhaltlich gestaltet ist und in welchen Fächern Freistellungen erteilt werden. Grundsätzlich werden solicitors aus England und Wales von der Eignungsprüfung freigestellt. Schottische Juristen müssen lediglich eine Eignungsprüfung in bestimmten Fächern bestehen. Bei der Anwendung der Umseizungsregelung hält man damit korrekterweise Rechnung mit der Vorkenntis der Kandidaten. Negativ muß festgestellt werden, daß die geforderten

1362. Siehe dazu die Ausfihnungen Seite 343 
Gebïhren sehr hoch bemessen sind und die Gebührenregelung hinsichtlich der Organisation der Eignungsprüfung äußerst willkürlich anmutet, weil sich die Gebührenhöhe je nach Anzahl der Kandidaten werändert. Handelt es sich lediglich um einen Kandidaten, so muß dieser den Gesamtbetrag von IR $£ 800.00$ erstatten. Dies erscheint unverhältnismäßig hoch zu sein. Positiv kann festgestellt werden, daß kein Nachweis hinsichtlich einer Einschreibung als Rechtsanwalt im Herkunftsstaat verlangt wird. Auch werden keine Kenntnisse der gälischen Sprache erwartet. Für die Beurteilung der Umsetzung für Barristers gelten die entsprechenden Anmerkungen.

\section{F. ITALIEN}

Gemäß Art. 6 Abs. 2 wird für die Berufe procuratore legale, avvocato, commercialista et consulente per la proprieta industriale die Eignungsprüfung als Anpassungsinstrument bestimmt. Für keinen dieser Berufe sind bisher die Ausführungsmaßnahmen ergangen, so daß eine inhaltliche Beurteilung nicht möglich ist.

Die Einstufung des Consulente in Proprietà Industriale als rechtsberatend erscheint gerechtfertigt, da auch die nationale Ausbildung entsprechende Anforderungen an die juristischen Kenntnisse der Kandidaten stellt. Der "Consulente in Proprietà Industriale" muß in Italien nach einem abgeschlossenen Hochschulstudium gleich welcher Fachrichtung eine mindestens zweijährige Tätigkeit auf dem Gebiet des gewerblichen Rechtsschutzes ausüben. Vor der Zulassung muß er in einer schriftlichen Prüfung eine Patentanmeldung ausarbeiten, und in einer mündlichen Prüfung unter anderem Kenntnisse des. Zivilrechts, des Zivilprozeßrechts, des Öffentlichen Rechts und des gewerblichen Rechtsschutzes sowie der Mechanik, der Elektrotechnik oder der Chemie und die Kenntnisse einer Fremdsprache nachweisen.

\section{G. LUXEMBURG}

\section{Einführung}

In Luxemburg wurde die Richtlinie 89/48/EWG für Rechtsanwallte durch Gesetz vom 10. August $1991^{1363}$ geregelt. Am selben Tag wurde auch eine generelle Berufsreform wirksam ${ }^{1364}$. Neben dem sektoriellen Umsetzungsgesetz für Rechtsanwälte findet auch das allgemeine Umsetzungsgesetz vom 13. August 1992 Anwendung ${ }^{1365}$. Nach Art. 1 des Umsetzungsgesetzes für Rechtsanwälte ist die Ablegung einer Eignungsprüfung obligatorisch. Die Möglichkeit einer Freistellung ist gesetzlich nicht vorgesehen. Art 2 entspricht im wesentlichen der Diplomdefinition der Richtlinie 89/48/EWG. Gemäß Art. 3 des Umsetzungsgesetzes soll durch die Eignungsprüfung

1363. Loi du 10 août 1991 déterminant, pour la professïon d'avocat, le système général de reconaissance des diplômes d"enseignement supérieur qui sanctioneent des formations professionelles d "une đurée mimimalle de trois ans, Memorial Nr. 58 vom 27. August 1991, 1119.

1364. Loi du 10 août sur la profession d"avocat, Mémorial Nr. 58 voni 27. August 1991, 1110.

1365. Mémorial Nr. 67 vom 11. September 1992. 
ausschließlich die Befähigung zur Ausübung des Anwaltberufs in Luxemburg geprüft werden. Die Prüfungskommission setzt sich gemäB Art. 4 aus Verwaltungsbeamten sowie Angehörigen der beiden Anwaltskammern zusammen. Der Antrag muß beim Justizminister gestellt werden. Der Antrag muß3 die notwendigen Diplome sowie einen Staatsangehörigkeitsnachweis enthalten. Über den Antrag muß durch eine vom Justizminister zusammengestellte Kommission gemäß Art. 6 innerhalb von vier Monaten hin sichtlich der Zulassung zur Eignungsprüfung entschieden werden. Diese Bestimmung steht in einem gewissen Widerspruch zu Art. 3 Abs. 2 des allgemeinen Umsetzungsgesetzes vom 13. August $1992^{1366}$. Nach dieser Regelung muß die Entscheidung bereits innerhalb von drei Monaten getroffen werden. Diese Frist entspricht den allgemeinen luxemburgischen Verwaltungsbestimmungen. Nach der Regel lex posterior müßte die verkürzte Frist auch für Rechtsanwälte gelten. Eine entsprechende Änderung von Art. 6 des Umsetzungsgesetzes für Rechtsanwälte erscheint dennoch zur Vermeidung won Mißverständnissen angezeigt.

Die Eignungsprüfung setzt sich gemäß Art. 7 aus einem schriftlichen und einem mündlichen Teil zusammen. Die schriftliche Prüfung erfolgt auf Französisch. Die mündliche Prüfung kann nach Wunsch des Kandidaten auch auf Deutsch oder Letzeburgisch abgenommen werden. Die schriftliche Prüfung bezieht sich auf die folgenden Fächer:

- Zivil- und Zivilprozeßrecht

- Straf- und Strafprozeßrecht

sowie nach Wahl des Kandidaten

- Verwaltungsrecht oder

- Handelsrecht

In der mündlichen Prüfung werden die anwaltlichen Standesregeln sowie die Fächer geprüft, die in der schriftlichen Prüfung nicht mit Erfolg bestanden wurden. Genauere Details der Prüfung werden dem Kandidaten zwei Monate vor dem Prüfungstermin mitgeteilt. Nach erfolgreicher Ablegung der Eignungsprïfung kann der Kandidat einen Antrag auf Einschreibung stellen. Nach Vorlage der notwendigen Nachweise der Ehrenhaftigkeit muß die Einschreibung erfolgen.

\section{Beurteilung der Umsetzung für den Rechtsanwalt}

Die bereits für Deutschland vorgebrachte Kritik gilt im wesentlichen auch im Falle Luxemburgs. Zusätzlich muß bemerkt werden, daß die luxemburgische Regelung im Gegensatz zur deutschen keine Freistellungsmöglichkeit enthält. Dies überrascht um so mehr als Luxemburg über keine eigene juristische Fakultät verfügt. Die luxemburgischen Rechtsanwälte haben daher im allgemeinen ihre Ausbildung in Frankreich oder Belgien genossen. Es wäre zu erwarten gewesen, daß diese Tatsache bei der Umsetzung mit berücksichtigt worden wäre. Statt dessen müssen sich auch französische und belgi-

1366. Mémorial $\mathrm{Nr}$. 67 vom 11. September 1992. 
sche Rechtsanwälte einer Eignungsprüfung in vollem Umfang unterziehen. Die Eignungsprüfung entspricht daher weitgehend der Prüfung, die auch luxemburgische Juristen zu bestehen haben, um die Zulassung zum Rechtsanwalt in Luxemburg zu erhalten. Sie kann als eine Art Sonderprïfung im Juxemburgischen Recht qualifiziert werden. Eine derartige Regelung entspricht jedoch nicht der Richtlinie 89/48/EWG.

\section{H. NIEDERLANDE}

\section{Rechtsanwalt}

a. Einleitung

In den Niederlanden hat die Umsetzung für Rechtsanwälte sehr lange auf sich warten lassen. Zunächst war die Ausführungsmaßnahme für Rechtsamwälte abhängig von der Verabschiedung des allgemeinen Gesetzes im Parlament. Nachdem dieses erst am 19. Januar 1994, d.h. drei Jahre nach dem gesetzten Umsetzungstermin, in Kraft getreten ist ${ }^{1367}$, dauerte es noch elf Monate bis schließlich der Umsetzungsprozeß mit der Veröffentlichung einer Verordnung und eines Reglements zur Eignungsprüfung durch den niederländischen Orde van Adwocaten abgeschlossen wurde ${ }^{136:}$. Zwischen diesen beiden Daten liegen noch weitere Umsetzungsetappen. Zunächst mußte der Justizminister gemäß Art. 11 des Allgemeinen Gesetzes die Instanz ernennen, die zur Abgabe von sogenannten EG-Erklärungen (EG-werklaringen) befugt ist. Dies geschah in zwei Phasen. Zunächst wurde mit Beschluß vom 15. Juni 1994 der Allgemeine Rat ${ }^{1369}$ des niederländischen Orde van Advacaten als befugte Instanz angewiesen ${ }^{1370}$. Des weiteren wurden mit ministeriellem Beschluß vom 31. Oktober 1994 die allgemeinen Verfahrensregeln zur Erlangung einer EG-Erklärung für Rechtsanwälte festgestellt ${ }^{137 !}$.

Begründet wurde die Wahl des allgemeinen Rats des Orde van Advocaten sowoh] formell wie materiell. Einerseits wurden die engen Beziehungen des Orde van Advocaten zu den niederlăndischen juristischen Fakultäten und den ausländischen Standesorganisationen unterstrichen, andererseits wurde darauf hingewiesen, daß der Orde van Advocaten auch für die Berufsausbildung der Rechtsanwailte die Verantwortung trägt ${ }^{1372}$. Die Kombination dieser Elemente - so die Beschlußbegründung - garantiere die inhaltlich notwendige Erfahrung bei der Ausführung und Organisation der Eignungsprüfung ${ }^{1373}$. Formell wurde die Anweisung des Rates als beschlußbefugtes Organ un-

1367. Algemene Wet erkeming EG-hoger-onderwijsdploma "s, Stb. 1994, 29.

1368. Verordening op de proeve wan bekwaamheid als bedoeld in de algemene wet erkenaing EG-hogeronderwijsdiploma's sowie Reglement op de proeve van bekwamheid als bedoeld in de algemene wet erkenming EQ-hoger-onderwijsdiploma"s. Diese Regelungen traten am 7. Dezember $1994 \mathrm{in} \mathrm{Kraft.}$

1369. Algemene Rato

1370. Beschlub vom 15. Juni 1994, Stb. 1994, 457

1371. Regeling EG-verklaring advocaten vom 31. Oktober 1994/Nr.464984/94/6, Stantscourant 215 vom 8. Noventber 1994, 13

1372. Art. 9c des Advocatenwet, Stb. 1984, 418.

1373. Stb. $1994,457,3$ 
ter Hinweis auf Art. 1.1. Abs. 1, Buchstabe a) des Algemene wet bestuursrecht (AWB) ${ }^{1374}$ begründet.

\section{b. Inhalt der Regeling EG-verklaring}

Gemäß Art. 2 der Regeling EG-verklaring vom 31. Oktober $1994^{1375}$ muß der Kandidat seinen Antrag auf Erteilung einer derartigen Erklärung an den Allgemeinen Rat richten. Dem Antrag müssen die folgenden Dokumente beigelegt werden: Das akademische Diplom einschlieBlich der Benotung und der Nachweis des erfolgreichen Abschlusses der Berufsausbildung zum Rechtsanwalt soweit der Herkunftsstaat eine derartige Berufsausbildung verpflichtend vorschreibt ${ }^{1376}$. Beide Dokumente müssen im Orginal oder als beglaubigte Kopie eingereicht werden. Falls der Antragsteller im Besitz eines Drittstaatsdiploms ist, muß er eine durch den erkennenden Mitgliedstaat ausgestellte Anerkennungsurkunde sowie den Beweis einer mindestens dreijährigen rechtmäßigen Berufsausübung in dem betreffenden Mitgliedstaat einreichen ${ }^{1377}$. Des weiteren muß der Antragsteller einen Staatsangehörigkeitsnachweis beifügen. Alle Dokumente müssen, soweit sie nicht auf niederländisch verfaßt sind, mit einer beglaubigten Übersetzung versehen werden. Der Antragsteller ist gemäß Art. 2 Abs. 5 der Regeling EG-verklaring verpflichtet, an den Allgemeinen Rat weitere Auskünfte hinsichtlich seiner Ausbildung zu erteilen. Falls der Antragsteller diese Voraussetzungen nicht erfüllt, kann der Allgemeine Rat seinen Antrag gemäß Art. 3 Abs. 1 der Regeling EG-verklaring abweisen. Gemäß Art. 3 Abs. 2 Buchstabe a) stellt der Allgemeine Rat eine EG-verklaring aus, wenn zwischen der Ausbildung des Antragstellers und der in den Niederlanden vorgeschriebenen Ausbildung zum Rechtsanwalt keine wesentlichen Unterschiede bestehen. $\mathrm{Zu}$ diesem Punkt heißt es in der Beschlußbegründung, daß es angesichts der Unterschiedlichkeit der Rechtssysteme nicht ausgeschlossen werden kann, daß derartige wesentlichen Unterschiede bei allen Anfragen festzustellen sind. Dies habe zur Konsequenz, daß nahezu sämtliche Antragsteller sich einer Eignungsprüfung unterziehen müssen. In diesem Fall erteilt der Allgemeine Rat eine sogenannte vorläufige EG-verklaring gemäß Art. 3 Abs. 2 Buchstabe b) Regeling EG-verklaring, worin er den genauen Inhallt sowie den zeitlichen Rahmen für die Eignungsprüfung festlegt. Dabei handelt es sich gemäß Art. 3 Abs. 4 Buchstabe a) um eine Ausbildung mit erfolgreicher Prüfung. Der Nederlandse Orde van Advocaten muB dabei gemäß Art. 3 Abs. 4 Buchstabe b) garantieren, daß diese Ausbildung sowie die Prüfung zumindest einmal im Jahr abgenommen wird. Bei erfolgreichem Abschluß wird dem Kandidaten eine EG-ver klaring ausgestellt. Die Prüfung wird auf niederländisch abgenommen. Bei der Beurteilung des Examens wird die Beherrschung der niederländischen Sprache mitberück-

1374. Stb. 1994, 1

1375. Regeling EG-verklaring advocaten vom 31. Oktober 1994/Nr. 464984/94/6, Staatscourant 215 vom 8. November $1994,13$.

1376. In der Begrüindung des Beschlusses wird auf das sogenannte "Endprodukt" bzw. "produit fin" , das bei der Anwendung der Richtlinie zugrunde gelegt wird.

1377. Verwurderlich ist, daß in dem Beschluß EG-verklaring nicht ausdrüicklicher auf eine entsprechende Anwendung für die Staaten des EWR-Abkommens hingewiesen wird. 
sichtigt und bildet dabei selbst gemäß Art. 3 Abs. 6 der Regeling EG-verklaring ${ }^{1378}$ einen für die Bewertung entscheidenden Faktor.

In der Regeling EG-verklaring advocaten wurde ferner in Art. 4 bestimmt, daß weitere Ausführungsregelungen zu erlassen sind, worin der Inhalt der Eignungsprüfung geregelt werden soll. Daraufhin hat der Orde van Advocaten mit Verordnung vom 25. November $1994^{1379}$ den Allgemeinen Rat angewiesen, ein entsprechendes Reglement zu erlassen. Der Allgemeine Rat ist dieser Aufforderung mit Verabschiedung eines Reglements vom 7. Dezember 1994 nachgekommen ${ }^{1380}$. Mit Veröffentlichung dieser Regelung kann der Umsetzungsprozeß für den Beruf des Rechtsanwalts in den Niederlanden als abgeschlossen angesehen werden.

c. Inhalt des Reglements

Art. 1 des Reglements gibt einen Definitionskatalog. Art. 2 des Reglements regelt den Fächerkatalog, auf den die Eignungsprüfung sich ganz oder teilweise zu erstrecken hat. Dabei werden unter den Nummern 1 - 7 die folgenden Fächer genannt:

1. Burgerlijk Recht ${ }^{1381}$

2. Strafrecht

3. Gedragsrecht ${ }^{1382}$

4. Burgerlijk Procesrecht ${ }^{1383}$

5. Strafprocesrecht

6. Bestuursprocesrecht ${ }^{1384}$

7. Belastingrecht ${ }^{1385}$

unter der Nummerierung 8 a und b, 9 a bis e folgen die weiteren Fächer:

8a. Bestuursrecht ${ }^{1386}$

8b. Handelsrech

9a. Echtscheidingsrecht ${ }^{1387}$

1378. In der Texistelle wird zweimal ein Absatz 5 genannt. Es mubs sich dabei jedoch um einen redaktionellen Fehler handeln, so daß in diesem Falle von Art. 3 Abs. 6 ausgegangen werden mußs.

1379. Verordening op de proeve van bekwaamheid als bedoeld in de algemene wet erkenning EG-HogerOnderwijsdliploma's von 25. Nowember 1994. Diese Verordnung ist am 7. Dezember 1994 in Kraft getreten. Staatscourant 249 vom 27 . Dezember 1994, 43.

1380. Regelement op de proeve van bekwaamheid als bedoeld in de algmene wet erkenning EG-Hoger Onderwijsdiploma's $s_{n}$ Staatscourant 249 vom 27 . Dezember 1994.

1381. Bürgerliches Recht

1382. Standestrecht

1383. Zivilprozeßrecht

1384. Verwaltungsprozels recht

1385. Steuerrecht

1386. Verwaltungsrecht

1387. Scheidungsrecht 


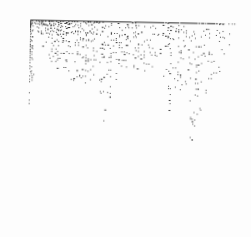

Teil V

\author{
9b. Arbeidsrecht \\ 9c. Sociaal Zekerheidsrecht ${ }^{1388}$ \\ 9d. Huurrecht ${ }^{1389}$ \\ 9e. Faillissementsrecht ${ }^{1390}$
}

Gemä̀B Art. 2 Abs. 2 des Reglements gilt im Falle einer Eignungsprüfung ohne Freistellung, daß der Kandidat zu einer Prüfung in den Fächern 1 bis 7 verpflichtet ist, während er von den Fächern unter der Nummerienung 8 und 9 jeweils ein Fach zu wählen hat. Des weiteren kann der Allgemeine Rat gemäß Art. 2 Abs. 3 des Reglements unter bestimmten Bedingungen Freistellungen erteilen. Diese Bestimmung ist äuBerst umständlich formuliert, weil sie nicht nur die Möglichkeit von Freistellungen regelt, sondern gleichzeitig den Allgemeinen Rat dazu ermächtigt, in bestimmten Fällen weitere Anforderungen an den Kandidaten zu stellen. Dabei wird ausdrücklich die Möglichkeit genannt, von einem Kandidaten eine Periode der Berufsausübung unter Aufsicht eines niederländischen Berufsangehörigen zu verlangen. Undeutlich ist, ob eine derartige Periode als Anpassungsstage zu qualifizieren ist. Art. 2. Abs. 4 des Reglements bestimmt die genauere Ausgestaltung der Prüfungen hinsichtlich der einzelnen Fächer. Dabei heißt es, daß die Fächer 1 bis 8 b mittels einer Prüfung abgenommen werden sollen, während die Fächer $9 \mathrm{a}$ bis e die Teilnahme an einem Kursus erforderlich macht. Art. 2 Abs. 5 des Reglements erklärt, daß die Fächer 3 bis 7 sowie die Fä́cher 9a bis e inhaltlïch mit denen der niederländischen Berufsausbildung für Rechtsanwälte übereinstimmen. Die anderen Fächer müssen dem sogenannten "basisdoctorallniveau" , d.h. dem Nivean der ersten zweieinhalb Jahre des niederländischen juristischen Studiums entsprechen.

Entsprechend der in Art. 2 Abs. 5 des Reglements vorgenommenen Verteilung soll gemäß Art. 3 Abs. 1 des Reglements die Organisation der Eignungsprüfung unterverteil werden, d.h. die Prüfungen der Fächer 3 bis 7 sowie die Kurse für die Fächer 9a bis e werden durch den Orde van Advocaten angeboten, während die weiteren Prüfungen, d.h. Prüfungen in den Fächern Bürgerliches Recht und Strafrecht sowie Verwaltungsrecht und Handelsrecht durch die Universitäten abgenommen werden müssen ${ }^{139}$. Dabei bestimmt Art. 3 Abs. 2, daß der Orde van Advocaten die Fächer 4 bis 7 zweimal im Jahr prüfen wird, während eine Prüfung im Standesrecht viermal im Jahr abgenommen wird. Die Universitäten sind gemäß Art. 3 Abs. 3 des Reglements frei, die Anzahl der Prüfungstermine zu bestimmmen. Nicht geregelt ist, wie oft die Kurse für die Fächer 9 a bis e angeboten werden. Allerdings bestimmt Art. 2 Abs. 4 des Reglements, daß die regelmäßige Teilnahme sowie Vorbereitung der Kurse ausreichend ist. Sonder-

1388. Sozialwersicherungsrecht

1389. Mietrecht

1390. Konkursrecht

1391. Bereits in der Begrindung zum BeschluB Regeling EG-verklaring wurde auf die Möglichkeit hingewiesen, daf der Orde van Adwocaten Teile der Eignungsprufung durch dile Universitäten (im Text heilat es: "instellingen in de zin van de Wet op het hoger onderwijs en wetenschappelijk odlerzoek") ausführen lassen könne. 
prüfungen werden in diesen Fächern nicht abgenommen. Ansonsten verweist Art. 4 des Reglements auf Kapitel IV der Examensbestimmungen der Ausbildungsordnung für Rechtsanwälte, das soweit möglich entsprechende Anwendung finden soll.

Auch in den übrigen Teilen des Reglements hinsichtlich der Zulassung zur Eignungsprüfung (Art. 5), der Beurteilung der Prüfungsergebnisse (Art. 6, 7 und 8), der Wiederholungsmöglichkeiten (Art. 9) sowie der Kosten (Art. 10) und der Berufungsmöglichkeiten (Art. 13 Abs. 1) wird auf die Examensbestimmmungen der Ausbildungsverordnung für Rechtsanwälte verwiesen. Eine Ausnahme gilt für die Prüfungsteile, die durch die Universitäten abgenommen werden sollen. Hier wird auf die entsprechenden universitären Regelungen Bezug genommen. Mit erfolgreichem Abschluß der gesamten Eignungsprüfung erhält der Kandidat vom Allgemeinen Rat gemäß Art. 12 des Reglements die sogenannte EG-verklaring. Diese berechtigt ihn zur Zulassung als niederländischer Rechtsanwalt.

\section{d. Beurteilung der Umsetzung für den Rechtsanwalt}

Die Umsetzung ist in werschiedener Hinsicht einmalig. Kein anderer Mitgliedstaat hat bei der Organisation der Eigmungsprüfung unterschiedliche Einrichtungen bemüht. Bei einigen Mitgliedstaaten wird die Eignungsprüfung durch den Berufsverband organisiert ${ }^{1392}$, in anderen Mitgliedstaaten sind es die staatlichen Instanzen, die für die Ausführung der Eignungsprüfung die Verantwortung übernehmen ${ }^{1393}$. In den Nieder\#anden hat man dagegen in gewisser Weise ein Mischsystem entwickelt. Zunächst heiBt es in Art. 6 Abs. 1 des Allgemeinen Umsetzungsgesetzes ${ }^{1394}$, daß es sich bei der zuständigen Behörde im Sinne der Richtlinie 89/48/EWG um den jeweiligen Fachminister handelt. Von dieser grundsätzlichen Anweisung kann gemäß Art. 6 Abs. 2 des Allgemeinen Umsetzungsgesetzes abgewichen werden. Der Unterrichtsminister hat als federführender Minister gemäß Art. 6 Abs. 2 des Allgemeinen Umsetzungsgesetzes den Allgmeinen Rat dles Orde van Advocaten als zuständige Behörde angewiesen ${ }^{1395 .}$ Dieser wiederum hat im Rahmen des Reglements die Durchführung der Eignungsprüfung teilweise an die Universitäten delegiert, ohne jedoch Sonderprüfungen an diesen Einrichtungen zu organisieren. Faktisch muß der Kandidat sowohl einen Teil der gewöhnlichen akademischen Ausbildung in den Fächern Bürgerliches Recht, Strafrecht und nach Wahl Handels- oder Verwaltungsrecht an den Universitäten absolvieren als auch den überwiegenden Teil der organisierten Berufsausbildung beim Orde van Advocaten durchlaufen. Diese Regelung entspricht jedoch in keimer Weise dem Grundprinzip der Richtlinie 89/48/EWG. Dabei soll ausdrücklich der Tatsache Rechnung getragen werden, daf es sich bei den Antragstellern um qualifizierte und im allgemeinen erfahrenen

1392. So besonders deutich in Großbritannien und Irland mit den chartered bodies als zuständigen Behörden. Aber auch in Frankneich und Luxemburg sind es die Berufsorganisationen, die für den Inhalt und dile Organisation der Eigmingsprijfung verantwortlich sind.

1393. So z.B. in Dänemark und Deutschland.

1394. Algemene Wet erkenning EG-hoger-onderwijsdiploma's, Stb. 1994, 29.

1395. Beschlußi vom 15. Juni 1994, Stb. 1994, 457. 
Berufsangehörige handelt. Die Eignungsprüfung soll nicht als eine Wiederholung der akademischen und beruflichen Ausbildung organisiert werden, sie soll vielmehr nur auf die wesentlichen Unterschiede begrenzt sein, wobei allerdings deren Kenntnis für die Berufsausübung als zwingend erforderlich angesehen wird ${ }^{13 \% 6}$.

Abgesehen von dieser grundsätzlichen Kritik muß die Regelung auch aus organisationstechnischen und inhalltichen Gründen abgelehnt werden. Von einem Kandidaten wird erwartet, daß er die Fächer Zivilrecht, Strafrecht, Handels- oder Verwaltungsrecht auf dem sogenannten "basisdoctoraalniveau" beherrscht. Da der Allgemeine Rat diesen Bereich der Eignungsprüfung vollkommen den Universitäten überläßt, ist der Kandidat damit auch dem Studienaufbau sowie der Examensorganisation der jeweiligen Universität unterworfen. In den meisten Fällen dürfte es organisationstechnisch beinahe unmöglich sein, Prüfungen in den drei verlangten Fächern in einer für die Kandidaten zumutbaren Zeitspanne abzulegen. Dies gilt umsomehr, da die Universitäten nicht speziell mit der Organisation dieser Eignungsprüfung betraut sind ${ }^{1397}$. Sie werden die Kandidaten daher als externe Studenten einstufen und damit der allgemeinen Examensorganisation unterwerfen. Dies bedeutet auch, daß die von den Kandidaten erhobenen Studienkosten erheblich höher sind, als die der im regulären Studium eingeschriebenen Studenten...

Neben diesen akademischen Prüfungen wird der Kandidat gleichzeitig verpflichtet, Examen in den Fächern Zivilprozeßrecht, Strafprozeßrecht, Verwaltungsprozeßreclat, Steuerrecht sowie dem Standesrecht beim Orde von Advocaten abzulegen sowie einen Kurs nach Wahl in einem der Fächer $9 a$ bis e zu folgen. Dabei spielt für die erfolgreiche Absolvierung dieses Kurses die ständige Anwesenheit des Kandidaten eine entscheidende Rolle. Eindeutig stellt das Reglement dabei in Art. 2 Abs. 5 fest, daß es sich inhaltlich um die gleichen Prüfungen und Kurse handelt, wie sie auch von einem Adwocatstagaire verlangt werden. Dies bedeutet jedoch, daß faktisch ein Großteil der akademischen und beruflichen Ausbildung wiederholt werden muß. Zunächst kann dabei erneut - ohne diese Regelung inhaltlich $z u$ bewerten - festgestellt werden, daß eine derartige Prüfungsorganisation eine längere, ununterbrochene Anwesenheit in den Niederlanden erforderlich macht. Dies führt jedoch zu einer beinahe unzumutbaren Belastung für die ausländischen Berufsangehörigen, die an einer derartigen Eignungsprüfung teilnehmen wollen. Von ihnen wird faktisch verlangt, sich für eine Periode von minmal einem Jahr in die Niederlande zu begeben. Das bedeutet jedoch in der Regel eine Aufgabe der bisherigen Niederlassung als Rechtsanwalt im Herkunftsstaat. Nur im Grenzgebiet dürfte es möglich sein, an den verschiedenen Prüfungen und Kursen teilzunehmen, ohne eine bestehende Niederlassung aufzugeben. Auch die insgesamt erhobenen Kosten können als nicht unbeachtlich bezeichnet werden.

1396. Protokollerklärung $\mathrm{Nr}$. 15 zur Richtlinie 89/48/EWG.

197. Soweit bekannt wurden sie bisher auch nicht nâher über thre neue Aufgabe informiert 
Fallstudie I: Die rechisberatenden Berufe

Inhaltlich besonders bedenklich ist die Bestimmung in Art. 2 Abs. 3 des Reglements. Danach kann der Allgemeine Rat nicht nur Freïstellungen gewähren, sondern noch ergänzende Anforderungen stellen. Hierbei wird ausdrütcklich die Berufsausübung unter der Aufsicht eines niederländischen Berufsangehörigen genannt. Diese Bestimmung läuft meines Erachtens eindeutig Art. 4 der Richtlinie 89/48/EWG zuwider. Gemäß dieser Regelung kann ein Mitgliedstaat lediglich ein Kompensationsinstrument verlangen, d.h. entweder die Eignungsprüfung oder den Anpassungslehrgang. Eine Kumulation der Anpassungsinstrumente ist nicht zulässig, ebensowenig wie der Nachweis entprechender Berufserfahrung kumuliert mit einem der Anpassungsinstrumente verlangt werden darf. Vermutlich sollte mit dieser Regelung spanischen Juristen Rechnung getragen werden, die keine spezielle Berufsausbildung genossen haben. Dies rechtfertigt jedoch nicht die Regelung. Bedenklich erscheint mir auch, daß im Rahmen der Freistellung lediglich auf die Ausbildung des Kandidaten abgestellt wird (Art. 3 Abs. Abs. 2 Buchstabe a und b der Regeling EG-verklaring), während die einschlägïge Berufserfahrung anscheinend keine Berücksichtigung findet. Eine derartige Anwendung der Freistellungsbestimmung würde meines Erachtens im Widerspruch zu den vom EuGH in den Entscheidungen Vlassopoulou und Newman aufgestellten Kriterien stehen ${ }^{1398}$.

Zusammengefaßt muß daher festgestellt werden, daß die durch den Allgemeinen Rat vorgelegte Umsetzungsmaßnahme weder inhaltlich noch verfahrenstechnisch mit der Richtlinie 89/48/EWG vereinbar ist.

\section{Patentanwalt}

\section{a. Einleitung}

In den Niederlanden ist die Zulassung als "Octrooigemachtigde" Voraussetzung für die Rechtsbesorgung auf dem Gebiet des gewerblichen Rechtsschutzes. Erworben wird die Berechtigung durch den Abschluß eines naturwissenschaftlichen oder eines technischen Studiums, der Befahigung als technischer Berufsoffizier oder als stellvertretendes technisches Mitglied des Patentamis sowie einer dreijährigen Tätigkeit bei einem Octrooigemachtigden. Die Kenntnisse sind in einer Prüfung vor dem niederländischen Patentamt nachzuweisen.

\section{b. Inhalt der Umsetzungsmaßnahme}

Hinsichtlich des Berufes "Octrooigemachtigden" wurde mit Beschluß vom. 8. Juli 1991 eine sektorielle Umsetzung der Richtlinie 89/48/EWG vorgenommen. Die Umsetzung beruhte auf einer Änderung des bestehenden Octrooigemachtigden-reglement (Stb. 1968, 595). Hierin wurde alls Ergänzung ein Art. 4 a eingefügt. Hierin wird als Voraussetzung

1398. Urteill vom 7. Mai 1991, Rs C-340/89 - Irène Vlassopoulou/Ministerium für Justiz, Bundes- und Europaangelegenheiten Baden-Württemberg - SIg. 1-2357 und Urteil vom 7. Mai 1992, Rs 104/91 Colegio Oficial de Agentes de la Propiedad Inmobilaria, Ministerio fiscal/J.L Aguirre Borrell, S. K Newman ul.a. «, Slg. I992, I-3003. 


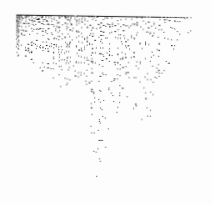

Teil V

für die Einschreibung als Patentanwalt bei Kandidaten mit einem Diplom aus einem anderen Mitgliedstaat der Gemeinschaft die Ablegung einer Eignungsprufung verlangt. Dabei wird in Art. 4 a Abs. 2 zum einen eine Umsetzung für Diplome im Sinne des Art. 1 a der Richtlinie 89/48/EWG vorgenommen. Zum anderen wird die Diplomanerkennung von Kandidaten geregelt, die im Sinne von Art. 3 b der Richtlinie 89/48/EWG über Ausbildungsnachweise verfügen, die sie in einem anderen Mitgliedstaat dazu berechtigen, den Beruf des Patentanwalts auszuüben, ohne daß dieser Beruf in dem Mitgliedstaat reglementiert ist. In diesem Falle wird gemäß Art. 4 a Abs. 2 der Nachweis einer zweijährigen Berufsausübung in den letzten zehn Jahren verlangt. Diese Voraussetzung entspricht Art. 3 b der Richtlinie 89/48/EWG.

Gemäß Art. 4 a Abs. 4 des Beschlusses muß der Kandidat im Rahmen der Eignungsprïfung seine Kennntisse des einschlägigen niederländischen Rechts (einschließlich des Bürgerlichen Rechts und des Handelsrechts) und der wichtigsten internationalen Regelungen auf dem Gebiet des intellektuellen Eigentums nachweisen. Zusätzlich wird von ihm ein Nachweis verlangt, ob er diese Kenntnisse auch in der Praxis anwenden kann. Dabei wird in der Vorschrift ausdrücklich festgestellt, daß eine Überprüfung der Kenntnisse nur insoweit stattfindet, als diese nicht bereits durch die vorgelegten Diplome und Prüfungszeugnïsse unterstellt werden können. Die Prüfung wird durch die Kommission abgenommen, die auch über die Zulassung von in den Niederlanden ausgebildeten Patentanwälten entscheidet.

c. Beurteilung der Umsetzung für den Patentanwalt

Grundsätzlich erscheint die Umsetzung in Übereinstimmung mit der Richtlinie 89/48/EWG. Bei der Zulassung zum Octrooigemachtigden kann man vertreten, daß der Mitgliedstaat dazu berechtigt ist, eine Einschränkung der Wahlmöglichkeiten hinsichtlich der Anpassungsinstrumente vorzunehmen, weil Kenntnisse des nationalen Rechts auch bei der generellen Zulassungsprufiung verlangt werden ${ }^{1399}$. Die Wahl wurde in der Umsetzungsmaßnahme zugunsten der Eignungsprüfung getroffen. Bei der inhaltichen Gestaltung der Eignungsprüfung werden die Vorkenntnisse mitberücksichtigt. Dagegen wird aus dem Beschluß nicht deutlich, welche genauere Form (schriftlich oder mündlich, Dauer der Prüfung, Kosten) die Eignungsprüfung annehmen wird. Diesbezüglich wird lediglich auf die bestehende Zulassungsprüfung verwiesen. Da die Eignungspruifüng jedoch nicht eine identische Wiederholung der Zulassungsprüfung darstellen soll, kann in dieser Hinsicht eine Fehlerhaftigkeit der Umsetzungsmaßnahme festgestellt werden.

1399. Eine ausführlichere Begründung wäre jedoch wünschenswert gewesen. 
Fallstudie I: Die rechtsberatenden Berufe

\section{PORTUGAL}

Gemäß der Anlage zum portugiesischen Umsetzungsgesetz ${ }^{1400}$ werden unter Nr. $\mathbb{1}$ drei Berufe als rechtsberatend eingestuft. Es handelt sich dabei um den Rechtsanwalt, den Wirtschaftsprüfer und den Patentanwalt ${ }^{1401}$. Für zwei dieser Berufe sind bisher konkrete Ausführungsmaßnahmen erlassen worden, wie dies in Art. 16 des allgemeinen Umsetzungsgesetzes auch ausdrücklich vorgesehen ist. Es handelt sich dabei um ein Ausfihhrungsgesetz für den Beruf des Rechtsanwalts vom 6. September $1994^{1402}$ sowie eine Spezialregelung für die Wirtschaftsprüfer ${ }^{1403}$. Die Ausfühungsmaßßnahme für Rechtsanwälte enthält jedoch lediglich eine Regelung, die die Einschreibung ausländischer Rechtsanwälte ermöglicht ${ }^{1404}$. Genauere Ausführungsbestimmungen hinsichtlich der inhaltlichen Gestaltung einer möglichen Eignungsprüfung sind in dieser Regelung jedoch nicht enthalten.

Zweifelhaft ist, ob die Einstufung des Consultore em Propriedade Industrial als rechtsberatend im Sinne der Richtlinie 89/48/EWG gerechtfertigt ist. In Portugal erfordert der Zugang zum Beruf des "Consultore em Propriedade Industrial " lediglich ein abgeschlossenes ingenieur-, wirtschafts- oder rechtswissenschaftliches Studium. Der geforderte Studienabschluß ist aber - soweit ersichtlich - alternativ und nicht kumulativ. Eine weitere Qualifikation wird nicht verlangt. Da somit die Zulassung zum Beruf nicht grandsätzlich von Kenntnissen im portugiesischen Recht abhängig ist, läßt sich die Notwendigkeit einer Eignungsprüfung als einzige Form der Kompensation kaum rechtfertigen. Eine endgültige Beurteilung der portugiesischen Umsetzung ist jedoch erst nach Veröffentlichung der Ausführungsmaßnahmen möglich.

\section{J. SPANIEN}

Gemäß Art. 5 a des allgemeinen spanischen Umsetzungsgesetzes ${ }^{1005}$ wurden vier in Annex. II genannte Berufe als rechtsberatend eingestuft. Das hat zur Konsequenz, daff eine Eignungsprüfung als Kompensationsinstrument vorgeschrieben wird. Es handelt sich dabei um den Abogado, den Procurador, den Auditor de Cuentas und den Graduado Social. Diese Einordnung ist bei den ersten drei der genannten Berufe nicht überraschend, weil es sich um Rechtsanwälte und Wirtschaftsprïfer handelt. Ungewöhnlich dagegen erscheint auf den ersten Blick die Einordnung des "Graduado Social" als rechtsberatend. Bei dem Graduado Sociall handelt es sich jedoch um einen Spezialisten des

1400. Decreto-Lei no $289 / 91$ vom 10. August 1991.

1401. Für diese Benfe werden der Ordem dos Advogados, die Comissäo de Inscrição na Lista dos Revisores Oficiais de Contas und das Instituto Nacional da Propriedlade Industrial als zustăndige Behörde angewiesen.

1402. Lei Nr. 33/94, Diario da Republica Nr. 206 wom 6. September 1994.

1403. Decreto-lei Mr. 422-A/93, Diario da Republica vom 30. Dezember 1993.

1404. Art. 33 e) und Art. 172 Abs. 1 und 2 des Lei No. 33/94 vom 6. September 1994, Diario da republica No, 206 wom 6. September 1994. Vermutlich müssen weitere Ausführungsmalinahmen won der zustâñigen Behònde, d.h. dem Ordem dos Adwogados, erlassen werden.

1405. Real decreto 1665/91 vom 25. Oktober 1991, BOE num. 280 wom 22. November 1991. 
Arbeits- und Sozialrechts, der sein Klientel auch in den entsprechenden Gerichtsverfahren vertritt, so daß die vorgenommene Qualifizierung gerechtfertigt erscheint. Korrekterweise wurde der Agente de la Propriedad Industrial nicht in die Liste der rechtsberatenden Berufe aufgenommen. Die Zulassung zum "Agente de la Propriedad Industrial" erhält man in Spanien nach Abschluß eines Hochschulstudiums gleich welcher Fachrichtung. Eine weitere Ausbildung oder Prüfung ist nicht vorgesehen. Es wäre daher unzulässig, eine derartige Prüfung von Patentanwälten aus anderen Mitgliedstaaten zu verlangen.

Obwohl die Eignungsprüfung als Kompensationsinstrument für die vier genannten Berufe vorgesehen ist, fehlen auch hier die notwendigen Ausführungsmaßnahmen. Es besteht lediglich ein Umsetzungsentwurf für die Anerkennung von Rechtsanwälten ${ }^{1406}$. Die fehlenden Ausführungsmaßnahmen lassen eine endgültige Beurteilung der spanischen Umsetzung nicht zu.

\section{K. VEREINIGTES KÖNIGREICH}

\section{Einführung}

Dem Sonderfall der im Vereinigten Königreich und in Irland üblichen Reglementierung durch private Verbände trägt die Richtlinie 89/48/EWG durch die Bestimmungen des Art. 1 Abs. 1 Buchstabe d) Unterabs. 2 und Art. 7 Abs. 3 Rechnung: Falls in einem Mitgliedstaat die Reglementierung der beruflichen Tätigkeit von Verbänden oder Organisationen ausgeübt wird, deren Ziel die Wahrung des Standesniveaus ist, und diese Ausübung der Berufsregellung durch den Mitgliedstaat anerkannt wird, dann ist eine derartig reglementierte berufliche Tätigkeit einer staatlich geregelten gleichzustellen. Im Anhang zur Richtlinie 89/48/EWG findet sich ein Verzeichnis der Berufsverbände oder -organisationen, die diese Bedingungen des Art. 1 Buchstabe d) Unterabs. 2 der Richtlinie 89/48/EWG erfüllen. In beiden Mitgliedstaaten wird ein wesentlicher Teil der Regelungsgewalt hinsichtlich der Berufsausbildung und der Standesregeln durch die Mitglieder des jeweiligen Berufsverbandes ausgeübt, den sogenannten chartered bodies ${ }^{100}$. Diese Berufsverbände und -organisation können sich darum nicht auf ihre private Natur berufen, um sich der Anwendung der Richtlinie und ihres Regelungsgehalts zu entziehen ${ }^{1408}$. Konsequenterweise haben beide Mitgliedstaaten die entsprechenden Berufsverbände als zuständige Behörde angewiesen.

1406. Proyecto: Orden Ministerial por la que se desarrola el real Decreto 1665/91, de 25 de octobre, en lo que se refiere al ejercicio en España de las profesiones de abogado y procurador por profesionales titulados de las Comunidades Europeas.

1407. Siehe dazu die Auflistung in Annex C II in: The single market, Europe open for professions, UK implementation, 2. Auflage 1991, 25

1408. Präambel der Richtlinie 89/48/EWG. 
Fallswitie 1: Die rechtsberatenden Bemufe

\section{Die rechtsberatenden Benfe im Vereinigten Königreich}

Im allgemeinen Umsetzungsgesetz (S.I. 1991 No 824) werden in Schedule 3 die Berufe genannt, die nach Ansicht Großbritanniens nationale Rechtskenntnisse unterstellen. Neben den klassischen juristischen Berufen Solicitor, Barrister und Advocate (Schottland) werden auch der Accountant ${ }^{1409}$, der Company Auditor, der Patent Agent und der Patent Attorney genannt. Für alle diese Berufe wurde die Eignungsprüfung als Anpassungsinstrument gewählt $(6 \$ 2$ S.I.), wobei die jeweils angewiesenen Berufforganisationen für die konkrete Ausgestaltung der Eignungsprüfung verantwortlich sind.

a. Solicitor (England und Wales)

Für die Zulassung als Solicitor in England und Wales ist die englische Law Society als zuständige Behörde angewiesen worden. Diese hat eine im Januar 1991 in Kraft getretene "Qualified Lawyers Transfer Regulation 1990" (Reg. 1990) erlassen, worin unter anderem auch die Zulassung zur Law Society für den von der Richtlinie 89/48/EWG erfaßten Personenkreis unter Nr. 12 (Reg. 1990) geregelt wird ${ }^{1410}$. Grundsätzlich wird dabei bestimmt, daß der Antragsteller eine Eignungsprüfung in den von der Law Society vorgeschriebenen Fächern abzulegen hat. Für Juristen aus Irland gilt gemäß Nr. 13 (Reg. 1990) eine Ausnahme. Danach müssen irische Solicitor keine Eignungsprüfung ablegen, irische Barrister werden lediglich im Berufsrecht und im Sachenrecht (property) geprïift.

Nach einer Auflistung der Law Society sind die Angehörigen der folgenden Berufsgruppen zur Anerkennung grundsätzlich zugelassen:

Belgien - Avocat/Advocaat/Rechtsanwalt, Magistrat, Notaire

Deutschland - Rechtsanwalt, Richter, Staatsanwalt, Notar/Numotar/Anwaltsnotar

Frankreich - Avocat, Avocat aux Conseils, Conseil Juridique/fiscal, Magistrat, Notaire

Griechenland - Dikastis, Dikigoros, Simvolaiografos

Irland - Barrister, Solicitor

Italien - Avvocato, Avvocatura generale dello stato, Richter, Staatsanwalt, Notaio, Procuratore

Niederlande - Advocat, Notaris, Rechterlijk Ambtenaar

Portugal - Avogado, Magistrado, Notario

Spanien - Abogado, Magistrado, Notario

Damit hat die Law Society das Zulassungsverfahren nicht nur für Rechtsanwälte aus anderen Mitgliedstaaten eröffnet, sondern den Begriff des äquivalenten Endproduktes in einer Richtlinien konformen Weise weit ausgelegt. Allerdings müßte zumindest für

1409. Certified accountant, chartered accountant, assaciate of the chartered institute of management accountants, public finance accountant.

1410. Dazu Wegerich, EuZW 1994, $275 \mathrm{ff}$. 
Deutschland auch der Assessor, als Absolvent des zweiten Staatsexamens und damit qualifiziertes Endprodukt, in die Liste aufgenommen werden. Undeutlich ist auch, warum zwar der italienische Procuratore jedoch nicht der spanische Procurador auf der Liste genannt wird. Auch bei ihm handelt es sich um einen qualifizierten Juristen, der als Endprodukt bezeichnet werden muß. Da der Procurador die Parteien vor Gericht vertritt, wäre es allerdings vertretbar, ihn in die Kategorie eines Barristers und nicht eines Solicitors einzustufen.

Der Antrag muß an die Law Society auf einem hierfür speziell ausgegebenen grünen Antragsformular gerichtet werden. Die Kosten für die Antragsbearbeitung betragen £ 200.00, die nicht zurückerstattet werden. Dem Antrag müssen die folgenden Dokumente und Bescheinigungen beigefügt werden: Original oder beglaubigte Kopien der akademischen und beruflichen Ausbildungsnachweise, ein durch Berufsorganisation oder Heimatgericht ausgestellter Nachweis der Ehrenhaftigkeit, Bescheinigungen darüber, daß der Antragsteller nicht in Konkurs geraten, kein Standesverfahren gegen ihn anhängig oder die Berufsausübung untersagt ist. Auch muß der Nachweis erbracht werden, daß der Antragsteller im Herkunftsstaat zur Berufsausübung berechtigt und nicht von der Berufsliste gestrichen worden ist ${ }^{1411}$.

Diese letzte Bedingung erscheint insoweit zweifelhaft, als ein Antragsteller, der zwar als Endprodukt im Sinne der Richtlinie qualifiziert werden muß, nicht unbedingt seinen Beruf überhaupt oder zumindest nicht im Zeitpunkt der Antragstellung im Herkunftsstaat ausüben muß. Angenommen, ein deutscher Jurist möchte direkt nach Abschluß des Zweiten Staatsexamens ohne je in Deutschland als Rechtsanwalt tătig gewesen zu sein, oder nach einem längeren Aufenthalt in Großbritannien zur Law Society zugelassen werden, wäre für ihn ein derartiger Nachweis nicht erbringbar, obwohl er ohne Zweifel die Voraussetzungen der Richtlinie erfüllt.

Die Zulässigkeit dieser Bedingung hängt wesentlich davon ab, wie "that your name has not been removed from the list of those so entitled" interpretiert wird. Handelt es sich hierbei lediglich um Personen, denen die Berufsausübung untersagt ist, so ist diese Forderung in Übereinstimmung mit Art. 6 Abs. 1 der Richtlinie 89/48/EWG. Muß der Antragsteller dagegen den Nachweis erbringen, daß er im Zeitpunkt der Antragstellung ein eingeschriebenes Mitglied der Anwaltskammer des Herkunftstaates ist, so verstößt diese Bedingung gegen die Richtlinie. Unter diesem Gesichtspunkt erscheint Nr. 21 des Antragsformulars sehr zweifelhaft ${ }^{1 / 12}$.

1411. "That you are still entitled to practice in your home jurisdiction and that your mame has not been removed from the list of those so entitled".

1412. "If you are not entitled to practice in your home jurisdiction (e.g. because you do not hold a current practising certificate) please prowide an explanation below stating, inter alia

(i) The reason why you are not entitled to practise in your home jurisdiction

(ii) Whether you know of any reason why, if you were to apply to become entitled to practise in your home jurisdiction, such an application would be refused. 
Fallstudie L: Die rechuberatenden Berufe

Nach Auffassung der Law Society ${ }^{1413}$ wird ein Antragsteller danach beurteilt, ob er berechtigt ist, den Berufstitel (professional title) zu führen. Das bedeutet, der Antragsteller muß zur Futhrung z. B. des Titels Rechtsanwalt befugt und damit Mitglied der entsprechenden Berufsorganisation des Herkunftsstaates sein. Kandidaten, die dieses Kriterium nicht erfüllen, werden als Ausnahmefalle behandelt. Ihnen kann die Zulassung gewährt werden. Sie können jedoch keinen Anspruch auf Anerkennung geltend machen. Damit stellt sich die Frage nach der relevanten Quallifikation des Endproduktes. GemäB Art. 3 a) der Richtlinie 89/48/EWG kann die zuständige Stelle einem Angehörigen eines Mitgliedstaates den Zugang zum Beruf nicht wegen mangelnder Qualifikation verweigern, wenn der Antragsteller das Diplom besitzt, das in einem anderen Mitgliedstaat erforderlich ist, um Zugang zu diesem Beruf zu erhalten. Die Richtlinie verlangt damit nicht die Berechtigung zur Führung des Berufstitels, die im Falle des Rechtsanwaltes nicht an das Diplom, sondern an die Einschreibung bei Gericht und an die Mitgliedschaft bei der Berufsorganisation gebunden ist.

Letztlich werden vom Antragsteller noch drei Referenzen verlangt. Von diesen müssen zwei von Berufsangehörigen mit mindestens fünfjăhriger Berufserfahrung stammen.

Über den Antrag muß innerhalb von vier Monaten entschieden werden. Bei der Entscheidung wird jeder Fall individuell beurteilt und je nach vorhandener Vorkenntnis wird der Antragsteller von Teilen der Eignungsprüfung freigestellt. Gegen die Entscheidung der Law Society kann der Antragsteller innerhalb eines Monats Widerspruch einlegen und eine interne Überprüfung fordern (Nr. 15 (a) Reg. 1990) oder aber innerhalb von drei Monaten beim Master of the Rolls ${ }^{1414}$ Beschwerde erheben (Nr. 15 (b) Reg. 1990).

Die Eignungsprufung setzt sich aus vier Prüfungsteilen zusammen, wobei drei schriftliche und ein mündlicher Prüfungsabschnitt. Die gesamte Prüfung wird in englischer Sprache durchgeführt.

Die schriftlichen Prüfungstelle beziehen sich auf die folgenden Fächer:

Head I: Property including Trust and Inheritance

Head II: Litigation

Head III: Professional conduct and accounts

Die mündliche Prüfung bezieht sich auf:

Head IV: Principals of Common Law including Contract and Tort and either criminal law of business organisations.

1413. Mündliche Auskunft von Mrs. Jenny Eden, Head of Transfer Unit.

1414. Der Master of the Rolls ist Mitglied des Coturt of Appeals, damit wird den. Anforderungen von Art. 8 Abs. 2 der Richulinie 89/48/EWG genüge getary wird, wonach die Möglichkeit eines gerichtlichen Rechtsbelnelfs gegeben sein mul. 
Die Kosten für die Eignungsprüfung wird durch die Anzahl der abzulegenden Prüfungsabschnitte bestimmt, wobei $£ 220.00$ für einen Prüfungsteil berechnet werden und f 440.00 für die gesamte Prüfung zu zahlen sind. Nach Bestehen der Eignungsprüfung ist der Kandidat berechtigt, die Eintragung auf "the Roll of Solicitors" zu beantragen. Hierbei wird eine weitere Gebühr in Höhe von $£ 65.00$ erhoben. Insgesamt erscheinen die Gebühren sehr hoch bemessen zu sein, nämlich $£ 705.00$ bei einer Eignungsprüfung über den gesamten Prüfungsstoff. Es erscheint zweifelhaft, ob diese Gebühren tatsächlich für die Deckung der gemachten Kosten notwendig sind. Die Eignungsprüfung wird zweimal jährlich organisiert.

b. Solicitor (Schottland)

Ähnlich wie seitens der Law Society von England und Wales wurde auch für Schottland vom Council of the Law Society of Scotland eine Zulassungsverordnung erlassen. Diese gilt jedoch ausschließlich für EG-Angehörige, mit der Einschränkung, daß diese sich nicht innerhalb des Vereinigten Königreiches für einen juristischen Beruf qualifiziert haben und wird dementsprechend als EC Qualified Lawyers Transfer (Scotland) Regulations 1990 bezeichnet. Eine Ausnahmeregel für irische Solicitors und Barristers wie sie die englische Regulation 1990 kennt, gibt es in dieser Regelung nicht. Im Gegenteil, sec. $7 \& 2$ EC Qualified Lawyers Transfer (Scotland) Regulations 1990 bestimmt ausdrïcklich die Anwendung der EC Qualified Lawyers Transfer (Scotland) Regulations 1990 auf die Juristen der Republik Irland ${ }^{1415}$.

In Bezug auf die Antragstellung ist die EC Qualified Lawyers Transfer (Scotland) Regulations 1990 wesentlich weniger detailliert als die englische.

Gemäß sec.4 $\$ 1$ (ii) EC Qualified Lawyers Transfer (Scotland) Regulations 1990 hat ein Antragsteller, die vom Council der Law Society verlangten Unterlagen zu erbringen. Dieses Erfordernis wird jedoch nicht năher spezifiziert. Ebensowenig wird die Höhe der für die Antragsbearbeitung erhobenen Gebühren näher bestimmt.

Die Eignungsprüfung setzt sich aus einem schriftlichen und einem mündlichen Teil zusammen. Insgesamt kann die Dauer der Prüfung zehn Stunden betragen. Der vorgeschriebene Fächerkanon umfaßt die folgenden Gebiete:

sec. 5 \& EC Qualified Lawyers Transfer (Scotland) Regulations 1990

a) the Scottish law of Property including for this purpose the law of trusts and sucession and family law; ( 3 hours)

b) the Scottish Legal System including for this purpose the law of evidence and civil and criminal procedure; ( 3 hours)

1415. Dieser Unterschied ist durchaus erklärlich aufgrund der Verwandtschaft des Rechtssystems von EngHand und Wales mit dem irischen. Dagegen weicht das schottische Recht aufgrund seiner römischrechtlichen Tradition erheblich von beiden $a b$. 
c) European Community Law and Institutions; ( 2 hours)

d) Professional Conduct including for this purpose a knowledge of the Solicitors (Scotland) Accounts Rules in force from time to time; (2 hours)

e) Such other subjects as the Council may from time to time resonably prescribe.

Gerade die letzte Regelung unter sec. $5 \$ 2$ (e) mutet zumindest nach kontinentaleuropäischem Rechtsverständnis zu unbestimmt an, um die in Art. $1 \mathrm{~g}$ ) der Richtlinie 89/48/EWG an den Inhalt der Eignungsprüfung gestellte Anforderung zu erfüllen. Danach sind für die Eignungsprüfung lediglich die Sachgebiete auszuwählen, deren Kenntnis eine wesentliche Voraussetzung für die Ausübung des Berufs im Aufnahmestaat ist. Es erscheint unwahrscheinlich, daß derartig grundlegende Fächer bei Erlaß der EC Qualified Lawyers Transfer (Scotland) Regulations 1990 nicht bestimmbar waren.

Hinsichtlich der unter sec. $5 \$ 2$ (c) verlangten Kenntnisse des Europäischen Gemeinschaftsrechts und der europäischen Institutionen, darf wohl davon ausgegangen werden, daf im allgemeinen eine Freistellung erteilt werden wird, zumindest insoweit ein Antragsteller dieses Rechtsgebiet bereits in der eigenen Ausbildung erlernt hat. Zweifelhaft erscheint insoweit die Bestimmung sec. $5 \$ 7$ :

"The Council may at its sole discretion and subject to such reasonable conditions as it may impose, in what it deems to be exceptional circumstances, and taking into account the particular merits of an applicant exempt him from all or any part of the Test" ....

Zumindest in einigen Mitgliedstaaten gehört das Recht der Europäischen Gemeinschaften bereits zum Pflichtfachkatalog, so daß in keinem Falle mehr von aussergewöhnlichen Umständen gesprochen werden kann. Interessanterweise hat die Bundesrepublik Deutschland gerade diesen Bereich bewußt aus der Eignungsprüfung ausgeklammert, weil diese Kenntnisse unterstellt wurden ${ }^{1416}$.

Anders als in der englischen Regulation 1990 findet sich unter sec. 5 \$ 5 EC Qualified Lawyers Transfer (Scotland) Regulations 1990 eine Begrenzung der Wiederholbarkeit der Eignungsprüfung. Nach viermaligem Scheitern wird der Kandidat nicht mehr zu einer weiteren Eignungsprüfung zugelassen.

Gemäß3 sec. $7 \& 1$ EC Qualified Lawyers Transfer (Scotland) Regulations 1990 tritt diese am 4. Januar 1991 in Kraft.

c. Solicitor (Nordirland)

Auch die Law Society von Nordirland hat eine entsprechende Verordnung erlassen, in der bestimmt ist, daß die Eignungsprüfung sich aus einem mündlichen und einem schriftlichen Teil zusammensetzt.

1416. Amtlliche Begründung der Verordnung über die Eigrungsprifung für die Zulassung zur Rechtsanwaltschaft, BR-Dracksache $712 / 90$ vom 16 . Oktober $1990,16$. 


\section{d. Barrister (England und Wales)}

Für die Zulassung zum. Barrister wurde the General Council of the Bar for England and Wales als zuständige Behörde angewiesen. Diese hat für die Zulassung und Durchführung der Eignungsprüfung Richtlinien veröffentlicht. Danach findlet die Eignungsprüfung zweimal jährlich statt (April/September).

Die Kosten für die Antragsbearbeitung betragen $£ 200.00$, die nicht rückerstattet werden. Dem Antrag müssen die folgenden Dokumente und Bescheinigungen beigefügt werden: Original oder beglaubigte Kopien der akademischen und beruflichen Ausbildungsnachweise, ein durch Berufsorganisation oder Heimatgericht ausgestellter Nachweis der Ehrenhaftigkeit, Bescheinigungen darüber, daß der Antragsteller nicht in Konkurs geraten, kein Standesverfahren gegen ihn anhängig oder die Berufsausübung untersagt ist. Auch muB der Nachweis erbracht werden, daß der Antragsteller im Herkunftsstaat zur Berufsausübung zugelassen ist ${ }^{1.417}$. Diese letztgenannte Vorausetzung ist - wie bereits hinsichtlich der Law Society (England and Wales) erörtert - bedenklich, zumal hier die Formulierung noch stärker eine Niederlassung als Rechtsanwalt im Herkunftsstaat unterstellt.

Die Eignungsprüfung setzt sich aus einem schriftlichen und einem mündlichen Teil zusammen. Dabei handelt es sich um die folgenden schriftlichen Prüfungsabschnitte:

Section (i) A paper on the Law of Contract, the Law of Tort; and the Law of Property including Equity and Trust.

Section (ii) A paper on the English Legal System, Constitutional and Administrative Law and Criminal Law;

Section (iii) A paper on Evidence and (at the election of the candidate) either

(A) Criminal Procedure or

(B) Civil Procedure

\section{Bewrteilung der Unsetzung für die rechtsberatenden Berufe}

Grundsätzlich müssen die verschiedenen Umsetzungsmaßnahmen positiv beurteilt werden. Zunächst ist bemerkenswert, daß entsprechend dem in Art. 3 der Richtlinie 89/48/EWG niedergelegten Grundsatz die automatische Anerkennung ausdrücklich praktiziert wird. Im Verhältnis zwischen England und Irland ist dieser Automatismus selbst rechtlich verankert. Jedoch auch im Verhältnis zu kontinentalen Rechtsanwälten werden Freistellungen in größerem oder k®einerem Umfang gewährt, abhängig von der Ausbildung und Berufserfahrung des Kandidaten. Die Anerkenrung von anderen Berufsangehörigen, die nicht Rechtsanwälte sind jedoch der "Endprodukt" Definition der Richtlinie 89/48/EWG entsprechen, muß ebenfalls positiv bewertet werden, da damit die Richtlinie in vollem Umfang Anwendung findet. Mit der Fall zu Fall Beurteilung

1417. Cumrent Practising Cenificate - if such are issued by your regulating authority, or by a declatration on oath or a slemn declaration. 
erfüllen die britischen zuständigen Instanzen, insbesondere die Law Society von England und Wales, die Zielsetzung des allgemeinen Anerkennungssystems. Die Kompensationsinstrumente des Art. 4 der Richtlinie 89/48/EWG sollen auf den Einzelfall bezogen Anwendung finden. Bei der Durchführung der Eignungsprüfung scheint jedoch ein sehr hoher Standard angelegt zu werden, weil die Durchfallquote zumindest bei den kontinentalen Rechtsanwälten sehr hoch liegt. Die Gesamtzahlen werden dadurch beschönigt, weil viele Teilnehmer an den Eignungsprüfungen aus Common Wealth Ländern stammen und daher bereits ihre juristische Ausbildung im Common Law erhalten haben. Diesem Personenkreis fällt die Absolvierung der Prüfung leichter als den Juristen, die in der kontinentalen Rechtstradition erzogen sind.

Es ist schwierig zu beurteilen, ob diese Tatsache der Organisation der Eignungsprüfung zur Last gelegt werden muß, oder ob die Unterschiede in den Rechtssystemen zu groB sind, um mittels einer durchschnittlich kurzen Vorbereitungsphase überbrückt werden zu können. Umgekehrtes Zahlenmaterial, d.h. der Erfolg britischer Rechtsanwälte bei kontinentalen Eignungsprüfungen im Vergleich zu anderen Kollegen, liegt in ungenügender Weise vor, um hieraus Schlüsse ziehen zu können. Jedenfalls negativ zu beurteilen sind die verhältnismäßig hohen Gebühren, die für die Zulassung und Abnahme der Eignungsprüfung erhoben werden. 


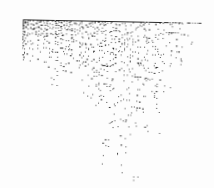

Teil V

Fallstudie II

\section{Ingenieur}

\section{\$ 1. Einleitung}

Der Fall des Ingenieurs hat während der Umsetzungsperiode vor allem Diskussionen in Hinblick auf die Frage ausgelöst, ob dieser Beruf in einigen Mitgliedstaaten als "reglementiert" i.S. der Richtlinie 89/48/EWG betrachtet werden muß. Besonders Dänemark, Frankreich und die Niederlande vertraten die Ansicht, daß der Beruf "Ingenieur" im jeweiligen Land nicht reglementiert sei. Sie lehnten damit auch einen Umsetzungsbedarf hinsichtlich der nationalen Gesetzgebung ab. Die Entscheidung hängt wesentlich von der Frage ab, ob unter "Reglementienung" im Sinne der Richtlinie 89/48/EWG eine Regelung zur Führung der Berufsbezeichnung und eine Berechtigung zum Führen des Ausbildungstitels zu verstehen ist. In einigen Mitgliedstaaten sind beide Bereiche eng miteinander verwoben, in anderen Mitgliedstaaten bedeutet die Reglementierung des eimen Bereichs nicht zwingend eine Reglementierung im anderen.

So regeln z.B. die Ingenieursgesetze der deutschen Bundesländer die Berechtigung zur Führung der Berufsbezeichnung "Ingenieur". Ein widerrechtliches Führen dieser Berufsbezeichnung wird als Ordnungswidrigkeit geahndet. Parallel dazu bestehen Länderverordnungen und -gesetze hinsichtlich des Führens akademischer Grade ${ }^{1418}$. Diese Regelungen beziehen sich auch auf die Führungsberechtigung von ausländischen akademischen Graden. So hat $\mathrm{z}$. B . das Land Nordrhein-Westfalen durch Gesetz vom 6 . Dezember 1991 das Führen von akademischen Graden der staatlichen oder staatlich anerkannten Hochschulen der Mitgliedstaaten der Europäischen Gemeinschaft einschließlïch der Europäischen Hochschulen in Florenz und Brügge und der Päpstlichen Hochschulen in Rom für zustimmungsfrei erklärt (\$ $141 \mathrm{Abs.} 1$ des Gesetzes über die wissenschaftlichen Hochschulen des Landes Nordrhein-Westfalen) ${ }^{1419}$. Ein Teil der Länderverordnungen beruht wiederum auf dem noch immer gültigen Gesetz über die Führung akademischer Grade vom 7. Juni 1939 (AkadGFG) ${ }^{1420}$ "Daneben besteht noch das bereits oben zitierte strafrechtliche Verbot gemäß $\S 132$ a StGB ${ }^{1421}$.

1418. Z B. Algemeine Genehmigung zur Fühnung won Hochschulgraden, Amtsblatt Wissenschaft und Kunst - Baden-Wüttemberg vom 19. Juni 1992

1419. Fünftes Gesetz zur Änderung des Gesetzes uber die wissenschaftlichen Hochschulen des Landes Nordrbein-Westifalen vom 6. Dezember 1991, GVBINW 1991, 518.

1420. RGBI, 1939 I $_{1} 985$

1421. Silehe Seite 182 
In Frankreich ist dagegen die Berufsbezeichnung "ingénieur" nicht geschützt, der akademische Titel "ingénieur diplö̀mé" darf aber nur mit dem Nachweis einer entsprechenden Qualifikation verwendet werden ${ }^{1422}$. Dänemark kennt ebenfalls keinen Schutz des Berufstitels "ingeni $\phi \mathrm{r}$ ", undeutlich ist jedoch, ob die Ausbildungstitel "Civilingeni $\phi r$, "Akademiingeni $\phi \mathrm{r}$ " und "Teknikumingeni $\phi \mathrm{r}$ " ohne entsprechende Qualifikation geführt werden dürfen ${ }^{1 * 23}$. An dieser Unterscheidung zwischen dem Berufstitel und dem akademischen Titel entzündete sich der Streit, ob der Beruf des Ingenieurs in Dänemark und Frankreich reglementiert ist oder nicht. Eine ähnliche Situation besteht auch in den Niederlanden, wo die akademischen Titelabkürzungen "IR" und "ing." geschützt sind, eine widerrechtliche Benutzung beider Titel auch strafbar ist ${ }^{1424}$, die mit dem Begriff "Ingenieur" zusammengesetzten Berufsbezeichnungen hingegen keinem Schutz unterliegen $^{1425}$. Dänemark, Frankreich und die Niederlande vertraten bei der Umsetzung der Richtlinie daher die Auffassung, daß von einer Reglementienung des Ingenieurberufes hinsichtlich ihrer nationalen Regelungen nicht gesprochen werden könne.

Entscheidend für die Beurteilung der Frage "reglementiert oder nicht reglementiert" ist, ob der Begriff des Titels gemäß Art. 1 Buchstabe d) sowohl die Berufs-wie die Ausbildungsbezeichnung umfaßt. Vertritt man die Auffassung, daß lediglich die Berufsbezeichnung als "Titel" im Sinne des Art. 1 Buchstabe d) erster Gedankenstrich der Richt" linie $89 / 48 / \mathrm{EWG}$ zu werten ist, dann liegt eine Reglementierung des Ingenieurberufes in den drei Mitgliedstaaten nicht vor. Sieht man dagegen den Begriff "Titel" als umfassend an, dann muß eine Regelung hinsichtlich der Ausbildungsbezeichnung als Reglementierung im Sinne der Richtlinie 89/48/EWG verstanden werden. Dieses Beurteilungsproblem kann nur im Gesamtzusammenhang gelöst werden.

Von Bedeutung sind dabei auch die unterschiedlichen sprachlichen Fassungen der Richtlinie. In der deutschen Fassung wird - wie bereits festgestellt - lediglich von einem "Titel" gesprochen. Damit sind beide Interpretationsmöglichkeiten zugelassen. Dagegen steht in der französischen Version des Art. $\mathbb{1}$ Buchstabe d) erster Gedankenstrich der Begriff "titre professionnel". Auch der englische Richtlinientext spricht an dieser Stelle von "professional title". Die niederländische Fassung benützt den Begriff "beroepstitel". Angesichts dieser drei in dem entscheidenden Punkt übereinstimmenden sprachlichen Fassungen der Richtlinie 89/48/EWG muß davon ausgegangen werden, daß der deutsche Text an dieser Stelle ungenau übersetzt ist. Korrekterweise hätte der Begriff "Berufsbezeichnung" anstatt "Titel" verwendet werden müssen. Die Ansicht Dänemarks, Frankreichs und der Niederlande, eine entsprechende Umsetzung der Richtlinie für den Beruf

1422. Wasillewsiki, Freie Berufe in Europa 1987, 377 (Frankreich), 399 (Niederlande). Pertek, Savoir 1992, 96 (108). Allgemein zur Reglementierung des Ingenieurberufs: Pertek 1991.

1423. Wasilewski, Frele Berufe in Europa 1987, 373 (Dänemark), behauptet, daß diese Bezeichnumgen in Dänemark einem Tïtelschutz unterliegen. Diese Behauptung konnte jedoch nicht anhand gesetzlicher Bestimmungen verifizient werden. Siehe dazu auch Pertek, Savoir 1992, 96 (106), der davon ausgeht, dafl die dătrische Situation weitgehend der französischen entspricht.

1424. Gemäß Art. 435 Abs. 3 Wetboek van Strafrecht i.V. mit Art. 7.20 Abs. 1 a/b und Art. 7.20 Abs. 2 Wet op het hoger onderwijs en wetenschappelijk onderzoek (W.H.W.) vom 8. Oktober 1992.

1425. Wasilewski, Freie Berufe in Europa, 399 (Niederlande). 
des Ingenieurs abzulehnen, kann daher grundsätzlich als berechtigt angesehen werden. Ob die Haltung der drei Mitgliedstaaten unter den gegebenen Umständen sehr klug war, muB jedoch bezweifelt werden.

Für die Niederlande war die Diskussion im Grunde vollkommen überflüssig, da die Berechtigung zur Fühnung eines akademischen Titels aus einem anderen Mitgliedstaat der Gemeinschaft bereits in der einschlägigen Gesetzgebung gewährt wurde ${ }^{1426}$. Daher könnte man auch die Ansicht vertreten, die Niederlande hätten mit dieser Bestimmung ihre Umsetzungsverpflichtung i.S. des Art. 7 Abs. 2 der Richtlinie 89/48/EWG erfüllt. Tatsächlich haben diese drei Mitgliedstaaten nur ihren eigenen Berufsangehörigen geschadet. Diese fallen nämlich nicht unter das Anerkennungssystem gemäß Art. 3 Buchstabe a), sondern müssen unter den erschwerten Bedingungen des Art. 3 Buchstabe b) der Richtlinie 89/48/EWG ihre Anerkennung durchführen, d.h. von ihnen kann der Nachweis einer mindestens zweijährigen Benufserfahrung in dem jeweiligen Herkunftsstaat verlangt werden. Im allgemeinen dürfte dies kein Problem darstellen, es sei denn, z. B. ein niederländischer Ingenieur hätte seit AbschluB seiner akademischen Ausbildung in den Niederlanden nur noch im Ausland gearbeitet und dies u.U. selbst für eimen niederländischen Konzern. Dieser Ingenieur könnte, bei einer formalistischen Anwendung des Anerkenmungssystems, mit Schwierigkeiten konfrontiert werden. Nur eine Berufung auf die Rechtsprechung des EuGH ${ }^{1427}$ könnte in einem solchen Falle die Anerkennung trotz der fehlenden inländischen Berufserfahrung bewirken. Falls der Betroffene seine Berufserfahrung in einem Drittstaat, $z$. B. in den Vereinigten Staaten, erworben hat, müßte diese nach der Rechtsprechung in der Rechtssache Haim ${ }^{1428}$ ebenfalls mitberücksichtigt werden. Das Beispiel zeigt jedoch, daß zumindest die Niederlande besser daran getan hätten, statt aus formalistischen und berufspolitischen Gründen auf einer "Nichtreglementierung" des Ingenieursberufs in den Niederlanden zu beharren, eine Titelreglementierung des Berufs zu vertreten, so daß niederländische Ingenieure in den Genu 3 der vereinfachten Anerkennung gemäß Art. 3 Buchstabe a) der Richtllinie gekommen wären.

In Irlland und dem Vereinigten Königreich liegt die Reglementierung des Ingenieurberufs in den Händen verschiedener chartered bodies ${ }^{1429}$. Diese wurden daher auch als $\mathrm{zu}$ ständige Behörden zur Durchführung der Anerkennungsverfahren angewiesen. In beiden Ländern wird dabei won den chartered bodies die Einzelfallbeurteilung angewandt, so daß keine generellen Spezialumsetzungsregelungen erlassen werden muBten. Die chartered bodies tendieren zu einer unmittelbaren Anerkennung, ohne die Forderung nach Kompensation im Sinne des Art. 4 der Richtlinie 89/48/EWG zu erheben ${ }^{1430}$.

1426. Art. 7.23 Wet op het hoger onderwijs en wetenschappelijk onderzoek (W.H.W.)

1427. Unteil vom 7. Mai 1991, Rs C-340/89 - Irène Vlassopoulou/Ministerium für Justiz, Bundes- und Europaangelegenheiten Baden-Württemberg -, S1g. I-1991, 2357.

1428. Ureil wom 9. Februar 1994, Rs C-319/92 - Salomone Haim/Kassenzahnärztiche Vereinigung Nordthein -, Slg. 1994, 425; Dazu Whouters, RW 1994-95, 57.

1429. Siehe dazu die Auflistung in den beiden allgemeinen Umsetzungsgesetzen.

1430. Nach dem ersten Erfahrungsbericht gemäß Art. 11 der Richtlinie 89/48/EWG wurde die Anerkennung in den meisten Fällen direkt ausgesprochen. 
Luxemburg hat selbst keine eigene universitäre Ingenieursausbildung ${ }^{1431}$. Es gibt jedoch ein Institut Supéreur de Technologie, das ungefähr einer deutschen Fachhochschule entspricht. Ähnlich wie in Deutschland ist in Luxemburg die Berufsbezeichnung im Rahmen des akademischen Titelschutzes geschützt ${ }^{1432}$. Auch in Italien ist der Titellschutz mit dem Schutz der Berufsbezeichnung verknüpft ${ }^{1433}$.

Von Belgien, Griechenland, Italien, Luxemburg und Portugal und liegen noch keine speziellen Umsetzungsmaßnahmen vor. Theoretisch könnten die Anerkennungsverfahren jedoch zumindest in Italien, Luxemburg und Portugal auch aufgrund der allgemeinen Unsetzungsgesetze durchgeführt werden. In Finnland und Schweden ist der Ingenieurberuf nicht reglementiert. Genaue Ausführungsbestimmungen liegen deshalb nur für die Bundesrepublik Deutschland, Spanien ${ }^{1434}$ sowie Österreich ${ }^{1435}$ zur Beurteilung vor.

\section{§ 2. Eine sektorielle Richtlinie für Ingenieure}

Die wenigen konkreten Umsetzungsmaßnahmen für Ingenieure überraschen insoweit als gerade die international operierenden Berufsorganisationen der Ingenieure mehrfach vehement auf die Notwendigkeit einer Spezialrichtlinie für Ingenieure verwiesen haben ${ }^{1436}$. Dieses Interesse an einer sektoriellen Richtlinie war allerdings erst durch die Tatsache geweckt worden, nachdem die Berufsorganisationen feststellen mußten, daß nach den langjährigen vergeblichen Unterhandlungen zu einer Spezialrichtlinie, die Kommission den Ingenieursberuf in das allgemeine Anerkennungssystem der Richtlinie 89/48/EWG integriert hat und keinerlei Interesse daran zeigte, die alten Kämpfe wieder aufleben zu lassen ${ }^{1437}$. Die FEANI ${ }^{1438}$ und andere einschlägige Berufsorganisation ${ }^{1439}$ versuchen daher dem Beispiel des CCBE zu folgen und durch Entwicklung

1431. Die meisten Luxemburger studieren in Frankreich, Belgien oder Deutschland. Fur sie gilt ein Schutz des akademitschen Ingenieurstitels.

1432. Urspribnglich galt das Gesetz vom 2. Juni 1962. Gemäß Art. 7 Abs. 10 dieses Gesetzes wird die berufliche Befahthigung eines sellbstầndigen Ingenieurs durch den Besitz eines Diploms oder Sudienabschlußzeugnisses nachgewiesen, die von dem Stat anerkannt ist, in dem die Hochschule ansässig ist. Dazu Jura Europae, Niedlerlassungsrecht, Bd. II, Luxemburg, 50.30. 42 quater. Se it dem Geseto vom 28 . Dezember 1988 wird für die Berechtigung, einen Ingenieurtitel zu führen, eine ministerielle Amerkennung werlangt.

1433. Gemall dem Gesetz vom 8. Dezember 1956 setzt die Berufsausubung ein staatliches Examen voratis. Dazu Pertek, Savoir 1992, 96 (99).

1434. Siehe die Verordnung 12. April 1993, BOE nr. 94 wom 20. Aprill 1993.

1435. Ziviltechnikergesetz 1993, BGBI (Österreich) vom 4. März 1994, 2275. Eine entsprechende Ausfuhrungsverordmung ist ebenfallis ergangen.

1436. Orzack, Technology Studies, 1989, 6u In einer Protokollerkllärung hatte der Rat die Kommission um eine sektorielle Ingenieurrichtlinie ersucht. in der der Besonderheiten dieses Bemufs Rechnung getragen wird.

1437. Siehe dazu die Studie von Dankelmann 1994.

1438. Die FEANI ist der Europäische Verband Nationaler Ingenieurswereine. Sie führt seir 1965 ein Register über die Einstu fung der höhtheren technischen Berufe. Diese wurde Ende der achziger Jahre grundsătzlich uiberarbeitet.

1439. FEANH; CEDIC; FIDIC; EUROFIET 
eines eigenen Richtlinienvorschlags die Kommission von der Nützlichkeit einer sektoriellen Richtlinie zu uberzeugen. Die FEANI hat dazu selbst den Titel eines "European Engineers" geschaffen ${ }^{140}$. Bisher hat die Kommission jedoch einen derartigen Vorschlag nicht übernommen. Eine tatsächliche Notwendigkeit scheint auch kaum gegeben zu sein, weil das System der Richtlinie 89/48/EWG soweit ersichtlich funktioniert.

\section{\$ 3. Die Umsetzung der Richtlinie 89/48/EWG für Ingenieure}

\section{A. DIE BundesREPUBLIK DEUTSCHLAND}

\section{Die Reglementierung des Ingenieurberufes in der Bundesrepublik Deutschland}

Zu den in der Bundesrepublik Deutschland im Sinne der Richtlinie "reglementierten Berufen" gehört auch der Beruf des Ingenieurs. Dabei besteht keine Regelung auf Bundesebene, vielmehr sind in den Bundesländern weitgehend übereinstimmende Ingenieursgesetze erlassen worden. Nach den im wesentlichen gleichlautenden Titeischutzbestimmungen der Ingenieursgesetze der "alten" Bundesländer ist die Führung der Berufsbezeichnung "Ingenieur" grundsätzlich nur Inhabern bestimmter deutscher Studienabschlüsse gestattet ${ }^{1441}$. Inhabern ausländischer Abschlußzeugnisse steht das Führen des Titels nur mit Genehmigung der zuständigen Behörde zu. Diese Genehmigung wird nur erteilt, wenn die Gleichwertigkeit dieser Zeugnisse mit den deutschen Hochschulzeugnissen feststeht. Obwohl diese Titelvorschriften nicht die berufliche Tătigkeit selbst betreffen, sind sie als "Reglementierung" einer beruflichen Tätigkeit im Sinne des Art. 1. Buchstabe d) der Richtlinie $89 / 48 / \mathrm{EWG}$ zu qualifizieren. Daher machte die Umsetzung der Richtlinie eine Änderung der Ingenieursgesetze der Bundesländer erforderlich. Die Bundesländer haben sich, da die Titelschutzvorschriften der Landesingenieursgesetze im wesentlichen übereinstimmten und eine bundesweit einheitliche Umsetzung zweckmäßig erschien, darauf verständigt, grundsätzlich weitgehend übereinstimmende Unsetzungsregelungen zu treffen. Auch haben die Bundesländer ein Abkommen tiber die Genehmigung zur Führung akademischer Grade ausländischer Hochschulen vereinbart ${ }^{1442}$. Die Bundesländer einigten sich in diesem Abkommen darauf, daß gemäß Art. 1 Abs. 1 eine nach dem jeweiligen Landesrecht für den Einzelfall erteilte Genehmigung auch in den anderen Ländern wirksam ist. Eine andere Lösung wäre für die Berufsangehörigen aus anderen Mitgliedstaaten auch kaum nachvollziehbar gewesen.

1440. YDI Nachrichten Nr. 48 vom 27. November 1987, 15; Guerin, European Engineer 1990, 18; Orzack, New Technology 1989,8 mit weiteren Hinweisen. Voraussetzung um nach den FEANI-Regelin die berufliche Bezeichnung "Europaingenieur" führen zu dürfen, sind ein vierjähriges Hochschulstudium oder eine gleichwertige dreijähriges Hochschulausbildung mit einem zusătzlichen won der Hochschulte gelenkten Praktikum sowie eine dreijährige Berufsertahrung als Ingenieur.

1441. Siehe z.B. I Ingenieurgesetz des Landes Nordrhein-Westfalien; 1 Hamburgisches Ingenieurgesetz.

1442. Abkommen zwischen den Landern in der Bundestepublik Deutschland juber die Genehmigung zur Fuhrung akade mischer Grade ausländischer Hochschulen und entsprechender auslandischer Grade wom 29. Oktober 1992. Siehe dazu das Hamburgische Zustimmungsgesetz vom 1. Nowember 1993, Hantburgisches GVBL. 1993, 295 
Neben der Berufsbezeichnung "Ingenieur" gibt es auch noch die Berufsbezeichmung "Beratender Ingenieur". Diesbezüglich haben einige Bundesländer Sonderregelungen erlassen, wonach freiberuflich tätige Ingenieure diese Berufsbezeichnung lediglich dann führen dürfen, wenn sie zur Titelführung "Ingenieur" berechtigt sind und zusätzlich den Nachweis einer dreijährigen einschlägigen Berufstätigkeit erbringen ${ }^{1643}$.

\section{Umsetzungsmaßnahmen für Ingenieure in der Bundesrepublik Deutschland}

Da die Änderung der Ingenieursgesetze in die Gesetzgebungskompetenz der Länder fält, sind diese auch für die Umsetzung der Richtlinie 89/48/EWG auf diesem Gebilet verantwortlich. Die Umsetzung ist jedoch noch nur mit erheblichen Verzögerungen in den Bundeslåndern durchgeführt worden. Bis zum Ende von 1992 lagen die Gesetze von Baden-Württemberg ${ }^{1444}$, Berlin ${ }^{1445}$, Brandenburg ${ }^{1446}$, Hamburg ${ }^{1447}$, Hessen $^{144}$, Niedersachsen ${ }^{1449}$, Nordrhein-Westfalen ${ }^{1450}$, RheinlandPfalz ${ }^{1451}$, dem Saarland ${ }^{1452}$, Sachsen-Anhalt ${ }^{1453}$, Schleswig-Holstein ${ }^{1454}$ sowie Thüringen ${ }^{1455}$ vor. Keine Umsetzungsmaßnahmen gab es zum Beginn des Binnenmarktes in den Ländern Bayern, Bremen, Mecklenburg-Vorpommern und Sachsen..

1443. Eine Umsetzung der Richtlinie 89/48/EWG beziiglich der "Beratenden Ingenieure" hat Nordrhe:in* Westfalen im Rahmen des "Gesetzes über den Schutz der Berufsbezeichnungen "Architekt". Anchitektin", Stadtplaner" und "Stadtplanerin" sowie über die Architektenkammer, über den Schutz der Berufsbezeichnung "Beratender Ingenieur" und "Beratende Ingenieurim" sowie über die IngenieurskammerBau-Baukammerngesetz (BauKaG NW) rom 15. Dezember 1992, Gesetz- und Verordnungsblatt NW vom 30. Dezember 1992, 534 ff. getroffen.

1444. Gesetz zur Ändenung des Ingenieurgesetzes vom 25. Februar 1992, GBI. 1992 vom 20. März 1992. Nr. 7, 151; zulletzt geändert durch Gesetz vom 16. Dezember 1993, GBI. 1993, 1.

1445. Gesetz vom 13. Oktober 1992, GVB Nr. 47 vom 24. November $1992,308$.

1446. Gesetz zum Schutz der Berufsbezeichmung "Ingenieur" vom 19. Oktober 1993, GVB Nr, 23 vom 21 , Oktober 1993,460 .

1447. Gesetz zur Änderung des Hamburgischen Ingenieurgesetzes vom 16. April 1991, Hamburgisches Giesetz- und Verordnungsblatt 1991, Nr. 19, 115 .

1448. Gesetz zur Änderung des Ingenieurgesetzes vom 20. Dezember 1990, Gesetz- und Verordmungsblatt für das Land Hessen, Teil I vom 28. Dezember 1990, Mr, 35, 771

1449. Gesetz zur Änderung des Niedersächsischen Ingenieurgesetzes wom 15. Mail 1992, Nieders. GVBI. NI 21/1992, atusgegeben am 20. Mai 1992, 150.

1450. Gesetz zur Änderung des Ingenieurgesetzes vom 15. Oktober 1991, Gesetz- und Verord nungsblatt für das Land Nordrhein-Westfalen 1991, Nr. 45 vom 4. Nowember 1991, 376; zuletzt geändert durch Gesetz vom 17. Mai 1994, GVBI. 1994, 438.

1451. Landesgesetz zur Änderung des Ingenieurgesetzes vom 28. November 1991, Gesetz-und Verordnung sw blatt fur das Land Rheinland-Pfalz 1991. Nr. 22 vom 29. Nowember 1991, 362.

1452. Gesetz $\mathrm{Nr}$ 1271 zur Änderung des Gesetzes zum Schutze der Berufsbezeichnung Ingenieur vom 20 Mârz 1991. Amtsblatt des Saarlandes vom 24. Mai 1991, 610.

1453. Ingenieurgesetz des Landes Sachsen-Anhalt vom 15. November 1991, GVBI. LSA Nr.38/1991, ausgegeben am 22. November 1991, 440.

1454. Gesetz zur Änderung des Ingenieurgesetzes vom 2. Juli 1991 , Geset $x$ - und Verordnungsblatt für Schleswig-Holstein 1991, Nr. 15, 375; Ingenieurgesetz vom 31. März 1992, zuletzt geändlent durch Gesetz yom 19. November 1993, GVB1. 1993, 531

1455. Landesgesetz zum Schutz der Berufsbezeichnung. "Ingenieur" wom 7. Januar 1992, GVB $\mathrm{Nr}$. I wom 10. Januar 1992,1 . 
Diese Lage hat sich inzwischen geändert. Bayern ${ }^{1456}$, Bremen ${ }^{1457}$, MecklenburgVorpommern ${ }^{1458}$ und Sachsen ${ }^{1459}$ haben umgesetzt. In Nordrhein-Westfalen wurde in einem weiteren Gesetz der Schutz der Berufsbezeichnung "Beratender Ingenieur" geregelt ${ }^{1460}$.

Generell erfolgte die Umsetzung durch die Einführung eines Genehmigungsverfahrens, in dessen Rahmen die Anerkennung der EG-Hochschuldiplome vorgenommen wird. Bei Vorliegen der von der Richtlinie vorgegebenen Voraussetzungen hat der Antragsteller einen Rechtsanspruch auf die Erteilung der Genehmigung. Allein Niedersachsen hat die Umsetzung ohne Einführung eines Genehmigungsverfahrens vorgenommen. Auf die Ablegung einer Eignungsprüfung oder eines Anpassungslehrganges haben alle Länder verzichtet. Die Änderung erfolgte durch Einfügung eines neuen Absatzes in die jeweiligen bestehenden Ingenieursgesetze der alten Bundesländer ${ }^{1461}$. In den neuen Bundesländern Brandenburg, Mecklenburg-Vorpommern, Sachsen, Sachsen-Anhalt und Thühringen wurde die Umsetzung im Rahmen der Verabschiedung eines neuen Ingenieurgesetzes durchgeführt ${ }^{1462}$.

Das Beispiel Niedersachsen zeigt, daß trotz der grundsätzlichen Übereinstimmung der Umsetzungsmaßnahmen in den Bundesländern sich auch. Unterschiede zwischen den einzelnen Regelungen feststellen lassen, wodurch die Qualität der Umsetzung je nach Bundesland unterschiedlich beurteilt werden muß.

Es folgt eine kurze Beschreibung des Kerns der U'msetzungsgesetze, wobei die Reihenfolge durch die Liberalität der Regelung bestimmt wird:

\section{Die Umsetzung durch Ländergesetzgebung}

\section{a. Niedersachsen}

Wie bereits festgestellt, haben die Bundesländer grundsätzlich die Führung eines im Ausland erworbenen Ingenieurstitel von einer Genehmigung abhängig gemacht. Insoweit

1456. Gesetz zur Änderung des Ingenieursgesetz vom 28. April 1994, Bayerisches GVB!. vom 30. April 1994 I, Nr. 10, 297.

1457. Bremisches Ingenieurgesetz vom 19. Mai 1994, Gesetzblatt der Freien Hansestadt Bremen 1.994 1, Nr. 19.131.

1458. Gesetz zum Ingenieurgesetz des Landes Mecklenburg-Vorpommern (IngG M-V) vom 8. November 1993, GVB 19931 . Nr. 21, 878.

1459. Sächsisches Ingenieurgesetz vom 23. Februar 1993, GVBI. 1993, 236.

1460. Gesetz über den Schutz der Berufsbezeichnung "Beratender Ingenieur", GVB Nr, 62 vom 30. Dezember 1992 .

1461. Baden-Württemberg $\$ 2$ Abs. 3 Ingenieurgesetz, Hamburg $\$ 2$ Abs. 3 Ingenieurgesetz, Hessen $\$ 2$ a Ingenieurgesetz, Niedersachsen \& IIngenieurgesetz, Nordrhein-Westfalen \& 2 Abs. 3 Ingenieurgesetz, Rheinland-Pfalz 2 Abs. 3 Ingenieurgesetz, Saarland $\$ 2$ Abs. 3 Ingenieurgesetz. Schleswig-Holstein $\$ 2$ Abs. 3 Ingenieurgesetz. Bremen und Schleswig-Holstein haben allerdings nete Ingenieurgesetze verabschiedet.

1462. Sachsen-Anhalt $\$ 2$ und 3 Ingenieurgesetz. 
weicht die Regelung für EG-Angehörige nicht won entsprechenden Bestimmungen für Inhaber ausländischer Ingenieurstitel ab. Der Unterschied liegt lediglich darin, daß EGAngehörige einen Rechtsanspruch auf Genehmigungserteilung haben.

Eine abweichende Regelung findet sich lediglich im Niedersächsischen Ingenieurgesetz. Hierin wird eine allgemeine Berechtigung zur Führung der Berufsbezeichnung "Ingenieur" erteilt, soweit die Voraussetzungen des \& 1 Niedersachsen IngG erfüllt sind. Interessanterweise werden dabei die einschlägigen deutschen Diplome unter $\$ 1$ Abs. $1 \mathrm{Nr}$. 5-8 IngG aufgelistet. Gemäß \& 1 Abs. $1 \mathrm{Nr} .1$ - 4 IngG gilt dies auch für die in einem anderen Mitgliedstaat erworbenen Diplome (Nr. 1), für Drittstaatsdiplome soweit diese von einem Mitgliedstaat anerkannt sind und dieser bescheinigt hat, daß der Betreffende mindestens drei Jahre in einem Mitgliedstaat einen Ingenieurbenf rechtmäßig ausgeubt hat (Nr. 2) und für die Personen, deren Ausbildung von einem Mitgliedstaat als gleichwertig anerkannt worden ist (Nr.3). Ist jemand nach dem Recht eines Mitgliedstaates - ohne daß er die Voraussetzungen des $\$ 1$ Abs. 1 Nr. 1 - 3 erfüllt - berechtigt, die Berufsbezeichnung "Ingenieur" oder eine vergleichbare Berufsbezeichung zu führen, so hat er das Führen dieser Berufsbezeichnung in Niedersachsen unter Vorlage der Bescheinigung des Mitgliedstaates der dortigen Ingenieurkammer anzuzeügen (Nr.4). Auch in diesem Fall wird die Berechtigung nicht von einer zuvor zu erteilenden Genehmigung abhängig gemacht, erforderlich ist jedoch die Anzeige. Gemäß \& 34 IngG wird lediglich festgestellt, daß das unberechtigte Führen der geschützten Berufsbezeichnung eine Ordnungswidrigkeit darstellt.

Bedeutsam für Ingenieure aus anderen Mitgliedstaaten, die sich nicht in Niedersachsen niederlassen wollen, jedoch im $\mathbb{R}$ ahmen der Dienstleistung unter anderem in Niedersachsen tätig sein möchten, ist auch noch die Bestimmung des $\$ 1$ Abs. $1 \mathrm{Nr}$. 8. Danach darf jemand, der nach dem Recht eines anderen Bundeslandes zur Führung der Berufsbezeichunung berechtigt ist, diese Berufsbezeichung auch in Niedersachsen führen. Eine Genehmigung, die in einem anderen Bundesland erteilt worden ist, gilt also auch in Niedersachsen.

b. Hamburg, Nordrhein-Westfalen, Rheinland-Pfalz

Nach $\$ 2$ Abs. 3 a) des IngG Hamburg, $\$ 2$ Abs. 3 a) des IngG NW, $\$ 2$ Abs. 3 (1) des IngG Rheinland-Pfalz wird die Genehmigung erteilt, wenn der Antragsteller Staatsangehöriger eínes Mitgliedstaates der Europäischen Gemeinschaften ist und ein Diplom erworben hat, das in einem anderen Mitgliedstaat für den Zugang zum Ingenieurberuf, dessen Ausübung oder die Führung eines der deutschen Berufsbezeichnung "Ingenieur" entsprechenden Berufsbezeichnung erforderlich ist. Mit diesem Wortlaut wird die Richtlinie entsprechend Art. 3 Buchstabe a) umgesetzt. Für den Begriff des Diploms wird auf die Definition in Art. 1 Buchstabe a) der Richtlinie 89/48/EWG verwiesen. Diplome, die auf Grund einer Ausbildung ausgestellt sind, die nicht überwiegend in einem Mitgliedstaat erfolgt ist, werden wie anerkannte Drittlanddiplome behandelt. In diesem Falle wird die Genehmigung erteilt, wenn der Inhaber des in Frage stehenden Diploms tatsächlich und rechtmäßig eine mindestens dreijährige Berufserfahrung als Ingenieur 
hat und dies von dem Mitgliedstaat bescheinigt wird, der das Diplom ausgestellt oder anerkannt hat (IngG Hamburg).

Falls in dem Herkunftsstaat die Ausübung des Berufes nicht an den Besitz eines bestimmten Ingenieur-Diploms gebunden ist, so wird die Genehmigung dennoch erteilt, wenn der Antragsteller den Beruf des Ingenieurs vollzeitig zwei Jahre lang in den vorhergegangenen zehn Jahren in einem Mitgliedstaat ausgeübt hat und dabei in Besitz won Ausbildungsnachweisen im Sinne des Art. 3 Buchstabe b) der Richtlinie 89/48/EWG ist. Diese Regelung bezieht sich auf Mitgliedstaaten, in denen der Beruf des Ingenieurs nicht reglementiert ist. Hiermit erfolgt eine Umsetzung des Art. 3 Buchstabe b) der Richtlinie $89 / 48 /$ EWG ( $\$ 2$ Abs. 3 b) IngG Hamburg und IngG NW, $\$ 2$ Abs. 3 (2) IngG Rheinland-Pfalz).

Des weiteren verweist $\$ 5$ Hamburg IngG auf das Gesetz über die Führung akademischer Grade vom 7. Juni 1939.

Gemäß \& 2 Abs. 5 IngG NW bedarf keiner Genehmigung, wer nach $\$ 141$ des Gesetzes über die wissenschaftichen Hochschulen des Landes Nordrhein-Westfalen berechtigt ist, den an einer ausländischen Hachschule erworbenen akademischen Grad des Ingenieurs zu führen. \$141 Abs. 1 Gesetz über die wissenschaftlichen Hochschulen des Landes Nordrhein-Westfalen lautet:

"Von einer staatlichen oder staatlich anerkannten. Hochschule in Deutschland oder in einem anderen Mitgliedstaat der Europäischen Gemeinschaft einschließlich der europäischen Hochschulen in Florenz und Brügge sowie der Päpstlichen Hochschulen in Rom verliehene Hochschulgrade, Hochschulbezeichnungen oder Hochschultitel sowie entsprechende staatliche Grade, Bezeichnungen oder Titel (Grade) können im Geltungsbereich dieses Gesetzes geführt werden. Der Grad ist grundsätzlich in der Form zu füren, die dem Wortlaut der Verleihungsurkunde entspricht. Der Berechtigte darf dem Grad eine Übersetzung hinzufügen, soweit das aus sprachlichen Gründen zum Verständnis erforderlich ist, eine im Herkunftsstaat zugelassene oder nachweisbar allgemein übliche Abkürzung verwenden und durch einen Zusatz auf den Herkunftsstaat oder die verleïhende Hochschule hinweisen."

Gemäß $\$ 5$ IngG NW ist die zuständige Behörde im Sinne dieser Bestimmungen der Regierungspräsident, in dessen Bezirk der Antragsteller berufstätig ist oder seinen Wohnsitz hat. Ist ein Ort der Berufstätigkeit, ein Wohnsitz oder ein gewöhnlicher Aufenthaltsort in der Bundesrepublik Deutschland nicht vorhanden und war dies bisher auch nicht der Fall, so ist der Regierungspräsident zuständig, in dessen Bezirk die Berufstätigkeit ausgeübt werden soll ${ }^{1463}$.

1463. \& S Satz 2 und 3 ingenieurgesetz. Nordrhein-Westfaten. 
Fallstudie 11: Ingenieur

Das Genehmigungsverfahren muß spätestens vier Monate nach Vorlage der vollstăndigen Unterlagen des Antragstellers mit eimer mit Gründen versehenen Entscheidung der zuständigen Behörde abgeschlossen werden ${ }^{1464}$. Mit dieser Regelung wird Art. 8 Abs. 2 der Richtlinie $89 / 48 / E W G$ umgesetzt. Da es sich bei der Genehmigung beziehungsweise ihrer Ablehnung um einen Verwaltungsakt im Sinne des Verwaltungsverfahrensgesetzes handelt, gegen den ein gerichtlicher Rechtsbehelf beim zuständigen Verwaltungsgericht besteht, erfüllt diese Bestimmung auch die Anforderungen des Art. 8 Abs. 2 Satz 2 der Richtlinie 89/48/EWG.

c. Baden-Württemberg, Hessen, Saarland, Sachsen-Anhallt, Schleswig-Holstein, Thüringen

Auch in diesen Bundesländern wurde ein Genehmigungsverfahren eingeführt ${ }^{1465}$

Abweichend jedoch von den Bestimmungen in Hamburg, Nordrhein-Westfalen und Rheinland-Pfalz wurde hinsichtlich der Diplome bzw. der erforderlichen Ausbildungsnachweise nicht nur auf die Definitionen der Richtlinie verwiesen, sondern es wurden Ergänzungen angebracht.

Hinsichtlich der Umsetzung des Art. 3 b) der Richtlinie 89/48/EWG enthalten die Regelungen von Baden-Württemberg, Hessen, des Saarlands, Sachsen-Anhalts, Schleswig-Holstein und Thüringen die inhaltliche Ergänzung, daß der Antragsteller im Besitz von Ausbildungsnachweisen sein $\mathrm{mu} \beta$, aus denen hervorgeht, daß der Inhaber ein mindestens dreijähriges überwiegend technisches oder naturwissenschaftliches Studium abgeschlossen hat.

In Sachsen-Anhalt bezieht sich die Ergänzung auch auf die Umsetzung von Art. 3 a) der Richtlinie 89/48/EWG in dem in \&3 Abs. $1 \mathrm{Nr} .1$ bestimmt wird, daß der Antragsteller das Diplom einer überwiegend technischen oder naturwissenschaftlichen Fachrichtung erworben haben muß.

Ähnlich wie \& 5 IngG Hamburg bestimmt auch \& 5 IngG Thüringen, daß einer Genehmigung nicht bedarf, wer nach dem Gesetz über die Führung akademischer Grade berechtigt ist, den an einer ausländischen Hochschule erworbenen akademischen Grad des Ingenieurs zu führen.

\section{Beurteilung der Umsetzung fiur Ingenieure}

1464. 2 Abs. 3 Satz 3 Hamburgisches Ingenieurgesetz; $\$ 2$ a Abs. 4 Ingenieurgesetz des Landes Hessen $\$ 5$ a des Landes Nordhein-Westfalen; 8 a Ingenieurgesetz des Saarlandes; $\$ 6$ Ingenieurgesetz won Schleswig Holstein.

1465. \$2 Abs. 3 IngG Baden-Württemberg. $\$ 2$ a IngG Hessen, $\$ 2$ Abs. 3 Saarland, $\$ 3$ Sachsen-Amhalt, $\$ 2$ Abs. 3 Schleswig-Holstein, 2 Abs. 3 Thüringen. 
Grundsätzlich muß die Umsetzung für Ingenieure durch die deutschen Bundesländer positiv beurteilt werden, da sie von einer direkten Anerkennung gemäß Art. 3 der Richtlinie 89/48/EWG ausgeht. Dennoch lassen sich Uinterschiede hinsichtlich der verschiedenen Regelungen aufzeigen. Bemerkswert ist dabei vor allem die automatische Berechtigung zur Titelführung nach der niedersächsischen Regelung, wohingegen die anderen Bundesländer zumindest formal an einem Anerkennungsverfahren festgehalten haben. Dabei ist die Regelung der für die Anerkennung zuständigen Stellen sehr verwirrend, da jedes Bundesland eine eigene Lösung gewählt hat. In einem Bundesland wurden die Regierungspräsidenten angewiesen ${ }^{1466}$, in anderen Bundesländern ist das Wissenschaftsministerium zuständig ${ }^{1467}$, wiederum andere Bundesländer haben andere Ministerien mit dieser Aufgabe betraut. Schließlich sind es in Schleswig-Holstein die Bürgermeister und Landräte, die als zuständige Behörden angewiesen wurden. Für einen mit dem Verwaltungsrecht Deutschlands vertrauten Juristen ist dieses "Sammelsurium" der Kompetenzwerteilung bereits schwer zu durchschauen. Für ausländische Ingenieure dürfte diese Regelungsvielfalt kaum nachvollziehbar sein. Vor allem im Falle einer Ingeniieurstätigkeit im Rahmen des Dienstleistungsverkehrs erscheint es mir nicht zumutbar, diesen Kompetenzenwirrwarr zu durchdringen. Meines Erachtens hätten die Bundesländer insgesamt besser daran getan, dem Beispiel Niedersachsens zu folgen und eine automatische Berechtigung zur. Titelführung zu gewähren. Dies hätte einen direkten Beitrag zur Deregulierung geleistet. Im Falle nichtberechtigter Titellführung hätten die selben Mittel zur Verfügung gestanden wie bei Deutschen.

\section{a. Beurteilung der Umsetzung für Ingenieure in Niedersachsen}

Diese Umsetzung erfüllt alle Anforderungen der Richtlinie 89/48/EWG. Sie geht selbst darüber hinaus. Der Berechtigte kann seinen Titel automatisch führen, ohne zuvor einer Genehmigung zu bedürfen. Mit Ausnahme bei Drittstaatsdiplomen wird von dem Berechtigten kein Nachweis verlangt, daß er den Ingenieurberuf bereits ausgeübt hat, d.h. auch nicht in den Fällen, die unter Art. 3 b) der Richtlinie 89/48/EWG zu subsumieren sind. Diese Regelung gilt nicht nur für Staatsangehörige der Mitgliedstaaten, sondern für jeden, der über die entsprechenden Ausbildungsnachweise und Diplome verfüigt. Mit dieser Regelung hat Niedersachsen eine tatsächliche Gleichstellung der ausländischen mit den deutschen Ingenieurstiteln erzielt. Wie bei diesen wird lediglich das unberechtigte Führen gemäls $\$ 34$ IngG als Ordnungswidrigkeit geahndet.

1466. So z.B. in Baden Wurtuemberg, Hessen, Sachsen 1467. Dies gilt für Brandenburg und Rheinland-Pfalz. 
Fallstudie II: Ingenieur

b. Beurteilung der Umsetzung für Ingenieure in Hamburg, Nordrhein-Westfalen und Rheinland-Pfalz

Grundsätzlich haben Hamburg, Nordrhein-Westfalen und Rheinland-Pfalz die Richtlinje im Sinne des Art. 3 der Richtlinie 89/48/EWG umgesetzt.

Undeutlich ist jedoch, wie in Nordrhein-Westfalen das Verhåltnis zwischen dem Gesetz zur Änderung des Ingenieurgesetzes und dem Gesetz über dïe wissenschaftlichen Hochschulen des Landes Nordrhein-Westfalen zu beurteilen ist. Nach dem Ingenieurgesetz ist der Berechtigte zur Führung der Berufsbezeichnung "Ingenieur" in der Form des Aufnahmestaates befugt (vgl. Art. 7 Abs. 1 der Richtlinie 89/48/EWG); er bedarf dazu aber einer Genehmigung. Nach $\S 141$ des Gesetzes über die wissenschaftlichen Hochschulen des Landes Nordrhein-Westfalen kann der Berechtigte den Ausbildungstitel des Herkunftsstaates automatisch führen (vgl. Art. 7 Abs. 2 der Richtlinie 89/48/EWG). Diese Zweigleisigkeit hinsichtlich der Titelführung trägt nicht zur Verdeutlichung der Rechtslage bei. Für Migranten ist es vollkommen undeutlich, welchen der beiden Wege sie einzuschlagen haben. Dies gilt zumal in den Fällen gleichllautender Berufsbezeichnung, die sich lediglich durch Groß-bzw. Kleinschreibung unterscheidet, so z.B. im Verhältnis Deutschland und den Niederlanden (Ingenieur/ingenieur). Allerdings unterscheidet sich bei diesem Beispiel die berufsübliche Abkürzung (Dipl.Ing./IR.). Das Beispiel zeigt die Absurdität der Unterscheidung zwischen professioneller und akademischer Anerkenmung im Falle einer reinen Titelreglementierung.

Ebenso unglücklich ist die Regelung der zuständigen Behörde in Nordrhein-Westfalen, da Migranten nicht an eine generell zuständige Stelle verwiesen werden, vielmehr die Zuständigkeit sich nach Sachlage verändert. Dies gilt um so mehr, als jedes Bundesland hinsichtlich der zuständigen Behörde eine eigene Regelung getroffen hat. Im allgemeinen wird jedoch in Nordrhein-Westfalen der Regierungspräsident zuständig sein, in dessen Bezirk die Berufstätigkeit ausgeübt werden soll.

c. Beurteilung der Umsetzung für Ingenieure in Baden-Württemberg, Hessen, Saarland, Sachsen-Anhalt, Schleswig-Holstein, Thüringen

Die in diesen Ländern vorgenommenen Ergänzungen entsprechen nicht der Zielsetzung der Richtlinie. Zwar wird in den meisten Mitgliedstaaten die Ausübung des Ingenieursberufs von einem überwiegend naturwissenschaftlichen oder technischen Studiums abhängig gemacht, dies muß jedoch nicht der Fall sein. 


\section{B. SPANIEN}

\section{Die Umsetzungsregelung}

Spanien hat die Umsetzung für Ingenieure durch eine Ministerialverordnung ausgeführt ${ }^{146 \%}$. Diese erging auf der Grundlage des Real decreto 1665/1991. Spanien hat sich im Gegensatz zu Deutschland nicht für eine direkte Anerkennung gemäß Art. 3 der Richtlinie 89/48/EWG entschieden. Vielmehr enthält die Verordnung auch die Möglichkeit, gegebenenfalls eine Eignungsprüfung oder einen Anpassungslehrgang zu verlangen ${ }^{1469} \mathrm{Im}$ Wesentlichen entsprechen die Bestimmungen der Verordnung dem Wortlaut der Richtlinie 89/48/EWG. Die Ausfïhrungsmaßnahme enthält keine genasere Fächerauflistung für den Fall der Eignungsprüfung oder des Anpassungslehrgangs. Im Einzelfall sollen die Fächer vom Secretaría General Téchnica del Ministerio de Obras Públicas y Transportes in Zusammenarbeit mit dem Secretaria General Téchnica del Ministerio de Educación und dem jeweiligen Colegio professional ${ }^{1470}$ bestimmt werden (Regelung Noveno). Der Fächerkatalog darf sich dabei allerdings nur auf die Bereiche beziehen, die nicht bereits durch die Ausbildung des Antragstellers abgedeckt werden.

\section{Die Beurteilung der Umsetzung}

Die ministerielle Verordnung entspricht nahezu wörtlich der Richtlinie. Inwieweit die Möglichkeit, vom Migranten eine Eignungsprüfung oder einen Anpassungslehrgang zu verlangen, einen Rückschritt zur bisherigen Praxis darstellt, läßt sïch nur sehr schwer beurteilen. Auch liegt bisher noch kein Zahlenmaterial dahingehend vor, wie häufig bei Anerkennungsverfahren eine Kompensation in Form einer Eignungsprüfung oder eines Anpassungslehrgangs verlangt worden ist. Solange dieses Zahlenmaterial nicht vorliegt, ist eine abschließende Beurteilung nur sehr schwer vorzunehmen. Jedenfalls halte ich das Erfordemis eines Anpassungslehrgangs oder einer umfassenden Eignungsprüfung im Falle der Ingenieurstätigkeit im Dienstleistungsverkehr nur schwer mit dem vom EuGH entwickelten Verhältnismäßigkeitsprinzip vereinbar.

1468. Siehe die Verordnung vom 12. April 1993, BOE Nr. 94 vom 20. April 1993, 1253.

1469. Regelung Octavo.

1470. Insgesamt gibt es neun verschiedene colegios professionalles für Ingenieure und weitere neun für technische Ingenieure, siehe dazu Pertek, Savoir 1992, 96 (100). Die Einschreibung bel einem colegio istt Voraussetzung für bestimmte Ingenieurstäigkeiten. 


\section{C. ÖSTERREICH \\ 1. Die Umserzungsregelung}

Österreich, das eine Vielzahl unterschiedlicher Ingenieurberufe kennt, hat eine Umsetzung im Rahmen des "Ziviltechnikergesetzes $1993^{\prime \prime}$ vorgenommen ${ }^{1471}$. Gemäß \& 32 Abs. 7 des Ziviltechnikergesetz bestimmt der Bundesminister für wirtschaftliche Angelegenheiten durch Verordnung, welche genauen Bedingungen für eine Anerkennung ausländischer Befähigung vorliegen müssen. Nach dieser Verordnung kann von dem Antragsteller sowohl im Falle des Dienstleistungsverkehrs als auch bei der Niederlassung eine Eignungsprïfung verlangt werden ${ }^{1472}$. Inhaltlich wird auf die in $\$ 9$ des Ziviltechnikergesetzes geregelte Ziviltechnikerprüfung verwiesen. Dabei sollen zumindest die in $\$ 9$ Abs. 3, Ziffer 1 und 3 genannten Fächer Bestandteil der Eignungsprüfung sein. Dies betrifft einerseits das österreichische Verwaltungsrecht, andererseits die für das Fachgebiet geltenden rechtlichen und fachlichen Vorschriften. Eine Befreiung von der Prüfung ist möglich. Die Eignungsprüfung soll mündlich abgenommen werden ( $\$ 4$ Abs. 2 der Verordnung). Eine Regelung für einen Anpassungslehrgang ist in der Umsetzungsgesetzgebung nicht vorgesehen.

\section{Beurteilung der Umsetzung}

Eine derartige Umsetzung ist meines Erachtens nicht mit dem System der Richtlinie 89/48/EWG zu vereinbaren, da dem Antragsteller zumindest eine Wahl hinsichtlich der Kompensationsinstrumente geboten werden muß. Die Tatsache, daß die Eignungsprüfung sich unter anderem auch auf das österreichische Verwaltungsrecht bezieht ( $\$ 9$ Abs. 3, Ziffer 1 des Ziviltechnikergesetzes) rechtfertigt nicht die Einstufung des Ingenieurberufs als einen "rechtsberatenden Beruf" im Sinne der Richtlinie 89/48/EWG. Falls Österreich die Wahl der Kompensationsinstrumente auf die Eignungsprüfung beschränken möchte, müßte ein Verfahren gemäß Art. 10 der Richtlinie 89/48/EWG durchgeführt werden. Dabei halte ich es für unwahrscheinlich, daß die Kommission eine derartige Beschrärkung befürwortet. Zweifelhaft ist meines Erachtens auch die Spezialregelung für den Dienstleistungsverkehr, die ebenfalls eine Eignungsprüfung vorsieht. Eine derartige Regelung entspricht nicht den von der Rechtsprechung zum Dienstleitungsverkehr entwickelten Prinzipien und wird sich nur in den seltensten Fällen durch ein zwingendes Allgemeininteresse rechtfertigen lassen.

1471. Ziviltechnikergesetz 1993, BGBI (Österreich) vom 4. Mărz 1994, 2275. Eine entsprechende Ausfuhungsverordnung ist ebenfalls ergangen.

1472. \$32 Abs. 7 Ziwiltechnikergesetz 1993 i.V. mit \$1 Abs. 3, \$3 und \$ 4 aer Verordnung. 


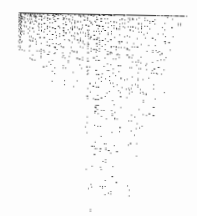

Teil V

Fallstudie III

\section{Lehrer}

\section{\$1. Einleitung}

Von der Richtlinie sind auch die Lehrer erfaßt. Während des Umsetzungsprozesses haben sich für diese Berufsgruppe drei deutliche Problemgebiete herauskristallisiert. Es handelt sich dabei 1. um das Verhältnis von Art. 48 Abs. 4 EGV zum Beamtenstatus der Lehrer in einigen Mitgliedstaaten, 2. um den Concours als Auswahl- und Einstellungssystem in Frankreich, Luxemburg, Italien, Portugal und Spanien und 3. um die zwei-Fächer Bedingung der deutschen Lehrbefähigung ${ }^{1473}$. Als ein weiteres, wenn auch kleines Problem könnte man den in den meisten Mitgliedstaaten geforderte Nachweis von Sprachkenntnissen bezeichnen ${ }^{1474}$.

Des weiteren muß konstatiert werden, daß in einigen Mitgliedstaaten die notwendigen Ausführungsregelungen noch fehlen, obwohl bereits allgemeine Umsetzungsgesetze erlassen sind. Diese Situation ist unproblematisch soweit im Rahmen einer Fall-zu-FallEnischeidung das allgemeine Umsetzungsgesetz durch die zuständigen Behörden angewendet wird. Bedenklich dagegen wird die Situation, wenn unter Berufung auf fehlende Ausführungsmaßnahmen eine Entscheidung über einen Anerkennungsfall gånzlich verweilgert wird. Bisher liegen keine voliständigen Ausführungsbestimmungen für Belgien $^{1475}$, Griechenland ${ }^{1476}$, Italien ${ }^{1477}$, Portugal ${ }^{1478}$ und Spanien ${ }^{1479}$ vor.

1473. Dieses Problemgebiet wird im Rahmen der Eröterung der hamburgischen Umsetzungsregelung zur Sprache kommen, siehe dazu Seite 383.

1474. Nach einer nicht veröffentlichten Protokollerklänng zur Richtlinie 89/48/EWG stimmten Rat und Kommission grundsätzlich darin überein, daff der Bewerber die Sprachkenntun̈sse besitzen mulf, die für die Ausübung seines Benfs erforderlich sind. Siehe auch Art. 3 Abs. 1 der Verordnung $1612 / 68$. Dazu die Erörterungen Seite 375 . Vergleiche De Witte $1995,263 \mathrm{f}$.

1475. Belgien hat eünige Umsetzungsmaßnahmen an die Kommission mitgeteilt, eine wollstăndige Unsetzung lluegt jedoch noch nicht wor. Siehe aber Décret der Flämischen Gemeinschaft wom 27. Mărz 1991 bezüglich der Rechtsposition von Lebrenden, Moniteur Belge vom 25. Mai 1991, 11454.

UmsetzungsmaBnatumen für Lehrer:

Ausfihrungsmaßnahmen der flämischen Gemeinschaft: Décret vom 12. Juni 1991, Moniteur Belge vom 4. Juli 1991 sowie der Ausführangsbeschluß bezäglich der Anpassungsinstrumente vom 30. September 1992. Moniteur Belge vom 22. Oktober 1992. 
In Belgien ist die Situation besonders kompliziert, da aufgrund der verfassungsrechtlichen Veränderungen sich auch die Befugnis zur Umsetzung der Richtlinie 89/48/EWG geändert hat. Für Berufe, die in den Zuständigkeitsbereich der Gemeinschaften fallen, wollen die Gemeinschaften auch die Anerkennungsbefugnis hinsichtlich ausländischer Berufsangehöriger. Dies gilt $2 . B$. auch für den Beruf des Lehrers ${ }^{1480}$. Aufgrund dieser rechtlich teillweise ungeklärten Lage, hat die Umsetzung der Richtlinie 89/48/EWG bisher nur einen sehr rudimentären Charakter ${ }^{148 \|}$. Obwohl die Richtlinie unzure"lchend umgesetzt ist, werden Anerkennungsverfahren aber mittels Einzelfallentscheidungen abgeschlossen ${ }^{14: 52}$.

Bedenklich ist die Lage auch in einigen Bundesländern der Bundesrepublik Deutschland, wo die bis Ende 1993 fehlende Änderung des Beamtenrechts auf Bundesebene lange Zeit zum Anlaß genommen wurde, eine Anwendung der Richtlinie 89/48/EWG oder ihre Umsetzung in die Ländergesetzgebung zu verweigern ${ }^{1483}$.

1475. $\rightarrow$

Ausführungsmaßnahmen der wallionischen Gemeinschaft: Décret vom 27. März 1991, Moniteur Belge vom 25. Mai 1991; Décret vam 26. Juni 1992, Moniteur Belge von 10. September 1992. Diese Maßnahmen können jedoch nicht als vollstĭndig angesehen werden.

1476. Griechenland plant eine sektorielle Umsetzung für die Lehrer. Konkrete Umsetzungsmalßnahmen sind jedoch bisher nicht veröffentlicht. Auch muB. Griechenland eine Verfassungsänderung oder zumindest Gesetzesänderung durchführen, um die Ernennung auslänclischer Lehrer zu ermöglichen.

1477. Italien könnte aufgrund des. Decreto Legislativo wom 27. Jamuar 1992 im Einzelfall die Anerkennungsfälle entscheiden. Bisher ist jedoch nicht bekannt, ob solche Ane rkennungsverfahren tatsächlich durchgefulurt worden sind.

1478. Durch Erlaf Nr. 8/91 vom 8. Januar 1991 erfolgte eine Umsetzung für ausländische Assistenten für den Fremdsprachenunterricht (Muttersprachler). Durch die regionalen Behörden sollen diese an das portugiesische Bildungssystern angepaBt werden, wobei die Absolvienung von Sprachtests fur Portugiesisch vorgesehen sind. Weitere Ausführungsmaßnahmen sind noch nicht ergangen. Obwohl Portugal ein allgemeines Umsetzungsgesetz erlassen hat, venweigern die portugiesischen Behörden dessen Anwendung bis zum Erlaß der Ausfühnugsverordnungen. Hierin ist ein Verstoß gegen die Umsetzungsverpflichtung sehen. Portugal gehört wie Italien, Frankreich, Luxemburg und Spanien zü den Concoursländern. Bisher ist jedoch noch nicht bekannt, ob Portugal den Concours alls Rekrutierungsmechanismus auch für EG-Angehörige vorschreiben würd.

1479. Die Situation in Spanien emtspricht weitgehend der in Portugal. Obwohl eine allgemeine Unsetzung durch königliches Dekret bereits am 25. Oktober 1991 vorgenommen wurde, gibt es noch innner keine AusführungsmaBnahmen.

1480. Verstegen, Tijdschrift voor Bestuurswetenschappen en Publiek Recht 1989, 30.

1481. Belgien wurde daher wegen der Nichtumsetzung der Richtlinie 89/48/EWG am 13. Juli 1995 vom EuGH verurteilt, Rs C-216/94 - Kommission/Belgien - (noch nicht veröffentlicht).

1482. De gelijkwaardigheid van diploma's in het hoger onderwijs, Ministerie van de Vlaamse Gemeenschap. Brussel 1994, $15 \mathrm{ff}$. .

1483. Diese Situation ist besonders in einigen der alten Bundesländern, so vor allem in Rheinland-Pfalz und Baden-Württemberg zu konstatieren. 


\section{\$ 2. Konsequenzen des Art. 48 Abs. 4 EGV für den Lehrerberuf}

\section{A. Einleitung}

In vielen Mitgliedstaaten wird der Schulbereich an öffentlichen Schulen zum öffentlichen Dienst gerechnet und sind die Lehrer in der Regel Beamte ${ }^{1484}$. Es war daher lange Zeit umstritten, ob und in welchem Umfang dieser Bereich von der Ausnahmebestimmung des Art. 48 Abs. 4 EGV umfaßt wird ${ }^{1485}$. Art. 48 Abs. 4 EGV bestimmt, daß die Freizügigkeitsrechte zugunsten der Arbeitnehmer keine Anwendung auf die Beschäftigung in der öffentllichen Verwaltung finden. Der Begriff "öffentliche Verwaltung" hat zu einer umfangreichen Rechtsprechung geführt. Die Mitgliedstaaten haben dabei lange Zeit die Auffassung vertreten, diesen Begriff nach ihren jeweiligen nationalen Rechtsordnungen ausfüllen zu können. Dieser Auffassung ist der Europäische Gerichtshof nicht gefolgt. Der Gerichtshof hat stattdessen eine eigene, gemeinschaftsrechtlichen Interpretation dieses Begriffs entwickelt ${ }^{1486}$. Nach dieser Interpretation sind vom Recht auf Freizügigkeit lediglich die Stellen ausgenommen, "eine unmittelbare und mittelbare Teilnahme an der Ausübung hoheitlicher Befugnisse und an der Wahrnehmung solcher Aufgaben mit sich bringen, die auf die Wahrung der allgemeinen Belange des Staates und anderer öffentlicher Körperschaften gerichtet sind. Die Beschäftigung auf derartigen Stellen setzt nämlich ein Verhältnis besonderer Verbundenheit des jeweilligen Stelleninhabers sowie die Gegenseitigkeiten von Rechten und Pflichten voraus, die dem Staatsangehörigkeitsband zugrunde liegen." 1487

1484. In zumindest sieben Mitgliedstaaten sind Lehrer in öfentlichen Schulen in der Regel im Beamten verhältnis beschäftigt, Kommission der Europäischen Gemeinschaft, Conditions of Teachers, 37. Dies gilt jedenfalls für Deutschland, Frankreich, Griechenland, Italien, Luxemburg, Spanien und Osterreich. In Belgien und Dänemark haben Lehrer einen beamtenahnlichen Status. In den Niedlerlanden sind Lehrer als Angestellte im öffentlichen Dienst beschäftigt. Dizu die Studie der KMK, Bestandsaufnahme der Lehrerausbildung in den Mitgliedstaaten der Europäischen Gemeinschaft.

1485. In der deutschen Literatur wurde vor allem von Lecheler die Rechtsprechung des EuGH scharf kritisient, ZBR 1991, 97, Lecheler 1990, 23; Loschelder, ZBR 1991, 102. Allgemein zur Diskussion uber das Verhältris des EG-Rechts zum Recht des nationalen öfentlichen Dienstes, siehe Avenarius., NVwZ. 1988. 385; Curall, Rev. franç. d"adm. publ. 1988, 573; Battis, Die Personalvertreturig 1990, 195; 1988. 385; Curall, Rev. franç. dadm. publ. 1988, 573; Battis, Die Personalvertretng 1990, 195; baum/Eiselstein 1988; Hochbaum, Der Stat 1990, 577; Riegel, Recht im Amt 1992, 228; Summer, ZBR 1993, 97

1486. Urteil vom 17. Dezember 1980, Rs 149/79 - Kommission/Belgien - SIg. 1980, 3881 (Zwischenurteil) und Urteil vom 26. Mai 1982, Slg. 1982, 1845 (Endurteil), siehe dazu die Urteilsanmerkung von Bleckmann, Administration publique, $1 / 1982,36$.

1487. Urteil vom 17. Dezember 1980, Rs 149/79-Kommission/Belgien -, Slg. 1980, 3881 (3900), Rdnr. 10. 
Eine ausführliche Erörterung der Rechtsprechung 20 Art. 48 Abs. 4 EGV ${ }^{1488}$ soll an dieser Stelle unterbleiben, da dies bereits häufig in der Literatur geschehen ist. ${ }^{148 \%}$. Eines der letzten Urteile in diesem Zusammenhang - die Rechtssache A. Bleis ${ }^{1490}$ - kann auch als Abschlußpunkt für die Lehrerberufe angesehen werden. Es handelte sich um die Qualifizierung der Rechtstellung eines geprïften Lehrers für das höhere Lehramt: an öffentlichen französischen Schulen. Die Klägerin Annegret Bleis ist eine deutsche Staatsangehörige mit einem französischen Studienabschluß. Ihr Antrag auf Zulassung zu einem externen Auswahlverfahren zur Erlangung eines Befähigungsnachweises für das Lehramt an höheren Schulen im Fach Deutsch ${ }^{1491}$ wurde wegen ihrer Staatsangehörigkeit abgelehnt. Begründet wurde diese Ablehnung durch das französische Bildungsministerium unter Hinweis auf Art. 5 des französischen Beamtengesetzes ${ }^{1492}$, wonach nur Beamter werden kann, wer die französische Staatsangehörigkeit besitzt.

Nachdem die Entscheidung in der Sache Lawrie Blum ${ }^{1493}$ ergangen war, wurde in der Literatur häufig noch darüber diskutiert, ob dieses Urteil ausschließlich auf Studienreferendare, d.h. Beamte auf Widerruf, Anwendung finde, oder ob damit der Lehrerberuf allgemein aus dem Regelungsbereich des Art. 48 Abs. 4 EGV ausgeschlossen sei ${ }^{1494}$. Diese Diskussion sollte nun spätestens mit der Entscheidung Bleis ihr Ende gefunden haben. Der Gerichtshof stellte nämlich unter Hinweis auf seine bisherige Rechtsprechung in den Rechtssachen Lawrie Blum ${ }^{1495}$ und Alluè und Connan ${ }^{1496}$ sehr lapidar fest ${ }^{1497}$.

1488. Rechtsprechung zu Art. 48 Abs. 4 EGV: Urteil wom 12. Febnar 1974, Rs 152/73-Sotgiu/Deutsche Bundespost, Slg. 1974, 153; Urteil vom 17. Dezember 1980, Rs 149/79 - Kommission/Belgien -, Slg. 1980, 3881 (Zwischenurteil) und Urteil vom 26. Mai 1982, Slg. 1982, 1845 (Endurteil); Urteil vom 3. Juni 1986, Rs 307/84 - Kommission/Frankreich, Sig. 1986, 1725; Urteil vom 3. Juli 1986, Rs 66/85 - Lawrie Blum/Land Baden Württemberg, Slg. 1986, 2121; Urteil vom 16. Junil 1987, Rs 225/85 - Kommission/ltalien, Slg. 1987, 2625; Urteil vom 30. Mail 1989, Rs 33/88. Allué und Coonan, Sig. 1989, 1591; Urteil vom 27. November 1991, Rs C-4/91 - A.Bleis/Ministère de I'Education nationale, Slg. 1991, 1-5627; Urteil vom 2. August 1993, verbundene Rs C-259, 331 und 332/91 Allué, Coonan u.a. - Slg. 1993, I-4309.

1489. Siehe dazu vor allem die ausfithrliche Analysen von Eschmann, 73 ff, : Everling in Battis 1989, 23; Everting, DVBI. 1990, 225, Fischer, NWVal 4/1989, 117; Handoll, ELR 1988, 223; Jager, Rivist di diritto europeo No 4/1990, 797; Ziekow, DoD 1991, 11; Martin, CDE 1993, 555; Mancini in Curtin/O'Keeffe $1992,67 \mathrm{ff}$.

1490. Urtail vom 27. November 1991, Rs.C-4/91 - A.Bleis/Ministère de l'Education nationale -, Slg. 1991 $1-5627$,

1491. Certificat d'aptitude au professorat de l'enseignement du second degré.

1492. Gesetz Nr. 83/634 vom 13. Juli 1983 uber die Rechte und Pflichten der Beamten, JORF vom 14, Juli $1983,2174$.

1493. Urteil vom 3. Juli 1986, Rs 66/85 - D. Lawrie Blum/Land Baden-Württemberg -, Sug. 1986, $2121 \mathrm{ff}$. Dazu Oppermann 1988, 14; Forch, NVwZ 1987, 28.

1494. Siehe dazu Forch, NVwZ 1987, 27 (31).

1495. Urteil wom 3. Juli 1986, Rs 66/85 - D. Lawrie Blum/Land Baden-Württemberg -, Slg. 1986, 2121 ff. Dazu Handoll, ELR 1988, $223 \mathrm{ff}$

1496. Urteil vom 30. Mai 1989, Rs 33/88, - Alluè und Coonan/Università degli Studi Venezia -, SIg. 1989, 1591 ff.. Dazu Watson, ELR 1989, 419.

1497. Urteil vom 27. November 1991, Rs C-4/91 - A. Bleis/Ministère de l'Education nationale -, Slg. 1991, 1-5627. 


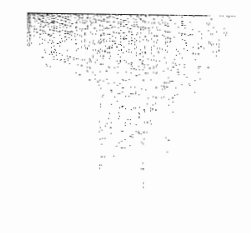

Teil $\mathrm{V}$

"Die Beschäftigung eines Lehrers für den höheren Schuldienst stellt keine Beschäftigung in der öffentlichen Verwaltung im Sinne des Art. 48 Abs. 4 EWGV dar."

Von Bedeutung ist jedoch die Reaktion der Mitgliedstaaten und der Kommission auf die Rechtsprechung zu Art. 48 Abs. $4 \mathrm{EGV}$. Hierbei haben sich gerade in jüngster Zeit noch einige interessante Gesetzesentwicklungen ergeben ${ }^{1498}$.

\section{B. DIE SYSTEMATISCHE AKTION DER KOMMISSION}

Die Kormmission hat die Rechtsprechung des Gerichtshofs bereits nach den Verfahren gegen Belgien ${ }^{1499}$, Frankreich ${ }^{1500}$ und Italien ${ }^{1501}$ sowie dem Urteil in der Rechtssache Lawrie Blum ${ }^{1502}$ zum Anlaß genommen, ihrerseits die Mitgliedstaaten zu einer Öffnung des öffentlichen Dienstes zu bewegen. Am 5. Januar 1988 sandte der Vizepräsident der Kommission, Manuel Marin Gonzalez, an die Außenminister der Mitgliedstaaten ein Schreiben, worin er die Haltung der Kommission zur Tragweite des Art. 48 Abs. 4 EGV erläuterte und ankündigte, daß die Kommission eine systematische Aktion beabsichtige, um für die richtige Anwendung dieser Vorschrift zu sorgen. Hierbei wurde ausdrücklich auf die beiden Entscheidungen des Gerichtshofes gegen Belgien verwiesen. Die Aktion wurde im März 1988 veröffentlicht ${ }^{1503}$.

Die Kommission rechtfertigte ihre Aktion u.a. damit, daß sich die Gemeinschaft in der Einheitlichen Europäischen Akte das Ziel gesetzt hat, bis Ende 1992 einen echten Binnenmarkt, eimen Raum ohne Grenzen zu schaffen, in dem der Personenverkehr eine grundlegende Stellung einnimmt. Nach Ansicht der Kommission fallen auf Grund der Rechtsprechung des Gerichtshofes nur noch die folgenden Bereiche unter die in Art. 48 Abs. 4 EWGV niedergelegte Ausnahme:

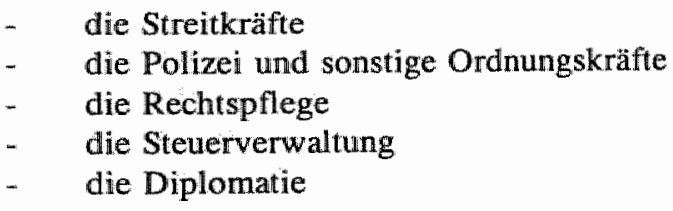

1498. Deutschland, Frankreich und Italien sahen sich, gezwungen einschneidende gesetzliche Änderungen ihres Beamtenrechts vorzunehmen. Auch Spanien hat eine Gesetzesänderung dunchgeführt. In den Niederlanden sind lediglich die Bereiche Justiz, Polizei, Diplomatischer Dienst und das Militar noch ausdrucklich niedertänd ischen Staatsangehörigen vorbehalten. Siehe dazu die einzelnen Landerberichte in Magiera/Siedentopf sowie Ziller 1993.

1499. Unteile wom 17. Dezember 1980 und vom 26. Mai 1982, Rs 149/799 - Kommission/Belgien -, Slg. 1980,3881 ff. (Zwischenurteil); Sig. 1982, 1845 ff. (Endurtell)

1500. Urteit vom 3. Juni 1986, Rs 307/84 - Kommission/Frankreich -, Slg. 1986,1725 ff,

1501. Urteil vom 16. Juni 1987, Rs. 225/85, - Kommission/talien -, Slg. 1987, $2625 \mathrm{ff}$.

1502 Urteil vom 3, Juli 1986, Rs 66/85 - D. Lawrie Blum/Land Baden-Würtemberg “, Slg "1986, $2121 \mathrm{ff}$

1503. Kommissionsbeschluß, ABI. Nr. C 72 vom 18. März 1988, 2. 
Dagegen sei bei anderen Bereichen nur noch in außergewöhnlichen Fällen der Ausnahmetatbestand des Art. 48 Abs. 4 EGV zu bejahen. Unter den Bereichen, auf die sich die systematische Aktion vorrangig erstreckt, findet sich auch der Unterricht an staatlichen Bildungseinrichtungen. Die Kommission erklärte mit einer aktiven und wirksamen Kooperation der Mitgliedstaaten zu rechnen, um Streitfälle nach Möglichkeit zu vermeiden. Gleichzeitig verwies sie allerdings mit drohendem Unterton auf die Möglichkeit eines Klageverfahrens vor dem EuGH.

Die Vorgehensweise der Kommission hat in der Bundesrepublik Deutschland Irritation ausgelöst ${ }^{1504}$. Es wurde Kritik sowohl hinsichtlich des Verfahrens wie hinsichtlich des Inhalts geâuffert ${ }^{1505}$. Hochbaum kritisiert dabei, daß bei den von der Kommission aus Art. 48 Abs. 4 EGV ausgegrenzten Bereichen von Fall zu Fall geprüft werden müße, ob die Voraussetzungen der Bestimmung nicht doch zum Tragen kommen ${ }^{1506}$. Vor allem auch der Bundesrat fühlte sich micht ausreichend beteiligt, zumal die Bundesregierung ihn sehr spät von dem Vorhaben der Kommission unterrichtet hat, obwohl dies bei der Beratung über den Richtlinienentwurf zur Anerkennung von Hochschuldiplomen von Interesse gewesen wäre. Interessanterweise warf der Bundesrat der Kommission vor, bei ihrer Aktion zu schematisch vorzugehen und funktionelle Gesichtspunkte nicht hïreichend zu berïcksichtigen ${ }^{1507}$.

\section{REAKTIONEN DER MITGLIEDSTAATEN}

\section{Die Bundesrepublik Deutschland}

Trotz dieser Bedenken wurde ein Gesetzesentwurf ${ }^{1508}$ vorgelegt, der als 10 . Gesetz zur Änderung dienstrechtlicher Vorschriften inzwischen in Kraft getreten ist ${ }^{1509}$. Mit diesem Zehnten Gesetz zur Änderung dienstrechtlicher Vorschriften vom 20. Dezember 1993 wurde nach einem schwierigen und stark umstrittenen Gesetzgebungsverfahren der öffentliche Dienst im Beamtenverhältnis für Staatsangehörige der anderen Mitgliedstaaten geöffnet. Damit wurde eine Änderung des Beamtenrechtsrahmengesetzes (BRRG) vorgenommen. Zielsetzung dieser Gesetzesänderung ist, daß Staatsangehörige anderer Mitglïedstaaten beim Zugang zum Beamtenverhältnis den Deutschen í. S. des Art. $116 \mathrm{GG}$ grundsätzlich gleichgestellt werden. Zugleich wurde mit dieser Gesetzesänderung die Richtlinie 89/48/EWG für die laufbahnrechtlichen Vorschriften umgesetzt. Gemäß $\$ 4$ Abs. 1 Unterabs. 1 BRRG können nunmehr nicht nur Deutsche, sondern auch Staatsangehörige der anderen Mitgliedstaaten in das Beamtenverhältnis berufen

1504. Hochbaum, ZBR 1989, 33; Hochbaum, Der Staat 1990, 577; Lecheler, Die Verwaltung 1989, 137; Meyer, BayVBl. $1990,97$.

1505. Siehe dazu auch Riotte/Fey, NWVBI. 1/1992, 7 .

1506. Hochbaum, ZBR 1989, 33.

1507. BR-Ducksache 80/88 vom 18 . März 1988 und BR-Drucksache $178 / 88$ vom 5. April 1988.

1508. BR-Drucksache $555 / 92$.

1509. Zehntes Gesetz zur Änderung dienstrechtlicher Vorsehriften wom 20. Dezember 1993 (betr. Beamtenrechtsrahmengesetz und Bundesbeamtengesetz), BGBI. I, 2136. 


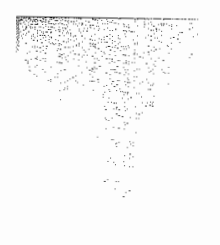

Teill V

werden. Dabei wird allerdings auch won dem EG-Angehörigen gemäß $\$ 4$ Abs. 1 Unterabs. 2 BRRG erwartet, daß er "die Gewähr dafür bietet, daß er jederzeit für die freiheitliche demokratische Grundordnung im Sinne des Grundgesetzes eintritt." Auch muB der Kandidat gemäß Unterabs. 3 die für seine Laufbahn erforderliche übliche Vorbildung besizzen. Daneben enthält $\$ 4$ Abs. 2 BRRG unter Hinweis auf Art. 48 Abs. 4 EGV die Ausnahmeregelung, daß "wenn es die Aufgaben erfordern, nur Deutsche im Sinne des Art. $116 \mathrm{GG}$ in ein Beamtenverhältnis berufen werden dürfen". Mit diesem Hinweis auf Art. 48 Abs. 4 EGV in einem Klammerzusatz soll die Möglichkeit geschaffen werden, künftigen europäischen Entwicklungen Rechnung zu tragen ${ }^{15 i 0}$. Eine entsprechende Änderung enthält $\$ 7$ des Bundesbeamtengesetzes.

Neben dieser grundsätzlichen Öffnung des Beamtenverhältnisses für EG-Angehörige können Ausländer gemäß $\S 4$ Abs. $3 \mathrm{BRRG}$ in das Beamtenverhältnis ernannt werden, wenn für die Gewinnung des Beamten ein dringendes dienstliches Bedürfnis besteht. Bei der Ernennung von Professoren, Hochschuldozenten und anderen Mitarbeitern an wissenschaftlichen und künstlerischen Einrichtungen können Ausnahmen auch aus anderen Gründen zugelassen werden. Diese Ausnahmebestimmung war im bereits geltenden Beamtenrecht bekannt. In einigen Bundesländern wurde, solange die Änderung des Beamtenrechtsrahmengesetzes noch nicht verwirklicht war, diese Ausnahmebestimmmung bei der Ernennung von EG-Angehörigen quasi zur Regel erkiärt, um eine der Rechtsprechung des EuGH konforme Anstellungspolitik betreiben zu können.

$\$ 14 \mathrm{c}$ des Änderungsesetzes beinhaltet die Anforderungen für die Staatsangehörigen der Mitgliedstaaten, die im Besitz eines Diploms sind, das zum unmittelbaren Zugang zu einem Beruf im Öffentlichen Dienst des Herkunftsstaates berechtigt. Danach darf gemäß $\$ 14 \mathrm{c}$ Abs. 1 BRRG die Ableistung des für die Laufbahn vorgeschriebenen Vorbereitungsdienstes oder die für den Erwerb der Befähigung für bestimmte Laufbahnen vorgeschriebene hauptberufliche Tätigkeit nicht verlangt werden. Voraussetzung ist ein Diplom für einen Beruf im öffentlichen Dienst des Herkunftsstaates, wobei das Berufsbild mit der Laufbahn im wesentlichen übereinstimmt. $\$ 14 \mathrm{c}$ Abs. 2 BRRG enthält die Diplomdefinition, die weitgehend mit der des Art. 1 a) der Richtlinie 89/48/EWG übereinstimmt. Gemäß \& 14 c Abs. 3 BRRG wird die Beherrschung der deutschen Sprache in Wort und Schrift vorausgesetzt. Abs. 4 der Bestimmung enthält eine allgemeine Ermächtigung. Danach sollte in den jeweiligen Laufbahnbestimmungen geregelt werden, welche Berufsqualifikationen innerhalb der Gemeinschaft mit dem Berufsbild der jeweiligen Laufbahn übereinstimmen. Auch solite in den Laufbahnvorschriften die inhaltliche Ausgestaltung etwaiger Kompensationsmaßnahmen i.S. des Art. 4 der Richtlinie 89/48/EWG bestimmt werden. Im Innenausschuß des Bundestages hat die Frage nach der Freistellung vom Vorbereitungsdienst zu erheblichen Diskussionen geführt, weil hierin eine ungerechtfertigte Diskriminierung der eigenen Staatsangehörigen gesehen wird. Auch wurde befürchtet, bei Bewerbern mit ausländischen Diplomen nicht über genügend Kriterien zu verfügen, um eine sachgerechte Auswahl durchführen zu

1510. BR-Drucksache 555/92 vom 14. August 1992, 13/14 
können ${ }^{151 !}$. Andererseits wurde anerkannt, daß eine generelle Verpflichtung zur Ableistung eines Vorbereitungsdienstes deutlich im Streit mit der Richtlinie 89/48/EWG anzusehen ist. Im Innenausschuß wurde zu diesem Punkt im April 1993 eine Sactiverständigenanhörung durchgeführt. Schließlich wurde das Gesetz im Dezember 1993 verabschiedet.

Nach der Änderung des Beamtenrechts auf Bundesebene folgten auch Länder mit entsprechenden Anpassungen der Landesbeamtengesetze. Bisher liegen die Regelungen der Länder Bayern, Bremen, Hamburg, Hessen, Niedersachsen, Nordrhein-Westfalen, Rheinland-Pfalz, Saarland, Sachsen und Thüringen vor ${ }^{1512}$. Die Bundesrepublik ist jedoch nicht der einzige Mitgliedstaat, der sich gezwungen sah, eine Öffnung seines öffentlichen Dienstes für EG-Angehörige in Angriff zu nehmen. Auch in anderen Mitgliedstaaten haben vergleichbare Entwicklungen eingesetzt.

\section{Frankreich}

Art. 5 des französischen Beamtengesetzes ${ }^{1513}$ bestimmte grundsätzlich, daß niemand die Beamteneigenschaft haben kann, der nicht die französische Staatsangehörigkeit besitzt. Zeitlich parallel zu dem Verfahren Bleis wurde aber in Frankreich ein Gesetz erlassen, das eine Ausnahmeregelung für einige Berufsgruppen von dem Staatsangehörigkeitserfordernis für Angehörige anderer Mitgliedstaaten vorsieht ${ }^{1514}$. Duch Ge setz 91 -715 vom 26. Juli 1991 wurde der Zugang zum französischen öffentlichen Dienst für Gemeinschaftsangehörige geöffnet. Mit diesem Gesetz wurde Art. 5 des Beamtengesetzes in der Form eines eingefügten Art. 5 bis ergänzt, dessen Absatz 1 EG-Angehörigen den Zugang zu Beantenstellen ermöglicht. Grundsätzlich bleibt zwar das Erfordernis der französischen Staatsangehörigkeit bestehen, hiervon kann jedoch gemäß Beamtengesetz 1983-86 Abschnitt $\mathbb{I}$, Art. 5 bis bei solchen Stellen abgewichen werden, die weder unmittelbar noch mittelbar an der Ausübung hoheitlicher Befugnisse des Staates teilhaben. Voraussetzung ist dabei, daß diese Stellen durch Einzeldekrete angewiesen werden. Gegen dieses Giesetz hatten 73 Senatoren Klage vor dem Verfassungsrat erho-

1511. Diese Argumentation ähnelt sehr den won den Vertretern der "Concoursländern" vorgebrachten Argumenten.

1512. Bayern: Zwölftes Gesetz zur Ånderung dienstrechtlicher Vorschriften vom 1. August 1994, GVB1 1994, 613; Bremen; Gesetz zur Änderung dienstrechtlicher Vorschriften vom 1. März 1994, GBI 1994, 107; Hamburg: Gesetz zur Änderung dienstrechticher Vorschriftem vom 1. August 1994, GVBI 1994; Hessen: Sechstes Gesetz zur Änderung dienstrechthicher Vorschriften vom 12. Dezember 1994, GVBII. 1994, 810; Niedersachsen: Viertes Gesetz zur Änderung des Niedersächsischem Beamtengesetzes und des Niedlersächsischen Richtergesetzes vom 10. Janwar 1994, GVBI. 1994, 2; Nordrhein-Westfalen: Gesetz zur Änderung dienstrechtlicher Vorschriften vom I. August 1994, GVBI. 1994; Rheinland-Pfalz: Zweites Gesetz zur Änderung dienstrechtlicher Vorschriften vom 21. Dezember 1993. GVBI. 1993, 647; Saarland: Gesetz zur Ändenung dienstrechitlicher Vorschriften vom 1. August 1994, GVBI. 1994; Sachsen: Beamtengesetz für den Freistaat Sachsen i.d.F. vom 16. Juni 1994, GVBI 1994, 1153; Thüringen: Thüringer Beamtengesetz (ThüBG) wom 10. Juni 1994, GVBI. 1994, 592.

1513. Gesetz Nr. 83-634 vom 13. Juli 1983 über die Rechte und Pflichten der Beamten, JORF vom 14. Juli $1983,2174$.

1514. Gesetz Nr. $91 / 715$ vom 26. Juli 1991, JORF, lois et décrets, vom 27. Juli 1991, 9952. 
ben, die dieser jedoch zurückgewiesen hat ${ }^{1515}$. Für eine Entscheidung im Verfahren Bleis bestand aber dennoch sowohl ein rechtliches wie tatsächliches Interesse, weil die zur Anwendung des Gesetzes notwendigen Durchführungsdekrete noch nicht erlassen waren. Inzwischen sind diese sind jedoch für die Lehrberufe ergangen.

\section{Italien}

In Italien zeichnete sich bereits seit 1990 eine entsprechende Entwicklung ab ${ }^{1516}$. Ein Gutachten des italienischen Staatsrates zur Öffnung des öffentilichen Dienstes an die italiensche Regierung lag bereits im Juli 1990 vor ${ }^{1517}$. Dies hat zunächst allerdings noch keinen Niederschlag in Gesetzesmaßnahmen gefunden. Dennoch hat der Verwaltungsgerichtshof der Lombardei im Oktober 1991 eine entsprechende Interpretation des Art. 48 Abs. 4 EWGV - d.h. also noch vor der Entscheidung Bleis, die im November 1991 ergangen ist - hinsichtlich der Zulassung zum öffentlichen Schuldienst vorgenommen ${ }^{1518}$. Inzwischen hat das Gutachten des Staatsrats zu einer grundsätzlichen Änderung des italienischen Beamtenrechts geführt. Mit dem Decreto Legislativo vom 3. Februar 1993, Nr. 93 wurde der italienische öffentliche Dienst auch für EG-Angehörige geöffnet. Art. 37 des Decreto Legislativo sowie die Ausführungsverordnung vom 7. Fiebruar 1994, Nr. 174 erlauben nun unter bestimmten Voraussetzungen die Ernennung von Gemeinschaftsangehörigen in den italienischen Staatsdienst.

\section{Niederlande}

In den Niederlanden war man bereits einen Schritt weiter. Die Rechtsprechung des Gerichtshofes sowie eine allgemeine gesellschaftliche Diskussion über die Rechtstellung von Ausländern und letztilich vielleicht auch noch die Aktion der Kommission haben bereits im April $1988 \mathrm{zu}$ einer Änderung des Beamtengesetzes ${ }^{1519}$ und einiger damit in Zusammenhang stehender Gesetze ${ }^{1520}$ geführt. Dabei stammte der ursprüngliche Gesetzesentwurf aus dem Jahre $1984^{1521}$. Eine dazu veröffentlichte Anlage enthălt eine Aufzăhllung der Funktionen, die noch unter den Staatsangehörigkeitsvorbehalt fal-

1515. JORF, lois et đécrets, vom 25. Juli 1991, 9854.

1516. Mit Gesetz vom 28 . Februar 1990 wurde bereits eine gewisse Öfnung des offentlichen Dienstes bewirkt.

1517. Siehe Consiglio di Stato n. $234 / 90$ vorn 20. Juii 1990 , Rivista Italiana di Diritto Pubblico Comunitario $1992,192$.

1518. Sjehe dazu die Urteilsanmerkung von Traina, Rivista Italiana di Diritio Pubblico Comumitario 1992, 202.

1519. Wet van 20. April 1988 tot wijziging van Armbtenaarwet 1929 terzake van de vitoefening van grondrechten, Stb. 1988, 229. Zuvor war bereits durch eine Verfassungsândenung die grundsấtzliche Möglichkeit der Ausländeremennung in das Beamtenverhältnis geschaffen worden (Neufassung des Art. 3 durch Grondwet 1983).

1520. Wet van 20.. April 1988 houdende intrekking van det wet van 4 juni 1858 regelende de benoembaarheid wan vreemdelingen tot landsbedieningen, Stb. 1988, 231

Wet wan 20. April 1988 houdence wijziging van de Militaire Ambtenarenwet 1931 en van de Wet Rechtstoestand dienstplichtigen terzake van de uitoefening van grondrechten, Stb. 1988, 288.

1521. Gesetzesentwurf Nr. 19076 
len ${ }^{1522 .}$. Man spricht dabei von sogenannten Vertrauensfunktionen. Diese Liste wird periodisch ïberprüft um festzustellen, ob der Staatsangehörigkeitsvorbehalt tatsächlich noch erforderlich ist. Mit dieser Anlage soll eine einfache Anpassung an die Rechtsprechung des Gerichtshofes ermöglicht werden. Tatsächlich wurde die Anlage seit Erlaß mehrfach abgeändert ${ }^{1523}$. Faktisch beschränkt sich der Vorbehalt der niederländischen Staatsangehörigkeit nur noch auf die Bereiche Justiz, Polizei, Militär, Diplomatischer Dienst und einige, spezielle Vertrauenspositionen ${ }^{1524}$.

\section{Dänemark, Großbritannien und Irland}

In Dänemark ist 1990 durch eine Gesetzesänderung dỉe Möglichkeit der Einstellung von Gemeinschaftsangehörigen unter beamtenähnlichen Bedingungen geschaffen worden ${ }^{1525}$. Auch in Großbritannien ist seit 1991 der Civil Service für Staatsangehörige der Mitgliedstaaten geöffnet. Für Lehrer war diese Gesetzesänderung allerdings nicht relevant, weill diese nicht als civil servants qualifiziert werden. Für sie gab es bereits vor der Gesetzesänderung keinen Staatsangehörigkeitsworbehalt. In Irland können Auswahlverfahren für den mittleren, gehobenen und höheren Dienst auf irische Staatsangehörige beschränkt werden ${ }^{1526}$. Dies bedeutet jedoch keine gesetzliche Verpflichtung, so daß der irische Civil Service für Staatsangehörige anderer Mitgliedstaaten grundsätzlich geöffnet ist ${ }^{1527}$. Lehrer werden in Irland ebenfalls nicht als Beamte qualifiziert.

\section{Spanien und Portugal}

Auch in Spanien ist ein Gesetz verabschiedet worden, das eine partielle Öffnung des Beamtentums für EG-Angehörige realisiert. Nach der bisherigen Regelung war für Staatsbeamte gemäß Art. 30 Abs. 1 Buchstabe a des Staatsbeamtengesetzes die spanische Staatsangehörigkeit bei der Einstellung erforderlich. Seit 1992 bereitete Spanien eine Gesetzesånderung vor ${ }^{152}$. Dieser Gesetzesentwurf konnte schließlich im Dezember 1993 verabschiedlet werden ${ }^{1529}$. Nach dieser Neuregelung müssen die Angehörigen der anderen Mitgliedstaaten unter den selben Bedingungen wie Spanier in bestimmte

1522. Groenedijk, NILR 1989, 107 ff.

1523. Staatscourant Nr. 248 vom 21. Dezember 1988.

1524. Zu diesen zähli $\mathbf{Z}, \mathbb{B}$. die Position des Bủrgermeisters.

1525. Andenung des $\$ 58$ dänisches Beamtengesetz. Ob damit der Rechtsprechung genüge getan wird muß man jedoch bezweifeln. Daneben bestimmt nämlich $\$ 27$ Abs. 1. der dänischen Verfassung, daß niemand zum Beamten ernannt werden kann, der nicht die danische Staatsangehorigkeit besitzt.

1526. Civil Service Comissioners" Act 1956.

1527. Zu überpnüfen wăre allerdings, in welchen Fällen von einer derartigen Einschränkung auf irische Staatsangehörige Gebrauch gemacht wind.

1528. Proyecto de ley sobre el acceso a determinados sectores de la function publica de los nacionales de los demas estados miembros de las comunidad economica europea vom 20 . November 1992.

1529. Ley Nr. 17/1993 vom 23. Dexember 1993, BOE Nr. 307 vom 24. Dezember 1993, 3472. 
Positionen im öffentlichen Dienst zugelassen werden ${ }^{1530}$. Da von dieser Regelung auch das Unterrichtswesen betroffen ist, müßte es seither möglich sein, Lehrer aus anderen Mitgliedstaaten in Spanien zu ernennen. In der praktischen Anwendung dieser Bestimmung scheinen jedoch noch immer Schwierigkeiten zu bestehen.

In Portugal scheint man zum niederländischen System zu tendieren. Bisher wurde jedloch noch keine Liste erstellt ${ }^{1531}$.

Die anderen Mitgliedstaaten so etwa Luxemburg ${ }^{1532}$, Griechenland ${ }^{1533}$ und auch Belgien ${ }^{1534}$ werden diesem Beispiel noch folgen müssen. Dies macht jedoch zumindest in Griechenland und Belgien ${ }^{1535}$ eine Verfassungsänderung erforderlich.

\section{VERGLEICH ZWISCHEN DER DEUTSCHEN UND DER NIEDERLÄNDISCHEN REGELUNG}

Vergleicht man die deutsche mit der miederländischen Regelung, so verdient meines Erachtens die letztgenannte den Vorzug. Beide gesetzlichen Maßnahmen haben teils durch ihre Formulierung teils durch Verwendung einer Anlage versucht, zukünftige Entwicklungen in der Rechtsprechung des europäischen Gerichtshofes aufzufangen. Grundsätzlich ist eine solche Vorgehensweise verständlich, selbst lobenswert, weil langwierige Gesetzesänderungsverfahren damit erspart bleiben. Vom Gesichtspunkt der gesetzgeberischen Klarheit ist die enumerative Aufzählung der einschlägigen Funktionen in einer Anlage jedoch wesentlich deutlicher, als die äußerst schwammige Formulierung des \& 4 Abs. 2 BRRG. Wann erfordert es die Aufgabe, daß sie nur von einem Deutschen bewăltigt werden kann? Nie, immer oder nur ab und zu? Wurde nicht auch in der Sache Lawrie Blum ${ }^{1536}$ vertreten, daß der Englischunterricht an einer deutschen Schule nicht von einer Engländerin, sondern nur von Deutschen bewältigt werden kann?

1530. Art. 1 des Ley Nr. 17/1993. Es handelt sich dabei vor allem rum die Bereiche Wissenschaft und Forschung, Unterricht, Transport und das Gesundheitswesen.

1531. Sithe dazu den portugiesischen Länderbericht won de Sousa in Magiera/Siedentopf, 729.

1532. Art. 2 des luxemburgischen Beamtenstatuts bestimmt, dai niemand als Beamter eingestellt werden darf, der nicht die luxemburgische Staatsangehörigkeit besitzt. Auch Angestellte des öfentlichen Diensts. müssen gemäb. Art. 3 dies Gesetzes von 1972 iber das Dienstverhältnis die luxemburgische Statsangehörigkeit besitzen.

1533. Art. $4 \mathrm{Abs} .4$ der griechischen Verfassung stellt die griechische Staatsangehörigkeit für den gesamten öffentlichen Dienst fest.

1534. Art. 10 der belgischen Verfassung wom 17. Februar 1994 (bisher Art, 6) bestimmt, daß vorbehalthich gesetzlich vorgesehener Ausnahmen nur Belgier zivile und mittărische Ämter bekleỉden können. Allerdings findet das Decreet der Flämischen Gemeinschaft vom 27. Mär 1991 bezuglich der Rechisposition won Lehrenden, Moniteur Belge vom 25. Mail 1991, 11454 auch auf Gemeinschaftsangehörige Anwendung.

1535. Allerdings enthält Art. 10 der belgischen Verfassung bereits đife Möglichkeit zu gesetzlichen Ausnahmeregelungen.

1536. Urteil vom 3. Juli 1986, Rs 66/85 - D. Lawrie Blum/Land Baden-Württemberg -, Slg, 1986, $2121 \mathrm{ff}$. 
Mit dieser Ausnahmebestimmung wird der schwarze Peter vom Gesetzgeber den Gerichten zugeschoben. Sie werden sich im Faille einer Ablehnung mit dieser Bestimmung auseinandersetzen und die für die Entscheidung erforderlichen Maßstäbe entwickeln müssen. Ob die Rechtsprechung des EuGH genügend Anhaltspunkte bietet, um den konkret umstrittenen Einstellungsfall zu beurteilen, mag bezweifelt werden. Der gegebene Interpretationsspielraum ist daher verfassungsrechtlich nicht unbedenklich. Zwar verbietet das rechtsstaatliche Bestimmtheitserfordernis weder die Verwendung von Generalklauseln ${ }^{1537}$ noch die Einräumung von Ermessensspielräumen ${ }^{1538}$, doch erscheint mit dieser weiten Formulierung die rechtsstaatlich gebotenen Grenzen erreicht zu sein. Bedenklich ist $\$ 4$ Abs. 2 BRRG aber auch im Hinblick auf die Rechtsprechung des Europäischen Gerichtshofes, weil die gewählte Formulierung nicht genau die vom EuGH gezogene Grenze widerspiegelt ${ }^{1539}$.

\section{§ 3. Der Concours als Auswahl- und Einstellungssystem}

In Frankreich, Luxemburg, Italien, Portugal und Spanien wird der Concours als Auswahl- und Einstellungssystem von Lehrem gehandhabt. Diese Tatsache hat zu einigen nicht unerheblichen Problemen bei der Umsetzung der Richtlinie für Berufe im öffentlichen Dienst gefuhrt. Die Problematik ergab sich besonders bei der Anerkennung won Lehrern. Dabei ist die Regelung des Concours in den einzelnen Mitgliedstaaten nicht identisch. In Frankreich findet der Concours für Lehrer am Ende des ersten praktischen Ausbildungsjahres statt. Nach erfolgreichem Concours wird der Kandidat als Professeur stagiare in einem Beamtenverhältnis auf Probe ernannt. Am Ende des zweiten Ausbildungsjahres erhält der professeur stagiaire ein Abschlußzeugnis und beendet damit seine Ausbildung. Ähnlich ist die Situation auch in Luxemburg. Hier findet der Concours allerdings vor Beginn der gesamten praktischen Ausbildungsperiode statt. Die Zulassung zu diesem Teil der Ausbildung erfolgt im Rahmen des jährlich auf fünf Jahre errechneten Lehrerbedarfs. In Italien werden dagegen alle drei Jahre Wettbewerbsprüfungen durchgeführt, an denen die voll qualifizierten Lehramtskandidaten teilnehmen können. Auch in Spanien erfolgt die Einstellung zum Lehrer nach einer erfolgreichen Prüfung. Teilnehmen kann an diesem Wettbewerb, wer von seiner Ausbildung her benuflich voll als Lehrer qualifiziert ist ${ }^{1540}$. Nach erfolgreichem Abschluß dieser Prüfung muß der Lehramtskandidat vor seiner endgültigen Ernennung eine Probezeit von drei Monaten durchlaufen. In Portugal muß eine Aufnahmeprüfung zur Einstellung in den Schuldienst bestanden werden.

Vergleicht man diese Bestimmungen miteinander, so ist vor allem das französische und das luxemburgische System im Zusammenhang mit der Richtlinie 89/48/EWG proble--

1537. BVerfGE $8,274(326) ; 13,153(1161)$

1538. BVerfGE 8, $274(327) ; 21,73(78)$.

1539. Nach den Urteilen der EuGH handelt es sich um Funktionen, die die Ausübung hoheütlicher Befugnisse umfassen und auf die Wahrung der allgemeinen Belange des States gerichtet sind. Siehe dazu die Ertäuterungen von Everling in Battis 1989, 23 (39)

1540. Real decreto vom 22. April 1991. 
matisch. In Italien, Portugall und Spanien können sich die ausländischen Diplominhaber, nachdem ihre Lehrbefähigung nach dem System der Richtlinie 89/48/EWG anerkannt worden ist, um eine Anstellung durch Teilnahme an den Wettbewerbs- und Aufnahmeprüfungen bewerben. Eine erfolgreiche Prüfung garantiert die Einstellung im Aufnahmestaat beziehungsweise gilt als Selektionskriterium für eine Einstellung. Für Italien, Portugal und Spanien kann der Concours daher als Auswahlverfahren qualifiziert werden. Âhnlich wie bei einer Zweiten Staatsprüfung ist das Prüfungsergebnis entscheidend für die Einstellung. Im Unterschied zur Zweiten Staatsprüfung schließt der Concours in diesen Mitgliedstaaten nicht die Ausbildung ab, sondern ist als Bewerbungsverfahren für die Aufnahme in den Staatsdienst zu qualifizieren. Es erscheint daher gerechtfertigt, auch Migranten einem solchen Auswahlverfahren zu unterwerfen, nachdem zuvor ihr Diplom nach dem System der Richtlinie 89/48/EWG anerkannt worden ist. Umgekehrt müssen Migranten mit einer italienischen, portugiesischen oder spanischen Lehrbefähigung von den zuständigen Behörden des jeweiligen Aufnahmestaats nach dem System der Richtlinie anerkannt werden, ohne daß diese den Nachweis erbringen, eine Wettbewerbsprüfung mit Erfolg bestanden zu haben. Dieses. Element gehört nicht zur beruflichen Ausbildung in Italien, Portugal und Spanien. Auch ohne bestandenen Concours kann ein Kandidat als Endprodukt im Sinne der Richtlinie 89/48/EWG qualifiziert werden.

Dagegen ist die Vergleichbarkeit zwischen dem Anerkennungssystem der Richtlinie 89/48/EWG und dem Auswahlsystem in Frankreich und Luxemburg wesentlich schwieriger zu bejahen. Der Concours in Frankreich und Luxemburg ist sowohl ein Teil der Ausbildung wie ein Selektionsverfahren zur Anstellung. Besonders deutlich ist dies in der luxemburgischen Regelung. Das Bestehen des Concours ist conditio sine qua non zum erfolgreichen Zugang und Abschluß der Ausbildung; gleichzeitig aber auch Garantie für die Einstellung. Ein derartiger Concours kann mit dem Anerkennungssystem der Richtlinie kaum in Einklang gebracht werden. Nach der Richtlinie muß ein "Endprodukt $^{*}, d . h$. ein voll qualifizierter Berufsangehöriger, nach den Grundsätzen des Art. 3 der Richtlinie 89/48/EWG anerkannt werden. Bei wesentlichen Unterschieden in der Ausbildung kann von dem Migranten nach seiner Wahl gemäß Art. 4 der Richtlinie 89/48/EWG entweder die Abnahme einer Eignungsprüfung oder Ableistung eines Anpassungslehrganges verlangen. Beide Kompensationsinstrumente dürfen nicht kumuliert werden.

Im Unterschied zur deutschen Referendarsausbildung mit abschließender Zweiter Staatspriffung findet die Selektion in Luxemburg am Anfang der pädagogischen Ausbildung statt. In Frankreich wird die entscheidende Auswahl in das zweite Ausbildungsjahr gelegt. Nach meiner Meinung kann ein französischer und luxemburgischer Lehramtsbewerber nur dann als "Endprodukt" im Sinne der Richtlinie qualifiziert werden, wenn er die pädagogische Ausbildung vollständig abgeschlossen hat. Dies erfordert jedoch, daß der Kandidat den nationalen Concours einschließlich der anschließenden Ausbildung mit Erfolg durchlaufen hat. Umgekehrt bedeutet dies, daß von Migranten, die in ihrem Herkunfisstaat bereits eine vollständige Berufsausbilldung erhalten haben, nicht erneut eine Ausbildung zum Endprodukt verlangt werden darf. Unzumutbar wäre auch von 
Migranten im Rahmen des Anerkennungsverfahrens die Ableistung einer Eignungsprüfung oder eines Anpassungslehrganges zu verlangen, um sie anschließend erneut mit einem Concours und einer anschließenden pädagogischen Ausbildung zu konfrontieren. In der praktischen Anwendung ist eine derartige Lösung jedoch nur schwer durchzuführen, weil der Concours in beiden Mitgliedstaaten gleichzeitig mit einer Bedarfsregelung korrespondiert. Ausländische Berufsangehörige sollten jedoch - soweit derartige Verfahren bestehen - zu einem Concours zugelassen werden, der für nationale Berufsangehörige organisiert wird ${ }$ die innerhalb des nationalen Systems eine andere Lehramtsstelle wechseln möchten (mutation). In einem solchen Falle wird der Tatsache Rechnung getragen, dafl sie bereits in ihrem Herkunftsstaat vollqualifizierte Berufsangehörige sind. Falls eine derartige Regelung nicht möglich ist, so darf den ausländischen Bewerbem zumindest keine Verpflichtung auferlegt werden, die an den Concours anschließende pädagogische Ausbildung erneut zu durchlaufen ${ }^{1541}$. Das erfolgreiche Bestehen des Auswahlwettbewerbs muß in diesem Fall für die Einstellung genügen.

Diese Lösung ist zwar nicht in jeder Hinsicht befriedigend, sie vereinbart jedoch soweit möglich die berechtigten Interessen der Migranten an einem ordnungsgemäßen Anerkennungsverfahren mit denen der betroffenen Mitgliedstaaten. Diese sind selbstverständlich sehr an der Erhaltung ihres traditionellen Rekrutierungssystems zum öffentlichen Dienst interessiert. Eine vollkommene Änderung dieser Verfahren wäre für diese Mitgliedstaaten vermutlich kaum zumutbar. Das Beispiel des Concours zeigt jedoch, daß sich in einigen Fällen das Anerkennungssystem kaum mit dem traditionellen Verwaltungssystem der Mitgliedstaaten in Einklang bringen läßt.

\section{\$ 4. Die Umsetzung der Richtlinie 89/48/EWG für Lehrer}

\section{A. DiE BundesRepublik Deutschland}

\section{Die Reglementierung der Lehrerausbildung in der Bundesrepublik Deutschland}

Der Beruf des Lehrers ist in der Bundesrepublik ein reglementierter Beruf. Dies ist unabhängig davon, ob die Tätigkeit an einer staatlichen oder an einer privaten Schule ausgeübt wird. Besonderes Merkmal der deutschen Lehramtsbefähigung ist, daß diese das Studium von mindestens zwei Fächern oder Fachrichtungen voraussetzt. Lehrer sind in der Regel Beamte im Sinne des Beamtenrechtsrahmengesetzes, können aber auch im Angestelltenverhältnis beschäftigt werden. Der Status kann von der Anzahl der Planstellen abhängig sein. Lange Zeit war vor allem in der deutschen beamtenrechtlichen Literatur die Frage umstritten, ob der Lehrerberuf unter die Ausnahmebestimmung des Art. 48 Abs. $4 \mathrm{EGV}$ zu rechnen war ${ }^{1542}$. Wie bereits ausgeführt findet nach der

1541. Problematisch ist daher die bisherige französüsche Umsetzung, die lediglich den Zugang zum Concours regell, ohne jedoch weitere Sonderbestimmungen für die ausländischen Concoursteilnehmer zu enthalten. Siehe unten Seite 391

1542. Verwiesen sei auf die verschiedenen Veröffentlichungen von Lecheler: DVBI. 1989, 417; Die Verwall tung 1989,137 . 
Rechtsprechung des Gerichtshofs die Ausnahmebestimmung des Art. 48 Abs. 4 EGV keine Anwendung auf den Lehrerberuf ${ }^{1543}$. Diese nach der Entscheidung in der Rechtssache Lawrie-Blum ${ }^{1544}$ noch sehr umstrittene Interpretation des Art. 48 Abs.4 EGV, hat inzwischen auch in der Bundesrepublik Deutschland Akzeptanz gefunden ${ }^{1545}$. Nur noch vereinzelt regten sich Stimmen, die versuchten, Inhalt und Wirkung der EuGH-Entscheidung zu diesem Punkt in Zweifel zu ziehen ${ }^{1546}$. Seit der Entscheidung des Gerichtshofes in der Sache Bleis ${ }^{1547}$ sind diese Stimmen jedoch mehrheitlich endgültig zum Schweigen gebracht.

\section{Umsetzungsmaßnahmen für Lehrer in der Bundesrepublik Deutschland}

Die Umsetzungsverpflichtung hinsichtlich der Lehrerausbildung fiel mangels einer entsprechenden Bundeskomptenz in den Bereich der Ländergesetzgebung. Jedes Bundesland regelte für seinen Kultusbereich das erforderliche Verfahren. Die Form der Umsetzung ist dementsprechend unterschiedlich. Inhaltlich stimmen die Umsetzungsmaßnahen jedoch weitgehend überein. Diese Übereinstimmung konnte aufgnund eines Beschlusses der Kultusministerkonferenz erzielt werden ${ }^{1548}$. In diesem Beschluß wurden verfahrensrechtliche und materiellrechtliche Bereiche festgelegt, die bei der Umsetzung durch die Landesgesetzgeber $z u$ berücksichtigen waren ${ }^{1549}$ :

1543. So zuletzt noch in der Rechtssache A.Bleis/Ministere de l'Education, Urteil vom 27. November 1991, Slg. 1991, 1-5627. worin die berreits bestehende Rechtsprechung bezdglich Art. 48 Abs 4 EGV erneut bestatigt wurde, in dem der Gerichtshof sehr lapidar feststellte, daB die Tatigkeit an einer Schule keine Beschäftigung in der offentlichen Verwaltung im Sinne des Ant. 48 Abs. 4 EGV darstellt.

1544. Unteil vom 3. Juli 1986, Rs 66/85-D. Lawrie Blum/Land Baden-Württemberg ־, Slg, 1986, 2121 f.

1545. Diese allgemeine Akzeptanz der Rechtsprechung zu diesem Punkt manifesticrt sich auch in der amtlichen Begründung zu dem hamburgischen Umsetzungsgesetz fur die Lehrãmter, Bürgerschiaft der Fre ien und Hansestadt Hamburg. Drucksache 13/6916, 3, worin ohne jede weitere Begründung festgestellt whind, daß đie Lehrämter nicht von dem Tatbestand des Art. 48 Abs. 4 EWGV erfaßt sind.

1546. Lecheler 1990; Loschelder, ZBR 1991, 102.

1547. Unteill vom 27. November 1991, Rs C-4/91 - A.Bleis/Ministère de l'Education nationale -, Slg. 1991, $1-5627$.

1548. Beschiluß der KMK vom 14. September 1990, KMK Erg. Lieferung 69 September 1991, Sammllung Luchterhand, 718

1549. Dobrich/Jeuthe, RarB 1992, 537. 
Bisher liegt eine vollkommen abgeschlossene Umsetzung lediglich von Bayem ${ }^{15 s a " ~}$ Hamburg ${ }^{155 l}$. Hessen ${ }^{1552}$, Nordrhein-Westfalen ${ }^{1553}$ "dem Saarland ${ }^{1554}$ sowie Berlin ${ }^{155 s}$ vor. Säumig sind in der ein oder anderen Weise bei den alten Bundesländern Baden-Württemberg, Bremen, Niedersachsen, Rheinland-Pfalz und Schleswig-Holstein sowie alle neuen Bundesländer. Dabei haben die meisten Bundesländern inzwischen Umsetzungsmaßnahmen verabschiedet, die Umsetzung ist jedoch noch nicht vollkommen abgeschlossen, weil die ausführenden Rechtsverordnungen nicht vorliegen oder wie einige Zeit im Falle von Nordrhein-Westfalen dje gesetzliche Grundlage eigentlich noch entsprechend angepaßt werden sollte.

Die Verzögerung beruht auf unterschiedlichen Ursachen: Wesentlich für die Verspätung einiger Bundesländer war die Tatsache, daß die geplante Änderung des Beamtenrechts, wodurch der Zugang zum Beamtenstatus für EG-Angehörige eröffnet werden sollte; zunăchst an einer Weigerung des Bundesrates scheiterte. Nachdem der Gesetzesentwurf diese Hürde passiert hatte, stieß er erneut auf Schwierigkeiten, nun jedoch im Innenausschuß des Bundestages. Dieser hatte beschlossen zunächst eine Sachverständigenanhörung durchzuführen, so daß sich die Verabschiedung des Gesetzesentwurfes noch weiter verzögerte.

Im Rahmen dieser Gesetzesänderung sollten auch die Laufbahnvoraussetzungen angepaßt werden. Die Verzögerung auf Bundesebene, das Beamtenrechtsrahmengesetz in zweifacher Weise zu ändern, nämlich einerseits eine Anpassung an die Rechtsprechung des EuGH zu Art. 48 Abs. 4 EGV zu gewährleisten und dabei gleichzeitig die Diplomanerkennung für die Tätigkeit im öffentlichen Dienst durchzuführen, hatte zur Konsequenz, daß einige Bundesländer das Gesetzgebungsverfahren trotz bereits vorliegender Referentenentwürfe unterbrachen ${ }^{1556}$. Dies galt besonders in den Ländern, die über kein spezielles Lehrerausbildungsgesetz als Grundlage verfügen, sondern in denen die Lehrerein-

1550. Gesetz zur Änderung des Bayerischen Lehrerbildungsgesetzes wom 27. Dezember 1991, Bayerisches GWB1. Nr. 28/1991, 492.

1551. Gesetz zur Umsetzung der Richtlinie des Rates der Europäischen Gemeinschaften vom 21. Dezember 1988 uber eine allgemeine Regelung zur Anerkennung der Hochschuldiplome, die eine mindestens drejiährige Berufsausbildung abschließen, für die Lehrämter (EG-RL-G-Lehrer) vom 21. Dezember

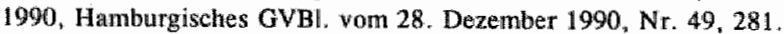

1552. Gesetz zur Änderung des Gesetzes über das Lehramt an öffentlichen Schulen vom 20. November 1991 , GVBI. für das Land Hessen, Teil I wom 26. November 1991, Nr. 26, 340.

1553. Verordmung zur Umsetzung der Richtinie des Rates der Europäischen Gemeinschaften wom 21 Dezember 1988 uber eine allgemeine Regelung zur Anerkennung der Hochschuldiplome im Lehrerbereich, die eine mindestens dreijahthige Berufsausbildung abschließen (AVO-EG) vom 21. Mai 1991, GVBI. für das Land. Nondrhein-Westfalen, Nr. 25 vom 21. Juni 1991 , 246.

1554. Gesetz Nr. 1284 zur Änderung won Vorschriften auf dem Gebiet des Schulrechts vom 22. Januar 1992, Amtsblatt des Saarlandes vom 24. April 1992, Nr. 18, 434 ff., Art. 6: Änderung des Saarländischen Lelrrerbildungsigeseizes

1555. Gesetz zur Umsetzung der Richtlinie 89/48/EWG des Rates der Europaischen Gemeinschaften vozn 21. Dezember 1988 über eine algemeine Regelung zur Anerkennung der Hochschuldiplome, die eime mindestens dreijtahrige Benffsausbildung abschlieBen, furr Lehrerbenfe (EG-RL-LehrG) vom 9. Juni 1993, GVBI. Berlin vom 19. Juni 1993, 250.

1556. Dies gilt jedlenfalls für Niedersachsen und angeblich auch für Baden-Württemberg. 
stellung im Rahmen allgemeiner Länderbeamtengesetze geregelt ist. Einige Bundesländer hielten es aufgrund der gegebenen Rechtslage nicht einmal für nötig, die notwendigen Vorbereitungen zur Umsetzung zu treffen. Ob diese Tatsache seine Ursache in der Säumnis des Bundes hatte oder auf einem allgemeinen Unwillen zur Umsetzung der Richtlinie 89/48/EWG für Lehrer beruht, mag dahinstehen. Nach Inkrafttreten des 10. Gesetzes zur Änderung dienstrechtlicher Vorschriften ${ }^{1557}$, kann sich kein Bundesland auf diesen Entschuldigungsgrund für die eigene Säumigkeit berufen. Inzwischen haben auch neun Bundesländer ihr Beamtenrecht entsprechend der Vorgabe des Beamtenrechtsrahmengesetzes geändert ${ }^{1558}$

Bei den neuen Bundesländern beruhte die Verzögerung dagegen grundsätzlich auf der Tatsache, dal ein vollständig neues Schul- und Lehrerausbildungssystem geschaffen werden mußte, in dessen Rahmen dann auch die Umsetzung der Richtlinie erfolgen sollte ${ }^{1559}$. Letzlich wurde von einigen Bundesländern ein Regierungswechsel bzw " eine umbildung für die nicht fristgerechte Verabschiedung der Umsetzungsmaßnahmen verantwortlich gemacht ${ }^{1560}$.

Betrachtet man den zeitlichen Verlauf des Umsetzungsprozeßes insgesamt, so ist dieser als äußerst unbefriedigend zu bezeichnen: Termingerecht hat lediglich Hamburg die Richtlinie umgesetzt ${ }^{1561}$. Bis zum Ende von 1992, d.h. bis zur angestrebten Vollendung des Binnenmarkts, hatten nur fünf der sechzehn Bundesländer Umsetzungsmaßnahmen ergriffen. Bayern hat einen Absatz 4 an Art. 7 des Bayerischen Lehrerbildungsgesetzes angefügt ${ }^{1562}$. Die dazu gehörige Rechtsverordnung ist ebenfalls ergangen ${ }^{1563}$. In Hamburg erließ die Bürgerschaft ein Spezialgesetz, in das die wesentlichsten Bestimmungen hinsichtlich der Lehramtsbefähigung, der Eignungsprüfung und des

1557. Zehntes Gesetz zur Änderung dienstrechtlicher Vorschriften vom 20. Dezember 1993 (betr. Beamtemrechtsralimengese(z und Bundesbeamtengesetz), BGBI. I, 2136.

1558. Bayem: Zwölftes Gesetz zur Ändenung dienstrechtlicher Vorschriften vom 1. August 1994, GVBi. 1994, 613; Bremen: Gesetz zur Änderung dienstreclytlicher Vorschriften vom 1. März 1994, GVB Nr. 12 vom 16. März 1994, 107; Hamburg: Drittes Gesetz zur Anderung dienstrechtlicher Vorschriften; Hessen: Sechstes Gesetz zur Ändenung dienstrecht licher Vorschriften vom 21. Dezember 1994, GVB, Teil I vom 28. Dezember 1994, 810; Nordrhein-Westfalen: Siebtes Gesetz zur Änderung dienstrechtlicher Vorschriften; Rheinland-Pfalz, A.rt. 27 a des Landesbeamtengesetzes: Zweites Giesetz zur Änderung dienstrechtlicher Vorschriften vom 21. Dezember 1993, GVBI, 1993, 647; Saarland: Gesetz zur Änderung dienstrechtlicher Vorschriften; Sachsen: Bekanntmachung der Neufassung des Beamtengesetzes vom 16. Juni 1994, GVB Nr. 39/1994 vom 14. Juli 1994, 1153; Thüringen: Beamtengesetz vom 10. Juni 1994, GVB Nr. 20 vom 17. Juni 1994, Teil I, 592.

1559. Döbrich/Jeuthe, RdJB 1992, 537 (540).

1560. Vier Jahre nach Abllauf der Umsetzungsfrist überzeugt dieses Argument jedoch niclht mehr

1561. Gesetz zur Umsetzung der Richtlinie des Rates der Europãischen Gemeinschaften vom 21. Dezember 1988 über eine allgemeine Regelung zur Anerkennung der Hochschuldiplome, die eine mindestens dreijährige Berufsausbildung abschließen, für die Lehrämter (EG-RL-G-Lehrer) vom 21. Dezember 1990, Hamburgisches Gesetz- und Verordnungstlatt vom 28. Dezember 1990, Nr. 49, 281.

1562. Gesetz zur Änderung des Bayerischen Lehrerbildungsgesetzes vom 27. Dezember 1991 und Gesetz zur Änderung des Bayerischen Lehrerbildungsgesetzes vom 23. Juli 1993 (für den EWR-Bereich).

1563. Verordnung zum Vollzug des Art. 7 Abs. 4 des Bayerischen Lehrerbildungsgesetzes (EGRiLV-Lehrer) vom 23. Juli 1992, GVBll 13/1992, 245. 
Anpassungslehrganges aufgenommen wurden ${ }^{15.64}$, während die genaueren verfahrenstechnischen Ausführungsbestimmungen in einer Verordnung niedergelegt wurden ${ }^{1565}$ : Hessen hat im Rahmen einer Gesetzesänderung einen \$ $8 \mathrm{a}$ in das Gesetz uber das Lehramt an öffentlichen Schulen eingefügt, worin wie in Hamburg die grundsätzlichen Bestimmungen geregelt sind ${ }^{1566}$. Die für die inhaltliche Ausgestaltung erforderliche Rechtsverordnung ist ebenfalls, allerdings mit erheblicher Verspätung ergangen "s6a?" Nordrhein-Westfalen hat in dem Dilemma zwischen Bundes- und Europarecht einen juristisch sehr unkonventionellen Weg gewählt und lediglich eine Verordnung erlassen, ohne die dazugehörige gesetzliche Bestimmung zuvor entsprechend anzupassen ${ }^{1566 .}$. Mit der Gesetzesänderung sollte bis zur Verabschiedung des Beamtenrechtsrahmengesetzes gewartet werden. Die Änderung wird jedoch aufgrund der $\$ \$ 16$ Abs. 5, 17 Abs. 5 und 19 Abs. 5 des Lehrerausbildungsgesetzes nicht als zwingend erforderlich erachtet ${ }^{1569}$. Das Saarland hatte die grundsätzliche Anerkennung der in einem anderen Mitgliedstaat der Europäischen Gemeinschaft erworbenen Diplome für den Lehrerberuf in der gesetzlichen Regelung verankert ${ }^{1570}$, die notwendigen Bestimmungen in Bezug auf die Kompensationsinstrumente sind jedoch in einer Rechtsverordnung niedergelegt, die erst am 27. Juli 1993 erlassen worden ist ${ }^{1571}$.

1564. Gesetz zur Umsetzung der Richtlinie des Rates der Europäischen Gemeinschaften vom 21. Dezember 1988 über eine allgemeine Regelung zur Amerkennung der Hochschuldiplome, die eine mindestens dreijahrige Berufsausbillung abschließen, für die Lehrämter (EG-RL-G-Lebrer) vom 21. Dezember 1990, Hamburgisches Gesetz- und Verordnungsblatt vom 28. Dezember $1990, \mathrm{Nr}$. 49, 281.

1565. Verordnung zur Ausfühnung des Gesetzes zur Umsetzung der Richulinie des Rates der Europäischen Gemeinschaften vom 21. Dezember 1988 über eine allgemeine Regelung zur Anerkennung der Hochschuld iplome, die eine mindestens dreijâhrige Benufsausbildung abschließlen, für die Lehrämter (EGRL-VO-Lehrer) vom S. November 1991, Hamburgisches Gesetz- und Verordnumgsblatt 1991, $\mathrm{Nr}$. 52 , 340 .

1566. Gesetz zur Änderung des Gesetzes über das Lehramt an öffentlichen Schulen wom 20. November 1991. GWB1. 1991, 340. Bekanntmachung der Neufassung des Gesetzes biber das Lehramt an öffentlichen Silialen wom 3. Mărz 1992, GVBi. 1992, 105.

1567. Verondnung uber die Anerkennung des Lehrerdiploms von Angehörigen anderer EU Mitgliedstaaten Nr: 23 vom 17. September 1994, 438

1568. Verotdnung zur Umsetzung der Richthinie des Rates der Europäischen Gemeinschaften vom 21. Dezember 1988 über eine allgemeime Regelung zur Anerkennung der Hochschuldiplome im Lehrerbereich, die eine mindestens dreijathrige Berufsausbildung abschliefen (AVO-EG) vom 21. Mai 1991, GV .NW, 246; Vgl. dazu das Lehrerausbildungsgesetz NW in der Fassung der Blekanntmachung vom 23. Juni 1989 GVBI. 1989, 421; Erste Verordnung zur Ändenung der Verordnung zur Anerkennung der Hochschuldiplome im Lehrerbereich, die eine mindestens drejiahrige Berufsausbildung abschlieBen, und zur Übertragung der Befugnis zur Anerkennung von Lehrbefähigungen, Lehramtsprüfungen und HochschulabschluBpritungen auf den Regierungspräsidenten vom 26. Mai 1994, GVB1, 1994, 320.

1569. Siehe dazu den Gesetzesentwurf wom 12. September 1994: Siebtes Gesetz zur Änderung dienstrechtlicher Vorschriften, Drucksache 11/7676 vom 8. September 1994.

1570. \$7 Abs 4 des Saarländischen Lehrerbildungsgesetzes; Gesetz Nr. 1284 zur Änderung von Vorschriften auf dem Gebiet des Schulrechts vom 22. Januar 1992, ABI. 1992. 434

1571. Verondmung zur Umsetzung für den Benuf des Lehrers (EG-RL-VO-Lehrer) vom 27. Juli 1993, ABI. 1993,763 . 
Seit dem 1. Januar 1993 sind won den meisten anderen Bundesländern Umsetzungsregelungen erlassen worden ${ }^{1572}$. Mit Ausnahme der Berliner Regelung sind diese jedoch zum überwiegenden. Teil nicht vollständig ${ }^{1573}$. Drei Bundesländer haben dagegen noch immer keine Umsetzungsmaßnahme vorgelegt. Es handelt sich dabei um Baden-Württemberg, Brandenburg ${ }^{1574}$ und Sachsen-Anhalt ${ }^{1575}$. Läßt sich dieses Versäumnis bei den neuen Bundesländern noch mit dem Aufbau eines neuen Schul- und Lehrerbildungssystems erklären, wenn auch nicht entschuldigen, so gibt es für das Land Baden-Württemberg weder eine Erklärung noch eine Entschuldigung. Vielleicht kommt es jedoch nicht von ungefähr, daß die Fälle Lawrie-Blum ${ }^{1576}$, Vlassopoulou ${ }^{1577}$ und Kraus ${ }^{1578}$ alle in diesem Bundesland ihren Ursprung hatten.

\section{Die Umsetzung in der Ländergeserzgebung ${ }^{1570}$}

\section{a. Hamburg}

Gemäß \& 1 des EG-RL-G-Lehrer steht eine in Hamburg oder nach dem Recht eines anderen Bundeslandes erworbene und in Hamburg anzuerkennende Lehramtsbefähigung einer Lehramtsbefähigung gleich, die die Voraussetzungen des Art. 1 Buchstabe a der Richtlinie 89/48/EWG erfült. Eine Lehramtsbefähigung berechtigt allerdings nur dann

1572. Berlin: Gesetz zur Umsetzung der Richtlinie 89/48/EWG für Lehrerberufe wom 9. Juni 1993, GVBI. vom 19. Juni 1993, 250; Verordnung vom 12. Juli 1993 (EG-RL-LehrVO), GVBl wom 3. August 1993, 334; Bremen: Gesetz zur Änderung dienstrechtlicher Vorschriften vom 1. Mărz 1994, GVB1. Nr. 12 rom 16. März 1994, 107; Niedersachsen: Viertes Änderungsgesetz vom 10. Januar 1994, GVBI, 1994, 2; Mecklenburg-Vorponnmern: EG-Lehreranerkennungswerordnung vom 2. Mărz 1995, GVOBI. 1995, 202; Rheinland-Pfalz: Zweites Gesetz zur Ändensng dienstrechticher Vorschriften vorn 21. Dezember 1993, GVBI. 647; Sachsen: Beamtengesetz vom 17. Dezember 1992 sowie Gesetz zur Änderung des Beamtengesetzes für den Freistaat Sachsen vom 19. April 1994, GVBI. 1994, 781; Schleswig-Holstein: Landesverordnung über die Ordnung des Vorbereitungsdienstes und die Zweiten Staatspriffungen der Lehrkräfte (Ausbildungs- und Prüfungsordnung Lehrkraffte II-OVP) vom \&, Juill 1993 sowie Gesekz zur Unsetzung der Richtinie 89/48/EWG vom 8. Dezember 1994, GVBI. 1995, 2; Thüringen: Thüringer Schulgesetz wom 6. August 1993, GVBI. 1993, 445.

1573. Gesetz zur Umsetzung der Richtlinie 89/48/EWG des Rates der Europäischen Gemeinschaften vom 21 Dezember 1988 über eine allgemeine Regelung zur Anerkennung der Hochschuldiplome, die eine mindestens dreijährige Berufsausbildung abschließen, für Lehrerberufe (EG-RL-LehrG) vom 9. Juni 1993, Gesetz- und Verordnung sblatt Berlin vom 19. Juni 1993, 250; Verordnung vorn 12 . Juli 1993 (EG-RL-LehrVO), GVBI vom 3. August 1993, 334.

1574. Das. Gesetz zur Umsetzung der Richtinie 89/48/EWG für Lehrer und die Durchifuhrungsverordnungen sollen dem Landtag im Sonmer 1995 zur Abstimmung zugeleitet werden.

1575. Es ist beabsichtigt, eine Umsetzung im Landesbeamtengesetz 1995 vorzunehmen.

1576. Urteil vom 3. Julli 1986, Rs 66/85 - D. Lawrie Blum/Land Baden-Württemberg -, Slg. 1986, 2121 ff.

1577. Urteil wom 7. Mai 1991. Rs C-340/89 - Irêne Vlassopoulou/Ministerium für Justiz, Bundes- und Europarangelegenheiten Baden-Württemberg, Slg. 1-1991, 2357.

1578. Urteil vom 31. März 1993, Rs C-19/92 -Kraus/Land Baden-Wurttemberg - Slg. 1993, 1-1663.

1579. Im einzelnen wird nur auf die Umsetzungsmaßnahmen der Lânder Bayern, Hamburg und Hesset eingegangen, weil die anderen Bundesländer soweit sie bisher Umsetzungsmaßnahmen ergriffen haben diese inhaltich mit den erörterten im wesendichen übereinstimmen. Dabei wird die Umsetzung durch das Land Hamburg exemplarisch am ausfuhrlichsten besprochen 
zur Ausübung der reglementierten beruflichen Tätigkeit eines Lehrers, wenn sie sich auf mindestens zwei. Fächer oder Fachrichtungen eines Lehramts an Hamburger Schulen erstreckt. Diese in $\& 2$ des EG-RL-G-Lehrer niedergelegte Bedingung ist ãußerst zwelfelhaft im Hinblick auf die Korrektheit der Umsetzungsmaßnahme. In der amtlichen Begründung heißt es hierzu, dal die Anforderung, die Lehrbefähigung in mindestens zwei Fächern zu besitzen, für Inländer ausnahmslos gelte, so daß Entsprechendes auch von EG-Angehörigen verlangt werden dürfe und im Interesse der Verwendbarkeit dieser Lehrer verlangt werde müsse. Abgestellt wird in der Begründung damit ausschließlich auf das Prinzip der Inländergleichbehandlung und der in Deutschland gebräuchlichen Mehrfachverwendbarkeit von Lehrkräften. Diese Begründung dürfte jedoch nicht ausreichen, diese gesetzgeberische Maßnahme generell zu rechtfertigen. Der Gerichtshof hat wiederholt festgestellt, daß auch Fälle versteckter Diskriminienung, wodurch es einem Angehörigen eines anderen Mitgliedstaates faktisch quasi unmöglich gemacht wird, seine garantierten Freizügigheitsrechte auszüben, unzulässig sind ${ }^{1580}$. Gerade ein solcher Fall von versteckter Diskriminierung könnte hier vorliegen. Die Bundesrepublik steht mit ihrer Forderung nach der Lehrbefähigung in zwei Fächern zwar nicht allein. Auch in einigen anderen Mitgliedstaaten wird von Lehramtsanwärtern die Befähigung in mehr als einem Lehrfach verlangt ${ }^{1581}$.

In anderen Mitgliedstaaten bezieht sich die Ausbildung meistens jedoch auf ein Fach ${ }^{1582}$. Studiert ein Kandidat zwei Fächer, so handelt es sich um ein Doppelstudium. Dies ist jedoch eher die Ausnahme als die Regel. Die steigenden Studienkosten sowie die zunehmende Zahl der Studienabsolventen wird hierin auch keine Veränderung bringen. Weit eher ist mit einem Rückgang derartiger Doppelstudien zu rechnen. Will nun ein solcher Lehramtskandidat, der in den Niederlanden ein Studium, z.B. das einer Sprache, mit Erfolg abgeschlossen hat, sich an einer deutschen Schule bewerben, so wird er mit dieser Zwei-Fächer Bedingung konfrontiert werden und vermutlich bereits an ihr scheitern. Zwar wird inoffiziell in Deutschland erklärt, daß die Zwei-Fächer Bedingung nicht so strikt gehandhabt werden soll; so könne z.B. die Muttersprache des Kandidaten unter Umständen als zweites Fach Berücksichtigung funden oder kömnten bestimmte naturwissenschaftliche Studien in zwei Fächer unterteilt werden. Diese Äußerungen sind jedoch in keiner Weise justiziabel ${ }^{15 \% 3}$. Ob hier ein Fall versteckter Diskriminerung vorliegt, wird wesentlich von der praktischen Anwendung der Zwei-Fächer Bedingung abhängen.

Neben der Zwei-Fächer Bedingung allgemein ist die Umsetzung auch insoweit problematisch, da nach der Formulierung in $\$ 2$ EG-RL-G-Lehrer ein deutlicher Bezug zu den Unterrichtsfächern an hamburgischen Schulen festgelegt wird. Eine Qualifikation in zwei Fächern ist somit nicht ausreichend, die Anerkennung wird vielmehr nur dann

1580. Urteil vom 12. Februar 1974, Rs 152/73 - Solgiu/Deutsche Bundespost -, Slg. 1974, 153

1581. So etwa in Belgien.

1582. Vergleiche die Ausbildung zum Doctorandus in den Niederlanden, den Bachalor of Arts in Grofbritannien.

1583. Verlautbarungen aus den einschlägigen Ministerien won Nordrhein-Westfalen und Hessen. 


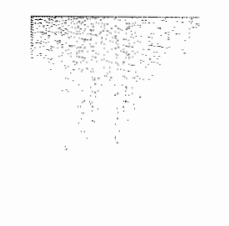

$$
\text { L... }
$$

ausgesprochen, wenn es sich um Fächer handelt, die in Hamburg an Schulen unterrichtet wird. Dies wird durch $\$ 3$ der EG-RL-VO-Lehrer bestätigt. Darin heißt es: "Die Zuordnung zu einem Lehramt an Hamburger Schulen erfolgt aufgrund eines Vergleichs der Ausbillung und gegebenfalls der beruflichen Tätigkeit des Antragstellers mit den in Hamburg geltenden lehramtstypischen Mindestanforderungen." Diese werden in der Bestimmung für die unterschiedlichen Lehramtstypen einzeln aufgelistet. Eine derartige Auflistung muß nahezu zwangsläufig bei Anerkennungsverfahren zu Problemen führen, da in anderen Mitgliedstaaten kaum eine vergleichbare Regelung bestehen wird. Probleme lassen sich auch zu diesem Punkt nur durch eine gemeinschaftsfreundliche Interpretation vermeiden.

Gemäß $\$ 3$ EG-RL-G-Lehrer ist die Beherrschung der deutschen Sprache in Wort und Schrift Bewerbungsvoraussetzung. In der amtlichen Begründung wird die Sprachbeherrschung als Wesensbestandteil der Berufsausübung bezeichnet. Diese Bedingung mutet zwar sehr strikt an - so läßt sich grundsätzlich etwa der Fremdsprachunterricht auch ohne eine derartige Beherrschung der deutschen Sprache vorstellen ${ }^{1584}$ - jedoch darf die Lehrertätigkeit selbstverständlich nicht auf die reine fachspezifische Unterrichtstătigkeit beschränkt werden. Lehrer sind auch verpflichtet als Klassenlehrer oder im Lehrerkollegium Aufgaben wahrzunehmen, deren Ausübung hinreichende Kenntnisse der deutschen Sprache in Wort und Schrift erforderlich machen. So muB etwa die Kommunikation zwischen Lehrer und Eltern grundsätzlich auf Deutsch stattfinden können. Die Frage ist jedoch, wie eine solche Bestimmung ausgelegt wird. Welche Anforderungen werden an die mündliche und schriftliche Beherrschung der Sprache gestellt? In $\$ 1$ Abs. 1 Nr. 4 EG-RL-VO-Lehrer wird dieser Punkt näher spezifiziert. Danach muß das Große Deutsche Sprachdiplom des Goethe-Instituts oder ein vergleichbarer Nachweis den Antragsunterlagen beigefügt werden, falls Deutsch nicht die Muttersprache des Antragstellers ist.

GemäB § 4 EG-RL-G-Lehrer wird vom Antragsteller der Nachweis won einschiägiger Berufserfahrung als Lehrer verlangt, falts seine Ausbildung um mindestens ein Jahr unter der in Hamburg für das jeweilige Lehramt geforderten Ausbildungsdauer liegt. Hinsichtlich der Dauer der Berufserfahrung wird in der Bestimmung auf Art. 4 Abs. 1 Buchstabe a der Richtlinie $89 / 48 /$ EWG verwiesen. In $\$ 5$ EG-RL-VO-Lehrer wird diese Regelung insoweit noch expliziert, daß die Dauer der nachzuweisenden Berufserfahrung das Doppelte der fehlenden Ausbildungszeit, höchstens jedoch vier Jahre betragen muß, wenn sich die fehlende Ausbildungszeit auf das Studium oder auf die schulpraktische Ausbildung mit Prüfung oder auf beides bezieht.

\$ 5 Abs. 1 EG-RL-G-Lehrer enthält die grundsätzliche Regeiung, daß der Antragsteller auf Verlangen der zuständigen Behörden, die in seiner Ausbildung fehlenden, für đie Ausübung des Lehramts in Hamburg aber erforderlichen fachwissenschaftlichen, fachdi-

1584. Der Erfolg von unzähligen Sprachschulen im Ausland mit Lehrkråften, die gerade nicht die Mutter sprache der Schüler sprechen, bestatigt diese These. Auch werden in der Bundesrepublik. Deutschland seit Jahren sogenannte Muttersprachler als Lehrer eingesetzt. 
daktischen und schulpraktischen Kenntnisse und Fähigkeiten nachweisen muß. Den Nachweis kann er im Rahmen eines Anpassungslehrganges oder einer Eignungsprüfung erbringen. Gemäß \& 5 Abs. 2 EG-RL-G-Lehrer schlie/3t das Verlangen von Anpassungslehrgang oder Eignungsprüfung die Forderung mach dem Nachweis von Berufserfahnung aus. Diese Bestimmung entspricht dem Kumulationsverbot der KompensationsmaBnahmen gemäB Art. 4 Abs. 2 der Richtlinie 89/48/EWG.

Nach $\$ 2$ EG-RL-VO-Lehrer ergeht eine mit Gründen versehene Entscheidung spätestens vier Monate nach Vorlage der vollständigen Unterlagen. Diese Entscheidung enthält Aussagen über die Gleichstellung " die Zuordnung der Ausbildung und beruflichen Tätigkeit des Antragstellers zu einem Lehramt an Hamburgischen Schulen sowie die Entscheidung darüber, ob der Antragsteller berufliche Erfahrung nachweisen muB und gegebenenfalls deren Dauer oder, ob von dem Bewerber wahlweise ein Anpassungslehrgang oder eine Eignungsprüfung verlangt wird.

Als Antragsunterlagen werden von dem Bewerber neben dem bereits erwähnten Sprachdiplom, das der Lehrerausbildung zugrundeliegende Diplom im Sinne des Art. I Buchstabe a der Richtlinie 89/48/EWG, der Nachweis der Studiens- und Ausbildungsinhalte, Nachweise über etwaige tatsächliche und rechtmäßige Ausübung des Lehrerberufs in einem anderen Mitgliedstaat der Europäischen Gemeinschaft, ein Lebenslauf mit tabellarischer Darstellung des Ausbildungsganges, ein Staatsangehörigkeitsnachweis sowie eine Erklärung darüber verlangt, ob und gegebenenfalls mit welchem Ergebnis der Bewerber in einem anderen Bundesland einen entsprechenden Antrag gestellt, eine Eignungsprüfung abgelegt oder einen Anpassungslehrgang durch】aufen hat. Die Unterlagen sind gemäß $\S 1$ Abs. 2 EG-RL-VO-Lehrer in deutscher Sprache, fremdsprachige in beglaubigter Übersetzung vorzulegen. Die von den zuständigen Behörden eines Mitgliedlstaates ausgestellten Bescheinigungen werden anerkannt. Nach dem Wortlaut der Bestimmung: bedürfen die letztgenannten auch nicht cler deutschen Übersetzung.

Wählt der Antragsteller im Falle einer geforderten Kompensationsmaßnahme den Anpassungslehrgang, so übt er als Angestellter auf Zeit die Tätigkeit eines Lehrers unter der Verantwortung eines qualifizierten Berufsangehörigen aus. Er nimmt, soweit dies erforderlich ist, an einer berufsbegleitenden Zusatzausbildung teil. Der Anpassungslehrgang wird vom Staatlichen Studienseminar für Lehrämter an Hamburgischen Schulen durchgeführt. Er beginnt mit dem Schuljahr und dauert höchstens drei Jahre. Der Anpassungslehrgang unterliegt einer Bewertung ( $\$ 6$ Abs. 1 EG-RL-G-Lehrer).

Gemäß \$13 Abs. 1 EG-RL-VO-Lehrer dauern die Anpassungslehrgänge ein, zwei oder dreil Jahre. Die zuständige Behörde bemißt die Dauer nach dem Umfang der für die Ausübung des betreffenden Lehramtes erforderlichen fachwissenschaftlichen, fachdidaktischen oder schulpraktischen Kenntnisse und Fähigkeiten, die in der Qualifikation des Antragstellers nicht enthallen sind. Nach Abs. 2 der Bestimmung kann ein Anpassungslehrgang weder verlängert noch wiederholt werden. Der Anpassungslehrgang unterliegt der Bewertung ( $\$ 15$ EG-RL-VO-Lehrer ). 
Entscheider sich der Antragsteller für die Eignungsprüfung ( \& 7 EG-RL-G-Lehrer), dann organisiert das Lehrerprüfungsamt die Prüfung gemälß $\$ 16$ Abs.l EG-RL-VOLehrer. Die Eignungsprüfung besteht aus Prüfungsunterricht und einer zweistündigen mündlichen Prüfung. Der Prüfungsunterricht umfaßt gemäß \$ 17 Abs. 1 EG-RL-VOLehrer je Fach zwei Unterrichtsstunden auf jeweils verschiedenen Schulstufen. Die Themenbereiche des Prüfungsunterrichts werden vom zuständigen Schulleiter nach Rüicksprache mit dem für den betreffenden Unterricht zuständigen Lehrer bestimmt und dem Antragsteller fünf Tage vor dem Prüfungsunterricht bekanntgegeben. Nach Abs. 4 der Bestimmung muß der Antragsteller dem Prüfungsausschuß einen schriftlichen Unterrichtsentwurf in deutscher Sprache übergeben, worin er seine didaktischen Absichten und seinen Unterrichtsplan erläutert. Gegenstand der mündlichen Prüfung sind die Kenntnisse und Fähigkeiten, die laut der Entscheidung der zuständigen Behörde nicht in der ursprünglichen Ausbildung des Antragstellers enthalten sind. Die Zusammensetzung des Prüfungsausschusses ist in § 19 EG-RL-VO-Lehrer geregelt. Die einzelnen Prifungsleistungen werden benotet. Das Gesamtergebnis der Eignungsprüfung ist der Mittelwert der Noten für den Prüfungsunterricht und der Note für die mündliche Prüfung. Im Falle eines negativen Prüfungsergebnisses kann die Eignungsprüfung innerhalb von drei Jahren einmal wiederholt werden ( $\$ 26$ EG-RL-VO-Lehrer.)

\section{b. Bayern}

Gemäß Art. 7 Abs. 4 Bayerisches Lehrerbildungsgesetz (BayLBG) sind für Angehörige eines Staates der Europäischen Gemeinschaften, die in einem Mitgliedstaat der Europäischen Gemeinschaften außerhalb der Bundesrepublik Deutschland ein Hochschuldiplom erworben haben, das eine mindestens dreijährige Ausbildung für den Beruf des Lehrers abschließt, die Richtlinie 89/48/EWG und die nach diesem Gesetz ergehenden Ausführungsvorschriften für die Feststellung der Lehramtsbefähigung maßgebend. Für diesen Bewerberkreis ist der Nachweis der für den Unterricht erforderlichen deutschen Sprachkenntnisse notwendig. Teilnehmer an einem Anpassungslehrgang werden für dessen Dauer in ein öffentlich-rechtliches Dienstverhältnis eingestellt und erhalten eine Unterhaltsbeihilfe in Höhe der Anwärterbezüge im Vorbereitungsdienst für die entsprechende Laufbahn.. Hinsichtlich der Vergleichbarkeit der Qualifikation bestimmt \$ 1 der Ausführungsverordnung ${ }^{1585}$, daß das Bayerische Lehrerbildungsgesetz, die Lehrerprüfungsordnung I (LPO I) und die Lehrerprüfungsordnung II (LPO II) maßgebend seien.

\section{c. Hessen}

Die Umsetzung der Richtlinie erfolgte durch die Einfügung des $\$ 8$ a in das Gesetz über das Lehramt an öffentlichen Schulen. Grundsätzlich wird auf den Wortlaut der Richtlinie verwiesen.

1585. Verordnung zum Vollzug des Art. 7 Abs. 4 des Bayerischen Lehrerbildungsgesetzes (EG-Richtlinienverordnung für Lehrer-EG-RiLV-Lehrer) vom 23. Juli 1992, Bayerisches GVBI. Nr. 13/1992, 245. 
Fallstudie III: Lehrer

Problematisch ist jedoch eine in $\$ 8 \mathrm{a}$ Abs. 3 Lehramtsgesetz Hessen enthaltene Bedingung, wonach die Zulassung zu einem bestimmten Anpassungslehrgang versagt werden kann, wenn die im Haushaltsplan des Landes zur Verfügung stehenden Mittel nicht ausreichen oder die personelle und sachliche Kapazität der Schulen eine sachgerechte Durchführung des Anpassungslehrgangs nicht gewährleistet. Sofern die Zahl der Anträge auf Durchführung eines Anpassungslehrgangs die Zahl der zur Verfügung stehenden Stellen übersteigt, ist der Zeitpunkt des Eingangs des Antrags maßgebend ( 8 8a Satz 2 Lehramtsgesetz Hessen). Diese Regelung wird in der amtlichen Begründung ohne genauere inhaltliche Erläuterung mit der Verweisung auf ein ähnliches Auswahlverfahren für die Zulassung zum Vorbereitungsdienst nach \& $3 a$ des Lehramtsgesetzes erklärt ${ }^{1586}$. Läßt sich ein derartiges Auswahlwerfahren für cen nationalen Vorbereitungsdienst aufgrund von Kapazitätsproblemen rechtfertigen, so kann eine Zulassungsbeschrärkung für den Anpassungslehrgang damit nicht begründet werden. Ist der Anpassungslehrgang nach Ansicht der zuständigen Behörde erforderlich, um die Anerkennung des Diploms vorzunehmen, so muß der Kandidat ohne jegliche weitere Beschränkung in die Lage wersetzt werden, die geforderte Anpassung auch durchzuführen. Ansonsten wird in einer nach dem Maßstab der Richtlinie unzulässigen Weise sein allgemeines Recht auf Anerkennung gemäß Art. 3 der Richtlinie 89/48/EWG geschmälert.

\section{Beurteilung der Umsetzung für Lehrer}

a. Beurteilung der Umsetzung für Lehrer in Hamburg

Die Hamburger Umsetzung erscheint, soweit die zwei-Fächer Bedingung in nicht allzu rigider Form gehandhabt wird, aus den genannten Gründen unbedenklich zu sein.

b. Beurteilung der Umsetzung für Lehrer in Bayern

Bedenklich ist die bayerische Umsetzung insoweit, als sie nicht die Definition der Richtlinie 89/48/EWG hinsichtlich des Begriffes "Diplom" verwendet. Dadurch wird der Anwendungsbereich in nicht unwesentlicher Weise beschränkt. Dies gilt in mehrfacher Hinsicht. Zum einen spricht das Umsetzungsgesetz lediglich von Hochschuldiplomen, zum anderen wird kein Bezug auf Drittstaatdiplome genommen. Auch findet keine Umsetzung des Art. 3 b) der Richtlinie 89/48/EWG statt. Die bloße Verweisung auf die Richtlinie 89/48/EWG erscheint unter diesem Gesichtspunkt nicht ausreichend zu sein.

c. Beurteilung der Umsetzung für Lehrer in Hessen

Die hessische Umsetzung ist soweit die Zulassung zu eine Anpassungslehrgang aus finanziellen oder Kapazitätsgründen versagt werden kann ( $\$ 8 \mathrm{a}$ Abs. 3) nicht ganz unbedenklich. Allerdings muß zugunsten der Umsetzung durch die Bundesländer zu 
diesem Punkt eingeräumt werden, daß die Anpassungsperiode vergütet wird. Dies ist nicht in allen Mitgliedstaaten der Fall. Ein gewisser Vorbehalt hinsichtlich der finanziellen Mittel ist daher nicht unverständlich, haushaltrechtlich wohl selbst unumgànglich. Die Versagungsmöglichkeit aus Kapazitärsgründen muß dagegen viel kritischer beurteilt werden.

\section{B. DÄNEMARK}

\section{Die Reglementierung der Lehrerausbildung in Dänemark}

In Dänemark sind die Lehrer der Primar- und Sekundarstufe reglementiert ${ }^{1587}$. Für die Primar- und die niedere Sekundarstufe findlet sich die Reglementierung in Section 27 und 28 des Primarschulgesetzes. Voraussetzung für den Zugang ist ein Diplom von einer Lehrerbildungseinrichtung, das nach einer Ausbildung von vier Jahren abgegeben wird. Das Diplom der höheren Sekundarstufe setzt eine fachspezifische Ausbildung von fünf bis sieben Jahre voraus ${ }^{1588}$. Grundsätzlich wird eine Qualifikation in zwei Fächern erworben. Die Anstellung als Lehrer für nur ein Fach ist jedoch möglich. In diesem Falle ist ein vierjahhriges Studium ausreichend. Nach der akademischen Ausbildung folgt ein erziehungswissenschaftlicher Teil nach dessen erfolgreichem Abschluß ein Zeugnis ausgestellt wird. Reglementiert sind auch die Hochschullehrer ${ }^{1589}$.

\section{Umsetzungsmaßnahmen für Lehrer in Dänemark}

Als zuständige Behörde für die Lehrberufe wurde das Erziehungsministerium angewiesen. Bisher sind verschiedene Anerkennungsverfahren für die Primar-- und Sekundarstufe durchgeführt worden, wobei die Wahl der Kandidaten, soweit eine Anpassung erforderlich war, auf die Eignungsprüfung gefallen ist. Diese wurden von Lehrerbildungseinrichtungen durchgeführt. Kenntnisse der dänischen Sprache werden sowohl schriftlich wie mündlich verlangt. Über die Notwendigkeit einer Sprachprüfung entscheidet allerdings die örtliche Einstellungsbehörde.

\section{Beurteilung der Umsetzung}

Eine spezielle Beurteilung der dänischen Umsetzung hinsichtlich der Lehrberufe läßt sich nur schwer vornehmen. Grundsätzlich beruht das Anerkennungsverfahren auf der allgemeinen gesetzlichen Regelung sowie der dazu ergangenen Verordnung. Ansonsten trifft die zuständige Behörde ihre Entscheidung nach den Gegebenheiten des Einzelfalls. Nach dem gemäß Art. 11 der Richtlinie 89/48/EWG an die Kommission gerichteten dänischen Bericht haben bisher neun Sekundarstufenlehrer und zwei Volksschullehrer

1587. Sekretariat der KMMK, Bestandsaufnahme zur Lehrerausbildung, 43.

1588. Die Regiementienung der höheren Sekundarstufe ist in Section 16 der Consolidating Order No 598 enthalten..

1589. Section 4 der Verordnung No 184 vom 14. Mai 1975, Section 1 der Verordinuing No 597 vom 3. Dezember 1975 . 
einen Antrag auf Anerkennung gestellt. Von diesen wurden sieben der Sekundarstufenlehrer automatisch anerkannt, die vier weiteren Anträge wurden dagegen abgellehnt. Aufgrund der geringen Anzahl läßt sich aus dieser Statistik kaum ableiten, ob von einer korrekten Anwendung der Richtlinie gesprochen werden kann. Der hohe Anteil an Anerkennungen ohne Anwendung der Kompensationsinstrumente, spricht jedoch für eine liberale Anerkennungspraxis.

Jedenfalls ist in Dänemark ein Staatsangehörigkeitsvorbehalt als Emennungsvoraussetzung für Lehrer unbekannt. Eine entsprechende gesetzliche Anpassung war daher nicht erforderlich. Auch gibt es keine Bestimmung, die die Lehrbefähigung in zwei Fächern voraussetzt wie dies z.B. in Deutschland der Fall ist. Ebenso unbekannt ist der Concours als Einstellungsverfahren.

\section{FRANKREICH}

\section{Die Reglementierung der Lehrerausbildung in Frankreich}

Frankreich kennt seit der Reform der Lehrerausbildung $1989^{1590}$ nur noch zwei Kategorien won Lehrern: Zum einen die Professeurs des écoles für den Vorschul- und Grundschulbereich und zum anderen die Professeurs du second degré für den Sekundarbereich $^{1591}$. Beide Kategorien werden seit 1990 an den Instituts Universitaires de Formation des Maîtres (IUFM) ausgebildet, die über einen universitären Status verfiigen. Zulassungsvoraussetzung zu einem IUFM ist der Nachweis einer licence, die nach drejjährigem Fachstudium an einer Universität erteilt wird. Nach dem ersten Ausbildungsjahr an einem IUFM muB ein Concours bestanden werden. Dieser Concours ist unterschiedlich für die künftigen Professeurs des écoles und die künftigen Professeurs du second degré gestaltet. Die Kandidaten der ersten Kategorie müssen vier schriftliche Prüfungen ${ }^{1592}$, eine praktische Prüfung in Sport sowie eine mündliche Prüfung mit schulpraktischem Inhalt bewältigen. Der Concours für die Sekundarschullehrer beschränkt sich dagegen auf eine schriftliche Prüfung in der gewählten Fachrichtung sowie eine Unterrichtsprobe. Mit dem erfolgreichen Bestehen des Concours wird der Status eines Professeur stagiaire im Beamtenverhältnis auf Probe verliehen. Diesen Status behalten die Kandidaten bis zum Ausbildungsabschluß nach einem weiteren Jahr am IUFM. Danach besteht - soweit die weiteren beamtenrechtlichen Voraussetzungen erfuillt sind - ein Anspruch auf Übernahme in das Beamtenverhältnis.

\section{Hochschullehrer}

Frankreich ist einer der wenigen Mitgliedstaaten, in dem nicht nur die Lehrtätigkeit im Primar- und Sekundarbereich reglementiert ist, sondern eine vergleichbare Reglementierung auch für den Hochschulbereich besteht. Für diesen Bereich hat eine Umsetzung

1590. Loi d'orientation sur l'education wom Juli 1989.

1591. Sekretariat der KMK. Bestandsaufnahme zur Lehrerausbildung, 51 .

1592. Franzosisch, Mathematik, ein natunwissenschaftliches Fach und ein sprachlich-künstlerisches Fach. 
bisher nicht stattgefunden. Das Ernennungsverfahren für eine Hochschulfunktion setzt grundsätzlich ebenfalls das erfolgreiche Bestehen eines Concours voraus. Daneben gibt es in diesem Bereich die mutation. So heißt es in art. 1 des einschlägigen arreté vom 27. April 1992: "Les emplois de professeur des universités figurant en annexe $A$ du présent arreté sont ouverts a la mutation, au detachement et au recrutement."

\section{Beurteilung der Umsetzung}

Sehr umstritten ist die französische Umsetzung im Bezug auf die.Berufe, die im öffentlichen Dienst ausgeübt werden. Dazu gehören auch die Lehrer. Streitgegenstand ist dabei weniger die Anerkennungsregelung als solche ${ }^{1593}$, sondern vielmehr die Frage des Concours. In Frankreich besteht für den Zugang zu den meisten Berufen des öffentlichen Dienstes ein externes Auswahlverfahren. Solch ein Verfahren wird auch zur Erlangung eines Befähigungsnachweises für das Lehramt durchgeführt. Die Umsetzung diesbezüglich erfolgte durch Gesetz vom 26. Juli $1991^{1544}$, wonach ausländischen $\mathrm{Be}$ werber aus den Mitgliedstaaten der Gemeinschaft an den nationalen Concours für die einzelnen Lehrerlaufbahnen teilnehmen können ${ }^{1595}$. Die Frage ist nun, ob der Inhaber einer Lehrbefähigung aus einem anderen Mitgliedstaat sich diesem Verfahren voll unterwerfen muß. Die Entscheidung darüber hängt davon ab, ob der Concours als Teil der Ausbildung oder aber als ein reines Auswahlverfahren zur Einstellung des Bewerbers einzustufen ist.

Der französische Standpunkt ist eindeutig. Danach ist der Concours kein Teil der Ausbildung, sondern ein Auswahlverfahren, dem sich alle Kandidaten unterziehen müssen, um für eine Einstellung in Frage zu kommen. Eine Diskriminierung liegt nach dieser Auffassung nicht vor, da lediglich der Grundsatz der Inländergleichbehandlung angewandt wird. Frankreich beruft sich dabei auch auf eine Ratserklărung 1596 bei Verabschiedung der Richtlinie 89/48/EWG, nach der die Richtlinie keinen Einfluß auf die Einstellungsmodalitäten in den einzelnen Mitgliedstaaten haben sollte ${ }^{1597}$.

Dagegen lassen sich verschiedene Argumente anführen. Problematisch erscheint zunächst, ob es sich beim französischen Concours für Lehrer - besonders seit der Ausbildungsreform von 1989 - tatsächlich um ein reines Auswahlverfahren handelt. Schließlich erhält der Bewerber erst nach erfolgreichem Abschluß des Verfahrens den zur Einstellung notwendigen Befähigungsnachweis. Der Bewerber kann somit erst dann als

1593. Die Ausführungsmaknahmen bestehen aus drei Arrêtes wom 2. Januar 1991, J0 vom 8. Januair 1991 bezüglich 1 . concours du certificat d"aptiudle au professorat de l'enseignement du second degrế, 2 concours du certificat d'aptitude au professorat de l'enseignement technique, 3. concours du certificat d'aptitude an professorat d'ếducation physique et sportive.

1594. Loi no $91-715$ vom 26. Tulli 1991,

1595. Siehe dazu die weiteren Ausfihnungsbestimmungen durch Décret nr. 92-1246 vom 30. November 1992, JO vom 2. Dezember 1992, Decret nr. 93-6 vom 13. Jaruar 1993. JO vorm 19. Januar 1993; Décret nr. 94-163 vom 16. Februar 1994, Jo von 25. Februar 1994.

1596. 12. Ratserklärung

1597. Siehe bezäglich der juristischen Qualifikation von Ratserklärungen Pechutsteinh, EuR 1990, 249. 
"Endprodukt" eingestuft werden, wenn er den Concours und ein weiteres Jahr Ausbildung an einem IUFM bestanden hat. Aus dieser Perspektive ist der Concours durchaus mit dem zweiten Staatsexamen für das Lehramt in der Bundesrepublik zu vergleichen. Auch das zweite Staatsexamen kann teilweise als ein Auswahlverfahren angesehen werden, da die darin erzielten Noten entscheidend für die spätere Einstellung sind. Gleichzeitig ist das zweite Staatsexamen aber Teil und Abschluß der Berufsausbildung. Zurecht wird daher eine Wiederholung dieser Prüfung oder des Referendariats als mit der Rïchtlinie unvereinbar angesehen. Warum soll dies nicht für den Concours gelten? Auch beim Concours besteht ein untrennbarer Zusammenhang zwischen Auswahll und Befăhigung. Die Reform der Lehrerausbilldung 1989 hat diesen Zusammenhang zwischen Ausbildung und Auswahl selbst noch verstärkt. Die IUFM müssen unzweifelhaft, als Ausbildungseintichtungen eingestuft werden. Damit ist der Concours, der nach einjähriger Ausbildung stattfindet, weit eher als eine Zwischenprüfung im Rahmen der Ausbildung als als Auswahlverfahren zur Einstellung zu qualifizieren. Zugunsten der Freizügigkeit sollte der Concours als Teil der Befähigung und damit nicht wiederholbar eingestuft werden. Dieser Eindruck wird noch verstärkt durch die Tatsache, daß ein Teil der praktischen Ausbildung erst nach Ablegung des Concours stattfindet. Als weiteres Argument gegen den Concours als reines Auswahlverfahren spricht auch die Tatsache, daß neben dem Concours noch die sogenannte Mutation als Einstellungsmodalität besteht. Die Möglichkeit zur Mutation besteht für die Bewerber, die bereits nach erfolgreichem Bestehen des Concours eine bestimmte Stelle einnehmen, nun aber im selben Rang einen örtlichen Wechsel vornehmen wollen. Besonders problematisch ist der Concours in den Fällen, in denen der Bewerber aus einem anderen "Concoursland." stammit ${ }^{4598}$.

Des weiteren ist der französische Concours ein sehr stark durch die französische Kultur geprägtes Phänomen. Der Zweifel liegt nahe, ob ein ausländischer Bewerber in einem solchen Verfahren überhaupt je chancengleich ist. Dies wird besonders deutlich fiur den Primarschulbereich, wo der Concours sich aus vier schriftlichen Prüfungen, einea" praktischen Prüfung in Sport sowie einer schulpraktischen mündlichen Prüfung zusammensetzt. Die Frage wird sich aber endgültig wohl erst mit einem Verfahren vor dem EuGH klärren lassen.

\section{IRLAND}

\section{Die Reglementierung der Lehrerausbildung in Irland}

In Irland wird zwischen zwei Lehrerkategorien unterschieden. Der Primarschulunterricht wird von national teachers versorgt, im Sekundarbereich unterrichten secondary teachers. Die Ausbildung der national teachers erfolgt an Colleges of Education. Sie umfaft ein dreijähriges fachwissenschaftliches Studium, das mit einer theoretischen und praktischen pädagogischen Ausbildung einhergeht. Für die Sekundarschullehrer gilt seit 


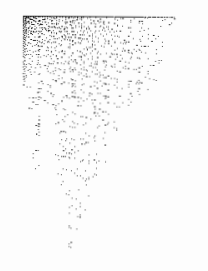

T经 $\mathrm{W}$

dem 1. August 1991 eine neue Ausbildungsordnung ${ }^{1599}$, wonach ein fachwissenschaftliches dreijähriges Universitätsstudium in einem für den Schulunterricht wichtigen Studienfach sowie eine einjährige pädagogische Ausbildung an einem der Colleges of Education für die Eintragung als Sekundarschullehrer vorausgesetzt wird. Ein vierjähriges Studium mit einer integrierten Lehrerausbildung erfüllt ebenfalls diese Kriterien. Alle Lehrer müssen die irische Sprache beherrschen. Ein Beamtenstatus ist mit der Lehrerernennung nicht verbunden. Neben den beiden genannten Lehrerkategorien für den allgemeinen Unterricht gibt es noch Berufsschullehrer (vocational teachers). Auch von dieser Gruppe wird seit 1991 ein Hochschulabschluß zur Erlangung der Lehrbefähigung verlangt.

\section{Umsetzungsmaßnahmen für Lehrer in Irland}

In Irland ist der Minister for Education als zuständíge Behörde für den "Community and comprehensive school teacher", den Primary School teacher", den "Teacher in regional and technological colleges" und für den "Vocational school teacher" angewiesen worden. Für den registered secondary school teacher" ist das Secondary Teachers Registration Council die zuständige Behörde. Der Minister for Education war federführend verantwortlich für die Ausarbeitung des allgemeinen Umsetzungsgesetzes (S.I. No 1991). Dieses allgemeine Gesetz wird als Grundlage für die individuellen Anerkennungsentscheidungen angewandt. Englisch- und Irischkenntnisse werden verlangt, um als Lehrer anerkannt zu werden. Für den Nachweis der Irischkenntnisse wird eine schriftliche und mündliche Prüfung (Irish Qualification Examination) abgenommen. Diese wird in der Regel nur einmal im Jahr durchgeführt.

\section{Beurteilung der Umsetzung}

Die Anerkennungsverfahren für Lehrer werden auf der Basis des allgemeinen Gesetzes durchgefuihrt. Grundsätzlich wird dabei von einer automatischen Anerkennung gemäß Art. 3 der Richtlinie 89/48/EWG ausgegangen. Die Kompensationsinstrumente sollen nur in Ausnahmefällen herangezogen werden. Der besonders hohe Anteil an automatischen Anerkennungen in der bisher vorliegenden Statistik beweist, daß in Irland diese Grumdphilosophie der Richtlinie zur Anwendung kommt. Allerdings handelt es sich bei der Mehrheit der Bewerber um Migranten aus dem Vereinigten Königreich, so daß diese Tatsache nicht weiter verwunderlich ist. Der geforderte Nachweis der irischen Sprachkenntnisse in einem schriftlichen und mündlichen Test entspricht der Regelung anderer Mitgliedstaaten ${ }^{1600}$. Auch kann Irland auf das Urteil des EuGH in der Rechtssache Groener 1601 verweisen, worin der Nachweis irischer Sprachkenntnisse für Lehrer nicht als eine versteckte Diskriminierung angesehen wurde.

1599. Sekretariat der KMK, Bestandsaufnahme zur Lehrerausbildung, 82.

1600. So z.B. Dänemark; Luxemburg verlangt selbst drei Sprachen: Franzosisch, Deutsch und Letzeburgisch.

1601. Urteil vom 28. Nowember 1989. Rs 379/87 - Anita Groener/Minister for Education and the City of Dublin Vocational Educational Committee, Slg. 1989, 3967. Dazu Mortelmans, Ars Aequi, 


\section{E. LUXEMBURG}

\section{Die Reglementierung der Lehrerausbildung in Luxemburg}

Der Sekundarschulunterricht (l'enseignement secondaire) umfaßt allgemeinbildenden Unterricht (l'enseignement secondaire général) und beruflichen Unterricht (l'enseignement secondaire technique). Die Lehrerausbildung ist in Luxemburg schulstufenbezogen. Dies erklärt die unterschiedlichen Umsetzungsmaßnahmen für professeurs de l'enseignement secondaire général und für die professeurs de l'enseignement secondaire technique. Beï der letzten Gruppe unterscheidet man zwischen folgenden Untergruppierungen: Professeur-ingénieur ou professeur-architecte, Professeur de sciences de l'enseignement secondaire technique, Professeur d'enseignement technique, maître de cours speciaux, maître d'enseignement technique.

Die nationale Lehrerausbildung in Luxemburg ist in zwei Phasen unterteilt. Die erste Phase umfaßt das fachwissenschaftliche Studium. Die zweite Phase umfaßt die pädagogische und schulpraktische Ausbildung. Sie erstreckt sich über drei Jahre. Die Zulassung zu diesem Ausbildungsteil ist bedarfsorientiert und erfolgt entsprechend der Rangliste nach Abschluß eines Concours. Die Ernenmung der Sekundarschullehrer erfolgt nach Abschluß der ersten und der zweiten Phase der Lehrerausbildung. Vor diesem allgemeinen Hintergrund muß die Umsetzung der Richtlinie 89/48/EWG für Lehrer beurteillt werden.

\section{Umsetzungsmaßnahmen für Lehrer in Luxemburg}

In Luxemburg wurde für die Umsetzung der Richtlinie 89/48/EWG hauptsächlich die sektorielle Methode gewählt. Dies gilt auch für die Lehrberufe. Luxemburg gehört wie Frankreich, Italien, Portugal und Spanien zu den Concoursländern und besteht auf Anwendung des Concours als Auswahlverfahren. Neben der inhaltlichen Umsetzung erfolgte darum ebenfalls eine Regelung hinsichtlich des Concours.

\section{Die Umsetzung für Lehrer des allgemeinen Sekundarschulbereichs}

Für alle Lehrer des l'enseignement secondaire gilt das allgemeine Gesetz vom 13. August $1992^{1602}$ sowie ein Lehrerbedarfsgesetz vom selben Tag ${ }^{1603}$. Daneben wurden unterschiedliche Ausführungsmaßnahmen erlassen. Für die professeurs de l'enseignement secondaire général gilt eine Großherzogliche Verordnung vom 26 . November

1602. Loi du 13 août 1992 portant

a) transposition de la directive du Conseil (89/48/CEE) relative à un système général de reconnaisance des diplômes d'enseignement supérieur qui sanctionnent des formations professionelles d'une durée minimale des trois ans;

b) créations d'un service de coordination pour la reconnaisance de diplồmes à des fins professionnelles.

1603. Loi du 13 aoüt 1992 modifiant la loi modifiée du 10 juin 1980 partant planification des besoins en personnel enseignant de l'enseignement postprimaire. 
$1992^{1604}$ und für die professeurs de l'enseignement secondaire technique gilt eine Großherzogliche Verordnung vom 26. Januar $1993^{1605}$.

\section{Loi du 13 août 1992 modifiant la loi modifièe du 10 juin 1980 portant planification des besoins en personnel enseignant de l'enseignement postprimaire}

In diesem Gesetz ist die grundsätzliche inhaltliche Ausgestaltung des Concours festgelegt. Danach wird von dem Kandidaten jedenfalls eine Prüfung in drei Sprachen abverlangt und zwar in letzeburgisch, französisch und deutsch. Von diesen drei Sprachen wird behauptet, daß sie alle drei im Unterricht verwendet werden. Des weiteren wird der Kandidat in seinem Hauptfach sowie in einem weiteren Fach nach Wahl des Kandidaten geprüft. In diesem Gesetz wird in Art. 1 Abs. $2^{1606}$ bestimmt, dałs grundsâtzlich die Inhaber eines Diploms i.S. der Richtlinie 89/48/EWG zum Concours zugelassen sind. Die genaueren Zulassungsbedingungen mußten jedoch durch eine Großherzogliche Verordnung festgelegt werden. Dies bedeutet aber, daß ein Kandidat - selbst wenn man einen erfolgreichen Abschluß im Concours unterstellt - damit nicht die Ernennung zum Lehramt, sondern lediglich die Zulassung zur zweiten Phase der luxemburgischen Lehrerausbildung erhält! Diese Regelung kann nicht mit der Richtlinie 89/48/EWG in Übereinstimmung gesehen werden.

\section{Règlement grand-ducal du 26 novembre 1992 concemant lé stage pédagogique des professeurs de l'enseignement secondaire}

Grundsätzliche Bedingung für die Ernennung zum Lehrer ist gemäß Art. 1 des Règlements die Ableistung einer pädagogischen Stage.

In Art. 2 Abs. 8 des Règlements ist die Anwendung auf Diplominhaber i.S. der Richtllinie 89/48/EWG geregelt. Hierbei wird ein Unterschied hinsichtlich der Ausbildungsdauer des Diplominhabers in der Weise gemacht, daß bei einer Ausbildung von drei Jahren der Nachweis einer zweijährigen Berufserfahrung verlangt wird. Diese Regelung ist äußerst problematisch, da sie ungeachtet der Tatsache Anwendung findet, ob gleichzeitig von dem Diplominhaber eine pädagogische und schulpraktische Ausbildungsperiode verlangt wird. Die Regelung verstößt damit ausdrücklich gegen das Kumulationsverbot gemäß Art. 4 Abs. 2 der Richtlinie 89/48/EWG. Die Stage wird wiederum in Phasen unterteilt und zwar 1 . in eine generelle pädagogische Ausbildungsperiode mit Lehrveranstaltungen (Stage de formation pédagogique general), 2 . in eine eigenständige wissenschaftliche Arbeit (travail de recherche scientifique) und 3. in eine schulpraktische Ausbildungsperiode (stage de formation pratique). Gemäß Art. 14 und Art. 28 Abs. 1 des Règlements werden beide Ausbildungsperioden mit jeweils einem Examen abge-

1604. Règlement grand-ducal du 26 novembre 1992 concernant le stage pédagogique des professeurs de l'enseigmement secondaire.

1605. Règlement grand-ducal du 26 janvier 1993 déterminant les conditions d'admissions au concours de Recientifique et péxllagogique et les conditiors de nomination des diffěrentes fonctions enseignantes de l'enseignememt secondaire technique.

606 Dietion 6 Paragraph IV des ursprïnglichen Giesetzestextes. 
schlossen. Diese Festlegung auf eine Ausbildungsperiode mit abschließendem Examen, entspricht in keiner Weise der Definition der Richtlinie von einem Anpassungslehrgang.

\section{Beurteilung der Umsetzung}

Die Umsetzung ist äußerst bedenklich, weil sie in keiner Weise mit den Bedingungen der Richtlinie 89/48/EWG übereinstimmt. Bei dem luxemburgischen Concours erscheint es äußerst zweifellhaft, daß dieser als reines Auswahlverfahren für eine Emennung um Schuldienst betrachtet werden kann. Vielmehr schließt sich an das erfolgreiche Bestehen des Concours die zweite Phase der luxemburgischen Lehrerausbildung an, so daß ein luxemburgischer Lehrer erst mit Abschluß beider Ausbildungsphasen als Endprodukt angesehen werden kann. Ein Migrant, der bereits das Kriterium eines Endprodukts in seinem Herkunftsstaat erfüllt, darf daher nicht gezwungen werden, sich erneut einer solchen Ausbildung zu unterziehen.

Auch wird dem Kandidaten kein Wahlrecht zwischen einer Eignungsprüfung und einer Anpassungslehrgang eingeräumt. Des weiteren erfüllt die in der Großherzoglichen Verordnung geregelte Ausbildungsperiode nicht die Bedingungen, die an einen Anpassungslehrgang i.S. der Richtlinie 89/48/EWG gestellt werden. Die sogenannte Stage wird vollkommen unabhängig von den Vorkenntnissen des Kandidaten eingerichtet und erfüllt insoweit deutlich eine reine Ausbildungsfunktion. Auch wird die Stage mit Prüfungen abgeschlossen, so daß dem Kandidaten nicht nur kein Wahlrecht eingeräumt wird, er vielmehr letztlich beiden Prüfungsformen unterworfen wird. Auch diese Tatsache bestätigt die Beurteilung, daß es sich bei der genannten Stage um einen nationalen Teil der Lehrerausbildung handelt. Sie erfüllt jedoch in keiner Weise die Funktion einer Eignungsprüfung oder eines Anpassungslehrganges i.S. der Richtlinie 89/48/EWG.

Art. 2 Abs. 8 des. Règlement grand-ducal verstößt gegen das Kumulationsverbot des Art. 4 Abs. 2 der Richtlinie 89/48/EWG. Bedenklich ist in Art. 2 Abs. 8 des Règlement grand-ducal auch die Formulierung des entsprechenden Berufs: "dans la même spéciallité, à la profession ou fonction correspondant á celle qui est visèe au Luxembourg" . Die starke Betonung, daß es sich um die gleiche Spezalisierung handeln muß, könnte bei restriktiver Anwendung zu Problemfällen führen.

Zweifelhaft ist auch die Anforderung, daß der Kandidat im Concours in drei Sprachen geprüft wird. Dieses Hindernis kann wohl nur von wenigen Bewerbern mit Erfolg genommen werden. Ob der Nachweis der Letzeburgischkenntnisse als versteckte Diskriminierung bezeichnet werden kann, wird wohl nur durch ein Verfahren vor dem EuGH geklärt werden können. Für den Gerichtshof wird es jedoch nicht leicht sein, gegenüber Luxemburg einen anderen Weg zu beschreiten, alls dies im Fall Groener geschah $^{1607}$. Warum sollten die - laut Groener - im Unterricht an einer Zeichenschule nicht notwendigen Irischkenntnisse schützenswerter sein als die Kenntnisse des Letze-

1607. Urteil vom 28. November 1989, Rs 379/87 - Anita Groener gegen Minister for Education and the City of Dublin Vocational Educational Committee -, Slg. 1989, 3967. 


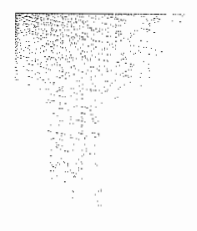

Teil $\mathrm{V}$

burgisch in einer Primar- oder Sekundarschule? Sicherheitshalber wurde Letzeburgisch inzwischen auch zur Nationalsprache erhoben.

Der Luxemburger "Hürdenlauf" ist nicht ohne Grund errichtet worden. Luxemburg hat - hier zeigt sich der deutliche Unterschied zum Vereinigten Königreich - die bestbezahlten Lehrer innerhalb der Gemeinschaft. Die (Un)Liberalität der Regelung ist auch hier proportional zu den ökonomischen Interessen ${ }^{1608}$.

Neben diesen verhältnismäßig deutlichen Verstößen gegen die Umsetzungsverpflichtungen aus der Richtlinie 89/48/EWG verbleiben auch einige undeutliche Punkte. Undeutlich ist, ob Luxemburg - wie die Bundesrepublik Deutschland - auf dem Nachweis von zwei Fächern besteht. Die Prüfung im Concours in einem zweiten Fach könnte darauf hindeuten. Unklar ist ebenfalls, ob der bisher geltende Staatsangehörigkeitsvorbehalt für Lehrer aufgehoben ist. Zumindest findet sich in keiner Umsetzungsmaßnahme hierüber eine deutliche Aussage.

Des weiteren ist das Verhältnis zum allgemeinen Umsetzungsgesetz vom 13. August 1992 nicht klar ersichtlich. Grundsätzlich sollte man davon ausgehen, daß dieses auf alle weiteren Ausführungsmaßnahmen Anwendung findet. Wie jedoch bereits oben für die Berufe im Gesundheitsbereich gezeigt, sind die Regelungen teilweise widersprüchlich ${ }^{1609}$. Die Ausführungsmaßnahme für die Lehrer enthält jedenfalls keine Verfahrensregeln, so daß darin ein Verstoß gegen Art. 8 der Richtlinie 89/48/EWG gesehen werden könnte, es sei denn, daß die Regeln des allgemeinen Gesetzes Anwendung finden.

\section{Die Umsetzung für Lehrer des technisch-beruftichen Sekundarschulbereichs}

Auch für die technischen Lehrberufe ${ }^{1610}$ wurde eine Großherzogliche Verordnung erlassen, wobei die Umsetzung für diese Berufe durch eine gesetzliche Maßnahme gemeinsam getroffen wurde ${ }^{1611}$. Wie für die Lehrer des l'enseignement secondaire gilt auch für die professeurs de l'enseignement secondaire technique generell das Lehrerbe-

1608. Siehe zur umgekehrten Proportionalität die Ausfulhrungen zum Vereingten Königreich, Seite 403

1609. Sielhe oben Seite 217 .

1610. * Professeur-ingénieur ou professeur-architect,

* Professeur de sciences de l'enseignement secondaire technique

* Professeur d'enseignement technique

* maitre de cours speciaux

* maitre d"enseignement technique

1611. Règlement grand-ducal du 26 janvier 1993 dêterminant les conditions d'admissions au concours de recrutement, la formation scientifique et pédagogique et les conditions de nomination des différentes fonctions enseignantes de l'enseignement secondaire techmique. 
darfsgesetz vom 13. August $1992^{1652}$. Insoweit gelten die dazu gemachten allgemeinen Ausführungen ${ }^{1613}$.

Hinsichtlich der konkreten Umsetzung durch die Großherzogliche Verordnung für die technischen Lehrberufe kann ebenfalls eine weitgehende Übereinstimmung mit der Umsetzungsmaßnahme für den allgemeinen Sekundarbereich festgestellt werden. So entspricht Art. 5 nahezu wörtlich Art. 2 Abs. 8 des Règlement grand-ducal für den allgemeinen Sekundarbereich. Bemerkenswert ist allerdings, daßß die Umsetzung lediglich fur die folgenden drei technischen Lehrberufe vorgenommen wird:

* Professeur-ingénieur ou professeur-architect

* Professeur de sciences de l'enseignement secondaire technique

* Professeur d'enseignement technique

Diese Beschränkung läßt sich damit erklären, daß weder der maître de cours speciaux noch der maitre d"enseignement technique in Luxemburg über ein abgeschlossenes Hochschulstudium verfügen muß.

Insgesamt kann hinsichtlich der Beurteilung im wesentlichen auf die Anmerkungen zum allgemeinen Sekundarbereich verwiesen werden.

\section{F. NIEDERLANDE}

\section{Die Reglementierung der Lehrerausbildung in den Niederlanden}

In den Niederlanden ist der Lehrerberuf reglementiert. Hierbei wird unterschieden zwischen Lehrern in der Primarstufe ${ }^{1614}$ und der Sekundarstufe ${ }^{1615}$. Die Lehrerberufe für den Sekundarbereich werden nach der Lehrbefugnis unterschieden, die wiederum in der Regel von der Art der Ausbildung abhängt ${ }^{1616}$. Dabei wird zwischen einer Lehrbefugnis "ersten" und "zweiten" Grades unterschieden. Sämtliche Lehrerausbilldungen erfolgen im Hochschulbereich, wobei zu bemerken ist, daß die sogenannten HBO im niederländischen Bildungssystem einen fachhochschulähnlichen Rang einnehmen. Die Ausbillung der Primarschullehrer und der Sekundarschullehrer zweiten Grades erfolgt an einer HBO, während die Sekundarschullehrer ersten Grades an den. Universitäten ausgebildet werden. Die Ausbildung der Sekundarschullehrer zweiten Grades erfolgte bis 1990 mit dem Ziel, die Lehrbefähigung für zwei Unterrichtsfächer zu erwerben. Aufgrund einer Neuregelung vom 1. August 1990 konzentriert sich die Ausbildung bei den allgemeinbildenden Fächern nur noch auf ein Fach. Für die beruflichen Fächer

1612. Loi du 13 aout 1992 modifiant la loi modifiée du 10 juin 1980 portant planification des besoins en personnel enseignant dle l'enseignement postprimaire.

1613. Siehe oben Seite $216 \mathrm{f}$.

1614. Leraar basisonderwijs

1615. Leraar voortgezet onderwijs und leraar 2 e graads voortgezet onderwijs.

1616. Siehe die Übersicht ân dem KMK-Bericht, Bestand saufnahme zur Lehrerausbildung in den Mitgliedstanten der Europäischen Gemeinschaft, $1992,128 \mathrm{ff}$. 


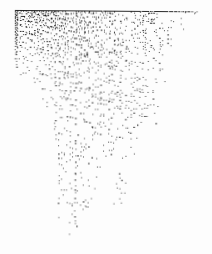

Teil V

besteht weiterhin das Erfordernis, die Lehrbefähigung für zwei Fächer zu erwerben. Diese Neuregelung kann erhebliche Konsequenzen für die Anerkennung der Lehrbefähigung im deutsch-niederländischen Verhältnis haben. Wie für Deutschland dargestellt ${ }^{1617}$, verlangen die Bundesländer übereinstimmend die Lehrbefugnis in zwei Fächern. Sekundarschullehrer zweiten Grades, die nach 1990 in den allgemeinbildenden Fächern ausgebildet wurden, werden daher mit erschwerten Anerkennungsbedingungen rechnen müssen. Dies gilt auch für die Sekundarschullehrer ersten Grades, deren fachwissenschaftliche Ausbildung an einer Universität in der Regel nur auf ein Fach bezogen sein wird. Auch die zweite Phase der Ausbildung, die sich auf den erziehungswissenschattilichen und fachdidaktischen Bereich bezieht, gibt lediglich die Lehrbefähigung für das Fach, das Gegenstand des Fachstudiums war. Die Ausbildung für den Primarschulbereich und für die Sekundarschullehrer zweiten Grades ist einphasig. Sie führt nach einer vierjährigen Ausbildung zur Berufsqualifikation. Dagegen ist die Ausbildung für den Sekundarschullehrer ersten Grades in zwei Phasen unterteilt. Das Fachstudium an der Universität dauert in der Regel vier Jahre, die anschließende fachdidaktische Ausbildung ersteckt sich über ein Jahr.

\section{Umsetzungsmaßnahmen für Lehrer in den Niederlanden}

In den Niederlanden wurde vom Unterrichtsministerium am 9 . Februar 1992 eine ministerielle Regelung für die Lehrbefähigung von EG-Angehörigen veröffentlicht, ohne daß das allgemeine Umsetzungsgesetz vom Parlament zu diesem Zeitpunkt verabschiedet worden war. Mit diesem aus gesetzgebungstechnischer Sicht ungewöhnlichen Schritt wollte das Ministerium sicherstellen, daß etwaige Anfragen innerhalb der durch die Richtlinie gestellten viermonatigen Frist beschieden werden konnten. Nach Verabschiedung des allgemeinen. Umsetzungsgesetzes soll die Regelung als Ausführungsmaßnahme auch weiter angewandt werden.

Nach dieser Regelung werden, falls erhebliche Ausbildungsdefizite bestehen, von dem Kandidaten die Absolvierung eines Anpassungslehrgangs oder die Ableistung einer Eignungsprüifung verlangt (Art. 7 Abs. 2). Zur Absolvierung des Anpassungslehrgangs kann sich der Bewerber direkt an die Schule wenden, für die er eine Lehrbefähigung anstrebt. Während des Anpassungslehrgangs erhält er dort Betreuung durch einen Lehrer, der von der Schule zugewiesen wird. Betreuer und Kandidat können nach gemeinsamer Beratung den Anpassungslehrgang mit einer Zusatzausbildung einhergehen lassen. Der Anpassungslehrgang dauert 40 Wochen und wird beurteilt. Die Beurteilung obliegt dem Unterrichtsministerium auf der Grundlage der Begutachtung durch Fachleute (Art. 9).

Die Ableistung einer Eignungsprüfung ist ebenfalls möglich (Art. 8). Das Unterrichtsministerium bestimmt die Fächer, in denen gemessen an den niederländischen Anforderungen Defizite in der bisherigen Ausbildung bestehen. Hierzu findet eine Beurteilung

1617. Siehe Seite $383 \mathrm{ff}$. 
der Lehrbefähigung des Bewerbers statt. Je nach Umfang der Eignungsprüfung wird durch das Ministerium die Höhe der zu entrichtenden Examensgebühr bestimmt. Auch weist der Minister das Institut an, das mit der Abnahme der Prüfung beauftragt wird. Dieses ist verpflichtet, die für die Prüfung relevante Literatur dem Kandidaten schriftlich mitzuteilen. Nachdem der Bewerber sich für die Eignungsprüfung entschieden und die Prüfungsgebühr entrichtet hat, muß die Eignungsprüfung innerhalb von vier Monaten abgenommen werden. Die Entscheidung über das Ergebnis muß dem Kandidaten und dem Ministerium so schnell wie möglich mitgeteilt werden.

Hinsichtlich der niederländischen Sprachkenntnisse gilt als Nachweis das "Certificaat Nederlands als vreemde taal ". Je nach Schulart werden unterschiedliche Anforderungen gestellt. Kein Nachweis in Niederländisch wird verlangt für den "Höheren berufsbildemden Unterricht" (HBO) und für die Lehrbefähigung in einem Fach mit internationaler Ausrichtung, das nicht auf Niederländisch unterrichtet wird (Art. 5 Abs. 2).

\section{Beurteilung der Umsetzung}

Die bisher in den Niederlanden vorgenommenen Anerkennungsverfahren betrafen in der überwiegenden Mehrheit Lehrer ${ }^{1618}$. Von diesen wurden bisher nur sehr wenige direkt anerkannt ${ }^{1619}$. In den meisten Fällen stehen die Entscheidungen noch aus. Zum großen Teil beruht die Verzögerung auf unvollständig eingereichten Unterlagen, so daß ein Abschluß des Anerkennungsverfahrens nicht möglich ist. Es kann daher noch nicht abschließend beurteilt werden, ob von einer erfolgreichen Umsetzung gesprochen werden kann. Jedenfalls entspricht die ministerielle Regelung im wesentlichen der Richtlinie. In den Niederlanden gibt es auch keinen Staatsangehörigkeitsvorbehalt als Ernennungsvoraussetzung für Lehrer. Eine entsprechende gesetzliche Anpassung war daher nicht erforderlich. Ebenso unbekannt ist eine Bestimmung, die die Lehrbefähigung in zwei Fächern voraussetzt, wie dies z.B. in Deutschland der Fall ist, oder der Concours als Einstellungsverfahren. Der Nachweis von ausreichenden niederländischen Sprachkenntnissen erscheint aus den bereits oben genannten Gründen gerechtfertigt ${ }^{1620}$. Positiv muß in diesem Zusammenhang die Bestimmung Art. 5 Abs. 2 hervorgehoben werden, wonach für den "Höheren berufsbilldenden Unterricht" (HBO) und für die Lehrbefăhigung in einem Fach mit internationaler Ausrichtung, das nicht auf Niederländisch unterrichtet wird, kein Nachweis der Sprachkenntnisse verlangt wird.

1618. Nach dem ersten Erfahrungsbericht gemäß Art. 11 der Richtlinie $89 / 48 /$ EWG betrafen 39 von insgesamt 56 Anfragen, Lehner in unterschiedtichen Schulstufen.

1619. Es handelte sich dabei um zweỉ Falle bezüglich des höheren benufsbildenden Unterrichts: (HBO). Diese können mit Sicherheit nicht als representativ angesehen werden, zumal gerade im höheren berufsbildenden Unterricht auch vor Inkrafttreten der Richtinie 89/48/EWG eine sehr liberale Anerkennungspraxis getiandhabt wurde.

1620. Siehe dazu Seite 385 


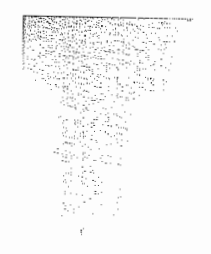

Tien $\mathrm{V}$

\section{G. VEREINIGTES KÖNIGREICH}

\section{Die Reglementierung der Lehrerausbildung im Vereinigten Königreich}

Das Schulwesen ist im Vereinigten Königreich nicht zentral geregelt. Vielmehr verfügen die Landesteile England, Wales, Nordirland und Schottland jeweils über eine eigene Kompetenz. Es läßt sich jedoch eine weitgehende Übereinstimmung der Regelungen von England, Wales und Nordirland feststellen. Diese Übereinstimmung beruht auf der Tatsache, daß die für England erlassenen Rechtsvorschriften in der Regel in Wales und Nordirland übernommen werden, während in Schottland Schulangelegenheiten autonom geregelt werden $^{1621}$. Diese Kompetenzverteilung zwischen den einzelnen Landesteilen hat ihren Niederschlag auch in der Lehrerausbildung gefunden. Sie ist ebenfalls Ursache der teilweise abweichenden Umsetzungsmaßnahmen.

In England, Wales und Nordirland wird der Zugang zum Lehrerberuf durch den sogemannten "Qualified Teacher Status" ((QTS) geregelt. Die Reglementierung betrifft ausschließlich die Lehrer an öffentlichen Schulen. Der Privatschulsektor ist nicht reglementiert. Voraussetzung für den QTS ist ein Studienabschluß an einer Universität, an Polytechnics oder an Colleges of Higher Education. Die letztgenannten werden ebenfalls als Hochschuleinrichtungen eingestuft. Die Studiendauer bemißt sich an einer Universität auf drei oder vier Jahre. Da es sich dabei um ein reines Fachstudium handelt, muß dieses durch ein einjähriges erziehungswissenschaftliches Studium ergänzt werden. Im Falle eines Studiums an einem College of Higher Education, wobei fach- und erziehungswissenschaftliche Ausbildung gemeinsam angeboten werden, kann die Lehrbefähigung mit Studienabschluß nach wier Jahren erworben werden ${ }^{1622}$. In Schottland bedarf es für den Zugang zum Lehrerberuf der Aufnahme in das Mitgliedsregister des " Scottish Gemeral Teaching Council". Die Lehrerausbildung erfolgt an den Colleges of Education.

Bei den Ausbildungsgängen wird danach unterschieden, ob sie sich auf den Primar- oder den Sekundarbereich beziehen ${ }^{1623}$, dabei werden die Kandidaten für den Sekundarschulbereich in ein bis zwei Fächern, die künftigen Primarschullehrer in bis zu drei Fä̀chern ausgebildet. Nach Abschluß des Studiums erfolgt die Einstellung durch die örtliche Schulbehörde oder die Schulen selbst. Lehrer werden an öffentlichen Schulen als "public employees" beschäftigt, ein Beamtenverhältnis wird damit nicht begründet.

\section{Umsetzungsmaßnahmen für Lehrer im Vereinigten Königreich}

Wie für die Lehrerausbildung gelten im Vereinigten Königreich unterschiedliche Ausführungsmaßnahmen für England und Wales, Schottland und Nordirland. Für die drei Gebiete sind auch drei verschiedene Behörden angewiesen worden. Zuständig für die

1621. Sekretariat der KMK. Bestandsaufnahme der Lehrerausbildung, 1992, 162ff.

1622. Es handelt sich dabei um eir sogenanntes "concurrent training".

1623. Sekretariat der KMK, Bestandsaufnahme der Lehrerausbilldung, 1992, 173. 
Anerkennung sind das Department of Education and Scienes für den Bereich England und Wales, der General Teaching Council für Schottland und das Department of Education für Nordirland.

\section{a. England und Wales}

Interessanterweise hatte die zuständige Behörde für England und Wales bereits lange vor Verabschiedung des allgemeinen Umsetzungsgesetzes (Statutory Instrument 1991 No 824) eine Spezialumsetzungsmaßnahme für den Lehrerberuf verabschiedet - und zwar bereits im Oktober 1989. Es handelt sich dabei um die Education (Teachers) Regulations 1982 (Statutory Instrument 1989 No 1319). Diese Regelung bestimmt allgemein die Lehrbefähigung won Lehrern in England und Wales. Es handelt sich dabei um den bereits erwähnten "qualified teacher status" (QTS). Die Zuerkennung des QTS erfolgt gemäß Schedule 5 Education (Teachers) Regulation. Gemäß $\S 2$ (d) von Schedule 5 kann der QTS an EG-Angehörigen erteilt werden, die die Voraussetzungen des Art. 3 der Richtlinie 89/48/EWG im Hinblick auf den Lehrerberuf erfüllen ${ }^{1624}$. Diese Bestimmung galt in England und Wales bis zum Erlaß des allgemeinen Gesetzes unmittelbar. Seither wird sie als Ausführungmaßnahme des allgemeinen Umsetzungsgesetzes angewandit.

Von Bedeutung ist, daß dabei für den Bereich England und Wales weder ein Kompensationsinstrument im Sinne des Art. 4 der Richtlinie 89/49/EWG, d.h. Eignungsprüfung oder Anpassungslehrgang, noch eine Sprachprüfung verlangt wird. Die Liberalität der Regelung kommt allerdings nicht von ungefähr. In Großbritannien herrscht ein derartiger Lehrermangel, daß ausländische Diplominhaber zur Bedarfsdeckung äußerst willkommen sind. Dementsprechend hoch sind die Zahlen der bereits erfolgreich abgeschlossenen Anerkennungsverfahren. Bereits vor Ende Januar 1991 wurden von 2155 Bewerbern 1853 anerkannt. Die Mehrheit der Bewerber kam wie bei den juristischen Berufen aus Irland, so daß sich auch aus diesem Grund eine Sprachprüfung erübrigte. Bei Ersteininstellung werden alle Kandidaten einer Probezeit unterworfen. Diese Regelung entspricht jedoch der für inländische Bewerber.

\section{b. Schottland}

In Schottland wird eine Anpassung gegebenenfalls auf der Grundlage des allgemeinen Umsetzungsgesetzes (S.I 1991 No. 824) gefordert. Bisher fiel die Wahl der Kandidaten mit wenigen Ausnahmen auf den Anpassungslehrgang ${ }^{1625}$. Auch in Schottland kommt die Mehrheit der Bewerber aus Irland, so daß der hohe Anteil an automatischen Anerkennungen nicht verwunderlich ist.

1624. Schedule 5, 2 (d) "who, as respects the profession of school teacher falls within Article 3 of Council Directive $89 / 48 / \mathrm{EWG}$ on a general system for the recognition of higher education diplomas on completion of professional education and training of at least 3 years duration."

1625. Schreiben des General Teaching Council for Scotlland vom 24. Februar 1992. 
In Nordirland gilt grundsätzlich ebenfalls das allgemeine Umsetzungsgesetz (S.I 199» No. 824). Hinsichtlich der Ausführung dieses Gesetzes wurde für Lehrer die Regulation 5 of the Teacher (Eligibility) Regulations (Northern Irleand) 1987 No 266 für anwenbar erklärt. Grundsätzlich wird keine Anpassung im Sinne der Richtlinie 89/48/EWG gefordert. Die überwältigende Mehrheit der Kandidaten kommt jedoch aus der Republik Irland, so daß auch eine Sprachprüfung sich selbstwerständlich erübrigt ${ }^{1626}$.

\section{Beurieilung der Umsetzung}

In Anbetracht der großen Anzahl der automatischen Anerkennungen ohne Einsatz von Kompensationsinstrumenten, kann festgestellt werden, daß die Anwendung der Richtlinie 89/48/EWG im Vereinigten Königreich für Lehrer hervorragend funktioniert. Ob jedoch der große Migrantenstrom tatsächlich durch die Richtlinie verursacht worden ist, mag man bezweifeln ${ }^{1627}$. Weit wahrscheinlicher ist, daß eine bereits bestehende Praxis durch die Richtlinie 89/48/EWG eine europarechtlich relevante Dimension erhalten hat, die jedenfalls zu einem mehr konkretisierten Verfahrensablauf beigetragen hat. Zweifeln haben darf man bis zu einem gewissen Grade auch an der Liberalität der Anerkennungspraxis als bewußte, europafreundiliche Grundhaltung. Mit Sicherheit ist diese im wesentlichen durch den großen Lehrermangel bestimmt. Trotz dieser Einschränkung muß der insgesamt bürgernahen Entscheidungspraxis jedoch Lob gezollt werden.

1626. Schreiben des Department of Education wom 22. April 1992

1627. Besonders zwischen Irland und Großbritannien bestand auch wor der Richtlinie 89/48/EWG ein reger Austausch an Lehrkräften. 
arvers: 
Teil VI

Gesamtbeurteilung des horizontalen Ansatzes 


\section{Gesamtbeurteilung des horizontalen Ansatzes}

\section{\$ 1. Beurteilung der Umsetzung der Richtlinie 89/48/EWG}

Bei einer Gesamtbetrachtung der verschiedenen Umsetzungsregeln und Umsetzungsmethoden, die von den Mitgliedstaaten zur Durchführung der Richtlinie 89/48/EWG eingesetzt worden sind, läßt sich eine generelle Kategorisierung nur schwer vornehmen. Einerseits sind die Methoden in den einzeinen Mitgliedstaaten sehr unterschiedich, andererseits haben einige Mitgliedstaaten die Umsetzung noch nicht vollkommen abgeschlossen oder sind selbst kaum mit ihrer Ausführung begonnen. Dennoch soll im folgenden eine vorläufige Gesamtbeurteilung vorgenommen werden.

\section{A. Formelle Kategorisierung}

Zunächst muß festgestellt werden, daß bei einer Kategorisierung vier Fallgruppen unterschieden werden könnnen.

1. Mitgliedstaaten haben ein allgemeines Umsetzungsgesetz erlassen und wenden ansonsten hauptsächlich die Einzelfallentscheidung an oder haben entsprechende Ausführungsbestimmungen ebenfalls verabschiedet.

2. Mitgliedstaaten haben sektorielle Umsetzungsgesetze für die einzelnen Berufsgruppen sowie die notwendigen Ausfuhrungsbestimmungen verabschiedet.

3. Mitgliedstaaten haben ein allgemeines. Umsetzungsgesetz erlassen. Ausfuhrungsmaßnahmen fehlen dagegen noch zum größten "Teil.

4. Mitgliedstaaten haben keine oder nur eine sehr beschränkte sektorielle Umsetzung bisher vorgenommen.

Wesentlich ist, daß zwischen der ersten und der zweiten Kategorie grundsätzlich kein Qualitätsunterschied besteht. Gemäß Art. $189 \mathrm{EGV}$ ist jede an einen Mitgliedstaat gerichtete Richtlinie für diesen verbindlich. Den innerstaatlichen Stellen bleibt die Wahi der Form und der Mittel jedoch überlassen. Bei einer vollstândigen Umsetzung durch entweder ein allgemeines Umsetzungsgesetzeinschließlich etwaiger Ausführungsregelun- 
gen oder durch einzelne sektorielle Umsetzungsmaßnahmen oder durch eine Kombination beider Umsetzungsformen, müssen diese verschiedenen Umsetzungsvariationen als gleichwertig eingestuft werden. Dagegen bestehen qualitative Unterschiede hinsichtlich der dritten und vierten Kategorie. Bei der dritten Kategorie kann man von einer Umsetzung im formellen Sinne sprechen, wobei die praktische Anwendung jedoch noch weitgehend unmöglïch ist, so daß die Umsetzung im materiellen Sinn noch nicht abgeschlossen ist. Im Falle der Kategorie vier besteht ein genereller Umsetzungsverzug.

Unter Voraussetzung dieser vier Fallgruppen soll die Umsetzung der Richtlinie 89/48/EWG in zwei Phasen beurteilt werden. Die erste Phase betrifft die Periode zwischen dem Inkrafttreten der Richtlinie 89/48/EWG am 4. Januar 1991 bis zum 31. Dezember 1992. Die zweite Beurteilungsphase bezieht sich auf den Zeitraum nach der Vollendung des Binnenmarkts. In diesem Zeitraum sollte auch die Umsetzung der zweiten Richtlinie 92/51/EWG abgeschlossen werden. Soweit möglich werden die Umsetzungsregelungen für die Richtlinie 92/51/EWG bei der Kategorisierung in der zweiten Beurteilungsphase mit berücksichtigt. Nach dieser Unterteilung läßt sich folgendes Bild aufzeigen:

\section{Beurteilungsphase I: Anfang 1991 - Ende 1992}

Zur Kategorie 1 müssen in diesem Zeitraum Dänemark, Irland und das Vereinigte Königreich gerechnet werden. Diese drei Mitgliedstaaten haben eine weitgehend vollständige Umsetzung vorgelegt. Dabei kann in Bezug auf Dänemark das Fehlen einer konkreten Ausführungsmaßnahme für die rechtsberatenden Berufe beanstandet werden. Da die praktische Anwendung des Anerkennungssystems in Dänemark auch für die rechtsberatenden Berufe durch Einzelfallentscheidungen garantiert scheint, muß die Umsetzung generell als abgeschlossen bezeichnet werden. Frankreich, die Bundesrepublik Deutschland und Luxemburg gehören zumindest bei einigen Berufen der Kategorie 2 an. Für Frankreich und Luxemburg kann von einer weitgehend abgeschlossenen Umsetzung gesprochen werden. Allerdings muß im Falle Frankreichs das Fehlen einer sektoriellen Umsetzung für die Wirtschaftsprüfer (Experts-comptables, Commissaires aux comptes) sowie für die Vermessungsingenieure (Géomètres-experts) gerügt werden. Des weiteren fehlten im ersten Beurteilungszeitraum die notwendigen Ausführungsbestimmungen für die Zulassung zum französischen Concours noch weitgehend. Dadurch war die praktische Bedeutung der Richtlinie 89/48/EWG für einige Berufe, z.B. für die Lehrer noch sehr beschränkt. Die Bundesrepublik kann die zweite Kategorie vor allem für die durch den Bund durchzuführenden Umsetzungsmaßnahmen beanspruchen. Dagegen muß das Fehlen der Umsetzungsgesetze in der Mehrheit der Bundesländer vor allem fuir Lehrer und Ingenieure sehr kritisiert werden, so daf die Bundesrepublik in diesen Bereichen teilweise zur Kategorie 4 gerechnet werden muß. Die Niederlande können für die Lehrer und Patentanwälte Kategorie 2 beanspruchen, müssen jedoch generell in die letzte Gruppe eingeordnet werden. Dies gilt auch für Griechenland. Die Umsetzung durch Verabschiedung. von lediglich zwei sektoriellen Ausführungsmaßnahmen kann mit Sicherheit nicht als abgeschlossen bezeichnet werden. Italien, Spanien und Portugal billden die dritte Gruppe. In diesen Ländern sind die allgemeinen Umsetzungs- 
gesetze zwar verabschiedet worden, damit haben sie die Umsetzungsverpflichtung in einem gewissen formellen Sinn auch erfüllt. Die Richtlinie 89/48/EWG findet jedoch keine praktische Anwendung, solange die notwendigen Ausführungsmaßnahmen fehlen. Eine materielle Umsetzung ist damit noch unzureichend durchgeführt. Belgien muß ăhnlich wie Griechenland zur vierten Kategorie gerechnet werden. Die von Belgien in diesem Zeitraum veröffentlichten Maßnahmen sind dermaßen unvollständig, daß von einer Nicht-Umsetzung gesprochen werden kann.

\section{Beurteilungsphase II: Anfang 1993 bis Anfang 1995}

Nach Vollendung des Binnenmarkts lassen sich zumindest für einige Mitgliedstaaten Veränderungen im positiven Sinne festgestellen. Dadurch kann die für die erste Phase angegebene Kategorisierung korrigiert werden:

Die Niederlande haben mit der Verabschiedung des allgemeinen Umsetzungsgesetzes im Dezember 1993 eine beachtlichen Schritt getan ${ }^{1628}$. Da dieses allgemeine Gesetz auch die wesentlichen Bestimmungen der einzelnen, einschlägigen sektoriellen Berufsgesetze ändert, kann seit dem Inkrafttreten dieser allgemeinen Regelung von einer weitgehend abgeschlossenen Umsetzung gesprochen werden. Lediglich die Ausführungsbestimmungen für die Rechtsanwälte ließen noch bis zum Dezember 1994 auf sich warten. Seit ihrer Veröffentlichung ist die Umsetzung weitgehend vollständig. Nahezu fristgerecht haben die Niederlande auch die Richtlinie 92/51/EWG in dieser Periode umgesetzt ${ }^{1629}$. Die Niederlande können daher seit dem Ende der zweiten Phase in die erste Kategorie eingestuft werden. Dies gilt nicht nur für die Umsetzung der Richtlinie 89/48/EWG, sondern auch für die Umsetzung hinsichtlich der zweiten allgemeinen Anerkennungsrichtlinie.

Frankreich hat die noch fehlenden Regelungen für die Experts-comptables ${ }^{1630}$. Commissaires aux comptes ${ }^{1631}$ sowie Géomètres-experts ${ }^{1632} \mathrm{im}$ Beurteilungszeitraum verabschiedet. Auch die Zulassung zum Concours im Unterrichtsbereich sowie für das Gesundheitswesen wurde geregelt ${ }^{1633}$. In Deutschland fiel auf Bundesebene die Änderung des Beamtenrechtsrahmengesetzes zeitlich in die zweite Bewrteilungsphase. Ferner sind in dieser Periode die meisten notwendigen Umsetzungsregelungen auf Länderebene verabschiedet worden ${ }^{1634}$. Dies bedeutet, daß für die Lehrer und Ingenieure die Umsetzung weitgehend abgeschlossen ist. Jedoch muß für einige Bundesländer auch bei Ab-

1628. Stbl. 1994, 29.

1629. Stbl. 1994,640 .

1630.

1631. Décret Nr.93-9 vom 4. Januar 1993, JORF vom 5. Januar 1993.

1632 Loi $\mathrm{Nr}$ 94-529 vom 28. Juni 1994, JORF vom 29. Juni 1994.

1632. Loi Nr. 94-529 von 28. Junil 1994,

1633. Décrets Nr. 93-101 vom 19. Januar 1993. JORF vom 28. Januar 1993 und Nr. 93-659 vom 25. Mam 2. 1993. JORF vom 26. Januar 1993. Décrets Nr. 92-1246 wom 30. Noventeer 1992, JORF vom 2. Dezember 1992, Nr. 93-60 vom 13. Janular 1993, JORF wom 19. Januar 1993, Nr. 94-163 vom 16. Februar 1994, JORF vom 25 . Februar 1994.

1634. Siehe dazu die Nachweise auf Seite 380 . 
schluß der zweiten Beurteilungsphase ein fortdauernder Umsetzungsverzug festgestellt werden ${ }^{4635}$. Beide Mitgliedstaaten können daher grundsätzlich der zweiten Kategorie zugeordnet werden. Für die Bundesrepublik muß jedoch eine Einschränkung hinsitchtlich einiger Bundesländer gemacht werden. Beide Mitgliedstaaten haben die sektorielle Umsetzungsmethode auch für die Umsetzung der zweiten Richtlinie gewählt und verschiedene Regelungen vor allem für Berufe des medizinisch-technischen Bereichs verabschiedet. In Deutschland wurde auch die Handwerksordnung an die Richtlinie $92 / 51 / \mathrm{EWG}$ angepaßt ${ }^{1636}$. Von einer vollständigen Umsetzung der Richtlinie 92/51/EWG kann bei beiden Mitgliedstaaten jedoch noch nicht gesprochen werden.

Dagegen haben Danemark ${ }^{1637}$, Luxemburg ${ }^{1638}$ und Italien ${ }^{1639}$ allgemeine Gesetze zur Umsetzung der Richtlinie 92/51/EWG verabschiedet. Italien scheint sich im Laufe des Umsetzungsprozesses grundsätzlich für die Fall-zu-Fall-Methode auf der Grundlage eines allgemeinen Gesetzes entschieden zu haben. Nachdem zunächst das erste Décreto legislativo $\mathrm{Nr}$. 115 zur Umsetzung der Richtlinie 89/48/EWG noch von der Verabschiedung weiterer Ausführungsmal3nahmen ausgeht, scheint man hiervon gänzlich Abstand genommen zu haben. Die Anerkennungswerfahren werden nun auf der Basis des allgemeinen Umsetzungsgesetzes durchgeführt. Dabei werden die genommenen Entscheidungen offiziell veröffentlicht. Italien kann daher grundsätzlich der ersten Kategorie zugeordnet werden, wobei allerdings zu bemerken ist, daß eine Ausführungsregelung für die Anerkennung der rechtsberatenden Berufe noch fehlt. Soweit derartige Regelungen zur Durchführung der Anerkennungsverfahren von den zuständigen Behörden für notwendig erachtet werden, muß die Umsetzung als nicht abgeschlossen beurteilt werden.

Ähnliches gilt auch für Portugall und Spanien. Portugal hat für die Wirtschaftsprüfer und Rechtsanwälte die notwendigen Ausführungsmaßnahmen während der zweiten Beurteilungsperiode erlassen ${ }^{1640}$. Dagegen fehlen noch sekundäre Umsetzungsregelungen für alle weiteren Berufe darunter auch für die Lehrer. Solange diese AusführungsmaßBnahmen nicht erlassen sind, obwohl sie für die Durchführung von Anerkennungsverfahren von den zuständigen Behörden für notwendig erachtet werden, kann die Umsetzuing nicht als abgeschlossen angesehen werden. Spanien hat im Gegensatz zu Portugal vor allem für technische Berufe sowie für Immobilienmakler die erforderlichen Ausführungsbestimmungen erlassen. Dagegen fehlen entsprechende Regelungen für die rechtsberatenden Berufe noch gänzlich, obwohl bereits seit 1993 ein Entwurf für eine Regelung der Eignungsprüfung für Rechtsanwälte vorliegt. Ebensowenig gibt es bisher

1635. Dies gi bei Lehrern namentlich für das Land Baden-Württemberg.

1636. Gesetz zur Anderung der Handwerksordnung vom 20. Dezember 19993, BGBI. II 1993, 2256.

1637. Law Nr. 52 vom 19. Januar 1995.

1638. Réglement vom 2. Juni 1994, Mśmorial A Br. 49 yom 17. Juni 1994.

1639. Decreto legislativo $\mathrm{Nr}$. 319 vom 2. Mai $1994, \mathrm{Gaz}$. uff. Nr. 123 vom 28. Mai 1994.

1640. Wirtichattspnüfer: Decreto-lei Nr. 422-A/93, Diaro da Republica Nr. 303 vom 30. Dezember 1993. Rechtsanwialice: Lei Nr. 33/94 vom 6. September 1994, Duario da Republica vom 6. September 1994. Das Umsetzungsgesetz für die Rechtsanwälte enthält jedoch keine genaueren Bestimmungen zur Eig nungsprijung 


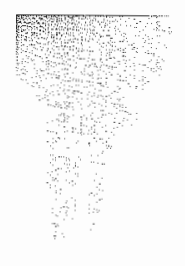

Teil VI

eine Regelung für Lehrer. Insgesamt müssen daher Portugal und Spanien auch bei $\mathrm{Ab-}$ schlul\$ der zweiten Beurteilungsperiode in die dritte Kategorie eingeordnet werden. Beide Mitgliedstaaten haben bisher noch keine Umsetzungsmaßnahmen hinsichtlich der Richtllinie 92/51/EWG veröffentlicht.

Griechenland und Belgien billen auch nach Abschlluß der zweiten Beurteilungsphase die Schlußlichter im Umsetzungsprozeß. Im Falle Griechenlands hat dieser Verzug bereits im März $1995 \mathrm{zu}$ einer Verurteilung durch den Europäischen Gerichtshof geführt ${ }^{1641}$. Die Verurteilung Belgiens erfolgte am 13. Juli $1995^{1642}$.

Irland und das Vereinigte Königreich haben bisher noch keine Umsetzungsmaßnahmen hinsichtlich der Richtlinie 92/51/EWG veröffentlicht. Sie haben damit ihre Vorreiterposition an andere Mitgliedstaaten, darunter auch die Niederlande, übergeben. Die neuen Mitgliedstaaten Finnland, Schweden und Österreich haben insgesamt die Umsetzung sehr zügig betrieben. Finnland folgte dem Beispiel Dänemarks mit einer Umsetzung durch eine allgemeine Regelung. Finnland hat dabei schon sehr frühzeitig auch eine Umsetzungsregelung hinsichtlich der Richtlinie $92 / 51 / \mathrm{EWG}$ worgelegt ${ }^{1643}$. Finnland hat sich dabei ausdrücklich für die Einzelfallentscheidung auf der Basis der allgemeinen Regelungen ausgesprochen. Es kann daher der ersten Kategorie zugeordnet werden. Schweden hat dagegen mehrere sektorielle Ausführungsmaßnahmen verabschiedet. Diese Umsetzung scheint vollständig zu sein, zumal in Schweden nur wenige Berufe reglementiert sind. Auch Österreich folgte dem Beispiel der Bundesrepublik Deutschland und führte die Umsetzung auf sektoriellem Wege durch. Diese Umsetzung ist weitgehend abgeschlossen. Österreich und Schweden können daher in vollem Umfang eine Einstufung in die zweite Kategorie beanspruchen.

\section{B. MAterielle KATEGorisierung}

Maßstab für eine materielle Beurteilung der unterschiedlichen Umsetzungsmaßnahmen ist die Richtlinie $89 / 48 / \mathrm{EWG}$. Richtlinien müssen dabei so umgesetzt werdlen, daßs dem Erfordernis der Rechtssicherheil voll entsprochen wird. Garantiert werden mull die volle Anwendung der Richtlinie in tatsächlicher und in rechtlicher Hinsicht ${ }^{1644}$. Eine Umsetzung lediglich auf der Grundlage einer bestehenden Verwaltungspraxis kann weder im formellen noch im materiellen Sinne als ausreichende Umsetzung qualifiziert werden ${ }^{1645}$. Auch sollte durch die Umsetzung eine eindeutige und klare Rechtslage geschaffen werden. Die Mitgliedstaaten waren daher gefordert, den gesamten Text der Richtlinie 89/48/EWG in nationale Rechtsvorschriften auf eine Weise umzusetzen, daß

1641. Urteit vom 23. Mărz 1995, Rs C-365/93 - Kommission/Griechenland - (noch nicht veröffentlicht) 1642. Urteil yom 13. Juli 1995. Rs C-216/94 - Kommission/Belgien - (noch nicht veröffentlicht)

1643. Laki/Lag wom 28 . Juni 1994.

. Kommission/Italien -, Slg, 1987, 1733; Urteil vom 28. Februar 1991 Rs C-131/88 - Kommission/Deutschland, Slg. 1991, I-825.

. Kom Urteile des Gerichtshofs zu Verwaltungsworschriften ohne AuRenwirkung. Urteil vom 30. Mai 1991. I-2567; Urteil wom 30. Mai 1991, Rs C-59/89, Sig. 1991, 1-2607. 
die Begünstigten von allen ihren Rechten Kenntnis erlangen und diese gegbenfalls vor den nationalen Gerichten geltend machen können ${ }^{1646}$. Bei der Umsetzung sollte auch die Grundphilosophie der Richtlinie 89/48/EWG, nämlich das gegenseitige Vertrauen in die beruflichen Ausbildungen anderer Mitgliedstaat, Berücksichtigung finden.

Unterstellt man diese Kriterien, so kann bei einer inhaltlichen Betrachtung der verschiedenen Umsetzungsregelungen ebenfalls eine gewisse Rangordnung angegeben werden. Vorbildlich sind auch in diesem Fall die drei hinsichtlich der ersten Beurteilungsperiode zunächst genannten Mitgliedstaaten: Dänemark, Irland und Großbritannien. Die allgemeinen Umsetzungsgesetze dieser Mitgliedstaaten sind deutlich und enthalten keine Regelungslücken. Im Falle von Dänemark muß besonders die Bürgernähe der Maßnahme hervorgehoben werden. Diese zeigt sich bereits daran, daß alle Anträge auf Anerkennung an eine in der Umsetzingsregelung genannte Adresse gerichtet werden können. Vergleicht man diese Bestimmung mit den teilweise unverständlichen Angaben in anderen Mitgliedstaaten ${ }^{1647}$, so zeichnet sie sich durch besondere Klarheit und Einfachheit aus. Allerdings kann bei dieser Feststellung nicht vollkommen unberücksichtigt bleiben, daß die Zahl der Anträge in Dänemark wesentlich geringer sein dürfte als die in den großen Mitgliedstaaten.

Bemerkenswert ist im Falle Großbritanniens und Irlands die grundsätzlich positive Einstellung der chartered bodies bei der Anwendung der Richtlinie 89/48/EWG. Vom kontinentalen Rechtsverständnis aus betrachtet, erschien es zunächst nicht selbstverständlich, daß die Zulassungsbestimmungen zu den verschiedenen Berufen durch die Berufsorganisationen selbst erlassen werden sollten und ihnen auch die Gesamtverantwortung der Ausführung der Anerkennungsverfahren übertragen wird. Die Gefahr einer protektionistischen Zulassungspolitik erschien beinahe unvermeidlich ${ }^{1648}$. Die Realität, in der die durchaus liberale und gemeinschaftsfreundliche Interpretation der Anerkennungsbestimmungen überwiegt, hat jedoch diese anfänglichen Bedenken als unbegründet erwiesen. Die Gründe für eine solche offene Anerkennungspolitik können verschiedene Ursachen haben. Aus den Kreisen der englischen Law Society wurde die liberale Einstellung mit deren grundsä̈zlichem Interesse daran erklärt, daß London das Zentrum für internationale Rechtsberatung ist und bleibt. Eine Abwanderung großer, international operierender Anwaltskanzleien nach Brüssel oder Paris wäre nicht im Interesse des Berufsstandes. Die Niederlassung ausländischer Anwälte wäre daher durchaus willkommen. Bei den Lehrern, deren Umsetzungsregelungen nicht durch private Standesorganisationen, sondern durch die zuständigen staatlichen Einrichtungen erfolgt, ist die Liberalităt hinsichtlich der Anerkennungsmechanismen dagegen weit eher mit dem dringenden Bedarf an Lehrkräften in Großbritannien zu erklären ${ }^{1649}$.

1646. Urteil vom 28. Februar 1991. Rs C $-131 / 88$ - Kommission/Deutschland, SIg. 1991, I-825.

1647. Verwiesen werden karn auf die Regelung der Ingenieure in der Bundesrepublik, so z. B. in NordrheinWestfalen.

1648. In einer nïcht veröffentlichten Protokollerklärung (Nr, 15) wird auf diesen Umstand besonders hingewiesen.

1649. Siehe dazu die Ausfifhrungen Seüte 403. 


\begin{abstract}
Allerdings muß festgestellt werden, daß die Durchfallquote bei der Eignungsprüfung zum englischen Solicitor nicht unbeachtlich ist. Ob hierin ein Verstoß gegen die Grundprinzipien der Richtlinie gesehen werden muß, läßt sich nicht mit Sicherheit angeben. Die Unterschiedlichkeit der Rechtssysteme könnte ebenfalls zur hohen Fehlerquote bei kontinentalen Rechtsanwälten beitragen. Lediglich aus einem statistischen Vergleich mit den Ergebnissen der britischen Kandidaten in den Eignungsprüfungen der kontinentalen Mitgliedstaaten könnten gewissen Schlüsse gezogen werden. Für einen derartigen Vergleich liegt jedoch bisher nicht das notwendige Zahllenmaterial vor. Beanstandet werden müssen jedenfalls die hohen Gebühren, die im Rahmen der Anerkennungsverfahren erhoben werden. Diese Gebührenbestimmung steht im besonders krassen Gegensatz zur Regelung in Deutschland, wo die Eignungsprüfung kostenfrei ist.
\end{abstract}

Die französische Umsetzung kann insgesamt als im wesentlichen vollständig angesehen werden. Grundsätzlich ist sie in den Hauptlinien nicht zu kritisieren, obwohl gerade in Frankreich noch einige schwerwiegende Probleme bei der Anwendung der Richtlinie bestehen. Dies gilt vor allem für den Eintritt in den öffentlichen Dienst und den damit verbundenen Concours. Die Frage nach der Zulässigkeit des Concourt ist noch nicht entschieden. Durch diese Problematik kann jedoch die Umsetzung der Richtlinie für den Lehrerberuf bisher noch keine volle Wirkung entfalten, weil der Concours als Einstellungshindernis weiterhin besteht. Diese Bemerkungen gelten selbstverständlich auch für alle anderen Concoursländer, so etwa für Luxemburg, Italien, Portugal und Spanien. Bei den letzten drei Mitgliedstaaten ist jedoch noch nicht vollkommen deutlich, wie und in welchem Verhältnis zur Richtlinie 89/48/EWG der Concours zur Anwendung kommen wird.

Für Luxemburg kann nun bereits festgestellt werden, daß die Anwendung des Concours - ebenso wie die Umsetzung der Richtlinie generell - in einer äußerst restriktiven Weise vorgenommen worden ist, so daß teilweise von einer sehr bedenklichen Umsetzung gesprochen werden muß. Dagegen scheint in Spanien, Italien und Portugal der Concours sich lediglich auf das reine Auswahlverfahren der Kandidaten zu beschränken, wăhrend in Frankreich und Luxemburg anschließend an den Concours eine Ausbildungsphase beginnt. Diese Kombination führt jedoch dazu, daß die Kandidaten neben einer Eignungsprüfung in Form des Concours eine Ausbildungsperiode absolvieren müssen. Eine derartige Kombination berücksichtigt jedoch nicht, daß die Betroffenen als "Endprodukt" bereits eine vollständige Ausbildung im Herkunftsstaat durchlaufen haben. Allerdings muß zugegeben werden, daß es grundsätzlich äußerst schwierig erscheint, die historisch so unterschiedlich entwickelten Ausbildungs- und Anstellungssysteme in einer für alle betroffenen Parteien akzeptablen Weise, d.h. auch für die Mitgliedstaaten, nebeneinander Anwendung finden zu lassen. Das Beispiel des Concours zeigt, daß es beinahe unmöglich ist, die Richtlinie 89/48/EWG in einer vollständig korrekten Weise auf Berufe in der öffentlichen Verwaltung anzuwenden, ohne von den betroffenen Mitgliedstaaten eine vollkommene Änderung ihres öffentlichen Dienstes zu verlangen. Es wird einiger Erfahrung bedürfen, um zu akzeptablen Lösungen zu gelangen. 
Gesambeurteillung des horizontalen Ansatzes

Des weiteren kann für Frankreich festgestellt werden, daß die Richtlinie im Bezug auf den Beruf des Rechtsanwalts grundsătzlich ordnungsgemäß umgesetżt wurde. Jedloch erscheint es mir berechtigt, einige Fragezeichen hinsichtlich der Neuordnung des Anwaltsberufs in Frankreich zu setzen. Mit dieser neuen Gesetzeslage wurde es in Frankreich für ausländische Rechtsanwälte quasi unmöglich, sich unter der Berufsbezeichnung des Herkunftsstaats nüederzulassen. Eine ähnliche Entwicklung kann auch für Luxemburg konstatiert werden. Mit diesen berufsrechtlichen Regelungen haben die betroffenen Mitgliedstaaten zwar nicht gegen die Richtlinie 89/48/EWG verstoßen, es erscheint mir jedoch erwägenswert zu prüfen, ob eine derartige Gesetzesänderung nicht mit Primärbestimmungen des EG-Vertrags unvereinbar ist. Gedacht werden muB an einen Verstoß gegen die Art. 53 und 5 EGV. Zwar wird in der Literatur nahezu einhellig unter Verweisung auf die einschlagige Rechtsprechung die Ansicht vertreten, daß Art. 53 EGW seit dem Ende der Übergangszeit seine Bedeutung verloren hat, weil seit diesem Zeitpunkt die Vertragsartikel zur Niederlassungsbeschränkung direkt anwendbar sind 1650 . Auch Generalanwalt Warner vertrat in seinem SchluBantrag im Fall Auer ${ }^{1651}$ sehr deutlich die Auffassung, daß seit dem Ende der Übergangszeit, d.h. seit dem 31. Dezember 1969, an die Stelle der "Stillhalte-Bestimmung" des Art. 53 EGV die allgemeine Regel des Art. 52 EGV getreten ist. Diese Ansicht war auch grundsätzlich überzeugend so lange der Gerichtshof die Niederlassungsvorschriften ausschließlich als Diskriminierungsverbote interpretierte. Da der Gerichtshof in jüngster Zeit seine Rechtsprechung aber dahingehend erweitert hat, Art. $52 \mathrm{EGV}$ auch auf nichtdiskriminierende Maßnahmen anzuwenden, erscheint mir eine Revision der Interpretation in Bezug auf Art. $53 \mathrm{EGV}$ notwendig. Die Stillhalteverpflichtung bezieht sich nun nicht mehr ausschließlich auf Regelungen, die eine Diskriminierung aufgrund der Staatsangehörigkeit beinhalten, sondern auch auf Beschränkungen, die nicht durch wesentliche Allgemeininteressen gerechtfertigt sind. Meiner Ansicht nach müßten die französischen und luxemburgischen Bestimmungen unter diesem Aspekt überprüft werden. Dabei wird sich herausstellen, daß die neuen Regelungen hinsichtlich der Niederlassung von Rechtsanwälten đeutliche neue Beschränkungen eingeführt haben. Es ist meines Erachtens sehr zweifelhaft, ob es der französischen Regierung gelänge, ausreichende Gründe anzufuihren, die diesen Teil der Neuregelung aufgrund zwingender Allgemeininteressen rechtfertigen könnte ${ }^{1652}$. Allerdings erklärt diese Analyse bis zu einem gewissen Grad die französische Haltung gegenüber dem CCBE-Entwurf zur Niederlassung unter "home title" sowie im Vorverfahren zum Entwurf der Kommission ${ }^{1653}$. Falls der Kommissionsentwurf in seiner heutigen Fassung vom Rat und Parlament verabschiedet würde, dann wäre die französische Rechtslage von der Niederlassungsrichtlinie weit-

1650. Troberg, Kommentar zu Art. 53 EGV, Rdnr. 3 in GTE-Handbuch; Randelzhofer in Grabitz-Kom mentar, Art. 53, Rdnr. 3.

1651. Urteil vom 7. Februar 1979, Rs 138/78 - Strafsache gegen Auer -, SIg. 1979, 437, (456).

1652. Eine Berufung auf Ant. 53 EGW hat meines Erachtens vor allem auch beweisrechtiche Vorteile. Ein Mitgliedstaat wird, awch wenn keine gemeinschaftsrechtliche Verpflichtung besteht, daran gehindiert. zu weniger liberalen Regelungen und Praktiken zurückzukehren.

1653. Dazu Seite $276 \mathrm{f}$. 
gehend gedeckt. Frankreich hat sich in dieser Hinsicht zu einem stark protektionistischen Land entwickelt.

Auch die Bundesrepublik kann nicht gerade als Vorreiter einer besonders liberalen und offenen Anerkennungspolitik bezeichnet werden. Im allgemeinen werden bei allen Umsetzungsmaß3nahmen die von der Richtlinie gewährten Möglichkeiten der Kompensation in vollem Umfang ausgeschöpft. Als Ausnahme von dieser Regel kann nur die Umsetzungsmaßnahme für Ingenieure angesehen werden. Hierbei verdient vor allem die miedersächsische Regelung besonderes Lob ${ }^{1654}$. Allerdings erklärt sich die deutsche Haltung im Falle der Ingenieure dadurch, daß eine liberale deutsche Anerkennungspolitik die beste Garantie bietet, daß auch die deutschen Fachhochschulingenieure in anderen Mitgliedstaaten ohne Einsatz des. Kompensationsinstrumentariums anerkannt werden. Dagegen verdient die Umsetzung für die rechtsberatenden Berufe, besonders die Organisationsweise der Eignungsprüfung für Rechtsanwälte, mit Sicherheit nicht das Prädikat einer gemeinschaftsfreundlichen Ausführungsregelung. Es wird sich noch erweisen müssen, ob diese Umsetzungsmaßnahmen auf Dauer der gerichilichen Überprüfung standhalten können. Allerdings muß konstatiert werden, daß die Anwendung der Regelung zu keiner hohen Durchfallquote bei den Eignungsprüfungen geführt hat. Im Gegensatz zu Großbritannien besteht die Mehrheit der Kandidaten die Eignungsprüfung. Ob hierin eine Reaktion auf die allgemeine Kritik an der gesetzlichen Regelung zu sehen ist, läßt sich nur schwer feststellen. Jedenfalls kann in jüngster Zeit festgestellt werden, daß die Bundesrepublik insgesamt einen liberaleren Weg einzuschlagen beginnt. Dies zeigt sich besonders deutlich durch die Gesetzesänderungen der BRAO, in der ausländischen Rechtsanwälten die Niederlassung unter "home title" weitgehend gestattet wird. Damit hat Deutschland einen gegenüber Frankreich umgekehrten Kurs beschritten. Auch die deutschen Standesvertreter plädieren für eine Öffnung des Marktes. Damit fältt die Gesamtbeurteilung der Umsetzung für die freien Berufe in der Bundesrepublik Deutschland letztlich besser aus, als die vorgelegten Umsetzungsmaßnahmen zunächst. erwarten ließen.

Bei den Lehrern ist die Situation zumindest in einigen Bundesländern dagegen noch immer bedenklich, da grundsätzlich an der Zwei-Fächer Bedingung festgehalten wird und diese nicht in allen Bundesländern eine liberale Auslegung erhält. Im Gegenteil, in Rheinland-Pfalz z. B. wurde die Anerkennung ausländischer Diplome gemäß der Richtlinie 89/48/EWG unter Berufung auf die Zwei-Fächer Bedingung von Lehrkräften verweigert, die seit Jahren im Angestelltenverhältnis in zwei Fächern Unterricht erteilten. Erst die Intervention der Kommission konnte die zuständige Behörde zu einem gemeinschaftskonformen Handeln bewegen. Ferner wird in allen Bundesländern die Notwendigkeit von einer Kompensation quasi unterstellt wird, wobei die Eignungsprüfung und der Anpassungslehrgang in ihrer Form von der Referendarausbildung und dem zweiten Staatsexamen inspiriert sind. Schlie/ßlich haben einige Bundesländer lange Zeit eine Anerkennung unter Berufung auf die fehlenden Bestimmungen im Beamten-

1654. Siehe dazu die Erläaterungen Seite 358. 
Belgien, Griechenland und die Niederlande waren - zumindest nach formellen Kriterien - die Hauptproblemfälle im ersten Beurteiltungszeitraum, weil entweder noch gar keine oder nur eine sehr beschränkte Zahl sektorieller Umsetzungsmaßnahmen vorlagem. Für die Niederlande kann man jedoch bezweifeln, ob im materiellen Sinne ein Umsetzungsproblem während der ersten Beurteilungsphase tatsächlich vorlag. Zumindest kann man die Frage stellen, ob die Problematik in den Niederlanden schwerwiegender war als in Spanien, Portugal oder Italien. Ohne jeden Zweifel ist zu beanstanden, daß der von dem niederländischen Unterrichtsministerium vorgelegte allgemeine Gesetzesentwurf so lange die parlamentarischen Hürden nicht genommen hat. Dennoch muß festgestellt werden, daß die Anerkennungsverfahren in den Niederlanden auch ohne eine allgemeine gesetzliche Grundlage zu diesem Zeitpunkt durchgeführt wurden. Dies geschah für die Mehrheit der Anerkennungsfälle in Bezug auf Lehrer auf der Basis der ministeriellen Verordnung. In anderen Fällen wurde die Entscheidung durch die zuständigen Behörden unter direkter Anwendung der Bestimmungen der Richtlinie 89/48/EWG und unter Berücksichtigung der einschlägigen Rechtsprechung des Gerichtshofs getroffen.

Des weiteren kann festgestellt werden, daß in den Niederlanden die Zahl der im Sinne der Richtlinie 89/48/EWG reglementierten freien Berufe nicht besonders groß ist. Vollkommen anders ist diese Situation in den südlichen Mitgliedstaaten Griechenland, Italien, Portugal und Spanien, wo eine hohes Reglementierungsniveau herrscht. Aufgrund des niederen Reglementierungsniveaus waren in den Niederlanden verhältnismäßig wenige freie Berufe direkt von der Richtlinie 89/48/EWG betroffen ${ }^{1658}$. Den Angehörigen nicht reglementierter Berufe stand die Niederlassung unter dem Berufstitel des Herkunftsstaates offen. Dies gilt z.B. für die Ingenieure und die Steuerberater, die nach der herrschenden niederländischen Auffassung nicht reglementiert sind. Auch war die akademische Titelführung für Ingenieure der anderen Mitgliedstaaten durch die entsprechenden gesetzliche Regelung garantiert ${ }^{1659}$.

Seit der Veröffentlichung des allgemeinen Umsetzungsgesetzes können die Niederlande insgesamt positiv beurteilt werden. Besonders hervorgehoben werden muß dabei die Tatsache, daß die Niederlande den Anwendungsbereich der Richtlinie sehr weit interpretiert haben. Auch Berufe, die grundsätzlich noch unter einem Staatsangehörigkeitsvorbehalt stehen, wurden in die gesetzliche Regelung aufgenommen 1660 . Auch sind die Niederlande ihrer Verpflichtung gemäß Art. 9 Abs. 3 der Richtlinie 89/48/EWG, die im Rahmen der Richtlinie erforderliche Information zur Verfügung zu stellen, durch Veröffentlichung einer speziellen Brochure vorbildlich nachgekommen. Von dieser grundsätzlich positiven Beurteilung muß allerdings die Durchführungsregelung für Rechtsanwälte ausgenommen werden. Diese Regelung entspricht in keiner Weise der Zielsetzung der Richtlinie. Ihre Anwendung wird zu unzumutbaren Ergebnissen führen, es sei denn, eine liberale Freistellungspolitk tritt an die Stelle der Grundsatzregelung.

658. Allerdings haben die Niederlande die Richtlinie für sehr viele Berufe im öffentlichen Dienst umgesert 659. Art 7.23 Wet op het hoger onderwijs en wetenschappelijk onderzoek (W.H.W). Siehe dazu dic Ausführungen Seite 352

$1660 . Z$. der Notar, der Richter und andere Berufe im Bereich der Justiz. 
In Belgien scheinen einige zuständige Behörden, soweit diese zumindest angewiesen worden sind, ebenfalls unter direkter Anwendung der Richtlinienbestimmungen die Anerkennungsverfahren durchzuführen. Betont werden muß dabei jedoch, daß weder die niederländische noch die belgische Situation dadurch konform mit dem Gemeinschaftsrecht wurde. Es liegen bzw. lagen vielmehr deutliche Verstösse gegen die Umsetzungsverpflichtung vor, nur ihre Auswirkung wurde durch die direkte Anwendung der Richtlinie 89/48/EWG gemildert. Selbst wenn die direkte Wirkung der Richtlinie 89/48/EWG unterstellt wird ${ }^{1661}$, ändert dies nichts an der grundsätzlichen Verpflichtung der Mitgliedstaaten ${ }_{n}$ diese in das nationale Recht umzusetzen. Die Berufung eines Mitgliedstaats auf eine richtlinienkonforme nationale Verwaltungspraxis ist nach der ständigen Rechtsprechung des Gerichtshofs irrelevant ${ }^{1662}$.

Zu dieser Problematik hat der Gerichtshof in einem Verfahren gegen die Bundesrepublik Deutschland die sehr deutliche Formulierung gewählt: Die Mitgliedstaaten müssen, "um die volle Anwendung der Richtlinien in rechtlicher und nicht nur in tatsächlicher Hinsicht zu gewährleisten, einen eindeutigen gesetzlichen Rahmen auf dem betreffenden Gebiet schaffen." 1663

Bei einem Gesamtüberblick über die Umsetzungsmaßnahmen in den einzelnen Mitgliedstaaten ist das Ergebnis für einige Staaten zu mindest für den ersten Beurteilungszeitraum beschämend, und zwar nicht zuletzt für die sich öffentlich so integrationsfreudig gerierenden Bundesrepublik Deutschland und die Niederlande ${ }^{1664}$. In beiden Staaten hat die Umsetzung in ihrer Gesamtheit sehr lang auf sich warten lassen. Aber auch Italien, Spanien und Portugal erfüllen bei weitem nicht den vom EuGH gesetzten Maßstab an eine ordnungsgemäße Umsetzung ${ }^{1665}$. Frankreich und Luxemburg können dem Mittelfeld zugeordnet werden, wobei jedoch inhaltliche Bedenken vor allem hinsichtlich der luxemburgischen Umsetzung anzumelden sind. Belgien und Griechenland liegen weit unter der Norm. Nur die in der Öffentlichkeit häufig wegen ihrer angeblich wenig europafreundlichen Haltung angegriffenen Dänen, Briten und Iren können mit ihren Umsetzungsmaßnahmen zufrieden sein. Sie erfüliten formell und materiell korrekt die Verpflichtungen aus der Richtlinie, wobei sie auch im Hinblick auf den zeitlichen Malfstab, eine Vorbildfunktion erfüllten. Diese Beurteilung ist nicht als eine Ausnahme in der Umsetzungspolitik zumindest von Dänemark und Großbritannien zu qualifizieren. Seit Jahren sind es vor allem die Dänen und die Briten, die um die Ehre der wenigsten Vertragsverletzungsverfahren wegen eines Verstosses gegen Umsetzungsverpflichtungen

1661. Siehe dazu die Ausführungen unten Seite 424 .

1662. Urteil vom 1. März 1983, Rs 301/81 - Kommission/Belgien -, Slg 1983, 467, Urteil wom 23. Mai 1985, Rs 29/84 - Kommission/Deutschland - Slg. 1985, 1661; Unteil wom 23. Februar 1988, Rs 429:85 - Kommission/Italien -, Slg. 1988, 843. Vgl dazu auch Jarass, NJW 1990; 2420; Jarass, NJW 1991, 2665 mit weiteren Nachweisen.

1663. Unteil vom 28. Februar 1991, Rs C-131/88 - Kommission/Deutschland - Slg. I-1991, 825, Rdnr. 72.

1664. Der Ausdruck stammo von Everling, der in anderem Zusammenhang ebenfalls die Haltung der Bundes. republik bei der Umsetzung won Richtlinien kritisiert, NVwZ 1993, 215.

1665. Siehe dazu die Ausfühungen von Everling, NVwZ 1993, 209, (215). 
miteinander wetteifern ${ }^{1666}$. Die neuen Mitgliedstaaten Finnland, Österreich und Schweden verdienen ebenfalls eine sehr positive Beurteilung, weil sie sehr zügig und grundsätzlich gemeinschaftsfreundlich ${ }^{1667}$ umgesetzt haben.

C. VERGLEICH MTT DEM GENERELLEN UMSETZUNGSPROZENTSATZ DER MITGLIEDSTAATEN

Umsetzungsprozentsatz hinsichtlich

Richtlinien zur Vollendung des Binnenmarkts

\begin{tabular}{|l|c|c|}
\hline & 1994 & 1991 \\
\hline Dänemark & $94 \%$ & $90 \%$ \\
\hline Vereinigtes Königreich & $89 \%$ & $84 \%$ \\
\hline Portugal & $89 \%$ & $80 \%$ \\
\hline Italien & $87 \%$ & $45 \%$ \\
\hline Luxemburg & $87 \%$ & $71 \%$ \\
\hline Spanien & $87 \%$ & $70 \%$ \\
\hline Frankreich & $86 \%$ & $86 \%$ \\
\hline Niederlande & $86 \%$ & $73 \%$ \\
\hline Belgien & $84 \%$ & $75 \%$ \\
\hline Deutschland & $82 \%$ & $80 \%$ \\
\hline Irland & $81 \%$ & $65 \%$ \\
\hline Griechenland & $80 \%$ & $77 \%$ \\
\hline
\end{tabular}

Gemäß dem von der Kommission veröffentlichten Zahlenmaterial nehmen Dänemark und das Vereinigte Königreich die ersten beiden Ränge bei der fristgerechten Umsetzung von Richtlinien ein. Diese Tabellen bestätigen damit das vorliegende Ergebnis hinsicht-

1666. Suehe die ähnliche Beurteilung von Everling, NVwZ 1993, 215. Siehe auch Karoff, RabelsZ 1984, 649 if.

1667. Eine Ausnahme gilt für die Umsetzung hinsichtlich Ingenieure durch das "Ziviltechnikergesetz 1993" in Österreich. Siehe dazu die Kritik in der Fallstudie "Ingenieure". 
lich der Richtlinie 89/48/EWG. Dagegen kann die irische Position im Umsetzungsprozeß zur Richtlinie 89/48/EWG als außergewöhnlich bezeichnet werden, weil Irland ansonsten zu den Schilußlichtern gerechnet werden muß.

Bemerkenswert ist auch die Position Italiens. Lange Jahre wurde Italien regelmäßig wegen Fristüberschreitungen verurteilt ${ }^{1668}$. Diese Situation hat sich jedoch in jüngster Zeit grundlegend geändert. Von einer Schlußlichtposition ist Italien auf den vierten Rang vorgerückt. Die rasche Umsetzung der Richtlinie 92/51/EWG zeigt, daß dieser Wandel kontinuiert wird ${ }^{1669}$. Die Ursache für diesen Positionswechsel muß in einer Veränderung der italienischen Gesetzgebung gesucht werden. Gemäß dem La Pergola-Gesetz von 1989 ist die italienische Regierung am 1. März jedes Jahres verpflichtet, einen Gesetzesentwurf zu einem sogenannten "legge comunitario" dem Parlament zu unterbreiten. Dieses "Gemeinschaftsgesetz" enthält eine Liste der Richtlinien, die ungesetzt werden müssen und legt für jede Richtlinie die gewählte Umsetzungsmethode fest ${ }^{1670}$. Dabei werden unterschiedliche Umsetzungsmethoden angewandt. Die prozessual einfachste Umsetzungstechunik besteht darin, dem "legge comunitario" ein Regelung beizufügen, wonach diese in Kraft tritt, sobald das "Gemeinschaftsgesetz" vom Parlament verabschiedet ist. Capelli nennt als Beispiel einer derartigen Umsetzung die Aufhebung der Beschränkung, nach der sich nur italienische Staatsbürger in der italienischen Journalistenkammer einschreiben durften ${ }^{1671}$. Nach Art. 9 des "Gemeinschaftsgesetzes" aus dem Jahr 1990 kann jeder Gemeinschaftsbürger, der im Besitz der erforderlichen Voraussetzungen ist, sich unabhängig von seiner Nationalität in der Journalistenkammer einschreiben. Damit hat Italien eine seit 1970 bestehende Verpflichtung schließlich erfültt. Eine andere Umsetzungsmethode besteht darin, die Regierung im legge comunitario zu ermächtigen, Umsetzungsdekrete zu erlassen. Diesen Weg hat Italien bei der Umsetzung der Richtlinien 89/48/EWG und 92/51/EWG beschritten ${ }^{1672}$. Der langwierige Gesetzgebungsproze ${ }^{1673}$ wurde dadurch erheblich verkürzt. Trotz dieser Verbesserungen kann jedoch nur dann von einer abgeschlossenen Umsetzung gesprochen werden, wenn entweder die Regelungen im "Gemeinschaftsgesetz" oder die Regierungsdekrete eine der Richtlinie entsprechende Entscheidung durch die zuständigen Behörden ermöglichen. Ansonsten kann eine derartige Umsetzungstechnik nur als Augenwischerei bezeichnet werden.

Luxemburg, Spanien und Frankreich sind nach den Zahlenangaben der Kommission dem Mittelfeld zuzurechnen. Diese Beurteilung kann mit Einschränkungen auch für die Umsetzung der Richtlinie 89/48/EWG bestätigt werden. Auch die Positionen der Nie-

1668. Siehe zu den in der Vergangenheit angewandten Umsetzungsmethoden Capelli, 6; La Pergola-Dell Duca, AJLL 1985, 598f.

1669. Decreto legislativo Nr. 319 vom 2. Mai 1994, Gaz. Uff. Nr. 123 vom 28. Mai 1994.

1670. Art 2 des La Pergola-Gesetzes.

1671. Capelli, 8.

1672. Decreto legislativo Nr. 115 vom 27. Januar 1992, Gaz. Uff. Nr. 40 vom 18. Februar 1992 und Decreto legislativo $\mathrm{Nr} .319$ vom 2. Mai 1994, Gaz. Uff. Nr. 123 wom 28. Mai 1994.

1673. Die häufigen Regienungskrisen verlängerten den Umsetzungsprozeß nicht unerheblich. 
derlande "Deutschlands, Belgiens und Griechenlands entsprechen weitgehend dem Untersuchungsergebnis. Belgien hat dabei in der vorliegenden Studie eine vergleichbar noch schlechtere Rangposition. Auch Portugal nimmt in der Statisitk einen besseren Rang ein als nach dem Untersuchungsergebnis zur Richtlinie 89/48/EWG. Beil der Beurteilung muß allerdings zwischen einer Gesamtumsetzung und der Verabschiedung einer einzelnen Umsetzungsmaßnahme unterschieden werden. Hierbei zeigt sich die Fragwürdigkeit statistischer Angaben. Es erscheint zweifelhaft, ob derartige Statistiken auch eine materielle Beurteilung der Umsetzungen ausreichend berüicksichtigen.

\section{VERGLEICH MTT DER UMSETZUNGSÜBERSICHT DER KOMMISSION ZU DEN DIPLO- MANERKENNUNGSRICHTLINIEN}

Besonders deutlich zeigt sich die Fragwürdigkeit von statistischen Angaben bei einem Vergleich zwischen der won der Kommission vorgelegten Übersicht zur Umsetzungspraxis der Mitgliedstaaten hinsichtlich der verschiedenen Diplomanerkennungsrichtllinien. Die Kommission hat in ihrem Elften Bericht an das Europäische Parlament eine derartige Umsetzungsübersicht hinsichllich der Richtlinien veröffentlicht, die sich auf die Anerkennung von Diplomen beziehen. Diese Übersicht nennt auch die Richtlinie 89/48/EWG. Laut dieser Übersicht haben Dänemark, Deutschland, Italien und Luxemburg zu allen anwendbaren Richtlinien Umsetzungsmaßnahmen an die Kommission zum 31. Dezember 1993 mitgeteilt. Diese Zahlenangabe überrascht bei einem Vergleich mit den Ergebnissen der vorliegenden Studie. Vor allem die Angabe hinsichtlich der Bundesrepublik Deutschland entspricht micht dem Untersuchungsergebnis, zumindest dann nicht, wenn von einer vollständigen Umsetzung die Rede sein soll. Geht man dagegen davon aus, daß die Mitteilung einer einzelnen Umsetzungsmaßnahme genügt, um zu einer statistisch positiven Beurteilung zu kommen, dann ist die Tabelle erklärbar. 


\begin{tabular}{|c|c|c|c|}
\hline \multicolumn{4}{|c|}{ Umsetzungsübersicht der Kommission zum 31. Dezember 1993} \\
\hline Mitgliedstalat & $\begin{array}{l}\text { Anzahl der an- } \\
\text { wendbaren } \\
\text { Richtlinien am } \\
31.12 .1993\end{array}$ & $\begin{array}{l}\text { Anzahl der Richt- } \\
\text { linien für die Um- } \\
\text { setzungsmaß- } \\
\text { nahmen an die Kom- } \\
\text { mission mitgeteilt } \\
\text { wurden }\end{array}$ & $\%$ \\
\hline Belgien & 61 & 59 & 97 \\
\hline Dänemark & 61 & 61 & 100 \\
\hline Deutschland & 61 & 61 & 100 \\
\hline Griechenland & 61 & 60 & 98 \\
\hline Spanien & 61 & 59 & 97 \\
\hline Frankreich & 61 & 60 & 98 \\
\hline Irland & 61 & 58 & 95 \\
\hline Italien & 61 & 61 & 100 \\
\hline Luxemburg & 61 & 61 & 100 \\
\hline Niederlande & 61 & 60 & 98 \\
\hline Portugal & 61 & 59 & 97 \\
\hline Vereinigtes Königreich & 61 & 59 & 97 \\
\hline
\end{tabular}

Die Übersicht bezieht sich auf die folgenden Richtlinien:

$63 / 261,63 / 262,64 / 222,64 / 223,64 / 224,64 / 427,64 / 428,64 / 429,65 / 001,66 / 162$, $67 / 043,67 / 530,67 / 531,67 / 532,67 / 654,68 / 192,68 / 363,68 / 364,68 / 365,68 / 366$, $68 / 367,68 / 368,68 / 369,68 / 415,69 / 077,69 / 082,70 / 451,70 / 522,70 / 523,71 / 018$, $74 / 566,74 / 566,74 / 577,75 / 362,75 / 363,75 / 368,75 / 369,77 / 249,77 / 452,77 / 453$, $78 / 686,78 / 687,78 / 1026,78 / 1027,80 / 154,80 / 155,80 / 1057,80 / 1273,82 / 470,82 / 489$, $85 / 384,85 / 432,85 / 433,85 / 584,85 / 614,86 / 017,86 / 457,89 / 048,89 / 594,89 / 595$, $90 / 658$. 


\section{E. GRÜNDE FÜR DIE VERSPÄTETE UMSETZUNG}

Das Umsetzungsdefizit kann in den einzelnen Mitgliedstaaten auf unterschiedliche Ursachen zurückgeführt werden. Einige der Ursachen bieten einen gewissen Entschuldigungsgrund, andere sind dagegen unverständlich und unentschuldbar. Zunächst kann festgestellt werden, daß die einzelnen Mitgliedstaaten sehr unterschiedliche Strategien bei den Verhandlungen über einen Richtlinienentwurf verwenden. In einigen Mitgliedstaaten wird bereits der Richtlinienentwurf in allen Einzelheiten im zuständigen Fachministerium besprochen, wobei der Fachreferent an den Verhandlungen aktiv beteiligt ist. In anderen Mitgliedstaaten werden die Verhandlungen im wesentlichen durch das AuRenministerium oder das Wirtschaftsministerium geführt. Die Fachreferenten werden mit dem Richtlinientext erst nach Annahme konfrontiert ${ }^{1674 .}$

Die dänische Spitzenposition im Umsetzungsprozeß läßt sich bereits dadurch erklären, daß es in Dänemark üblich ist, Richtlinienentwüfe direkt nach ihrer Veröffentlichung durch die Kommission in einem zuständigen Spezialausschuß ausführlichst zu analysieren ${ }^{1675}$. Einerseits verstärkt diese Vorgehensweise die dänische Position während der Ratsverhandlungen, weil eine genaue Sachkenntnis hinsichtlich einzelner Entwurfsbestimmungen besteht, andererseits kann eine Richtlinie nach ihrer Verabschiedung sehr zügig umgesetzt werden, da die gesetzgeberischen Konsequenzen auf nationaler Ebene bereits in der Vorphase ausführlich zur Sprache gekommen sind.

In den Mitgliedstaaten, in denen der nationale Koordinator der Richtlinie 89/48/EWG nicht an den Verhandlungen beteiligt war, traten dagegen häufig Probleme während des Umsetzungsprozesses auf. Zunächst konnte der Koordinator sich erst in einem Zeitpunkt in den Richtlinientext und die dadurch bedingten gesetzgeberischen Konsequenzen einarbeiten, in dern die Umsetzungsfrist bereits angelaufen war. Dies führte in einigen Mitgliedstaaten, so z.B. in den Niederlanden zu einer nicht unerheblichen Verzögerung. Auch inhaltlich ist es von Bedeutung, daß eine gewisse Kontinuităt so weit wie möglich gewahrt bleibt. In einigen Mitgliedstaaten waren die nationalen Koordinatoren der Richtlinie 89/48/EWG bereits bei den Verhandlungen zu sektoriellen Anerkennungsrichtlinien anwesend oder hatten die Verantwortung für deren Umsetzung. Diese Erfahrung bedeutete häufig einen Vorteil gegenüber Koordinatoren, die sich neu in die Anerkennungsmaterie einarbeiten mußten. Auch ein Koordinatorenwechsel kann unter Umständen zu einer Verzögerung im Umsetzungsprozeß führen. Des weiteren ist es von Bedeutung, dalß der nationale Koordinator bei einer Umsetzung durch ein allgemeines Umsetzungs gesetz mit genügend Befugnissen oder zumindest einem ausreichenden Handlungsspielraum ausgestattet ist, der ihm die Durchsetzung seines Umsetzungsentwurfs gegenüber

1674. Siehe dazu die ausführliche Studie von Pappass (Hrsg.), National Administrative Procedures for the Preparation and Implementation of Community Decisions, ETPA 1995, worin die unterschiedlichen Methoden in Länderberichten dargestellt werden. Zu den unterschiedlichen Methoden siehe bereits die ron Siedentopf/Ziller 1988 veróffentlichte Sturilie.

1675. Nedergaard, in: Pappas (Hrsg.), EIPA 1995, 111 (118 ff.). 
den anderen betroffenen Behörden ermöglicht. Im Falle der Niederlande haben vor allem auch inner- und interministerielle Querelen zu der Verzögerung beigetragen.

Bereits in der von Stedentopf/Ziller 1988 veröffentlichten Studie haben Kooiman/Yntema/Lintsen für die Niederlande festgestellt, daß die Gründe für die verspätete Umsetzung von Richtlinien teil weise in der schlechten Koordination zwischen den zuständigen nationalen Behörden, teilweise in der Trennung zwischen Verhandlungs- und Umsetzungsphase zu suchen sind. Des weiteren wurde von ihnen ein behördliches Desinteresse an europäischen Gesetzgebungsinitiativen konstatiert ${ }^{1676}$. Diese Ursachenanalyse kann für den Umsetzungsprozeß hinsichtlich der Richtlinie 89/48/EWG bestätigt werden. Auch der allgemein langwierige und sehr gründliche nationale Gesetzbungsprozeß trug dazu bei, daß sich die Niederlande lange Zeit in einer Schlußlichtposition befanden. Das nationale Gesetzgebungsverfahren ist in den Niederlanden darauf gerichtet, soweit wie möglich bei Gesetzgebungsprojekten einen Konsens zwischen den betroffenen Gruppierungen zu erzielen ${ }^{1677}$. Diese Methode ist jedoch nicht sehr geeignet, fristgemäße Unsetzungen von Richtlinien durchzusetzen. Allerdings muß dabei bemerkt werden, daß in den Niederlanden seit 1991 ein Wandel eingetreten ist. Der allgemeine politische Wille zu einer zügigen Umsetzung hat erheblich zugenommen ${ }^{1678}$. Die rasche Umsetzung der Richtlinie 92/51/EWG bestätigt diese Veränderung. Eine vergleichbare Veränderung konnte bereits für Italien mit Einführung der La Pergola-Gesetzgebung konstatiert werden ${ }^{167 \%}$.

In der Bundesrepublik. Deutschland ebenso wie in Belgien beruhten die Verzögerungen zum Teil auf der föderalen Struktur beider Staten ${ }^{1680}$. Für die Deutschland kann dabei festgestellt werden, daß die Umsetzung - soweit diese durch Bundesgesetze möglich war - weitgehend fristgemäß vorgenommen ist, während die Verzögerungen vor allem im Bereich der Ländergesetzgebung zu suchen sind. Als Ausnahme von dieser Regel muf die Verabschiedung der beamtenrechtlichen Bestimmungen durch den Bundestag genannt werden ${ }^{1681}$. Deren Verzögerung war unmittelbar auch ursächlich für die verspåttete Umsetzung auf Länderebene für den Beruf des Lehrers. Bei den Ländern kann eine allgemeine Fristüberschreitung bei den neuen Bundesländern konstatiert werden. Diese Verspätung läßt sich in einem gewissen Rahmen mit dem allgemeinen Gesetzgebungsdruck erklăren und entschuldigen ${ }^{1682}$, der auf den Ministerien und Parlamenten

1676. Siedentopf/2iller, $573 \mathrm{ff}$; Dommes, Bestuurswetenschappen 1991, 40; Maas/van Haersholte, SEW 1994, 703; Bekkers/Bonnes u.a., $185 \mathrm{ff}$

1677. Bekkers u.a. in: Pappas (Hrsg.), EIPA 1995, 397 (410)

1678. Bekkers u.a. in: Pappas (Hrsg.), EIPA 1995, 397" Maas/van Haersholte, SEW 1994, 703

1679. Siehe dazu Seite 408 .

1680. Siehe dazu auch die Landerberichte von Streinz/Pechstein für die Bundesrepublik Deutschland und Lejeune für Belgien, wobei in beiden der Einflufs der federalen Stnuktur auf den Umsetzungsprozeb unterstrichen wird, in: Pappas (Hrsg.), EIPA 1995, 59 ff. (Belgien) wnd $123 \mathrm{ff}$. (Deutschland).

1681. Siehe dazu Seite $380 \mathrm{f}$.

1682. Gemeinschaftsrechtlich ist die inteme Situation in einem Mitgliedlstaat kein Entschuldigungsgrund für eine verspätete Umsetzung. Siehe dazu das Unteil vom 16. Mai 1991, Rs C-168/90-Kommissiony- 
der neuen Bundesländer ruht. Allerdings findet diese Erklärung insoweit eine Einschränkung, als für einige Umsetzungsprojekte Musterentwürfe vorlagen. Dies galt zumindest für die Lehrer und Ingenieure. Auf der Basis dieser Vorlagen hätte meines Erachtens die Umsetzung auch in den neuen Bundesländern rascher durchgeführt werden können. Vollkommen unverständlich ist allerdings, warum in einigen der alten Bundesländer die Umsetzung nicht fristgemäß durchgeführt worden ist. In diesem Fall zeigt sich sehr deutlich, daß der nationale Koordinator und auch der Koordinator auf Länderebene über unzureichende Mittel und Befugnisse verfügen, um die Länderbehörden zur Umsetzung zu zwingen. Diese Situation ist besonders unbefriedigend, weil etwaige Vertragsverletzungswerfahren der Kommission gemäß Art. 169 EGV gegen die Bundesrepublik Deutschland, d.h. gegen den Bund und nicht gegen das betroffene Bundesland gerichtet werden. Der Umsetzungsunwille einiger Länder steht im krassen Gegensatz zu dem erklärten Wunsch der Bundesländer, am europäischen Gesetzgebungsprozeß aktiv beteiligt zu sein ${ }^{1683}$. Ob die entsprechenden Veränderungen zu einer Verbesserung der Umsetzungskultur bei den Bundesländern führen, muß noch abgewartet werden. Die Kritik an den Bundesländern kann allerdings nicht verallgemeinert werden. Einige Bundesländer haben fristgemäß umgesetzt. Als Vorbild muß Hamburg genannt werden, wohingegen Baden-Württemberg die zweifelhafte Ehre hat, als Schlußlicht hinsichtlich der Umsetzung für Lehrer zu fungieren.

Die zunehmende Föderalisierung Belgiens war ebenfalls - zumindest teilweise - ursächlich für die Verzögerungen bei der Umsetzung der Richtlinie $89 / 48 / \mathrm{EWG}^{1684}$. Nach der Verabschiedung der Richtlinie $89 / 48 / \mathrm{EWG}$ sollte zunächst deren Umsetzung durch ein allgemeines Gesetz vorgenommen werden. Die Durchführung dieses Gesetzgebungsvorhabens scheiterte letztlich an einer Regierungskrise in Belgien. Die verfassungsrechtlichen Veränderungen führten dazu, daß die Kompetenz zur Umsetzung sich weitgehend von Bundesebene auf die Ebene der Gemeinschaften verschob. Dies gilt zumindest für die Bereiche, die das Unterrichtswesen betreffen, so z.B. der Beruf des Lehrers ${ }^{1685}$. Damit war eine Umsetzung durch ein allgemeines Umsetzungesetz verfassungsrechtlich unmöglich geworden, da die Kompetenzen der belgischen Gemeinschaften exklusiv sind. Die Umsetzung erfolgt seither durch sektorielle Umsetzungsmaßnahmen.

Allerdings kann die Föderalisierung nicht allein für das Umsetzungsdefizit Belgiens verantwortlich gemacht werden. Am 27. März 1992 verabschiedete der belgische Minister-

1682. $\rightarrow$

Luxemburg - , Slg. 1991, 1-2539, worin der Gerichtshof unter Himweis auf seine stândige Rechtsprechung das luxemburgische Vorbringen intemer Schwierigkeiten als unbeachtlich zurückwies

1683. Durch die Andenug des. Art. 146 EGV kann die Delegationsleitung durch Landerminister im Rat wahrgenommen werden. Siehe dazu Clostermey er in Barkenhagen/Bruns-Klöss/Memminger/Stein, 171 (1181).

684. Am Gemeinschaften und Regionen zusammengesetzt ist. Siehe zu den verschiedenen Verfassungsänderungen Alen/Ergec 1994.

1685. Verstegen, Tijdschrift voor Bestuurswetenschappen en Publiek Recht, 1989, 30. 
rat ein Notprogramm, in dem die notwendigen Schritte festgellegt wurden, die Umsetzungsmaßnahmen für die Binnenmarktsrichtlinien soweit möglich noch bis zum Ende des Jahres 1992 zu verabschieden. Dieses Notprogramm war erforderlich, weil zu diesem Zeitpunkt bereits ein gravierender Rückstand bei den Umsetzungsverfahren konstatiert werden mußte ${ }^{1686}$. Trotz dieser Notmaßnahme war eine zügige Umsetzung der Richtlinie 89/48/EWG nicht gewährleistet. Auch sektorielle Maßnahmen, die auf Bundesebene erlassen werden könnten, so z.B. eine Anerkennungsregelung für die Rechtsanwälte, fehlen noch immer. Die Verurteillung Belgiens am 13. Juli 1995 ist daher auch vollkommen berechtigt ${ }^{1687}$.

Allgemein ist festzustellen, daß eine Umsetzung im Wege der sektoriellen Gesetzgebung zeitraubender, als die Verabschiedung eines allgemeinen Umsetzungsgesetzes ist. Das belgische und deutsche Vorbild belegen dies deutlich. Auch der griechische Umsetzungsprozeß verläuft äußerst mühsam. Von einer vollkommen abgeschlossenen Uimsetzung wird man in Griechenland wohl erst in einigen Jahren sprechen können. Dagegen zeigen die Beispiele von Frankreich, Luxemburg, Österreich und Schweden, daß auch eine sektorielle Umsetzung verhältnismäßig zügig vorgenommen werden kann. Bemerkt werden muß dabei allerdings, daß es sich bei Luxemburg und Frankreich um zentralistische Staaten handelt, so daß die sektorielle Umsetzung leichter als im Falle Belgiens und Deutschlands koordiniert werden kann. Auch in Österreich wurden die sektoriellen Gesetze auf Bundesebene verabschiedet, ohne daß wie in Deutschland eine erhebliche Verzögerung des Umsetzungsprozesses durch die Bundesländer konstatiert werden muß.

Dagegen beweisen Dänemark, Großbritannien, Irland, Italien, Spanien und Portugal sowie Finnland, daß eine Umsetzung durch ein allgemeines Umsetzungsgesetz grundsätzlich rascher durchgeführt werden kann. Fehlt es jedoch an den notwendigen Ausführungsmaßnahmen, so erweist sich eine derartige Umsetzung in der praktischen Anwendung als unzureichend, es sei denn, die zuständigen Behörden entscheiden jeden Fall individuell.

\section{\$2. Die direkte Anwendung der Richtlinie 89/48/EWG}

Die Nichtumsetzung oder die häufig auch unvollständige Umsetzung der Richtlinie 89/48/EWG in einigen Mitgliedstaaten läßt die Frage nach der unmittelbaren Anwendung der Anerkennungsvorschriften laut werden. Nach der Rechtsprechung des EuGH können Bestimmungen, die klar und bestimmt sind, und auf die sich der einzelne zu seinen Gunsten berufen kann, unmittelbare Wirkung entfalten ${ }^{1698}$. Weitere Vorausset-

1686. Siehe dazu Lejeune, in: Pappas (Hrsg), EIPA 1995, 59 (83 f.).

1687. Unteil vom 13, Juli 1995, Rs 216/94 - Kommission/Belgien - (noch nicht veröffentlicht).

1688. Zu den einzelnen Voraussetzungen siehe bereits Generalanwalt Mayras in der Rechtssache 41/74 - Van Duyn/Home Office - Urteil vom 4. Dezember 1974, Slg. 1974, 1337 (1354); Kapteyn/VerLoren van Themaat $1990,333 \mathrm{ff}$. Grundlegend für die direkte Wirkung von Richtlinien die Entscheidung des Gerichtshofs rom 19. Januar 1982 in der Rechtssache $8 / 81$ - Ursula Becker/Finanzamt Münster 
zung ist, dal keine Bedingungen an die Anwendung der Bestimmung geknüpft sind ${ }^{1689}$. Dies gilt auch für Richtlinienbestimmungen, soweit der Umsetzungstermin verstrichen ist $16 \%$

Die Frage ist also, ob die Anerkennungsbestimmungen der Richtlinie 89/48/EWG so klar und bestimmt sind, daß sie gemäß der Rechtsprechung des Gerichtshofs eine unmittelbare Anwendung zulassen. Von zentraler Bedeutung für die Entscheidung dieser Frage ist die Formulierung von Art. 3 der Richtlinie 89/48/EWG. Hierin ist in Art. 3 Buchstabe a) der normale Fall der Anerkennung klar und bestimmt formuliert: Ein Mitgliedstaat darf einem Angehörigen aus einem Mitgliedstaat den Zugang zu einem reglementierten Beruf nicht verweigern, "wenn der Antragsteller das Diplom besitzt, das in einem anderen Mitgliedstaat erforderlich ist, um Zugang zu diesem Beruf in seinem Hoheitsgebiet zu erhalten oder ihn dort auszuüben, und wenn dieses Diplom in einem Mitgliedstaat erworben wurdle" ${ }^{\prime \prime}$. Alle Elemente dieser Bestimmung können durch einen nationalen Richter überprüft werden. Auch der Fall des Berufsangehörigen, der den Beruf in einem Mitgliedstaat ausgeübt hat, der diesen Beruf nicht reglementiert, Art. 3 Buchstabe b), ist eindeutig. Der Antragsteller muß über ein Diplom im Sinne der Richtlinie 89/48/EWG verfügen, und er muß eine mindestens zweijährige Berufserfahrung nachweisen können. Ausgehend von dieser Formulierung ist im Falle einer Nichtumsetzung eine Anerkenmung auf der Grundlage der direkten Anwendung von Art. 3 der Richtlinie 89/48/EWG möglich; es sei denn, die Anpassungsinstrumente des Art. 4 der Richtlinie 89/48/EWG müssen als Bedingungen angesehen werden, die eine direkte Berufung auf Art. 3 verhindern.

Gemäß Art. 4 Abs. 1 a) der Richtlinie 89/48/EWG kann ein Mitgliedstaat, falls Unterschiede in der Ausbildungsdauer zwischen Herkunftsstaat und Aufnahmestaat bestehen, vom Antragsteller als Kompensation dieses Defizits, den Nachweis einer bestimmten Berufserfahrung verlangen. Gemäß Art. 4 b) ist es möglich, bei wesentlichen Unterschieden in den Ausbildungsinhalten - fall/s dies für die Berufsausübung erforderlich ist zur Kompensation eine Eignungsprüfung oder einen Anpassungslehrgang zu verlangen. In beiden Fällen handelt es sich um eine "Kann"-Vorschrift. Mitgliedstaaten sind nicht verpflichtet, vor einer Anerkennung ein Anpassungsinstrument im Sinne des Art. 4 der Richtlinie 89/48/EWG einzusetzen. Im Gegenteil, Mitgliedstaaten haben - im Hinblick auf eine Eignungsprüfung oder einen Anpassungslehrgang - die Beweislast, daß die geforderten Kenntnisse eine wesentliche Voraussetzung für die Ausübung eines bestimm-

$1688 . \rightarrow$

Innenstadt -, Slg. 1982, 53. Zur Entwicklung der Annahme der direkten Wirkung von Richtinienbe stimnungen siehe Pescatore, ELR 1983, 155 ff; ; Prechal 1995, 246 ff (za den einzelnen Bedingungen vor allem 277 ff.); Pieper, DVB1.1990, 684 ff. Grundlegend bereits Pescatore, Cromique Dalloz 1980. 171 (176).

1689. Prechal 1995, 282 ff.

1690. Urteil vom 19. Januar 1982, Rs 8/81 - Ursula Becker/Fìnanzamt Münster Innenstadt -, Slg. 1982, 53 (70 ff.). Urteil vom 15. Juli 1982, Rs $270 / 81$ - Felicitas Rickmers-Linie/Finanzamt für Verkehrssteuern Hamburg, SIg. 1982, 2771. Siehe auch das Unteil des Gerichts Erster Instanz vom 41 . Februar 1992. Rs T 16/90 - A. Panagiotopoulou/Europäisches Parlament -, Sig. 1992, 89, Rdnr. 42. 
ten Berufs im Aufnahmestaat sind ${ }^{1691}$. Die Frage, ob Art. 4 der Richtlinie eine Bedingung darstellt, die eine direkte Anwendung von Art. 3 der Richtlinie 89/48/EWG verhindern könnte, muf daher meines Erachtens verneint werden. Wenn ein Mitgliedstaat keine oder keine vollständige Umsetzungsmaßnahme erlassen hat, ist nach dem klaren Wortlaut des Art. 3 der Richtlinie 89/48/EWG dawon auszugehen, daß der Mitgliedstaat die Anwendung von Kompensationsinstrumenten nicht für erforderlich hält. Es wäre Sache des Mitgliedstaates gewesen, das Gegenteil - nämlich ein Bedürfnis zur Kompensation - zu begründen und zu regeln. Im Einzelfall kann ein nationales Gericht auf dieser Grundlage entscheiden.

Auch für die rechtsberatenden Berufe gilt keine andere Regelung. Zwar haben gemäß Art. 4 b) Unterabs. 2 der Richtlinie $89 / 48 / E W G$ die Mitgliedstaaten das Wahlrecht hinsichtlich der Art der Anpassung. Dies bedeutet jedoch nicht, daß, falls ein Mitgliedstaat von seinem Wahlrecht keinen Gebrauch macht, damit eine Anwendung der Richtlinie auf der Basis von Art. 3 ausgeschlossen wäre ${ }^{1692}$. Die automatische Anerkennung der irischen solicitors in England beweist, daß auch für die rechtsberatenden Berufe die Grundnorm in Art. 3 zu suchen ist und Art. 4 nur gegebenemfalls zur Anwendung kommt, wenn dafür die Erforderlichkeit nachgewiesen wird.

Diese Interpretation der Richtlinie stimmt voll mit der Rechtsprechung des Gerichtshofs in den Rechtssachen Heyllens ${ }^{1693}$ "Vlassopoulou ${ }^{1694}$ und Newman ${ }^{1695}$ überein. Gerade die Entscheidung Newman beweist, daß ein Mitgliedstaat auch bei mangelnder Umsetzung der Anerkennungsrichtlinie ein Verfahren entwickeln muß, das eine Entscheidung über die Anerkennung und die Zulassung zum Beruf ermöglicht. Diese Entscheidung muß genügend begründet sein, um einer gerichtlichen Überprüfung standhalten zu können. Auch die Forderung nach Anpassung des Antragstellers als notwendige Voraussetzung für die Berufsausübung im Aufnahmestaat müßte daher hinreichend begruindet werden.

In der bisher einzigen Entscheidung, in der die direkte Anwendung der Richtlinie $89 / 48 /$ EWG bisher zur Sprache gekommen ist ${ }^{169}$, hat das Gericht Erster Instanz diese Frage nur sehr vorsichtig angesprochen. Nach Auffassung des Gerichts will die Richtlinie 89/48/EWG zwar ein System der gegenseitigen Anerkennung der Diplome im Verhältnis zwischen den Mitgliedstaaten schaffen, jedoch keine bedingungslose Anerkennung der Diplome vorschreiben. Das Gericht verweist dabei auf Art. 4 der Richtlinie. Ungeachtet dieses Hinweises schließt das Gericht jedoch nicht aus, "daß die

1691. Vgl. dazu die Definition der Eignungsprüfung in Art. 1 Buchstabe gl der Richtlinie 89/48/EWG

1692. Siehe dazu oben Seite 188.

1693. Urteil vom 15, Oktober 1987, Rs 222/86 - UNECTEF/Heylens -. Sig. 1987, 4097.

1694. Urteil vom 7. Mai 1991, Rs C-340/89 - Irène Vlassopoulou/Ministerium für Justiz, Bundes- und Europaangelegenheiten Baden-Württemberg, Slg. I-1991, 2357.

1695. Urteil vom 7. Mai 1992, Rs C-104/91 - Colegio Oficial de Agentes de la Propriedad Immobiliaria, Ministerio fiscal/J.L. Aguirre Borrel, S.K. Newman ti.a. „Slg. 1992, I.-3003.

1696. Unteil des Gerichts Erster Instanz wom 11. Febnar 1992, Rs T 16/90 - A. Panagiotopoulou/Eu ropäilo sches Parlament -, Slg. 1992, 89, Rdmr. 44 ff. 
Teill VI

Bestimmungen der Richtlinie trotz eines solchen Ermessensspielraums, jene Unbedingtheit und Genauigkeit aufweisen können, die unerläßlich sind, um ihnen Wirkungen zuzuerkennen, auf die sich die einzelnen gegenüber einem Mitgliedstaat berufen können." 1697 Unter Berufung auf die Entscheidung Francovitch und Bonifaci ${ }^{1698}$ stellt das Gericht fest, daß ein Mitgliedstaat, der seiner Verpflichtung zur Umsetzung einer Richtlinie nicht nachgekommen ist, die Rechte, die diese zugunsten der einzelnen begründet, nicht dadurch zunichte machen kann, daß er sich auf seine Befugnis beruft, die Austibung dieser Rechte von bestimmten Einzelvoraussetzungen abhängig zu machen. Es handelt sich dabei nämlich um eine Befugnis, von der der Mitgliedstaat hätte Gebrauch machen können, wenn er die zur Durchführung der Richtlinie erforderlichen Maßßnahmen fristgemäßł erlassen hätte.

Das Gericht war bedauerlicherweise nicht gezwungen, eine endgültige Entscheidung hinsichtlich der direkten Anwendung der Richtlinienworschriften zu treffen, weil die Umsetzungsfrist im strittigen Zeitpunkt noch nicht abgelaufen war, so daß eine direkte Anwendung der Richtlinienbestimmungen schon aus diesem Grund verneint werden mußte. Dagegen hat ein italienisches Gericht die direkte Anwendung der Richtlinienbestimmungen ausdrücklich bejaht. Es bleibt abzuwarten, ob diese Auffassung durch den EuGH im Rahmen eines Vorlageverfahrens gemäß Art. 177 EGV bestätigt wird.

\section{§ 3. Vergleich zwischen dem horizontalen und dem vertikalen Aner- kennungssystem}

\section{A. EINFÜHRUNG}

Nach der Darstellung des sektoriellen und des horizontalen Ansatzes sowie der Beurteilung der Umsetzung der Richtlinie 89/48/EWG in den Mitgliedstaaten stellt sich nun die Frage, welches System den Vorzug verdient. Die Kommission hat bereits deutlich erklärt, wenig Interesse an einer Wiederaufnahme des sektoriellen Ansatzes zu haben. Die Analyse des Richtlinientexts sowie die Untersuchung hinsichtlich der Umsetzung der Richtlinie 89/48/EWG hat jedoch auch einige Schwächen des allgemeinen Anerkennungssystems offenbart. Für die Richtlinie 92/51/EWG sind noch größere Schwierigkeiten bei der Umsetzung und Anwendung zu erwarten. Bei einem Vergleich zwischen dem sektoriellen Anerkennungssystem mit dem allgemeinen System der beiden Richtlinien 89/48/EWG und 92/51/EWG können daher für beide Systeme Vor- und Nachteile genannt werden. Für eine Beurteilung einer zukünftigen Gemeinschaftspolitik auf dem Gebiet der Anerkennung von Diplomen erscheint mir eine genaue Abwägung der Vorund Nachteile beider Systeme notwendig.

1697. Unteill des Gerichts Erster Instanz vom 11. Februar 1992, Rs. T 16/90-A. Panagiotopoulou/Europäisches Parlament -, Slg. 1992, 89, Rdnr. 44.

1698. Urteil vom 19. November 1991 in den verbunderuen Rechtssachen C-6/90 und C-9/90-Francovitch und Bonifaci -, Sig. 1991, I 5357, Rdnr. 21 


\section{B. VOR- UND NACHTEILE DER BEIDEN ANERKENNUNGSSYSTEME}

Der überzeugendste und augenscheinlichste Nachteil des vertikalen Anerkennungssystems besteht in dem langwierigen Verhandlungsprozeß. Die Annahme einer Koordinierungsrichtlinie gemäß Art. 57 Abs. 2 EGV, in der zumindest die Mindestbedingungen für die Aufnahme und Ausübung eines einzelnen Berufes festgelegt werden, dauerte in der Vergangenheit unverhältnismäBig lang. Das Beispiel der Architektenrichtlinie zeigt, daß selbst ohne Koordinierungsrichtlinie der Verhandlungsverlauf bei sektoriellen Anerkennungsrichtlinien sehr mühsam sein kann. Mit dem Beitritt neuer Mitgliedstaaten ist die Beschlußfassung zu derartigen Richtlinien noch erheblich erschwert. Auch gilt für die Annahme einer solchen Richtlinie das Verfahren gemäß Art. $189 \mathrm{~b}$ EGV. Falls die Durchführung der Richtlinie eine Änderung bestehender Grundsätze der Berufsordnung hinsichtlich der Ausbildung und der Bedingungen für den Zugang zum Beruf umfaßt, muß gemäß Art. 57 Abs. 2 EGV die Richtlinie selbst einstimmig angenommen werden. Eine Einstimmigkeit dürfte in einem solchen Fall unter den fünfzehn Mitgliedstaaten nur schwer zu erzielen sein. Als weiteren Nachteil des sektoriellen Systems muß die Schwerfälligkeit genannt werden, mit denen Änderungen und Anpassungen des Richtlinientextes durchgeführt werden können. Der Koordinierungsstand wird quasi zementiert. Neuen Entwicklungen kann nur durch eine Änderungsrichtlinie Rechnung getragen werden. Eine solche Änderungsrichtlinie muß jedoch im Rat erneut nach dem Verfahren des Art. 189 b verabschiedet werden. Die Kommission ist nur selten bereit, ein so schwerfälliges Verfahren in Gang zu setzen. Der Aufwand steht häufig nicht im Verhältnis zum Mehrwert an Freizügigkeit.

Vorteil des sektoriellen Anerkennungssystems ist dagegen seine grundsätzliche Deutlichkeit. Berufe, die in den Anwendungsbereich sektorieller Anerkennungsrichtlinien fallen, genießen eine automatische Anerkennung im gesamten Bereich der Gemeinschaft. Dies bedeutet für die vom System einer sektoriellen Richtlinie erfaßte Einzelperson eine territorial ungehinderte Freizügigkeit in der Gemeinschaft. Anerkennungsverfahren sowie die Forderung nach Kompensation sind im sektoriellen System umbekannt. Der deutsche Zahnarzt kann nach Italien, nach Frankreich oder in die Niederlande wechseln ohne dabei mit einer Eignungsprüfung oder einem Anpassungslehrgang konfrontiert zu werden. Für den sehr mobilen Individualisten ist dieses System äußerst attraktiv.

Einschrănkungen für die grenzenlose Mobilität gelten allerdings bereits dann, wenn Fachspezialisationen zur Anerkennung stehen, die im Aufnahmestaat unbekannt sind oder, wenn die Anerkennung eines Drittstaatsdiploms gefordert wird. Gemäß den sektoriellen Richtlinien sind die Mitgliedstaaten nicht verpflichtet, Drittstaatsdiplome anzuerkennen ${ }^{1699}$. Die Kommission hat zwar den Versuch unternommen, die Anerkennung von Drittstaatsdiplomen auch in den Bereich der sektoriellen Richtlinien aufzunehmen. Bisher wurden derartige Bestrebungen von den Mitgliedstaaten aber kategorisch

1699. Siehe dazu die Entscheidungen Haim und Tawil-Albertini, Urteile vom 9. Februar 1994 - Rs C-319/92 - Haim/Kassenzahnäztliche Vereinigung Nordrhein -, Slg. 1994, I-425 und Rs C-154/92 - Tawil/ Albertini -, Slg. 1994, 1-451. 
abgelehnt, obwohl der Rat dementsprechende Empfehlungen an die Mitgliedstaaten gerichtet hat. Zu einer Anerkennungsverpflichtung wollten sich die Mitgliedstaaten jedoch nicht bekennen. Die Haltung der Mitgliedstaaten ist dabei nicht vollkommen unverstândlich, weil Drittstaatsausbildungen nicht von den Koordinierungsrichtlinien gedeckt sind. Die durch die Koordinierungsrichtlinien garantierte Mindestausbildung kann für Drittstaatsausbildungen nicht automatisch angenommen werden. Der Gerichtshof hat allerdings in der Rechtssache Haim ${ }^{1700}$ die Möglichkeit eröffnet, die entsprechende Berufserfahrung gemäß den in der Entscheidung Vlassopoulou ${ }^{1701}$ garantierten Prinzipien anzuerkennen. Damit ist auch für den Bereich der sektoriellen Anerkennungsrichtlinien eine gewisse Öffnung hinsichtlich der Anerkennung von Drittstaatsbefähigungen zu konstatieren. Es handelt sich dabei jedoch nicht um eine automatische Anerkennung. Der Gerichtshof hat ausdrücklich die Auffassung zurückgewiesen, daß die Anerkennung eines Drittstaatsdiploms in einem Mitgliedstaat eine Verpflichtung zur Anerkennung dieses Diploms für andere Mitgliedstaaten bewirkt ${ }^{1702}$. Hierin ist ein deutlicher Unterschied zum System der allgemeinen Anerkennungsrichtlinien zu sehen. Bei einer Revision der sektoriellen Richtlinien sollten die Erfahrungen mit der Anerkennung von Drittstaatsdiplomen gemäß dem horizontalen Anerkennungssystem analysiert werden.

Neben der Regelung für Drittstaatsdiplome kann vor ailem der unbegrenzte Anwendungsbereich als Vorteil der allgemeinen Richtlinien genannt werden. Die Definitionen beider Richtlinien sind so formuliert, daß auch bei zukünftigen Entwicklungen ihre Anwendung garantiert ist. Nur die Beilagen $C$ und D der Richtlinie 92/51/EWG werden bei berufsrechtlichen Änderungen einer Anpassung bedürfen. Einige der genannten Berufe werden in Zukunft gestrichen werden müssen, weil sie inzwischen die Ausbildungskriterien der Richtlinie $89 / 48 / \mathrm{EWG}$ erfüllen, andere Berufe werden neu in die Liste aufgenommen werden müssen. Das in der Richtlinie 92/51/EWG geregelte Verfahren garantiert jedoch, daß derartige Anpassungen möglich sind ${ }^{1203}$.

Nachteil des horizontalen Anerkennungssystems ist der verwaltungstechnische Aufwand. Obwohl Art. 3 der Richtlinie 89/48/EWG als Grundnorm Anwendung finden sollte, werden die Anerkennungsverfahren häufig durch die Forderung der Aufnahmestaaten nach Kompensationen gemäß Art. 4 der Richtlinie 89/48/EWG erschwert. Der bürokratische Aufwand der Anerkennungsverfahren gemäß dem horizontalen System ist dadurch wesentlich umfangreicher als bei den sektoriellen Richtlinien. Von diesem Nachteil besonders betroffen sind die sehr mobilen Einzelfälle. Migranten, die sich nicht nur in einem anderen Mitgliedstaat niederlassen wollen, sonderen Mehrfachniederlassungen

1700. Urteil vom 9. Februar 1994, Rs C-319/92 -Salomone Haim/Kassenärztliche Vereinigung Nordrhein -. SIg. 1994,425 .

1701. Urteil wom 7. Mai 1991, Rs C-340/89 - Irène Vlassopoulou/Ministerium für Justiz, Bundes- und Europaangelegenheiten Baden-Württemberg -, Słg. 1-1991, 2357.

1702. Siehe dazu Seite 80 ff..

1703. Die bereits seit der Veröffentlichung der Richtlinie 92/51/EWG eümal vorgenommene Anpassung der Listen zeigt, daß dieses System grundsätzlich funktioniert, Richtlinie 94/38/EG der Kommission vom 26. Juli 1994, ABl. Nr. L 217 vom 23. August 1994. 
anstreben, werden bei jeder neuen Migration auch mit einem erneuten Anerkennungsverfahren konfrontiert werden. Eine Berufung auf ein bereits abgeschlossenenes Anerkennungsverfahren in einem anderen Mitgliedstaat wird nur nach den von der Rechtsprechung entwickelten Prinzipien einen gewissen Erfolg garantieren.

Das propagierte gegenseitige Vertrauen in die Qualität der Ausbildungen anderer Mitgliedstaaten hat sich noch nicht der selben Weise entwickelt als bei den durch sektorielle Anerkennungsrichtlinien erfaßten Berufe. Dabei zeigt sich, daß die für die sektoriellen Richtlinien geschaffenen Beratenden Ausschüsse einen nicht unwesentlichen Beitrag zur Entwicklung dieses Vertrauensverhältnisses geleistet haben. Vergleichbare Institutionen sind bei den vom horizontalen Anerkennungssystem erfaßten Berufe weitgehend unbekannt. Lediglich einige der freien Berufe verfügen über europäische Standesvertretungen, die zur Vertrauensbildung beitragen können. Es wird daher einige Zeit dauern, bis die zuständigen Behörden in den Mitgliedstaaten über die notwendige Erfahrung und Information verfügen, um adäquate Einzelfallentscheidungen treffen zu können.

Als einen weiteren Nachteil des allgemeinen Anerkennungssystems muß die Regelung hinsichtlich der Dienstleistungsfreiheit genannt werden. Die Richtlinien 89/48/EWG und 92/51/EWG sind nicht nur auf Art. 57 Abs. 1 E(W)GV gestïtzt, sondern ebenso auf die Art. 49 und 66 E(W)GV. Damit sind die Richtlinien nicht nur auf die Niederlassungsfreiheit, sondern auch auf die Freizügigkeit von Arbeitnehmern und auf die gremzüberschreitende Dienstleistung anzuwenden. Insoweit weicht der Anwendungsbereich des allgemeinen Anerkennungssystems nicht von den sektoriellen Richtlinien ab. Im Unterschïed aber zu den sektoriellen Richtlinien kennt weder die Richtlinie 89/48/EWG noch die Richtlinie 92/51/EWG ein besonderes Regelungssystem für den Dienstleistungsverkehr. Der Dienstleistungswillige ist in vollem Umfang an die Verfahrensvorschriften der Richtlinie 89/48/EWG einschließlich der in Art. 4 geregelten Anpassungsinstrumente sowie an die entsprechenden Bestimmungen der Richtlinie 92/51/EWG gebunden. Auch in den Umsetzungsgesetzen der Mitgliedstaaten finden sich keine Sonderregelungen für den Dienstleistangsverkehr, die etwa ein vereinfachtes Anerkennungssystem für den grenzüberschreitenden Dienstleistungsverkehr verpflichten.

Diese Tatsache steht in krassem Gegensatz zu der Entwicklung der Rechtsprechung zur Dienstleistungsfreiheit ${ }^{1704}$. Gerade in der jüngsten Zeit hat der Gerichtshof im Falle der Dienstleistungsfreiheit an das Erfordernis nationaler Berufsregelungen strenge Anforderungen gesetzt. Es mutet daher sehr eigenartig an, daß die allgemeinen Anerkennungsrichtlinien dieser Entwicklung in keiner Weise Rechnung getragen haben. Dies bedeutet jedoch, daß die Richtlinien in Übereinstimmung mit der Rechtsprechung interpretiert werden müssen.

Die Anwendung der Richtlinien 89/48/EWG und 92/51/EWG und ihres Regelungsmechanismus ist meines Erachtens daher auch nur auf die Dienstleistungsfälle anwendbar, 


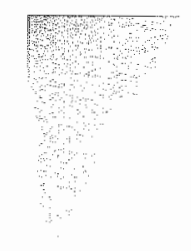

Teil VI

bei denen eine tatsächlliche Notwendigkeit für ein offizielles Anerkennungsverfahren besteht. Ansonsten muß die grenzüberschreitende Dienstleistung für Berufsangehörige ohne bürokratischen Verfahrensaufwand möglich sein. Dies ergibt sich schon aus der Tatsache, daß durch die modernen Kommunikationsmittel, eine wirksame Kontrolle des grenzüberschreitenden Dienstleistungsverkehrs von staatlicher Seite häufig unmöglich wird. Die Anwendung der Richtlinie 89/48/EWG oder der Richtlinie $92 / 51 / \mathrm{EWG}$ ist daher mur dann tatsächlich notwendig, wenn etwa der Verbraucher durch die Führung der Berufsbezeichnung des Aufnahmestaates in einer bedenklichen Weise getäuscht werden könnte. Ansonsten muß auf der Grundlage von Art. 59 EGV ein freier Dienstleistungsverkehr von Berufsangehörigen unter "home title" möglich sein, ohne daß3 von dem Berufsangehörigen die Einhaltung der Verfahrensworschriften der Richtlinie 89/48/EWG oder der Richtlinie 92/51/EWG verlangt werden kann ${ }^{1705}$. Jedenfalls sollten die Richtlinien nicht dazu benützt werden, eine bisher bestehende Praxis zu erschweren. War es bisher möglich, einen Beruf im Rahmen des grenzüberschreitenden Dienstleistungsverkehrs auszuüben, ohne mit einem bürokratischen Anerkennungsverfahren belästigt zu werden, so sollten die Anerkennungsrichtlinien nun nicht zum Anlaß genommen werden, erschwerte Bedingungen einzuführen. Bei einer solchen Handlungsweise müßte meines Erachtens ein Verstoß gegen die Stillhalteverpflichtungen der Art. 53 und 66 EGV in Verbindung mit Art. 5 EGV konstatiert werden.

Bei einer abschließenden Beurteilung beider Systeme überwiegen - trotz der genannten Kritikpunkte - zum heutigen Zeitpunkt die Vorteile des horizontalen Ansatzes. Die allgemeinen Anerkennungsrichtlinien haben bewirkt, daß ein wesentlicher Schritt zur Freizügigkeit für eine Vielzahl von Berufsangehörigen genommen ist. Damit sind nicht alle Hürden beseitigt. Auf dieser Grundlage kann das System jedoch weiter entwickelt werden. Trotz dieser generellen Einschätzung sollten die Vorteile der sektoriellen Richtlinien nicht unterschätzt werden. Sie haben den Grundstein für die Entwicklung europäischer Berufe auf der Basis einer Mindestausbildung gelegt. In der Zukunft sollte danach gestrebt werden, beide Systeme soweit möglich aufeinander zu entwickeln zu lassen. In einigen Jahren wird man genügend Erfahrung mit dem allgemeinen System gewonnen haben um zu beurteilen, für welche Berufe eine Koordinierung der Ausbildungsvorschriften gemäß Art. 57 Abs. 2 EGV erstrebenswert ist. Es sollte sich dabei ausschließlich um Berufe handeln, deren Anerkennung im Rahmen des allgemeinen Systems zu erheblichen Schwierigkeiten geführt hat. Dies kann vor allem dann angenommen werden, wenn die Mitgliedstaaten aufgrund der unterschiedlichen Ausbildungen zu Recht sehr umfassende Eignungsprüfungen oder Anpassungslehrgänge verlangt haben. In solchen Fällen sollte erwogen werden, ob eine Minimalkoordinierung gemäß Art. 57 Abs. 2 EGV dem allgemeinen Anerkennungssystem nicht vorzuziehen wäre.

1705. So wäre es meiner Ansicht nach im Streit mit dem Verhältrismäßg̈gkeitsprinzip, wenn won einem dä rischen Ingenitur im Rahmen einer grenzüberschireitenden Dienstleistung zunächst unter Berufung auf Art. 3 b) der Richtlimie 89/48/EWG der Nachweis einer zweijaihrigen Benfferfahrung mit der Begrindung verlangt würde, daB der Beruf des Ingenieurs in Däremark nicht reglementient ist. 


\section{SCHLUBFOLGERUNGEN FÜR EINE ZUKÜNFTIGE HARMONISIERUNGSPOLTTK}

Nach der bisher von der Kommission vertretenen Auffassung soll der sektorielle Weg in Zukunft nur noch in den Fällen beschritten werden, in denen die nationalen Berufsorganisationen zu einer Übereinstimmung gelangt sind, auf deren Basis die Kommission in der Lage ist, einen Richtlinienentwurf zu formulieren ${ }^{1706}$. Die Kommission hält an dieser Bedingung fest, weil sie ansonsten befürchtet, erneut mit langen Verhandlungen bis zur Verabschiedung einer sektoriellen Richtlinie belastet zu werden. Grundsâtzlich ist diese zurückhaltende Haltung der Kommission angesichts der in der Vergangenheit gemachten Erfahrungen werständlich. Es wäre jedoch bedauerlich, wenn die Kommission in dieser Frage keinen flexibleren Standpunkt einnimmt, weil meines Erachtens die Verhältnisse im Jahre 2,000 nicht mit denen der siebziger Jahre vergleichbar sind.

Von großer Bedeutung ist in diesem Zusammenhang, daß die Unterrichtsinstitutionen innerhalb der Gemeinschaft - vor allem die Universitäten - in den letzten Jahren zunehmend zusammengearbeitet haben. Die Anerkennung von ausländischen Studienresultaten gehört seit der Verabschiedung der ERASMUS-Programme ${ }^{1707}$ zum Alltag der Fakultäten. Auch unter SOCRATES wird sich dieser Prozeß fortsetzen ${ }^{1708}$. Andere Aktionsprogramme haben auf verschiedenen Ebenen die Zusammenarbeit zwischen den Bildungsinstitutionen in den Mitgliedstaaten angeregt ${ }^{1709}$. Das Vertrauen in das Ausbildungssystem anderer Mitgliedstaaten wird damit von unten aufgebaut. Dieser Prozeß wird sich in den kommenden Jahren noch intensivieren. Bildungseinrichtungen sind in zunehmendem Maße bereit, gemeinsame Curricula und Doppeldiplomierungen $\mathrm{zu}$ entwickeln. Es erscheint mir unter diesen Voraussetzungen wesentlich einfacher als in den sechziger und siebziger Jahren, zu einem Konsens zwischen den betroffenen Ministerien und Bildungseinrichtungen zu gelangen. Vor allem bei diesen schwierigen Fällen sollte die Kommission auf eine Zusammenarbeit zwischen den nationalen Bildungsinstitutionen hinwirken. An diesem Punkt berühren sich jedoch die Anerkennungspolitk und die europäische Bildungspolitik. In allen anderen Fällen, vor allem dann, wenn die Anerkennungsverfahren gemäß der Richtlinie $89 / 48 / \mathrm{EWG}$ oder der Richtlinie

1706. Der neue Richtlinienvorschlag für Rechtsanwälte kamn als Beispiel genannt werden, KOM (94) 572 emdg..

1707. Beschluß des Rates vom 15. Juni 1987 über ein gemeinschaftliches Aktionsprogramm zur Fordterung der Mobilitit yon Hochschulstudenten, AB1. 1987, L Nr. 166 und Änderungsbeschluf vom 14. Dezember 1989, ABl. 1989, Nr. L 395, 23. Siehe dazu Antoine, RMC 1988, 554; Sieveking, ZAR 1987, 99; Lichtenberg in FSS Steindorf, 1269 (1285).

1708. Beschluß Nr. 819/95/EG des Europäischen Parllaments und des Rates vom 14. Mărz 1995, ABl. Nr. 87 vom 20. April 1995, 10. Siehe auch den Beschluß vom selben Tag Nr. 818/95/EWG "Jugend fur Europa", ABl. Nr. 87 vom 20. Aprill 1995, 1.

1709. Zu den einzelnen Aktionsprogrammen siehe Weber, $27 \mathrm{ff}$; Claasen, EuR 1990, 10. Zilioli in De Witte 1989, 51 (63 ff.). Zur Entwicklung der Bildungs- und Kulturpolitik in der Gemeinschaft siehe die jährlichen Beiträge von Janssen, Jahrbuch der Europäischen Integration vor allem ab 1985: 1985, 211 . $1986 / 87,215 ; 1987 / 88,192 ; 1988 / 89,192 ; 1989 / 90,208$; Feuchthofen, RdIB 1994, 326. 
92/51/EWG in der Regel ohne Einsatz der Kompensationsinstrumente abgeschlossen werden, sollte von einer Koordinierung abgesehen werden.

Des weiteren sollte man die Niederlassung und den Dienstleistungswerkehr unter "home title" fördern. Die Berufsausübung unter "home title" gewährleistet, daß der Verbraucher, das Klientel, in ausreichender Weise gewarnt wird, mit einem ausländischen Berufsangehörigen zu tun zu haben. Andererseits bietet die einfache Niederlassung unter der Berufsbezeichnung des Herkunftsstaats dem Berufsangehörigen die Gelegenheit, sich ohme bürokratischen Aufwand - vor allem ohne den Einsatz von Kompensationsinstrumenten im Sinne der allgemeinen Anerkennungssysteme - in einem von ihm gewünschten Mitgliedstaat niederzulassen. Einige Mitgliedstaaten haben bereits entsprechende Maßnahmen ergriffen. Als positives Beispiel kann die nun bestehende Möglichkeit für ausländische Rechtsanwälte genannt werden, sich in der Bundesrepublik Deutschland ohne Eignungprïfung unter der Berufsbezeichnung des Herkunftsstaats niederzulassen. Dagegen ist die entgegengesetzte Entwicklung in Frankreich stark zu kritisieren ${ }^{1710}$. Haben die Mitgliedstaaten tatsächlich Vertrauen in die Berufsausbildung der anderen Mitgliedstaaten, so läßt sich dieses Vertrauen am deutlichsten durch eine Öffnung des innerstaatlichen Berufsmarktes manifestieren. Bestehen dagegen noch so schwerwiegende Unterschiede, daß von einer Situation des gegenseitigen Vertrauens micht die Rede sein kann, dann sollten Kommission und Mitgliedstaaten den Weg zu einer Basisharmonisierung zurückfinden. In diesem Zusammenhang ist es dann geboten auch die Harmonisierung akadlemischer Ausbildungen zu erwägen. Die gemeinschaftsrechtlichen Möglichkeiten zu einer derartigen Harmonisierungspolitik sollen im Epilog kurz angerissen werden. 


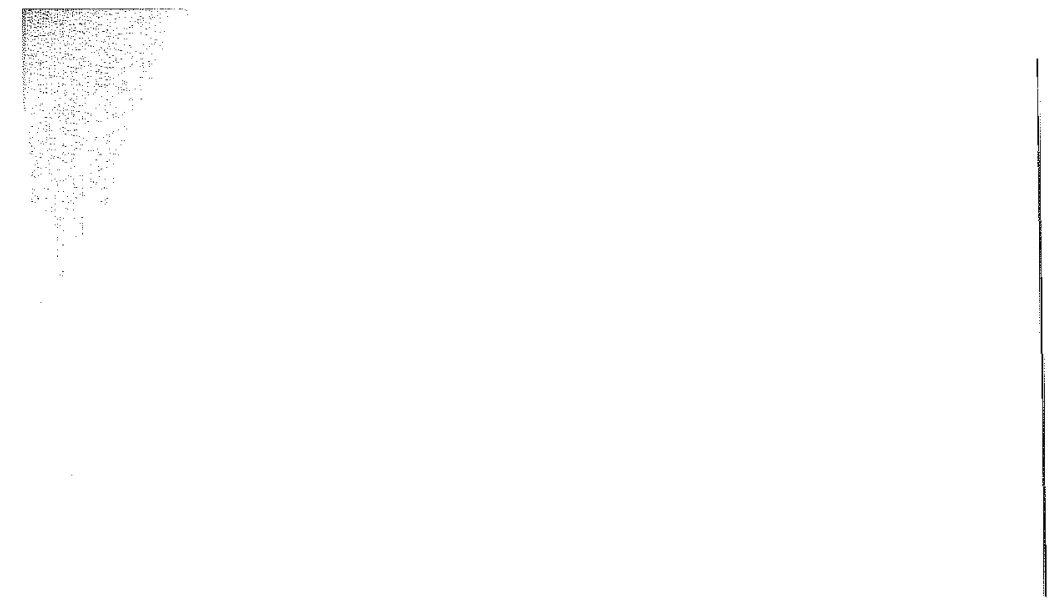

Epilog 


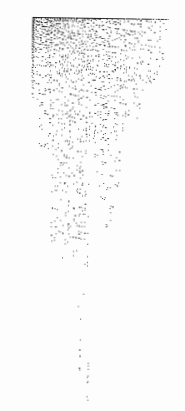

\section{Epilog}

\section{\$1. Die Mitteilung der Kommission über die akademische und beruf- liche Anerkennung}

Die Kommission hat die enge Verknüpfung zwischen der Anerkennung von Befähigungsnachweisen und einer europäischen Dimension des Bildungswesens erkannt. Im WeiBbuch der Kommission Wachstum, Wettbewerbsfähigkeit, Beschäftigung bezeichnete die Kommission unter dem Stichwort "Herausforderungen der Gegenwart und Wege ins 21 . Jahrhundert" die Ausbildung als Katalysator einer Gesellschaft im Wandel "71!. Bei der Wiederbelebung des Wachstums sowie der Wiederherstellung der Wettbewerbsfähigkeit und eines sozial annehmbaren Beschäftigungsniveaus in der Gemeinschaft werden der Bildung und Ausbildung eine entscheidende Rolle zugewiesen. Die Kommission hielt es daher für erforderlich, daß "in Weiterführung der bisher angenommenen Programme und Rechtsvorschriften sowie im Kontext der Realisienung der Leitlinien für die künftigen Programme im Bereich der allgemeinen und beruflichen Bildung das erste Ziel darin bestehen müßte, die europäissche Dimension im Bildungswesen noch weiter zu verstärken". Betont wurde dabei die Notwendigkeit der "Schaffung eines wirklichen europăischen Raums und europäischen Markts der Qualifikationen und Ausbildungen durch Verbesserungen der Transparenz und Weiterentwicklung der gegenseitigen Anerkennung der Qualifikationen und Befähigungsnachweise., 1712 In anderem Zusammeninang bezeichnete die Kommission ihr Engagement für neue Konzepte in der europäischen Bildungspolitik als "Vorarbeiten zu einer neuen Generation von Gemeinschaftsinitiativen in den Bereichen allgemeine und berufliche Bildung sowie Jugend" ${ }^{1713}$. Bereits in ihrem Grünbuch vom Dezember 1993 hat die Kommission die Bündelung verschiedener Gemeinschaftsinitiativen im Bereich des Bildungswesens angekündigt ${ }^{1714}$

1711. WeiBbuch der Kommission Wachstum, Wettbewerbsfahigkeit, Beschaftigung - Herausfordering dler Gegenwart und Wege ins 21. Jahrhundert, Luxemburg 1994, Kapitel 7, 143.

1712. Weißbuch der Karnmission Wachstum, Wettbewerbsfiahigkeit, Beschäftigung - Herausfordenung der Gegenwart und Wege ins 21. Jahrhundert, Luxemburg 1994, Kapitel 7, 149

1713. XXVII. Gesamtbericht über die Tätigkeit der Europäischen Gemeinschaften, Brüssel 1994.

1714. KOM (93) 457. Siehe ebenfalls aus 1.993 das Grübuch über die europáische Sozialpolitik KOM (93) 551 . 
Mit einer Mitteilung über die akademische und professionelle Anerkennung von Hochschul- und Fachdiplomen ${ }^{1715}$ hat die Kommission den Ansatz im Weißbuch aufgegriffen. Sie stellte darin im Dezember 1994 fest, daß es notwendig ist, die Aktionen zur beruflichen und zur akademischen Anerkennung zu koordinieren und in Einklang zu bringen. Ziel dieser Initiative soll die Schaffung von "Synergien" im Dienste eines "wahrhaftigen gemeinsamen europäischen Raums der Berufe und Ausbildungen" sein ${ }^{1716}$. Dabei sollen auch die verschiedenen Gemeinschaftsinstitutionen einbezogen sowie eine Diskussion auf allen Ebenen in den Mitgliedstaaten ausgelöst werden. Die Mitteilung wird von der Kommission als erste Reflexion über dile sogenannten Synergien zwischen den verschiedenen Arten der Anerkennung von Ausbildungstiteln bezeichnet. Dabei verweist die Kommission auf die reichhaltige Erfahrung der Gemeinschaft hinsichtlich der Anerkennung von Ausbildungsnachweisen zu beruflichen und akademischen Zwecken. Nach Ansicht der Kommission haben beide Bereiche der Anerkennung ein gemeinsames Grundziel, nämlich die Beseitigung der durch die Koexistenz von zwölf ${ }^{1717}$ unterschiedlichen Bildungssystemen verursachten Hindernisse, die der Mobilität von Berufsangehörigen und von Studenten im Wege stehen. Der Unterschied zwischen den beiden auf verschiedenen juristischen Grundlagen beruhenden Bereiche erkläre sich durch ihre unterschiedlichen Zielsetzungen: Die im wesentlichen juristischen Instrumente der Anerkennung zu beruflichen Zwecke würden der Durchsetzung eines europäischen Berufsraumes dienen, während die Maßnahmen zur Anerkennung für akademische Zwecke beitragen sollten, die europäische Dimension in der Bildung und Ausbildung zu fördern ${ }^{178}$

Grundsätzlich muß diese Initiative der Kommission begrüßt werden. Die vorliegende Studie hat deutlich den engen Zusammenhang zwischen akademischer und beruflicher Anerkennung von Befähigungsnachweisen ergeben. Erinnert sei an die Entscheidung des Europäischen Gerichtshofs in der Rechtssache Kraus, in der gerade die Berechtigung zur Führung eines akademischen Titels im Rahmen der Berufsausübung zur Debatte stand ${ }^{1719}$. Gedacht werden muß auch an die Entscheidungen des EuGHs in den Rechtssachen Thieffry und Patrick, in denen die akademische Anerkenniung zu berufsrechtlichen Folgen führte ${ }^{1720}$. In Thieffry hatte der Gerichtshof dabei festgestellt, daß es den nationalen Behörden obliegt, die notwendige Information einzuholen, die es ihnen erlaubt, zu entscheiden, ob die durch eine universitäre Instanz ausgesprochene Anerkennung über ihre akademische Gültigkeit hinaus auch als Titel einer beruflichen Befähigung gelten kann ${ }^{1721}$. Des weiteren führte der Gerichtshof in dieser Entscheidung aus, "die Tatsache, daß die nationale Gesetzgebung eine Anerkennung nur für universitäre Zwecke

1715. KOM (94) 596 endg. vom 13. Dezember 1994

1716. Mitteilung der Kommission über die akademische und professionelle Anerkennung von Hochschul- und Fachdiplomen, KOM (94) 596 endg., 2.

1717. Seit dem 1. Januar 1995 handelt es sich um fünfzehn Bildungssysteme.

1718. Mitteilung der Kommission über die akademische und professionelle Anerkennung won Hochschul-und Fachdiplomen, KOM (94) 596 endg., 1.

1719. Siehe dazu die Erörterungen Seite 77 sowie Staudenmayer, WissR 1994249 (278).

1720. Siehe dazu Seire $48 \mathrm{ff}$.

1721. Urteil vom 28. April 1977, Rs 71/76 - Thieffry -. Slg, 1977, 756, Rdnt. 24. 
vorsieht, rechtfertigt für sich alleine genommen nicht, daß man diese Äquwivalenz nicht auch als Titel einer beruflichen Befähigung anerkennt" 1722 . Diese Ausführungen des Gerichtshofs zeigen deutlich, daß bereits 1977 die klassische Zweiteilung zwischen akademischer und beruflicher Anerkennung eigentlich nicht durch die Realität gedeckt war. Auch die Diskussion um die Reglementierung des Ingenieurberufs in den Niederlanden, in Frankreich und in Dänemark hat die Problematik der Unterscheidung zwischen akademischer und professioneller Anerkennung und Reglementierung verdeutlicht ${ }^{1723}$.

Die Entwicklung der letzten Jahre mit einer zunehmenden Europäisierung der Bildungspolitik hat die Interaktion beider Anerkennungsformen noch stärker in den Vordergrund gerückt ${ }^{1724}$. Die Anerkennung der beruflichen Qualifikationen gemäß den Anerkennungssystemen der allgemeinen Richtlinien 89/48/EWG und 92/51/EWG kann in zunehmendem Maße nicht mehr losgelöst von akademischen Anerkennungen im Rahmen der verschiedenen Austauschprogramme betrachtet werden ${ }^{125}$. Eine Aktion auf Gemeinschaftsebene, in der die Berührungspunkte beider Bereiche herausgearbeitet und weiter verstärkt werden sollen, ist vom Ansatz her daher zu befürworten.

Trotz dieser prinzipiell positiven Beurteilung verdient die vorliegende Mitteilung der Kommission aber Kritik. Zunächst sind Sprache und Stil der Mitteilung zu beanstanden. Die deutsche Fassung der Mitteilung ist nahezu unverständlich; auch andere sprachliche Fassungen zeichnen sich nicht durch besondere Deutlichkeit aus. Neben dieser linguistischen Kritik an der Mitteilung sind jedoch auch Bedenken gegen die inhaltliche Ausgestaltung vorzubringen. Eine zentrale Rolle in der Mitteilung nehmen die sogenannten "Synergien" ein, die zwischen den verschiedenen Arten der Anerkennung von Ausbildungstiteln geschaffen werden sollen.

1722. Urteil yom 28. April 1977, Rs. 71/76 - Thieffry -, Slg. 1977, 756, Rdnr. 25.

1723. Siehe dazu Seite $351 \mathrm{f}$.

1724. Siehe zu dieser Entwicklung die verschiedenen Beitrảge in De Witte 1989 sowie De Witte in Bieber/Ress 1987, 261; De Witte, Jura Falconis 1990, 535; De Witte in Pertek 1992, 73; Oppermann 1987; Biever 1987; Cerych, European Journal of Education 1989, 321; Cludius, Eur. Integration 1988, 26: Fahle 1989; Issac in Philip, 11; Lenz, in Magiera 1990, 183; Lichtenberg, FS Steindorff, 1269; Janssen stellt die Entwicklung der europäischen Bildungspalitik in jährlichen Beiträgen im JbEl dar. Hermans, School \& Wel 1992, 34; Hochbaum 1986, 206; Konow, RDJB 1989, 118; Schneider in Bleckmann, 783; Schröder 1990; Sieveking, ZAR 1987, 99; Sieveking, Kritische Vierteljahreszeitschrift für Gesetzgebung und Rechtswissenschaft 1990, 344, Ausfuhrlich auch die Studie von Verbrugren 1992: Curall in GTE-Kommentar zu Art. 128; Curall, RdJB 1992, 139; Schleicher 1993 Schleicher/Bos. Sehr früh bereits Janne 1973; Antoine, RMC 1976, 543; Hiemaier, 81; Maass 1978; Mickel 1978; Neave 1984; Nicolaysen RdJB 1980, 406; Rübsaamen, RdJB 1978, 238; Schnidt-Wenzel 1980. Das Verhältris zwischen einer Europäischen Bildungspolitik und dem Subsidiaritätsprinzip wird in verschiedenen Beiträgen in Hrbek 1994 erörtert. Zur Rechtsprechung des Gerichtshofs im Bereich des Bildungswesens siehe auch Lenz, EA 1989, 125; Gilliams, RW 1989-90, 494; Mead, Migrantenrecht 1988, 260; Oppermann 1988; Wittkowski 1991.

1725. Zur akademischen Anerkennung siehe Dalichow in Pertek, EIPA 1992, 91; Cox. 


$$
\text { Epilog }
$$

Es werden dabei vier Aktionsschwerpunkte aufgezählt, worin sich die Synergien billden sollen ${ }^{\sharp 726}$ : Die Kommilssion nennt ausdrücklich den Austausch von Informationen zu den verschiedenen Bildungssystemen, die Schaffung von Hochschul- und Berufsverbandnetzen, die Anpassung der Ausbildungsgänge sowie schließlich die Qualitätsbewertung der Ausbildungssysteme. Warum gerade diese Bereiche ausgewähllt worden sind, wird nicht näher verdeutlicht. Jedoch ergibt sich aus der Wahl und Formulierung dieser Aktionspunkte, daß die Kommission den Anwendungsbereich des vorgelegten Dokuments auf den Hochschul- und Fachhochschulbereich beschränken will. Die Bedürfnisse von Arbeitnehmern mit Berufsabschluß oder Fachdiplom werden dagegen nicht angesprochen. Unberücksichtigt bleibt anscheinend auch die Rechtsprechung des Europäischen Gerichtshofs. An keiner Stelle des Dokuments wird auf die einschlägigen Entscheidungen hingewiesen. Auch werden keine Konsequenzen aus dieser Rechtsprechung gezogen. Die won CEDEFOP geleistete Arbeit wird ebensowenig in das Maßnahmenpaket einbezogen wie die Zusammenhänge zwischen den gemeinschaftspolitischen Maßnahmen und vergleichbaren Initiativen des Europarats und der UNESCO hergestellt werden. Dabei werdient der Mangel an Koordination auf diesem Gebiet eine deutliche Kritik.

Kennzeichnend für die Mitteilung ist ferner die Undeutlichkeit, mit der die Kommission die Gemeinschaftskompetenzen in diesem Bereich behandelt. In ihren Schlußfolgenungen bestätigt die Kommission zwar die weitere Unterstützung der bereits ergriffenen Initiativen und kündigt an, weitere Maßnahmen ihrer Kompetenz entsprechend zu ergreifen $^{1727}$. An keiner Stelle in der Mitteilung wird von der Kommission jedoch dargestellt, wie die Kompetenzen zwischen Gemeinschaft und den Mitgliedstaaten im Bereich der Berufs- und Ausbildungspolitik seit dem Inkrafttreten des Vertrages über die Europäische Union ${ }^{1728}$ genau verteilt sind. Vielmehr wird allgemein auf die Artikel 126, 127 EGV und 57 EGV' sowie auf die Interaktion beider Bereiche verwiesen. Dabei wäre eine genauere Abgrenzung dieser Handlungsermächtigungen notwendig, um den Umfang und die Tragfähigkeit der vorgenommenen Aktion auf der Gemeinschaftsebene beurteillen zu kömnen.

Die Kommission erwartete bis zum 1. Juli 1995 Reaktionen der Institutionen der Gemeinschaft sowie angesprochener Personen und Einrichtungen in den Mitgliedstaaten. In den Mitgliedstaaten wurde zur Koordination dieser Reaktionen jeweils ein Koordinator ernannt. Es ist zu erwarten, daß die Reaktionen der Mitgliedstaaten nicht nur positiv sein werden, Eine besonders kritische Haltung wird vermutlich von den Staaten eingenommen werden, in denen die bildungsrechtliche Kompetenz verfassungsrechtlich nicht beim Bund bzw. dem föderalen Staat liegt. Dies gilt insbesondere für die Bundesrepublik Deutschland, aber auch in Belgien und Spanien sind die Gemeinschaften und Provinzen mit

1726. Mitteilung der Kommission über die akademische und professionelle Anerkennung von Hochsclyul- und Fachdiplomer. KOM (94) 596 endg., 2 und $12 \mathrm{f}$.

1727. Mittejlung der Konmission über die akademische und professionelle Anerkennung von Hochschul| und Fachdiplomen. KOM (94) 596 endg., 16.

1728. 1. November 1993. 
billungsrechtlichen Kompetenzen betraut ${ }^{1729}$. Gerade die Länder und Gemeinschaften mißtrauen jedoch europäischen Initiativen auf diesem Gebiet, weil sie eine eigene Kompetenzeinbuße befürchten. So haben sich die deutschen Bundesländer mit Vehemenz

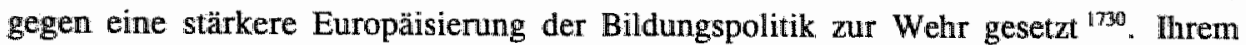
Einfluß ist weitgehend die Neufassung des Maastrichter Vertrages im Bildungsbereich sowie die Verankerung des Subsidiaritätsprinzips zu verdanken ${ }^{1731}$.

\section{\$ 2. Die Kompetenz der EG im Bereich der allgemeinen und berufli- chen Bildung}

Mit dem Unionsvertrag wurde in den Zielkatalog des Art. 3 EGV unter Buchstabe p die Bestimmung aufgenommen, daß die Gemeinschaft einen Beitrag zu einer qualitativ hochstehenden allgemeinen und beruflichen Bildung leistet. Auch wurde der bisherige Titel III "Sozialpolitik" durch einen nun als Titel VIII nummerierten Teil mit der Überschrift "Sozialpolitk, allgemeine und berufliche Bildung und Jugend" ausgetauscht. Der alte Art. 128 EWGV wurde gestrichen und durch zwei neue Artikel ersetzt. Dabei handelt es sich um den Art. 126 EGV mit der Überschrift "Beitrag der Gemeinschaft; Ziele", sowie dem Art. $127 \mathrm{EGV}$, in dem die berufliche Bildung Erwähnung findet. Aus dieser Formulierung in Art. 127 EGV wird abgeleitet, daß der Ausdruck Bildung in Art. 126 EGV mit dem Begriff "allgemeine Bildung" gleichzusetzen ist ${ }^{1732}$. Neben diesen neu formulierten Kompetenzen gemäß der Artikel 126 und 127 EGV verweisen auch die Artikel 41, 118 und 123 EGV auf die berufliche Bildung bzw. Art. 57 Abs. 2 EGV auf die Ausbildung zum Beruf. Bei der Frage des Verhältnisses der Art. 126, 127 EGV zu den bisher anwendbaren Kompetenztiteln ist zunächst der inhaltliche Anwendungsbereich dieser Normen zu klären.

\section{A. DER ANWENDUNGSBEREICH DES ART. 126 EGV}

Gemä/3 Art. 126 Abs. 1 EGV trägt die Gemeinschaft zur Entwicklung einer quantitativ hochstehenden Bildung dadurch bei, daß sie die Zusammenarbeit zwischen den Mitgliedstaaten fördert und wenm nötig unterstützt und ergänzt. Dabei ist die Gemeinschaft verpflichtet die Verantwortung der Mitgliedstaaten für die Lehrinhalte und die Gestaltung des Bildungswesens ebenso wie die Vielfalt der Kulturen und Sprachen strikt zu beachten. In Art. 126 Abs. 2 EGV wird das Tätigwerden der Gemeinschaft mit einem bestimmten Zielkatalog verknüpft. Genannt werden ausdrücklich die Entwicklung einer europäischen

1729. Zur Rolle der Regionen in der Europäischen Gemeinschaf,, siehe Engel in Borkenhagen/Bruns-Klöss, 183 sowie Borchmann/Kaiser in Borkenhagen/Bruns-Klŏss, 36 (43).

1730. Siehe dazu bereïts die Erklärung der Ministerpräsidenten der Bundesländer vom Oktober 1987 in Mânchen, abgedruckt in Borkhagen/Bruns-Klöss, $233 \mathrm{f}$. . Sieh dazu auch Eiselstein, NVwZ 1989, 323; Engler in Battis 1989, 63; Hochbaum, Bay VB1. 1987, 481; Hochbaum in De Witte 1989, 145. Zu den die Ratifizierung der Einheitlichen Europäischen Akte in der Bundesrepublik (Gesetz zur Einheitlichen Europäischen Akte - EEAG - vom 16. Dezember 1986) begleitenden Kontroversen siehe die verschiedenen Beiträge in Hrbek/Thaysen 1986.

1731. Bergreen/Hochbaum in Borkhagen/Bruns-Klöss, 47 (50) mit weiteren Nachweissen.

1732. Dohms, RdJB 1992, 451 (452); Bergreen/Hochbaum, in: Borkliagen u.a., 47 (54). 
Dimension im Bildungswesen, insbesondere durch Erlermen und Verbreitung der Sprachen der Mitgliedstaaten, die Förderung der Mobilität von Lernenden und Lehrenden. Hierzu wird auch die Förderung der akademischen Anerkennung der Diplome und Studienzeiten gerechnet. Des weiteren werden die Förderung der Zusammenarbeit zwischen den Bildungseinrichtungen, der Ausbau des Informations- und Erfahrungsaustausches im Bildungsbereich, die Förderung des Ausbaus des Jugendaustausches sowie die Förderung. der Entwicklung der Fernlehre aufgezählt. Nach Dohms ist die Aufzählung dieser einzelnen Handlungsziele als abschlieBender Katalog zu betrachten ${ }^{1733}$. Er begründet diese Auffassung damit, daß der Wortlaut keinen Hinweis auf einen bloß beispielhaften Charakter gibt. In Absatz 3 der Bestimmung wird daneben auch die bildungspolitische Zusammenarbeit mit Drittstaaten und internationalen Organisationen in den Kompetenzbereich der Gemeinschaft gezogen. Dabei wird keine klare Abgrenzung zwischen dem Zuständigkeitsbereich der Gemeinschaft und denen der Mitgliedstaaten gezogen. Art. 126 Abs. 4 EGV nennt zwei Handlungsinstrumente. In der praktischen Anwendung dürfte dabei das an zweiter Stelle genannte Handlungsinstrument der Empfehlung nicht problematisch sein, weil diese gemäß Art. 189 Abs, 5 EGV unverbindlich ist. Interessanter dagegen dürften die gemäß dem Verfahren des Art. 189 b EGV zu erlassenden Fördermaßnahmen sein. Der Begriff "Fördermaßnahme" dürfte dabei im Gegensatz zum ansonsten sämtliche Rechtsakte des Art. 189 EGV umfassenden Begriff der "Maßnahme" enger zu verstehen sein ${ }^{1734}$. Dies ergibt sich bereits daraus, daß in Art. 127 Abs. 4 EGV ausdrücklich Maßnahmen zur Verwirklichung des im Absatz 2 aufgelisteten Zielkatalogs zur Verfügung gestellt werden. Diese terminologische Unterscheidung muß auch materiellrechtliche Konsequenzen haben. Hieraus folgt, daß sich die in Art. 126 Abs. 4 EGV genannten Fördermaßnahmen vor allem auf die Schaffung von Anreizen, insbesondere finanzieller Art, beschränken müssen. Des weiteren stehen die gemäß dem Verfahren des Art. 189 b EGV und nach Anhörung des Wirtschafts- und Sozialausschusses und des Ausschusses der Regionen erlassenen Fördermaßnahmen unter einem ausdrücklichen Harmonisierungsverbot der Rechts- und Verwaltungsvorschriften der Mitgliedsstaaten. Es lassen sich jedoch durchaus rechtsverbindliche Fördermaßnahmen vorstellen, die keinen harmonisierenden Effekt haben. Berggreen/Hochbaum nennen Z.B. eine Komplementärfinanzierungsverpflichtung der Mitgliedstaaten zu Gemeinschaftsprogrammen in Form einer Entscheidung des Rates ${ }^{173.5}$.

\section{B. DER ANWENDUNGSBEREICH DES ART. 127 EGV}

Gemäß Art. 127 Abs. 1 EGV führt die Gemeinschaft eine Politik der beruflichen Bildung. durch, die die Maßnahmen der Mitgliedstaaten unter strikter Beachtung der Verantwortung der Mitgliedstaaten für Inhalt und Gestaltung der beruflichen Bildung unterstiitzt und ergänzt. Wie Art. 126 EGV so enthält auch der 2. Absatz des Art. 127 EGV einen Zielkatalog. Dieser Katalog muß nach seiner Formulierung ebenfalls als abschließ3end eingestuft werden. Allerdings enthalten die verschiedenen Zielsetzungen so viele unbe-

1733. Dohums, RdIB 1992, 451 (462).

1734. Dittmann/Fehrembacher, RdIB 1992, 478 (484).

1735. Berggreen/Hochbatum, in Borkhagen u.a., 56 . 
stimmte Rechtsbegriffe, daßs viele Auslegungsmöglichkeiten gegeben sind ${ }^{1736}$. Im Gegensatz zu Art. 126 EGV ist bei der beruflichen Bildung in Art. 127 Abs. 4 EGV von Maßnahmen als Handlungsinstrumenten die Rede. Dies bedeutet, daß auch andere $\mathrm{Maß}$ nahmen i.S. des Art. 189 EGV als Fördermaßnahmen zur Verfügung stehen. Allerdings gilt gemäß Art. 127 Abs. 4 EGV für diese Maßnahmen ebenfalls ein Harmonisierungsverbot hinsichtlich der Rechts- und Verwaltungsvorschriften der Mitgliedstaaten.

\section{DAS VERHÄLTNIS DER ART. 126, 127 EGV ZU DEN BISHERIGEN KOMPETENZEN}

Hinsichtlich der ausdrücklichen anderweitigen Kompetenzen im EG-Vertrag gilt, daß sie ungeachtet unterschiedlicher Instrumente und Verfahren ihre volle Geltung behalten. Dies ergibt sich unter anderem auch daraus, daß gemäß Art. B 5. Spiegelstrich des Unionsvertrages die volle Wahrung des gemeinschaftlichen Besitzstandes von den Vertragsparteien ausdrücklich gewollt war. Zum gemeinsamen Besitzstand zählt das gesante Gemeinschaftsrecht, d.h. das Primär- und Sekundärrecht einschließlich der durch den EuGH gegebenen Interpretation. Dies hat auch Konsequenzen für das Verhältnis zwischen Art. 126, 127 EGV und Art. 57 EGV. Soweit gemäß Art. 57 EGV eine Rechtsangleichung betrieben werden konnte, ist dies auch in Zukunft möglich und zwar unabhängig davon, ob die Ziele jener Kompetenztitel ganz oder teilweise auch in den Zielen der Art. 126, 127 EGV enthallen sind ${ }^{1737}$. Dies bedeutet jedoch, daß die Kommission in Zukunft ihre Maßnahmen nicht ausschließlich auf die beschränkten Kompetenzen der Art. 126, $127 \mathrm{EGV}$ zu basieren hat, vielmehr gegebenenfalls eine Koordinierung gemäß Art. 57 Abs. 2 EGV in Erwägung ziehen muß. Wie bereits oben dargestellt ${ }^{1738}$, hat der Gerichtshof in der Rechtssache Kraus die Anwendung der Freizuigigkeitsbestimmungen auch für Fälle bejaht, in denen die Anerkennung eines akadlemischen Titels zur Förderung der beruffichen Karriere beiträgt. Diese Verbindung zwischen beruflichem Fortkommen und akademischer Bildung eröffnet eine Möglichkeit zur Koordinierung der Ausbildungen auf der Grundlage des Art. 57 EGV ungeachtet des Harmonisierungsverbots gemäß Art. 126 Abs. 4 EGV.

\section{SCHLUSSFOLGERUNG ZUR KOMPETENZABGRENZUNG}

Die Kommission sollte bei der Schaffung eines europäischen Berufs- und Ausbildungsraumes diesen Kompetenzbereich gemäß Art. 57 EGV nicht unbeachtet lassen. Hierbei wird die Kommission mit Sicherheit auf Schwierigkeiten bei den deutschen Bundesländern stoßen, die wesentlich an der Einfügung des Harmonisierungsverbots in die Art.

1736. So läBtz.B. die Formulierung "Verbessenng der beruftichen Erstausbildung und Weiterbildung" keine inhalt iche Einschränkung dergemeinschaftlichen Berufsbildungspolitikzu. Dazu Bergreen/Hochbaum, in: Borkhagen u.a., 57.

1737. So die meines Erachtens zutreffende Auslegung des Harmonisierungsverbots von Dittmann/Fehrenbacher, RdJB 1992, 478 (488/489).

1738. Siehe dazu die Ausführungen Seite 108 ff.. 
126, 127 EGV beteiligt waren ${ }^{1739}$ und die auch für die Zukunft in diesem Bereich eine anderweitige Entwicklung strikt ablehnen. Nach Auffassung der Kultusminister der Bundesländer zur EU-Regierungskonferenz 1996 sollte die Europäische Gemeinschaft vielmehr im Bildungsbereich lediglich befugt sein, Fördermaßnahmen auf den Gebieten des Austausches und der Zusammenarbeit in der allgemeinen Bildung sowie Fördermaßnahmen in der beruflichen Ausbildung zu gewähren. Die ausschließliche Verantwortung der Mitgliedstaaten für Inhalt, Strukturen und Organisationsformen des Bildungswesens: sei dagegen strikt zu wahren ${ }^{1740}$. Der zu erwartende Widerstand der Bundesländer sollte die Kommission jedoch nicht prinzipiell daran hindern, eine größere Interaktion $z$ wischen den verschiedenen Zielen der Anerkennung der Diplome zu bewirken. Für die tatsächliche Entwicklung eines Europas der Bürger ist dieser Bereich von zu großer Bedeutung, als daß man einer Provinzialisierung der Bildungspolitk weiter das Wort reden sollte. Die ohne jeden Zweifel wünschenswerte Erhaltung einer kulturellen Vielfalt innerhalb Eturopas, darf nicht als Argument benützt werden, notwendige Maßnahmen zur Fördlerung der Mobilitẩt von Berufsangehörigen und Lernenden zu verhindern. Dabei sollte nicht übersehen werden daß auch der Europarat und die UNESCO (Region Europa) vergleichbare Initiativen ergriffen haben. Beide Organisationen sind dazu entschlossen, eine gemeinsame Konvention über die akademische Anerkennung und Mobilităt auszuarbeiten, die ihre bereits bestehenden Konventionen ersetzen soll. Eine Koordinierung dieser Initiative mit den auf Gemeinschaftsebene genommenen Maßnahmen ist im Interesse aller europäischen Bürger, die auf einem europäischen Arbeitsmarkt in seiner Gesamtheit tätig werden wollen.

\section{\$ 3. Ein Ausblick in die Zukunft}

Im Prolog wurde auf den Wandel eingegangen, den die freien Berufe und der öffentliche Dienst aufgrund der zunehmenden europäischen Integration durchlaufen. In einigen Mitgliedstaaten wurden aufgrund dieser Entwicklung die Ausbildungssysteme einer grïndlichen Revision unterworfen, in anderen Mitgliedstaaten ist dieser Prozeß noch nicht abgeschlossen oder steht gerade an seinem Anfang. Festgestellt werden kann jedoch bereits heute, daß - zumindest im Hochschulbereich - der allgemeine Trend zu einer stärkeren Internationalisierung der Ausbildung nicht mehr weggedacht werden kann. War es in den sechziger und siebziger Jahren nur wenigen Studenten gegönnt, ein Studium im Ausland zu bestreiten, so gehört heute der Auslandsaufenthalt als ERASMUS-Student oder im Rahmen eines anderen Austauschprogramms zum studentischen Alltag. Fakultäten in ganz Europa sind mehr und mehr gezwungen, ihre Ausbildungsprogramme diesem

1739. Siehe dazu Bergreen/Hochbaum in Borkhagen/Bnuns-Kloss u.a., 47.; Konow, Rd.JB 1992, 428; Zumschlinge, Die Verwaltung 1989, 217; Schröder 1990. Zu der Entwicklung der Landerbeteiligung siehe Clostermeyer in Borkhagen/Bruns.KIöss, 171. Zum Verhältais der Bundestander zur Europäischen Gemeinschaft siehe: Schröder, JöR NF 1986, 83; Zur Hausen, EuR 1987, 322; Jooss/Scheuerle, EuR 1989. 226; Schütz, Der Staat 1989, 206; von Welck 1990; Streinz in Heckmann/Meflersclwmidt, 15; sowie die Beiträge in Magiem/Menten 1988; Hrbek/Thaysen 1986 sowie Hrbek 1994.

1740. Vorläufige Position der Kultusministerkonferenz zur Vorbereitung der EU-Regienungskonferenz 1996 und zum Bericht der Europaministerkonferenz; Beschluß der KMK vom 31. März 1995. 
neuen Publikum anzupassen. In den Niederlanden wird es z.B. in zunehmendem Maße üblich, den Unterricht auf Englisch zu erteilen, so daß ERASMUS-Studenten aus den verschiedenen Mitgliedstaaten an diesen Veranstaltungen teilnehmen können. Ähnliche Entwicklungen kann man auch in anderen Mitgliedstaaten konstatieren. Auch die Ernennung von ausländischen Wissenschaftlern an den Universitäten hat in den letzten Jahren sprunghaft zugenommen. Selbst so national orientierte Fachbereiche wie die rechtswissenschaftlichen Fakultäten öffnen in zunehmendem Maße ihre Pforten. Diese personalpolitischen Entscheidungen haben auch Einfluß auf den Inhalt der Lehrstoffe. In den juristischen Fakultäten beginnt die Rechtsvergleichung, die in den Jahren vor ERASMUS ein eher esoterischen Platz eingenommen hat, nun in den Mittelpunkt des allgemeinen Interesses vorzurücken. Es beginnt zum guten Ton zu gehören, auch Grundlagenfächer mit einer rechtsvergleichenden bzw. europäischen Schleife zu verzieren. Die Europäisierung der Rechtswissenschaft, die Entwicklung eines neuen "ius commune" wird an vielen Stelle besungen ${ }^{1741}$. Auch bei anderen Fakultäten sind vergleichbare Tendenzen festzustellen ${ }^{1742}$.

Zwar sind die häufig etwas romantisierten Zustände seit dem ausgehenden Mittelalter bis zu Beginn des 19. Jahrhunderts, einer Epoche in der Professoren und Studenten sich auf lateinisch unterhielten und nacheinander die Universitäten von Bologna, Heidelberg. Paris und Oxford besuchten, um dort zu studieren und zu lehren, noch nicht vollkommen wi ieder hergestellt - es gibt noch immer nationale Studienordmungen, die einen derartigen Studienverlauf erschweren; auch tragen die nationalen Pensions- und Sozialversicherungsregelungen nicht gerade zur Mobilität der Hochschulangehörigen bei - doch beginnen wir uns, nach mehr als einem Jahrhundert national orientierter Wissenschaft ${ }^{1743}$, einer vergleichbaren Situation langsam wieder anzunähern. Diese Veränderung ist zum überwiegenden Teil den bildungspolitischen Initiativen der europäischen Gemeinschaft zu verdanken. Mit diesen Maßnahmen hat die Gemeinschaft - mehr als in vielen anderen Bereichen - eine fühlbaren Erfolg im Hinblick auf die Entwicklung eines Europas der Bürger erzielt. Dieser Erfolg sollte in Zukunft noch weiter ausgebaut werden. Die Entwicklung europäischer Netzwerke zwischen verschiedenen Universitäten wird von der Gemeinschaft allgemein stark gefördert. Diese Zusammenarbeitsinitiativen tragen wiederum zu einem besseren gegenseitigen Verständis zwischen den einzelnen beteiligten Bildungseinrichtungen bei. Der Austausch von Wissenschaftlern und Studenten wird in Zukunft von großer Bedeutung dafür sein, daß sich das von der Richtlinie 89/48/EWG und dem horizontalen Harmonisierungsansatz propagierte gegenseitige Vertrauen in die akademische und berufliche Ausbildung anderer Mitgliedstaaten tatsảchlich entwickelt.

174t. Una in Cappelletti, 31; Coing 1989; Remien, JZ 1992, 277 sowie die verschiedtenen Beiträge in De Witte/ Forder.

1742. So läßit sich vor allem bei den Betriebs- und Volkswintschaftlichen Fakultăten eine vergleichbare Entwicklung feststellen.

1743. Daniber de Groot 1989,15 mit Hinweis auf von Ihering, Geist des romischen Rechts, Teil 1, der sich in deuthichen Worten darüher beklagt hatte, daß die Rechtswissenschaft zur Landesjurisprudenz degrain deutichen $Z$ wistand als eine demütigende und unwürdige Form von Wissenschaft. 
Die Fortführung der Austauschprogramme, die Erweiterung dieser Programme auf alle Ausbildungsbereiche ist dabei von grundlegender Bedeutung. Die neuen gemeinschaftliche Aktionsprogramme SOCRATES ${ }^{174}$ und LEONARDO $^{1745}$ müssen dazu den notwendigen Beitrag leisten.

Neben den bisher genommenen und genannten Initiativen sollte die Kommission in einem weiteren Bereich durch Austauschprogramme zu einer besseren Verständigung beitragen. Es handelt sich dabei um den öffentlichen Dienst. Wie an mehreren Stellen im Verllauf dieser Studie dargestellt, wird der öfentliche Dienst in zunehmenden Maße vom europäischen Einigungsprozeß erfaßt. Die Kenntnis über Organisation und Struktur der anderen öffentlichen Dienste ist bisher in den Mitgliedstaaten jedoch nur rudimentär entwickellt. Rabe nannte einmal die europäische Gesetzgebung "ein unbekanntes. Wesen". Diese Aussage gilt noch vielmehr für die Kenntnis hinsichtlich der genauen Verwaltungs- und Ausbildungsstrukturen in den anderen Mitgliedstaaten. Da eine gemeinschaftskonforme Anwendung der Anerkennungsrichtlinien durch die zuständigen Behörden woraussetzt, daß diese ein Vertrauen in die verschiedenen Ausbildungssysteme und in das Funktionieren der Behörden im jeweils anderen Mitgliedstaat entwickeln, wäre es notwendig ähnlich wie für den Hochschulbereich - ein Austauschprogramm zu entwickeln, in dessen Rahmen sich Strukturen einer Zusanmenarbeit auf Behördenebene bilden könnten. Diese Zusammenarbeit müßte vor allem zwischen den Erziehungs- und Bildungsministerien in den Mitgliedstaaten gefördert werden. Ein solches Austauschprogramm könnte dazu führen, das die zuständigen Behörden mehr Verständnis für die Unterschiedlichkeit der Ausbildungssysteme entwickeln, wodurch letztlich die Grundlage für eine Vertrauensbildung geschaffen würde.

Von vergleichbarer Bedeutung für ein ordnungsgemäßes Funktionieren des allgemeinen Anerkennungssystems wäre es, die genaue Information über die Reglementierung und über die jeweiligen akademischen und beruflichen Ausbildungsvorausetzungen von allen durch die Richtlinien 89/48/EWG und 92/51/EWG erfaßten Berufe zu sammeln. Nur wenn diese Information für alle zur Entscheidung befugten Behörden in zugänglicher Weise zur Verfügung steht, kann eine ordnungsgemäße Anwendung der Richtlinien garantiert werden. In ihrer Mitteilung zur akademischen und professionellen Anerkennung hat die Kommission den dringenden Bedarf an Information über die Bildungssysteme der Mitgliedstaaten selbst angesprochen. Dieser allgemeine Aufruf nach einem Informationsaustausch bedarf jedoch dringend einer Konkretisierung hinsichtlich der einzelnen reglementierten Berufe und beruflichen Tätigkeiten. Zwar gibt es in den Mitgliedstaaten vereinzelt derartige Studien ${ }^{1746}$, eine systematische Erfassung aller europäischen reglementierten Berufe fehlt jedoch noch gänzlich. Es wäre daher von entscheidender Bedeu-

1744. Beschluß 819/95 des Rates und des Europäischen Parlaments vom 14. März 1995, ABl. Nr. L 87 wom 20. April 1995, 10.

1745. Beschluß 94/819/EG des Rates vom 6. Dezember 1994, ABI. Nr. 340 vom 29. Dezember 1994, 8.

1746. Siehe etwa die beinahe jährlich erscheinende Veröffentlichung "Britisch Qualifications", ein match eigener Aussage "complete guide to educational, technical, professional and academic qualifications in Britain". Vergleiche anch die Studie des Instituts für Freie Berufe aus dem Jahr 1993. 
Epilog:

tung für ein ordnungsgemäßes Funktionieren des horizontalen Anerkennungssystems, wenn die Kommission sich zu einer derartigen systematischen Erfassung aller reglementierten Berufe und Berufstätigkeiten entschließen könnte.

Gelingt es der Kommission, die vorgenommenen Maßnahmen in Zusammenarbeit mit den Mitgliedstaaten durchzuführen, so wird das nächste Jahrtausend mit einer wirklichen Freizügigkeit für die europäischen Bürger beginnen. 
Samenvatting

\section{De erkenning van diploma's in de Europese Gemeenschap}

Eén van de belangrijkste doelstellingen van het EG-Verdrag is het scheppen van een gemeenschappelijke markt voor alle economische activiteiten. Deze doelstelling heeft ook consequenties voor beroepsactiviteiten. Nationale regels die ten gevolge hebben, dat personen belemmerd worden in het aambieden van hun professionele diensten in een andere Lid-Staat of het zich daar vestigen bemoeilijken, moeten worden weggenomen. Een van de hinderpalen bij de realisatie van een dergelijk vrij personenverkeer bleek te liggen in het vereiste van nationale diploma's enerzijds en de uiteenlopende waardering wan buitenlandse diploma's anderzijds. De mobiliteitsbeperking veroorzaakt door het vereiste van een nationaal diploma kan evenzeer een belemmering voor het tot stand komen van een interne markt opleveren als verschillende veiligheidsvoorschriften voor technische produkten.

Vele wan dergelijke belemmeringen zijn weggenomen door interpretatie van Europeesrechtelijke voorschriften door het Europese Hof van Justitie. Dit geldt in het bijzonder voor belemmeringen die gebaseerd waren op nationaliteit. Ook nationale vereisten betreffende kwalificaties en diploma's kunnen echter onderdamen van andere Lid-Statem belemmeren in de uitoefening van hun rechten van vestiging en bet aanbieden van diensten zoals gegarandeerd door de artt. 52 en 59 van het EG-Verdrag zonder, dat echter sprake is van discriminatie op grond van nationaliteit. In deel II van dit boek wordt de jurisprudentie van het Europese Hof van Justitie ten aanzien van het vrij verkeer van beroepsbeoefenaren in chronologische volgorde geanalyseerd. Speciale aandacht wordt besteed aan de vraag, of art. 52 van het EG-Verdrag slechts betrekking heeft op discriminerende maatregelen, of dat kan worden gesteld, dat art. 52 alle beperkingen verbiedt, tenzij deze objectief worden gerechtvaardigd door het algemeen belang. Andere onderwerpen die in deel II aan de orde komen zijn de ontwikkelingen in de jurisprudentie met betrekking tot "omgekeerde discriminatie" en met betrekking tot de erkenning van in derde landen verworven diploma"s. 
Ten aanzien van de vrijheid van dienstverlening heeft het Hof van Justitie al sinds $1974^{1747}$ een rechtvaardigingstoets ontwikkeld die vergelijkbaar is met de Cassis de Dijon-formule. In de -vooral Duitse - literatuur werd intensief gediscussieerd over de vraag, of soortgelijke regels ook golden ten aanzien van de vrijheid van vestiging. In de meeste arresten met betrekking tot art. 52 EG-Verdrag tot het einde van de jaren tachtig waren de litigieuze belemmeringen op de een of andere manier direct of indirect discriminerend. In het Kraus-arrest ${ }^{1748}$ uit maart 1993 eiste het Hof van Justitie echter, dat de Lid-Staat een objectieve rechtsvaardiging zou aanvoeren en de beginselen van noodzaak en proportionaliteit in acht moest nemen, opdat een nationale maatregel in overeenstemming zou zijin met art. 52 van het Verdrag. Daaruit blijkt overduidelijk, dat het Hof aanvaardt dat binnen een interne markt ook niet-discriminerende beperkingen onder het toepassingsgebied van de vermelde bepalingen vallen. In het Vlassopoulou arrest ${ }^{174}$, twee jaar voor de uitspraak in Kraus gewezen, besliste het Hof, dat Lid-Staten moeten rekening houden met elke opleiding en training die een EG-migrant heeft gehad en dat de Lid-Staat in geval van gelijkwaardigheid de in een andere Lid-Staat verworven kwalificatie moet erkennen. De Vlassopoulou uitspraak is evident beïnvloed door de zogenaamde horizontale benadering van de erkenning van diploma's zoals de Commissie deze sinds het midden van de jaren tachtig heeft ontwikkeld.

In de loop van de jaren heeft de Gemeenschap verschillende stategiën met betrekking tot de erkenning van diploma's gevolgd. Eén van de doelstellingen van dit boek is een beschrijving van deze verschillende benaderingen. De kern van de uitspraak van het Hof in de zaak Vlassopoulou lijkt sterk op de beginselen neergelegd in Richtlijn 89/48/EG betreffende een algemeen stelsel van erkenning van hoger-onderwijsdiploma's waarmee beroepsopleidingen van tenminste drie jaar worden afgesloten (RAS I). In deel IV wordit speciale aandacht geschonken aan deze richtlijn en de daarin gekozen horizontale aanpak.

Vóór de totstandkoming van deze Richtlijn benaderde de Gemeenschap de problematiek van de erkenning van diploma's op een verticale wijze; dat will zeggen, dat de erkenning beroep voor beroep tot stand werd gebracht na een voorafgaande minimale harmonisatie of coördinatie van de opleiding en training in de diverse $\mathbb{L i d - S t a t e n . ~ D e e l ~ I I I ~ i s ~ a a n ~ d e z e ~}$ zogenaamde verticale of sectoriële harmonisatie gewijd. De eerste richtlijnen die van deze benadering uitgingen, betroffen artsen (1975). Deze artsenrichtlijnen stonden vervolgens model voor richtlijnen betreffende andere medische, verwante en farmaceutische beroepen: verpleegsters (1977), tandartsen (1978), dierenartsen (1978), vroedvrouwen (1980) en apothekers (1985).

Voor elk van deze beroepen zijn er twee richtlijnen: een erkenningsrichtlijn en een coördinatierichtlijn. Naast de vermelde richtlijnen voor medische beroepen zijn ook nog

1747. Zaak 33/74, Van Binsbergen tegen Bestuur van de Bedrijsvereniging woor de Metaalnijwerheid, Jur 1974, 1299 .

1748. Zaak C-19/92, Kraus tegen Land Baden-Württemberg, Jur, 1993 , I-1663.

1749. Zaak C-340/89, L. Vlassopoulou tegen Ministerium für Justiz, Bundes- und Europaangellegenheitten Baden-Württemberg, Jur, $1991,1-2357$. 


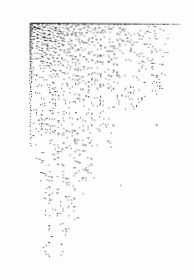

Samenvalting

richtlijnen tot stand gebracht voor advocaten (1977) en architecten (1985). In afwijking van de richtlijnen voor de medische beroepen coordineert de architectenrichtlijn evenwel niet de opleiding en training. De advocatenrichtlijn gaat overigens slechts over de mogelijkheid" "diensten" in een andere Lid-Staat aan te bieden.

Het systeem van de sectoriële richtlijnen wordt in deel III in het bijzonder door een bespreking van de artsenrichtlijnen toegelicht. De regels van andere sectoriële richtlijnen worden slechts uiteengezet voorzover deze van de artsenrichtlijnen verschillen of indien speciale problemen ten aanzien van de toepassing van die andere richtlijnen zijn opgekomen. De precieze inhoud van de advocatenrichtlijn wordt in een case study over "juridische beroepen" samen met de nationale tenuitvoerleggingen van Richtlijn 89/48/EG ten aanzien van juridische beroepen in deel $\mathrm{V}$ behandeld. Voorts wordt in dat kader aandacht geschonken aan de nieuwe ontwerprichtlijn over het vrije vestigen van advocaten.

De ervaring leert, dat het proces van het ontwerpen van, het onderhandelen over en het uitvoeren van sectorièle richtlijnen lang en moeizaam is. In sommige gevallen, bijvoorbeeld bij de richtlijnen voor architecten en voor apothekers, waren er meer dan achttien jaren mee gemoeid alvorens de Raad het fiat voor een richtlijn gaf. In sommige andere gevallen, bijwoorbeeld ten aanzien van ingenieurs, kon in de Raad geen overeenstemming worden bereikt zodat het plan om te komen tot een sectoriële ingenieursrichtlij.jn wan de agenda werd gevoerd. Zoals reeds vermeld, werd deze sectoriële strategie echter door de Commissie verlaten ten gunste van een nieuwe strategie betreffende wederzijdse erkenning zonder voorafgaande harmonisatie.

Richtlijn 89/48/EG is een uiting van de "euroforie" die na het in werking treden van de Europese Akte en de hoop op voltooiing van een interne markt eind 1992 het Europese eenwordingsproces bepaalde. Deze doelstelling was oorspronkelijk verwoord in het Witboek van de Commissie over de voltooiing van de interne markt ${ }^{1750}$. Het Witboek stelde dat het nodig was juridische en economische drempels tussen Lid-Staten weg te nemen ten einde een geïntegreerde interne markt te scheppen. De nieuwe strategie was een belangrijke stap in de richting van wederzijdse erkenning zonder daaraan voorafgaande harmonisatie. Overeenkomstig deze nieuwe strategie stelde de Commissie een algemeen stelsel van erkenning van diploma's voor. De Raad aanvaardde deze Richtlijn op 21 december 1988 . Het doel van de Richtlijn was een daadwerklijke vrijheid van vestiging voor beroepen in de Europese Gemeenschap te bevorderen. De grondgedachte achter de Richtlijn is het beginsel van wederzijds vertrouwen in de kwaliteit van de onderwijssystemen en de beroepsopleidingen in andere Lid-Staten. In aanvulling op Richtlijn 89/48/EG, aanvaardde de Raad Richtlijn 92/51/EG, welke dezelfde horizontale aampak volgt. Deze laatste richtlijn betreft een tweede algemeen stelsell van erkenning van beroepsopleidingen ter aanvulling van Richtlijn 89/48/EEG (RAS II). RAS II richt zich op het basisonderwijs tot en met het kort hoger onderwijs.

1750. COM (85) 310, Juni 1985. 
Richtlijn 89/48/EG verplichte Lid-Staten ertoe om maatregelen te nemen teneinde voor 4 januari 1991 aan de richtlijn te voldoen. De bepalingen van RAS I en RAS II en de tenuitvoerlegging daarvan in de Lid-Staten, alsmede een kritische evaluatie van de nationale maatregelen is een van de kernstukken van dit onderzoek. Daarbij wordt speciale aandacht besteed aan de verschillende uitvoeringsmethoden. Dikwijls vinden deze verschillen hun oorzaak in culturele verschillen tussen de Lid-Staten.

Sommige $\mathbb{L i d - S t a t e n}$ voeren de richtlijn uit door een algemene wettelijke regeling. Dit is bijvoorbeeld het geval in Denemarken, Ierland, Italië, Nederland, Portugal, Spanje en het Verenigd Koninkrijk. Ierland, Denemarken en het Verenigd Koninkrijk waren de eersten die algemene uitvoeringsmaatregelen publiceerden. Andere Lid-Staten volgden een methode van sectoriële uitvoering, zodat verschillende wetgevingshandelingen noodzakelijk zijn. Deze methode werd in het bijzonder gehanteerd door Duitsland; Frankrijk en Luxemburg. Nederland heeft enkele sectoriële maatregelen genomen naast de reeds vermelde algemene uitvoeringsmatregel. België en Griekenland zijn reeds weroordeeld door het Europese Hof van Justitie wegens niet tijdige tenuitvoerlegging van de Richtlijn. Beide staten hebben slechts een zeer beperkte hoeveelheid sectoriële uitwoeringsmaatregelen genomen. Een procedure tegen Nederland werd gestaakt na de publicatie van de algemene uitvoeringswet. Niettemin kan worden onderstreept, dat Nederland met de uitwoering van RAS I opvallend laat was. De nieuwe Lid-Staten zijn daarentegen hum uitwoeringswerplichting snel en met groot succes nagekomen. Oostenrijk en Zweden hebben de Richtlijn op sectoriële wijze uitgevoerd, terwijl Finland een a]gemene wet en een daarop voortbouwende verordening heeft aangenomen.

De tenuitvoerlegging van Richtlijn 92/51/EEG die voor 18 juli 1994 door de Lid-Staten had moeten worden afgerond, is nog niet door alle Lid-Staten gerealiseerd. In Nederland, Italië, Denemarken, Luxemburg en Finland is een algemene uitvoeringswet in werking getreden. Frankrijk en Duitsland hebben enkele sectoriële maatregelen genomen. In deze latstvermelde landen is de tenuitvoerlegging echter nog niet afgerond.

De implementatie van Richtlijn $89 / 48 / \mathrm{EG}$ was geen eenvoudige opgave. Eén van de redenen daarvoor is, dat het toepassingsgebied van de Richtlijn niet kan worden aangegeven door te refereren aan bepaalde beroepen of beroepsactiviteiten, zoals bij een verticale richtlijn het geval is. In feite worden circa honderd verschillende beroepen in de diverse Lid-Staten door de Richtlijn geraakt. Richtlijn 89/48/EG heeft betrekking op gereglementeerde beroepen en gereglementeerde beroepsactiviteiten. Een beroep of een beroepsactiviteit is gereglementeerd, indien er sprake is van hetzij een monopoliepositie met betrekking tot de uitoefening van die activiteit, hetzij een monopoliepositie gerelateerd aan een beroepstitel, welke is geschapen door regels van nationale oorsprong die het bezit van een diploma vereisen na de voltooiing van tenminste een driejarige hoger beroepsopleiding. Terwijl op het continent beroepen in het algemeen door wetten of van de overheid afkomstige andere regelingen zijn gereglementeerd, heeft de regulering in Ierland en in het Verenigd Koninkrijk, dikwijls plaats gevonden door beroepsorganisaties, de zogenaamde "chartered bodies". 


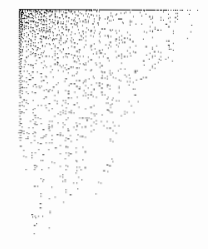

Samenvautting

Een diploma in de zin van de Richtlijn omvat niet slechts een academisch getuigschrift maar ook een eventueel vereiste bijzondere beroepskwalificatie, b.v. een stagecertificaat. De Richtlijn heeft derhalwe slechts betrekking op zogenaamde "eindprodukten" ${ }^{\text {" }}$, personen die hun academische en beroepsopleiding hebben afgerond. De grondgedachte achter de Richtlijn is dat zelfs indien de opleidingssystemen in de Lid-Staten uiteenlopen, de "eindprodukten" toch in voldoende mate met elkaar overeenkomen. Overeenkomstig art. 3 van de Richtlijn moet een Lid-Staat een migrant toestaan om een gereglementeerde beroepsactiviteit uit te oefenen, indien de desbetreffende migrant in een andere Lid-Staat volledig gekwalificeerd is voor de uitoefening van die activiteit en een diploma in de zin van de Richtlijn bezit. Substantiële verschillen in opleiding of training mogen worden gecompenseerd. Art. 4 betreft derhalve zogenaamde aanvullende maatregelen. De Richtlijn laat twee soorten compensaties toe in geval van substantiële verschillen met betrekking tot de inhoud van de opleiding, de proeve van bekwaamheid en de aanpassingsstage, en slechts één aanvullende matregel in geval van verschil van de duur van de opleiding of training. In dit geval kan de ontvangende Lid-Staat het aantonen van beroepservaring eisen. De nationale implementaties, uitgewerkt in deel IV en deel V van de onderhavige studie, laten zien, dat Lid-Staten dikwijls het zicht op de algemene regel van wederzijdse erkenning zijn kwijtgeraakt en zich vrijwel uitsluitend op thet formulleren van aanvullende eisen hebben geconcentreerd.

Een andere reden voor het feit, dat het uitvoeringsproces in vele Lid-Staten zo langzaam is verlopen, is het gegeven dat de tenuitwoerlegging van de Richtlijn voor vele beroepen een algemene discussie losmaakte over de gewenste inhoud van de opleiding en beroepstraining als dusdanig. Hervormingsplannen werden tijdens de discussie over de wijze van tenuitvoerlegging van de Richtlijn gelanceerd. Het scheppen van een interne markt was met name een "hot item" voor de zogenaamde "vrije beroepen", maar zeker niet alleen voor die beroepen. Ook de overheidsdienst kon de deuren niet meer geheel gesloten houden voor gekwalificeerde personen uit andere Lid-Staten. De jurisprudentie wan het Europese Hof van Justitie dwong Lid-Staten er toe om zich te herbezinnen over de vraag, wie tot ambtenaar kon worden benoemd, waarbij met name de kwestie of een nationaliteitseis kon worden gesteld centraal stond. Richtlijn 89/48/EG zette de deuren van dit "verboden" terrein wijd open, daar sommige beroepen die onder het toepassingsgebied van de Richtlijn vallen in vele Lid-Staten door personen met ambtenarenstatus worden uitgeoefend, zoals bijvoorbeeld leraren in Duitsland en Frankrijk.

Deel $V$ is aan drie case studies gewijd: de eerste case study betreft juridische beroepen. Case study II gaat over ingenieurs, terwijl tenslotte case study III aan leraren gewijd is. In deze case studies wordt de nationale tenuitvoerlegging met betrekking tot deze beroepen gedetailleerd uitgewerkt. De vermelde beroepen werden ter nadere bespreking gekozen, daar zij verschillende probleemvelden bij de discussie over de implementatie van de Richtlijn illustreren.

De juridische beroepen worden aan de orde gesteld, daar de Richtlijn bijzondere voorschriften over deze beroepsgroep bevat. In het algemeen mag de migrant kiezen tussen de twee verschillende aanvullende maatregelen: een proeve van bekwaamheid of een 
aanpassingsstage. Bij juridische beroepen mag de Lid-Staat in kwestie echter de desbetreffende keuze maken. De meeste Lid-Staten hebben bij juristen voor de proeve van bekwaamheid geopteerd; slechts Denemarken lijkt een uitzondering te vormen. "Juridische beroepen" in de zin van de Richtlijn zijn in elk geval advocaten, accountants, octrooigemachtigden, belastingadviseurs, en onder bepaalde omstandigheden notarissen. Met name de notarissen vormen een aparte groep. Niet alle Lidl-Staten hebben in dit verband de wederzijdse erkenning van de kwalificatie als notaris geregeld. Vele LidStaten stelden dat bij notarissen sprake is van de uitzondering van art. 55 EG-Verdrag: deze beroepsgroep zou overheidsgezag uitoefenen. Of notarissen inderdaad kunnen worden uitgesloten van het vrij verkeer van personen is een kwestie die in de desbetreffende case study uitvoerig aan de orde wordt gesteld.

Een ander probleemgebied betreft de recente ontwerprichtlijn over het vrije vestigen van advocaten. In beginsel heeft de Commissie de verticale benadering verlaten, maar daarop bestaat een uitzondering. De Commissie is bereid om het initiatief tot speciale richtlijnen te nemen, indien twee voorwaarden vervuld zijn: binnen de beroepsgroep moet een overeenstemming bestaan over de wenselijkheid van een specifieke regeling en nationale autoriteiten moeten deze wens steunen. Met betrekking tot advocaten werden deze voorwaarden inderdaad vervuld. Op uitnodiging van de Commissie, heeft de "Council of the Bars and Law Societies of the European Community" (CCBE) een ontwerp voor een Richtlijn gemaakt, die door de CCBE na zeventien jaar durende onderhandelingen in oktober 1992 werd aangenomen. De Commissie publiceerde eind 1994 een eigen ontwerp dat op het voorstel van de CCBE gebaseerd was.

Het voorstel van de Commissie verschilt echter op twee zeer belangrijke punten aanzienlijk van het originele CCBE ontwerp. Volgens het CCBE-ontwerp mogen advocaten zich in een andere Lid-Staat permanent vestigen onder "home title", terwijl het voorstel van de Commissie de migrant verplicht om na een periode van vijf jaren volledig te integreren in de beroepsgroep van de Lid-Staat van verblijf. Na de vermelde vijf jaren kan de integratie op verschillende manieren gestalte krijgen.

1. Indien de beroepsactiviteiten van de migrant gedurende een periode van tenminste drie jaren ook het recht wan de ontvangende Lid-Staat betroffen, verwerft de migrant volledige toegang tot de beroepsuitoefening in die Lid-Staat met vrijstelling van een proeve van bekwaamheid.

2. Indien de onder "home title" praktiserende jurist drie jaren heeft gewerkt zonder dat deze werkzaamheden ook het recht van de ontwangende Lid-Staat betroffen, kan worden geëist dat hij zich aan een proeve van bekwaamheid overeenkomstig art. 4 van Richtlijn 89/48/EG onderwerpt. Deze proeve moet zich in dat geval echter beperken tot het procesrecht en de beroepscode in de ontvangende Lid-Staat.

3. Uiteraard heeft de migrant overigens het recht om gedurende de periode van vijf jaren op elk gewenst moment een verzoek tot erkenning conform Richtlijn $89 / 48 / \mathrm{EG}$ in te dienen. 
In de desbetreffende case study wordt het Commissie-ontwerp zwaar bekritiseerd. De beperking van het recht om onder "home title" in andere Lid-Staten langer dan vijf jaar te praktiseren, is niet in overeenstemming met art. 52 van het $\mathbb{E G - V e r d r a g . ~ H e t ~ p r a k t i - ~}$ seren onder "home title" kan verder niet worden gezien als een soort aanpassingsstage die tot volledige integratie moet leiden. Een verplichting om na vijf jaren volledig in de beroepsgroep van de ontvangende Lid-Staat te integreren, kan niet worden gerechtvaardigd door enig algemeen belang, terwijl een dergelijke regel evenmin in overeenstemming is met de beginselen van noodzaak en proportionaliteit.

Bowendien kan ook nog worden betwijfeld, of een integratie na een driejarige beroepservaring die mede betrekking heeft op het recht van de ontvangende Lid-Staat, zonder enige proeve van bekwaamheid altijd in het belang van de cliënten is. Overeenkomstig de grondslagen van Richtlijn 89/48/EG, mogen aanvullende maatregelen - een proeve van bekwaamheid of een aanpassingsstage - uitsluitend worden geëist, indien substantiële elementen missen in de opleiding en training van de migrant die wezenlijk zijn voor de beroepsuitoefening. Volgens de Vlassopoulou-formule moet een Lid-Staat daarbij rekening houden met elke vorm van beroepservaring, inclusief beroepservaring met betrekking tot het recht van de ontvangendle Lid-Staat. Ingeval een migrant reeds gedurende een periode van drie jaren in de ontvangende Lid-Staat heeft gewerkt en daarbij tevens heeft gepraktiseerd in het recht van die Staat, is het verder twijfelachtig of het eisen van een proeve van bekwaamheid niet in strijd is met het systeem van Richtlijn 89/49/EEG. Aan de andere kant is het echter zo, dat als met betrekking tot belangrijke delen van het nationale recht geen ervaring is opgedaan, het in het belang van de cliënten is om de kennis op die gebieden te toetsen. Cliënten moeten kunnen vertrouwen op de professionele kwaliteiten en kennis van een jurist die gebruik makt van de beroepstitel van de ontvangende Lid-Staat. Zolang de proeve van bekwaamheid niet wordt benut om onnodige en discriminerende belemmeringen te scheppen, kan deze in het belang van consumenten worden gerechtvaardigd.

De tweede case study gaat over ingenieurs. Het bleek in de jaren zeventig en in het begin van de jaren tachtig niet mogelijk om in de Raad tot overeenstemming te komen ten aanzien van een sectoriële richtlijn voor ingenieurs. De verschillende manieren waarop dit beroep is geregeld in de Lid-Staten, alsmede de uiteenlopende opleidingsniweau's maakten het onmogelijk om tot een bijzondere richtlijn te komen. In het bijzonder de drie jaren durende ingenieursopleiding aan de Duitse Fachhochschulen werd door vele Lid-Staten als niet equivalent met de langere universitaire opleiding van de hand gewezen. Het lag daarom in de lijn der verwachtingen, dat de uitvoering van Richtlijn 89/48/EG woor ingenieurs tot grote problemen zou leiden, daar de implementatie immers zowel betrekking moest hebben op aan universiteiten opgeleide ingenieurs als op de ingenieurs die cen Fachhochschul-opleiding hadden genoten. De problemen bleken echter minder groot dan verwacht. Het belangrijkste punt van discussie was daarentegen de vraag, of het beroep van ingenieur in bepaalde Lid-Staten wel of niet is gereglementeerd.

Denemarken, Frankrijk en Nederland namen het standpunt in, dat dit beroep niet is gereglementeerd in de zin van de Richtlijn. Naar de mening van deze landen was het 
derhalve niet noodzakelijk om met betrekking tot deze beroepsgroep implementatiestappen te ondernemen. Hetzelfde standpunt werd ingenomen door Finland en Zweden. In Ierland en in het Verenigd Koninkrijk is het beroep door de zogenaamde "chartered bodies" gereglementeerd. Deze besloten om op basis van de algemene implementatiewetten van geval tot geval beslissingen te nemen over de erkenning en de daarbij te stellen aanvullende voorwaarden. In de meeste gevallen werden de kwalificaties van de migranten direct erkend, slechts in enkele gevallen werden een proeve van bekwaamheid of een aanpassingsstage geêist. In Duitsland is de ingenieurstitel door diverse wetten op Laanderniveau geregeld. Staatsrechtelijk waren de Länder derhalve verantwoordelijk voor de implementatie van de Richtlijn voor deze beroepsgroep. De Länder beslisten om buitenlandse ingenieurs direct te erkennen zonder enige aanvullende eisen te stellen. Niedersachsen besliste zelfs om buitenlandse ingenieurs het recht te geven om zonder enige bureaucratische procedure hwn beroepstitel te gebruiken. Spanje heeft daarentegen een speciale wet aangenomen voor de diverse soorten ingenieurs met speciale regels voor de erkenning van buitenlandse ingenieurs inclusief de mogelijkheid om een proeve van bekwaamheid of een aanpassingsstage te eisen. Portugal en Italiẻ hebben de Richtlijn ook door middel van algemene wetten geimplementeerd, maar hebben nog geen specifieke op ingenieurs toegesneden uitwerkingen in lagere wetgeving tot stand gebracht. In Griekenland en in België is zulks evenmin gebeurd.

De derde case study gaat niet over een klassiek "vrij beroep", maar over een beroep dat dikwijls in overheidsdienst wordt uitgeoefend. Het lerarenberoep was in het verleden voorwerp van discussie in het perspectief van de uitzonderingsbepaling van art. 48 lid 4 EG-Verdrag. De jurisprudentie van het Hof van Justitie veroorzaakte een ontwikkelling in de diverse nationale wetgevingen met betrekking tot de rechtspositie van ambtenaren. In de meeste Lid-Staten moesten ambtenaren tot voor kort de nationaliteit van het desbetreffende land bezitten. Nederland vormde op het continent een uitzondering, nadat aan het eind van de jaren tachtig de nationaliteiseis voor ambtenaren - behalve in enkele exceptionele gevallen, zoals voor leden van de rechterlijke macht - was geschrapt. In andere landen, zoals in Duitsland en Frankrijk, werd het openstellen van een benoeming als ambtenaar voor buitenlanders heftig bediscussieerd. Deze discussie en de daarmee verband houdende wetgevingsprocedure hebben de implementatie van de Richtlijn voor leraren bemoeilijkt. In het bijzonder enkele Duitse Länder weigerden de implementatie van de Richtlijn zonder voorafgaande wijziging van het federale kaderwet voor ambtenaren (Beamtenrechtsrahmengesetz).

Het voorbeeld van de leraren laat overigens zien, dat de houding van een Lid-Staat ten opzichte van buitenlandse beroepsbeoefenaars dikwijls niet slechts door beroeps- en opleidingskwesties wordt beinvloed, maar ook door sociale en economische factoren. Het Verenigd Koninkrijk lijdt onder een ernstig gebrek aan leraren, in het bijzonder trouwens omdat leraren heel slecht worden betaald. Een gevolg hiervan is een uitermate liberaal en open beleid betreffende de erkenning van buitenlandse kwalificaties. Luxemburg heeft daarentegen de best betaalde leraren van Europa en een waarschijnlijk mede daardoor veroorzaakte lange wachtlijst van reeds gekwalificeerde personen, die op zoek zijn naar een baan als leraar: het wekt derhalve wellicht geen verbazing, dat juist dit land de Richt- 
lijn met betrekking tot leraren restrictief heeft geïmplementeerd. Men eist vloeiende beheersing van de drie nationale talen: Frans, Duits en Luxemburgs.

Een andere moeilijkheid met betrekking tot leraren en andere ambtenaren is de werving via een zogenaamd "concours". Vijf Lid-Staten (Frankrijk, Italië, Luxemburg, Portugal en Spanje) gebruiken het concours als wervingsmethode. De Richtijn 89/48/EG zegt niets over deze wijze van werving. Het concours bleek vooral moeilijkheden te veroorzaken bij de implementatie in Frankrijk en Luxemburg. In beide Ianden heeft het concours plaats gedurende de professionele trainingsperiode voor leraren. In beide landen ronden kandidaten die het concours met succes achter de rug hebben, pas daarna hun beroepsopleiding af. Het zou daarom zeker in strijd zijn met de algemene beginselen van de richtlijn om een dergelijk examen plus een beroepsopleiding te eisen van een migrant, die in het buitenland reeds een "eindprodukt" is. Aan de andere kant is het echter ook moeilijk om een speciale manier van werving te ontwikkelen voor migranten zonder deze te discrimineren. En nagenoeg onmogelijk is het om een Lid-Staat te dwingen hun traditionele manier van werven van ambtenaren drastisch te wijzigen. Een mogelijke oplossing zou zijn om de migrant toe te laten tot het concours zonder een verdere opleiding te eisen. Maar zelfs dan is het twijfelachtig of migranten met een andere opleidingsachtergrond en een afwijkende beroepservaring een faire kans in een dergelijk vergelijkend concours zouden hebben. Het uiteindelijke oordeel over het concours zal zonder de geringste twijfell door Hof van Justitie moeten worden geveld.

Een ander probleem met betrekking tot leraren is de kwestie van de anciënniteit. In de zaak Scholz ${ }^{175 i}$ heeft het Hof van Justitie geoordeeld dat Lid-Staten rekening moeten houden met de beroepservaring die in overheidsdienst van een andere Lid-Staat is verworven. Deze regel is bij de toepassing van de Richtlijn van bijzonder belang woor leraren met een zekere beroepservaring. Een Lid-Staat zal derhalve niet elke erkenning van de anciënniteit van de migrant mogen weigeren. Toepassing van dit uitgangspunt in de praktijk zal evenwel soms grote moeilijkheden opleveren, zolang er op dit gebied geen sprake is van harmonisatie.

In deel VI wordt Richtlijn 89/48/EG en zijn implementatie in de verschillende Lid-Staten geëvalueerd. Deze evaluatie is niet in alle opzichten even complimenteus voor bepaalde Lid-Staten. Sommige Lid-Staten waren extreem langzaam bij de implementatie van de Richtlijn. Dit geldt in het bijzonder voor België, Nederland en Griekenland, alsmede voor de Duitse Länder met betrekking tot de omzetting voor leraren. De constitutionele veranderingen die in België optraden, respectievelijk de Duitse eenwording, waardoor nieuwe Länder ontstonden, kunnen gedeeltelijk de vertraging verklaren, maar vormen daarvoor geen verontschuldiging. Nederland heeft geen enkell excuus behalve de grondige maar trage nationale wetgevingsprocedure. De implementatie in Italië, Portugal en Spanje was en is ten dele nog zeer problematisch omdat deze landen weliswaar algemene omzettingswetten hebben gepubliceerd, maar in vele gevallen hebben nagelaten orn de in die alge- 
De erkeruning van diploma's in de Europese Gemeenschap

mene wetten vastgelegde beginselen in lagere wetgeving uit te werken, zodat het erkenningssysteem in praktijk dikwijls niet werkt.

Geheel anders is de situatie in Denemarken, Ierland en het Verenigd Koninkrijk. Denemarken verdient een uitdrukkelijk compliment vanwege de onbureaucratische wijze waarop met verzoeken wordit omgegaan. In de meeste gevallen passen in Ierland en het Verenigd Koninkrijk de "chartered bodies" de geval-tot-geval-methode toe om op basis van de algemene implementatieregelingen over verzoeken te beslissen. In zijn algemeenheid hebben deze staten een heel liberale houding ten aanzien van migranten met buitenlandse kwalifikaties.

Uitsluitend de Law Society of England and Wales kent een opvallend hoog percentage gezakte continentaal-Europese advocaten bij het afnemen van proeven van bekwaamheid, hoewel de Richtlijn op papier niet al te strikt is geïmplementeerd. Of dit feit wordt veroorzaakt door een discriminatoir gebruik van de proeve van bekwaamheid, of gewoonweg door de verschillen tussen de common en civil law-traditie, kan thans nog niet met zekerheid worden vastgesteld. Er zijn momenteel namelijk onvoldoende cijfers bekend over de examenresultaten van common law lawyers bij het afleggen van proeven van bekwaamheid op het continent. Ierse beroepsgenoten worden in de regel direct door de Law Society erkend zonder dat enige aanvullende maatregelen worden geëist. De kosten wan een proeve van bekwaamheid bij beroepsorganisaties in Ierland en het Verenigd Koninkrijk zijn overigens zeer aanzienlijk hoger dan in vrijwel alle andere Lid-Staten. Slechts de organisatie van de proeve van bekwaamheid door de Nederlandse Orde van Advocaten is zo ingewikkeld, dat de kosten daarvan wellicht die in Ierland en het Verenigd Koninkrijk overtreffen. In andere landen zijn de kosten voor de aanvullende maatregelen heel laag of zelfs gratis.

Het gegeven, dat sommige Lid-Staten in gebreke zijn gebleven om de Richtlijn tijdig te implementeren, leidt tot de vraag of de regelingen van de Richtlijn directe werking hebben, zodat daar voor nationale rechters een beroep op kan worden gedaan. Het Hof van Justitie heeft over deze kwestie nog geen uitspraak gedaan. In een zaak voor het Gerecht van Eerste Aanleg is deze vraag echter aan de orde geweest. Jammer genoeg hoefde de vratag echter toen nog niet te worden beantwoord, omdat de implementatietermijn op dat ogenblik nog niet was verstreken.

Naar mijn mening kunnen we evenwel het volgende concluderen. Dikwijls wordt door Lid-Staten vergeten, dat de algemene regel van Richtlijn $89 / 48 / \mathrm{EG}$ in art. 3 is neergelegd. In beginsel is het een migrant toegestaan om van zijn Lid-Staat van oorsprong naar een Lid-Staat van ontvangst te gaan, waar hij, indien hij in het bezit is van diploma's in de zin van de Richtlijn tot uitoefening van zijn beroep moet worden toegelaten. Deze regeling is duidelijk en onvoorwaardelijk en vervult derhalve de voorwaarden die het Hof stelt om direkte werking te kunnen aannemen. Een nationale rechter zal daarom art. 3 moeten toepassen. Het feit, dat Lid-Staten overeenkomstig art. 4 onder bepaalde omstandigheden de mogelijkheid hebben om aanvullende maatregelen te eisen, doet niet af aan het onvoorwaardelijke karakter van art. 3. Art. 4 is een uitzondering. Als een Lid- 
Staat gebruik wil maken van de mogelijkheden van art. 4 , moet worden aangetoond dat de woorwaarden voor de uitzondering zijn vervuld. Heeft een Lid-Staat de Richtlijn niet uitgevooerd, dan kan deze zich niet verweren met een beroep op het feit, dat nog geen regelingen voor aanvullende maatregelen zijn vastgesteld, teneinde de directe werking van de Richtlijn te voorkomen.

Tenslotte wordt een poging gedaan een brug te slaan tussen twee in het gemeenschapsrecht gescheiden gebieden, namelijk het gebied van de erkenning van beroepskwalificaties enerzijds en de mogelijkkheid en grenzen van een Europees onderwijsbeleid anderzijds. Wil een dergelijk beleid kans van slagen hebben, dan moet de klassieke onderscheiding tussen academische erkenning en beroepserkenning van diploma's worden verlaten. Aanleiding daartoe zijn enerzijds de richtlijnen $89 / 48 / \mathrm{EG}$ en $92 / 51 / \mathrm{EG}$ en anderzijds de diverse programma's van de Europese Gemeenschap ter stimulering van de mobiliteit van studenten. Zo heeft met name het ERASMUS-programma voor universitaire studenten er aanmerkelijk toe bijgedragen om de academische erkenning van in een andere LidStaat verworven studieresultaten te bevorderen. Deze ontwikkeling wordt ook onder SOCRATES voortgezet. Ook de voor het Hof van Justitie gevoerde procedure van Dieter Kraus heeft een nieuw licht geworpen op de verhouding tussen academische erkenning en beroepserkenning. In deze procedure stond het vereiste van overheidsinstemming voor het voeren van een buitenlandse academische graad ter discussie. Achtergrond van die discussie vormde de totstandkoming van een Europese Unie, in het kader waarvan de competentie van de Gemeenschap op het gebied van onderwijs opnieuw is geformuleerd. In het kader van deze nieuwe ontwikkeling heeft de Commissie door een mededelling aan de Lid-Staten de discussie over een interactie tussen beide soorten erkenningen geopend. De Commissie hoopt dalardoor een open Europese markt voor beroepen en opleidingen te bewerkstelligen. 


\section{The recognition of diplomas in the European Community}

One of the main goals of the $\mathbb{E C}$ Treaty is to create a common market for all economic activites. This includes the free movement of professionals. National rules which have the effect of preventing persons from providing professional services or establishing themselves in another Member State have to be progressively abolished. The barrier to mobility, constituted by the requirement of a national diploma, can be as much an obstacle to completing the internal market as different safety standards for technical goods.

Many such obstacles have been removed through interpretation of European law by the European Court of Justice. This has been the case in particular where the restrictions were based on nationality. National requirements concerning qualifications and diplomas may, however, have the effect of hindering nationals of other Member States in the exercise of their rights of establishment or to provide services guaranteed to them by the Articles 52 and 59 of the EC Treaty without being discriminatory on grounds of nationality. In Part II of this book the case law of the European Court of Justice regarding the free movement of professionals is analyzed in chronological order. Special attention is given to the question whether Article 52 of the EC Treaty covers only discriminatory measures, or whether it can be said that Article 52 prohibits all restrictions unless they are objectively justified by a public interest. Other areas dealt with in Part II are the developments of the case law with regard to "reverse discrimination" and with regard to the recognition of third country diplomas.

With respect to the freedom to provide services, the Court of Justice has since $1974^{1752}$ developed a justificatory test similar to the Cassis de Dijon "rule of reason" in the freedom of goods context. Doctrinally, therefore, it has been heavily discussed whether the same principles apply to the freedom of establishment. Until the end of the eighties in most cases, the restrictions in question were in some way directly or indirectly discriminatory. The Court was not faced with deciding a case with a purely nondicriminatory restriction. However, in the Kraus case, such a restriction was to be deci-

1752. Case 33/74 Van Binsbergen v. Bestuur van de Bedrijfsvereniging voor de Metallnijverheid, [1974], ECR 1299. 
The recognition of diplomas in the European Community

ded upon. In its judgment ${ }^{1753}$ of 13 March 1993, the Court of Justice required the Member State to demonstrate an objective justification and to comply with the principles of necessity and proportionality before the national measure in question could be considered to be compatible with Article 52 of the EC Treaty. This clearly shows that the Court accepted that in an internal market non-discriminatory restrictions fall under the scope of the establishment provisions. In the Vlassopoulou judgement ${ }^{1754}$, decided two years before the Kraus decision, the Court ruled that Member States are required to consider any education and training received by the migrant. The Member State must in case of equivalence recognize the qualification obtained in another Member State. The Vlasoppoulou decision is clearly influenced by the so-called horizontal approach to the recognition of diplomas, an approach favored by the Commission since the mid-eighties.

Through the years the Community has followed different strategies in regard to the recognition of diplomas. One of the objects of this book is to describe these different approaches. The ruling of the Court in the Vlassopoulou decision is very similar to the principles laid down in Directive $89 / 48 / \mathrm{EEC}$ on a general system for the recognition of higher educational diplomas awarded on completion of professional education and training of at least three years' duration. In Part IV particular reference is given to Directive 89/48/EEC and its horizontal approach.

Prior to Directive $89 / 48 / E E C$, the Community's approach to the problem of recognition of diplomas was vertical; that is to say, recognition was provided profession by profession, with minimum harmonization or coordination of the education and training required for each profession in the Member States. Part III is dedicated to this so-called vertical or sectoral method of harmonization. The first sectoral directives dealing with a traditional profession concerns doctors (1975). These directives set the pattern for subsequent directives dealing with other "medical, allied and pharmaceutical professions": nurses (1977), dentists (1978), veterinary surgeons (1978), midwives (1980) and pharmacists (1985).

For each profession there are two directives: the Mutual Recognition Directive and the Comordination Directive. Apart from directives for the medical professions directives have been adopted for lawyers (1977) and architects (1985). Different from the directives for the medical professions, the Architects" Directive does not coordinate the minimum education and training. The Lawyers" Directive deals only with "services".

The system of the sectoral directives is illustrated in Part III with special reference towards the Doctors Directives. The rules of the other sectoral directives are explained only as far as their provisions differ from the Doctors' Directives, or where special problems have arisen in the application of these directives. The precise content of the Lawyers' Directive is dealt with in a special case study: "Legal Professions" in Part V

1753. Case C-19/92, Kraus v. Land Baden-Württemberg [1993], ECR I-1663.

1754. Case C-340/89 - I. Vlassopoulou v. Ministerium für Justiz, Bundes- und Europaangelegenheiten BadenWürttemberg, ECR [1991], [-2357, 
together with the national implementations of Directive $89 / 48 / \mathrm{EEC}$ with respect to the legal professions. Attention is given as well to the new Draft Directive concerning establishment for lawyers.

Experience has shown that the process of drafting, agreeing upon and implementing sectoral directives is long and laborious. In some cases, e.g. the directives for architects and parmacists, it took more than eighteen years to pass the directives in the Councill. In some cases, regarding for example, engineers, the Council could not come to an agreement. The sectoral Engineers Directive was dropped from the Council's agenda. The sectoral harmonization method has, therefore, been abandoned by the Commission. Instead, a new strategy of mutual recognition without prior harmonization for the mutual recognition of diplomas has been introduced with Directive $89 / 48 / \mathrm{EEC}$.

Directive $89 / 48 / \mathrm{EEC}$ is a manifestation of the "europhoria" which followed the Single European Act and the prospect of the completion of the internal market by the end of 1992. This goal was initially set out in the Commission"s White paper on Completing the Internal Market ${ }^{17 s}$. The White Paper proclaimed the need to eliminate legal and economic barriers among the Member States in order to create a single integrated market. The new strategy was a broader shift towards mutual recognition without prior harmonization as a means of eliminating barriers to the establishment of the internal market. According to this new strategy, the Commission proposed a general system of recognition of diplomas. The EC Council adopted this Directive on 21 December 1988. The aim of the Directive has been to speed up the process of giving effect to the freedom of establishment for the professions in the European Community. The basic philosophy which underlies the Directive is the principle of mutual trust in the quality of the educational systems and the professional training in the other Member States. In addition to Directive $89 / 48 / \mathrm{EEC}$, the Council adopted Directive $92 / 51 / \mathrm{EEC}$, which follows the same horizontal approach. It covers the recognition of diplomas of post-secondary courses of less than three years and vocational training certificates.

Directive $89 / 48 / \mathrm{EEC}$ required Member States to take the appropriate measures to comply with it until the 4 January 1991. An explanation of the provisions of both Generall System Directives and their implementation in the Member States, as well as a critical evaluation of these national measures, is one of the main aims of this research. Special attention is given to the different implementation methods used by the Member States. Very often these differences find their origins in cultural differences between the Member States.

Some of the Member States implemented the Directive by one general act of legislation. This was done in Denmark, Ireland, Italy, the Netherlands, Portugal, Spain and the United Kingdom. Ireland, Denmark and the United Kingdom were the first to pass general legislative acts. Other Member States used a sectoral implementation method, implementing the Directive with different acts for each profession involved. This method

1755. COM (85) 310, June 1985. 
The recognition of diplomas in the European Community

was especially used by Germany, France and Luxembourg. The Netherlands have passed some sectoral measures as well. In the case of Belgium and Greece, however, the Court of Justice has already established their failure to implement the Directive in time. Both Member States have passed only a very limited number of sectoral implementation measures. A case against the Netherlands was dropped after the Dutch implementation law was published. Nevertheless, the Netherlands can be considered as being very late with the implementation of the first General System Directive. The new Member States, on the contrary, have finished their task with great success. Austria and Sweden have implemented the Directive in the sectoral way, while Finland has passed a general law and a corresponding regulation.

The implementation of Directive $92 / 51 / E E C$, which should have been passed by the Member States until 18 July 1994, has not been finalized by all the Member States. This time, the Netherlands, Italy, Denmark and Luxemburg as well as Finland can claim to be on the top of the rank by passing a general law in time. France and Germany have passed some sectoral measures. Implementation is not completed in these countries, however.

The implementation of Directive $89 / 48 /$ EEC has been no easy task for the Member States. One reason is that the scope of the Directive cannot be defined by reference to a particular professional activity as in the case of a vertical directive. In fact, approximately a hundred different professions in the various Member States are affected by the Directive. Directive $89 / 48 /$ EEC refers to the concepts of regulated profession and regulated activity. An activity is considered to be regulated as soon as either a monopoly relating to the activity or a monoploy relating to the professional title is created by rules of national origin requiring the holding of a diploma awarded upon completion of at least three years' higher education. Whereas on the continent professions are regulated by law or any other form of state rules, in the United Kingdom and Ireland, regulation of professional activites has often been left to professional bodies, the so-called chartered bodies. In these countries, the professional bodies are mainly responsible for the practical application of the Directive.

A diploma, according to the Directive, means not only the academic award, but also, if necessary, the professional training certificate. Therefore, the Directive applies only to the so-called "final product", the person who has completed the academic and the professional education required to take up a regulated professional activity. The principal idea of the Directive is that even if the educational systems of the Member States differ, the professional "end products" are compatible with each other. According to Article 3 of the Directive, a host Member state has to permit a migrant to take up a regulated activity if the migrant is fully qualified to pursue this profession in another Member State and holds a diploma in the sense of the Directive. Substantial differences in education or training may be compensated. Therefore, Article 4 contains the so-called compensatory mechanisms. The Directive offers two types of compensatory instruments in case of substantial differences with regard to the content of the education, the aptitude test and the adaptation period. One compensatory mechanism can be required in case of time 
differences with regard to the duration of the education and training. In such a case the host Member State can ask for evidence of professional experience. The national implementations, elaborated in Part IV and Part V, show that Member States often lost sight of the general rule of mutual recognition and concentrated nearly exclusively on regulating compensatory instruments.

One other reason for the fact that the implementation process in many Member States has been very slow, is that the implementation of the Directive started a general discussion for many professions in which the national education and the professional training as such was at issue. Reform plans were launched during the implementation process. The opening of the internal market has been of great importance for the "liberal professions", but not only they have got involved in the general discussion. National public services could no longer close the doors to adequately qualified persons from other Member States. The case law of the European Court of Justice has forced the Member States to reconsider their civil servants acts, especially the nationality requirement for appointment to the civil service. Directive $89 / 48 / \mathrm{EEC}$ forced the doors of this "forbidden" territory wide open because professions which fall under the definition of the Directive are exercised in many Member States by civill servants, e.g. teachers in Germany and France.

Part V is dedicated to three case studies: Case study I concerns the legal professions. Case study II deals with engineers. Case study III is dedicated to teachers. In these case studies national implementation with regard to the different professions is elaborated in more detail. The professions in the case studies were chosen because they represent different problematic areas especially under discussion during the implementation process.

The legal profession was chosen because the Directive includes special rules for this profession. Generally, the migrant can choose between the two different compensatory mechanisms, aptitude test and adaptation period. In case of the legal profession it is up to the Member State to make that choice. Most Member States have chosen the aptitude test for the legal profession. Only Denmark seems to take an exceptional stand. "Legal professions" in the sense of the Directive means in any case lawyers (advocates), accountants, patent attornies, tax advisors and, under certain conditions, notaries. Notaries form a speciall category. Not all the Member States have passed a law for notaries. Many Member States relied on the exception of Art. 55 EC Treaty. Whether the notaries can still be excluded as a profession from the principles of the free movement of persons is a question dealt with in this case study.

Another problematic area is the recent Draft Directive of Establishment for Lawyers. In principle, the Commission has abandoned the vertical approach, with one exception. The Commission is prepared to draft specific directives if two preconditions are fulfilled: An agreement must have been reached within the profession and the national authorities must show their support for such an initiative. These conditions were fulfilled for an establishment directive for lawyers. At the invitation of the Commission, the Council of the Bars and Law Societies of the European Community (CCBE) drafted a directive which was 
accepted by the CCBE in October 1992 after seventeen years of negotiations. The Commission published its own proposal based on the CCBE draft at the end of 1994.

The Commission's proposal differs considerably on two very essential points from the original CCBE draft. According to the CCBE draft, the lawyers are allowed to establish under "home title" in another Member State on a permant basis, while the proposal of the Commission includes the obligation for the migrant to integrate fully into the profession of the host Member State after a period of five years. After this period the integration can take place in different ways:

1. If the migrant has pursued his or her professional activity for a period of at least three years involving the law of the host Member State, the migrant gaining admission to the profession of the host Member State will be fully exempted from any aptitude test.

2. A lawyer practising under home title effectively for three years not involving the national law of the host Member State, may be required to take an aptitude test as Article 4 of Directive $89 / 48 / \mathrm{EEC}$ provides for. This test, however, must be limited to the law of procedure and the rules of professional conduct of the host Member State.

3. During the five year period the migrant can, of course, at any moment make an application for recognition pursuant to Directive $89 / 48 / \mathrm{EEC}$.

In the case study, the Commission's Draft Directive is heavily critizised. The five year limitation on the right to practise under home title in other Member States, one of the Commission's alterations, cannot be considered to be in accordance with Art. 52 of the EC Treaty. The practice under home title cannot be seen as a practical professional training period which has to lead to full integration. An obligation to integrate fully in the profession of the host Member State after five years of professional activities in this Member State cannot be justified by any public interest. Neither would such a rule comply with the principles of necessity and proportionality.

On the other hand, it is doubtful whether the integration without any aptitude test in case of a three year effective professional activity involving the law of the host Member State is always in the interest of clients. According to the principles of Directive $89 / 48 / \mathrm{EEC}$, an aptitude test or an adaptation period may only be required if substantial elements are missing in the education and training of the migrant. These elements must be essential for the professional activity in the host Member State. According to the Vlassopoulou ruling, the Member State has to take into account any form of professional experience, including professional experience in the law of the host Member State. In cases where a migrant has effectively worked with regard to the law of the host Member State for a period of three years, it is doubtful whether the host Member state could require an aptitude test according to the Gieneral System Directive. On the other hand, if important parts of the national law were not dealt with during this period, it seemed to be absolutely 


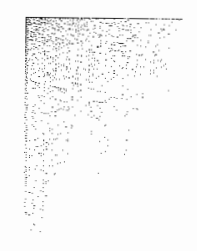

Shmmary

justifiable to test this knowledge in the interest of clients. The clients in the host Member State must be able to rely on the professional qualities and knowledge of a lawyer using the professional title of this State. As long as the aptitude test is not used to create unnecessary and discriminatory barriers it can be justified in the interest of the consumer.

The second case study deals with engineers. In the seventies and early eighties it was not possible to reach an agreement in the Council with regard to a sectoral directive for engineers. The different ways in which the profession is regulated in the Member States, as well as, different educational standards have made it impossible to reach general acceptance for a specific directive. In particular, the three year engineering education at the German Fachhochschulen was rejected by many Member States as not equivalent with their longer, university level education. It had been expected that the implementation of Directive $89 / 48 / \mathrm{EEC}$ which includes engineers at the university and Fachhochschul levels, would cause many problems. In fact, the case seems to be less problematic than expected. One of the main discussion points during the implementation process was whether the engineering profession is regulated or not in certain Member States.

Denmark, France and the Netherlands took the view that the profession is not regulated in the sense of the Directive in their countries. According to these countries' opinion, it was therefore not necessary to take any implementing steps with regard to this profession. The same point of view has been taken by Finland and Sweden. In the United Kingdom and Ireland the engineering profession is regulated by chartered bodies. They make decisions on a case by case basis. In most cases migrants were recognised directly. In few cases were additional measures - an aptitude test or an adaptation period - required. In Germany the professional title of engineer is regulated by different laws of the Länder. Constitutionally, the Länder were responsible for implementing the Directive for this profession. They have decided to recognize foreign engineers directly without any compensatory instruments. Lower Saxony decided to give foreign engineers the right to use their professional title without any form of bureaucratic procedure. Spain has passed a special regulation for different types of engineers with special rules for the recognition of foreign engineers including the possibility of requiring either an aptitude test or an adaptation period. The same is true for Austria. Portugal and Italy have implemented the Directive with a general law, but have not yet passed any secondary legislation for engineers. Neither has this been done by Greece and Belgium.

The third case study did not deal with a "liberal profession", but with a profession in the public service. The case of teachers was for a long period a discussion point with regard to the exception of Article 48 (4) EC Treaty. The case law of the Court of Justice started a development in the different national laws with regard to the status of civil servants. In most Member States the civil service was until recently combined with a nationality requirement. The Netherlands was an exception of the continental countries in which the nationality requirement in the civil service, except for some cases such as professions in the judiciary, was already abolished in the end of the eighties. In other countries, like Germany and France, the opening of the civil service to foreigners was discussed very heavily. These discussions and the legislative procedures which followed have prolonged 
The recognition of diplomas in the European Community

the implementation of the Directive for teachers. Especially some of the German Lander refused to implement the Directive without a prior amendment of the federal civil service act (Beamtenrechtsrahmengesetz).

The example of teachers also shows that the attitude of a Member State towards foreign professionals is very often not only influenced by purely professional and educational questions, but allso by social and economic ones. The United Kingdom, having a serious demand for teaching staff, especially because teachers are very poorly remunerated, has a very liberal and open policy towards recognition of foreign teaching qualifications. Luxembourg on the other hand, with the best paid teachers in Europe and many national candidates waiting for a job, implemented the Directive extremely restrictively, requiring, for example, proficiency in the three national languages: French, German and Luxembourgois.

Another difficulty with regard to teachers and the civil service in general is the recruitment by "Concours". Five Member States, France, Italy, Luxembourg, Portugal and Spain use a Concours as a recruitment procedure. Directive $89 / 48 /$ EEC does not say anything about recruitment. The "Concours" has shown to be especially problematic in France and Luxembourg. In both countries the "Concours" take place during the professional training period of teachers. In both countries, the candidates having sucessfully passed the "Concours" must complete their professional education afterwards. To require such an examination plus a professional training period from a migrant who is considered to be a "final product" would certainly be contrary to the general principles of the Directive. On the other hand, it is very difficult to find a special way of recruitment for migrants without discriminating against them. And it is nearly impossible to force Member States to radically change their traditional way of recruiting civil servants. One of the solutions could be to require from the migrant to pass the "Concours" without any demand of further professional training. Even under this condition, it is doubtful whether migrants with a different educational and professional background will have a fair chance in such a competition. For a final answer, the "Concours" will have to be challenged before the Court of Justice.

Another problem for teachers is the question of seniority. In the Scholz case ${ }^{1756}$ the Court of Justice ruled that Member States have to take into account the professional experience acquired in the public service of another Member State. This ruling is of special importance for the application of the Directive in case of teachers with a certain professional experience. A Member State will not be able to refuse some acknowledgement of the migrant's senority. However, the applicability of this principle in practice will be very difficult as long as there is no harmonization in this area.

Part VI gives a general evaluation of Directive 89/48/EEC and its implementation in the different Member States. This evaluation is not in all aspects a compliment to certain 


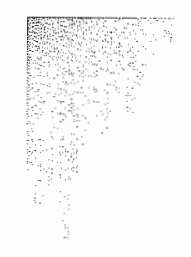

Summary

Member States. Some Member States have been extremely slow in implementing the Directive. This is especially true for the Netherlands, Belgium and Greece, as well as the German Länder with regard to the profession of teachers. The changing constitutional situation in Belgium as well as the German unification can partly - e.g. in regard to the new Länder - explain, but not excuse the delay. The Netherlands has no excuse except the time consuming Parliamentary legislative procedure. The implementation in Italy, Portugal and Spain was - and partly is - very problematic because these countries have passed general implementation laws but not always the necessary secondary legislation. This often leads to the fact that the system does not work in practice.

The situation is different in Denmark, Ireland and the United Kingdom. Denmark has to be praised especially for the unbureaucratic way it deals with applications. In the United Kingdom and Ireland most cases are decided by the chartered bodies following a case by case method using the national implementation statutes as the legal basis for their decisions. Generally, these countries seem to be very liberal in their attitude towards migrants with foreign qualifications.

Only the Law Society of England and Wales, although having not implemented the Directive too strictly on paper, has quite a high failure rate in the aptitude tests with regard to continental migrant lawyers. Whether this fact is based on a discriminatory use of the aptitude test, or finds its origin in the differences between the common and civil law systems cannot be decided with absolute certainty. There are not enough comparablle figures available with regard to the results of common law lawyers in the aptitude tests on the continent. Irish lawyers are in general recognized by the Law Saciety directly without any form of compensatory requirements. The costs for the aptitude tests before the professional bodies in the United Kingdom and Ireland are, in any case, considerably higher than for the ones in the continental countries. Only in the Netherlands is the organization of the compensatory mechanism by the Dutch Bar so complicated that its costs in time and money might even be higher than the ones in the United Kingdom and Ireland. In other countries the costs for the compensatory instruments are quite low. In some cases the organization is even free.

The failure of many Member States to complete the implementation on time leads to the question whether the provisions of the Directive have direct effect and can be challenged before a national court. There has been no final decision on that point by the Court of Justice. The question, however, was raised in a case before the Court of First Instance. Unfortunately, the issue was decided in that case because the implementation period had not yet expired at the moment the case was pending.

If we want to decide the question whether the Directive has direct effect or not, we have to take into account the following observations: The general rule of Directive $89 / 48 / \mathrm{EEC}$ is laid down in Article 3, although this is very often forgotten by the Member States. The principle allows the migrant to go from the Member State of origin to the host Member State and, having the necessary diplomas required by the Directive, to be permitted to practice the same regulated profession in the host Member State. This provision is clear 
and unconditional, and therefore fulfills the criteria of the Court's rulings for direct effect of directives. A national judge will be able to pass a judgment on all the relevant elements. The fact that under Article 4 of the Directive, Member States have the possibility under certain conditions to ask for compensatory instruments does not change the unconditionality of Article 3 of the Directive. Article 4 is an exception. If a Member State wants to make use of this provision it is up to this Member State to prove that the criteria for the exception are fulfilled. Has a Member State not implemented the Directive, it cannot rely on the fact that it has not provided for compensatory instruments to challenge the possible direct effect of the Directive.

Another topic which has been raised in Part VI is the relationship between the vertical and the horizontal approaches. Both harmonization strategies have advantages and disadvantages. At the moment, the Commission refuses to take up the vertical approach again. The Lawyers' Directive has to be seen as an exception. With the experience of Directive $89 / 48 / \mathrm{EEC}$, it might be advisable to change this attitude for special difficult cases. In such cases a minimum harmonization of the educational standard might help the recognition system work better. Furthermore, Directive $89 / 48 /$ EEC and its recognition system should not be used in cases of free movement of services. Only in very exceptional situations does a bureaucratic recognition procedure seem to be justified by a public interest in the case of cross border professional services.

Finally, the Epilogue is dedicated to two generally separated subjects: professional and academic recognition of diplomas. New ways have to be found to better combine the two areas which are very much related with each other. Some proposals are made. 


\section{Literaturverzeichnis}

Abell 1988

Abell MLR $\llbracket 989$

AbullLewis

Addamson

Adriån Amáiz

Ablgrimm,

Ahlgrimm, Pharm.Z. 1981

Ahigrimm, Pharm,Z. 1983

Ahrens, AnwBL. 1992

Alltenhoff/Busch u.a.

Alvarez

Anraths

Anrys

Anrys, JT 1975

Antoine, RMC 1976 Antoine, RMC 1980

Antoine RMC 1988 Antonopoulos/Laguette

Arends, AdvBl 1994 Armann Amoid

Arnold, AnwBl. 1959 Arnull, ELR 1988 Armull

Arnull/Jacobs
Abel, Richardi $L$. The Legal Profession in England and Wales, Oxford 1988 , Abel, Richard L., Between Market and State: The Legal Profession in Turmoil, Modern Law Review 1989, 285-325.

Abel, Richard L./Lewis, P.S. Lawyers in Sociery. Vol. Two, The Civil Law World, Berkeley/Los Angeles/London 1989.

Adamson, Hamish, Free Movements of Lawyers, London/Dublin/Edinburgh/Brussel 1992 .

Adrián Amáiz, Antonio Javier, La Libra Circulazione Dei Laureati Nella CEE, Universita di Ferrara, 1-33.

Ahlgrimm, Ernst-Dietrich, Neue Ríchtlinien-Worschläge kritisch durchleuchtet. Weitere Harmonisierung angestrebt durch gegenseitige Anerkennung der Apotheker-Diplome und Forderung eines freien Arzneimittelverkehrs, Pharm. $Z$. $1981,459-461$.

Alilgrimm, Enst-Dietrich, Die gegenseitige Anerkennung der Apotheker Diplome in der Europäischen Geameinschaft, Pharm. Z. 1983, 1865-1868.

Alurens, Hans-Jürgen, Deregulienung für rechtsberatende freie Berufe, AnwBI. $1992,247-249$

Alltenhoff, Rudolf/ Busch, Hans/ Kampmann, Kurt/ Chemnitz, Jürgen, Rechtsberatungsgesetz, Kommentar, 9. Auflage, Münster 1991

Alvarez, Adriana (red.), De advocaat-generaal gehoord, Essays over de totstandkoming van Europees gemeenschapsrecht, Antwerpen 1995.

Anraths, $K_{\text {. }}$ Das Wesen der sogenannten wissenscharthichen freien Berufe, Düsseldorf 1930 .

Anrys. Henri, Les professions médicales et paramédicales dans le Marché Commun, Brussel 1971.

Anrys, Henri, Les directives médecins, cas test ou act politique, Journal des Tribuinaux, 6.9.1975, Nr. 4920, 453-461.

Antoine, Gerard, L"Europe de l'éducation, RMC 1976, 543-547.

Antoine, Géraurd, Des équivallences des dipliones ả l"Europe die l'education, RMC $1980,595-602$

Antoine, Gérard, D'ERASMUS à Comet et solidarite, RMC 1988, 554-557.

Antonopoulos, Nicollas/Laguette, Serge Pierre, La profession d"avocaten Greece, in Gazette du Pala is, 1980 , No 289 -90, 4-7.

Arends, Willemün, Advocatat in Europa, AdvBl. 1994, 282-285.

Armann. W./Amold. M. Das medizinische Versorgungssy stem in Österreichn Koln 1991 .

Amold, Hans, Amwait und Gemeinsamer Markt, AnwBI. 1959, 27-31.

Amull, Anthony, Of strip cartoonists, vets and gunsmiths, ELR 1988, 260 267. Arnull. Anthony, The General Principles of EEC Law and the Individual, Leicester 1990

Arnull, Anthony/Jacobs, Francis, Applying the common rules on the free movement of persons in: H. G. Schermers et al. (Hrsg.). Free movenment of persons in Europe, Den Haag 1993, 272-285. 
Audinet, JDI 1959

Avemarius, NVwZ 1988

Baclet-Hainque, AJDA 1990

Bacrot/Frontbressin Bahlmann, EuR 1982

Bain/Endréo/Simpson, sem. jur. 1988

Bakker, AnwBl 1993

Baldi, Dir. Sc.Int. 19

Baldi, RivDIPP 199

Ball/Egin

Baracca/Corioni/Guiliani

Barents, CMLRev, 1981

Barents, GYblL 1990

Barents, MJ 1994

Barents/Brinkhorst

Barsade, Int. Lawyer 199

Basedow, NJW 1990

Basedow, LuZW 1990

Basedow Rabelsz 199

Battis 1989

Battis in Magiera (1990)

Battis, NJW 1992

Bawr/Hopt/Mailänder (Hrsg) FS Steindorf

Bayless, Texas ILJ 1975

Bizex, RTDE 1984

Beckedorf/Henze, NWwZ 1993

Becker,

Reclut im Amt 199
Audlinet, Jacques, Le droit d"Établissement dans la Communauté économique européenne "IDI 1959, 982-1049.

Avenarius. Hiermann, Zugangsrechte von EG-Ausländern im Bildungswesen der Bundesrepublik Deutschland, NVwZ 1988, 385-393.

Baclet-Hainque, Rosy, L"Europe des emplois dans l'administration publique, AIDA 1990, 224-232.

Bacrot/Frontbressin, Le nouvel Awocat, Paris 1992.

Bahlimann, Kai, Der Gnundrechtsschutz in der Europäischen Gemeinschaft-Wege der Verwitklichung. "EuR 1982, 1-20

Bain, R. /Endrếo, G. /Simpsion. J., Le libre établissement des juristes en Europe: Mythes et réalités, Semaine juridique 1988. 1. 3324.

Bakker, Rainer, RechtsanwaltsgesellschafteninEngland, Ein rechtsvergleichender Beitrag zum Reformdiskussion des anwaltlichem Berufs- und Organisationsrectits, AnwB1 1993, 245-247.

Baldi, Roberto, La Commisione concultiva degli ordini forensi della Cornunita Europea, Dir. Sc. Int. 1981, 705-733.

Baldi, Roberto, La Liberalizzazione della Professione Forense nel Quadro della Direttiva Comunitaria 21 Dicembre 1988 (89/48 CEE), Rivista di Diritto Internazionale Privato e Processuale $1991,345-354$

Ball, Sir Christopher/ Eggins, Heather (Hrsg.), Higher Education to the $1990 \mathrm{~s}$ New Dimensions, London 1989

Baracca, Claudio/Corioni, Giorgio/Giuliani, Massimo, Professione architetto in Europa, Mailand 1991.

Barents, René, New Developments in Measures Having Equivalent Effect, CMLRev. 1981, 271-308.

Barents, René, The Commumity and the Unity of the Common Market, Some Reflections on the Economic Constitution of the Community, GYbIL 1990, 9-36. Barents, René, The Quality of Community Legislation, Maastricht Journal of European and Comparative Law 1994, 101-114.

Barents, René/Brinkhorst, L.J., Grondlijnen van Eunopees Recht, 6. Auflage, Alphen aan den Rijn 1994.

Barsade, Jonathan, The effect of EC Regulations upon the ability of U, S. lawyers to establish a Pan-European Practice. The International Lawyer 1994, 313-329. Basedow, Jürgen, Juristen für den Binnemmarkt: Die Ausbildungsdiskussion inm Lichte einer Arbeitsmarktanalyse, NJW 1990, 959-963.

Basedow, Jürgen, Deregulierung I, EuZW 1990,73.

Basedow, Jürgen, Zwischen Amt und Wettbewerb-Perspektiven des Notariats in Europa, RabelsZ 1991, 409-435.

Battis, Ulrich (Hrsg.), Europăischer Binnenmarkt und nationaler bffentlicher Dienst, Regensburg 1989.

Battis, Ulrich. Freizugigkeit und Beschaftigung in der offentlichen Verwaltung. in: Magiera, S. (Hrste). Das Europa der Burger in einer Gempinschaft ohne Binnengrenzen, Baden-Baden 1990, 47-59.

Battis, Ulrich, Die Entwicklung des Beamtenrechts im Jahre 1991, NJW 1992, $1208 \cdot 1215$

Baur, Jürgen F./ Hopt, Klaus J./ Mailänder K. Peter (Hrsg.), FS für Emst Steindorff zum 70. Geburtstag. Berlin/New York 1990

Bayless, Natalie, EEC Right of Establishment-Nationals of other Member States may not be barred from the practice of law on grounds of nationality, Texas ILJ $1975,419-429$.

Bazex, Michel, Note Rs 271/82, RTDE 1984, 516-521.

Beckedorf, Ingo/Henze, Thomas, Neuere Entwicklungen in der Bildungspolitik der Europaischen Gemeinschaft, NVwZ 1993, 125-130.

Becker, Hans Joachim, Aktuelle Entwicklungen und Probleme im Beamtenrecht, Recht im Ant 1991, 178-186. 
Becker

Behrems, RabelsZ 1986

Behrens, RabelsZ 1988

Behrens, Jura 1989

Behrens, IPRax 1989

Behrens 1990

Behrens, EuR 1992

Bekemans/Balodimos

Bekkers/Bonnes u.a.

Benedettelli.

Riw.dir.eur 1983

Berchx, TBP 1982

Berggreen, Schulverwaltoung 1988

Berggreen,

Schuireport 1989

Berggreen,

Das Forum 1990

Berggreen.

ZPadagogik 1990

Berggreen, RdJB 1992

Berggreen/Hochbaum

Bermann,

ColliJransL 1989

Bermitz, LIEI 1992

Berscheid/Kirschbaum

Bethge

Beutler, RdJB 1989

Beutler/Bieber

Pipkom/Streil

Beuve-Mëry in Philip
Becker, Heinz Bn, Europäisches Gemeinschaftsrecht und deutsches Berufsbeamtentum, Münster 1992.

Behrens, Peter, Voraussetzungen und Grenzen der Rechtsfontbildung durch Rechisvereinheitlichung. RabetsZ 1986, 19-34.

Behrens, Peter, Niederlassungsfreitheit und Internationales Gesellschaftsrecht, RabellsZ 1988, 498-525

Behrens, Peter, Das Wirtschaftsrecht des Europäischen Binnerumarkts, Ein Überblick: Jura 1989,561-577.

Behrens, Peter, Die grenzuberschreitende Sitzverlegung von Gesellschaften in der EWG, IPRax 1989, 354-361.

Behrens, Peter, Internationale Aspekte der Juristenausbildung, in; Giehring, Heinz/Hag, Fritz/Hoffimann-Riem, Wolfgang/Ott, Claus (Hrsg.), Juristenatusbildung-emeut uberdacht, Baden-Baden 1990, 185-207.

Behrens, Peter, Die Konvergenz der wirtschaftlichen Freiheiten im europaischen Gemeinschaftsrecht, EuR 1992, 145-162.

Bekemans, L./Balodimos A., Le traité de Maastricht et l'éducation, la formation professionelle et la cuiture, Rev. Marché unique evropéen, 2/1993, $99-142$

Bekkers, V.J./Bonnes, J.M./ de Moor-yan Vugt, Ai.C.VVoermans, W.J.M., Brussel en Nederland" tegenliggers, spookrijders of reisgenoten?, Zwolle 1993.

Benedettelli, Massimo V., Principio di eguaglianza e diviet di discriminatione mella guirispndenza communitaria in materia di diritti di mobiliata territoriale e professionale dei lavoratori, Riv. dir. eur. 1983, 325-370.

Berchx, P., De nationaliteitswoorschriften voor betrekkingen in overheidsdienst en het vrije verkeer vam werknemers binnen de E.E.G. TBP 1982, 246-459.

Berggreen, Ingeborg, Aktuelle Fragen zur Bildungspolitik der Europătischen Gemeinschaft, Schulwerwaltung 1988, 299-306.

Berggreen, Ingeborg, Der europäisclue Binnenmarkt. Konsequenzen für die Bildungspolitik, in: Schulreport (Tatsachen und Meinungen zur Bildungspolitik in Bayern) Juni 1989, 19-21.

Berggreen, Ingeborg, Rechtliche Dimension für dias Bildungswesen, Das Forum, Heft $2 / 1990,18-22$.

Berggreen, Ingeborg, Europa 1992, Zeitschrift für Pädlagogik 1,990, 827-847'. Berggreen, Ingeborg, Das Bildungswesen in Europa nach Maastricht, $\mathbb{R} d J B 1992$, 436-450.

Bergreen Ingeborg/Hochbaum, Ingo, Politikfelder zwischen Landerzustàndigkeit Bergreen Ingeborg/Hochbaum, Ingo, Politikfelder
und EG-Kompetenz, in: Borkhagen/Bruns-Kloss/Memminger/Ste in (Hrsg.). Die deutschen Länder in Europa, Baden-Baden 1992, 47-60.

Bermann, George A. The Single European Act: A New Constitution for the Community?, Columbia Journal of Transmational Law 1989, 529

Bernitz, Uif, Sweden and the EEA, LIEI 1992, 51-70.

Bernitz. Ulf, Grard/ Kirschbaum, Christiane. Frele Berufe in der EG, Bonn 1991 Berscheid, Gerard/ Kolle der Lander im deutschen Bundesstaat und ihre rechuiche Bethge, Horst, Die Rolle der Lander im deutschen Bundesstaatund in ationale Gemeinschaftspolitik, in: Dite Einflu moglichkeiten auf die nationale Bundestepublik und das Konigreich Spanien 22-50.

Beutler Bengt Aufenthaltsrechtliche Stellung von Auslandern im Rahmnen den Bildungsmignation, RdJB $1989,150-157$.

Beutier, Bengt/Bieber, Roland/ Pipkorn, Jörn/Streil, Jochen "Die Ëuropaische Beution, Bengt/ Bieber, Roland Politik - 4. Auflage, Baden-Baden 1993.

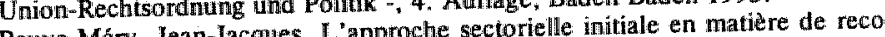
Beuve-Méry, Jean-Jacques, L approche sectorielle in niveau uniwersitaire, in naissance mutuelle des formations professionelles de noveau uniwersitaire, in: 
Beuve-Méry, RMC 1990

Bever

Beyrerlin; EuR 1987

Bieber, ELR 1988

Bieber in Bieber/Ress

Bieber/Bleckmann

Bieber Ress

Bieber/Dehousse/

Pinder/Weiler

Bilda, JuS 1989

Bishop, MLR 1989

Blanc-Jouvan,

Rev. int droit comp 1988

Bleckmann, DVBI 1976

Bleckmann, RTDE 1976

Bleckmann, CMLRev 1978 Bleckmann, Albert, German nationality within the meaning of the EEC Treaty, Bleckmann, EuR 1979

Bleckmann,

Adrinisistration

pulblique 1981

Bleckmann in Fis Sasse

Bleckmann, NIW 1982

Bleckmann, RIW 1985

Bleckmann, IZ 1985

Bleckmann in

Fis Carsten Bd.I

Bleckmann in

Lefson/Großfeld

Bleckmann, MDR 1986

Bleckmann

GRUR Int. 1986

Beuve-Mery, Jean-Jacques, La reconna îssance des diplômes: le système gênéral adopté le 21 "12.1989 par le Conseil des Communautés européennes, RMC 1990 293-304.

Bever, Sigrun, Die Rolle des Bildungsnechts in Prozeß der Europäischen Irtegration, Bochum 1987.

Beyerfin, Ulrich, Umsetzung von EG-Richtinien durch Verwaltungsworschriften

EnR $1987,126-148$

Bieber, Roland, On the Mutual Completion of Overlapping legal Systems: The Case of the European Community and the national legal orders, ELR 1988, 147 . 158.

Bieber, Roland, Zur Rolle der Mitgliedstaaten bei der Ausfüllung von Lï̈cken im EG-Recht, in: Bieber/Ress (Hrstg.). Die Dynamik des Europâischen Gemein schaftsrechts, Baden-Baden 1987, 283-310.

Bieber, Roland/Bleckmann, Albert/ Capotorti, Francesco u.a., Das Europa der zweiten Generation, Gedächnisschrift für Christoph Sasse, Band I und II, Kehl/. Straßburg 1981

Bieber, Roland/ Ress, Georg (Hrsg.), Die Dynamik des Europäischen Gemeinschaftsrechts, Baden-Baden 1987.

Bieber, R./Dehousse, R./Pinder, J./Weiller, J., 1992 One European Market?, Baden-Baden 1988.

Bilda, Klaus, Zur Reform der Juristenausbildung, JuS 1989, 681-683.

Bishop, William, Regulating the Market for legal Services in England: Enforced Seperation of Function and Restrictions on Forms of Enterprise, Modern Law Review $1989,326-351$

Blanc-Jouvan, X., L'Enseignement du droit comparê, Rapport Gemeral, Rew.int droit comp. 1988, 703-707.

Bleckmann, Albert, Art. 5 EWG-Vertrag und die Gemeinschaftstrene, DVBL. $1976,483-487$

Bleckmann, Albert, Considérations sur l"interprétation de l'article 7 du Traité CEE, RTDE 1976, 469-482.

CMLRev 1978, 435-446

Bleckmann, Albert, Teleologie und dynamische Auslegung des Europäischen Gemeinschaftsrechts, EuR 1979, 239-260.

Bleckmann, Albert, L"arrêt de la Coùr de Justice du "l 7 decembre 1980 et le droit allemand des functionnaire. Administration publique 1981, 36-42.

Bleckmann, Albert, Die Freiheiten des Gemeinsamen Marktes als: Grundrechte, in: Das Europa der Zweiten Generation, GS für Christoph Sasse, Bd. II. Kehl am Rhein/Stallburg 1981, $665-684$.

Bleckmann, Albert, Zu den Auslegungsmethoden des Europäischen Gerichtshofs, NJW 1982, 1177-1182.

Bleckmann, Albert, Die umgekehrte Diskriminierung (discrimination à rebours) im EWG Vertrag, RIW 1985, 917-921.

Bleckmann, Albert, Zur Anerkenung auslandischer Verwaltungsakte im Europaischen Gemeinschaftsrecht, JZ 1985, 1072-1077.

Bleckmann, Albert, Handlungspflichten und Zustandsicherung im Europäischen Gemeinschaftsrecht, FS tür Karl Carstens I, 1985, 43-61.

Bleckmann, Albert, Die Richtlinie im Europäischen Gemeinschaftsrecht und im deutschen Recht, in: Leffson, Rüickle, GroBfeld (Hrsg.): Handwörterbuch

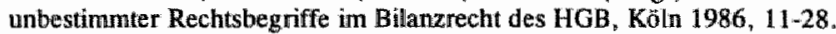

Bleckmann. Albert, Zum Begriff des Gemeinsamen Marktes im $\mathbb{E}$ WGi-Vertrag. MDR 1986, 5-10.

Bleckmarn, Albert, Zur Problematik der Cassis de Dijon Rechtsprechung des Europäischen Gerichtshofs, GRUR Int. 1986, $172-183$. 
Bleckmann, DVB॥ $\Perp 986$

Bleckmann,

Wintschaft und

Verwaltung 1987

Bleckmann, EuR 1987

Bleckmann in Bieber/Res

Dleckmann, JZ 1988

Bleckmann, JZ 1990

Bleckmann, ZRP 1.990

Bleckmann, Europarecht

Bleckmann, DVBI 1992

Blois, SEW 1991

Blumenwitz, NJW 1989

Bühm

Bösche, NJW 1978

Bogdan, JWTL 1977

Bohr/Albert, ZRP 1993

Bohrer

MitiBay No

Sondertheft 1990

Boie, NJW 1977

Boivin/Camelutiti Rew fr adm publ. 1988

Boizimu, RMC 1970 Bonger

Bonnes

Bontemps

Boon/Duncan, New Law Journal $\$ 990$

Borchmann, DöV 1988

Borchmann, EA 1991
Bleckmann, Albert, Die Personemwerkehrsfrëheit im Recht der EG-Vom Gleichheitssatz zur Verankerung absoluter Grundrechte, DVBl. 1986, 69-75.

Bleckmann, Albent, Zur Dogmatik des Niedertassungsrechts im EWG-Vertrag. Wirtschaft und Verwaltung 1987, 119-136.

Bleckmann, Albert, Die Ausnahmen der Dienstleistungsfreiheit nach dem EWGVertrag. EuR 1987, 28-51.

Bleckmann, Albert, Die Binciungswirkung der Praxis der Organe und der Mitgliedstaaten der EG bei der Auslegung und Luickenfüllung des Europäischen Gemeinschaftsrechts, in: Bieber/Ress (Hrsg.). Die Dynamik des Europaiischen Gemeinschaftsrechts, Baden-Baden 1987, 161-228.

Bleckmann, Albert, Zum Diemstleistungswerkelr der Rechtsanwälte-Anmerkung zum EnGH-Urteil vom 25. 2. 1988, JZ 1988, 506-511.

Bleckmann, Albert, Chancen und Gefahren der europäischen Integration, JZ $1990,3011-306$

Bleckmann, Albert, Politische Aspekte der europảischen Integration unter dem Vorzeichen des Binnenmarktes 1992, ZRP. 1990, 265-269.

Bleckrnann, Albert, Europarecht, 5. Auflage, Köln, Boma, Berlin, München 1990

Bleckmann, Albert, Der Vertrag über die Europäische Union, DVBl 1992, 335 343.

Blois, Matthijs de, Europees Gemeenschapsrecht en onderwijs, SEW 1991, 513537.

Blumenwitz, Dieter, Rechtsprobleme im Zusammenhang mir der Angleichung von Rechtsvorschriften auf dem Gebiet des Niederlassungsrecht der freien Berufe. Eirue Darstellung anhand einer aktuellen Problematik in Bereich der arztlichen Heilberufe, NJW 1989, 621-627.

Böhm, Reinhard, Kompetenzenauslegung und Kompetenzlücken im Gemeinschaftsrecht, Frankfurt a.M. 1985.

Bösche, Jürgen W., Das Gesetz zur Ä Ädenung der Bundesärzteordnung, NJW $1978,575-576$

Bogdan, M. Free movement of tourists within the EEC" JWTL 1977, 468.475. Bohr, Kurt/Albert, Helmut, Die Europäische Union-Ende der eigenständigen Kulturpolitik der deutschen Bundesländer?, ZRP 1993, 61-66.

Bohrer, Michael, Stellung und Aufgabe des Notars im Recht der Bundesrepublik Deutschland, in: Standort und Zukunft der Notare in Europa, MittBay Not 1990 , Sonderheft, 16-19.

Boie. Hans Hinrich, Ein Schritt zur freizugigkeit der Rechtsanwailte in der EG, NJW $1977,1567-1569$

Boiwin, J.-P./ Carnelutti. A., Les professions réglementées face a 1992 Rev .fr.adm.publ. 1988, 523-539.

Boiziau, Hélène, La mobiluté des hommes, RMC 1970,743-746.

Bongen, Wolfgang. Schranken der Freizügigkeit aus Gründen der öffentlichen Ordrung und Sichertheit im Recht der Europäischen Wirtschaftsgemeinschaft Berlin 1975.

Bonnes, J M Uitwoering van EG-verordeningen in Nederlnad, Zwolle 1994 Bontemps, M.,Liberté d'établissement et libre prestation des services dans le Marché commun, Brüssel 1968.

Boon, Andrew/Duncian, Nigel, Legal education and the profession of the future New Law Journal 1990, 200-201; 294-295.

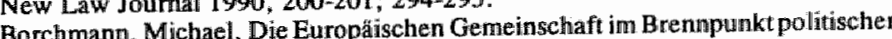
Aktivităten der Bundesländer, DôV 1988, 623-633.

Borchmann, Michael, Doppelter Foderalismus., EA 1991, 340-348. 
Borchmann/Memminger in Borkentigen u.i.

Borgreve, RIW 1984

Borkhigen u.a.

Bothe, RalsB 1978

Boulouis,

Droit social 1989

Boulouing 1992

Bourtembourg

Administration

publique 1988

Boyd,

Bus. Law Review 1986

Boyd, ELR 1982

Brackers d'Hugo

Bradley, ELR 1988

Brangsch, NJW 1981

Brangsch, AnwB1 1962

Braun, JT 1989

de Brauw CDE 1978

Bredimas

Breinsdorfer/Zimmerling, 121986

Briquet, RMC 1970

Bronkhorst, ELR 1977

Bronkhorst, CMLRev 1975 Bronkhorst, H.J., Freedom of establishment and fneedom to provide serwices

Bronkhorst, SEW 1976

Brothwood.

J. Bus. Law 1979

Ariterle, ZGR 1990

Bnuha, ZaokV 1986

Bnumois, RTDE 1970

Brunois

Bnunoîs, RTDE 1977

Borchmann, Michael/Memminger. Gerd, Das Subsidiaritätsprinzip, in Borkenhagen/Bruns-Klöss Memminger/Stein (Hrsg), Die Deutschen Länder und Europa, Baden-Baden, 1992.

Borgreve, Carlo, Mehrfache Zulassung eines Rechtsanwalts im Bereich der Europäischen Gemeinschaft, RTW 1984, 988-993

Borkhagen, Fanz H. U.J Bruns-Klöss, Christian/Memminger, Gerhard/ Stein, Otti (Hrsg.), Die deutschen Lănder in Europa, Baden-Biden 1992

Bothe., Michat, Bildungswesen und Föderalismus in rechtsvergleichender Sicht, RdJB 1978, 181-187.

Boullouis, J. . La jurisprudence professionelle et sociale de la Cour de Justice de Communautés europiennes en 1988, Droit social 1989, 337-341.

Boulouis, $J_{\star}$ Fonction publique et nationalité, Mélanges $R$. Chapus, 1992, 81-89.

Bourtembourg, J., L'enseignement et la communautarisation, Administration publique 1988, 183-199

Boyd, John, Mutual Recognition of Lawyers' Qualifications, Bus. L.R. 1986, $163 \sqrt{164}$

Boyd, AM S and the Inhouse Lawyer, ELR 1982,493-496.

Brackers d'Hugo, La Communauté européenne et la profession d"avocat, Le Barteau du France, Juli-August 1958, 8-10.

Bradley, Kieran St. C., The European Court and the Legal Basis of Commenity Legishation, ELR 1988, 379-402.

Brangsch, Heinz, Grenzüberschreitende Dienstleistungen der Anwälte in det Europäischen Gemeinschaft, NJW 1981, 1177-1180.

Bramgsch, Heinz, Die Entwicklung des Anwaltsrechts in der EWG, Anwaltsbiatt $1962,234-240$

Braun, A., Code de déontologie des avocats de la Communauté europénne, J. de Tribunaux 1989,469 .

de Brauw, P.J.W, La libéralisation de la profession d'avocat en Europe après la directive émise par le Conseil des Ministres des Communautés Europëennes do 22 mars 1977, CDE 1978, 33-58.

Bredimas, Anna, Methods of Interpretation and Community Law, Amster$\mathrm{dam} /$ New York/Oxford, 1978.

Breinsdorfer, A.W./ Zimmerling, W., Der Hochschulaulassungsansprach ausländischer Studienbewerber, JZ, 1986, 431-434.

riquet, Libertẻ d'établissement et libre prestation de services, RMC 1970, 311 318 .

Bronkhorst, H.J., Lawyer's freedom under the new directive, ELR 1977, 224 229. under the EEC Treaty, CMLRev $1975,245-253$

Bronkhorst, H.J. De ontwikkelung op het gebied van het vestingsrecht en het wrij werrichten van diensten in de Europese Gemeenschap, SEW 1976, 330-346.

Brothwood, International Law Offices, J.Bus.L 1979, 8-13

Briderle, Rainer, Aktuelles Anwaltsrecht-Neue Gesellschaftsformen für Freie Berufe-, ZGR 1990, 157-168.

Bruha, Rechtsangleichung in der europäischen Wirtschaftsgemeinschaft, ZaöRW $1986,1-33$.

Binunois, Albert, Considerations Gênérales sur les Activités de l'Avocat dans les Six Pays des Communautes Europeennes, RTDE 1970, 433-453

Brunois, Albert u.a., La profession dil'avocat dans les six êtats membres des Communautes Européennes, R'TDE 1970, 607-624.

Brunois, Albert, Le barreau et la libération des prestations de services et des établissements dans la communauté Economique Européenne, RTDE 1977, 397 434. 
Brunois, RTDE 1985

Brunois, RTDE 1988

Bruns-Wüstenfeld

Büchting/Heussen

Büschges

Bundesrat

de Burca, YbEL 1993

Burkhard,

Int. Lawyer 1986

Burrows

Busch, Int, Lawyer 1969

Biuzelay, RMC 1980

Caesar, ZRP 1990

Cagnani

Cambell, YbEL 1991

Cambell

Capelli 1993

Cappelletti

Cappelletti/

Seccombe/Weiller

Carbone,

RewDirittoE 1978

Carcini,

European Journal of Education 1989

Carmellutti,

Rev du Marché

unique européen 199

Carsin in Pertek, EIPA 1992

FS Carstens
Brumois, Albent, Après l'arrét Klopp-étar des prestations dr service et des etablissements des avocats en Europe, RTDE 1985, 65-76

Brunois, Albert, Le barreau d'Europe demain: l'affaire Gullung, RTDE 1988 , 421.435 .

Bruns-Wüstefeld, Ulrich, Die Rechtsangleichung zur Herstellwing der freien gewerblichen und beruflichen Betätigung, in: Einführung in die Rechtsfragen der europäischen Integration, KöIn 1969, 218-225.

Büchting, Hans-Ulrich/ Heussen, Benno, Beck"sches Rechtsanwalts-Handbuch, 2. Auflage, München 1991.

Büschges, Günter, Die Freien Benffe in Europa, Minteilungen der Deutschen Patentanwalle $1986,121-126$.

Bundesrat (Hrsg.), Vierzig Ialure Bundesrat, Tagung sband zum wissenschaftlichen Symposium in der evangelischen Akademie Tutzing vom 11. bis 14. April 1989, Baden-Baden 1989

de Burca, Grainne, The Principles of Proportionality and its Application in EC Law, YbEL 1993, 105-150.

Burkhard Peter H., Attorney-Client Priviledge th the EEC: The Perspective of Multinational Corporate Counsel, The International Lawyer 1986, 677-688. Burrows, Francis, Free Mowement in European Community Law, Oxford 1987. Busch, Benjanin, The Right of the U.S. Lawyers to Practice Abroad, The International Lawyer $1969,297-311 ; 617-641 ; 903-907$.

Buzelay, Alain, La liberté d'établissement comme facteur d"accentuation des disparitês régionales intra-commenautaires en l'absence d'une politique régionale et budgétaire adéquate, RMC 1980, 85-90.

Caesar, Peter, Zur Reform der Juristenausbildung, ZRP 1990, 346-347.

Cagnani, Il trattato di Roma e il dirito di stabilimento (Relazione al 16 Congresso nazionale giuridico forense, Brescia-Gardone Ruviera, 11-16 settembre 1981), Roma, 1981.

Campbell, Cathrine, The Legal Profession in a Umited Germany, YB of European Law Vol. $111991,339-382$.

Campbell, Dennis. (Hrsg.), Transnational Legal Practice: A Survey of Selected Countries, Deventer, 1982.

Capelli, Fausto, Die Anwendung des Gemeinschaftsrechts in Italien, Vorträge und Berichte Nr. 29 des Zentnims für Europäisches Wirtsehaftsrecht "Bonn 1993

Cappelletti, Mauro (Hrsg.), New Perspectives for a Common Law of Europe. Florenx 1978.

Cappelletti, Mauro/ Seccombe, / Weiler, Joseph, (Hrsg, Integration through Law, Vol.1, Book 3, Berlin, New York 1986.

Carbone, Sergio M.,., Dirutto di stabitumento e libertà di prestazione dei servizi degli operatori dell diritto: esigenza di una loro preparazione e qualificazione omogenea programmata a livello europea. RDE $1978,493,500$

Carinci, Franco, The Impact of Post-1992 Europe on Law Studies, European Jowirnal of Education 1989, No 4, 381-387.

Carnelutti. Alexandre, L'Europe des professions libérales:" la reconmaissance mutuelle des diplômes d'enseignement supérieur. Revue du Marché unique européen $1991,23-46$.

Carsin, Bertrand, National Measures. Taken to Incorporate the Directive of 21 December 1988, in: Pertek, Jacques (Hrsg.), General Recognition of Diplomas and Free Movement of Professionals, Seminar Proceedings EIPA. Maastricht

$1992,55-62$. Börner, Bodlo/JahrreiB, Hermann/Stern, Kebus, Eing Bd. 1, München 1984. 
Cassan, RTDE 1976

Caty/Lesguillons, RMC 1970

CEDEFOP

Cerych,

European Journal of

Education 1989

Cimolino, RDIPP 1966

Classen, EuR 1990

Classen, ZRP 1993

Clausnitzer

BRAK-Mitt 1989

Clausnilzzer in Lenz (1991)

Close. ELR 1978

Cludius,

Eur: Integration 1988

Coen/Holscheidu/ Pieper

Cohn, ICLQ 1960

Coing in Cappelletti

Coing 1989

Coing. NJW 1990

Collard, JT 1964

Collard 1968

Cornina

Commichan $J 21988$

Commichau, IPRax 1989

Cone

Cone, Int. Lawyer 1975

Conrad, WissR 1989

Conrad, WissR 1991

CCBE

Constantinesco

Constantinesco, Integration 1990
Cassan, Herve, Le principe de non-discrimination dans le domaine social travers la jurisprudence récente de la Cour de Justice des Communatutés européennes, RTDE $1976,259-270$.

Cary, Gilbert/ Lesguillons, Henry, Cooperation between European universities. RMC 1970, 614-629.

CEDEFOP. Beschreibung der Berufsbildungssysteme in den Mitgliedstanten der EG-Vergleijchende Studie - Luxemburg, 1982.

Cerych, Ladislaw, Higher Education and Europe after 1992: the framework, European Joumal of Education 1989, 321-332.

Cimolino, Gian Paulo, Professione forense e Communita economica europea, RDIPP 1966, 316-326.

Classen; Claus Dieter, Bildungspolitïsche Förderprogramme der EG-Eune kritische Untersuchung der vertragsrechtlichen Grundlagen, EuR 1990, 10-19.

Classen, Claus Dieter, Maastricht und die Verfassung: kritische Bemerkungen zum neuen "Europa-Artikel" 23 GG, ZRP 1993, 57-61.

Clausnitzer, Martin, Niederlassungs- und Dienstleistungsfreiheit der Anwailte, BRAK-Mitt. $1989,59 \% 66$

Clausnitzer, Martin, Niederlassungs- und Dienstleistungsfreiheit der Selbständigen, in: Lenz, Carl Otto (Hrsg.), EG-Handbuch, Recht im Binnenmarkt, Herne/Berlin 1991, 183-234.

Close, George, Harmonisation of laws: use or abuse of the powers under the EEC Treaty, ELR 1978,461-481.

Chudius, Stefan, Bildungs- und Kulturpolitik in der Europäischen Gemeinschaft, Eunopia ische Integration 1988, 26-40.

Coen, Martin/ Holscheidt, Swen/ Pieper, Stefan Ulrich (Hrsg.), Europa'93-Auf dem Weg zur Europäischen Union, FS für Albert Bleckmann zum 60. Geburtstag, Heme/Berlin 1993, 87-103.

Cohn, E J., The German Attorney-Experiences with a Unified Profession, $\mathbb{I C L Q}$ $1960,580-599$, ICLO 1961, 103-122.

Coing, Hellmut, European Common Law: Historical Foundations, in: Cappelletti (Hrsg.), New Perspectives for a Common Law of Europe, Florenz 1978, 31 . Coing, Helmut, Von Bolonga bis Brissel, Köln 1989.

Coing, Helmut, Europäisienang der Rechtswissenschaft, NJW 1990, 937-941 Collard, J", La liberté d"établissement des avocats dans la communauté euro peenne, Jourmal des Tribunaux 1964 No $4432,37-40$

Collard, J., Barreau et médecins face au droit d"etablissement, Louvain 1968. Comina, (Hrsg), Formation des ingenieurs en Europe-Engineering education in Europe, Lüttich 1983

Commichau, Gerhard Der Markt anwalticher Dienstleistung JZ 1988, 314, 824 830

Commichau, Gerhand, Fragen zum Europäischen Amwaitsrecht, IPRax 1989, 1214.

Cone, Sydney, The Regulation of Foreign Lawyers, 3. Auflage, Chicago 1984. Cone, Sydney, Foreign Lawyers in France and New York. The International Lawyer $1975,465-674$

Conrad, Holger, Die Rechtsprechung des Gerichtshofs der Europäischen Gemeinschaften auf dem Gebiet des Bildungswesens, WissR 1989, 97-110.

Conrad. Holger, Anerkennungsprobleme bei Studienabschlissen aus der ehernaligen DDR, WissR 1991, 108-121.

Conseil de Barreaux de la Cormmunauté Européenne (Hrsg.), Cross Border Practice Compendium, München 1991.

Constantinesco, Leontin-Jean, Das Rechtder Europä ischen Gemeinschaften, Band I. Das institutionelle Recht, Baden-Baden, 1977.

Constantinesco, Vlad, Subsidiarität: Zentrales Verfassungsprinzïp für die Politische Union, Integration $1990,167 \times 178$ 


\section{Constantinesco.} EuZW 1991

Corapiti 1980

Corapi 1981

Cordiplanil 1980 $\operatorname{Cox}$

Crabb, Col..Law Rev 1983 Crabb, Kelly, Providing Legal Services in a Foreign Country: Making Room for the American Attomey, Col. Law Rev. 1983, 1767-1823.

de Crayencour, RMC 1960 de Crayencour, Jean Pierre, Les professions liberales devant te Manché Commun de Crayencour. RTDE 1967 $1960,58-61$.

Traité de Rome, RTDE $1967,24-33$.

de Crayencour, CDE 1968 de Crayencour, Jean Pierre, Propos sur le droit d'établissement dans le traité de Rome, CDE 1968, 420-435.

de Crayencour, RMC 1968 de Crayencot r, Jean Pierre, Le droit d'établissement pour les architectes, RMC $1968,570-577$

de Crayencour, RMC 1968 de Crayencour, Jean Pierre, Le droit d'établissement et la presse, RMC 1968. $972-978$.

de Crayencour, RMC 1969 de Crayencour, Jean Pierre, Le droit d'établissement et les ingénieurs, RMC $1969,299-311$.

de Crayencour, RMC 1969 de Crayencour, Jean Pierre, Le droit d'établissement et les professions du domaine de la santé, - médecins, dentistes, pharmaciens-une première étape dans Ia voie de l'Europe médicale et pharmaceutique, RMC 1969, 167-182.

de Crayencour, RMC 1970 de Crayencour, Jean Pierre, La profession d'avocat et le Traité de Rome, RMC $1970,158-1168$

de Crayencour, RMC 1970 de Crayencour, Jean Pierre, La reconaissance mumelle des diplömes dans le trä́té de Rome, RMC 1970, 447-474.

de Crayencour.

Rev des Sc Econ 1970

de Crayencour, Jean Pierre, Aspects économiques de la mise en oeuvre, pour les professions libérales, de la liberté d"établissement prévue au Traitê de Rome. Rev. des Sc. econ. No $164,1970,255-262$.

de Crayencour, RMC 1973 de Crayencour, Jean Pierre, La reconnaissance mutuelle des diplömes, un retentissant échec, RMC 1973, 257-268.

die Crayencour RTDE 1976

de Crayencour 1983

de Crayencour, Jean Pierre, La reconnaissance mutuelle des diplồnes dans le Traité de Rome, RTDE 1976, 204-212.

de Crayencour, Jean Pierre. Die Europäische Gemeinschaft und die Freizugigkei der freien BerufuGegenseitige Anerkennung der Dipllome, Luxemburg 1983

Crimstham CMLRev 1978 Crimsham. C.A., Case 71/76 Jean Thieffry, CMLRev 1978, 359-370

Currall.

Rev fr. d"adm pub. 1988

Curralli, GTE-Kommentar

Cumali, RdJB 1992

Curtin, CMLRev. 1993

Curtin/O'Keeffe

Dabin

Daillier, RTDE 1976

Daintith, MLR 1989
Currall, Julian, La Communauté et les fonctions publiques nationales (1'artlicle 48 \& 4 du traité (CEE), Revue française d'adminstration publique $1988,573-582$. 48 \$ du traite CEE, Revue française d 128 EWGV in: Groeben/Thiesing/Eh Currall, Julian, Kommentar zu Art. 128, EWG in: Groeben/Thiesing Currall, Julian, Bildung und Ausbildung im Recht der Europäischen Giemein schaft, RdJB 1992, $139-161$.

Schiaf, Rd B 1992 , Constitutional structure of the Union: A Europe of Bits and Pieces, CMLRew. 1993, 17-69.

Pieces, CMLReW. Curtin, Deidre/O'Keeffe, David

Do Létablissement, Universite de Liege, 1972.

Dabin, Jean, Droit d etablissement, Drillier, Patrick, Libente d acce
nautaire, RTDE $1976,439-468$.

nautaire, RTDE 1976, 439-468. 352-368. 
Dal, CDE 1978

Dalichow in Pertek (1992)

Damien. GdP 1974

Dankelmamin

Dann, IStR 1993

Davanzo,

Rivista di diritto

internazionale comparato

e del lawaro 1964

Dauses, RIW 1984

Dauses in Bieber/Ress

Dauses, BayVBI 1989

Dauses, EuZW 1990

Dauses-Hand buch

Dauwe, SEW 1978

Dehaussy, JDI 1990

Dehousse, LIEI 1989

Delannay, CDE 1976

Deliege

De Meyer

Dencke 1956

Deneke 1969

Deregulierungskommission

Deringer, CMLRew 1973 Deringer, Arved, European Integration: a Challenge to Lawyers, CMLRew 1973

Deringer/Sedemund, NJW 1977

Desmet. RW 1967

Detienme, JT 1973

Deutscher Richterbund,

DRIZ 1992

De Witte in Biebert

Ress 1987

De Witte 1989

De Witte,

Jura Falconis 1990

Dal, G.A. Droit de libre établissement et équivalence des diplomes: Jurisprudence, CDE 1978, 228-245.

Dalichow, Fritz, Academic Recognition in the EC, in: Pertek, Jacques (Hrsg.) General Recognition of Diplomas and Free Movement of Professionals, Seminar Proceedings, Maastricht 1992,91-98.

Damien, Andre, Les Conditions de Nationalite pour l'Inscription au Barreau propos diu 21 juin 1974, GdP 13.2 . 1975 No $43-44,2-5,63$

Dankelmann, Sarder M., De erkenning varn ingenieurs in Europa, Rotterdam 1994.

Dann, Winfried, Das Leistumgsspektrum des Steuerberaters in Europa und seine beinufsirechtichen Grundllagen, IStR 1993, 46-49

Davanzo, Mario, I limiti alla libertà di stabilimento e alla libera prestazione de servizi nell'interno della CEE con riguardlo alle professioni forensi, Rivista di diritto internazionale comparato e del lawaro 1964, 100-118.

Dauses, Manfred. Dogmatik des. Freien Warenverkehrs in der Europäischen Gemeinschafit, RTW 1984, 197.

Dauses, Manfred, Quelques reflexions sur la signification et la portée de l'article 5 du Traité CEE, in: Bieber/Ress (Hrsg.), Die Dymamik des Europäischen Gemeinschafitsrechts, Baden-Baden 1987, 229-240

Dauses, Manfred, Grundlagen der Rechtsprechung des Europäischen Gerichtshofes-Auswirkung auf Bund und Länder, BayVBI. 1989, 609-613. Dauses, Manfred, Die rechtliche Dimension des Binnenmarktes, EuZW 1990, 8 11.

Dauses, Manfred, Handbuch des EG-Wirtschaftsrecht, München, 1994.

Dauwe, Brigitte, Annotatie arresten Thieffry en Patrick, SEW 1978, 221-230.

Dehuassy, Jacques, La supériorité des normes internationales sur les normes internes, Journ.Droit int. 1990, 5-33.

Dehousse, Renaud, 1992 and beyond: the institutional dimension of the interna market programme, LIEI 1989, 109-136.

Delannay, Philippe, Obserwations à Cour de Justice aff. n. 36/74, Union cycliste internationale, CDE $1976,204-226$

Deliege, R.D., Le Médecin face au marché Commun, 1967.

De Meyer, J., "Betrekkingen in overheidsdienst" een opmerkelijk arrest, in Liber amicorum Jose Mertens de Wilmars, Zwolle 1982, 47-67.

Deneke, J.F. V. Die Freien Berufe, Stutgart 1956

Deneke, J.F.V. Kiassifizierung der Freien Berufe, Köln 1969. $208-217$.

Deringer ${ }_{\text {w }}$ Arved/ Sedemund, Joachim, Europäisches Gemeinschaftsrecht, NJW $1977,988-991$

Desmet, Herwig A., Het Beroep wan de Advocaat en de Europese Economische Gemeenschap, Rechtskundig Weekblad 1967, 721-730.

Detienne L"accession aux activités économique dans la Communauté économique européenne, JT 1973, 341, 361, 381.

Deutscher Richterbund, Reform des anwalticher Berufsrechts, DRiZ 1992, 29

De Witte, Bruno, The scope of Community Powers in Education and Culture in the Light of Subsequent Practice, in: Bieber/Ress (Hrsg.). Die Dynamik des Europãischen Gemeinschaftsrechts, 1987, 261-281.

De Witte, Bruno, (Hrsg.), European Community Law of Education, BadenBaden, 1989 .

De Witte, Bruno, Recht op onderwijs zonder grenzen? Jura Falconis 1990,535 549. 
De Witte 1990

De Witte in Pertek 1992

De Witte 1992

De Witte 1995

De Witte/Post

De Witte/Fonder

Dewost in Bieber/Ress

Dhavan

Dieblich,

BRAK-Mitt. 1986

Di Fabia, NJW 1990

Ditlimar, AnwBl. 1989

Dittmann, RdJB 1978

Dittmann/Fehrenbacher, RdJB 1992

Döbrich/Jeuthe RdJB 1992

Doehring, ZRP 1993

Dörig. NJW 1990

Dơrig. NJW 1990

Dörig, EuZW 1991

Dörig/Garcia-Castañer AnwB1. 1990

Dörr, NWVBI. 1988

Dörr, EulZW 1991

Dörr, Rabels: 1990

Dohms, RdJE 1992

Dolzer Hahndorf
De Witte, Bruno, Higher Education and the Constitution of the European Community, Report for Conference on "Changing Patterns in European Higher Education" Florence, November 1990

De Witte, Bruno, The Influence of European Community Law on National Systems of Higher Education, in: Pertek, Jacques (Hrsg. $\lambda$, General Recognition of Diplomas and Free Movement of professionals, Seminar Proceedings, Maas tricht $1992,73-90$

De Witte, Binuno, Het Europees onderwijsrecht in Europa en het onderwijis, Zwolle, $1992,13-42$.

De Witte, Bruno. The Cultural Dimension of Community Law" Collected Courses of the Academy of Eur. Law 1993, 229-299.

De Witte, Bruno/Post, Harry, Educational and Cultural Rights, in: Casseses/ Clapham/Weiler (Hrsg.). Human Rights and the European Community: The Substantive Law, Baden-Baden 1991, 123-173.

De Witte, Bruno/Forder, Caroline (Hrsg.), The common law of Europe and the future of legal education, Deventer 1992.

Dewost, Jean-Louis, Décisions des Instifutions en wue du développement des Compétences et des lnstruments juridiques, in: Bieber/Ress (HIrsg. ), Die Dynamik des Europäischen Gemeinschaftsrechts, Baden-Baden 1987, $321 \mathrm{~m}-342$.

Dhawan, Rajew et al. (Hrsg.). Access to Legal Education and Professions, London, 1989.

Dieblich. Die geplante Anerkennungsrichtlinüe des Rates der EG and das französische Dekret vom 22. 10. 1985-Impulse für eine Europa-Lösung der Niederlassungsfreiheit? BRAK-Mitt 1986, 128-130.

DiFabio, Udo, Richtlinienkonformitär als rangluöchstes Normaustegungsprinzip? , NJW 1990, 947-954.

Dithmar, Ulrich, Neue Entwicklungen im Berufsrecht der Anwaltnotare, AnwBl. $1989,475-482$

Dittmann, Armin, Das Bildungswesen im föderalistischen Kompetenzgefüge-eine kritische Bestandsaufnahme, RdJB 1978, 168-180.

Ditmann, Arnim/Fehrenbacher, Claus, Die bildungstechtlichen Harmanisierungsverbote (Art. 126 Abs. 4, 127 Abs. 4 EGV) und thre Bedeutung fiur die nationale "Bildungshoheit", RdJB 1992, 478-493.

Döbrich, Peter/Jeuthe, Eberhard, Aus Distanz gibt es Einvernehmen und Harmonie, RdJB 1992, 537-547.

Doehring, Karl, Staat und Verfassung in einem zusammenwachsenden Europa, ZRP 1993, 98-103.

Dörig, Harald, Anerkennung juristischer Abschüsse aus der DDR, NJW 1990 889-891.

Dörig. Harald Bundesrepublik ermöglicht Niederlassung und Rechtsbesorgung für DDR-Anwalte. NIW 1990, 2117-2118.

Dörig. Harald, Der Zugang zur Anwaltschaft nach der EG-Diplomanerkennungsrichtlinie, EuZW $1991,243-246$.

Dörig, Harald/Garcia-Castaner, Silwia, Juristenausbildung in Spanien, AnwBI

1990, 314-316.
Dóm, Dieter, Die Europáischen Gemeinschaften und die Deutschen BundesDör, Dieter, Die Europálschen

Deamtenrecht und das Europäische Gemeinschaftsrecht, EuZW 1991, 565-571.

schaftsrech,, EuzW W Dörr, Oliver, Die Warenverkehrsireiheit mach Ar. 30 ein Diskriminierungsverbot? , Rabels $Z$ 1990, 677-691.
Dohms, Rüdiger, Die Kompetenz der EG im Bereich der allgemeinen Bildung Doh Art 126 EGV, RdJB 1992, 451-468.

nach Art. 126 EGV, RdBB 1992, $451-468$. Dolzer, Rudorion, Heidelberg 1986. 
Literaturwerzeichnis

Dolzer

Dominers,

Bestuwrswetenschappen 1991

de Dorlodot, RMC 1974

Drobnig, Rabels2 1970

Druesne , RTDE 1979

Druesne, RTDE 1981

Druesne, RTDE 1981

Druesne, RTDE 1982

Druesne, RTDE 1982

Druesne, RTDE 1985

Druesne 1991

Drijber, NJB 1988

Dubach, DVBA. 1995

Dubois, EG 1977

Duboils

Trente Jours

d"Europe 1977

Dubouis, Rev, franc.

Droit adm. 1987

Dubouis, Rev. franç.

Droit adm. 1991

Dubouis, Rev. dr. san. et social 199

Dubou is 1993

Due

Durand, ELR 1979

Dybodahl Osterborg.

GRUR Int. 1994
Dolzer, Rudolf ${ }_{n}$ Die Niederlassungsfreiheit der freien Berufe im europalischen Pecht, in: Dolzerf Hahndorf (Hrsg.), Nhederlassungsfreiheit yon freien Berufen in Europa, Deutsche Sektion derInternationalen Juristen-Kommission, Heidelberg $1986,3-15$

Dommers, J., De Nederlandse uitwoering van EEG-richtijnen, Bestuurswetenschappen $1991,40-52$

de Dorlodot. F.-X., L'avocal au regard du Traité de Rome après l'arret de la Cour de la Justice du 21 juin 1974, RMC 1974, 473-480.

Drobnig, Ulrich, Verstôßt das Staatsangehörigkeitsprinzip gegen das Diskriminierungsverbot des EWG-Vertrages?, RabelsZ 1970, 637-662

Drwesne, Gerard, Remarques sur le champ d'application personnel du droit communautaire: des "discriminations à rebours" peuvent-elles tenir en échec la liberté de circulation des personnes?, RTDE, 1979, 429-439.

Druesne, Gérard, La liberté de circulation des personnes dans la CEE et les "emplois dans l'administration publique" (sur un arrêt du 17 décembre 1980 de la Cour de justice des Communautés européennes, RTDE 1981, 286-300.

Druesne, Gérard, Note sous CJCE 6 octobre 1981 (aff n. 246/80). Liberte d'établissement des médecins-Reconnaissance mutuelle des diplomes, RTDE $1981,772-778$.

Druesne, Gérard, Libenté de prestation des services et travailleurs sajariés, RTDE $1982,75-81$.

Druesne, Gerrard, Liberté de circulation des personnes. Les prolongements de la libre circulation des salariés: Droit de séjour et progrès sociall, RTDE 1982,556567.

Druesne, Gérard, Liberté de circulation des personnes et des services, RTDE $1985,719-735$

Druesne, Gérard, L'achévement du marché intérieur européen et l'éxercise des activités indéperudantes, Mélanges $\mathbb{I}$. Boulouis, 1991 "193-205.

Drijber, Berend-Jan, Gelijke behandeling van studenten wit de EEG-zijn er nog grenzen?, NJE 1988, 1635-1640.

Dubach, Alexander, Freier Warenverkehr in der Europäischen Union: Der Gerichtshof auf neuen Pfaden, DVB1. 1995, 595-603.

Dubois, Alain, Adwocaten krijgen meer vijheid, Europese Gemeenschap, $\mathrm{Nr}$. 203, Juni/Juli $1977,8-9$.

Dubois, Alain, Vers la libre circulation des avocats, Trente Jours d'Europe, Mai $1977, \mathrm{Nr}, 226,19$.

Dubouis, Louis "La notion d'emplois dans I"Administration publique, (art. 48 \& 4 traité C. E. E.) et l'accès des ressortisants communautiares aux emplois publique, Rew, franc. Droit adm. 1987, 949-962.

Dubouis, Louis, L'ouverture de la fonction publique aux ressortissants des autre Etats membres de la Communauté européenne, Rev. franc. Droil adm. 1991. 903-919.

Dubouis, Louis, Du bon usage du droit communautaire relatif it la liberte d'établissement des membres des professions de santé, Rev. dr. sanitaire tet social $1991,211$.

Dubouis, Louis, L'Europe de la sante, AnnDr..Louv. 1993, 143-164.

Due, Ole, Der Gnindsatz der Gemeinschaftstreue in der Europäischen Gemeinschaft nach der neueren Rechtsprechung des Gerichtshofs, Zentrum für Europäisches Wirtschaftsrecht, Vorträge und Berichte, Nr. 9, Bonn 1992. Durand, Andrew, European Citizenship, ELR 1979, 3-14

Dybdahl Osterborg, Lise, Der Europatische Patentvertreter-ein neuer Beruf, ein neuer Beruffsstand, GRUR Int. 1994, 193-201. 
Easson, ICLQ 1979

Easson, Journal of

Eur. Integration 1989

von Ebel/Mohr

Eckstein/Kappus NJW 1990

Edward 1983

Edward, ELRR 1987

Ehlermann in Hrbek/Thaysen

Ehlermann CMLRev. 1987

Ehlermann,

Revue du Marché

Unique Eur. 1992

Ehliermann, RMC 1993

Eidenmülller, MLR 1990

Eiselstein, NVwZ 1989

Elgeti

Engler in Battis 1989

Ensthaler, ZRP 1992

Einel/Heinemann

wan der Esch, WuW 1988

Eschmanu

Everling. BB 1958

Ewering, BB 1958

Everling, BB 1960

Everling, BB 1961

Everling 1963
Easson, A.I., The "Direct Effect ${ }^{\text {to }}$ of EEC Directives, ICLQ 1979, 319 353.

Easson, A.J., Legal approaches to european integration: the role of Count and legislator in the completion of the european common market, Journal of European Integration 1989, 101-119.

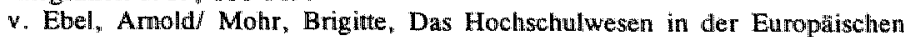
Gemeinschaft, 4. Auflage, Bonn-Bad Godesberg 1986.

Eckstein, F./ Kappus, A., "Europaische" Wege zur Fachanwaltschaft, NJW $1990,963-965$

Edward, David, The Legal Profession in the Comnunity, in: In Memoriam J.D.B. Mitchell, Lomdon 1983, 225-236.

Edward, David, Establishment and Services: A Analysis of the Insurance Cases, ELR 1987, 231-256

Ehlermann, Claus-Dieter, Die Einflußnahme der deutschen Linder auf den Entscheidungsproze in der Europaischen Gemeinschaft aus Brüsseler Sicht in: Hrbek/Thaysen, Die deutschen Länder und die Europäischen Gemeinschaften, Baden-Baden 1986, 139-148.

Ehlermann, Claus-Dieter, The Internal Market Following the Single European Act, CMLRev 1987, 361-409.

Ehlermann, Claus-Dieter, Quelques refflexions sulr la communication de la Commissio relative au principe de subsidiariê, Revue du Marché Unique Eur. $1992 / 4,215-220$.

Ehlermann, Claus-Dieter, Concurrence et professions libérales: antagonisme ou compatibilité?, RMC 1993, 136-140.

Eidenmuller, Horst, Deregulating the Market for Legal Serwices in the European Community: Freedom of Establishment and Freedom to Provide Services for EC Lawyers in the Federal Republic of Germany, Modern Law Rewiew 1990, 604 608 .

Eiselstein, Claus, Verlust der Bundesstaatlichkeit? NVwZ 1989, 323-330.

Elgeti, Axel, Inthalt und Grenzen der Föderativklausel des Art.79 $\mathrm{II}$ GG. Marburg 11968.

Engler, Helmut, Die deutschen Länder und die EG, dargestellt an den Politikfeldern Bildung, Ausbildung, öffentlicher Dienst, in: Battis, Ulrich (Hrsg.) Europäischer Birunenmarke und nationaler öffentlicher Dienst. Regensburg 1989 , 63-76

Ensthaler, Jürgen, Die Maastrichter Beschlösse zur Wirtschafts- und Wăhrungsunion, ZRP 1992, 426-430.

Ertel, R. Heinemann, H.-J. (Hrsg.), Die Liberalisierung ausgew Dienstleistungen im Europäischen Binneninarkt, Hannover 1989.

van der Esch, Bastiaan, Der Stellenwert des unwerfalischtem Wetibewerbs in der Rechtsprechung des Europäischen Gerichtshofes und der Verwaltungsprax is der Kommission, WuW 1988, 563-575.

Eschmann, Harald, Die Freizügigkeit der EG-Bürger und der Zugang zur offentlichen Verwaltung, Baden-Baden 1992.

Everling, Ulrich, Die Regelung der selbständigen beruflichen Tätigkeiten im Gemeinsamen Markt, BB 1958, 817-820.

Everlimg. Ulrich, Einzelheiten der Regelung der selbständigen benflichen Everling, Ulrich, Einzelheiten der Regelung der selbst

Tatigkeiten im Gemeinsamen der Kommission der Europäischen Wirtschaftsgemeinschaft zur Regelung des Niederlassungsrechts, BB 1960, 568-573.

gemeinschaft zur Regelung des Niedertassungsrech, Bis 1960 , Everling, Ulrich, Niederlassumgsfreiheit und freier Dienstleistungswerkehr in der Europäischen Wirtschaftsgemeinschaft. Die Alige

bung der Beschränkungen $\mathrm{BB}$ 1961,1257-1261.

Evering, Ulrich, Das Niederlassungsrecht im Giemeinsamen Markt, Berlin, Frankfurt a.M., 1963. 
Everling:

Beiheft ZHR 1965

Everling, Beiträge 1965

Everling, NJW 1967

Ewerling, FS Mosler

Ewerting.

GS Constantinesco

Everling, CDE 1984

Everling, FS Schmidt

Everling, Rabels2, 1986

Everling, EuR 1987

Everling, NVWZ 1987

Everling in Bieber/Ress

Everling in

Irs $\mathrm{S}$ von der Groeben

Everling in FS Pescatore

Everling, EuR 1989

Everling in FS Doehring

Everling,

BRAK-Mitt. 1989

Everling in Bartis 1989

Everling 1989

Everling, DE 1990

Everling, DVBL 1990
Everting. Ulrich, Die Rechtsangleichung in der Europäischen Wirtschaftsgemeinschaft auf dem Gebiet des, Niederlassungsrechts, in: Aktuelle Fragen der europaischen Gemeinschaftsrechts ${ }_{\mathrm{s}} 29$. Beiheft der ZHR, Stutgart 1965, 60-90. Everling, Ulrich, Rechtsprobleme der Gemeinsamen Handelspolitik in der

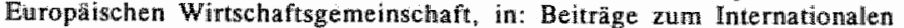
Wirtschaftsrecht und Atomenergierecht, Band 1, Heft 5, Göttingen 1965, 189 230

Everling, Ulrich, Europáisches Gemeïnschaftsrecht und nationales Recht in der praktischen Rechtsanwendung. NIW 1967, 465-473

Everling, Ulrich, Sind die Mitgliedstaaten der Europäischen Gemeinschaft noch Herren der Verträge? Zum Verhälthis Europarecht und Völkerrecht, in: FS Mosler, Berlin 1983, 173-191.

Everling, Uirich "Zur rechtlichen Wirkung von Beschlüßen, Entschlieflungen, Erklärungen und Vereinbarungen des Rates und der Mitgliedstaaten der Europäüschen Gemeinschaft, in: GS für Léontin Constantinesco, Köln 1983, 133 156* Ausgewăhlte Aufsätze, Baden-Baden 1985, $105-128$.

Everling, Ulriclt, Sur la jurisprudence récente de la Cour de Justice en matiére de libre préstation des services rendus dans d'autres Etats membres, CDE 1984. 3-14.

Everling, Ulrich, Möglichkeiten und Grenzen der Rechtsangleichung in der Europäischen Gemeinschaft, in: FS für Reimer Schmidt, Karlsnuhe 1976, 165185; Ausgewählte Aufisảize, Baden-Baden 1985, 318-339.

Everling, Ulrich, Rechtsvereinheitlichung durch Richterrecht inder Eu ropäischen Gemeinschaft, Rabels2 1986, 193-232.

Everling, Uirich, Gestaltungsbedarf des Europïischen Rechts, EuR 1987, 214 235 .

Everling, Uirich, Auf dem Wege zu eimem europäischen Verwaltungsrecht, NWwZ 1987, 1-10.

Everling, Ulrich, Probleme atypischer Rechts- und Handungsformen bei der Auslegung des europäischen Gemeinschaftsrechts, im: Bieber/Ress (Hrsg.), Die Dymamik des Europäischen Gemeinschaftsrechts, Baden-Baden 1987, 417-433.

Everling, Ulrich, Vertragswerhandlungen 1957 und Vertragspraxis 1987dargestellt an den Kapiteln Niederlassungsrecht und Dienstleistungen des EWGVertrages, in: FS futr Hans von der Groeben zu seinem 80. Geburtstag, BadenBaden 1987, $111-130$.

Everling, Ulrich, Zur Funktion der Rechtsangleichung in der Europäischen Gemeinuschaft-Vom Abbau der Verzernungen zur Schaffung des Binnenmarkts, in: Capotori, F./ Ehtermam, C.D. U.a. (Hrsg.), Liber amiconum Pierre Pescatore, Baden-Baden $1987,227-245$.

Everlimg, Ulrich, Niederlassungsrecht und Dienstleisturgswerkehr der Rechtsanwalte în der Eu ropảischen Gemeinschaft, EuR 1989, 338-355

Everling, Ulrich, Zur föderalen Struktur der Europaisischen Gerneinschaft, in: FS für Karl Doelhring, Berlin 1989, 179-198.

Everling, Ulrich, Entwicklung im anwalltichen Berufsrecht unter dem Blickwinkel des Rechts der EG, BRAK-Mitt. 1989, 166-174.

Everling, Ulrich, Die Rechtsprechung des Europäischen Gerichtshofes zur Freizitgigkeit im offentlichen Dienst, in" Battï, Ulrich (Hrsg., ), Europäischer Binnenmarkt und nationaler offentlicher Dienst, Regensburg 1989, 23-44.

Everling. Ulrich, Der Gegensitand des Niederlassungsrechts in der Europäischen Gemeinschaft, Saarbrücken 1989

Everling, Ulrich, Das Niederlassungsrecht inder Europäischen Gemeinschaft, DB $1990,1853-1859$

Everling, Ulrich, Zur Rechtsprechung des Europäiscchen Gerichtshofs uber die Beschätigung von EG-Ausländern in der ơffentlichen Verwaltung, DVBI 1990. $225-231$. 
Everling,

Gutachten 58. DJT

Everling, EuR 1990

Everling, FS Steindorff

Everling, EuR 1991

Ewerling 1992

Everling, ZRRV 1992

Everling, ZGR 1992

Everling, CMLRev. 1992

Everling, DVB1. 1993

Everling, NVwR 1993

Everts

Evrigenis, EuGRZ 1981

Eyles

Fahle

Fain

Falconetti, GdP 1972

Faller, EuGRZ 198

Faller, WissR 1987

Fastenrath, JZ 1987

Faauln, ELR 1985

Faure/Finsinger

Feger

Feldman, MLR 1989

van der Feltz
Everling, Ulrich, Welche gesetzlichen Regelungen empfehlen sich für das Recht der rechtsberatenden Berufe, insbesondere im Hinblick auf die Entwicklung in der Europäischen Gemeinschaft? Gutachten $\mathbb{C}$ für den 58 . Deutschen Juristentag. München 1990.

Everling. Ulrich, Von der Freizügigkeit der Arbeitnehmer zum Europäischen Bürgerrecht, EuR 1990, Beiheft 1, 81-103.

Everling, Ulrich, Probleme der Rechtsangleichung zur Verwirklichung des Europäischen Binnenmarktes, in: Baur/Hopt/Mailänder (Hrsg, ), FS für Steindorff, Berlin/New York 1990, 1155-1191.

Everling, Ulrich, Abgrenzung der Rechtsangleichung zur Verwirklichung des Binnemmarktes mach Art.100 a EWGV durch den Gerichtshof, EuR 1991, 179 182.

Everling, Ulrich, Die Einwirkung der Grundfreiheiten des EWG-Vertrages auf das Werberecht der Mitgliedstaaten, Zentrum für Europäisches Wirtschaftsrecht. Vorträge und Berichte Nr. 17, Bonn 1992.

Everłing, Ulrich, Die Stellung des Bürgers in der Europäischen Gemeinschaft, ZfRV 1992, 241-256.

Ewerling, Ulrich, Zur Auslegung des durch EG-Richtlinien angeglichenen nationalen Rechts, ZGR 1992, 376-395.

Everling, Ulrich, Reflections on the structure of the European Union, CMLRew 1992, 1053-1077.

Everling, Ulrich, Üherlegungen zur Struktur der Europăischen Union und zum neuen Europa-Artikel des Grundgesetzes, DVBI. 1993, 936-947.

Everling, Ulrich, Durchfühnung und Umsetzung des Europäischen Gemein schaftsrechts im Bereich des Umweltschutzes unter Berücksichtigung der Rechtsprechung des EuGH, NVwR 1993, 209-215.

Everts, B. F., Vrijheid vam vestiging en dienstverlening: het verzekeringsverkeer, in: Vrijheid van vestiging en dienstverlening in de EEG, Europese Monografieèn, Deventer 1965, 101-130.

Evrigenis, Dimitrios, Der Europäische Gerichtshof für Menschenrechte und das Recht auf Bildung, EuGRZ 1981, 637-639.

Eyles, Uwe, Das Niedierlassungsrecht der Kapitalgesellschaften in der Europäischen Gemeinschaft, Baden-Baden 1990.

Fahle, Klaus, Die Politik der Europäischen Gemeinschaften in den Bereichen Erriehung, Bíldung und Wissenschaft, Gutachten der Max-Traeger-Stiftung, Frankfurt 1989

Fain, Gaël, Professions libérales et Marché Commun, RMC 1959, 68-75.

Falconetti, Hélène, Moyens juridique donnés par le "Traité de Rome aux Avocats, GdP 10. 6. 1972, 945

Faller, Hans Joachim, Bestand und Bedeutung der Grundrechte im Bildungsbereich, EuGRZ 1981, 611-633.

Faller, Hans Joachim, Zur Zulässigkeit einer "Anerkennungsprufung" für Sudienbewerber mit deutscher Staarsangehörigkeit und ausländischer Hochschulizugangsberechtigung aus verfassungs-und europarechticher Sicht, WissR $1987,1-21$.

Fastennath, Ulrich, Inländerdiskriminierung-Zum Gleichbehandlungsge bot beim Fustenrath, Uirken mehrerer (Teil)rechtsondnungen im vertikal gegliederten und Zusammenwirken mehrerer (Teil)rechtsond 170-178.

Faull, Jonan Legal Professional Privilege (AM\&S); The Commission proposes international negotiations, ELR 1985 119-124.

Froposes Michael/Finsinger, Jörg/Siegers, Jacques/Van den Bergh, Roger. regulation of Professions, Antwerpen 1993.

Feger, Dieter Die Grundrechte im Recht der Europäischen GemeinschaftenBestand und Entwicklungs-, Frankfurt a.M., 1984.

Bestand und Entwicklung-, Frankfurt 498-5®7.

Baron van der Feltz, F., Vrijheid van vestiging en dienstvertening: de vrije Baron van der Felta, Fr vestiging en dienstvertening in de EEG. Europese beroepen, in: Vrjiheid van vestiging en 
Ferret, RTDE 1992

Feuch thofen WuBE 1989

Feuchthofen, RdISB 1994

Feuchthofen/Arackmann RdJB 1992

Feverich, AnwBl. 1989 Feuerich, NJW 1991

Feuerich

Fiedler in Magiera 1990

Fiedler/Ress

Fierstra, SEW 1992

Fierstra, SEW 1992

Fischer, VwR 1989

Fischer, NWVBI 1989

Fischer, DNotZ 1989

Fischer, EuZW 1992 Fischer 1993

Flécheux/Deninolle

Flécheux, G./Deninolle, Jur.Cl. Europe, Fasc. 730 Flessner, RabelsZ 1992

Flinterman

Publiek Domein 1988

van der Flier/Oosterkamp. SEW 1994

Flory, Savoir 1990

Flory 1991

Flynn, ICLQ 1988

Flynn, YbEL 1988

Forch, NVwZ 1987

Forlati
Ferret, Jean-Pierre, Les notaires face à l'ouverture des frontières, RTDE 1992, 11.1.115.

Feuchthofen, Jörg, Europäischer Gerichtshof stärkt Bildungskompetenz, WuBE $1989,294-300$

Feuchthofen, Jörg, Dỉe Neuordnung der Europăischen Bildungspolitik, RdJJB $1994,326 \cdots 339$

Feuchthofen, Jörg E./Brackmann, Hans-Jürgen, Berufliche Bildung im Maastrichter Unionswertrag, RdJB 1992, 468-477.

Feuerich, Wilhelm, Die überörtliche Anwaltsozietät, AnwB1. 1989, 360-368.

Feuerich, Wilhelm, Die Umsetzung der Diplomanerkennungsrichtlinie durch das Eignungsprufungsgesetz für die Zulassung zur Rechtsanwaltschaft, NJW 1991, $1144-1151$.

Feuerich, Wilhelm, Bundesrechtsanwaltsordnung, Kommentar, 2. Auflage, München 1992.

Fiedler, Wilfried, Impulse der Europäischen Gemeinschaft im kulturellen Bereich-Rechtliche Grundlagen und politische Fortentwicklung. in: Magiera, Siegfried, Das Europa der Bürger in einer Gemeinschaft ohne Binnengrenzen, Baden-Baden 1990, 147.177.

Fiedler, Wilfried/ Ress, Georg, Verfassungsrecht und Völkerrecht: Gedächnisschnift für Willhelm Karl Geck, Köln/Berlin/Bonn/München 1989.

Fierstra, Marc A., C-340/89, Vlassopoulou/Ministerium für Justiz, Bundes- und Europaangelegenheiten Baden Württemberg, SEW 1992, 640-649.

Fierstra, Marc A., C-154/89, Commissie/Frankrijk; C-1 80/89, Commissie/Italië; C-198/89, Commissie/Griekenland, arresten wan het Hof van 26 februari 1991 SEW 1992, 821-831.

Fischer, Hans Georg, Zur Freizuggigkeit von Arbeitnehmern im europäischen Geneinschaftsrecht, VwR 1989, 43.

Fischer, Hans Georg, Freizügigkeit der Arbeitnehmer snd Zugang zur öffentlichen Verwaltung im Europäischen Gemeinschaftsrecht, NWVBL 1989, 117 124.

Figcher, Hans Georg. Die Rechtstellung des deutschen Notars im Recht der Europaiischen Wirtschaftsgemeinschaft, DNotZ 1989, 467-501.

Fischer, Hans Georg, Die Unionsbürgerschaft, EuZW 1992, 566-569.

Fischer, Kristian, Die Kollision von nationalem Berufsrecht mit der Niederlassungsfreitheit in der Europäischen Gemeinschaft. Dargestellt am. Beispiel der Rechtsanwaltschatt und der Steuerberatung., Frankfurt 1993.

Flecheux, G.JDeninolle, S., Pour un Barreau européenne, La semaine juridique 1987 I, 3298.

Flecheux, G./Deninolle, La Profession d'avocat, Jur.Cl. Europe, Fasc. 730.

Flessner, Axel, Recltsvereinheitlichung durch Rechtswissenschaft und Juristenausbildung, Rabelis $1992,243-260$.

Flinterman, Cees, Nederlands recht en het onderwijs, Publiek Domein 1988, 8386.

wan der Flier, P.J./Oosterkamp, J.S., Voortvarende implementatie van EGrichtijnen, mede in het licht van de Algemene wet bestuursnecht en de Aanwijzingen voor de regelgeving, SEW 1994, 727-752.

Flory, M., La liberté de circulation des enseignants dans la Communauté europénne, Savoir 1990, 291.

Flory, M., le mythe d'ERASME, Mélanges J. Boulouis, 1991, 257.

Flynn, James, Insurance: Recent judgements of the European Court of Justice, ICLQ $1988,154-172$.

Flynn, James, Vocational Training in Community Law and Practice, YbEL 1988. 59-85.

Forch, Stefan, Freizügïgkeit für Studienreferendare, NVwZ 1987, 27-31.

Forlati Picchio, II regime comunitario delle professioni sanitarie-Riflessi nell'ordimamento italiano, Le nuevo leggi civili commentate 1983, 1299. 
Forrest, RMC 1987

Forwood/Clough, ELR 1986

Foster, ICLQ 1991

Fredebeul, BArbBI. 1965

Frésia, RMC 1975

Friedlaender

Friedlander

Friedman/Teubner

Friese, AnwBl. 1987

Friese, NJW 1988

Friese

Fröhlich

Garth

Gaudet, ZHR 1961

Geisen

Gellmer, BRAK-Mitt. 1986

Gerrittsen

Glvandi, ELR

Giehring/Haag u.a.

Gilliams, TBP 1986

Gilliams, RW 1989-90

Gilliams/Nihoul/

Wouters/Wytinck, TBH 1993

Gilliams/Van Gerven/ Wouters/Wytinck. "TBH 1994

Girolami
Forrest A., La dimension culturelle de la Commumauté europénne, RMC 1987 $326-332$

Forwood, Nicholas/ Clough, Mark, The Single European Act and Free movemert. Legal Implications of the Prowisions for the Completion of the Internal Market, ELR 1986, 383-408.

Foster, Nigel. European Community Law and the Freedom of Lawyers in the United Kingdom and Germany. ICLQ 1991, 607-634.

Fredebeul, Franzheinz, Gemeinsanne Politik der Berufsausbildung in der EWG, BArbBL, 1965, 192 ...

Frésia, Alain, La libre circulation des personnes et le principe de non-discrimination dans la jurisprudence de la cour de justice des communatés europerennes, RMC 1975, 550-564.

Friedlaender, Ernst, Wie Europa begann: Die geistigen und politischen Wurzeln der europääischen Einigung, 2. Auflage, Köln 1968.

Friedlander, Jacqueline, Securing a Lawyer's Freedom of Establishment Within the European Community, Ford ham Int'I L.J. 1987, 733-749.

Friedman, Lawrencel Teubner, Günther, Legal Education and Legal Integration: European Hopes and American Experience, in: Cappelletti, Secombe, Weiler (Hrsg.). Integration. Through Law, Vol.1 Book 3 Forms and Potential for a European Identity, $345-379$.

Friese, Franz-Josef, Die freie Advokatur in Deutschland im Lichte des Grundgesetzes und des EWG-Vertrages, Anw131 1987, 3-13.

Friese, Franz-Josef, Nochmals: Internationales Anwaltsrecht-Dienstleistung und Niederlassung, NJW 1988, 3072-3073.

Friese. Franz-Josef, Die Freie Advokatur in Deutschland, Frankfurt 1989.

Fröhlich, Stephan, Niederlassungsrecht und Freizügigkeit in der EWG und EFTA, Zürich, 1965.

Garth. Bryant G., Migrant Workers and Rights of Mobility in the European Community and the United States: A Study of Law, Community and Citizenship in Welfare State, in: Cappelletti. Mauro/Seccombe, /Weiler, Joseph, in the Welfare State, in: Cappeilett, Mauro/Seccomb,

Gaudet, Michel, Rechtliche Aspekte der Niederlassungsfreiheit im Gemeinsamen Marki, ZHR 1961, 66-87.

Geisen, Bernd, Unbekannte Zukunft für Europas Lehrer, EGmagazin 1989, 10. Gellner, Elmagr, Bilaterale Vereinbaningen mit Frankreich, BRAK-Mitt 1986, 13

15. Gerritsen, M. C.., De "nieuwe aanpak van disatie van wetgeving. RHI-Themis 1989, 323-332.

Ghandi, S. Legal Professional Privilege in European Community Law, ELR $1982,308-316$

1982, 308-316. Giehring, Heinz/Haag, Fritz/ Hoffmann-Riem, Woifgang/

Juristenausbildung-erneut dberdacht, Baden-Baden 1990 . Gilliams, Hans W. Procedurele bescherming van de wrijheid wan beroepskre

en beroepsuitoefening in de Verenigde Staten en Europa, TBP $1986,3-14$, the Gilliams, Hans W. Van "Gravier" tot "ERASMUS": Over de bijdrage van het Hof wan Justitie tot de uitbouw wan

Weekblad 1989-1990, 494-504.

Gilliams, Hans W/Nhoul, Paul/Wouters, Jan/ Wytinek, Peter, Kroniek van rechtspraak: Europees ondernemingsrecht (jamuari 1992-jull 1993), Tijdschrift voor Belgisch Handelsrecht, 1993, 497-608.

Gilliams, Hans W./Van Gerven, Yves/Wouters, Jan/Wytinck, Peter, Kroniek van rechtspraak: Europees ondememingsrecht (januari 1993-juli 1994). Tijdschrift voor Belgisch Handelsrecht, 1994, 743-872.

voor Belg Girolami, Note sulla direione dei servizi da parte degli avvocati, in relazione all relativa alla libera prestazione dei servizi da Temi Romana 1980, 757. 
Giuffrida

Giuffrida

\section{Glaesner in Schwarze 1985}

Glorieux

Gleichmann, ZHR 1985

Gleiss

Gneist

Goebel, Tulane Law Review 1989

Goebel, A.CL 1981

Goebel, Fordham Int.L.J. 1991-1992

Gölter Goehrlich, DVBI. 1986

Goebrlich/Bräth, DóV 1987

Goehrlich/Bräth, Dỏ 1989

Goffin, JT 1969

Goldman 1971

Goidman 1973

Goldman/Lyon-Caen

Goll, ZG 1989

Goowin-Gill

Goose, AWD/RIW 1975

Gormley, ELR 1982

Gormley, ELR 1983

Gormley, ELR 1984

Gormley, ELR 1985 Gormley , ELR 1986 Gormley, LIEI 1989

Gormley, ELR 1994 Gornig. NJW 1989

Gornig, Deutsche Apotheker-Zeitung 1989
Giuffrida, La professione forense in Europa: il diritto di stabilimento, in Temi Romana, 1982, 23

Giuffrida , La professione forense in Europa: la libera prestazione di serwizi, Temi Romanta $1982,546$.

Gilaesner, Hans-Joachim, Die Einführung und Entwicklung neuer Politiken in der Europäischen Gemeinschaft, in: Schwarze, Jürgen (Hrsg.), Gesetzgebung in der Europäischen Gemeinschaft, Badlen-Baden 1985, 31.

Glorieux, P., Médicine et Marché Commun, in: Barreau et médicins face au droit d'etablissement, Louwain 1968, 117-142.

Gleichmann, Karl, Europäische wirtschaftliche Inte ressenvereinigung, ZHR 1985. $633-650$.

Gleiss, Alfred (Hrsg.). Facetten des Anwaltberufs, Heidelberg 1990.

Gneist, Rudolf, Freie Adwocatur. Die erste Forderung aller Justizreform zu PreuBen, Berlin 1867.

Goebel, Roger J., Professional Qualification and Educational Requirements for Law Practice in a Foreign Country; Bridging the Cultural Gap, Tulane Law Rev. $63(1989), 443-523$.

Goebel, Roger J., Professional Responsiblity Issues in International Law Practice, AJCL 1981, 1-58.

Goebel, Roger J., Lawyers in the European Community: Progress towards. Community-wide Rights of Practice, Fordham Int.L. ., 556-651.

Gölter, Georg, Kein kulturelles Einheitseuropa, MittHV 1989, 133-137.

Goehrlich, Helmut, Das Dienstleistungsrecht der Europäischen Wirtschaftsgemeinschaft, DVBI 1986, 1192-1196.

Goerlich, Helmut/ Bräth, Peter, Europäische Freizügigkeit und nationaler Ämterzugang, DöV 1987, 1038-1049.

Goerlich, Helmut/ Brïth, Peter, Zur europäischen Freizügigkeit in offentichen Sektor, NVwZ 1989, 330-332.

Goffin, LL. L'européanisation de la profession d'avocat, uth projet de directive, JT $1969,410$.

Goldman, Bertholdd "Droit Commercial Européen, Paris 1971.

Goldman, Berthold, Europäisches Handelsrecht, Karlsruhe 1973.

Goldman, Berthold/Lyon-Caen. Antoine, Droit Commercial Européenne, 4. Auflage. Paris 1983.

Goll, Utrich, Mitwirkung der Landtage bei EG-Worthaben: Preisgabe von Beteiligungsrechten?, ZG 1989, 258.

Goodwin-Gill, Guy S, International law and the movement of persons between states, Oxford 1978.

Goose, Peter Ernst, Die Niederlassungsfreiheit im Gemeinsamen Markt, AWD/RTW 1975, 36-42.

Gomley, Laurence, Registration of General Practicioners (Case 246/80), ELR $1982,37-42$.

Gormley, Laurence, Freedom of establishment-Freedom to provide services. Free movement for hairdressers, ELR 1983, 335-336.

Gormley. Laurence, Freedom to practice at the Bar in more than one Member State, ELR 1984, 439-441.

Gormley, Laurence, The Common Market, ELR 1985, 47-48.

Gormley, Laurence, Workers and services distinguished, ELR 1986, 63-67.

Gormley, Laurence, Some Reflections on the Internal market and the free mowement of goods, L.I.E.I 1989, Heft 1, 9-20.

Gornley, Laurence, Case C-275/92-Schindler -, ELR 1994, 644-660.

Gornig, Gilbert, Probleme der Niederlassungsfreiheit und Dienstieistungsfreiheit für Rechtsanwälte in den Europåischen Gemeinschaften, NJW 1989, 1120-1127.

Gornig, Gilbert, Europảisches Gemeinschaftsrecht. Freizügigkeit und Niederlassungsfreiheit von Apothekern, Deutsche Apotheker-Zeitung 1989, 12521255. 
Gould, MLR 1989

Goyard, DöV 1989

Grabitz 1971

Grabitz in Hrbek/ Thaysen

Grabitz-Kommentar

Grabitz, EuR 1987

Grabitz/won Bogdandy

Gramlich, BayVBI. 1991

Gray, Rabelsz 1986

Graziadei 1967

Graziadei, JDI 1981

Graziadei, Foro It. 1981

Graziadei, Foro It. 1975

Graziadei, Foro It. 1978

Green in Ball/Eggins

Green/Hartley/ Usher

Greenword, YbEL 1987

Grégoire, RMC 1978

Gresser, MittBayNot 1990

Sonderheft

Gnewe/Rupp/Schneider

FS Kutscher

GBTE-Kormmentar

GTE-Kommentar

GTE-Handbuch

Groenendijk, Migrantenrecht 1992

Groenendijk,

C.A., NILR 1989
Gould, Mark, Equality of Access to Education, Modem Law Review 1989, 540550.

Goyard, Die Stellung des Gemeinschaftsrechts im französischen Recht, DöW 1989, 259-264.

Grabitz, Eberhard, Europä isches Bürgerrecht zwischen Marktbürgersehaft und Staatsbürgerschaft, Köln 1971 .

Grabitz, Eberhard, Die deutschen Länder in der EG-Politik: Verfassungsrechtliche Gntndlagen, in: Mrbek/Thaysen, Die Dewtschen Lander und die Europåische Gemeinschaften, Baden-Baden 1986, 169-195.

Grabitz, Eberhard, (Hrsg.), Kommentar zum EWG-Vertrag, Munchen, 1986. (Loseblatt)

Grabitz, Eberhard, Die dewtschen Lander in der Geneinschaft. Das Ratifi: zierungsgesetz zur Einheitlichen Europäischen Akte aus der Sicht des Grundgesetzes, EuR 1987, 310-321.

Grabitz, Eberhard/Bogdandy, Armin von, Vom Gemeinsamen Markt zum Binnenmarkt, Statik und Dynamik des Europäilischen Marktes, JuS 1990, 170-175. Gramlich, Ludwig, Europäische Inländer? Bay VBl. 1991, 417-419.

Gray, E Pluribus Unum: A Bicentennial Report on Unification of Law in the United States, RabelsZ 1986, 111-159.

Graziadei, Ercole. Per una Comunita europea degli avvocati, in Giur. it., 1967. IV, 84-87.

Graziadei, Ercolle, La Commision consultative des barreaux de la Communante européenne: C.C.B.E., JDI-Clunet $1981, n$, 3, 551

Graziadei, Ercole, CCBE (nota a ordinanza 7 maggio 1980 , causa 155/79, AM. S. Europe Lid), Foro It. 1981, IV, 153.

Graziadei, Ercole, La condizione della professione legale nella CEE: Un passo avanti, in Foro 1t. 1975, IV, 243.

Graziadei, Ercole, La condizione delle libre professioni nella CEE: un altro passo avanti, in Foro It. 1978, IV, 18

Green, Diana, 1992: Higher Education and the Challerige of the Single European Market, in: Ball/Eggins (Mrsg.). Higher Education to the 1990s: New Dimensions, London 1989, 97-111.

Green, Nicholas/ Hartley, Trevor C.J Usher, John A., The Legal Foundations of the Singlle European Market, Oxford 1991.

Greenwood, Christopher, Nationality and the Limits of Free Moverments of Persons in Community Law. YbEL 1987, 185-210.

Grépoire, Robert, L'Action Commurautaire dans le Secteur Culturel, RMC 1978. 229-238.

Gresser, Edmond, Das framzösische Notariatswesen, in: Standort und Zukunftder Notare in Europa, MittBay Not 1990, Sonderheft, $7-10$.

Grewe, Wilhelm G./ Rupp, Hans/ Schneider, Hans, Europäischene Ge riche.", stag von Hans Kutsicher, Baden-Baden. 1981

stag von Hans Kutsicher, Baden-Baden. 1981. von der Groeben, Hans 1983.

von der Groeben, Hans/ Thiesing, Jochen/ Ehlermann, Claus-Dieter, Kommentar von der Groeben, Hans/ Thüesing, Jochen/Ehlermann, Claus-Dien 1991.

zum EWG-Vertrag, Band I bis 1W, A. An/ Ehlemann ${ }_{x}$ Claus-Dieter, Handbuch des Europäischen Rechts, Baden-Baden, Loseblattausgabe

Groenendijk C.A. Europese migratiepolitiek na Maastricht:uitbreiding en beperking van vrijheden, Migrantenrecht 1992, 76-86

Groenendijk, C.A., Nationality and Access to Public Employment in the Public Groenendik, C.A., Nactice in the Netherlands, Netherlands International Law Review $1989,107-129$. 
Literatorventichnis

de Gropt.

Stalatsangehörigkeit 1989 de Groot, Gerard-René, Staatsangehörigkeit im Wandel. Eủnẻ rechtsvergleichende Studie zu dem Erwerb- und Verlustgrinden der Staatsangebörigkeit. Köln/Bond Berlin/München 1989

de Groot:

in de Wiltre/Forder.

de Groot, Gerard-Rene, European education in the 21 st century in: De Witte/Forder, The common law of Europe and the future of legal education, Deventer 1992, 7-29.

de Groot 1989 de Groot, Gerard-René, Vergelijkt alles en behoudt het goede-Beschounvingen over onderwijs en onderzoek op het gebied van rechtsverglijking. Deventer 1989

de Groot in WS Bleckmann de Groot, Gerard-Rene, Auf dem Weg zu einer europäischen Staatsangehörigkeit, in: Coen/HôlscheidtPieper (Hrsg.). Europa"93-Auf dem: Weg zur Europiaischen Union, FS für AJbert Bleckmann zum 60. Geburtstag, Herne/Berlin 1993,87103.

Grobfeld 1984

Großfeld, Bemhard, Macht und Omnmacht der Rechtswergleichung, Tübingen 1984

Großfeld, JZ 1986

Großfelld, Bernhard, Das Elend des Jurastudiums, JZ 1986, 357-360.

Groffeld, NJW 1989

Großfelld, Bernhard, Rechtsausbildung und Rechtskontrolle, NJW 1989, 875-880.

Guerin $_{\text {i }}$ M., Does engineering as a profession exist in Europe ?, European Engineer, September 1990, 18-19.

Gueron

Gueron, M.J, La recherche scientifique et la coopération des universités, RMC $1970,711-715$

Guigne

Guinand

Gunderson, NIW 1975

Dalloz 5 Juli 1978,163 Guinand, Jean, The implications of European integration for higher educational institutions in non-EEC countries, Higher Education Managememt, Juli 1990 202-212.

Guy, ELR 1979

Gunderson, F., Das Diskriminierungsverbot im EWG-Vertrag, NJW 1975, 472476.

Harick, AnwBI. 1985

Guy, D. Freedom to Provide Legal Service, ELR 1979, 135-139.

Haack, Brunhilde, Dienst- und Niederlassungsfreiheit von Reclitsanwälten unnerhalb der Europäuschen Gemeinschaft, AnwB1. 1985, 554-559.

Haas, DöV 1988

Haas, BRAK-Mitt. 1989 623.

Habscheid, NJW 1962

Haas, Evelyn, Gedanken zur Zukunft der deutschen Juristenausbildung, BRAKMitt. 1989, 68/69.

$\begin{array}{ll}\text { Habscheid, NJW } 1962 \text { Habsch } \\ \text { Mackl } & 1991 . \\ & \text { Hackl, }\end{array}$

. Walther J., Die Unabhängigkeit des Rechtsanwalts, NJW 1962, 1985

auf das Recht der Freien Berufe, Bayrenth 1992.

Hadding. NJW 1990

Hadding, Walther, "Werkotrung und Straffung der Juristenausbildung" aus der Sicht eines Universitätslehrers, NJW 1990, 1873-1877.

Háberle

HagemaniJanssen

Hahndorf 1984

Haberle, Peter, Kulturstaatlichkeit und Kulturverfassungsrecht, Darmstadt 1982

Hagemann, Comelia/Janssen, Bemd, Europäische Politik, Die Bildungs-und Kul urpolitik westeuropäischer Organisationen, Bonn 1986.

Hahndorf, Ramar, Auf dem Weg zum Europäischen Anwalt, in: 25 Jahre Bundesrechtsanwaltskanmer, Minchen 1984, 45-56.

Hahidorf 1986

Hahndorf, Raimar, Die Niederlassungsfreiheit von Rechtsanwälțen mit besonderer Berilcksichtigung des Standlesrechts, in: Niederlassung sfreiheit von freien Berufen in Europa, Deutsche Sektionder Internationalen Juristen-Kommission, Heidelberg $1986,37 \times 42$.

Hahndorf, AnwBll, 1989 Hahndorf, Raimar, Grenzen und Möglichkeiten heutiger berutsrechtlicher Regelungen fur den Anwalt, AnwBl. 1989, 430-435.

Hailbronner, DöV 1978 Hailbromner, Kay, Die Freizugigkeit im Spanmungsfeld zwischen Staatsrä son und europaischem Gemeinschaftsrecht, DôV 1978, 857-866.

Hailbronner, ZAR 1984 Hailbronner, Kay, Die Einreise und der Aufenthalt von EG-Angehörigen, ZAR 1984, 176-185.

Hailbronner, ZAR 1985 Hailbronner, Kay, Aufenthaltsbeschränkungen gegenüber EG-Angehörigen und neuere Entwicklungen im EG-Aufenthaltsrecht, ZAR 1985, 108-116. 
Hailbronner, ZAR 1988 Hailbronner, Kay, Die neuere Rechtsprechung zumEG-Freïzügigkeitsrecht, ZAR 1988,3

Hailbronner, Ausläderrecht Hailbronner, Kay, Ausländerrecht, 2. Auflage, Heidelberg 1989.

Hailbronner, ZAR 1990 Hailbronner, Kay, Zur Entwicklung der Freilzulgigkeit in der Europäischen Gemeinschaft-Rechtsprechung und Rechtspolitik, ZAR $1990,107-114$.

Hailbronner, JZ 1990 Hailbronner, Kay, Die deutschen Bundesländer in der EG, JZ 1990, 149-158.

Haillbronner, EuZW 1991

Hailbronner, Kay, Die soziale DimensionderEG-Freizügigkeit-Gleichbehandtung und Territorialiütsprinzip, EuZW 1991, 171-180.

Hailbronner, JuS 1991 Haillbronner, Kay, Europa 1992-Freizügigkeit für Studenten und Auszubildende in der Europäischen Gemeinschaft, JuS 1991, 9-18.

Hailbronner, JuS 1991 Hailbronner, Kay, Prüfungspflicht der Mitgliedstaten zur Vargleichbarkeit auslandischer Diplome und Prüfungszeugnisse-EuGH, NJW 1991, 2073, JuS $1991,917-921$

Hailbronmer, JZ, 1992

Hailbronner, Kay, Staatshaftung bei säumiger Umsetzung von EG-Richtiriten, JZ $1992.284-289$

Hailbronmer/Nachbauer, EuZW 1992

Hailbronner, Kaw/Nachbauer, Andreas, Die Dienstleistungsfreiheit in der Rechtsprechung des EuGH, EuZW 1992, 105-113.

Halbronner/Ress/ Stein

Hailbronmer, Kai/ Ress, Georg/ Stein, Torsten, Staat und Völkerrechtsordnung, FS für Karl Doehring, Berlin, Heidelberg, New York 1989

Hailbrominer/Klein/ Magiera/Muller-Graff-

Hand kommentar

Hailbronner, Kay/Klein, Eckart/Magiera, Siegfried//Müller-Graff, Peter-Chr. Hand kommentarzum EWG-Vertrag, Köl/Berlin/Bonn/München, Loseblatt 1991 ff.

Halaczinsky, INF 1991

Hallstein, RabelsZ 1964

Halaczinsky, R., Fünftes Gesetz zur Ändenung des Steuerberatungsgesetzes, INF $1991,17$.

Hallstein, Walter, Angleichung des Privat-und Prozeßrechtes in der Europäischen Wirtschaftsgemeinschaft, RabelsZ 1964, $211-231$.

Hallstein

Handoll.

Dublin Uniw.LJ 1987

Handoll, ELR 1988

Gallstein, Walter, Die Europäische Gemeinschafti, 5.Aut1. Dülisseldorf 1979

Handoll in De Witte 1989

Harbrecht

Harris

Harte-Bawendamm. AnwBl. 1989

Hartley, ELRR 1979

Hartley

Hartley, CDE 1989

Hartstang 1986

Hartstang 1991

Hartung, AnwBl. 1988

Hassemer/Kübler.

Gutachter zum 58.DJT?

Hattenhauer, JuS 1989

Handoll, John, State-definition and the free movement of workers, Dublin Unixersity Law Joumal 1987, 64-81.

Handoll, John, Article 48 (4) EEC and Non-National Access to Public Em-

ployment, ELR 1988, 223-241. Handoll, John, Forelgn teachers and pubic Baden-Baden 1989, 31-50.

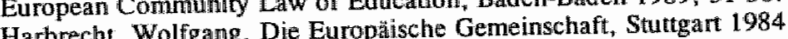

Harris Bryan, Freedom to provide professional services, New Law Journall 1989 164-165.

Harte-Bavendamm, Henning, Uberörtiche Anwaltssozietäten-Wettbewerber und "rechtsuchendes Publikum"', AnwBl. 1989, 546-551.

Hamey, Trevor G. Community Nationals at British Universities: the issue of sudent arants and fees, ELR 1979, 133-135; 222-224.

student grants and fees, ELR 1979, Eur Hartley, Trevor G. "The Foundations of European Com Community, Oxford, 3. Auflage 1994.

Cor $G$, libre circulation des etudiants en droit communataire CDE 1989, 325-344.

CDE 1989 , 325-344. Heidelberg 1986.

Hartstang, Gerhard Der deutsche Rechtsanwalt, Heidelberg 1986.

Hartstang, Gerhard, Anwalisrecht, Koln/Berin/ Bon/Mubl. 1988, 374-377

Hartung. Wolfgang " Das anwalttiche Standesrecha AnwBich-auch

Hassemer, Winfried/Kubler. Friedrich, Welche MaßBnahmem empfehlensich-auch im Hinblick auf den Wettbewerb zwischen Juristen aus den EG-Stanten-zul im Hinblick auf den Wuratenten E fur den 58 . Deut Verkürzung und Straffung der Juristen

schen Juristentag. München 1990. . Geschichte und Probleme, JuS 1989, 513 520 . 

Wirtschaft Europas, AnwBl. 1988, 553-557.

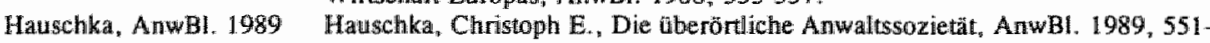
554.

Hayder, RabelsZ 1989 Hayder, Roberto, Neue Wege der EG-Rechtsangleichung? RabelsZ 53 (1989), $622-698$.

Heckmann/Meferschmidt Heckmann, Dirk/ MeBerschmidt, Klaus (Hrsg.) Gegenwartsfragen des offertli. chen Rechts, Betin 1988.

won Hehn,

BRAK-Mitt. 1985

Hehn, Paul-Adolf von, Niederlassungsfreiheit für deutsche Anwälte im Ausland. BRAK-Mitt 1985, 183-187.

Heidemann Heidemann, Winfried, Qwalifikation und Europäischer Binnenmarkt, Gewerkschaffliche Bildungspolitik, 1989, 13*15.

Heintzen Heintzen. M., Die überörtiche Anwaltssozietăt, Stutigart 1990.

Heintzem, IZ $1991 \quad$ Heintzen, Subsidiaritätsprinzip und Europäische Gemeinschaften, JZ 1991, 317 323.

Hellwig in Hrbek/Thaysen Hellwig. Renate, Anspruch und Wirklichkeit parlamentarischer Mitwirkung des Bundesstaates, in: Hrbek/Thaysen (Hrsg.), Die Deutschen Länder und die Europäischen Gemeinschaften, Baden-Baden 1986, 111-117.

Hellwig. EA 1987 Hellwig. Renate, Die Rolle der Bundeslânder in der Europa-Politik, Das Beispiel der Ratifikation der Einheitlichen Europäischen Akte, EA 1987, 297-302.

Henninger, GewArch 1989 Henninger, Michaell-Peter, Richtlinie des Rates äber eine allgemeine Regelung zur Anerkennung der Hochschuldiplome, die eine mindestens dreijahrigge Berufsausbildung abschlieben, Gew Arch. 11989, 259-262.

Henninger, BB 1990 Henninger, Michael-Peter, Europäüsches Benfsrecht. Allgemeine EG-Regelung zur Anerkennung von Benfsausbildungen, zur Gewährung der Freiziägigkeit der Arbeitnehmer und der freien Niederlassung. BB 1990, 73-78.

Hennis, LeidemIL 1990 Hennis, Edgard, Access to Education in the Europesn Communities, Leiden Journal of International Law $1990,35-44$.

Henrichs, EuGRZ 1990 Herrichs, Helmut, Gemeinschaftsrechtund nationale Verfassungen Organisatios und verfainrensrechttiche Aspekte einer Konfiktlage, EuGRZ 1990 413-423.

Henrichfreise

Henrichfreise, S. Frankreichs Anwaltschaft im Wandel: Die Entwicklung des französischen Anwaltsrechts, Kỏln 1992

Herbots, CDE 1988 Herbots" Jacques, L"avocal européen de service face au principe de la territorialite de la postullation, CDE 1988, 499-519.

Hermans/Casparie/ Patinck

Hermans,

Sichool \& Wet 1992

Hermans, H.E.G.M.KCasparie A.F./ Paelinck, J.H.P., Health care in Europe after 1992. Aldershot 1992.

Hermans, H.L.C., Het onderwijs in het Verdrag inzake een Europese Politieke Unie, School \& Wet 1992, 34-37.

Herberg. JuS 1988

Herzog

Herberg. Dieter, Das Elend des Referendarexamens ? JuS 1988, 239-244.

Herzog, Dieter, Die Problematik des Art. 57 Abs. 2 des Vertrages zur Grindung der Europäischen Wirtschaftsgemeinschaft, München 1968.

Hesse, CEDEFOP Hesse, Hans Albrecht, Der Zugang zur Berufsausbildung in den EG-Ländern CEDEFOP News/Berufsausbildung Nr.19, Dezember 1985, 1.

Hesse

Hesse, Konrad, Grundzüge des Verfassungsrechts der Bundestrepublik Deutschland, 18. Auflage, Heidelberg 1992.

Hettinger,

BRAK-Mitt, 1988

Heyning, RIW/ AWD 1968

Hettinger, Gerhard, Für und wider den Lokalisienungsgrundsatz, BRAK-Mitt. $1988,98-103$.

Hiermaier

Heyning, E. Frreizüg igkeit der Arbeitnehmer in der Europäischen Gemeinschaft endgüittig hergestellt, RiW/AWD 1968, 337-339.

Hiermaier, Werner, Der Einflub der Europäischen Gemeinschaft auf das Deutsche Bildungswesen, in: Kulturverwaltungsrecht im Wandel, Thomas Opm permann zum 50. Geburtstag, Stuttgart 1981,81-110.

Hilf, NJW 1984 Hilf, Meinhard, Die Freizügigkeit des BerutsfuBballspielers innerhalb der europäischen Gemeinschaft, NJW 1984, 517-523. 
Hilf, EuGRZ 1985

Hilf in Bieber/Ress

Hilf, EJIL 1990

Hillman,Int. Lawyer 1985

Hilmann, Die Wirtschaftsprüfung 1986

Hochbaum 1986

Hochbaum, ZBR 1989

Hochbaum, MittHW 1989

Hochbaum, MittHV 1989

Hochbaum, Der Stat 1990

Hochbaum, Bay VBI. 1987 Hochbaum, Ingo, Politik und Kompetenzen der EG im Bildungswesen, Bay VBI $1987,481-490$.

Hochbaum in

De Witte 1989

Hochbaum, DUZ 1980

Hochbaum, RallB 1992

Hochbaum, DöV 1992

Hochbrum/Eiselstein

Hoefnagel in Pertek 1992

Hoffmann

Hoffmamn-Riem in Nicolaysen

Quaritsch

Hofstede

Holch, NJW 1969

Hondius, NJB 1991

Hoppe/Snow

HarvILJ 1974

House of Lords

Select Committee

House of Lords Select Committee 1995

Hilf, Meinhard, Gerichtshof der Europaischen Gemeinschatten, Luxemburg Rechtsprechungsbericht, 1. Quartal 1985, EuGRZ 1985, 647; 2. Halbjahr 1984, EuGRZ 1985, 343-352.

Hilf, Meinhard, Maßnahmen zur Erweitenung des Wirkungsbereichs der Verträge, Bieber/Ress (Hrsg.), Die Dymamik des Europâischen Gemeinschaftsrechts, Baden-Baden 1987, 251.

Hilf, Meinhard, The SEA and 1992: legal implications for third countries, EJIL $1990,89-117$. Transactions, The Intemational Lawyer $19(1985), 3-28$.

Hillmann, Henning, Niederlassungs- und Dienstleistungsfreiheit für freie Berufe in der $\mathrm{EG}_{3}$, Die Wirtschaftisprüfung $1986,3,86-389$

Hochbaum, Ingo, Die Hochschulpolitik der Europäischen Gemeinschaften Zeitschrift für $\mathbb{R}$ echt und Verwaltung der wissenschaftlichen Hochschulen 1986, 206-219.

Ingo, Die Aktion der FG-Kommission zur Liberalisienung des fffemtichen Dienstes, ZBR 1989, Heft 2, 33-40.

Hochbaum, Ingo, ERASMUS in der Krise, MittHV 1989, 311-312.

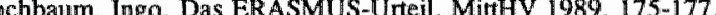

Hochbaum, Ingo, Die Liberalisierung des öffentlichen Düenstes im Binnenmarkt.

Hochbaum, Ingo, The federal structure of Member States as a limit to common educational policy: the case of Germany, in: De Witte, (ed), European Community Law of Education, Baden-Baden 1989, 145-158.

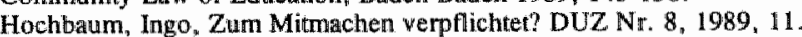

Hochbaum, Ingo, Nationale und geme inschafthiches Interesse, RdJB 1992, 505 520 .

Hochbaum, Ingo, Kohäsion und Subsidiarităt-Maastricht und die Länderkulturhoheit, DöV $1992,285-292$.

Hochbaum, Ingo, / Eiselstein, Claus, Die Freizügigkeit des Art. 48 EWG-Vertrag und deróffentliche Dienst, Arbeitnehmerbegriff, Ausbildong und Berufsausübung in europarechtlicher Sicht, Verantwortung und Leistung Heft 17, Bonn, Krefeld 1988.

Hoefnagel, Dessirée, The Work of the Coordinators' Group, in: Pertek, Jacques (Hrsg.), General Recognition of Diplomas amd Iree Movement of Professionals . Seminar Proceedings, Maastricht 1992, 63-72.

Hoffmann, Garriet, Kulurelle Beziehungem zwischen Nationen, in: Franz Greils Friz W. Meyer (Hrsg.), Wirtschaft, Gesellschaft und Kuitur, Festgabe fur Alfred Müler-Armack. Bertin 1961, 399-414

end

Hoffmann-Riem, Wolfgang, Rundfunk in Europa zwischen Wirtschafts- und Kulturfreiheit, in: Nicolaysen, /Quaritsch ( $\mathrm{Mrsg}$ ), Lüneburger Symposium fur Hans Peter Ipsen zur Feier des 80. Geburtstages, Baden-Baden 1988, 75-85. Hofstede, Geen, Cultural Differences in teaching and learning, Joumal of Intercultural Relations 1986, 301-319.

Holch, Georg, Auf dem Weg zum "europilischen" Rechtsanwalt?, NJW 1969 1505-1509.

Hondius, E.H., Naar een Europese rechtenstudie, NHB 1991, 517-520.

Hoppe, John C. I Snow, Zachary, International Legal Practice Restrictionss on the Migrant Attorney, HarvilJ 1974, 298-332.

House of Lords Select Committee on the European Communities, Recognition of Higher Education Diplomas, HL Session 1985-86, 22nd Report, Londion 1986.

House of Lords Select Commitee of the European Communities, Establishment of Lawyers, HL Session 1994-95, 14th Report, London 1995 
Hrbek 1988

Hrbelle in Hrbek/ Thaysen

Hrbek 1994

Hrbek/Thaysen

Hubeau, CDE 1981

Hidbner, JZ 1987

Huchuting AnwBI. 1978

Hüchting,

BRAKM-Mit. 1984

Hüchting,

BRAK Mitt. 1989

Hüchting, AnwBI. 1989

Huglo, RTDE 1993

Hummer, ZfRV 1992

Hurwitz

Hustädt

Institut fur Freie Benufe Ipsen, DIT 1964

Insen

Ipsen, EuR 1978

Ipsen in GS für Geck

Issac in Philip

Isensee/Kirchnof

Jach, RdJB 1992

Iacolbs

Jacobs, CLP 1977

Jacobs, ELR 1992

Jacolss, CDE 1970

Jaeger, Riw.dir eur. 1990
Hrbek, Rudolf, Die Beteiligung der deutschen Länder an den innerstathlichen Beratungen und Entscheidungen in EG-Angelegenheiten (Insbesondere im Lich von Art. 2 EEA-Gesetz und der Bund-Länder-Vereinbarung), hrsigg. vom EuropaInstitut der Universität des Saarlandes, Vorträge. Redien und Berichte aus dom Europa-Instinut Bd.117, Saarbricken 1988.

Hrbelk: Rudolf ${ }_{\text {w }}$ Doppelte Politikverflechtung: Deutscher Föderalisnus und Europaische Integration. Die deutschen Lander im $\mathbb{E G}$-EntscheidungsprozeB, in: Hrbek/Thaysen (Hrsg.), Die Deutschen Länder und die Europäischen Gemeinschaften, Baden-Baden $1986,17 \ldots 36$

Hrbek. Rudolf (Hrsg.). Europäische Bildungspolitik und die Anforderungen des Subsidiaritätsprinzips, Baden-Baden 1994.

Hrbek, Rudolf, /Thaysen, Uwe (Hrsg.), Die Deutschen Länder und die Europpatischen Gemeinschaften, Baden-Baden 1986.

Hubeau, L"exception d"ordre public et la circulation des personnes, CDE 1981 207.

Hüboner, Ulrich, Dỉe Dienstleistungsfreiheit indereuropä ischen Gemeinschaft und inre Grenzen, JZ 1987, 330-335

Hiichting, Heinrich, Europäisches Standesrecht, AnwB1. 1978, 121-123.

Hüchting, Heinrich, Freies Niederlassungsrecht für Rechtsamwälte in der EG: Wo stèthen wir? . BRAK-Mitt. 1984, 2.

Hüchting, Heinrich, Im Angesicht der EG*Richtinie zur Anerkennung von Hochschuldiplomen, BRAK-Mitt. 1989, 2-3.

Huthting, Heinrich, Die Relevanz des internationalem Wettbewerbs für die dewstsche Anwaltschaft, AnwB1. 1989, 440 447.

Huglo, J.G. "Droit d'établissement et libre prestation des serwices, RTDE 1993 655-662.

Hummer, Waldemar, Subsidliarität und Föderalismus als Strukturprinzipien der Europäischen Gemeinschaften, ZfRV $1992,81-91$.

Hurwitz, Leon, The Free Circulation of Physicians Within the European Community, Aldershat 1990.

Hustädt, Ernst W., Europäisches Gemeinschaftsrecht und Ausbildung sförderung . InfAusiR 1988, 329-330.

Institut für Freie Berufe (Hrsg.), Freie Berufe in Europa, Bonn 1993.

Ipsen, Hans Peter, Der deutsche Jurist und das europäische Gemeinschafusrecht, in: Verhandlungeta des 45. Deutschen Juristentages, Band II, Teil I, S. L 5, 1964 Ipsen, Hans Peter, Europäisches Gemeinschaftsrecht, Tübingen, 1972.

Ipsen, Hans Peter, Grenzen der Dienstleistungsfreilheit, EuR 1978, 199-241.

Ipsen, Hans Peter, Der "Kulturbegriff" im Zugriff der Europäischen Gemein schaft in: Fiedler, Wilfried/Ress Georg (Hrsg.), Verfassungsrecht und Voul kerrrecht, GS für Willheim Karl Geck, Köln/Berlin/Bonn/München 1989, 339 354.

Issac, Guy, L'enseignement supérieur et le champ d'application du Trahité CEE, in: Philip . L enseignement supérieur et la dimension européenne, Paris 1989, 11 17 .

Isensee, Josef/Kirchhof, Paul, Handbuch des Staatsrechts der Bundesrepublik Deutschland, Band VI, Freiheitsrechte, Heidellberg 1989

Jach, Frank-Rüdiger, Das neue Subsidiaritätsprinzip im Gemeinschaftsrecht, RdJB 1992, 493-504.

Jacobs, Francis G. (Hrsg.). European law and the individual, Amsterdam 1976 Jacobs, Francis G. The free mowement of persons within the EEC, CLP 1977 $123-139$

Jacobs, Francis G. Preparing English Lawyers for Eu rope, ELR 1992, 232-243.

Jacobs, P. La Directive concernant les modalités de la téalisation de la libre prestation des services pour certaines actiwités de l'avocat, CDE 1970, 663-686. Jaeger, Marc, La notion "I'emploi dans l'administration publique" au sens de I"article 48 , paragraphe 4 , du traité CEE, ä travers la jurispnudence de la Cour. Riv.dir.eur. 1990, 785-802. 
Jaeger, FS Delvaux

Jagtenberger,

Ars Aequil 1989

Janis, Int. Lawyer 1982

Janne

Janne/Schwartz

Jansen, NJB 1991

Janssen, JbEl 1980

Janssen, JbEI 1981

Janssen, JbEI 1982

Janssen, JbEI 1983

Janssen, JbEI 1984

Janssen, JbEI 1985

Janssen, JbEI 1986/87

Janssen, JbEI 1987/88

Janssen $_{*}$ JbEI $1988 / 89$

Janssen, JbEI 1989/90

Jarass, Eur 1986

Jarass, NJW 1990

Jarass, NJW 1991

Jaspert in Magiera/ Merte

Jeder

Jekewitz

Jekcwitz/Melzer

Jerrentrup

Jessnitzer

BRAK-Mitt. 1985

Jessnitzer/Blumberg
Jaeger, Marc, L accès des resortissants des autres Etats membres aux emplois dans administration publique (article 48 \& du traité CEE) in: Mélanges dédiés Michel Delvaux, Luxembourg 1990, 139-182

Jagtenberger, 1992 en het juridisch onderwijs, Ars Aequi 1989, 507-513.

Janis. M.W., The Lawyer"s Responsibility for Foneign Law and Foneign Lawyers, The International Lawyer 1982, 693-704.

Janne, Hemri, Fur eine gemeinschaftliche Bildungspolitik, Brüssel, Luxemburg 1973.

Janne, Henri Schwartz, Bertrand, Le développement europeen de l"éducation permanente, Bruxelles, 1977.

Jansen, C.J.H. De werhouding tussen wetenschap en praktijk in de juridische opleiding van de $18 \mathrm{e}$ en $19 \mathrm{e}$ eeuw. NIB 1991, 564-570.

Janssen, Bernd, Bildungspolitik, in: Jahrbuch der Europäischem Integration 1980 $211-219$

Janssen, Bernd, Bildungs und Kulturpolitk, in: Jahrbuch der Europäischen Integration 1981, 262-270.

Janssen. Bernd, Bildungs und Kulturpolitk, in: Jahrbuch der Europäischen Integration 1982, 200-208.

Janssen, Bernd, Bildungs und Kulturpolitk in: Jahrbuch der Europäischen Integration $1983,196-204$

Janssen, Bernd, Bildungs und Kulturpolitk, in: Jahrbuch der Europanischen Integration $1984,203-213$

Janssen, Bernd, Bildungs und Kulturpolitk, in: Jahrbuch der Europäischen Integration 1985, 211-219.

Janssen, Bernd, Bildungs und Kulturpolitk, in: Jahrbuch der Europäischen Integration $1986 / 87,215$

Janssen, Bernd, Bildungs und Kulturpolitk, in: Jahrbuch der Europäischen Integration $1987 / 88,222$.

Janssen, Bernd, Bildungs- und Kulturpolitik, in: Jahrbuch der Europáischen Integration 1988/89, 192-198.

Janssen, Bernd, Bildumgs- und Jugendpolitik, in* Jahrbuch der Europäischen Integration 1989/90, 208-212.

Jarass, Hans, EG-Reclat und nationales Rundfunkrecht-Zugleich ein Beitrag zur Reichweite der Dienstleistungsfreiheit, EuR 1986, 75-86.

Jarass, Hans, Voraussetzungen der innerstaatlichen Wirkung des EG-Rechis, NJW $1990,2420-2425$.

Jarass, Hans, Folgen der innerstaatlichen Wirkung von EG-Richtlinien N.JW $1991,2665-2669$

aspert, Günter, Die Beteiligung des Bundesrates an der europäischen Integration, in: Magiera/Merten (Mrsg.). Bundeständer und Europäische Gemeinschaft, Schriftenre ihe der Hochschule Speyer Bd.103, Berlin 1988. 87.

Jeder, Petra, Die Meisterprufung auf dem Prüfstand-Zur Vereirbarkeit der Berufszulassingsvorschriften des deutschen Handwerksrechts mil dern Niederlassungsrecht des $\mathbb{E}$ WGV und den Grundrechten des GG, Pfaffenweiler 1992 Jekewitz, Jurgen, Die Mitwirkung des: Bundestages bei der Regelung von Fachanwaltsbezeichnungen, ZRP 1991, 281-286.

Jekewitz, Jürgen/ Melzer, Michael/ Zeh, Wolfgang, Politik als gelebte Ver fassung Aktuelle Probleme des modernen Verfassungsstaates, Festschrift fü Friedrich Schäfer, Opladen 1980.

Jerrentrup, Hans-Heinrich, Die Niederlassungsfreiheit im Gemeinsarnen Mark umter besonderer Berucksichtigung der Rechtsprechung des Gerichtshofs der Europăischen Gemeinschaften-Folgerungen aus der unmittelbaren Geltung des Art.52 EWG-Vertrag für die Niederlassung natürlicher Personen-, Diss. Köln 1976.

Jessnitzer, Kurt, Anwaltstätigkeit im Ausland, insbesondere im Rahmen de Europäischen Gemeinschaft, BRAK.Mutt. 1985, 78-84.

Jessnitzer, Kurt,/Blumberg, Hanno, Bundestechtsanwallsordnung, 6. Auflage, Köln/Berlin/Bonn/ München 1992. 
Jessurun d"Olviera, Hans-Ulrich. The Community Case: Is Reverse Discrimination still Permissible under the Single European Act? in Centrum voor Buitenlands Recht en International Privaatrecht "The Evolution of Postwar Private International Law in Europe, Amsterdam 1990.

Jett Jett, Emest C., The Free Movement of Labour in the E.E.C., Texas international Law Journal 1973, 375-402.

Jochimsen, HdJB 1978

Jochimsen, Reimut, Ein Mindestmaß an Einheitlichkeit in unserem Bildungswesen sichern und die Parlamentarische Verantwortung stäken, RdIB 1978, 162-180.

Johansson Johansson, Ernst, Die Freizügigkeit der freien Berufe in der Europäuschen Gemeinschaft, in: Niederlassungsfreiheit von freien Benfen in Europa, Deutsche

Johnson/O'Keefe, CMLRev. 1994 Sektion der Internationalen Juristen-Kommission, Heidelberg 1986, 17-36.

Joliet. JTDE 1994 Joliet, René, La libre circulation des marchandises. L'arrêt Keck et Mithoulard et

Johnson, Ester/O'Keefe, David, From discrimination to obstacles to free movement: recent developments concerning the free movement of workers 1989 . 1994, CMLRev. 1994, 1313-1346. les nouvelles orientations de la jurisprudence, JTDE 1994, 145-151.

Jooss/Scheuerle, EuR 1989 Jooss, Gerhard/ Scheuerle, Klaus-Dieter, Die bundesstaatliche Ordnung im Integrationsprozeb-unterbesondererBerücksichtigungderEuGH-Rechtsprechung und der Rechtsschutzmöglichkeiten der Länder, EuR 1989, 226-236.

Joris/Veny, RW 1987-1988 Joris, Tony/Veny, Lado, Bijkomende inschrijvingsgelden voor buitenlandse studenten. Welke wetgeving is wan toepassing? Rechtskundig Weekblad 1987 $1988,735-740$

Joris/Veny, RW 1989-1990 Joris, Tony/Veny, Ludo, De erkeniningsrichtlijin, een stap woprwalarts in de richting van het vrije verkeer van personen, Rechtskundig Weekblad 1989-1990, $521-531$.

Yütther, Bildung und

Erziellung 1993

Jurai Europae

Jüttmer, Binnenmarkt der Bildung? , Bildung und Erziehung, 1993, 5-17.

Jura Europae, Droiltd'établissement-Niederlassungsrecht, Paris-München, Stand: Oktober 1994.

Kablert

Kahmann in

FG Müller-Armack

mut Peter, Niederlassungsfreiheit "Bledurfnisprüfung und Ar. 12 GG, Probleme bei der Rechtsangleüchung der Benufsregelungen in den sechs Mitgliedstaaten. Diss. Münster 1970.

Kahn-Freund

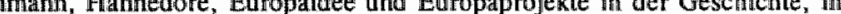
Framz Greiß, Fritz W. Meyer (Hrsg.), Wirtschaft, Gesellschaft und Kultur, Festgabe für Alfred Müller-Armack, Berlin 1961, 345-362.

Kahn Freund in

Cappelletti 1978 $82(1966), 40-61$.

Kalbe, RIW/AWD 1969

Kahn-Freund, Otto, Common Law and Civil Law, Imaginary and Real Obstacles to Assimilation, in: Cappelletti (Hrsg.), New Perspectives for a Common Law of Europe, ?, 1978, 137-168.

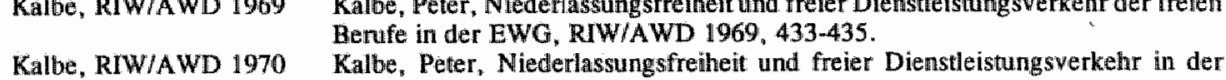
Kalbe, Peter, Niederlassungsfreiheit und freier Dienstleistungswerkeh
Europäischen Wirtschaftsgemeinschaft, RWW/AWD 1970, 163\%167.

Kalbe, RIW/AWD $1970 \quad$ Kalbe, Peter, Vorschläge zur Verwirklichung der Freizügigkeit für die freien wirtschaftsberatenden Berufe in der EWG, RIW/AWD 1970, 487-489.

Kalisch, NJW 1967

Kappus, AnwBi. 1991 Kalisch, Werner, EWG-Niederlassungsrecht und deutsches Recht der Fühning akademischer Grade, NJW 1967, 2094-2096. AnwBI. $1991,68-70$

Kapteyn/VerLoren van Themaat

Kapteyn, P.J.G./VerLoren van Themat, Introduction to the Law of the European Community, 2. Auflage bearbeitet von L. Gormley, Deventer/Boston 1989.

Karl, EuZW 199』 Karl, Joachim, Zur Multilateralisierung bilateraler Abkommen in der Europäischen Gemeinschaft, EuZW 1991, 363-367. 
Karle/Kennedy. European Joumal of Education 1989

Karoff, RabeisZ 1984

Karpenstein in GS Constantinesco

Karschmia

Kennedy, Haw.ILJ 1985

Kerschensteiner Kespohl-Willemer. EuZW 1990

Kespohl-Willemer, JZ 1990

Kewenig

Kewenig , JZ 1990

Kewenig, JZ 1990

Kewenig, JZ 1990

Kirchhof, JZ 1989 Klaier, RIW 1988

Klein, DöV 1984

Klein/Beckmarn, DöV 1990

Kleine-Cosack NJW 198 Kleine-Cosack Kleine-Cosack, NJW 1992 Kleine-Cosack, Michael, Vom Universalanwalt zum Spezialanwalt, NJW 1992,

Kinge 1980

Klinge, WuV 1987

Klis, AdvB1. 1991

Knemeyer, DVBI. 1990

Knapp

Knobbe-Keuk, DB 1990

Knobbe-Keuk, EuZW 1991

Knobbe-Kewk: DB 1991

Knobbe-Keuk,

CMLRew. 1993

Karle, Klaus/ Kennedy, Thomas, Medical Education in the European Communities: moving towand 1993 and beyond, European Joumal of Education 1989 399-410.

Kanoff, Martina, Richtllinie und Umsetzungspraxis, Eine Bestandsaufnahme anhand der Freizügigkeitsrichtlinien, Rabels Z 1984, 649-720.

Karpenstein, Peter, Zur Tragweite des Art, 48 Abs.4 EWG-Verrag, in: GS fur Léontin Jean Constantinesco, 1983, 377-392.

Karschmia, Roman, La libre circulation des médecins dans l'Europe de Neuf, LA Revue du Practicien, Nr.38, 1977

Kenmedy "David, International Legal Education, Harv. Int'1 L.J. 26 (1985), 361 385

Kerschensteiner, Georg, Theorie der Bildung, Berlin 1926.

Kespolal-Willemer, Annette, Standesregelen ơer Rechtsanwälte der Eunopäischen Gemeinschaft, EuZW 1990, 88-90.

Kespohl-Willemer, Annette, Der deutsche Anwalt in der Europäischen Gemeinschaft-rechtliche Rahmenbedingungen und Moglichkeiten, IZ 1990, 28-31. Keweng. Wilhelm A., Uberörtliche Anwaltssozietät und geltendes Recht, Frankfurt 1989

Kewenig, Wilhelm A., Die Europäischen Gemeinschaften und die bundesstaatliche Ordnung der Bundesmepublik Deutschland, IZ 1990, 458-466.

Kewenig. Wilhelm A., Niederlassungstreiheit, Freiheit des Dienstleistungs verkehrs und Inländerdiskriminienung, $J Z$ 1990, 20-28

Kewenig, Wilhelm A. Das Rechi der rechtsberatenden Berufe-eine Herausforderung für den Gesetzgeber ond die Standesorganisationen, $\$ Z, 1990,782$ 78.4 Kirchhof, Paul, Gegenwartsfragen an das Grundgesetz, JZ 1989, 453-465.

Kleier, Ulrich, Freier Warenverkehr (Art.30.EWG-Vertrag) und die Diskriminierung inlaindisclter Erzetugnisse, RIW 1988, 523-632.

Klein, Eckart, Neuere Entwicklungen im Recht der Europäischen Gemeinschaften, Dov 1984, 1010-1016.

Klein, Eckart Beckmann, Martina "Newere Entwicklungen im Recht der Europäischen Gemeinscluaften, DöV 1990, 179-189.

Cosack, Michael, Verfassungswidriges Standesrecht NJW KJeine-Cosack, Michael, Anwaltliches Berufsrecht. in: Buchting, Hans-Ulrich/Heussen, Benno, Beck" sches Rechtsanwalts-Handbuch, 2. Auflatge, München $785-791$.

Klinge, Gabriele, Die Begriffe Beschaftigung in der offentlichen Verwaltung und "Ausübung offentlicher Gewalt" im Gemeinschaftsmecht, Düsseldorf 1980

Klinge, Gabriele, Europaisches Niederiassungsrecht im Handwerk, Wirtschaft und Verwaltung 1987, 137-1.58.

Klis, G.W. van der, De witoefening van het beroep van advocaat in de EG. Advocatenblad 1991, 363-366.

Knemeyer, Subsidiarität-Foderalusmus, Dezentralismus, DVBI 1990, $450 \times 454$. Knapp, W., Der Verteidiger-Ein Organ der Rechtspflege?, Koln 1974,

Knobbe-Keuk, Brigitte, Niederlassungsfreiheit: Diskriminierungs- oder Beschränkungsverbot?, DB 1990, 2573-2584. lassungsfreiheit auf die beschränkte Steuerpflicht, EuZW 1991, 649m658.

Knobbe-Keuk. Brigitte, Wegzug und Eimbringung von Untermehmen zwischem Niederlassungsfreiheit, Fusionsrichtlinie und nationalem Stemerrech, DB 1991, 298-306.

Knoblbe-Kewk, Brigitte, Case-112/91-Hans Werner $v$. Finanzamt Aachen Intenstadt, CMLRev. 1993, 1229-1236. 
Literaturverzeichnis

Knobbe-Keuk, EuZW 1995 Knobbe-Keuk, Brigitte, Freizugigkeitund direkte Besteuerung, EuZW $1995,167$. 169.

Knoke, ZVersWiss 1987 Knoke, Udo, Einzelfragen zur Interpretation des EuGH-U rteils vom 4. Dezember 1986, ZVersWiss 1987, 227.

Koch, ZRP 1989

Koch, ZRP 1990

Kossinger

Kotz, FS für Zweigert

283.

(1)

Kach, Karl Heinz, Überlegungen zur Reform der Juristenausbildung, ZRP 1990, 41

Kössinger, Winfried, Die Durchführung des Europälischen Gemeinschaftsrechts in Bundesstaat, Schriften zum öffentlichen Recht Bd. 570, Berlin 1989.

Kötz, Hein, Gemeineuropäisches Ziwilrecht, in: FiS für Zweigert, Tübingen, $1981,481-500$

Kötz, ZRP 1980

Kötz, Rabets'Z 1986

Kotz, Glanz und Elend der juristischen Einheitsausbildung, ZRP 1980, 94-100.

Kötz, Hein, Rechtswereinheitlichung-Nutzen, Kosten, Methoderi, Ziele, RabelsZ $50(1986), 1-18$

Kötz, AnwB1. 1988

Kötz. Hein, Juristemausbildung und Anwaltsberuf, AnwBI. 1988, 320.

Kötz in De Wittel Fonder Kötz, Hein, A Common Private Law for Europe, Perspectives for the Reform off European Legal Education in: De Witte/Forder. The cormon law of Europe and the future of legal education, Deventer 1992, 31-41

Kon, ELR 1981

Kon, Stephen D. Aspects of reverse Discrimination in Community Law, ELR $1981,75-101$.

Konow, RoJB 1989

Konow, RdJB 1992

Konow, DoV 1993

Koopmans, AJCL 1991

Konow, Gerhard, Bildungs- und Kulturpolitik in der Europäischen Gemeinschaft. RdJB 1989, 125-131.

Konow, Gerhard, Bildungspolitik nach "Maastricht", RdJB 1992, 428-435.

Konow, Gerhard, Zum Subsidiaritätsprinzip des Vertrages von Maastricht, DöV $1993,405-411$

Koopmans in

De Witte/Fordier

Kornblum, BB 1985

Kornbium, ZRP' 1988

Koopmans, Thijmen, The birth of european Jaw at the crossroads of legal traditions, AJCL 1991, 493-507.

Koopmans, Thijmen, Towards a new "ius commune" in: De Witte/Forder, The common law of Europe and the futmre of legal education., Deventer 1992, 43-51. Komblum, Udo, Zum Werbeverbot für die rechts- und wirtschaftsberatenden akademischen freien Berufe, BB 1985, 65-75.

Komblum, Udo, Vom "Standesrecht" zum Berufsrecht der freien Berufe, ZRP $1988,465-471$.

Korte,

Migrantenrecht 1988

Korte, Zaak 426/85, Migrantenrecht 1988, 271-273.

Kosugi AJ

Kosugi, Takeo, Regulation of Practice by Foreign Lawyers, AJCL. 1979, 678703.

Kouwenaur

Kouwenaar, C.T.M. Higher Education in Europe. Comparative studies on the recognition of degrees and diplomas, Nuffic Paper 1, Den Harag 1994.

Kuämer, NJW' 1975

Krdimer Krămer, A., Der Rechtsanwalt, ein "staatich gebundener Vertrauensberuff?", NJW $1975,849-853$

$$
\text { Binnenmarkies, Kiel } 1987 .
$$

Kranz, AWD/RWW 1978 Kranz, Jürgen, Die Entwicklung der Dienstleistungs-und Niederlassungsfreiheit der Rechtsanwälte innerhalb der EG, AWD/RTW 1978, 160-166.

Kranz

Kraus

Kranz, Jürgen, Die Ausuibung offentlicher Gewalt durch Private nach dem Europäischen Gemeinschaftsrecht, 1984 .

Kraus, Elisabeth, Niederlassungsfreiheit der freien Berufe in der Europaischen Gemeinschaftunter besonderer Berücksichtigung der Apotheker, Würzburg 1989.

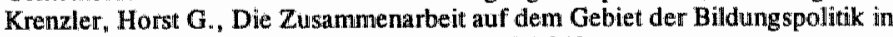
der Europüischen Gemeinschaft, EA 1975, 237-242.

Krenzler, EA 1975

Kröpil, Jus 1990 Krôpil., Karl, Zur Verkürzung der Studienzeit im Rahmen des geltenden Rechts, JuS 1990, 75-77.

Kröpil. NJW 1993 Kröpil, Karl, Gesetz. zur Verkürzung der Juristenausbildung, NJW 1993, 365 368 .

Kroppenstedt in Battis $19: 89$

Kroppenstedit, Franz, Europäische Freizügigkeitsrechteund nationaleröffentlicher Dienst, in: Battis, Ulrich (Hrsg.), Europäischer Binnenmarkt und nationaler of fentlicher Dienst, Regensburg 1989, 45-59. 
Käbler

Kühn, AnwBI 1988

Laguette, RTDE 1966

Laguette 1978

Laguette, GdP 1979

Laguette, GdP 1984

Laguette 1987

Lando, CMLRev. 1971

Lando, RabelsZ 1980

Lane, CMLRev. 1993

Lanfranchi، RDIPP 1968

Lang, BRAK-Mitt. 1990

Laslett, LIEI 1990

Lasok 1986

Lasok, ColJTL 1991

Lasak, Law Society

Gazette 1989

Lasok/Bridge

Laursen/

Vanhoonacker 1994

Lecheler

Lecheler, AöR 1978

Lecheler, BayVBI.1989

Lecheler.

Die Verwaltung 1989

Lecheler in Battis 1989

Lecheler 1990

Lecheler, ZBR 1991

Leclecq

Leenen, CMLRev. 1980
Kübler, Friedrich (Hrsg ), Anwaltsbenuf im Wandel, Frankfurt 1982

Kühn, Wolfgang, Deutsche Anwälte international in der Abstiegszone, AnwBI $1988,129-132$

Laguette, Serge-Pierre, Essai d'une application de l'article 55 dư Traité CEE à une profession liberrale: la profession d'avocat, RTDE 1966, 242-255

Laguette, Serge-Pierre, L'avocat dans les 9 Etats de la Communauté Européenne, Versailles, 1978.

Laguette, Serge-Pierre, La directive du Conseil des Communautes europennes du 22 mars 1977, Gazette du Pallais 1979 No. 2, 134-136.

Laguette, Serge-P Perre. Textes pris par les Etats de la CEE pour l'application de la Directives du Conseil des CE concernant la libre prestation des services des avocats, Gazette du Palais 1984, Nr. 8-10, 11-12.

Laguette, Serge-Pierre, Lawyers in the European Comnaunity, 1987.

Lando, Ole, The liberal professions in the European Communities, CMLRev. $1971,343-351$.

Lando, Ole, The EEC draft directive relating to self-employed commercial agents: the english Law Commission versus the E.C. Commission, RabelsZ 1980, $1-16$.

Lane, R., New Community competences under the Maastricht Treaty, CMLRev. 1993, 939-979.

Lanfranchi, Fausto, Il trattamento dello straniero nelle clausole relative allo stabilimento degli accordi bilaterali in vigore tra l"ltalia e gli esteri, RDIPP 1968 , $331-350$

Lang, Helmar, Zur Eignungsprüfung von EG-Anwälten, BRAK-Mitt. 1990, 13 16.

Laslett, Julia M., The mutual recognition of diplomas, certificates and other evidence of formal qualifications in the European Community, LIEI 1990, 1-66. Lasok, Dominik. The Profession and Services in the EEC. Deventer 1986. Lasok, Dominik, The Professions in the European Community: The Treaty Framework. Columbia Journal of Transnational Law 1991, 41-68.

Lasok, Dominik, Lawyers facing 1992, Law Society Gazette, 25. Oktober 1989, 19-25.

Lasok, Dominik/ Bridge, J., Law and Institutions of the Ezuropean Communities, 6. Auflage, London 1994

Laursen $_{\mathrm{r}}$ Finn/Vanhoonacker, Sophie (ed.), The Ratification of the Maastricht Treaty: Issues, debates and Future Implications, EIPA, Maastricht 1994.

Lecheler, Helmut, Art. 12 GG-Freiheit des Berufs und Grundrecht der Arbeit, VVDStLR 43,48

Lecheler, Helmut, Die "hergebrachten Grundsätze des Berufsbeamtentums" in der Rechtsprechung des Bundesverfarssungsgerichts und des Bundesverwaltungsgerichts, AöR 1978 (103), 349-382.

Lecheler, Helmut, Der nationale offentliche Dienst und der Europäische Binmenmarkt, Bay VBI. 1989, 417-421.

Lecheler, Helmut, Öffentliche Verwaltung in den Mirgliedstaaten nach Maßgabe der "Dynamik der Europäischen Integration", Die Verwaltung 1989, 137-149. Lecheler, Helmut. Nationaler offentlicher Dienst und europaisches Freizilgigkeitsrecht, in: Battis, Ulrich (Hrsg.), Europä ischer Binnenmarkt und nationaler öffentlicher Dienst, Regensburg 1989, 127-141.

Lecheler, Helmut, Die Interpretation des Art. 48 Abs. 4 EWGV und ihre konsequenzen für die Beschäftigung im (nationalen) öffentlichen Dienst, Berlin 1990.

Lecheler, Helmut, Die Konsequenzen des Art. 48 Abs. 4 EWGV für den nationalen offentlichen Dienst, ZBR 1991, 97-102.

Leclecq, L'awocat et le Traité de Rome, Louvain 1968.

Leenen, A.Th.S. Recent case law of the Court of Justice of the European Communities on the freedom of establishment and the freedom to provide services, CMLRev. 1980, 259-268. 
Leenen, SEW 1985

Leiliten, NJB 199 Leibrock, EuZW 199

Lethrmann

Leleux, CDE 1976

Leteux, wa. CDE 1976

Lenaerts, CMLRev. 1986

Lenaerts in De Witte 1989

Lenaerts. ZfRV 1992

Lenaerts, CMLRev. 1994

Lenaerts, K.Ivan Yperselle

CDE 1994

Lenż, LIEI 1989

Lenz, ZRP 1988

Lenx, EA 1989

Lenz in Batts 1989

Lenz in Magiera 1990

Lenz 1991

Lew, JuS 1990

Lichtenberg Vierteljahreszeitschrift fur Sozialrecht 1978

Lichtenberg in

FS Steindorff

Liebich

Lindrier

Lipsmeier, RaJB 1980

Lochner, ZStaatsw. 1962

Lonbay, ELR 1988
Leeneri, A.Th.S., Recente ontwikkelingen op het terrein van de vrijheid wan vestiging ende vrijheid vand ienstwerleming binnende $\mathbb{E E G}$, SEW 1985, 543-563. Leijten, J.C.M., De Jurist wan Morgen, NIB 1991, 503-505.

Leibrock, Gero, Stand und perspektiven der gegenseitigen Anerkennung der Diplome, EuZW 1992, 465-467.

Lehmann, Hans Georg (Hrsg.), Die Europäische Integration in der interdisziplinăren Lehrerbildung. Bonn 1981.

Leleux, Paul, La libre circulation des awacats. Problemes actuells, ler Rapport CDE 1976, 676-688

Leleux, Paul/Pettiti, Louis/Wâgrenbaur, Rolf/Rowe, Alan, La libre circulationdes dwocats et des medecins darts la CEE, CDE 1976, 673-763.

Lenaerts, Koenraad, The application of Community Law in Belgium, CMLRew. $1986,253,-286$

enaerts, Koenraad ERASMUS: legal basis and implementation, in: De Witte (ed). European Community Law of Education, Baden-Baden, 1989. 113-126. Lenaerts, Koenraad, Grundrechtsschutz in den Europäischen Gemeinschaften und im Rahmen der Europä ischen Menschenrechtskonvention, ZfRV 1992, 281-298.

Lemaerts, Koemraad, Education in European Community Law CMLRev, 1994 $7-41$.

Lenaerts, K./van Ypersele, $P_{n}$, Le principe de subsidiarité et son context: étude de l'article $3 \mathrm{~B}$ du traité $\mathrm{CE}, \mathrm{CDE} 1994,3-85$.

Lenz, Brigitte, The public serwice in article 48 (4) EEC with special reference to the law in England and in the Federal Republie of Germany, LIEI 1989/2, 75118.

Lenz, Carl Otro, Gemeinsame Grundlagen und Grundwerte des Rechts der Europäischen Gemeinschaften, ZRPP 1988, 449.

Lenz, Carl Otto, Die Rechtsprechung des Europäischen Gerichtshofs im Bereich des Billungswesens, EA 1989, 125-134.

Lenz, Carl Otto ${ }_{n}$ Die Rolle des Europäischen Gerichtshofes und des Genera lanwalls bei der Verwirklichung des EG-Binnenmarktes "in: Battis "Ulrich (Hrsg.), Europäischer Binnenmarkt und nationaler offentlicher Dienst, Regensburg 1989, 1-21.

Lenz, Carl Otto, Zuständigkeiten und Initiatiwen der Europäischen Gemeinschaft im Bereich des Bildungswesens im Lichte der Rechtsprechung des Gerichtshofs (EuGH), in: Magiera, Siegfried, Das Europa der Bürger in einer Gemeinschaft ohne Binnengrenzen, Baden-Baden 1990, 183-208.

Lent, Cart Otto (Hrsg.), EG-Handbuch, Recht im Binnenmarkt, Heme/Bertin 1991 .

Leo, Hubertus, Reform tut not! -Uberlegungen zur Änderung der juristischen Ausbildung, JuS 1990, 242-244.

Lidhtenberg, Hagen, Arztliche Tätigkeiten, klinische Leistungen und freier Dienstleistungsverkehr im Gemeinsamen Markt, Vierteljahreszeitschrift für Sozialrecht 1978, 125-150.

Lichtenberg, Hagen, Freizügigkeit und Bildungswesen in der Europäischen Gemeinschaft and der Schwelle zum gemeinsamen Binnenmarkt, in: FS für Ernst Steindorff zum 70. Geburtstag, Berlin. New York 1990, 1269-1286.

Liebich, Ferdinand K., Kultur ohne Handelsschranken, Mûnchen-Pullach, Berlin 1972.

Lindner ${ }_{\text {, Roland }}$ Europälische Politik für Forschung und Bildung, Möglichkeiten und Grenzen einer Europäischen Union, Baden-Baden, 1977.

Lipsmeier Antonius, Situation und Probleme der Benufsbildung in Europa, RdJ $1980,411-424$.

Lochner, Nobert, Was bedeuten die Begriffe Hamonisienung, Koordinierung und gemeinsame Politik in den europäischen Verträgen?. ZStaatsw., Bd.118, 1962. 35-61

Lonbay, Julian, Free movement for professionals, ELR 1988, 275-279. 
Literaturverzeichnis

Lonbay, ELR 1988

Lonbay, ELR 1989

Lonbay 1990

Lonbay ELR 1991

Lonbay in De Witte/Forder

Loschelder

Loschelder, ZBR 1991

Louis, JT 1974

Loussouran, RTDE 1969

Loussouran, RTDE 1975 Loy, JDII 1968

Loy, JDI 1975

Liike/Ress/Will,

GS Constantinesco

Lussan

Maas

Maas, H.H. Nan Haersolte, SEW 1994

Maass, DUZ 1977

Maass 1978

Maestripieri, RDIPP 1967

Matestripieri, RMC 1971

Maestripier 1972

Maestripieri

CMLRew. 1973

Magiera, DọV 1987

Magiera in

Magiera/Merten

Mangiera in FS Geck
Lonbay, Julian, Case 427/85 Commission w. Federal Republic of Germany, ELR $1988,347-352$

Lonbay, Julian, Education and Law: The Community context, ELR 1989, 363387.

Lonbay , Julian Report on the Professional Qualifications of the Legal Professions in the Non-Common Law Jurisdictions of the European Communities, Birmingham 1990.

Lonbay, Julian ${ }_{4}$ Picking over the Bones:" Rights of Establishment reviewed, ELR $1991,507-520$.

Lonbay. Julian, Differences in Legal Education in: De Witte/Forder, The common law of Europe and the future of legal education, Deventer 1992, 75-93. Loschelder, Michael, Probleme bei der Umsetzunig und Anwendung des Giemeinschaftsrechts aus anwalticher Sicht; Bonn 1992.

Loschelder, Wolfgang, Der Staatsangehơrigkeitsvorbehalt des deutschen Beamtenrechts und die gemeinschaftsrechtliche Freizulgigkeit der Arbeitnehmer: Zu den werfassungsrechulichen Grenzen supranationaler Definitionsmacht, ZBR $1991,102-112$

Louis, Jean-Wictor, Urteilsanmerkung zun Urteil des Europäischen Gerichtshofes vom $21.6,1974$ in der Rs $2 / 74, J T 1974,549$.

Loussouran, Yvon, L'harmonisation du droik d'établissement, RTDE 1969, 275 292.

Loussouran, Yvon, Droit d'établissement, RTDE 1975, 518-531.

Loy, Oderte $L$ application de la liberté d"établissement dans les Etats membres de la Communaudé économique éuropéenne, JDI-Clunet 1968,673-694.

Loy, Odetre. Le dy namisme de la Cour de Justice des Communatutés Européennes dans la libếration de l"établissement et des prestations de serwices, JDI-Clunet $1975,728-752$.

Lüke, Gerard/ Ress, Georg/Will Michael R., Rechtsvergleichung, Europarecht und Staatsintegration, Gedächnisschrift fürr Léontïn-Jean Constantinesco, Köln, Berlin, Bonn, München 1983.

Lussan, Claude, Les Communautés européennes et leur incidences sur les professions d'avocat, Le Droit Européen 1958, 49-63

Maas, H. H., De Algemene Programma's em de uitwoering daarvan, in: Vrijheid van vestiging en dienstwerlening in de EEG, Europese Monografieën, Deventer $1965,27-47$

Maas, H.H.Jvan Haersolte, J.C., Tijdige uitwoering van EG-regelgeving in Nederland door middel van wetgeving, SEW 1994, 703-726.

Mass, Kurt-Jürgen, Bildung auf europäisch, Deutsche Universitätszeitung 1977. $36,6-370$ Maass, Kurt-Jürgen, Die Bildungspolitik der Europaischen Gemeinscheft, Bonn, 1978.

Maestripieri, Cesare, Noterelle sul diritto di stabilimento e sulla libera prestazione di servizi nella CEE, RDIPP $1967,292$.

Maestripieri "Cesare, Liberté d établissement et libre prestation des services dans la CEE au lendemain de la periode de transition, RMC 1971, 48-58.

Maestripieri, Cesare, La libre circulation des personnes et des services dans la CEE, Heule, 1972.

Maestripieri, Cesare, Freedom of Establishment and freedom to Supply Services, CMLRev. 1973, 150-173.

Magiera, Siegfried, Die Europaische Gemeinschaft auf dem Weg zu einem Europa der Bürger, DoV 1987, 221-231.

Magiera, Siegfried, Als Bundesstaat in der Europäischen Gemeinschaft, in Magiera/Merten (Hrsg.), Bundeständer und Europäische Gemeinschaft Schriftenreihe der Hochschule Speyer Bd.103, Berlin 1988.

Magiera, Siegfried, Die Einheitliche Akte und die Fortentwicklung der Europäischen Gemeinschaft zur Eunopáischen Union, in: FS für Karl Geck, Manchen $1989,507-530$ 
Magiera 1989

Magtera 1990

Magiera/Merten

Magiera/Siedentopf

Mahieu/Baudrez

Maier, AnwBl. 1989

Mancini, CMLRev. 1989

Mancini in

Cuntin/O'Keeffe

Mansel, IZ 1991

Marenco, YbEL 1991

Marias, EIPA 1994

Martin, CDE 1993

Martin 1994

Martin Berna

Mattera, RMC 1990

Mattera, Rew. Marche unique eur. 11991

Mattera, Rev. Marche unique eur. 1993

Maturer, Integration 1995

Mauro, GdP 1979

Màuro. GdP 1980

Mauro/Weil, Anw Bl.. 1981 Mauro, Jacques/Weil, Heinz, Die freie Dienstleistung von Rechtsanwälten aus der Europaischen Gemeinschaft, Anwaltsblatt 1981, 128-133.

Mead,

Migrantenrecht 1988

Meier, NJW 1976

Meier, 2RP 1987

Memminger in

Magiera/Merten 1988

Magiera, Siegfried, The Emergence of a "Europe of Citizens" in a Community without Frontiers, Speyererforschungsberichte 78, 1989

Magiera, Siegfried, (Hrsg.), Das Europa der Bürger in einer Gemeinschaft ohne Binnengrenzen, Baden-Baden, 1990.

Magiera ${ }_{\text {Siegfried/Merten }}$ Detlef (Hrsg.), Bundesländer und Europäische Gemeinschaft: Schriftenreihe der Hochschule Speyer Bd. 103, Berlin 1988.

Magiera, Siegfried/Siedentopf, Heinrich, Das Recht de offentlichen Dienstes in den Mitgliedstaaten der Europailschen Gemeinschaft, Berlin 1994.

Malieu, Marc/Baudrez, Jos, De Belgische Advocatuur, Kuume 1980.

Maier, Arno, Die Zulkunft des Anwallsberufs in Frankreich, AnwBI. 1989, 320 324.

Mancini, G. F., The making of a Constitution for Europe, CMLRev. 1989, 595 614.

Mancini, G. F. The Free Movement of Workers in the Case-Law of the European Court of Justice, Curtim, D./O'Keeffe, D. (ed.), Essays for the Hon Mr. Justice T.F. O'Higgins, Dublin/London, 1992, 67-77.

Mansell, Heinz-Peter, Rechtsvergleichung und europäische Rechtseinheit, $₫ Z$. $1991,529-534$.

Marenco, Giuliano. The Notion of Restriction on the Freedom of Establishment and Provision of Services in the Case-law of the Court, Yb of European Law Vol. $111991,111-150$.

Marias, Epaminondas (ed.), European Citizenship, EIPA Masstricht 1994.

Martin, Denis, Reflexions sur le champ d"application matériel de l'article $48 \mathrm{du}$ Traite CE (à la lumière de la jurisprudence récent de la Cour de Justice) CDE $1993,555-596$

Martin, Denis, La libre circulation des personnes dans l"union eunopenne, Bǚlssel 1994

Martin Bernal, José Manuel, Abogados y jueces ante la comunidad Europea, Madrid 1990 .

Mattera, A. L'Elimination des barrières techniques et la mise en ouvre de la reconnaissance mutuelle, RMC 1990, 80-92

Mattera, A., Les principes de "proportionalité". et de "reconnaissance mutuelle" dans la jurisprudence de la Cour en matière de libre circulation des personnes et des services: de l'arret "Thieffry" aux arrêts "Vlassopoulou". "Mediawer" et "Dennemeyer", Rev. Marché unique europénne 1991/4, 191-203.

Mattera, A., La libre circulation des travailleurs à l'interieur de la Communaut to europénine, Rev. Marché unique europénne 1993/4, 47-108.

Maurer, Andrea, Sokrates, Erasmus, Comenius. Die Reform der Bildungsprogramme in der Europäischen Union, Integration 1995, 117-124.

Mauro, Jacques, L"application de la directiwe du 22 mars 1977 sur la libre prestation des avociats dans les différents pays de la Communauté, in Gazette du Palais 1979 No. 3, 322-326.

Mauro, Jacques, Le projet de loi allemand pour l'application de la directive communavitaire sur la libre prestation des avocats du 22 mars 1977, in Gazette du

Mead, Philip, Free movements of students: access to higher education in another member state, Migrantenrecht 1988, 260-263.

Meier, Gert, Die Einzelperson und das Europäische Recht, NJW 1976, 15571562 .

Meier, Gert, Die Beteiligung der Bundesländer an der Gestzgebung der Europăischen Gemeinschaften-ein Ende der Diskussion, ZRP 1987. 228-230.

Memminger, Gerhard, Die Zusammenarbeit von Bund und Ländern bei der Wahrmehmung yon EG-Aufgaben, in: Magiera/Merten(Hrsg.), Bundesländer und 
Mengel

Merten 1990

Messerschmidt, AnwBl. 1989

Mestmäcker in FS von der Groeben

Metzemaekers

Meyer-Cording in FG Müller-Armack

Meyer-Marsilius

Meyer-Marsilius, NJW 1960

Michaelis, JuS 1991

Michalski

Mickel

Mickel in CEDEFOP

Mignon in

Barreau et médicins

Minor in Pertek 1992

Mitchell, CMLRev. 1976

Mittermaier, AcP 186 Möhring, NJW 1965

Moessinger

Mohn, GewArch 1990

Molnin

Mohn, GewArch 1991

Morard

Morse, ELR 1977

Morse, ELR 1978

Morse, ELR 1978

Morse, ELR 1979
Eu ropäische Gemeinschaft, Schriftenreine der Hochschule Speyer Bd. 103, Berlin 1988,61 . Mengel, Anja, Die Ausbildung zum Anwalt in Frankreich, AnwBl. 1993, 258 260.

Merten, Detlef (Hrsg.), Föderalismus und Europäische Gemeinschaften unter besonderer Beruckstichtigung von Umwelt und Gesundheit, Kultur und Bildung, Berlin 1990.

Messerschmidt, Burkhardt, Berufsibild und Ausbildung des Adwakaten im 17. Bis 19. Jahrhundert, AnwBi. 1989, 629-636.

Mestmäcker, Ernst-Joachim/Möller, Hans/ Schwarz, Hans-Peter (Hrsg.), Eine Ordnungspolitik für Europa. Festschrift für Hans voln der Groeben zu seinem 80 . Geburtstag, Baden-Baden 1987.

Metzemaekers, L. Het rapport-Tindemans: samenwatting en karakteristiek, Nieuw Europa $1976,1-18$.

Meyer-Cording, Die europäisch Integration als geistiger Entwicklungsprozeb, in: Franz Greils, Fritz W. Meyer (Hrgg.), Wirtschaft, Gesellschaft und Kultur, Festgabe für Alfred Müller-Armack, Berlin 1961, 291 -319.

Meyer-Marsilius, Hans-Joachim, Das Niederlassungsrecht in der Europatischen Wirtschaftgemeinschaft. Heft 12 det Schriftenreihe zum Handbuch för Europäische Wirtschaft, Baden-Baden, Bonn 1960.

Meyer-Marsilius, Hans-Joachim, Das Niederlassungsrecht in der Europäischen Wirtschaftgemeinschaft. NJW 1960,756-757.

Michaelis, Karl, Die heutige Juristenausbildung und ilhr Verhältnis zur Rechtswirklichkeit, JuS $1991,798-805$.

Michalski, L., Das Gesellschafts- und Kartellrecht der rechtich gebundenen freien Berufe, Köln 1989.

Mickell, Wolfgang W. Europäische Bildungspolitik. Neuwied 1978.

Mickel, Wolfgang W., Benffs(aus)bildungssysteme in der EG: Wer oder was verhindert ihre Annäherung?, in: CEDEFOP, Berufsbildung, Annishenng der Ausbildungssufen, $\mathrm{Nr}$. 10 Dezember 1982.

Mignon, J., La liberté d'etablissement et de service des médicins, in: Barreau et médicins face au droit d'etablissement, Louvain 1968, 100-116.

Minor, Jacqueline, Introductory Lecture on the Directive of 21. December 1988 , in: Pertek, Jacques (Hrsg.), General Recognition of Diplomas and Free

Movement of Professionals, Seminar Proceedings, Mastricht 1992, 3-16.
Mitchell, J. D B. The Tindemans Report-Retrospect and Prospect, CMLRev. $1976,455 \times 484$

Mittermaier, Die würdlige Stellung des Advokatenstandes, AcP 1861, 361 .

Möhring, Ph., Aktuelle Wirkungen des EWG-Vertrages auf das Kartell recht, das Niedierlassung srecht, den Dienstleistungsverkehrund das Agrarrecht, M.JW 1965 , 1633-1648.

Moessinger, Mario, Zweifel an Europa, Stuttgart-Degerloch, 1961.

Mohn, Sybille Astrid, Das Gewerbe in Europa 1993-Die Verwirklichung des Binnenmarktes im Bereich des Niederlassungsrechts "GewArch 1990, 203-206. Mohn, Sybille Astrid, Der Gleichheitssatz im Gemeinschaftsrecht. Differenzierumgen im europäischen Gemeinschaftsrecht und ihre Vereinbarkeit mit dem Gleichheitssatz, Kehl/Strabburg/Arlington 1990.

Mohn, Sybille Astrid, Neue Entwicklungen im Bereich der Niederlassungsfreiheit der Europäischen Gemeinschaften, GewArch 1991, 55-59.

Morard, Marie-Christine, Les Diplômes en Europe, Paris 1991.

Morse G Mutual Recognition of Nursing Qualifications, ELR 1977, 363-364.

Morse, G., Mutual Recognition of Dental Qualifications, ELRR 1978, 494-450.

Morse, $G$.. The accountancy profession: progress of establishment legislation, ELR 1978, 57-71.

Morse, G., Mutual Recognition of Veterenary Qualifications, ELR 1979, $111-$ 113. 
Morse, ELR 1979

Morse, ELR 1979

Morse, ELR 1979

Morse, ELR 1980

Mortelmans, SEW 1974

Mortelmans, SEW 1979

Mortelmans,

CMLRev. 199

Mülbert, ZHR 1995

Moller:

Recht im Amt 1990

Mülller, DRIZ 1990

Müller-Bemhardt RUJB 1989

Müller-Graff, EuR 1989

Moller-Graff in FS Lukes

Múller-Graff 1991

Müller-Graff 1989

Müller-Graff, ZHR 1995

vorn Munch

Münch

Mitnnich

Nachbaur, EuZW 1991

Nagy, WR 1969

Narr

Neave, European Journal of Teacher Education 198

Neave

Neave, European Joumal of Education 1990

Neave/van Vught

Nealer, EuR 1994 Neumayer in FS Zweiger

Nickel/Bieber,
Morse, $G_{\text {. }}$ Right of Establishment and Professional Examinations in the matter of Dieter Haug. ELR 1979, 343-344.

Morse, $G$. Provision of Services: the professional supervision exception (Joined Cases 110 and $111 / 78$ ), ELR 1979, 375-377.

Morise. G., Establishment; restrictions based on qualifications (Case 136/78) ELR 1979, 378-379.

Morse, G., Mutual Recognition of Midwives Qualifications, ELR 1980, 222-224. Mortelmans, K.J., Oorzaken van de stagnatie op vestigingsgebied in de Europese Gemeenschappen, SEW 1974, 613-625.

Mortelmans, K. J. De rechtsbescherming bij pseudowetgeving in het Europees economisch recht, SEW 1979, 654-674

Mortelmans, Airt. 30 of the EEC Treaty and legislation relating market cir cumstances: Time to consider a new direction, CMLRev. 1991, 115-136.

Mulbert, Peter O., Privatrecht, die EG-Grundfreiheiten und der Binmenmarkt, ZHR $1995,2-33$

Muller, Gerd, Auswirkungen des EG-Binnenmarktes auf die ôffentliche Verwaltung. Recht in Amt 1990, 53-60.

Miller, Wolfgang, Die deutsche Juristenausbildung und Europa, DRiZ 1990, 81 102.

Müller-Bernhardt, Ulrich, Anerkentnung von Hochschuldiplomen im Gemeinschaftsrecht, RdJB 1989, 130-139.

Müller -Graff, Die Rechtsangleichung zur Verwirklichung des Binnenmarkts, EuR $1989,107-151$

Müller-Graff, Peter-Chr., Dienstleistungsfreiheit und Erbringunsformen grenzüberschreitender Dienstleistungen. FS für Rudolf Lukes zum 65. Geburtstag, Köln/Berlin/Bonn/München 1989, 471-493.

Müller-Graff, Peter-Chr., Privatrecht und Europäisches Gemeinschaftsrecht, 2. Auflage, Baden-Baden 1991.

Muller-Graff, Peter-Chr. , Binnenmarktziel und Rechtsordnung, Bergisch Gladbach/Köln 1989

Muller-Graff, Peter-Chr., Binnenmarktauftrag und Subsidiaritätsprinzip, ZHR $1995,34-77$.

von Münch, Ingo, Statsrecht-Völkerrecht-Europarecht, Festschrift für HansJirgen Schlochauer, Berlin-New York, 1981.

Münch, Werner, Europa als Bildungsgemeinschaft-Neue Herausforderungen am unsere Bildungspolitik durch den Europäischen Binnenmarkt, Europa als Auftrag, Heft $7,1990,1 \times 19$

Münnich, Lutz, Art. 7 und Inländerdiskriminienmg, ZfRV 1992, 92-100.

Nachbaur, Andreas, Art. 52 EWGV-Mehr als nur ein Diskriminierungsverbot?, EuZW 1991, 470-472.

Nagy, N. Le droit d'établissement et les prestations de services 'dans la Communaute Eeonomique Europeenne, WR 1969, 173,191.

Narr, H., Ärtliches Berufsrecht: Ausbildung. Weiterbildung, Berufsausübung, 11. Ergänzungsi ieferung, Köln 1989.

Neave, Guy, Community policy and teacher education, European Journal of Teacher Education 1982, Vol. 5, Nr, 1-2.

Neave, Guy, The EEC and Education, Stoke-on-Trent, 1984.

Neave, Guy, On Preparing for markets: Trends in Higher Education in Western Europe 1988-1990, European Journal of Education 1990, 105-122.

Neawe, Guy/van Vught, Frans, The changing rellationship between government and higher education in Western Europe, Oxford 1991.

Nealer, V, Die "neue Landermitwirkung" mach Maastricht, EuR 1994, 216-229.

Neumayer, Karl, Rechtsvergleichung als Unterrichtsfach an deutschen Universităten, in: FS für Z Zweigent, Tübingen, 1981, 501-523. 
EuGRZ 1979

Nickel, ZRP $\llbracket 980$

Nicolaysen,

Beiheft der ZHR 1965

Nicolaysen, EuR 1975

Nicolaysen, RdJB 1980

Nicolaysen in Battis 1989

Nicolaysen/Quaritsch,

Niedobitek

Niessen, Die

Wirtschaftsprüfung 1984

Niehus, Die

Wirtschaftsprïfung 1989

Niggemann,

BRAK-Mitt. 1986

Nordemann, Die

Wirtschaftsprüfung 1989

Norgaardi, EuGRZ 1981

Notte

Nowack, BB 1993

van Nuffel, SEW 1984

van Nuffel, SEW 1990

Oberreit/Knapp,

AnwBI. 1980

Oellers, BRAK-Mitt. 1884 Oellers, Bernhard, Das nächste Jahrzehnt Anwaltsschwemme, BRAK-Mitt 1984, 113.

O'Caoinh, ELR 1980

$\mathrm{O}^{\prime}$ Caoinh, A., The Implementation of the Directive on Lawyers Freedom to Supply Services in Ireland, ELR 1980, 235-240.

O"Keeffe. CMLRew. 1982 O'Keeffe, David, Practical Difficulties in the Application of Art.48 of the EEC

O'Keeffe, Y'bEL 1986 Trealty. CMLRev 1982, 35-60

O'Keeffe, David, Equal rights for migrants: the concept of social advantages in Art.7 (2) Regulation 1612/68, YbEL 1986,93-123.

O'Keeffe, David, Judicial Interpretation of the Public Service Exception the the Free Movement of Workers, in Curtin, D./O'Keeffe (eds.). Constitutional Adjudication in European Community and National Law "Essiays for the Hon. Mr. Justice O'Higgins, London $1992,89$.

O'Keefe, ELR 1992

$O^{3}$ Keefe, David. The free movement of persons and the single market, ELR 1992, 3-19.

O'Keeffe, LIEI $1992 \quad$ O'Keeffe, David, The Agreement of the European Economic Area, LIEI 1992.

Oppenhoff
1.27.

Oppenhoff, Walter, Anwall tliche Dienstleistung-national und international, FS 25 Jahre Bundespatentgericht, Koln 1986, 83-90. 
Oppermann, BB 1964

Oppermann, RMC 1964

Oppermann 1969

Oppermann 1987

Oppermann 1988

Oppermann in Nicolaysen Quaritsch

Oppermann in

FS Doehring

Oppermann

Orzack, Higher

Edtucation 1980

Orzack, Social Science and Medicine 198

Orzack, Law and Human Behavior 1983

Orzack, Technology Studies 1989

Orzack in Lopata

Orzack in

Hurwitz/Lequesne

Oschatz in Merten 1993

Ostler

Ostler, NJW 1987

Osder, AnwDI. 1988

Palm, JZ 1990

Panebianco.

Dir. Sc. Int. 1981

Papier

Prappas, EIPA 1995
Oppermann, Thomas, Die Durchfühnng der EWG -Niederlassungs- und Dienstleistungsprogramme seit 1961, BB 1964, 563-570.

Oppermann, Thoma $S_{\text {. }}$ 'application des programmes généraux de la communauté êconomicue européeime concernant la liberté d"établissement et la libre prestation des services, RMC 1964, 544-559

Oppermann, Thomas, Kulturverwaltungsrecht. Bildung-Wissenschaft-Kunst, Tübingen 1969.

Oppermann, Thomas, Europäisches Gemeinschaftsrecht und die deutsche Blldurigsordnung. Schriftenreihe Studien zu Bildung und Wissenschaft Bd.44 hrsgg. vom BMBW, Bonn 1987

Oppermann, Thomas, Von der EG-Freizügigkeit zur gemeinsamen Ausbildungspolitik?, Die "Gravier" Doktrin des Gerichtshofes der Europaiischen Gemeinschaften, Schriftenreihe der Juristischen Gesellschaft zu Berlin Bd. 109 Bertin 1988.

Oppermann, Thomas, Vom Markt-Bürger zum EG-Bürger?, in: Gert, NicoJaysen/Helmut, Quaritsch (Hrsg.), Lïneburger Symposium fülr Hans-Peter Ipsen zur Feier des 80. Geburtstages, Baden-Baden 1988, 87-93.

Oppermann, Thomas, Sinn und Grenzen einer EG-Angehörigkeit, in: Kay Hailbronner u.a. (Hrsg.), Staat und Völkerrechtsordnung, Festschrift für Karl Doehring, Berlin 1989, 713

Oppermarn, Thomas, Europarecht, München 1991.

Orzack, Louis H. Educators, Practitioners and Politicians in the European Common Market, Higher Education 1980, 307-323.

Orzack, Louis H., New Profession by Fiat: Italian Dentists and the European Common Market, Social Science and Medicine 1981, 807-816.

Orzack, Louis H., Architects, Engineers, and the European Economic Community, Law and Human Behavior 1983, $251-264$

Orzack, Louis H. Engineers in Europe: 1992 and Beyond, Technology Studies 1989 (Spring), 6\%8.

Orzack Louis H., Midwives, Societal Variation and diplonatic Discourse in the European Community, in: Lopata (Hrgg.). Current Research on Occupations and Professions, Greenwich 1990 .

Orzack, Louis H. The General Systems Directive: Education and the Liberal Professions, in: Hurwitz/Lequesne (Hrsg.). The Shate of the European Community. Politics, Institutions and Debates in the Transition Years, 1989-1990, London 1991 .

Oschatz, Georg-Berndt, Die Mitwirkung der Länder an der europäischen Rechtssetzung als Mittel zur Wahnung des Subsidiaritätsprinzips in D. Merten Die Subsidiaritat Europas, Betlin 1993, 41-51.

Ostler, Fritz, Die deutschen Rechtsanwälte 1871-1971, Essen 1971

Ostler, Fritz, Neueste Entwicklungen in der Rechtsanwaltschaft, NIW 1987, 281 289 .

Ostler, Frit, Neuestes zum Europa-Anwaltsrecht und etwas über seine Folgen, AnwBi. 1988, 577 -578 .

Palm, Heinz, Gedanken zum Einheitsjuristen, JZ 1990, 609-618.

Panebianco, Massimo, La direttiva prestazione di servizi 2 marzo 1977 . Dir. Sc Int. $1981,765-786$.

Papier, Hans-Jürgen, Die überbrtliche Anwaltssozietät aus der Sicht des Verfassungs- und Gemeinschaftsrechts, JZ 1990, 253-261.

Pappas, Spyros A. (ed.), National Administrative Procedures for the Preparation and Implementation of Community Decisions, EIPA, Maastricht 1995. 
Parkins in Pentek 1992

Pechstein, EuR 1990

Peege

Pertek, RTDE 1989

Pertek. Savoir 1989

Pertek, Sawoir 1989

Pertek, EIPA 1990

Pertek, Sawoir 1990

Pertek, AJDA 1990

Pertek, RMC 1990

Pertek 1991

Pertek, RTDE 1991

Pertek in EIPA 1991

Pertek, Savoir 1991

Pertek in:

De Witte/Fonder 1992

Pertek, Rev. Marche unique eur. 1992

Pertek, YbEL 1991

Pentek, EIPA 1992

Pertek in: EIPA 1992

Pertek, Savoir 1992

Pertek, ELR 1993

Pertek, YbEL 1992

Pertek, J.Cl. Europe, Fasc. 720

Pertek, J.Cl. Europe, False, 731

Pertek, J.Cl. Europe, Fasc. 740

Pertek 1994
Parkins, Nicola, Directive 89/48/EEC: Progress Towards Implementation, in: Pertek, Jacques (Hrsg.). General Recognition of Diplomas and Free Movenent of Professionals, Seminar Proceedings, Marastricht 1992, 37.54.

Pechstein, Mathias, Die Bedeutung von Protokollerklänngen zu Rechtsak ten der Europäischen Gemeinschaft, EuR 1990, 249-322.

Peege, Friedrich-Karl, Die wirtschafts- und sozialpolitisohen Aspekte der gemeinsamen Benufsbildungspolitik in der $\mathrm{EWG}_{\mathrm{n}}$ Diss. Mainz 1973.

Pertek, Jacques, La reconnaissance nutuelle des diplomes d'enseignement supérieur, RTDE 1989, 623-646.

Pertek, Jacques, Mobilité dans la communauté européenne et situatiory sociale des étudiants, Savoir 1989, 725-734.

Pertek, Jacques, La reconnaissance mutuelle des diplômes di domaine de l'architechure dans la Communauté européenne, Savour 1989, 735-745.

Pertek. Jacques, L'application aux salariés des directives wisant a faciliter l"access aux activités non sallariées et leur exercise: le cas des ingeneurs, EIPA 1990.

Pertek, Jacques, La reconnaissance mutuelle des diplomes du domaine de la santé dans la communauré européenne, Savoir 1990, 677-683.

Pertek, Jacques, L'Europe des universités, AJDA 1990, 233-241.

Pertek, Jacques, L'Europe des diplômes doit se réaliser pour le début de 1991 , RMC 1990, 167-171.

Pertek, Jacques, l'ingenieur et le droit, PUF 1991.

Pertek, Jacques, Note: Un arret d'une grande importance sur de questions de principe, RTDE 1991, 132-137.

Pertek, Jacques, Reconnaissance des diplômes et ouwerture des emplois publics atux ressortisants communautaires, in: EIPA (Hrsg.), L"Europe de 1992 et atldelà-Défis et résponse. Implicautions pour l'administration publique dans les Etats membres de la CEE, Maastricht 1991, 75-99.

Pertek, Jacques, La reconnaissance mutuelle des diplómes et la libre circulation des awocats dans la Communauté européenne., Savoir 1991, 538.

Pertek Jacques, Un éffet de 1992: De nouveaux besoins pour l'enseignement du droit européen, De Witte/Forder The common law of Europe and the future of legal education, Deventer 1992, 65-74.

Pertek Jacques, De nouveaux besoins pour l'enseignement du droit européen, Rev. Marché unique européen 1992/3, 159-1.85 Pertek, Jacques, The Europe of Universities, Yb of European Law Vol, 111991 , 257-271.

Pertek, Jacques (Hrsg.), General Recognition of Diplomas and Firee Movement of Professionals, Seminar Proceedings $\mathrm{EIPA}_{\text {, Matsitricht } 1992 .}$

Pertek, Jacques, The Concept of Regulated Activity, in: Pertek Jacques (Hrsg.). General Recognition of Diplomas and Free Movement of Professionals, Seminar Proceedings EIPA, Marastricht 1992, 17-36.

Pertek, Jacques, L'Europe des ingénieurs, Savoir 1992; 96-113.

Pertek, Jacques, New needs for education and training on European Law, ELR $1993,388-407$.

Pertek, Jacques, Free Movement of Professionals and Recognition of HiglierEducation diplomas, YbEL 1992, 293-324.

Pertek Jacques, La recounaissance de diplomes. Systemes sectoriels. Systemes gênéraux., J.Cl.Europe, Fasc. 720.

Pertek, Jacques, Les professions juridiques et judicaires. Libre circullation. Reconnaissance de diplömes. J.Cl.Europe, Fasc. 731 .

Pertek, Jacques, Les professions médicales et paramédicales. Libre circulation. Reconnaissance de diplômes. J.Cl.Europe, Fasc. 740.

Pertek, Jacques, L"Europe des diplômes et des professions, Brussel 1994.

Pescatore. 
Ree. Dalloz 1980

Pescatore, ELR 1983

Pescatore, EuR I986

Pescatore, CMLRev 1986

Pescatore, NZZ 1991

Pettiti, RMC 1972

Pettiti, CDE 1976

Pettiti, RMC 1977

Pettiti, Juris-classeur 1986

Pettiti/Laguette, GdP 1979

Philip

Philipp, EG Magazin 1984

Piazolo, Integration 1984

Picht, EA 1987

Picht 1993

Pickup, CMLRev, 1986

Piehl

Pieper ZRP 1989

Piepier. DVBL. 1990

Pieper 1994

Pilluofer

Pipkorn, GTE-Kommentai

Pipkorn, EuZW 1992

Pisulis se, SEW 1987

Platz

Plender in Jacols

Pourvoyeur. Tijdschrift voo

Bestuurwetenschappen

en Publuek recht 1961

du Pre/Sevinga, SEW 1990

Prechal, NJB 1990
Pescatore, Pierre, L"effet des directives communauaires: une tentative de démythification, Rec. Dalloz, Cromique, 1980, 171-176.

Pescatore, Pierre, The Doctrine of "Direct Effect": An Infant Disease of Community law, ELR 1983, 155-177.

Pescatore, Pierre, Die "Einheiliche Europäische Akte"-Eine emste Gefahr für den Gemeinsamen Markt, EuR 1986, 153-169.

Pescatore, Pierre, Some Critical remarks on the "Single European Act", CMLRev. 1986, 9-18.

Pescatore. Pierre, Europataugliches Subsidiaritătsprinzip? Ein Irrweg der Unionspolitik, NZZ vom $15,116,9.1991,13$

Petriti, Louis-Edmond, Le droit d'établissement et la liberalisation de la prestation des stervices concernant la profession d'avocat, RMC 1972, 800-811.

Pettiti, Louis-Edmond, La libre circulation des awocats. Problemes actuels, 2 eme Rapport, CDE 1976, 689-706.

Pettiti, 1 Louis-Ed mond, La directiwe sur la libre prestation des services d'a wociats, RMC 1977, 239-245.

Petriti, Louis-Edmond/Sylvie Deniniolle, Les Barreaux vers l'horizon 2000 , Les suiltes de l'arrêt Klopp de la Cour de Justice des Communautés, Juris-classeur 1986,326043265 .

Pettiti, Louis-Edmond/Laguette, Serge-Pierre, Le 22 mars 1979 paraissait le décret d"application pour la France de la directive des Communautés européennes du 22 mars 1977 (ler sem), Gazette du Palais 1979, Doctr, 266.

Philip, Christian, (Hrsg ) , L'enseignement supérieur et la dimension européenne, Paris 1989.

Philipp, Otmar, Europäisches Recht auch für Rechtsanwälte, EG Magazin 1984, 7-8.

Piazolo, Europäische Kulturgemeinschaft-notwendige Schritte aufeingroßes Ziel Integration 1984, 79-90

Picht, Robert, Die "Kulturmauer" durchbrechen. Kulturelle Dimension politischer und wirtschaftlicher Zusammenarbeit in Europa, EA 1987, 279-286.

Picht, Robert (Hrsg.), L"identité européenne, 1993.

Pickup, David MW., Reverse discrimination and freedom of movement for workers, CMLRev. 1986, 135-156.

Piehl, Ernst. Uberblick uber die Entwicklung zu einer Beru fsbildungspolitik der Europai ischen Gemieinschaft unter besonderer Berücksichtigung der Beiträge des. CEDFOP, CEDFOP $1989 \mathrm{Nr} .1,40$

Pieper, Stefan-Ulrich, Leid und Elend der Referendarzeit, ZRP 1989, $201-205$ Pieper, Stefan-Ulrich, Direktwirkung v on EG-Riclutlinien, DVBI. 1990.684-687. Pieper, Stefan-Llrich, Subsidiarität. Ein Beitrag zur Begrenzung der Gemeinschaftskompetenzen, Köln 1994.

Pilhofer, Peter, Die Niederlassungsfreiheit von Notaren, in: Niederllassungss* freiheit von freien Berufen in Europa, Deutsche Sektion der Intemationalen Juristen Kommission, Heidelberg 1986, 47-49.

Pipkom, Jorm, Kommentienung au Art. 8, 8 a-c EWG-Vertrag, in GTE. Kommentar zum EWG-Vertrag, 4. Auflage, Bd. 1, Baden-Baden 1991.

Pipkom, Jorn, Das Subsidiaritätsprinzip im Vertrag über die Europäische Unionrechtliche Bedeutung und gerichtliche Uberprüfbarkeit, EuZW 1992, 697-700. Pisuisse, C.S., De bevoegdheid van de Europese Gemeenschap met betrekking tot de liberalisatie van de internationale dienstverlening, SEW 1987, 179-193.

Platz, Klaus Wilhelm, EWG-Niederlassungstecht und individuelle Rechts positionen, Koln, Berlin 1966.

Plender, Richard, "An Incipient Form of European Citizenship", in: Francis Jacobs (Hrsg.), European Law and the Individual, New York 1976, 39-53.

Pourvoyeur, Robert, Het algemeen programma betreffende de opheffing van de beperkingen wan wrijheid van vestiging in de Euromarkt, Tijdischrift voor Bestuurwetenschappen en Publiek recht 1961, 315-325.

du Pré, F, M./Sevinga, $K_{\text {", }}$ De Gemeenschap en gezondheidszorg; "een terreinverkenning, SEW 1990, 350-378.

Prechal., Sacha, EG-recht 1988 en 1989, NJB 1990, 57'-63. 
Prechal

Prinz

Proietto Rivista

Studi Europei 1.960

Prittirng, IZ 1989

Prüting

Prùtting, Anwill. 1990

Putzhammer, RdJB 1989

Rabe, NJW 1987

Rabe, AnwBL. 1987

Rabe, NJW 1989

Rabe, RabelsZ 1991

Rabe 1992

Raczinski/Rogalla/

Tomsche

Raiser, NJW $\llbracket 991$

Randelzhofer

Randelzhofer u.a. GS Grabitz

yon Randenborgh

Rapaceitulo

Rapacciuolo. Soziales Europa 1989

Rasmussen, EuR 1985

Rat der $\mathbb{E G} \mathbb{1 9 8 7}$

Rat der EG 1989

Redeker, NJW $\$ 987$

Redeker, NJW 1987

Redeker, AnwBl. 1989

Reich, ZHR 1989

Reich "EuZW 1991

Reinmübler, IPRax 1989
Prechal, Sacha, Directives in European Community Law, Amsterdam 1995 Prinz, M. Anwaltswerbung. Eine rechtsvergleichende Darstellung des deutschen und amerikanischen Rechts, Frankfurt 1986.

Proietto, Benito, Marché Commun, liberté d'etablissement et titres professionnelis: le probleme des équivalences, Riwista Studi Europei 1969, 358-375.

Prïtting. Hanns, Die Zulässigkeit der überötlichen Anwaltssozietä nach geltendem Recht, JZ 1989, 705-712.

Prütting, Harns, Die deutsche Anwaltschaft zwischen heute und morgen, Köln/Berlin/Bonv/München 1990.

Prïtting, Hanns, Die Rechtsanwaltschaft im Unbnuch, AnwBI. 1990, 346.

Putzhammer, Heinz, EG-Ausländer im deutschen öffentlichen Dienst? RdJB $1989,157-169$

Rabe, Hans-Jürgen, Internationales Amwaltsrecht-Dienstleistung und Niederlassung, NJW 1987, 2185-2193.

Rabe, Hans-Jirgen, Internationales Amwaltsrecht-Dienstleistung und Niederlassung, AnwBl 1987, 394-401.

Rabe, Hans-Jürgen, Auf dem Weg zum meuen anwattlichen Berufsrecht, NJW $1989,1113-1119$

Rabe, Hans-Jürgen, Dienstleistungs- and Niederlassungsfreiheit der rechtsberatenden Berufe in der Europäischen Gemeinscluaft, RabelsZ 1991, 291-302. Rabe. Hans Jürgen, Dienstleistungs- und Niederlassungsfreiheit der Anwallte in der EG, Zentrum für Europäisches: Wirtschaftsrecht, Vorträge und Berichte Nr. 13, Bonn 1992

Raczinski, Bernd/Rogalla, Dieter/Tomsche, Eberhard, Die Freiheit des Dienstleistungsverkehrs der deutschen. Rechtsanwälte in der Europăischen Gemeinschaft, AnwB1 1989, 583-592.

Raiser, Gottfried, Die Haftung des deutschen Rechtsanwalts bei grenziberschreitender Tätigkeit, NJW 1991, 2049-2057.

Randelzhofer, Albrecht, Der EinfluB des Völker- und Europarechts auf das deutsche Ausländerrecht, Berlin, New York 1980.

Randelzhofer, Albrecht/Scholz, Rupen/Wilke, Dieter, Gedächnisschrift für Eberlard Grabitz, Müchen 1995.

von Randenborgh, Zum franzôsischen Notariatswesen, Kiel Diss. 1990.

Rapacciuolo, Durante, Die Bedingung der Staatsangehörigkeit für den Zugang zur Beschafftigung in der offentlichen Verwaltung und die Freizügigkeit der $\mathrm{Ar}$ beitmehmer, Soziales Europa 2/1984, 26.

Rapaceiuclo, Durante, Die Bedeunung des Art. 48 Abs. 4 EWG-Vertrag und die Modalităten der Aktion der Kommission der Europäischen Gerneinschaften im Hinblick auf die Rechtsprechung des Europäischen Gerichtshofes, Soziales Europa 1/1989, 111.

Rasmussen, Hjalte, Uber die Durchsetzung des Gemeinschafturechts in Danemark, EuR 1985, 66-74.

Rat der EG (Hrsg.), Erklänungen zur europalischen Bildungspolitik, 3. Auflage Luxemburg/Brissel 1987.

Rat der EG (Hrsg.), Eüklärungen zur Europäischen Bildung:spolitik, Ergănzung der 3. Auflage, Luxemburg/Drüssel 1989

Redeker, Konrad. Freiheit der Advokatur-heute, NJW 1987, 2610-2616,

Redeker, Konrad, Vom Sinn unseres anwalticher Standesrecht, NJW 1987, 304 305.

Redeker, Konrad Anwaltschaft und Rechtswissenschaft, AnwBI 1989, 189-194. Reich, Norbert, Die Freiheit des Dienstleistungswerkehirs als Grundfreiheit, ZHR $1989,571-594$

Reich, Norbert, Binnenmarkt als Rechtsbegriff, EuZW 1991, 203-210.

Reinmüller, B., Anwalthiches Z weigbüround Niederlassungsfreiheit in Frankreich und in der Bundesrepublik Deutschland, IPRax 1989, 54-56. 
Reuirmaier

Remien, JZ 1992

Remmentz,

ZWgL.R.Wiss. 1994

Rento

Ress

Ress, EuGRZ 1986

Ress, EuGRZ 1987

Ress/Ukrow

Rhode, Stanf.

Law Rev. 1982

Richter, MittBayNot 1990 Sonderhefit

Richter, DöV 1979

Richter, Integration 1989

Richter in: Schlteicher 1993

Riegell, DVBl. 1979

Riegel, NJW 1978

Riegel, RIW 1986

Riegel, ZRP 1989

Riezebos, NJB 1991

Ring

Rijksbaron/Roobol/

Weisglas

Riotte/Fey, NWVBI. 1992

Rochard

Roellecke, JuS 1990

scherming, NJB 1990, 100-104.

Roscam Abbing Kehl am Rhein/Strals burg 1984 $277-284$ $202-217$ Monaco Milano 1977, 611-636. $1981,311-350$. EuGRZ 1986, 549-558. Stuttgart 1991 (1982), 1-112. 26 DöW 1979, 185-193. Integration 1989, 185-188. Einheit, Darmstadt: 1993, 27-44. $468-469$. NWVBL $1992,7-10$
Reitmaier Marion-Angela, Inländerdiskriminienung nach dem EWG-Vertrag.

Remien, Oliver, Illusion und Realitait eines europäischen Privatrechts, JZ 1992,

Remmertz, Frank, Die englische Anwaltschaft im Wandel, ZVgl.R.Wiss. 1994,

Reriato, Guiseppe, II processo evolutivo nel diritto comunitario per la libera circolazione delle persone: ill diritto di stabilimento e la libera prestazione dei servizi nei paesi della CEE, in: Studi di diritto europeo in onore di Ricardo

Ress, Georg, Freier Personen-, Dienstleistungs- und Kapitalverkehr, in: Kommission der EG, Dreißig Jahre Gemeinschaftsrecht. Brüssel, Luxembura

Ress, Georg, Die Europäische Gemeinschaft und der deutsche Föderalismus,

Ress, Georg, Das deutsche Zustimmungsgesetz zur Einheitlichen Europäischen Akte-Ein Schritt zur "Fóderalisienung "der Europapolitik, EuGRZ 1987, 361-367. Ress, Georg/Uk.row, Jörg. Niederlassungstecht won Apothekern in Europa,

Rhode, Deborah L., Policing the Professional Monopoly: A Constitutional an Empirical Analysis of Unauthorized Practice Prohibitions, Stanf. Law Rew. 34,

Richter, Gert-Jïrgen, Der Notar im Recht der Europäüschen Gemeinschaften, in: Standort und Zukunft der Notare in Europa, MitBBayNot 1990. Sonderheft, 20

Richter, Ingo, Alte rutiven zur Kompetenzverschiebung imBildungsföderalismus,

Richter, Ingo, Erasmus-Erfahnungen mit der Hochschullkooperation in Europa, (Hrsg.), Zukunft der Bildung in Europa. Nationale Vielfalt und Europäische

Riegel, Reinhard, Gliedstaatkompetenzen im Bundesstaat und Europäisches Gemeingchaftstecht, DVBI $1979,245-251$

Riegel, Reimhard, Zum Anwendungsbereich des Art. 48 ff. EWGW, NJW 1978,

Riegel, $\mathbb{R}$ einhard, Das Recht der Untemehmen und die Niederlassungsfreiheit in Europäischen Gemeinschaftsrecht, RIW 1986, 667-669.

Riegel, Reinhard, Zu Recht und Praxis, der Verfasstungstreue- bzw. Einstellumgsïberprüfung, ZRP 1989, 321-.

Riezebos, C., Opleiding tot jurist in Duitsland em Nederland, NJB 1991, 536-544. Ring, O., Wettbewerbsrecht der freien Berufe, Baden-Baden 1989.

Rijksbaron, A./ Roobol, W.H./ Weisglas, M. (Hrsg.), Europe from a Cultural Perspective-Historiography and Perceptions -, Den Haag 1987. mationales Dienstrecht-Probleme bei der Koordinierung zweier Rechtssysteme,

Rochard, Patricia, Niederlassungsrecht, freier Dienstleistungsverkehr und europalische Integration an Beispiel der Freizügigkeit der Arzte in der Europäischen Gemeinschaft, Mainz, Jur. Diss. 1985.

Roellecke, Gerd, Erziehung zum Bürokraten? Zur Tradition der deutschen luristanausbildung JuS $1990,337-343$. Roscam Abbing, H.D.C. Patiènt en gezondheidszorg in thet recht van de Europese Gemeenschap, Preadvies uitgebracht ten behoeve van de jaarwer- 
Ross, ELR 1989

Roth in Fufs

Roth, EuR 1986

Roth, CMLRew. 1988

Roth, ZUM 1989

Roth, RabelsZ 1990

Roth, RabelsZ 199

Roth, CMLRev. 1993,

Roth,

CMLRev. 1993, 1251

Rowe, CDE 1976

Rübsaamen, RdJB 1978

Rupp, NJW 1976

Samkalden

Sahner/Herrmann

Trautwein

Schäuble

Schardey, AnwBI. 1989

Schardey, AnwBI. 199

Schaus, JT 1962

Scherer, WuV 1987

Sichermers

Ars Aequi 1986

Schermers, NJB 199

Schermers

CMLRev. 1993

Schermers, 1993

Scheuing, JZ 1975

Schiedermair,

MittHV 1989

Schiefer, NJW 1987

Schippel, Sonderheft gadering van de vereniging voor gezondheidsrecht op 16 aprill 1993, Utrecht 1993.

Ross, M. Mutual Recognition of Professional Qualifications, EL.R 1989, 162 166.

Roth, Wulf-Henning, Aktuelle Probleme des europaischen Wettbewerbsrechts in: FuB, Ernst-Werner (Hrsg.). Der Beitrag des Gerichtshofes der Europäischen Ge meinschaften zur Verwirklichung des Gemeinsamen Marktes, Baden-Baden 1980 $53-83$.

Roth, Wulf-Henning, Die Harmonisienung des Dienstleistungsrechts in der EWG. EuR 1986, 340-369; 1987, 7-27.

Roth, Wulf-Henning. The European Community's Law on Services: Harmonization, CMLRev. $1988,35-94$

Roth, Wulf-Henning, Grundfreiheiten des Gemeinsamen Marktes für kulnurschaffende Tärigkeiten und kulturelle. Leistungstrăger, ZUM 1989, 101-110.

Roth, Wulf-Henning, Grundlagen des gemeinsamen weuropäischen Versicherungsmarktes, RabelsZ 1990, 65-137.

Roth, Wulf-Henning, Der EinfluB des Europăischen Gemeinschaftsrechts, RabelsZ 1991,623-673.

5 Roth, Wulf-Henning, Calse C-76/90, Manfred Säger v. Dennemeyer \& Co. Ltd. Judgment of 25 July 1991, CMLRev 1993, 145-154.

Roth, Wulf-Henning, Case C-19/92, Dieter Kraus v. Land Baden-Württemberg, Judgment of 13 March 1993, CMLRev. 1993, 1251-1258.

Rowe, Allan, La libre circulation des médecins dans la Communauté européenne, problèmes actuels, 2eme Rapport, CDE 1976, 736-753.

Rübsaamen, Dieter, Möglichkeiten und Grenzen supranationaler Kultur'- und Bildungspolitik, RdJB 1978, 238-273.

Rupp, Hans Heinrich, Die gewerblichen Schutzrechte im Konflikt zwischen mationalen Grund rechten und Europäischem Gemeinschaftsrecht, NJW 1976, 993 . 1000

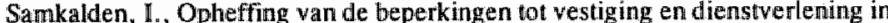
de Gemeenschappelijke Markt, in: Vrijheid van vestiging en dienstverlening in de EEG, Europese Monografieën, Deventer $1965,9-26$

Sahner, He inz/Herrmann, Harald/Rönnau, Andreas/Trautwein, Hars-Michael Zur Lage der Freien Berufe, Teil I, II und IIt, Forschungsinstitut Freie Berufe Universität Lüneburg (Hrsg.), Lüneburg 1989.

Schäuble. Wolfgang. Perspektiven des öffentlichen Dienstes im europdischen Binnenmarkt, Bulletin der Bundesregierung vom 12. Januar 1990, 33.

Schardey, Günter, Das neue anwaltiche Berufsreeht, AnwBl. 1989, 432.

Schardey, Günter, Zur Lage der Anwalischaft und zum Stand der Bertifsrechtsdiskussion, AnwBI. 1991, 2-4.

Schaus $_{4} \mathbf{L}$. La professiond'avocat dans la Cormunaute economique europétenne, Joumal des Tribunaux 1962, 73 .

Scherer, Joachim, Europäisches Niederlassungsrecht fïr Freibenufler, Wirtschaft und Verwaltung 1987, 159-178.

Schermers, H.G., De minerval woor buitenlanders, 35 Ars Aequi 1986, 37-40. Schermers, H.G., Jurist voor morgen, NJB 1991, 521-522.

Schermers, Henry G., Legal Education in Europe, CMLRev 1993, 9-15.

Schermers, H.G.,/Flinterman, C., u.a., (eds.), Firee Movement of Persons in Europe., Dordrecht 1993.

Schewing, Dieter H., Das Niederlassungsrecht im Prozeß der Integration, JZ $1975,151-159$

Schiedermair, Hartmut, Schlußwor zum 39. Hochschulverbandstag, MittHW $1989,155-162$.

Schiefer, Wolfgang. Anwalt Hm Zeitalter der Dienstleistung-Herausfordenung zum Wandel, NJW 1987, 1969-1978. 
der DNotZ 1989

Schlachter, Annuaire de I'AAA 1981/82/83

Sehlachter

Schleicher 1993

Sehleicher/Bos

Schllitz

Schmalz,

BRAK-Mitt, 1986

Schmalx,

BRAK-Mitt. 1989

Schmidhuber in Battis

Schmidt-Meimecke

Schmnidt-Răntsch

Schmiltz-Wenzel

Schneider in Bteckmann

Schneider, Ars Avequi 1989

Schneider in Coen Hölscheidt/Pieper

Schneider 1994

Schneider, L. 1979

Schneider, R. 1976

Schneider, U.H. CMLRev. 1971

Schnichels

Schone

Schöne, RIW 1989

Scholsen, CDE 1989

Schröđler, JöR 1986
Schippel, Helmut, Auswirkungen des europãischen Binnenmarkts auf das deutsche Notariat, in: 23. Deutscher Notartag. Frankfurt 1989-Sonderheft der DNotZ 1989, 189

Schlachter, Ernest, Reflexions sur la situation accuelle de lavocat dans la Communauté Economique Europeenne, Annuaire de l'AAA 1981/82/83, 136143.

Schlachter, Hedwig, Dicrimination a rebours. Die Inländerdiskriminierung nach der Rechtsprechung des EuOH und des französischen Conseil d"Etat, Frankfurt am Main 1984

Schleicher, K. (Hrsg.), Zulkunftit der Bildung in Europa. Natjonale Vielfalt und Europaische Einheit Darmstadt 1993.

Schleicher, K./Bos, W. (Hrsg.). Realisierung der Bildung in Europa. Europäisches Bewu/tsein trotz kultureller Identität?, Darmstadt 1994.

Schlitz, C., Quel avocat pour l'Europe du XXIe siècle?, in: Diagonales a travers le troit luxembourgois. Luxembourg 1986, 653-683.

Schmalz, KJaus, Freizůgigkeit der Anwälte in Europa BRAK-Mitt. 1986, 1.

Schmalz, Kllaus, Europälsches Standesrecht, BRAK-Mitt. 1989, 165.

Schmidhuber, Peter M., Die Politik der EG-Kommission zur Freizügigkent der Arbeitnehmer zum Beschäftigungszugang in der offentlichen Verwaltung, in: Battis, Ulrich (Hrsg.), Europäischer Binmenmarkt und nationaler öffentlicher Dienst, Regensburg 1989, 109-121.

Schmidt-Meinecke, Stefan, Bundesländer und Europäische Gemeinschaften, Speyerer Forschungsberichte Bd. 59, 2. Auflage, 1988.

Schmidt-Räntsch, Jürgen, Erlaß von Forderprogrammen durch den Rat der EG aufgrund Art. 128 EWGV, NJW 1989, 3071-3072.

Schmitz-Wenzel, Hermann (Hrsg ) ), Billdungspolitik in der EG-Aktuelle Probleme und Awsblick, Badien-Baden 1980 .

Schneider, Hildegard, Kultur- und Bildungspolitik, in: A. Bleckmann "Eurom parecht, 5. Auflage, Köln, Berlin, Bonn, München 1990, 783.

Schneider, Hildegard, Een klein stapje in de richting van echte "Europese" juristen?, Ars Aequi 1989, 368-374.

Schneider, Hildegard, Die Freizügigkeit für Lehrer im europäischen Binnenmarkt, in: Coen/Hölscheidt/Pleper (Hrsg.), Europa'93-Auf dem Weg zur Europäischen Union, FS für Albert Bleckmann zum 60. Geburtstag , Herne/Berlín $1993,283-303$

Schneider, Hildegard, Die niederländischen Regeln bezüglich der Ausübung von Hellberufen in: Boesken, W.H./Kühne, H.H./Heusel, W., Facharztausbildung und ärztliche Niederlassung im Binnenmarkt, Köln 1994, 87-97.

Schneider, Ludwig, Anwaltsrecht im EG-Raum (Der freie Dienstleistungsverkehr der Rechtsanwälte innerhalb der europäischen Gemeinschaft), Köln. Berlin, Bonn, München 1979

Schneider, R., Der Rechtsanwalt, ein unabhängiges Organ der Rechtspflege, Berlin 1976.

Schneider, U.- H., Towards a European Lawyer, CMLRev 1971, 44-51.

Schnichels, Dominik, Reichweite der Niedderlassungsfreiheit, Baden-Baden 1995

Schöne, Franz-Josef, Dienstleistungsfreiheit in der EG und deutsche Wirtschaftsaufsicht, Köln, Berlin, Bonn, München 1989

Schône, Franz-Josef, Die "umgekehrte Diskriminierung" im EWG-Vertrag nach der Rechtsprechung des Europäischen Gerichtshofs, dargestellt am Beispiel der Dienstleistungsfreiheit nach Art. 59 ff. EWG-Vertrag, RIW 1989, 450-454.

Scholsem, Jean-Claude, A propos de la circulation des étudiants: vers un fédéralisme financier européen?, CDE 1989, 306-324.

Schröder, Meinhard, Bundesstaatliche Erosionen im ProzeB der europäischen Integration, in: Jahrbuch des öffentlichen Rechts der Gegenwart NF, Bd. 35 $(1986), 83-102$ 
Schröder

Schütz, Der Staat 1989

Schütze, DNotZ 1992

Schultz, AnwBl. 1981

Schumann, AnwBl. 1990

Schwachter, MittBay Not 199

Sonderhert

Sichwarz in

FS von der Groeben

Sichwarze in FS Carstens

Schwarze 1985

Schwarze 1987

Schwarze, 1988

Schwarze/Bieber

Schwarze/Govarere

Schwarze/Schermers

Schwarze/Becker/Pollack

Schweinitz

Schweitzer in Merten

Schweitzer/Herzog,

ZrRechtsvgl. 1991

Schweizer in: Randelzhofer

u.a., GS Grabilz

Sclsweitzer/Humme

Séchë, CDE 1976

Séché, CMLRew. 1977

Séché, CDE 1984

Seche

Sedemund, NJW 1986
Schröder, Meïhhard, Europäische Bildungspolitik und die bundessteatliche Ordnung, Baden-Baden, 1990

Sehütz, Hans-Joachim, Bund, Länder und Europäische Gemeinschaften, Der Stast $1989,206-224$.

Schütze, Rolf A. Intemationales Notarverfahrensrecht, DNotZ 1992,66-84

Schultz, Ulrike, Zum Gesetz zur Durchführung der EG-Richtlinie zur Erleichtenung des freien Dienstleistungswerkehrs der Rechnsanwalte. Anwaltsblat $1981,41-44$.

Schumann, Ekkehard, Die Befreiung der Rechtsanwaltschaft von obrigkeitlichen Schranken, AnwBI. 1990, 466-475; NIW 1990, 2089-2097.

Schwachtgen, Andrế, Die Notare in den Benelux-Staten und in Grolbbritannien. in: Standort und Zukunft der Notare in Europa, MittBayNot 1990, Sondertueft $5-6$.

Schwarz, Ivo, 30 Jahre EG-Rechtsangleichung, in: Mestmäcker, Ertust-Joachim/Moller, Hans/Schwarz, Hans-Peter (Hrsg.), Eine Ordnungspolitik für Europa. Festschrift für Hans von der Groeben zu seinem 80. Geburtstag, BadenBaden 1987, 333-368.

Schwarze, Jürgen, Entwicklungsstufen des Europäischen Gemeinschaftsrechts, in: Bömer, Bodo/Jahrreio, Hermann/Stern, Klaus (Hrsg.), Einigkeit und Recha and Freiheit. FS für Karl Carstens. Bd. 1, Köiln 1984, 259-272.

Schwarze, Jürgen (Hrsg.), Gesetzgebung in der Europäischen Geneinschaft, Baden-Baden 1985

Schwarze, Jürgen (Hrsg.), Der Gemeinsame Markt: Bestand und Zukunft in wirtschaftsrechilicher Perspektive, Baden-Baden 1987.

Schwarze, Jürgen, Europäisches Verwaltungsrecht, Baden-Baden 1988.

Schwarze, Jürgen/ Bieber, Roland (Hrsg.), Eine Verfassung für Eu ropa. Von der Europäischen Gemeinschaft zur Europäischen Union, Baden-Baden 1984.

Schwarze, Jürgen/Govaere/ Hellin/ Van den Bossche, Peter (Hrsg.), The 1992 Challenge at National Level, Baden-Baden, 1990.

Schwarze, Jürgen/ Schermers (HIrsg.). Structune and Dimensions of European Community Policy, Baden-Baden, $19: 88$.

Schwarze, Jürgen/Blecker, Ulrich/Christina, Pollack, Die Implementation von Gemeinschaftsrecht, Baden-Baden 1993.

Schweinitz, Wolf Bernhard won, Rechtsberatung durch Juristen und Nichtjuristen insbesondere durch Wirtschaftsprufer, Berlin 1975.

Schweitzer, Michael, EG-Kompetenzen im Bereich der Kultur und Bildung in: Merten, Detlef (Hrsg.), Foderalismus und Europäische Gemeinschaften unte: besonderer Beraicksichtigung von Umwelt and Gesundheit, Kultur und Bildung. Berlin $1990,147-159$

Schweitzer, Michael/Herzog, Wolfgang. Bildungspolitik und EWG-Vertrag-eine Bestandsanfinahme, Zeitschrift für Rechtsvergleichung, IPR und Europarecht $1991,14-25$

Schweitzer, Michael, Lehrerbenuf und Arbeitnehmerfreizuigigkeit, in: Randelizhofer, Albrecht/Scholy, Rupert/Wilke, Dieter, Geduchnisschrift für Eberhard Grabitz, München 1995, 747-762.

Schweitzer, Michael/ Hummer, Waldemar, Europarecht, 4. Auflage, Frankfurt 1993.

Seché, Jean-Claude, Les directives du Conseill des Communauté curopéennes du 16 juin 1975, concernant les activités du médecin, CDE 1976, 32-49.

Séché, Jean-Claude, Free Movement of Workers under Community Law. CMLRev. 1977, 385-410.

Seche, Jean-Claude, Libre prestation des services el allocation de devises aux touristes, CDE 1984, 706-713.

Séchë, Jean-Claude, Libre circulation des personnes, des services et des capitaux. Transport, Commentaire Mégret, Le droit de la CEE, Vol. 3. 2. Auflage, Brüssel 1990.

Sedemund, Jochim, Europâisches Gemeinschaftsrecht, NJW 1986, 634*638. 
Sedfemund in

Schwarze 1987

Sedemund/Montag. NJW 1989

Sedemund/Montag. NJW 199

Sedemund/Montag, NJW 1995

Seidel. NJW 1985

Seidel, EA 1987

Seidel in Schwarze 1987

Seidel, Jura 1990

Seidl-Hohenveldern

LIEI 1992

Sellin, RdJB 1980

Senninger, AnwBl. 1989

Siedentopf/Ziller

Sieveking, WuV 1987

Sieveking, ZAR 1987 Sieveking, RdJB 1989

Sieveking, Kritische Vierteljahiresschrift für Gesetzgebung und echutswissenschaft 1990

Simon-Depitre, Revue eritique de droit international prive 1970

Sinagra, Dir. Sc. Int. 1983

Siskind, The Int

Lawyer 1992

Skarlatos, LIEI 199

Skouris in

Schwarze/Schermers

Skouris in De Witte

Slot
Sedemund, Jochim, "Cassis de Dijon" und das newe Harmonisherungskonzept der Kommission, in: Schwarze, Jirgen (Hrsg.) Der Gemeinsame Markt: Bestand und Zukwnft in wirtschaftsrechtlicher Perspektiwe, Baden-Baden 1987, 37-54.

Sedemund, Jochim/Montag, Frank, Die Entwicklung des Europäischen Gemeinschaftsrechts, NIW 1989, 1409-1415.

Sedemund, Jochim/Montag, Frank, Die Entwickung des Europäischen Gemeinschaftsrechts, NJW 1994, 625-634.

Sedemund, Jochim/Montag, Frank, Die Entw/cklung des Europåischen Gemeinschaftsrechis, NJW 1995, 1226.

Seidel Martin, Die Direkt- oder Drittwirkung von Richtlinien des Gemeinschaftsrechits. NJW 1985, 517-522.

Seidel, Martin, Grundsätzliche rechtspolitische Probleme bei der Verwirklichung des Binnenmarktes, EA 1987, 553-558.

Seidel, Martin, Die Dienstleistungsfreilheit in der neusten Rechtsentwicklung, in: Schwarze (Hrsg.), Der Gemeinsame Markt: Bestand und Zukunft in wirtschaftsrechtlicher Perspektive, Baden-Baden 1987, 113-136.

Seidel, Martin, Rechtliche Stellung und Aufgaben des Juristen im Rahmen der EG und 1992, Jura 1990, 281-287.

Seidl-Hohenweldern, H.C.I., Austria and the EEA, LIEI 1992, 29-49.

Sellin, Burkhart, Zur Entwicklung der Berufsbildung in der EG, RdJB 1980, 424429 .

Senninger, Erhard, Die Entwicklung der Anwaltschaft an der Schwelle des Europåischen Binnenmarktes, AnwBI. 1989, 298-303.

Siedentopf, H./Ziller, J. (eds.), Making European Policies Work, Brussel 1988. Sieveking, Klaus, Das EG-Aufenthaltsrecht für Niederlassungsberechtigte und ihre Familienangehörigen, Wirtschaft und Verwaltung 1987, 179-193.

Sieveking, Klaws, Europäisienung der Bildung spolitik?, ZAR 1987, 99-107.

Sieveking. Klaus, Recht und Politik der Weiterbildung in der Europäischen Gemeinschaft, RdJB 1989, $\mathbb{4} 40-150$.

Sieveking, Klaus, Bildung im Europäischen Gemeinschaftsrecht, Kritische Vierteljahresschrift fuir Gesetzgebung und Rechtswissenschaft 1990, 344-373.

Simon-Depitre, Marthe, $L$ " application en France des mesures communautaires en matière de liberté d'stablissement. Rewue critique de droil international privé $1970,227-245$.

(1) Augusto, Attivita forense e libera prestazione dei servizi nella Comunit europea, Dir. Sc. Int. 1983, 105-125.

Siskind, Gregory. Freedom of Movenent for Lawyers in the New Europe, The International Lawyer 1992, 899-931.

Skarlatos, N.J. "European Lawyer"s Righis io transnational legal practice in the European Community. LIEI 1991, 49-66.

Skouris, Wassilios, Communication: La formation professionelle de la Cour de Justice de Communautés européennes, in: Schwarze/Schermers (Hrsg.), Structure and Dimensions of European Community Policy, Baden-Baden, 1988, 205-213. Skouris, Wassilios, La liberté d'ëtablissement et de prestation de services en matière d'enseignement, De Witte (Hrsg.). European Community Law of Education, Baden-Baden, 1989, 21-30.

Slot, B.P., Zoeklicht op de Harvard Law School, NJB 1991, 530-533. 
Smit/Herzog

Smith, ELR 1994

Simith, MLR 1989

Sokol, The Int

Lawyer 1992

Soubeyrol, RTDE 1976

Spart

Spediding

Speyer, EuZW 1991

Sprang

Staats, DRiZ 1990

van der Staay

Stadler, JZ 1989

Sitadler

Staudenmayer,

WissR 1994

Stauffenberg/

Langenfeld, ZRP 1992

Stavron

Steenbergen, SEW 1993

Stefener, AnwBl. 1988

Steiger. ZRP 1989

Sitein, CMLRev. 1992

Steindorf 1965

Steindorff, NJW 1982

Steindorff, NJW 1983

Steindorf, RIW 1983

Steindorf, ZHR 1984

Steindorff, ZHR 1986

Steindorff, EuR 1988

Steindorff,

Fordham Int.L.J. 1988

Steiner, The Law Quaterly

Review 1982

Sieiner, ELR 1985
Smit, Hans/ Herzog, Peter (Hrsg.), The law of the European Economic Community: a Commentary on the EC-Treaty, New York, San Fransisco, 4 Bände $1976 \mathrm{ff}$; Loseblattausgabe.

Smith. L.. . , Postgraduatedegrees, vocational training and reverse discrimination: the narrow divide ELR 1994, 67-75

Smith, Roger, The Green Paper and Legal Services, Modern Law Review 1989 $527-539$

Sokol, Ronald P., Reforming the French Legal Profession, The International Lawyer 1992, 1025-1036.

Soubey rol, Jacques, Les medecins dans la Communaute economique europétene RTDE $1976,601-623$.

Sparr, Jürgen, Kulturhoheit und EWG-Vertrag, Baden-Baden 1991.

Spedding , Linda S., Transmational Legal Practice in the EEC and the U.S., New York 1987.

Speyer, Stefan, Anwendung der Cassis-de-Dijon-Doktrin und Spaltbarkeit reglementierter Tätigkeiten als neue Etappen der Dienstleisturagsfreiheit, EuZW $1991,588-590$.

Sprang, Udo, Dubbele diplomering: vitweg uit het erkenuingsmoeras, Visum Nieuris 1989, 7-9.

Staats, Johann-Friedrich, Die Juristenausbildung in den Mitgliedstaaten der EG, DRiZ $1990,193-195$

van der Stalay, A.J. Europese cultuur en europese politiek, Nieuw Europa, 1988 30-37.

Stadler, Christoph. Freiheit des Dienstleiswngsverkehrs und Vollendung des Bimmenmurktes, JZ 1989, 285-286.

Stadler, Rupert, Die Benffsfreiheit in der Europäischen Gerneinschatt, München 1980.

Staudemmayer, Dirk, Mittelbare Auswirkungen des Gemeinschaftsrechts auf das Bildungswesen, WissR 1994, 249-281.

Stauffenberg, Franz Ludwig Grafl Langenfeld, Christine, Maastricht-ein Fortschritt für Europa? "ZRP 1992, 252-259.

Stavron, Stavros, Das berufliche Bildungswesen in Griechenland, Europäisches Zentrum für die Förderung des Berufsbildung, Luxemburg, 1986.

Steenbergen. J. Het EER-Verdrag, een beknopte samenvatting. SEW 1993, 140 152

Stefener, Wolfgang, EuGH-Dienstleistungsurteil, AmwB1. 1988, 367-373.

Steiger, Heinhard, Deutsehe Juristenausbildung und das Jahr 1992, ZRP 1989 , $283-287$.

Stein, Torsten., Case C-340/89, Vlassopoulou w. Ministe rium für Justiz, Bundesund Europaangelegenleiten Baden-Württemberg, CML Rev. 1992, 625-635.

Steindorff, Ernst, Der Gleichheitssatz im Wirtschaftsrecht des Gemeinsamen Marktes, Berlin 1965

Steindorf, Ermst, Berufsfreiheit fürnicht-wissenschafth iche Zwecke im EG-Recht, NIW $1982,1902-1905$

Steindorff, Ernst, Ausbildungsrechte im EG-Recht, NJW 1983, 1231-1233.

Steindorff, Emst, Dienstleistungsfreiheit wn EG-Recht, RIW 1983, $831-839$

Steindorff, Emst, Probleme des Art. 30 EWG-Vertrag ZHR 148, 1984, 338-355.

Steindorff, Emst, Gemeinsamer Markt als Binnenmarkt, ZHR 150, 1986, 687 Steindorff, Ernst, Reichweite der Niederlassungsfreiheil, EuR 1988, 19-32.

Steindorff, Ernst, Freedom of Services in the EEC, Fordham Int.L.J. 1988, 347 408 .

Steiner, Josephine, Direct Applicability in EEC Law-A Chameleon Concept The Law Quaterly Review 1982, 229-248.

Steiner. Josephine, Freedom. of establishment-Freedom to provide services: Recipients of services-some are more equal than others, European Court 
Literalurveruethnis

Steiner, "The Law Quaterly Review 1990

Steiner

Steiner, CMLRev, 1992

Judgement of February 13, 1985, Case 293/83, Gravier v. City of Liège, ELR $1985,348-352$.

Steiner, Josephine, Coming to terms with directives, The Law Quarterly Review $1990,144-159$

Steiner, Josephine, Textbook on EEC Law, 3. Auflage, London 1993.

Steiner, Josephine, Drawing the line: uses and abuses of Art. 30 EEC. CMLRev, $1992,749-77.4$

Stephan in Schmitz-Wenzel Stepham, Rüdiger, Akademische Mobilităt in Europa, in: Schmitz-Wenzel, Hermann, (Hrsg.). Bildungspolitik in der EG-Aktuelle Probleme und Ausblick, Baden-Baden $1980,39-52$.

Stern

Stern, NWWBL 1992

Krern, Klaus, Anwaltschafi und Verfassungsstaat, München 1980

Stevens

Stem, Klaus, Art. 48 Absatz 4 EWG-Vertrag und nationales DienstrechtProbleme bei der Koordinienung zweier Rechtssy steme, NWVBL. 1992, 7-10. Stevens, J., Regels en gebruiken van de advocatuur te Antwerpen. Antwerpen 1990 .

Stevens " RW 1969

Stevens, W.F.C., De advocatuur en de E.E.G., en uitdaging of een gemiste kans?, Rechtskundig Weekblad 1969, 1920-1929.

Stewing, DVB. 1992

Stewing, Clemens, Das Subsidiaritätsprinzip alts Kompetenzverteilungsregel im Europäischen Recht, DVBI. 1992, 1516-1518.

Stobbe, AnwBil. 1990

Stobbe, Utrich, Reform der Juristenausbildung-Fordening und Herausfordenung der Anwaltschaft, AnwBI. 1990, 225-234.

Stobbe, NJW 1991

Stobbe, Ulrich, Die Kompetenz der Anwaltschaft-Weichenstellung in Ausbildung und Berufisrecht, NIW 1991,2041-2049.

Stocker, CDE 1976 Stocker, O., Libre circulation des avocats et des médecins, Resume des debats, CDE 1976, 754-763.

Stuyck/Geens, SEW 1993 Stuyck, J./Geens, K., Wrij werkeer van adwocaten in de EEG, SEW 1993, 111 139.

Sudhof, Kritische Justiz 1990

Sifs

Sudhof, Margaretha, Vorwissenschaftich, worindustriell, vordemokratischvoreuropäisch? Zur gegenwärtigen Diskussion um die Juristenausbildung. Kritische Justiz 1990, 341-346.

Sïi, Giesela, Die Zullassung von Zahnärzten aus dem EG-Bereich zur deutschen Kassenpraxis, Ein Beitrag zu Standort und Bedeutung der Grundrechte in der EG, Frankfurt, Bern, New York, Paris 1988

Sundberg-Weitmann Sundberg-Weitmann, Brita, Discrimination on grounds of nationality. Free movement of workers and freedom of establishment under EEC Treaty. Amsterdam, 1977.

Taupitz, ZHR 1989

Taupitz 1991

Teicliler

Taupitz, Jochen, Das berufsordnende Kammerrecht der freien Berufe in der freiheitswahrenden Zwangsjacke des Kartellrechts, ZHR 11989, 681-706.

Taupitz, Die Standesordnung der freien Berufe, Berlin 1991.

Teichler, Ulrich, Changing Parterns of the Higher Education System: The Experience of Three Decades, London 1988.

Teichler, Aus Polik und Zeilgeschichte 1989

Teichler, Ulrich, Hochschulen in Europa, in: Aus Politik und Zeitgeschichte, B $50 / 89$ vom 8. Dezember $1989,25-39$.

Temple Lang.

CMLREv. 1990

Tarre, JDI 1967

Teske, Euzw 1991

Tettinger, Aob

Tettinger, JZ 1988

Temple Lang, John, Community Constitutional Law: Article 5 EEC Treaty, CMLRev, 1990, 645-681.

Terré, François, La liberté d'etablissement dans les professions judictiares et la Communauté Economique Européenne, Joumal du droit international-Clunet $1967,265-289$.

Teske, Wolfgang, BafoG und EG-Recht, EuZW 1991, 54-55

Tettinger, Peter J., Das Grundrecht der Berufstreiheit in der Rechtsprechung des Bundesverfassungsgerichts, AöR 1983 (108), 92-133

Tettinger, Peter J., "Abschied vom Werbeverbot" + Gedanken zum freiberuflichen Standesrecht, JZ 1988, 228 $\ldots 233$

Thiele, Willi, Zum Problem der Freizügìgkeit von Arbeitnehmem und Beamten in der Europiäischen Gemeinschaft: Zugang zu nationalen Amtern, DÖD 1990 , 229-235. 
Thieme

Trumpf

Tiemarn,

BRAL-Mitt. 1989

Timmermans,

CMLRev. 1979

Tinmermans,

RM Themis 1980

Timmermans, SEW 1982

Tirmmermans, SEW 1986

Timmermans

Ars Aequil 1989

Tindemans, Beilage

EG-Bulletin 1976

Tizzano, Froro It. 1977

Tizzano

Tomuschat, Zä̈RV 1967

Toumlin, Fordham Int.

L.J. 1991-92

Toumlin, New L.J., 1990

Toth, CMLRev 1986

Toth, ELR 1994 ,

Traversa, RTDE 1989

Treffkorn

Neue Justiz 1991

Triebel, AnwBH. 1989

Troberg in

GTE-Kommentar

Tyrell/Yaqub

Uechtritz, Bay VBI 1988

Ulmer, IZ 1992

Universităt Lyon

Uniwersittät Valladolid

Urlesberger,

ZfRechtswergl. 1977

Van den Bossche
Thieme, Werner, Deutsches Hochschulrecht, 2. Auflage, Kalm, Betin Bonn München 1986.

Twimpf, Jürgen, Vom Binnenmarkt zur Europaaischen Union, Bonn 1992.

Tiemann, Susanne, Binnenmarkt der Diplome, BRAK-Mitt. 1989, 3.

Timmermans, C.W.A. Directives: Their effect within the national legall system, CMLRev, $1979,533-555$

Timmermans, C.W.A., EEG harmonisatie en Nederlands recht: cen beeld van bewogen beweging, RM Themis 1980, 406-431

Tinmermans, C.W.A., Verboden discriminatie of (geboden) differentatie, SEW $1982,427-460$

Timmemans, C.W.A., Zaak 293/83, Françoise Gravier/Stad Luik, SEW 1986 $86-94$.

Timmermans, C.W.A. , Zaak 222/86, Unctef/Heylens, Ars Aequil 1989, 287-291.

Tindemans, Leo, Die Europäische Union, Bericht von Leo Tindemans, Premierminister von Beigien an den Europäischen Rat, in: Beilage 1/76 zum Bulletin der EG.

Tizzano, Antonio, Stabilimento e prestazione di servizi nella giurisprudenza comunitaria, Foro It.1977, V, col.345-362.

Tizzano, Antonio, (Hrsg.), Professioni e servizi nella CEE, Padova 1985

Tomuschat, Christian, Der Vorbehalı der Ausübung offentlicher Gewalt in then Berufsfreiheitstegelungen des EWG-Vertrages und die freie Adwokatur im Gemeinsamen Markt. ZaöRV 1967, 53-93

Toumlin, John, A Worldwide Common Code of Professional Ethics?, Fordham International Law Journal, 1991-1992, 673-685.

Toumlin, Johm, The rights of barristers to practice in the EEC, New L.J. 1990 , $1309 / 1310$.

Toth, A.G. The Legal Status of the Declarations annexed to the Single European Act, CMLRev 1986,803-812.

Toth, Is subsidiarity justiciable?, ELR 1994, 268-285.

Trawersa, Enrico, L"interdiction de discrimination en raison de la nationalité en matière d"acces à l"enseignement, RTDE 1989, 45-69.

Trefflkorm, Matthias, Anwaltsnotariat oder Nur-Notariat, Neue Justiz 1991, 304. 307

Triebel, Volker, Fneier Wettbewerb fut juristische Dienstleistungen in England. AnwBI. 1989, $578-583$

Troberg, Peter, Kommentar zu den Artt. 52-66 EWGV, in: Von der GroebenVon Boeckh-Thiesing-Ehlermann, Kommentar zum EWGimertrag. 4. Auflage 1991 und 3. Auflage 1986.

Tyrell, Alan/Yaqub, Zahd, The Legal Professions in the New Europe, Oxford 1993.

Uechtritz, Michael, Freizügigkeit und Personalvertretungsrecht, BayVBI 1988, $743-747$.

Ulmer, Peter, Vom deutschen zum europäischen Privatrecht?, JZ 1992, 1-8. Universitäl Lyon, La libre circulation des avocats dans la CEE. Centre de documentation et de recherche européennes. Lyon 1986.

Universită⿱t Valladolid, Libre circulacion de professionales laberales en la C.E.E., Centro de documentacion europea, Valladolid 1991.

Urlesberger, Franz, Die Niederlassungsfreiheit and der freie Dienstleistungsverkehr für selbständige Tätigkeiten der Kreditinstitute in der EWG, Z. fur Rechtsvergl. 1977, 89-117. 
Literaturverzeichnis

in Alvarez

Van Camp

Van Craeyenest in: De Witte

Van Gerven, JJT 1964

Van Gerven,

CMLRew. 1965

Van Gerven, in:

Smit/Herzog

Van Gerven, in:

FS Schoordijk

Van Gerven,

RM Themis 1995

Van Gerven/Gilliams, RW 1989-90

Van Gerven/Wouters

Vandersanden

Varano

Verbruggen,

TORB 1991-92

Verbrugen

VerLoren wan Themat in Fs Bobrner

Verschueren

Verstegen

Verstegen,

Jura Falconis 1990

Verstegen

Vignes, AFDI 196

Vignes

Vổker
Van den Bossche, De advocalat-generaal wikt, het hof beschikt! Enkele kanttekeningen bij de onderwijs-conclusies Yan Adwocaatmgeneraal W. Van Gerven in Alvarez, A. (red), De advocaatugeneraal gehoond, 67-77.

Van Camp, Het Statuut wan de advocaat in het Europese Gemeenschapsrecht Antwerpen 1989.

Van Craeyemest, Felix, La nature juridique de résolutions sur la coopération en matière d'éducation, in: De Witte, (ed) European Community Law of Education Badem-Baden, 1989, 127-134

Van Gerven, Walter, Les droits d'établissement et de prestation de services dans le Marché Commun, JT 1964, 357-362.

Van Gerven, Walter, The right of establishment and free supply of services within the Common Market, CMLRev. 1965, 344-362.

Van Gerven, Kommentar zu den Art. 52 EGV ff., in: Smiv/Herzog. The Law of the European Economic Community, Looseleaf commentary.

Van Gerven, Walter, Het evenredigheidsbeginsel.: een beginsel met een groot werleden en een grote toekomst, in: In het nu, wat worden zal, Afscheidsbundel für Prof. Mr H.C.P. Schoordijk, 1991 , 75-89.

Van, Gerven, Walter, Naar een Europees gemeen recht van algemene rechtsbeginselen, RM Themis, 1995, 233-243.

Van Gerven, Walter/Gilliams, Hans, Gemeenschapstrouw: goede trouw in E.G.verband, $\mathbb{R} . W, 1989-90,1158-1169$

Van Gerven, Walter/Wouters, Jan, Free Movement of Financial Services and the European Contracts Convention, in: Andenas, M./Kenyon-Slade, St. E.C Market Regulation and Company Law, London 1993, 43-79.

Vandersanden, Georges, La sentencia ERASMUS, Revista de instituciones europeas $1990,479-498$.

Varano, Vincenzo, Legge 9 febbraio 1982, n. 31. Libera prestazione di servizi da parte degli avwocati cittadini degli stati membri delle Cornunità europee, in Le nueve leggi civili commentate, $1.983,47-61$

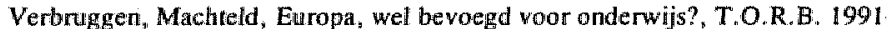
$92,131-141$.

Verbruggen ${ }_{m}$ Machtheld, De invloed van het Europees Gemeenschapsrecht op het onderwijsrecht in de Vlamse Gemeenschap, Leuven 1992

VerLoren van Themaat, P., Einige Bemerkungen zu dem Verhältnis zwischen den Begriffen Gemeinsamer Markt, Wirtschaftsunion, Währungsunion, Politische Union tund Souveränität, in FS B. Bömer zum 70. Geburtstag, Kobln 1992, 459 472 .

Verschueren, Herwig, Internationale Arbeidsmigratie, Brugge 1990

Verstegen, Raphael, De gemeenschappen bevoegd voor het onderwijs, Tijd schrift woor bestuurswettenschappen en publiekrecht $1990,3-36$.

Verstegen, Raphael, Examens kennen grenzen-Overzicht wan de mogelijke knelpumen, Jura Fulconis 1990, 593-633.

Verstegen, Raphael, Pour une formation juridique européenne généralisée in: De Witte/Fonder, The common law of Europe and the future of legal education. Deventer 1992, 53-64.

Vignes, Daniel, Le droit d"établissement et les services dans la Communauté economique européenne, AFDI 1961, 668-725.

Vignes, Daniel, Etablissement et services, in Megret (ed.), Le droit de la CEE, Bruxelles 1971, III, 124 .

Völker, Stefan, Passive Dienstleistungsfreiheit im Europåischen Gemein schaftsrecht, Berlin $\mathbb{1 9 9 0}$. 
Vogel, NJW 1977

Vogelaar/Wermuth, SEW 1988

Vorbrugg, AnwBl. 1989

de Vries,

The Int. Lawyer 1987

de Vries, Tijdschrift voor Gezondheidsrecht 1977

de Vries, Tijdschrift voor Gezondlineidsrecht 1983

Wackie Eysten

Wackie Eysten,

EuZW 1993

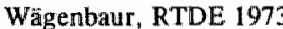

Wägenbaur, CDE 1976

Wägenbaur in: Jacobs

Wägendaar, KSE

Wägenbaur, EuGRZ 1977

Wâgenbaur, RMC 1977

Wagenbaur, RTDE 1979

Wägenbaur,

CMLRev. 1986

Wảgenbaur, EuR 1987

Wagenbaur, ZfG 1988

Wägenbaur, MittHV 1989

Wägenbaur, BB 1989

Wăgenbaur

Nuove Tendenze

Wägenbaur, EuR 1990

Wăgenbaur in:Merten

Wăgenbaur, EuZW 1.991

Wägenbaur, in: Randelzhofer
Yogel, Hans-Jochen, Die Europåische Gemeinschaft auf dem Weg zur Rechtsumion, NJW 1977, 977-982.

Vogelaar Th. W./ Wermuth, E. Legal aspects of community actions in the field of culture, SEW 1988, 321-332.

Vorbrugg, G., Der deutsche Anwalt im intemationalen Wetbewerb, AnwBI. $1989,451-456$.

de Vries, $H$., The International Legal Profession, -The Fundwmental right of Association, The International Lawyer 21 (1987), 845-851

de Vries, I., De wederzijidse erkenning van de artsdiploma's in de Europese Gemeenschappen, Tijdschritt voor Gezondheidsrecht 1977, 27-38

de Vries., J., De erkenuing van artsen, verpleegkundigen, tandartsen en verloskundigen in de Europese Gemeenschappen, Tijd schrift voor Gezondhe idsrecht $1983,109-118$.

Eysten, Piet W., Establishment Directive, European Lawyer, 19911.13, 6-8

Wackie Eysten, P.A., The Legal Profession in Europe: officium nobile et mobile. EuZW 1993, 721-725

Wägenbaur, Rolf, Ou en est la reconnaissance mutuelle des diplồmes des medecins dans la CEE, RTDE 1973, 426-437.

Wägenbaur, Rolf, La libre circulation des médecins dans la Communaate europénne, problèmes actuels, 1er Rapport, CDE 1976, 707-735.

Wägenbaur, Rolf, The Mutual Recognition of Qualifications in the EEC in: $F$. Jacobs (Hrss.), European Law and the Individual, Arnstendam 1976, 95-112. Wägenbaur, Rolf, Schutzmaßnahmen auf dem Gebiet des Personem-und Dienstleistungsverkehrs, in: Schutzmafinahmen im Gemeinsamen Markit, Köln, Berlin, Bonn, München 1977, KSE 28, $1-27$.

Wägenbaur, Rolf, Das Thieffry-Urteil und das Niederlassungsrecht der Rechtsanwälte in den. Europäischen Gemeinschaften, EuGRZ 1977, 260-262.

Wägenbaur, Rolf, La mise en ouvre de la libre circulation des medecins dans In Communauté Européenne, RMC 1977, 311-318.

Wägenbaur, Rolf, L'Europe des vétérinaires, RTDE 1979, 653-663

Wägenbanr, Rolf, Free Movement in the Professions: The New EEC Proposal on Professional Qualifications, CMLRew. 1.986, 91-109.

Wägenbaur, Rolf, Neue Wege zur Anerkennung der Hochschuldiplome-Die Verwirklichung der Freizugigkeit in der Gemeinschaft - EuR 1987, 113-125. Wagenbaur, Rolf, Die Unsetzong von EG-Recht in deutsches Recht und ihre gesetzgeberische Problematik, Zeitschrift für Gesetzgebung 1988, 303-318.

Wagenbaur, Rolf, Die deutsche Universität und die Europäische Gemeinschaft MittHV $1989,138$.

Wagenbaur, Rolf Personalberatung als freie Dienstleistung aus Sictut des EWG Vertrags, BB 1989, Beillage 3, 15-20.

Wägenbaur, Rolf, La liberalisation des prestations che service dans la perspective du marche interieur, in: Nuove Tendenze del Commercio Intemazionale, Mailand $1989,144-238$

Wägenbaur, Rolf, Die Einbeziehung der Hochschulen in den europăischen Integrationsprozeßüberstaatliche Elemente in der Hochschulpolitik?, EuR 1990. 135-142.

Wägenbaur, Rolf, Die Rechusprechung des Europäische Gerichtshofis auf den Gebieten Umwelt wnd Gesundheit, Kultur und Bildung, in: Merten, (Hrsg.) Föderalismus und Europâische Gemeinschaften unter besonderer Berlicksichtigung yon Umwelt und Gesundheit, Kultur und Bildung, Berlin 1990, 161-173. Wagenbaur, Rolf, Inhalt und Etappen der Niederlassungsfreiheit, EuZW 1991 . $427-434$. 
4.a., CS Grabitz

Wagner

van ter Wal, NJG 1985

Wallace, EA 1988

Wallace, NewL 1977

Wallace, NewLJ 1981

Wallace, NewLJ 1989

Walters, ELR 1978

Wasilewski

Wasilewski

Wasmund

Wassermann, N.JW 1990

Watson, CMLRev. 1983

Watson, CMLRew. 1987

Watson, CMLRev. 1985

Weber, NVwZ 1990

Weber, $\mathbb{Z} 1989$

Weber, IL 199

Weberling, WISR 1991

Webert

Wegerich

Wegerich, EuZW 1994

Wehrens, Ost. NotZ 1990

Weidenfeld

Integration $1989 / 90$

Weil, AnwBil. 1988

Weil, BRAK-Mitt. 199 Weil. Lawyers 1990

Weil. BRAK-Mitt. 1993
Wägenbaur, Rolf, Auf dem Weg zur Bildungs- und Kulturgemeinschaft, in: Randelzhofer, Albrechu/Scholz, Rupert/Wilke, Dieter, Gedächnisschrift fü Eberhard Grabitz, München 1995, 851-866.

Wagner, Karin, Die Beziehungen zwischen Bïldung, Besichäfigung und Produktivitat und ihre Bildungs- und Beschaftigungspolitischen Auswirkangen-ein deutsch-englischer Vergleich, Europäisches Zentrum für die Förderung der Berufsbildung, Luxemburg 1986.

van der Wal, G., De wrijheid van vestiging wan advocaten in de EEG: hel arrestKlopp, NJB 1985, 857 .

Wallace, Helen, Europäische Integration: Auf dem Weg nach 1992, EA 1988, 583-590.

Wallace, Rebecca M.M., Recognition of Foreign Qualifications, NewLJ 1977 1007-1008.

Wallace, Rebecca M.M., "Right of Establishment": Doctor"s interpretation of Community measures, NewLJ 1981, 1259-1260.

Wallace, Rebecca M.M. Freedom to practise in the EEC, New LJ 1989, 1004 1005.

Walters, D.B., Uncertain steps towards a European legal profession, ELR 1978 , 265.277 .

Wasilewski, Rainer Freie Berufe in Europa, Nürmberg 1993

Wasilewski, Rainer, Konsequenzen des EG-Binnenmarktes für die Freien Berufe in der Bundesrepublik Deutschland, in: Ertel, R. Heinemann, H -I (Hrsg ) Die Liberalisierung ausgewählter Dienstleistungen im Europäischen Binnenmarkt, Hannover $1989,7$.

Wasmund, P., Stand und Perspektiwen der Verwirklichung des Europäischen Bunnenmarktes, in: Ernsthaler, Jürgen (Hrsg.), Europäischer Binnenmarkt-Stand und Perspektiven der Rechtsharmonisierung. Berlin 1989, 9-45.

Wassermann, Rudolf, Welche Maßnahmen empfehlen sich-auch im Hinblick auf den Wettbewerb zwischen Juristen aus den EG-Staten-zur Verkürzung und Straffung der Juristenausbildung? NJW 1990, 1877-1884

Watson, Philippa, Freedom of Establishment and Freedom to provide Services: Some recent Developments, CMLRev. 1983, 767-824.

Watson, Philippa, Case 293/83 -Gravier-, CMLRev. 1987, 89-97.

Watson, Philipa, Ordre des Avocats du Barreau de Pariss y, Onno Klopp. CMLRev. 1985, 736-75i.

Weber, Albrecht, Benfsausbildung und Berufszugang fur Juristen im EGBinnenmarkt, NVwZ 1990, 1-8.

Weber. Albrecht, Die Grundrechte im IntegrationsprozeB der Gemeinschaft in vergleichender Perspektive, JZ 1989, 965-973.

Weber, Albrectrt, Zur künftigen Verfassung der Europäischen Gemeinschaft, $I Z$ $1993,325-330$.

Weberling Johannes, Die Rechtssprechung des. Europailischen Gerichtshof Wissenschaftsrecht in den Jahren 1989 und 1990, WISR, 1991, 123-139.

Webert. Fabienne, Les professions médicales et paramédicales dans lle CEE, Presses univ., Nancy 1982

Wegerich, Thomas Christian, Das englische Anwaltsrecht, Bestandsaufnahme und berufliche Neuregelung, Regensburg 1992.

Wegerich, Thomas, Der "Qualified Lawyers Transfer Test", EuzW 1994, 275 277 .

Wehrens, Kurze Charakteristik des französischen Notariats heute: Öst.NotZ 1990,57 .

Weidenfeld, Werner/ Wessels, Wolfgang, Jahrbuch der Europäischen Integration $1989 / 90,1990$.

Weil, Heinz, Standesregeln in der Europäischen Gemeinschaft-Warum?, AnwB1 1988,632 .

Weil, Heinz, Die Eignungsprüfung für EG-Anwälte, Brak-Mitt. 1991, $15-18$. Weil, Heinz, Germany: Oni with the old and in with the new, Lawyers 6/1990, 5-7

Weil, Heinz, Ein Wunder in Lissabon?, BRAK,-Mitt. 1993, 2-6. 
Weil, Fordham. Int. L.J. 1991-1992

Weiler, YbEL 1981

Weiler, Yale Law Journal 1991

Weis, NJW 1983

Welck

Wende

Wendling, RMC 1982

Wessels in: Hrbek Thaysen

Wetter, ICLQ 1980

Wiedmann, AöR 1992

Wiesand

de Wilde, SEW 1994

Willandsen, NJW 1989

Willoweit, DUZ 1988

Willoweit/Groffeld, JZ 1990

Wilson, Harvilu 1978

Wirnmer/Mederer

Wimmer, NJW 1989

Winkel, NJW 1975

Winkel, NJW 1976

Winkel in Schmitz-Wenzel

Winkel,

Derr freie Beruf 1991

Wittkopp
Weil, Heinz, The Proposal for a Directive on the Right of Establishment for Lawyers in the European Community, Fordham Int. L.J. 1991-1992, 699-710. Weiler, Joseph H.H., The Community System: The Dual Character of Supranationalism, Yb of European Law 1981, 267-306.

Weiler, Joseph H.H., The Transformation of Europe, Yale Law Journal 1991, 2404-2500.

Weis, Hubert, Inländendiskriminierung zwischen Gemeinschaftsrecht und nationalem Verfassungsrecht, NrW 1983, 2721-2726.

Welck, Georg von, Die Bundesländer und die Einheitliche Europäische Akte, München 1990.

Wende, Marijk van der, Study abroad. Does it count? An inquiry into the transfer of credit for study abroad, Nuffic Paper 2, Den Haag 1994.

Wendling. S., La liberté d'établissement et la libre prestation des services dans la Communauté economique Européenne. Vingt ans de rẻalisation des programmes genéraux de libêration c̀e l'établissement et des services, RMC 1982. 132-155.

Wessels, Wolfgang, Die deutschen Länder in der EG-Politik: Selbstblockierung oder pluralistische Dynamik?, in: Hrbelk, Rudolf, /Thaysen, Uwe (Hrsg.), Die Deutschen Länder und die Europäischen Gemeinschaften, Baden-Baden 1986, $181-195$.

Wetter, J. Gillis, The Case for International Law Schools and an International Legal Profession, ICLQ 1980, 206-218.

Wiedmann, Thomas, Föderalismus als europäische Utopie, Archiv des öffentlichen Rechts 1992, 46-70.

Wiesand, A.J., Kunst ohne Grenzen? Kulturelle ldentität und Freizügigkeit in Europa, Köln 1987.

de Wilde, E.L.H. Modernisering van het Nederlandse vestigingsbeleid, SEW 1994, 775-799.

Willandsen $n_{*} V$, Die verwaltungs und standesrechtliche Stellung des auch im Ausland zugelassenen deutschen Rechtsanwaltes und Rechtsbeistandes, NJW $1989,1128-1130$.

Willoweit, Dietmar, Praxisbezug ohne Wissenschaft. Wider den Provinzialismus der deutschen Juristenausbildung, Deutsche Universitätszeitung, DUZ $1988 \mathrm{Nr}$. $15 / 16,17$.

Willoweit, Dietmar/ Großfeld, Bernhard, Juristen für Europ\&, JZ 1990, 605-609. Wilson, Peter S., EEC: Freedom to Provide Services for EEC Lawyers, HarviLJ $1978,379-384$.

Wimmer, Norbert/ Mederer, Wolfgang. Das Subsidiaritătsprinzip und seine Entdeckung durch die Europăische Gemeinschaft, Österr.JZ 1991, $586-592$. Wimmer, R., Wer gibt das neue anwaldiche Benffsrecht? Zur Kompetenzaufteilung zwischen Gesetz- und Satzung sgeber, NJW 1989, 1772-1776.

Winkel, Kulaus, Der Ausbau der Freizügigkeit des Marktbürgers durch die Rechtsprechung des Europäischen Gerichtshofs, NJW 1975, 1057-1061.

Winkel, Klaus, Das Niederlassungsrecht der freien Berufe im Gemeinsamen Markt, NJW 1976, 446-451.

Winkel, Klaus, Die Gewährung des Niederlassungsrecht für freie Berufe, der Freizúgigkeit der Arbeitnehmer und der akademische Freizilgigkeit unter bildungspolitischen Aspekten ü: Schmitz-Wenzel (Hrsg.), Bildungspolitik in der Europäischen Gemeinschaft, Baden-Baden 1980, 25-37.

Winkel, Klaus, Die Anerkennung der Diplome der Freien Benufe in der EG unter besonderer Berücksichtigung der Umsetzung der Hochschuldiplom-Richtlinie. Der freie Beruf, Nr.8 1991, 22/23

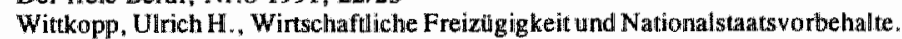
Eine Untersuchung der Art. 48 Abs. 4 und 55 Abs. 1 des EWG-Vertrages, BadenBaden 1977. 
Wittkowski

Wohlfarth/Everling

Wollenschläger, ZAR 1986

Wouters/Schneider

Wouters, THH 1993

Wouters, MJ 1994

Wouters in Marias, EIPA 1994

Wyatt, ELR 1981

Wyatt/Dashwood

Zacker, RIW 1989

Zander, The Int.

Lawyer 1990

Ziekow, DóD 1991

Zilioli in De Witte

Ziller 1988

Ziller, Rew franç.

d'adm. publ. 1990

Ziller 1993

Ziller in Hrbek/Thaysen

Zuck, NJW 1987

Zuck, AnwBil. 1987

Zuck. EuGRZ 1987

Zuck AnwBI. 1988

Zuck, EuR 1988

Zuck. NJW 1990

Zuck "BRAK-Mitt. 1993

Zuleeg, EuR 1969

Zuleeg, GTE-Kommentar
Wittkowski, Bernd, Die Rechtsprechung des Europăischen Gerichtshofs zur Freizügigkeit und Gleichbehandlung won Angehörigen der EG-Mitgliedstaaten hinsichtlich đes Besuchs von Ausbilidungsstätten und deren Auswirkung für die Bundesrepublik Deutscliland, Frankfur/Bem/New York/Paris 1991.

Wolfarth, Emst/ Everling, Ulrich/ Glaesner, Hans-Joachim/ Sprung, Rudolf, Kommentar zur EWG Vertrag, Berlin/Frankfurt am Main 1960.

Deutschland, ZAR 1986, 155-165.

Wouters, Jan/Schneider, Hildegard, Current Issues of Cross-Border Establishment of Companies in the European Union, Antwerpen 1995.

Wouters, Jan, Vrij verkeer van bedrijfsrevisoren in de Europese Gemeenschap, TBH. 1993, 344-365

Wouters, Jan "The Case-Law of the European Court of Justice on Direct taxes: Varjations upon a Theme, Maastricht Joumal of European and Comparative Law $1994,179-220$

Wouters, Jan, Europeran Citizenship and the Case-Law of the Court of Justice of the European Communities on the Free Movement of Persons in E. Marias (ed.), European Citizenship, EIPA Maastricht 1994, 25-68.

Wyatt, Derrick, Article 48 (4) EEC: scope of the public service prowision, ELR $1981,459-463$.

Wyatt, Derrick/Dashwood, Alan, European Community Law, London 1993.

Zacker, Christian, Binnenmarkt und Gemeinsamer Markt. Zwei Begriffe desselben Inhalts?, RiW 1989, 489-490.

Zander, Michael, The Thatcher Government's Onslaught on the Lawyers: Who Won?, The International Lawyer, 24 (1990), 753-785.

Ziekow, Jan, Die Freizz̈gigkeit nach Europäischem Gemeinsehaftsrecht im Bereich des öffentlichen Dienstes, DöD 1991, 11-19.

Zillioli, Chiara, The recognition of diplomas and its impact on educational policies, in: De Witte, Bruno (Hrsg.), European Community Law of Education, Baden-Baden, 1989, $51-70$

Zillter, Jacques, Egalitế et mérite-L'accèss à fonction publique dans les Etats de If Conmunauté europếenme, Brìssel, 1988.

Ziller, Jacques, Emploi et mérite dans la fonction publique néerlandaise, Rev. franci. d'adm. publ. 1990, 379-571.

Ziller, Jacques, Administrations comparées, Paris 1993.

Ziller, Gebhard, Die EG*politische Mitwirkung des Bundesrates, in: Hrbek, Rudolf/Thaysen, Uwe (Hrsg.). Die Deutschen Länder und die Europäischen Gemeinschaften, Baden-Baden 1986, 89-103.

Zuck, Internationales Anwaltsrecht, NJW 1987, 3033-3036.

Zuck. Ruidiger, Internationales Anwaltsrecht-Dienstleistung und Niederlassung, AnwBI. 1987, 394-397.

Zuck, Riudiger, Die Neuordnung des anwaltlichen Berufs- und Standesrechts im Lichte der europäischen Rechtsentwicklung, EuGRZ 1987, 585-589.

Zuck, Rüdiger, Beruffs- und standesrechtliche Rahmenbedingungen der künftigen Formen anwaltticher Zusammenarbeit und anwaltlicher Werbung, AnwBil. 1988. 351-354.

Zuck, Rüdiger $r_{i}$ Freier Dienstleistungsverkehr der Rechtsanwälte, EuR 1988, 186190.

Zuck, Rüdiger, Die Europåische wirtschaftliche Interessenvereinigung als Instrument anwaltlicher Zusammenarbeit, NJW 1990, 954-959.

Zuck, Rüdiger, Neuordnung des anwaltlichen Berufsrechts, BRAK-Mitt. 1993, 66/67.

Zuleeg, Manfred, Die Auslegung des europăischen Gemeinschaftsrechts, EuR 1969, 97-108.

Zuleeg, Manfred, Kommentierung zu Art. 7 EWG-Vertrag, in GTE, Kommentar zum EWG-Vertrag, 4. Auflage, Bd. 1. Baden-Baden 1991. 
Zumschlinge,

Die Verwaltung 1989

Zur Hausen, EuR 1987
Zumschlinge, Konrad, Das Verhältnis der Bundesländer zu den Europãischen Gemeinschaften (EG), Die Verwaltung 1989, 217-236.

Zur Hausen, Götz-Eike, Die deutschen Länder als Souffleure auf der Brüsseler Bühne? Das Ratifizierungsgesetz zur Einheitlichen Europälischen Akte aus Brüsseler Sicht, EuR 1987, 322-332. 


\section{Curriculum vitae}

Hildegard Schneider wurde am 13. Februar 1955 in Rottweil (Bundesrepublik Deutschland) geboren.

Nach dem Abitur 1974 am Albertus Magnus Gymnasium in Rottweil studierte sie Jura, Politikwissenschaften und Kunstgeschichte in Freiburg, London, Paris und Münster i.W. . In Münster legte sie 1980 das erste juristische Staatsexamen ab. 1980-1983 war sie als Wissenschaftliche Hilfskraft am Lehrstuhl für öffentliches Recht und Völkerrecht an der Westfälischen Wilhelms-Universität in Münster tätig. Mit erfolgreichem Abschluß der Referendarzeit im Juni 1986 erwarb sie die Befähigung zum Richterant. Seit September 1986 arbeitet sie an der Rijksuniversiteit Limburg in Maastricht, wo sie als Universitätsdozentin für Europarecht tätig ist.

Seit 1982 ist sie mit René de Groot verheiratet und hat zwei Kinder: David und Sophia. 